


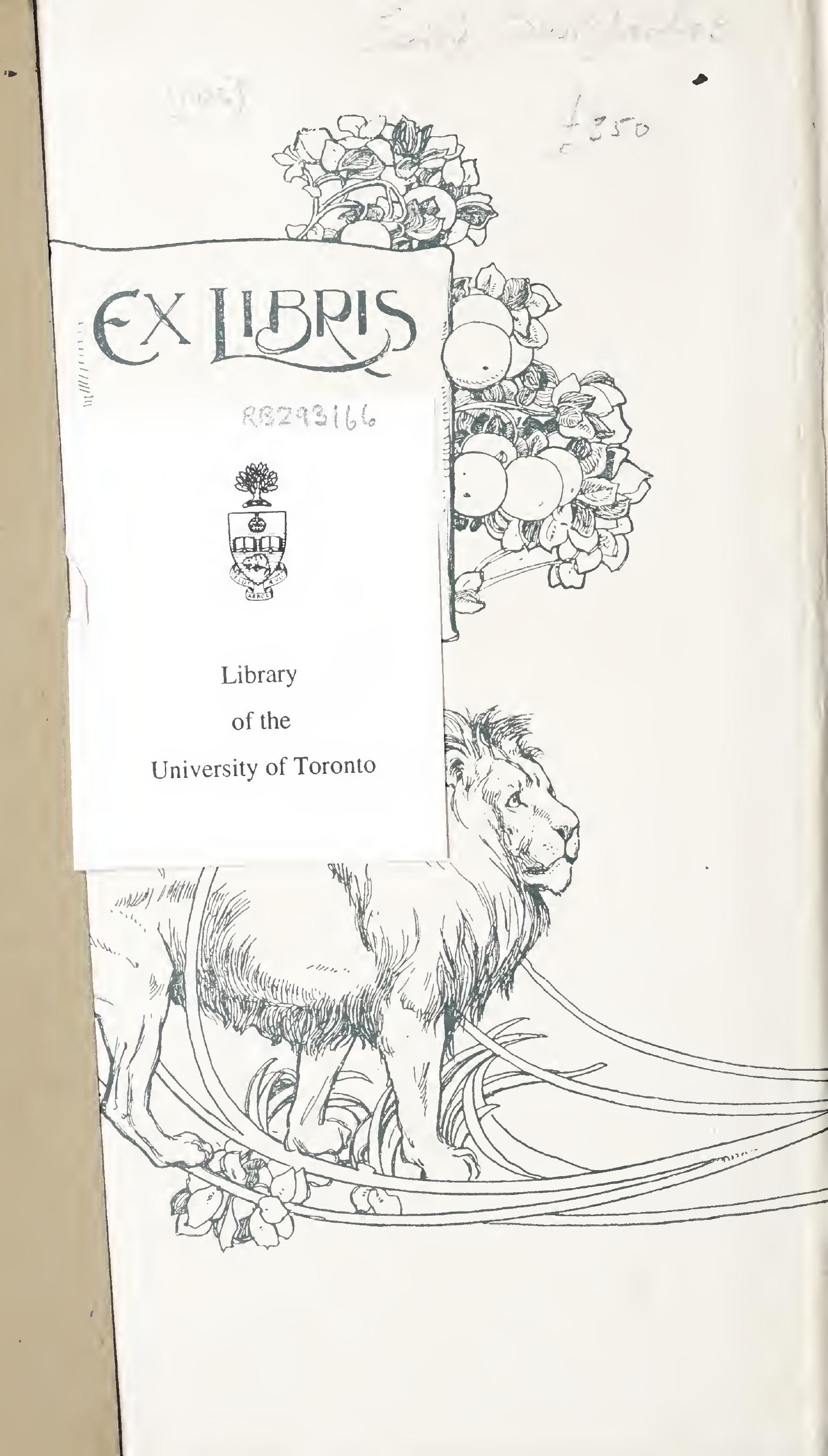


Digitized by the Internet Archive in 2018 with funding from University of Toronto 
A $\mathcal{X} A T U R A L$ HISTORT FOR TOUXCG PEOPLE. 


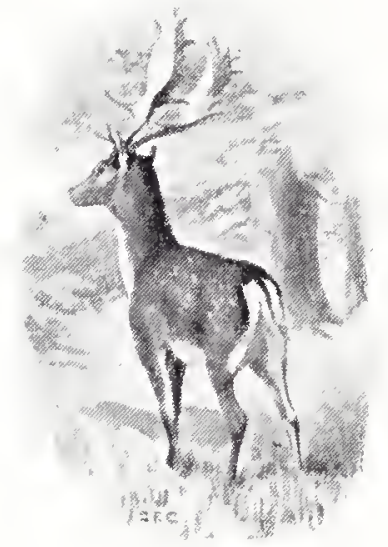




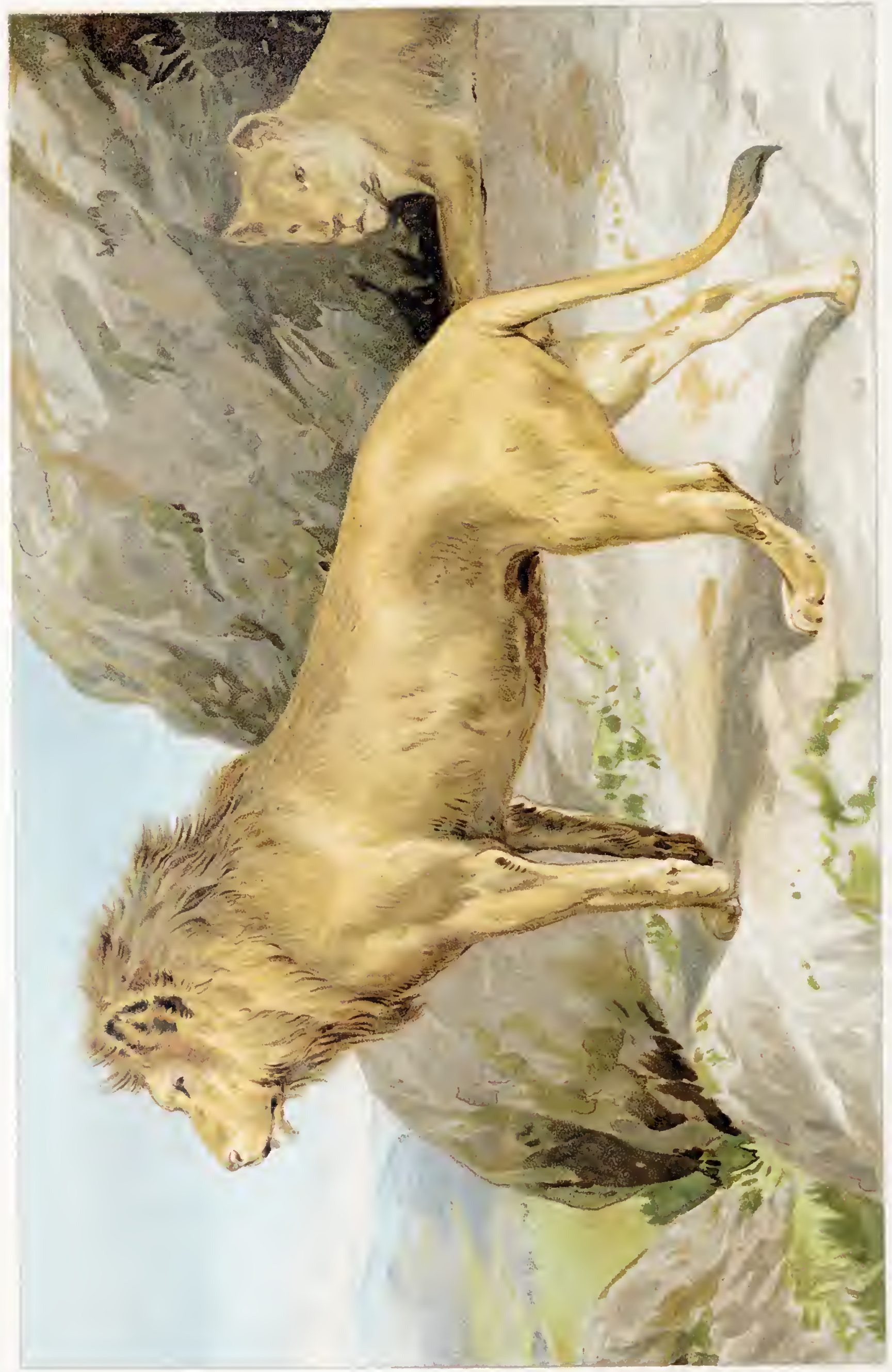




\section{A NATURAL HISTORY}

FOR YOUNG PEOPLE

BY THE

REV. THEODORE WOOD, F.E.S.

WITH

TIVELVE COLOUR AND OVER THREE HUNDRED BLACK AND WHITE ILLUSTRATIONS

CHAS. COLLINS, R.B.A., J. HALIIDAY,

G. EDIVARD COLLINS, R.B.A., AND A. T. ELIVES.

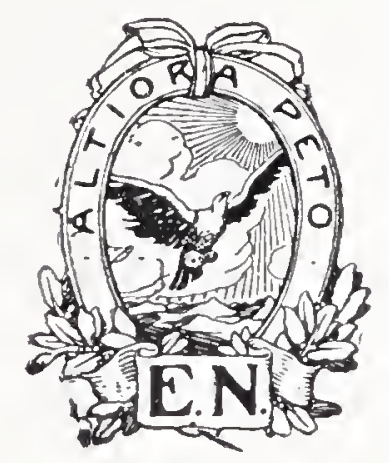

LONDON:

NEW YORK:

ERNEST NISTER.

E. P. DUTTON \& CO. 


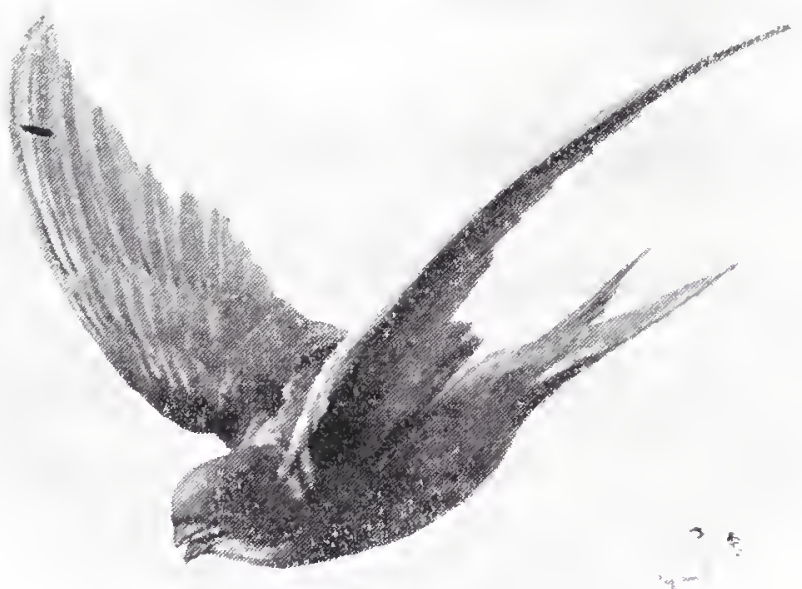

SWIET. 


\section{CONTENTS.}

INTRODUCTION . . . . . . . . . . 7

Chap. I. The Apes and Gibions . . . .

II. BaBOONS . . . . . . . It

III. The Mmerican Monkeys and the Lemurs • 23

IV. THE Bats . • . • . . . . 35

V. The Insect Eaters. . . . . + +

VI. The Larger Cats . . . . . . . 57

VII. The Sialier Cats . . . • . 7 I

VIII. The Civets, the Mard Molf, and the Hyenas 79

IX. The Dog Tribe . . . . . . Sg

Х. The Measel Tribe. . . . IOZ

XI. The Bear TribE . . . . I I 5

Xit. The Seal Tribe . . . . . I $2 S$

XII. The Whale Tribe . . . . . I 36

XIV. The Rodent Animals . . . . . 152

XV. The Mild Oxen . . . I . I

XVI. The Giraffes, Deer, Camels and Zebras . ist

, IVII. The Elephants, Rhinoceroses. Hippopotami,

ANd Mild Sivine . . . . 2OI

, XVIII. The Edentates, or Toothless Mannals • 2 I7

XiX. The Marsupials . . . . 224

XX. Birds of Prey . . . . 2 .

XXI. Cuchoos, Nightjars, Mumaing Lirds, MoodPECKERS, AND TOUCANS • • . 252

,XXIi. Crows, Birdos of Paradise, and Finches . 262

, XXili. Magtails, Shrikes: Thrushes, Etc. • • 274

, MIIV. Parrots, Pigeons, Pea-Fowl, Pheasants, etc. 287

" IXV. Ostriches, Herons, Cranes, Ibises, etc. . 299

, XIVI. Siviming Birios . . . . 3I2 


\section{CONTENTSS.}

Chap. Xyvil. Tortoises, Turtles and Lizards • • 323

" TXVili. Snakes. . . . . . . 337

. Mil. Amphibians. . . . . . . . 349

.. AXX. Fresh-lVater Fishes . . . . 355

. MXIi. Salt-Itater Fishes . . . . 365

.. XXXil. Insects . . . . . . . 385

. XXIII. Insects (contimued) . . . . 400

". MXYi. Spiders and Scorpions . . . 4 I7

. MXti. Crustaceans . . . . . . 429

. Xixit. Sea-Urchins, Star Fishes, and Sea Cucumbers . . . . . . $44 \mathrm{I}$

"XXXVil. Molluscs . . . . . . . 447

..XXtili. Annelids and Celenterates • . . 463

\section{CORRECTIONS.}

ON page $5+$, the third line from top of page, instead of "A Midsummer Night's Dream" read "Tempest." Page 448, in line 8, for Chapter NIII. read Chapter XXXII. 


\section{INTRODUCTION.}

I $N$ this book I am going to talk to you about animals, and to show you, as well as I can, what interesting creatures they are, and what wonderful things they do. But first of all I think that I ought to tell you something about the way in which they have been arranged by Nature.

We find, then, to begin with, that all living animals belong to one or other of two great groups-those which have bones, and those which have none. And we call those which possess bones "Vertebrates," those which have none, "Invertebrates."

Each of these great groups is divided into smaller ones, which we term Classes. In the Vertebrate animals there are four of these, known as

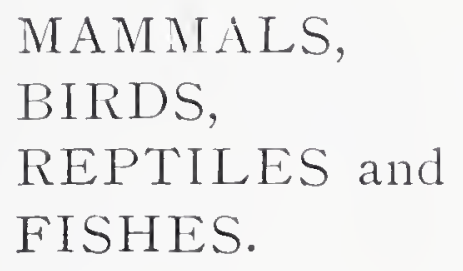

MAMMALS, BIRDS, REPTILES and FISHES.

And we may roughly describe Mammals as hot-blooded animals which are clothed either with fur or with scales, Birds as hot-blooded animals which are clothed with feather's, Reptiles as cold-blooded animals which breathe air, and Fishes as cold-blooded animals which breathe water.

That is quite easy to recollect, isn't it? But I ought to tell you that there are just one or two creatures which seem to come half-ivay, so to speak, between one group and another. There is a very curious animal known as the Lancelet, for example, and no one seems to feel quite sure whether it is really a fish or not.

The Invertebrates are divided into classes in just the same way. There are the Molluscs, or Soft-bodied Animals, for instance; the Articulates, or Jointed Animals; and so on. About these I shall have to talk to you by and by.

Then these Classes are divided into smaller groups still, which we may call Tribes. Among mammals we have the Monkey Tribe, the Cat Tribe, and the Dog Tribe; among birds, the Hawk Tribe, the Humming-bird Tribe, the Parrot Tribe, and many others. And even these Tribes are divided again into smaller groups still, which are known as Families. About these, however, we shall read as we go on. So we will pass at once to the animals themselves, and see what we can learn about their lives and their habits, and the work which they have to do in the world. 


\section{CHAPTER I. \\ THE APES AND GIBBONS.}

FIRST among the Nammals come the Monkers. First among the Nonkeys come the Apes. And first among the Ipes come the Chimpanzens.

These are almost the largest of all monkeys, for when it is fully grown a male chimpanzee stands nearly five feet high. And it would be even taller still if only it could stand upright.

But that is a thing which no monkey can ever do, because instead of having feet as we have, which can be planted flat upon the ground, these animals only have hind hands. There is no real sole to them, no instep, and no heel; while the great toe is ever so much more like a huge thumb. The consequence is that when a monkey tries to stand upright he can only rest upon the outside edges of these hand-like feet, while his knees have to be bent awkwardly outwards. So he looks at least three inches shorter than he really is, while he can only hobble along in a very clumsy and ungraceful manner.

But then, on the other hand, he is far better able to climb about in the trees than we are, because while we are only able to place our feet flat upon a branch, so as to stand upon it, he can grasp the branches with all four hands, and obtain a very much firmer hold.

Chimpanzees are found in the great forests of Central and Vestern Africa, where they feed upon the wild fruits which grow there so abundantly. They spend almost the whole of their lives among the trees, and have a most curious way of making nests for their families to live in, by twisting the smaller branches of the trees together, so as to form a small platform. The mother and her little ones occupy this nest, while the father generally sleeps on a bough just underneath it. Sometimes quite a number of these nests may be seen close together, the chimpanzees having built a lind of village for themselves in the midst of the forest.

If you visit the 7oological Gardens in London you may be quite sure of seeing two or three chimpanzees. They are nearly ahways brought there when they are quite young, and the keepers teach them to perform all kinds of clever tricks. One of them, who was called "Sally," and who lived there for several years, actually learned to count! If she was asked for two, three, four, or five straws, she would pick up just the right number from the bottom of her cage and hand them to the keeper, without ever making a mistalie. Generally, too, she would pick up six or seven straws if the keeper asked for them. But if eight, nine, or ten were asked for she often became confused, and could not be quite sure how many to give. She was a very 
cunning animal, however, and when she became tired of counting she would sometimes pick up two straws only and double them over, so as to make them look like four!

"Sally" could talk, too, after a fashion, and used to make three different sounds. One of these evidently meant "Yes," another signified "No," and the third seemed to be intended for "Thank you," as she always used it when the lieeper gave her a nut or a banana.

Two kinds of chimpanzees are known, namely the Conmon Chimpanzee, which is by far the more plentiful of the two, and the Bald Chimpanzee, which has scarcely any hair on the upper

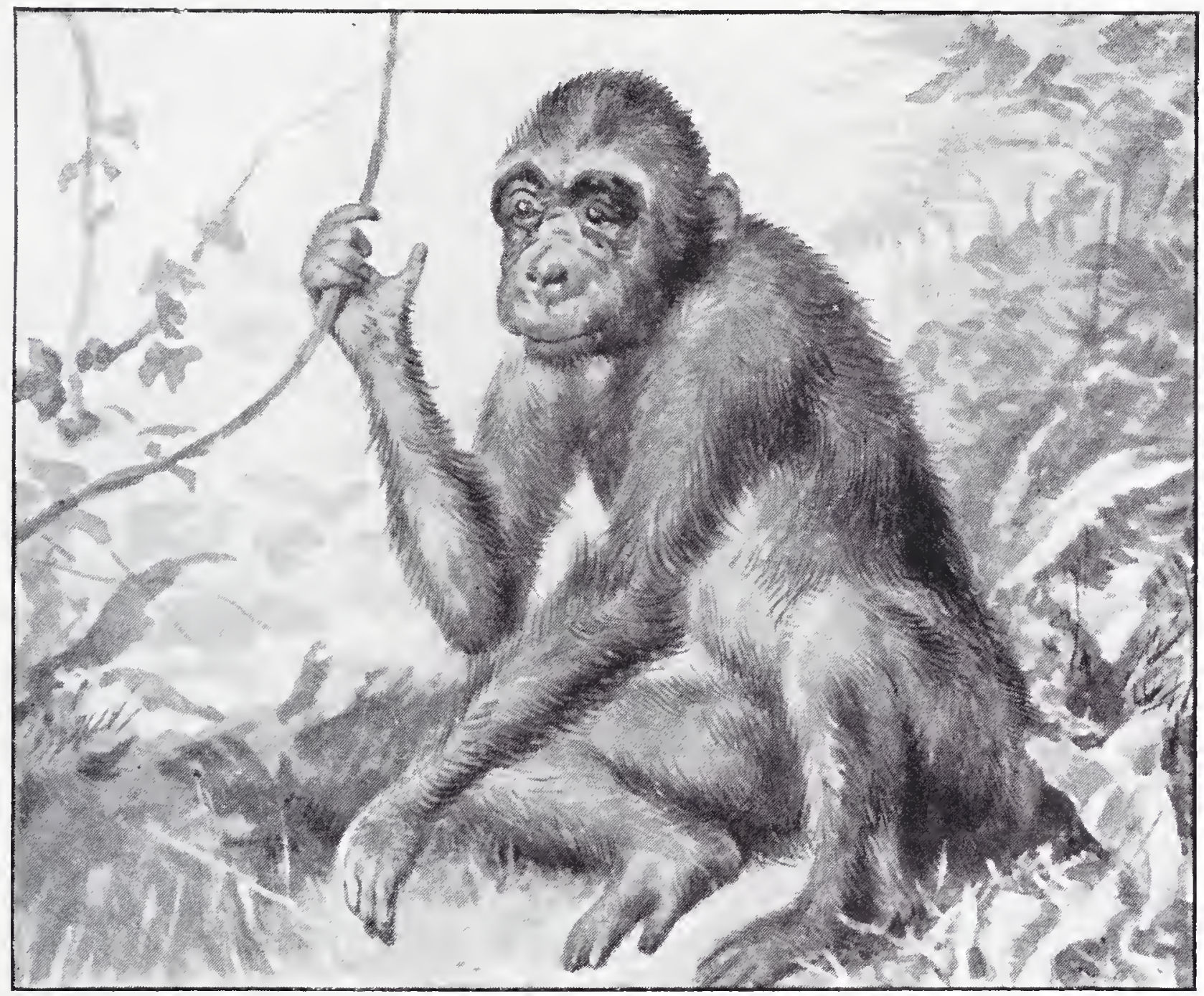

CHIMI'ANZJE.

part of its head. One very intelligent bald chimpanzee was brought over to England in Barnum's Menagerie, and was even more clever, in some ways, than the famous "Sally" herself.

Larger even than the chimpanzee is the famous Gokilla, the biggest and strongest of all the apes, which sometimes grows to a height of nearly six feet. It is only found in Western Africa, close to the equator, and has hardly ever been seen by white travellers, since it lives in the densest and darkest parts of the great forests. But several gorillas-nearly all quite small ones-have been caught alive and brought to England. 
Onc of these, named "Ciena," lived for about three weelis in the Crystal Palace. She was a most timid little creature, and if anybody went to look at her she would hide behind a chimpanzee, which inhabited the same cage, and watched over her in the most motherly way. Another, who was called "Pongo," lived for rather more than two months in the Zoological Gardens, and seemed even more nervous still, for he used to become quite terrified if eren his lieeper went into the cage. But when the animal has grown up it is said to be a most savage and formidable foe, and the natives of Central Africa are even more afraid of it than they are of the lion.

Lilie most of the great apes, the gorilla has a most curious way of sheltering itself luring a heavy shower of rain. If you were to look at its arms, you would notice that the hair upon them is very thick and very long indeed, and that while it grows donmards from the shoulder to the elbow, from the elbow to the wrist it grows upwards. So when it is caught in heavy rain, the animal covers its head and shoulders with its arms. Then the long hair upon them acts just like thatch and carries off the water, so that it hardly gets wet at all!

When the gorilla is upon the ground it generally wallis upon all fours, bending the fingers of the hands inwards, so that it rests upon the knuckles. But it is very much more active in the trees, and is said to be able to leap to the ground from a branch twenty or thirty feet high, without being hurt in the least by the fall.

Another very famous ape is the OrAng-UTAN, which is found in Borneo and Sumatra. It is reddish-brown in colour, and is clothed with very much longer hair than either the gorilla or the chimpanzee, while its face is surprisingly large and broad, with a very high forehead indeed. But the most curious feature of this animal is the great length of its arms. When a man stands upright, and allows his arms to hang down by his sides, the tips of his fingers reach about half-way between his hips and his linees. When a chimpanzee stands as upright as possible, the tips of its fingers almost touch its knees. But when an orang-utan does the same its fingers very nearly touch the ground! Of course, when the animal is walling, it finds that these long arms are very much in its way. So it generally uses them as crutches, resting the knucliles upon the ground, and swinging its body between them!

But the orang very seldom comes down to the ground, for it is far more at its ease among the branches of the trees. And although it never seems to be in a hurry, it will swing itself along from bough to bough, and from tree to tree, quite as fast as a man can rum below. Like the gorilla and the chimpanzee, it makes rough nests of twisted boughs, in which the female animal and the little ones sleep. And if it is mortally wounded, it nearly always malies a platform of branches in just the same way, and sits upon it waiting for death. 


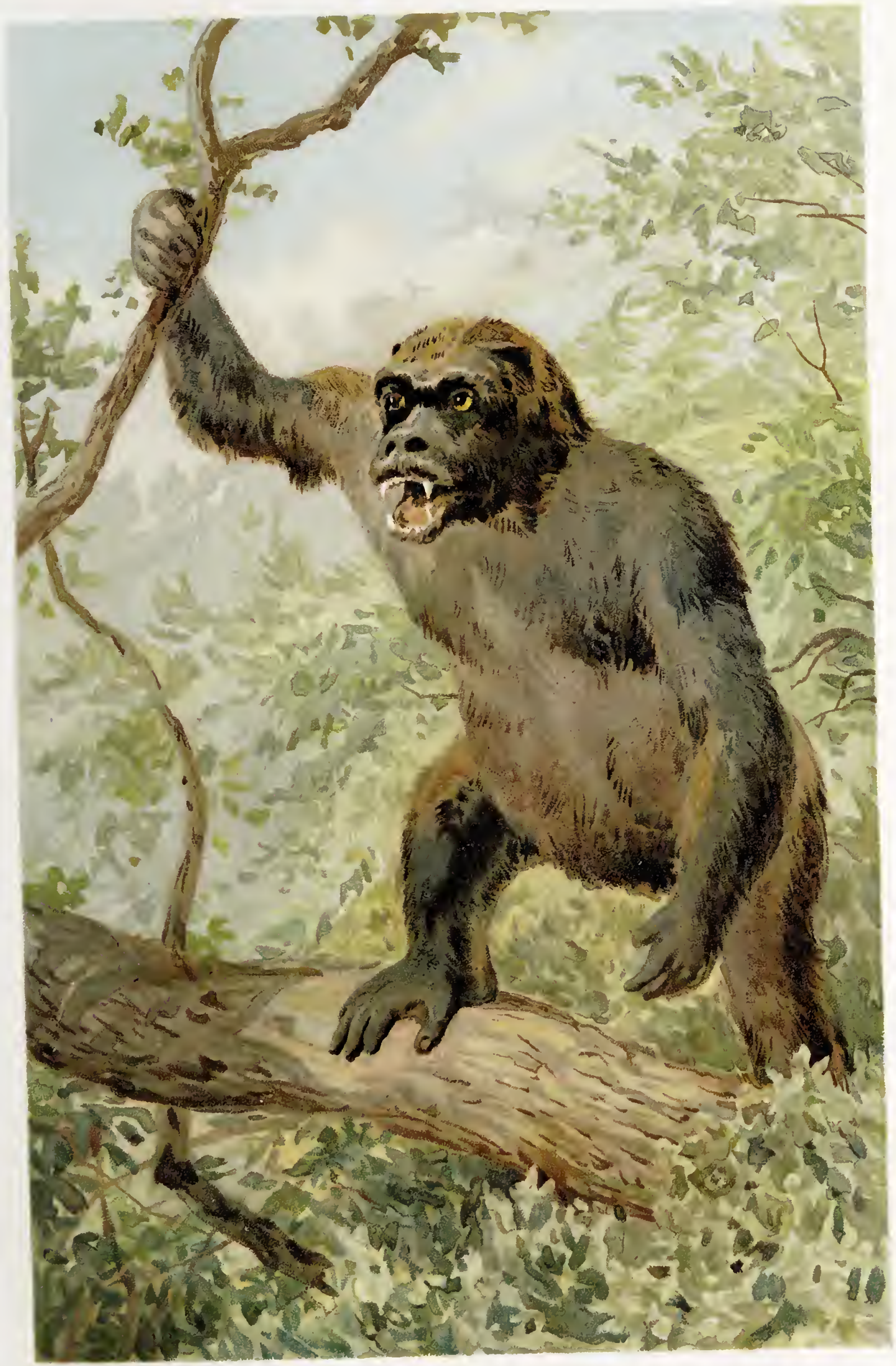



Orangs have often been brought to England, and although they are so delicate that they do not thrive at all well in captivity, you may nearly always see them in the Apes' House at the Zoo. One of these animals, which lived there for some little time, had learned a very clever trick. Leaning up against his cage was a placard, on which were the words "The animals in this cage must not be fed." The orang very soon found out that when this notice was up nobody gave him any nuts or

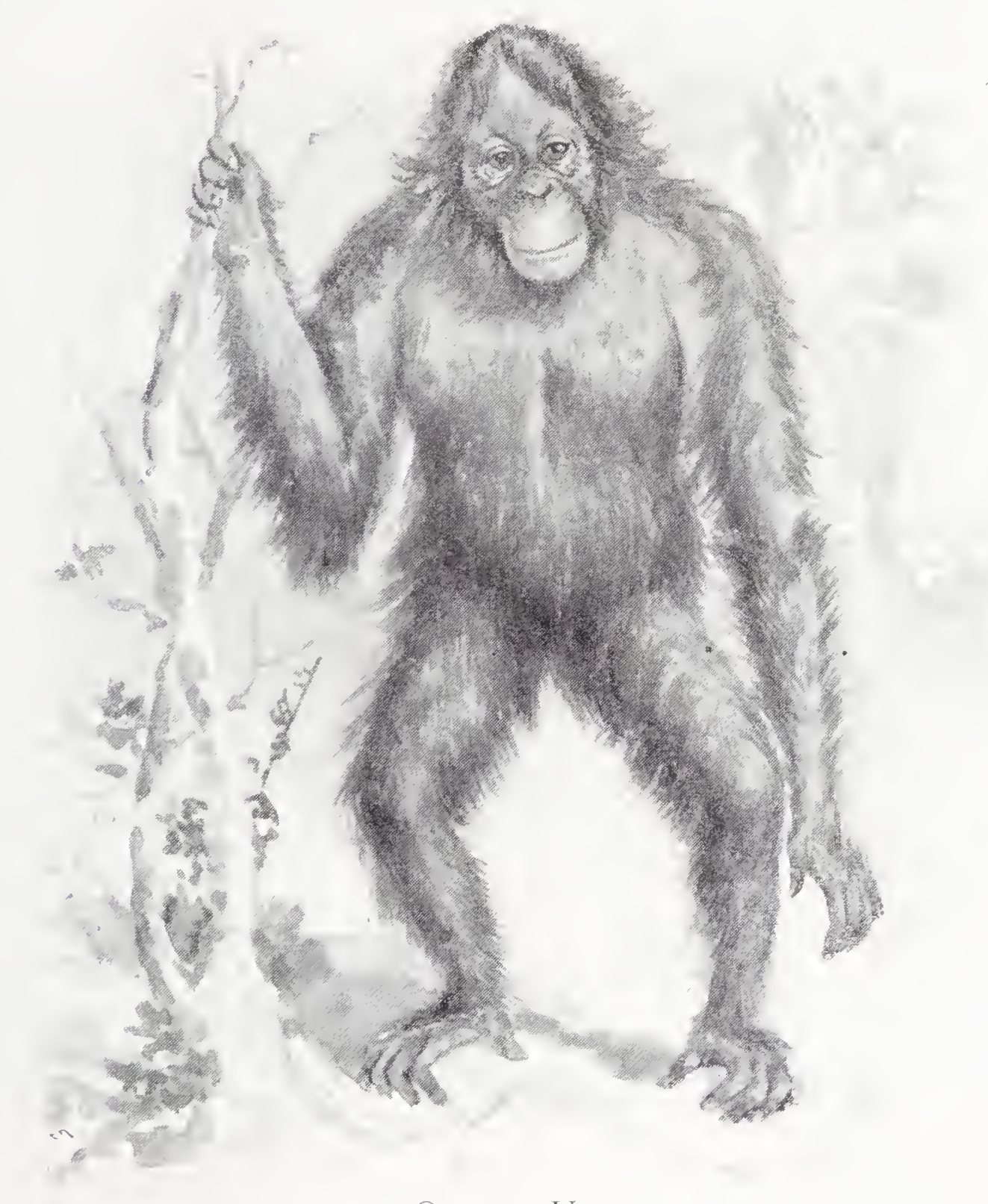

ORING-UTANO

biscuits. So he would wait intil the keeper's back was turned, linock the placard down with the printed words underneath, and then hold out his paw for food!

As a general rule, orangs seem far too lazy to be at all savage. Those which one sees at the \%oo nearly always lie about on the floor of their cage all day, wrapped in their blanliets, with a lind of good-humoured grin upon their great broad faces. But when they are roused into passion they seem to be very formidable 
creatures indeed, and $M I^{\circ}$. A. R. Wallace tells us of an orang which turned upon a Dyak who was trying to spear it, tore his arm so terribly with its teeth that he never recovered the proper use of the limb, and would almost certainly have killed him if some of his companions had not come to his rescue.

Next we come to the GibBons, which are very wonderful creatures indeed. For they are such astonishing gymnasts. Most monkeys are rery active in the trees, but the gibbons almost seem to be flying from bough to bough, dashing about with such marvellous speed that the eye can scarcely follow their morements.

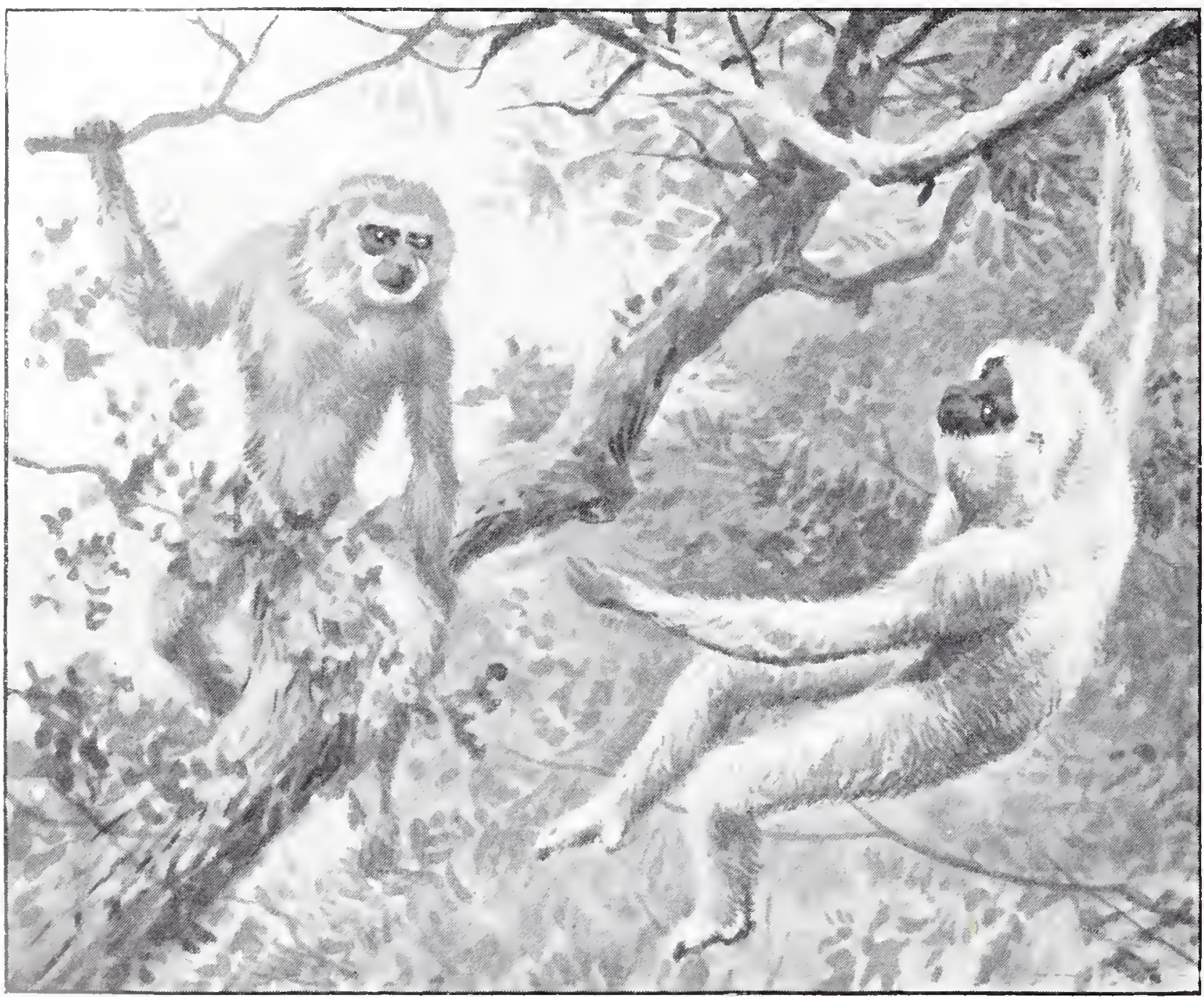

GIBBONS.

'Travellers, indeed, on seeing them for the first time, have: often mistaken them for big blackbirds. They hardly seem to swing themselves from one branch to another. They just dart and dash about, upwards, downwards, sideways, baclivards, often taking leaps of twenty or thirty feet through the air. And yet, so far as one can see, they only just touch the boughs as they pass with the tips of their fingers.

If there should happen to be a gibbon in the Apes' House at the $\%$ oo when next you pay it a risit, be sure to ask the lieeper to offer the animal a grape, or a piece of banana, and I 
feel sure that you will be more than surprised at its marvellous activity.

The arms of the gribbons are very long indeed although not quite so long as those of the orang-utan-so that when these animals stand as upright as they can the tips of their fingers nearly touch the ground. But they do not use these limbs as crutches, as the orang does. Instead of that, they either clasp the hands behind the neck while they are walking, or else stretch out the arms on either side with the elbows bent downwards, to help them in leeping their balance. So that when a gibbon leaves the trees and takes a short stroll upon the ground below, it looks rather like a big letter IV suspended on a forked pole! Gibbons generally live together in large companies, which often consist of from

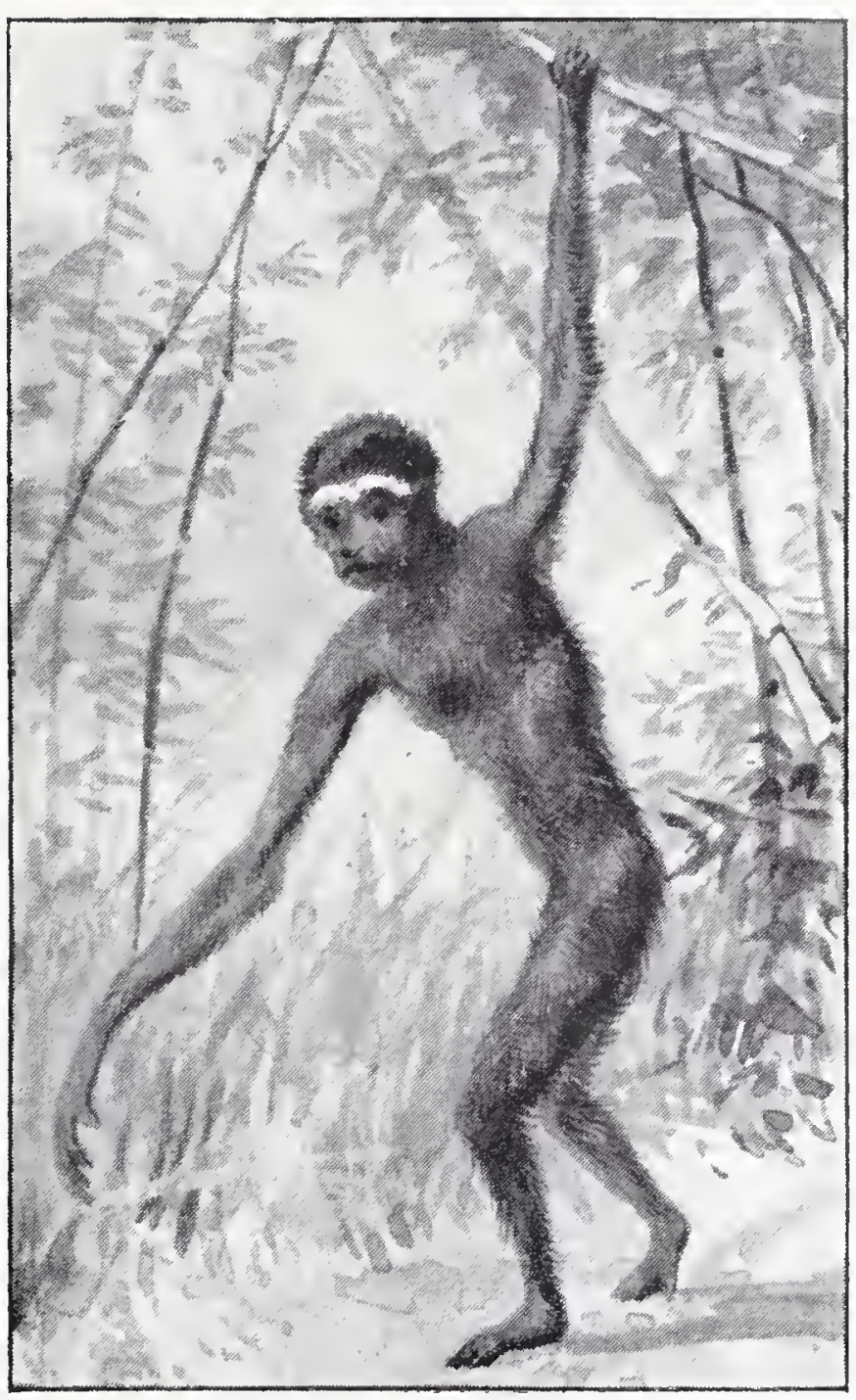

HOOLOCK. fifty to a hundred animals, and they have a very odd habit of sitting in the top-most branches of tall trees at sunrise, and again at sunset, and joining in a lind of concert. The leader always seems to be the animal with the strongest roice, and after he has uttered a peculiar barking cry perhaps half a dozen times, the others all begin to bark in chorus. For quite a couple of hours, very often, the outcry is liept up, and is so loud that it may be heard on a still day from a distance of two or three miles. Then by degrees it dies away, and the animals are ahmost silent until the time for their next performance comes round.

Several different kinds of gibbons are known, the largest of which is the Siamang. This animal is found only in Sumatra, and is a little over three feet high when fully grown. If you ever see it at the Zoo you may know it at once by its glassy black colour, and its odd whitish beard. Then there is the Hoolock, which is common in many parts of India, and has a white band across its eyebrows, while the LAR GibBos, of the Malay Peninsula, has a broad ring of white all round its face. Besides these there are one or two others, but they are all so much alike in their habits that there is no need for me to mention them separately. 


\section{CHAPTER II.}

\section{BABOONS.}

HONV can we tell a Baboon from an Ape?

That is quite easy. Just glance at his face. You will notice at once that he has a long, broad muzzle, like that of a dog, with the nostrils at the very tip. For this reason the baboons are sometimes known as "Dog-faced Monlieys." Then look at his limbs. You will see directly that his arms are no longer than his legs. That is because he does not live in the trees, as the apes do. He lives in rough, rocky places on the sides of mountains, where there are no trees at all, so that arms like those of the giblons or the orang-utan would be of no use to him. He does not want to climb. He wants to be able to scamper over the roclis, and to run swiftly up steep cliffs where there is only just room enough to gain a footing. So his limbs are made in such a way that he can go on all fours like a dog, and gallop along so fast among the stones and boulders that it is hard indeed to overtalie him.

Perhaps the best linown of the Baboons is the famous Chacma, which is found in South Africa. There is nearly always an example to be seen in the Zoo, and the animal is so big, and so strong, and so very, very savage, that if he is put into a large cage in company with other monlieys, he always has to be secured in a cormer by a stout chain. A chacma which lived for some years in the Crystal Palace was fastened up in this way, and the smaller monkeys, who knew exactly how far his chain would allow him to go, would sit just about a couple of inches out of his reach, and eat their nuts in front of him. This used to make the chacma perfectly furious, and after chattering and scolding away for some little time, and evidently telling his tormentors what dreadful things he would do to them if ever he got the chance, he would snatch up an armful of straw from the bottom of his cage, and fling it at them with both hands. And if I fed the smaller monkeys with nuts, instead of giving them to him, he would fling the straw at me.

Chacmas live in large bands among the South African mountains, and are very difficult to watch, as they always post two or three of their number to act as sentinels. Is soon as any sign of danger appears one of the vigilant watchers gives a short, sharp bark. Nll the rest of the band understand the signal, and scamper away as fast as they can.

Sometimes, however, the animals will hold their ground. 
A hunter was once riding over a mountain ridge when he came upon a band of chacmas, which were sitting upon a rock. Thinking that they would at once rum away he rode at them. They did not move, however, and when he came a little closer they looked so threatening that he thought it wiser to turn back again.

And an angry chacma is a very formidable foe indeed, for it is nearly as big as a mastiff dog, and ever so much stronger, while its great tusk-like teeth cut like razors. When one of these animals is hunted with dogs it will often gallop along until

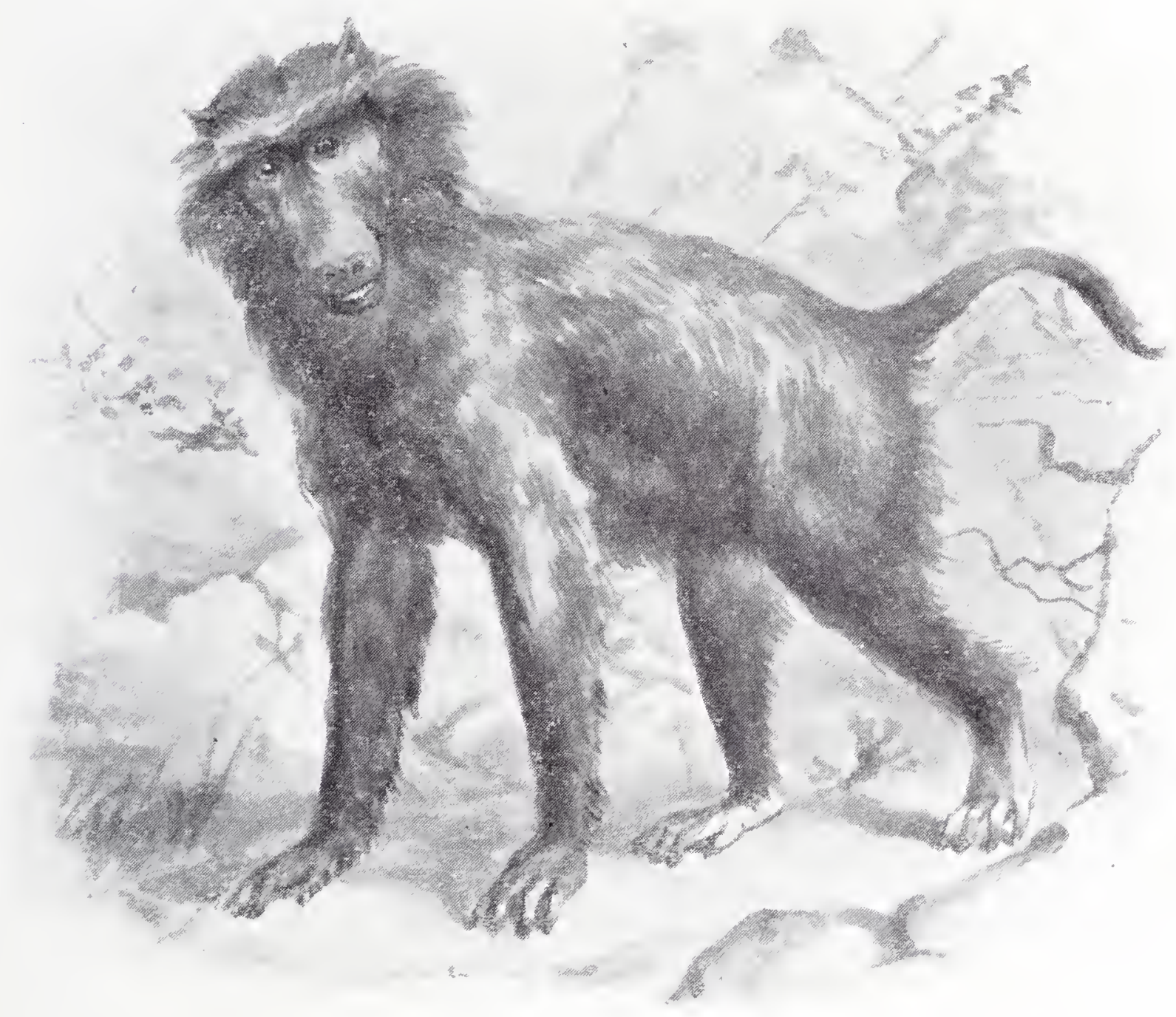

('H) $1 \mathrm{C} M \mathrm{M}$

one of its pursuers has outstripped the rest, and will then suddenly turn and spring upon him, plunge its teeth into his neck, and, while its jaws are still clenched, thrust the body of its victim away. The result is that the throat of the poor dog is torn completely open, and a moment later its body is lying bleeding on the ground, while the chacma is galloping on as before.

These baboons are very mischievous creatures, for they come down from their mountain retreats by night in order to plunder the orchards. And so cautiously is the theft carried out, 
that even the dogs on guard know nothing of what is going on, and the animals nearly always succeed in getting away.

When it cannot obtain fruit, the chacma feeds chiefly upon the bulb of a kind of iris, which it digs out of the ground with its paw, and then carefully peels. But it is also fond of insects, and may often be seen turning over stones, and catching the beetles which were lying hidden beneath them. It will even eat scorpions, but is most careful to pull off their stings before doing so.

Another very interesting baboon is the MAxDRILL, which one does not often see in captivity. It comes from Vestern Ifrica,

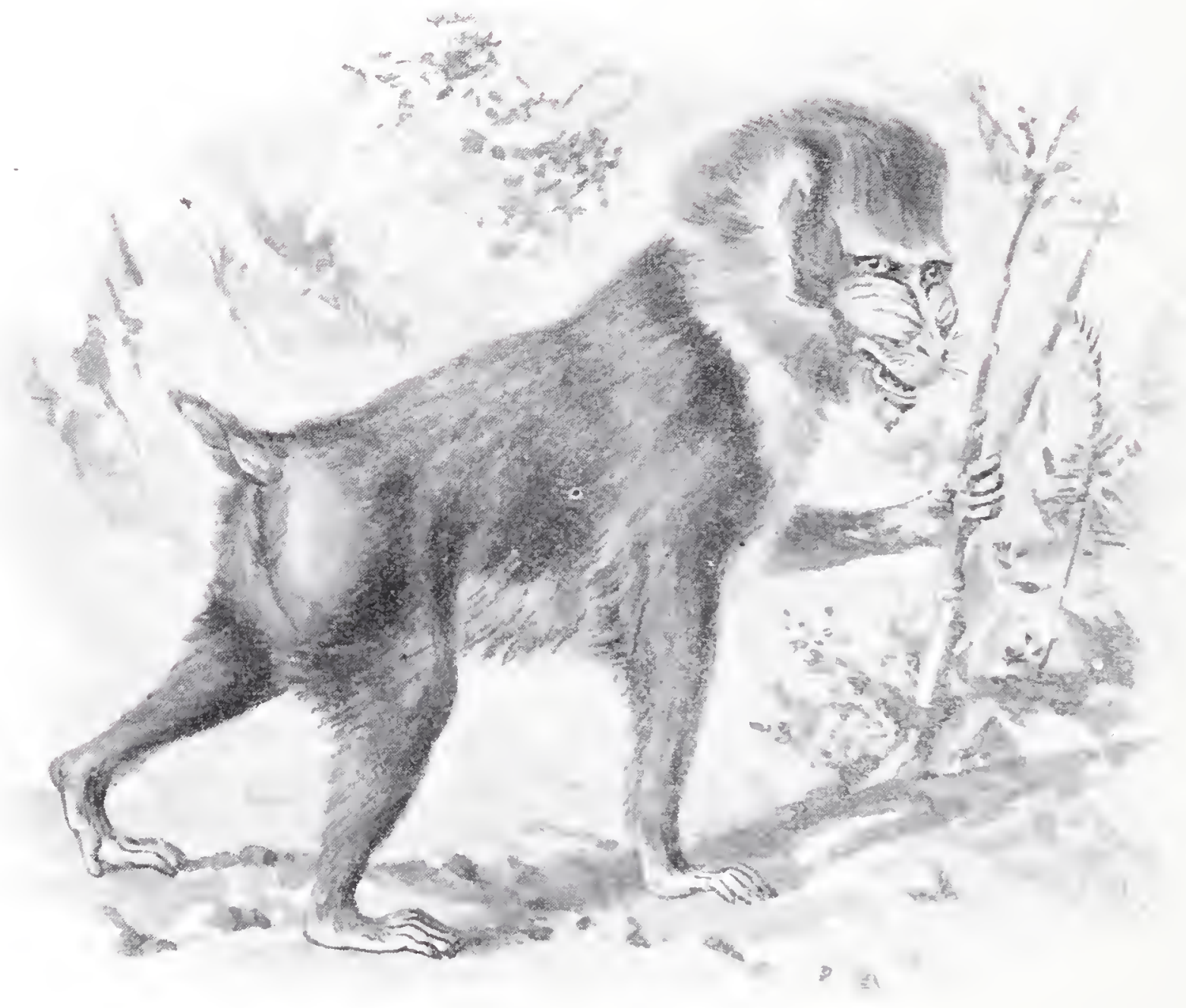

MINDRILI.

and while it is roung there is little that is remarkable about it. But the fully-grown male is a most strange-looking animal, for on each of its cheelis there is a swelling as big as a large sausage, which runs upwards from just above the nostrils to just below the eyes. These swellings are light blue, and have a number of grooves running down them, which are coloured a rich purple, while the line between them, as well as the tip of the nose, is bright scarlet. Then the face is very large indeed in proportion to the size of the hody, and the forehead is topped by a pointer crest of upright black hair, while underneath the chin is a beard 


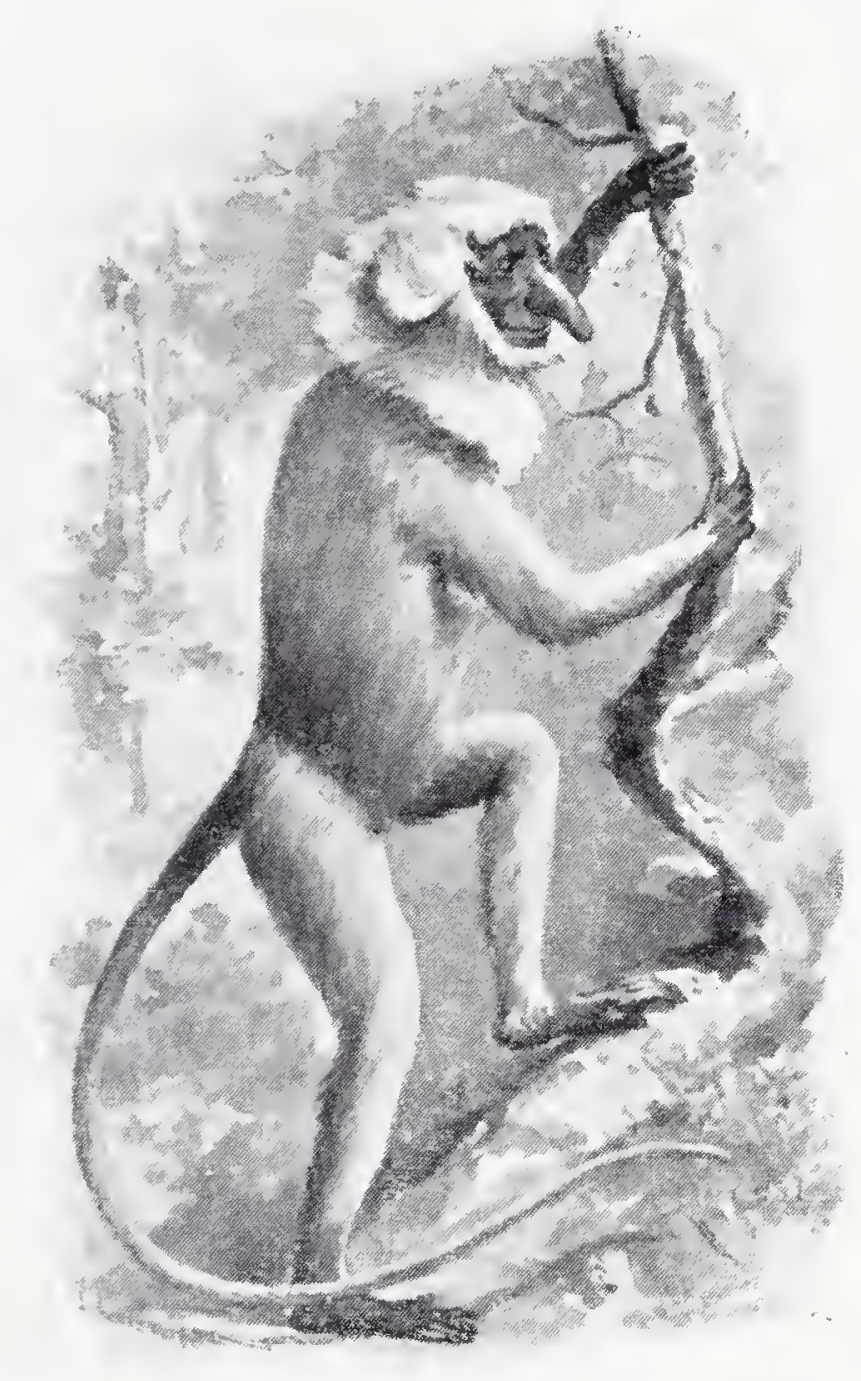

Proboscis MONKEI.

of orange yellow. Even this is not all, for on the hind quarters are two large bare patches of the same brilliant scarlet as the nose, so that altogether a grownup male mandrill is a very oddlooking creature indeed.

The female mandrill has much smaller swellings on her face, which are dull blue in colour, without any lines of either purple or scarlet.

Almost all monkeys are subject at times to terrible fits of passion, but the mandrill seems to be the worst-tempered of all. Fancy an animal dying simply from rage! It sounds impossible, doesn't it? Yet the mandrill has been linown to do so. And the natives of the countries in which it lives are quite as much afraid of it as they are of a lion.

Yet it has once or twice been tamed. If you visit the Natural History Museum at South Kensington, you may see the slin of a mandrill which lived for some years in London, during the earlier part of the nineteenth century. His name was Jerry, and he was so quiet and contented that he was generally known as "Happy Jerry" in consequence. He learned to smoke a pipe. He was very fond of a glass of beer. He even used to sit at table for his meals, and to eat from a plate by means of a knife and fork. And he became so famous that he was actually taken down to Windsor to appear before King George the Fourth!

There is another baboon called the DRILL, which is not unlike the mandrill in many respects. But the swellings on its face are not nearly so large and remain black all through its life. It is a much smaller animal, too, and looks, on the whole, very much like a mandrill while it is quite young.

Almost as odd-looking as the mandrill, although in quite a different way, is the Gelada, which is found in Abyssinia. Perhaps we may compare it to a black poodle with a very long and thick mane upon its neck and shoulders. When the animal sits upright this mane entirely covers the upper part of its shoulders, so that a gelada looks very much as if it were wearing a coachman's mantle of long fur. 
In some parts of Abyssinia geladas are very plentiful, living among the mountains in bands of two or three hundred. Like the chacmas in South Africa, they are rery mischievous in the orchards and plantations, always making their raids by night. And it is said that on one occasion they actually stopped no less a person than a l)uke of Coburg-Gotha, and prevented him from proceeding on his journey for sereral hours.

The story is that as the Dulie was travelling through Abyssinia his road lay through a narrow pass, overhung with rocky cliffs; that one of his attendants, catching sight of a number of geladas upon the rocks ahove, fired at them; that the angry baboons at once hegan to roll down great stones upon the path helow, and that hefore they could be driven off they succeeded in completely blocking the road, so that the Duke's carriage could not he moved until the stones had been cleared away.

Whether this story is altogether true or not, l cannot say. But there can be no doubt that geladas are very warlike animals. Not only will they attack human beings who interfere with them, they also attack other bahoons. When they are raiding an orchard, for instance, they sometimes meet with a band of Arabian baboons, which have come there for the same purpose as themselves. A fierce battle then talies place. First of all the geladas try to roll down stones upon their rivals. Then they rush down and attack them with the utmost fury, and very soon the orchard is filled with maddened baboons, tumbling and rolling over one another, biting and tearing and scratching each other, and shrieking with furious rage.

The Arabian Baboon itself is a very interesting creature, for it is one of the animals which were worshipped by the ancient Egyptians. They considered it as sacred to their god Thoth, and treated it with the greatest possible honour; and when it died they made its body into a mummy, and buried it in the tombs of the lings. Sometimes, too, they made use of the animal while it lived, for they would train it to climb a fig tree, pluck the ripe figs, and hand them down to the slaves waiting below.

These baboons sometimes travel along in great companies. The old males always go first, and are closely followed by the females, those which have little ones carrying them upon their hacks. As they march along, perhaps, one of the younger animals finds a bush with fruit upon it, and stops to eat a little. As soon as they see what he is doing, a number of others rush to the spot, and begin fighting for a share. But generally one of the old males hears the noise, boxes all their ears and drives them away, and then sits down and eats the fruit himself.

Next we come to a group of animals which are called "Dog-shaped MIonkey's," and the most curious of them all is the Proboscis Monkey.

This is the only monlicy which really possesses a nose. 


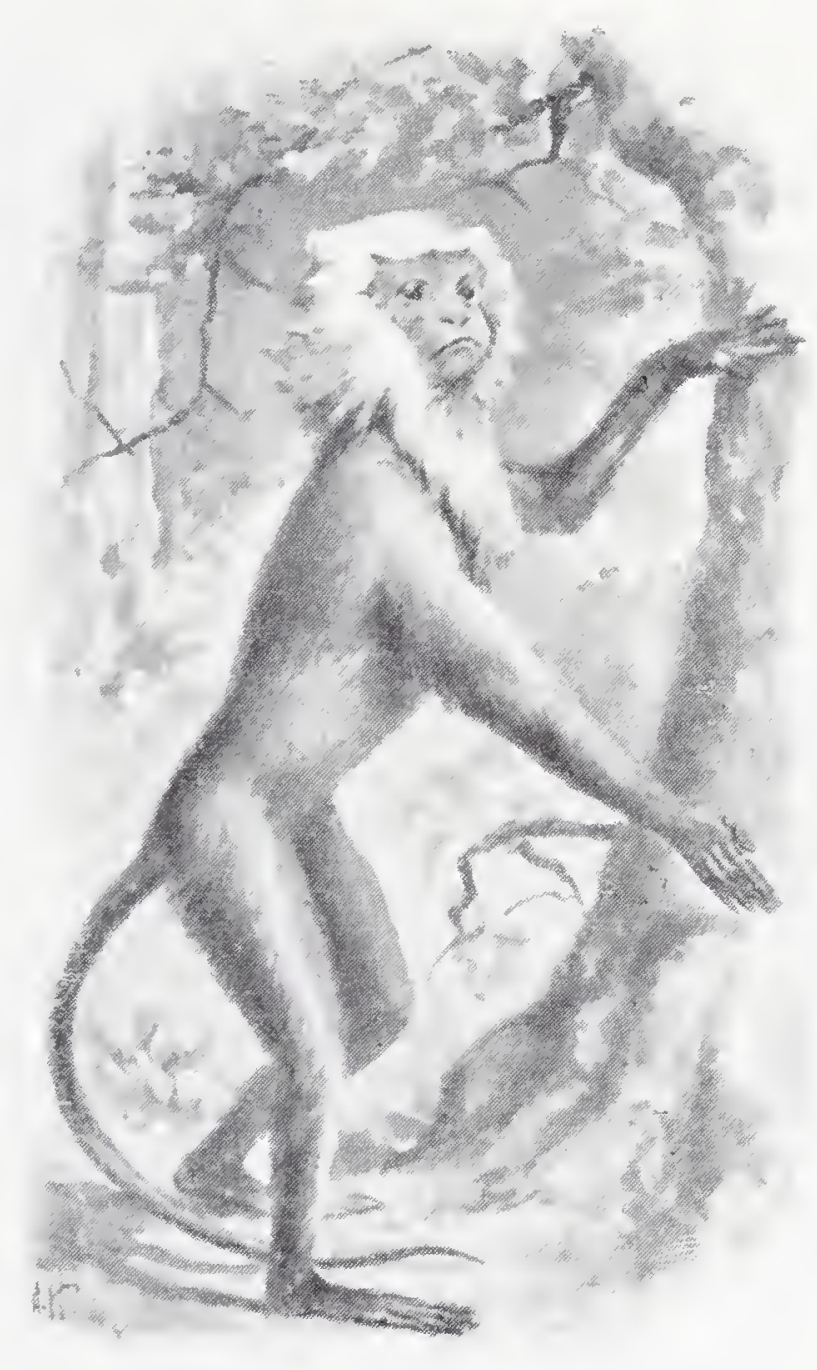

HANUMAN.

Some monkeys possess nostrils only, and some have muzzles, but the proboscis monkey has not inerely a nose, but a very long nose indeed. So long is this member, in fact, that when one of these monkeys is leaping about in the trees it is said always to keep its nose carefully covered with one hand, so that it may not be injured by a knock against a bough.

Strange to say, it is only the maleanimal which possesses this very long nose, and even he does not get it until he is grown up. Indeed, you can tell pretty well how old a male proboscis monley is just by glancing at his nose. When he is young it is quite small. As he gets older it grows bigger. And by the time that he reaches his full size it is three or four inches long.

Naturally this long nose gives him a very strange appearance, and his great bushy whisliers, which meet underneath his chin, make him look even more curious still.

Tre do not know very much about the habits of the proboscis monkey, for it has only once been brought alive to this country, and even then it only lived for a very few weelis. But in Borneo, its native country, it lives in the thick forests, and is said to be almost as active among the branches of the trees as the gibbons themselves. The Dyalis do not believe that it is a monkey at all, but say that it is really a very hairy man, who insists on living in the forests in order to escape paying taxes.

The Hanuman, another of the dog-shaped monlieys, lives in India, where it is treated with almost as much reverence as the Arabian Baboon was in Egypt in days of old.

The natives do not exactly worship these monkeys, but they think that they are sacred to the god Ilanuman, from whom they take their name. Besicles that, they believe that these animals are not really monlieys at all, but that their bodies are inhabited by the souls of great and holy men, who lived and died long ago, but have now come back to earth again in a different form. So no Hindoo will ever lill a hanmman monkey or injure it in any way, no matter how much mischief it may do. The conse- 
quence is that these animals are terrible thieves. They know perfectly well that no one will try to kill them, or even to trap them, so they come into the villages, visit the bazaars, and help themselves to anything to which they may take a fancy. Yet all that the fruit-sellers will do is to place thorn-bushes on the roofs of their shops to prevent the monkeys from sitting there.

European sportsmen, however, often find the hanuman very useful indeed. For its greatest enemy is the tiger, and when one of these animals is being hunted a number of hanumans will follow it wherever it goes, and point it out to the beaters by their excited chattering.

Next to the tiger, the hanuman dislikes snalies more than any living creature, and when it finds one of these reptiles asleep it will creep cautiously up to it, seize it by the neck, and then rub its head backwards and forwards upon a branch till its jaws have been completely ground away.

The hanuman belongs to a group of monkeys which are called Langurs. They may be known by their long and almost lanky bodies, by the great length of their tails, and by the fact that they do not possess the cheek pouches which many other monkeys find so useful. And it is very curious that while the arms of the apes are longer than their legs, the legs of the langurs-which are almost as active in the trees-are longer than their arms.

If you ever happen to see a hanuman-at the \%oo, perhaps -you may know it at once by its black face and feet, and by its very odd eyebrows, which are very bushy indeed, and project quite a long way in front of its face.

We now come to the GuEnons, of which there are a great many kinds. Let us take two of these as examples of the rest. The first shall be the Green MonkEY, which comes from the great forests of Western Africa. You must linow it very well indeed by sight, because it is the commonest monkey in every menagerie. It is one of the monkeys, too, which organgrinders so often carry about on their organs. But they do not care to have it except when it is quite young, for although it is very gentle and playful until it reaches its full size, it afterwards becomes fierce and sullen, and as apt at any moment to break out into furious passion.

Like most of the guenons, green monkeys go about in droves, each under the leadership of an old male, who wins and keeps his position by fighting all his rivals. Strange to say, each of these droves seems to have its own district allotted to it; and if by any chance it should cross its boundary, the band into whose territory it has trespassed will at once come and fight it, and do their utmost to drive it back.

Wouldn't it be interesting to know how the animals mark out their own domains, and how they let one another know just how far they will be permitted to go? 
Our second example of the guenons shall be the DIANA Monker, which you may at once recognise by its long, pointed, snow-white beard. It seems to be very proud indeed of this heard, and always holds it carefully back with one hand, while it is drinking, in order to prevent it from getting wet.

Why is it called the "Diana" monkey? Because of the curious white mark upon its forehead, which is shaped like the

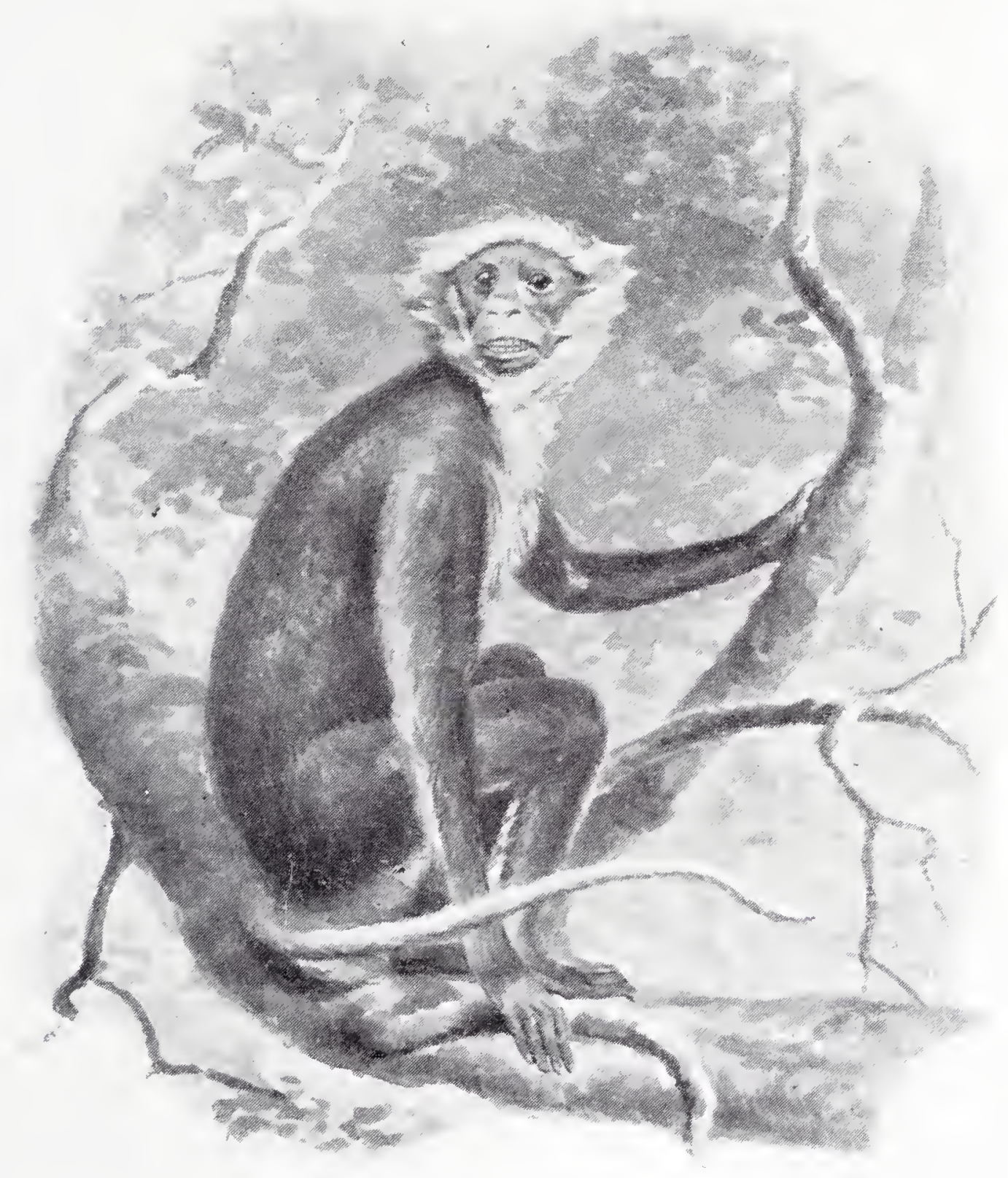

CIRERA MONKEI.

crescent which the ancients used to think was borne by the goddess Diana. It is a very handsome animal, for its back is rich chestnut brown in colour, and the lower part of its body is orange yellow, while between the two is a band of pure white. Its face and tail and hands and feet are black. It is a very gentle animal, and is very easily tamed.

The Mangabeys are very odd-looking monkeys, for they 
all have white eyelids, which are very conspicuous in their sootyblacli faces. Indeed, they always give one a kind of idea that they must spend their whole lives in sweeping chimneys.

These are among the most interesting of all monkeys to watch, for they are not only so active and full of life that they scarcely seem able to keep still, but they are always twisting their bodies about into all sorts of extraordinary attitudes. When they are kept in captivity they very soon find out that visitors are amused by their antics, and are always ready to go through their performances in order to obtain a nut or a piece of cake.

Then they have an odd way, when they are walking about their cages, of lifting their upper lips and showing their teeth, so that they really look just as if they were grinning at you. And instead of carrying their tails behind them, as monkeys generally do, or holding them straight up in the air, they throw them forward over their back, so that the tip comes just above the head.

Only four kinds of mangabey are known, and they are all found in Western Africa.

There is just one more family of monkeys found in the Old World which I must mention, and that consists of the animals which are known as MACAQUES. They are natives of Asia, with one exception, and that is the famous MAGOT, the only monkey which lives wild in any part of Europe. It inhabits the Rock of Gibraltar, and though it is not nearly as common as it used to be, there is still a band of twenty or twenty-five of these animals with which nobody is allowed to interfere. They move about the Rock a good deal. When the weather is warm and sumny, they prefer the side which faces the Mediterranean, but as soon as a cold easterly wind springs up they all travel round to the western side, which is much more sheltered. They always lieep to the steepest parts of the cliff, and it is not at all easy to get near enough to watch them. And generally the only way to see them at all is by means of a telescope.

The Nagot is sometimes known as the Barbary Ape, althougl $h_{1}$ of course it is not really an ape at all. But it is very common in Barbary, and two or three times, when the little band of monkeys on the Rock seemed in danger of dying out, a few specimens have been brought over from Africa just to malie up the number.

The only other member of this family that I can mention is the Crab-eating Macague, which is found in Siam and Burmah. It owes its name to its fondness for crabs, spending most of its time on the banlis of salt-water creels in order to search for them. But perhaps the strangest thing about it is that it is a splendid swimmer, and an equally good diver, for it has been known to jump overboard and to swim more than fifty yards under water, in its attempts to avoid recapture. 


\section{CHAP'TER III.}

\section{THE AMERICAN MONKEYS ANI) THE LEMURS.}

A GREA'l many very curious monleys live in America; and in several ways they are very different from those of Africa and Asia.

Most of the Old Irorld monkeys, for example, possess large cheek-pouches, in which, after eating a meal, they can carry away nearly enough food for another. No doubt you have often seen a monliey with its cheelis perfectly stuffed out with nuts. But in the American monlieys these pouches are never found.

Then no American monliey has those bare patches on its hind quarters which are present in all the monkeys of the Okl World, with the exception of the great apes, and which are often so brightly coloured. And, more curious still, no American monkey has a proper thumb. The fingers are generally very long and strong; but the thumb is either wanting altogether, or else it is so small that it cannot be of the slightest use.

Perhaps the most curious of all the American monkeys are the Spider Monkeys, which really look very much indeed like big black spiders when one sees them gambolling among the branches of the trees. The reason is that their bodies are very slightly built, and their arms and legs are very long and stender, while the tail is often longer than the head and body together, and looks just like an extra liml. And indeed it is used as an extra limb, for it is "prehensile"; that is, it can be coiled round any" small object so tightly as to obtain a very firm hold. A spider monkey never likes to take a single step without first twisting the tip of its tail round a branch, so that this member really serves as a sort of fifth hand. Sometimes, too, the animal will feed itself with its tail instead of with its paws. Ind it can even hang from a bough for some little time by means of its tail alone, in order to pluck fruit which would otherwise be out of its reach.

Owing partly, no doubt, to constant use, the last few inches of this wonderful tail are quite bare underneath, without any hair at all.

When a spider monkey finds itself upon level ground, where its tail, of course, is of no use to it, it always seems very uncomfortable. But it manages to keep its balance as it walks along by holding the tail over its back, and just turning it first to one side, and then to the other side, just as the need of the moment may require. It uses it, in fact, very much as an acrobat uses his pole when walling upon the tight rope. 
It is rather curious to find that while other monkeys are very fond of nibbling the tips of their own tails, often making them quite raw, spider monkeys never do so. They evidently know far too well how useful those members are to injure them by giving way to such a very silly and unpleasant habit-which is even worse than biting one's nails, isn't it?

When a spider monkey is shot as it sits in a tree, it always coils its tail round a branch at once. And even after it dies, the lody will often hang for several days suspended by the tail alone.

These monkeys spend almost the whole of their lives in the trees, feeding upon fruit and leaves, and only coming down to the ground when they want to drink. As a general rule they are dreadfully lazy creatures, and will sit on a bough for hours together without moving a limb. But when they are playful, or excited, they swing themselves to and fro and dart from branch to branch, almost as actively as the gibbons themselves.

Very much like the spider monlieys are the Howlers, which are very common indeed in the great forests of Central America. They owe their name to the horrible cries which they utter as they move about in the trees by night. You remember, no doubt, how the gibbons hold a lind of concert in the tree-tops every morning and every evening, as though to salute the rising and the setting sun. Well, the howlers behave in just the same way, except that their concert begins soon after darli and goes on all through the night. 'They have very powerful voices indeed, and travellers who are not used to their noise say that it is quite impossible to sleep in the forest if there is a troop of howlers anywhere within a couple of miles. And it is very hard to believe that the outcry comes from the throats of monkeys at all. "You would suppose," says a famous traveller, "that half the wild beasts of the forest were collecting for the work of carnage. Now it is the tremendous roar of the jaguar, as he springs upon his prey; now it changes to his terrible and deep-toned growlings, as he is pressed on all sides by superior force; and now you hear his last dying groan beneath a mortal wound. One of them alone is capable of producing all these sounds; and if you advance cautiously, and get under the high and tufted trees where he is sitting, you may have a capital opportunity of witnessing his wonderful powers of producing these dreadful and discordant sounds."

If one monkey alone is capable of roaring as loudly as a jaguar, think what the noise must be when fifty or sixty howlers - perhaps even more-are all howling at the same time. No wonder travellers find it difficult to sleep in the forest.

Perhaps the best known of these monlieys is the RED Howler, which has severai times been brought to the Zoo. Its colour is reddish brown, with a broad band of golden yellow running along the spine, while its face is surrounded by bushy whiskers and beard. 


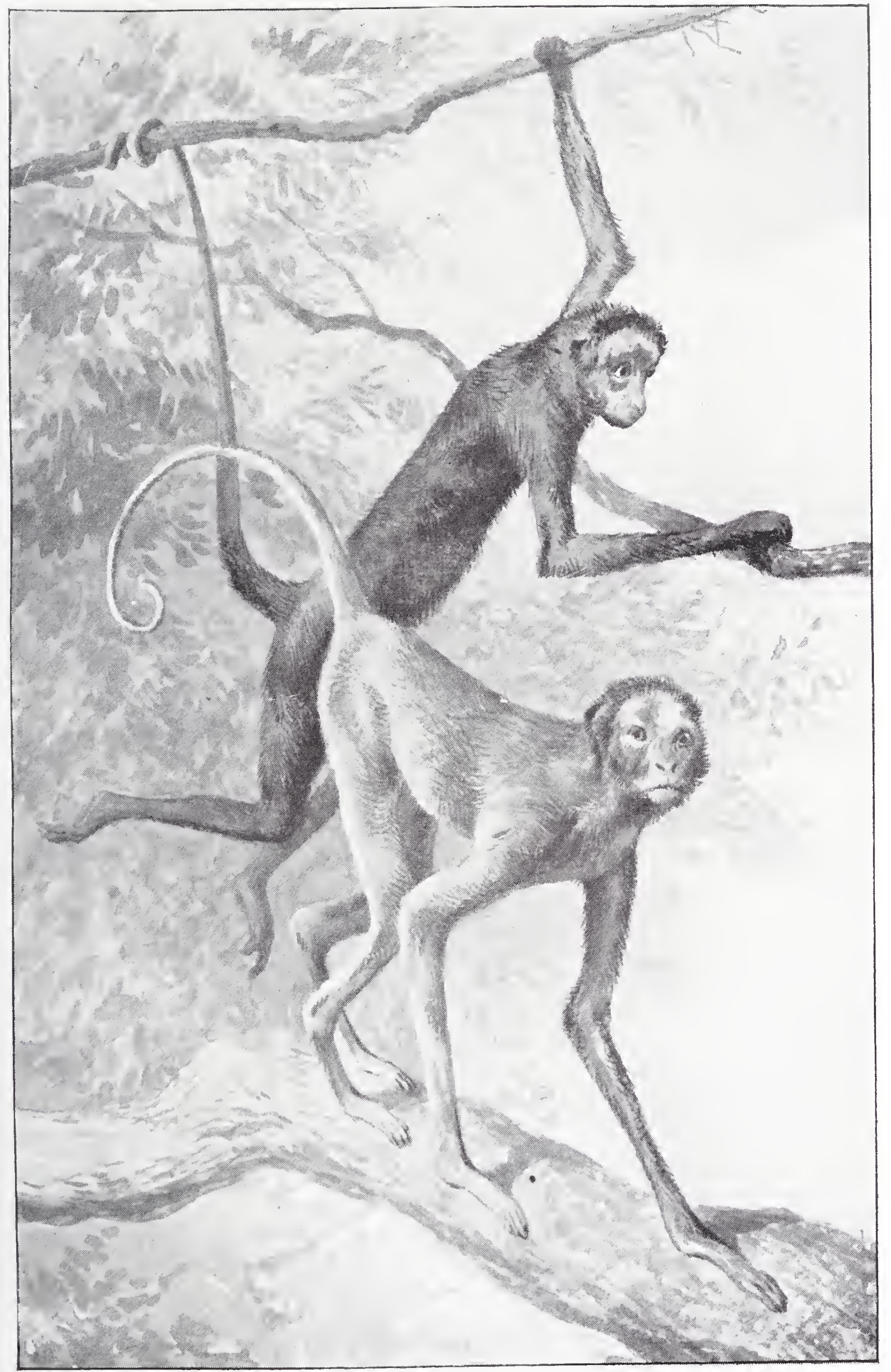

SPIDEK MONKEJS. 

Another very curious American monkey is the RED-FACED OU.MKIRI. If you were to see it from a little distance you would most likely think that it was suffering from a bad attack of scarlet fever; for the face and the upper part of the neck are bright red in colour, as though they had been smeared with vermilion paint. And as its whiskers and beard are sancly yellow, it is really a very odd-looking animal indeed.

If an ouakari is unwell, strange to say, the bright colour

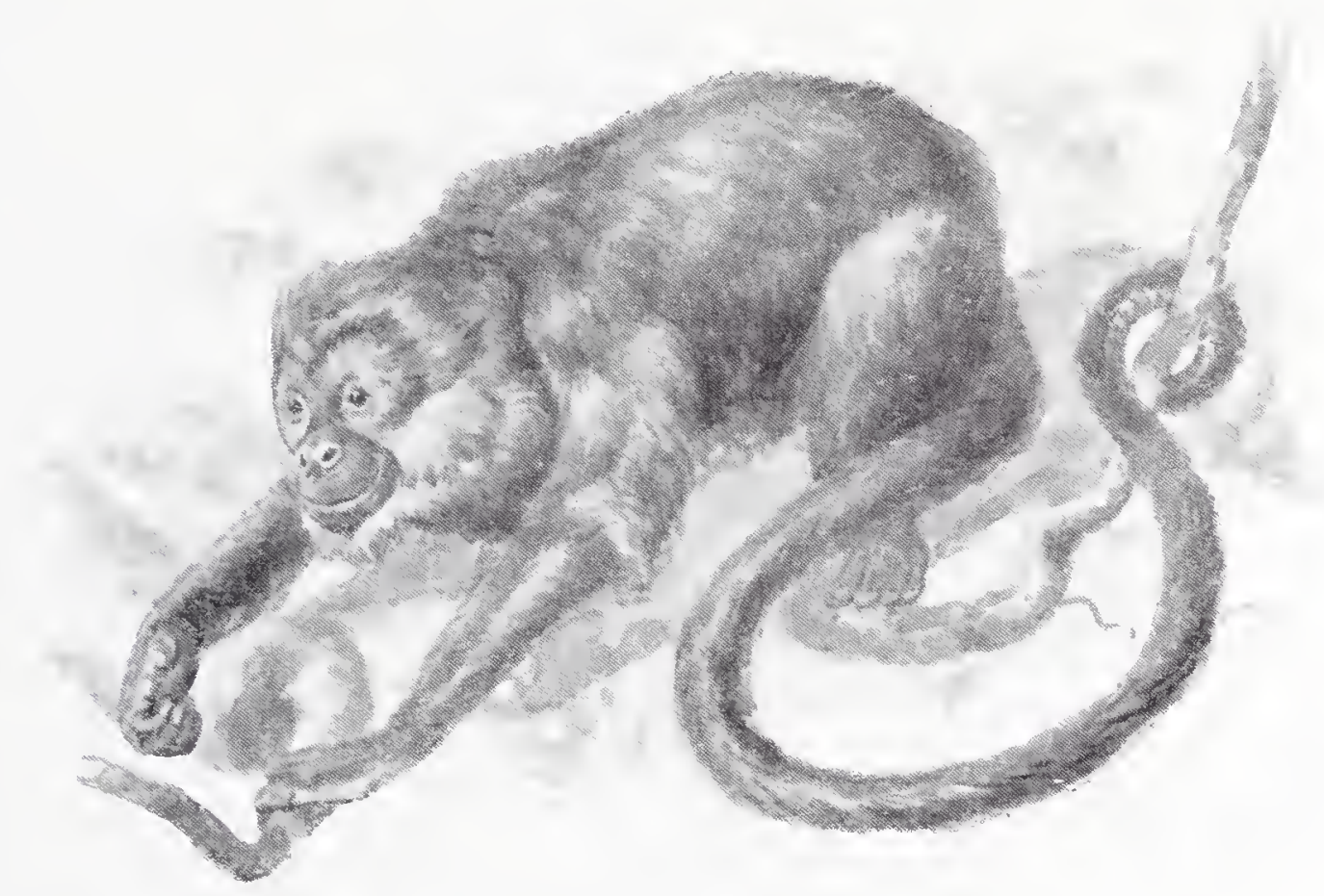

RED HOWIER.

of its face begins to fade at once, and very soon after death it disappears altogether.

Ouakaris are generally caught in a very singular way. They are only found in a very small district on the southern bank of the River Amazon, and spend their whole lives in the topmos: branches of the tallest trees, where it is quite impossible to follow them. And if they were shot with a gun, of course, they would almost certainly be killed. So they are shot with a blow-pipe instead. A slender arrow is dipped into a kind of poison called "wourali," which has been diluted to about half its usual strength, and is then discharged at the animal from below. Only a very slight wound is caused, but the poison is still so strong that the ouakari soon faints, and falls from its perch in the branches. But the hunter, who is carefully watching, catches it in his arms as it falls, and puts a little salt into its mouth. This overcomes the effect of the poison, and very soon the little animal is as well as ever.

Ouakaris which are caught in this way, however, are generally very bad-tempered, and the gentle and playful little animals which are sometimes brought over to this country have 
generally been born in captivity, or else have been taticn whon they werc very young indeed. 'They are very delicate creatures, and nearly always die after a very few weelis of confinement.

If you were to see a Cuxio, or Black Salis, as it is often called, the first thing that you would say would most likely be, "Vliat an extraordinary beard!" And your next remark would be, "Vlhy, it looks as if it were wearing a wig!" For its projecting blacli leard is as big as that of the most heavilylearded man you ever saw, while on its head is a rreat mass of long blacli hair, neatly parted in the middle, and hanging down on either side, so that it looks just like a wig which has heen rather clumsily made.

The cuxio is extremely proud of its beard, and talies very sreat pains to prevent it from getting either dirty or wet. Do you remember how the Diana monliey holds its beard with one hand while drinking, so as to keep it from touching the water? Well, the cuxio is more careful still, for it will not put its lips to the water at all, but carries it to its mouth, a very little at a time, in the palm of its hand. But the odd thing is that it seems rather asluamed of thinling so much about its personal appearance, and, if it knows that anybody is looking at it, will drink just like any other monliey, and pretend not to care about wetting its beard at all.

Like most of the salis, the cuxio is not at all a goodtompered animal, and is apt to give way to sudden fits of furious passion. So savagely will it bite when enraged that it has actually been known to drive its teeth deeply into a deal board. The cuxio is found only in Brazil.

Very odd little animals, too, are the Douroucoulis. Sometimes they are called "Night Monlieys," because all day lons they are fast asleep in a hollow tree. Soon after sunset they wake up. Then all night long they are prowling about the branches of the trees, searching for roosting birds, and for the other small creatures upon which they feed. 'They are very active, and will often strike at a moth or a beetle as it flies by, and catch it in their deft little paws. And their eyes are made very much like those of cats, so that they can see just as well on a darli night as other monkeys can during the day.

The eyes, too, are very large. If you were to look at the skull of a douroucouli, you would notice that the eye-socliets almost meet in the middle, only a very narrow strip of bone dividing them. And the hair which surrounds them is set in a circle, just like the feathers which surround the eyes of an owl.

But perhaps the most curious fact about these animals is that sometimes they roar lilie jaguars, and sometimes they barli like dogs, and sometimes they mew like cats.

There are several different kinds of these little monkeys, the most plentiful, perhaps, being the ThrEe-BANDen Douroucour., 
which has three upright black stripes upon its forehead. They are all natives of Brazil, and other parts of tropical America.

One of the prettiest-perhaps the very prettiest-of all monkeys is the MARMOset, which is found in the same part of the world. It is quite a small animal, being no bigger in body than an English squirrel, with a tail about a foot long. This tail, which is very thick and bushy, is white in colour, encircled

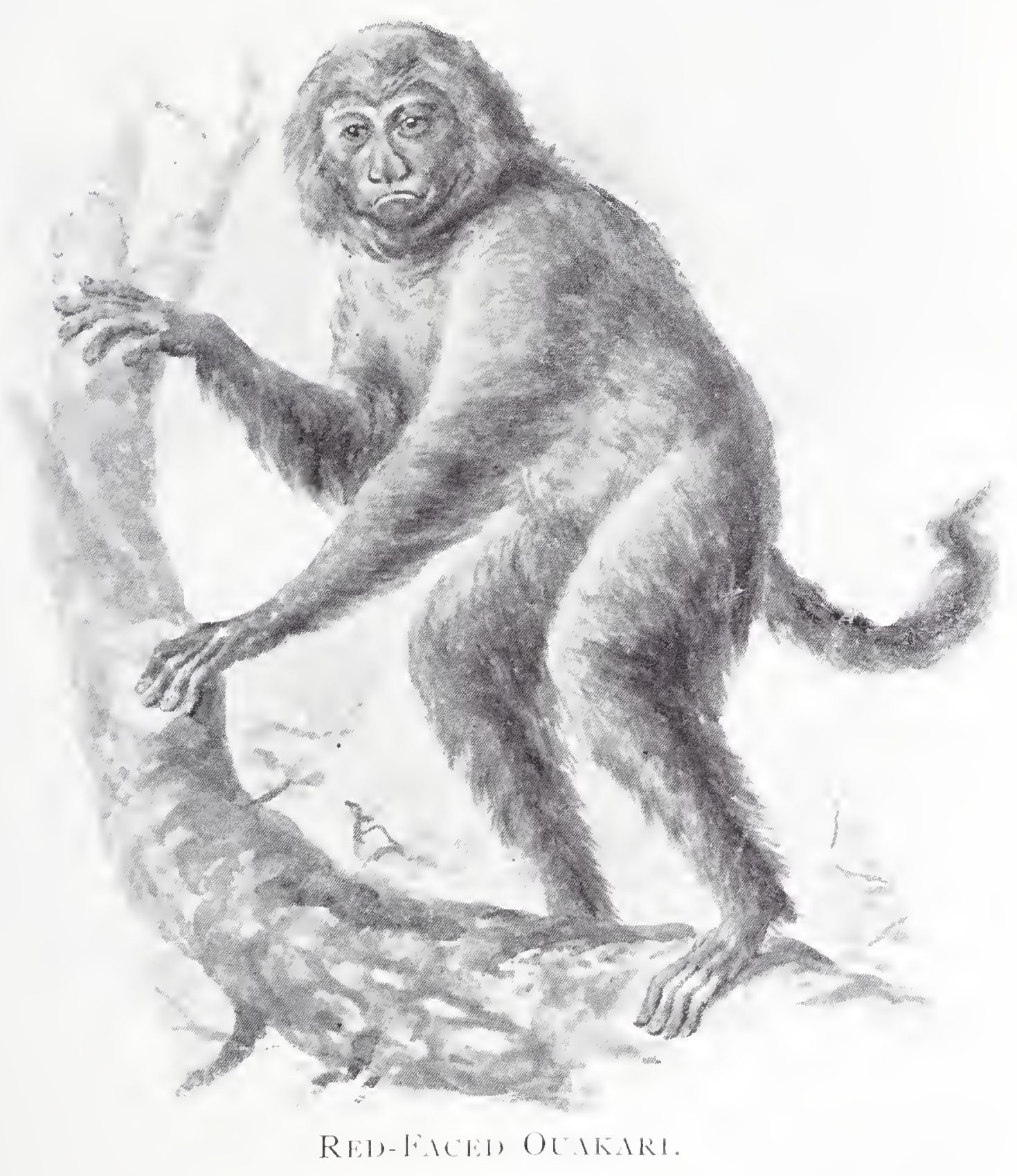

with a number of black rings, while the body is blackish with grey markings, and the face is black with a white nose. But what one notices more than anything else is the long tufts of snowy white hair upon the ears, which make the little animal look something like a white-haired negro.

Marmosets are very easily tamed, and they are so gentle in their ways, and so engaging in their habits, that if only they were a little more hardy we should most likely see them in this 


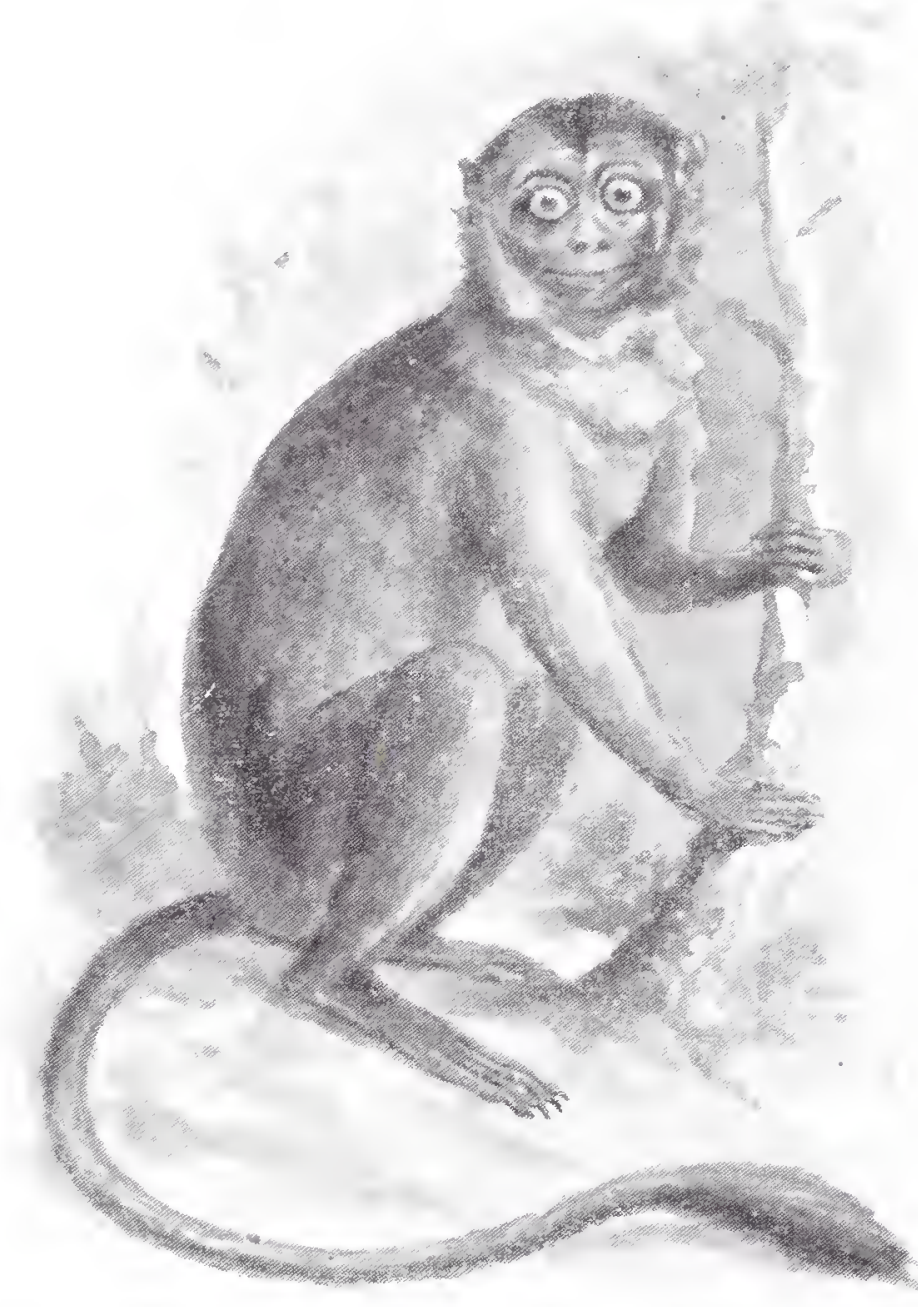

1)OLROLCOLISIS.

country as often as we see pet cats. Thut they are delicate little creatures, and cannot bear cold, so that they sekiom live for more than a very few months when they are brought over to England. This is a great pity, because what they like to eat most of all is the so-called "Hlack bectle" of our litchens. If only we could lieep pet marmosets, they would very soon clear our houses of cockroaches, as these troublesome creatures ought to be called. They will spend hours in hunting for the insects, and whenever they catch one they pull off its legs and wings, and then proceed to devour its body.

When a marmoset is suddenly alarmed, it utters an odd little whistling cry. Owing to this habit it is sometimes known as the Onistiti.

Last among the monkeys come those very strange animals which are called Lenurs. The reason why that name has been given to them is this. "Lemurs," by the ancients, were supposed to be ghosts which wandered about by night. Now most of the lemurs are never seen abroad by day. Their eyes cannot bear the bright sunlight; so all day long they sleep in hollow trees. But when it is quite dark they come out, prowling about the branches so silently and so stealthily that they really seem more like spectres than living animals.

When you see them close, they do not look very much like monkeys. Their faces are much more like those of foxes, and they have enormous staring eyes without any expression in them at all.

The true lemurs are only found in Madagascar, where they are so plentiful that two or three at least may be found in every little copse throughout the island. More than thirty different linds are known, of which, however, we cannot mention more than two.

'The first of these is the Ring-TAILED Lenur, which may be recognized at once by the fact that its tail is marlied just like that of the marmoset. The head and hody are shaped like those 
of a very small fox, and the colour of the fur is ashy grey, rather darker on the back, and rather lighter underneath. It lives in troops in Central Madagascar, and every morning and every night each troop joins in a little concert, just like the gibbons and the howlers.

But, oddly enough, this lemur is very seldom seen in the trees. It lives on the ground, in rough and rocky places, and its hands and feet are made in such a way as to enable it to cling firmly to the wet and slippery boulders. In fact, they are not

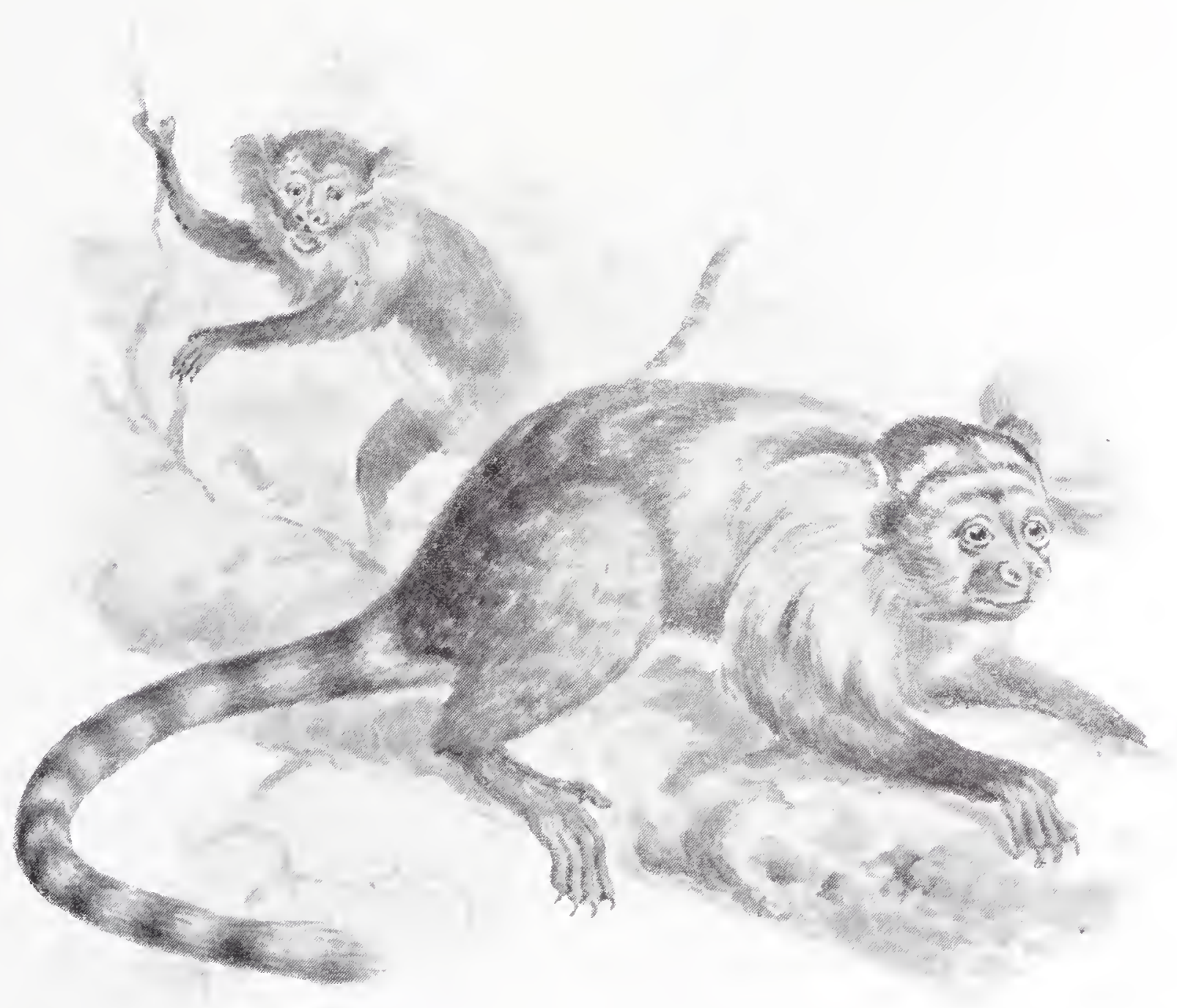

MARMOSETS.

at all unlike the feet of a house-fly. The body is clothed with very long fur, and when a mother lemur carries her little one about on her back it burrows down so deeply into her thicli coat that one can scarcely see it at all.

The RUfFeD Learur is the largest of these curious animals, being about as big as a good-sized cat. The oddest thing about it is that it varies so very much in colour. Sometimes it is white all over, sometimes it is partly white and partly black, and sometimes it is reddish brown. Generally, however, the shoulders and 
front legs, the middle of the back, and the tail are black, or very dark brown, while the rest of the body is white. And there is a great thick "ruff" of white hairs all round the face.

The eyes of this lemur are very singular. You know, of course, how the pupil of a cat's-eye becomes narrower and narrower in a strong light, until at last it looks merely like an upright slit in the eyeball. Well, that of the lemur is made in very much the same way, except that the pupil closes up from above and below instead of from the sides, so that the slit runs arross the eyeball, and not up and down.

The Stender Loris may be described as a lemur without a tail, and is found in the forests of Southern India and Ceylon. It is quite small, the head and body being only about eight inches long, and in general appearance it gives one rather the idea of a bat without any wings. In colour it is dark grey, with a narrow white stripe between the eyes.

This animal has a very queer way of going to sleep. It sits on a bough and rolls itself up into a ball with its head tuclied away between its thighs, while its hands are tightly folded round a branch springing up from the one on which it is seated. In this attitude it spends the whole of the day. At night it hunts for sleeping birds, moving so slowly and silently among the branches as never to give the alarm, and always plucking off all their feathers before it proceeds to eat them. Strange to say, while many monkeys have no thumbs, the slender loris has no forefingers, while the great toes on its feet are very long indeed, and are directed backwards instead of forwards.

Then there are two lemurlike animals which are so extraordinary that each of them has heen put into a family all by itself.

The first of these is the 'TARSIER, which is found in several of the larger islands in the Malay Archipelago. Imagine an animal about as big as a small rat, with a long tail covered thickly with hair at the root and the tip, the middle part being smooth and hare. The eyes are perfectly round, and are so big that they seem to occupy almost the whole

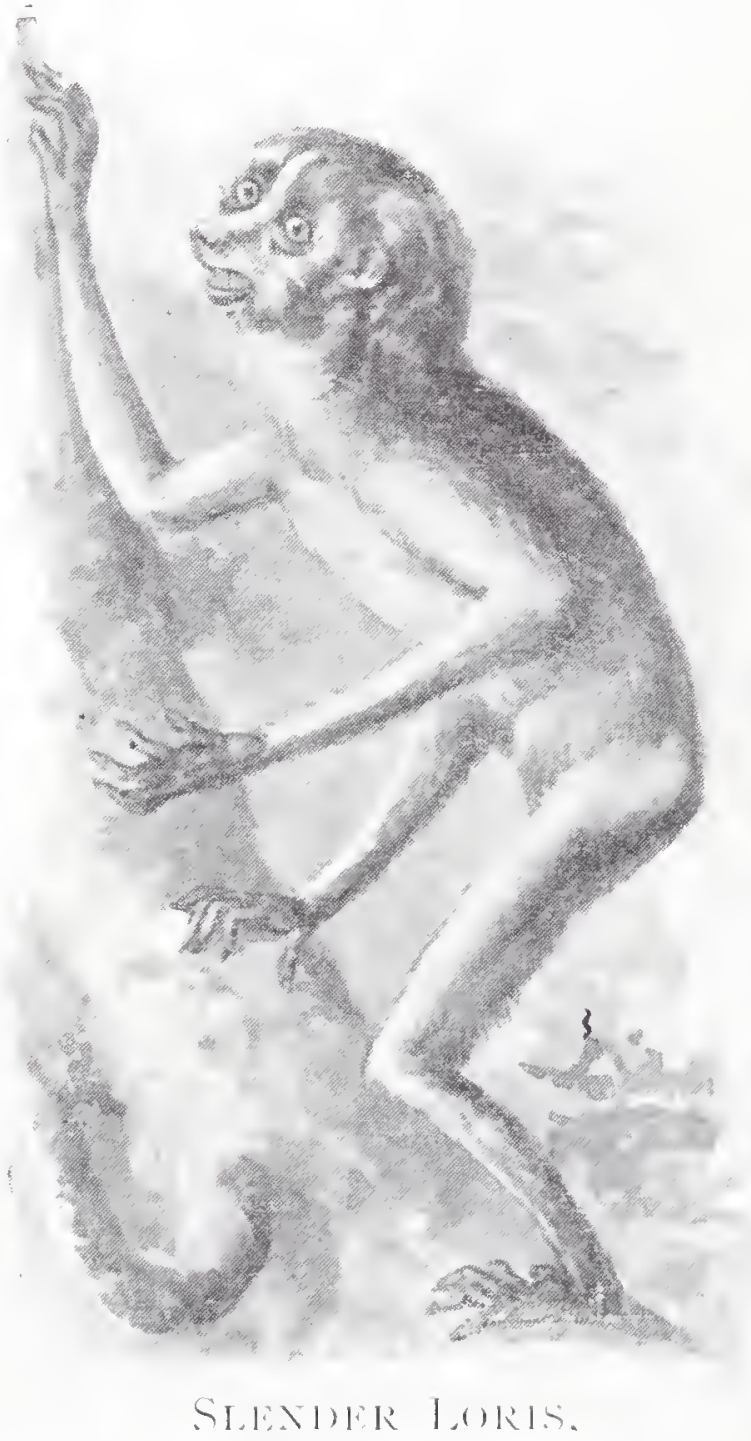


of the face-great goggle staring eyes, with very small pupils. The ears are very long and pointed, and stand almost straight up from the head. Then the hind legs are so very long that they remind one of those of a kangaroo, while all the fingers and all the toes have large round pads underneath the tips, which seem to be used as suckers, and to have a wonderful power of grasp. Altogether, the tarsier scarcely looks like an animal at all. It looks like a goblin.

This singular creature seldom seems to walk. It hops along the branches instead, just as a kangaroo hops upon the ground. And when it wants to feed it sits upright on its hind quarters, and uses its forepaws just as a squirrel does. Even more curious still is the Aye-AYE, of Madagascar, which has puzzled natural-

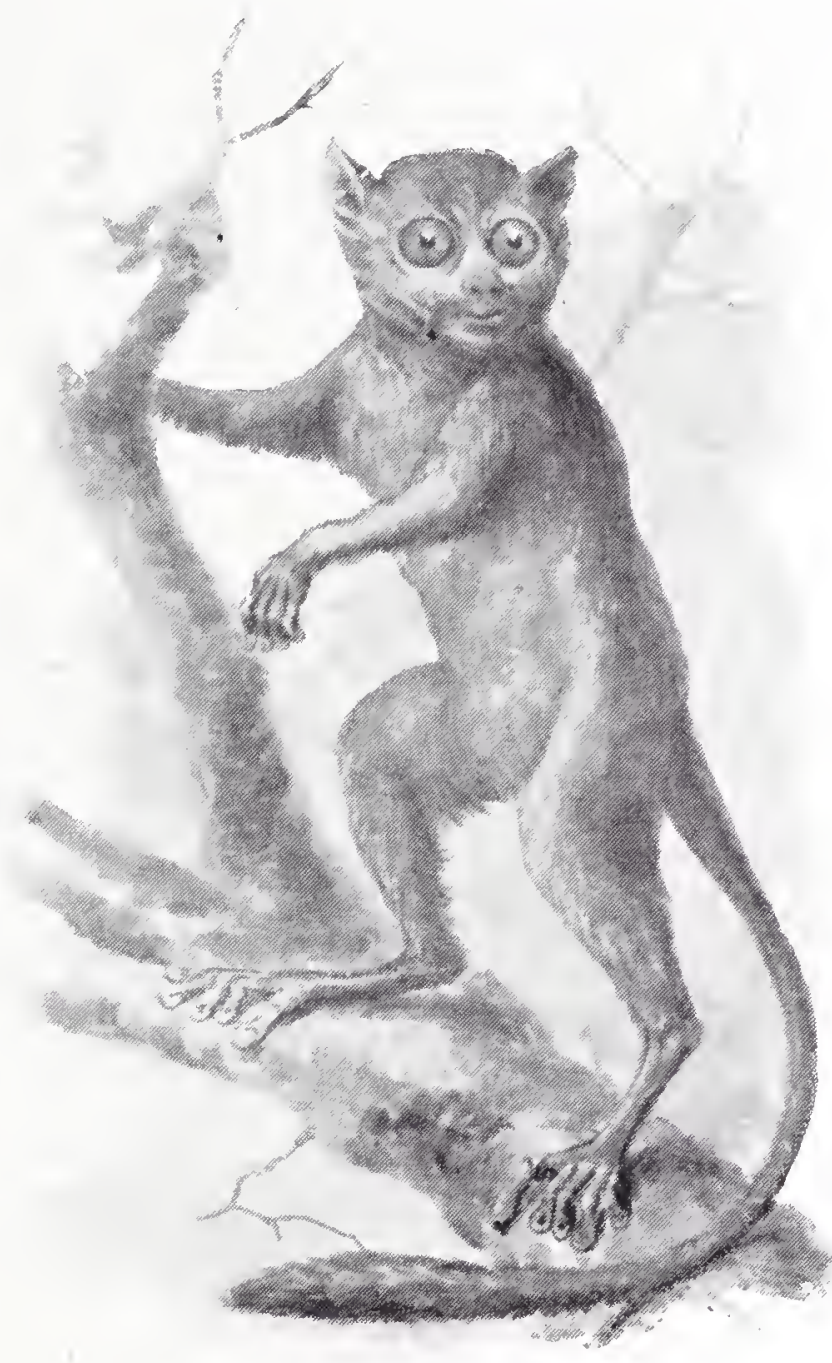

TARSIER. ists very much indeed. For its incisor teeth-the sharp cutting teeth, that is, in the middle of each jaw-are formed just like those of the rat and the rabbit. They are made, that is, not for cutting but for gnawing; and as fast as they are worn away from above they grow from beneath. For this reason it has sometimes been thought that the aye-aye is not really a monkey at all. But the way in which its hands and feet are formed shows that, odd as it is, it undoubtedly belongs to the group of the lemurs.

The hands, especially, are most curious. All the fingers are long and slender; but the middle one is longer than all the rest, and is so very thin that it looks like nothing but slin and bone. Most likely this finger, which has a sharp little claw at the tip, is used in hooking out insects from their burrows in the bark of trees. But the aye-aye does not feed only upon insects, for it often does some little damage in the sugar plantations, ripping up the canes with its sharp front teeth in order to get at the sweet juices. And it is also said at times to catch small birds, either for the purpose of eating them or else to drink their blood. And it seems to eat fruit as well, while, when it is kept in captivity, it thrives very well indeed on boiled rice. 
In size, the aye-aye is about as big as a rather small cat, and its great bushy tail is longer than its head and body put together. It is not a common animal, cven in Míadagascar, and its name of "aye-aye" is said to have been given it owing to the exclamations of surprise which were uttered by the natives when it was shown to them for the first time by an European traveller. But it is more likely that the name comes from the cry of the animal, which is a sort of sharp little bark twice repented.

Strange to say, the natives of Madagascar are very much afraid of the aye-aye. Of course it cannot do very much mischief with its teeth or claws; but they seem to think that it possesses some magic power by means of which it can injure those who try to catch it, or even cause them to die. So that they cannot be bribed to capture it even by the offer of a large reward. Sometimes, however, they catch it by mistalie, finding an aye-aye in a trap which has been set for lemurs. In that case they smear it all over with fat, which they think will please it very much indeed, and then allow it to go free.

Just now and then, however, one of these animals is brought to this country; and more than once an aye-aye has lived for some little time in the Zoo. But hardly anyone ever saw it, for all day long it was fast asleep in the middle of its straw, only coming out after sunset, when all the visitors had left the Gardens. 


\section{CHAPTER IV.}

THE BATS.

NIEXT in order to the monkeys come the BATs, the only mammals which are able to $\mathrm{fly}$. It is quite true that there are animals linown as "flying squirrels," which are sometimes thought to have the power of flight. But all that these can do, as we shall see by and by, is to talie very long leaps through the air, aided by the curious manner in which the loose slin of the body is fastened to the inner surface of the legs.

Bats, however, really can fly, and the way in which their wings are made is very curious indeed. If you were to look at a bat's skeleton, you would notice, first of all, that the front limbs were very much larger than the hinder ones. The upper arm-bone is very long indeed, the lower arm-bone is longer still, and the bones of the fingers are longest of all. The middle finger of a bat, indeed, is often longer than the whole of its body! Now these bones form the framework of the wing. You know how the silk or satin of a lady's fan is stretched upon the ribs. Well, a very thin and delicate skin is stretched upon the bones of a bat's arm and hand in just the same way. And when the little animal wants to $\mathrm{fly}$, it stretches its fingers apart, and so spreads the wing. When it wants to rest it closes them, and so folds it against its body.

'Then you would notice that a high bony ridge rums down the bat's breast-bone. Now such a ridge as this always signifies great strength. Because muscles must be fastened at each end to bones; and when the muscles are very large and powerful, the bones must be very strong in order to carry them. So, when an animal wants very strong breast muscles, so that it may be able to fly well, we always find a high bony ridge running down its breastbone; and to this ridge the great muscles which work the wings are fastened.

Something more is necessary, however, if the animal is to fly properly. It must be able to steer itself in the air just as a boat has to be steered in the water. Otherwise it would never be alnle to fly in the right direction. So Nature has given it a lind of air-rudder; for the slin which is stretched upon the wings is carried on round the end of the body, and is supported there, partly by the hind legs, and partly by the hones of the tail. And by turning this curious rudder to one side or the other, or tilting 
it just a little bit up or a little bit down, the bat is able to alter its course at will.

But you would notice something else on looking at a bat's skeleton. You would notice that the bones of the thumb are not long and slender, like those of the fingers, but that they are quite short and stout, with a sharp hooked claw at the tip. The bat uses this claw when it finds itself upon the ground. It cannot wakk, of course, as it has no front feet; so it hitches itself along by means of its thumbs, hooking first one claw into the gromnt

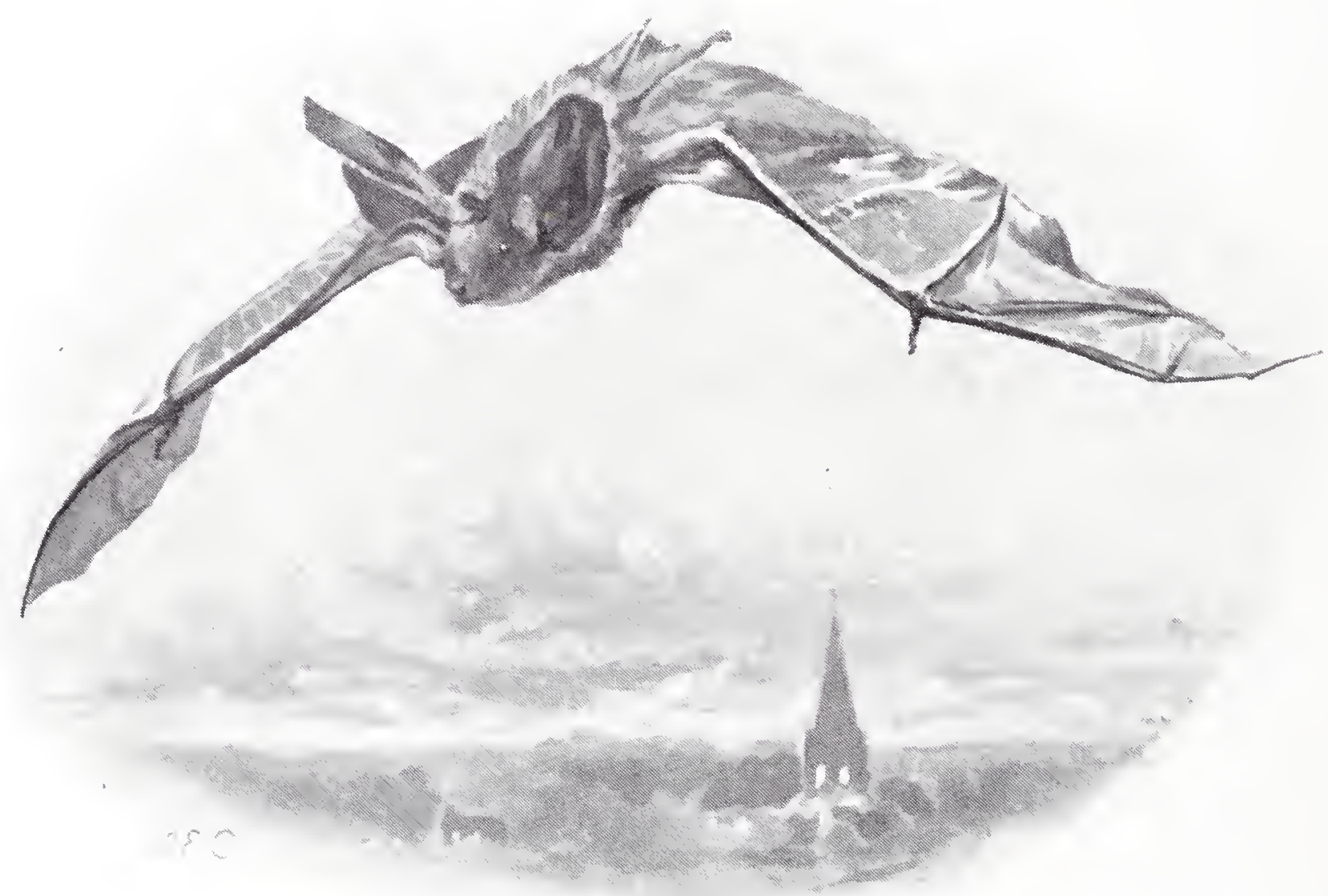

L.ONG-EAREIT-BAT'

and then the other, and so managing to drag itself slowly and awkwardly over the ground.

It is not at all fond of shuffling along in this way, however, and always talies to flight as soon as it possibly can. But as it cannot rise from the ground it always has to climb to a little height and let itself drop, so that as it falls it may spread its wings and fly away. And it always climbs in a very curious manner, with its tail upwards and its head towards the gromd, using first the claws of one little foot and then those of the other, just as we might climb a ladder hand over hand.

When a bat goes to sleep, too, it always hangs itself up by the claws of its hinder feet. In an old church tower, or a stable loft, you may often find bats suspended in this singular way. And there is a reason for it. The bat wants to be able, at the very 
lirst sign of danger, to fly away at once. Now if it lay flat upon the ground to sleep, as most animals do, it would not he able to do so; for it would have to clamber up a wall or a post to some little height before it could spread its wings. And this would take time. But if it should be alarmed while it is hanging by its hind feet, all that it has to do is to drop into the air and fly off immediately.

There is something else, too, which I must tell you about hats. They have the most wonderful power of flying about on the darkest night, without ever knocking up against the branches of trees, or any other obstacles which they may meet on their way. It used to be thought that this was because they had very lieen eyes. But it has been found that even a blind bat has this power, which seems really to be due to very sensitive nerves in the wings. You and I can feel a branch by touching it. But a bat is able to feel a branch without touching it, while it is eight or ten inches away, and so has time to swerve to one side without striking against it. Isn't that strainge?

Several different linds of bats are found in Great Britain, one of the commonest of which is the LONG-EAREI Bat. You may find it by day hanging up in a hollow tree, or perhaps behind a loose sheet of dead bark; and you can hardly go out on a warm evening between March and October without seeing it flying in some numbers. But what becomes of it between October and March? One scarcely ever sees it during the winter, except, perhaps, on a day which is very much warmer than usual,

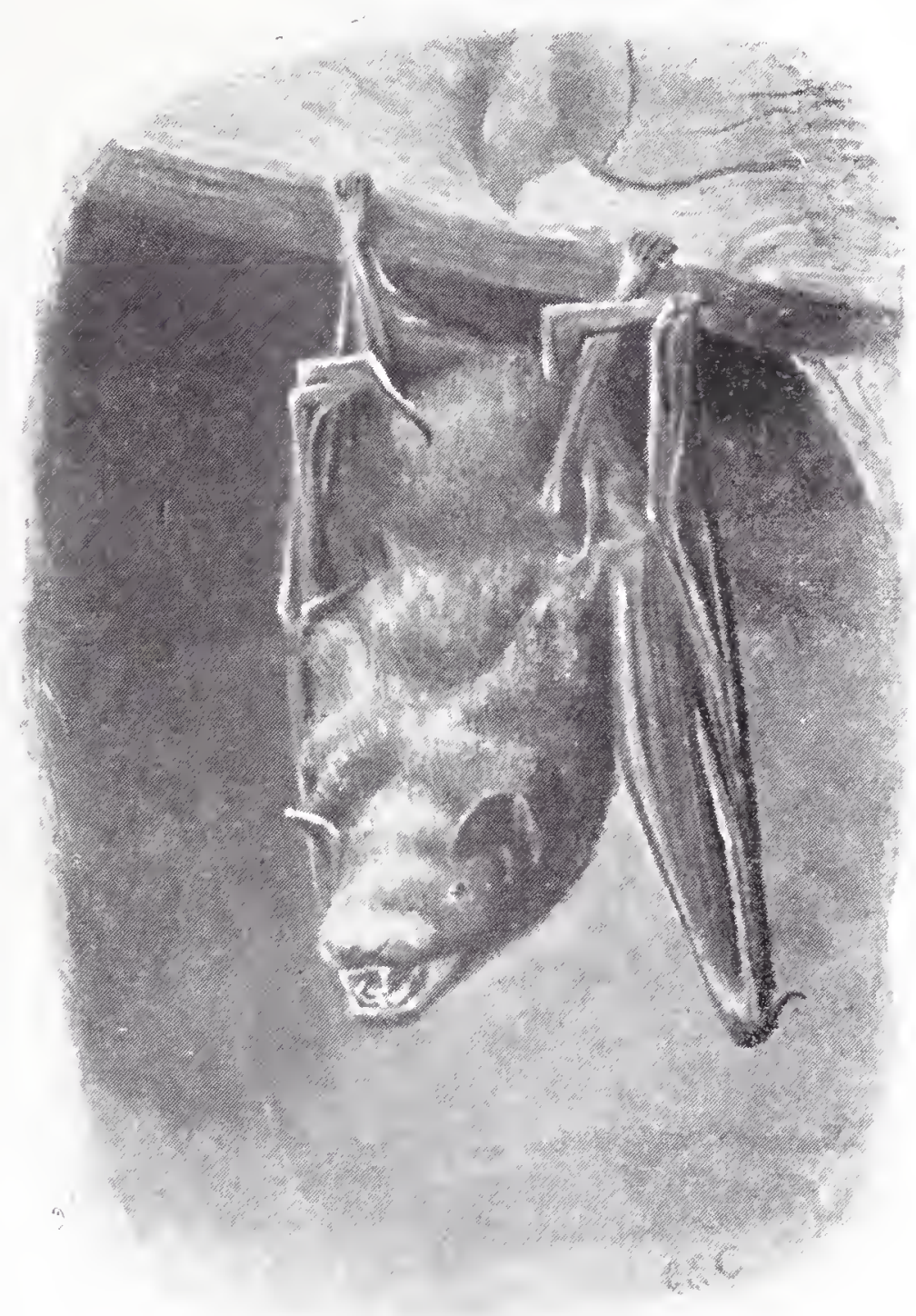

Noctule.

when one sometimes notices it hawking for flies. And then it will disappear again for weeks, or even for months.

The fact is that bats, like hedgehogs and squirrels, pass through the winter in a kind of deep sleep, which we call "hiber- 
nation." It is more than ordinary sleep, for they do not require any food for months together, while they scarcely breathe once in twent $y$ four hours, and their hearts almost cease to beat. And if the winter is cold throughout, they do not wake at all until the spring. But two or three hours' warm sunshine arouses them from their slumber. They wake up, feel hungry, go out to looli for a little food, and then return to their retreats and pass into the same strange sleep again.

I once liept a long-eared bat as a pet, and a most interesting little creature he was. One of his wings had been injured by the person who caught him, so that he could not fly, and was obliged to live on the floor of his cage. I'et, although he could take no exercise, he used to eat no less than seventy large blue-bottle flies every day, or rather every evening. As long as the daylight lasted, he would take no notice of the flies at all. They might crawl about all over him, but still he would never move. lint soon after sunset, when the flies began to get sleepy, the bat would wake up. Fixing his eyes on the nearest fly, he would begin to creep towards it so slowly, so cautiously, that it was almost impossible to see that he was moving. By degrees he would get within a couple of inches. Then, quite suddenly, he would leap upon it, and cover it with his wings, pressing them down on either side of his body so as to form a lind of tent. Next he would tuck down his head, catch the fly in his mouth, and crunch it up. And finally he would creep on towards another victim, always leaving the legs and the wings behind him, which in some strange way he had managed to strip off, just as we strip the legs from shrimps.

I often watched him, too, when he was drinking. As he was so crippled, I used to pour a few drops of water on the floor of his cage, and when he felt thirsty he would scoop up a little in his lower jaw, and then throw his head back in order to let it run down his throat. Jut in a state of freedom bats drink by just dipping the lower jaw into the water as they slim along close to the surface of a pond or a stream, and you may often see them loing so on a warm summer's evening.

I wonder whether you can hear the cry of the long-eared bat? Some people can, but a great many people are quite unable to do so, for it is so very shrill that it produces no effect upon their ears. It is just a very high and very thin scream-something like that of the swift, only higher and thinner still,-and very often, to those who can hear them, the air seems full of these screams, as the bats are flying to and fro, wild with excitement as they chase their insect rictims.

All the British bats utter these shrill cries, but that of the long-eared bat is different from all the rest, and anyone who has noticed it once can always recognize it, even if he hears it without seeing the bat. 
You can always tell this bat at sight by the great size of its ears. Sometimes they stand straight from the head, and give the animal a very alert and intelligent appearance. But as a rule they are in constant motion, the bat throwing them into graceful folls at every movement of its body. And when it goes to sleep it tucks them away underneath its wings.

Another bat which is frequently to be seen in Great Britain is the Noctule, or Great Bat. It is the largest of the British bats, measuring about fourteen inches from tip to tip of the wings when they are fully spread, while the head and the body together are about three inches in length. It generally flies very high in the air, where you can see it hawling for insects on warm summer's evenings; but about the first or second week in

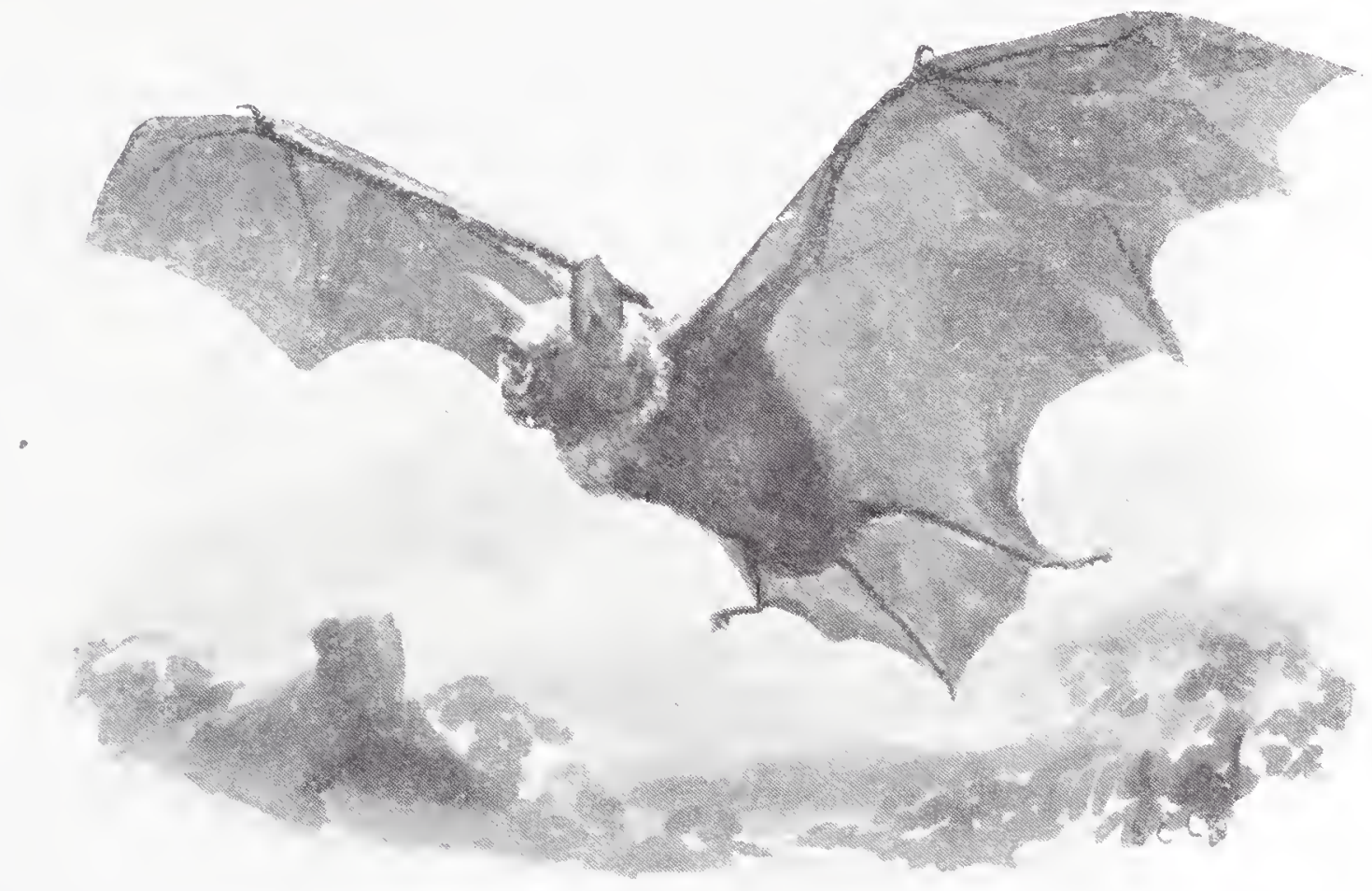

GRLAT HORSE-SHOE BIT

July, when the summer chafers come out, it descends lower, and devours them in great numbers.

No doubt jou know these chafers by sight. They are like small cockichafers with very hairy bodies, and they tly round and round the tops of small trees in great numbers for about twenty minutes soon after sunset, looking almost like a swarm of bees. The noctule is very fond of these beetles, and although they are rather stoutly-built insects, with very large bodies, is said to be able to eat a dozen, one after the other!

The winter sleep of this bat is a very long one, for it generally goes into retreat by the middle of September at the very latest, and is seldom seen again till the end of the following April.

The most plentiful of all the British bats is the Pipistrelle. It is only about half as big as the noctule, for the head and body 
together only noasure a little more than an inch and a lialf in length, while the spread of the wings is less than nine inches. And you can generally recognize it in the air by the swiftness of its flight, and by the fact that jt does not turn and twist and louble in its course nearly so much as all the other bats.

The pipistrelle is said to feed chiefly upon gnats, of which it must devour a very large number, and as it much prefers to live near human habitations, there can be no doubt that it helps to liecp our houses free from these disagreeable insects. In captivity it will feed freely upon raw meat chopped very small. It appears earlier in the spring than the other bats, and remains about until later in the autumn. Indeed, there are very few evenings from the beginning of March until the end of November on which it may not be seen busily hawking to and fro in search of its insect victims.

The Horse-shoe Bats have a most curious leaf-lilie membrane upon the face, which gives them a very odd appearance indeed. In the Great Horse-shoe Bat, which is found in Great Britain, though not very commonly, this membrane is double, like one leaf placed above another. The lower one springs from just below the nostrils, and spreads outwards and upwards on either side, so that it is shaped very much like a horse-shoe, while the upper one is pointed and stands upright, so as partly to cover. the forehead. The ears, too, are very large, and are ribbed cross-wise from the base to the tips; so that altogether this bat is a strangelooking creature.

Perhaps none of the British bats is so seldom seen as this, for it cannot bear the light at all, and never comes out from its retreat until darkness has quite set in. And one very seldom finds it asleep during the day, for it almost always hides in darli and sloomy caverns, which are hardly ever entered by any human being. In France, however, there are certain caves in which great numbers of these bats congregate together for their long winter sleep. As many as a hundred and eighty of them have been counted in a single colony. And it is a very strange fact that all the male bats seem to assemble in one colony, and all the female bats in another.

In Central and Soutl America, and also in the West Indian Islands, a number of bats are found which are known as Vampires. Some of these eat insects, just like the bats of our own country, and one of them-known as the Long-TONGUED VAapirelias a most singular tongue, which is very long and very slender, with a brush-likie tip, so that it can be used for licling out insects from the flowers in which they are hiding. 'Then there are other rampires which eat fruit, like the Flying Foxes, about which I shall have something to tell you very shortly. But the best known of these bats, and certainly the strangest, are those which feed upon the blood of living animals. 
If you were to tether a horse in those parts of the forest where these vampires live, and to pay it a visit just as the evening twilight was fading into darkness, you would be very likely to see a shadowy form hovering over its shoulders, or perhaps even clinging to its body. This would be a vampire bat; and when you came to examine the horse, you would find that, just where you had seen the bat, its skin would be stained with blood. For this bat has the singular power of making a wound in the skin of an animal, and sucling its blood, without either alarming it or appearing to cause it any pain. And if a traveller in the forest

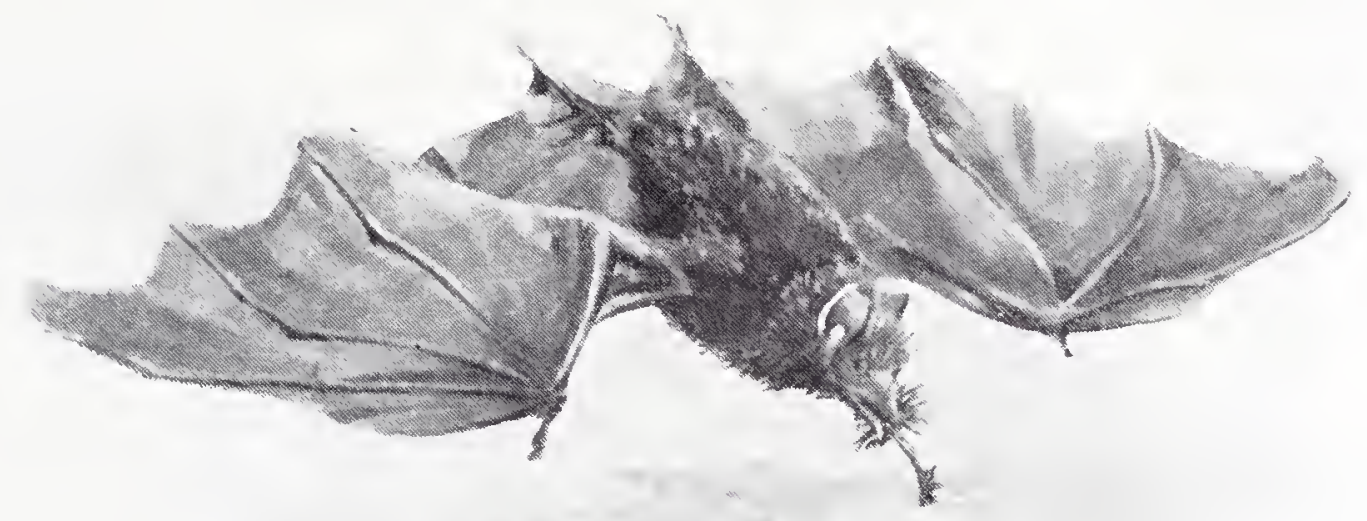

LONG-TONGED VAMPIRE.

happens to lie asleep in his hammock with his feet uncovered, he is very likely to find in the morning that his great toe has been bitten by one of these bats, and that he has lost a considerable quantity of blood. Yet the bat never wakes him as it scrapes away the skin with its sharply-edged front teeth!

Strangely enough, however, there are many persons whom vampires will never bite. They may sleep night after night in the open, and leave their feet entirely uncovered, and yet the bats will always pass them by. Mr. Charles Vaterton, for example, the famous traveller, was most anxious to be bitten by a vampire, so that he might learn by his own experience whether the infliction of the wound caused any pain or not. But though he slept for eleven months in an open loft, through which the bats were constantly passing, they never attempted to touch him, while an Indian lad who slept in the same loft was bitten again and again.

But as these bats cannot always obtain blood, it is most likely that they do not really live upon it, but only drink it when they have the chance, and that as a rule their food consists of insects.

Now we come to the Flying Foxes which I mentioned just now. Of course they are not really foxes. They are just big 
bats which feed upon fruit, instead of upon insects or upon blood. But their long, narrow faces are so curiously fox-like that we cannot feel surprised that such a name should have been given to them.

You can always see a number of these creatures in the Monliey House at the Zoo.

Flying foxes are found in many parts of Asia, as well as in Madagascar and in Australia, and in some places they are rery common indeed. In India, for example, long strings of these bats may be seen regularly every evening, as they fly off from their sleeping-places to the orchards in search of fruit. In some parts

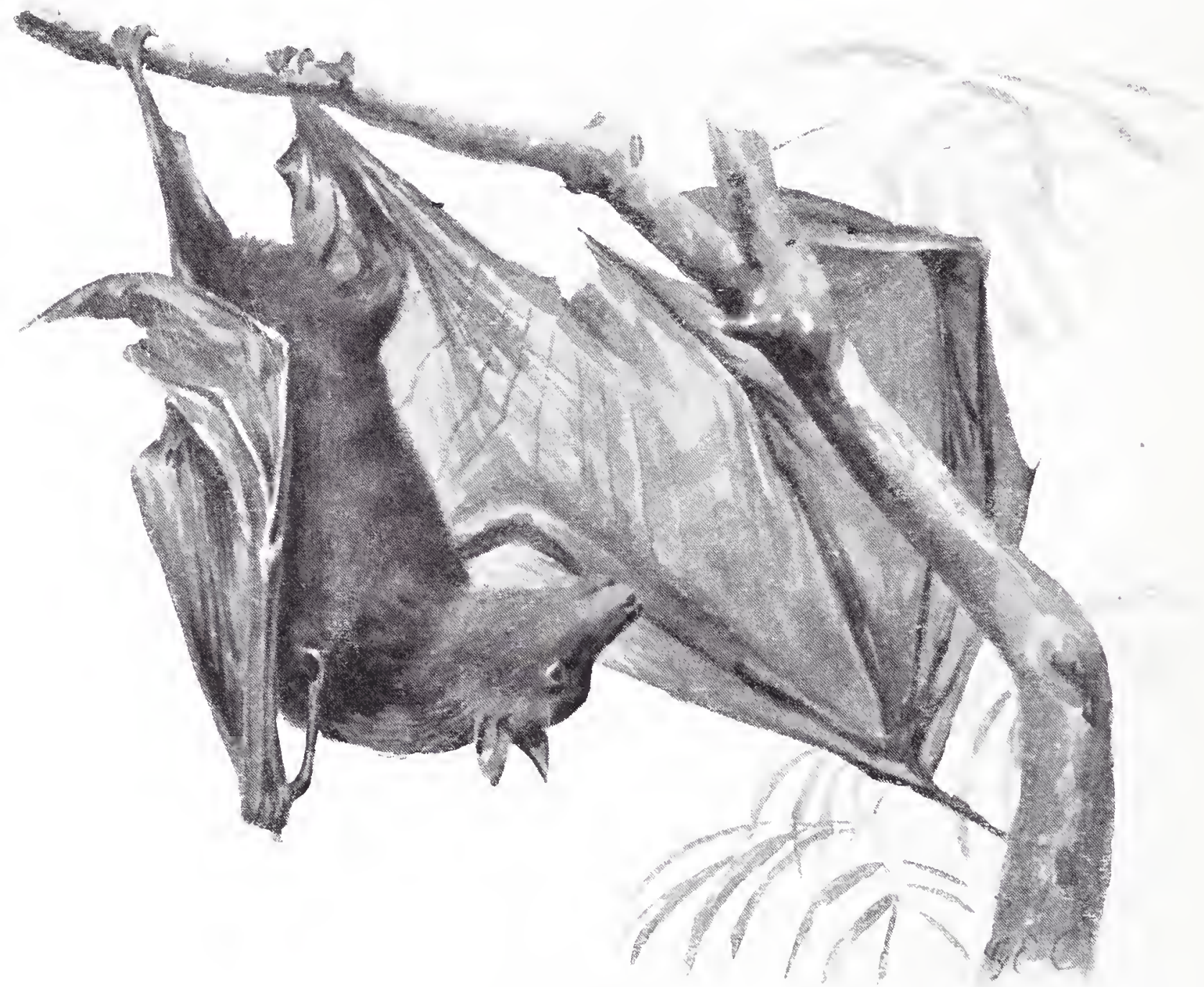

KNIONG.

of India, indeed, early in the morning and agrain in the evening, the sliy is often black with them as far as the eye can reach, and they continue to pass overhead in an unbroken stream for nearly three-quarters of an hour. And as they roost in great numbers on the branches of tall trees, every bat being suspended by its hinder feet, with its wings wrapped round his body, they look from a little distance just like bunches of fruit themselves.

It is rather curious to find that when they are returning to 
the trees in which they roost, early in the morning, these bats quarrel and fight for the best places, just as birds do.

In districts where they are at all plentiful, flying foxes to a great deal of mischief, for it is almost impossible to protect the orchards from their attaclis. Even if the trees are covered all over with netting they will creep underneath it, and pick out all the best and ripest of the fruit; while, as they only pay their visits of destruction under cover of darkness, it is impossible to lie in wait for them and shoot them as they come.

The flight of the fruit bats is not at all like that of the bats which we see in England, for as they do not feed upon insects there is no need for them to be constantly changing their course, and darting first to one side and then to the other in search of victims. So they fly slowly and steadily on, following one another just as rooks do, and never turning from their course until they reach their feeding ground.

The largest of these fruit bats is the KALONG, which is found in the islands of the Malay Archipelago, and actually measures orer five feet from tip to tip of the extended wings! The Malays often use it for food, and its flesh is said to be very delicate and well-flavoured. 


\section{CHAPTER V.}

\section{THE INSECT EATERS.}

NEXT to the Bats comes the important tribe of the Insect Eaters, containing a number of animals which are so called because most of them feed chiefly upon insects.

One of the strangest of these is the Colugo, or Cobego, which lives in Siam, Java, and the islands of the Malay Archipelago. It is remarkable for its wonderful power of leaping, for it will climb a tall tree, spring through the air, and alight on the trunk of another tree seventy or eighty yards away. For this reason it has sometimes been called the "lilying Colugo"; hut it does not really fly. It merely skims from tree to tree. And if you could examine its body rou would he able to see at once how it does so.

First of all, you would notice that the skin of the lower surface is very loose indeed. You know how loose the slin of a dog's neck is, and how you can pull it up ever so far from the flesh. Well, the skin of the colugo is quite as loose as that on the sides and lower parts of its body.

Then you would notice that this loose slin was fastened along the inner side of each leg, so that the limbs are connected by membrane just like the toes of a duck's foot. And you would also see that when the legs are stretched out at right angles to the body, this membrane must be stretched out with them.

Now when a colugo wishes to take a long leap, it springs from the tree on which it is resting, spreads out its limbs, and skims through the air just as an oyster-shell does if you throw it sideways from the hand. The air buoys it up, you see, and enables it to travel ten times as far as it could without this loose skin. Jut of course this is not flight. The animal does not beat the air with the membrane between the legs, as bats and birds do with their wings. It cannot alter its course in the air; and it is always obliged to alight at a lower level than that from which it sprang.

The colugo is about as big as a good-sized cat, and its fur is olive or brown in colour, mottled with whitish blotches and spots. The consequence is that when it clings closely to the trunk of a tree, and remains perfectly motionless, it may very easily he overlooked, for it looks just like a patch of bark covered with lichens and mosses. It is said to sleep suspended from a branch with its head downwards, like the bats; and whether this is the case or not, its tail is certainly prehensile, like that of a 
spider monliey. And strangest of all, perhaps, is the fact that, although it belongs to the group of the Insect Eaters, it feeds upon leaves.

The common IIEDgenog also belongs to the tribe of the Insect Eaters.

Everybody, of course, knows this curious animal by sight. One can scarcely walk through the meadows on a summer's evening without seeing it, as it moves clumsily about in search of prey. And everybody is familiar with its spiky coat, which affords such an excellent protection against almost all its enemies.

But it is not everybody who knows how the animal raises

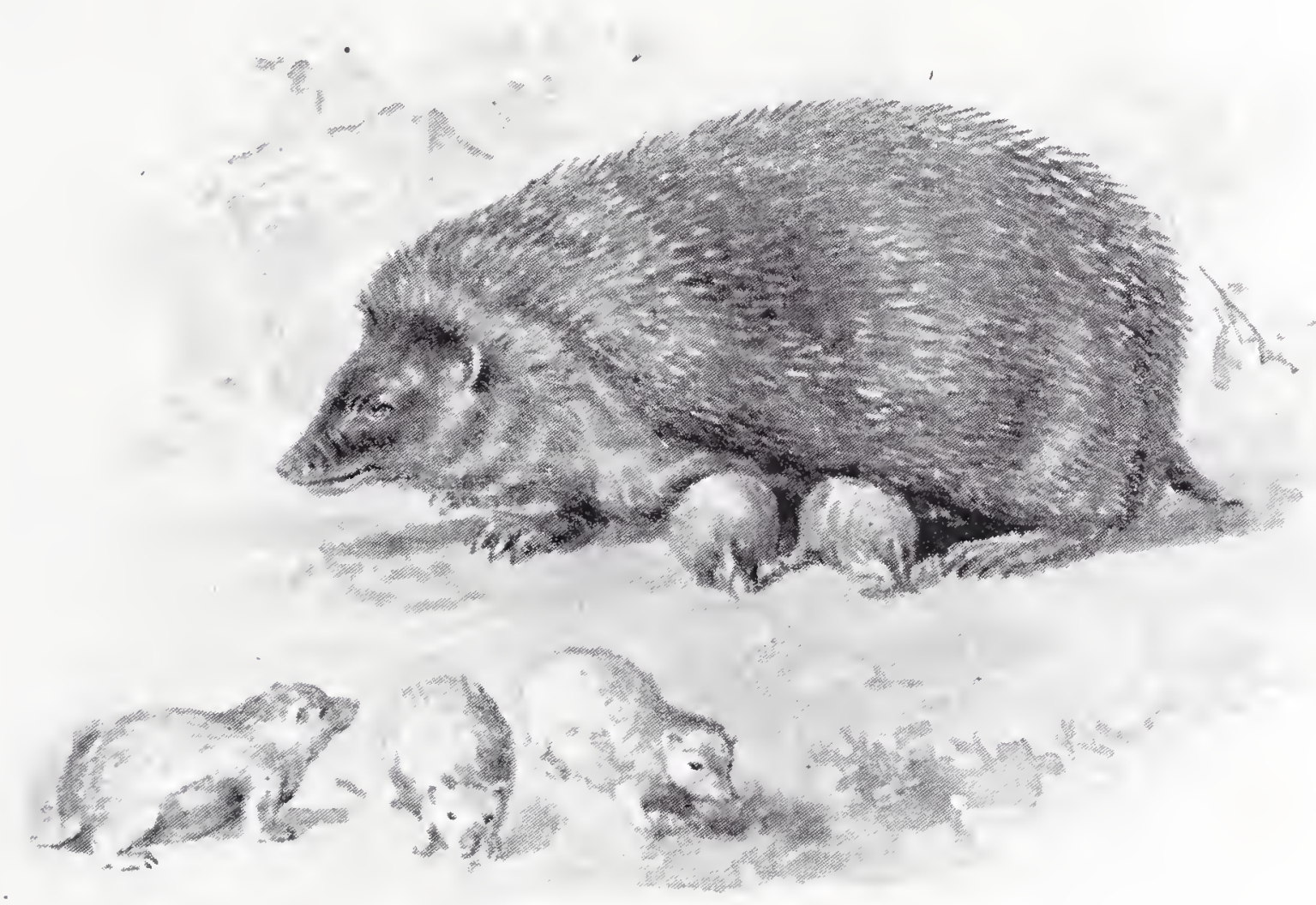

HEIGEHOG.

and lowers its spines. It has them perfectly under control; we all know that. If you pick a hedgehog up it raises its spines at once, even if it does not roll itself up into a ball and so cause them to project straight out from its body in all directions. but if you keep the creature as a pet, and treat it lindly, it will very soon allow you to handle it freely without raising its spines at all.

The fact is this. The spines are shaped just lilie slightly bent pins, each having a sort of rounded head at the base. And they are pinned, as it were, through the skin, the heads lying underneath it. Besides this, the whole body is wrapperl up in a lind of muscular cloak, and in this the heads of the spines are buried. So if the muscle is pulled in one direction, the spines 
must stand up, because the heads are carried along with it. If it is pulled in the other direction they must lie down, for the same reason. And it is just by pulling this muscle in one direction or the other that the animal raises and lowers its spines.

We do not often see the hedgehog wandering about by day, because it is then fast asleep, snugly rolled up in a ball under the spreading roots of a tree, or among the dead leaves at the bottom of a hedge. But very soon after sunset it comes out from its retreat, and begins to hunt about for food. Its diet is very varied. Sometimes it will eat birds' eggs, being very fond of those of the partridge; for which reason it is not at all a favourite with the gamekeeper. It will devour small birds, too, if it can obtain them, together with lizards, snails, shugs and insects. It has often been known to kill snakes and to feed upon their bodies afterwards. It is a cannibal, too, at times, and will kill and eat one of its own lind. But what it likes best of all is earthworms.

The number of these which it will crunch up one after another is perfectly astonishing. I once liept a tame hedgehog, and fed him almost entirely upon worms; and he used to eat, on an average, something like an ordinary jampotful every night of his life. He never took the slightest notice of the worms as long as the daylight lasted; but when it began to grow dark he would wake up, go sniffing about his cage till he came to the jampot, and then stand up on his hind feet, put his fore-paws on the edge, and tip it over. And after about an hour and a half of steady crunching, every worm had disappeared.

In most parts of the country the farmers persecute the hedgehog, and kill it whenever they have a chance of doing so. And if you ask the reason, the answer is generally to the effect that hedgehogs steal milk from sleeping cows at night. Now it does not seem very likely that a cow would allow such a spiky creature as a hedgehog to come and nestle up against her body. But, on the other hand, it cannot be denied that hedgehogs are very often to be seen close by cows as they rest upon the ground. But they have not gone there in search of milk. Don't you know what happens if you lay a heavy weight, such as a big pavingstone, on the ground? The worms which are buried underneath it feel the pressure, and come up to the surface in alarm. Now a cow is a very heavy weight; so that when she lies down a number of worms are sure to come up all round her. And the hedgehog visits the spot in search, not of milk, but of worms!

The young of the hedgehog, which are usually four in number, do not look in the least like their parents, and you might easily mistalie them for young birds; for their spilies are very soft and are quite white, so that they look much more like growing feathers. The little creatures are not only quite blind, but also quite deaf, for several days after birth, and they cannot roll themselves up till they have grown to some little size. The mother animal 
alivays makes a lind of warm nest to serve as a nursery, and thatches it so carefully that even a heavy shower of rain never seems to soak its way through.

Strange to say, the hedgehog appears to be quite unaffected by many kinds of poison. It will eat substances which would cause speedy death to almost any other animal. And over and over again it has been bitten by a viper without appearing to suffer any ill results whatever.

About the middle of October the hedgehog retires to some smug and well-hidden retreat, and there makes a warm nest of moss and dry leaves. In this it hibernates, just as bats do in hollow trees, only waking up now and then for an hour or two on very mild days, and often passing three or four months without taking any food at all.

During the earlier part of the autumn, you may very often find a curious mouse-like little animal lying dead upon the ground.

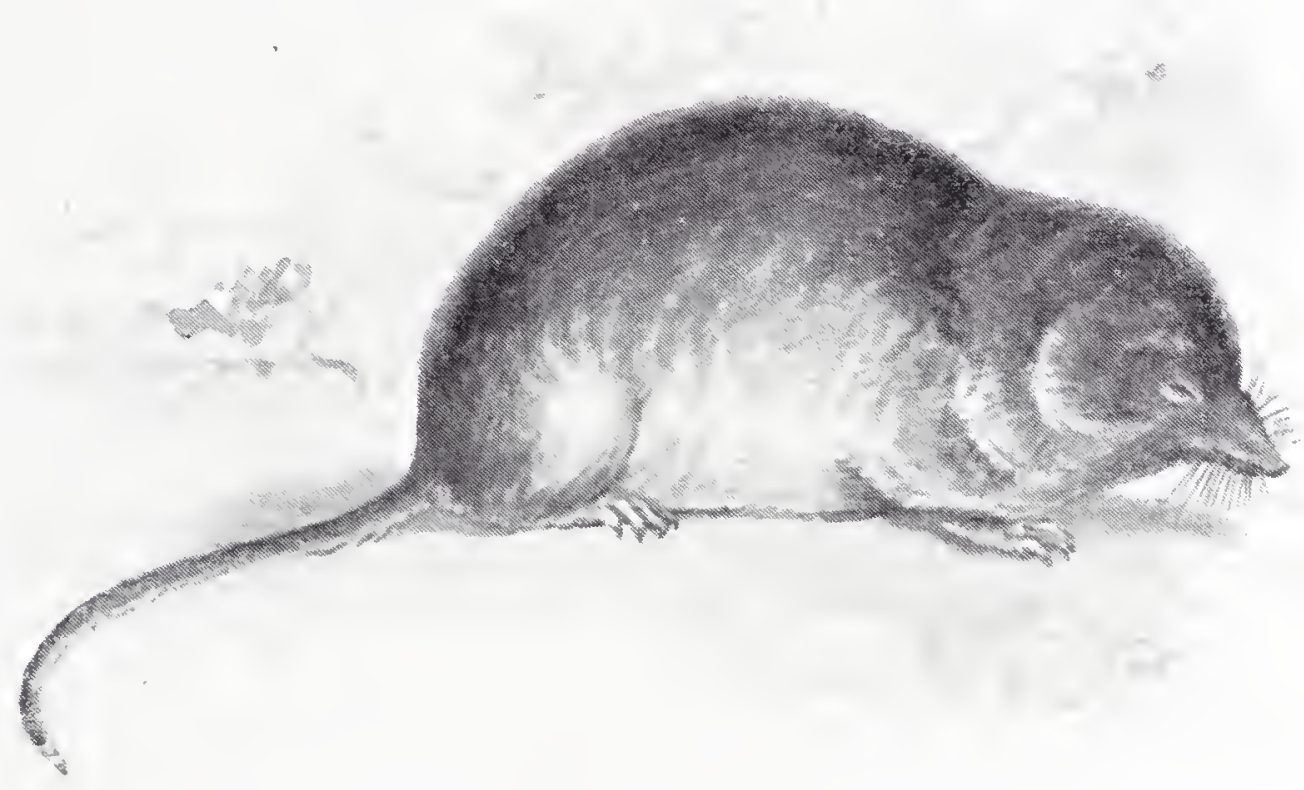

COMHON SIIREN.

liut if you look at it carefully, you will see at once that in several respects it is quite different from the true mice.

In the first place you will notice that its mouth is produced into a long snout, which projects far in front of the lower jaw. Now no mouse ever has a snout like that. Then you will find that all its teeth are sharply pointed, while the front teeth of a mouse have broad, flat edges specially meant for nibbling at hard substances. And, thirdly, you will see that its tail, instead of gradually tapering to a pointed tip, is comparatively short, and is squared in a very curions manner. 'The fact is that the little animal is not a mouse at all, but a lind of shrew.

These creatures are very common almost everywhere. But we very seldom see them alive, hecause they are so timid that the first sound of an approaching footstep sends them away into 
hiding. Yet they are not at all timid among themselves. On the contrary, they are most quarrelsome little creatures, and are constantly fighting. If two shrews meet, they are almost sure to have a battle, and if you were to try to keep two of them in the same cage, one would be quite

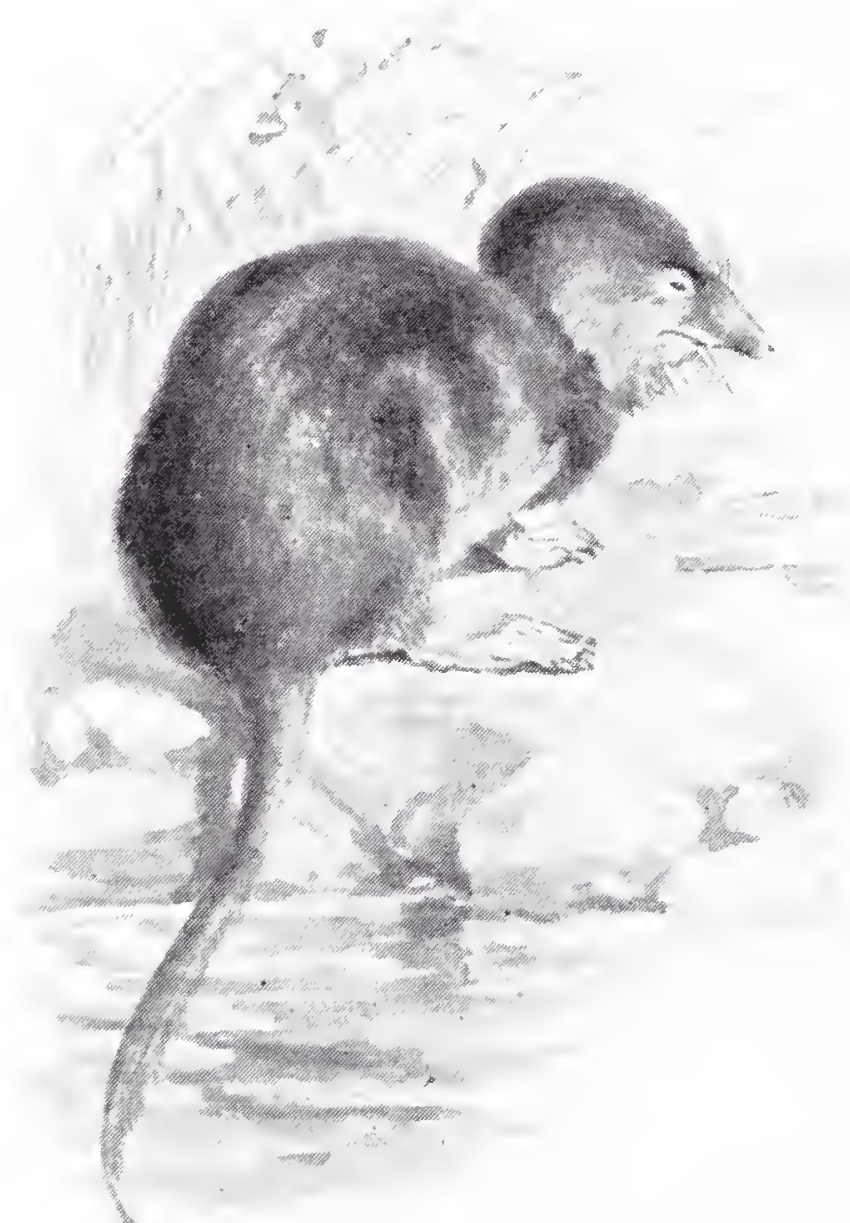
certain to kill and eat the other before very long. They are not cannibals as a rule, however, for they feed upon worms and insects, and just now and then upon snails and slugs. And no doubt they do a great deal of good by devouring the mischievous grubs which cause so much damage to our crops.

Why these little animals die in such numbers just at the beginning of autumn, nobody quite seems to know. It used to be thought that they were killed by cats, or hawks, or owls, which refused to eat them because of some unpleasant flavour in their flesh. But then one never finds any mark of violence on their bodies. A much

WATER SHREW. more absurd idea was that they always die if they run across a path which has been trodden by the foot of man! Perhaps the real reason may be that just at that season of the year they find a difficulty in obtaining food, so that many of them perish from starvation.

The Common SHrew, which is found plentifully in all parts of Great Britain, is about three inches long without the tail, and is of a reddish grey colour, which becomes rather paler on the lower parts of the body. But sometimes it is banded with white.

Almost as common, if one knows how to look for it, is the VAter Shrew. The best way to see this pretty little creature is to go and lie down on the bank of a stream, and to keep perfectly still for five or ten minutes. If you do this-not moving even a finger-you will very likely see half a dozen or more of the little animals at play. They go rushing about in the wildest excitement, chasing one another, tumbling over one another, and uttering curious little sharp, short squealis, just like a party of boys let out from school after a long morning's work. Suddenly one will dash into the water and dive, quickly followed by another 
and then by a third. As they swim away beneath the surface they look just like balls of quicksilver, because their soft, silky fur entangles thousands of little air-bubbles, which reflect back the light just as a looking-glass does. And you will notice that they lo not swim straight. First they turn to one side, and then to the other side, exactly like someone who lias just learned to ride a bicycle, but does not yet know how to keep the front wheel straight. And the reason is this. The shrew swims by means of its hind feet, which are fringed with long hairs, so as to make them more useful as paddles; and it uses them by striking out first with one and then with the other. 'The consequence is that when it strikes with the right foot its head turns to the left, while when it strikes with the left foot its head turns to the right.

But it would not be able to swim even as straight as it does if it were not for its tail, which is fringed with long hairs just like the hinder feet. And as the little animal paddles its way through the water it lieeps its tail stretched out behind it, and uses it as a rudder, turning it a little bit to one side or the other, so as to help it in lieeping its conrse.

After chasing one another under water for a minute or two, the little animals give up their game. And now, if you watch them carefully, you can see them hunting for food. First they go to one stone down at the bottom of the stream, and then to another, poling their long snouts underneath in search of fresh-water shrimps, or the grubs of water insects. But a minute or two later they are all back on the bank again, dashing about and chasing one another and squeaking as merrily as ever.

Sometimes you may see a water shrew which is very much darker in colour than the others, the fur on the upper part of its body being almost black. It used to be thought that such animals as this belonged to a different species, to which the name of "Oared Shrew" was given. But we know now that they are only dark varieties of the common water shrew.

The Jumping Sinews are all found in Africa. These are most curious little creatures with extremely long hind feet, by means of which they leap along just as if they were tiny liangaroos. So swift are they, indeed, that it is very difficult for the eye to follow their movements. And as they disappear into their burrows at the slightest alarm and do not come out again for some little time, very few people ever have a chance of watching their habits.

The snouts of these shrews are so very long that the little animals are often known as "Elephant Shrews" in consequence. There is a group of these animals, too, called Tres SHREws, because they spend ahmost the whole of their lives in the trees. In some ways they are not unlike tiny squirrels, being very nearly as active in their movements, and sitting up on their hind quarters to feed, while the food is held in their forepaws. They are found in various parts of Southern Asia. and 
soon become very tame, actually entering houses, and climbing up on the table while the occupants are sitting at meals. They will even drink tea and coffee out of the cups! And if they are encouraged they make themselves quite at home, and will drive away any other tree shrews which may venture into the house.

The largest animal of this group is the Tupis, which lives in Jorneo and Sumatra. But the most curious is the PENTaned Tree Sirrew, which has a double fringe of long hairs at the end of its tail, arranged just like the barbs of a feather, so that its tail looks very much like a quill pen. The rest of the tail, which is very long, is covered with square scales; and while the tail itself is black, the fringe of hairs is white, so that the appearance of the animal is very odd indeed. It is found in

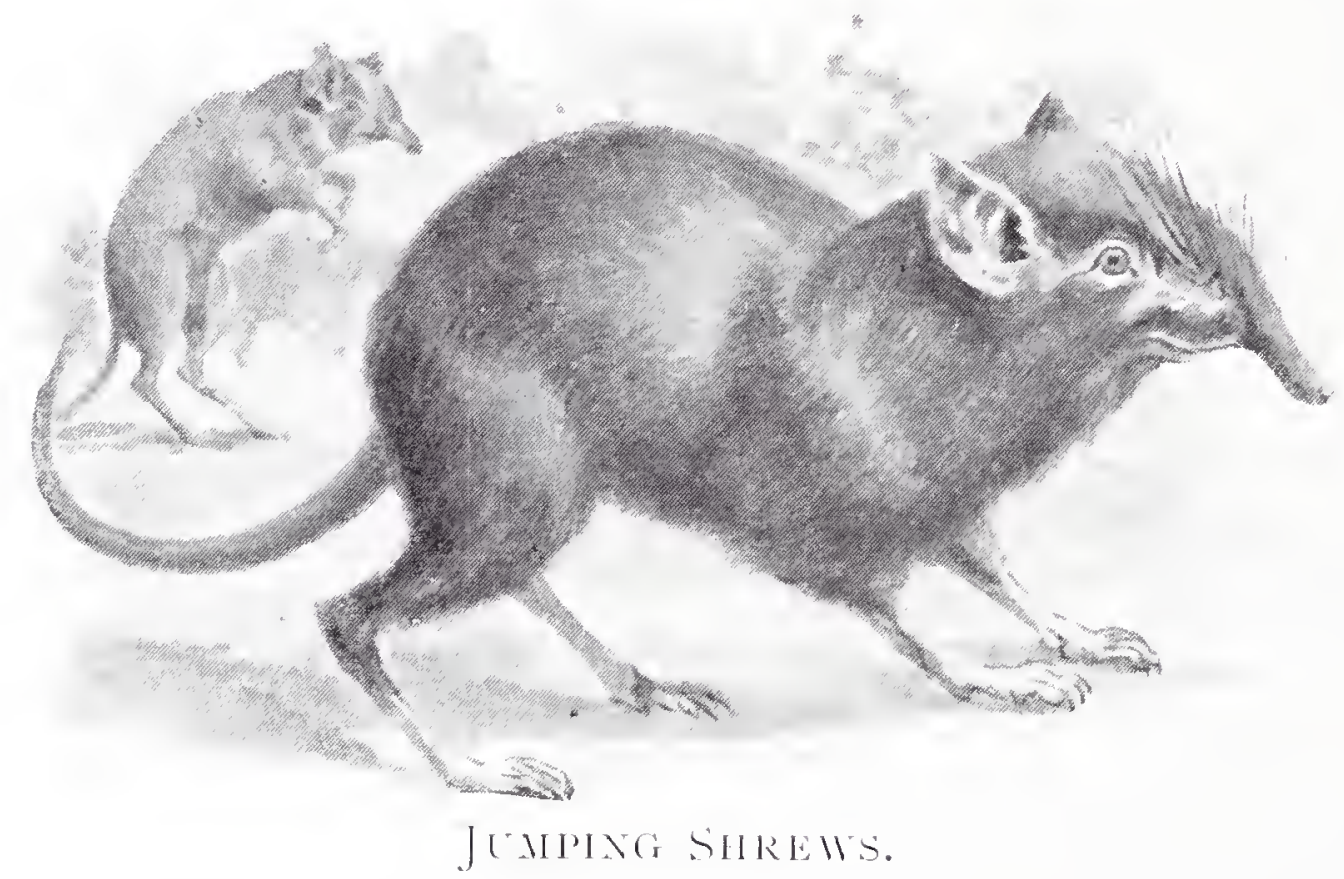

Saravals, and also in some of the smaller islands of the Malay Archipelago.

The Desinn may be described as a kind of mixture of an elephant shrew and a water shrew; for it has an extremely long and flexible snout, and it spends almost its whole life in the water. Its feet are very well adapted for swimming, the toes being joined together by a web-like membrane like those of the duck and the swan, so that they form most exquisite paddles. And the animal is so fond of the water that, although it lives in a hurrow in the bank of a stream, it always makes the entrance below the surface.

This is a very good plan in one way, for if the little animal is chased by one of its enemies, it can easily take refuge in its long, winding tunnel, which twists about so curiously, and has so many side passages, that the pursuer is almost sure to be baffled. But in another way it is a bad plan, for as the burrow has no other entrance except the one under water, it never gets properly 
ventilated, the only connection with the outer air being just some chance cranny in the ground. And in winter time, when deep snow has covered up this cranny, while the surface of the stream is frozen to a depth of several inches, the poor little desman can

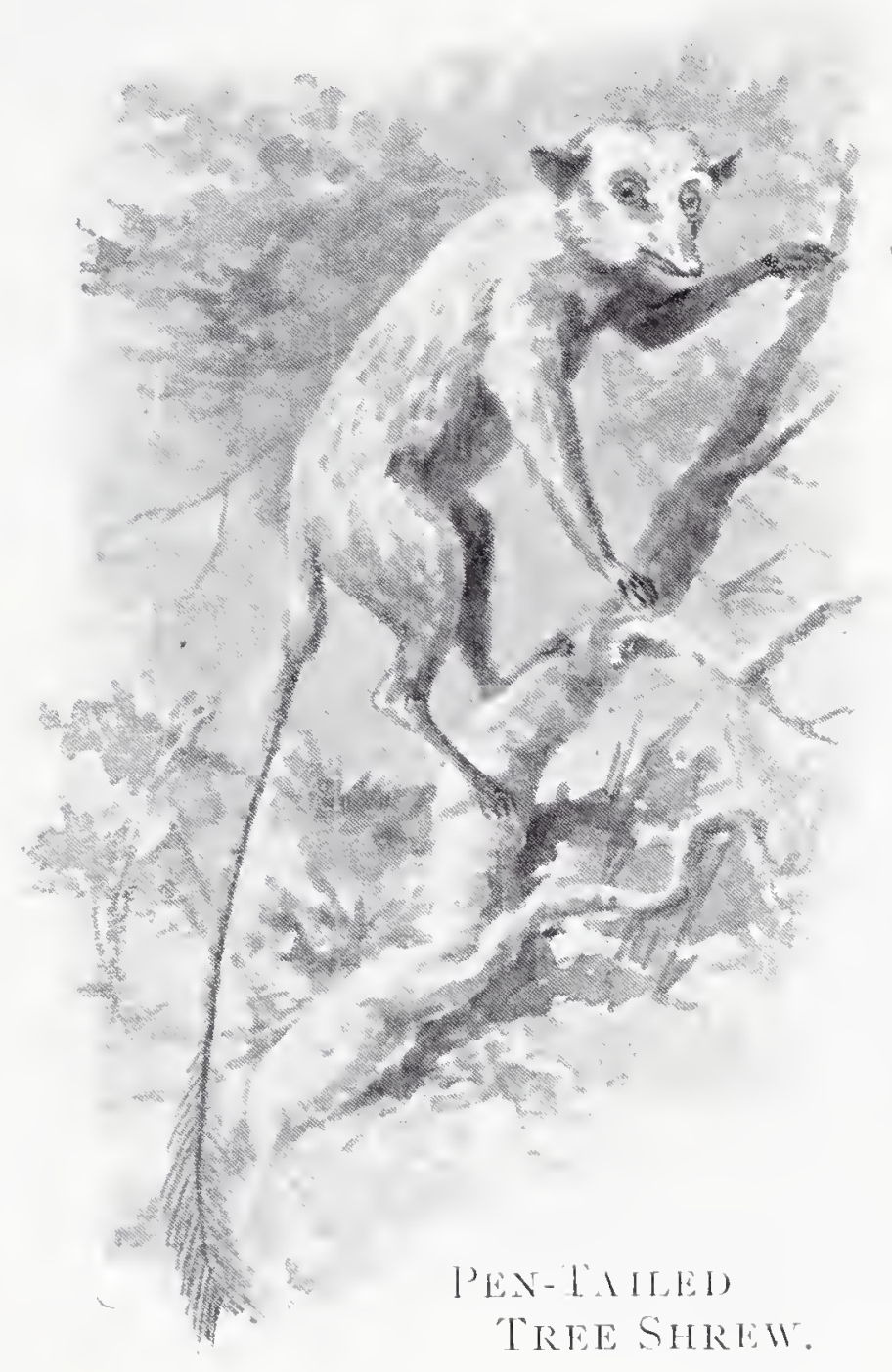
get no fresh air at all, and very often dies in its own burrow from suffocation!

This animal has a curious musky odour, which is due to certain glands near the root of the tail. So strong is this odour, that if a pilie happens to have swallowed a desman a few days before it is caught, its flesh cannot be eaten, for its whole body both smells and tastes strongly of musk.

Two kinds of desman are known. One is the Russian Desman, which is found in the Steppes, and the other is the Pyrenean Desman, which lives in the range of mountains from which it takes its name. In days of old the former of these two animals was an inhabitant of the British Islands.

Next we come to a little animal which is perhaps the most interesting of all the Insect Laters-namely, the Common Mole.

Have you ever noticed how wonderfully it is suited for a life which is almost entirely spent under the ground?

Notice, first of all, the shape of its body. It is a pointed cylinder. Now that is the very best shape for a burrowing animal, because it offers so little resistance to the ground as the creature forces its way along. And nowadays we make all our boring tools and weapons of that shape. The gimlet, which has to bore through wood; the bullet, which has to bore through air; the torpedo and the submarine boat, which have to bore through water-they are all made in the form of pointed cylinders. And the mole is a pointed cylinder too. Its body is the cylinder, and its head is the point; and so the animal is able to work its way through the soil with as little difficulty as possible.

Then notice the character of its fur. It has no "set" in it. 
You can stroke it backwards or forwards with equal ease. And this is most important in an animal which lives in a burrow. If a mole had fur like that of a cat, it would be able to travel head foremost through its tumnel quite easily; but it could not more backivarts. And this would never do, for sometimes the mole is attacked by an enemy in front, while it has no room to turn round in order to retreat. So nature has made its fur in such a way that it "gives" in either direction, and enables the little animal to move either forwards or hackivards with equal ease.

Then mark what wonderful front paws it has-so broad, so very strong, and armed witl such great, stout claws. They are partly pick-axes, and partly spades, which can tear away the earth and fling it up into "mole-hills" with the most wonderful speed. The rapidity with which a mole can dig is really marvellous. 'Three times I have seen moles walking about on the ground. Each

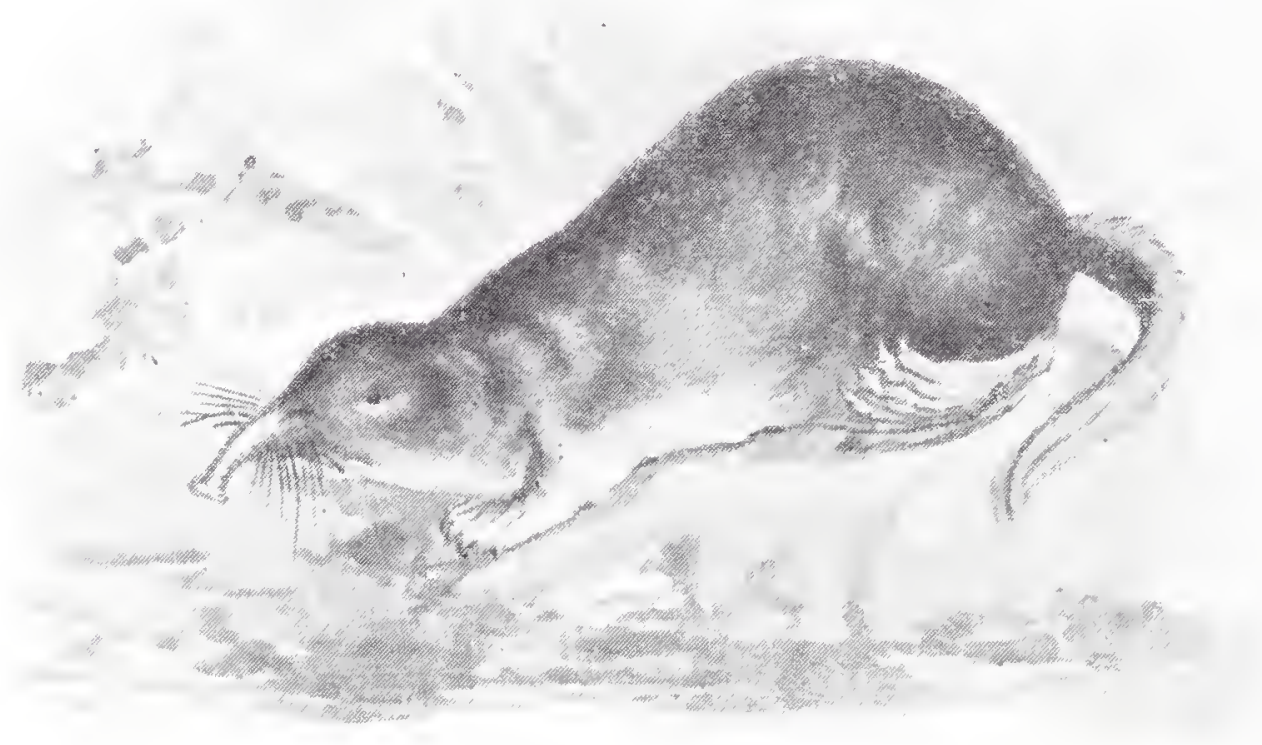

1) I:SMLAN

time I was within ten yards of the animal; each time I ran to the spot. And yet each time the little creature had disappeared into the ground before I could get there! It did not seem to be digging. It simply seemed to sink into the soil, just as though it were sinking into water.

Then just see how hard and horny the skin of the paws is. If it were not for this, the mole would be alivays cutting itself with sharp flints as it dug its way through the ground. Notice, too, how hoth the eyes and ears are hidden away underneath the fur, so that fragments of earth may not fall into them. Nature has heen very careful, hasn't she, to suit the mole to the strange life which she calls upon it to lead?

Perhaps no animal is so strong for its size as the mole. Its muscles and sinews are so hard that they will turn the edge of a knife! If a mole conkl be magnificl, indeed, to the size of 
a lion or a tiger, and its strength could be increased in corresponding degree, it would be by far the more powerful animal of the two.

The reason why the mole is so strong, and so well suited for a life underground, is that it is meant to feed partly upon worms, and partly upon such grubs as "wire worms" and "leatherjackets," which live on the roots of plants. And the appetite of the animal is perfectly astonishing. It is perpetually eating, and yet never appears to be satisfied. Don't think of keeping a mole as a pet; because, if you do, you will have to spend almost the

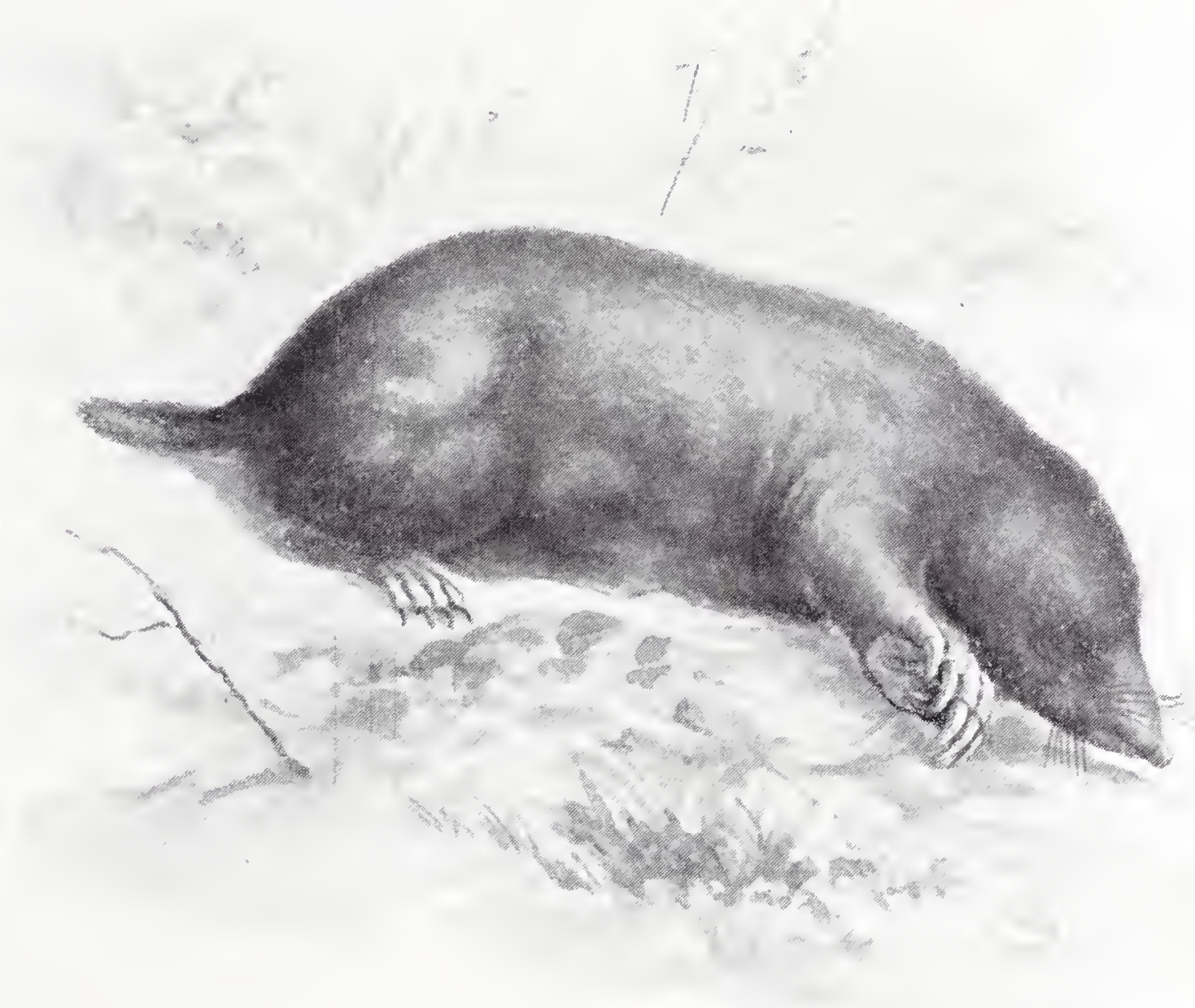

MOLE.

whole of your time in digging up worms for it to eat! Molecatchers say, indeed, that if a mole goes without eating for three hours it is in danger of starvation! So that the animal must spend the greater part of the day, and of the night too, in searching for food.

How does it find the worms and grubs? WVell, of course it cannot see underground; so sometimes, I think, it smells them, for its scent is certainly very lieen. But far more often, most likely, it hears them moving about; for its ears are even keener still. Haven't you noticed that, although you may often walk through fields which are almost covered with mole-hills, you never see the earth being thrown up? That is because the mole hears 
you coming. It hears your footsteps when you are a hundred yards distant, or eren more, and immediately stops work until you have crone away again. In the "Midsummer Night's Dream," Caliban tells Prospero to "tread softly, that the blind mole may not hear a footfall." And although Shakespeare was mistaken in thinking that moles are blind, he was quite right in reminding us that they have very sharp ears.

Now, are we to think of the mole as a friend or a foe?

The gardener, of course, looks upon it as a foe; and so it is when it drives its tunnels under our lawns, and throws up great heaps of earth on the surface of the grass. And the farmer regards it as a foe too, and kills it whenever he has an opportunity. But I do not think that the farmer quite linows what a busy little animal the mole is, and what thousands and thousands of mischievous grubs it devours. There are wire worms, which nibble away at the roots of plants till they kill them, and then move on to destroy other plants in the same way. There are "leatherjacliets," or daddy-long-legs grubs, which feed upon the roots of grass, and sometimes ruin all the turf in a meadow. 'There are the great fat white grubs of the coclichafer, which are worse, perhaps, than either; and many others as well. Now the mole is always preying upon these. It eats them in hundreds every day of its life. And just think of all the mischief that they would have done if they had been allowed to live! No doubt it is annoying to the farmer to have mole-hills among his hay, which blunt the linives of the reaping-machines, and prevent them from cutting properly. But even that is better than having no hay to cut; and there would be none if all these mischievous grubs were allowed to live.

But there is another way as well in which the mole is useful; for the earth which it digs up from down below, and throws up in heaps on the surface of the ground, serves for what the farmer calls a "top-dressing." After a time, you see, the nourishment in the soil at the surface is sucked out of it by the roots of the grass. If it were in a garden, the farmer could dig it. If it were in a corn-field, or a turnip-field, he could plough it. But in a meadow, he can do neither, without destroying the pasture. So he applies a "top-dressing." He gets some good, rich earth from elsewhere, and spreads it over the surface; and this earth works lown to the grass roots, and gives them just the nourishment which they require.

Now this is exactly what the mole is always doing. The earth which it throws up is fresh, rich earth from down below, which the roots have not reached. It is just what the failing grass requires. And if the farmer just rakes the mole-hills down, so as to spread this earth evenly over the surface of the field, he finds that it forms a "top-dressing" quite as good as any which he could apply himself. 
So instead of looking upon the mole as one of his enemies, he ought to include it in the list of his labourers.

Another thing that I must tell you about the mole is the way in which it obtains water. It is a very thirsty animal, and constantly requires to drink. At the same time, it cannot leave its burrow half a dozen times a day, in order to visit a stream or a pond, for it would almost certainly be killed by one of its many enemies. So it actually digs little wells of its own, always doing so in the dampest parts of its tunnels, where they fill up almost immediately! And when it wants to drink it just goes off to the nearest of these wells, and satisfies its thirst.

But the most wonderful thing that the mole does is to make what we call a "fortress," surrounding the chamber in which it sleeps. This fortress is situated either in a natural mound of earth, or else beneath the spreading roots of a tree or a lirge

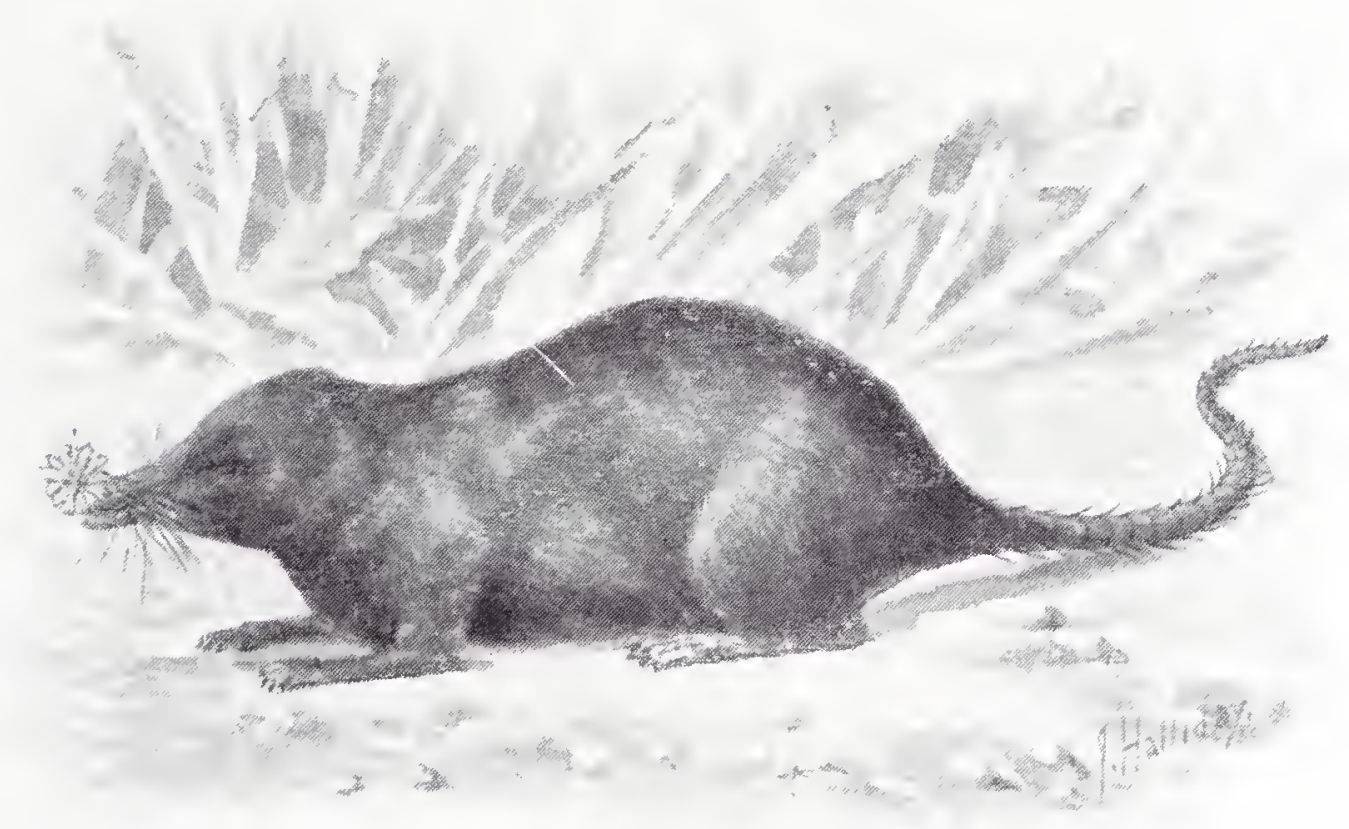

S'TM-NOSEA, MOLE.

bush; and it is made in this way. First the mole digs a short circular gallery. A little way underneath this it digs another, rather larger in diameter, and connects the two by means of five short passages. In the mildle of the mound, and about half way between the two galleries, it scoops out a large round hole, from which three passages run to the lower gallery. This is the mole's bedroom, and it communicates with the main burrow by a tunnel which dips underneath the lower gallery. Finally, a number of runs branch out from the lower gallery in all directions.

So, you see, if a mole is chased by an enemy, it can nearly always escape by passing through its fortress. It goes up one passage, down another, up again by a third, down again by a fourth, and then off by one of the side runs; so that its pursuer is almost sure to be bewildered. And if the little animal should 
be surprised while asleep, it can escape in any direction without losing even a moment.

As the mole always likes to make itself comfortable, it collects together a quantity of dry grass, moss and leaves, and piles them up in the central chamber, so as to make a warm and cosy bed! And the female mole makes a nursery for her little ones in much the same way.

Sad to say, moles are very quarrelsome little animals, and frequently fight if they happen to meet. Here is an account of one of their battles, written by a passer-by who happened to witness it.

"Walking along a quiet lane on May ist, is87, I heard some very funny little squeaks proceeding from the other side of the hedge. I am perfectly used to all sorts of animal and bird sounds, hut had never heard the like of these before. On getting cautiously over the hedge, I found two moles fighting in the ditch. I went to within two yards of them, but they took not the slightest notice of me, so intent were both on their business. I at once looked at my watch. They kept on, up and down, scratch and bite, for seven minutes, when one turned the other completely over on his back, and seized him by the throat, which he cut as cleanly as if done by a knife, thus finishing the fight. The way in which they used their formidable front feet was surprising."

Another lind of mole, called the STAR-Noser Mole, is found in Canada and the United States. It is a very odd-looking animal, for its muzzle is produced into a long snout, at the tip of which is a circle of fleshy rays of a rosy red colour, which look lilie the petals of a red daisy, or the spreading arms of a sea anemone! These rays can be opened widely out or closed up at pleasure, and seem to serve as very delicate organs of touch, helping the animal in finding and catching its prey.

This mole-which resembles the common Linglish mole in colour-is also remarkable for having a very long tail, which is more than half the length of the head and body. The total length is about seven inclies. 


\section{CHAPTER VI.}

THE T.ARGER CATS.

YUNV we come to the Beasts of Prey, foremost among which stand the members of the great Cat Tribe. All these animals have their bodies formed in a very wonderful way.

First of all, their eyes are intended for use chiefly by night. If you look at a cat's eyes during broad daylight, when the sun is shining, you will notice that the pupils, through which she sees, are nothing more then mere narrow slits in the middle. Look at them again towards evening, when the twilight is just beginning to creep on, and you will see that the pupils are a good deal bigger, occupying nearly half the eyeball. Look at them once again, when it is almost dark, and you will find that they are bigger still, having widened out over pretty well the whole of the eye.

Now the eyes of a lion and a tiger are made in just the same way. The darker the night, the more the pupils expand, so that they may be able to take in the few rays of light that there are. We sometimes say that these animals can see in the darli. That, of course, is a mistalie, for in perfect darliness no animal can see at all. But evein on the darkest night there is always some light, and no matter how little there is it is enough to allow lions and tigers to see perfectly well, just because of the wonderful way in which their eyes are made.

But these creatures do not only want to be able to see their victims on a dark night; they also want to be able to creep up to them without making the slightest sound. It would be quite useless, for instance, for a lion to chase a deer, because the deer is by far the swifter animal of the two. If the lion is to catch the deer at all he must spring upon it unawares, and strilie it down before it knows its danger. And this is not at all easy, for the ears of a deer are very sharp, and if the lion were to make the least noise while creeping up, it would take the alarm directly. But underneath his great broad paws the lion has soft, fleshy cushions, which enable him to walk along without making any noise at all. Haven't you noticed how silent a cat's tread is? You simply cannot hear her place her foot upon the ground. WVell, lions and tigers walk in just the same noiseless manner, so that the deer never hears them creeping up, and is struck down and killed before it has time to realise its danger. 
But suppose that there are bushes in the way. Suppose, for example, that in order to approach the decr at all the lion must creep through a thicliet. Is he not quite sure to hrush up? against a loanch as he does so, causing the leaves to rustle? And will not the deer hear the sound and take the alarm?

Vrell, no doubt this would happen if the lion had to depend for his silent approach only on the soft cushions underneath his feet. l'ut then, you see, he has whiskers as well! l'erhaps you thought these were only meant for ornament. But they are meant for use; and they are employed in a very curious manner. When they are spread out on either side, they measure from tip to tip exactly the width of the body. Besides this, there is a very delicate sensitive nerve at the root of crery whislier, which runs straight to the brain. So, you see, if the tip of the whisker is touched, the brain feels it directly; and if as the lion is creeping through the bushes his outspread whiskers lrush against the branches, he knows at once that there is no room for him to pass without making a noise and alarming his victim. So he draws his head back, and creeps up by another way.

Then it is very important that his claws should be liept sharp; for he depends upon them for tearing his victim down. So every claw fits into a sheath, which protects the point, and prevents it from being worn down by rubbing against the ground. You can easily see these sheaths by examining the paw of a cat; and those of the lion and tiger are formed in just the same way. And the muscles which work them are so arranged that they keep the claws always drawn back, except just when the animal uses its paw in striking.

And then, once more, these animals have very curious tongrues. Haven't you noticed when a cat has licked your hanch how very dry and rough her tongue feels? It is quite different from the smooth, wet tongue of a dos. Nell, the tongue of a lion or tiger is even rougher still; and if you were to look at it sideways, you would see why. It is covered all over with sharp, hooklike projections, the points of which are directed towards the throat.

The reason is this: A lion or a tiger does not succeed in killing prey every night. Sometimes it hunts for one night, sometimes for two nights, sometimes even for three nights, without any success at all. So that when it does catch a victim, it rants to eat as much of its flesh as it possibly can. And if its tongue were not made in this singular manner, it would have to waste a great deal; for its sharp-pointed teeth cannot tear off nearly all the flesh of the bones. By means of its rough tongue, however, it can lick off even the tiniest scraps; and not even the smallest atom has to be wasted.

If you give a $\log$ a bone which is too big for him to 
crunch up and swallow, you will always fincl that he leaves a sood deal of meat upon it. Suut if you give a similar bone to a hungry cat, you will find that she liclis it perfectly clean. That is because her tongue is made in just the same way as that of a lion.

About forty different kinds of Cats are known altogether, most of which are found in the warmer parts of Africa and Asia. The most famous of all, of course, is the Lion, which is spread over the greater part of the African continent, and is also found in Persia and in India.

I need not describe the lion, for everybody knows perfectly well what it is like. But perhaps you do not know that the Indian lion hardly ever has a mane. For this reason it was formerly thought that there were two different kinds of lions, the Indian animal being quite different from that found in Ifrica. But we now know that this is not the case, and that the Indian lion is only a lind of variety, not a distinct species.

But there are very few lions left in India now, while even in Persia they are not nearly so plentiful as they used to be. In many parts of Africa, however, these animals abound, and it is not at all an uncommon thing for six or eight to be seen together.

During the daytime, the lion is generally fast asleep, lying up in a thicket, or in a bed of reeds by the side of a pool or a river. But as soon as night falls he leaves his retreat, and begins to prowl about in search of prey, roaring loudly from time to time. One would think that this would only alarm other animals, and lead them to seek safety in flight. But when a lion roars he generally puts his head close to the ground, and this has the effect of making it almost impossible for them to tell from which direction the sound is coming, so that they do not know how best to try to escape him. And very often, in their bewilderment, they rush to the very spot where he is lying in wait.

When a lion springs upon his victim, he either kills it by a stroke from his terrible paw, or else bites it in the throat or across the back of the neck. He then drags it away to some convenient retreat, eats his fill, and returns to his lair to sleep. Next day, very likely, he will return to the carcase for another meal. But when he gets there he often finds that the jaclials and hyenas have discovered it, and have left very little indeed for hin.

Wherever a lion goes, indeed, he is almost sure to be followed by a number of jaclials, all anxious to feast on the remains of the animals which he kills. But he never allows them to approach until he has eaten as much as he can possibly swallow, and it is said that if one of them attempts to do so he 
will catch it and lite off all its paws as a warning to the others to be more respectlul.

Iccording to a great many lunters, the lion is not nearly so courageous as it is generally supposed to be, and is really rather a cowardly animal. They say, for example, that it will lardly ever face a man unless it is brought to bay, but will always try to slink away and escape. If they litil a deer, too, and want to protect its hody from the lions, they can always do so by tying two or three streamers of white cloth to sticlis planted round the carcase, so that they flutter in the wind. And though the animals may prowl round and round all through the night, roaring loudly from time to time, they will never venture to approach within fifteen or twenty yards. Neither will they attack a tethered horse if the bridle is left hanging from its neck.

All hunters agree, lowever, that if a lion is wounded, or if it sees no chance of escape, it is a most terrible foe, and cannot be encountered without the utmost peril.

If a lion is captured while quite young, it is very easily tamed, and can even be taught to perform all kinds of tricks at the word of command. But lions which are born in captivity are not nearly so easy to manage, and can never be depended upon for a moment.

Lions generally have three or four cubs at a birth, and the little animals are just as playful as kittens. But although they are always ready for a good romp it is not wise to play with them, for a baby lion is as big as a good-sized cat, and is very much stronger, so that a bite from its teeth or a blow from its paw is rather a serious matter. For the first few months of their lives the culss are brindled, almost like tigers, the stripes disappearing by degrees as the fur grows darker. They do not reach their full size until they are about four years old.

The Trger is found principally in the jungles of India, although it is spread over the greater part of Central and Southern Asia. In some respects it is a finer animal than even the lion. It is certainly stronger; it is quite as courageous; and it is very nearly as large, although the shortness of its legs and the absence of a mane cause it to appear a good deal smaller.

I suppose that anyone, on seeing a tiger for the first time, would imagine that it must be a very conspicuous animal in its native jungle. But, as a matter of fact, this is not the case at all. As long as a tiger keeps perfectly still it is most difficult to see him, even if you happen to be looking straight at him; for his bright orange fur, marked with glossy black stripes, looks just like the yellow leaves of the jungle grass, with streaks of deep shadow between them. This colouring, of course, helps the 


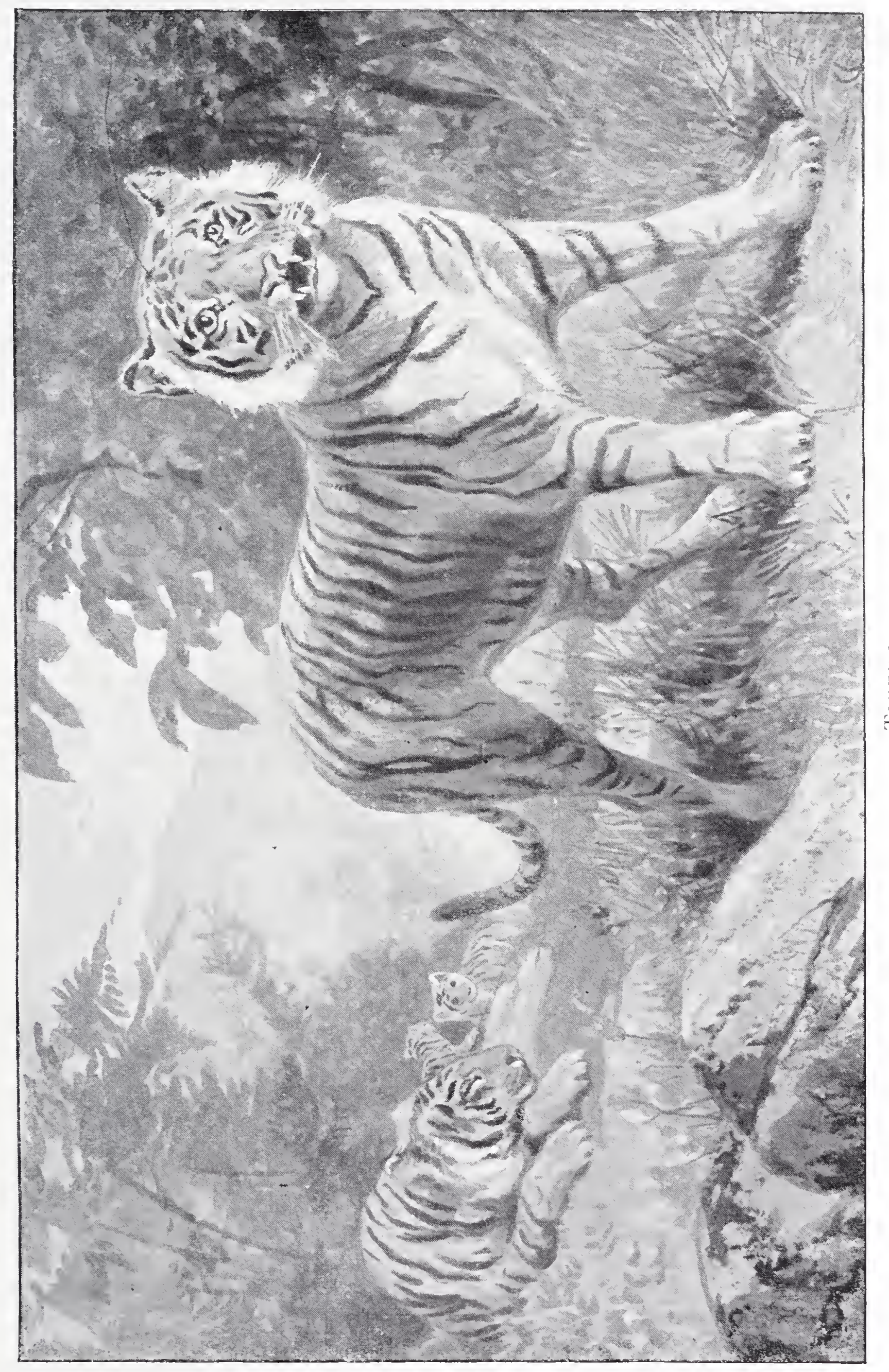



tiger in two ways. In the first place, when he is hunting, it enables him to creep up to his victims without being seen; and in the second place, when he is being hunted himself, it often allows him to crawl away without being noticed.

In some parts of India tigers are still extremely common; and of course they do a great deal of mischief. They are very fond, for example, of preying upon domesticated cattle, and sometimes, evary four or five days for months together, the same tiger will lill and carry away a bullock from the same herd. I Ie generally kills his victims by springing upon them suddenly, seizing their throats with his jaws, and then wrenching their heads hackwards and sideways, so as to break their necks. Then he will either dras away the carcase into the jungle at once, or will hide close by, and come back in order to feast upon it when night is heginning to fall.

Of course a tiger cannot devour the whole of a bullocli's body at one meal; but at the same time lie loes not care to leave the remainder for the jackals. So when he has eaten his fill he nearly always finds a sleeping place close by, so that if he should wake up and hear a party of jackals quarrelling over the carcase, he can rush out at them and drive them aray.

But worse-by far than the cattle-destroying tigers are the man-eaters. 'These are sometimes said to be the old and almost toothless animals which can no longer kill a buffalo or a bullock, and therefore take to preying upon human beings instead. But very often quite a young animal becomes a man-eater; and it is said that if a tiger should once taste human blood, he will always prefer it afterwarls to any other foocl.

A man-eating tiger will often throw a whole district into a state of terror. Day after day he will conceal himself among the thick bushes which border a native road, and lie in wait for solitary passers by. One day, perhaps, a man will he carried off; the next lay a woman; the day afterwards a child. No one knows whereaibouts the animal is hiding; and sometimes he will succeed in killing fifty or sixty human beings before he is discovered and destroyed.

When the natives kill a tiger, they generally do so by driving hin into a small clump of jungle, surrounding it with stout netting, and then spearing him through the meshes. Or perhaps they will climb a tree close to the carcase of a bullock which the animal has lilled, and shoot him when he comes at dusk to feast upon its remains. J'ut in Oude the tiger is said to have been formerly clestroyed in a very curious way. A number of leaves of the pranss tree, which are large and broad like those of a sycamore, were smeared with a kind of bird-lime, and laid upon the sround in the animal's path. When he came along one of these leaves would sticli to his paws, and he would find that he could not shake it off. So he would try to remove it hy 
rubling it against his face. The only result, of course, would be that his nose and eyes became covered with bird-lime. Meanwhile he had trodden upon other leaves, which he tried to remove in the same way. Before very long his eyelids were stuck down so that he could not open them. Then he would lie down and rub his face upon the ground, covering it with earth, and so making matters worse. By this time he would be thoroughly frightened and begin to howl pitifully, so that when the hunters came running up they found the poor beast an easy prey.

Europeans, however, hunt the tiger by means of elephants, which of course have to be most carefully trained before they can be depended upon to face the furious animal. A number of elephants are generally employed, the hunters riding in "howdahs" upon their baclis, while several hundred natives, perhaps, act as beaters, shouting and yelling, beating drums, firing off guns, and making as much din as they possibly can to frighten the animal from its retreat. Sometimes it is so terrified that it slinks out, and falls an easy prey. But now and then it will charge the nearest elephant with the utmost fury, sometimes springing upon it and almost reaching the howdah before it is killed by a well-directed bullet.

The number of tiger cubs in a litter varies from two to five, or even six, although families of more than three are not very common. The little ones do not reach their full size until they are three years old, and during the whole of that time they so about with their parents.

Much smaller than either the lion or the tiger, but still a very large and powerful animal, is the LEOPARD, which is sometimes known as the Panther. It is spread over almost the whole of Africa, and also over the greater part of Asia, and in many districts is very common indeed.

You can always recognise the leopard by its markings. The ground colour of the fur is bright yellow, with just a tinge of red in it, becoming lighter on the flanks, and passing into white on the lower surface of the boly. The spots are black, and those on the backi and sides are always ring-shaped, enclosing a patch of yellow. Sometimes, however, the whole of the fur is hlack. But even then you can see the spots, which look something like the markings in watered silk.

Strange to say, these black leopards always seem far more savage than the others, and those who have had them under their care say that it is quite impossible to tame them.

In spite of its smaller size, the leopard is very nearly as powerful as the tiger, and in some ways is an even more formidable foe. It is much more active, for instance, and is more easily roused into rage; while it can climb trees likie a cat, and spring down upon a passer-by from among the branches. It does not as a rule attack man, and will always seek safety in flight if 
it can. But if it is brought to bay it will fight with the utmost fury, and nothing will check it but a bullet through the heart or the brain.

When it can do so, the leopard always likes to live near the habitations of man, because there it has so many opportunities of springing upon a pony, a sheep or a goat. At night, too, it will rob the hen roosts, or make its way into the pens where the calves are liept, and carry one of them off hefore its presence is even suspected. Dogs, too, fall victims to it in great numbers, and now and then it succeeds in pouncing upon an unwary

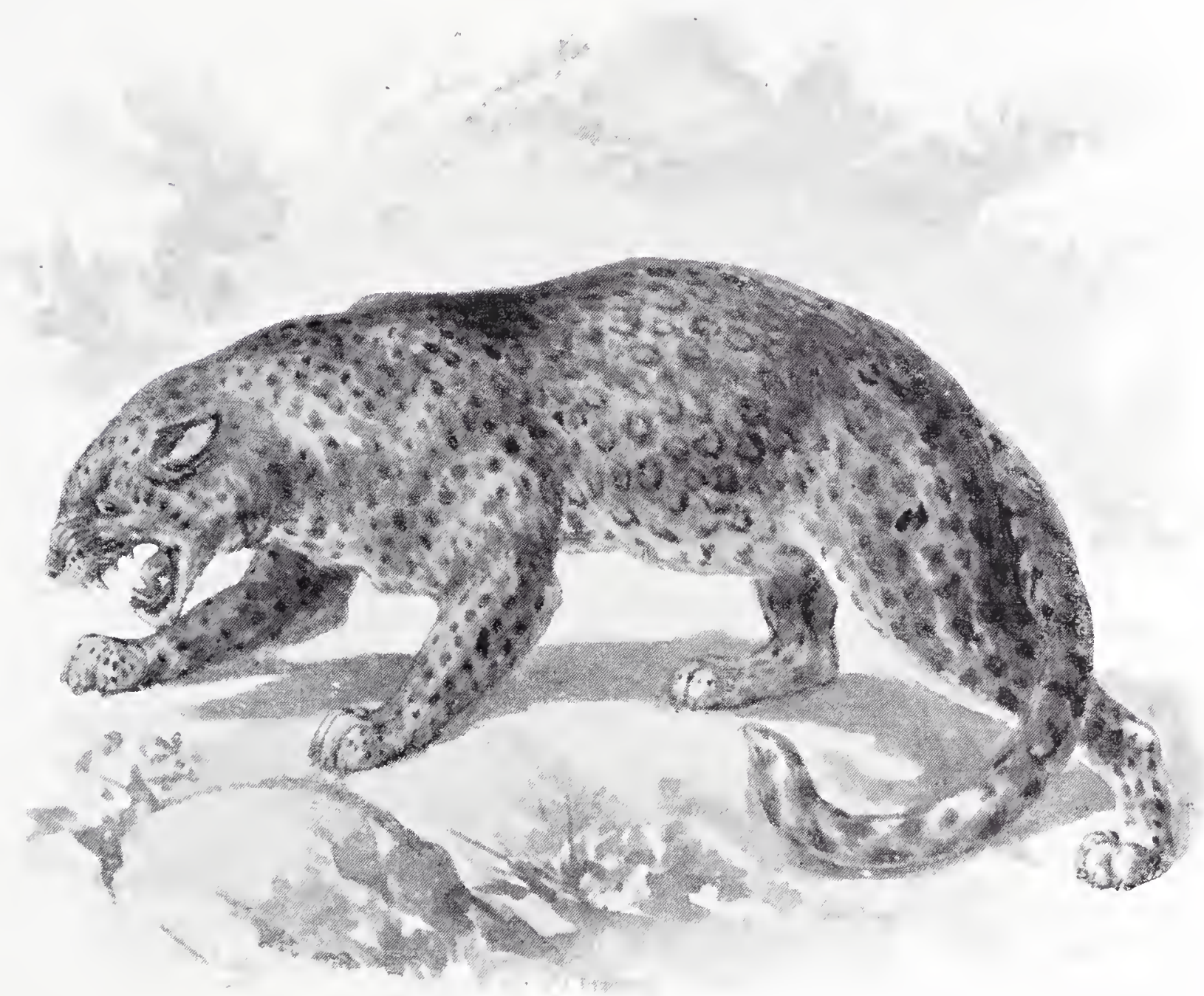

LEOPARD.

monkey. When it lills an animal it does not leave the carcase lying on the ground as the tiger does, and visit it night after night until it is consumed, but carries parts of its body up into a tree, and hides them in a kind of larder which it has made among the branches.

Those who have hunted it say that the leopard is a far more difficult animal to kill than the tiger. 'The reason is that it is so much more wary. A tiger, as it creeps through the jungle, will look most carefully in front of it as it moves along, as well as on either side, hut it never seems to think of looking 
up into the lranches of a tree above, to sec if an enemy is hiding therc. So very often the hunter is able to shoot it hefore it has the least idea that it is in danger. But a leopard is much more cantious, and never comes hack to its lair, or to the remains of its "kill," without

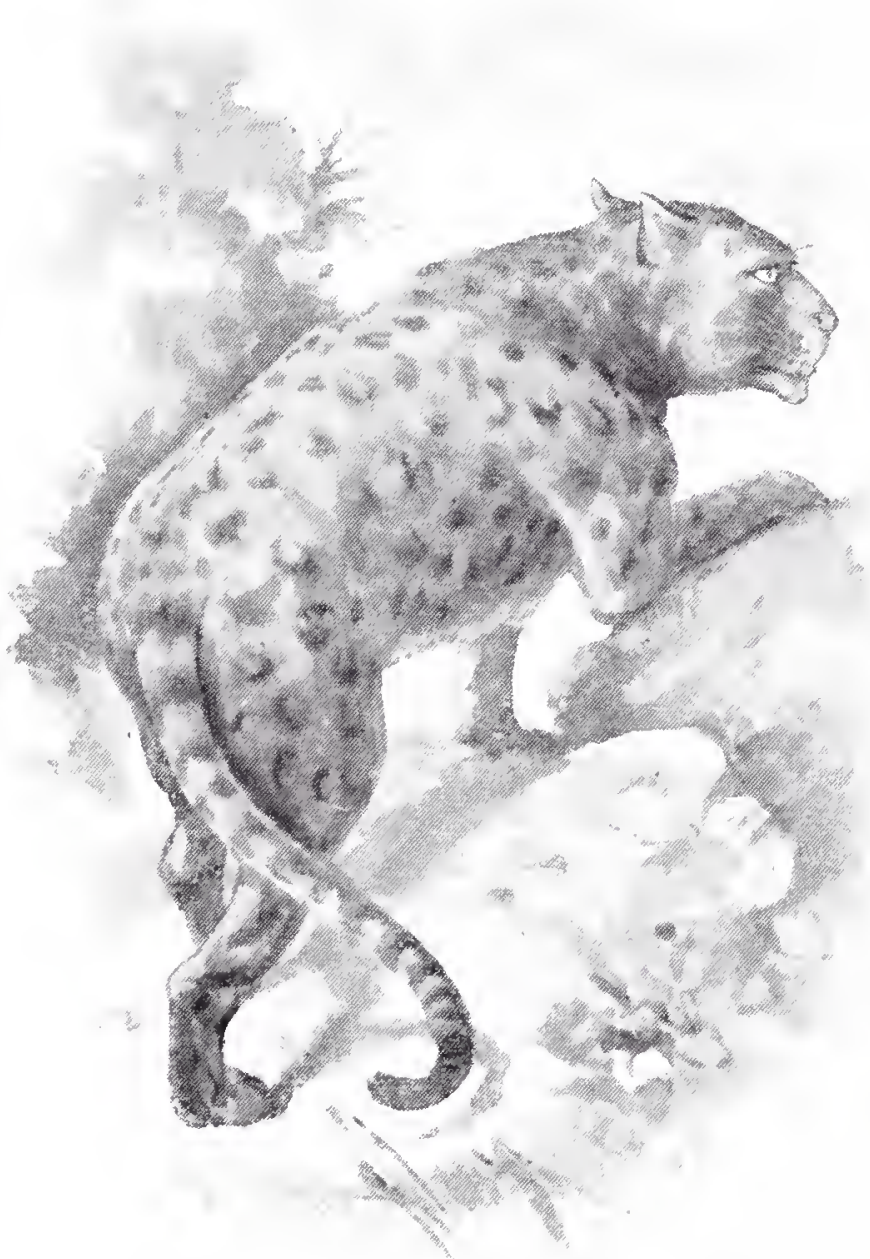

OLNCl:. carefully examining the boughs above as well as the bushes below; so that inless the hunter is very well concealed indeed, the animal is almost sure to discover him and to crawl silently away hefore he has the chance of a shot.

The Ounce looks rather like a leopard with very lightcoloured fur. But the rosettelike spots are a srood deal larger, the fur is rery much longer and thiclier, and the tail is almost as bushy as that of a Persian cat. 'The reason why the fur is so thick is that the ounce lives in rery cold countries. It is found high up) in the mountains of Central Isia, ascending during the summer to a height of perhaps eighteen thousand feetjust fancy it, a good deal higher than the summit of Mont Blanc!--and coming down to the lower levels in winter. In other words, it is hardly ever seen below the snow line, and is often linown as the "Snow Leopard" in consequence. So it wants good thick, warm fur, doesn't it? Of course we do not know very much about its habits, for it is a very difficult animal to watch in a state of nature. Tery few people, indeed, ever see it. And it has only once or twice been brought to Europe alive. But it seems to prey chiefly upon wild goats, wild sheep, and those odd little burrowing animals which we call marmots, and also upon domesticated sheep and cattle which are sent up to graze on the higher slopes of the mountains. It is said never to venture to attack man.

Still more like a leopard is the JAGUAR, which lives in Contral and South America. But you can tell it at once by looking at the rosette-like marks on its body, most of which have either one or two small patches of darli brown fur in the middle. It also has three or four bold black streaks across its breast, which are never seen in the leopard. And its tail, too, is ever so 
much shorter, the tip scarcely reaching to the ground when the animal is standing upright.

The jaguar is perhaps an even better climber than the leopard, and seems far more at its ease among the branches than upon the ground. Indeed, there are some parts of the great sivampy forests of Brazil in which the animal is said never to descend to the ground at all, but to spend its whole life in the trees which stand so closely side by side that it can easily spring from one to another. You wonder, perhaps, what it feeds upon. Why, upon monlieys, and very active indeed it has to be if it wishes to catch them. But then, when a band of monkeys discover a jaguar, they are never able to resist the temptation of getting as close to him as they dare, and chattering and screaming as loudly as they can, just to annoy him.

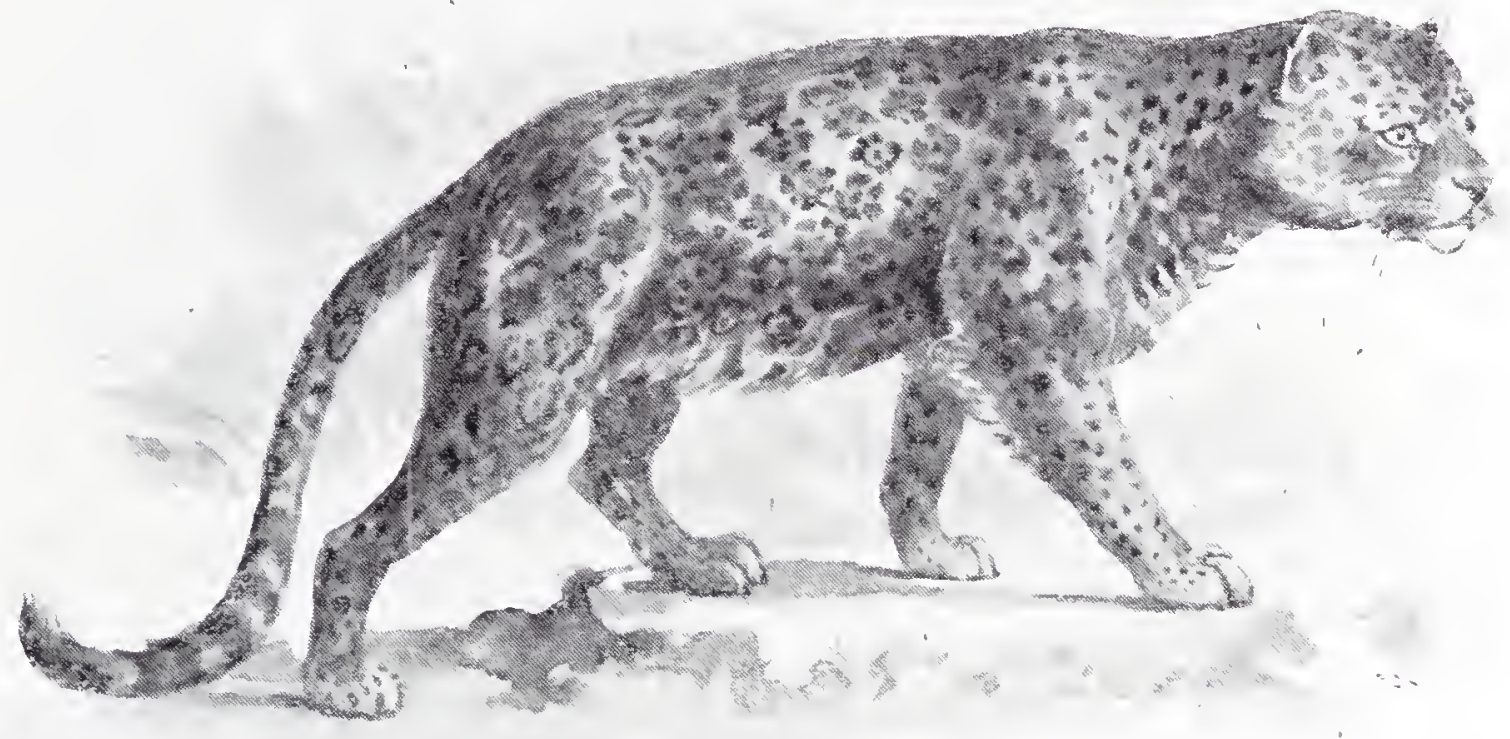

JULIR.

Isn't that exactly like monkeys? But sometimes they venture just a little too close, and then, with a sudden spring, he seizes the nearest of his impudent tormentors and carries it shrieking away.

Birds, too, are often caught by the jaguar, who pounces upon them as they are roosting upon a branch. But he is not at all particular as to what he eats, and sometimes he will leave the trees altogether, and go hunting in the reed-beds by the river-side for capybaras. He is very fond of these animais, for they are so slow in their movements that they cannot run away, so badly provided with natural weapons that they cannot fight, and so fat and delicate that they afford most excellent eating.

Then, just for a change, perhaps, he will stroll down to the sea-shore, and look for a good big turtle. When he sees one-which is generally a female on her way hack to the 
water after laying her eggs in the sand-he seizes it suddeniy with his fore-paws, and turns it over on its back, so that it cannot possibly escape. Then, perhaps, if he is not very hungry indeed, he leaves it for a little while. but very soon he returns, and manages to scoop out all the Hesh of the animal from between the shells by means of his long hooked talons, thrusting in his paw over and over again, till scarcely the smallest particle is left remaining.

Very likely, too, he will find the spot where the turtle had laid her eggs, dig them up, and devour them as well.

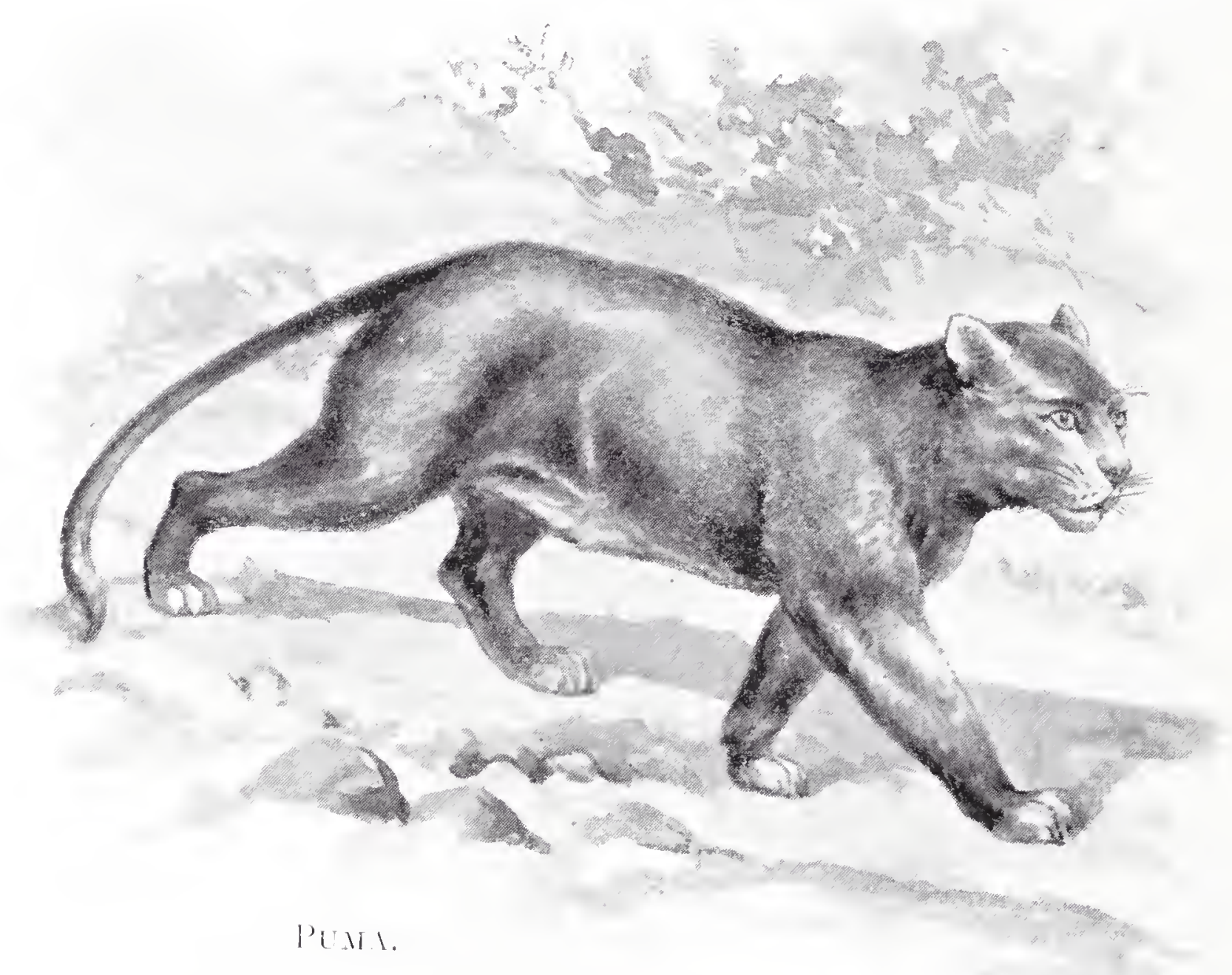

Sometimes, too, he will crouch on the bank of a stream, quite close to the water, and hook out the fish that pass by with his claws. And when he is rery hungry indeed, he will eat lizards and even insects.

Lilie the ounce, however, the jaguar seldom or never ventures to attack a human being, although he will fight with the utmost fury if he is driven to bay. But he will often spring upon horses and cattle, and in such cases he nearly always kills them by seizing their heads between his front paws, and giving a sulden wrench sideways and upwards so as to break their necks. 
Like most of the cats, the jaguar sharpens its claws hy scratching the trunks of trees, and sometimes a tree may be found with gashes in its hark quite an inch deep and more than a vard long.

Next to the jaguar, the Puna is the largest of the American cats, a fully-grown male being sometimes as much as eight feet in total length, of which about three feet is taken up by the tail. In colour it is tawny brown, becoming lighter on the lower surface, and without any spots at all. But the odd thing is that its young are marked all over with large blotches of blackish brown, while their tails are ringed with black like that of the tiger. And these markings do not disappear until they are more than six months old.

The puma is found in almost all parts of the American continent, from British Columbia in the north to Patagonia

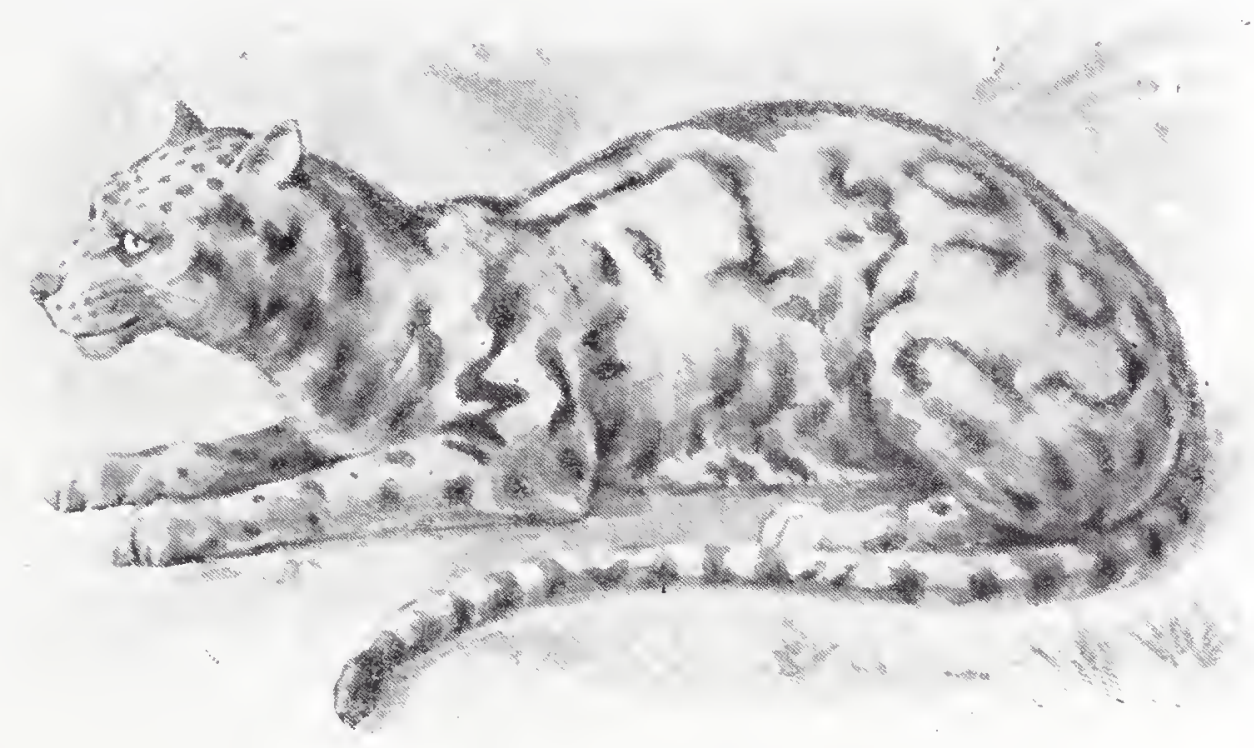

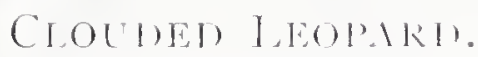

in the south, and it is even said to have been seen in Tierra del Fuego. It spends the greater part of its life in the trees, heing almost as good a climber as the jaguar. But it almost always hunts upon the ground, trying to creep stealthily up to its victim, and to spring upon it before its presence is even suspected.

It scarcely ever ventures to attack a man, but will often follow him for a long distance as though it were waiting an opportunity to pounce upon him unavares. But if he suddenly turns and faces the animal, it will always slink away, even if he is quite unarmed. Sometimes, too, it will allow itself to be killed without attempting to defend itself at all. So hunters have a rather poor opinion of its courage. The farmers, however, have very good reason for dreading the animal, for it is a terrible enemy to sheep, and has heen known to kill no less than fifty 
in the course of a single night. And it will also leap sudkenly upon horses and cattle and break their neclis, just as the jaguar does.

Strange to say, too, although in some ways it is such a cowardly creature, the puma will often fight the jaguar itself. Of course it is the weaker animal of the two, but it is so exceedingly quicli and active in its morements, and makes such excellent use of its teeth and talons, that in very many cases it gets the best of the battle. Sometimes, when a jaguar is liilled by a hunter, its back is found to be deeply scored all over by the claws of a puma.

In many parts of America the puma is linown as the "panther," or even the "painter," while hunters often call it the "lion."

There is still one more of the larger cats which we must not pass by without mention, and that is the Clouded Leor'srd, or Clouded Tiger, which is found in the south-eastern parts of Asia, and in the larger islands of the Malay Archipelago. In size it is about as big as a small leopard, and its yellow-brown fur is marked with stripes like those of the tiger, spots like those of the leopard, rosettes like those of the jaguar, and blotches liike those of the ocelots, while its tail is adorned with rings of glossy 1)lack. So, you see, it is a very handsome animal indeed.

We do not know very much about its habits, for it has only once or twice been brought to Europe alive. But it seems to live almost entirely in the trees, and to prey chiefly upon birds, while those who have caught and tamed it say that it is very gentle and playful. The Malays call it the Rimau-dahan, or "tree-tiger"; and there is a smaller variety, found in the same localities, which is generally known as the Marbled Cat. 


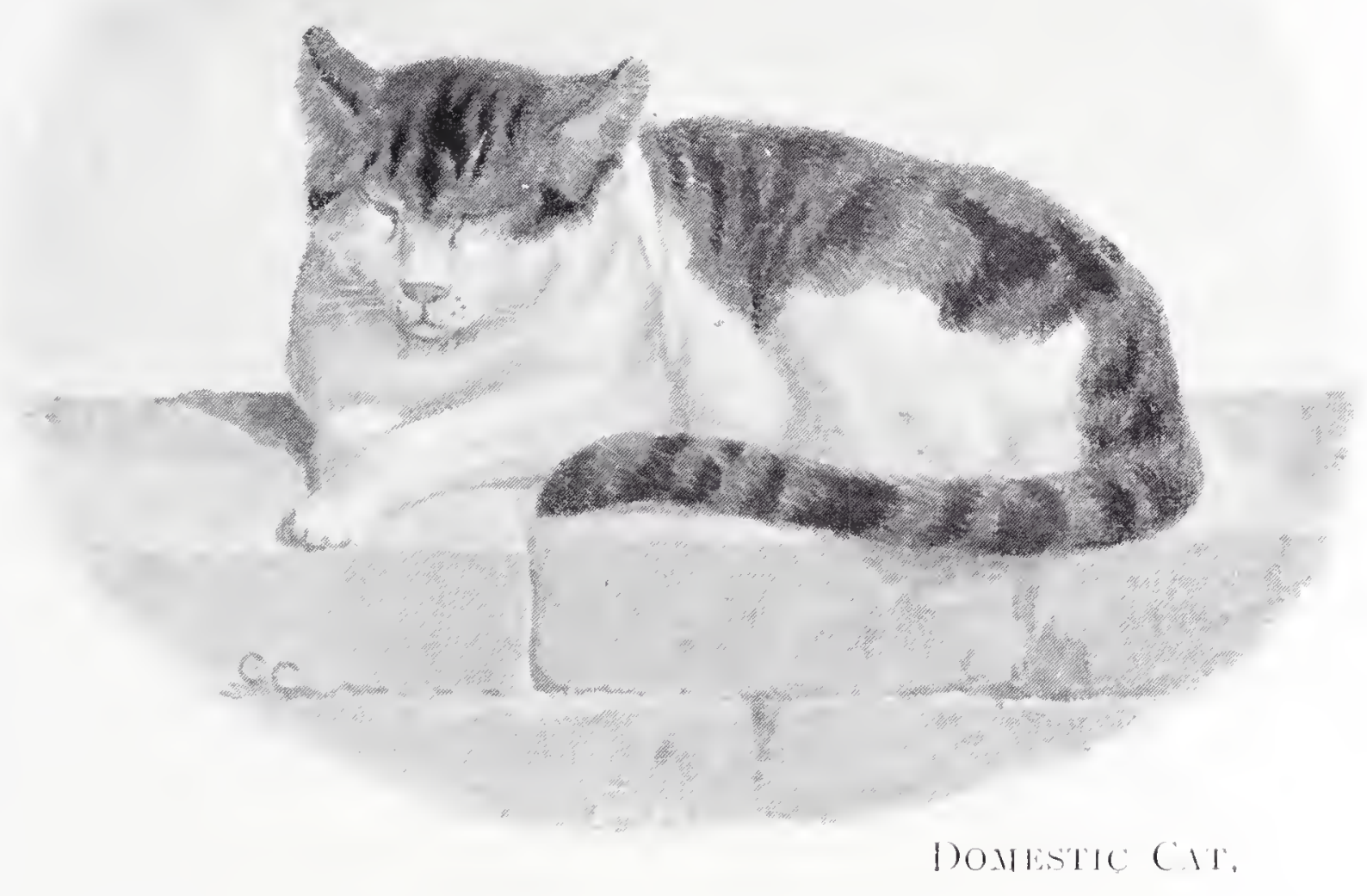

CHAPTER VII.

THE STALIER CATS.

Noll we come to the smaller members of the cat tribe; and first of all, let us notice the Serval.

Unfortunately, however, although it is quite a common animal in many parts of Africa, we linow very little indeed about its habits. But it appears to prey chiefly upon the smaller antelopes, creeping silently up to them as they are grazing, and springing upon them so suddenly that they never linow that they are in danger until they are struck down.

In Southern Africa, where it is a good deal more plentiful than it is in the northern parts of the Continent, the Dutch call the serval the "Bosch-liatte," or "bush-cat," because it loolis like a rather big cat, and lives in the thick bushy parts of the veldt. It is a pretty animal, and would be prettier still if its short, stumpy tail were a little longer, for its fur is bright golden yellow, marlicd with darti spots, some of which run into one another, and so form stripes. Underncath the hody the fur is nearly white, while the ears are jetty black with a broad white band running across them. In length the animal measures about thrce feet, ten inches of which are talien up by the tail; and it stands about eighteen inches in height. 
One of the handsomest of all the cats is the OcELot, which is found in almost all parts of tropical America. But it is not a very easy animal to describe, hecause it varies so much in colour that until a fer years ago naturalists thought that there

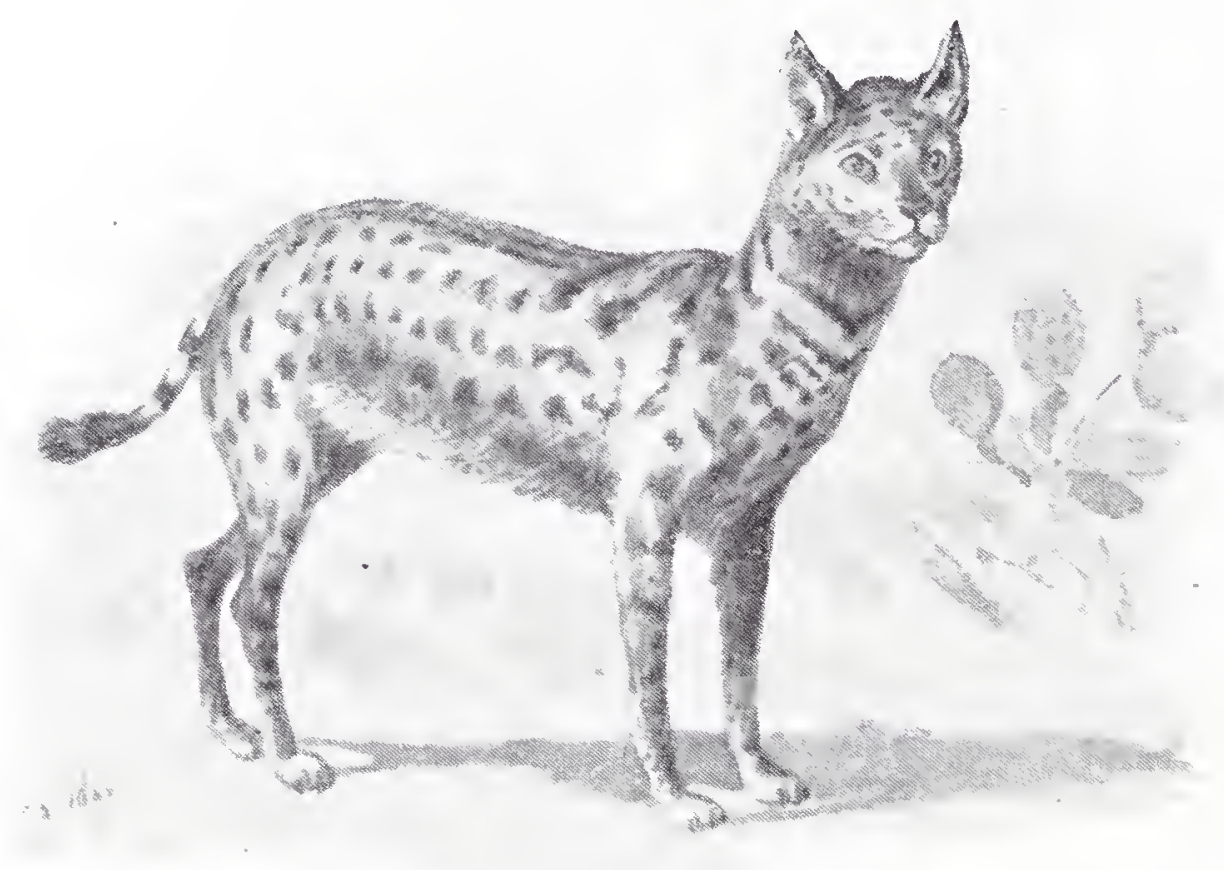

SERTIL, OR BITHECAT.

were several different kinds of ocelots, to all of which they gave separate names. As a rule, however, the ground colour of the fur is either brownish yellow or reduish grey, while the back and sides are marked with rows of streaks and spots and blotches, which sometimes run into one another in such a way as to look almost like stripes. The length of the animal is about four feet, of which about fifteen inches is occupied by the tail, and it stands from sixteen to eighteen inches in height.

The ocelot is only found in forest districts, and is an excellent climber, spending most of its life in the trees. It feeds chiefly upon birds, hiding among the thick foliage until they settle within reach, and then knocking them over with its ready paw. Or it will spring down upon them as they alight on the ground below. It seems to lilie the head of a bird best of all, and senerally eats that first; and very often it will pluck its victim most carefully before proceeding to devour it.

The animal called the Margay is really a kind of small ocelot, and is sometimes known as the Tiger Cat.

The EGYPtian Cat is a most interesting animal, not only hecause it seems quite likely that it is the ancestor of the cats which we keep now as pets, but also because in days of old the people of Egypt used to worship it, just as they worshipped the Arabian baboon. In every way they treated it with the greatest possible honour. Indeed, to liill a cat, in those days, 
was a far more serious offence than to kill a man, and if the offender was discovered he was certain to be made to pay the penalty with his life. And when the animal died its body was carefully embalmed and wrapped in spices, and was then solemnly buried in the tombs of the lings.

If you go to the British Museum, and visit the Egyptian galleries, you may see the mummied remains of some of the very cats which were worshipped by the people of Egypt five thousand years ago.

There, too, you may see an old painting which is every bit as interesting, although in a different way. For it shows us that, although the ancient Egyptians held the cat in such high honour, they expected it to make itself useful in return. The picture represents a hunter and his family going out on an expedition in search of water birds, and from it we learn that they would embark in a boat with several decoy birds, together with a carefully trained cat. 'They would then push off into the great beds of tall reeds which fringed the sides of the river, and sit in the boat while the cat went and caught birds for them, which were attracted within reach by the decoys. In the picture you will see that the cat is represented with one bird in her mouth, another in her fore-paws, and a third between her hind paws; so that if she got all three back to the boat, she must have been a very clever cat indeed.

This animal is sometimes known as the CAFFRE CAT, and

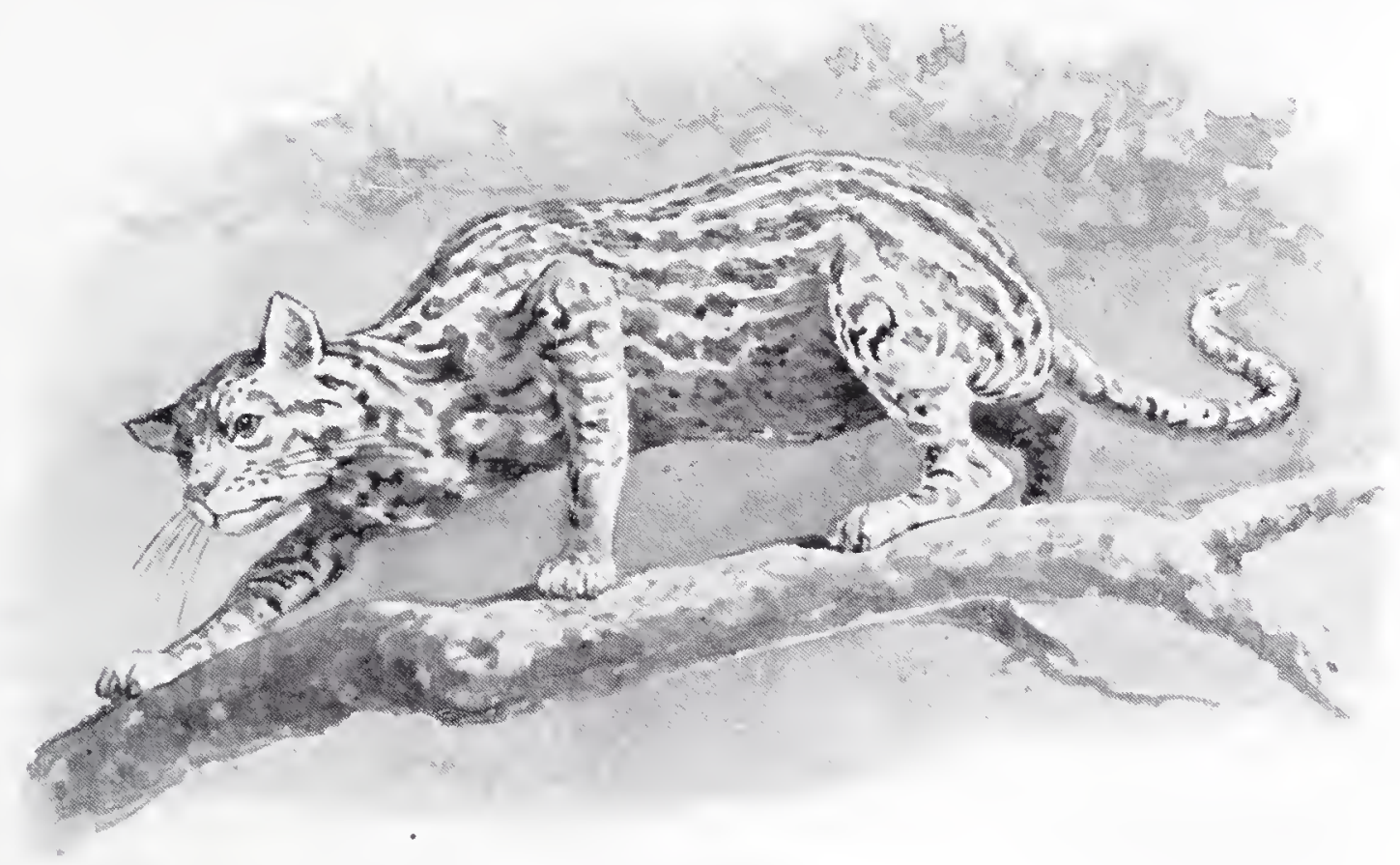

OCELOT:

it is found wild in almost all parts of Africa, and also in Syria and Arabia. In size it is about as big as a rather large domestic cat, and in colour is generally yellowish grey, with a few faint stripes across the back and several darlier ones on the hind quarters, 
while the tail is marked with black rings and always has a black tip.

Then there is the WILA CAT, which is still found in some of the rough and mountainous wilder parts of the British Islands. It is a very scarce animal

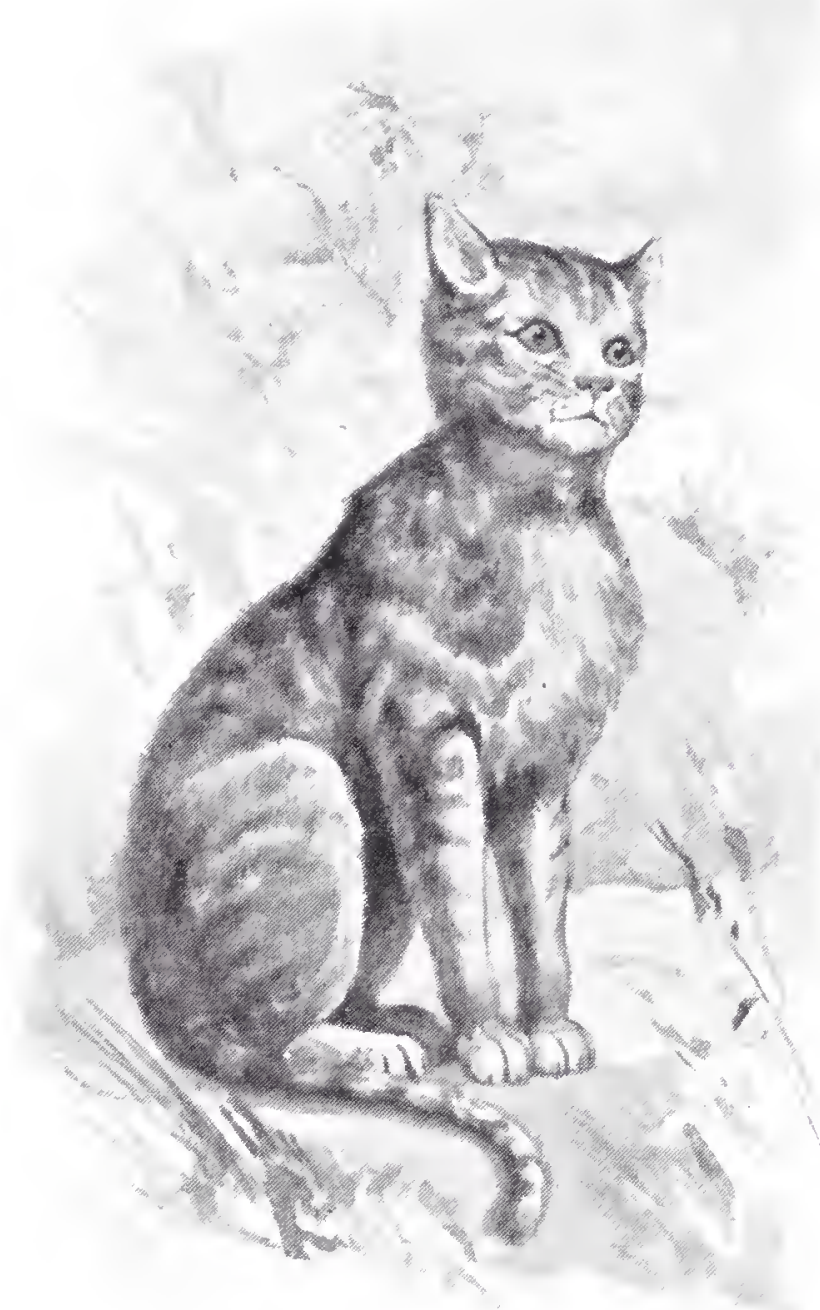

EGITPTAN CAT. nowadlays, liowever, for it does so much mischief to game that the lieepers destroy it whenever they get a chance. It is true, of course, that so-called "wild cats" are very often caught or lilled, even in England. 13ut these are almost always tame cats which have escaped from captivity and have taken to a life in the woods.

If you were to see a real wild cat in captivity, you would most likely think that it loolied a very sentle creature. But in reality it is one of the fiercest and most savage of all living animals, and no matter how lindly it is treated it never seems to become tame.

Vild cats are nearly always found in thicliets in mountain districts which are hardly ever trodden by the foot of man. They mostly live either in hollow trees, or in crevices among the rocks, where they bring up their

litters of little ones. They licep their littens in very sood order. ()nly a few days before these lines were written I heard of a wild cat which was liept in a large otter's cage, with a pool of water in the midlle; and there she brought up three kittens. One day she heard a strange footstep approaching. Now she could not hear strangers, and would never allow them to look at her little ones; so she jumped into the sleeping compartment, and called to her littens to come in after her. 'Two of them obeyed; the third preferred to stay outside. So out she jumped, soused it threc times in the water, just to teach it to be more obedient in future, and then carried it off by the scruff of its neck.

A fully-grown wild cat is about twenty-eight inches long without the tail, which is much shorter and more stumpy than that of the domestic cat. The thick soft fur is grey in colour, brindled with blacli.

Another lind of wild cat is found in the northern parts of 
Ifrica, and also in Persia and India. Sometimes it is called the JUNGLE CAT, and sometimes the Chaus. It is rather bigger than an ordinary cat, and is sandy grey or greyish brown in colour, with just a few darker strealis across the legs. It lives, as a rule, among long grass and reeds, and in cornfields, coming out to hunt only by night. So very few people ever see it in a wild state, and we do not linow very much about its habits. But it must be rather a formidable animal to meet, for the late Sir O. B. St. John tells us that a jungle cat which he liept for some years as a pet was more than a match for two porverful English bull-terriers, which used to attack her day after day, but always grot the worst of the battle.

Next we come to the Caracal.

You may generally see this animal at the \%oo; and if you go to look at it your first idea will most likely be that it is a

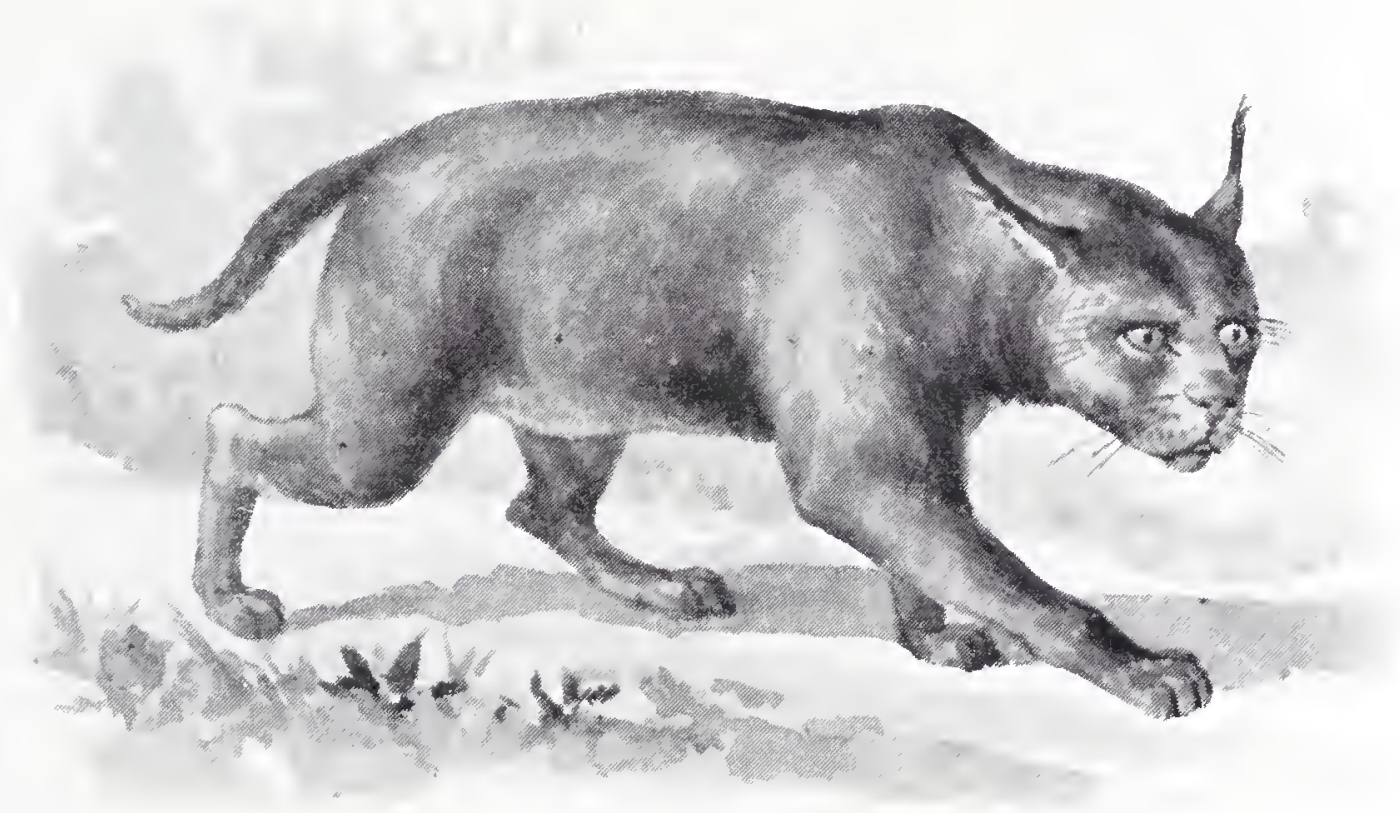

CIRICAL。

very had-tempered creature indeed. For as soon as you come near its cage it is almost sure to throw back its ears, show its teeth, and spit and hiss and snarl at you, and to look as if it would fly at you in a moment if only the bars were not in its way. And so, no doubt it would, for it is one of the most savage of all the cats, and cannot be tamed without very great difficulty, unless it is caught while very young indeed.

The name "caracal" signifies "black-eared," and has been given to the animal because its ears are jetty black in colour. They also have a long tuft of dark hairs at the tip. The head, body and legs are bright reddish brown. But some caracals are a good deal lighter than others, and now and then the lower parts of the body are marked with dull reddish spots. The height of the animal is about eighteen inches at the shoulder, and the length of the body and tail together is from three to four feet. 
Caracals are found in India and Arabia, and also in most parts of Ifrica. They live among bushes and long grass, as at rule, and prey upon the smaller deer and antelopes and also upon birds, which they are said sometimes to capture even upon the wing, springing into the air and seizing them lectween their fore-paws as they fly past.

Now we come to a very odd-looking animal indeed; namely, the I,rix.

This creature loolis rather like a stontly-built caracal. But the ears are grey instead of black, the tufts of hair upon them are a good deal longer, and the fur of the body is grey, generally marlied with a number of darlier spots. Its curious appearance, however, is due to the fact that it has an enormous pair of very bushy whiskers, which hang down far helow the chin.

Not so very long ago the lynx was found commonly in

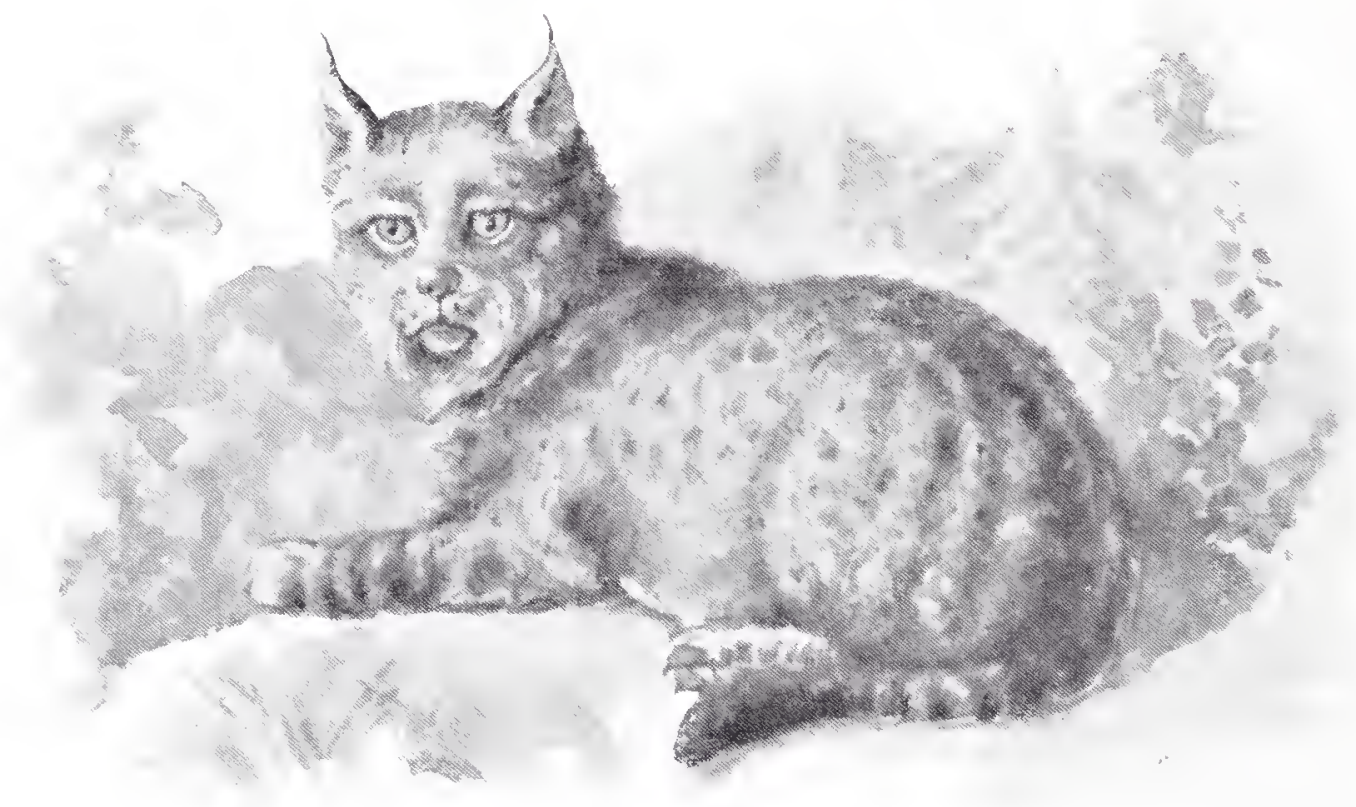

LYX.

many parts of Europe, and it is still tolerably plentiful in Norway, Swoden, and the northern parts of Russia as well as in Northern Asia. lint it is very much persecuted by the hunters for two reasons. In the first place, it is a very destructive creature. I comple of lynxes have been linown to libll six sheep between them in a single night. And, in the second place, its fur is so thick, so soft, and so warm that its slin sells for a good deal of money. So a sreat many lynxes are shot or trapped every year, and before very long the animal will most likely disappear from Europe altogether.

No doubt you have sometimes heard the expression "lynxeyed" used of somebody whose sight is unusually good. And certainly the lynx is very sharp-sighted indeed. But in days of old it was actually thought that the animal could see right through a solicl wall as easily as we can through a pane of glass.

The lynx is a very good climber, and spends a great part 
of its life in the trees, often lurking among the branches in order to spring down upon an unsuspecting victim as it passes below. But it mostly makes its lair among rocks, just as the wild cat does. There it brings up its two or three little ones, which are very playful little creatures, but are very bad tempered if anyone interferes with them. IIowever, they are easily tamed if they are captured while quite small, and will follow their master about just like a dog.

Another lind of lynx, called the PARDINE LrNx, inhabits the south of Europe, from Spain as far as Turkey.

Lymxes are also found in Canada; but it is not quite certain whether these belong to a different species or not. It any rate, they are rather smaller than those which live in Europe and Asia, and their tails are hardly ever more than five inches long. They live in the deepest parts of the forests, and in thick

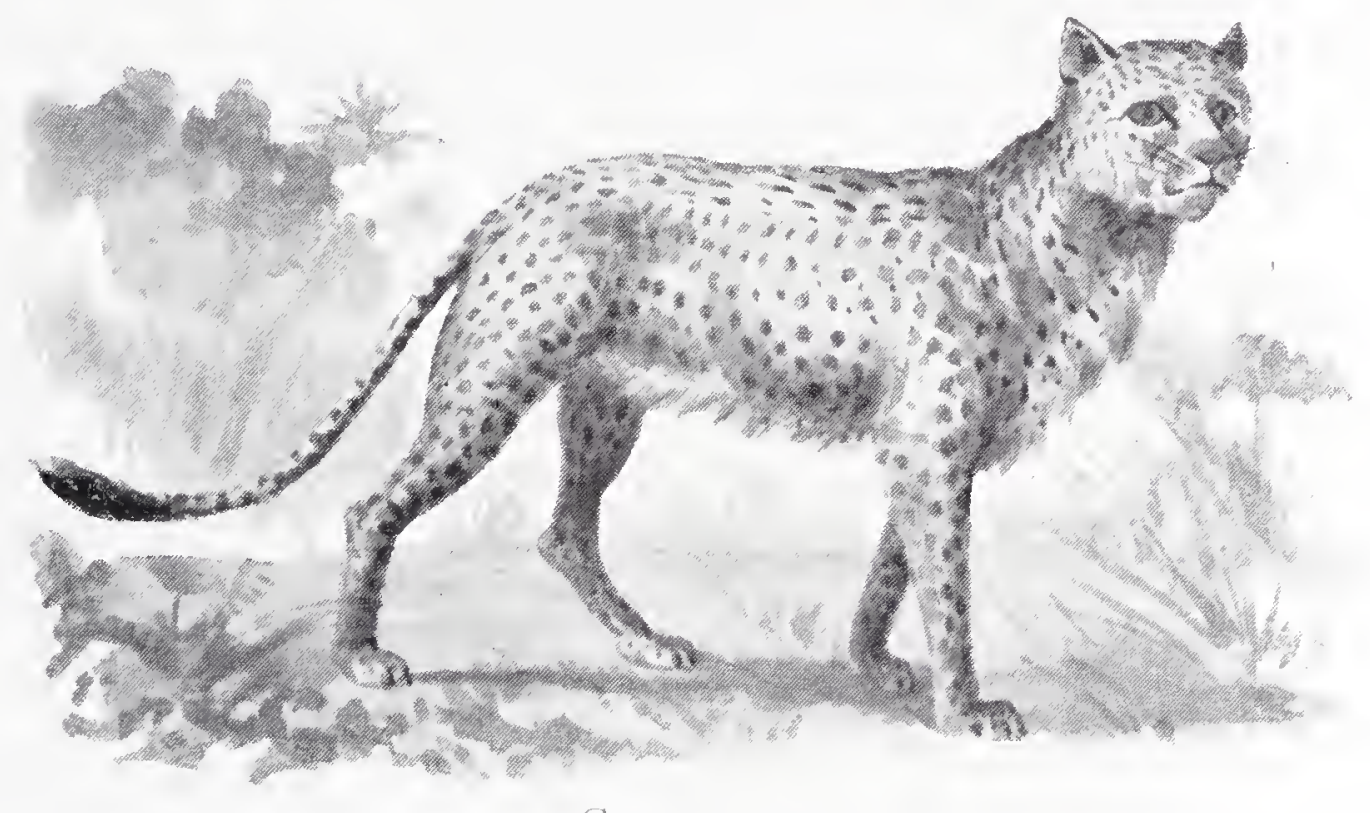

CHETIH.

bushy districts, so that they are not very often seen; and they prey upon hares and other small animals, and also upon such birds as grouse and partridges.

When one of these lynxes is rumning through long grass it looks very odd indeed; for it travels by means of a series of leaps, all four of its feet coming to the ground together.

Last among the cats comes the very curious Cuntar, or Hunting Leopard, which is found both in Africa and in India.

In some ways, however, it is much more like a dog than a cat. Its head, for instance, is quite small and round, its hody is very slender, and its legs are much longer in proportion to its size than they are in any other nember of the family. But, more remarkable still, the claws are not entirely drawn back into their sheaths while not in use, as they are in all the true cats, but partly project, so that the points are worn away by constantly rubling against the ground. So I think that we may consider 
the chetah as partly a cat and partly a dog-a connecting link joining the two families together.

If it were not for the length of its limbs, however, the chetah might very well be mistaken for a leopard, for its head and hody are coloured and marked in much the same way. But the spots are solid, so to speak, and not ring-like as they are in the leopard. The animal stands from thirty to thirty-three inches in height at the shoulders and the hody and tail together are about seven feet long.

The chetah does not capture its prey as other cats do. Lions, tigers and leopards, for example, always try to creep up quite close to their victims, so that they may be able to pounce upon them at a single spring. But the chetah only creeps up to within a comple of hundred yards, and then runs them down in fair chase. It is exceedingly swift of foot, being able easily to outrun a greyhound, so that when once it starts in pursuit its victim has but little chance of escape, Indeed, a chetah has actually been seen to put up a lilack buck two hundred yards away, and to run it down within a quarter of a mile.

Just fancy being able to run nearly twice as fast as an antelope!

In India the chetah is often caught and tamed, in order that it may catch game for its master. It is always talien ont to the hunting-ground in a light cart, drawn by a couple of bulloclis, and its eyes are covered with a kind of hood. When a deer or an antelope is sighted, this hood is taken off, and the chetah is released from its chain. No sooner does it catch sight of its quarry than it creeps quietly towards it until it is within distance, and then starts off in pursuit like an arrow shot from a bow. The hunters ricle quietly after it, and before they have gone very far they are sure to find the chetah with its victim pinned upon the ground. Then the throat of the animal is cut, and some of the blood is given to the chetah to drink, after which it is again blindfolded and is led back to the cart.

When the natives want to catch a chetah or two, in order to train them for hunting, they do so in rather a curious way. Although these animals cannot climb trees, because of the manner in which their claws are made, there are certain trees to which they are very fond of resorting, in order to sharpen their talons upon the bark. So the natives malie a number of nooses of raw hide, and arrange them on the ground all round one of these trees: and when they visit them next day, they are almost sure to find that two or three chetahs have been snared.

It is needless to say that this beautiful and interesting animal is very easily tamed. If it is kindly treated it will rub its great round head against one, put up its tail, and purr loudly, just like a very lig cat. 


\section{CHAPTER VIII.}

\section{THE CIVETS, THE AARI) WOLF, AND THE HYENAS.}

BETUEEN the great tribes of the Dogs and the Cats come three small but rather important families, one of which contains the Civets, while the Aard Wolf belongs to the second, and the Iyenas to the third. I must tell you a little ahout each.

First of all, then, come the Civets; and first among the cirets is the Fossa, which is found in Madagascar.

This is a very curious animal indeed. It is about five feet long from the end of its snout to the tip of its tail, and has a body shaped very much like that of a weasel. Its fur is pale reddish brown in colour, and reminds one of the coat of a dachshund dog. But the oddest thing about the fossa is its way of walling. Some animals walli on the tips of their toes, like the cats and the dogs. We call these digitigrades. Others plant their feet flat upon the ground, like the bears. We call these plantigrades. But the fossa does neither, for its feet have half-soles only, the front part being quite bare underneath, while the hind part is covered with hair. And as it walls the animal places the hare part of its feet upon the ground, while the hind part is lifted up; so that it is half a digitigrade and half a plantigrade.

Then it has claws just like those of a cat, which are drawn hack into sheaths while not in use, so that their sharp points may not be worn down by rubbing against the ground. No doult this is the reason why the animal is able to climb so well. If you go to look at the fossa in the Zoo you will he quite surprised at its activity. Its cage is a double one, with onc compartment ahove the other, and two or three stout branches on which it can take exercise, and it goes rumning up and down from one to the other, and backwards and forwards from the branches to the walls, and from the walls to the branches, with such wonderful swiftness that it is really not at all easy to follow its movements.

But don't he tempted to stroke the animal, if it happens to be lying quietly near the hars, for although it looks very gentle it is in reality a most savage creature, and has hardly ever been tamed. And partly for this reason, and partly because it only comes out to hunt for prey liy night, we know very little incleed about its halits.

The true civets have much stouter bodies than the fossa. 'Their hearls are long and narrow, with the muzzle drawn ont 
almost into a point, their legs are quite short, and along the back runs a crest of stiff hairs, which can be raised and lowered at will, just like the spines of the hedgehog.

Six different kinds of civets are known, five of them being found in Asia, and one in Africa, and they are chiefly remarkable for producing a most powerful perfume. 'l'his perfume is obtained in a very curious way. It is secreted in a lind of double pouch underneath the body, close to the root of the tail, and as it is continually being formed, the animal is much too valuable to be killed in order that its pouch may be emptied. At the same time, its sharp teeth and claws are so sharp and strong, and

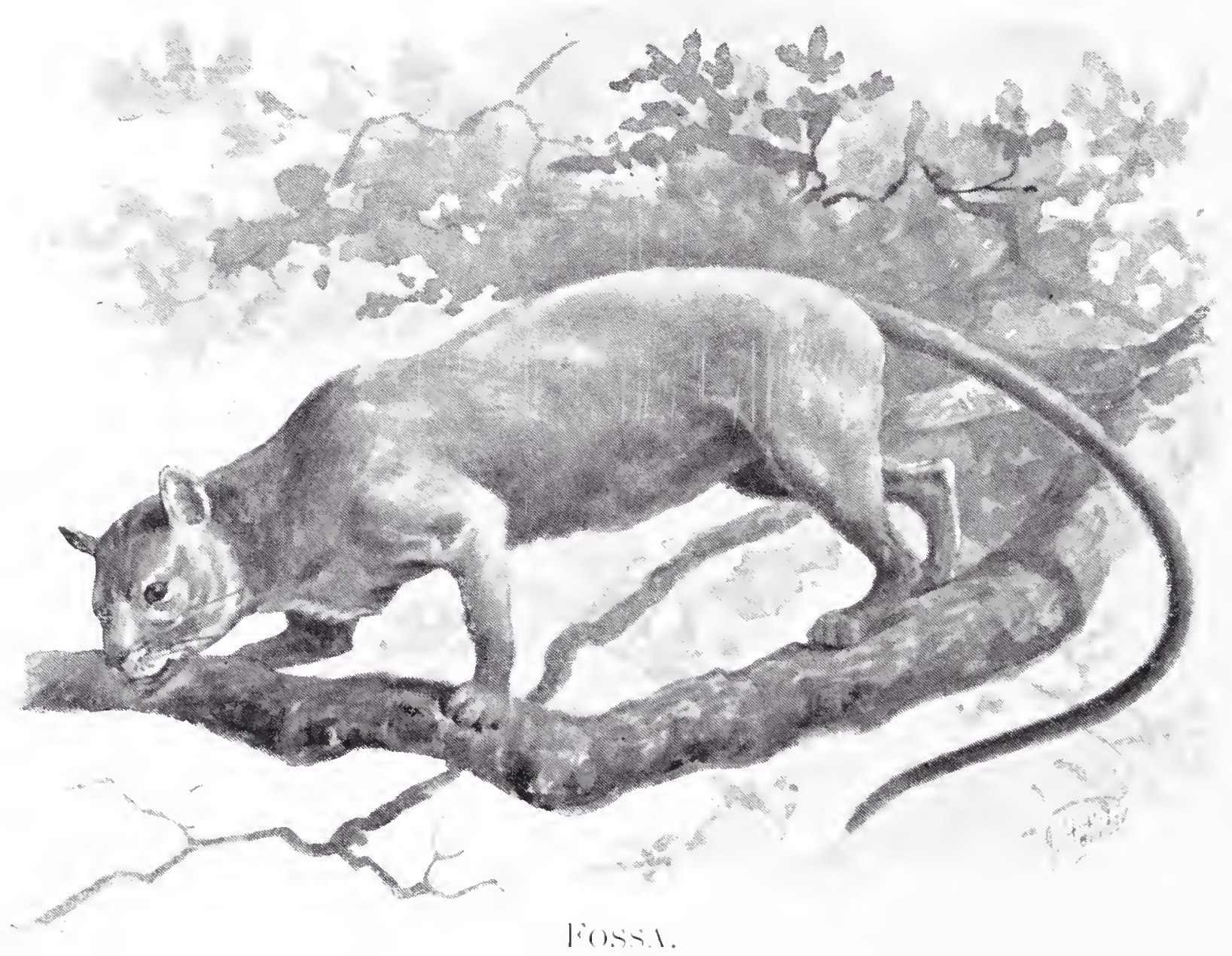

it linows so well how to use them, that it would be a most dangerous creature to handle. So when the perfume has to be taken, the animal is forced into a long and very narrow cage, in which it is held so close a prisoner that it can neither scratch nor bite. Then the contents of the pouch are scraped out by means of a long, slender spoon, which is passed through a hole underneath the cage.

Each side of this pouch is about as big as an almond, and the contents are thicli and greasy in character, almost like butter. When the animal is at liberty the perfume is dropped from time to time, in lumps about as big as an ordinary hazel nut. The best known of these animals is the fNDIAN Civet, 
which is about four fect in length, including the tail. The general colour of its fur is darli grey, sometimes with a yellowish tinge, and on the chest, shoulders, and thighs there are a number of dark stripes. 'The crest of hairs along the back is glossy black, and the tail is marlied with six black rings and five white ones. It is a solitary animal, and is hardly ever seen during the daytime, which it spends in hiding among bushes, or in long, thick grass, coming out after darli to search for the lizards, frogs, birds and other small creatures upon which it feeds.

The Genets may be described as small civets, with narrower bodies, shorter legs, and longer tails, and without the curious pouch for producing perfume.

One of these animals - the COMnON GENET-is found in Spain and the South of lirance, as well as in South-west Asia, and the Northern parts of Africa. It is between three and

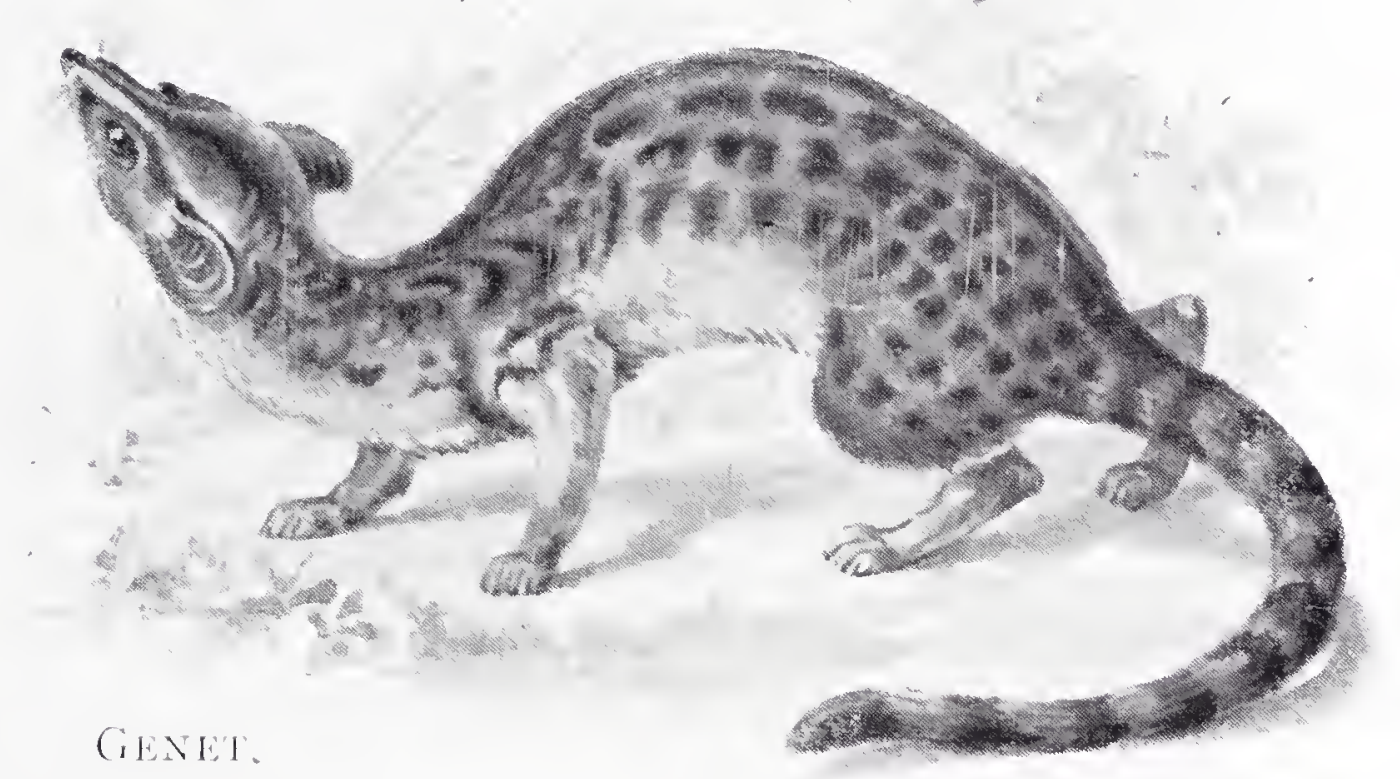

four feet in total length, and is yellowish grey in colour, with blotches of dark brown scattered all over the body. It is a very sentle creature, and is easily tamed, being often liept in houses to destroy rats and mice, just as we keep cats in lingland.

The Palm Civets live in trees, chiefly in palm trees, and they are so fond of drinking the siveet juice, or "toddy," which the natives collect in small vessels suspended on the trunks, that they are often known as "toddy-cats."

One of these animals is very common in many parts of India, where it is in the habit of taking up its abode in the thatched roofs of the native huts. It is often tamed, too, by Enropeans, and after roaming about the house all night in search of mice and cocliroaches will come up to its master's bedroom, jump up on his bed, snuggle away under his pillow, and there sleep soundly until late in the following day. But if it finds a chance it will get into the poultry-houses and kill some of the 
fowls, in order to suck their blood; so that it has to be looked after very carefully.

There are ten or eleven different kinds of these animals, the commonest of which is the Ixngan PaLM Civet. It is about

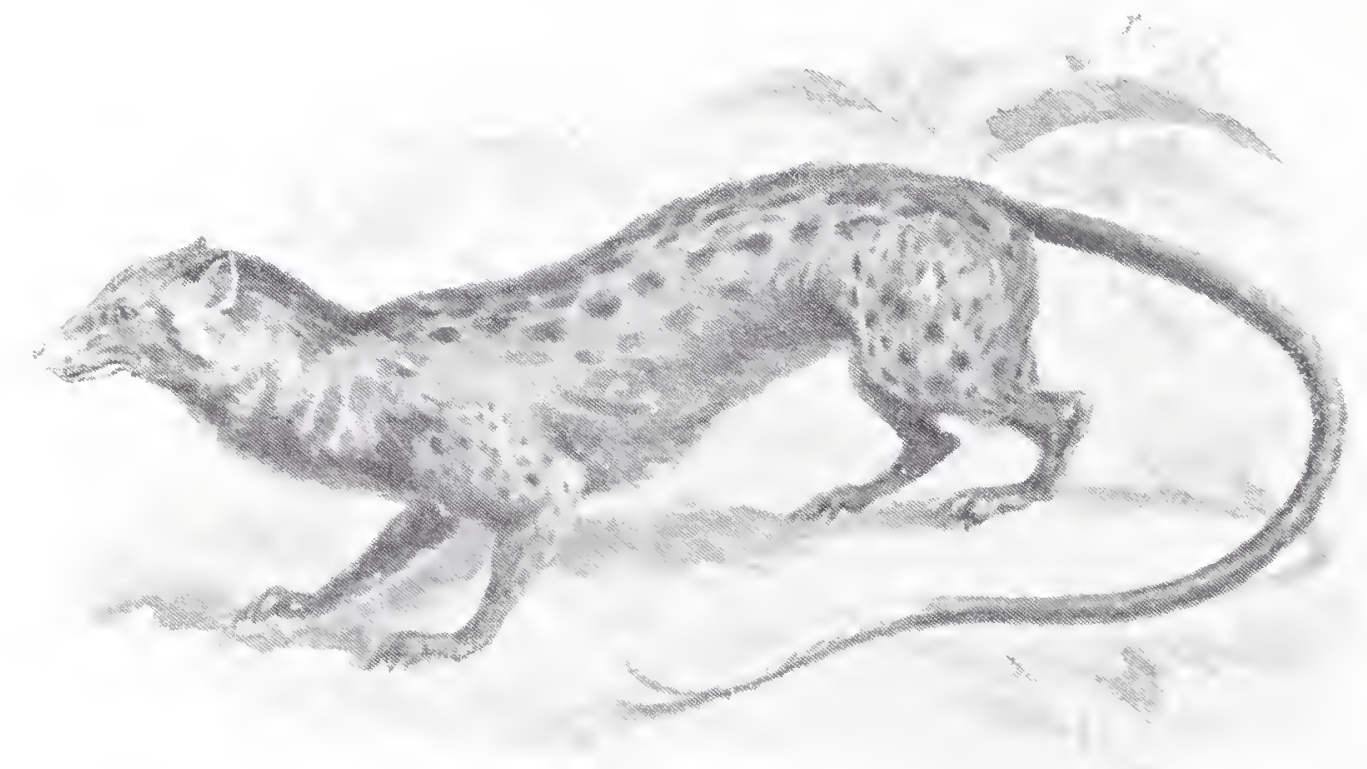

IXIMANAPALA CINET.

as ligg as a rather big cat, and is brownish grey in colour, with very coarse and rather ragged fur. It has an odd way of twisting up its tail into a very tight coil, and for this reason is sometimes known by the name of "paradoxure," a word which signifies "queer tailed."

Next we come to the Binturong, or "bear-cat," as it is often called, which may be recognised at once by the long tufts of black hair upon its ears. Its fur, too, is entirely black, withont any gloss upon it, except upon the head, which is grey, and its tail is very long indeed, and very bushy, and is prehensile at the tip, like that of a spider monkey. When the animal is climbing it makes a great deal of use of this organ, seldom moving unless it is tightly coiled around a branch. But it hardly ever seems to hang from a bough by its tail alone, as the spider monkeys so often do.

The binturong is a native of Assam, Siam, and some of the larger islands in the Malay Archipelago. It is not at all an uncommon animal, but is very seldom seen, for it not only lives in the thiskest and darkest parts of the forests, which are scarcely ever trodden by the foot of man, lut spends the whole of the day fast asleep in some snug retreat, with its hoad completely luried beneath its big bushy tail. And even if it is founcl and disturbed it only gives an angry snarl and shows its teeth, and then goes to sleep again.

Of course you have heard of the Mongooses. They look rather like weasels with very long tails, which are thickly covered with hair. 'The hearl is pointed, with a rather sharp nose, the 
ears are small and rounded, the legs are rery short indeed, and the claws cannot be drawn back into sheaths, so that they are always projecting like those of a log. The general colour of the body is either brownish or reddish grey. But the fur has a peculiar speckled appearance, which is due to the fact that all the longer hairs are marked with alternate rings of black and white, like those upon a surveyor's measuring pole.

At least sixteen linds of mongooses are found in different parts of the world, but I shall only be able to tell you about two.

The first of these is the INDIAN MONGOOSE, which is common in almost all parts of the great country from which it takes its

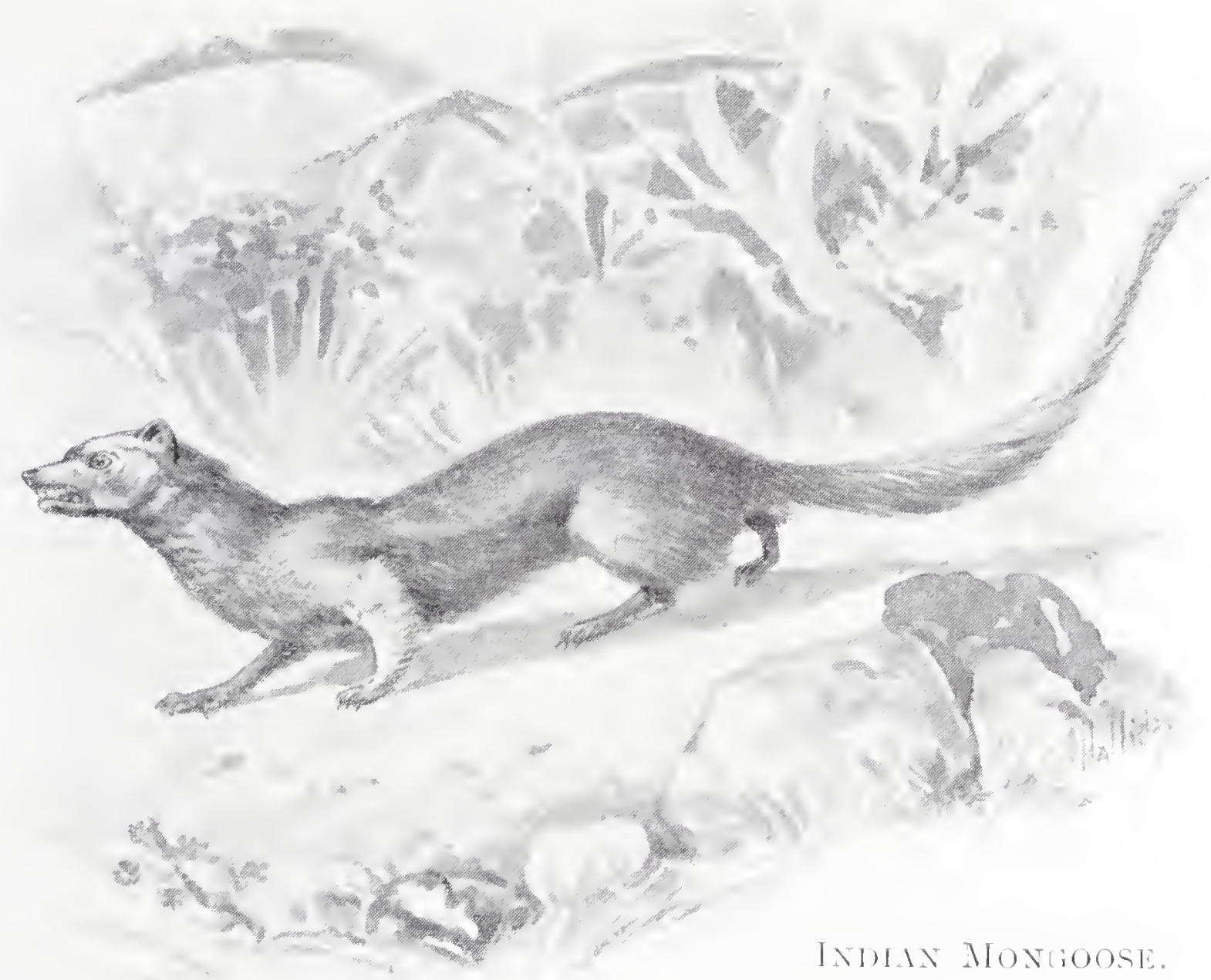

name. And it is one of the most useful of all animals, for although it will feed upon mice, small birds and their eggs, lizards, and even upon insects and fruit when it is really hungry, there is nothing of which it is so fond as a snake.

Now snakes are more plentiful in India, perhaps, than in any other country in the world. Many of them, too, are terrilly poisonous, and kill at least twenty thousand people every year; so that an animal which destroys them is a very useful animal indeed. And many people lieep tame mongooses in their houses just as we lieep cats, knowing that if a snake shoukl find its way incloors they are sure to find it and kill it. 
When a mongoose attaclis a snake it dances about in front of the reptile, and pretends to be about to spring upon it, until the snalie strikes. Then, like lightning, it leaps over the snake's head, or underneath its open jaws, or round to one side, and gives it a sharp bite just at the back of its neck. This renders the snalie quite harmless, paralysing it so that it cannot use its fangs. Then the mongoose crunches up its head, eats a little of the body also if it is very hungry indeed, and goes off to look for another.

Rats, too, are killed in great numbers by the mongoose. So in the year ISy, when these animals swarmed in some of the Trest Indian Islands to such an extent that it was feared that the sugar cane plantations would be wholly destroyed by them, nine mongooses were set free in Jamaica. Tery soon they hegan to multiply, and the rats began to decrease, till in about two years' time the mischievous little animals were almost entirely destroyed. So mongooses were turned down in other islands, with equally satisfactory results. Unfortunately, however, the mongooses soon found out that fowls and chickens were even nicer than rats, and hegan to visit the hen-roosts at night. Then they took to liklling young lambs, and even small pigs, while they also did a great deal of damage to mangoes and yams.

So now the planters had to turn their attention to destroying mongooses, and on one estate alone more than Ifoo were trapped in about a couple of months.

The Egrptian Mongoose is a rather larger animal, being about three feet in length from the head to the tip of the tail. Like its Indian relation, it preys upon snakes; but it also feeds very largely upon crocodiles' eggs, which it digs out of the sand on the banks of the rivers. For this reason it was worshipped by the ancient Egyptians, who used to treat it with the greatest reverence while it lived, and to embalm its body and bury it in the tombs of the kings when it died, just as they did with the cat and the sacred baboon.

The last of the civet-like animals about which I can tell you is the MeEriat, which is sometimes known as the Suricate. It is found in South Africa, and is a small, slender-bodied animal of a light grizzled grey colour, with a number of black stripes rumning across its back, while the ears are black, and the tail is yellowish with a black tip.

Meerkats live in large colonies, almost like rabbits, each animal scratching out for itself a deep hole in the ground. If you were to drive across the South African veldt, you would very likely come across one of these curious meerliat warrens, and would see several hundred of the little animals sitting upright on their hind legs with their front paws hanging down, just like so many small dogs "begging." Until you came quite close they would remain quietly watching you. But the moment that you stopper and attempted to seize one of them there would be a 
sudden whisk of hundreds of tails, and down they would all pop into their burrows as if by magic.

As they are very gentle creatures, and very clean in their habits, meerkats are often liept as pets, and in many parts of Cape Colony there is scarcely a single house without them. You would think that the dogs would be very jealous of them, wouldn't you, and that they would be very much afraid of the dogs? But, strange to say, the two are nearly always the best of friends, and may often be seen trotting about after their master together.

The AARI WOLF is such a very odd animal that it has been placed in a family all by itself, though there can be no douht

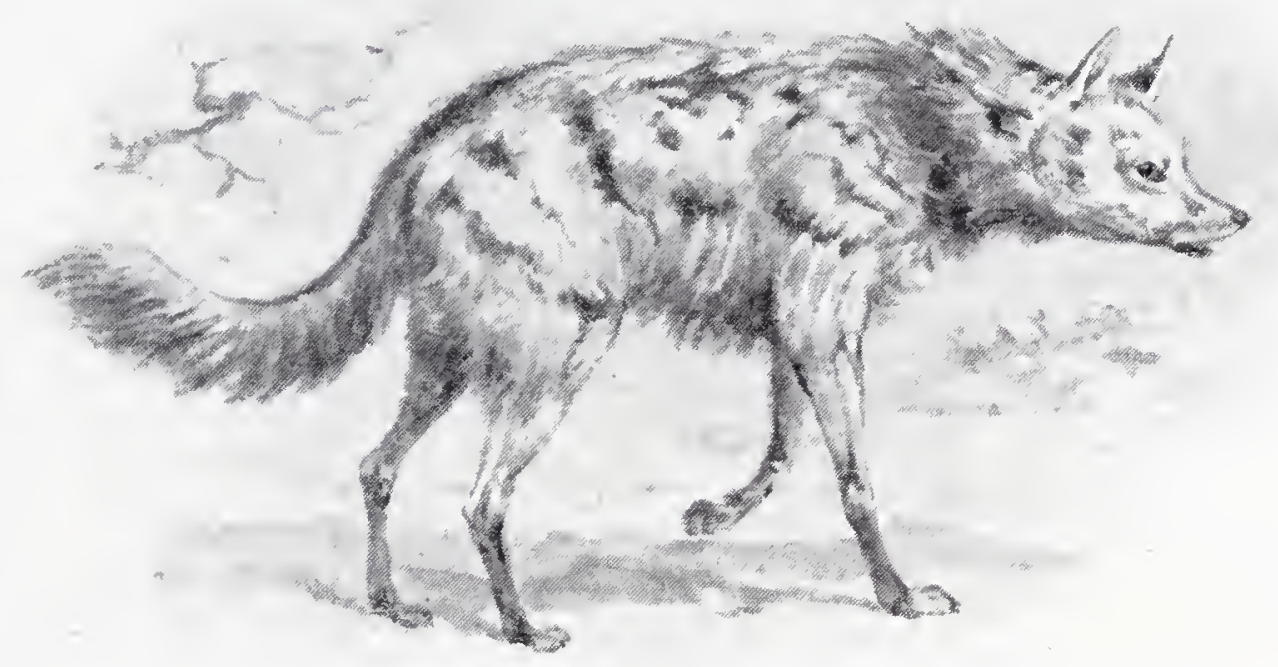

AARV WOLF.

whatever that it is related to the civets on the one side and to the hyenas on the other. In size it is about as big as a fox, but with very much. longer legs; and in general appearance it certainly resembles a halfgrown striped hyena. but then its skull and teeth are not like those of a hyena at all; they are like those of a very big mongoose. So the aard wolf evidently forms a connecting link between the two creatures.

The name "aard wolf" means "earth wolf," and has been given to this animal because the Dutch people in South Africa thought that it really was a kind of wolf, and because it lives in deep burrows which it digs in the ground. Strange to say, although each aard wolf digs its own burrow, several of these tunnels often unite in one large central chamber-a common sitting-room, as it were-which is used by all the animals alilie. but each always goes in and out by its own front door.

During the daytime the aard wolf is nearly always fast asleep underground, so that it is hardly ever seen except by those who so out to hunt it. But it is not often hunted, being so timid and cowardly that when it is turned out of its burrow its only idea is to run away as fast as it possibly can, so that it affords very poor sport indeed.

This animal is not a creature of prey, and feeds chiefly upon carrion. Ijut it is rather fond of insects, and will sometimes hreali a hole in the side of a termite's nest, and lick up 
the inmates by thousands as they come hurrying up to repair the breach in the walls.

Now we come to the Ilyenas. 'They are not very pleasantlooking animals, for their sloping hind quarters give them a very slinking and cowardly appearance. In their habits, too, they are most

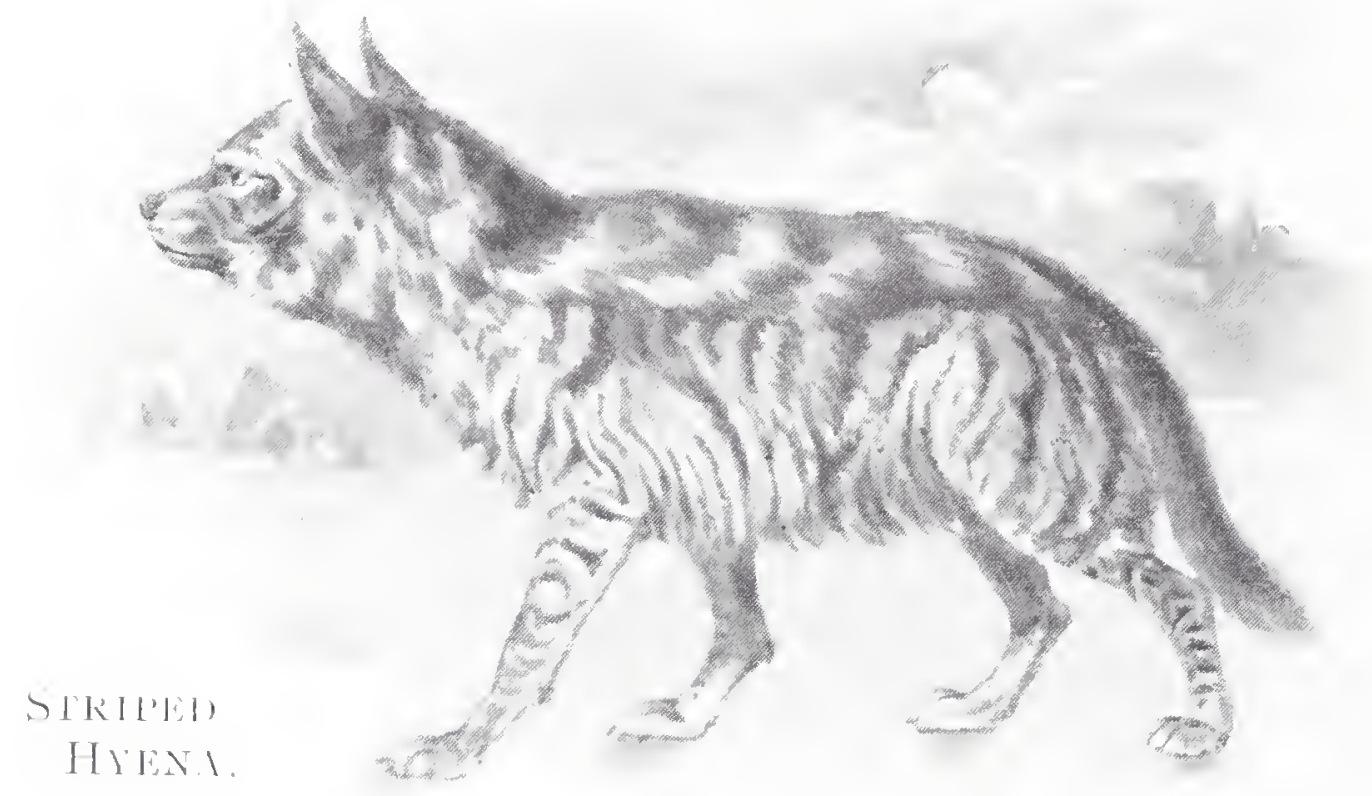

disgusting. But nevertheless they are most useful creatures in the countries in which they live.

Ifor they belong to that vast group of animals which I always like to call "Nature's Dustmen," because their great work in life is to clear away the rubbish from the world. There are millions upon millions of these natural scavengers, and some of them have to clear away carrion, some to clear away slins, and some to clear away decaying vegetable matter. Isut the principal duty of the hyenas is to clear away bones, and very thoroughly they do it.

For their jaws and teeth are most immensely strong. A hyena will seize the thigh bone of an $\mathrm{ox}$, and crush it up into splinters as casily as a dor will crush a chicken bone. And when a lion or a tiger liills a victim, he always leaves a great part of the carcase lying on the ground. Some of it he has no time to eat because the jaclials come and steal it while he is fast asleep after the big meal which lie always takes as soon as he has killed his victim. Some of it neither le nor the jaclials can eat because their teeth are not nearly strong enough to crush the larger bones. So they have to leave these for the hyenas which come up in numbers to the "liill," and quarrel and fight over it, until nothing even of the skeleton is left remaining.

Although the hyena is a much stronger animal than the aard wolf, it is quite as cowardly, and will hardly ever show fight, even when it is driven to bay. The Arab lunters despise it very much for its want of comage, and if they find it hiding in a burrow will never condescend to kill it themselves. Neither 
will they use any weapon against it. They just fling a handful of wet mud into its face, drag it out by its hind feet, and hand it over to be stoned to death by the women. ljut sometimes, after all, it contrives to escape, for it is so cunning that it will pretend to be dead when it is not really injured, allowing itself to be pulled about, or even to be severely beaten, without moving a limb. Then quite suddenly, when the attention of its captors is taken off for a moment, it will jump up and run away.

Perhaps you wonder why they should want to lill the hyena

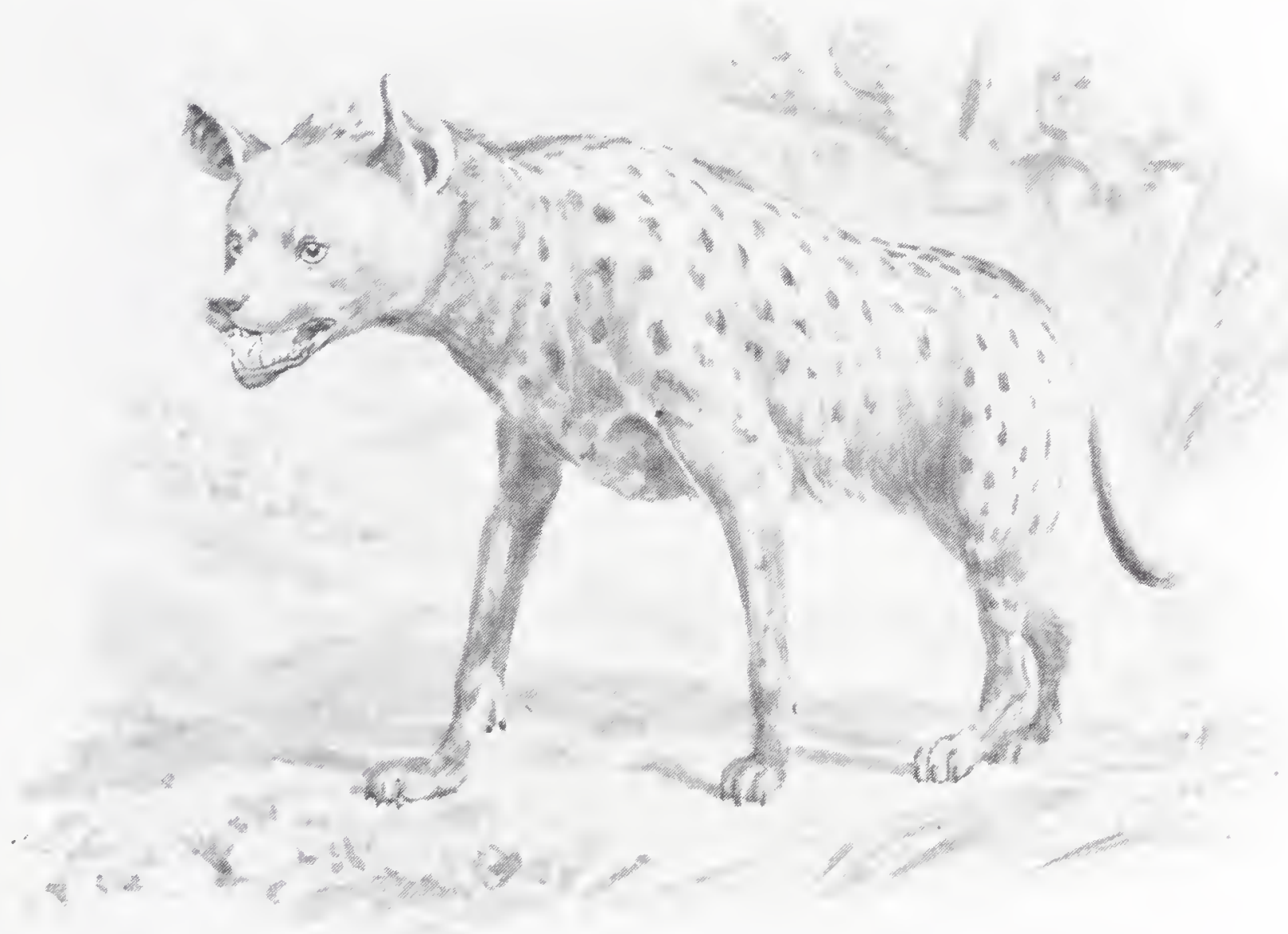

SHOTEI) HVENA.

if it is such a useful creature and never attacks human heings. Jint the reason is that it is very fond of prowling about the outskirts of the villages in order to prey upon the cattle. It is much too cowardly to attack them openly, and ahways tries to frighten them and make them rum away, so that it can leap upon thom from behind. It gencrally does this hy creeping as close to them as it can, and then springing up suddenly just under their eyes. liut if they stand and face it instead of rumning away it just looks at them for a few moments and then slinks off without attempting to touch them.

Three different linds of these animals are linown, the commonest being the Striped HYena, which is found in India, Syria, Persia, Arabia and Northern Africa. It is about as big as a collie dog, and is brownish grey in colour, with a number of black stripes rumning across the body and round the legs. The cars are 
long and pointed, the tail is big and bushy, and a kind of mane of long hairs runs down the neck and along the middle of the back.

In some parts of Africa these animals roam about by night in large packs, entering the native villages, and searching the streets for the offal which has been thrown out from the huts. And more than once, when they have been very hungy indeed, they have been linown to enter a house, and to carry off a sleeping man.

Sometimes, too, they will set a lind of snare for a dog. One liyena will lie in wait belind a bush, while another will run holdly up to within two or three hundred yards of the village and utter a series of loud howls. A dog is almost sure to hear him and to rush out in pursuit. Then the hyena, pretending to be clreadfully frightened, runs away past the bush where his companion is hiding, and the log is pounced upon and lilled almost before he realises that he has two enemies to deal with instead of only one.

The Brown Hrexa, which is found in Soutl Africa, is not nearly so plentiful. It is about the same size as the striped hyena, but may be recognised at once by the great length of its mane, which hangs down on either side below the body. In fact, the animal looks just as if it were wearing a mantle of thick, shaggy fur. It lives chiefly in rocliy ground, on the lower slopes of the mountains, but it is very fond of visiting the sea-shore by night, and prowling about in search of the dead bodies of tishes and other creatures which have been flung up by the waves.

Nuch more dangerous is the SPOTTED Hyena, or Tiger Wolf, which is a larger and more powerful animal than either of its relations, and is not nearly so cowardly. It will enter a sheepfold or cattle-pen, for instance, under cover of darkness, and boldly attack and carry off one of the animals. But even an mnarmed man need not be afraid of it, for though it will come fuite close, and will follow him for a long distance, it will never venture to spring upon lim.

This animal is often linown as the Laughing Hyena, hecause of the extraordinary sounds which it utters when very much excited. These sounds are not in the least like a yell or a liowl, but resemble a peal of strange, unearthly laugliter, and while they are heing uttered the hyena dances about on its hind legs, nods its head up and down, rums to and fro, and twists itself into all sorts of singular positions, just as though it had suddenly gone mad. Travellers tell us that sometimes for nights together sleep is rendered impossible by the hideous outcry of these creatures, which surround the camp as soon as darliness sets in, and never cease from their horrible din till sunrise.

The spotted hyena is found throughout Southern Africa, and may be known from the other two species by its larger size, and also hy the dark brown spots with which the body and the limbs are marlied. 


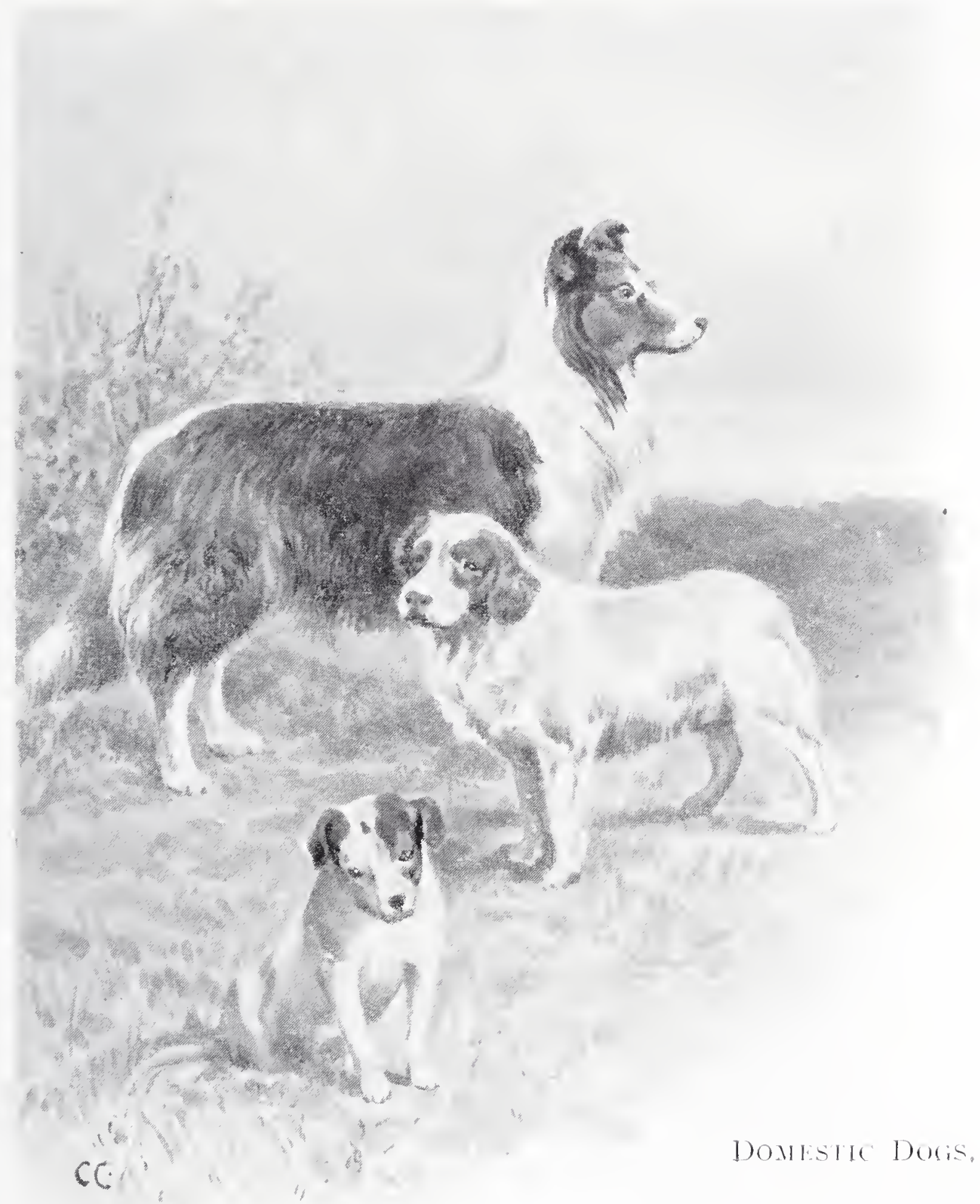

CHAPTER IX.

THE IOOG TRIBE.

NEXT in order comes the great tribe of the Dogs, which includes altogether about forty different animals. I am not speaking of domestic dogs, for I have no space in which to tell you about those. Indeed, if I were to say all that might be said about them, they would want a very big book all to themselves. But besides these there are two or three wild dogs in the 
Dog 'Tribe, several wolves, several jackals, and several foxes; and many of them are very interesting creatures.

First of all, there is a log which is linown by three different names. Sometimes it is called the Difole, sometimes the Kinomen, and sometimes the Bunsusi. It lives in India, but it

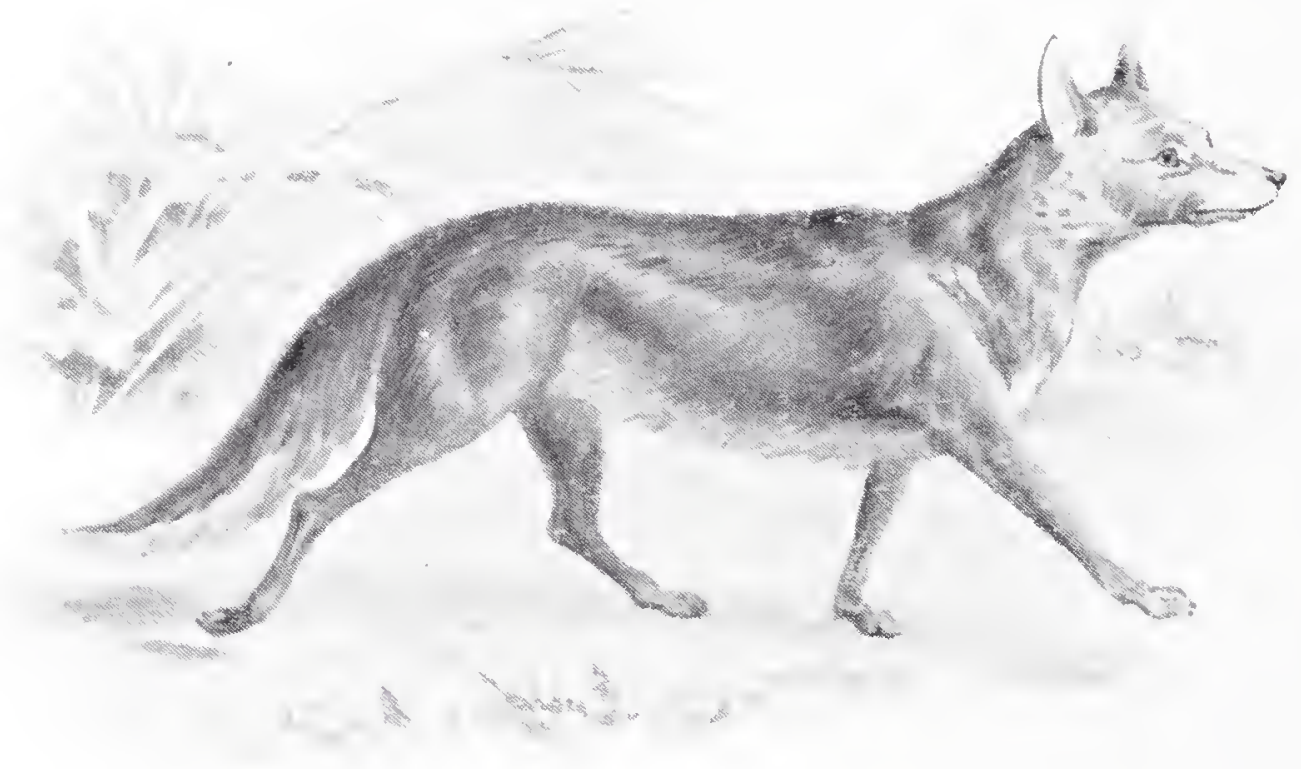

1)H(1) L.

is not very often seen, for it lieeps to the thicliest parts of the jungle, and never ventures near the habitations of man. Yet it is by no means a cowardly animal, like the hyenas and the aard wolf. On the contrary, it is extremely courageous, and does not seem to know what fear is, for it will even attack the tiger itself, and more than that, will liill it.

Of course the tiger is by far the stronger and more formidable animal of the two, and if he only had one dhole to reclion with, there would be no doubt at all as to the issue of the combat. lint the Hhole always hunts in packs. Sometimes there are eight or ten animals in one of these packs; sometimes there are fifteen; sometimes there are as many as twenty, or even thirty. And so fierce are they, and so determined, and so persevering, that it is said that when they once put up an animal, no matter whether it be large or small, they never fail to liill it. the deer, of course, are swifter than they are. lint then the decr become tired much sooner than the dholes; and while they are resting their pursuers catch them up. The tiger is much more powerful, and has his talons and fangs to fight with. but while he is liilling one of his foes three or four more are leaping upon him; and even if he should succeed in killing half the pacli the rest will still go on fighting as savagely as ever. They do not dread the horns of the buffalo, or the tuslis of the wild boar. In fact, they dread nothing, and no animals are so feared in the jungle.

When the pack are running, they never hark, or yelp, 
or bay, as almost all domesticated dogs do. For the most part they are silent, the only sound which they utter being a lind of low whimper.

In colour the dhole is a rich bay, which becomes rather darker upon the ears, the muzzle, and the tip of the tail.

Another very interesting animal is the DINGO.

This is the only member of the dog tribe which is found in Australia, and many naturalists think that it is not really a native of that continent, but was brought there a very long time agro from some other country. But as the dingo is not now

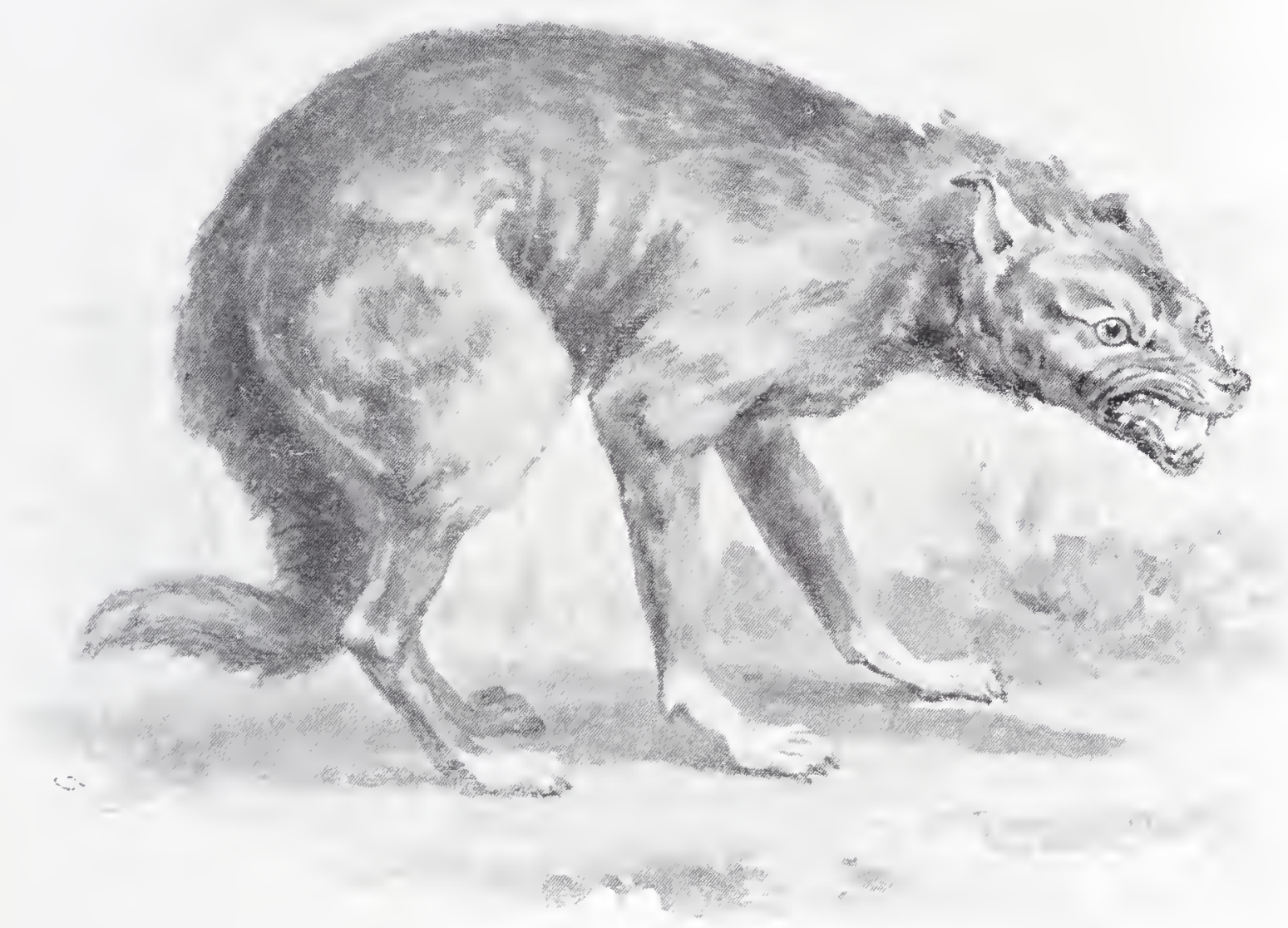

I)IXion.

found in any other part of the world, it is quite impossible to say whether this is actually the case or not. It is a very fine looking animal, about as big as a large sheep dog, with a reddish brown coat, pointed, upright ears, and a bushy tail. And if you were to see it you would most likely think that it must be a very gentle animal indeed. We have already seen, however, that there are several creatures which look very gentle, but are in reality most savage and ferocions, and though the dingo is not quite so fierce as the fossa or the wild cat, its appearance is not at all in keeping with its character, for it is very bad. 
tempered indeed, and very lard to tame, and is always liable to fits of furious rage.

In many ways the dingo is not unlike the dhole. It lives in paclis, for instance, which scour the country in search of prey. 'These packs are always led ly one of the strongest and most experienced animals, which has won its position by fighting and overcoming all the rest; and when the leader begins to grow oll and feeble, a younger and stronger animal takes his place 1)y orercoming him in the same way. In some strange manner, these paclis divide up the country among themselves. Each paclis has its own district allotted to it, over which it may roam at will, while it is never permitted to hunt outside its own horders. Wouldn't it he interesting to know how these districts are marked out, and how the animals arrange what part of the country shall be allotted to each pack?

When the first white colonists settled down in Tasmania, they found these packs of dingoes most terribly troublesome, for they would visit the folds night after night, and carry off the sheep and lambs in numbers. Watchers were employed to shoot them, traps were set for them, lugge bonfires were lighted to lieep them away; but all to no purpose. One Colony lost I,200 sheep from their ravages in less than three months; another lost 700. So at last the settlers banded themselves together in a war against the dingoes, and by hanging pieces of poisoned meat to the branches of trees, aloout a foot from the sround, they succeeded in greatly reducing their numbers, so that now they are comparatively scarce.

There is generally a dingo to he seen at the \%oo, and one which was kept there many years ago used to sit outside his kennel and hay at the moon so loudly, that his dismal howling could he heard all over the Regent's "Park.

Two or three kinds of wild dog are also found in South America; but of these I can only mention the CRAb-eAting Dor, which is chiefly found in the forests of Cimiana, Demerara, and I)razil.

This animal owes its name to its rreat fondness for crabs. Even English dogs will often eat these creatures. I once had a l) lack and tan terrier, for instance, called "Jock," whose greatest delight was to be taken for a walk along the sea-shore, so that he might hunt for crabs. Whenever he found one he would fling it up into the air half a clozen times or so, until it was perfectly dazed. 'Then holding it down with one paw, he would twist off the great claws so that it could not nip him; and finally he would crunch up its body and lick out pieces of flesh from the shell. Now and then, however, he would get a pinch and I would see him dancing alout on his hind legs with a crab) hanging to his lip, howling pitifully for me to come and set lim free.

Whether the crab-cating dog gets nipped in the same way, 


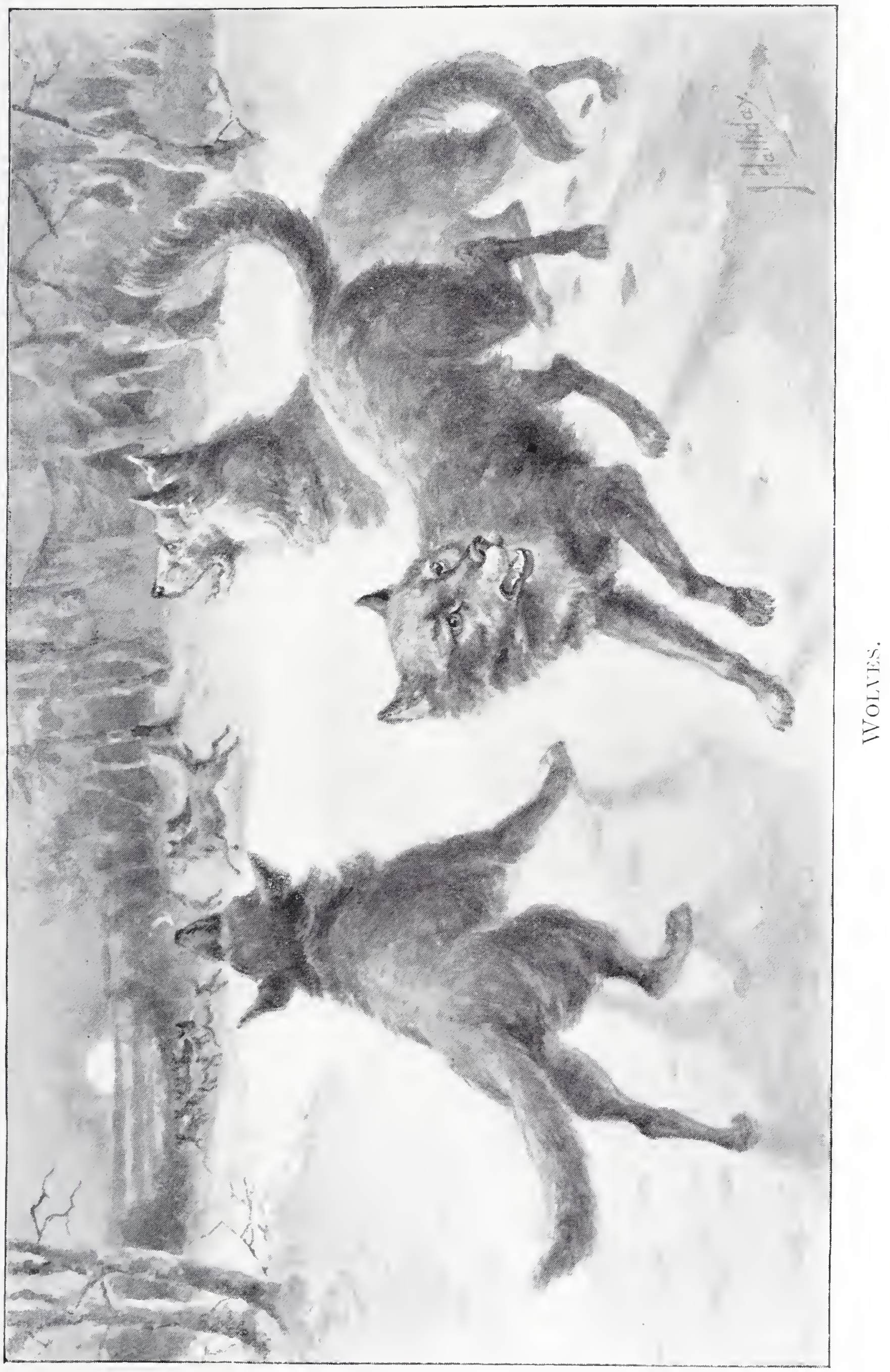



sometimes, I cannot tell you. Most likely he does. But at any rate he spends a great deal of his time in hunting for cralss on the shore. He also feeds on small animals and lirds, however, and it is said that sometimes he hunts in packs, like the dingo and the dhole, which even run down and lisil the swift-footed deer themselves.

Of wolves-which are really only very large and very savage wild dogs - there are several different linds.

First of all, of course, there is the Connon Wors, of Europe. We have all read accounts of its ferocity, and of the way in which it sometimes pursues travellers through the Russian forests during the depths of winter. In days of old, too, it was plentiful in England, while the last wild wolf in Scotland was not killed mintil the middle of the cightecnth century.

During the spring, summer, and autumn, the wolf is mostly found singly, or at any rate only in pairs. Bnt when the ground is covered with snow, and food becomes scarce, the hungry animals gather together in packs, which scour the forest in all directions and lill cvery living creature which they meet. In the year I875 no less than I6I human heings fell victims to them in Russia, while the mischief which they do in the farmyards and sheep-folds is very great indeed. In Livonia alone, for instance, during a single year, I5, I 82 sheep, I, 807 cattle, I, $8+$ I horses, 3,270 goats, 4,190 pigs, 703 dogs, and 1,873 geese and fowls were destroyed by wolves.

In some parts of France, too, these animals are still not uncommon, although a reward of Ioo francs is paid for every adult wolf that is killed, and thirty francs for each cul). And they are also found in almost every other country in Europe.

When they are not famished with hunger, wolves are by no means courageous animals, and if we have many tales of their savage ferocity we have quite as many more which bear witness to their cowardice. In Norway, for example, a large tract of country, in which wolves had always been only too plentiful, was suddenly deserted by them; and what do you think was the reason? Simply that a telegraph wire had heen put up, which frightened the wolves so much that they left the neighbourhood altogether, and never came near it again! And if a hunter lills a decr, and wishes to leave the carcase lying on the ground for a while, and at the same time to protect it from the wolves, all that he has to do is to plant three or four sticks besicle it with strenmers of white cloth fastened to the tips; for not a wolf will dare to approach the spot as long as these are fluttering in the wind.

When wolves are rumning, they generally utter a series of dismal howls, which are so lond that they can be heard from a distance of many miles away. And even one wolf can make snch an outcry that more than once a traveller, hearing one of these 
animals howling, lias imagined that a large pack were in pursuit of him, and has climbed up into a tree and spent the whole night among the branches before discovering his mistake.

Wolres usually make their lairs among rocks, or in a trunk of a hollow tree, or among very thick bushes. Jiut sometimes they live in holes in the gromnd, which they seem to dig out for themselves. There are generally from six to ten culs in a litter, which are horn in the spring, and lo not leave their parents for at least eight or nine months. Strange to say, the father often seems much fonder of them than the mother, for he will talie care of them, and hunt for them, and teach them how to hunt for themselves for weeks after she has left them altogether.

The common wolf is by no means confined to burope, but is also found in many parts of Asia, and throughout almost the whole of North America. In India, however, there is another kind of wolf which is rather smaller, and has very much shorter fur. It is seldom seen in large packs, and hardly ever howls as the common wolf does. It is not in the habit, as a rule, of attacling human beings. But now and then two or three of these animals will band together to attack a man, while sometimes they will prowl round the outskirts of a native village, in the hope of being able to carry off some of the smaller children.

These animals have a very clever way, too, of killing deer. Three or four of them will creep quietly up and hide themselves near the spot where the deer are feeding. Then another will come dashing up from just the opposite direction, the result of course being that when the frightened animals run away they pass close to the very place where their enemies are lying concealed.

On the great plains of North Imerica lives a very handsome wolf called the Corotr. It is a good deal smaller than the common wolf, but has much thicker and longer fur, so that it looks bigger than it really is. Ind a very odd thing about it is that it is differently coloured at different seasons of the year, being reddish yellowish-brown in summer, and greyish, or even quite rrey, in winter. The hack is generally darlier than the rest of the body, and the tail is rather long, and is very bushy incleed.

The coyote is an exceedingly cumning animal. Then it wants to rol a poultry yard, for example, and finds that the dogs are loose, it will get two or three of its companions to come and help it. 'They will then come and howl close by, linowing perfectly well that the dogs will answer by barking, and that they will be able to tell by the sounds how many of them there are. If they find that there are several, they trot quietly away. But if there is only one, three of the coyotes will hide while the fourth entices the dog towards them, when they will all set upon him together and liill him. 
It is not at all an easy matter to destroy coyotes, for they are so wary that it is almost impossible to approach within gunshot. If a trap is set for them, too, they nearly always discover it and carefully pass it by. And even if poisoned meat is laid lown they are generally much too suspicious to touch it. So very often cven a single coyote will do a great cleal of mischief before it can be lisiled.

Next we come to the Jackals, which perhaps we may describe as being half wolves and half foxes.

One of these animals - the Common Jackat-is found very plentifully indeed in the south of Asia, the north of Africa, and the south-eastern corner of Europe. Sometimes it is seen singly, sometimes in pairs; but generally it associates in great packs, which go roaming about the country together. In India these

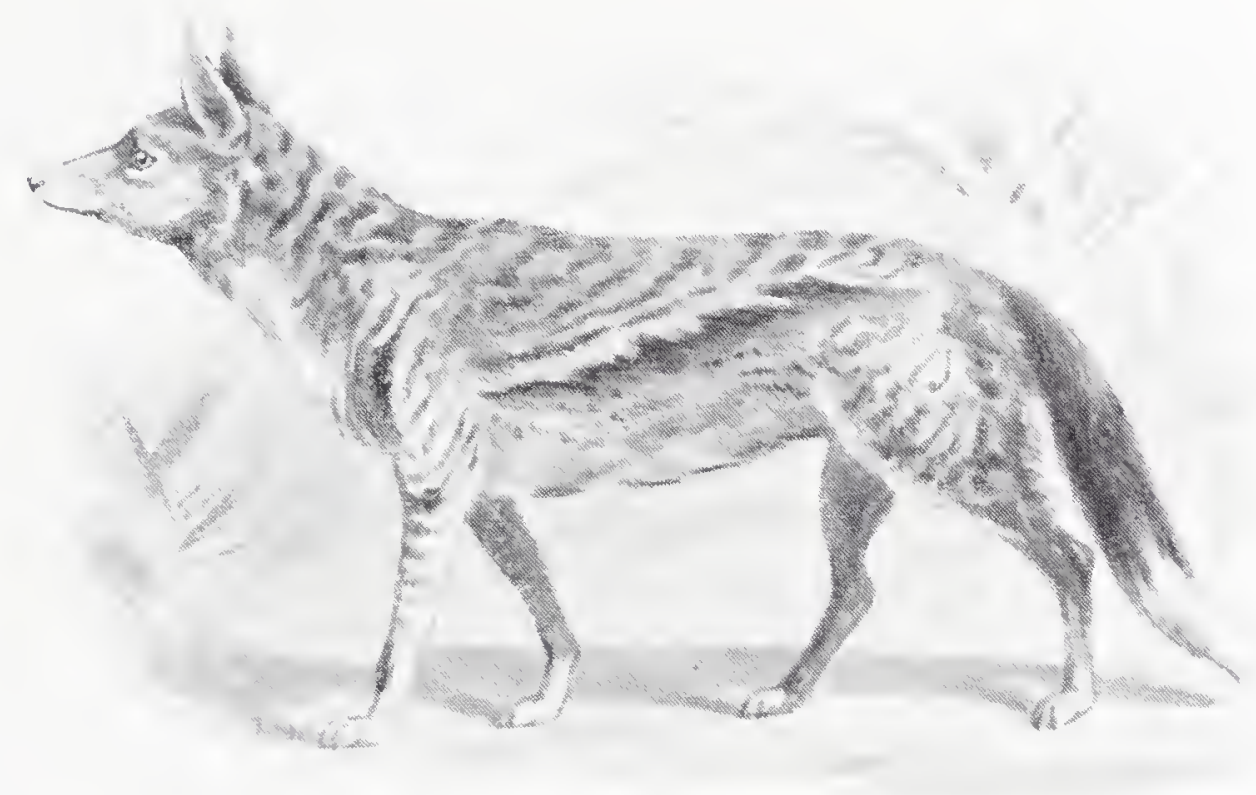

SIDE-STRIPED JACKAL.

packs visit the native villages hy night, to carry off any offal which may have been thrown out of the houses. They are "natural dustmen," you see, like the hyenas. Then they will follow a lion or a tiger about for weelis, in order to feast upon the carcases of the animals which he lills after he has eaten his fill. And when twenty or thirty of these ravenous creatures are all struggling and fighting over the body of a dcer or an antelope, you can easily imagine that in a short time there is not very much of it left.

'The jaclial is sometimes called "the lion's provider," but I think that the lion ought rather to be called "the jackal's provider." Don't you?

The natives of Africa say that the jackals stand very much in awe of the lion, and very seldom dare even to show themselves until he has caten his fill of his victim's body, and has grone away to sleep. And they also declare that if a jackal comes 
too near the carcase before the lion has finished his meal, the lion catches him and bites off all his paws in order to teach the rest of the pack better manners.

The howling cry of the jackal is very strange and weird, and the animals call to one another, and answer one another, just as if they were carrying on a conversation. Iirst comes a long, wailing yell; then another, rather higher, then another, a little hisher still, and then three short, sharp barks. And so on, over and over again.

When a jaclial is caught, it often pretends to he dead, and will he perfectly still for a very long time in the hope of leing able to make its escape when the attention of its captors is taken off. On one occasion one of these animals lay without moving for a whole hour although several times over it was picked up and "worried" by a dog. Then quite suddenly it jumped up and rushed away apparently unhurt.

The common jackal is reclish brown in colour, sometimes lighter and sometimes larlier, while the tip of the tail is black. Bnt there is another kind of jackal found in Sonth Africa which has the whole upper part of the back hlack, and the lower part of the body and the inner sides of the limbs nearly white. This animal is called the Black-hacked Jackal, while a third, which has a pale streak rumning across its flanks, is called the Sidestriped Jackal. In habits, the three animals are almost exactly alike.

The best-known of the foxes, of course, is the Comarov fox of Cireat Britain, which is also found in many other parts of the world.

This animal is famous for its cunning, and certainly, in many ways, it is very clever indeed. It has all sorts of tricks, for example, to throw the hounds off its track when it is being hunted. It seems to know perfectly well that it is followed by scent, and sometimes it will sudkenly leap to one side so as to break the trail, and then make off in quite a different direction. Sometimes, when it has a sufficient start, it will return on its track for sixty or seventy yards, and then leap aside. Or it will roll in carrion in order to clisguise its own peculiar odour. I once found an "earth," too, which was very cleverly made. The entrance to the burrow was ahout twenty feet from the edge of a sand-pit, in the middle of a thicli clump or bushes, and there was a "bolt-hole" abont half way clown the side of the pit. So when the fox was chased he conld run into his burrow by the upper entrance, slip out by the lower one and so make his escape through the pit while the hounds were all gathered round the hole up above.

Tery often, too, a fox will climb a tree, sometimes to a great height, and hicle among the hranches, and I have heard of a fox which baffled the hounds over and orer again in a most ingenious way. He nsed to rmu to a certain fence, spring to the 
Lop, and then walk along for several hundred yards before leaping (lown again to the ground. By doing this, of course, he loroke the scent most thoroughly, and long before the hounds could fincl it again he had reached a place of safety.

But although the fox is generally so exccedingly clever, he sometimes does the most stupid things possible. Mr. Charles Waterton, for instance, tells us of a fox which visited a poultry yard near Stonyhurst, and carried off eight young turkeys. He could not eat them all, of course, so he buried five in the ground, meaning, no doult, to come and fetch them arvay on the following evening. But apparently he thought that if he buried them entirely he might not be able to find them again. So he carefully left one wing of each bird sticking up ahove the surface to serve as a guide, and never seemed to reflect that others would

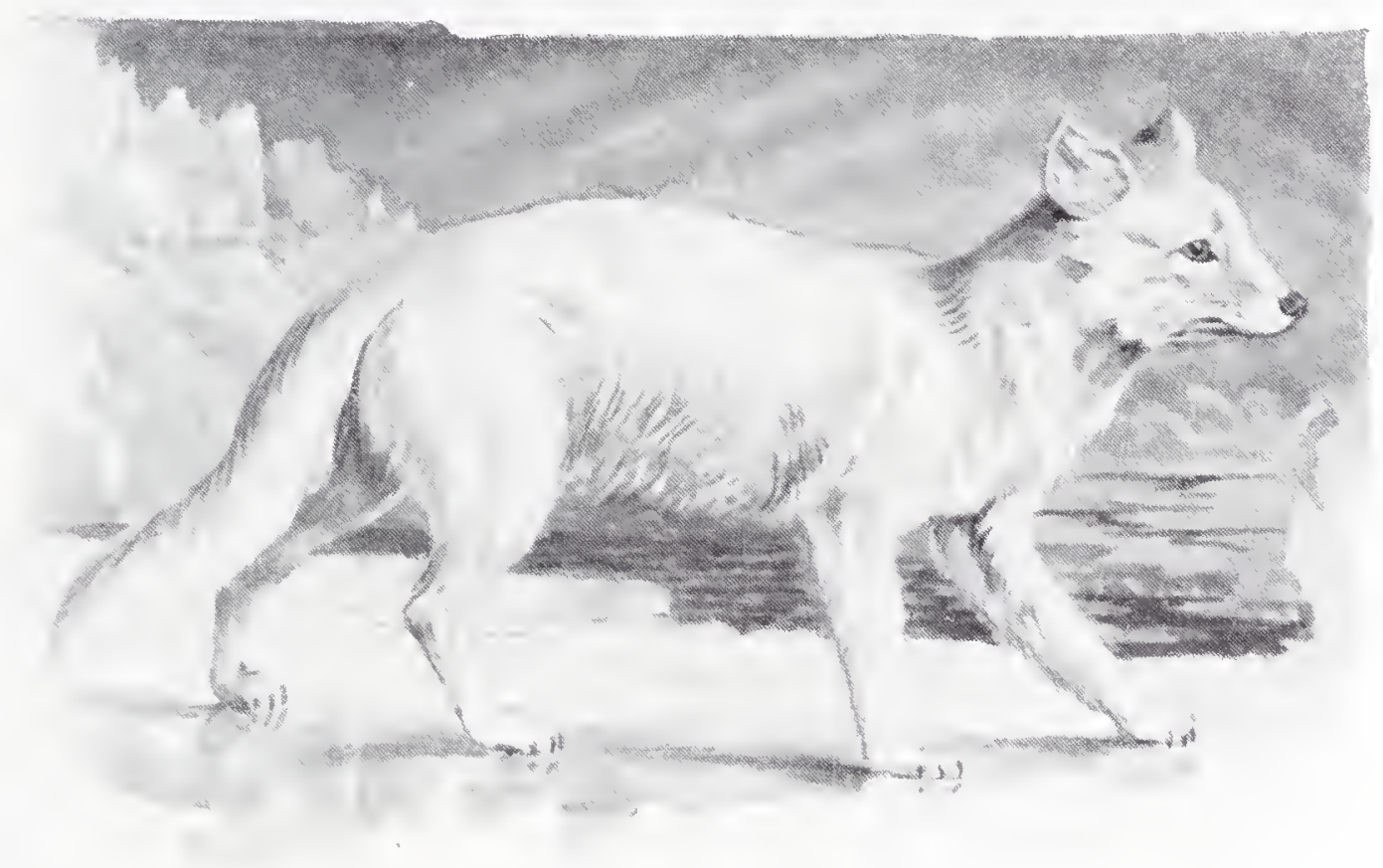

IRCTIC FON.

be able to see it as well as himself! So the farmer recovered his turkeys, and when Reynard came to look for his supper next night he found that it had disappeared.

The "earth" of a fox is sometimes an old rabbit-hole enlarged to a suitable size. But generally the animal scrapes out a burrow for himself, frequently choosing the roots of a large tree as a situation, or a very rocky piece of ground from which it will be very difficult to dig him out. In this burrow four or five little ones are brought up. They are odd-looking creatures, with very snub noses, and if you did not know what they were you would never take them for young foxes.

More interesting still, perhaps, is the ARctic Fox, which lives in the ice-bound regions of the far north. There are generally several of these animals to he seen at the Zoo, and the first thing that one notices on seeing them is that no two of them 
are alike. One, perhaps, is reddish hrown above and yellowish white beneath. Another is grey all over. A third, very likely, is mottled; while a fourth may be of that curious bluish colour which we see in Russian cats.

That is strange, isn't it? You would almost think that rou were looking at three or four different kinds of foxes instead of only one. But it is stranger still to know that in the great snow-fields of the polar regions a great many of these foxes turn perfectly white in winter. No doubt this is to allow them to creep over the snow without being seen by their victims. Then, when

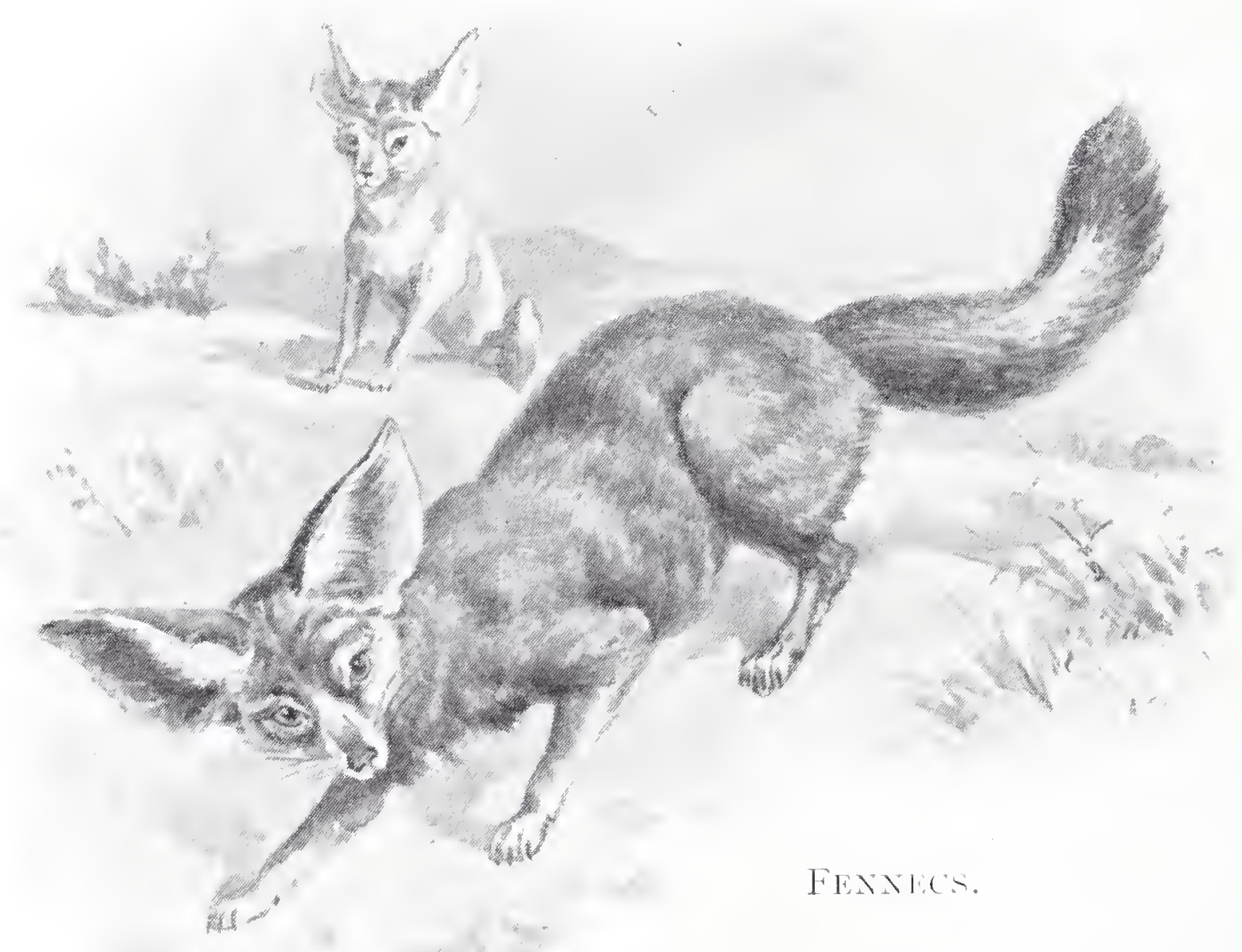

warmer weather comes, and the snow begins to melt, their fur passes back again to its original colour.

During the spring and summer the arctic fox feeds on sea birds and their eggs, and it is said to attract the birds to the place where it is lying in wait by imitating their peculiar cries. lisut I do not think that that is true. What it feeds upon during the rest of the year is rather doubtful. It cannot catch birds, for they have all flown away farther south. It cannot catch fishes, for the water is covered in by ice several feet in thickness. Most likely it catches numbers of those odd little animals known as lemmings just as winter hegins, and stores.them away in a kind of larder, where the cold prevents their bodies from decaying. 
In order to allow it to travel over the slippery ice, the arctic fox has the soles of its feet covered with long stiff hairs, which give it a perfectly firm foothold on the frozen surface.

The arctic fox is not nearly such a clever animal as our own linglish fox, and is very easily trapped. If a hunter follows it, too, it will certainly rum into its hole; but a moment or two later it is almost sure to poke out its head in order to yelp at him, so that he is easily able to shoot it. The consequence is that these animals are destroyed in very great numbers for the sake of their skins, those with bluish fur heing especially valuahle.

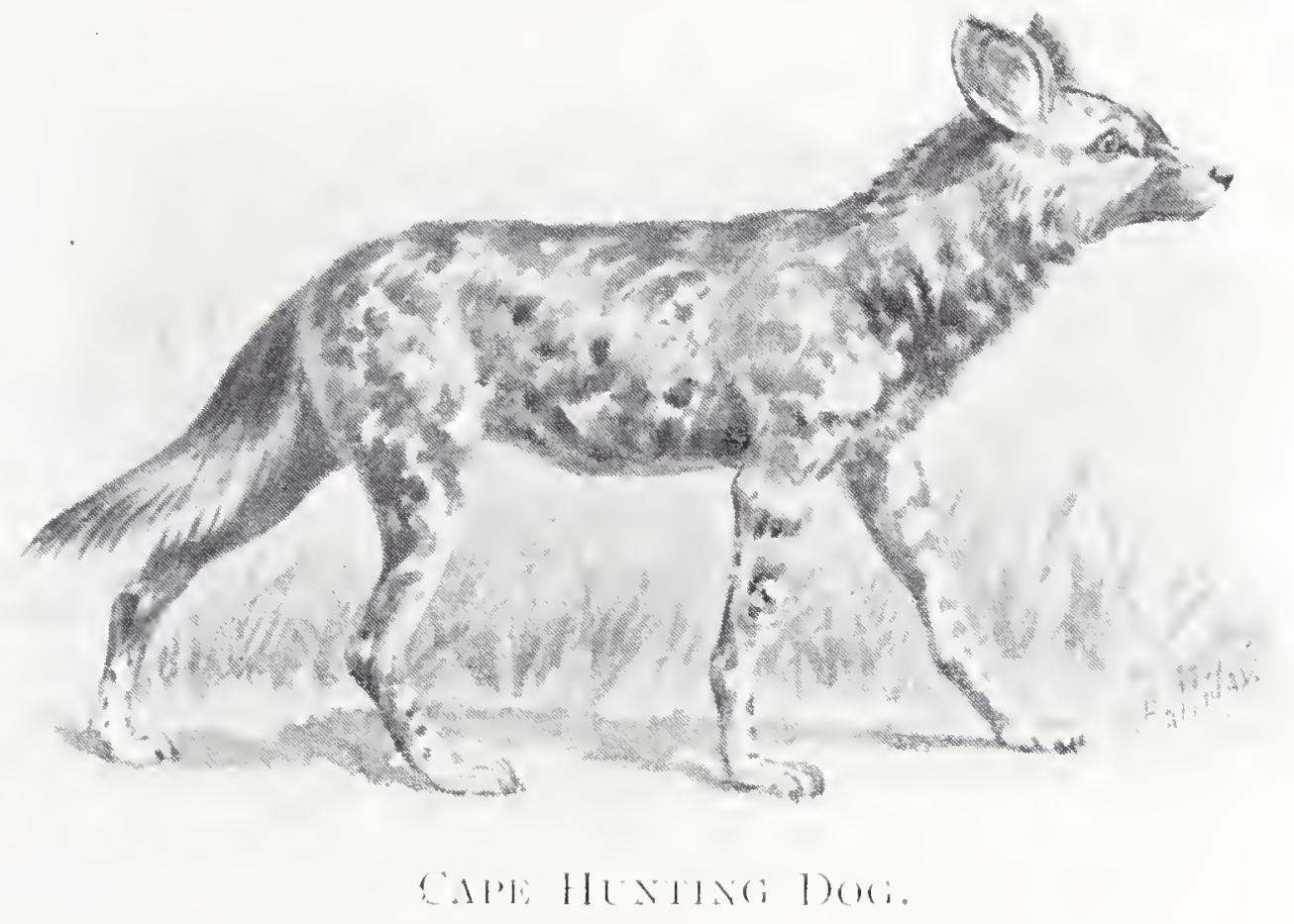

They are mischievous creatures too, and will steal anything that they can carry away. When Nansen was making his famous journey in the "Fram" through the Arctic regions he had his thermometers stolen time after time by foxes. So that even travellers who do not wish for the slins of these creatures are not at all sorry to have an opportunity of destroying them.

The arctic fox is a good deal smaller than our English fox, and has ears so short and rounded that they look just as if they had been cropped.

Next must be mentioned the FENNEC, a very pretty foxlike little animal found in Nubia and Egypt. It is only about twenty inches long, including its big bushy tail, and its fur is sometimes pale fawn colour, and sometimes creamy white. But what strikes one most about it is the extraordinary size of its ears, which are always carried perfectly upright, and look as if they were intended for an animal at least five times as big as itself.

The fennec is a creature of the desert, and lives in burrows which it scoops out in the sand. In order to malie these burrows more comfortable, it lines them with leaves, hair, and the feathers of birds, while they are nearly always situated beneath the roots 
of plants, where the sand is softer and more casy to work. 'The animal digs with the most wonderful speed, and those who have surprised it while at a distance from its burrow say that it disappears in the sand just as though it were sinling into water, and is lost to sight in about a couple of seconds.

The fennee spends the heat of the day comfortably curled up in its burrow, with its nose tucked away under its big bushy tail. When the sun sets it wakes up and goes off to the nearest water to drink, after which it bunts for jerboas, birds, lizards, insects and the various other small creatures upon which it feeds.

There is only one more member of the great Dog Tribe which I can mention, and that is the CApe HunTng Dog. It is not really a dog, in spite of its name. It looks very much lilie a spotted hyena and yet it is not really a hyena. Sometimes it is known as the Hyena Dog; and perhaps that is the best name which can be given to it.

This animal is found throughout Southern Ifrica, and is especially plentiful in Cape Colony. It hunts in paclis of from ten to fifty or sixty, which run with such wonderful speed that even the swiftest antelopes cannot escape them. When they catch up with their guarry they all spring upon it torgether, snapping at it over and over again until they bring it to the ground. And in a very few minutes there is nothing left of its carcase but just a few of the larger bones.

In size the hyena dog is about as big as a wolf. In colour it varies a good deal, but the head is alway's black, with a white marls round the eyes, while the body is more or less mottled with black, white and yellow. The long bushy tail is yellow at the root, black in the middle, and white at the tip. 


\section{CHAPTER X.}

THE VEASET, TRIBE.

A LNOST all the animals which belong to this tribe have very long, slender bodies and very short legs; and the reason is a simple one. 'They feed on living prey, which they often have to follow through a long and winding burrow. Now if they had stout bodies or long legs they could not do this. Most likely they could not cnter the burrow at all; and even if they did so they would be almost sure to find, before they had gone very far, that they could neither move forwards nor backwards. But, having such snalie-lilie bodies and such very short limbs, they can wind their way through the tunnels without any difficulty, and then spring upon their victim at the end.

They always try to seize their prey by the throat, in order to tear open the great blood vessels which pass through that part of the body, and I once had a personal experience of the strength and sharpness of their teeth. I was walking through a parti one day early in the autumm, when I noticed that the dead loaves underneath a tree were tossing and tumbling about in a very curious manner. On groing a little closer I found that a mother weasel and her little ones were having a game of play together. When I cameup, of course, they all ran away. So I ran after them, and caught one of the little animals by putting my foot on it, just hard enough to loold it down on the ground without hurting

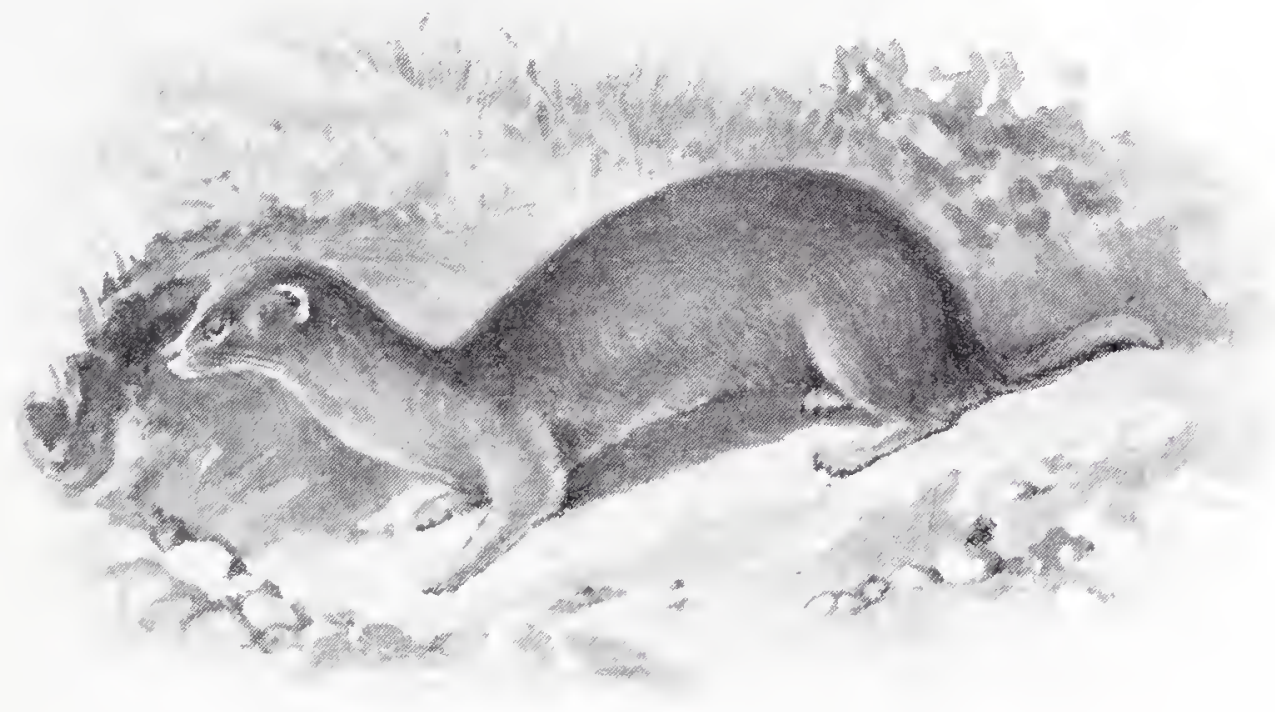

WELSEL.

it. Ind immediately the little creature, which was only about six inclies long, twisted itself round, and drove its sharp "eye" teeth deeply into the edge of the sole of my shoe, both from above and below. So that if I had done what I thought of doing at first. and had stooped to pick it up, its teeth would certainly have met in my finger. 
The Veaser is very common in most parts of Great Britain, and rou can scarcely take a walk through the lanes and the meadows without catching sight of it. Tery likely it will polie its head out of a hole in the banli at the side of the road, and watch you in the most inquisitive manner as you go past. Or you may notice it slipping in and out of the herbage at the foot of a hedge, as it searches for the small creatures on which it feeds. But very often it will leave the hedge, and follow a mole along its burrow. Or it will make its way to a wheatstack, and pursue the mice through their "runs." And it is very fond indeed of going out birds'-nestirg,

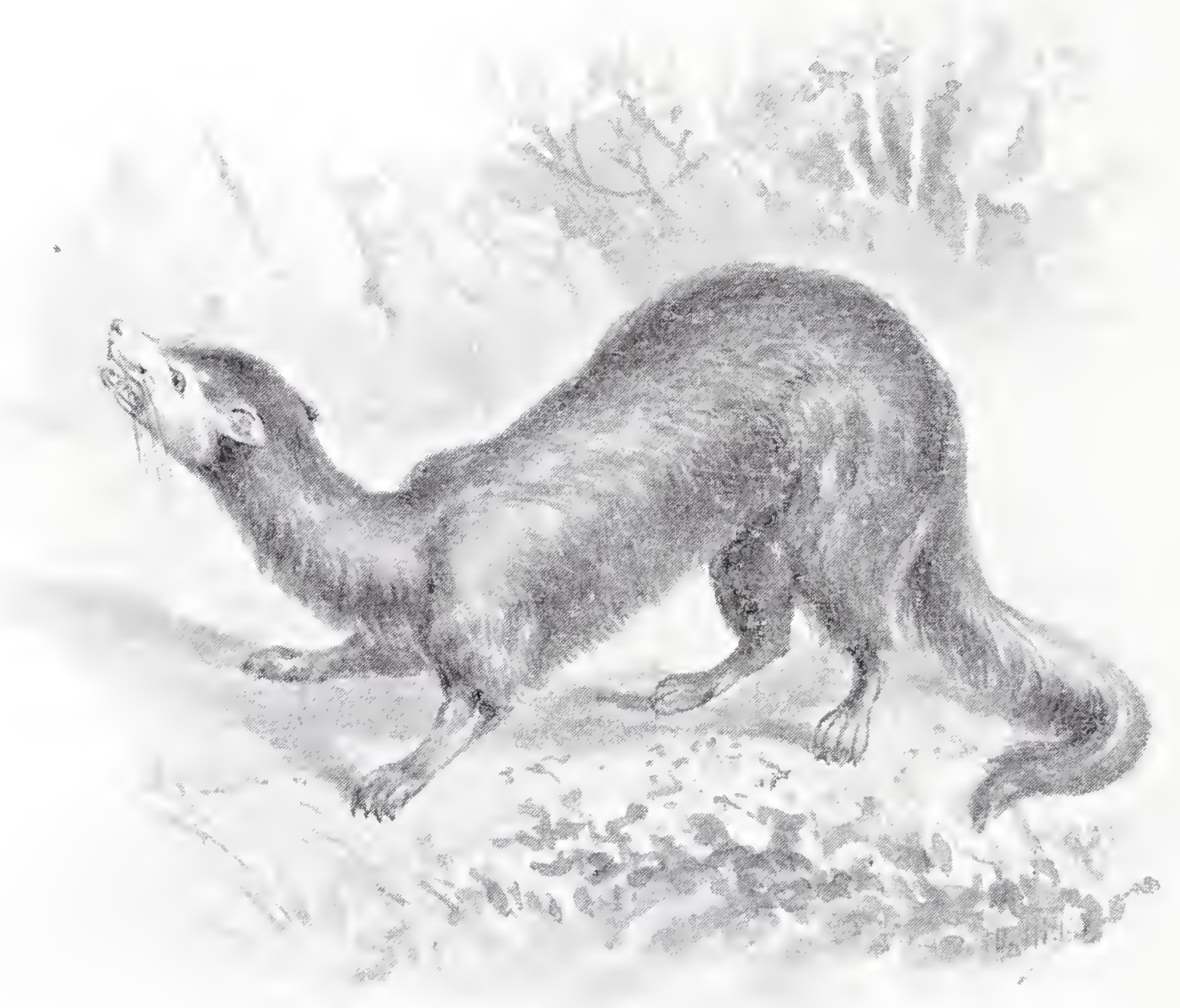

POLE CAT.

and robbing the nests of the eggs or little ones which they contain. but the weasel is not always successful when he sets out on one of these expeditions. While coming down Helvellyn, for instance, I once witnessed a most interesting little scene. Hearing a loud chattering, I looked up, and saw just above me a pair of stonechats and a weasel. Evidently the weasel had come too near the nest of the birds, and they were trying to entice him away. And this is how they managed it. First the cocli bird sat down on a stone about a yard in front of the weasel, and began to flap his wings, and to chatter and scream. The weasel immediately darted at him, and the bird flew away. Next the hen bird sat 
duwn on another stone a yard farther on, and began to flap her wings and to chatter and scream. Then the weasel darted at her, and she flew away. As soon as she had gone the cock came back, sat on a third stone, and played the same trick again. And so

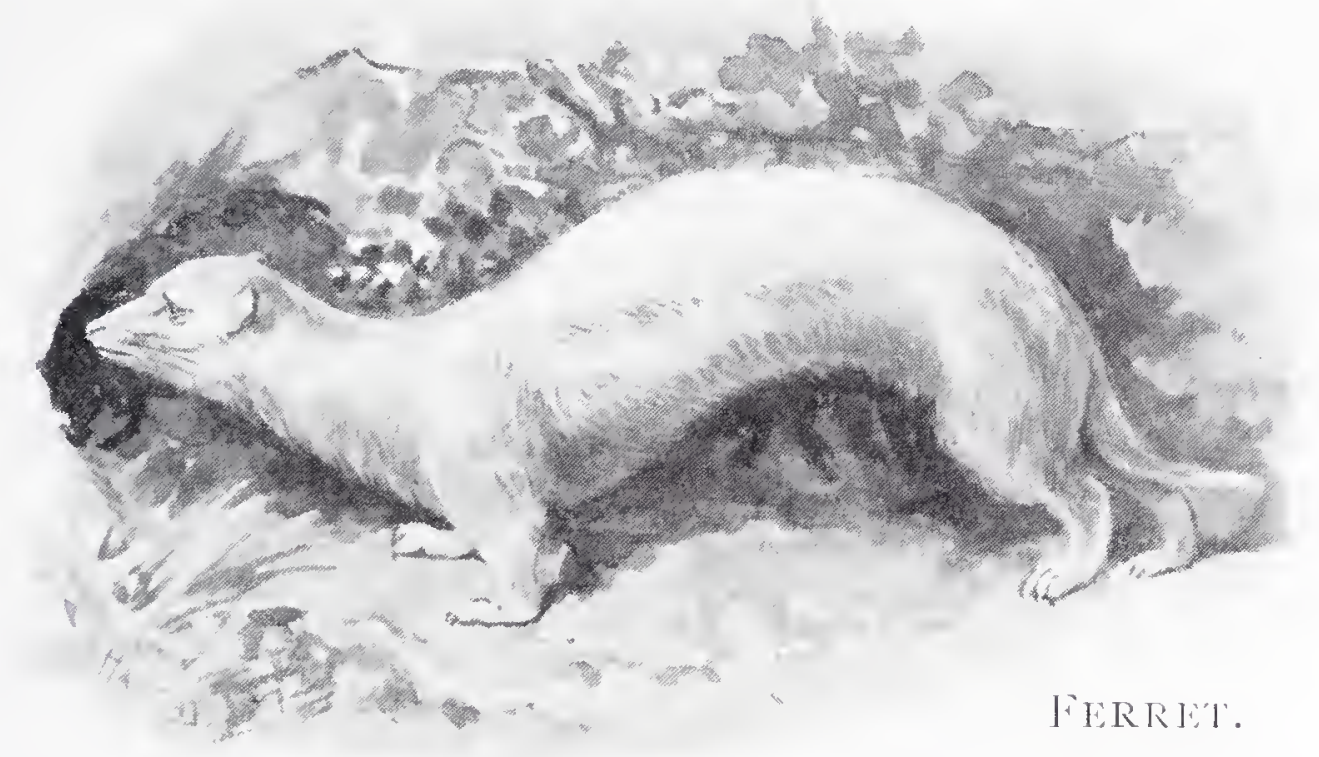

the two birds went on over and over again, till they got the weasel far up the mountain side, quite two hundred yards from the nest, when they quietly left him and flew away together.

Vasn't it clever of them? And the odd thing was that the weasel never realized that he was being taken in, but evidently thought that he was going to catch one of the birds every time that he darted at them.

When fully grown the weasel is from eight to ten inches long, about one-fourth of that length being occupied by the tail. The fur of the upper parts of the body is brownish-red in colour, while that of the throat and lover surface is white.

The StoAT, which is almost as plentiful as the weasel, is nearly half as large again, and you can also distinguish it by the fact that the fur of the lower parts of the body is pale yellow instead of white, while the tip of the tail is black. In very cold countries the whole of the fur becomes white in winter, lilie that of the arctic fox, the tip of the tail alone excepted. Indeed, the famous "ermine" fur which we value so highly, and which even the King wears when he puts on his robes of state, is nothing but the coat of the stoat in its winter dress.

The stoat preys upon rather larger animals than the weasel, and many a hare and rabbit falls victim to its sharp little fangs. Strange to say, when one of these creatures is being followed by a stoat it seens almost paralysed with fear, and instead of making its escape by dashing away at its utmost speed, drags itself slowly and painfully over the ground, uttcring shrill crics of terror, although it has not been injured in any way at all. 
In poultry yards the stoat is sometimes most terribly mischierous, for it does not seek merely to satisfy its appetite, but appears to kill for the mere sake of lilling. One stoat, indeed, has been known to destroy no less than forty fowls in a single night. So both the gamekeeper and the farmer have very good reason for disliking it. But in some ways it is really very useful. It kills large numbers of mice and rats and voles, for instance, which often do such terrible damage in our fields. And if we could set the good which it does against the evil, I think we should find that the former more than makes up for the latter.

The POLECAT was formerly very common in Great Britain. But owing to its mischievous habits it has been greatly persecuted, and now it is rery seldom met with. It is a good deal larger than the stoat, being nearly two feet in length from the nose to the tip of the tail, and you would think, on looking at it, that its fur was brown, yet it scarcely has a brown hair on the whole of its body. The fact is that the long outer hairs are so dark as to be almost black, while the soft under-fur next the slin is pale yellow; and as the inner coat shows through the outer one, the effect is very much the same as if the whole of the fur were brown.

The polecat is sometimes called the "foumart." This name is formed from the two words "foul marten," and has been given to the animal because it looks like a marten, and has a most foul and disagreeable smell. In its habits it is very much like the stoat. It comes out chiefly by night, and preys upon any birds or small animals which it may meet with, following rablits down their burrows, tracking hares to their "forms," and sometimes killing nearly all the poultry, geese, and turlieys in a farm -

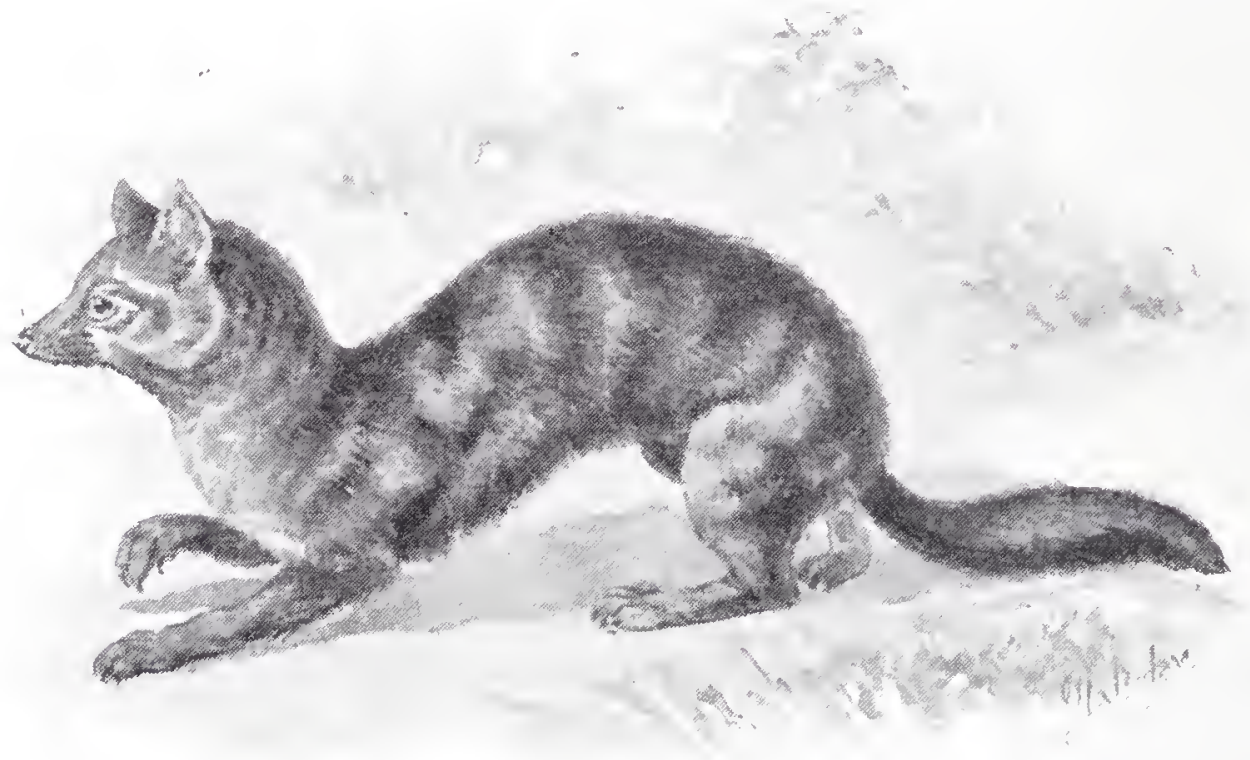

SAFLE. yard. Early in April it makes a kind of nest in a deserted rabbithole, or in a crevice among the rocks, and there brings up its family of from three to eight little ones.

The FERRET, which is so much used in hunting rabbits and rats, seems to be really a variety of the polecat, and is usually of a yellowish white colour with pink eyes. But there is also a hrown form, which is generally called the "polecat-ferret." 
The Martens may be described as very large weasels which live in the trees. One of them-the PINE MARTEN-is still found in the wilder parts of Great Britain, although it is eron scarcer, perhaps, than the polecat.

This animal is about as big as a cat. But it does not look as large as it really is, because of the shortness of its legs. In colour it is rich brown above and yellowish white below, while the tail is very long, and is almost as bushy as that of a squirrel.

Martens are only found in the thickest
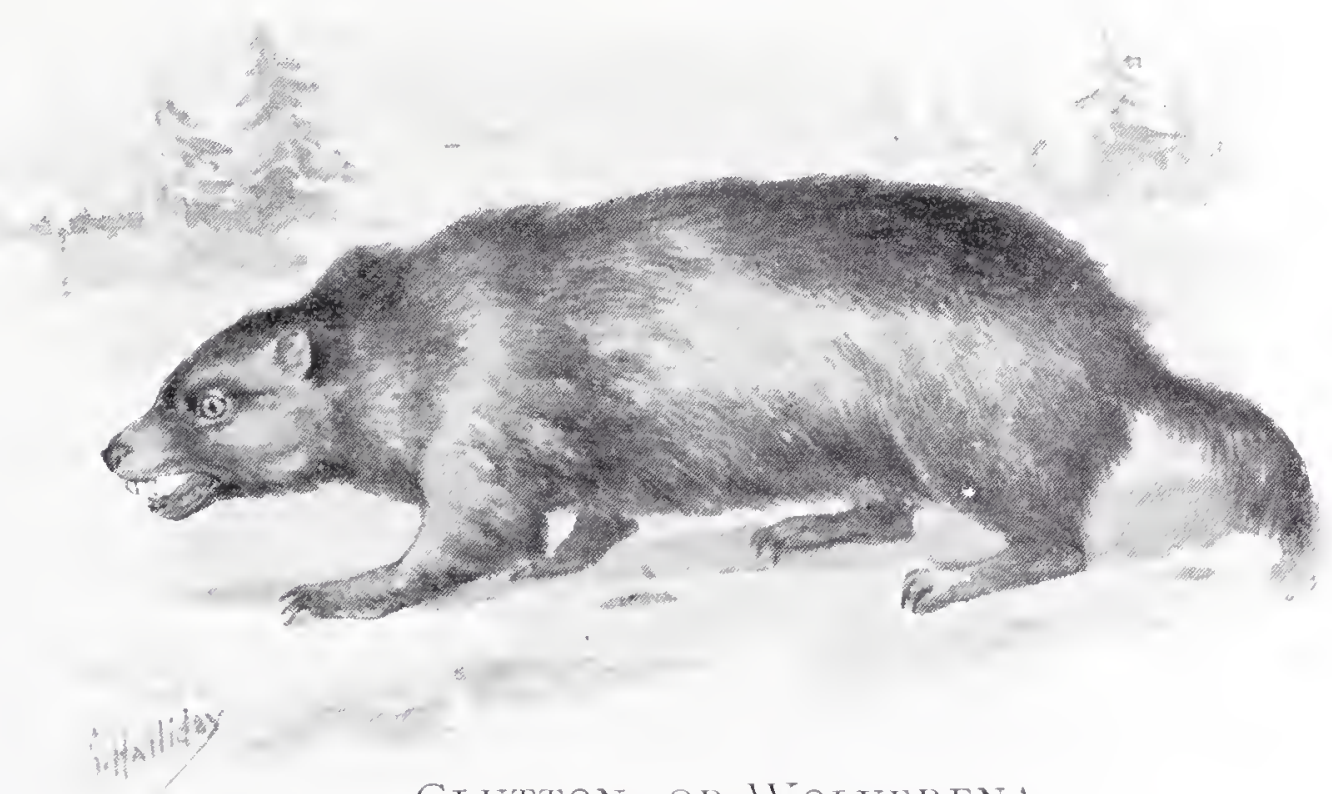

parts of the forests, and spend almost the whole of their lives in the trees, running up and down the trunlis, and leaping from bough to bough with the most wonderful activity. They even make nests among the branches, in which to bring up their little ones, weaving a quantity of leaves and moss together in such a way as to malie a most cosy little nursery. But I am afraid that they are rather lazy animals, for sometimes, just to save themselves trouble, they will turn squirrels or woodpeckers out of their nests, and take possession of them for themselves.

Martens feed on any small animals which they can find, and have more than once been known to kill lambs, and even fawns. When they happen to live near the sea, it is said that they will visit the shore by night in order to hunt for mussels.

The SABLE, which is found in the mountainous forests of Northern Asia, seems to be nothing more than a variety of the pine marten with very long fur. This fur is so much in request that the animal is greatly persecuted, more than two thousand slins being sometimes taken in a single season.

The Glution, or Wolverena, hardly looks like a weasel at all, for it is very heavily and clumsily built, and, including the tail, is often as much as four feet long. If you did not know what it was, you might almost take it for a bear cub with a tail. It is blackish brown in colour, with a lighter band which runs from the" shoulders along the sides and across the flanks, as far as the root of the tail. "Glutton" is rather an odd name for this creature, isn't it? But certainly the animal deserves it, for it will go on eating, and 
cating, and eating, long after you woukd think that it could not possibly swallow a morsel more. Indeed, a glutton has been known to devour, at a single meal, a great joint of meat, which would have been more than sufficient for a lion or a tiger for a whole day! It lives in North America, and also in Northern Europe and Northern Asia, and the hunters find it a terrible nuisance, for night after night it will go round their traps and devour all the animals which have been caught in them. Then, too, if they bury a quantity of provisions in the ground, meaning

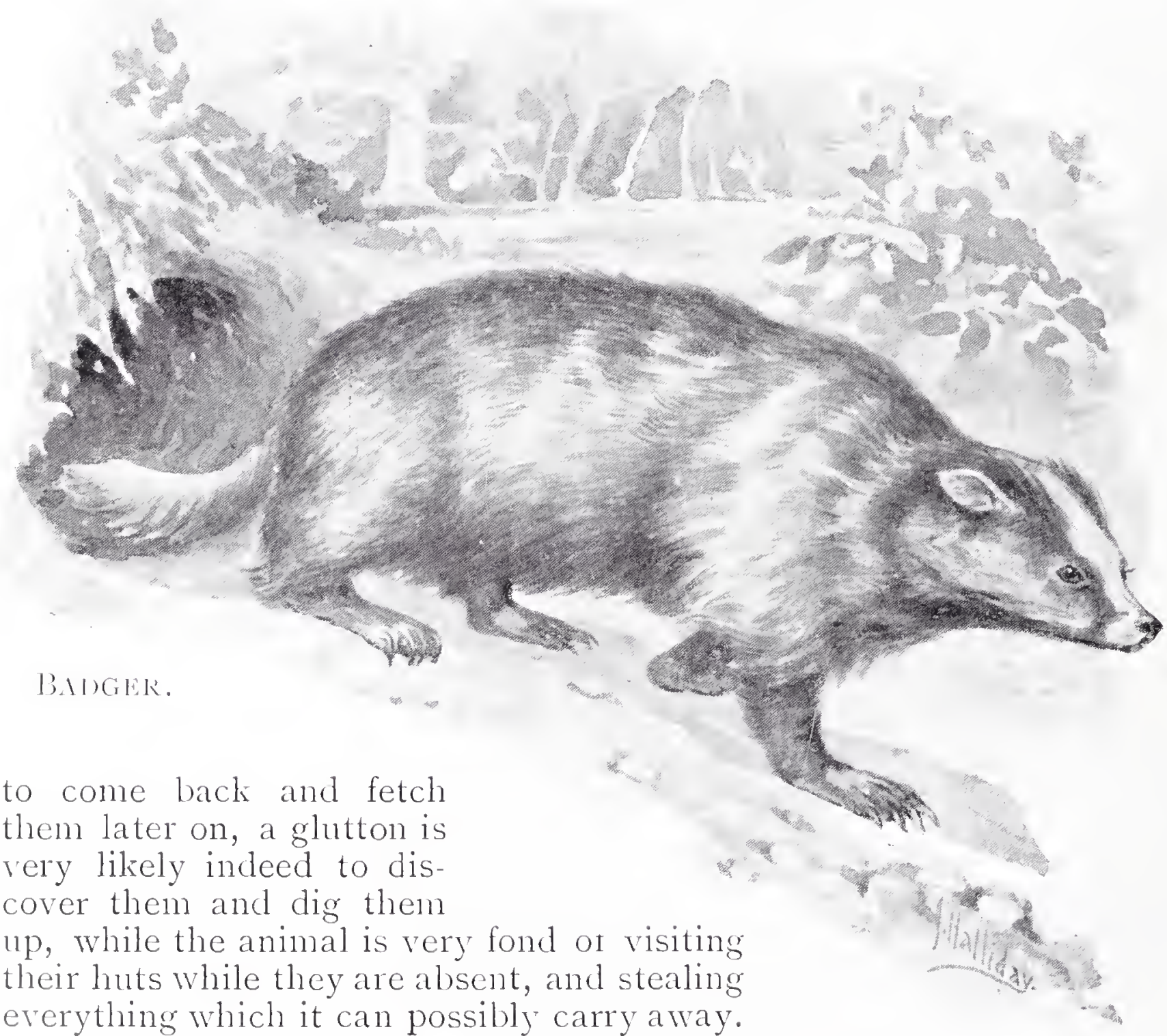

Blankets, knives, axes, and even sauce-

pans and frying-pans have been stolen in this way by gluttons, and once one of these animals actually succeeded in dragging away and hiding a gun! It is even a worse robber, in fact, than the arctic fox. And it can hardly ever be trapped, because it is so cumning that it almost alway's discovers the traps, and either passes them by or pulls them to pieces, while it is so wary, and so swift of foot, that the hunter very seldom has a chance of shooting it.

It was formerly supposed that this animal was even more cunning still, and that it would collect a quantity of the mosses of 
which deer are so fond, lay it upon the ground as a bait, and hide in the foliage of an overhanging bough, so as to spring down upon the animals when they stopped to feed. But this story seems to be quite untrue.

More curious still is the Ratel, which belongs to the family of Badgers. You cannot possibly mistake it if you see it, for all the upper part of its body is greyish white, and all the lower part is black. So that it looks rather like a lady wearing a white mantle and a black skirt!

But if the ratel is odd in appearance, it is odder still in habits. A couple of these animals are nearly always to be seen at the Zoo, and if you go to look at them you are sure to find them trotting leisurely round and round their cage in a perfect circle, one behind the other. And when they come to a certain spot they always stop, turn head over heels, pick themselves up; and then run on again. Why they do so nobody linows, but for hours every day they keep up this singular performance.

The ratel is very fond of honey-so fond, indeed, that it is often called the Honey Ratel, or Honey IVeasel, in consequence; and it spends a good deal of time in prowling about in search of the nests of wild bees. You would think that it would get badly stung by the bees, wouldn't you, when it tore their nests open and robbed them of their sweet stores. But its coat is so very thick that the insects can scarcely even force their stings through it, while even if they do so there is a thick loose skin underneath it, and a layer of fat underneath that. So it seems quite certain that a ratel never gets stung, no matter how many nests he may rob.

The animal does not live entirely on honey, however, but also feeds upon rats, mice, small birds, lizards, and even insects.

Two kinds of ratels are known, one of which lives in Africa and the other in India.

The BaDger, in days of old, was very common in Great Britain. It was generally lnown as the "Brock," and when we find a place called by such a name as Brockley, or Brockenhurst, we may be quite sure that it was once inhabited by a great many badgers. Nowadays, however, these animals are scarce, and are only to be found in the wildest parts of the country; and as they only come out of their burrows by night, very few people even see them in a state of freedom.

These burrows are generally made either in the very thicliest part of a dense forest, or else on the side of a steep cliff which is well covered with trees. They run for some distance into the ground, and generally open out into several chambers, while at the end there is always a large hollow which the animals use as a bedroom. 'They like to be comfortable, so they always line this hollow with a good thick layer of dried fern and dead leaves. You woukl be quite astonished to find how much of this hedding is often packed away in the burrow of a single badger. 
These animals are most cleanly in their habits, and are very careful not to take any dirt into their burrows with them. They have heen known, for example, to use a low branch near the entrance as a scraper, and always to rub their feet upon it leefore going in. And every now and then they have a grand house-cleaning, turning out all their bedding, and taking in a perfectly fresh supply.

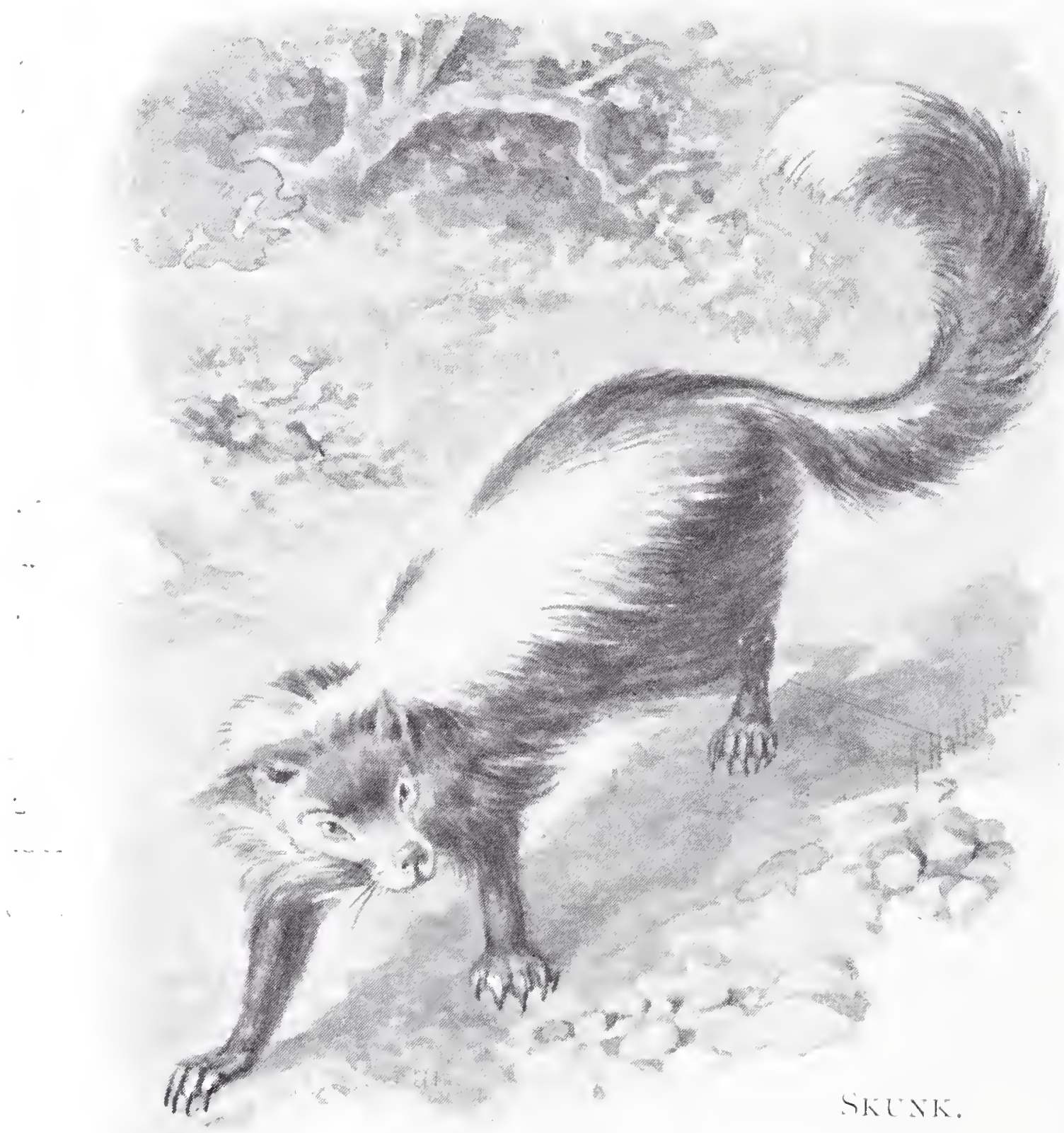

When the badger is digging, it uses its nose as well as its paws, shovelling the earth aside with it from time to time. And crery now and then it walls backwards to the entrance of the burrow pushing out the loosened earth in a heap behind it.

The teeth of the badger are made in a very curious way, for they intertock with one another just like those of a steel trap. 'The jaws, too, are exceedingly strong, so that the animal is able to inflict a very severe bite incleed. But it is a most peaceable creature, and never attempts to attack unless it is driven to bay. 


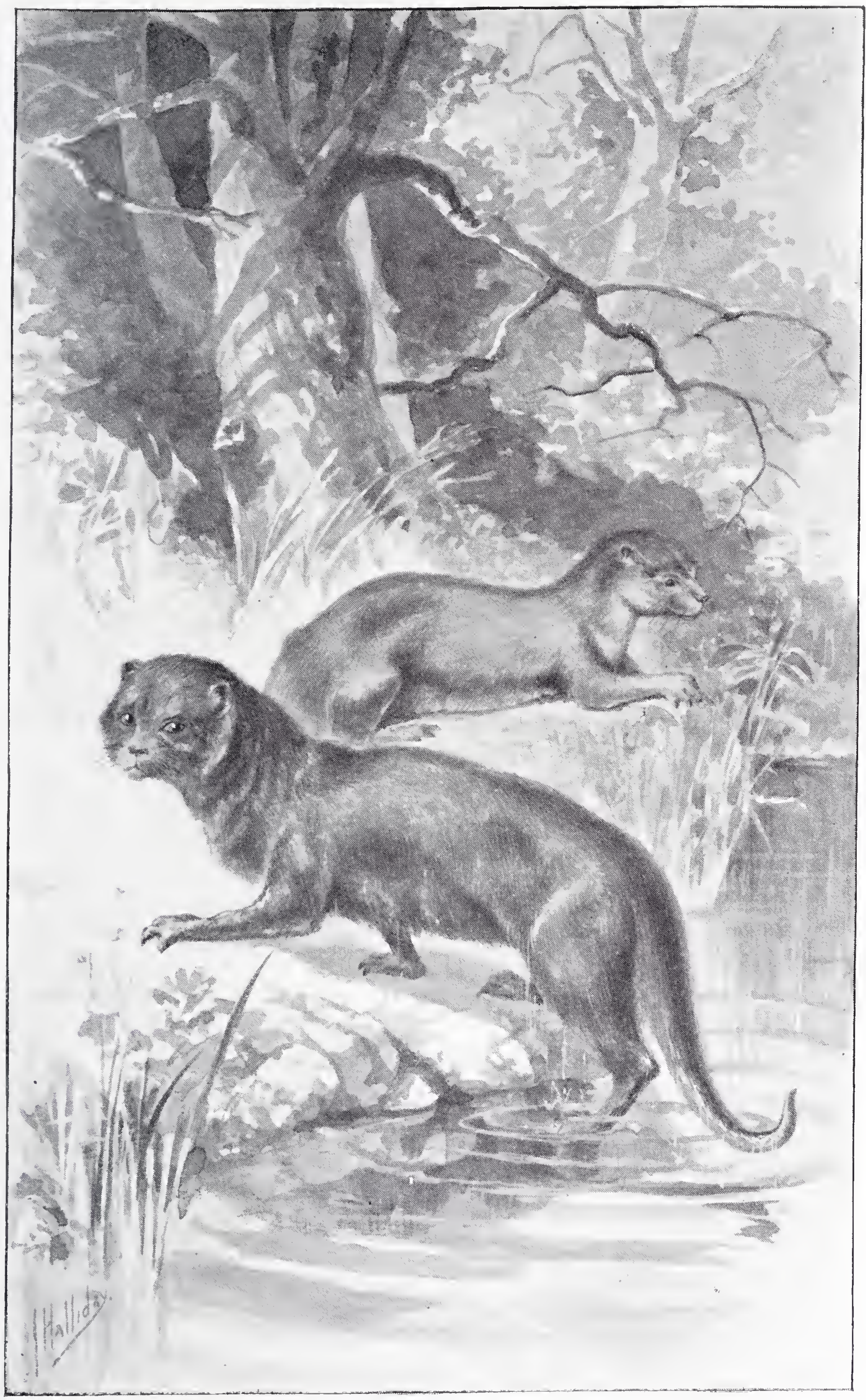

( ) TERS. 


\section{.}


Is regards food, the badger will eat almost anything. It scems equally fond of mice, frogs, lizards, birds' eggs, snails, worms, fruit, beech-mast, and roots. If it finds a wasps' or a lnumble bees' nest, too, it will dig it up and devour all the grubs and the food which has been stored up for them, caring nothing for the stings of the angry insects. And very often it gathers a quantity of provisions together in a small chamber opening out of its burrow, which it uses as a larder.

The head of the badger is white, with a broad black streak on either side, which encloses both the eye and the ear. The body is reddish grey ahove, whitish grey on the sides, and blackish brown below, and the flanks and tail are nearly white. In length it is very nearly three feet from the muzzle to the tip of the tail.

Many of the animals of the weasel tribe have a most disagreeable odlour; but there is none whose scent is so horribly disgusting as that of the Siunk.

This is a North American animal of about the size of a cat, with a long, narrow head, a stoutly-built body and a big bushy tail. In colour it is black; with a white streak on the forehead, a white patch on the neck, and a broad stripe of the same colour rumning along either side of the back.

The offensive odour of the skunk is due to a liquid which is stored up in certain glands near the root of the tail. This liquid can he squirted out at will to a distance of twelve or fifteen feet, and if the animal is attacked, or thinks itself in danger, it does not attempt to use its teeth, but just turns round, raises its tail, and sends a perfect shower of the vile fluid over its enemy. And it is almost impossible to wash the smell away. A drop or two once fell on the coat of a log. The animal was washed orer and over again, most thoroughly, with various linds of soap. Iet a week later, when he happened to rub himself against one of the legs of a table, no one could bear to sit by it afterwards.

The sliunk seems to know perfectly well how offensive its odour is, and never runs away if it meets a man, or even a large dog. It just stands perfectly quiet, like a cat expecting to be strolied, ready to make use of its evil-smelling fluid if necessary.

This singular animal lives in holes in the ground, maling a warm little nest at the end in which to bring up its young. It feeds upon small animals, small birds and their eggs, frogs, lizards and insects.

Last among the members of the IVeasel Tribe come the OTTERS.

These animals are specially formed for living in the water. The paws, for example, are very large and broad, and the toes are fastened together by means of a lind of web, like that on the foot of a swan or a duck, so that they form very useful paddles. Then the body is long, lithe, and almost snake-like, and the tail is so broad and flat that it serves as a capital rudder, and enables 
the animal to direct its course. The fur, too, consists of two coats of hair instead of only one, the outer, which is composed of long, stiff bristles, lying upon the inner like a very close thatch, and quite preventing water from passing through. So although an otter is dripping from head to foot when it comes out of the water, it never gets really wet.

The animal is wonderfully active in the water, and can easily overtalie and capture the swiftest of fishes. Sometimes it is very destructive, for when fishes are plentiful it becomes so dainty that it never eats its victims, but just talies a bite or two from the best part of the flesh at the back of the neck, and then leaves the rest of the body lying upon the ground. So fishermen are not at all fond of it, and kill it whenever they can. But sometimes, when the rivers are very low, or when the surface of the water is thiclily covered with ice, the otters find it very difficult to obtain a sufficient supply of food. So they leave the streams and wander far inland, sometimes making their way into the farmyards, and feasting upon poultry, or even upon young pigs and lambs. But they only do this when they are in real danger of starvation, and always return to the river banks as soon as they possibly can.

The home of the otter is generally situated beneath the spreading roots of a large tree on the bank of a stream. The animal does not dig a burrow if it can help it, but prefers to take advantage of some natural cleft in the ground, at the end of which it makes a nest of flags and rushes. In this nest from three to five little ones are brought up, and if you were to lie very quietly indeed on the bank for some little time quite early on a warm spring morning, you would very likely see the mother otter having a game of play with her little ones, or teaching them how to swim and to catch fish.

The bite of the otter is very severe, and it is almost impossible to force the animal to loose its hold.

In India there is a lind of otter which is often trained to catch fish for its master. It is taught, first of all, to pursue an imitation fish as it is drawn through the water by a string, and to bring it ashore and lay it down upon the ground. Then a dead fish is substituted for the false one, and when the otter has learnt to bring this to its owner, and to give it up at the word of command, it is sent in pursuit of a live fish fastened to a line. And before very long it learns its duties so thoroughly that it will catch fish after fish, and bring them back without attempting to eat them, just as a well-trained retriever dog will bring back the birds or the rabbits which its master has shot.

There is also a lind of otter which lives in the sea, and is called the SeA OtTer in consequence. It is also linown as the Kalan. It is found on the coasts of the northern Pacific, and is much larger than the common otter, often weighing as much as seventy or eighty pounds, and being nearly four feet in total length. 


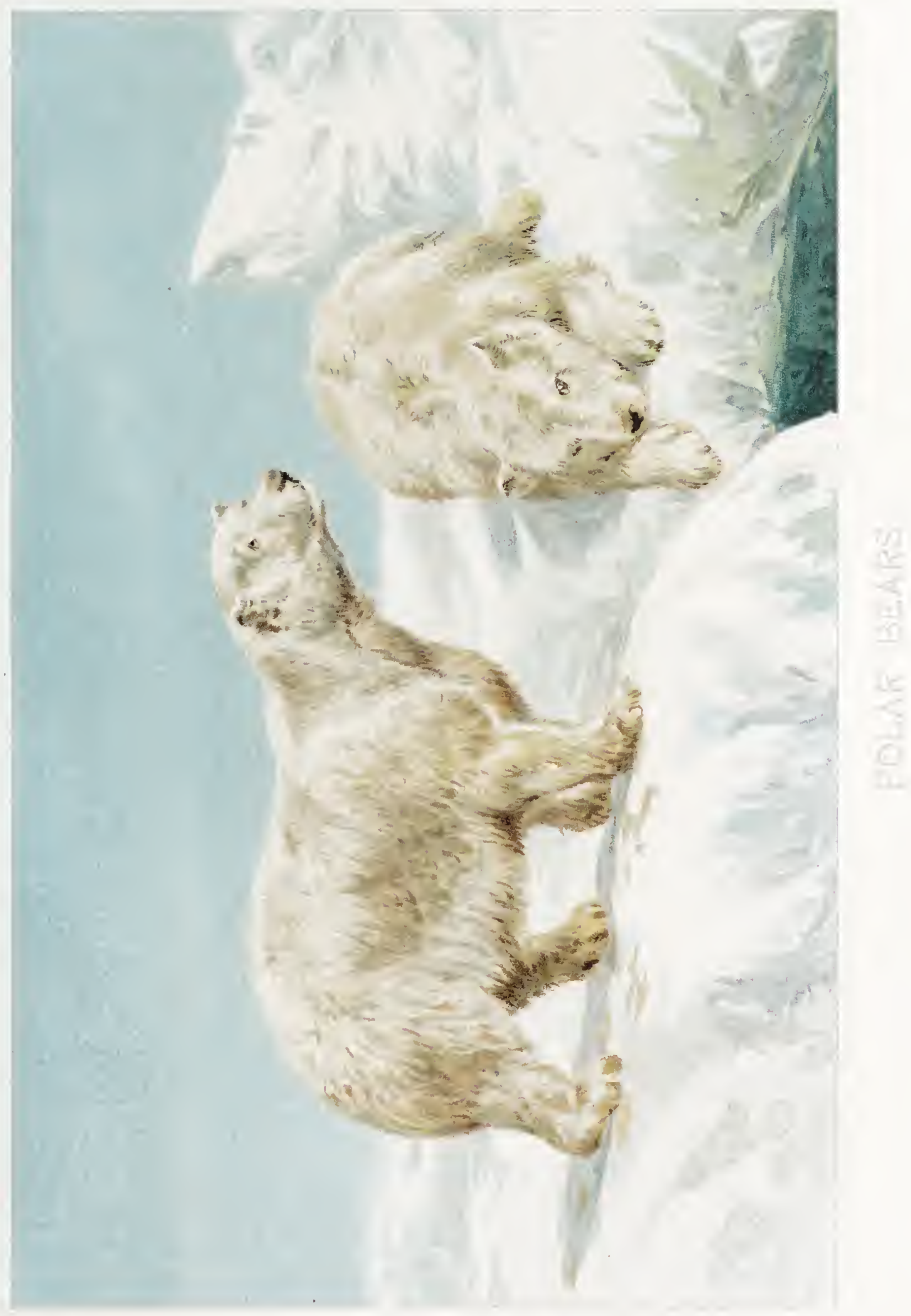





\section{CHAPTER XI.}

\section{THE BEAR 'IRTBE。}

THE Bears are very interesting animals incleed, and one of the most interesting of them all is the POLAR BEAR, which is found in almost all parts of the Arctic regions. Sometimes it is called the White Bear, on account of the colour of its coat. But this is very seldom really white. Generally it is creamy yellow. And sometimes, in an old male, it is dingy yellow, and not even of the colour of cream.

This is one of the largest of the bears, for it often grows to a length of nine feet, and weighs 800 or even 900 pounds. Yet it is wonderfully active, and it can run with very great speed. Indeed, if it were to pursue a man, he would have very little chance of escape. But it is not at all a quarrelsome animal, and although it will fight most savagely if it is wounded or driven to bay, using both teeth and claws with terrible effect, it very seldom attacks if it is not molested.

One of the first things that we notice on looking at a polar bear is the small size of its head and the length of its neck. This, no doubt, is to help it in swimming; for if it had a head as hig as that of an ordinary bear it would find it very much harder to force its way through the water. And of course it must be able to swim very well indeed, for otherwise it could never catch the porpoises and fishes upon which it feeds. We notice, too, the huge size of its paws, which are nearly eighteen inches long, and very broad as well. These form most excellent paddles, while the thick fur is so oily that it quite prevents the icy water from coming into contact with the slin.

The bear is very fond of feeding upon seals, however, as well as upon porpoises and fishes. But these are so active in the water that it very seldom attempts to chase them, preferring to creep quietly up to them as they lie sleeping on the ice instead. Then it lills them with one strolie of its terrible paw. Sometimes, too, it is said to prey upon the walrus, crushing in its skull by a series of tremendous blows before it can shuffle off the ice into the sea.

The feet of the polar bear are specially suited for travelling over the ice, for the soles are covered with long, thick hairs, which give it a firm foothold, and at the same time prevent it from feeling the cold of the frozen surface.

The young of these bears are horn and brought up in il 
kind of nursery underneath the snow, which is so warm and snug that they do not feel the cold at all. Here they live with their mother until the snow melts at the return of warmer weather, and then for some months father, mother, and cubs all wander alout together.

Polar bears sometimes live for a very long time in captivity. One of these animals lived in the Zoo for no less than thirty-four years, and another for thirty-three. The former of these once gave the keepers a terrible fright, for early one morning he managed to climb out of his enclosure, and when they found him he was just setting off on a journey of discovery into the Regent's Park. After a good deal of trouble, however, they got him back,

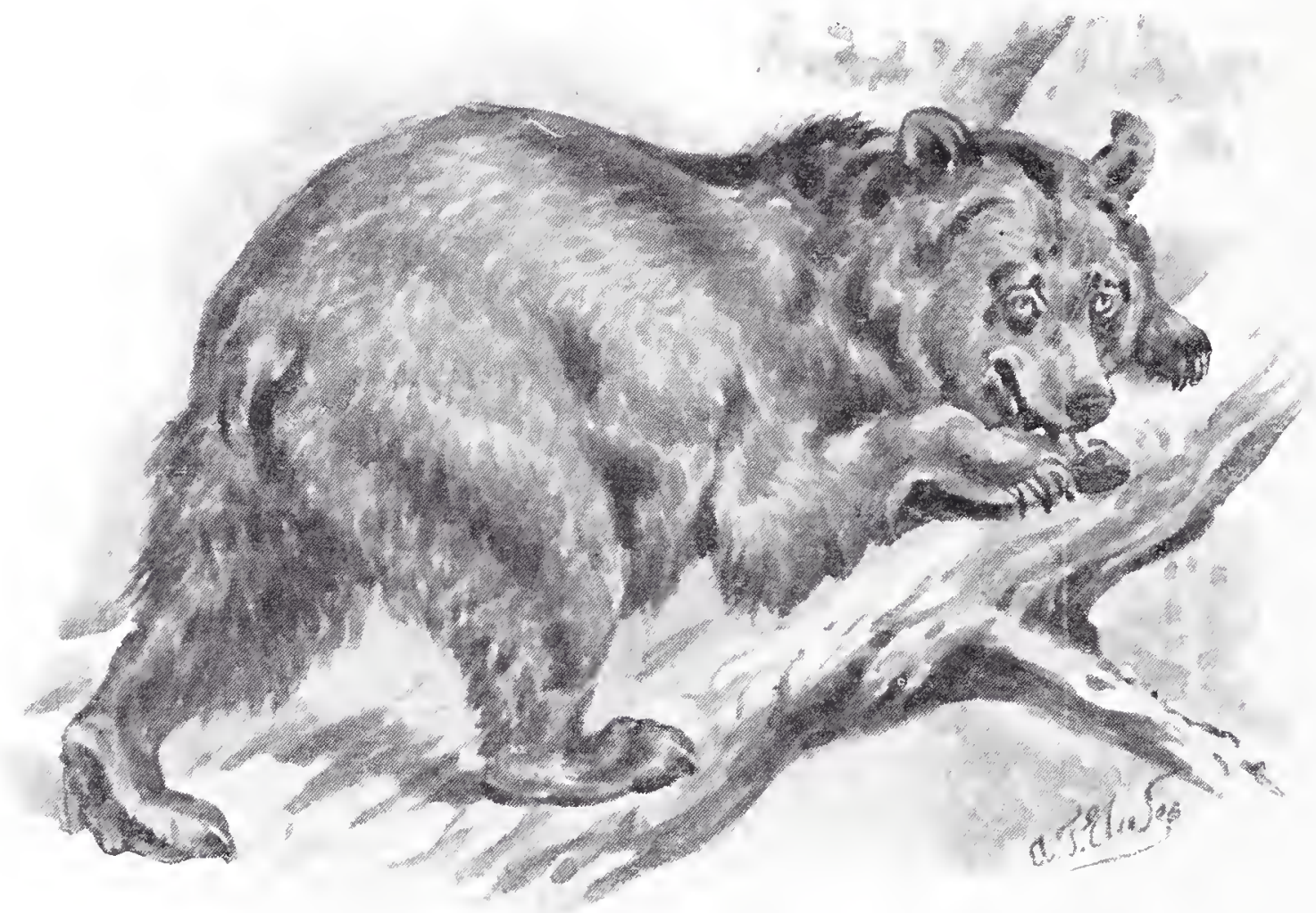

リROW BEAR。

and altered his enclosure in such a way that he could never make his escape again.

The BRow J BEAR is found in most parts of liurope, and also throughout almost the whole of Asia north of the Himalayas. In former days it was not uncommon even in England, and in the time of Edward the Confessor the city of Norwich was obliged to kill a bear every year and send its body to the ling.

'These bears are found in wooded, hilly districts, often ascending to considerable heights in the mountains. In some parts of Asia they make regular tracks through the forest, in the form of pathways about two feet wide; and it is said that these tracks sometimes run for hundreds of miles. They are solitary animals, and it is not often that even a pair are seen together. But for 
several months after they are born the cubs go about with their mother.

This bear is generally supposed, when it fights, to try to "hug" its enemies to leath, throwing its fore limbs round them, and crushing them in its embrace. But in reality it strikes a kind of side blow, and forces its great claws into its victim's hody, thus causing a most terrible wound. Just before it strikes it rears its body erect, and sits for a moment almost perfectly still; and it is for this moment that an experienced hunter waits in order to send a bullet through its heart.

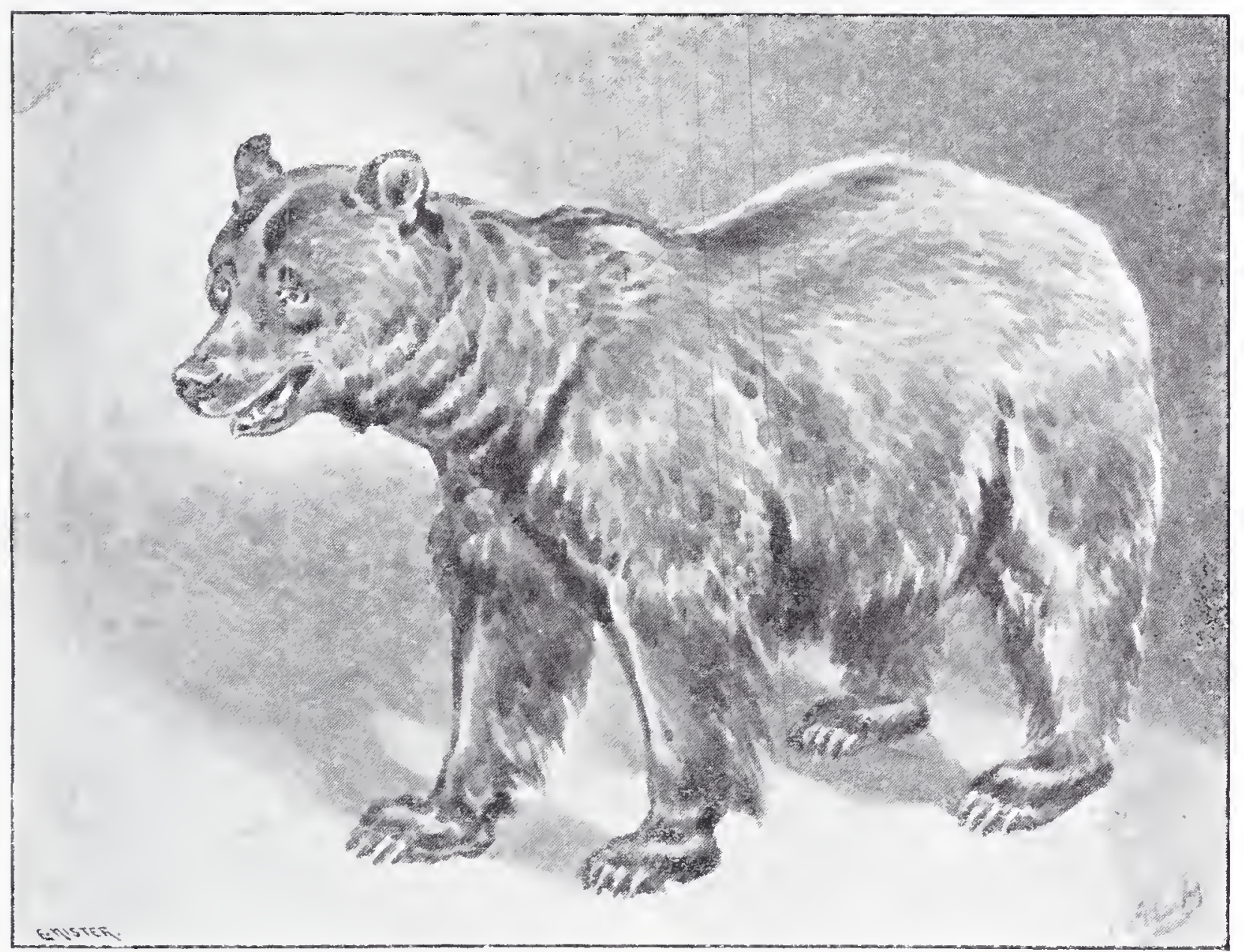

GRIYKS BRAR.

The brown bear can scarcely be called a beast of prey, though now and then, when it is very hungry, it will lill a pony or a sheep and feast upon its Hesh. It eats roots, as a rule, digging them up with its great paws; and it is also very fond of fruit. It will rob the nests of wild bees, too, and feed greedily upon the honey, appearing to pay no attention to the stings of the angry insects. And sometimes it may be seen turning over large stones, in order to catch and eat the beetles, earwigs, centipedes, etc., which have been hiding beneath it.

Now and then, too, brown bears have been known to catch fish. Their usual plan seems to be to wacle out into a stream, in 
some place where the water is not more than about eighteen inches deep, and there to stand perfectly motionless until a fish comes swimming past. Then with one quick, sudden stroke the victim is killed, and the bear seizes it in its month and carries it to the bank to be deroured.

When bears catch fish in this way they are usually rather dainty, and only eat the best part of the flesh upon the back.

In cold countries the brown bear often hibernates during the winter, just as bats and hedgehogs do in Great Britain. It cats a great deal of food towards the end of summer, and becomes exceedingly fat, and then retires to a hollow tree, or a cave, and falls asleep for several months, during which it lives on its own fat. In the spring, of course, when it wakes up, it is very thin

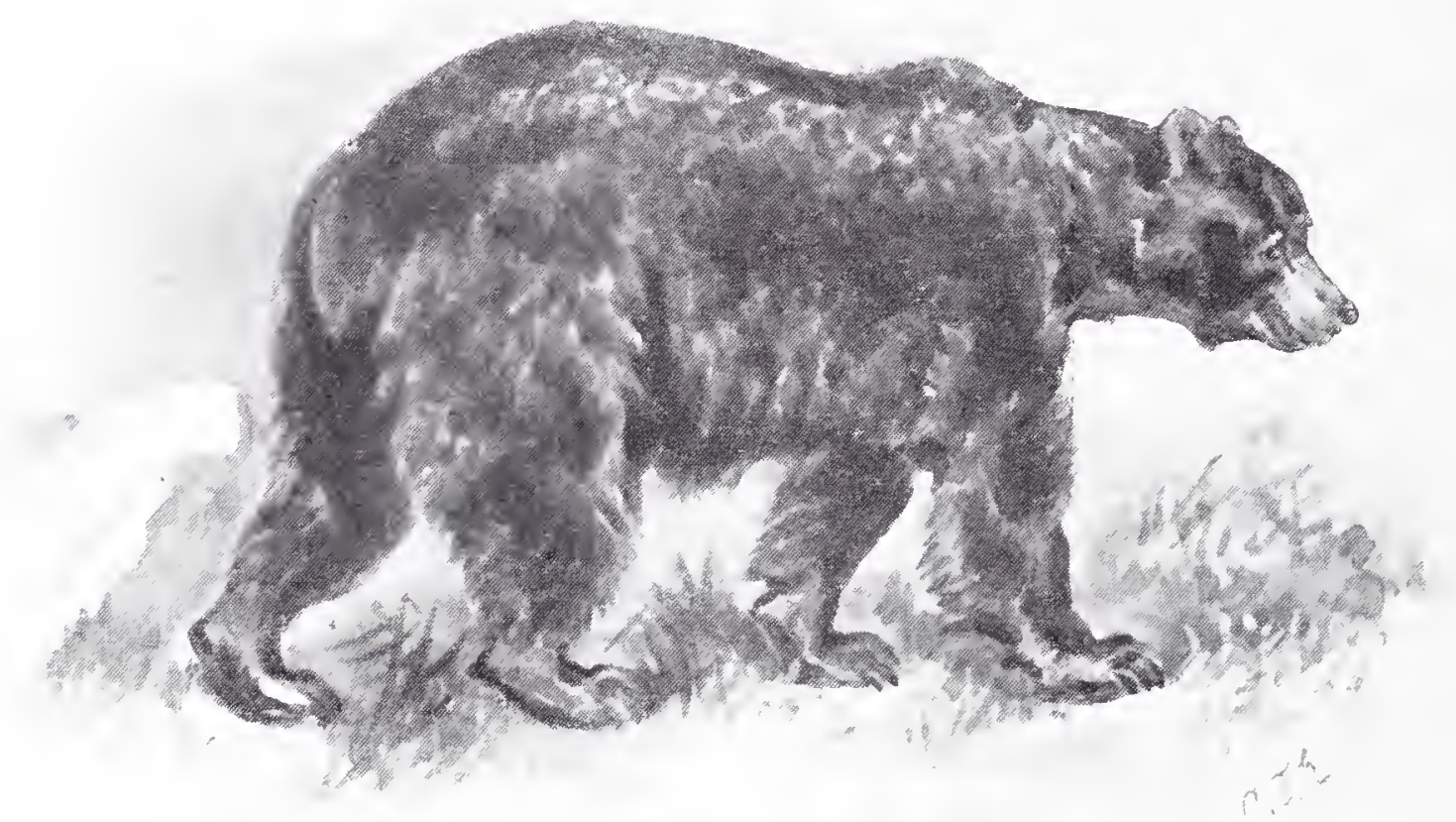

BIルK IIEIK.

indeed. But a week or two of good feeding very soon brings it backi into proper condition.

The brown bear is very easily tamed, and the "performing" bears" which we often see almost always belong to this species. It is not nearly such a large animal as the polar bear, its arerage length being only about six feet.

The famous Grizzly Bear, however, which lives in North America, is much bigger and stronger and more savage, so that it is really a very formidable animal indeed. When fully grown, this huge creature is sometimes as much as nine feet long from the tip of the snout to the root of the tail, while it weighs at least 800 or 900 pounds.

The grizzly bear-or "old Ephraim," as the hunters call 


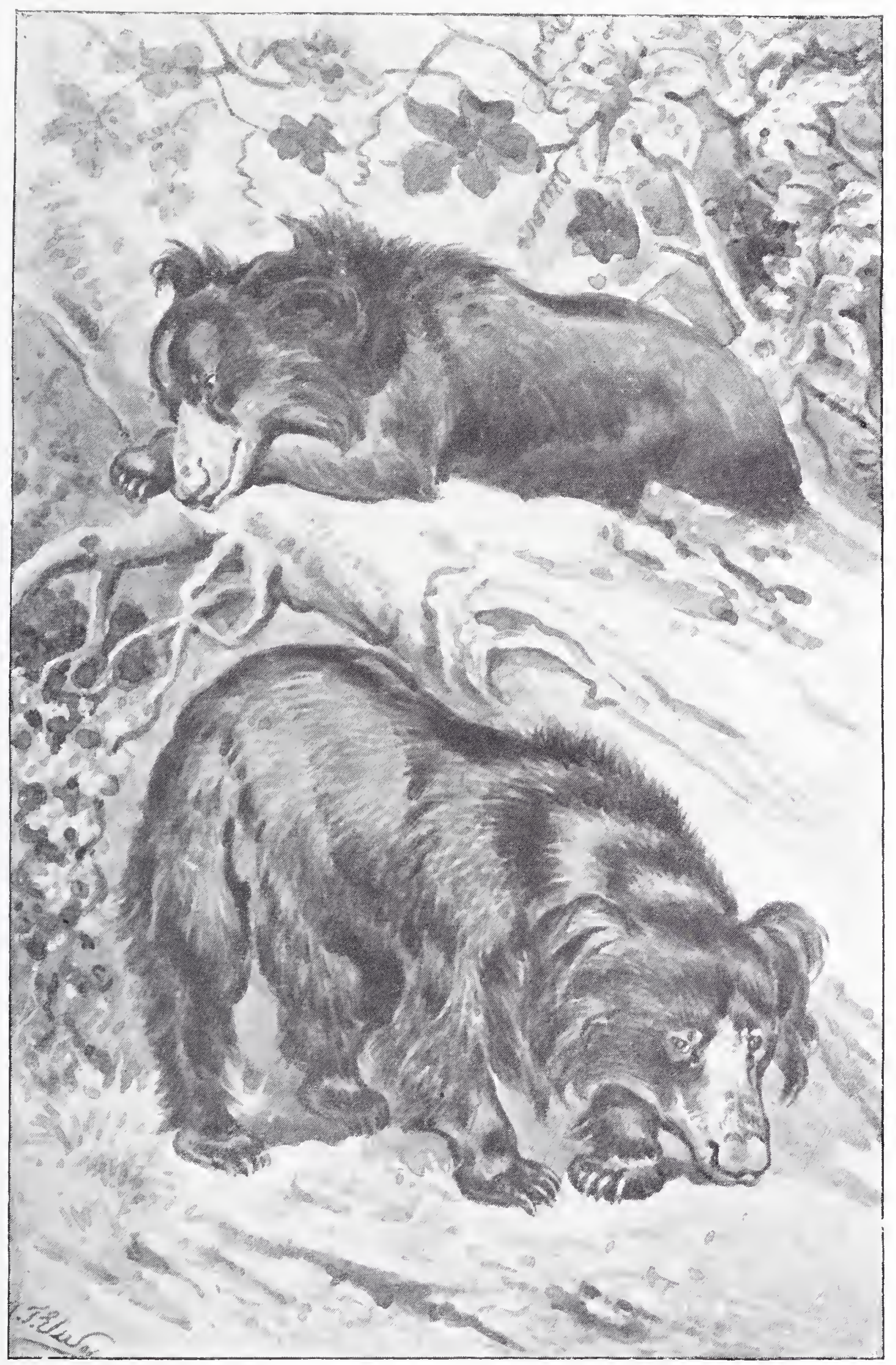

SLOTH BEARS. 

it-preys largely upon deer, and when it has lilled one it generally scratches a hole in the ground and buries the body, returning to it when in want of a meal. If it finds the carcase of an animal it treats it in the same way. It is said, too, that more than once a hunter, who had been caught by one of these bears, has contrived to escape by pretending to be dead, allowing the bear to bury him, and then breaking out of his shallow grave when it had gone away to sleep.

But the animal is a vegetable feeder as well, and is very fond of acorns. It gets these by climbing a tree, shaling or

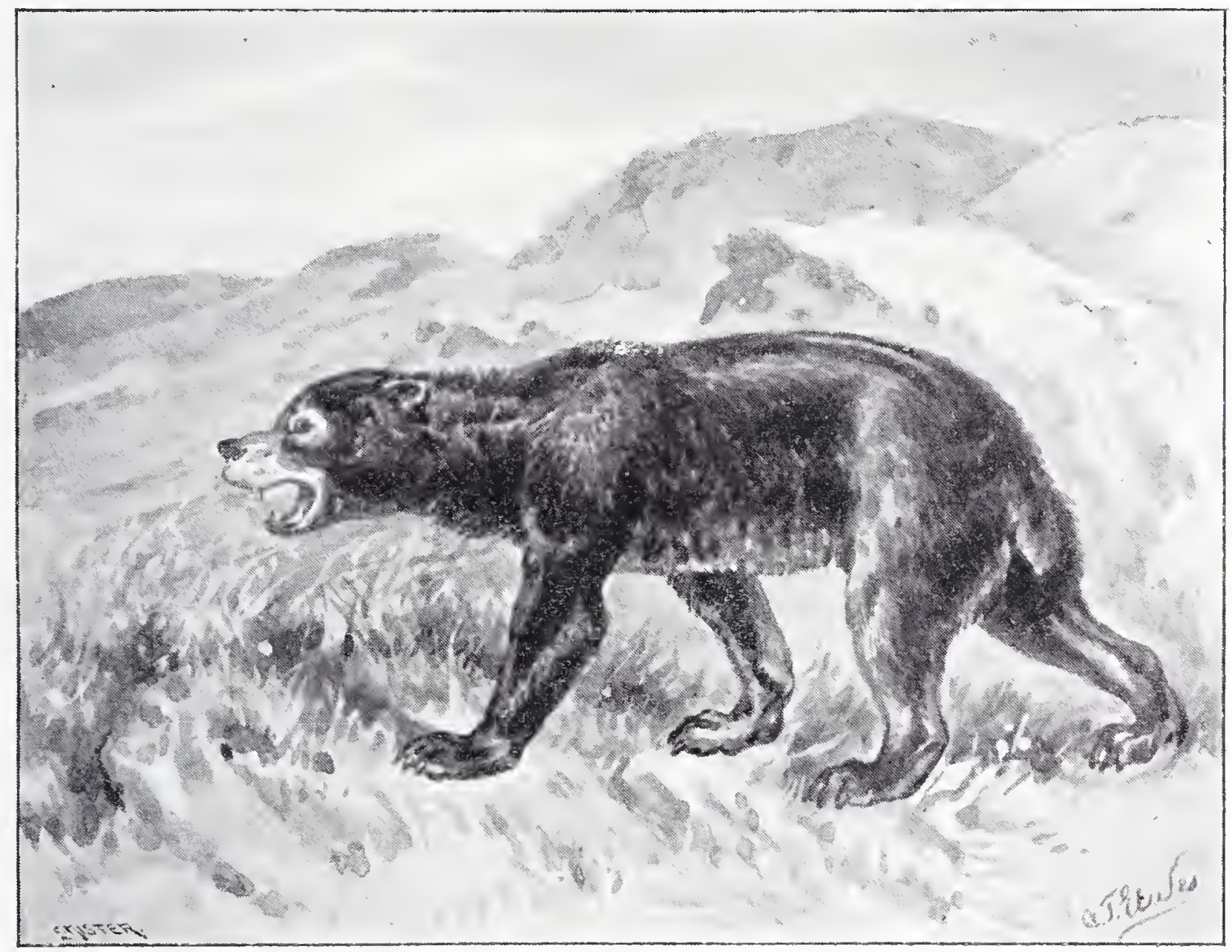

SUN BER.

striking the branches with all the force of its mighty limbs, and then coming down to feast on the results of its labours.

It is sometimes said, however, that the grizzly bear cannot climb trees. But this seems to be true only of the old animals, for the younger ones can climb quite as well as brown bears.

The BLACk BEAR is also an inhabitant of North America, but is neither so common or so widely distributed as it used to be.

There are two reasons for this. The first is that this bear is an extremely mischievous animal, and is very fond of visiting 
farmyards, and carrying of sheep, calves, pigs and poultry. So the farmer loses no opportunity of shooting or trapping it. And the other reason is, that its coat is very valuable, so that the hunters follow it eren into the wilder parts of the country, where settlers, as yet, have not made their appearance.

This animal is only about half as big as the srizzly bear, for it seldom cxceeds five feet in total length. It never attaclis man unless it is provolied. When driven to bay, however, it becomes a most formidable opponent, dealing terrific blorrs with its forc-paws, and fighting on with furious energy even after it has received a mortal wound.

Early in the autumn the black hear generally goes into winter quarters. Finding a hollow underneath a fallen tree, or a care of suitable size, it gathers together about a cartload of

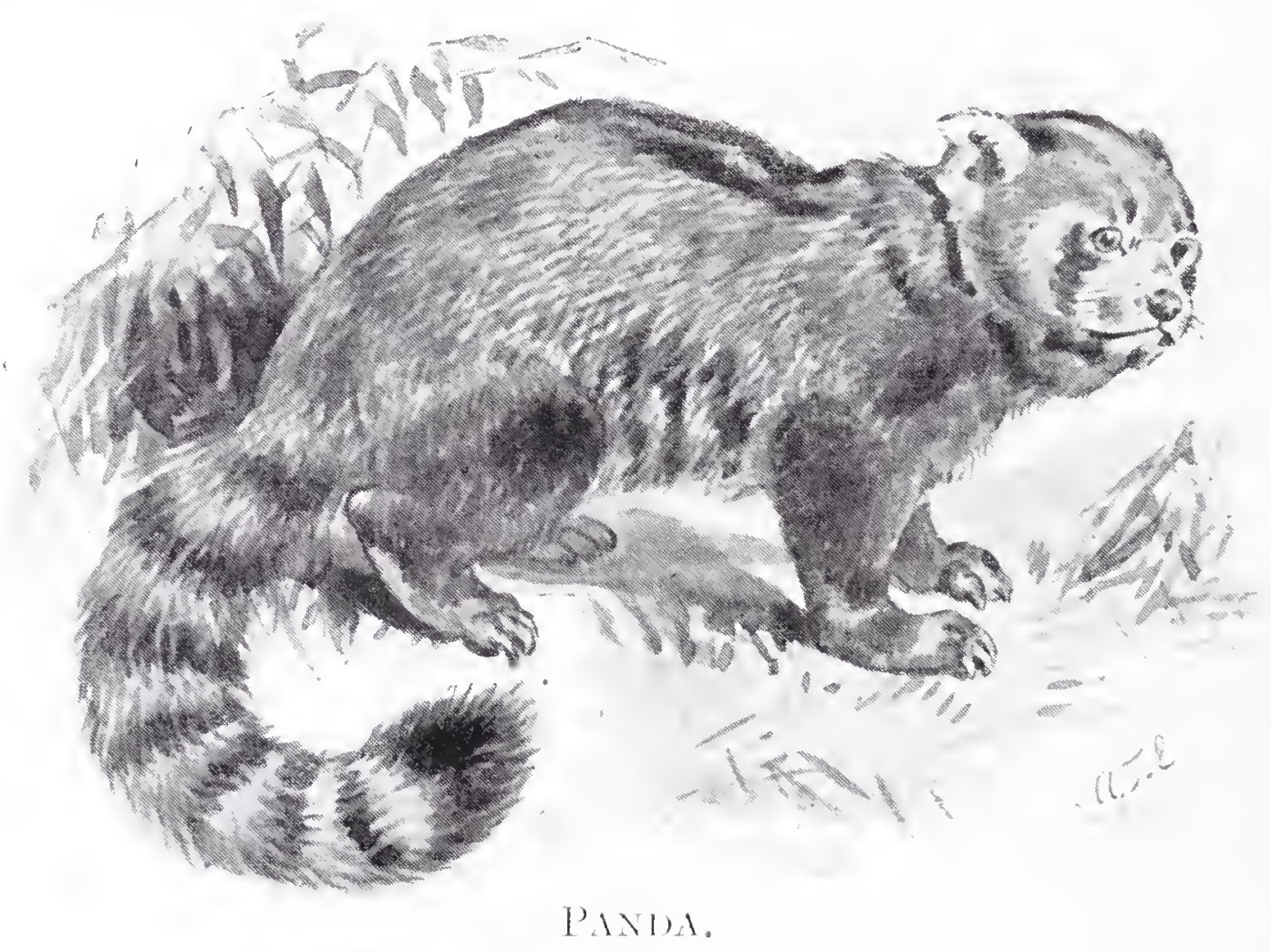

dead leaves and ferns, and makes a snug, cosy nest. Very often it lays a number of branches on the top, to prevent the leaves from blowing away. Before very long, of course, this nest is deeply covered with snow, and the bear lies fast asleep inside it for four or five months, living on the fat which it stored up inside its body during the summer.

This bear is sometimes linown as the Musquaw.

The Sur Bears are so called because they wander about by day, and like to bask in the hottest sunshine, instead of hiding away in some dark retreat, as most of the other bears do. They live in India, China, and the larger islands of the Nalay Archipelago, and are excellent climbers, spending a great part of their lives among the branches of the trees.

These bears have most curious tongues, which are very long 
indeed, and rery slender, and can be coiled and twisted about in the most singular way. Apparently they are used for licking out honey from the nests of wild bees.

Sun bears are very gentle creatures, and are easily tamed. 'Those at the Zoo are extremely playful, and you may often sec them standing upon their hind legs and wrestling with one another, and then tumbling over and rolling upon the floor, and evidently enjoying themselves very much indeed. 'Their fur is very smooth and glossy, and is jet black in colour, the chin and a crescent-shaped patch underneath the throat being white.

The Aswai, or Sloth Bear, is perhaps the oddest of all the bears, for it has very long and shaggy hair, a flexible snout which it is alvays curling and twisting about, and a rery awliwardly and clumsily built body. It walks, too, with a curious rolling gait, crossing its paws over one another at every step that it takes. And it has a queer way of eating termites and ants by breaking open their nests with its great fore-paws, blowing away the dust and fine earth, and then sucking up the insects by forcibly drawing in its breath through its lips. It makes such a noise when doing this that it can be heard from a distance of two or three hundred yards.

The aswail is very seldom seen abroad during the daytime, for a very odd reason-viz., that the slin of the soles of its feet is so delicate that it cannot bear to valk upon ground which is heated by the rays of the sum. Sometimes, when a hunter has driven an asmail from its lair and pursued it by day, he has found its feet most terribly scorched and blistered when at last he killed it, simply because it had been obliged to walk over rocks on which the midday sun was beating down!

When a mother aswail has little ones, she always carries them about on her back. If she stops to feed they at once jump down, but always spring up again as soon as she moves on. Even when they are quite big they travel about in this way, and an aswail may often be seen with a cul) as large as a retriever dog perched upon her back, and another one trotting along by her side. And from time to time she makes the little ones change places.

If a mother aswail is wounded while her culss are with her, she always seems to think that one of them must have bitten her, and immediately gives them both a good sound box on the ears. If several of these animals are together, too, and one of them is struck by a bullet, it begins to howl and cry at the top of its voice. The other bears at once come running up to see what is the matter, and begin to howl and cry too, out of pure sympathy for its sufferings. 'Then the wounded animal thinks that they have caused his injuries, and begins to cuff them with his paws. They, of course, strike back, and very soon all the 
bears are buffeting and biting and scratching one another. They must be very stupid creatures, mustn't they?

The aswail is a little more than five feet long when fully grown, and stands from twenty-seven to thirty-three inches in height at the shoulder. In colour it is black, with a white crescentshaped mark on the upper part of its chest, like that of the sun bear.

Besides the true bears, there are a number of smaller animals which belong to the same tribe.

One of these is the PANDA, or WAH, which is only about as

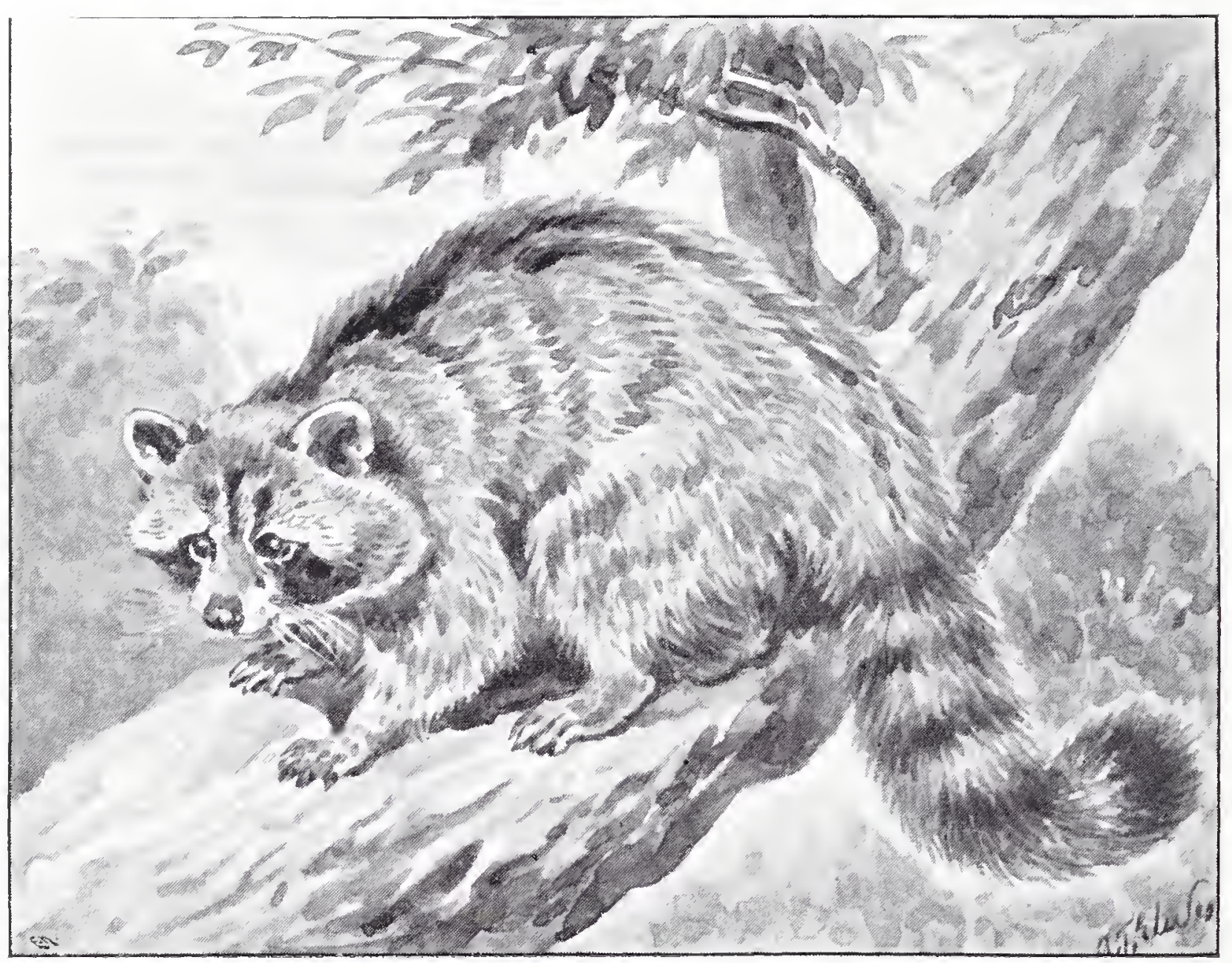

RACOON.

big as a rather large cat. It is rusty red in colour, with darker rings upon the tail, the tip of which is black. The face is white, and the lower parts of the body are very dark brown.

The panda is found in the forests of the Eastern Himalayas, and also in Eastern Thibet. It is a very good climber and spends much of its time in the trees, searching for the nuts, fruits, and acorns on which it feeds. If it happens to find a bird's-nest with eggs in it, too, it will suck them all, one after the other. And sometimes it will come down to the ground to make a meal upon roots, or the young shoots of bamboo.

The panda has rather large claws-just like those of 
a bear-and one would think that they would form very serviceable weapons. But the animal seems to have very little idea of fighting, and scarcely tries even to defend itself if it is attaclied.

Next come the Racoons, all of which live in America. The best known of them is the Common Racoon, which is found throughout the United States, and also in Central America as far south as Costa Rica.

This is a very pretty animal. In size it is about as big as a rather large cat, and is brown or greyish brown in colour, with a tail which is very bushy and is beautifully ringed with grey and black. The head is rather like that of a fox, with a whitish forehead, and a black patch just below it, enclosing the eyes.

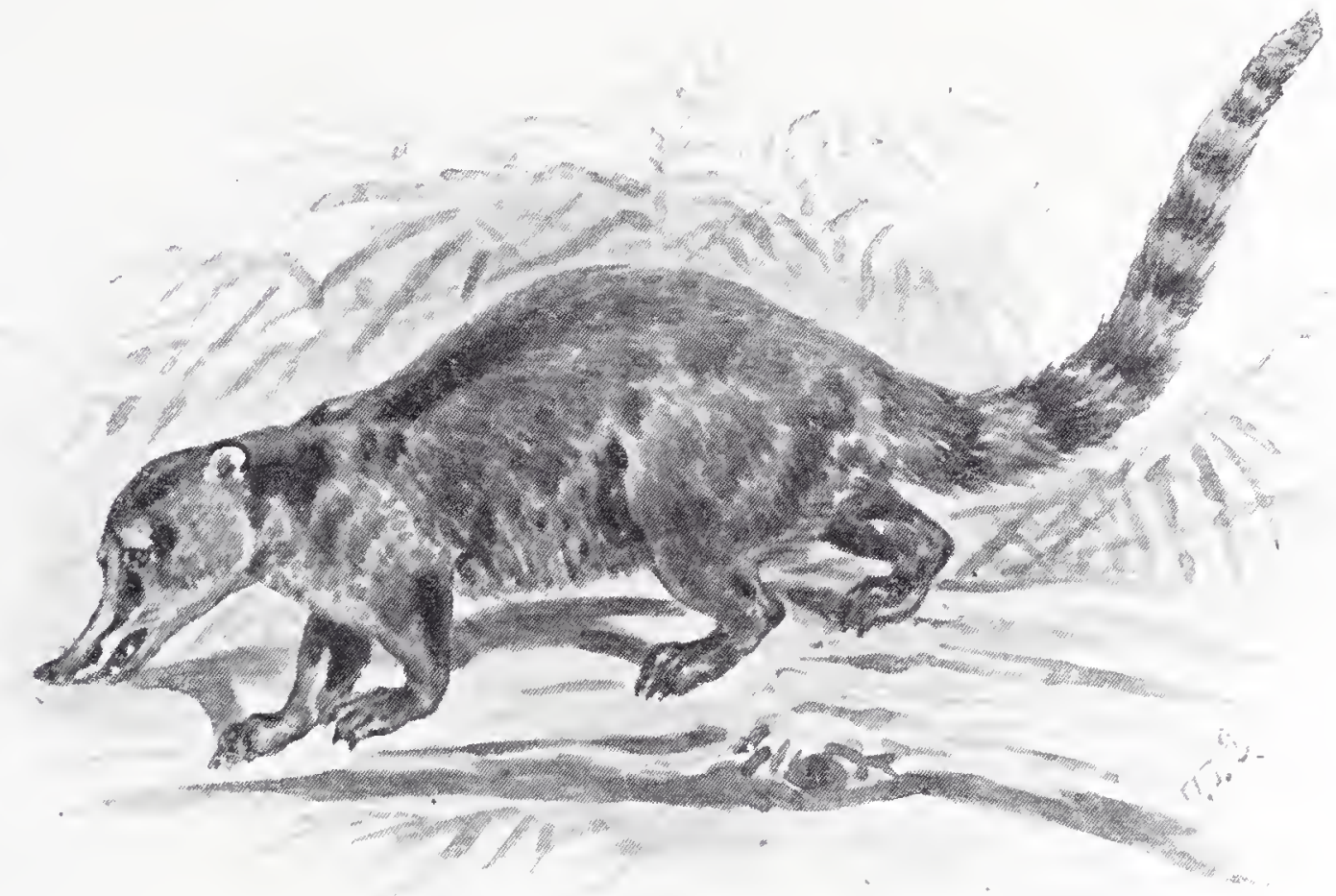

COATI.

There are always two or three racoons to be seen in the \%oo, and if you give one of them a piece of bread or biscuit it will take it in its fore-paws, just as if it were a monkey, and then go and rinse it carefully in the little pond in the middle of its cage. It never eats a scrap of food without washing it in this curious manner, and for this reason the Germans have given it the name of "Waschbär" or "washing bear."

The fur of the racoon is so soft and thick that it is very valuable, and the animal is very much persecuted in consequence. It is generally hunted by night, the hunters going out with a number of dogs, which soon drive the animal into a tree. They then sit in a circle round the trunk, while one of the hunters climbs the tree, drives the racoon to the end of the branch, and then shakes it violently till the poor creature falls to the ground, where it is ruickly seized and dispatched. 
Racoons will eat ahnost anything. Sometimes they will visit a poultry-yard and lill a number of the fowls by biting off their heads. Or they will go down to the seashore when the tide is out to search for crabs and oysters, or to the creelis and streams to hunt for crayfish. They are fond, too, of mice, and young birds, and eggs, and lizards, and fresh-water tortoises, and even insects, while they will occasionally malie a meal on nuts, or fruit. But although they are such capital climbers, and can run about among the tree-branches as actively as squirrels, they never seem to plucli these as they grow, hut only pick up those which have fallen on the ground below.

Closely allied to the racoons is the Conirs, or CoartsMoxd, which you may recognize at once by its very long

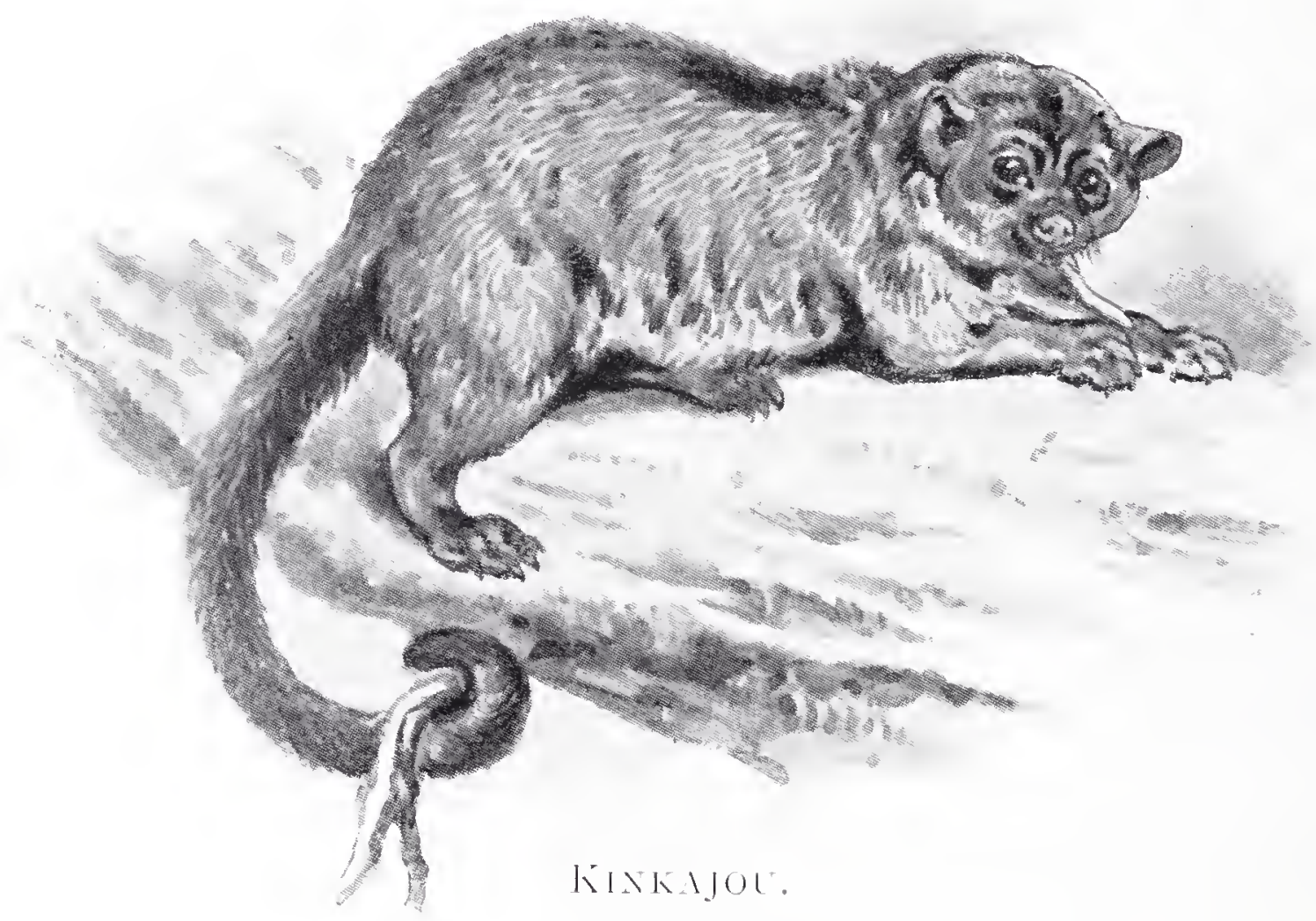

snout. This snout is turned up at the tip, and gives to the animal a most curious appearance, while it is continually being curled and twisted about lilie that of the aswail. It is chiefly used for rooting about in the sround in search of worms and insects, and when the animal is drinling it always turns up the tip of its snout as far as possible, in order that it may not get wet.

The coaiti can climb quite as well as the racoons and spends most of its life in the trees, very seldom coming down to the ground except to feed or to drink. It has a queer way of descending a tree with its head downwards, turning the linder feet round in a such way that it can hook its claws into the little crevices in the hark. Droring the day-time it is generally fast 
aslecp, using its long bushy tail partly as a pillow and partly as a blanket. But almost immediately after sunset it wakes up and begins to scamper about among the branches with the most wonderful activity, stopping every now and then to rob a bird'snest, or to polie its snout into a hole in search of insects.

The coaiti is about a yard in length, very nearly half of which is occupied by the tail. In colour it is chestnut brown, with black ears and legs, while the tail is ringed with black and brownish yellow.

Only one more nember of the Bear Tribe remains to be mentioned, and that is the very curious Kinkajou, which is found in the forests of Central America. It is about as big as a cat, with very woolly fur of a light brown colour, and a very long tail. This tail is prehensile, like that of a spider monkey, and the animal never seems quite happy unless the tip is coiled round a branch. And if you make a pet of it, and carry it about in your arms, it will always try to coil its tail round one of your wrists.

It has a very odd tongue, too, so round and long that it looks almost like a worm. The animal can poke this tongue into the cells of a honeycomb, in order to lick out the honey, or use it in plucking fruit which would otherwise be out of its reach. And it descends the trunks of trees head first, just as the coaiti does.

This animal is also known as the Potto. 


\section{CHAPTER NII.}

THE SEAT, TRIBE.

WE now come to a group of carnivorous or flesh-eating mammals which live in the water-namely, the SEals.

People sometimes think that these creatures are fishes; but that is quite a mistake, for their blood is as hot as our own, and they breathe by means of nostrils and lungs just as we do, and not by means of gills, like the fishes. Then they have no fins to keep their hodies upright in the water as fishes have, neither do they swim by means of their tails. And their hodies are covered with fur, not with scales.

So, you see, seals are very different indeed from fishes, although they spend almost the whole of their lives in the water. but nature has formed them in such a way that they can swim and dive quite as well as the fishes can. Yet it is very difficult indeed to see how they do so. If you watch a tame seal swimming about in a large tank of water, you will see that it glides smoothly and swiftly and easily and gracefully along, rising and diving and turning with the most perfect ease; but how it swims you will not be able to tell at all.

Perliaps you linow, however, that you can row a boat by means of a single oar, if you work it from side to side at the stern. You will not travel very fast, partly because the oar is not very big, and partly because you are not very strong. But still the boat will move.

Now if you look at the hinder feet of a seal, you will see that they are very broad indeed, that they are set very far back upon the body, and that, if necessary, they can be placed side by side together. Then think of the body of the seal as a live boat, and of these great broad feet as an oar worked from the stern, and you will be able to understand how the animal swims. It just places these feet side by side, and uses them in such a way that they act ipon the water exactly as an oar does, while their strength is so great that they drive the body along very swiftly indeed.

But if the seal is a hot-blooded animal, how can it remain in the sea for days together without being chilled? If we go to the seaside, and wish to bathe, we are advised not to stay in the water for more than ten or fifteen minutes; and if we were to do so, we might be made seriously ill. Tet the seal can live for days, or even weelis, in the icy seas of the far North and yet never seem to suffer from the cold at all. How is this? 
Well, the fact is that, first of all, Nature has supplied the seal with a kind of mackintosh, to keep it dry.

This mackintosh, in most seals, is made of a double coat of fur. First there is an outer layer of long, stout hairs, almost like bristles; and underneath there is generally another layer of soft, close hairs - those which you see in a lady's sealskin jacket. And in order to keep the water from passing through it, this double coat of fur is liept constantly oiled. All over the surface of a seal's skin are thousands upon thousands of little holes, each of which opens into a tiny bag of oil, and this oil is constantly oozing out on to the fur. So, you see, the furry coat really does act like a mackintosh, for it quite prevents the seal from ever getting wet.

When an animal lives in water which is often covered with ice, however, something more than a mackintosh is necessary in order to keep it warm; so under the mackintosh Nature has

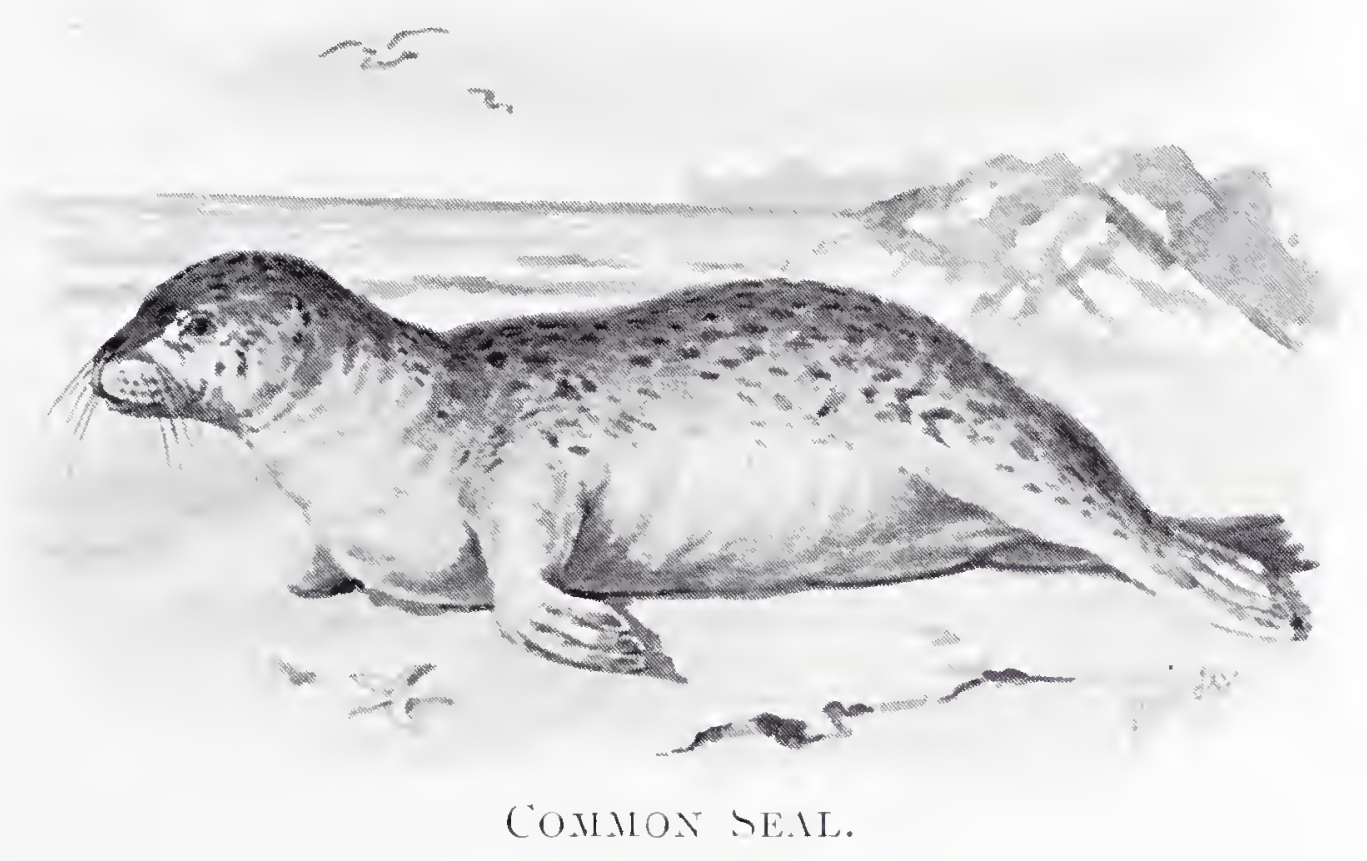

provided the seal with a thick great-coat. And this great-coat is made of a substance much warmer than cloth, or even than fur. It is made of fat. Just underneath the skin, covering the whole of the body, is a layer of fat two or three inches in thicliness. And this keeps the seal so warm that even when it is lying upon ice it never gets chilled in the least.

Then the nostrils and the ears of the seal are made in such a way that water cannot enter them when the animal is diving. They are furnished with little valves, which are so arranged that they close as soon as the water presses upon them. And the greater the pressure the more tightly they shut up, so that not the tiniest drop of water can ever enter them.

There is still one more way in which the animal is specially fitted for its life in the water.

It has to feed on fishes; and fishes are very slippery 
creatures. If you have ever tried to hold a live fish in your hand you will know that it is a most difficult thing to do, for the fish just gives a wriggle and a twist, and slips out of your grasp as if it had heen oiled. So that it would seem quite impossible for the seal to hold its finny victims, even if it orertook and seized them. But when we come to look at its teeth we find that those which we call "molars," or "grinders," are set with long, sharp points; so that when a fish is seized they enter its body, and hold it in a grip from which there is no escape.

There are a good many different linds of seais, but I shall only be able to tell you about four or five of the best known.

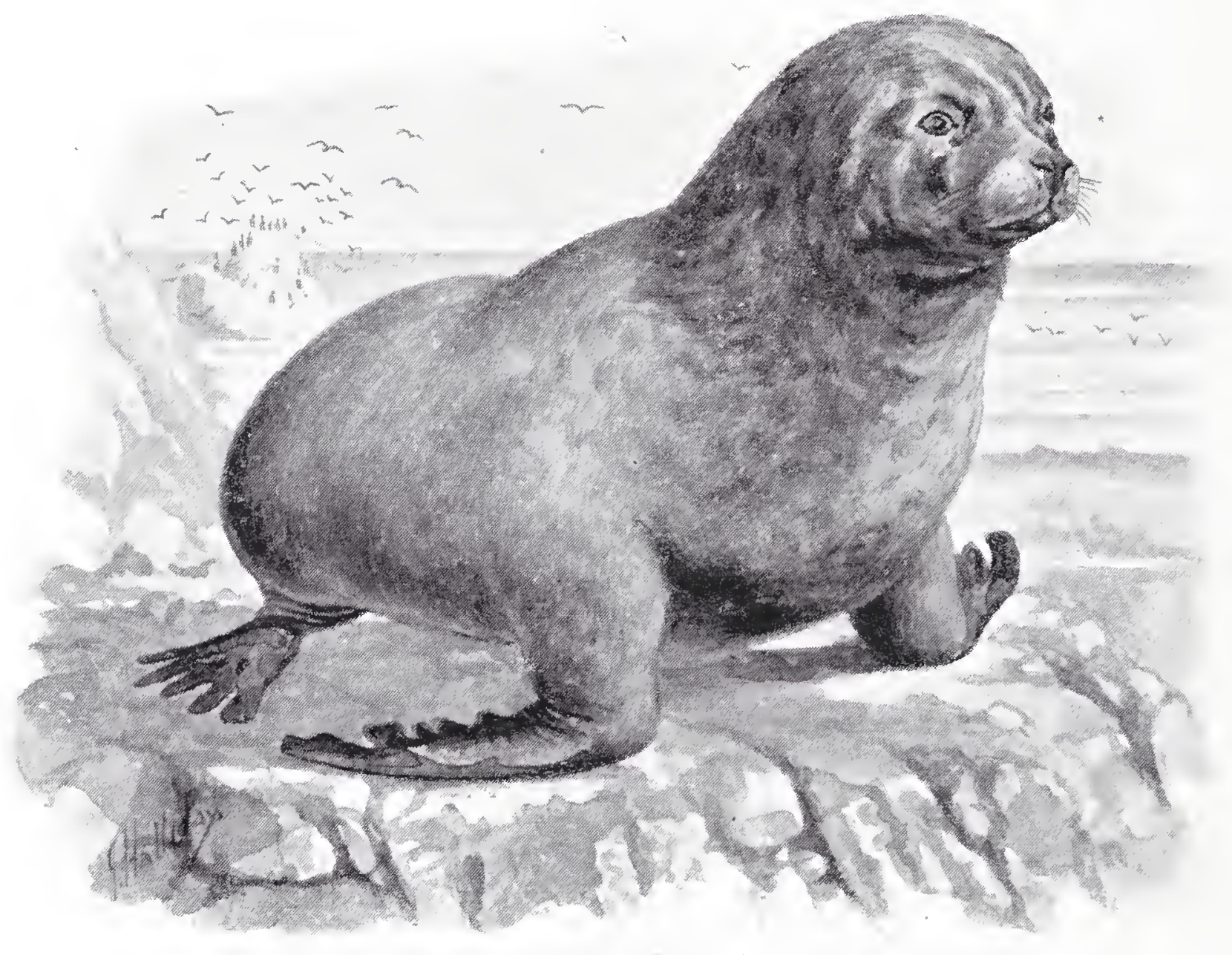

"TTHGNIIN SEA IJON.

The first of these, of course, is the Comaon SEAL, which may still be seen in many parts of our own British coasts. It is very much disliked by the fishermen, owing to the great number of fishes which it devours, while it is so cunning that it will even find its way in among the nets which they have let lown, feast heartily upon the captive fish, and then quietly swim out again, often doing the same thing day after day for weeks together. And it is almost impossible to destroy it, for it seems to know perfectly well when its enemies are on the watch, and will only expose just its nostrils above the water when it comes up to the surface to lireathe. 
Very often, however, the fishermen consider that it is "unlucliy" to lill a seal, so that the animal is able to carry on its robberies without being interfered with.

The common seal, when fully grown, is about five feet long, and is yellowish-grey in colour, with a number of darlier spots sprinliled over the body and sides. It is very active indeed in the sea, and fairly active upon land, for although it cannot walls it will shuffle along over the beach at a really wonderful pace.

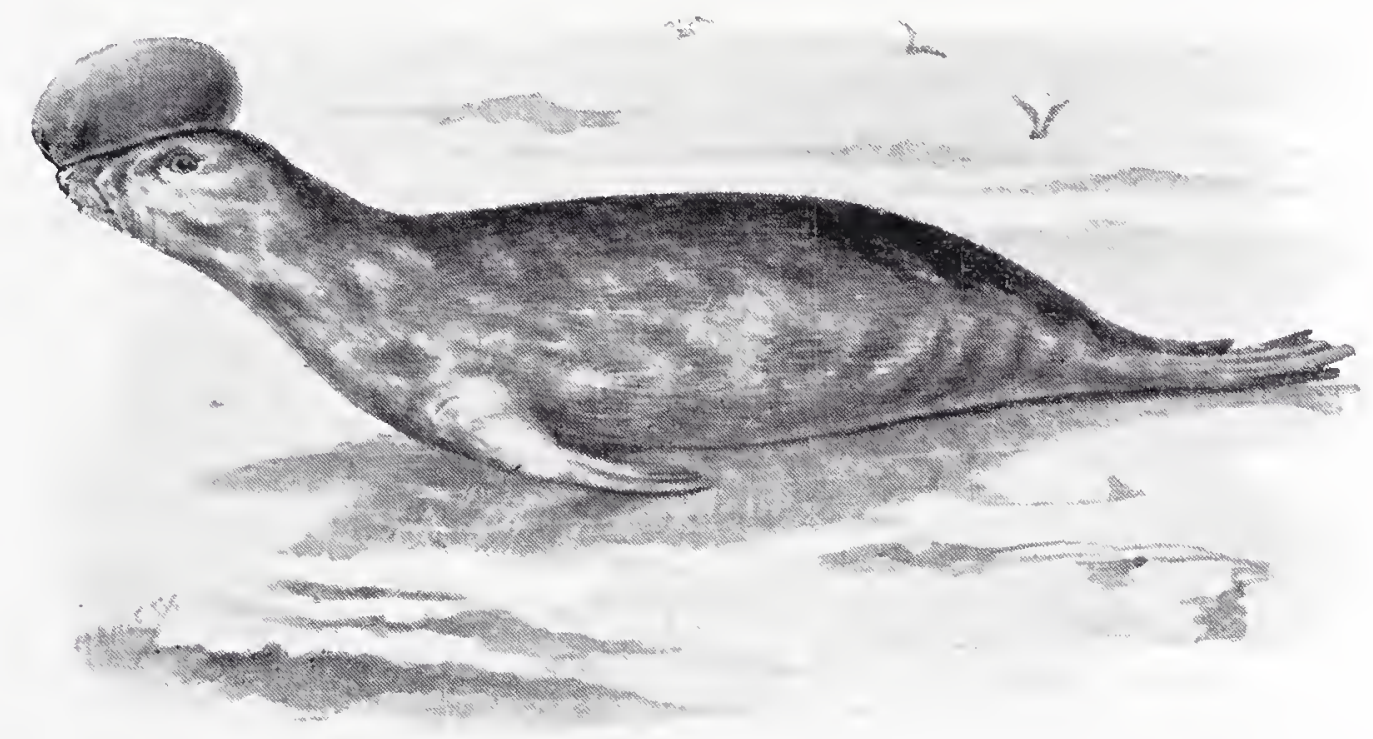

CRIETHE, SEML.

As it does so, it throws up a perfect shower of stones with its hinder flippers, and those who have chased it have often thought that it was doing so on purpose, and was actually throwing stones at them.

If this seal is caught when quite young and treated lindly, it soon becomes exceedingly tame. It has even been linown to live indoors, like a dog or a cat, and to lie for hours together basking in front of the fire. And in more than one case, when its owner wished to get rid of it, and put it lacki into the sea, it swam after him, crying so pitifully as he rowed away that he could not bear to leave it, and took it lome with him again after all.

The Sea Lions are so called because they are supposed to look very much like lions. But it is not easy to see the resemblance. Sometimes they are called Hair Seals, because there is no soft woolly under-fur beneath the coating of thick bristles, as there is in most of the animals belonging to this family. There are nearly always two or three sea lions to be? seen at the Zoo, and they are so intelligent and clever that the lieeper is able to teach them to perform all linds of triclis. A wooden platform has been built for them, with the upper end standing some feet above the surface of the water, and they are very fond of shuffling up this, lying at the end until a number of visitors have come close to the railings to look at them, and then diving 
into the water with a great splash, so as to send a perfect shower of spray over the spectators.

There are several different kinds of these animals, of which the Patagonian Sea Lion is perluaps the best known. It is found on both the Atlantic and the Pacific coasts of South America, and is rather more lion-like than its relations, since it has a crest of long hairs on the back of its neck, which really looks something like a mane. But you cannot see this crest when the animal is wet, as it then lies down flat upon the skin. The colour of the fur varies very much, for the old males are brown, the females are grey, and the young ones are a rich chocolate, which begins to grow paler when they are almost twelve months old.

One of these animals, which lived for a good many years in the \%oo, was exceedingly clever, for it would climb up and lown a ladder, with either its head or its tail first, fire off a gun, kiss its keeper, and catch fishes in its mouth if they were thrown to it, just as a dog will catch a piece of biscuit. And several others which have been liept in the gardens since have been quite as highly trained. Cleverest of all, however, were a party of sea lions which were established at the London IIppodrome in Igo2, for they would play a lind of football with their heads, catching the ball and passing it from one to the other in a most wonderful way, and scarcely ever missing it or making a mistalie. They would take part, too, in a musical performance, one playing the drum, another cymbals, a third the horn, and a fourth the bells, while their trainer stood in the middle and beat time. And one of them would actually balance an upright pole, with a fish on the top, on the tip of its nose, waddle across the stage, still holding the pole upright, and then suddenly jerk the pole aside, and catch the fish in its mouth as it fell.

But sea lions are rather expensive pets to keep, for they have such very large appetites. A single sea lion, indeed, will eat about twenty-five pounds weight of fish in a single day! And when one remembers that these seals are sometimes found in herds of hundreds of thousands, one would almost think that they must very soon devour all the fishes in the sea.

When fully grown this animal is about seven feet long.

The Fur Seals are sometimes known as Sea Bears, although they are not even as much like bears as the sea lions are like lions. 'They are destroyed in very great numbers for the salie of their skins, which have a thick coating of soft fur underneath the stiff outer bristles. These bristles, of comrse, have to be removed before the fur can be used, and this is done by shaving the inner surface of the slin away until their roots are cut off. 'They can then be pulled out without any difficulty, while the roots of the under fur, which are not nearly so deeply buried, are not hurt in the least. But the operation is not at 
all an easy one, and can only be performed by a highly-skilled worliman, and that is one reason why sealskin jackets are so expensive.

Another reason is that in almost every skin there are a number of "flaws," all of which have to be most carefully cut out, after which the holes have to be filled up in such a way as to leave no traces of the operation. Then the fur has to be cleaned, and combed and prepared and dyed, so that the garments which are made from it really cannot be sold except at a very high price.

These seals are not hunted in the sea, for they are such grood swimmers that it would be very difficult indeed to kill them. So during the greater part of the year they are allowed to live in peace. But during the breeding season they live upon land, lying upon certain parts of the coast in enormous

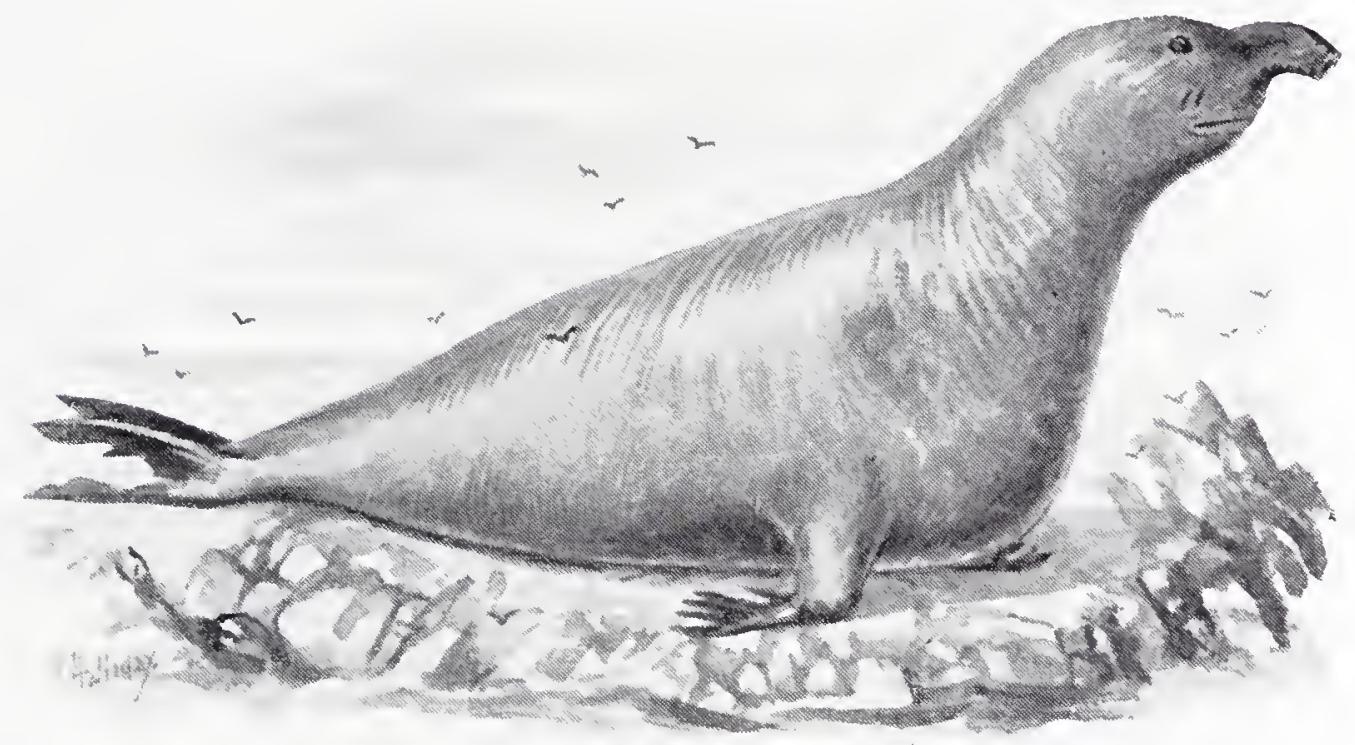

SEA ELEPHANT.

herds, which are mostly linown as "roolieries"; and the seal hunters visit these places, drive the young males to a distance from the rest, and there kill them by striling them on the head with a heavy club.

Such vast numbers of fur seals were destroyed in this way that at last it became necessary to protect them, for fear lest they should be entirely killed off. So only a certain number may now be killed in each year.

The best linown of the fur seals is the Northern Sea BEAR, which is found on both shores of the Northern Pacific. It visits the Prybilaff Islands in enormous numbers during the breeding season, and in the year 1872 it was estimated that there were at least three million of the animals on one island alone,

Another seal whose fur is very valuable is called the Crested Seal, because the adult male has a most singular crest upon the front part of the head. This crest consists of a lind of 
las of skin which lies just above the nose, and can be inflated with air at will. What its use may be in a state of nature is not known. But when the seal is hunted it is often of the areatest service, for the force of a blow which woukd otherwise have caused instant death, is so broken by the crest, that the animal is merely stunned for a few moments, and is able to slip into the water before the hunter returns to take off its skin.

This seal is rather a formidable animal when it is enraged, for it is ten or eleven feet long when fully grown, and

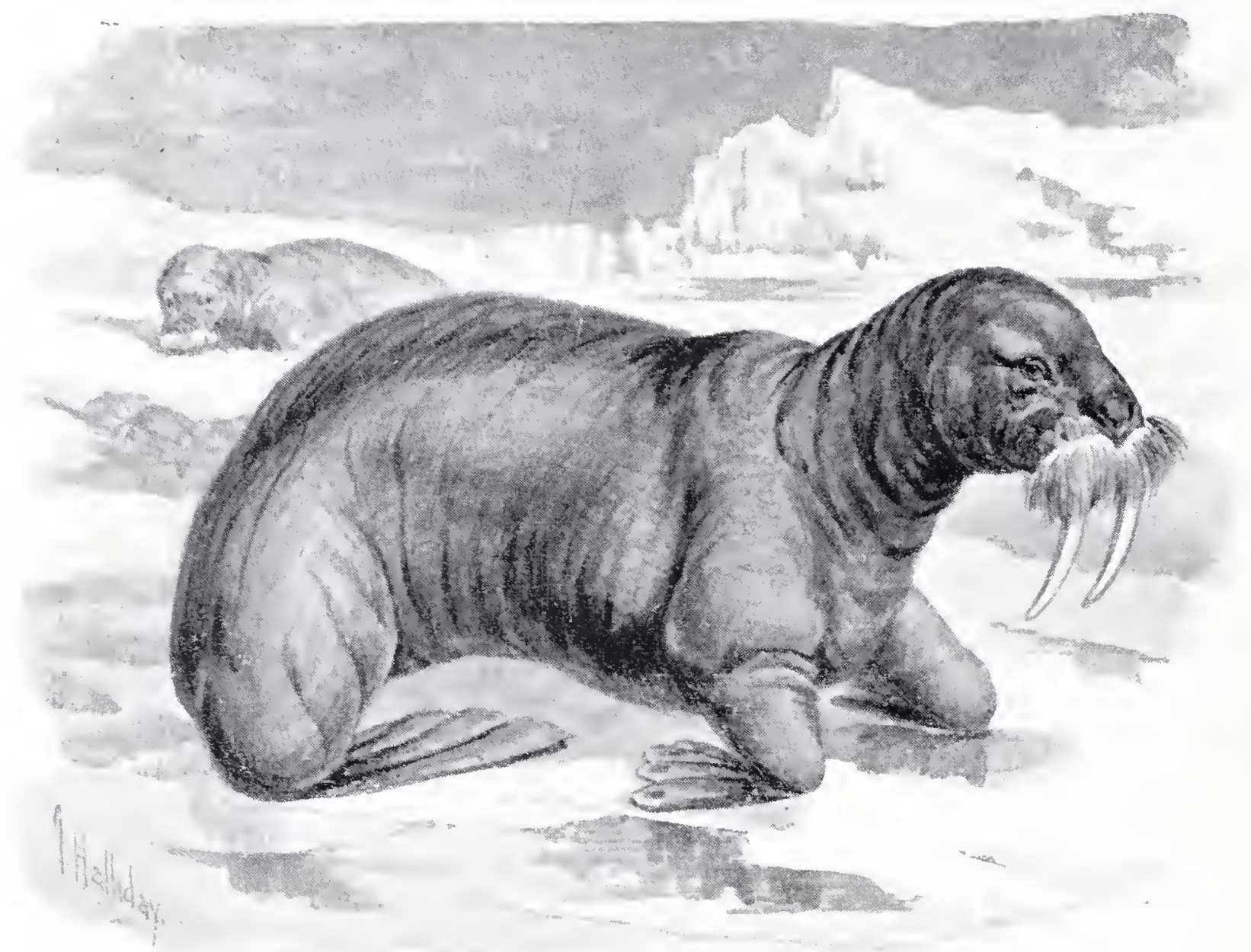

M.MRUS.

uses both its claws and its teeth in fighting. The male animals are very quarrelsome among themselves, and most desperate battles take place, the combatants screaming so loudly with rage as they attack one another, that they can be heard from a very long distance away.

The crested seal is chicfly found off the coast of Southern (ireenland, where large herds may sometimes be seen lying on the ice.

One of the biggest of all the seals is the great Sra Eimpran? which frequents the shores of many of the islands in 
the Intarctic Ocean. It owes its name, partly to its enomous size, the old males sometimes reaching to a length of eighteen or cren twenty feet, and partly to its rery curious trunk, which is sometimes as much as a foot long. In the females and the young animals this trunk is vanting, and even in the male it is seldom seen unless the animal is excited, when it can be blown out very much like the bladder-like crest of the crested seal.

The fur of the sea elephant is much too coarse to be of any great value. But its skin can be made into most excellent leather, while the thick coat of lubber which lies beneath it furnishes large quantities of most useful oil. The consequence is that the animal has been greatly persecuted, and is now comparatively scarce even in districts where it was once exceedingly plentiful. It is not nearly so fierce as the crested seal, and almost always takes to flight if it is attacked, its huge body quivering like a vast mass of jelly as it shuffles awkwardly along over the beach. But the males fight most fiercely with one another, inflicting really terible wounds by means of their tusklike teetl.

The strangest of all the seals, howerer, is the MALKLs, whose upper "eye" teeth really do leserve to be called luslis, since they are sometimes as much as two feet long.

This animal is found only in the Northern parts of the Allantic and Pacific Oceans, and is not very often seen outside the Arctic Circle. Formerly, however, it was much more widely distributed, and was even seen more than once off the coasts of Scotland. But it luas been so persecuted by the linnters that it is not nearly so plentiful as it used to be, and lias quite disappeared from many districts where once it was fornd in numbers.

The walrus is not quite so large as the sea elephant, nevertheless, it is a very big animal, for a fully-grown male will often measure twelve or thirteen feet in length, and will weigh very nearly a ton. It uses its tusks for all sorts of different purposes. When it wants to climb upon an ice-floe, for example, it will dis them deeply into the ice, and so obtain "purchase" while it raises its huge body out of the water. They are very formidable weapons, too, and the animal can strike so quiclily with them, both sideways and downwards, that it is not at all easy to avoid their stroke. Then they are very useful in olstaining food. If a walrus finds the body of a dead whale, it will cut off huge lumps of the flesh by means of its tuslis; and very often it will dig in the sandy mud with them for mussels and cockles. 'The consequence is that the tusks are frequently broken, while they are nearly always very much worn at the tips.

The name "walrus" is a corruption of "whale-liorse." "The animal is sometimes known as the "Sea Horse," and also as the Morse. 


\section{CHAPTER XII.}

\section{THE ITHALE TRIBL.}

THE Whales are more thoroughly creatures of the water than even the seals, for they never come upon dry land at all, even during the breeding season. Indeed, if a whale is unfortunate enough to be thrown upon the shore by a great wave, and left stranded, it cannot possibly make its way back into the sea, but is obliged to lie there helplessly until it dies.

Yet we must not think that these giant creatures are fishes; for they are as truly mammals as the seals are. Their blood is hot, and is driven through the body by a heart made up of four chambers, instead of only two. They breathe by means of nostrils and lungs, and not by means of gills. And besides that they suckle their young, just as all other mammals do.

Then, once more, if you look at the body of a whale, you will see that its tail is quite different from that of a fish. The tail of a fish is upright, but that of a whale is set cross-wise. So that there is only one respect in which whales are really lilie fishes, and that is the general shape of the body.

These huge animals fall naturally into two families, the first consisting of those which have teeth, and the other of those which have whalebone, or "baleen" instead. But in many ways the members of both these families are alilie.

All whales, for example, breathe in a very curious way. No doubt you have heard of the "spouting" of these animals, and perhaps you may have seen a picture of a whale lying on the surface of the sea, and throwing up a great column of water from its nostrils, or "blow-holes." These pictures, however, are rather exaggerated, for what really happens is this: a whale, as of course you know, often remains under water for a very long time, and when at last it rises to the surface, the air in its lungs is heavily laden with moisture. When this air is discharged through the "blow-holes" into the cold atmosphere the moisture condenses at once into a kind of misty spray, just as that in our own breath does in very cold weather. This is what one sees when a whale is "spouting," although as the animal sometimes begins to blow while its nostrils are still beneath the surface, a small quantity of sea water may, perhaps, be thrown up too.

A whale, if it is not disturbed, will often "blow" fifty or sixty times in succession. Let me try to explain why it does so. If you try to hold your breath, you will find that it is very 


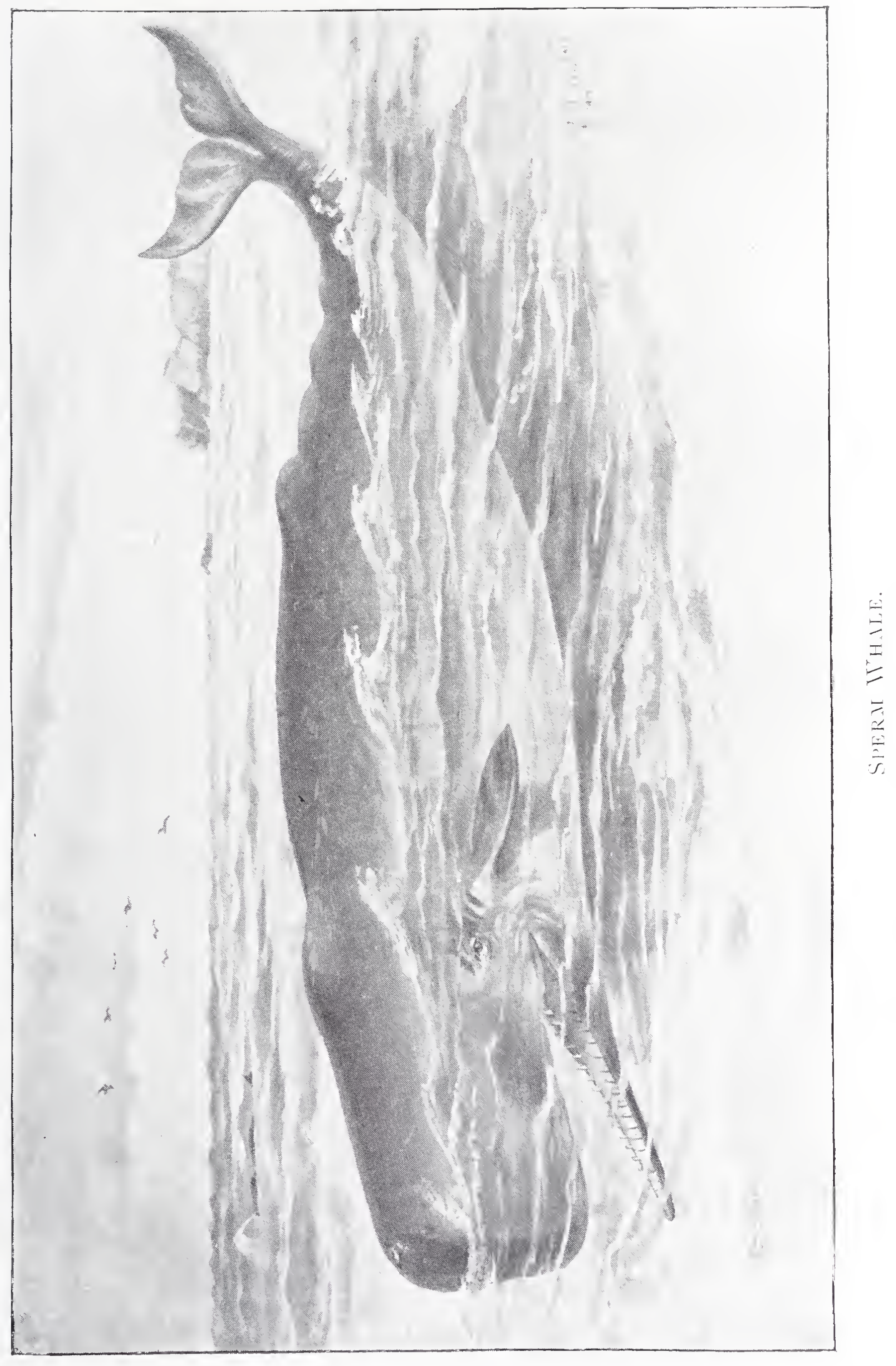


difficult to do so for more than three-quarters of a minute. But if, before you make the attempt, you get rid of as much of the air in your lungs as you possibly can, draw in a very deep breath and get rid of that, and then repeat the process about half a dozen times, you will find that you can hold your breath quite easily for at least a minute and a half. The reason is that by breathing so often and so deeply you have purified all the blood in your body, instead of having, as usual, a very large quantity which has done its work, and requires to be refreshed in the lungs before it can be of any fuirther use.

Now the whale "spouts" fifty or sixty times in succession for just the same reason. It is taking a series of deep breaths so that it may purify all the blood in its body, and be able to remain under water for as long a time as possible without having to rise to the surface for air. And, besides this, there is a most wonderful arrangement in its body which enables it to stay below for very much longer than would otherwise be possible. Inside its chest it has a sort of blood-cistern, so to speak, consisting of a number of large vessels, which contain a great quantity of extra blood, besides that which is circulating through the body. This blood, also, is purified when the whale "spouts." Then, when the animal has remained under water for some little time, and begins to feel the want of air, it does not rise to the surface at once, in order to breathe, but just pumps some of the extra blood from this curious cistern into its veins and arteries, to take the place of that which is used up and requires to be purified. This it can do over and over again until all the extra blood-supply is used up too, when it is obliged to rise and "spout."

As a general rule a whale spends from ten to twelve minutes in "spouting," and can then remain under water, if necessary, for considerably more than an hour.

It is owing to this singular method of breathing that whales can be so easily lilled. The object of the hunters is simply to drive them below before they have finished "spouting." They do this again and again, and the consequence is that the poor animal soon becomes completely exhausted and falls an easy prey.

You remember, don't you, how the seals are protected from cold, partly by their thick and oily fur, and partly by the layer of fat which lies just underneath the skin. Well, the whales are protected in much the same way. They have no fur, of course; but the layer of fat, which we call blubber, is always several inches in thicliness, and is sometimes as much as two feet; so that the whale is never chilled by living in the water, even when it has to make its way through floating ice.

This blubber has another use as well. When the whale dives to a great depth-and sometimes it sinks nearly half a mile beneath the surface of the sea-the pressure on its body becomes 
enormously great, because of the weight of the water above it. If you were to dive to half that depth you would die. But the blubber of the whale is so elastic that it resists the pressure just as a great thick sheet of indiarubber would, so that the animal does not suffer from it in the very least.

Sometimes you see pictures in which whales are drawn with very big eyes, very long ears, and perhaps even with their tongues hanging out of their mouths. Now such pictures are drawn by artists who know nothing about whales, for the eyes of these animals are quite small, their outward cars are merely little

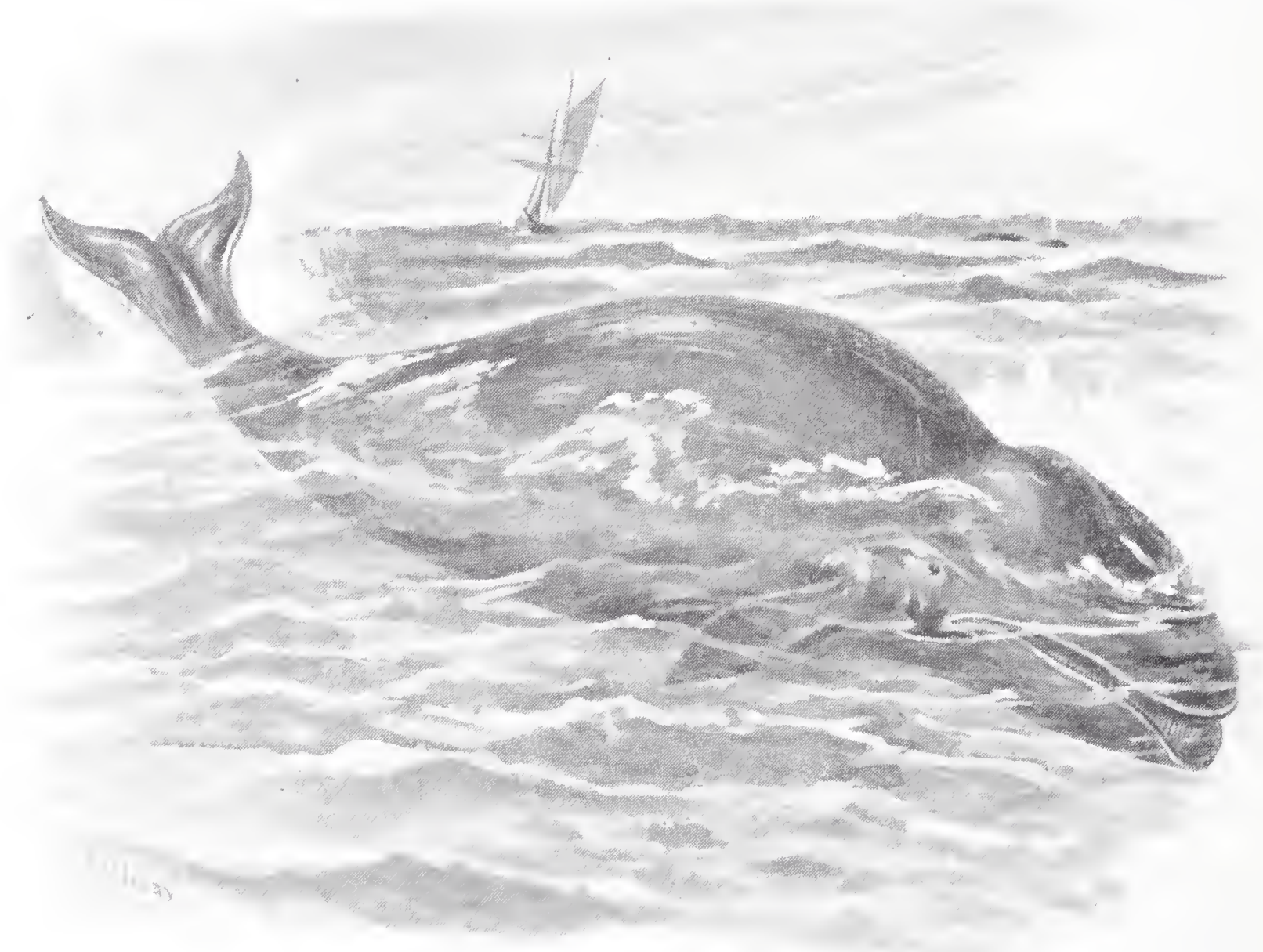

GREENIANT MHARE.

holes in the skin, closing ly means of self-acting valves like those of the seals, and the tongue cannot be poked out of the mouth at all.

Now let us learn something about the different linds of whales.

Irirst, then, come the toothed whales or Donticotes. Is an cxample of these we will take the famous Srerar, or Spermaceti whale, which is also known as the Cachalot.

This whale has nearly all its teeth in the lower jaw, the upper one only having a very short row of small teeth on either side. The lower teeth are five or six inches long, and fit into pits in the upper jaw when the mouth is closed. 'These teeth are composed of most heautiful ivory, and were formerly valued 
so highly by the natives of the South Sea Islands, that more than once a tribe has actually gone to war with another tribe simply to obtain possession of a single whale's tooth.

Now that it is so persecuted, apparently the sperm whale loes not grow to so great a size as it did in days gone by. Y'et it is a very big animal indeed, for a fully-grown male will attain to a length of sixty or eren seventy feet, while even a baby whale is from eleven to fourteen feet long, or as big as a bigr walrus. And, strange to say, the head is almost as large as the hody and tail put together. This is chiefly due to the fact that there is a great cavity in the sliull, which contains the valuable substance which we call "spermaceti." When one of these whales is killed, the head is cut off, and a kind of well is dug in the forehead, from which the spermaceti is drawn to the

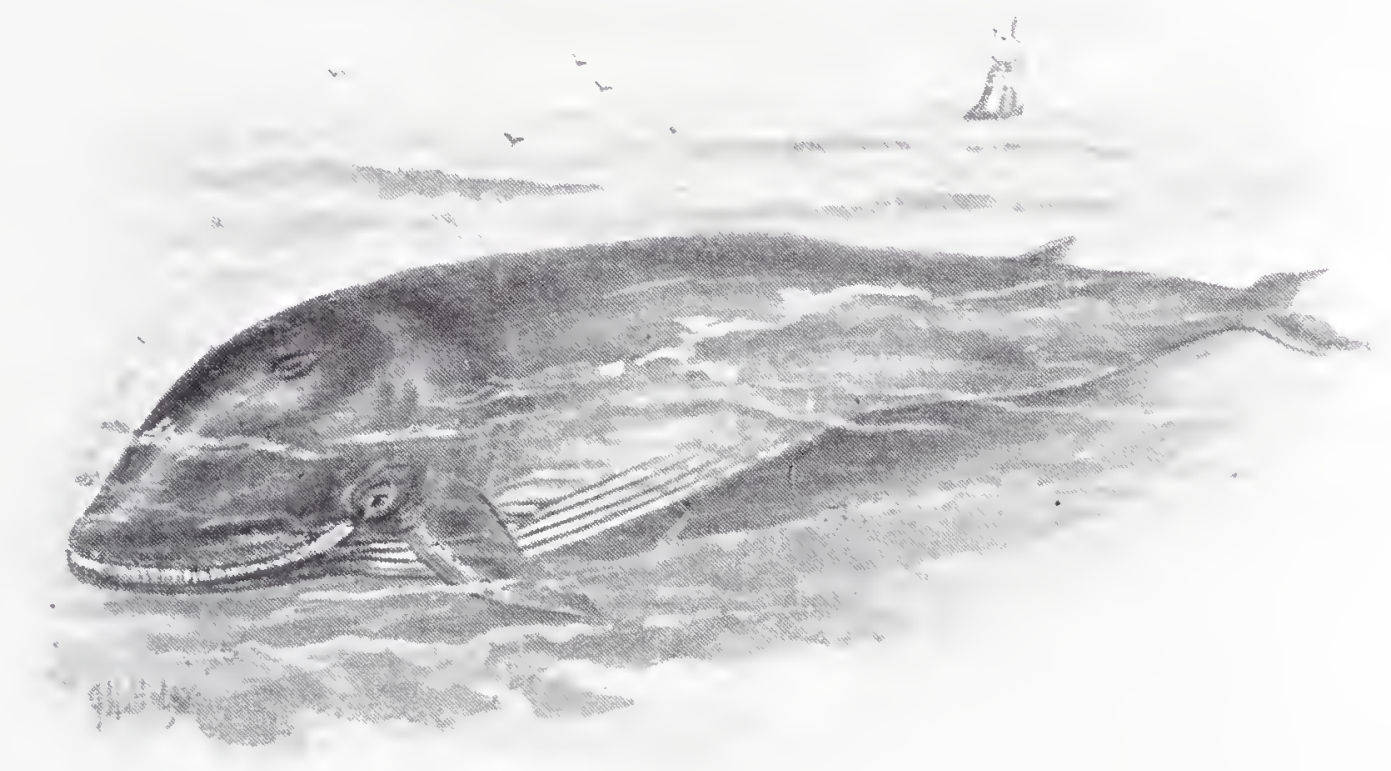

RORQLAL.

surface in bucliets, as much as thirty barrels heing sometimes taken from a single animal.

Besides this, the blubber yields a large quantity of very valuable oil, which burns with a much clearer and stronger light than ordinary whale oil. And sometimes a most curious substance cailed "ambergris" is found in its body. It is used in making certain kinds of scent, and is worth about f I per ounce, although no less than fifty pounds of it have once or twice heen taken from a single whale.

Sperm whales are generally seen in companies, which are known as "schools." In olden days there were sometimes as many as a couple of hundred whales in one of these "schools." But so many of the great creatures have been liilled by whalers that it is now quite the exception to see more than four or five together. These whales are very playful creatures, and may often he 
seen gambolling on the surface of the sea, and now and then "breaching," or leaping completely out of the water and falling back again with a tremendous splash. They feed chiefly upon the great cuttles, or squids, which are so plentiful in some parts of the ocean, but also devour large numbers of cod and other fishes. But how they manage to catch these fishes nobody quite seems to know.

These whales were formerly liunted by means of a small boat, in the bow of which stood a man with a long spear, or "harpoon," in his hand, attached to an enormous coil of rope. As soon as this was hurled at a whale the boat was backed, so as to escape the stroke of its tail, and the whale would then "sound," or dive to the depth of perhaps three-quarters of a mile. As sjon as he rose he was driven down again, as already described, before he had had time to finish "spouting," and at last, when quite exhausted, was killed by means of a very long and sharply-edged lance. Nowadays, however, the harpoon is generally fired from the ship by means of a gun, and as a charge of dynamite or gum-cotton is placed in the head, which explodes as soon as the weapon enters the body of the whale, such a severe wound is caused that the animal very soon dies.

Sometimes one hears of whales being seen off our own British shores. 'These are nearly always Bottuenose IVhales, which are so called because their muzzles are produced into leaks shaped somewhat like bottles. Although they belong to the toothed whales they only have two teeth in the lower jaw, and even these are so small that they are completely buried in the gum.

By the side of the cachalct the bottlenose whale seems quite a small animal, for even the fully-grown male seldom exceeds thirty feet in length, while the female is quite six feet shorter. It yields, on an average, about two hundredweight of spermaceti and a couple of tons of oil. Its colour, strange to say, is continually changing all through its life, for the young animals are blacli above and the older ones brown, which grows lighter and lighter as time goes on, till at last it becomes almost yellow.

These whales seem to be very sympathetic creatures, for if one of them is wounded, its companions generally sivim round and round it, and will even allow themselves to be liilled one after the other rather than take to flight. But they are also rather stupid animals, for if they happen to find themselves near the coast they seldom seem to realise that they can easily escape by turning round and swimming out to sea, but leap and tumble about in a state of great terror till at last a big wave comes and throws them up on the beach.

The members of the other great group of these animals are called Whatebone IVhates, because they have whalebone in their mouths instead of teeth. 
Of course this substance is not really bone at all. It consists of a kind of horny material which grows all round the upper jaw in a series of flattened plates, which are usually very long, and hang downwards from the edge of the palate. Each of these plates, at the tip, is broken up into a sort of hair-like fringe; so that when the jaws are partly closed there is a kind of sieve, or strainer, between them, through which everything must pass that goes in or out of the mouth.

This sieve is used in feeding. It seems strange that an animal so huge as a whale should feed on some of the smallest

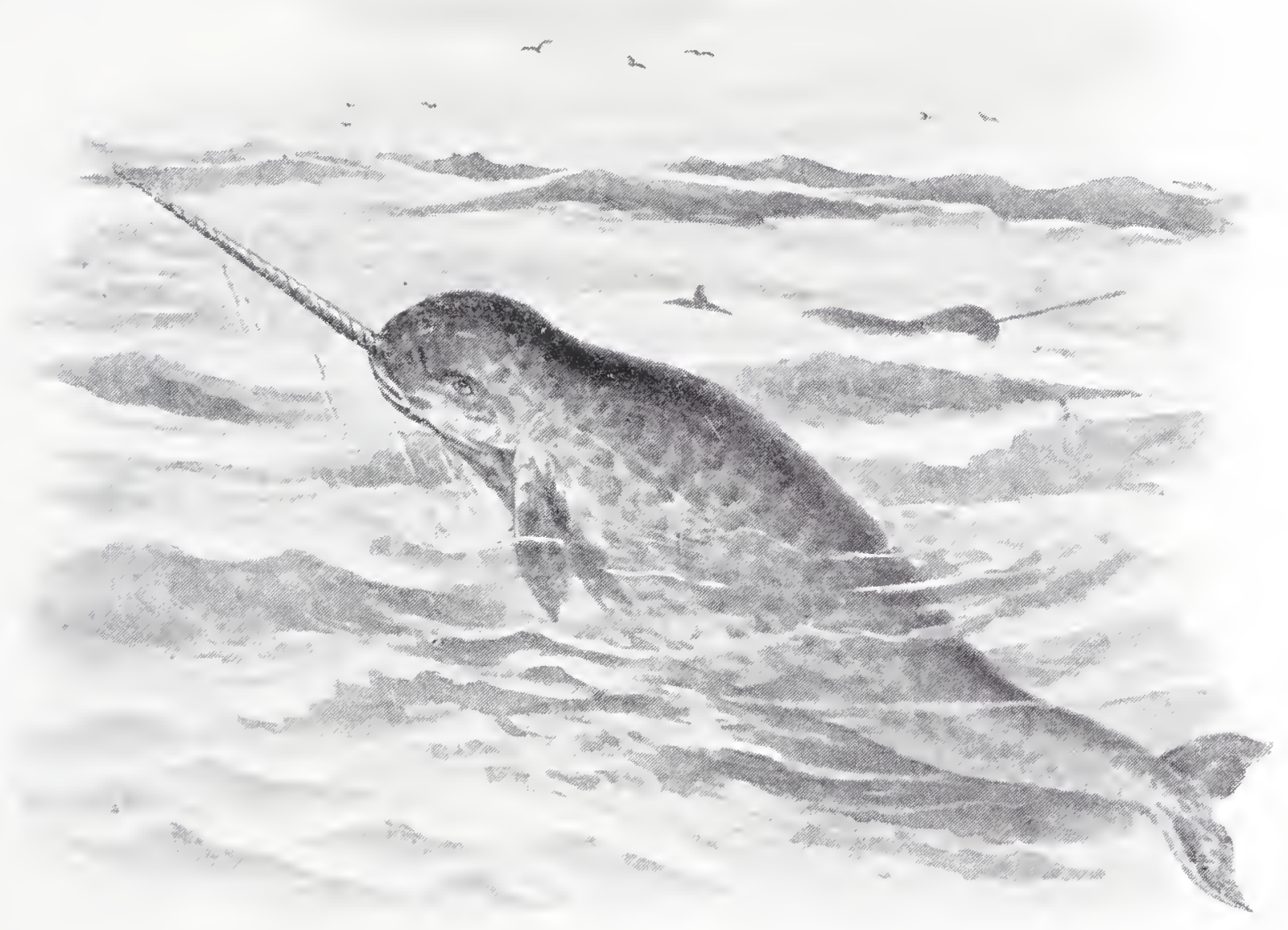

NARWHAL.

creatures which live in the sea. I'et such is the case, for the throats of the whalebone whales are so narrow that one of these animals would almost certainly be choled if it tried to swallow a herring. So these whales live upon very small jelly-fishes, and the young of shrimps, prawns, tiny crabs, etc., which often swim about in such vast shoals that for miles and miles the sea is quite alive with them. When the whale meets with one of these shoals it opens its mouth wide and swims through it. Then it partly closes its mouth, and squirts out the water which it has taken in through the whale-bone strainer, the little animals, of course, remaining behind. These are then swallowed, a few 
thousand at a gulp, and the whale opens its mouth and repeats the operation over and over again, until its enormous appetite is satisfied.

Most of the whalebone which we use is ol,tained from the Grentand Winate, which is found in the northern seas. This animal is from fifty to sixty feet long when fully grown, and the baleen plates are often ten or even twelve feet in length, while there are nearly four hundred of them on each side of the upper jaw. In a large whale these plates weigh more than a ton, and are worth at least 63,000 . Then from I 30 to $\mathrm{I} 50$ harrels of oil will be olstained from its lolubber; so that a lice Greenland whale is a very valuahle animal indeed.

But whales of this size are now very rarely met with, and there seems to be some danger that before many years have passed away these giant creatures will be almost extinct.

The Rorquals are sometimes known as Fin Whales, because they have an upright fin on the hinder part of the back. They are not so valuable as the Greenland whale, lecause their haleen is of inferior quality, and is very much shorter, while their hlubber (loes not yield nearly so much oil, and they swim with such speed that they are very much harder to catch.

The Commox Roroual grows to a length of alout sixty or sixty-five feet, and is found throughout all the northern seas, and occasionally eren in the Mediterranean. Sometimes it risits our British coasts, for two dead examples were found floating in the Channel in I $88_{5}$, while another was stranded at Skegness two years later. It is a solitary animal as a rule, but "schools" of from ten to fifteen individuals are sometimes met with, and may he seen leaping into the air, and rolling and tumbling about in the water, as though they were having a game of play together.

The rorqual feeds partly upon the small creatures which it captures hy means of its whalebone "strainer," and partly upon fishes. How rast its appetite is you can judge from the fact that no less than six hundred large codfish have heen found in the stomach of one of these animals, together with a number of pilchards. Sometimes a rorqual will come quite near the coast, and remain in a fishing-ground for weeks together, and as it swallows several boatloads of fishes every day, it is scarcely necessary to say that the fishermen are not at all pleased to see it.

There is another lind of whale, called the LEsser ROROUAL, which only grows to the length of about five-and-twenty or thirty feet. It is an occasional visitor to the British coasts, but is commoner off the shores of Norway, and commoner still in North American waters, where it is generally known as the Sharpnosed Finner. It is a rery playful animal, and is said sometimes to gambol round and round a ship for miles, now and then diving inderneath it on one side and coming np on the other.

Next we come to the Dolphin family, which includes the 
Narwhal, the Grampuses, and the Porpoises, as well as the true Dolphins.

The Narwha is a very curious animal indeed, for the male has a very long straight tusk projecting from one side of its upper jaw. This tusk is often as much as seven or eight feet in length, and the ivory of which it is made is twisted round and round in a spiral from base to tip. In olden days this tusk was thought to be the horn of the unicorn, and the narwhal is often linown as the Sea Unicorn in consequence.

In reality, this tusk is the left-hand upper "eye" tooth of the animal, that on the right-hand side being very small indeed, and completely buried in the bone of the jaw. Just now and then, however, both teeth are developed, and a narwhal was once killed which had one tusk seven feet five inches long, and the

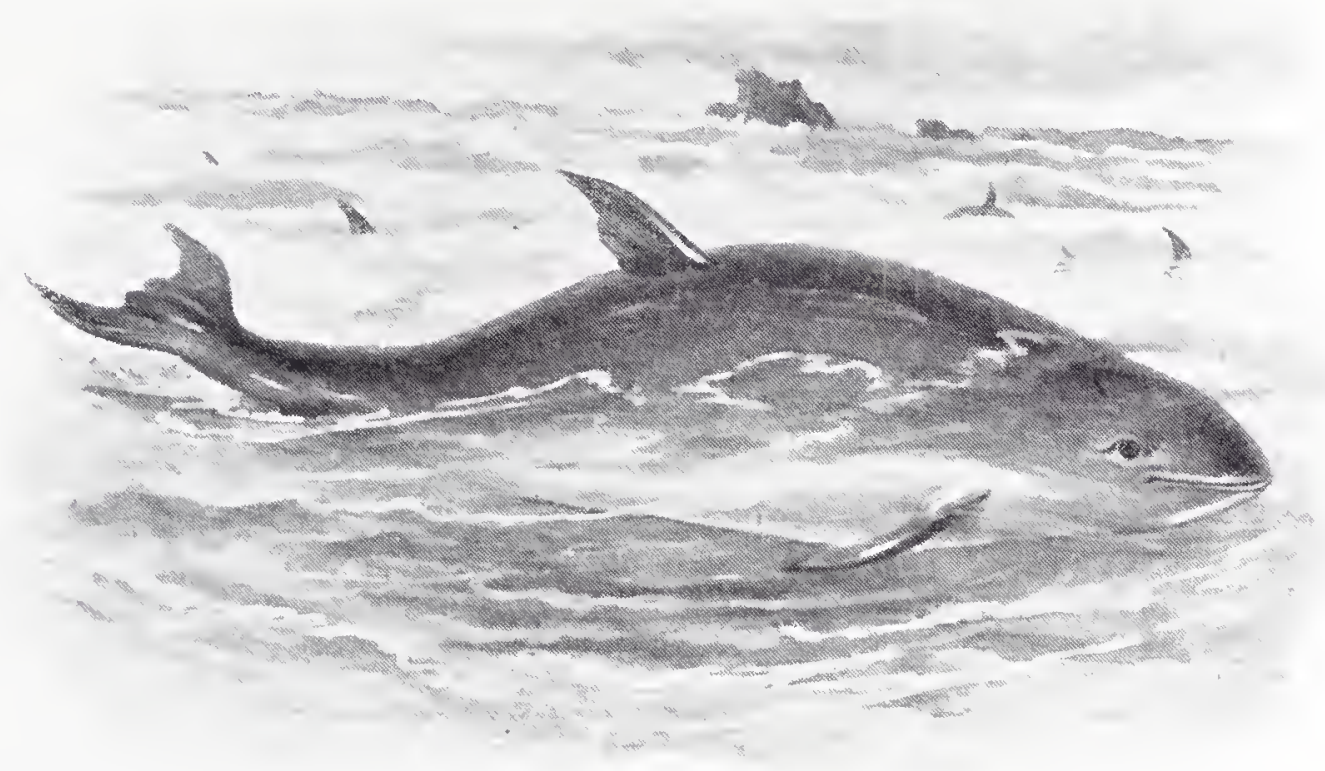

PORPOISL.

other seven feet. 'There are no other teeth in the mouth, and the female animal has no tusks at all.

Now what is the use of this singular weapon?

Well, two or three answers have been given to that question. Some people have supposed, for example, that it is used in spearing fish, or in digging up buried molluscs from the mud at the bottom of the sea. But the female narwhals require food just as much as the males do; how is it that they are not provided with tusks also?

Other people have thought that when the winter is very severe indeed, and the ice on the surface of the sea is very thick, the animal could bore a hole through it with its tusk, and so be able to breathe. But then again, female narwhals require air just as they require food. So this suggestion will not do either. And the only explanation which we can really give is that 
the narwhal's tusk is a weapon used in fighting, just like the antlers of the male deer. At any rate, narwhals have several times been seen as they were taking part in a lind of makebelieve battle, and striking and clashing their tusks together just as though they were fencing with swords. And when they are fighting in earnest they must be able to use their long spears with terrible effect, for several times a narwhal has charged a ship, and driven its tusk so deeply into her timbers that it was quite unable to withdraw it.

The ivory of which this weapon is made is of very fine quality. But as the tusk is hollow for the greater part of its length it is not very valuable.

Narwhals are only found in the half-frozen seas of the far north, where they are sometimes seen swimming side by side together in large companies. They grow to a length of from twelve to sixteen feet, and are dark grey in colour on the upper part of the body, and white underneath, the hack and sides heing more or less mottled with grey.

The White Whale, or Beluga, is something like a large narwhal without a tusk, and is also a dweller in the northern seas. But it often ascends the larger rivers for hundreds of miles in search of fish. Just now and then it has been litled off the coasts of Scotland, and one example lived for quite a long time in the Firth of Forth, going up the river day after day as the tide came in, and always retreating as it began to fall. The fishermen were very anxious to lill it, because of the quantities of fish which it devoured. But it was so quick and active that it eluded them over and over again, and three whole months passed away before at last they succeeded.

In one or two of the great rivers of North America white whales are regularly hunted, the animals being first driven up the stream, and then intercepted by nets as they return. They yield a large quantity of very pure oil, and the "porpoise-hide," which is used so largely in making boots and shoes, is in reality prepared from their skins.

The true Porpoise, or Sea Hog, is much more widely distributed, and you may often see a herd of these animals tumbling and gambolling on the surface of the sea quite close to our own coasts. They will ascend tidal rivers too. I once saw quite a large number in the Thames just above Gravesend, and they have several times been known to swim up as far as London Bridge.

Porpoises have a most curious way of swimming, for they travel along by a series of bounds, first of all leaping almost out of the water, and then diving underneath it. Then a number of them are moving along in this way one behind the other, as they very often do, they look from a little distance just like an enormous snake winding its way through the water, and no 
doubt have given rise to some of the tales about the great sea serpent.

A herd of porpoises will frequently follow a sailing ship for days, sometimes, apparently, out of pure curiosity, and sometimes in the hope of picking up something eatable among the rubbish that is thrown overboard. But they are very much afraid of steamers, and always keep at a very respectful distance from them. They feed chiefly upon fish, and are so quick and active that even the salmon cannot escape from them, while they will follow up shoals of mackerel and herrings and destroy them in enormous numbers.

When fully grown the porpoise is rather more than five feet long. The upper part of the body is almost black in colour, becoming paler on the sides, while the lower surface is almost pure white.

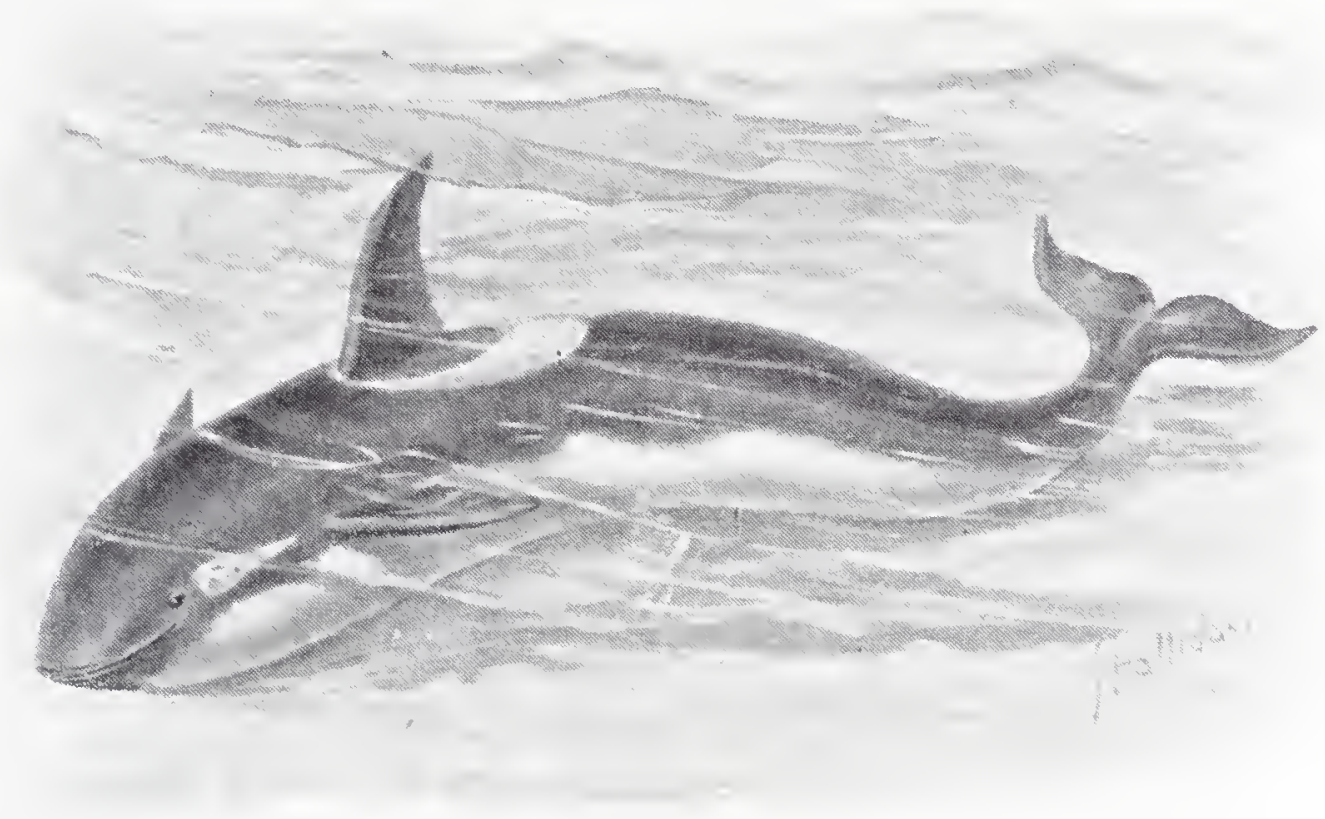

GRAMPLS.

The largest and fiercest of all the members of the Dolphin family is undoubtedly the Granpus, which is also known as the Killer Whale. It often reaches a length of twenty feet, or even more, and is so savage and voracious that it has sometimes been called the Wolf of the Sea. One of these animals was once found floating on the surface of the sea, choked by a seal which it had attempted to swallow; and when its body was opened, no less than fourteen other seals and thirteen porpoises were taken from its stomach.

Three or four grampuses will often combine, too, in an attack upon even a whalebone whale, leaping upon it again and again, and striking terrific blows upon its body with their tails, hanging upon its lips like so many bull-dogs, biting and tearing its flesh, and often actually lilling it, in spite of its enormous size. The whale seems perfectly terrified by the onslaught of the 
ferocious creatures, and sometimes scarcely attempts to resist them, apparently knowing quite well that they are sure to be victorious in the end.

The grampus is most plentiful in the northern seas, but is found now and then in almost all parts of the ocean. It occasionally visits the British shores, and on one occasion no less than three examples were seen swimming about in the Thames between Battersea and Chelsea Bridges, where they remained for several hours before they turned and swam back again to the sea. Ind once a living specimen was exhibited in the Brighton Aquarium, and did very well for some little time. But one day it got its snout jammed in the rock-work in the botton of its tank, so that it could not rise to the surface to "spout." And when the keeper discovered what had happened to it the poor creature was clead.

Almost as large as the grampus, but not nearly so savage, is the BLAckish, which is so called on account of its colour. It is found in great shoals, generally consisting of two or three hundred animals, and often of a great many more, which are always under the guidance of a single leader. Wherever he goes they will always follow, and they are such stupid creatures that if he swims into shallow water and casts himself ashore, ther will all swim after him and fling themselves on the beach also. In Iceland, and also in the Faroe Islands, large numbers of them are often lisled, the fishermen arranging their boats in a semicircle between the shoal and the deep sea, and then driving them forwards till they strand themselves upon the shore in their efforts to escape. And large herds have also been driven ashore in the Orkneys and the Shetlands, and even in the Firth of Forth.

This animal is also linown by the rather curious name of Caaing Whale.

There are two groups of Dolphins, the first of which contains three animals which live in rivers, and therefore are generally called Fresh-water Dolphins.

The only one of these that I can mention is the GangeTic DOLPIIN, which inhabits the great rivers of India. Its chief peculiarity is that it is almost totally blind. Although the animal grows to the length of seven or eight feet, and is bulliy in proportion, yet its eyeballs are no larger than peas, while the nerves of sight are so imperfect that it is quite possible that it may not be able to see at all. This is no deprivation to it, however, for the rivers in which it lives are always so thick with mud that even if it had properly developed eyes it would be quite unahle to use them.

The Gangetic dolphin is very seldom seen, lecause when it comes up to breathe, it only raises just the blow-holes above the surface of the water. For the same reason, we linow very little indeed ahout its hahits. But it seems to feed on fresh-water 
shrimps and molluscs, and also on certain fishes which lic halfburied in the mud at the bottom of the water, rooting about for them with its snout after the manner of a pig.

This animal is often known as the Susu.

Of the Sea Dolphins we can only notice two.

The first of these is the Common Dolphin, which is found in great numbers in almost all parts of the temperate and tropical seas. Now and then it is seen off the southern coasts of England. It generally lives in herds, which will follow ships for hours

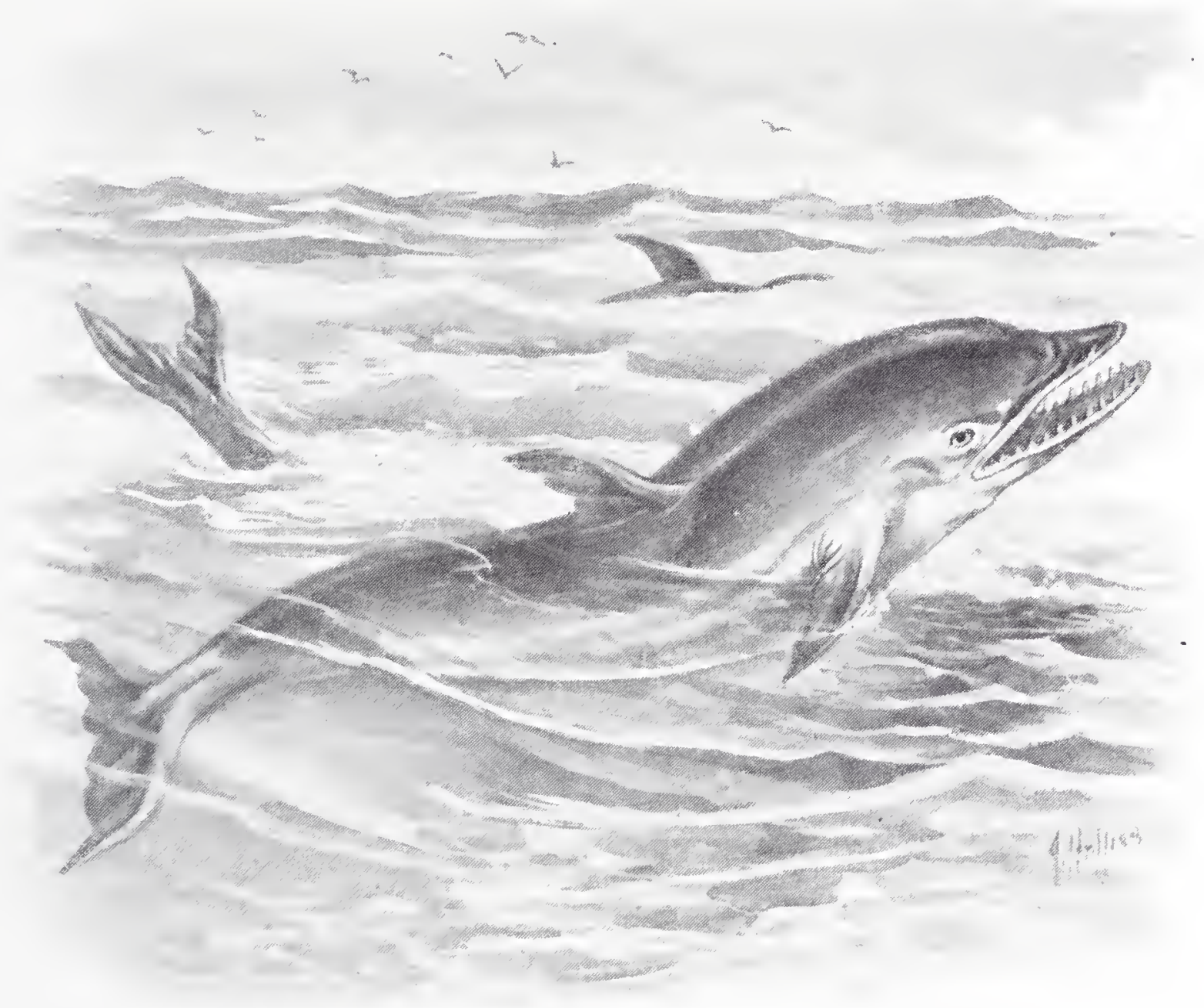

COMALON DOHPHIN.

together, leaping and gambolling and playing about on the surface of the sea, and yet lieeping pace with the vessel without the least apparent effort. It feeds on fishes, and in order to capture them and hold them firmly it has no less than one hundred and ninety teeth, which are arranged in such a way that when the mouth is closed the upper and lower ones fit in between one another like those of a steel trap, and hold the prey in a grip from which there is no escape.

A fully-grown dolphin is usually about seren feet long, but specimens are occasionally found which are very much larger. 
The colour is glossy black above, and almost pure white on the lower parts of the body.

The Bottle-nosed Dolphin is a rather smaller animal, with a shorter and more pointed beak which is shaped rather like the neck of a bottle, and is purple black above and greyish white below. It has once or twice been met with off the British coasts, but is most abundant near the shores of North Carolina.

There is just one other family of water mammals which it will be convenient to mention here, although they do not really belong to the Whale Tribe. These are the very curious creatures known as Sirenia, the best-known of them being the Manatee and tl,e Dugong.

Of course, you have heard of "mermaids," those imaginary creatures of the sea, which were supposed in days of old to

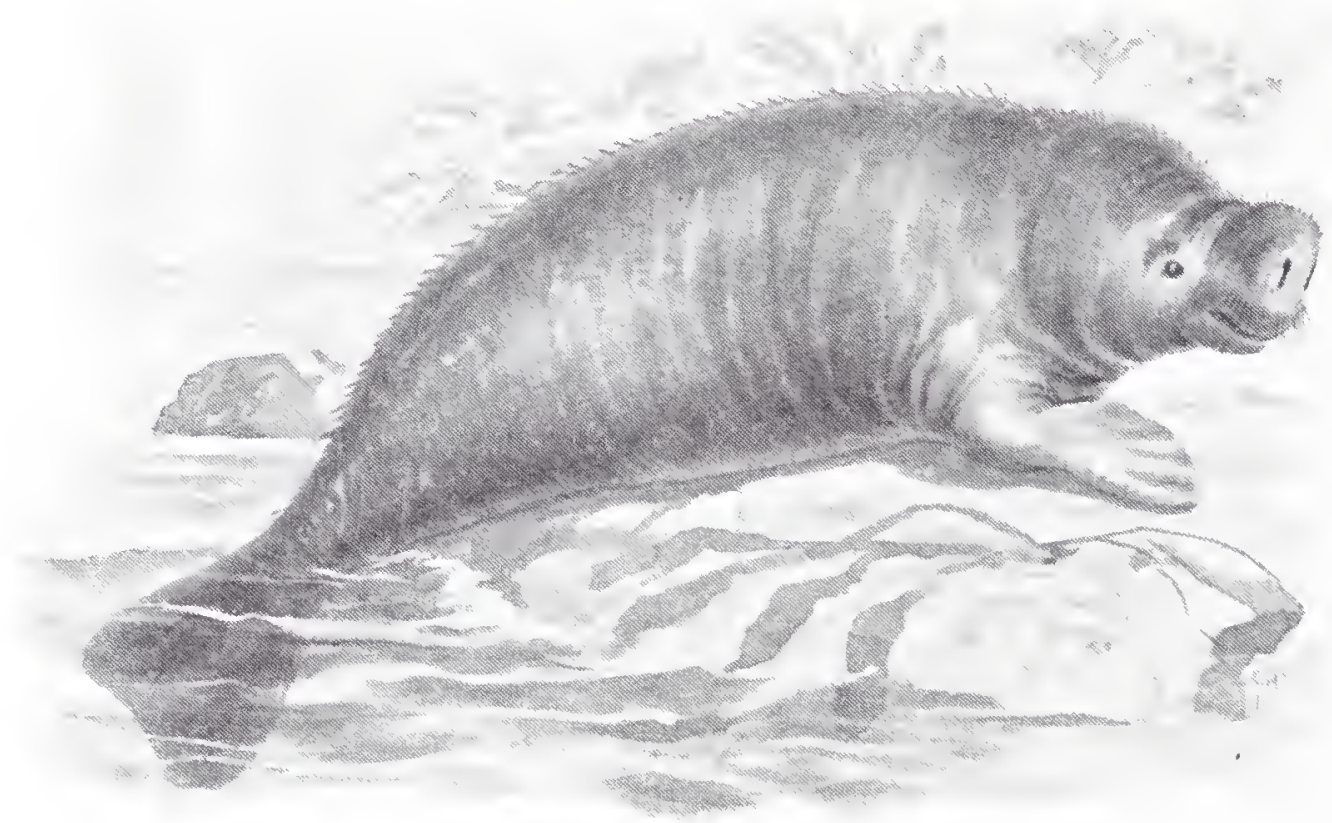

MANITEE.

combine the lead and body of a woman with the tail of a fish. Well, very likely these stories were told in the first place by some traveller who had seen a manatee, for the animal has a queer way of raising its lead and the upper part of its body almost upright out of the water and cuddling its little one in its flippers, so that from a little distance it really looks something like a human being with a child. But at close quarters the comparison would not be a very flattering one, for there is a lind of disc-like swelling at the end of the snout, and the slim is black and coarse, and wrinkled like that of an elephant.

Manatees are found on the west coast of Africa, and also on the shores of South America, living near the mouths of the larger rivers. They never seem to leave the water of their own accord, and if by any chance they find themselves upon dry land, they are perfectly helpless, and can only roll over and over. Two 
or three examples have been brought to this country, one of which lived for some little time in the Zoo. It was quite a small animal, and had to be fed with milk out of a baby's bottle, while the keeper nursed it upon his knees. When it grew a little higger it became very playful, and would tumble and roll about in its tank almost like a dolphin or a porpoise. And more than once it even succeeded in knocking its keeper into the water.

Another of these animals, which was caught at the mouth of the Essequibo River, was brought to the Royal Aquarium in London in 1878 , where it lived for no less than sixteen months. It was about eight feet long, and its tail was so enormously powerful that everyone was afraid that the sides of its tank would be broken in by its tremendous blows.

Its appetite was remarliably good, for it used to eat no less than eighty-four pounds of lettuces every day.

The dugong is found on the east coast of Africa, and also on the coasts of Mauritius, Ceylon, the islands of the Indian Archipelago, and IVestern Australia. In many respects it is very much like the manatee. But it has a forked tail instead of a rourded one, and its body is bluish black above and whitish below. It lives in shallow water near the mouths of rivers, feeds upon various water plants, and is said to be so affectionate that if one of a pair is killed the other cannot be induced to leave the dead body, but will remain by it and allow itself to be slaughtered also.

Not very many years ago dugongs were found in large herds, sometimes consisting of two or three hundred individuals, and were so tame that they would even permit themselves to be touched without attempting to escape. But they have been very much persecuted for the salie of their hides, and also for that of a valuable oil which is extracted from their bodies, so that nowadays it very seldom happens that more than two or three are seen together.

A fully-grown dugong is generally from seven to eight feet long, and measures about six feet round the body. 


\section{CHAPTER XIV.}

\section{THE ROIIINT \NIMIIS.}

THE group of the Rodents is the largest of all the tribes of Mammals, for it contains more than a thousand different animals. Indeed, nearly one third of all the mammals in the world belong to this very important division.

The word "rodent" signifies "gnawing," and is given to these creatures because their front teeth are specially formed for the purpose of gnawing hard substances. You linow, of course, how long and sharp the front teeth of a rat or a mouse are, and how easily these animals can nibble their way through a stout piece of board. Well, all the rodent animals have these teeth formed in just the same way. And when we come to examine them we find that they are most beautifully suited to their purpose.

You would think that as they are so constantly in use, these teeth would be very quiclily worn down to the gums, wouldn't you? Ours woukl, if we employed them in the same way. But then, in the rodent animals, these teeth never stop growing, so that as fast as they are worn away from above they are pushed up again from below.

Sometimes this fact leads to a very singular result. It happens now and then that a rodent animal meets with an accident, and breaks off onc of its front teeth. Now these teeth, remember, cannot be used unless they have one another to work against, just as the blades of a pair of scissors cannot be used unless they have one another to cut against. So, you see, when one tooth is broken short off, the opposite tooth in the other jaw becomes useless. It has nothing to work against. So it is no longer worn away from above. But of course it still goes on growing. So before very long it projects in front of the other teeth. Still it continues to grow, and in course of time its natural curve brings it round in a semi-circle, with the point towards the face. And at last, if it is a lower tooth, it picrces first the flesh of the forehead and then the sliull beneath it, and enters the brain and liils the animal; while, if it happens to be an upper tooth, the point curls round under the chin and at length prevents the poor creature from opening its mouth, so that it dies miserably of starvation! It seems impossible, doesn't it? Yet in several of our great museums there are skeletons of hares and rabbits which have been liilled in this singular way by one of their own front teeth. But how are these teeth liept sharp? One would think that their edges, at any rate, must very soon be worn away. 
Nature has guarded against this danger, however, by making these teeth of two different substances. The face of the tooth is made of a very thin plate of exceedingly hard enamel, the rest of the tooth of much softer bone. During use, of course, the soft bone is worn away very much faster than the hard enamel, and so the sharp, cutting edge is preserved.

It is interesting to find that we make our chisels in a very similar way. The blade is not a solid piece of steel, of the same quality throughout; it consists of steel of two different qualities. The face of the tool is a very thin plate of extremely hard steel, but the rest is of much softer metal. And as it is with the rodent's tooth, so it is with the chisel. The soft metal is worn away during use much faster than the hard, so that the edge is not destroyed.

Only two pairs of front teeth are developed in the rodent animals, and as the "eye" teeth are wanting there is always a gap in each jaw between these and the grinders.

First on our list of rodent animals comes the common

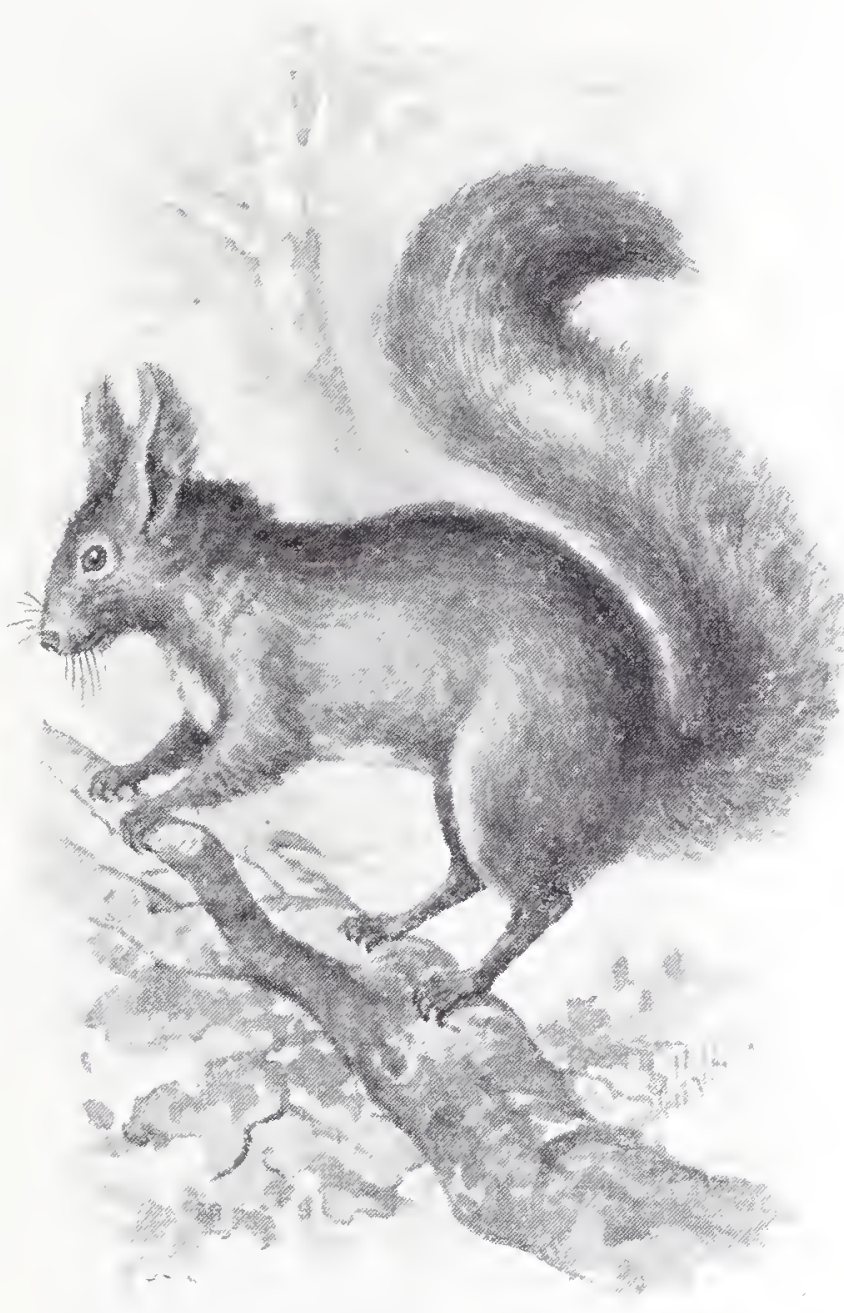

SQUIRREI.

SQUirRel, which of course you know by sight very well indeed. There are very few parts of the country where we may not see it frisking and gambolling among the branches of the trees, or sitting upright on its hind quarters and nibbling away at a nut, which is delicately held between its front paws.

It skips up the trunk of a tree quite as easily as it runs along the ground. That is because its sharp little claws enter the bark, and give it a firm foothold. And it scarcely ever falls from a branch because its big bushy tail acts as a kind of balancing pole, like that of a man walling upon a tight-rope; and by stretching it straight out behind its body, and turning it a little bit to one side or a little bit to the other, the animal can nearly always manage to save itself from a tumble.

Even if it does fall, however, it does not hurt itself, for the skin of the lower part of the body is very loose, and it is fastened for a little distance along the inner surface of each leg. So, when the animal falls from a height, it merely stretches out its limbs 
at right angles to its boly - stretching out the loose skin, of course, with them-and so turns itself into a kind of open umbrella, just like the parachutes which are sometimes sent down from balloons. And instead of tumbling headlong to the ground and being litled lyy the fall, it is buoyed up by the air and floats down comparatively slowly, so that it is not hurt in the least.

The squirrel feeds on nuts, acorns, beech-mast, bark, buds, and the young shoots of certain trees. But it is also very fond of fir-cones, which it nibbles right down to the core: and sometimes it will eat birds' eggs. Early in the autumn it always lays up a store of provisions, hiding them away in a hole in a tree, or burying them in the ground. Then, when a warmer day than usual rouses it from its long winter-sleep, it goes off to its hoard and enjoys a hearty meal.

Sometimes, however, it forgets where it has buried its nuts, so that they remain in the ground and grow. There is many a fine chestnut and oak tree,

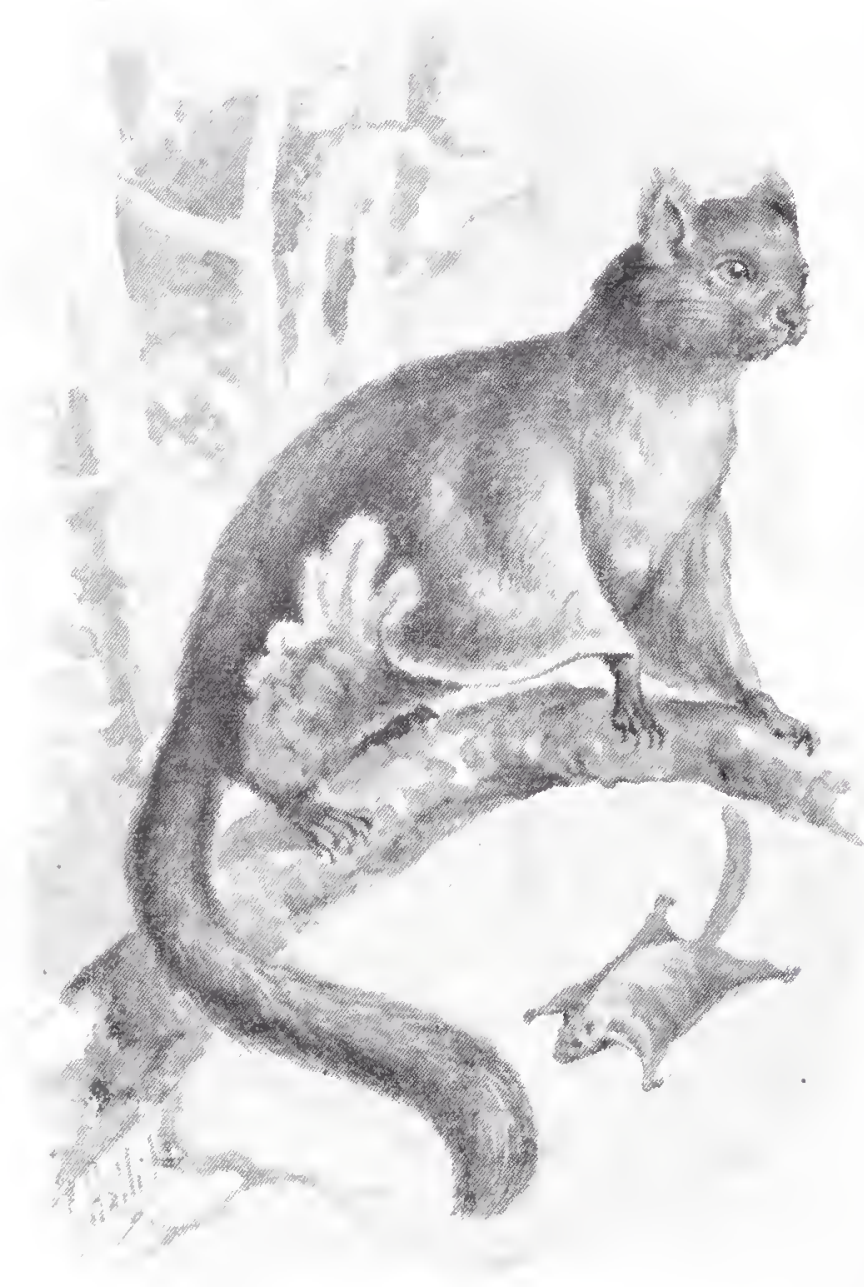

HITIR SOLIRREI. indeed, which has really been planted by a squirrel.

con These prettylittleanimals generally go about in pairs, and the little ones are brought up in a warm cosy nest made of leaves and moss. This "drey," as it is often called, is placed cither in the forli of a lofty branch or in a hole high up in a tree-trunk, and is so beautifully made that rain never soaks through it, and the wind never blows it away.

So-called" FingugourREIS" are found in some parts of the world; but like the colugo, of which we have read already, they do not really fly. They merely slim from one tree to another by spreading out the very loose slin of the sides of the body and then leaping into the air. In this way they can travel for perhaps two or three hundred feet.

But as a rule they merely spring from branch to branch, just like our common English squirrel.

The largest and perhaps the best-known of these squirrels is the 'Taguan, which is found in India and Siam, and is about 
two feet in length, not including the tail. It is tolerably plentiful, but is not very often seen, for all day long it is fast asleep in it hole in some tree, only coming out of its retreat after sunset. In colour it is greyish black ahove and greyish white below, with brownish heacl and limbs.

'Then there are several squirrels which live upon the ground, and do not climb trees at all. The most famous of these is the Hacklie, which is very common indeed in many parts of North America. It is often known as the "Chipping Squirrel," or "Chipmucli," because when it is

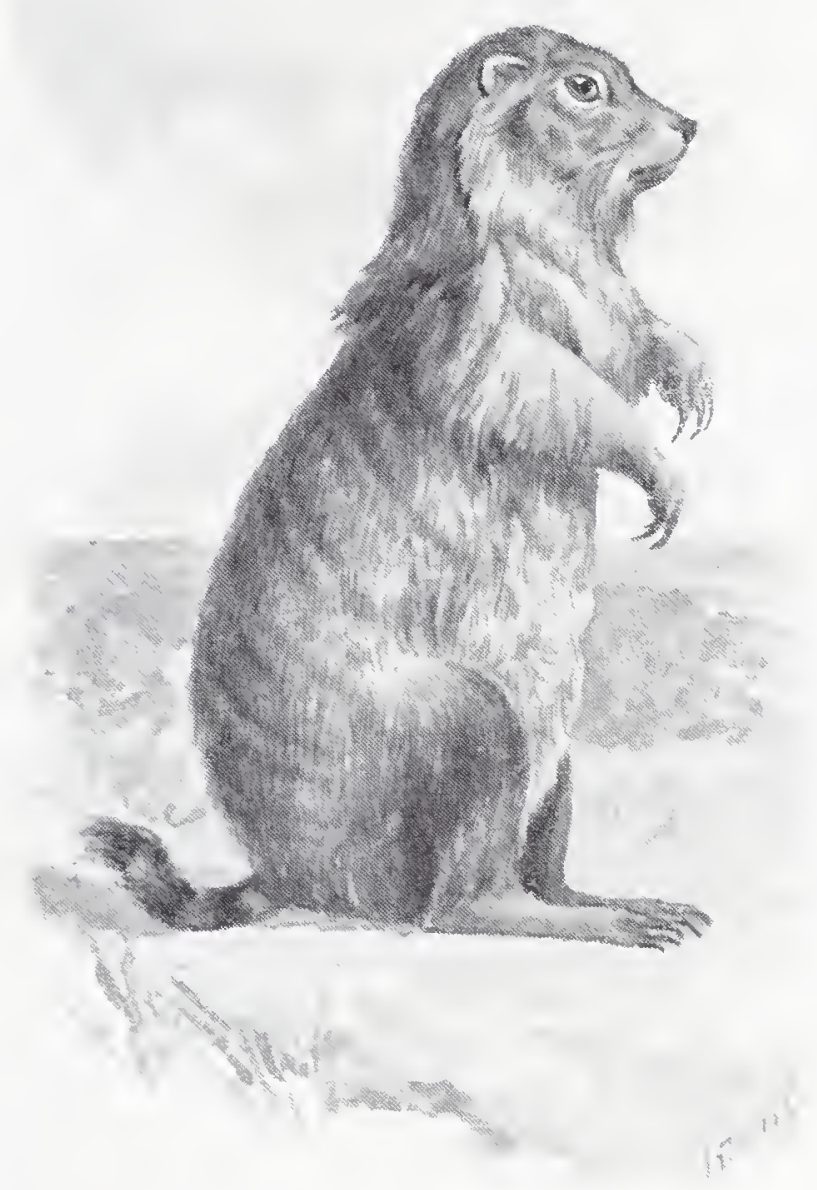

PRIRIE I)O(i. excited or alarmed it utters a sharp little cry like the work "chip-r-r-r," over and over again.

'This is an extremely pretty little animal, its fur being hownish grey on the back and orangebrown on the forehead and hind quarters, while a broad black stripe runs alons the hack, and a yellowish-white stripe ectred with black along each sicle. 'The throat and the lower part of the body are white.

The hackee lives in burrows which it digs in the ground, and rery wonderful little burrows they are, seldom less than eight or nine feet long, with a large sleeping-chamber at the end, filled with moss and grass and clry leaves. Then on either side of the main burrow are several shorter ones which are used as larders, and in which large stores of provisions are packed away. From a single hackee's nest have been taken nearly a peck of acorns, together with about a quart of beaked nuts, two quarts of buckwheat, a few grains of maize, and a quantity of grass seeds! Only three hacliees were found in this burrow, so that they were in no langer of starving during the winter, were they?

These "beaked nuts" have very sharp points, and the hackee bites these carefully off before it attempts to pack the nuts away in its mouth. It always carries four nuts to its burrow at a time, putting one into each of its odd cheel-pouches, which are very much like those of certain monkeys, and one into the mouth itself, wile the fourth is held between the tecth.

The hacliee is a very active little creature, and its quicli, 
jerky movements as it larts in and out among the herbage have often been compared to those of the wren.

Of course you have heard of the PraIRIE Doc, which is so called because it lives on the prairies of North America, and utters an odd little yelping cry which is something like the bark of a very small dog. But it has sereral other names as well, for sometimes it is known as the Barking Squirrel, sometimes as the Prairie Marmot, and sometimes as the Wish-ton-wish. It is quite a small animal, being seldom more than twelve inches in length without counting the tail, and is reddish brown or brownish grey above, and yellowish or brownish white beneath. The tail is about four inches long.

In the great prairie-lands which lie to the east of the Rocky Mountains, this quaint little animal is exceedingly plentiful. It lives in underground burrows, and the earth which it digs out in making them is always piled up just outside the entrance in the form of a mound about two feet high, on the top of which it likes to sit upright, squatting on its hind quarters as a dog does when "begging." At the slightest alarm it utters its queer little yelping cry, throws a sort of half-somersault, and dives into its burrow, to re-appear a few minutes later when it thinls that the danger lias passed away.

A large number of prairie logs always live together, like rabluts in a warren, and sometimes the prairie, as far as one can see, is dotted all over with their mounds. And in almost every case the animals are steadily moving eastward. The reason is that as they feed upon the prairie-grass in summer, and upon its roots in winter, they very soon destroy it altogether, and are obliged to travel onwards in order to avoid starvation.

It was formerly thought that prairie dogs take in lodgers, so to speak, for small owls, known as Burrowing Owls, are often found in their tunnels, together with rattlesnalies; and it was supposed that all three lived peaceably together. But now we know that this is not the case, for the owls are nearly always found in deserted burrows, while the rattlesnakes undoubtedly enter the homes of the prairie dogs for the purpose of feeding upon their young.

Not unlike a rather big prairie log is the Common Marmor, which is found in considerable numbers in the mountainous parts of Northern Europe. It is about as large as a rabbit, and has greyish-yellow fur, which is very much darker upon the head and tail, that of the latter being almost black.

Marmots live in warrens, just as prairie dogs do, and during the summer months they are very active and busy. From about the middle of autumn till the beginning of spring, however, they are fast asleep in their burrows, not waking up at all for at least six months! Before entering upon this long slumber they pack their sleeping-chamber full of dry grass, and sometimes as many 
as fifteen of the little animals have been found snuggling up together in a single burrow.

Another lind of marmot, called the BoBAc, is found both in Northern Europe and in Asia. It is sometimes eaten as food, but is most difficult to kill, for unless it is actually shot dead as it sits it will nearly always contrive to get back into its burrow. And if the animals are startled by the report of a gun they all disappear underground, and will not be seen again for several hours.

Quite one of the most interesting of all the rodent animals is the BEAYER, which is found in the northern parts of Europe, Asia, and America. It spends a great part of its life in the water, and no doubt you have heard of the wonderful dams which it makes in order to prevent the rivers from drying up during the summer months.

When the animals want to construct one of these dams,

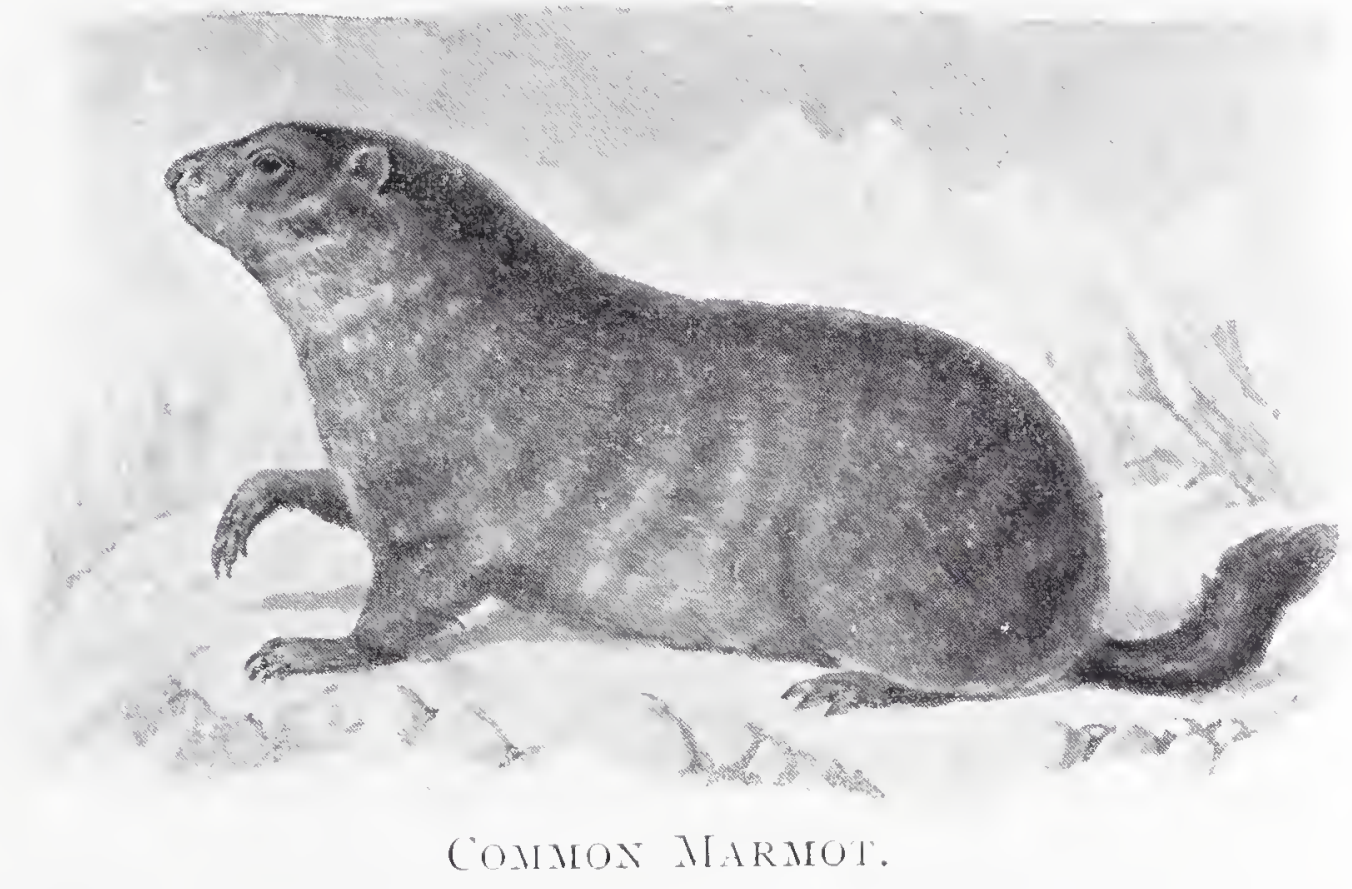

the first thing they do is to fell a number of trees which stand near the banks of the river. They do this by gnawing through the stems quite close to the ground, and are able easily to cut through trunks ten or even twelve inches in diameter. Most likely one of the trees falls across the stream. In that case they leave it as it is. Then they strip off the bark from the others, and cut up both the trunlis and the larger branches into $\log s$ about four or five feet long. These logs they arrange most carefully in position, piling them upon one another, and keeping them in their places by heaping stones and mud upon them. They also fill up all the gaps between them with mud, and so hard do they work that by the time the dam is finished it is often a couple of hundred yards long, fifteen or even twenty feet thicli at the bottom, and six or eight feet high! And when the river runs swiftly, they are clever enough to make their dam in the form of a curve, so that it may be better able to resist the force of the current. 
The effect of this dam, of course, is to cause the river to swell out into a broad, shallow pool, and in districts where beavers are plentiful the whole course of a stream is sometimes converted into a series of pools, made in this curious manner. After a time peat is formed round the edges, and gradually spreads, and then the marshy ground round the pool is called a "beaver-meadow."

But beavers do not only make dams. They construct what are called "lodges" as well, to serve as dwelling-places. These are made by piling up a number of logs, plastering them all over with clay, and digging out the soil from underneath them, so as

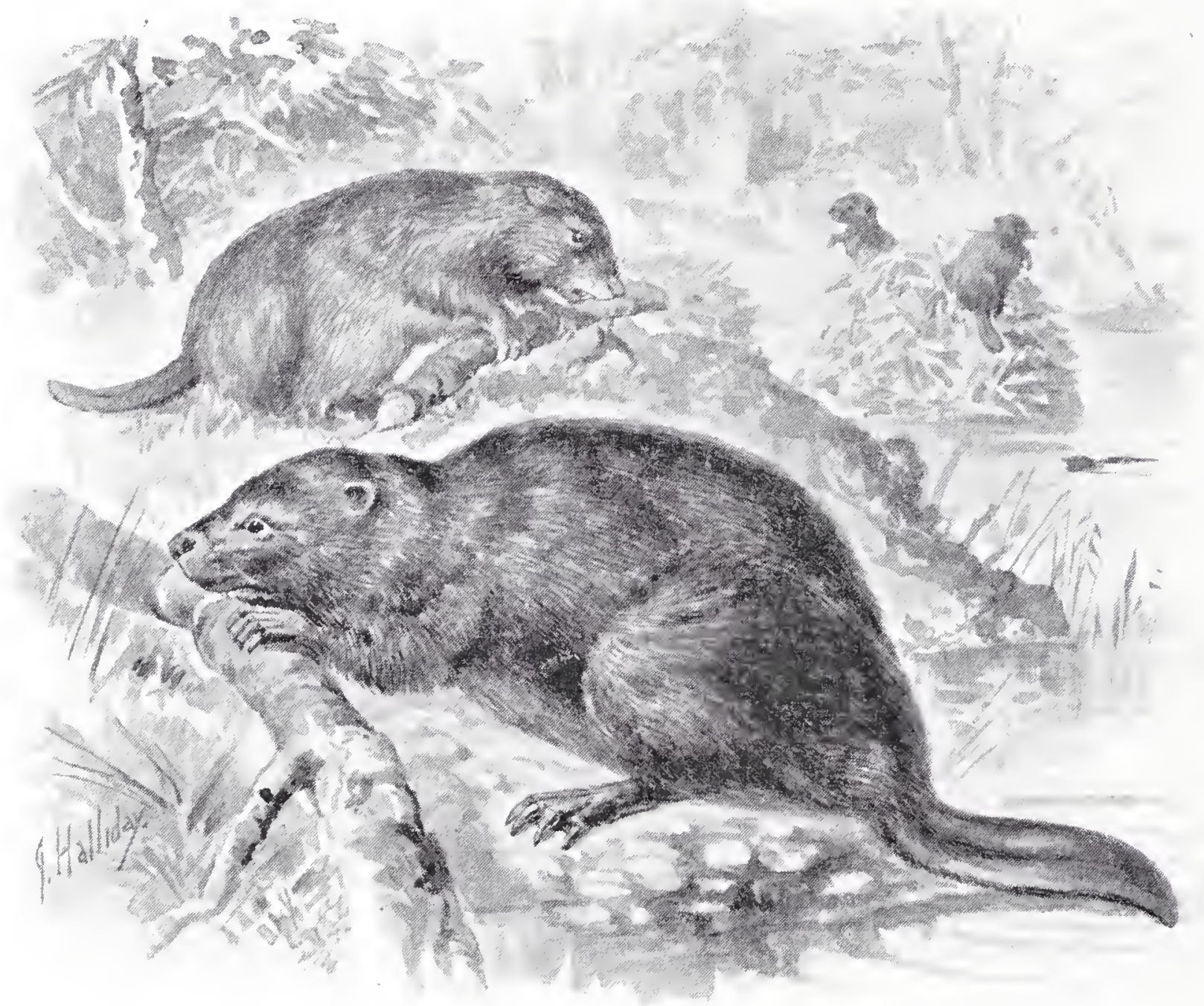

BEATERS.

to form a sort of hut. These lodges are oven-shaped, and are from twelve to twenty feet in diameter, the inside chamber being ahout seven feet wide. So, you see, they have very thick walls. And they are generally entered by several underground passages, all of which open in the river bank below the surface of the water, so that the animals can go straight from their lodge into the river without showing themselves above ground at all.

Inside each lodge is a bed of soft warm grasses and woodchips, on which the animals sleep; and it is even said by some hunters that each heaver has his own bed! At any rate, five or 
six animals live together in each lodge. Then all round the lodge these wonderful creatures make a ditch, which is so deep that even in the hardest winter the water in it never freezes quite to the very bottom. And close by they pile up a great quantity of logs and branches, so that they may always be able to go and cat as much bark as they require.

Beavers are capital swimmers, for the toes of their hinder feet are joined together with webbing, and make excellent oars, while the hroad, flat tail is very useful as a rudder. They

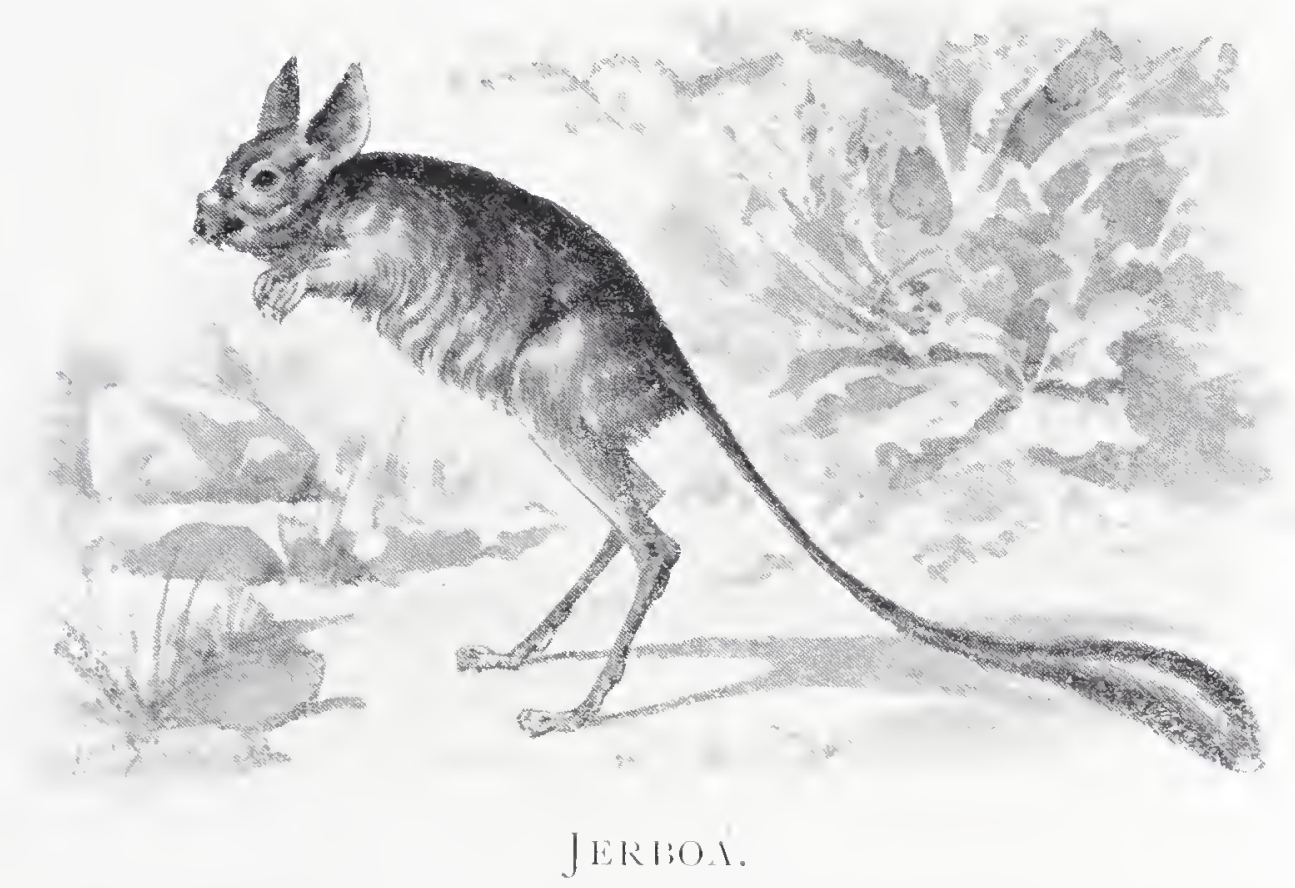

are very much persccuted by hunters, tor their fur is valuable, while they also secrete a curious substance known as "castorem," which is used in medicine, and is worth about two guineas a pound. So in some parts of North America these animals are strictly preserved, and only a certain number may be killed every third year.

Everybody knows what the Dormouse is like, so that it is not necessary for me to describe it. And everybody knows, too, what a sleepy little creature it is, so that very often it may actually be piclied up and handled without waking! It always sleeps all day long, and hibernates from the middle of Octolier till the beginning of April as well, so that it fully deserves its title of "dormouse," or "sleepy-mouse."

In Germany it is called the "haselmaus," or "hazel-mouse," hecause it is so fond of hazel nuts. It eats these just as the squirrel does, holding them in its fore-paws as it sits upright on its hind quarters. But it also feeds upon acorns, beech-mast, "hips and haws," and corn when it can get it.

Dormice always malie two nests during the year, one being used during the summer, and the other during the winter. They are very warm and cosy little retreats, about six inches in diameter, and are madle of grass, leaves, and moss. L'ou may sometimes 
find numbers of the summer's nests in thick bushes, or among the low herbage at the bottom of a hedge, perhaps with the dormice fast asleep in them. But the winter nests are generally more carefully hidden, so that it is not very easy to find them even when the leaves are off the bushes.

Before it goes into hibernation in the autumn the dormouse becomes exceedingly fat. But it does not sleep right through the winter without taking any food at all, for on very mild days it wakes up for an hour or two, and eats one of the nuts or acorns which it has carefully stored away in its nest.

The JERBOA is an extremely curious animal, and if you were to see it in the sandy deserts of Northern Africa, from which it comes, you would be very likely indeed to mistake it for a small bird. For it has very short forelegs, which it tuclis up against its breast in such a way that they can hardly be seen, and very long hind ones, on which it hops about in a very birdlike manner. But you would soon notice that it has a long tail, rather like that of a mouse, but with a tuft of hairs at the tip.

When it is leaping about it stretches this tail out behind it, and seems to find it of very great use in keeping its balance. Jerboas are very common indeed in Egypt, and other parts of North Africa, and live in burrows which they dig in the sandy soil. In order to enable them to obtain a firm foothold on the slippery sand, the soles of their feet are covered with long hairs, which also prevent them from leing scorched by contact with the heated ground. But as a rule they do not come out of their burrows until the evening, when the sun is not so powerful as it is during the middle of the day. They feed upon grasses and dry shrubs; but how they find enough to eat in the desert places in which they live it is rather hard to understand.

About twenty different linds of jerboas are known. The best-known of these, the Common JERBOA, is about as big as a small rat, and has a tail about eight inches long. In colour it is so much like the sand that from a few yards away it is almost impossible to see it, even when it is skipping about.

The Hanster is a queer little rodent which is found very plentifully in Germany, and also in many districts between that country and Siberia. It is a rather stoutly-built animal, and measures nearly, a foot in length including the tail, which is about two inches long. In colour it is generally light brownish-yellow above and black beneath, with a black stripe on the forehead, a yellow patch on the back, and white feet. But hamsters are by no means all alilie, and some are entirely black, some pied, and some entirely white.

You remember, don't you, how dormice make summer and winter nests? Well, just in the same way, hamsters malie summer and winter burrows. The summer burrow is quite a small one, not more than a foot or two deep, with a small sleeping chamber 
at the bottom. But the winter one is very much larger, for it is not only six feet long at least, with quite a big sleeping chamber, but there are from one to five side-chambers as well, which are used as granaries. In these the animal stores up vast quantities of grain, peas, and beans, no less than sixty pounds of corn having been taken from the burrow of a single hamster, and a hundredweight of beans from that of another. Then about the middle of October it stops up the entrances to its home, and passes into a state of hibernation, in which it remains till the beginning of Narch. For about a month longer it still remains in its burrow, feeding on its stores of provisions, till early in April it resumes its active life, and returns to its summer habitation.

Of course hamsters are terribly destructive in cultivated land, and large numbers are destroyed every year. In one district alone nearly 100,000 have been killed in a single season, while an enormous quantity of grain was recovered from their tunnels.

As you walk along the bank of a stream, you may often hear a splash, and see a brownish animal about eight inches long swimming away through the water. This is a WATER VOLE, which many people call a "Water Rat," although it belongs to quite a different family from that of the true rats. And if you look down the side of the bank you will see its burrow, which generally runs into the ground for some little distance.

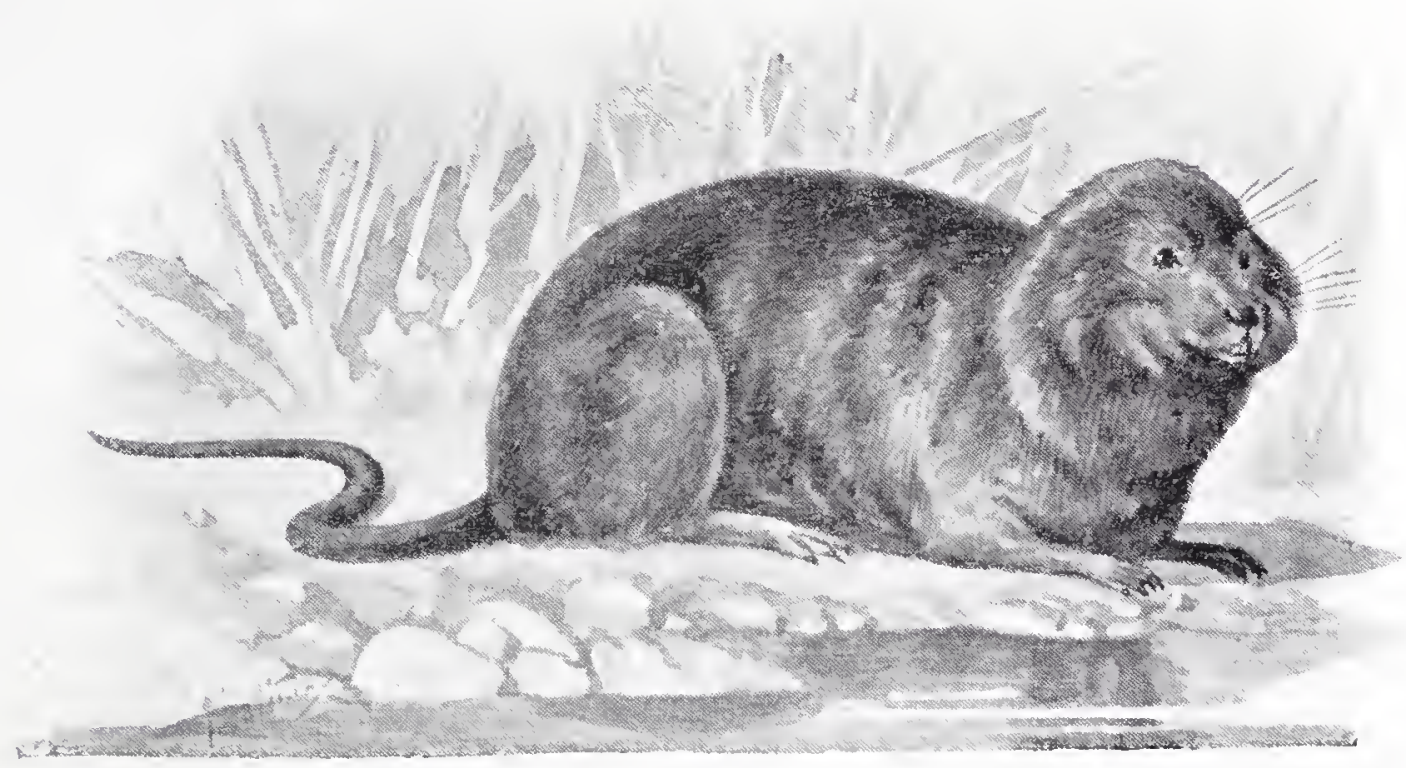

MATER VOLE.

Water voles are usually supposed to be mischievous; but during the greater part of the year they feed only on water plants, being specially fond of the sweet pith of the wild flags. In winter, however, when food of this kind is scarce, they will nibble away the bark of small trees and shrubs, and sometimes do a good deal of damage in osier beds, while they will also visit cultivated fields in order to feed on the mangolds and turnips. But they never 
liill fishes, as has sometimes been stated, and never seem to touch animal food at all.

The water vole is a very good swimmer, although its toes are not webbed, and its fur is so close and so glossy that it throws off the water just like the feathers on a duck's hack.

$A$ near relation of the water vole is the Field Vore, which is found very commonly in England and Scotland, and also in most parts of Europe. It is about as big as an ordinary mouse, and is greyish brown in colour, which becomes rather paler on the lower parts of the body. You can recognize it at once by its very short tail.

This animal is found chiefly in meadows, where it makes

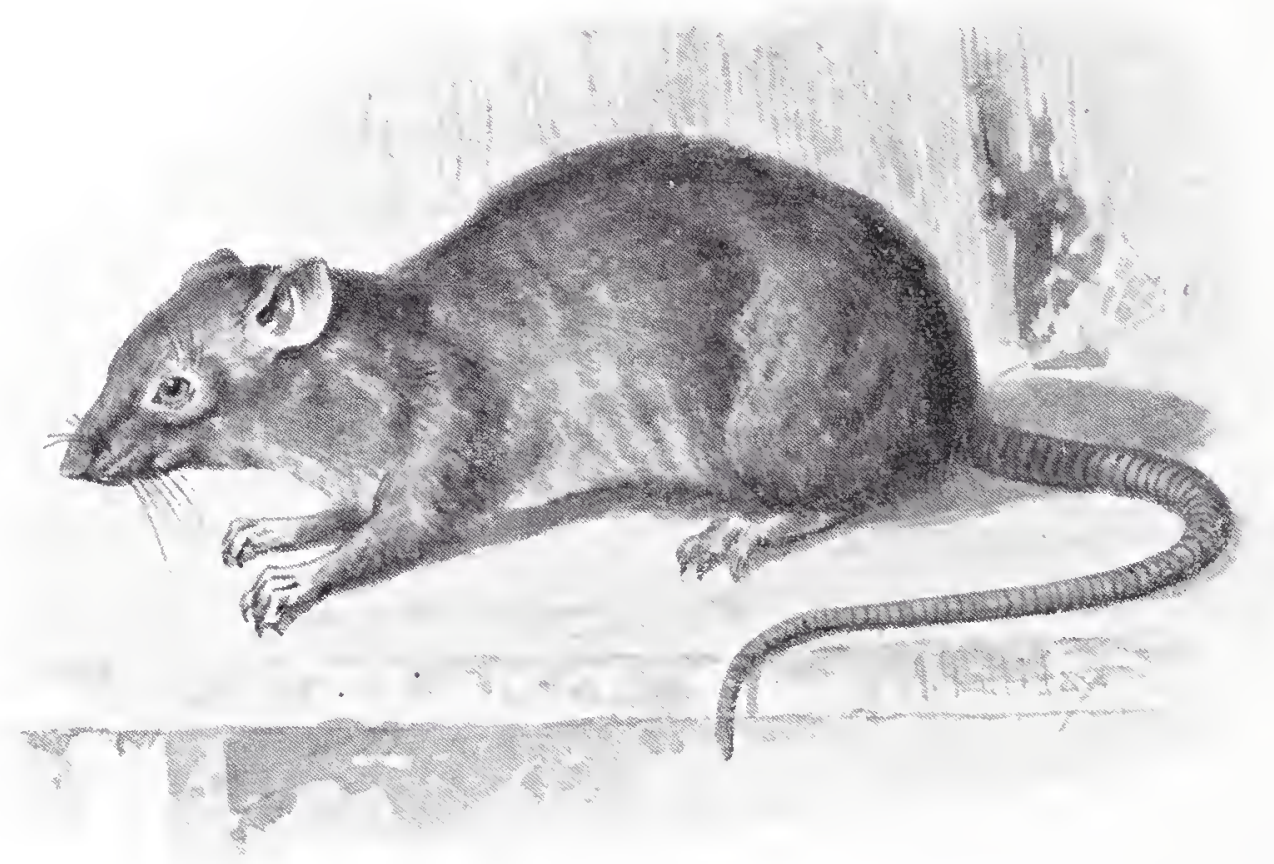

BKOWN RNT.

long "runs" heneath the grass, and also burrows into the ground. It is always plentiful, but sometimes appears in such vast numbers that it can only be described as a plague. In isge, for instance, parts of Dumfriesshire and Roxburgh were overrun by field voles, which did most terrible mischief, and although enomous numbers of the little animals were killed, it was nearly two years before they could be brought under control.

Still more mischievous, in Norway and Sweden, are the ofd little rodents known as Lenalngs, which make their appearance from time to time literally in millions. They always seem to come lown from the mountains, and when once they have hegun their journey nothing will stop them. If they come to a river they swim across it; if to a house they climb over it; if to a stack of corn or hay, they eat their way through it. Large numbers of wolves, foxes, weasels, stoats, hawlis, and owls soon discover the swarm, and kill off the animals in thousands; but still the great army moves steadily on, leaving the country perfectly bare behind 
it, until it reaches the sea. And then those behind push on those in front, till almost the whole rast host perish in the waves.

These reat migrations talie place, as a rule, about once in seren years, and no one seems to know quite where the lemmings come from, or why they travel in this singular manner.

These strange little animals do not seem to know what fear

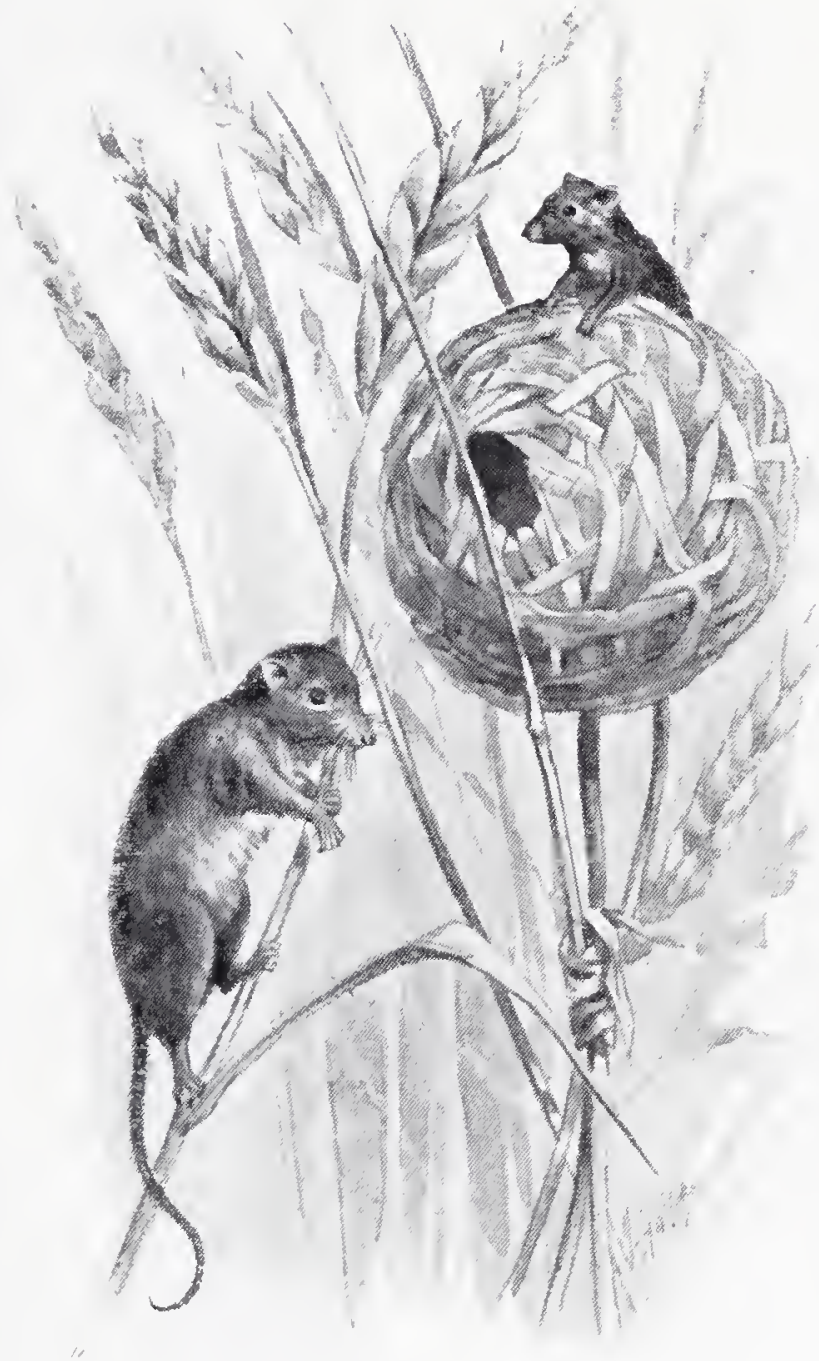

HARVEST MOISIS. is, for if a passer-by happens to meet one of them it will never turn aside, but will sit up and yelp defiantly at him, while if a dog goes up and examines it, the chances are that it will try to bite his nose!

In colour the lemming is blackish brown above and yellowish white below, while its length is about six inches.

The Brown Rat, of course, is only too common everywhere; but, strange to say, it is not really a native of Great Britain. It seems to have come in the first place from China, and has now spread to almost all parts of the world. For almost every ship that sails the sea is infested with rats, some of which are nearly certain to make their way ashore at every port at which she touches.

Stranger still, the Black Rat, which really was a native of Great Britain, has been almost entirely driven away by these fierce invaders, and is now hardly ever found in any part of the country.

But rats are really rather formidable animals, for in addition to being very savage, a number of them will often combine together in order to attack a common foe. I have known a large cat, for example, to be so severely wounded by rats, that after lying in great pain for two or three days it actually died of its injuries! They are very blood-thirsty creatures, too, for if one of their own number is caught in a trap, they will actually tear it in pieces and devour it. 'They will enter fowl-houses at night, too, and liill the hirds as they roost upon their perches, while if they can find their way into a rabhit hutch they will even destroy the rabbits.

Then in barns and farmyards they are very mischievous indeed. Corn-staclss, too, are often infested by them, while sometimes they get into houses. But on the other hand, they often do 
a great deal of good, by devouring substances which would otherwise decay and poison the air; so that they are not altogether without their uses.

Rats generally have three broods of little ones in the course of the year, and as there are from eight to fourteen in each brood, you can easily understand how it is that these animals multiply so rapidly.

Still more plentiful, and almost as mischievous, is the Common Mouse, which is found both in town and country. And this, too, seems to have been in the first place a native of Asia, and to have since spread to almost all parts of the world.

There is no need, of course, to describe its appearance, and most of us are familiar with its habits. So we will pass on at once to one of its near relations which is not quite so well known, namely, the Long-Tailed Field Mouse.

In some respects this animal is very much like the Field Vole. But you can tell it at once by its more pointed muzzle, by its much larger ears, and, above all, by its very much longer tail. It lives in gardens, fields, and hedgerows, but sometimes takes shelter in houses and barns during the winter. But all through the spring, summer, and autumn it occupies burrows in the ground, and very often it lays up quite large quantities of provisions in its tunnels for winter use, just as the hamster does in Germany. It does not always dig these burrows for itself, however, for very often it will talie possession of the deserted "run" of a mole, or even of a natural hollow beneath the spreading roots of a tree.

As a general rule, this little animal is a vegetable eater only. But when food is scarce it will kill and devour small animals, and has even been linown to prey upon its own kind.

The pretty little Harvest Mouse is the smallest of the British rodents. Indeed, with the exception of the Pigmy Shrew, it is the tiniest of all the British mammals. A fully-grown harvest mouse is very seldom more than four and a half inches long, of which almost one half is occupied by the tail. And it would actually take six of the little creatures to weigh an ounce!

The harvest mouse is rather local, but in many parts of the British Islands it is very common indeed. It is not found, as a rule, near human habitations, but lives in corn-fields and pastures. But sometimes it is carried home in sheares of corn at harvest time, and in that case it lives in the ricks during the winter. Generally, however, it spends the winter months fast asleep in a burrow in the ground. Then, when the warm months of spring come round, it wakes up, and sets about building a most beautiful little nest of grasses and leaves, which it always suspends among corn-stalks or grass-stems at some little height from the ground. This nest is about as large as a cricket-ball, and the odd thing about it is that you can never find any entrance! Apparently, when the little builder wishes to go in and out, it pushes its way 
letreen the strips of grass of which the nest is composed, and then carefully arranges them again in position. And it is so cleverly built that when eight or nine little mice which are brought up inside it begin to grow, it stretches to suit their increasing size, so that their nursery is always just big enough to contain them!

The harvest mouse is a capital climber, and runs up and down the corn-stalks with great activity, even though they bend nearly to the ground beneath its weight. The tip of its tail, strange to say, is prehensile, just like that of a spider monkey.

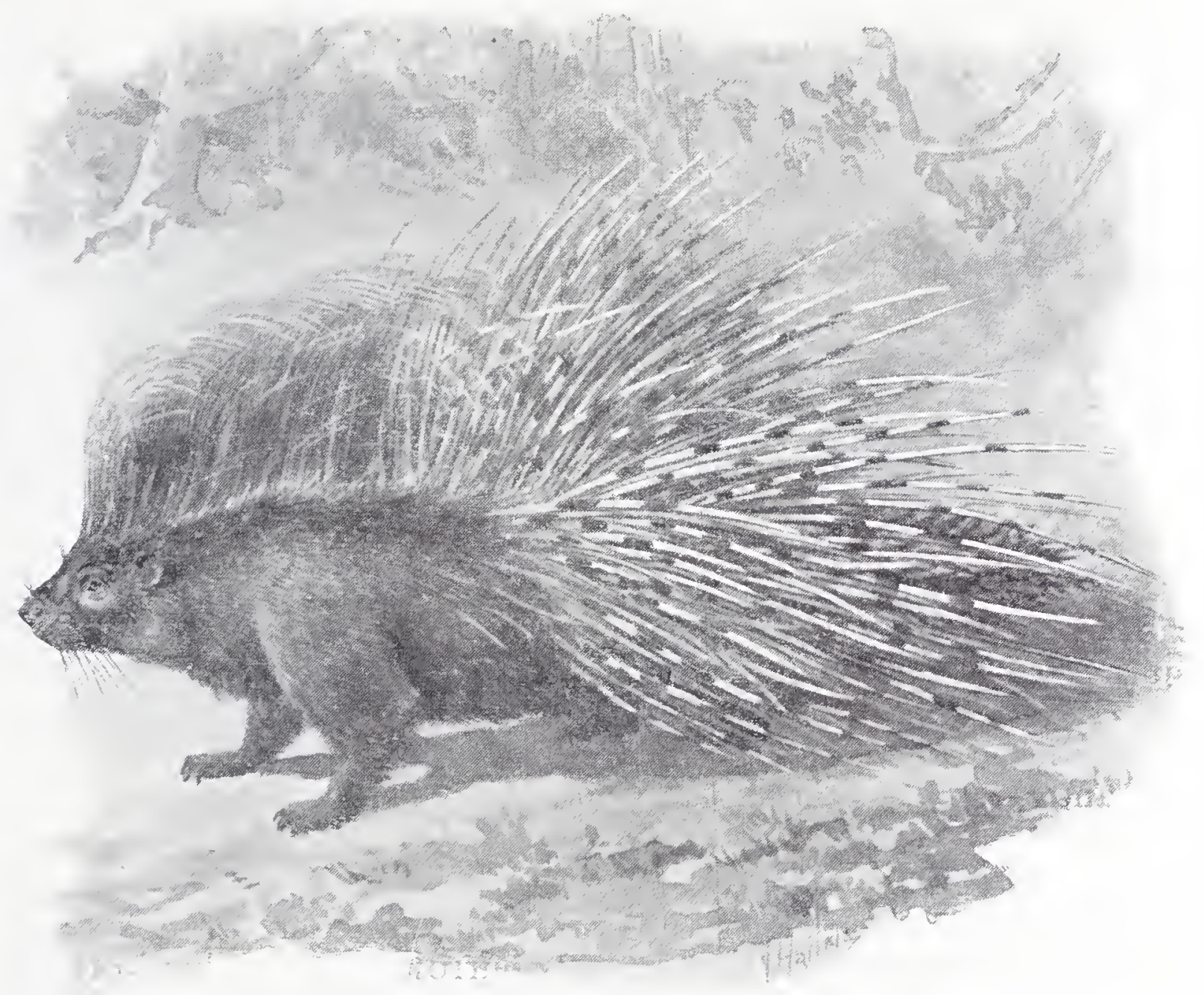

COMMON P'ORCLPHNE.

The Porcupine, too, belongs to the Rodent tribe. Of course you know what this animal is like, with its coat of long, bristling spines. Indeed, the word "porcupine" means "spiny-pig," and refers partly to the quill-like spikes, and partly to the odd grunting noise which the animal utters from time to time.

There are several different kinds of porcupine, but the only one about which I can tell you is the Common Porcupine. It is found in the south of Europe, and also in the northern and western parts of Africa, and grows to a length of about two feet four inches, not including the tail. The quills are of two kinds. First of all, there are a number of long, slender spines, which bend 
quite easily, and are not of very much use as weapons. But under these is a close array of very much stiffer ones from five to ten inches long; and these are very formidable indeed. I or they are so loosely fastened to the skin that when the animal baclis upon a foe a good many of them are sure to be left sticling in its flesh; while, further, they are made in such a manner that they lieep on boring their way farther and farther in, and in course of time may penetrate a vital organ, and cause death. Even tigers have sometimes lost their lives through the quills of a porcupine which they had been trying to kill and devour.

The animal is not at all fond of fighting, however, and never attaclis unless it is provolied.

During the day-time the porcupine is very seldom seen, being fast asleep in its burrow. But soon after sunset it leares its retreat, and wanders to long distances in search of the roots, etc., upon which it feeds.

The pretty little rodent linown as the CHinchilla is famous for its beautiful silliy fur, which is in much request for ladies' garments. In appearance it is rather like a large dormouse, with very big rounded ears, and a short, hairy tail. It is found in Bolivia, Chili, and Peru, and lives high up among the moun-

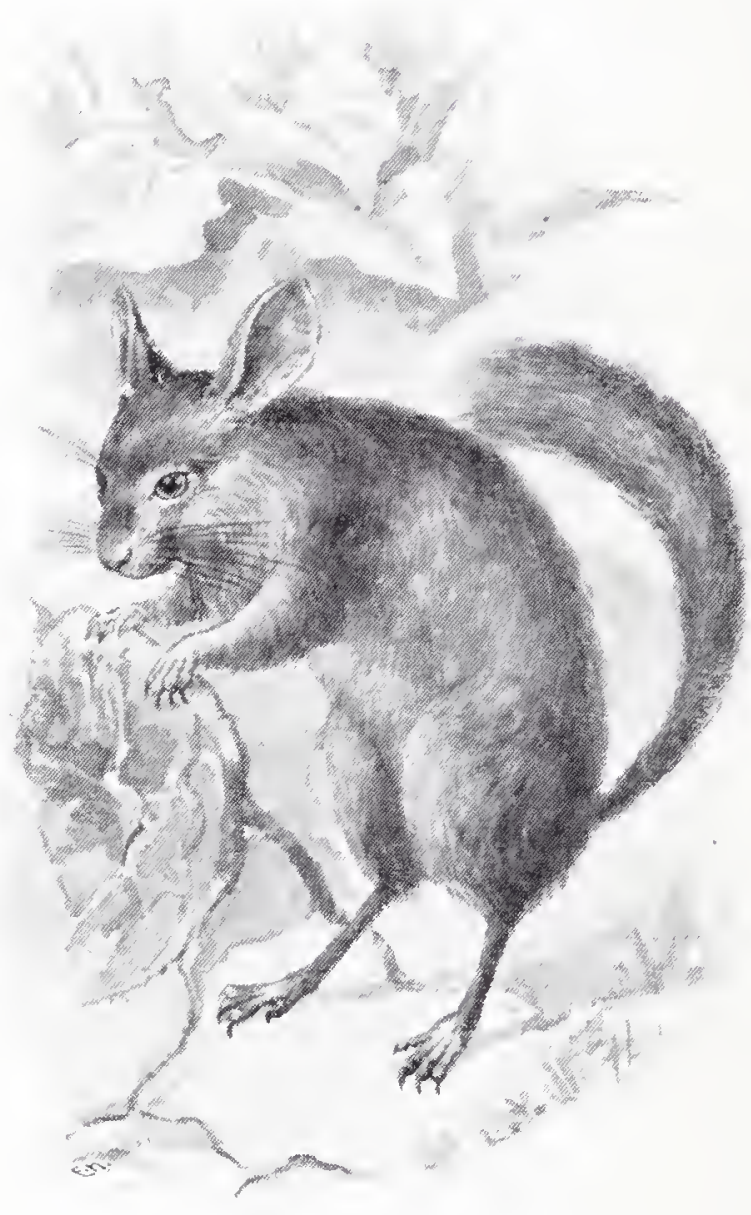

CHINCHIIAA. tains in burrows in the ground. A large number of the animals always dwell together, so that their burrows form a lind of large warren, and they dart up and down the steep rocks with such wonderful speed that it is almost impossible to follow their movements.

When it is feeding the chinchilla sits upright, like a squirrel, and conveys the food to its mouth with its fore-paws. It lives chiefly upon roots, and as the districts in which it lives are so wild and barren it often has to travel for long distances in order to obtain them.

Closely related to the chinchilla is the ViscacHA, which is found very abundantly in the great pampas districts of South America. It generally lives in little colonies of from twenty to thirty animals, which dig their burrows close together, and heap up the earth which they scrape out into one common mound. These burrows are generally dug in the form of the letter Y, and very often a number of them communicate with one another by 
means of short passages, so that if the little animals feel in want of society they can easily go and see their friends.

These colonies are called "viscacheras," and in some parts of the Irgentine Republic the plains are closely studded with them as far as the eye can reach.

Viscachas have a curious way of clearing off all the vergetation that grows near their burrows, and piling up the refuse in a mound near the entrance. They will also collect together any hard objects which they may happen to find, and we are told by Darwin that sometimes quite a barrow-load of bones, stones, thistle stalks, and lumps of earth may be found outside the entrance to a single burrow, and that a traveller who dropped his watch one evening found it next day by searching the viscacha mounds in the neiglibourhood.

In appearance the viscacha is not unlike a rather small

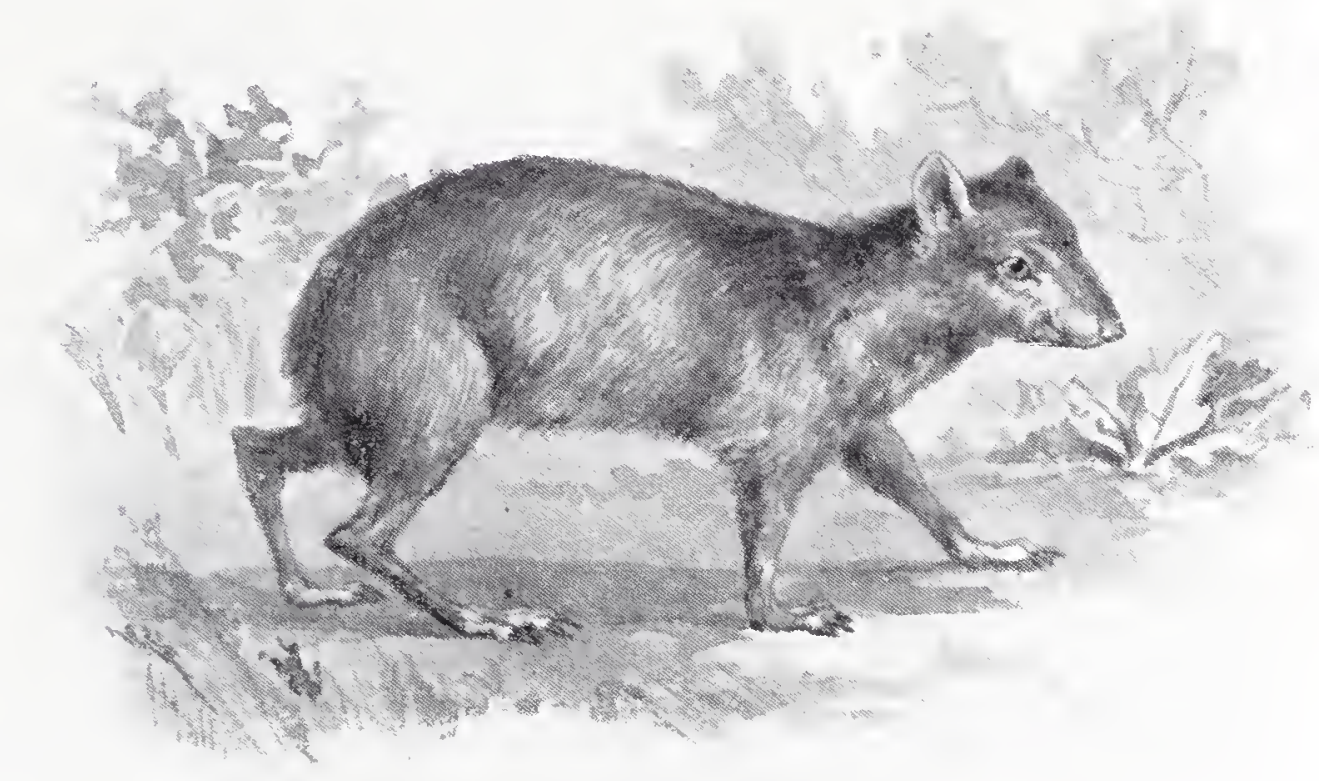

ArotTI.

marmot. But the fur is grey above, with dusky markings, and white below, while the face is crossed by two black bands, with a broad white stripe between them.

Next we come to the Agoutr, which is found in South America. Formerly it was very plentiful indeed, literally swarming in some parts of the country. But it did so much mischief in cultivated ground that it was trapped and shot in immense numbers, and it has now almost entirely disappeared from many districts in which it once abounded.

The first point that strikes one on looking at the agouti is the great length of its hind legs. So long are these limbs, indeed, that the animal finds a grood deal of difficulty in running down hill, and often tumbles head over heels and rolls for several yards before it can recover its footing. And for the same reason, when it is running at any pace on level gromu, it travels along by a kind of gallop, which is really made up of a series of leaps. 
As the agouti comes out only by night it is a most difficult animal to watch, and it is, besides, so very wary that it cannot be approached without the very greatest caution. All the time while it is feeding, indeed, it keeps on turning its head first to one side and then to the other, so that it can scarcely ever be taken by surprise.

If it should be captured, however, it never seems to fight, and has no idea of using either its sharp teeth or its claws to defend itself. So sometimes it has been thought that an agouti would make a very nice pet. Those who have allowed it to run loose in the house, however, have seldom repeated the experiment, for it will ruin any article of furniture in a very short time, and will cut its way through the stoutest door in a few minutes!

When fully grown, the agouti is rather more than eighteen

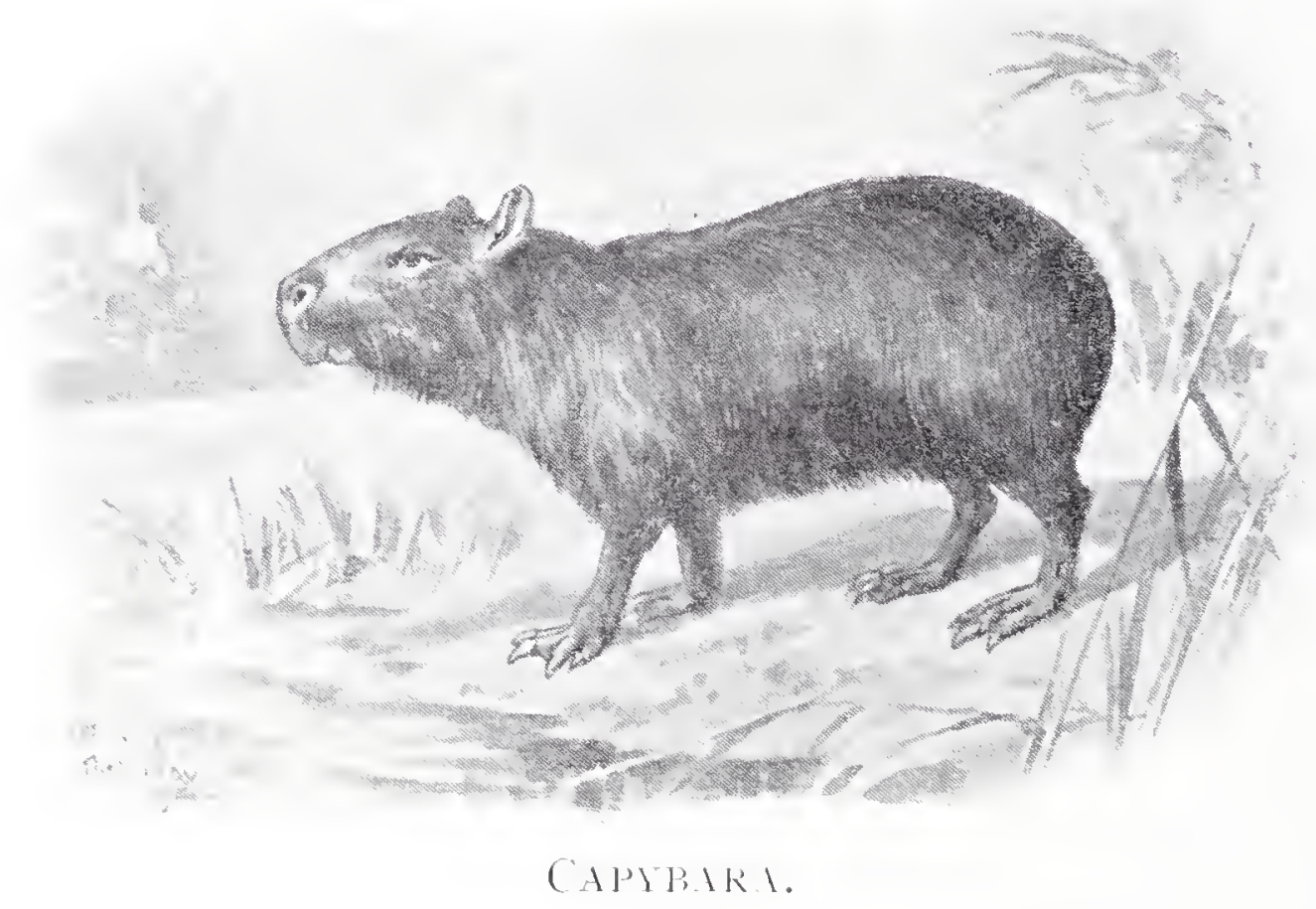

inches long, and in general colour it is olive brown. But the hair of the hinder quarters, which is very much longer than that of the rest of the body, is golden brown, while the middle line of the lower part of the body is almost white.

Very few people, on seeing a CAPYBARA for the first time, would take it to be a rodent. It looks misch more like a wild pig, for it has a very heavily-built body, which almost touches the ground as it waddles along, short, stiff, bristly hair, and great hoof-like feet. Indeed, it is sometimes called the "water-hog." Yet we only have to look at its front teeth to see that it really is a rodent after all.

The capybara is a native of South America, and is generally found in the damp, marshy ground near the banks of the larger rivers. It is a very good swimmer, and always makes for the water when alarmed. It is a very good diver, too, and can easily 
remain below the surface for seven or eight minutes without requiring to breathe, so that if it can once plunge into the river it is safe from almost any foe. When fully grown, the capybara is about four feet long, and weighs very nearly roo pounds. In fact, it is the largest of all the rodent animals. In colour it is reddishbrown above, and brownish-yellow beneath, and it is further remarkable for having no tail at all.

Two more rodents remain to be mentioned, although they are so well known that it is not necessary to say very much about them.

The first of these is the Common RabBit, which is so very plentiful in all parts of the British Islands. In many places, indeed, it is almost too plentiful, for it is apt to be very destructive in cultivated ground. But as a rule it prefers to live on sandy commons, where it can casily burrow into the ground, and where

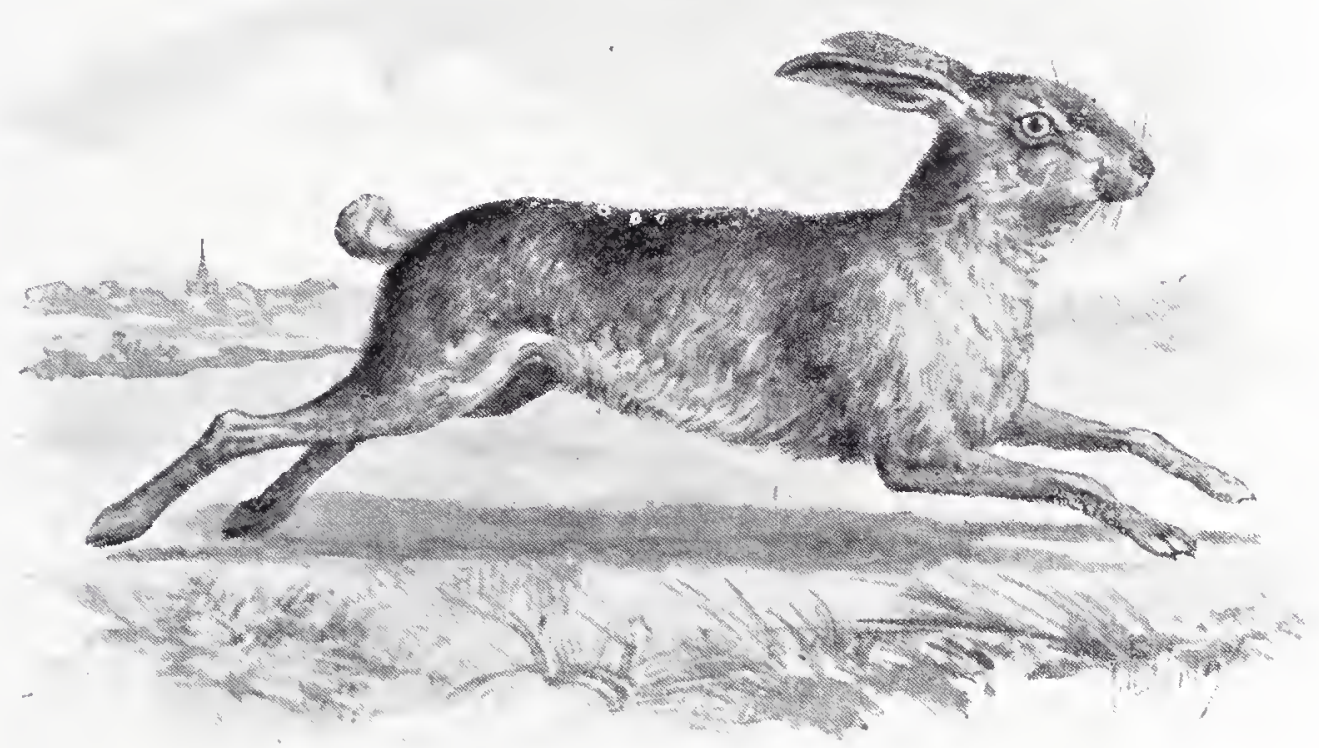

H、RE.

there are plenty of furze bushes, on the young shoots of which it can feed.

The best time to watch rabbits is just after sunset, as then they leave their burrows and indulge in all linds of pranlis and games. But at the very slightest alarm they all dash back into their holes and do not reappear for some little time. The burrow generally has two entrances, so that if an enemy should enter by one they can dart out by the other. But when the mother rabbit has little ones to look after, she digs a burrow with only one entrance, at the end of which she malies a soft, warm bed for them with her own fur. There are from five to eight little ones in a brood, and when the mother has to leave them for a little while she carefully stops up the entrance to the burrow with earth.

The Hare does not make a burrow at all, but sits and sleeps in what is mostly linown as its "form." Sometimes this is a slight 
hollow in the ground, sometimes a flattened resting-place among long grass, and sometimes merely the sheltered side of a large stone. Generally the animal spends the whole day in its "form," going out to seek for food soon after sunset. And if a heavy snowstorm comes on the animal does not leave the "form," but just moves its body slightly to and fro, so as to press the snow together as it falls. In this way a kind of domed chamber is formed underneath the snow, in which the hare remains, quite warm and comfortable, until the thaw comes.

While the animal is lying in this chamber, however, it is very easily found by dogs, for the warmth of its breath lieeps a hole open through the snow above, and up this passage comes its scent.

The hare is remarkable for three qualities.

The first is its wonderful speed of foot. It runs so fast that only a very swift greyhound can overtake it, while it can "double" on its track just as it is on the point of being seized, so that it often contrives to escape its pursuers.

The next quality is its cunning. For the hare is almost as crafty as the fox, and plays all sorts of tricks in order to throw its foes off its track. It will return npon its line, for example, for two or three hundred yards, leap suddenly to one side so as to break the scent, and there lic hidden till the hounds have rushed by, when it will take to flight in the opposite direction.

And the third guality is its seeming cowardice. I say its "seeming" cowardice, for really the hare is not cowardly at all. It will run away, of course, when hunted by men or dogs. But what else can it do? And sometimes it is very brave indeed. A mother hare, for instance, will fight to the death in defence of her young. And many a case has been recorded in which a hare has valiantly attacked an enemy much bigger and stronger than itself, and has had the best of the encounter.

'The young of the hare are called "leverets." and there are generally four or five in a hrood. 


\title{
CHAPTER $\mathrm{XV}$.
}

\author{
THE IVIT,D OXEN.
}

WE now come to a very important group of mammals called "Ungulates," or "hoofed animals," because of the way in which their feet are formed. The oxen, sheep, goats, antelopes, deer, horses, swine, elephants, and rhinoceroses all belong to this order.

First let us notice some of the wild oxen.

The largest of these is the Gaur, which is found in India. It is a very big animal indeed, for it sometimes stands more than six feet in height at the shoulder, and as it has long and very powerful horns, it is much dreaded by the natives. As a rule, however, it is a very gentle and peaceable animal, scarcely ever venturing to attack man, and only divelling in those remote parts of the jungle to which even hunters seldom find their way.

The gaur lives in small herds, generally of from ten to twenty in number. Each of these is led by an old bull, and there are generally two or three younger ones, the rest being cows and calves. When the younger bulls grow up they mostly fight the old one in order to take his place. For some time he contrives to hold his own; but when at last he is beaten he goes off and lives in the thickets by himself.

These "solitaries," as they are called, are generally very savage, and will often rush out and attack a passer-by, even when he has not provolied them at all.

The gaur is a very wary animal, and sentries are always posted near the herd, in order to give warning of the approach of a foe. When feeding, too, they are said to stand in a circle with their heads outwards, so that they can see in every direction.

The old male gaurs are nearly black in colour, and the younger ones and the cows reddish brown, while they all have white "stocliings" from the knee downwards.

The YAK, which lives in Thibet, is something like an ox with great masses of hair on its flanks, limbs, and tail. In colour it is blackish brown, with a little white upon the muzzle, and in height is about five feet six inches at the shoulder. The thick fringes of hair do not begin to grow till it is about three months old, and the young calf is covered all over with curly black hair, like a Newfoundland dog.

The yak lives among the mountains, sometimes climbing to a lieight of fully 20,000 feet, and scrambles about among the boulders with really wonderful activity. Large herds of these animals, however, have been domesticated, and are used as beasts 
of burden, while their flesh is said to be almost as tender and well-flavoured as beef. The big, tufted tail, too, is highty valued, for it is dyed in various colours, and is then employed in making the "fly-flappers" which are used so much in Eastern countries.

The famous Bison of North America, sad to say, is now almost extinct, for there are only a few small herds living under special protection. Yet, not so very many years ago, this magnificent animal wandered over the prairies literally in millions. Even a single herd, sometimes, would extend further than the eye could

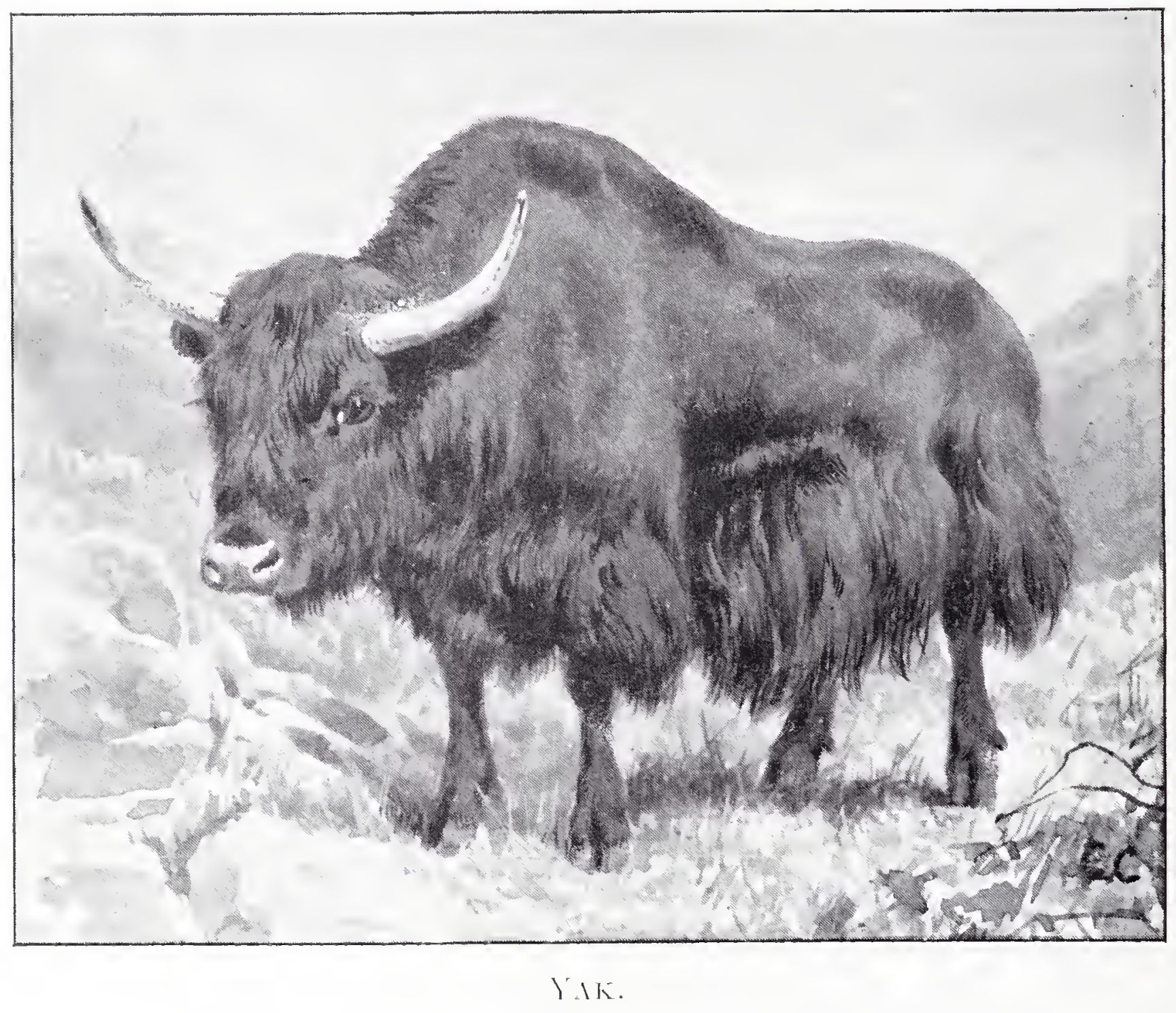

reach, and we read of one herd which covered a tract or country fifty miles long and twenty-five miles broad! But these herds were reclilessly destroyed for the sake of their hides and tongues, and now, probably, there are not more than two or three hundred bison left alive altogether.

Generally, however, a couple are to be seen in the Zoo, and if you go to look at them you will most likely think that the male looks rather like a very big lion. For it has an enormous mane of long, shaggy hair, which covers the head and shoulders. There is also a sort of long beard underneath the chin, and the 


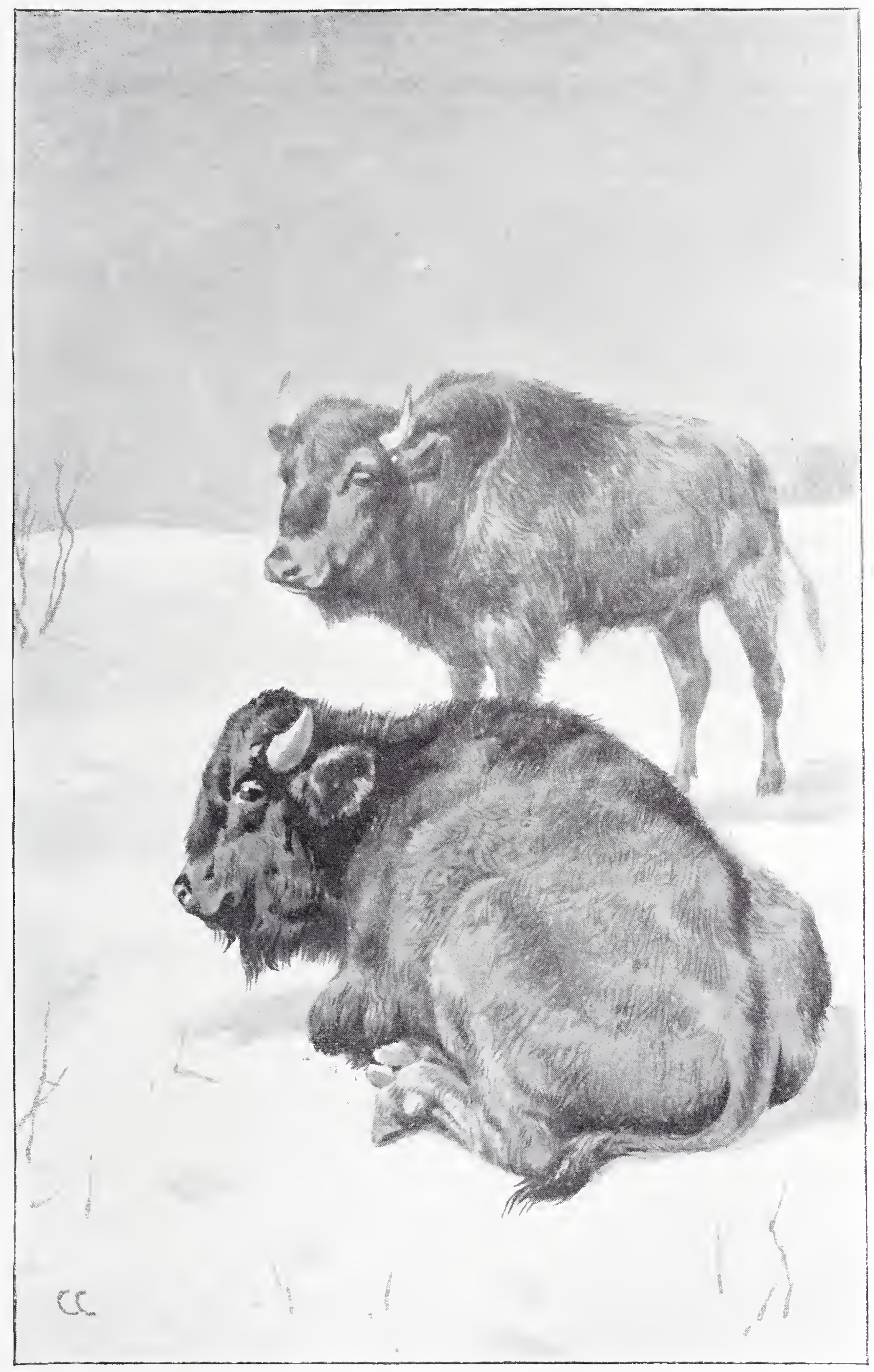

Brson. 

hair of the sides and hind quarters is very thick. The consequence is that the animal looks a great deal bigger than it really is, although it stands well over five feet high at the shoulders.

In spite of this great mass of hair, the bison is a very active animal, and can both trot and gallop with very considerable speed. When galloping it always holds its head close to the ground, and its tail high up in the air. It is not by any means a courageous animal, notwithstanding its size and strength. But the bulls fight most savagely with one another, roaring so loudly as they do so, that in the days of the great herds the noise was compared to thunder, and could be heard from many miles away.

Another kind of bison, sometimes, but wrongly, called the Aurochs, lives in the great forests of Northern Europe. Its mane is not so long and thick as that of the American animal, hut its horns are longer, and not so strongly curved.

Smaller than the bison, but very much more formidable, is the Cape Buffalo, which is spread over almost the whole of Africa south of the Equator. It is about as big as an ordinary bullock, and has a pair of massive and sharply-pointed curred horns, which are sometimes as much as three feet in length.

This animal lives in reedy swamps, and is generally found in herds, which often number from 250 to 300 individuals. They are very wary, and difficult to approach, while they are so swift of foot that only a very fast horse can escape from them when carrying a rider on its back. In charging they throw their heads hack, with the horns upon the shoulders, and then suddenly bend down and strike upwards when they come within reach.

The buffalo does not usually attack unless it is wounded, however, though "solitaries" will often lie in concealment and rush out upon the hunter as he passes by.

There is another kind of buffalo found in India, which is a very different animal in every way. It is different in appearance, for it has its head drawn out into a lind of muzzle, while its horns are very long indeed, and taper gradually from base to tip, at the same time curring outwards and upwards and backwards. And it is different in disposition, because it is easily tamed, and is employed in many parts of India as a beast of draught and burden. You might see buffaloes drawing a plough, for example, or dragging a cart, and for these and similar purposes they have been introduced into Egypt, and even into Italy. The wild bulls, however, are apt to be very savage when they live alone. But a herd of buffaloes, strange to say, though they will gallop up close, and toss their heads, and behave in a most threatening manner, seem never to actually attack a man so long as he has the courage to stand perfectly still.

The Musk Ox, though it is called an ox, and looks like an $\mathrm{ox}$, is in reality much more closely related to the sheep. It is of ahout the size of a rather large ram, but looks much bigger than 
it really is, owing to the great masses of long hair, which cover the whole of its body, and hang down so far that one can scarcely see its legs at all. It is even more hairy, indeed, than the yak. The horns of the male animal are very curiously formed, for they are so broad and flat at the base that they form a kind of helmet, which covers almost the whole of the forehead. They then droop downward on either side of the face, but curve upward and outward at the tips. Those of the cow, however, are very much smaller.

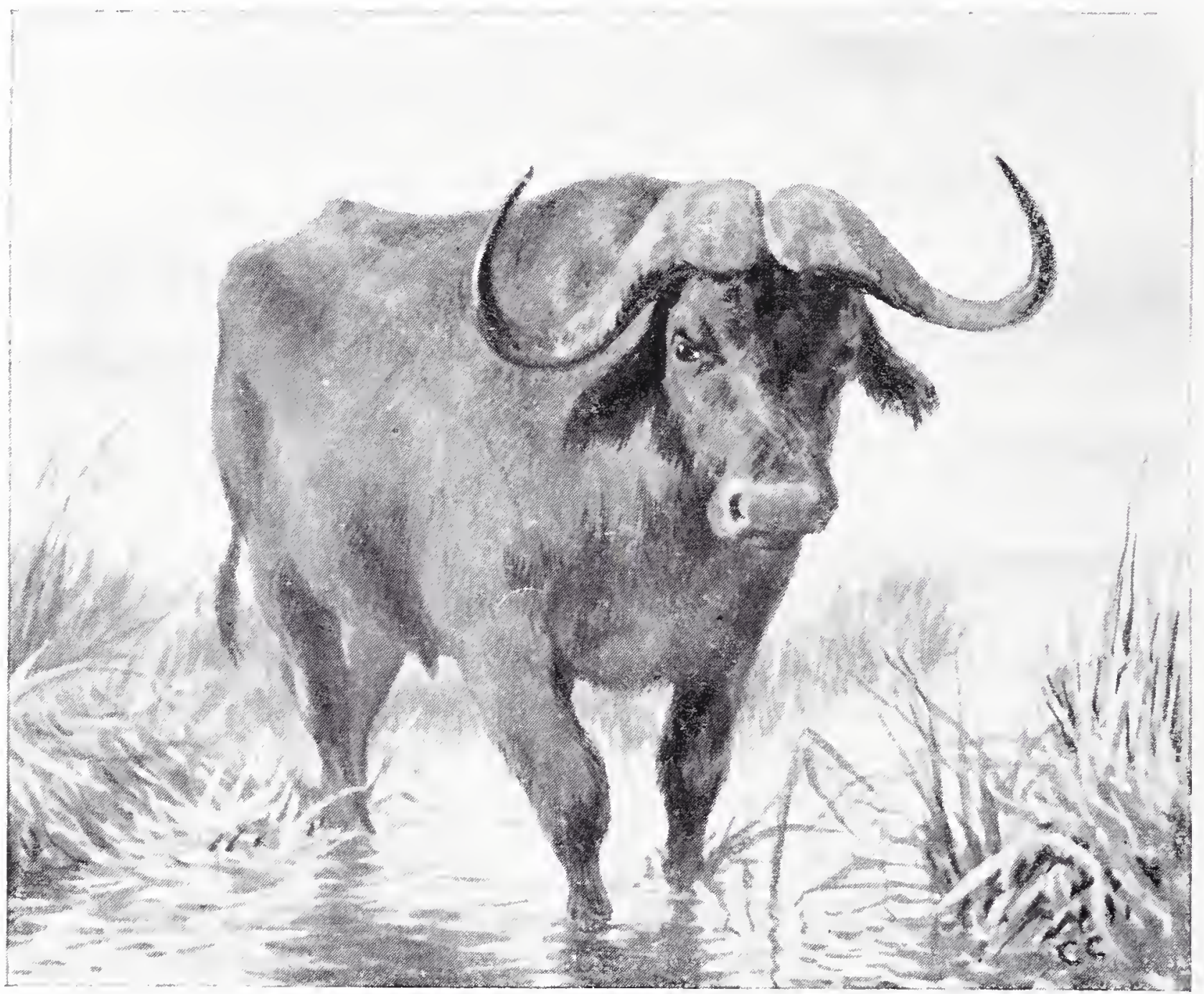

Cale BUFFalo.

The musk ox lives in the most northerly parts of North America. It is perfectly at home amid the snow and ice, and lives in the wildest and dreariest regions, in which the ground scarcely thaws during the whole of the year; so that the life of those who hunt it is a very hard one. But, as a rule, its only enemies are the arctic wolves, which drive it to bay on some rocky mountain slope, and tear it to the ground by the mere force of numbers.

The name of this animal is due to the musky flavour of its flesh, which is, nevertheless, said to be very tender and delicate. As an example of the wild sheep, let us take the Argati, 


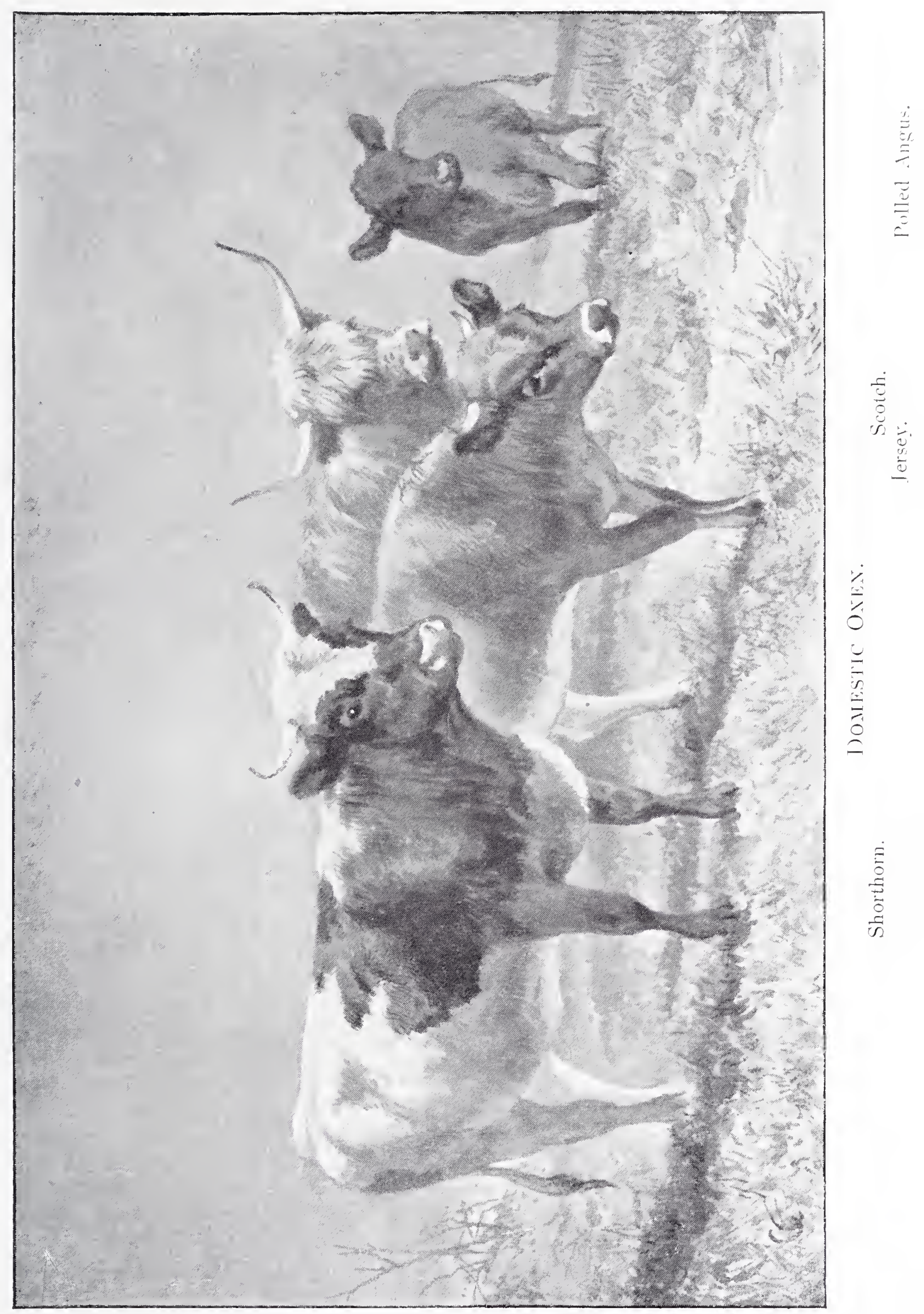



$\checkmark$ 
which is found in Mongolia, and also in Thibet. It is about as big as a large donkey, and has most enormous twisted and wrinkled horns, which are sometimes as much as four feet long, and nineteen inches round at the base.

The argali rams are very fond of fighting one another, and such fierce conflicts take place that sometimes their horns are broken short off, and left lying upon the ground. And it will give you some idea of the size of these horns when I tell you that more than once a fox has been found lying fast asleep in one of them!

The argali is a mountain-loving animal, seldom seen at a

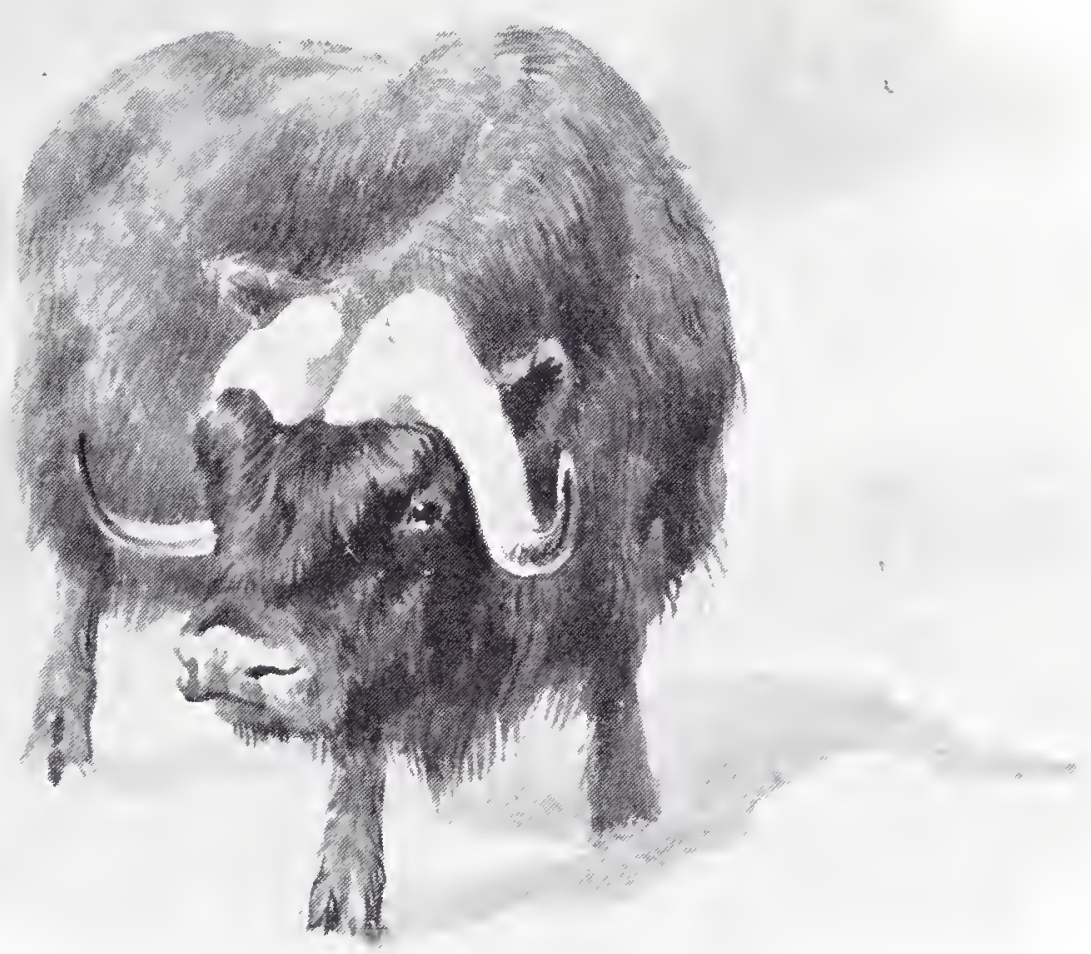

Misk Ox.

lower level than twelve or thirteen thousand feet cven in winter, while in summer it ascends much higher. It is a most difficult creature to approach, for it lives in small flocks, which always post a sentry to keep careful watch while they are feeding. At the slightest sign of danger the alert sentinel gives the alarm, and a moment later the animals are dispersing in all directions, scrambling so actively over rocks and up and down precipices that it is quite impossible to follow them.

It has sometimes been said that when the argali leaps from a height it alights on its horns, which break the force of its fall. but this statement seems to be quite untrue. 
Next come the wild goats, of which we may take the IBEx as one example.

In some respects this animal is not at all unlike the argali. It lives high up among the mountains, for instance, and goes about in small herds, which always post one of their number to keep watch while they are feeding or resting. And it is quite as active and sure-footed when scrambling about among the crags

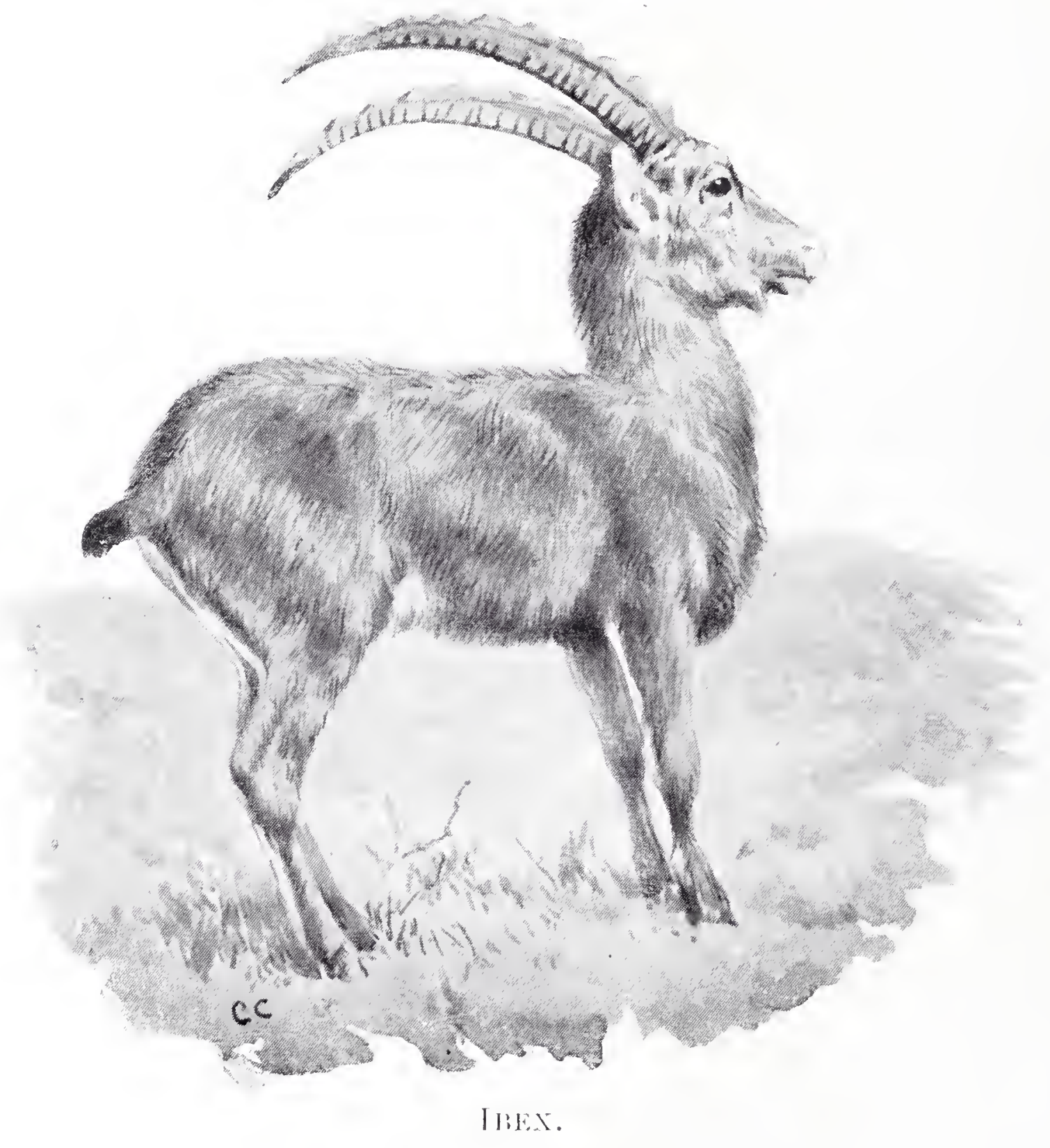

and roclis. But in appearance it is very difterent, for it has a long beard underneath its chin, like almost all the goats, while the horns spring upwards and backwards from the head, instead of drooping downwards. Besides this, there is a row of strong ridges running crosswise up the horns from the base almost to the tip. In a large ibex these horns are sometimes more than four feet long.

Until a few years ago the ibex was found in the Alps. But as a wild animal it is now extinct in Europe, the few remaining 
herds having been brought under domestication. In the Himalayas, however, it is still very plentiful, although a large number are destroyed by wild dogs and also by avalanches, to say nothing of those which are killed by hunters. Although they are very wary, they never seem to understand that they can be attacked from above, so that if a hunter can creep down upon an overhanging rock, he can generally obtain a shot without very much difficulty.

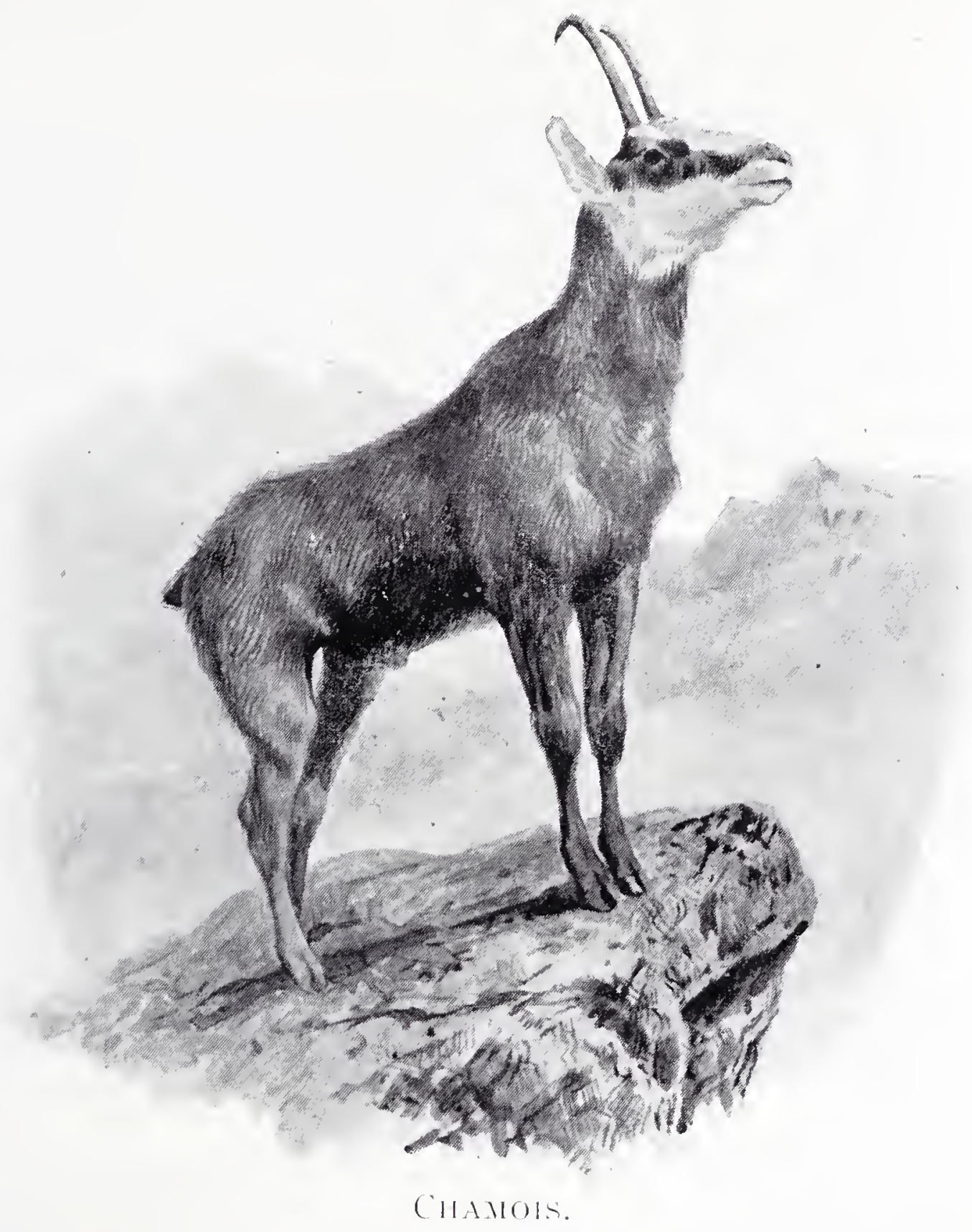

The colour of the ibex varies at different times of the year, its coat being reddish-brown in summer, and greyish-brown in winter. It stands from thirty to forty inches in height at the shoulder.

The goats are linked with the antelopes by the famous Chamors, which is especially interesting because it makes its home among the snow-clad mountains of Europe. It is a pretty little creature about two feet in height, with a pair of short black horns which spring upright from the forehead, and are then sharply 
hooked, with the points directed backwards. And its coat, strange to say, instead of becoming paler in winter grows darker, so that from brownish-yellow it deepens into rich chestnut.

The chamois is one of the most active of all living animals, leaping from rock to rock, and skipping up and down steep cliffs, where it would seem quite impossible for it to obtain any foothold at all. It will often spring down, too, from a very great height, never seeming to injure itself, and always alighting upon its feet. And as it is very sharp-sighted and exceedingly wary, a hunter finds the utmost difficulty in approaching, and very often for days together he never has the chance of obtaining a shot.

When a chamois notices any sign of danger, it utters a shrill whistling cry, on hearing which all the members of the herd instantly take to flight. There are generally from fifteen to twenty animals in each herd, consisting partly of does and partly of young buclis. The old bucks spend most of the year quite by themselves. But early in the autumn they rejoin the herds, drive away their younger rivals, and then fight fierce battles with one another for the mastery.

The young of the chamois are horn in May or June, and are so strong and active that when they are only a day old they can follow their mother almost anywhere.

Now we come to the true Antelopes, the finest of which is the ELAND.

This is a really magnificent animal, for it stands from five to six feet high at the shoulder, and sometimes weighs nearly I,500 pounds! Both the buck and the doe have spirally twisted horns, which are generally about two feet long, and there is a heavy dewlap underneath the throat. In colour the animal is pale fawn, but sometimes the old males are bluish grey.

In former days the eland was spread all over Southern and Eastern Africa. But it has been so much persecuted on account of its hide that it has quite disappeared from South Africa, and is fast disappearing elsewhere. Indeed, there seems only too much reason to fear that in a few years' time this splendid antelope will be altogether extinct. It lives for the most part in wooded plains, and is generally found in large herds, which spend the clay-time hiding in the forests, and come out into the open country by night to graze and drink.

In the desert districts, however, where water is scarce, they quench their thirst by feeding upon melons.

The eland is a difficult animal to hunt, for besides being very wary and very timid, it is often accompanied by a "rhinoceros bird," which gives it early warning of the approach of a foe. And, further, it is very swift of foot, so that it cant only be ridden down by a good horse. As a rule it will never fight. But when a doe has calves with her, she will withstand the onset of dogs, and has even been linown to impale them upon her horns. 
The KOoDoo, another very fine antelope, can easily be distinguished from the eland by the shape of the horns of the male, which are twisted just like a corkscrew, while the female has none at all. Besides this, it has a white mark across its face, shaped something like the letter $\mathrm{V}$, several white spots on its cheeks and throat, a white streak along its back, and several others running down its sides and hinder quarters. It stands rather more than four feet in height at the shoulder, and the horns are often more than three feet long.

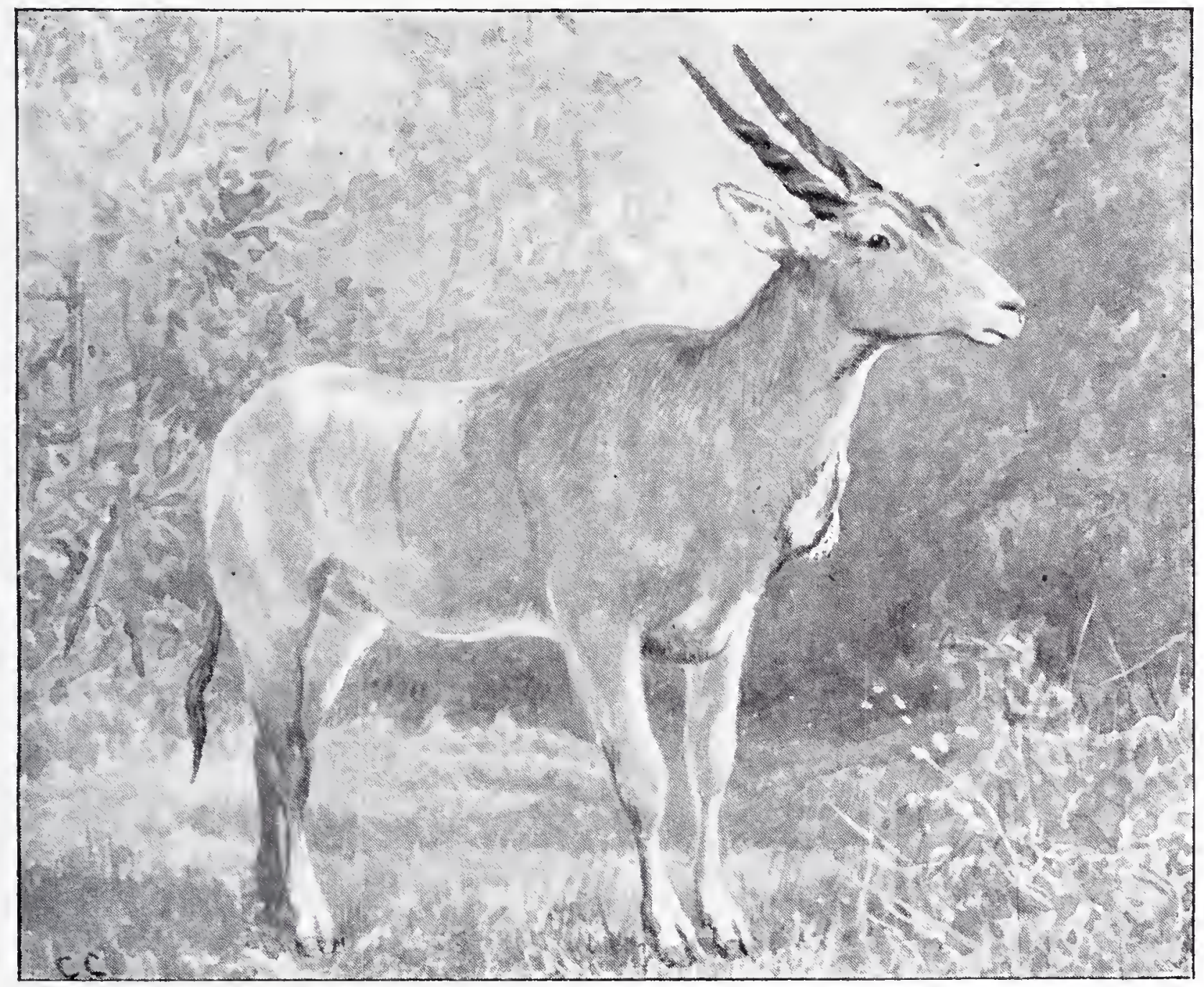

E1.1N1).

The koodoo is found all over Africa, from the Cape to Abyssinia, though it is now very rare in the extreme south. It does not live in herds, as a rule, but is generally found in pairs, which pass the day in dense thickets, and come out to graze in the evening. It is not very swift of foot, and can easily be run down by a man on horseback. But as it is chiefly found in the country infested by the terrible "tsetse fly," whose bite kills horses in a very few days, it is generally hunted only with dogs. Another very fine antelope is the GEMSBOK, which is found in the more desert regions of South-western Ifrica. It is remark- 
able for its very long straight horns, which sometimes measure nearly four feet from base to tip, and are such very formidable weapons, that the animal has been linown to drive off even the lion. Nore than once, indeed, a lion and a gemsbok have been found lying dead together, the antelope having thrust his horns deeply into the lion's body, and been quite unable to withdraw them.

What the gemsbol feeds upon is rather a mystery, for it is often found in districts where there is no vegetation at all except a little dry scrub. Yet it nearly always seems to be in

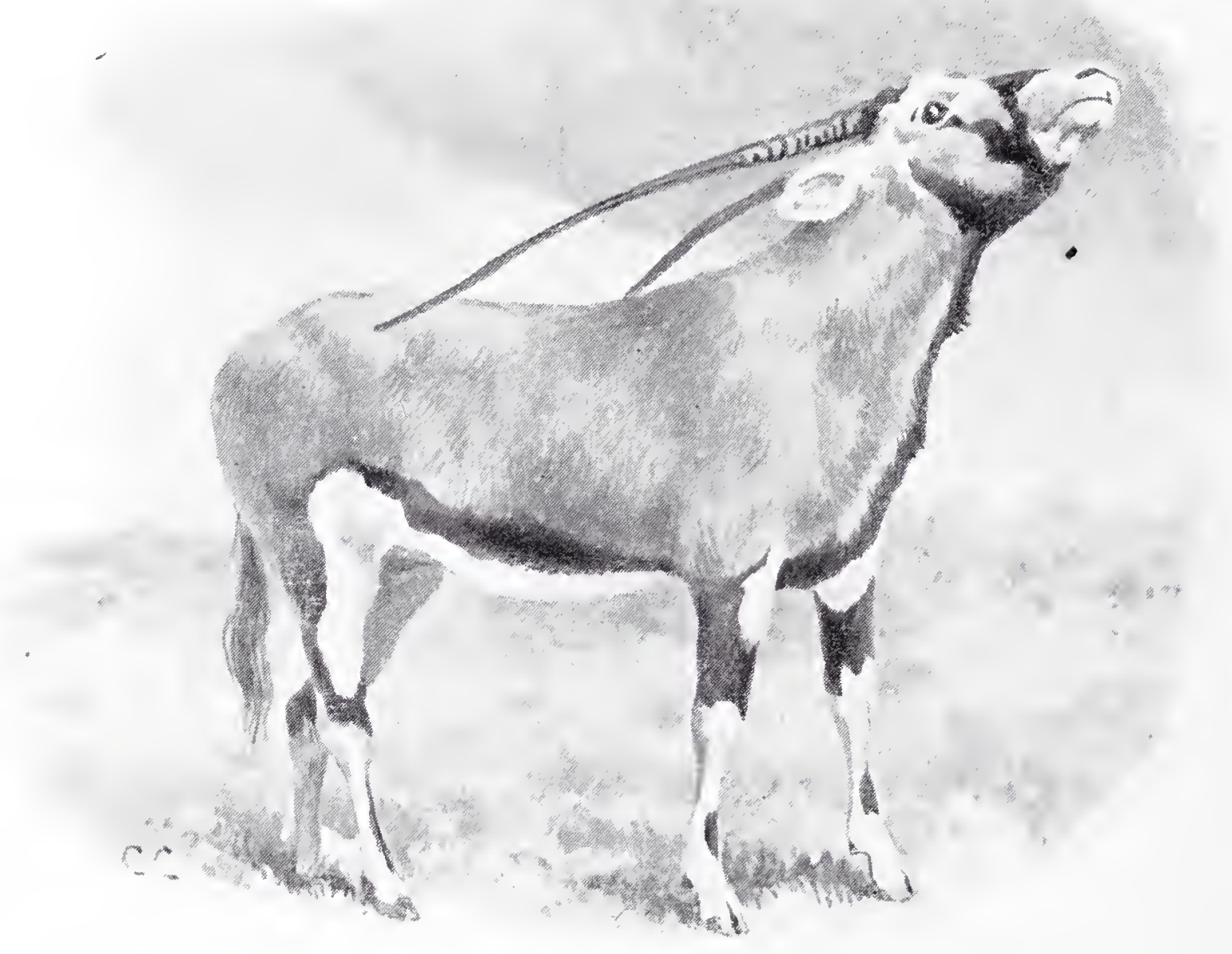

GHMSIOK.

good condition. And it is odder still to find that or months together sometimes it must go without drinking! Some hunters, indeed, have declared that they are quite positive that the animal never drinks at all, obtaining all the moisture it needs from small water melons and certain bulbous roots.

The gemsbok is of about the same size as the koodoo, and is grey in colour above and white below. But there is a black streals across the face, while another streak, which is much broader, runs along the sides, dividing the grey of the upper parts from the white of the lower. This antelope is hunted on horseback, and is so swift and so enduring, that there is said to be no animal in Africa which is harder to overtake. 
The most graceful and clegant of all the antelopes are the gazelles, of which we may talie the SPRingBor as an example.

In former day's this was by far the most abundant of all the African game animals, and would sometimes be seen travelling from one district to another in enormous herds, covering the country as far as the eye could reach. So vast were these herds, indeed, and so closely did the animals march side by side together, that sometimes a lion would be seen in their ranks marching along

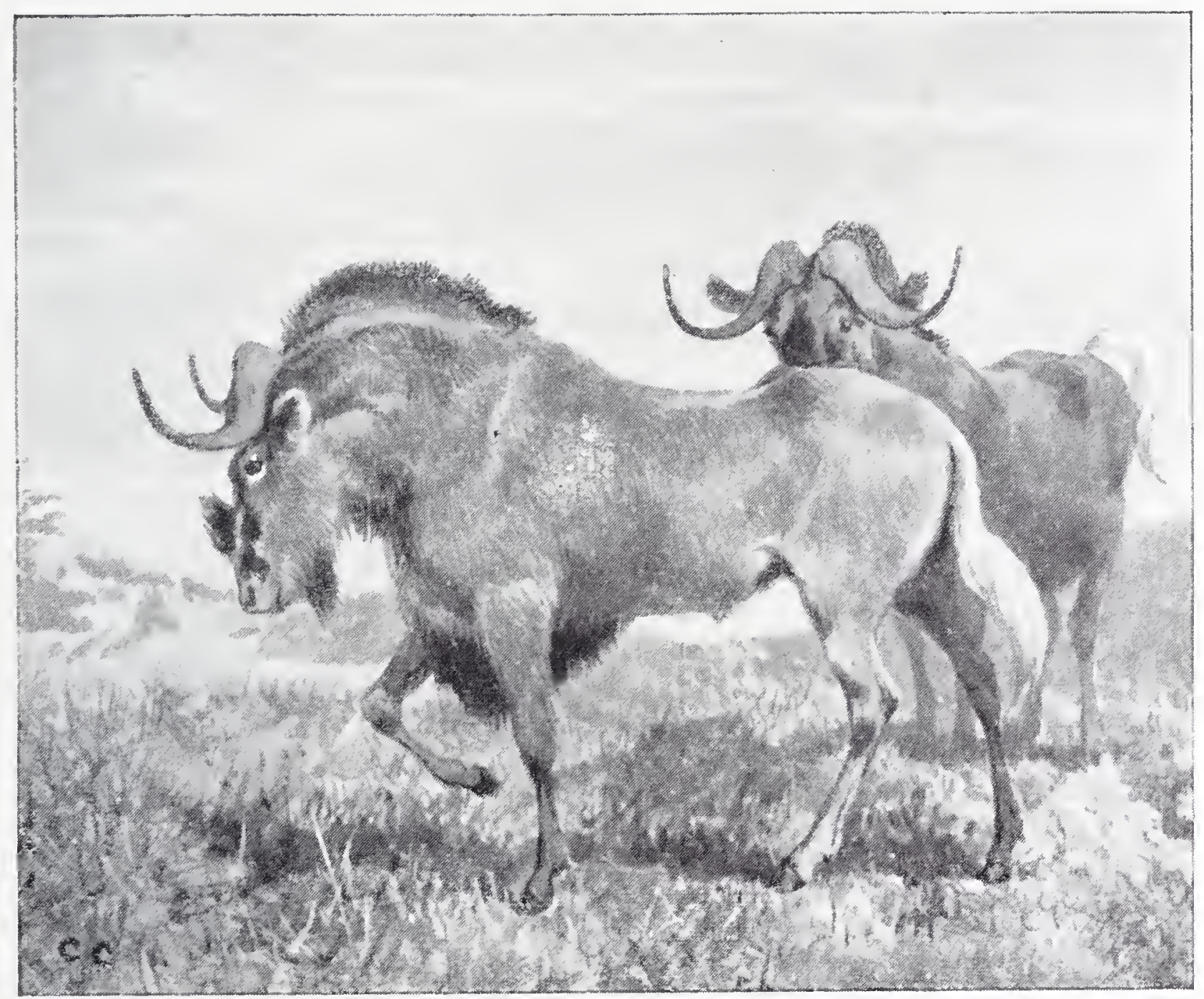

GNTS.

with them, quite unable to stop, or to make his escape, because of the pressure all round him!

The springbok, or "spring buck," owes its name to its marvellous activity, and to its curious habit of suddenly leaping straight up into the air. In this way it can easily spring to a height of eight or ten feet.

The springbok is easily tamed, and soon comes to linow who are its friends. One of these animals was kept as a pet by a lady living at Klerksdorp, in South Africa, and would wander about the town by itself, not seeming to be in the least afraid of the passers-by, or even of the dogs. Every morning, too, it would 
cross the river, and go out upon the veldt to feed; and, strange to say, although it would mix freely with its wild companions during the day, it always left them in the evening and came home to sleep.

In height the springbok stands about two feet six inches, and it can easily be distinguished from all the other gazelles by the white streak which runs along the middle of the back. The horns are black, with a number of ridge-like rings running round them, and the colour of the coat is dark cinnamon-yellow above and white beneath, with a blackish stripe on the flanks between the two.

If the gazelles are the most graceful of all the antelopes, the Gnus are certainly the most ungainly, their great broad heads, and very high shoulders giving them an extremely awkward appearance. Then the curved horns are very broad at the base, and are set so closely together on the forehead that they form a sort of helmet, like those of the Cape buffalo, white the muzzle is fringed with long bristles, and there is an upright mane of stiff hairs upon the neck. So that altogether the gnu cannot be considered as a handsome animal!

Two kinds of gnus are known, toth of which are found in Southern and Eastern Africa. The commoner of the two is called the IVhite-TAIled Gnu, because it has a long white tail, while the other, or BrindeED GNu, has a black one. Both animals stand about four feet six inches in height at the shoulder.

Gnus are very suspicious, very inquisitive, and very timid, and when they catch sight of a human being, they often behave in a most extraordinary way, prancing about, pawing the ground, capering on their hind legs, leaping into the air, and whisking their long tails about in the most absurd manner. Then some will chase the others round and round in circles. Next they will come charging on in a long line like cavalry, as though they meant to attack. And then, quite suddenly, the whole herd will wheel round, and dash off together, enveloped in a cloud of dust!

They are so inquisitive, too, that a hunter has often attracted a gnu to within a very few yards just by tying a red handlierchief to the muzzle of his gun, and allowing it to flutter in the breeze like a flag!

These animals are also known as Wilchebeests. 


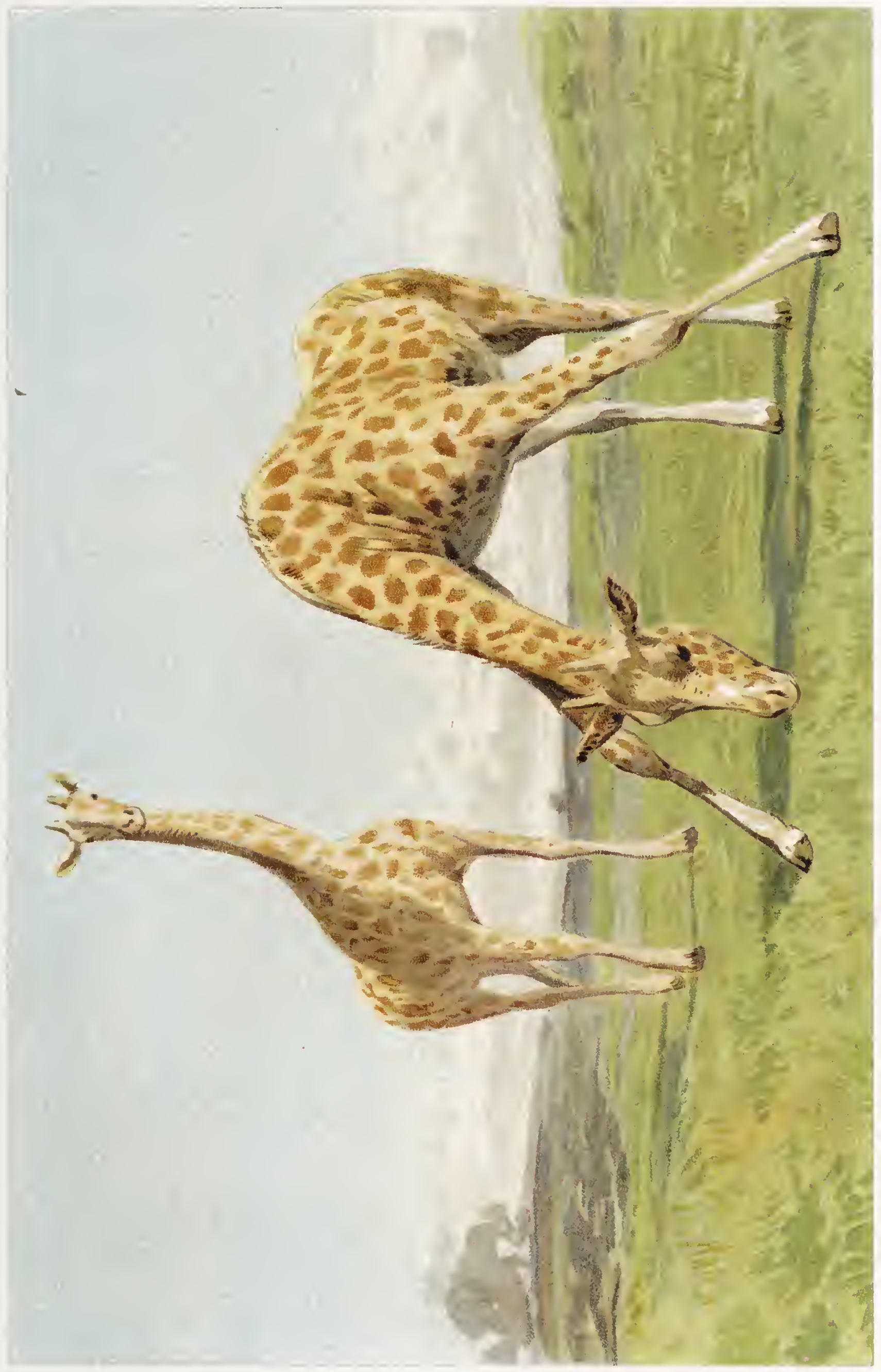





\section{CHAPTER XVI.}

THE GIRAFFES, DIEER, CAMETS IND ZEBRAS.

GIR.IFEES are the tallest of all living animals, for a fully-grown male may stand eighteen or even nineteen feet in height. Just think of it. If one elephant were to stand upon another elephant's back a giraffe could look over them both!

This wonderful height is chiefly due to the great length of the neck. Yet there are only seven vertebra, or joints of the spine, in that part of the body, just as there are in our own necks. But then each of these joints may be as much as a foot long! When the animal is hungry, its height is of very great use to it, enabling it to feed upon the leaves of trees which do not throw out branches near the ground. And in captivity, of course, its manger has to be put quite close to the roof of its stable!

Strange to say, the giraffe pluclis each leaf separately by means of its tongue, which is rery long indeed and very slender, and is prehensile at the tip, like the tail of a spider monkey. So it can be coiled round the stem of a leaf in order to pull it from the branch. And sometimes at the Zoo a giraffe will snatch flowers out of ladies' hats and bonnets by means of this curious tongue.

If a giraffe wants to feed upon grass instead of leaves, it stradklles its front legs very widely apart, and then bends its long neck down between them. And it does just the same when it drinks.

The giraffe is a very fast runner, and only a swift horse can overtake it. It runs in a most singular manner, using the two legs on one side together, and throwing out the hinder ones with a semi-circular movement, while its long neck goes rocking backwards and forwards like that of a toy donkey, and the long tail switches up and down as regularly as if it were moved by clockwork. So a long line of giraffes all running away together must look very odd indeed.

You would think that giraffes would be very easily seen, even in the forest, wouldn't you? Yet every hunter tells us that as long as they are standing still it is almost impossible to detect them, since they look just like the stems and foliage of the trees, with the sunlight shining in patches between the leares!

Giraffes are found in various parts of Africa, south of the Sahara, and two different varieties are known, that from South Africa being much the darker of the two, and having the spots much larger and closer together. A third kind, with five of the so-called "horns" on the head, has lately been recorded by Sir Harry Johnston, who brought home the sliulls of two males and two females from the great Semliki Forest. 
I still more remarkable discovery, made in the same great forest district by the same famous explorer, was that of the OKAPI, which is a very singular animal indeed. Perhaps I can best describe it to you by saying that it is something like a giraffe, and something like an antelope, and something like a zebra, and something like an ox! The colour of its coat is like that of a very red cow, there are zebra-lilie stripes on the fore and hind quarters, and the legs are cream-coloured, while on the skull are faint traces of "horns" like those of the giraffe.

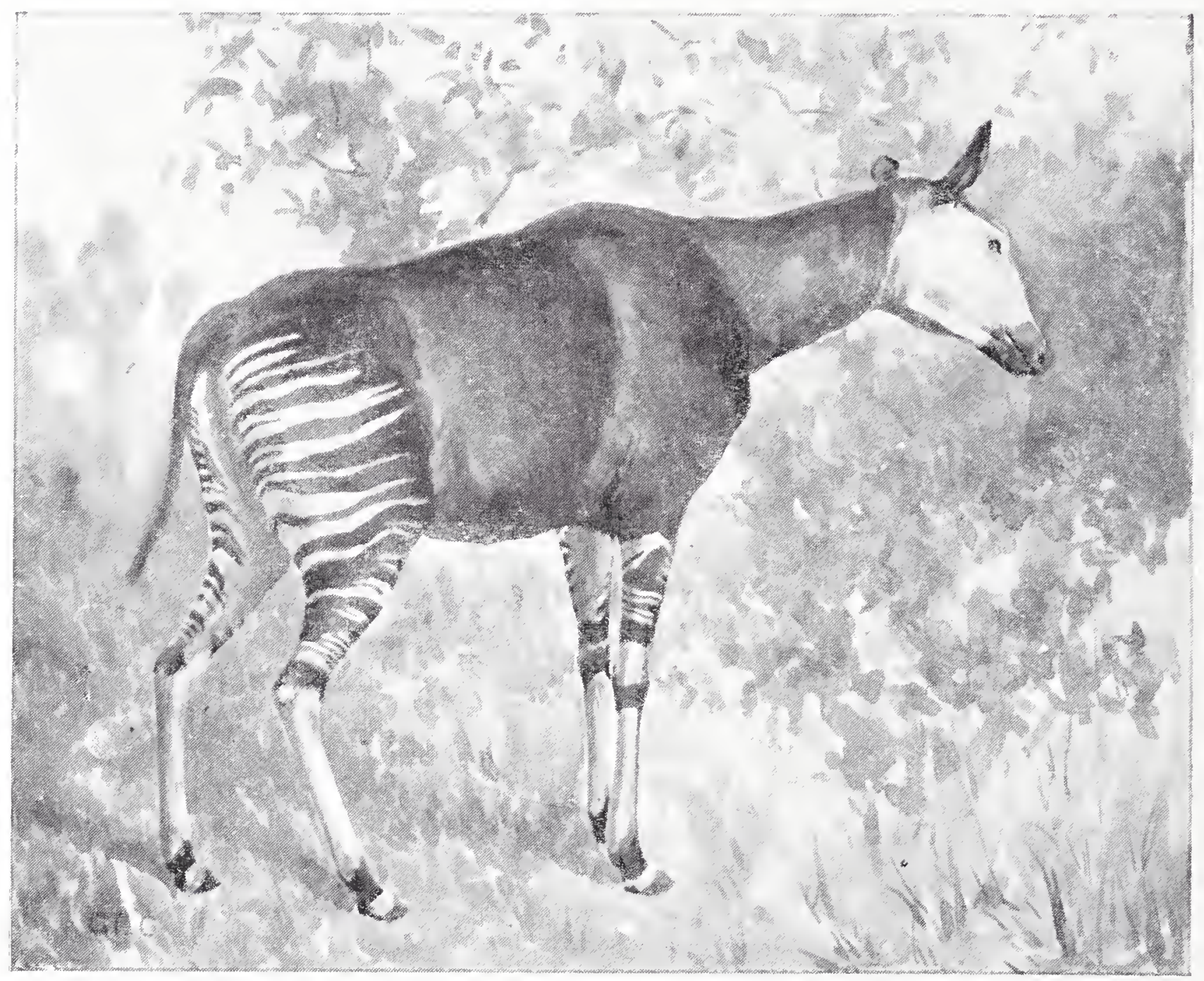

OKAPl.

TVe do not as yet know anything about the habits of this wonderful animal, except that it lives in the thickest parts of the forest and seems to go about in pairs. But a slin which has been brought to this country, and carefully set up, may now be seen in the Natural History Museum at South Kensington.

Next in order come the DeER.

In some ways these animals are not unlike antelopes. But one great difference between the two is this. In the antelopes the horns are hollow, growing upon bony cores which spring from the skull, and remain all through the life of the animal. But in the deer they are solid, and are thrown off every year, fresh ones 
srowing in their places in the course of two or three months. Then the material of which they are made is altogether different, for whereas the horns of the antelopes really consist of highlycompressed hair, those of the deer are composed of lime, and are very much more like bone. For this reason the horns of deer are generally called "antlers."

The way in which these antlers grow is very curious. For some little time after they are shed the animal is extremely timid, for he knows perfectly well that he has lost his natural weapons.

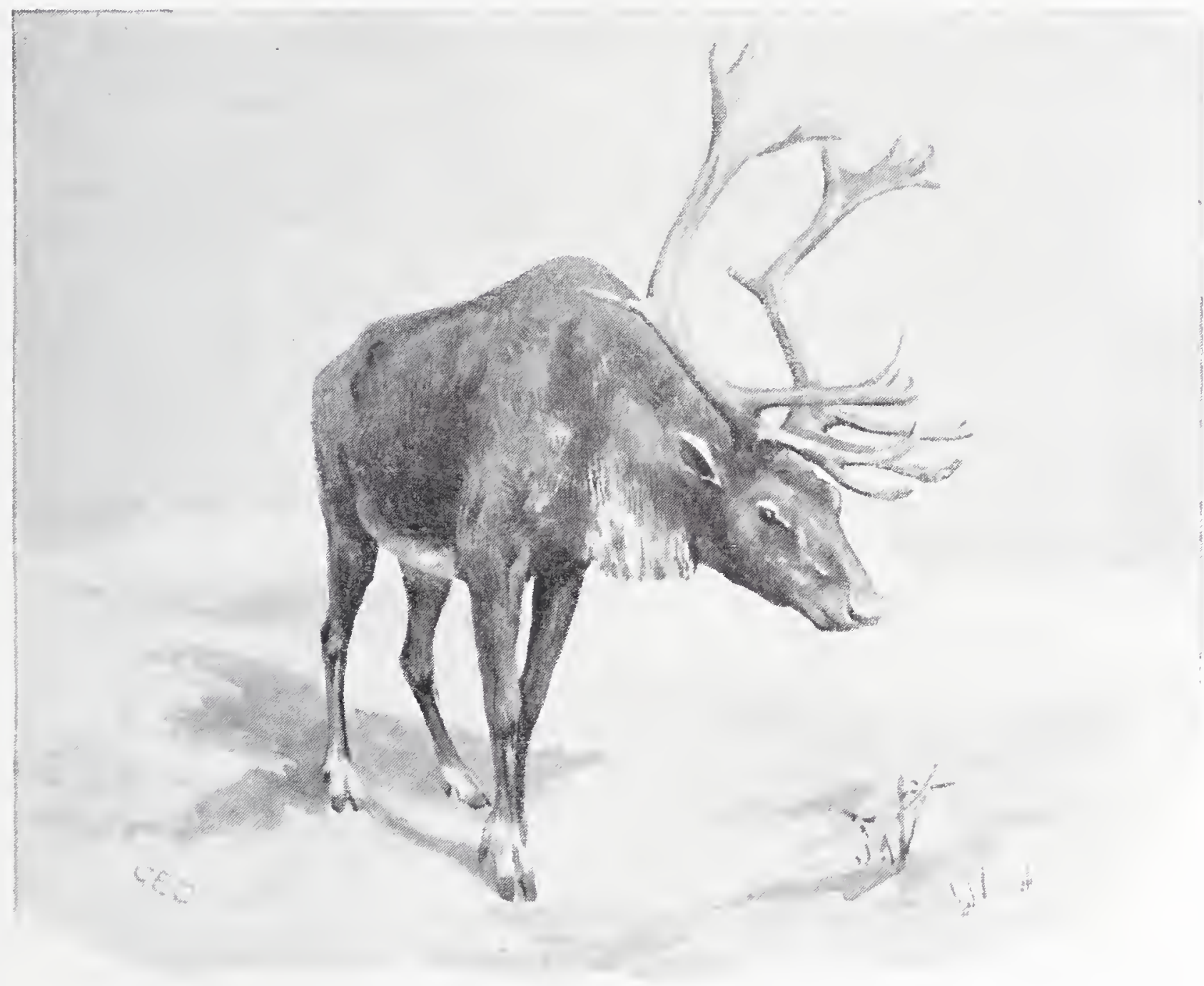

REINISER.

So he hides away in the thickest parts of the forest, where none of his enemies are likely to find him. After a while, two little knobs make their appearance on the head, just where the horns used to be. These linobs are covered with a close furry skin, which is known as the "velvet," and if you were to take hold of them you would find that they were quite hot to the touch. That is because the blood is coursing rapidly through them, and leaving particles of lime behind it as it goes. Day by day they increase in size, throwing out branches as they do so, until they are rather larger than the pair which were cast off. Then the blood ressels 
close up, and the velvet becomes dry and begins to fall off, sometimes hanging down in long strips, which are at last rubbed off against the trees and bushes.

A great many linds of deer are found in different parts of the world, perhaps the most famous of all being the ReindeEr.

This is the only deer in which the does possess horns as well as the stags. It is found in the northern parts of Europe and Asia and also of North America, where it is called the caribon and generally lives in large herds. During the winter and spring these herds remain in the forests. But in the summer-time they are so persecuted by flies that they make their way to the hills, ascending to such a height that their insect enemies cannot follow them, and there they remain until the autumn. A number of herds usually join together when they are migrating in this way, and the appearance of thousands upon thousands of the animals travelling slowly along, each with its antlers uplifted, has been compared to that of a moving forest of leafless trees.

In Siberia, Lapland, and Norway, large herds of reindeer are liept as we lieep cattle, and are used as beasts both of draught and burden. A single reindeer can carry a weight of about I 30 pounds upon its back, or draw a load of Igo pounds upon a sledge, and it is so enduring that it will travel at the rate of from eight to ten miles an hour for twelve hours togrether.

During summer-time reindeer can obtain plenty of food, but in the winter they have to live upon a kind of white lichen, which grows in waste, dry places. Very often, of course, this is covered with snow, which the animals have to scrape away with their hoofs. But when a slight thaw is followed by a frost they find it very difficult to do this, and sometimes they actually perish from starvation.

The colour of the reindeer varies slightly at different seasons of the year, the coat usually being sooty-brown in summer and brownish-grey in winter. The nose, neck, hind quarters and lower parts of the body are always white or whitish grey.

The ELk, which is found in the same parts of the world as the reindeer, is a much larger animal. Indeed, it is the biggest of all living deer, a fully-grown stag standing well over six feet in height at the withers, and sometimes weighing as much as I, 200 pounds. It is not at all a graceful creature, for the necli is very short, and the head is held below the level of the shoulders, while the antlers are so enormously large that it hardly seems possible that the animal should be able to carry them.

One would think that when the elk was travelling through the forest these huge antlers would be constantly getting entangled among the branches of the trees. But the animal is able to throw them well back upon its shoulders, so that they do not really interfere with its progress in the least.

In Canada this animal is linown as the moose, and is generally found in small parties, consisting of a buck, a doe, and 


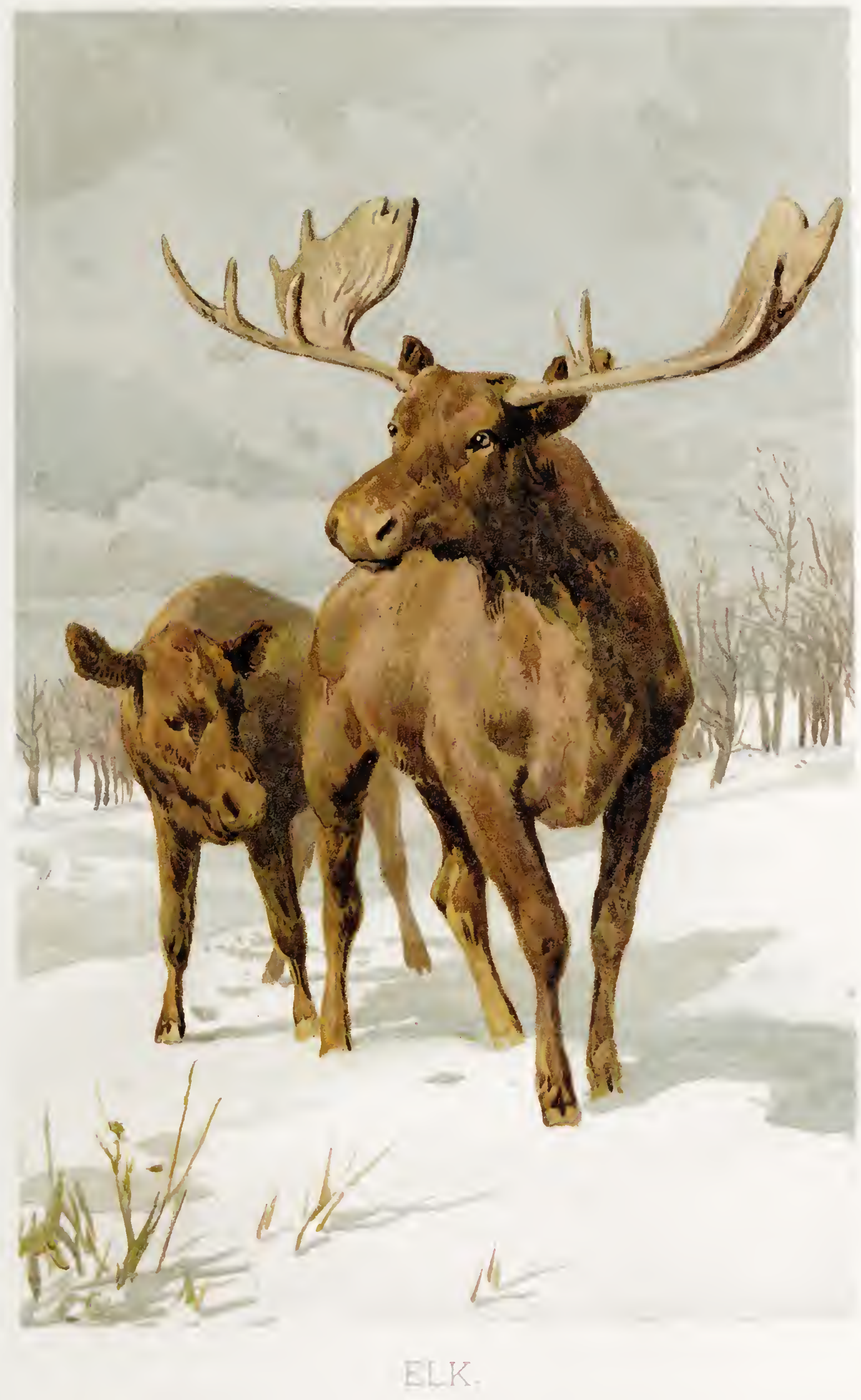



their fawns of two seasons. During the summer they live near swamps or rivers, where there is plenty of rich, long grass. But as soon as winter comes on they retire to higher ground and spend the next few months in a small clearing in the midst of the thickest forest. These clearings are generally called "moose yards," and you might think, perhaps, that when a hunter had discovered one, he would have no difficulty in shooting the animals. But they are so very wary that it is almost impossible to approach them, either by day or by night, and many a hunter has followed them for weeks without obtaining a shot.

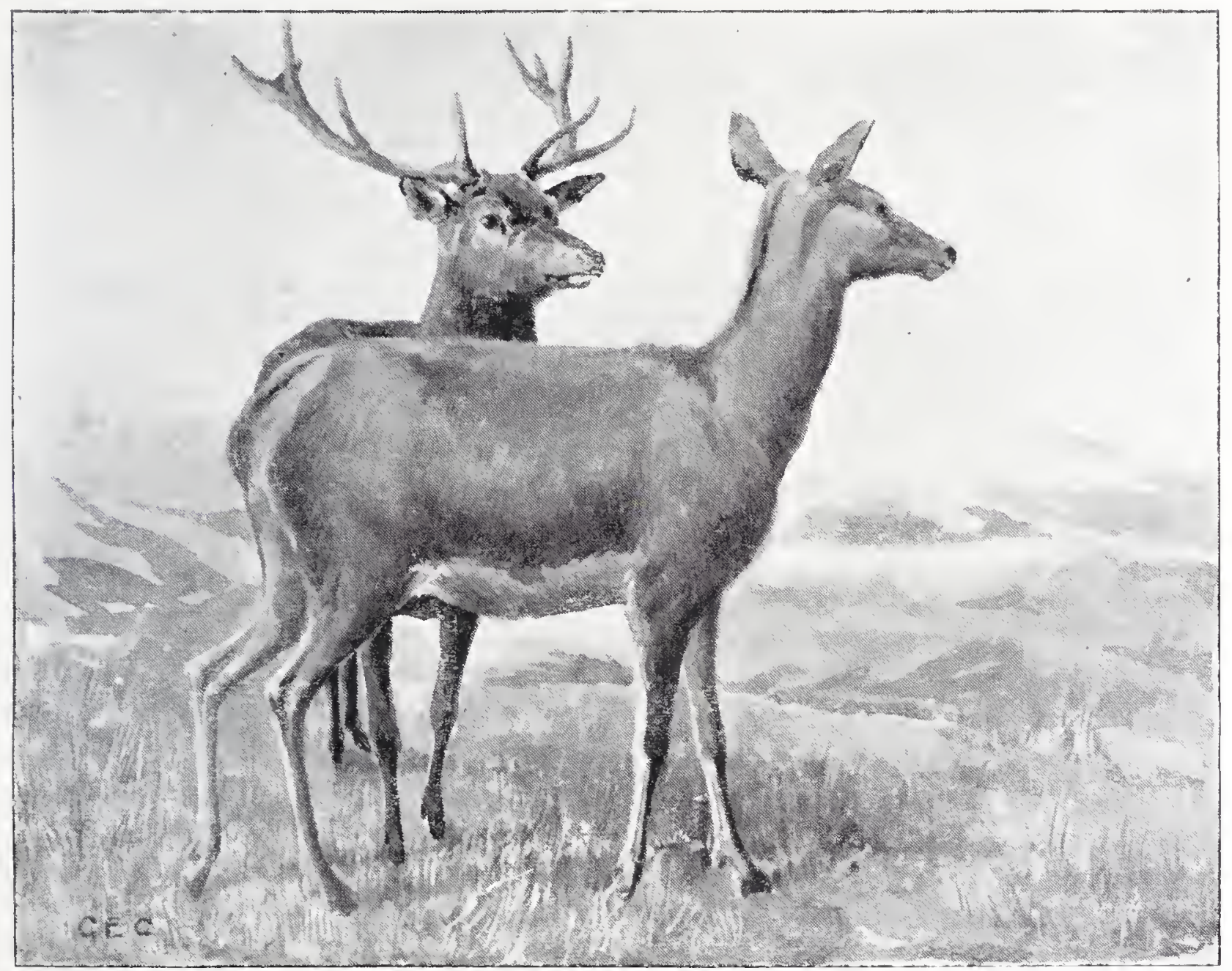

REDTDEER.

The Indians attract the moose within range by imitating the cry of the doe, which they do so cleverly that if a buck is within hearing he is sure to come up to the spot. Or they will rattle a moose's shoulder bone against the bark of a tree so as to make a sound like the call of the buck, which any buck in the neighbourhood is sure to take as a challenge to fight. For these animals are very quarrelsome creatures, and wage fierce battles with one another, sometimes using their antlers with such effect that both combatants die from their wounds.

Three kinds of deer are found in Creat Britain, the finest 
of which is the RED DEER. The only part of England in which it is now really wild is Exmoor, where it is still quite plentiful. But in many parts of the Scottish Highlands it is carefully preserved, large moorland districts being given up to it under the title of "deer forests."

When these animals are fed during the winter they soon become almost tame. Only a few months before writing these lines, for instance, I was sitting on a $\log$ in the Black Wood of Rannoch, eating some sandwiches, while a stag stood quietly watching me, scarcely fifty yards away.

When the female deer has a little fawn to take care of, she generally hides it among very tall heather, pressing it gently with her nose to make it lie down. There it will remain all day long without moving, till she returns to it in the evening. But she is never very far a way, and is always ready to come at once to its aid if it should be attacked ly a fox or a wild cat.

The stag of this animal is a good deal larger than the doe, and may stand as much as four feet high at the shoulder, while its antlers may be more than three feet long. In colour it is a bright reddish brown, which often becomes a good deal paler during the winter.

Next comes the Faldow DEER, which is not nearly so big.

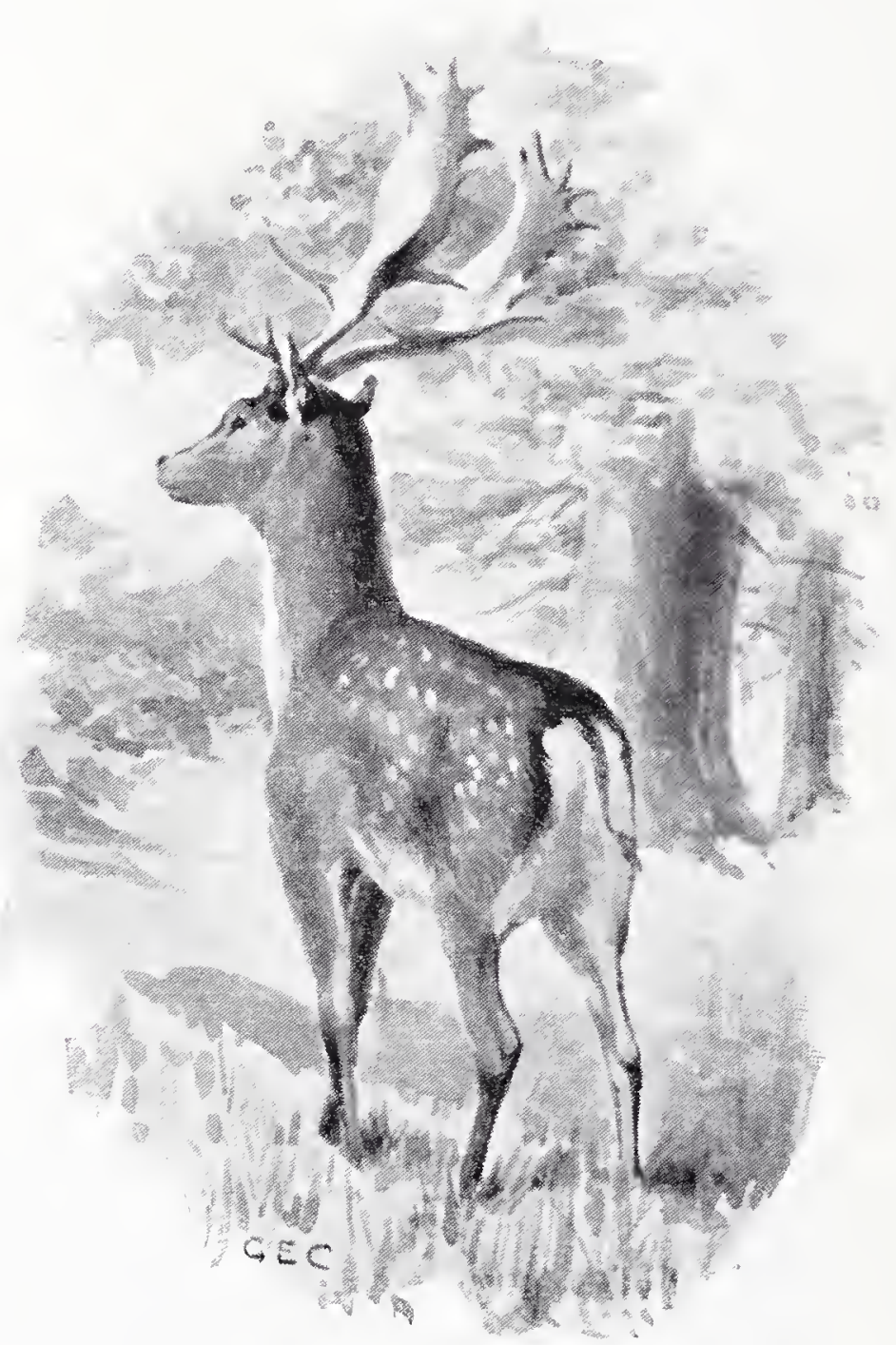

FAIJOW I)EER.

Indeed, it is never more than three feet in height, while you can also distinguish it by the fact that the antlers are flattened out at the tip into a broad plate, and that the coat is spotted with white.

This is the deer which is kept in so many of our great parks, where you may often see a herd of a hundred or more of the pretty, graceful animals moving about together.

There is always a "master" deer in each of these herds, who has won his post by fighting and overcoming all his rivals. He does not always remain with the herd, but often lives apart for weeks together, accompanied, perhaps, by three or four favourite does; and in his absence the herd is led by some of the younger hucks. But whenever he makes his appearance these make way 
for him, and no one disputes his sway until he becomes too old and infirm to hold his position any longer.

The male fallow deer is known by different names at different times of his life. In the first year he is called a "fawn," in the

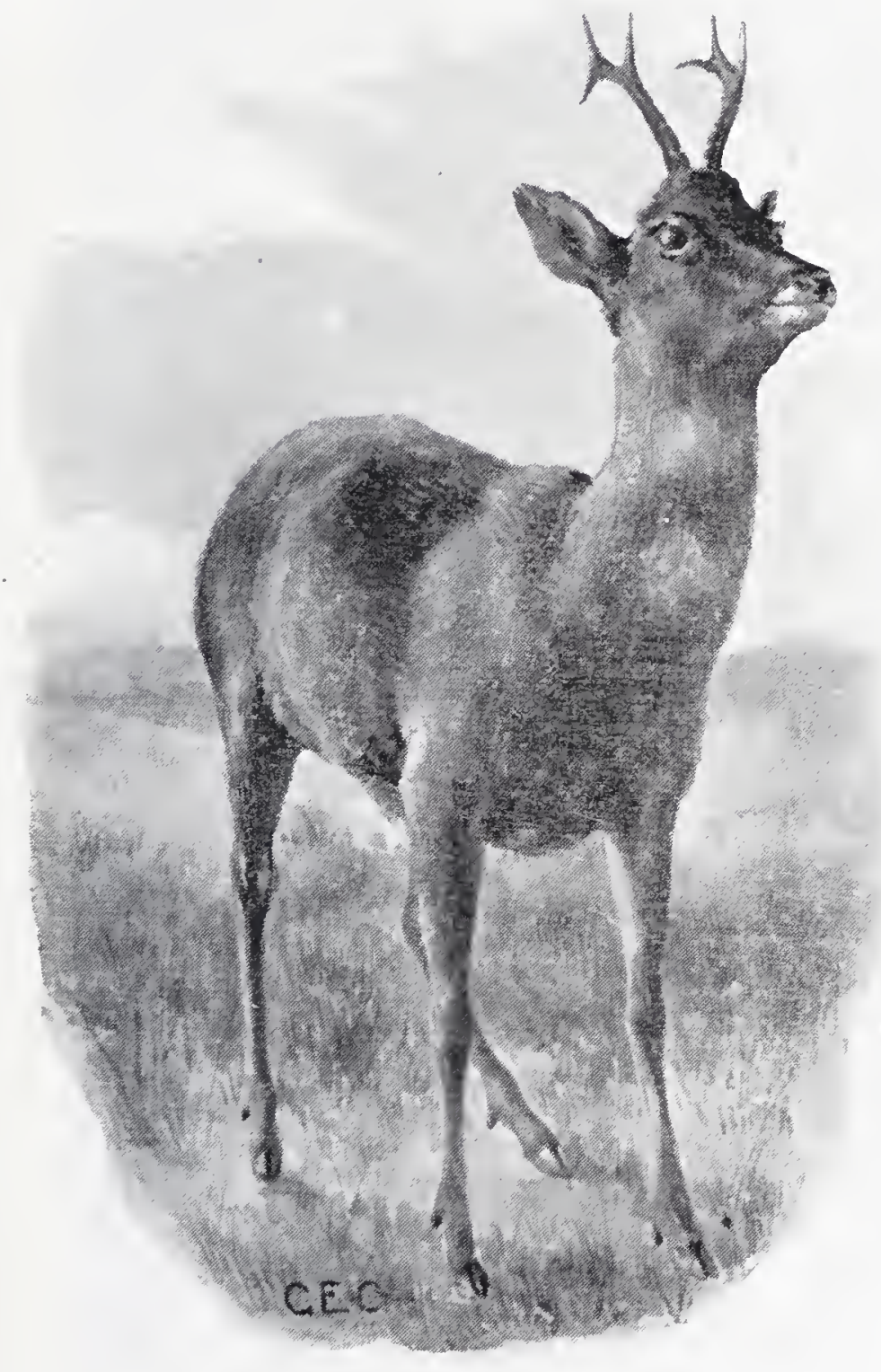

ROEBUCK. second year a "pricliet," in the third a "sorrel," and in the fourth a "soare," while when he is five years old he is described as a "buck of the first lead," and when he is six as a "buck complete."

The last of the British deer is the Roebuck, which is quite a small animal, seldom exceeding twentysix inches in height at the shoulder. In colour it is reddish or greyish brown above and greyish white underneath, with a white patch on the chin and another round the root of the tail. The antlers stand nearly upright, and throw off one "tine," or spur, in front, and two more behind.

There is only one part of England where the roebuck is found wild, and that is Blackmoor Vale, in Dorsetshire. But it is common in many of the Scottish moors and forests. It is never seen in herds, like the fallow deer, but goes about in pairs, although when there are fawns they accompany their parents.

The roebuck sheds its antlers in-December, and the new ones are fully developed by about the end of February. Although they are seldom more than eight or nine inches long they are really formidable weapons, more especially as the deer is very powerful in proportion to its size. The buclis are very quarrelsome creatures and fight most savagely with one another, while more than once they have been known to attack human beings, and to inflict severe wounds before they could be driven away.

There are a good many other deer about which I should like to tell you. But I have only space to mention one more, and that shall be the very curious Musk DeEr, which is found in the 
Himalaya Mountains. In many ways this animal is unlike almost all the other members of the tribe. It has no antlers, for example, the head of the buck being as smooth as that of the doe. Then in its upper jaw the male animal has a pair of tusks, which sometimes project for quite three inches underneath the lips. Besides this, the hind legs are longer than the front ones, so that while the deer can run uphill very easily, it has to be most careful in descending a slope, lest it should lose its balance and roll to the bottom. So in this respect it is more like a hare than a deer, and strange to say, it

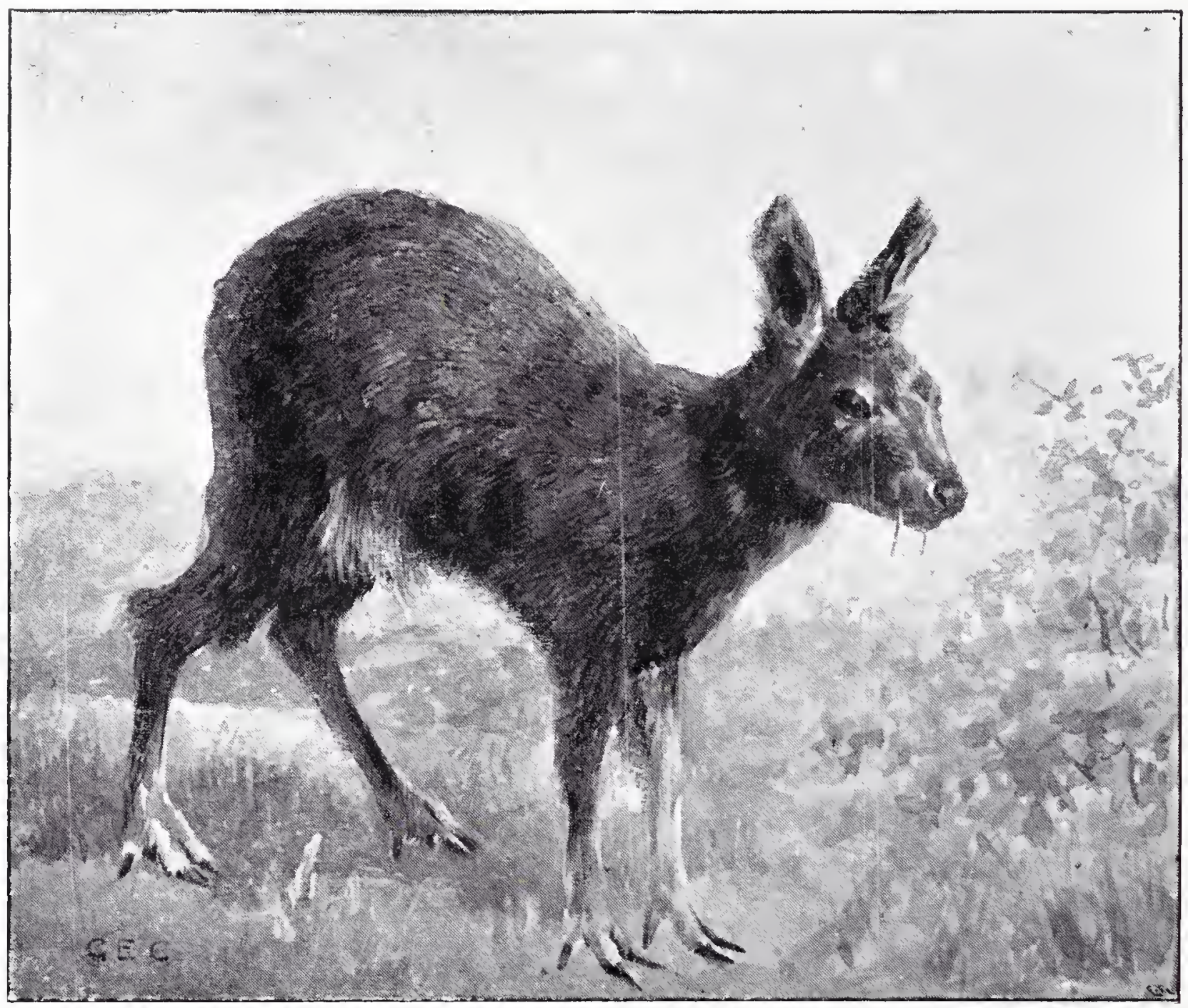

MLSK DEER.

actually makes a "form," just as the hare does, and lies in it all clay, coming out to feed only in the early morning and in the evening.

But the oddest thing of all about this little animal is the substance from which it talies its name. This is produced in a small gland near the tail of the buck, and when it is first taken out it is quite soft and smells very nasty. But as it dries it begins to give out its peculiar odour, which is so strong and enduring that a very tiny piece will scent a whole room, while even after several years have passed it will not seem to have diminished in size and will be as powerful as ever. 


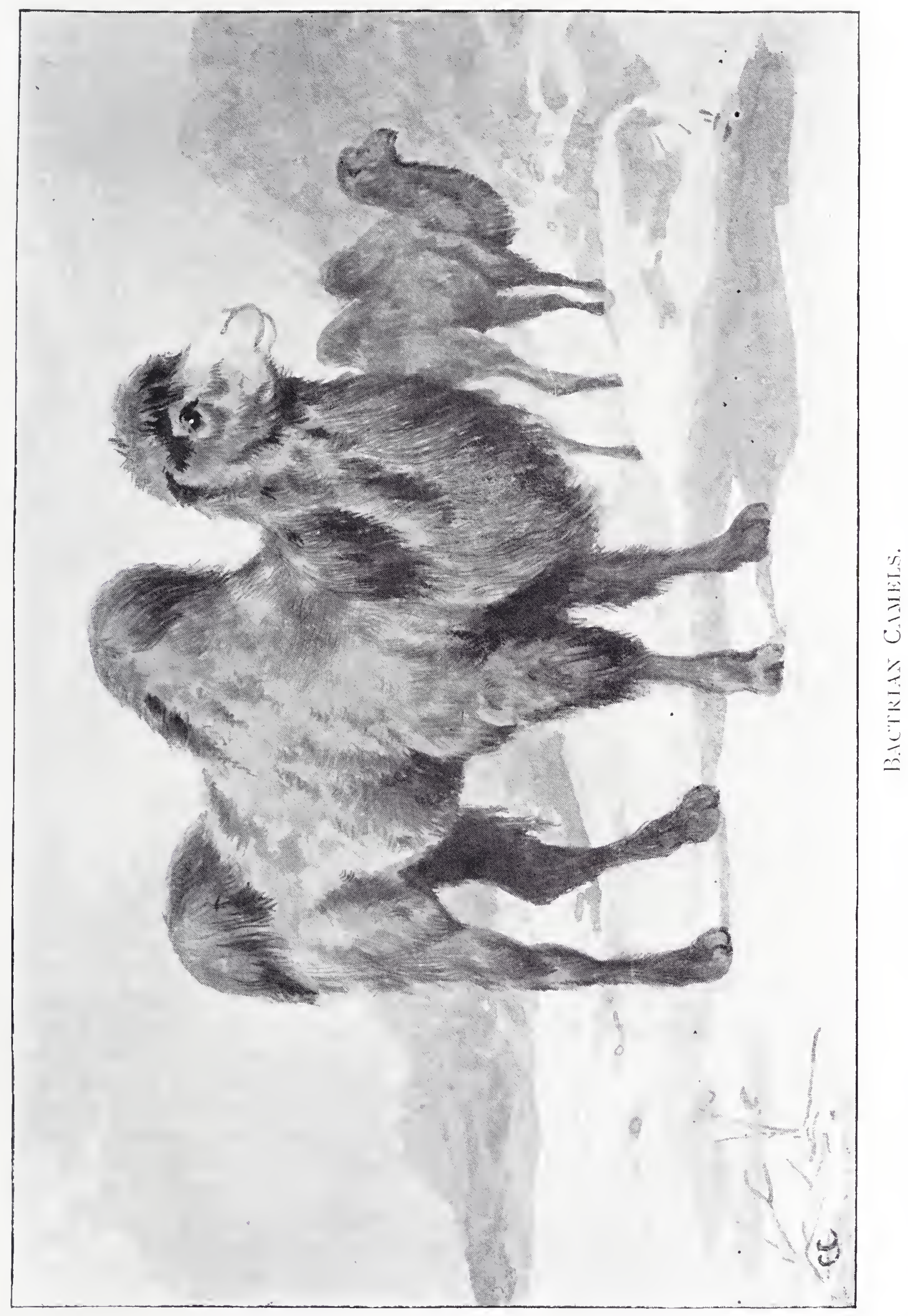



About an ounce of musk is taken from each animal, and is at once tied up in a little bag made from the skin which covers the gland. 'This is called a "musk-pod," and is worth about thirty shillings.

The musk deer is a very active creature, and cannot be pursued without very great difficulty. So it is generally snared by building a very long fence, making gaps here and there through which the animals can pass, and arranging nooses in the gaps. Many thousands are caught in this way every year, yet it still seems to be as plentiful as ever. the Camel.

IVe now come to a very interesting animal indeed; namely,

First let me tell you how wonderfully it is suited to a life in the desert.

In the first place, it has great spreading feet. Now this is very important, for if the animal had small, hard hoofs, like those of the horse or the donkey, it would sink deeply into the loose sand at every step, and would soon be so tired out that it would be quite unable to travel any farther. But its broad, splay, cushion-like toes do not sink into the sand at all, and it can march easily along, hour after hour, where a horse could scarcely travel a couple of miles.

Then it can go for several weeks with hardly any food at all. All that it finds as it journeys through the desert is a mouthful or two of dry thorns, and even at the end of the day its master has nothing to give it but a few dates. And on this meagre diet it has to travel for forty or fifty miles a day with a heavy load upon its back.

But then, you must remember, the camel has a hump. Now this hump consists almost entirely of fat, and as the animal marches on day after day with scarcely any food, this fat passes back by degrees into its system, and actually serves as nourishment! So, you see, while the camel is travelling through the desert it really lives chiefly on its own hump! By the time that it reaches its journey's end, the hump has almost entirely disappeared. Little more is left in its place than a loose bag of empty skin. The animal is then unfit for work and has to be allowed to graze for two or three weeks in the richest possible pasture. Day by day, however, the hump fills out again, and when it is firm and solicl once more the camel is fit for another journey.

More wonderful still, perhaps, is its way of carrying enough water about with it to last for several days.

"Ruminating" animals, or those which chew the cud, have the stomach divided into four separate compartments, through which the food passes in turn. These are called the "paunch," the "honeycomb bag," the "manyplies" and the "abomasum." In the camel, however, the third of these is wanting, and the first and second are provided with a number of deep cells, which can be opened or closed at the will of the animal. 
In these cells the animal is able to store up water. When it has the opportunity of drinling, it not only quenches its thirst, but fills up all these cells as well. In this way it can store up guite a gallon and a half of liquid. 'Then, when it grows thirsty, and camnot find a pool or a stream, all that it has to do is to open one or two of the cells and allow the contents to flow out, and so on from time to

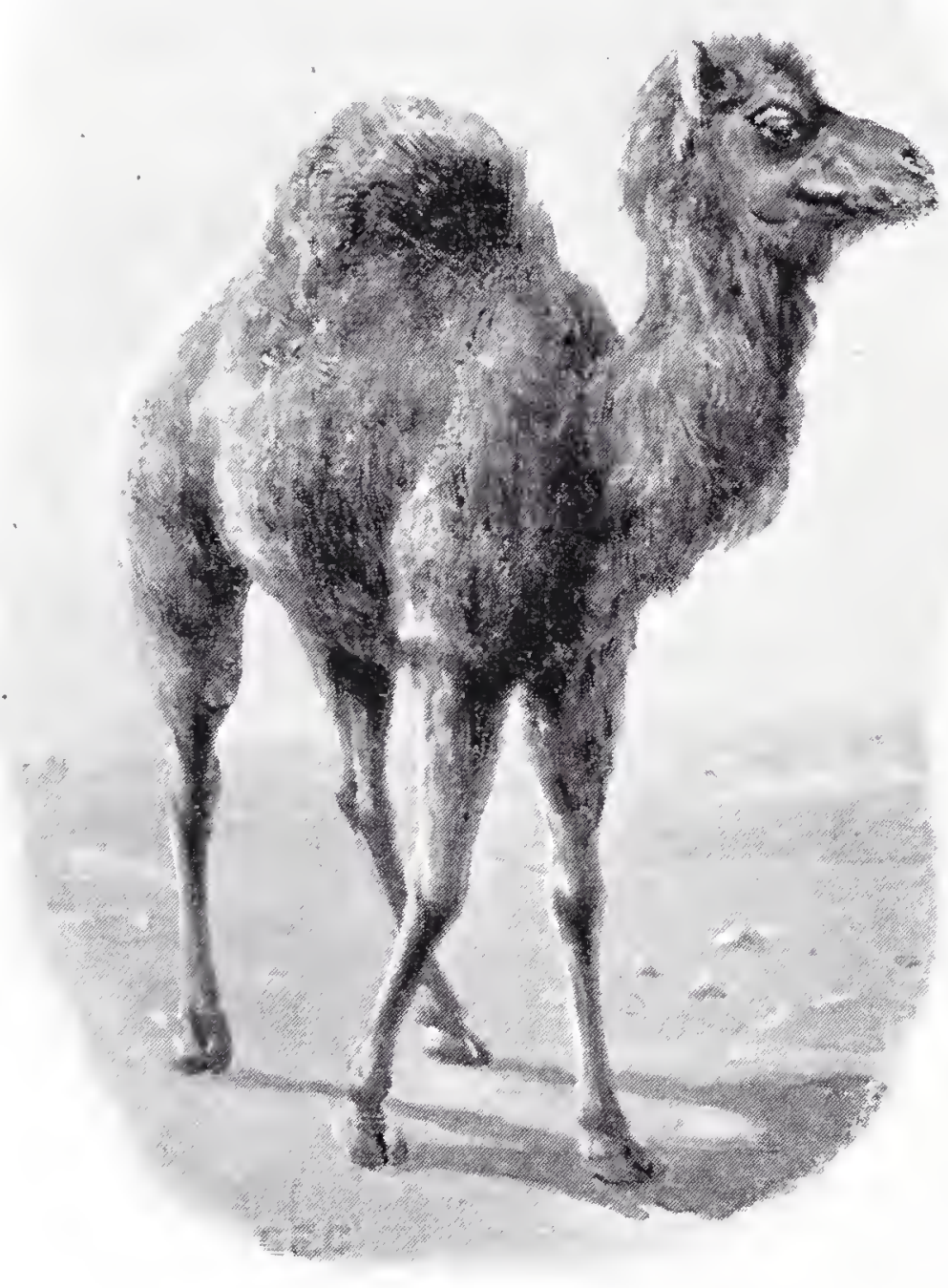

I)ROMEDARY. time until the whole supply is exhausted.

In this way a camel can easily go for five or even six days without requiring to drink, even when marching under the burning sun of the desert. T'wo kinds of camels are known, neither of which is now found in a wild state.

The first of these is the Arabian Camizl, which only has one hump upon its back, and is so very well known that there is no need for me to describe it. It is very largely used in many parts of Africa and Asia as a beast of both draught and burden. Camels for riding upon, however, are generally called "dromedaries," and may be regarded as a separate

breed, just as hunters are a separate breed from cart-horses. And while they will travel with a rider upon their backs at a pace of eight or nine miles an hour, an ordinary camel with a load upon its back will scarcely cover a third of that distance in the same space of time.

This camel is a very bad-tempered animal. It gets very cross when it is made to lineel down to be loaded, and crosser still when it has to kneel again in the evening for its burden to be removed, and all day long it goes grunting and snarling and groaning along, ready to bite anyone who may come near it. And it is so stupid that if it should wander off the path for a yard or two, in order to nibble at a tempting patch of herbage, it will go 
straight on in the new direction, without ever thinking of turning back in order to regain the road.

Besides being used for riding and for carrying loads, the camel is valuable on account of its flesh and also of its milk, while its hair is woven into a kind of coarse cloth.

The Bactrian Canel, which comes from Central Asia, has two humps upon its back instead of one. It is not quite so tall as the Arabian animal, and is more stoutly and strongly built, while its hair is much longer and more shaggy. For these reasons

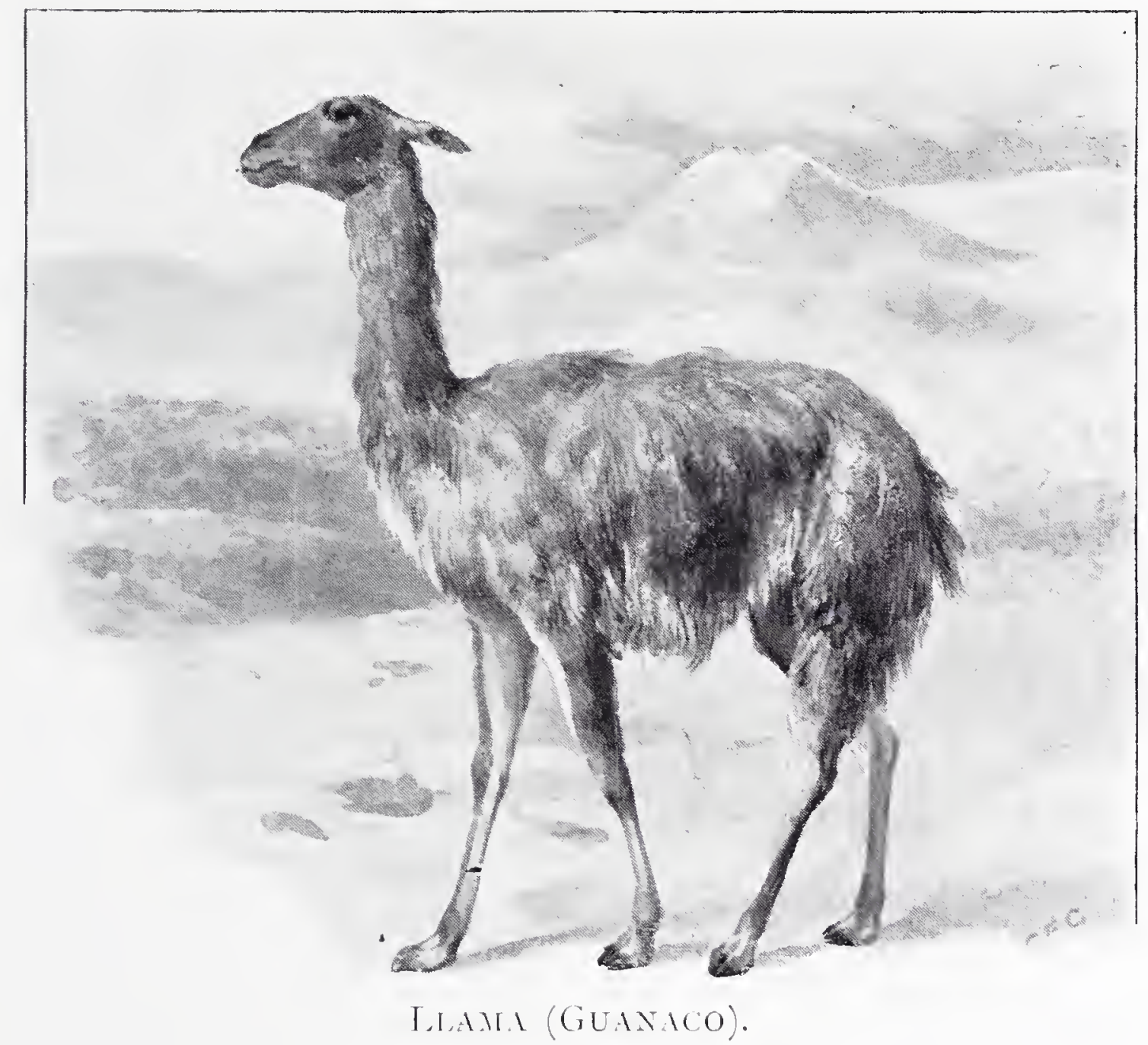

it is very useful in rocky and hilly country, for it can scramble about for hours on steep and stony ground without getting tired, while its thick coat protects it from the cold.

Llamas may be described as South American camels. But they are much smalier than the true camels, and have no humps upon their backs at all. Their feet, too, are not nearly so broad and cushion-like, while their thick woolly coat grows in dense masses, which sometimes reach almost to the ground.

There are four kinds of llamas, but I can only tell you about one of them, namely the Guanaco.

This animal lives both among the mountains and in the plains. It is generally found in flocks, consisting of a single male 
and from twelve to fifteen females. But sometimes the flocks are very much larger, and more than once several hundred animals liave been seen together. The male always keeps behind the flock, and if he notices any sign of clanger he utters a curious whistling cry. The does know exactly what this means and at once take to flight, while the male follows, stopping every now and then to look back and see if they are being pursued.

If two male guanacos meet they nearly always fight, biting one another most savagely, and squealing loudly with rage. When one of these animals is lilled, its shin is nearly always found to be deeply scored by the wounds which it has received from its numerous antagonists.

If you go to look at the llamas in the Zoo, I would advise you not to stand too near the bars of their enclosure, for they have a nasty habit of spitting straight into one's face! When they are used for riding they will often turn their heads round and spit at their rider, just to show that they are getting tired. And if once they lie lown no amount of persuasion or even of beating will make them get up again, until they consider that they have had a proper rest!

Next we come to the \% EmRas.

There are three different linds of these beautiful animals. The largest and finest is linown as GREVY'S ZEBRA, which is found in the mountains of Somaliland. It has many more stripes than the other two, while the ground colour is quite white. The smallest is the Mountain ZmBra, which is only about as big as a good-sized pony, and has its legs striped right down to the hoofs. This is now a very scarce animal, being only found in one or two mountainous districts in South Africa, where no one is allowech to interfere with it. And between the two is the BuRCHELL'S ZEBRA, which is about as large as a small horse, and has its legs white, with only a very few markings. This animal is quite common in many parts of the South African plains, and has often been domesticated, and taught to draw carriages and carts. Indeed, in some districts of Southern Africa, a coach drawn by a team of zebras instead of horses is not a very uncommon sight.

You would think that an animal coloured like the zebra would be very easily seen, even by night, wouldn't you? But strange to say, these creatures are almost invisible from a distance of even a few yards. Indeed, hunters say that they have often been so close to a zebra at night that they could hear him breathing, yet have been quite unable to see him!

This seems to be due to his stripes, for it has been found that while a pony can be easily seen from forty or fifty yards away on a moonlight night, it at once becomes invisible if it is clothed with ribbons in such a way as to resemble the stripes of the zebra!

Zebras are generally found in herds, and they have a curious habit of travelling about in company with a number of brindled gnus and ostriches, which all seem to be as friendly as possible together. 


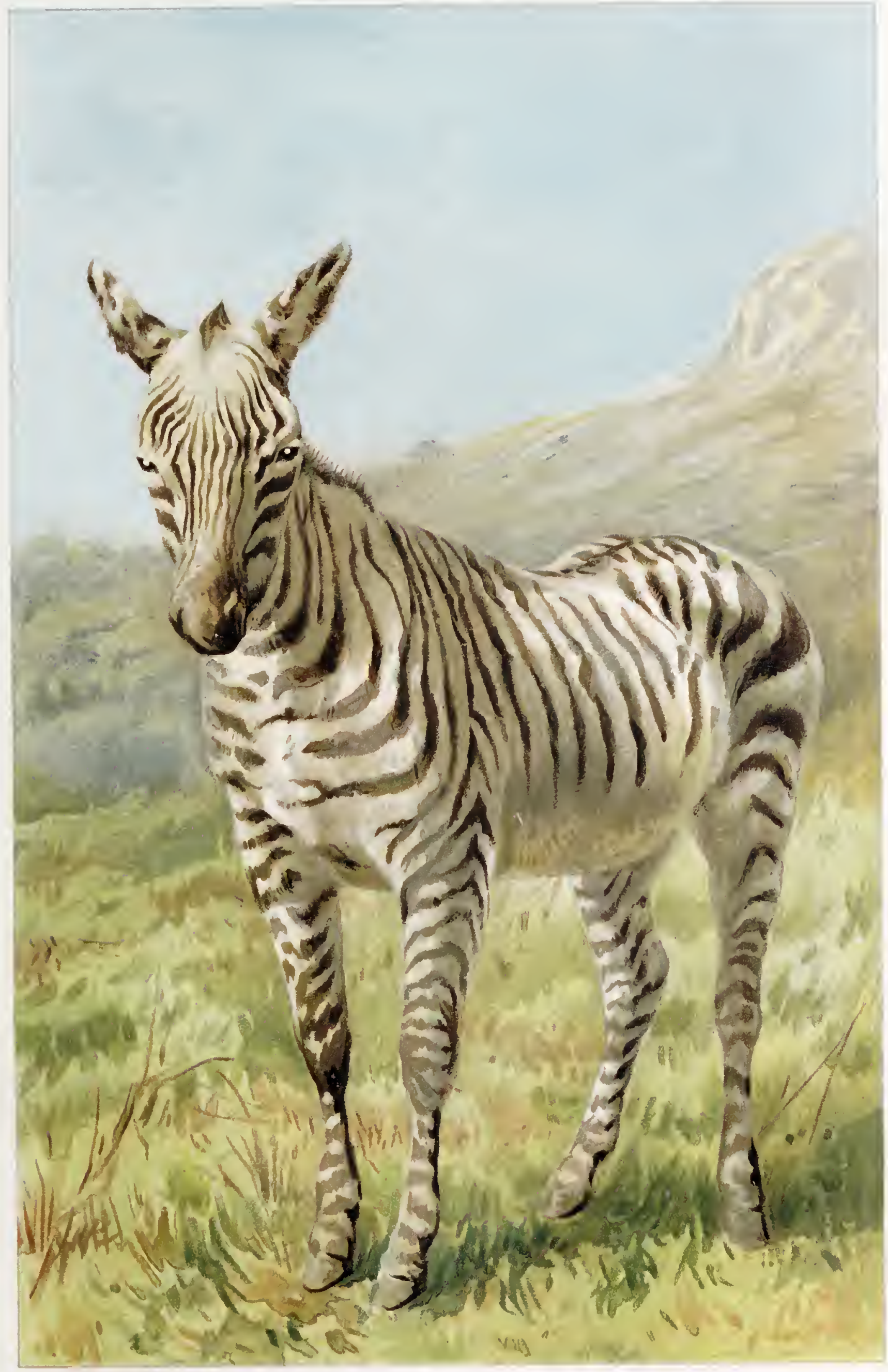





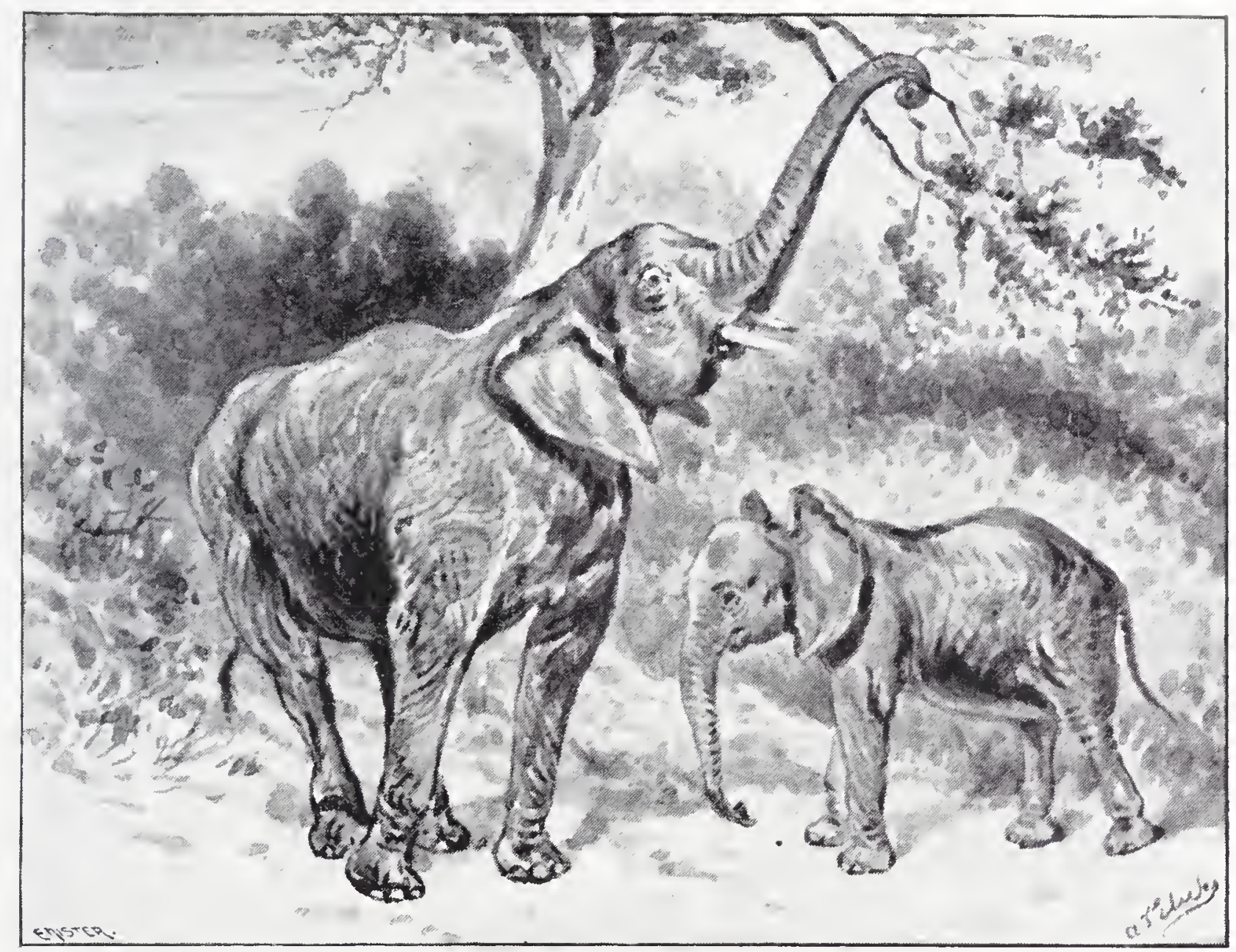

AFRICAN ELEPHANTS.

\section{CHAPTER XVII.}

THE EI,EPHANTS, RHINOCEROSES, HIPIOPOTAMI, AND IVITD SIVINE.

THERE are three reasons, perhaps, why Elephants interest us so greatly.

The first is their enormous size. They are by far the largest of all the animals which live upon land. "Jumbo,' for instance, the famous elephant which lived for so many years in the Zoo, was no less than twelve feet in height at the withers, and weighed more than six tons and a half, while a height of ten feet is quite common.

Next, there is their wonderful docility. When wild, no doubt, they are often very fierce and savage. Yet they are very easily tamed; and it is a strange sight to see one of these giant creatures walking about with a load of children upon its back, and meekly obeying the lightest word of a man whom it could crush to death in a moment hy simply placing its foot upon him.

And then, once more, there is that marvellous trunk, so strong that it can tear down great branches from the trees, and 
yet so delicate that it can pick up the smallest scrap of food from the ground. When the elephant wishes to feed, it seizes the food with its trunk and poles it into its mouth. When it wishes to drink, it fills the same organ with water, and then squirts the contents down its throat. If it should be hot, it can talie a shower bath by squirting water over its body instead. And it breathes through its trunk and smells with it as well, so that this wonderful member is used for a great many different purposes.

As it is so valuable, the elephant takes very great care of

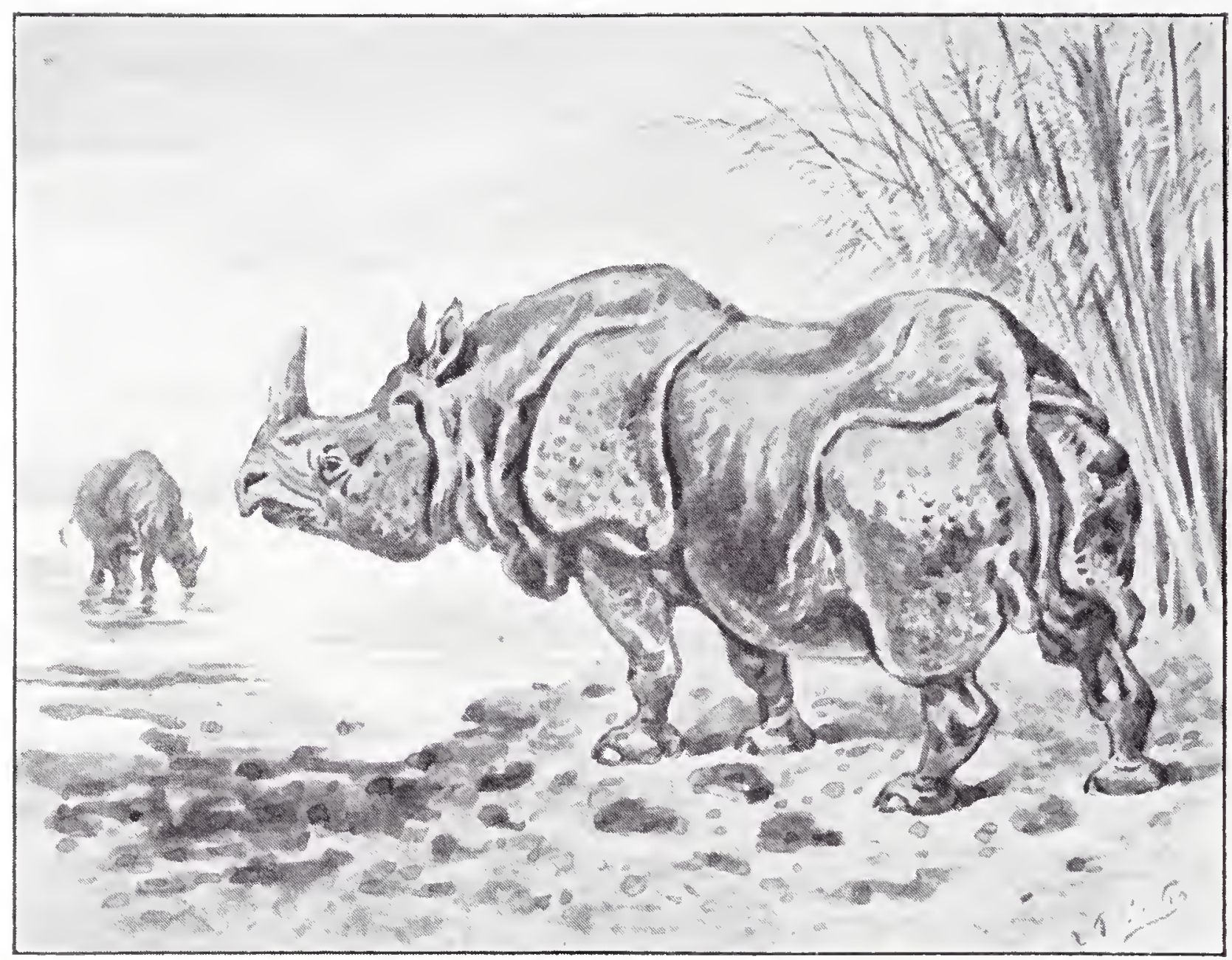

INIDAN RHINOCEROS.

its trunk, always curling it up out of harm's way, for example, if it should find itself in any danger.

Two different kinds of elephants are known, one of which is found in Africa and the other in Asia.

You can easily tell the ArRICAN ELEHANT by the great size of his ears, which are so large that a man might almost hide himself behind one of them. "Jumbo's" ear, indeed, measured no less than five feet five inches from side to side. When the animal is excited these enormous ears stand out at right angles to the head. Then the legs are much longer than those of the Indian elephant, while the trunk, instead of having one finger-like projection 


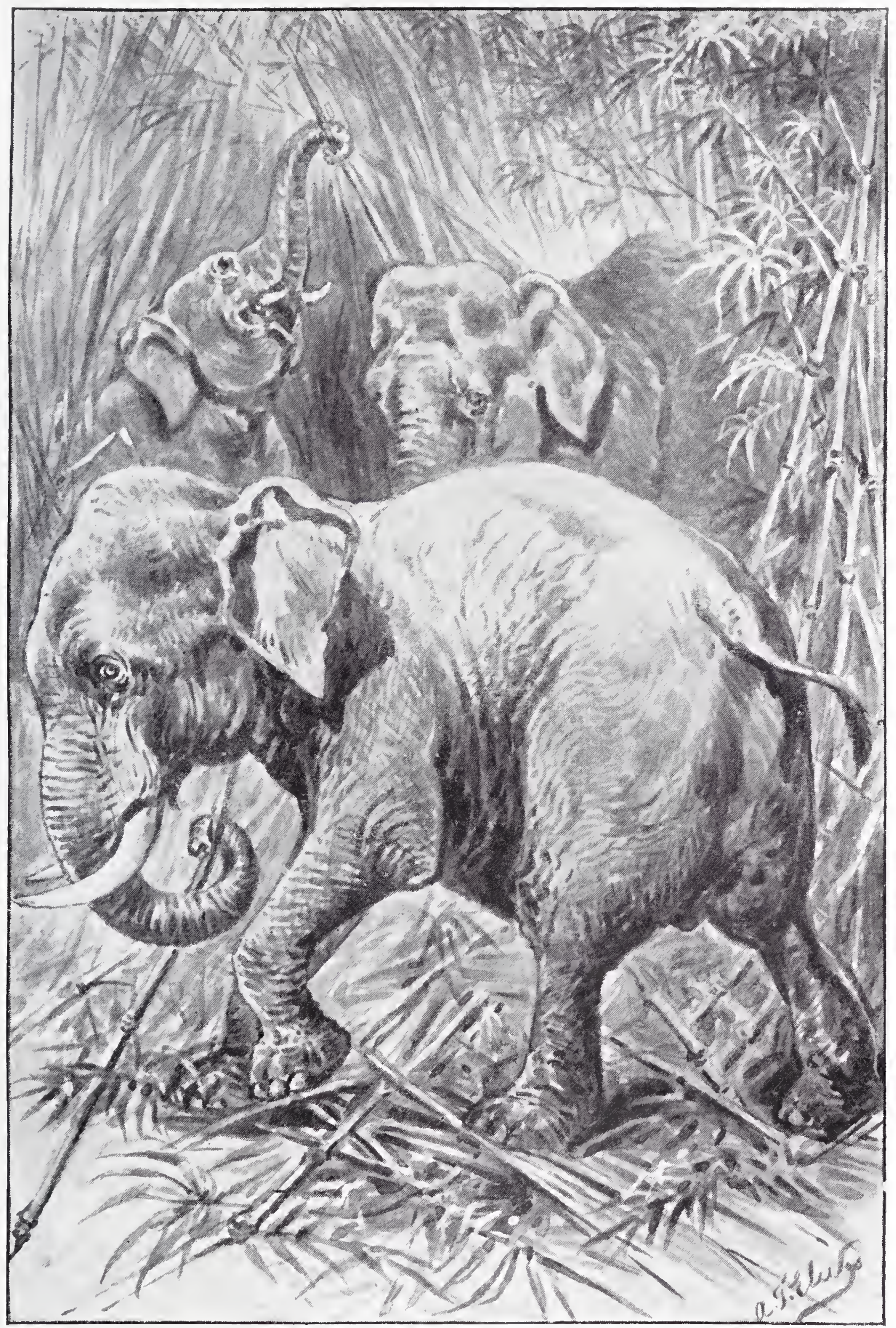

INIIAN ELEPHANTS. 

at the tip, has two, one in front and one behind. Both the male and female animal, as a rule, too, possess tusks, while in Indian elephants these weapons are only occasionally present in the male, and hardly ever in the female.

The tusks of the male elephant, however, are always very much larger than those of his mate, and sometimes they grow to a very great size. A length of nine feet, indeed, is not very uncommon, while tusks ten feet long, or even more, have sometimes been recorded. Generally one tusk is several inches shorter than the other, having been worn down in digging for the roots

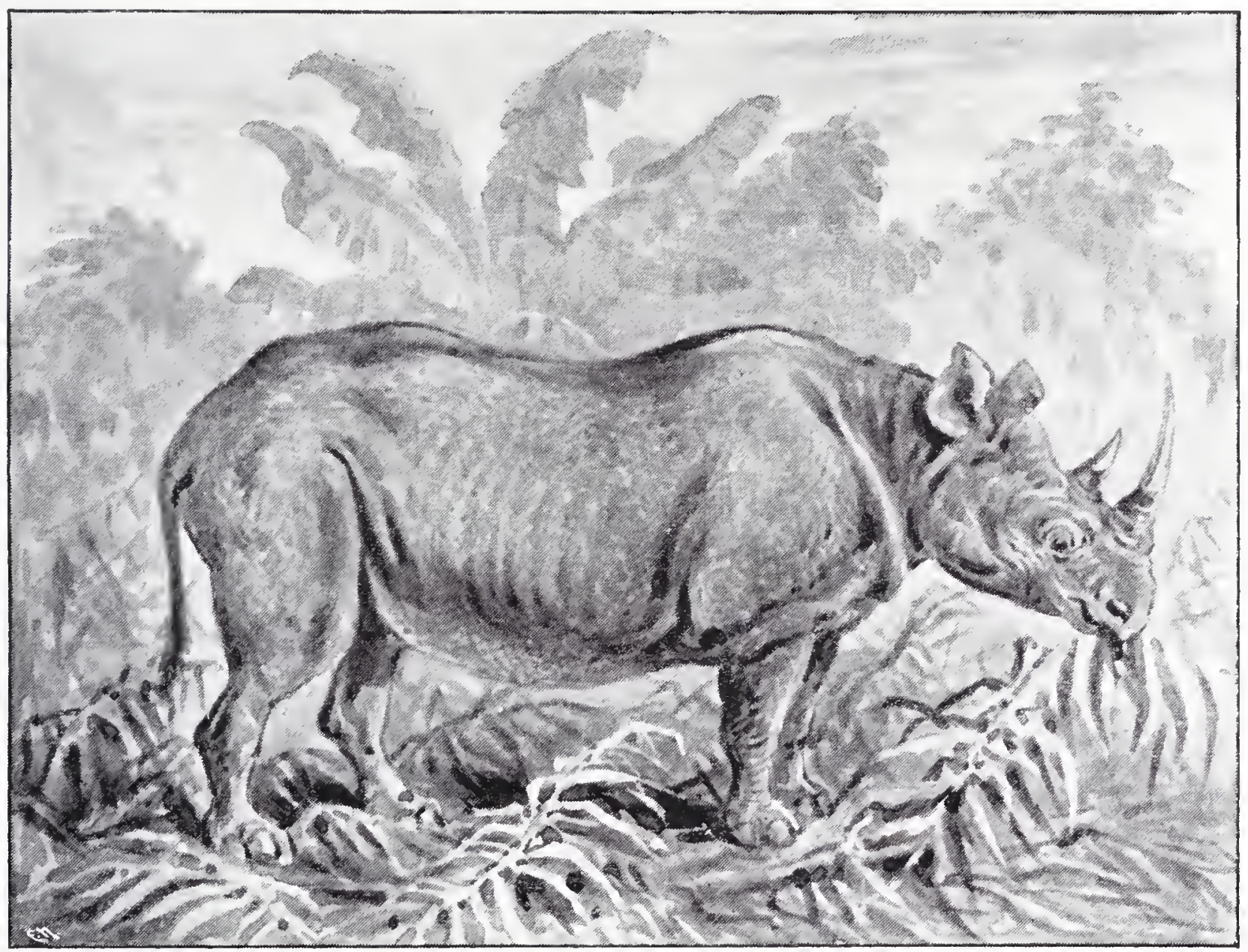

AFRICAN RHINOCEROS.

on which the animal is fond of feeding: for elephants seem to dig with one of the tuslis only, and never with both.

The ivory of which these tusks are composed is so valuable that the African elephant has been most terribly persecuted, and in many districts where it was formerly plentiful it has disappeared altogether. It lives as a rule in herds, which seek the thickest parts of the forest during the day, and come out at night to search for food and water. And even a small herd of elephants will sometimes do a great deal of damage, for they will uproot trees of eighteen or even twenty feet high, in order to feed upon the foliage of the upper branches, or snap off the stems quite 
close to the ground. When the tree is a large one, it is said that two elephants will unite in breaking it down.

You would think that a herd of elephants would be very conspicuous indeed, even in the thick forest, wouldn't you? Yet all liunters unite in saying that as long as they remain still it is almost impossible to see them, while they make their way through the bushes so silently that even when they are moving it is not at all easy to hear them.

The Indian Elepinant seldom exceeds nine feet in height at the shoulder, although larger examples are sometimes found. It lives in the thick jungle in herds of forty or fifty, which sometimes wander by night into cultivated ground, and do terrible damage to the crops. Now and then, however, a male elephant will live entirely alone. These solitary animals are

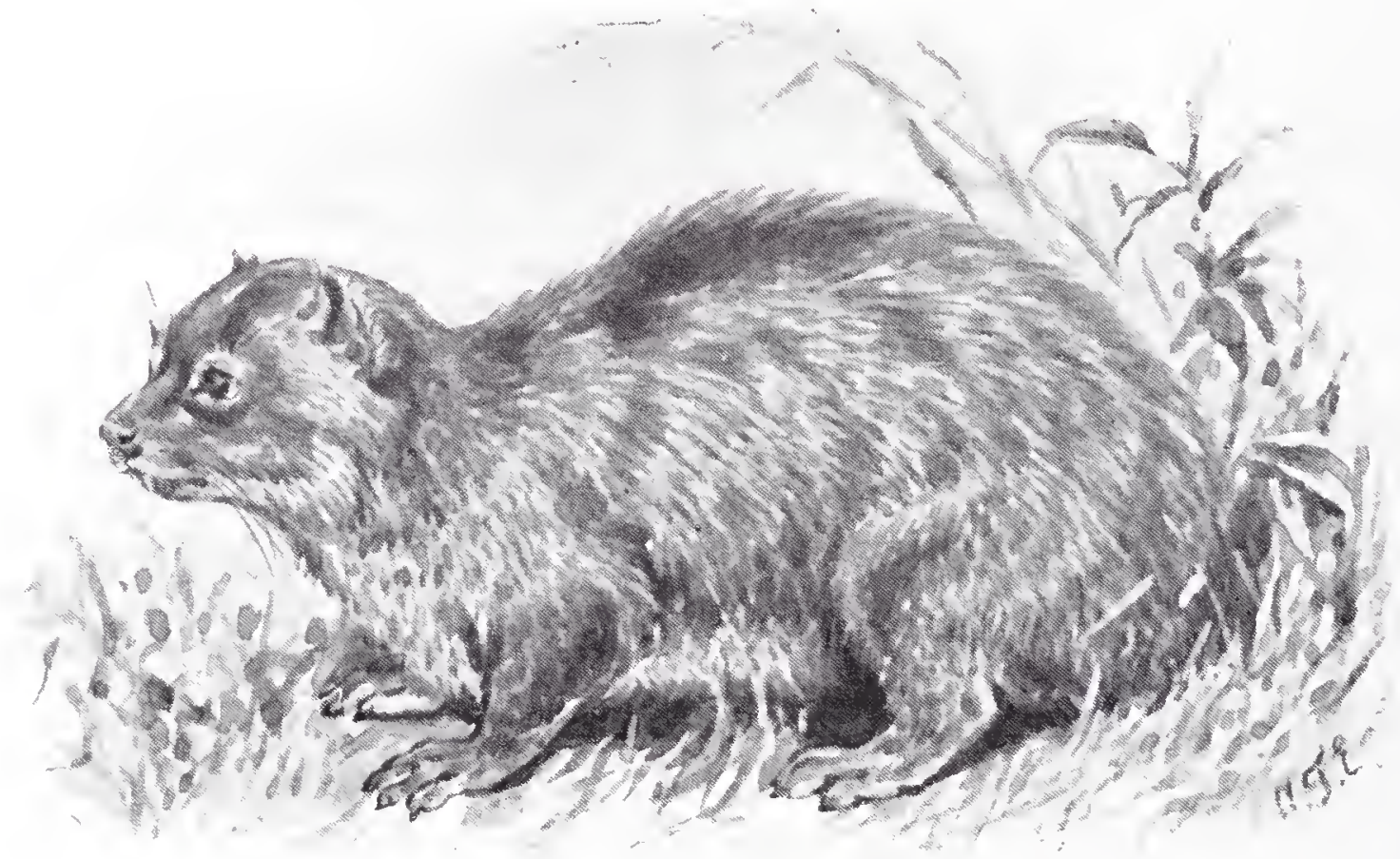

HYRAX.

always very fierce and savage, and will rush out and attack anyone who may pass by. For this reason they are known as "rogues."

The Indian elephant is very often tamed, and is taught to perform all linds of lieavy work, such as dragging timber or piling logs. It is also used for riding, a "howdaln" with several seats being placed upon its back, while it is guided by a native driver, called a "mahout," who sits mpon its neck and directs its movements by means of a "haunlius," or spilied hook. It is largely employed, too, in hunting the tiger. I3ut for this purpose it has to he most carefully trained, for elephants are naturally very much afraid of tigers, and even after a long course of instruction will sometimes take to flight when the furious animal springs at them with open jaws and eyes flaming with rage.

Elephants in India are mostly captured by being driven 
into a large "keddah," or enclosure of stout posts, from which they are unable to make their escape. In this way a large herd of the lnuge animals are often taken prisoners together.

Next in size to the elephants are the great creatures known as Rhinoceroses, which are found both in Africa and in Asia. Five different kinds are known altogether, but I shall only be able to tell you about two.

The first of these is the common Indian RHInoceros, in which the hide falls into great folds upon the shoulders and in front of the thighs, while there are smaller folds upon the necli and the hinder quarters. The sides of the body are marlied with a large number of round projections, sometimes as much as an inch in diameter, which look very much like the rivets in the iron

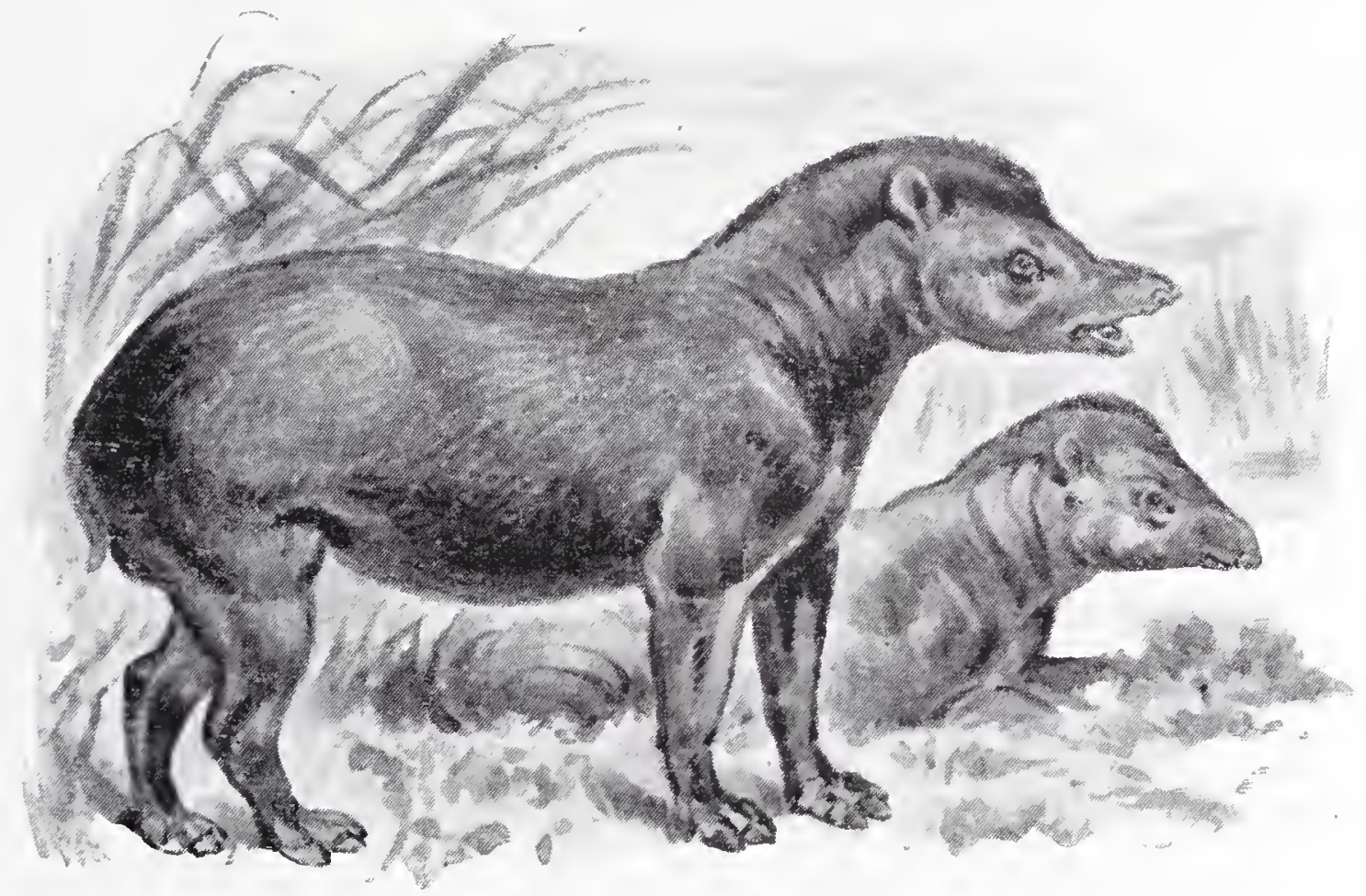

AMERICIN TIPR.

plates of a boiler. When fully grown this animal stands rather over five feet in height at the shoulder.

'The Indian rhinoceros, only has one horn, which is generally about a foot long. This horn, strange to say, is not connected in any way with the bones of the sliull, but is really a growth from the shin, although there is a bony prominence underneath it on which it is set. By means of a sharp knife, indeed, it could be cut away without difficulty. But it is a very formidable weapon, and some of the rhinoceroses with longer horns have been known to rush at a mounted hunter with lowered head, and then to strike upwards with such terrible force that the horn has actually pierced the horse's body, and entered the thigh of the rider.

Sometimes a rhinoceros will rush along with its head bent 
downwards so far that the horn ploughs up a deep furrow in the ground.

This animal is chiefly found in the swampy parts of the great grass-jungles of India. It is very fond of taling a mudbath, from which it comes out with its whole body thickly calied with clay. This serves as a great protection from flies and other insects, which persecute it terribly, forcing their way under the thick folds of hide at the shoulders and thighs, where the slin is thinner, and driving it nearly mad by the irritation of their bites.

In spite of its great size this rhinoceros is a rather timid animal, and nearly always runs away when it is attaclied. But if it is wounded or brought to bay it becomes a most terrible foe,

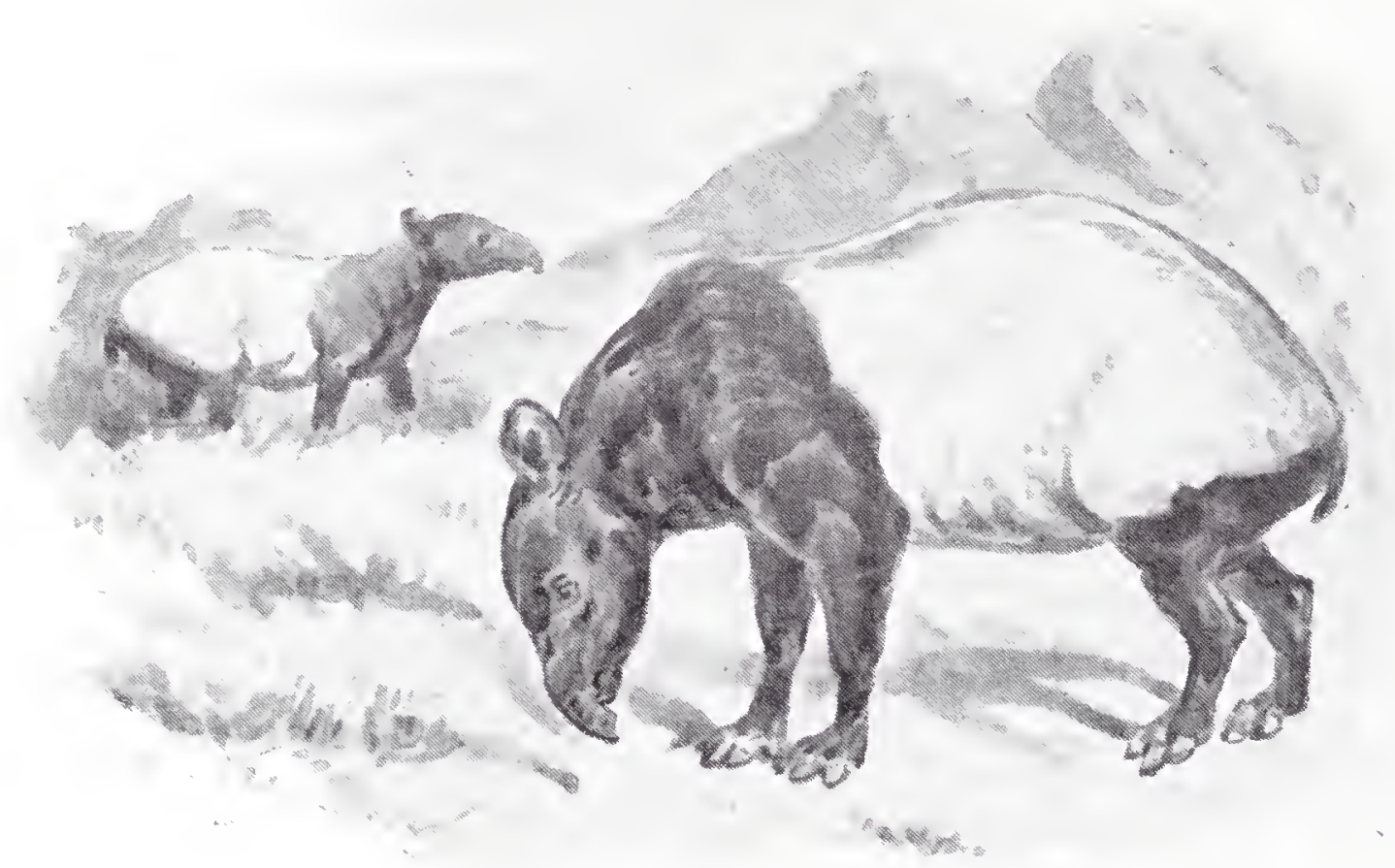

MILAYN TALIR.

charging with the utmost fury again and again, and striling savagely with its horns, and sometimes with its tuslis as well.

The African rhinoceroses are without the folds of slin which are found in the Indian species, and have two horns on the head instead of one. Sometimes these horns are of very great length. I have in my possession, for instance, a walkingstick, which might well be used by a very tall man, and which was cut from the core of a rhinoceros' horn.

The Common Rhinoceros is the better known of the two species found in Africa, and is found in almost all the wilder districts, from Abyssinia to Cape Colony. It lives in the very thicliest parts of the forest, brealing away the bushes and the lower branches of the trees in such a way as to leave a clear 
space perhaps fifteen or twenty feet in diameter. These retreats are called "rhinoceros houses," and the animals remain in them cluring the heat of the day.

The common rhinoceros is wonderfully quick and active for so large and heavy an animal, and is said to be able to overtalie a man riding upon a fast horse. But it does not seem, as a rule, to be savage in disposition, and very seldom attaclis a human foe. One great hunter tells us, indeed, that although many rhinoceroses have advanced towards him to within twenty or thirty yards, they always ran away if he threw stones at them, or even

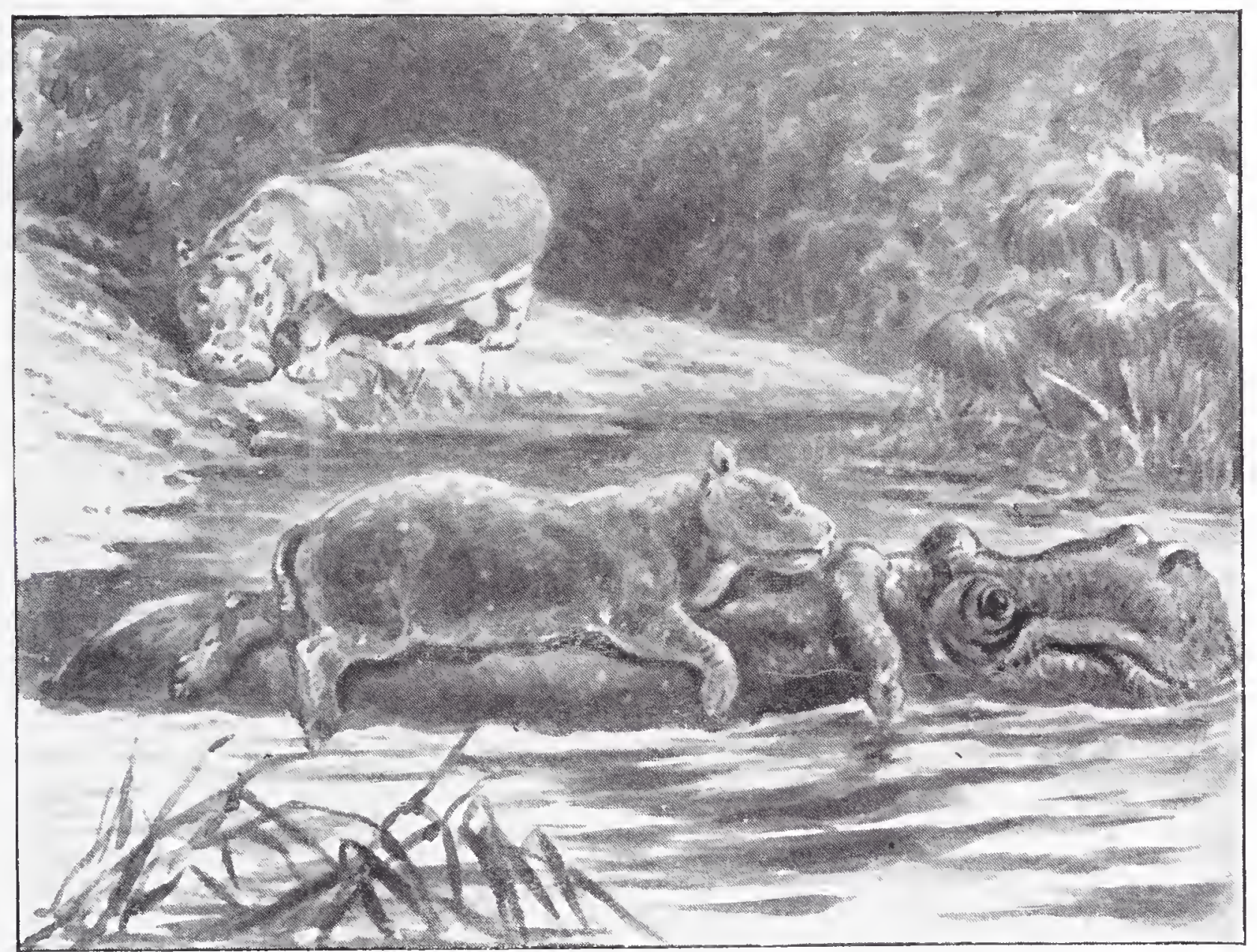

Hinomotime

if he waved his arms and shouted. When wounded, however, they will sometimes attack most furiously. But they never think of looking for their enemy in a tree, and if he can climb on to a bough even three or four feet from the ground he is perfectly safe. Oddly enough, one of the animals which are most closely related to the rhinoceroses is very much more like a rabbit, and actually lives in burrows in the ground. This is the HrRax, or "coney," as it is called in the Bible, which almost anybody would mistake at first sight for a rodent. Yet when one comes to look at its front teeth one sees at once that instead of having flat, sharp edges, like a chisel, they are pointed; and these teeth 
do not continue to grow all through life, like those of the rodent animals. And, besides this, there are several other points in its bodily structure which show us that it really is a relation of the rhinoceroses.

About fourteen different kinds of hyrax are known, some of which are found in Africa, and the others in Arabia, Syria, and Palestine. They all live in rocky districts high up on the sides of mountains, a great number making their burrows close to one another, just as rabbits do in a warren. They are very active and sure of foot, and scamper up and down the sides of the rocks with the greatest ease. It is very difficult indeed to watch them, however, for they are so shy that they will not leave their holes if they think that anyone can see them, while they only come

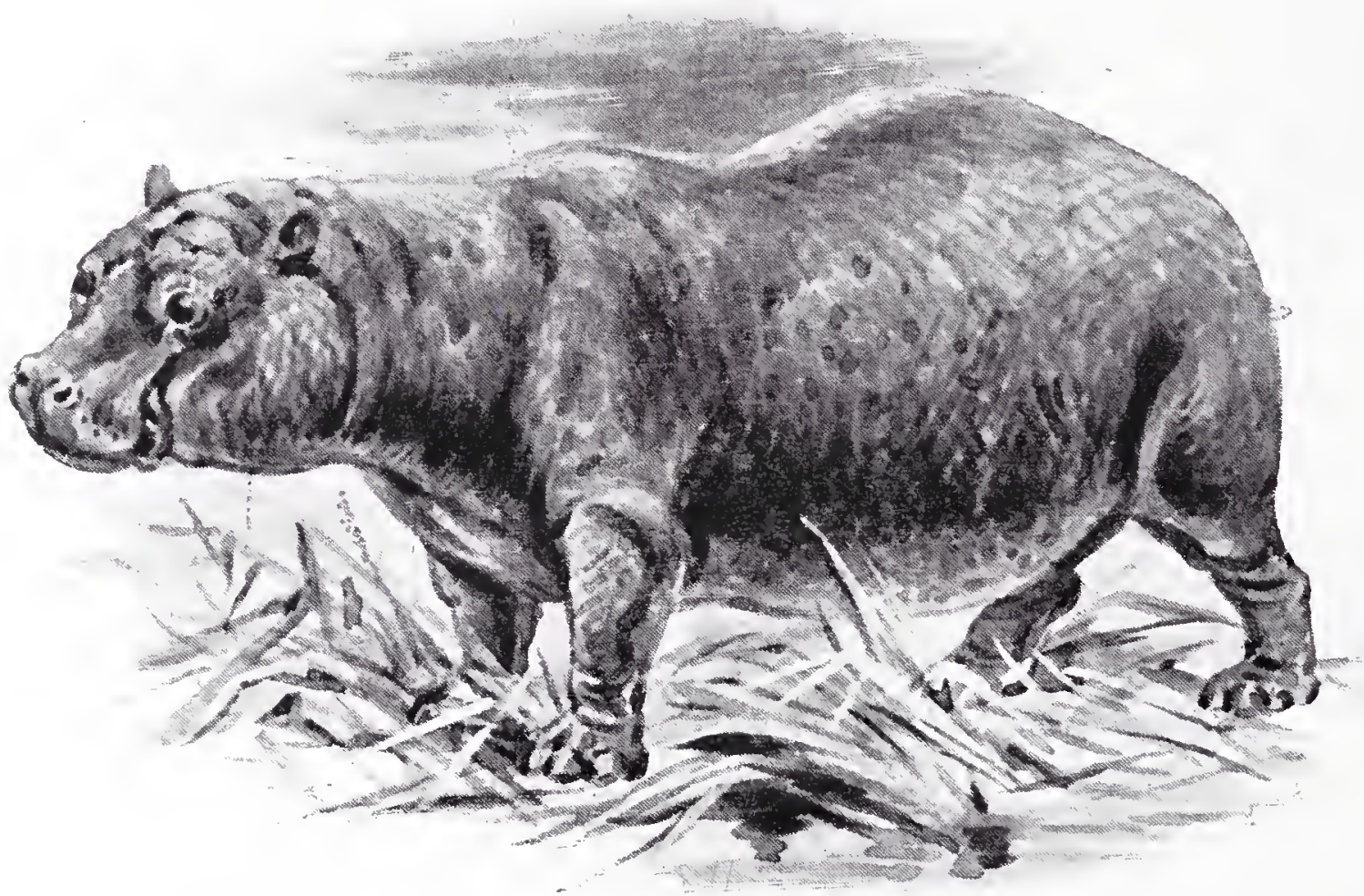

PIGMY Hippopotames.

out to feed at night and very carly in the morning. Sometimes, it is true, they will lie out on the roclis during the day, enjoying the hot sunshine. But one of them is always appointed to act as a sentinel, and as soon as he notices the slightest sign of danger he gives the alarm, and then they all disappear into their holes.

Very odd-looking animals indeed are the TAPIRs, which are found both in Central and South America, and also in some of the islands of the Malay Archipelago. They are about as large as donlieys, but look more like very big pigs. On the neck is a short, stiff, upright mane of blacli hairs, and the upper lip is lengthened out into a kind of trunk, something like that of an elephant, but on a very much smaller scale, and without the odd finger-like organ at the tip.

'These curious animals live in thick forests near the banks 
of great rivers, and come out from their retreats chiefly by night. by constantly travelling backwards and forwards they make regular pathways through the thickets. They swim very well, and are very fond of gambolling in the water, and also of rolling about on the muddy banks. But they are so timid that it is very difficult indeed to watch them; and it is said that they will run away in terror from even a tiny dog.

But if a mother tapir thinks that her little one is in danger she seems to lose all sense of fear, and will even dash at a man and try to linock him down. And if she succeeds she will trample upon him and even bite him, just like the wild swine.

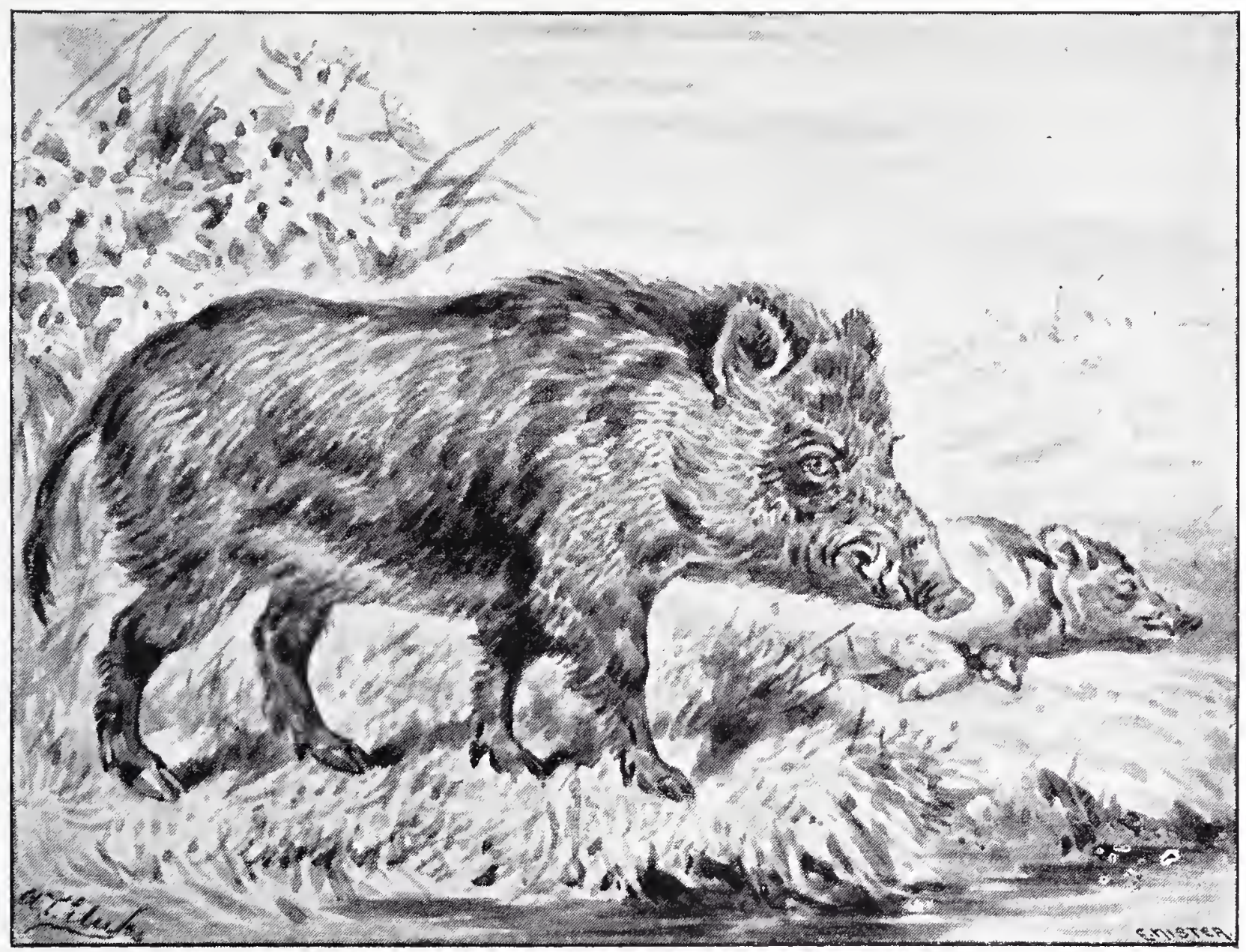

WIILD BOAR.

In America the great enemy of the tapirs is the jaguar, which springs upon them unexpectedly, and generally succeeds in tearing them to the ground. But sometimes they manage to escape either by rushing at once into the very thickest bushes, which sweep away their terrible enemy from his hold, or else by plunging into the water, when he is obliged to loose his grip for fear of being drowned.

The American tapirs are sooty lorown in colour, but that which is found in the Malayan Islands is white on the sides and the hinder parts of the body, while the young animal is spotted and strealied with white all over. 
The Hippopotamus, or River Horse, is perhaps the most awkward and ungainly animal in the world. I Iis huge body almost touches the ground as he waddles ciumsily along, while his short stout legs are set so far apart that they actually make a double track through the herbage. So you can easily understand that when a herd of twenty or thirty of these enormous creatures find their way into a plantation they do most terrible damage, eating a very good deal, and trampling down far more than they eat.

Then what tremendous mouths they have! When they open their jaws widely, their heads really look as if they were splitting in two right down into their neclis. And they have a most formidable array of tusks and teeth, which are arranged in

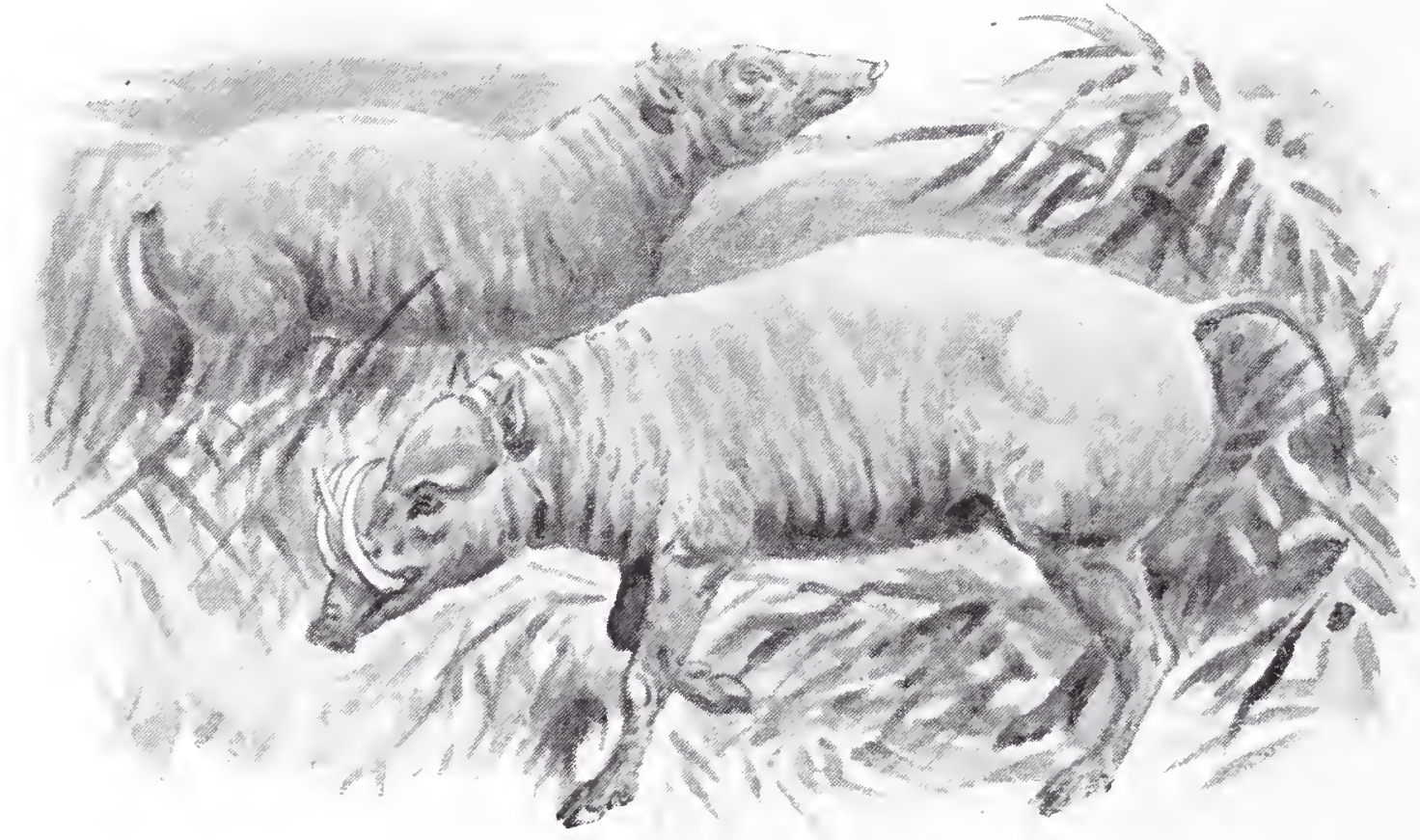

B.\BIRLSA.

such a manner that they mow down the herbage almost like the blade of a scythe.

The hippopotamus is a native of Africa, and is found in great numbers in many of the rivers and lakes. It spends a great deal of its time in the water, often sinking its body so low that only its nostrils appear above the surface. And it can live for eight or even ten minutes at a time, without resuiring to breathe. When it rises again it generally begins to blow out the exhausted air from it lungs just before reaching the surface, and the consequence is that a column of spray is forced np into the air, just as it is by a whale when "spouting."

When a mother hippopotamus has a little one, she generally carries it about on her back.

The first hippopotamus that was ever brought to the \%oo was caught when it was quite young, on one of the islands in 
the White Nile. As its mother had gone away to feed, the hunter who found it picked it up in his arms and ran off with it towards the boat. The slin of these animals, however, is thickly covered with a kind of natural oil, and the result was that the little creature was so slippery that it wriggled out of his arms just as he reached the water's edge, and plunged into the river. But luckily the boathook was lying close by, and with this he strucli at the escaping animal, "gaffed" it like a fish, and succeeded in capturing it again with nothing more than a wound in its thick skin which very soon healed. After a great deal of tronble it was safely brought to England, and lived in the Zoo for no less than twenty-nine years.

Another kind of hippopotamus, called the Pignr Hirpo-

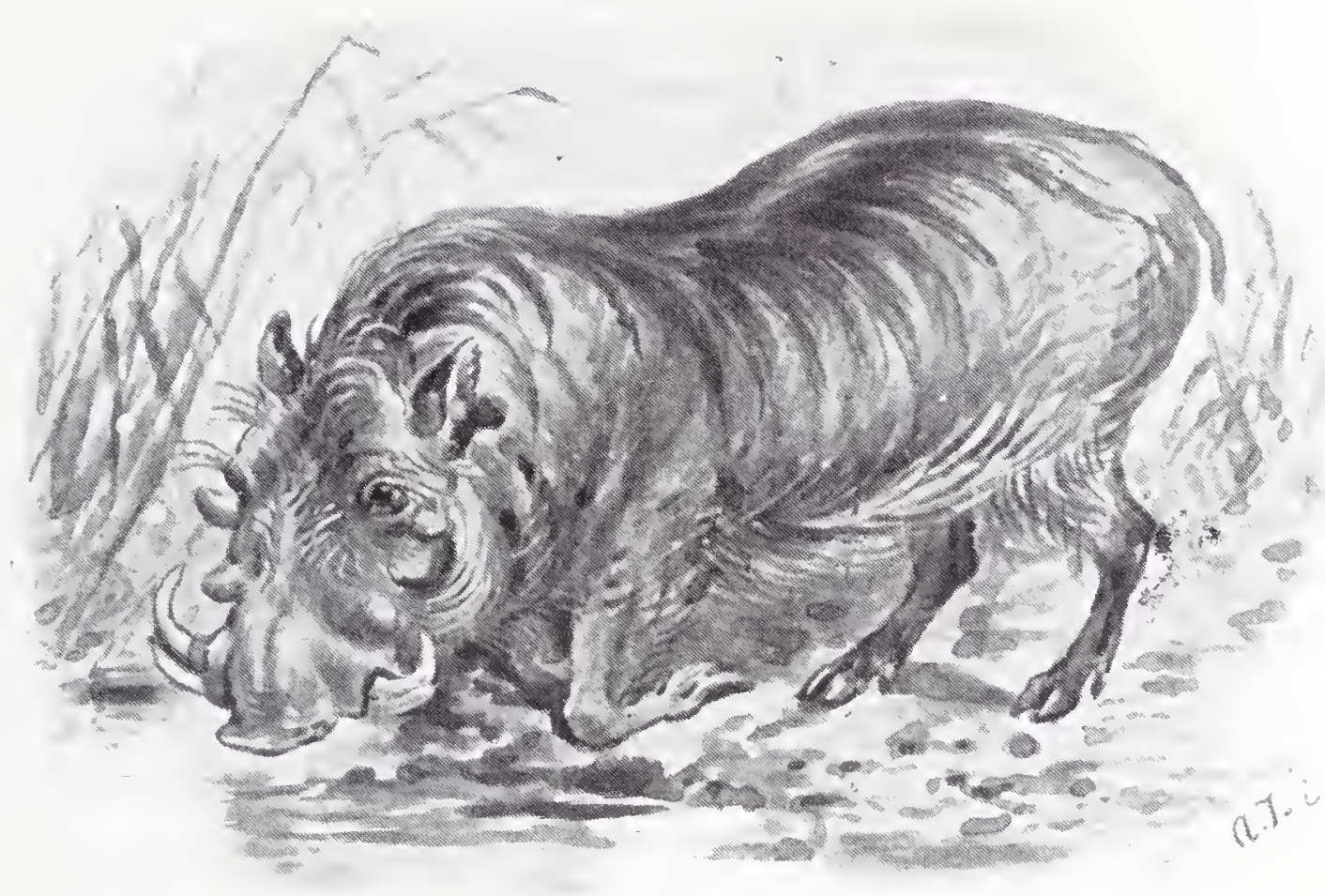

WART HOG.

PotAmus, is found in Western Africa. It is a very much smaller animal, being only about as big as a good-sized pig.

Next on our list come the Swine, among the most famous of which is the WILD BOAR.

Until about the middle of the sixteenth century this animal was plentiful in the British Islands, and it is still found commonly in the great forests of Europe. It is one of the fiercest and most savage of animals, for it does not seem to know what fear is, and will attack over and over again with the utmost fury, even after receiving the most severe wounds. And its tusks are so sharp and powerful that they have been linown to rip up the body of a horse at a single strolie. When removed from the jaw these tusks are generally about eight or nine inches long. 
In India, where wild boars are very plentiful, they generally make their lair among thick bushes in some marshy district, and often do a great deal of mischief to cultivated crops in the neighbourhood. They are fond of roots, too, which they grub out of the ground with their snouts, and in hot summers, when the ponds dry up, they are said to dig in the mud at the bottom in search of the fish which have buried themselves until the rainy season. The old boars generally live by themselves, like "rogue" elephants, but the younger ones and the sows go about together in droves of fifteen or twenty, all of which, most likely, are members of the same family.

One of the most curious of the swine is the Babirusa, which is found in the islands of Celebes and Borneo.

In the boar of this animal the tusks in both jaws spring upwards, and then curve towards the eyes, so that there is a sort of fringe, as it were, of tusks all round the face. Sometimes the upper pairs are thirteen or fourteen inches long, without counting the part that is buried in the jaw. These, however, are not very useful as weapons. But very severe wounds can be inflicted by the lower tusks, although they are a good deal smaller, and an enraged babirusa is a most formidable foe.

When fully grown, the babirusa stands about three feet six inches in height in the middle of the back, which is always very much arched. The colour of the skin is dark ashy grey.

The WART Hog, or Vlaclie Vark, which is found in Eastern Africa, is certainly the ugliest of all the swine. Its head is enormously large in comparison with its body, the muzzle is very long and very broad, underneath each eye is a great wart-like limp, with two others a little distance below it, and on either side of the mouth two great stout tusks spring upward. Altogether, it would be very hard to imagine a more sullen and ferociouslooking animal.

It is not nearly so savage as the babirusa, however, and if it is attacked it nearly always rums away, and tries to take refuge in some hole in the ground, such as the deserted burrow of an antbear. When it takes to ground in this way, it always turns round just before entering, and backs in tail foremost. Sometimes, if two or three men stand just over the burrow and jump heavily up and down in time together, it can be induced to bolt. But it is advisable to do so with a good deal of caution, for the animal has a singular way of turning a kind of back somersault just as it leaves its burrow, which lands it upon the top, just where the hunters would most likely be standing. And if they are not very careful indeed, one of them at least is almost sure to receive a slashing cut from the terrible tusks, which will certainly cause a very severe wound, and may even render him a cripple for life.

When it it running away from a pursuer, and wishes to see whether it is gaining upon him, the wart hog presents a most 
ridiculous appearance, for its neck is so short that it cannot turn its head round to look behind it. So it lifts its snout straight up into the air instead and looks over its shoulders. Besides this, it always carries its tail perfectly stiff and upright.

In South America the wild swine are represented by the PECcaries, of which there are two different kinds. They are not very large animals, being only about three feet in length, and weighing not more than fifty or sixty pounds; but they are nevertheless very dangerous creatures, for three different reasons.

In the first place, they travel about in packs, sometimes consisting of thirty or forty animals, which all attack a foe together. Then, in the second place, although their tusks are not nearly_so long as those of the preceding animals, they are almost

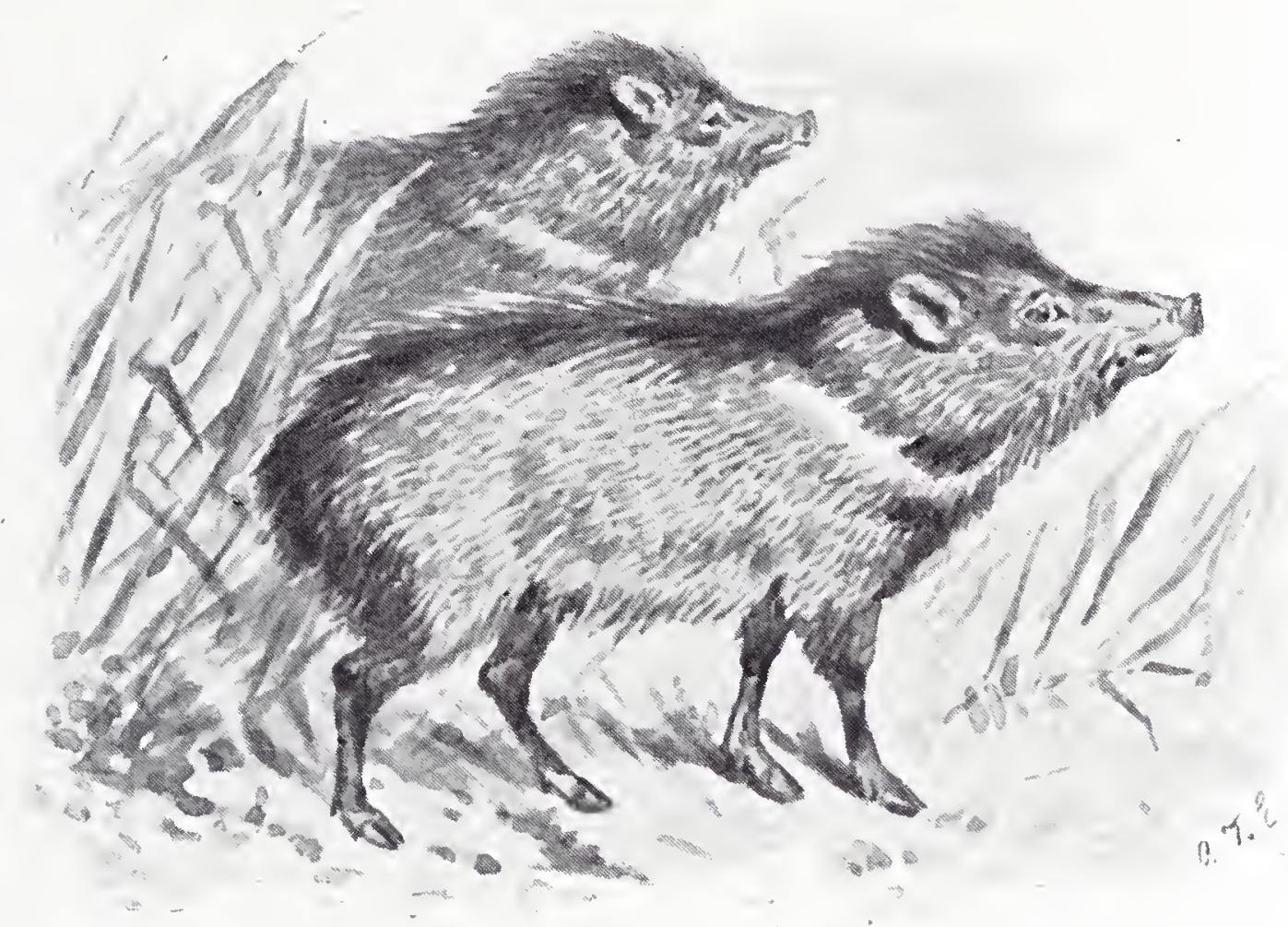

PECCARIES.

as sharp as razors, and can inflict most terrible wounds. And, thirdly, the animals know no fear at all, and will go on savagely attacking any enemy, over and over again, until the last of them is killed. So if a hunter should meet with a herd of peccaries in the forest, even if he be armed with a gun, his only chance of escape is to climb into a tree and to stop there until they go away.

When a herd of peccaries is not very large-consisting, perhaps, of only ten or twelve individuals - they are very fond of taking up their abode in the hollow trunk of some fallen tree. In this case they can be very easily destroyed, for one animal is always placed at the entrance to act as a sentinel; and, if a hunter conceals himself in some convenient place close ly, takes careful 
aim, and shoots the watching pecarry dead upon the spot, the animal behind him will just push out his carcase and take his place, to he himself shot in like manner. And in this way the whole herd may be killed one after another.

Peccaries will eat almost any kind of food, and though they live as a rule in the thickest parts of the forests, they will often wander to long distances in order to feed upon the crops in cultivated ground. There they sometimes do an immense amount of damage, and as they generally come during the night, and leave again before daybreak, it is very difficult to trap or shoot them. 


\section{CHAPTER XVIII.}

\section{THE EIONTATES, OR TOOTHLESS MAMMALS.}

THE animals which belong to this order are distinguished by having no front teeth, while some of them have no teeth at all. And in many other ways they are very curious and interesting creatures.

The Sioths, for example, live almost entirely in the trees, scarcely ever clescending to the ground. Not only that, they walk along undemeath the branches instead of upon them, suspending themselves by means of their great hooked claws. So they actually spend almost the whole of their lives upside down, with their backs towards the ground.

Yet they manage to travel along from bough to bough and from tree to tree with some little speed, and when there is a high wind, so that the branches are blown together, they will often wander for long distances. And the odd thing is that they never seem to get tired, although even during the night they still hang suspended, just as they do during the day.

Sloths are very odd-looking creatures, and if you were to see one of them hanging from a bough in its native forests you would find it rather hard to believe that it was really an animal at all. For it looks much more like a bundle of twigs overgrown with lichens. And the strange thing is that it really is covered with lichens, which grow upon its long, coarse hairs just as they do on the twigs of the trees. These give the fur of the sloth a curious green appearance, which disappears very soon after death, so that one never sees it in a stuffed specimen in a museum.

When a sloth is hungry, there is always plenty of food close by, for it feeds only upon the leaves and fruits and the tender young shoots of trees. And as there is plenty of moisture in these, it never requires to drink at all.

There are two different groups of these singular animals, the first consisting of those which have three toes on the front feet, and the other of those which have only two. They are only found in the great forests of Central and Soutl America.

Equally curious, although in quite a different way, are the Ant-eaters, or Ant-bears, as they are sometimes called, the largest of which is the GREaT ANT-EATER of tropical America.

When fully grown this animal is about four feet long, without counting the tail, while it is about two feet high at the shoulder. And it has two most strange peculiarities. 
In the first place, its head is drawn out into a kincl of long, narrow heak, with the little round nostrils at the very tip. Then its tongue is very long and worm-like, and is exceedingly sticliy, so that when it is swept to and fro among a number of ants, or other small insects, hundreds of them adhere to it and are carried into the mouth. This is the way in which the animal fecels, and if you go to look at the anteater in the ' $/$ oo you may

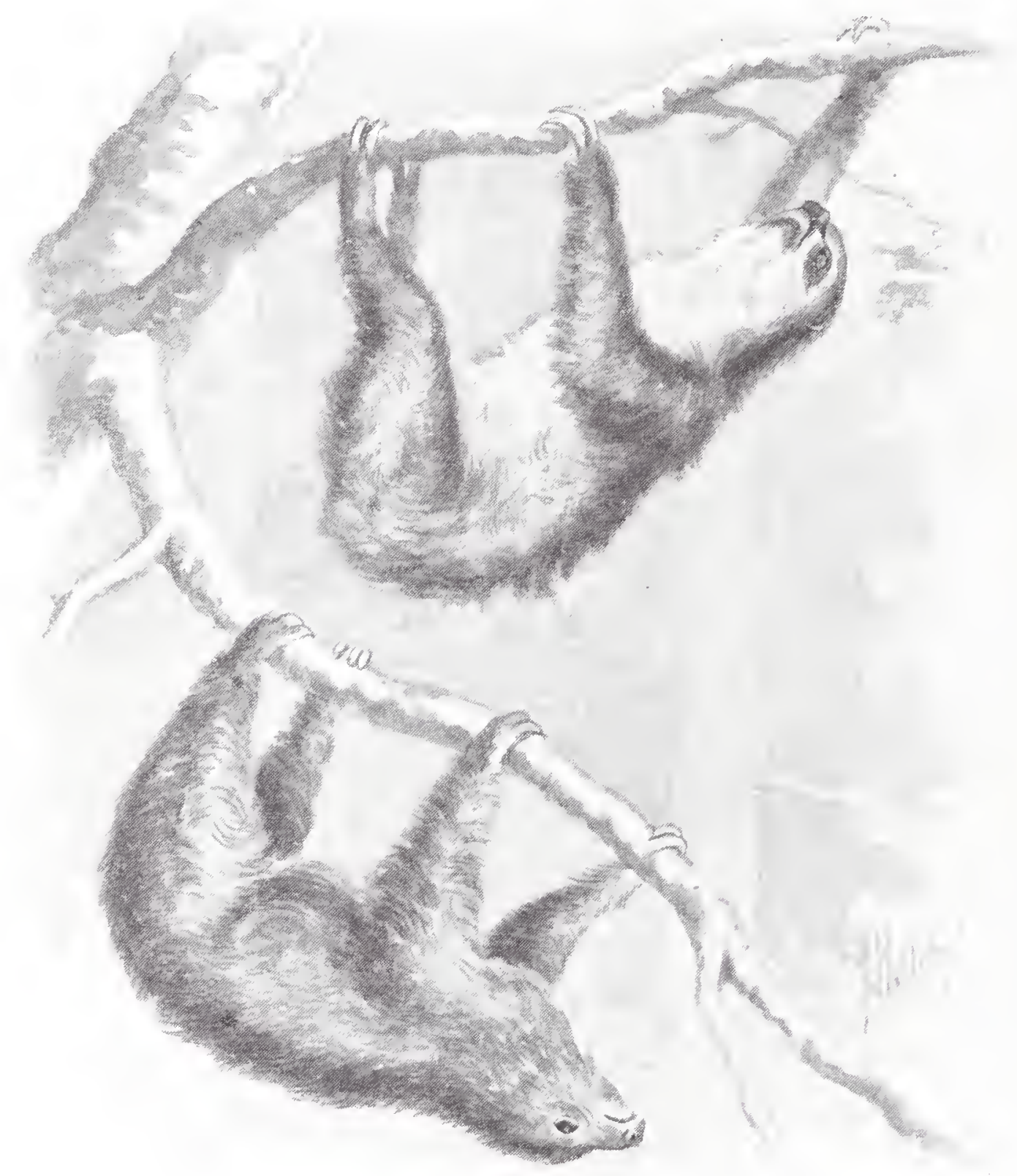

SLOTHS.

often see it polie its long tongue down between the boards at the bottom of its cage and bring up a cockroach which had vainly been seeking a place of refuge.

The other peculiarity is the enormous size of the tail, the hair of which is so long that when it is carried over the back it completely covers the whole of the body, and makes the animal look just like a haycock.

On its front feet the great ant-eater has very strong curved 
claws, with which it tears open the nests of the insects on which it feeds. When it is walling, of course, these claws are rather in its way, and it is obliged to tread on the sides of its feet instead of on the soles. But it manages, nevertheless, to shuffle along with some little speed, although its movements are very far from being graceful. And sometimes it uses them as weapons, for although it always tries to hug an enemy with its powerful forelimbs and squeeze him to death, the claws often enter his body and inflict a serious or even a fatal wound.

When a mother ant-eater has a little one to take care of,

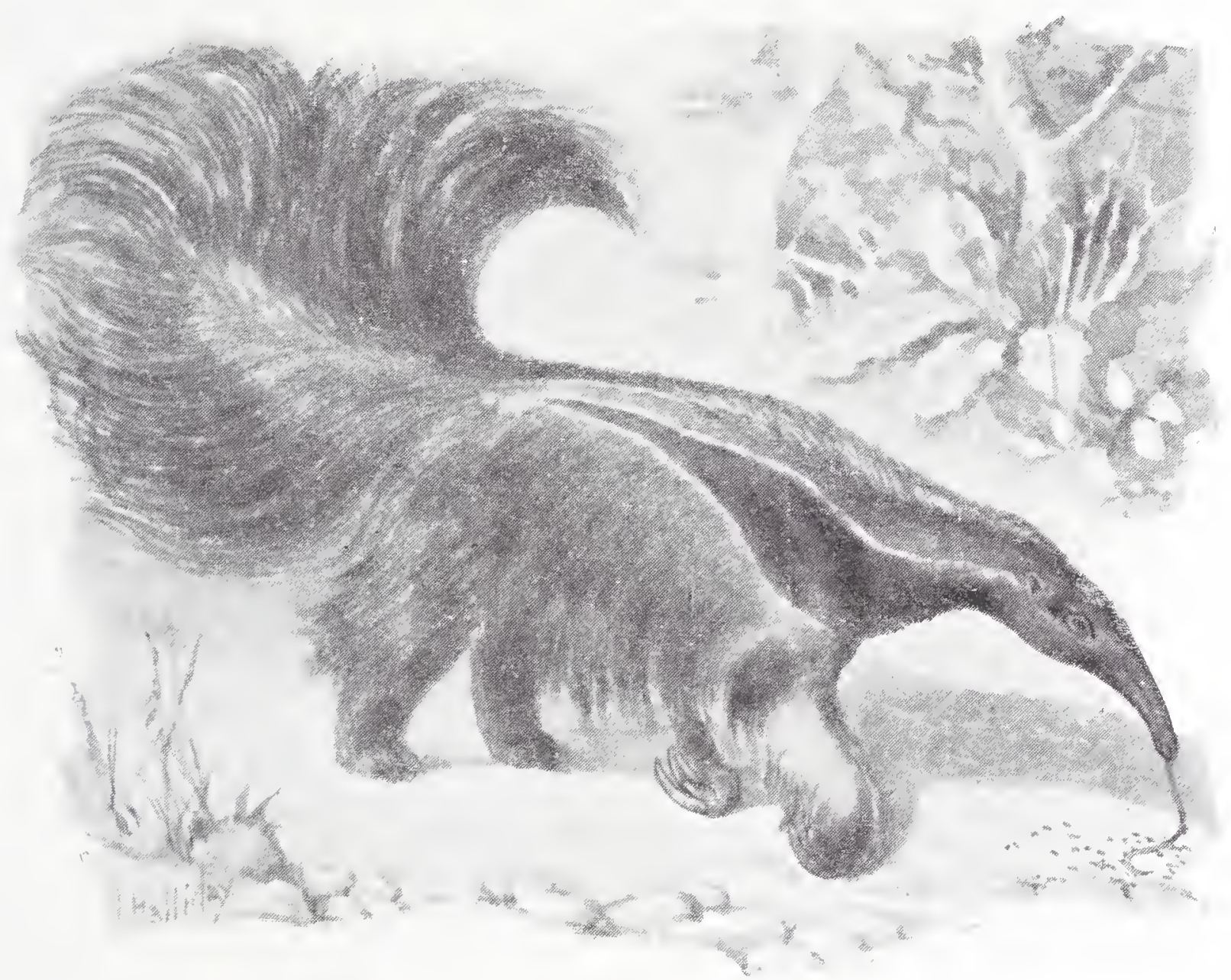

GREAT DNT- HATER.

she always carries it about on her back, and only allows it to get down just now and then in order to feed.

There is another lisind of ant-eater called the Tamandua, which lives in the trees and has a prehensile tail, just like that of a spider monkey. It is much smaller than the great ant-eater, and has a shorter and stouter head, while its tail is scarcely as bushy as that of a Persian cat. In colour it is yellowish white, with a broad black patch which runs from the neck to the hind quarters, and then widens out so as to cover the whole of the flanks. The tip of the snout is also black. The animal, like the preceding, is a native of tropical America. 
The Armaliblos are remarkable for having their bodies ahmost entirely covered by a lind of natural armour, which consists of several bony plates growing in the slin. There are three of these plates altogether, one covering the head and shoulders, another protecting the back, while the third clothes the hinder quarters. And they are fastened together by means of bony rings, so that when the animal rolls itself into a ball no gap is left between them. You know what a pill millepede loolis like when it rolls itself up, don't you? Well, imagine a pill millepede as big as a football, and you will have a very good idea of an armadillo.

These animals do not appear to be in the least inconvenienced by their singular armour, and are able to run with considerable speed. They are able to dig very well, too, by means of the large and powerful claws with which their front feet are furnished,

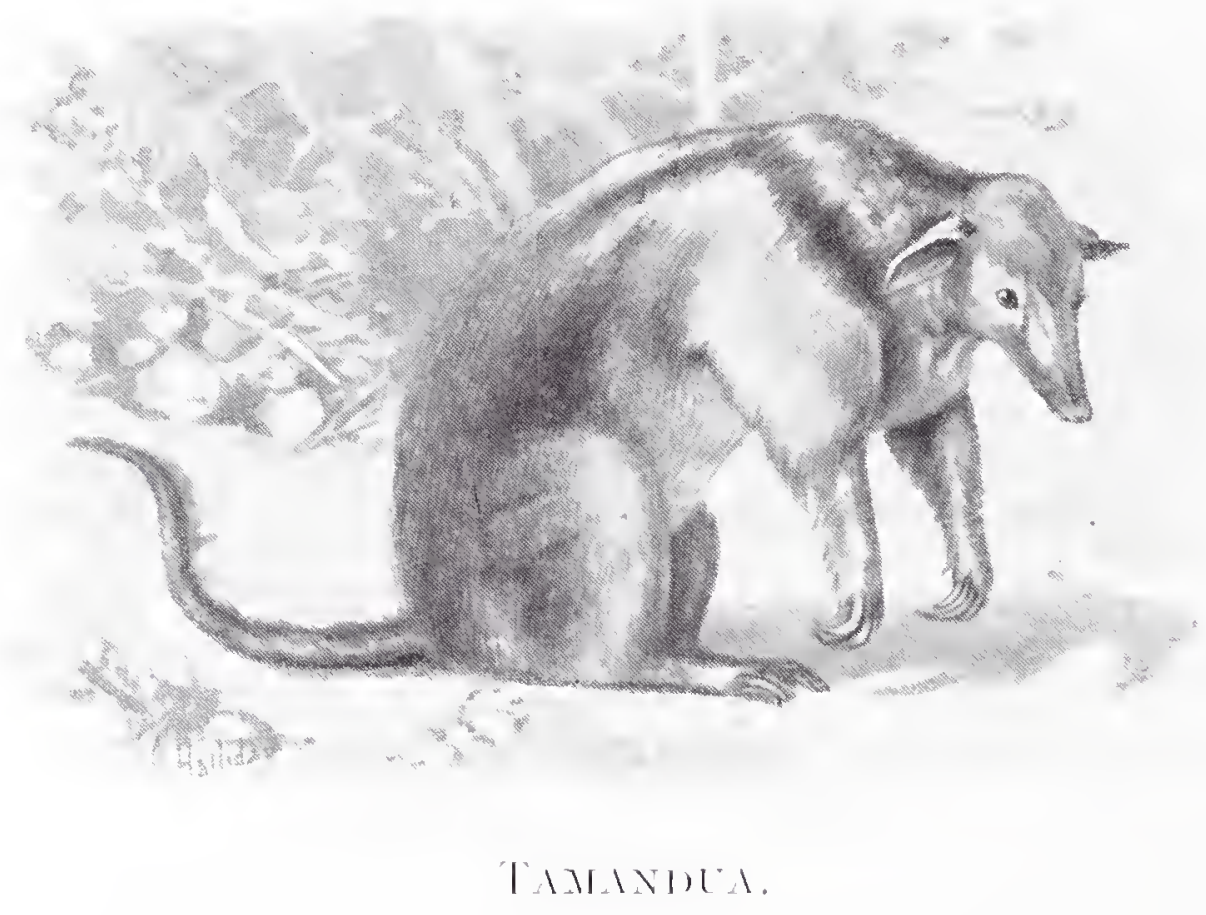

and it is said that if a man on horselack sees an armadillo running by his side, and leaps to the ground to secure it, he will nearly always find that it has succeeded in burying itself before he is able to seize it.

The Six-banded Armadillo is so called hecause the horny plate upon its back is broken up into six separate bands, all of which, however, are closely linked together by bony rings. Sometimes it is called the "weasel-headed armadillo," because its head is thought to be rather like that of a weasel. It is about sixteen inches in length, without including the tail, and is found in Brazil and Paraguay.

The Giant Armadillo is very much larger, growing to the length of nearly a yard from the tip of the snout to the root of the tail. It lives in Jirazil and Surinam, and feeds chiefly on ants and termites. 
But perhaps the most interesting of these creatures is the odd little Pichiciago, which is only about five inches long, and has a pink shield upon its back, and fur of snowy white. It is found in the western parts of the Argentine Republic, in open sandy places, but nowhere seems to be very plentiful. It digs in a most curious manner. First of all, it scratches away for a minute or two with its front feet, just to loosen the soil. Then, supporting itself partly on its front feet and partly on its tail, it uses the hinder feet with the most astonishing rapidity, so that it sinks down into the ground as if by magic. And, strange to say, it does not leave its burrow open behind it when "it has"gone

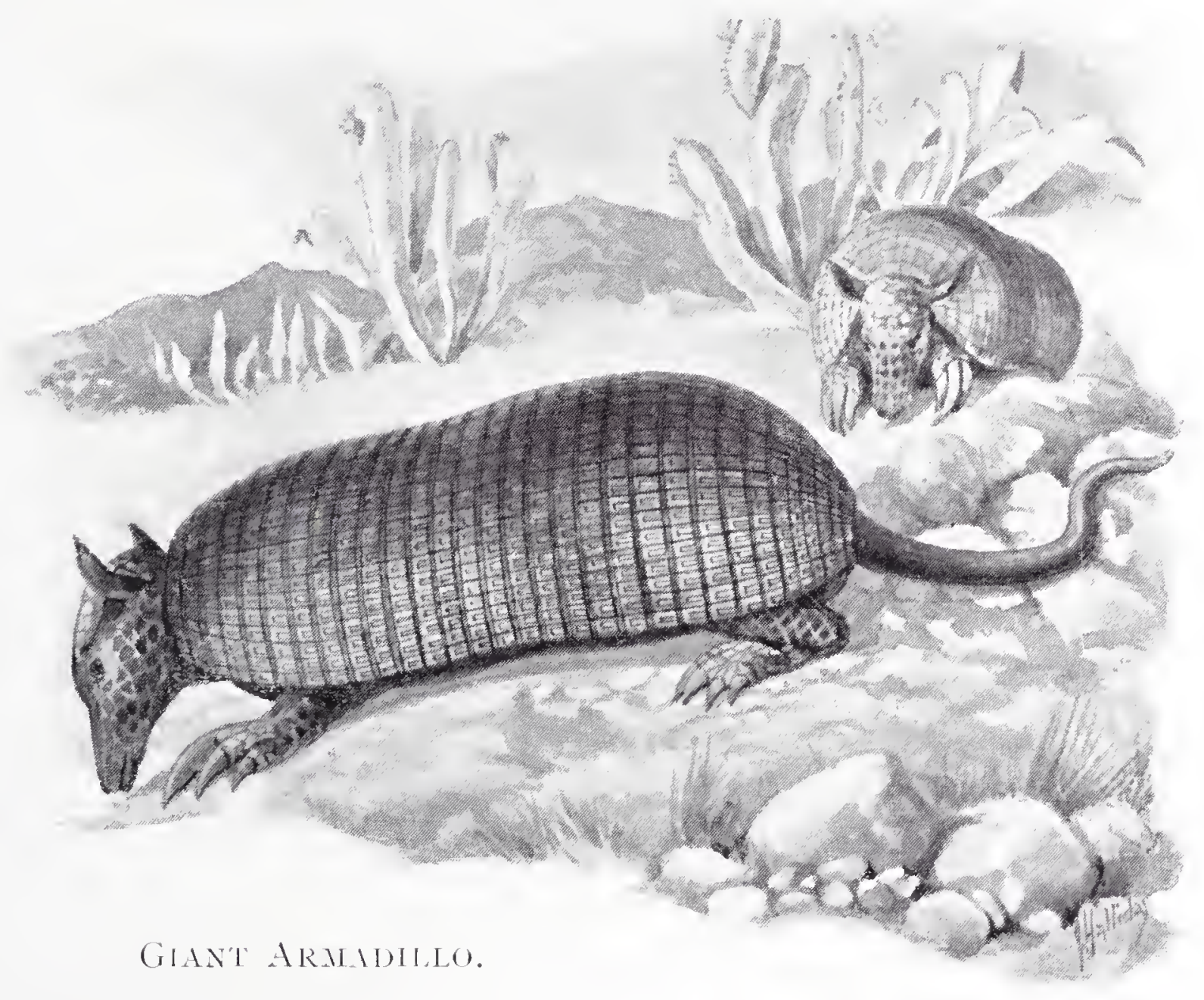

in, but carefully closes the entrance, ramming the earth hard by means of the bony shield at the end of its hody.

More remarkable still are the PANGolins, or scaly ant-eaters, whose heads, bodies and tails are covered with large, pointed oval scales, which overlap one another very much like the tiles on the roof of a house. When they are alarmed they coil themselves up into balls, just as most of the armadillos do, and their muscles are so wonderfully strong that it is quite impossible to unroll them. Seven different kinds of pangolins are known, four of which live in Africa, and three in Asia. They all feed chiefly upon ants and termites, which they catch by breaking down the walls 
of their nests, and licking up the insects with their long, wormlike tongues as they run about in confusion. They live either in crevices among rocks, or else in luurrows which they dig for themselves in the ground. Sometimes these burrows are of very great size, that of the Indian pangolin often rumning for ten or twelve feet downwards into the ground, and having a sleeping chamber at the end of at least five or six feet in diameter.

When a pangolin comes to the edge of an overhanging rock, and wishes to descend to the ground helow, it coils itself up into a ball and then rolls over, alighting on the edges of its scales just as a hedgehog does upon its spines. In this way it can drop for ten or fifteen feet without receiving any injury.

The different species of pangolin vary a good deal in size,

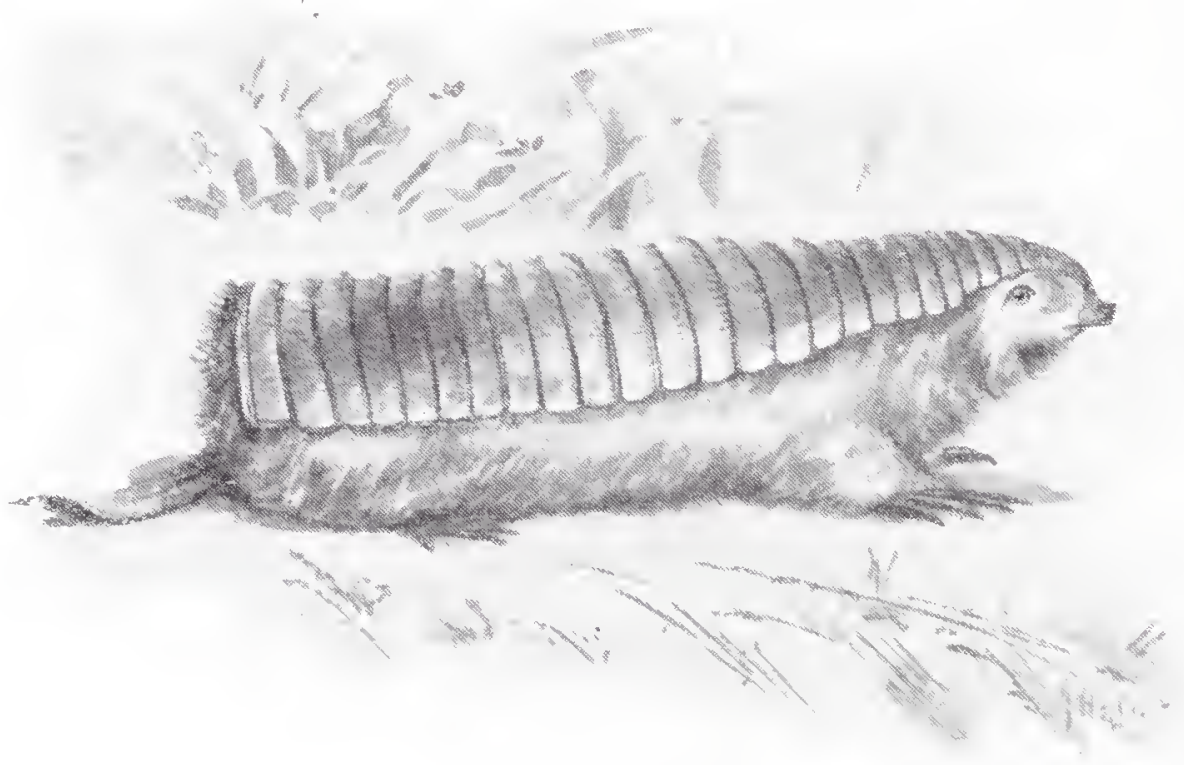

PICHICLA(io)

but the largest of them, which is known as the Giant Pangolin, is between four and five feet long when fully grown, including the tail.

Very curious, too, is the AARD TARK.

This name means "earth-hog," and has been given to the animal by the Boers of South Africa, because in general appearance it is rather like a pig. But then it has ears like those of a hare, and a muzzle and tongue like those of an ant-eater, while all its feet are furnished with very long and very stout claws. So that altogether it is a very odd-looking creature.

The aard vark feeds entirely upon termites and ants, and is nearly always to be found where the nests of those insects are plentiful. It digs with very great rapidity, and is said to he able to burrow into the ground faster than a man armed with a spade can dig it out. So it has no difficulty in tearing a hole through the walls of the termites' and ants' nests, and then licks out the insects in thousands. 
During the day-time the aard vark is hardly ever to be seen, for it lies fast asleep in its burrow, which it seldom leaves until after sumset. Before digging this hurrow, strange to say,

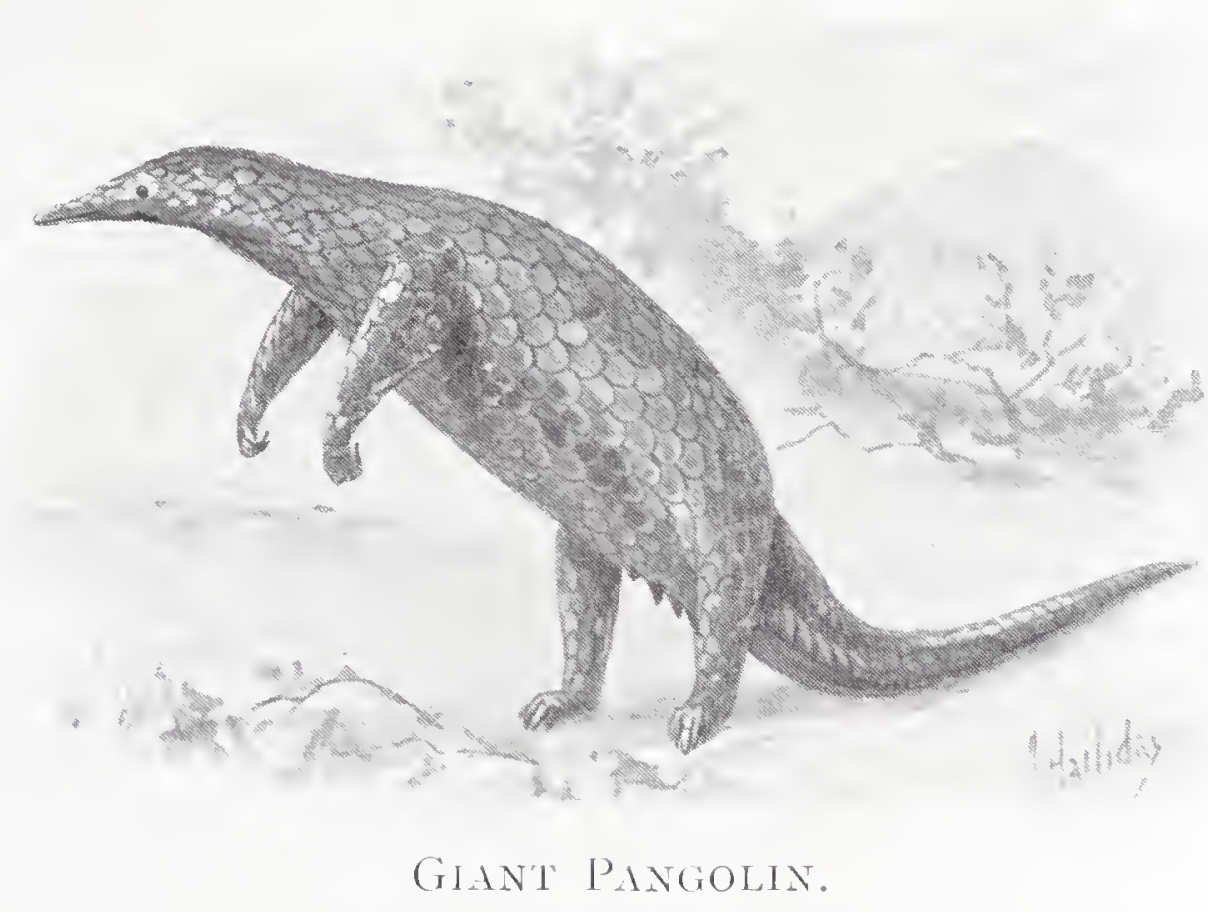

it mostly scoops out quite a number of half-finished ones, scraping a hole two or three feet in depth, and then leaving it and beginning on another. Why it does this nobody seems to know.

In olden days it was thought that the lion and the elephant were in the habit of hunting the aard vark together, the elephant flooding its burrow by means of a stream of water from his trunk, and the lion pouncing upon the animal as it ran out.

When fully grown the aard vark is rather over six feet in total length, about one third of which is occupied by the tail. The body is very heavily and clumsily built, and the back is a good deal arched in the middle. In colour it is yellowish brown, with a tinge of red on the back and sides, while the lower surface is rather paler. 


\section{CIAPTER NIX.}

THE MARSUPIATS.

THE last order of mammals is a very curious one indeed, for in most of the animals which belong to it there is a large pouch on the lower part of the body of the female, in which she carries her little ones about for several weeks, or even sereral months, after they are born. That is why these creatures are called "marsupials," for that word signifies "pouched." Iiven after the little animals are quite able to take care of themselves they will hurry back to their mother and jump into her pouch in moments of danger.

It is quite true that in a good many marsupials this pouch is wanting. But traces of it are almost always to be found, although sometimes they are so slight that only a very careful observer would be likely to notice them.

In days of old, marsupial animals lived in almost all parts of the world, for there are very few countries in which their fossil remains liave not been discovered. But now they are almost entirely restricted to Australia, the only exceptions being the Opossums, which are found in America.

The largest, and in some respects the most interesting, of the marsupials are the Kingaroos. In some ways they are rather like gigantic hares. But their front legs are so much smaller than the hinder ones that they cannot run on all fours, but travel by means of a series of leaps, skipping about, in fact, instead of running. And besides this they have very long and stout tails, which serve to support them when they are sitting upright, and also help them to balance their bodies when they are leaping.

'The male kangaroo, which is often known as the "boomer," or as the "old man," is very mucl larger than the female, scmetimes attaining to a total length of eight feet six inches, or even nine feet, nearly half of which is occupied by the tail. But when he is sitting upright he is nearly as tall as a tall man. The female is about two feet shorter.

Althougl it is obliged to hop along instead of running, the kangaroo is a very swift animal, and can only be run down by fast and porverful dogs. At every leap it covers about fifteen feet of ground, the distances between the holes which its great claws make in the ground being as regular as if they had been marked out with a measuring tape.

These huge claws are very formidable weapons, and the kangaroo well knows how to use them. As a rule it is a rery 


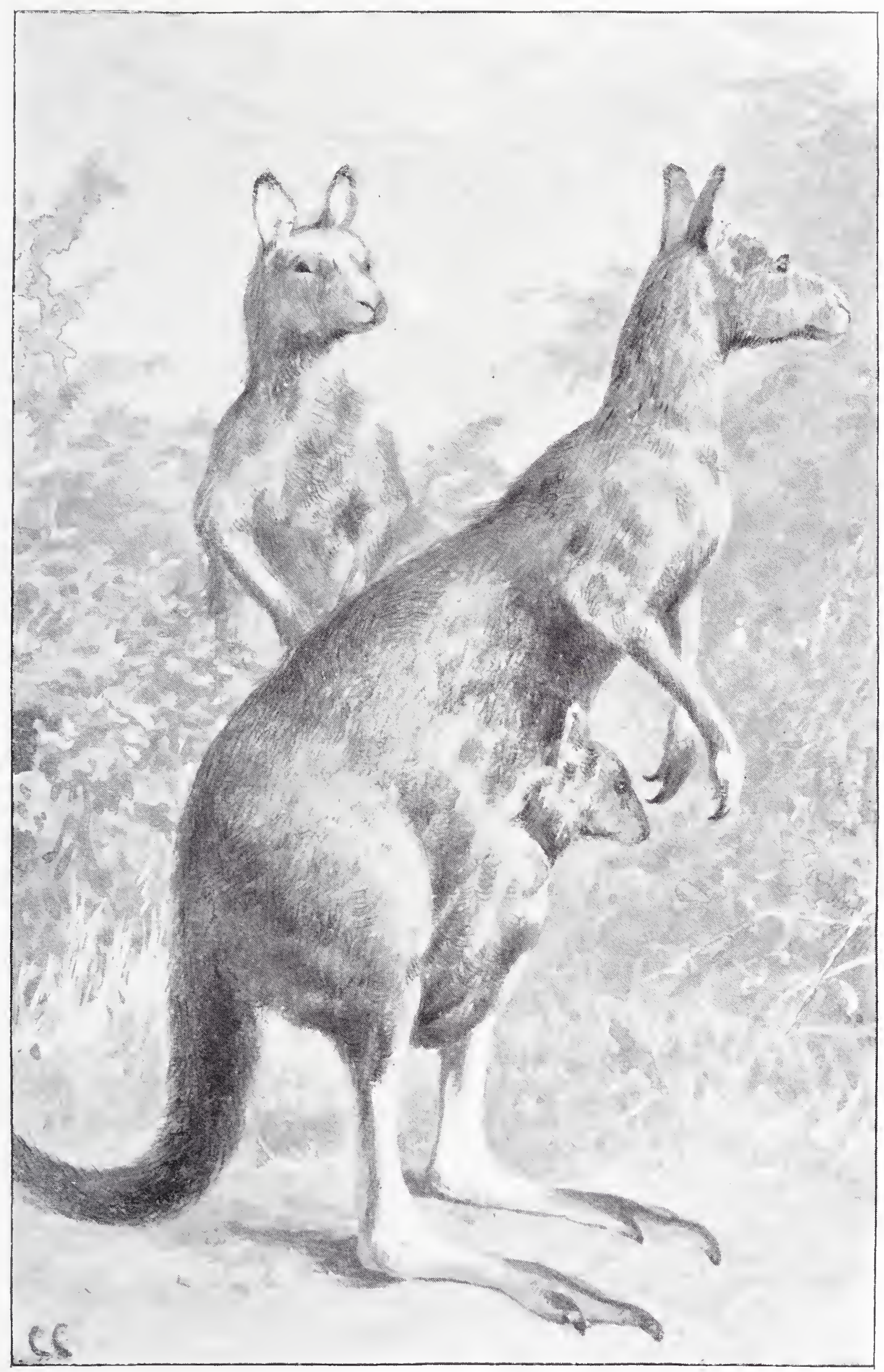

KANGAROOS. 
timid animal, and when it is attaclied its first idea is always to seck safety in flight. But if it is driven to bay it takes up its post with its back against a tree, so that it camnot be approached from hehind, and quietly awaits the onslaught of its enemies.

Then, as soon as one of them conles

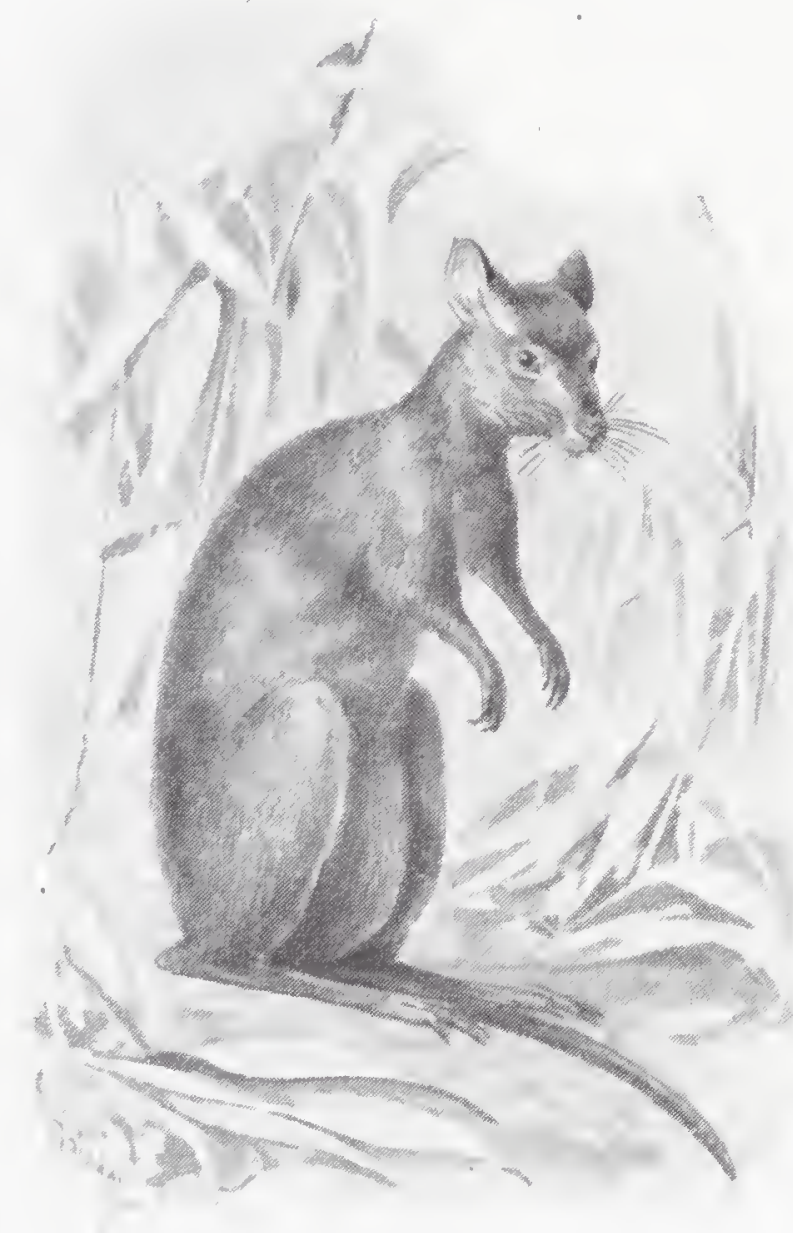

KINGAROORAT. within reach, it kicks suddenly out with one of its hinder fect, delivering its strolic with such force that the great sharp claw has heen known to rip up the hody of a large log from end to end, and to stretch the poor beast dying upon the ground. For this reason hounds which are used in liangaroo hunting are made to wear collars of twisted steel chain, to protect them from the stroke of their quarry.

Sometimes, too, when a hunted kangaroo finds that it cannot escape simply by speed, it will wade into a pool or river, wait until the dogs sivim up to it, and then seize them with its fore limbs one after another, and hold them under water until they are drowned. Although they are not large, these front limbs are wonderfully strong, and if even a powerful man were to be embraced by them he would find it very difficult to make his escape.

The female kangaroo, however, is not nearly so well able to defend herself, and sometimes she has been known, when chased by hounds, to lic down and dic simply from fear. But sometimes she escapes by taking a sudden leap sideways into thick lushes, lying perfectly still until hor pursuers have rushed past her, and then making off in the opposite direction.

As the mother kangaroo hops ahout, the head of her little one, or "joey," as it is called, may often be seen poking ont of her pouch. And she is so clever that if an enemy should appear when the "joey" is playing on the ground or feeding, she will snatch it up and put it into her pouch even while she is hopping avay, without pausing for a moment in her retreat.

Kangaroos are very affectionate animals, and a touching story is told of a couple which lived together in captivity. They hecame the very best of fricnds, hut when they were sent from Australia to P'hiladelphia, they had to travel hy different ships. As soon as they were separated, they hecame perfectly miserable, 
moping in their cages, refusing to talie food, and calling for each other all day long. "Jack," as the male was called, reached Philadelphia first, and for a whole week seemed to be constantly on the watch to see if "Flora," his mate, was coming. At last she arrived, and both aninals at once became madly excited, leaping out in their cages so willly that at last they were put together, to prevent them from injuring themselves against the lars. Then they cuddled up against one another, licked each other with their tongues, and seemed so overjoyed to meet that the lieeper promised that they should never be parted again.

Kangaroos generally live in droves, sometimes consisting of only a few animals, sometimes of as many as a hundred and fifty, or even more. But a "boomer" often lives during the greater part of the year quite alone, like a "rogue" elephant.

There are at least twenty-three different kinds of kangaroos, the smaller ones being generally known as "Wallabies." And these are again divided into "large wallabies" and "small wallabies."

The large wallabies are also called "bush kangaroos," because they live in the thick "bush," or bushy jungle, which occupies so large a part of the Australian continent. 'The biggest of them is really quite a large animal, for when fully grown it is six feet long, from the tip of the muzzle to the end of the tail. some of the small wallabies, however, are very small indeed, several of them being no bigger than rabbits.

Then there are some of these animals which spend most of their life in the trees and are called Tree Kangaroos in consequence. Four of these creatures lived for some time in the Apes' House at the Zoo, and very odd indeed they used to look as they sat on the branches with their long tails hanging down behind them. But even when they were on the floor of their cage one could not possibly mistake them for ground kangaroos, for their front limbs were almost as long as their hind ones.

T'he best known of these animals is found in Queensland where it is known as the BUNGart. But it is very seldom seen, for in the first place it spends the day in sleep, only coming out from its retreat among the foliage when darliness has set in, and, in the second, it lives in the very thicliest part of the bush, which is hardly ever visited even by the natives. It does not seem to he a very good climber, for it is rather slow in its movements, and appears to be a little afraid of falling; for it clings so tightly to the branch on which it is resting that it is very difficult indeed to force it to loose its hold.

The natives generally catch this curious liangaroo by climbing the tree in which it is sleeping, jerling it from its perch by a riolent pull at its tail, and throwing it to the ground to be killed by the dogs below. But if it reaches the ground unhurt it makes off with very great speed, hopping along with great flying leaps just like all the other members of the fanily. 
The Kaxgaroo Rats, or Potoroos, as they are often called, are quite small, even the largest of them being scarcely as big as a rabbit. They do not jump so well as the true kangaroos, and generally run on all fours in a kind of gallop. But when they are at rest they sit upright on their hinder quarters.

One of these animals, which is known as the Brush-TAILED BETTONG, puts its tail to a most curious use. It makes its nest of grasses and leaves in a hollow in the ground, and when it is collecting materials for building it gathers them up into a bundle, twists the tip of its tail round them, and then hops swiftly

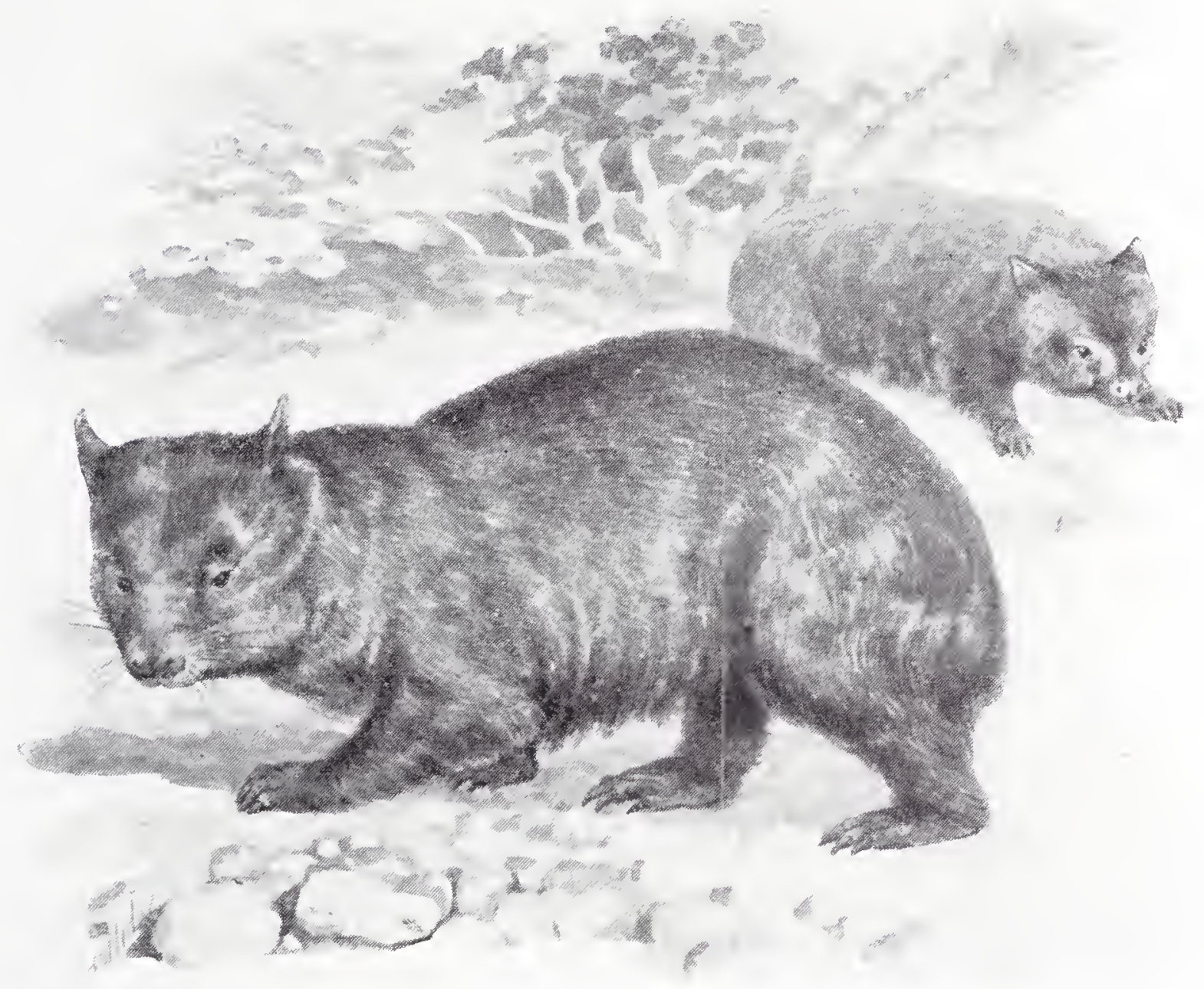

IVOMBNTS.

away, holding its little sheat well away from its body. It is a most clever little builder, for when it has chosen a suitable hollow in the ground for its nest, it first of all enlarges it until it is big enough for its requirements, and then weaves its materials carefully together until the top of its little home is just on a level with the herbage growing all round it. And whenever it goes in or out, it pulls a tuft of grass over the entrance in order to prevent it from being noticed. So well is the nest concealed, indeed, that you might pass within a couple of feet and look straight at it, and yet never see it at all. 
This animal is sometimes known as the Jerboa Kangaroo.

Among the Australian mammats we find a good many which are really very much like those found in other parts of the workl, and might easily be mistalien for them if it were not for the presence of the marsupial pouch. One of these is the curious Sugar Squrrel, or Squirrel Petaurist, which is really very much like the flying squirrels of Asia and North America. It has the slin of the sides and flanks dereloped in just the same manner, and uses it in exactly the same way, leaping from a lofty bough, spreading its limlis at right angles to its body so that the skin is stretched out between them, and thus contriving to skim for long distances through the air. And the big, bushy tail serves partly to help it in keeping its balance, and partly to enable it to lieep a straight course.

During the day-time sugar squirrels are nearly alway's asleep in a hollow tree, or in some other convenient retreat. But as soon as it grows dark they all come out from their hiding-places and hegin to frisk about, and to leap from tree to tree, with the utmost activity. After a time they will stop, in order to search for insects, or to feast upon the honey which they find in the l)lossoms of the trees. But very shortly they recommence their sambols, and so they go on, alternately playing and feeding, until the dawn.

The sugar squirrel is a very pretty little creature, the fur heing brownish grey alove, with a black stripe along the back, and a rich brown edging to the umbrella-like slin of the sides. The lower parts of the bocty are nearly white, and the tail is brown ahove and white beneath. In length it is about nineteen or twenty inches, rather more than half of which is occupied by the tail.

Then there is an animal which is very much like a small bear. Indeed it is often known as the Australian BEar, although its proper name is the Koald. When fully grown it is about as big as a poodle dog. And it has a very stoutly-built body, very short legs, large and almost square ears, with a fringe of stiff hairs round the edges, and no visible tail at all, while the fur is very thick and very woolly. In colour it is ashy grey above and yellowish white underneath the body.

The koala spends most of its life in the trees. Yet it is not a very good climber, for its movements are curiously slow, and it always seems to feel in danger of falling. On the ground, however, it is slower and more awkward still, for its feet are much more suited for grasping a branch than for use upon a level surface. But it does not often come down from the trees unless it wishes to drink, or to vary its diet of leaves and buds by digging for roots.

When a mother koala has a little one to talie care of, she always carries it about on her hack, and even when it is nearly half as hig as she is it may sometimes be seen riding pick-a-back. 
The lioala is a very gentle animal, and even when it is captured it seldom attempts to scratch or bite. But sometimes it gets in a great passion over nothing at all, and shows its teeth and yclls and screams in such a threatening manner that anyone who did not know how harmless it really is would most likely be a sood deal afraid of it.

Owing to the fact that it spends so much of its life in the trees this animal is sometimes called the "Australian monkey"; and it is curious to find that it has pouches in its cheeks in which it can store away food, just as many of the true monkeys have.

The WonBAT might easily be mistaken for a rodent, for its front teeth are formed almost exactly like those of the rabbit and the rat. But as it possesses a marsupial pouch, there can be no doubt at all as to which order it really belongs to. It is not at all a handsome animal. In fact, it is fat, and awkward, and

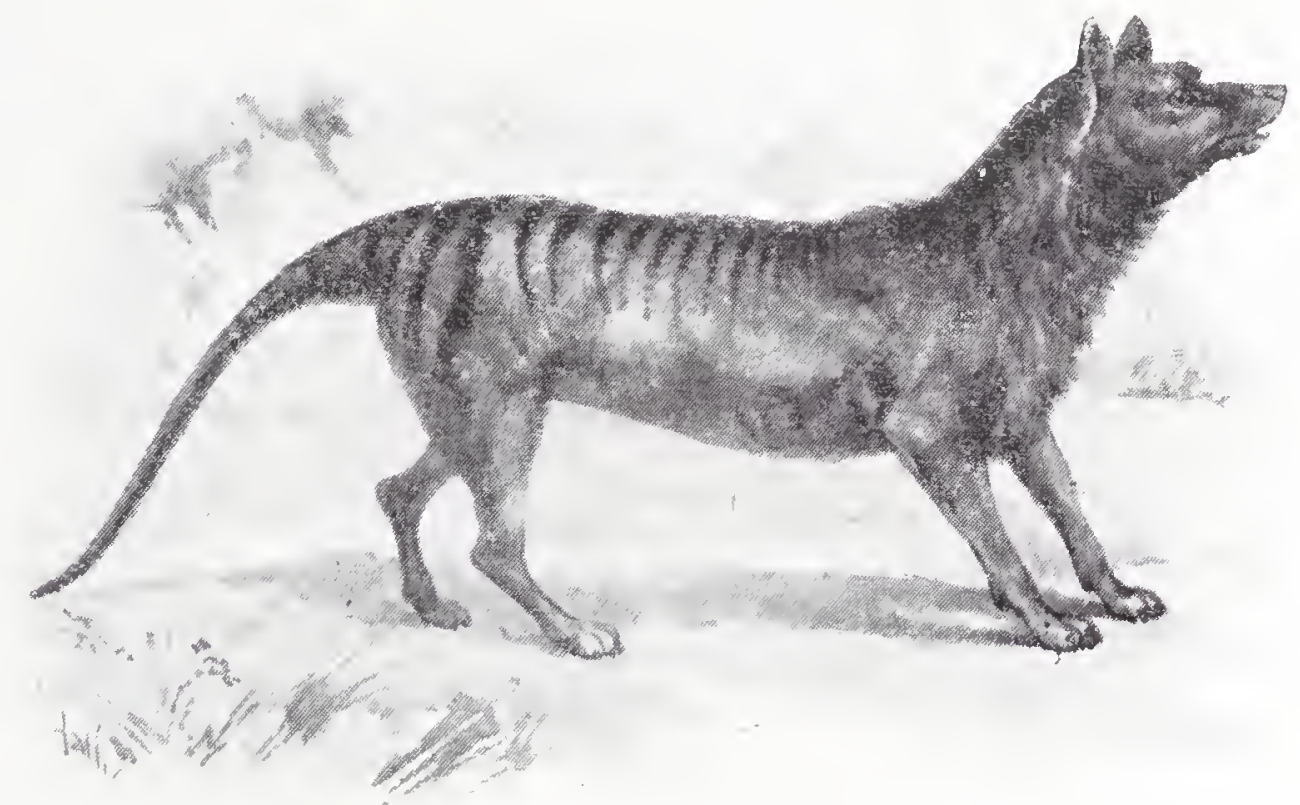

TISMANIAN MULF.

clumsy, and heavy-something like a very much over-grown guineapig-and it seems to spend its whole life in eating and sleeping. It can dig very well, however, and makes deep burrows in the ground, with a large sleeping chamber at the end of it. And if it is liept in captivity it will often male its escape by digging its way out underneath the walls.

When fully grown the wombat is about three feet in length, and its legs are so short that its body almost touches the ground as it waddles awkwardly along. Like the lioala, it is very gentle in disposition, and hardly even struggles when it is captured, although it is subject to sudden fits of passion. If it is kept as a pet it soon becomes very affectionate, and likes to go to sleep on its owner's linees, like a cat.

In colour this animal is darli greyish brown. It is found in New South VVales, Victoria, and South Australia. 
The Bandicoots, of which there are about a dozen different linds, are very odd-looking animals. Perhaps I can hest describe them by saying that if you can imagine a rat with a snout drawn out like that of a shrew, very large ears, three very long toes with still longer claws on each foot, together with two toes with no claws at all, and a rather short, hairy tail-then that is what a bandicoot loolis like.

Owing to the very odd way in which their feet are formed, bandicoots cannot run like other animals, but travel along by means of a curious mixture of running and jumping. They are very common indeed in most parts of Australia-so common, in fact, that they are generally regarded as a great nuisance. For they do a terrible amount of mischief both in gardens and in cultivated fields, feeding both upon grain and fruits, as well as upon the roots and bulbs which they scratch up out of the ground. During the day-time they are hardly ever seen, for they hide themselves away in holes in the ground, or in hollow trees, and remain fast asleep until after sunset. Some of them, however, malie nests of dry leaves and grasses which are so cleverly concealed among the herbage that it is very difficult indeed to find them.

Then there are certain marsupial animals which look as though they belonged to the $\log$ and cat tribes. One of these is the 'Tasmanian Wolf, or Thy'macine, as it is often called, which is so wolf-like both in appearance and habits that it fully deserves its name. But you can tell it from the true wolves at a glance by the dark, zchra-like stripes upon its back, and also by its long slender tail, which tapers down almost to a point.

The Tasmanian wolf used to be very common indeed, for it was the most powerful of all the Tasmanian animals, so that it had no natural foes, while it was very seldom liilled by the natives. But when white settlers came to live in the country they found that it lilled so many of their sheep, that it was necessary for them to do all that they could to destroy it. So numbers of Tasmanian wolves were shot, and numbers more were caught in traps, and by degrees the animal was driven back, until now it is only found in wild and rocky districts among the mountains, which are scarcely ever trodden by the foot of man.

There are very few of the Australian animals which do not fall victims to this fierce and savage creature. Even liangaroos are killed by it at times. And it has actually been known to destroy and devour the echidna, which is something like a small porcupine. But besides feeding upon living prey, it will feed heartily upon any carrion that it may find, and will also prowl about on the seashore in search of the various dead animals which are flung up by the waves.

The T'asmanian wolf is a nocturnal animal, remaining hidden all day long in some deep recess among the rocks, into which no 
ray of sunshine can ever penetrate. It does not like the daylight at all, and seems most uneasy if it is brought out from its retreat. And, strange to say, it has a kind of inner eyelid, like the "nictitating membrane" of the owls, which it draws across its eyes every moment or two in order to lieep out the light as much as possible.

Just as the Tasmanian wolf is likie a dog, so the Tasmanian Devil is like a small bear-and a very wild, fierce, savage bear too. Its name has been given to it on account of its disposition, and there is perhaps no animal which it is so difficult to tame. No matter how kindly it is treated, it is always sullen and always ferocious. It will fly at the very hand that gives it food. If you merely look at it as it lies in its cage, it will dash furiously at the bars with its teeth bared, uttering yells and screams of passion. You cannot help feeling that it would tear you to pieces if only

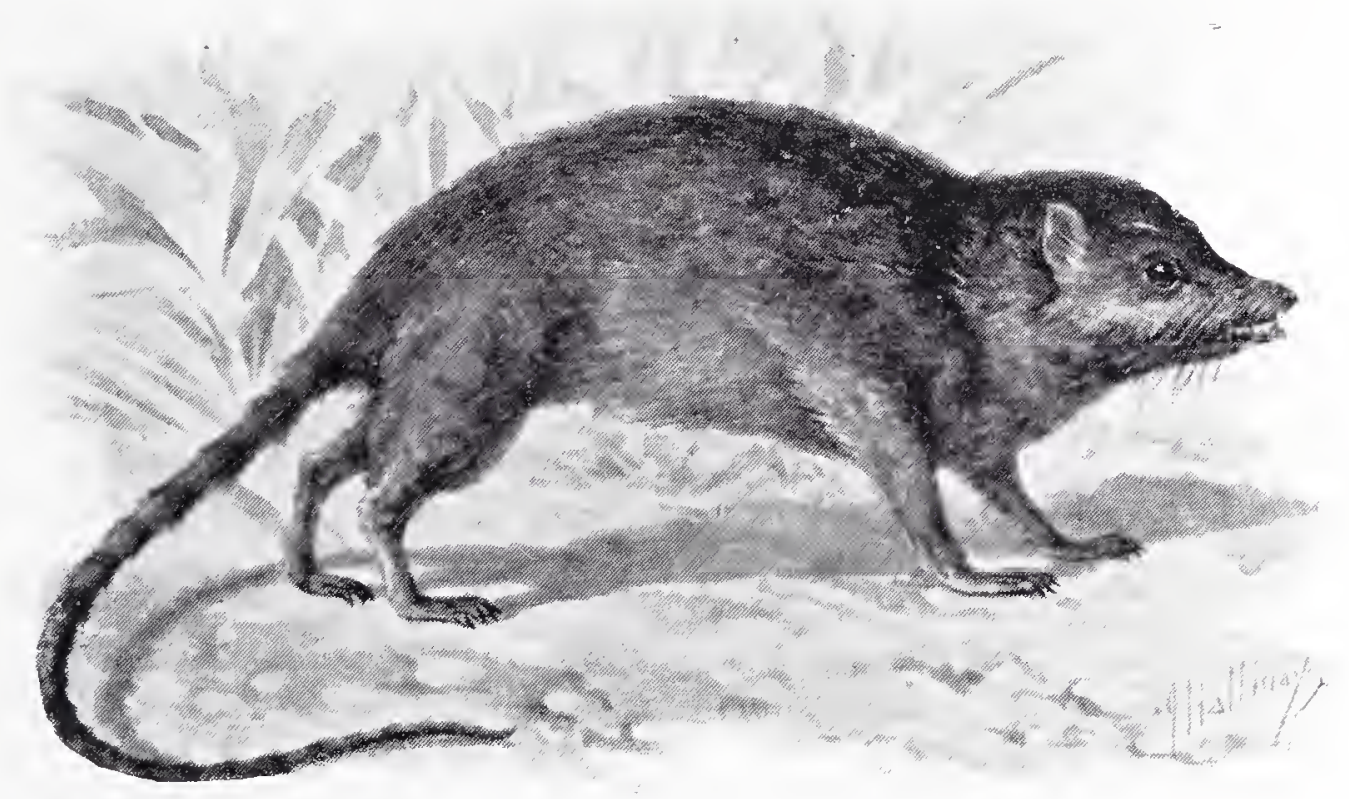

Pouched Mouse.

it had the chance. And its teeth are so sharp and its jaws are so powerful, that there are very few dogs indeed which could overcome it in fair fight.

The Tasmanian devil has its eyes protected by a nictitating membrane, just as the Tasmanian wolf has, and, like that animal, it is very seldom seen abroad by day. It is extremely mischievous, for night after night it will visit the hen-roosts and the sheepfolds, not only preying upon the poultry and the young lambs, but seeming to kill for the very sake of killing. So it has been almost as greatly persecuted as the Tasmanian wolf, and has altogether disappeared from many districts where it used to be plentiful, while in many others it is very seldom found.

In size the Tasmanian devil is about as big as a badger, and in colour it is dull sooty black, with a white collar-like streak on the lower part of the throat. 
Then the larger Dasyures may be compared to cats, to which they are just about equal in size. In Tasmania, indeed, they are called "wild cats." They live in trees, sleeping in hollows in the trunks during the day, and prowling about in search of prey by night. And they are almost as mischievous in poultry yards as the Tasmanian devil. But then, on the other hand, they will learn to catch rats and mice if they are tamed and trained, just as a cat will.

'There are several different linds of these animals, but they all agree in having greyish or greyish-brown fur, with a number of white spots on the sides of the body.

Very pretty and graceful little creatures are the Pouched Mice, of which there are a good many different kinds. They are all small, the largest of them being no bigger than a half-grown rat, while some of them are not equal in size even to an ordinary English mouse. And as they breed very freely, and have quite a number of little ones at every birth, they are among the most plentiful of all the Australian mammals.

Pouched mice always spend a great deal of their time in the trees, where they seem quite as much at their ease as they do on the ground. They run up and down the trunk with the utmost activity, scamper along the branches, leap from one bough to another, and never seem to miss their footing. And they are continually poling their sharp little muzzles into the cracks and crevices of the bark in order to search for tiny insects and spiders. Their habits, indeed, are not very much like those of mice, and one cannot help thinking that they ought to be called "pouched shrews."

Then there is a kind of marsupial ant-eater.

This is the Mrrmecobius, or Banded Ant-Eater, as it is often called, which is found in Southern and Western Australia. It is a prettily-marked little animal of about the same size as a squirrel, with a pointed snout, a long slender body, and a rather long and bushy tail. In colour it is dark chestnut brown above and white below, while a number of white stripes run across the hinder part of the back and loins, beginning just behind the shoulders, and ending a little above the root of the tail.

The myrmecobius lives principally on the ground. But it is a very good climber nevertheless, and can ascend trees and run about on the branches with some little activity. It feeds on ants and termites, catching them by means of its long and wormlike tongue, which is so sticky that the insects adhere to it as soon as they are touched. The marsupial pouch is almost entirely wanting, so that one might almost be led to suppose that the animal must be a true ant-eater. But then the ant-eaters have no teeth at all, while the myrmecohius has no less than fifty-two, or more than any other mammal with the exception of one or two nembers of the whale tribe and the armadillo. 
This curious and pretty little animal is very gentle in disposition, and never seems to bite or scratch even if it is taken prisoner. It makes its home either in the decaying trunk of a fallen tree, or else in a hole in the ground.

One of the most curious of all the marsupial animals is the Pouched Mole, which was quite unknown until a very few years ago. In size and shape it is very much like the common English mole, and it has its fore-paws armed with enormous claws for

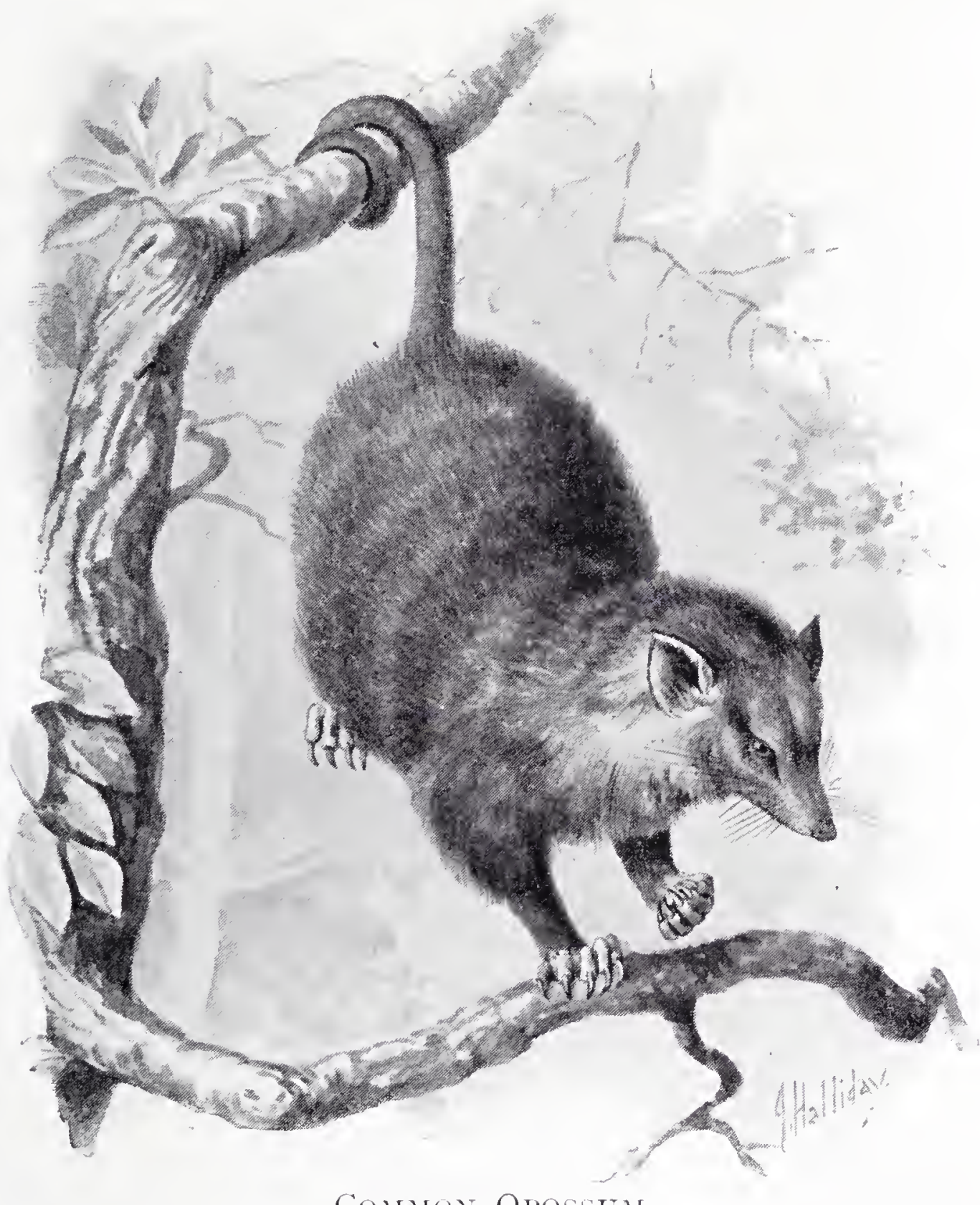

Comalon Opossum.

digging in just the same manner. But instead of being brownish black in colour it is pale yellow. Then it has no outward ears at all, while its eyes are so very tiny, and so deeply buried in the skin, that it must be almost, if not quite, unable to see with them. And in front of its snout is an odd kind of shield made of thick, horny slin, which is evidently intended to protect the face as the animal forces its way through the ground. 
This singular creature lives in sandy districts in the deserts of South Australia. It appears to burrow through the soil for a few feet, then to come to the surface and crawl for a little distance, and then to burrow again. And as it creeps over the sand it leaves three tracks behind it, one being made by the feet on either side, and the third by the stiff and stumpy little tail, which appears to be pressed down upon the ground. These tracks, of course, can only be seen after rain, for in dry weather the sand very soon falls in upon them, and fills them up.

The next group of the marsupial animals consists of the Opossuns, which are found, not in Australia, but in America.

There are several different kinds of these creatures, most of which live in the trees. They are excellent climbers, for they not only have their hinder feet made more like hands, with a thumblike great toe which enables them to grasp the branches, but are also the possessors of long prehensile tails, just like those of the spider monkeys. So powerful is the tail of an opossum that it can bear the entire weight of the body as the animal swings from a branch to pluck fruit which would otherwise be out of its reach.

But opossums do not feed upon fruit alone. Indeed, there are very few things which they will not eat. They are very fond of maize, for example, obtaining it sometimes by climbing up the stems of the plants, and sometimes by cutting them down close to the ground. Nuts, too, they devour in great quantities, together with acorns, and beech-mast, and berries. Sometimes they dig up roots out of the ground. Then they will search for birds'nests, and carry oft the eggs or the unfledged little ones. They will pounce upon a rabbit, too, or a young squirrel, and do not disdain mice, or lizards, or frogs, or even insects. And the farmer has very good cause for disliling them, for they not only get into his fields and steal his grain, but find their way into his henroosts and carry off the eggs and the young chicliens.

But then they are very easily caught, for they are attracted by any kind of bait, and will walli into the simplest of traps. Tet in some ways they are exceedingly cunning. If they are caught, for example, and are injured in even the slightest degree, they will pretend to be dead, and will allow themselves to be pulled about, or kiclied, or beaten, without showing the slightest sign of life. Then the moment they think that no one is looking at them they will rise to their feet and quietly slink a way.

During the day-time the opossum is always fast asleep in its nest, which is sometimes made by itself, and sometimes consists of the deserted home of a squirrel. So it has to be hunted by night.

A moonlight night is always chosen for this purpose, and the animal is first of all driven into a tree by dogs. One of the hunters then climbs the tree and shakes it down from the branch 
to which it is clinging, and the moment it reaches the ground it is pounced upon and destroyed by the dogs.

The opossum runs in a very curious manner, moving both limbs of the same side together.

When the little opossums are born, they are not only blind likie puppies and kittens, but are quite deaf as well, and do not get their sight and hearing for some little time. When they are fifteen days old, the mother places them in her pouch, and there they remain for five or six weeks.

The Common Opossum is about as big as a cat. But it

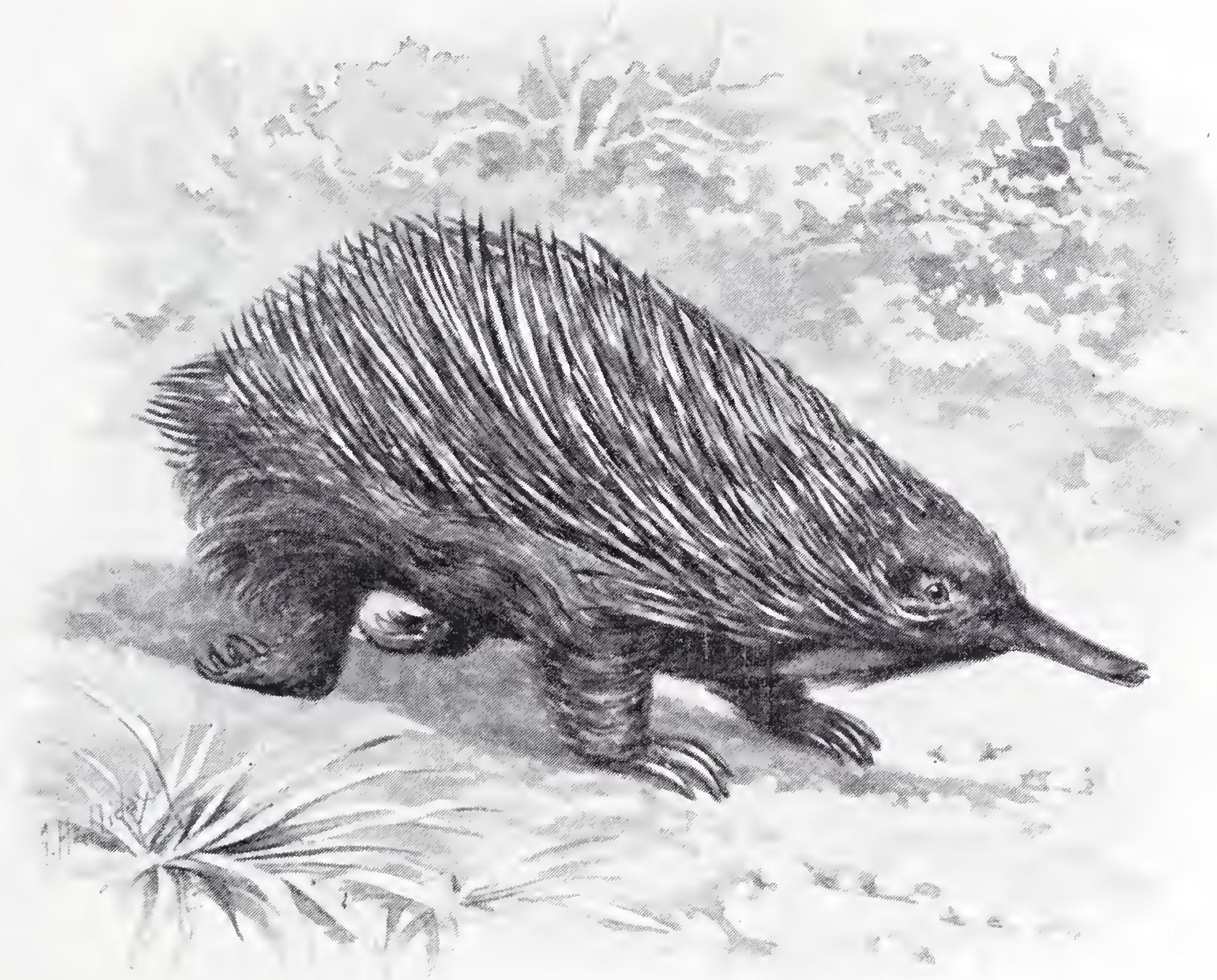

CUMMION ECHIDNA.

looks much more like a very big rat, for its tail is long and scaly. It is found in North America. In South America there is a different species, called the Crab-eating Opossum, because it is so fond of the crabs and crayfishes which abound in the salt creelis and the great swamps of Brazil. Then Merian's Opossun, in which the marsupial pouch is not developed, has a most curious way of carrying its young about, for the little ones stand in a row on their mother's back, with their tiny tails coiled tightly round hers, to prevent them from falling off. And the Yapoci Opossun spends 
most of its life in the water, and lives upon fish, being such an excellent swimmer that it is able easily to overtake them.

Last of all, we come to two most extraordinary animals, which differ from all other mammals in the fact that they lay eggs, while in some parts of their skeletons they closely resemble the reptiles.

The first of these creatures is called the EcHidna, and is also linown as the Spiny Ant-eater. It is from fifteen to nine-

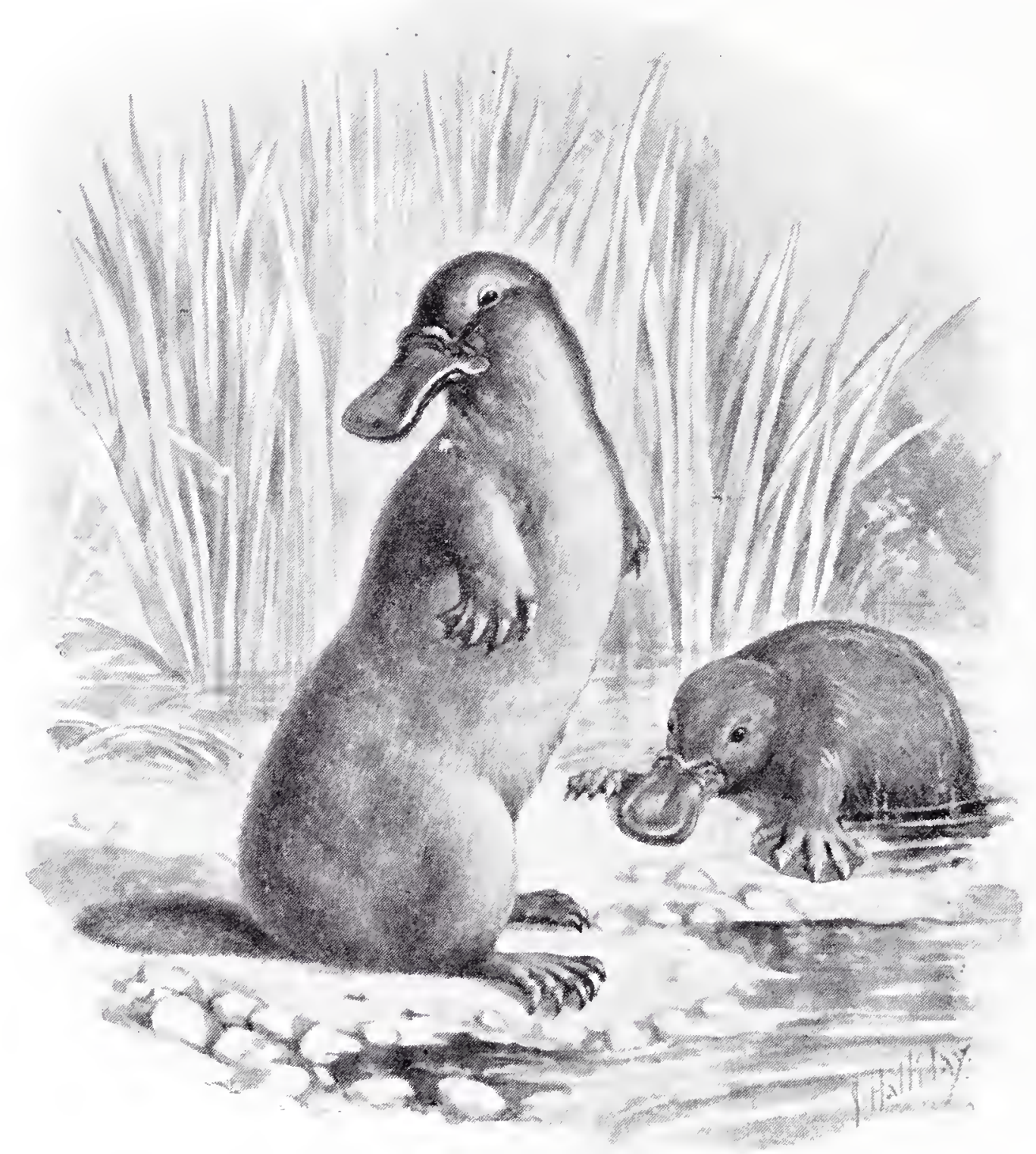

I) UCKLHL.

teen inches in length, and has the whole upper surface of the head and body covered with a mixture of stiff hairs and short sharp spines, something like those of a hedgehog. The head is drawn out into a very long, slender, beak-like snout, at the tip of which the nostrils are placed, and the tongue is long and worm-like and very sticky, just as it is in the true ant-eaters. The feet are furnished with enormous claws, which are used in tearing open the nests of the insects upon which the animal feeds, and those 
of the hind feet, strange to say, are turned backwards in walking, so that they point towards the tail instead of the head.

These claws are also used in digging, and can be used with such effect that if the animal is surprised when on sandy soil, it sinks into the ground as if by magic. But if the ground is so hard that it cannot use its claws, it rolls itself up like a hedgehog, and trusts to its spiny coat for protection.

The Common Echidna is found in Australia, Tasmania, and New Guinea. Besides this there is another species, called the Three-toed Echidna, which is found in New Guinea only.

Even more curious still is the Duckille, or Duckilled Platypus, which not only lays eggs like a bird, but resembles a bird in several other ways as well.

It has a bill, for example, just like that of a duck-broad and flat, with a number of grooves round the edges. And it feeds by taling a bealiful of mud from the bottom of a pond or ditch, squirting out the mud itself through the grooves, and then swallowing the grubs and other small creatures which are left behind.

Then its feet are like those of a duck, the toes being joined together by webbing, so that they can be used as paddles. And even the tail is rather like that of a duck, for it is very broad and very flat, so that it can serve as a rudder when the animal is swimming.

This very remarkable creature is found in Southern and Eastern Australia, and also in Tasmania. It is not at all uncommon, but is very seldom seen, for it spends most of its time in the water, or else in its burrow, which is always made in the bank of a pool or stream. This burrow is generally a long one, running to a distance of forty or even fifty feet, and terminates in a large chamber, which is used as a nursery. And it always has two entrances, one below the surface of the water and one above, so that if the animal is alarmed in any way it can run in by one door and out again by the other.

Two eggs are laid by this most curious creature, which measure about three-quarters of an inch in length, and are enclosed in a tough white shell. How they are hatched nobody seems quite to know; but when the little ones first malie their appearance they are quite blind and quite naked, and have hardly any beaks at all.

When fully grown the duckbill is about eighteen inches long from the end of the snout to the tip of the tail. 


\section{CHAPTER XX.}

\section{EIRDS OF PREY.}

WE have now first to think of the great Class of the Birds, which are distinguished from all other living creatures by having their bodies covered with feathers.

These feathers serve a double purpose.

In the first place, they help to preserve the warmth of the body. Birds are hot-blooded animals-indeed, their blood is a good deal warmer than yours and mine-and they often have to fly very fast through very cold air. So it is most important that they should be clothed with some sort of covering which is very warm indeed, and at the same time very light. And nothing is warmer, and at the same time lighter, than a coat of feathers.

And then, in the second place, many of these feathers are most useful in flight. Without them, indeed, a bird could not fly at all. If we want to lieep a tame bird from escaping, we have only to clip its wings, and then it can no longer raise itself into the air. But it is not only the feathers of the wings that are used in flight. Those of the tail are employed as well, for they serve as a rudder, and enable the bird to steer its way through the air. So that in both these respects the very life of a bird depends upon its feathers.

Now birds are divided into Orders and Tribes and Families, just as the mammals are. But scientific men are not quite sure which of the Orders ought to be placed first. Among the Birds of Prey, however, we find some of the largest and finest and most powerful of all the feathered race; so that I do not think that we can do better than to place these at the head of our list.

You can always tell a bird of prey by two points in its structure. The first we find in its beak, which is always very large, and very strong, and very sharply hooked. And the second we find in its talons, which are specially made for seizing and litling the animals upon which it feeds. People sometimes think that an eagle or a hawk liils its victims with its beak. But that is a great mistake, for the beak is only used for tearing the flesh from off its bones after it is dead. The real weapons are the talons, which are so sharp and so strong that they can be pressed deeply into the vitals of a captured animal and lill it at once. So that all the birds of prey have very large and very powerful claws. 
First among the Birds of Prey come the Vultures. Yet very often, strange to say, they never kill any prey at all. The reason of this is that they much prefer to feed on carrion, so that if they can find the dead body of an animal they will never talie the trouble to seek and lill victims for themselves. When an animal dies in a country in which vultures live, several of these

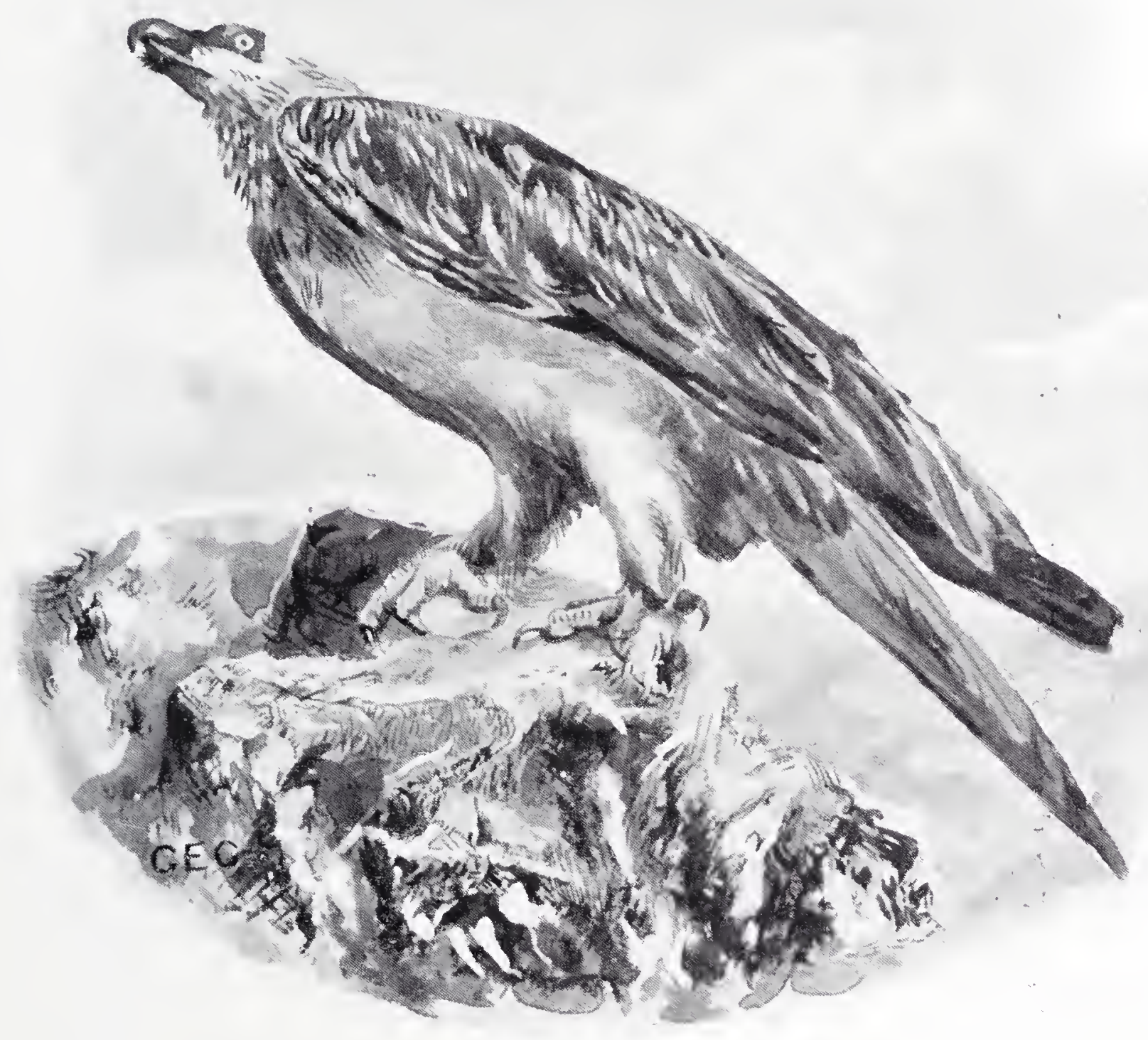

I.AMMERGEIER.

birds are sure to find its carcase almost immediately. And in a very short time nothing will be left of it but just the bare slieleton.

So, you see, these birds are really very useful. They belong to the great army of "Nature's Dustmen," just like the jackals and the hyenas. For by destroying these carcases before they can putrefy, they help to lieep the air pure.

How vultures find the dead body of an animal is just a little bit doubtful. Some naturalists have thought that they find 
it by means of sight, and others that they do so by means of smell. It seems almost certain, however, that when they are hovering high in the air they are really watching one another; so that when one of them sees a carcase and swoops down upon it, all the other vultures within sight notice what he is doing, and come hurrying up for a share in the banquet. And this explains how it is that if an animal is killed when not a vulture is to be seen, quite a number of these great, strong, ravenous birds will make their appearance in a very short time.

The finest of all the Vultures is the LAMMERGEIER, which is found in Southern Europe, in Northern Africa, and in Western Asia, and is sometimes as much as four feet in length from the tip of the beak to the end of the tail, while its wings may measure more than ten feet across when fully spread. It is one of the very few vultures which have the head and neck clothed with feathers. Besides this, a curious tuft of bristle-like hairs covers the nostrils, while a similar tuft grows just underneath the base of the bill. For this reason the bird is sometimes known as the Bearded Vulture.

Lammergeiers are generally found among high mountains, where they prey upon hares and marmots, and even upon rats and mice. They will visit the flocks, too, which are feeding upon the grassy slopes, and carry off kids and lambs. Chamois, again, are often attacked by them, and their favourite plan is to swoop down upon them when they are standing on the brink of a precipice, strilie them over into the depths below by a stroke of their powerful wings, and then descend to feed upon their mangled bodies.

The plumage of the Lammergeier is greyish-brown above and nearly white below. The feathers of the neck are white, and there is also a pale streak running down the middle of those upon the back.

The Lammergeier makes a great clumsy nest of sticks, which is sometimes placed on a ledge of a lofty cliff, and sometimes in the topmost branches of a very tall tree. Two eggs are laid, which are dirty white in colour, with brownish blotches.

Another very large vulture is the Condor, which inhabits the great mountain chain of the Andes. There it may be seen soaring high in air, its keen eyes intently scanning the ground beneath it. And the odd thing is that it may fly to and fro for hours, rising and falling and sweeping round in great circles, and yet never once flapping its wings!

Condors live for the most part on llamas which have died a natural death, or which have been killed by pumas and only partly devoured. But two or three of them will unite together, when they are hungry, in order to lill sheep or cattle, and even a powerful bull has been linown to fall a victim to their combined attack. 
In colour the condor is greyish-black, with a ruff of white feathers round the lower part of the neck. On the head of the male is a large fleshy wattle. It makes no nest at all, but simply lays its two white eggs on a rocky ledge high up on the mountain side.

The SEcretary Bird was formerly regarded as a kind of crane, on account of its long stilt-like legs. But we now know

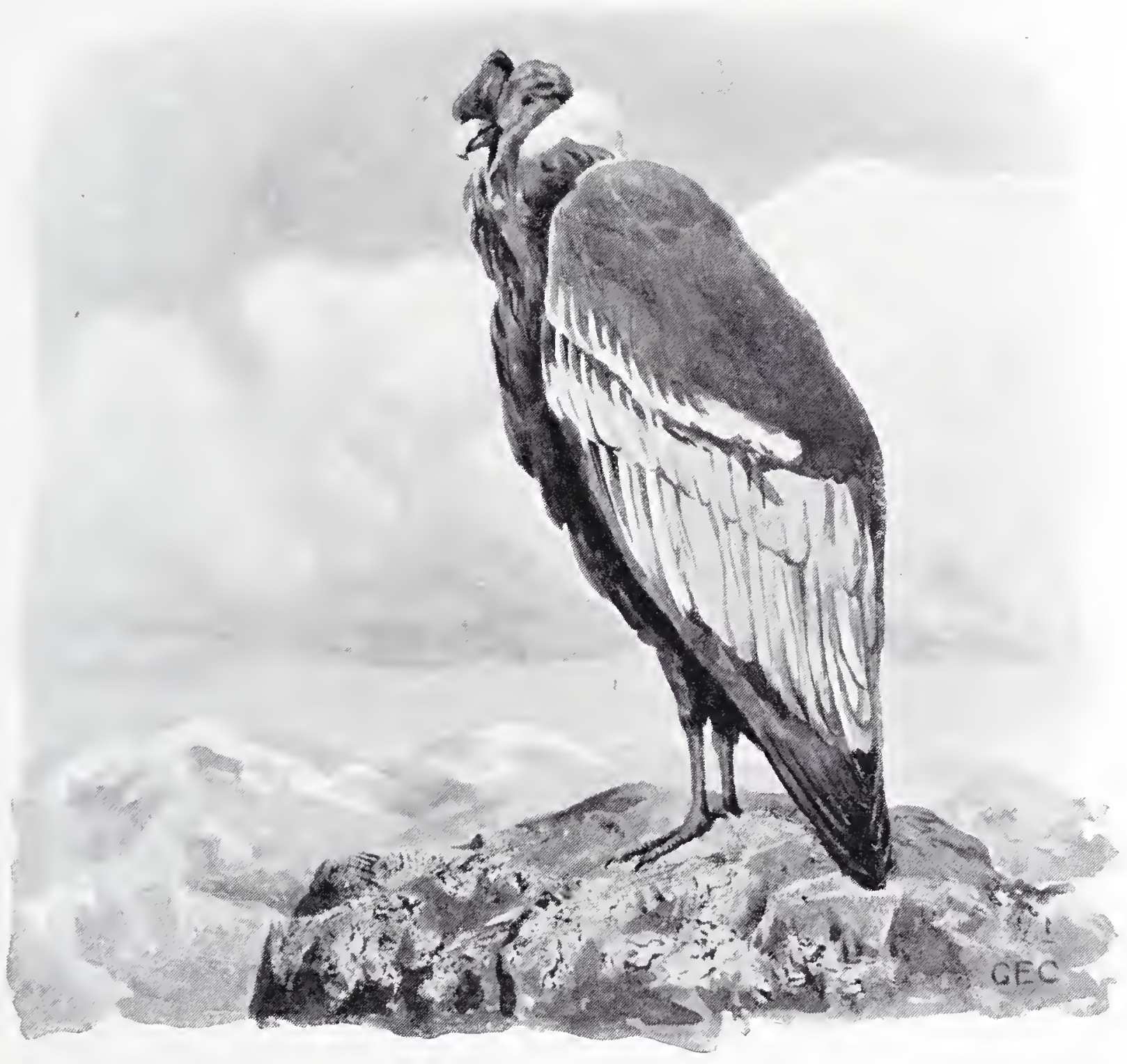

CONDOR.

it to be one of the vultures. It owes its name to the curious tuft of very long feathers at the back of its head, which cause it to look rather as though it were carrying a number of quill pens behind its ears. The two middle feathers of the tail, also, are exceedingly long, so that when the bird is standing upright their tips almost rest upon the ground.

The secretary bird comes from Africa, and is generally seen in pairs. It feeds upon small mammals, lizards, tortoises, frogs, and locusts, and is also said to kill and devour even large snakes. But whether it really does so is not quite certain. 
Next to the Vultures come the LAgLES, of which we will take the Golden Eagle as our example.

This magnificent bird was once quite common in the British Islands, and even now may sometimes be seen soaring high in air in the wilder parts of Scotland and Ireland. It is also found throughout Europe, Northern Asia, and Northern America. It is one of the largest of the eagles, for the female bird is sometimes nearly three feet in total length, while her outspread wings

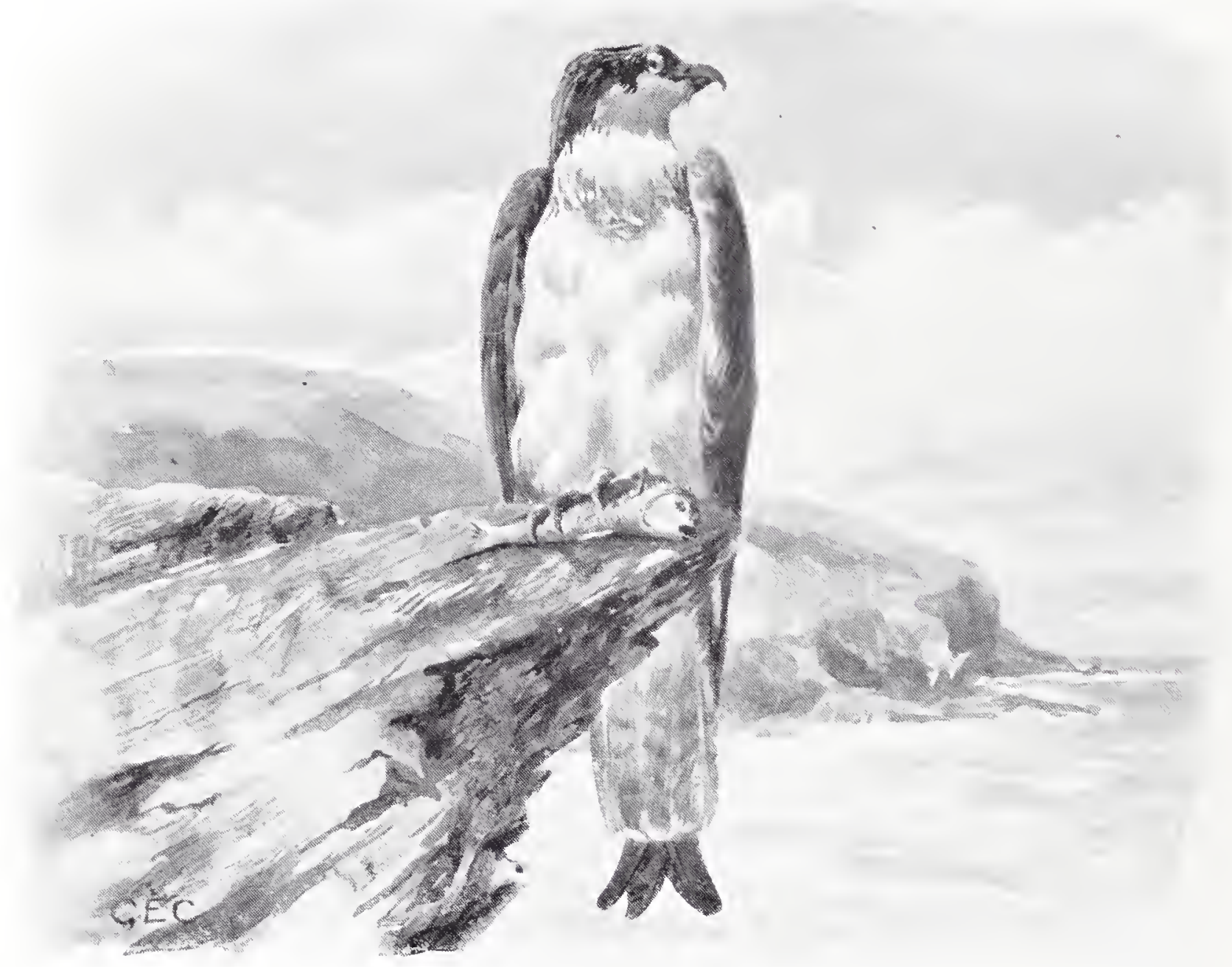

OSTREY.

measure between eight and nine feet from tip to tip. The male is rather smaller.

The "eyrie," as the nest of this grand bird is called, is built of sticks, and is generally placed upon a lofty ledge of rock. It is not at all well built; indeed, the sticks seem to be heaped up together anyhow. But it is often of very great size. A nest found in Scotland, indeed, was nine feet high, five feet across at the top, and twenty feet in width at the bottom; so that it was really as big as a good-sized haystack!

Round this nest were the bones of between forty and fifty grouse, besides those of a number of lambs, rabbits, and hares, 


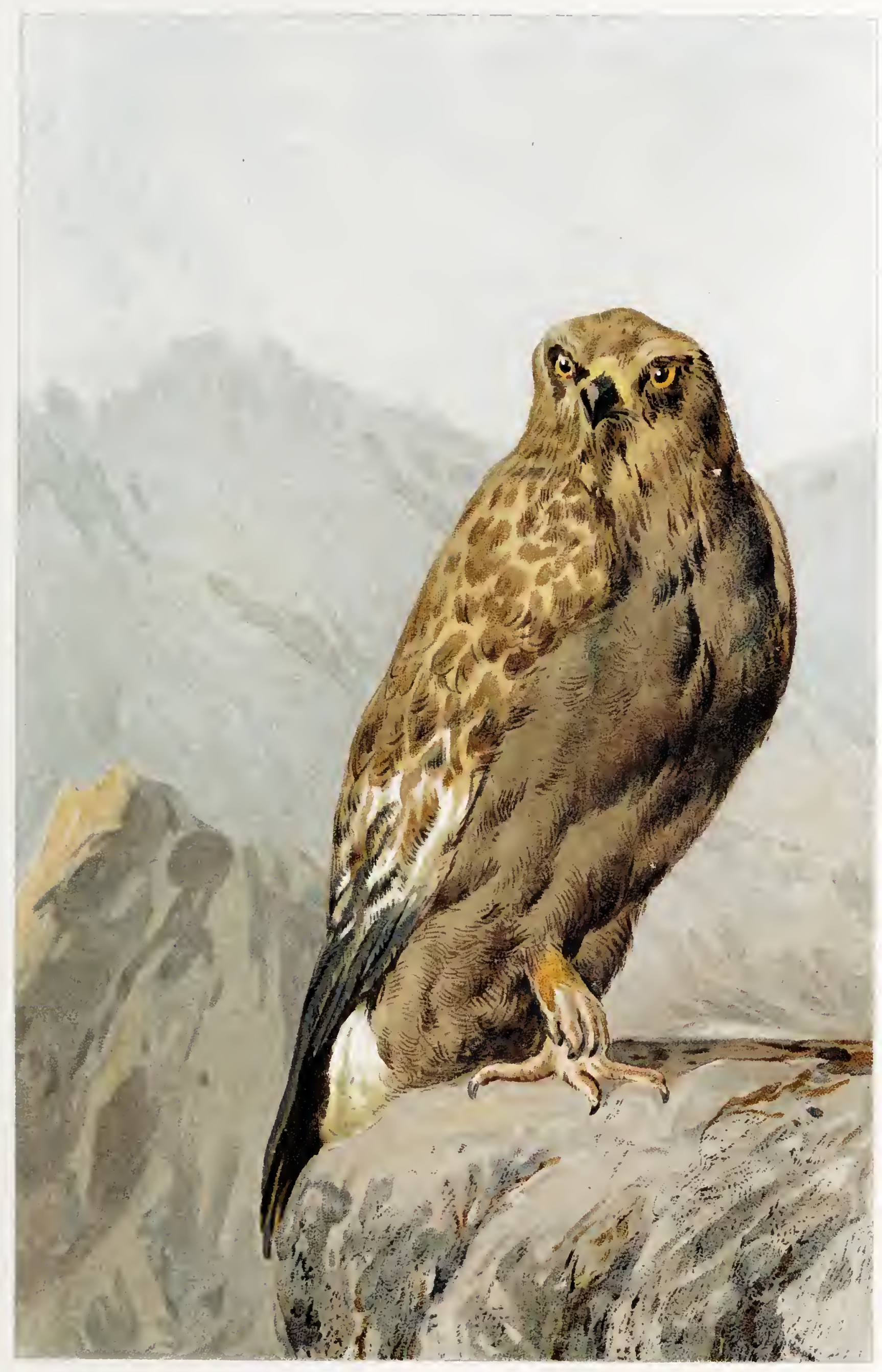



which had been brought there by the parent birds for the use of the young.

Very often a ledge close to the eyrie is used as a larder, where the old birds put their victims as soon as they are caught, and leave them until they are wanted. When they are hunting the two birds generally work together, one dashing in among bushes and low herbage, among which hares and rabbits are likely to be hiding, and the other lying in wait to pounce upon them as they rush out in alarm.

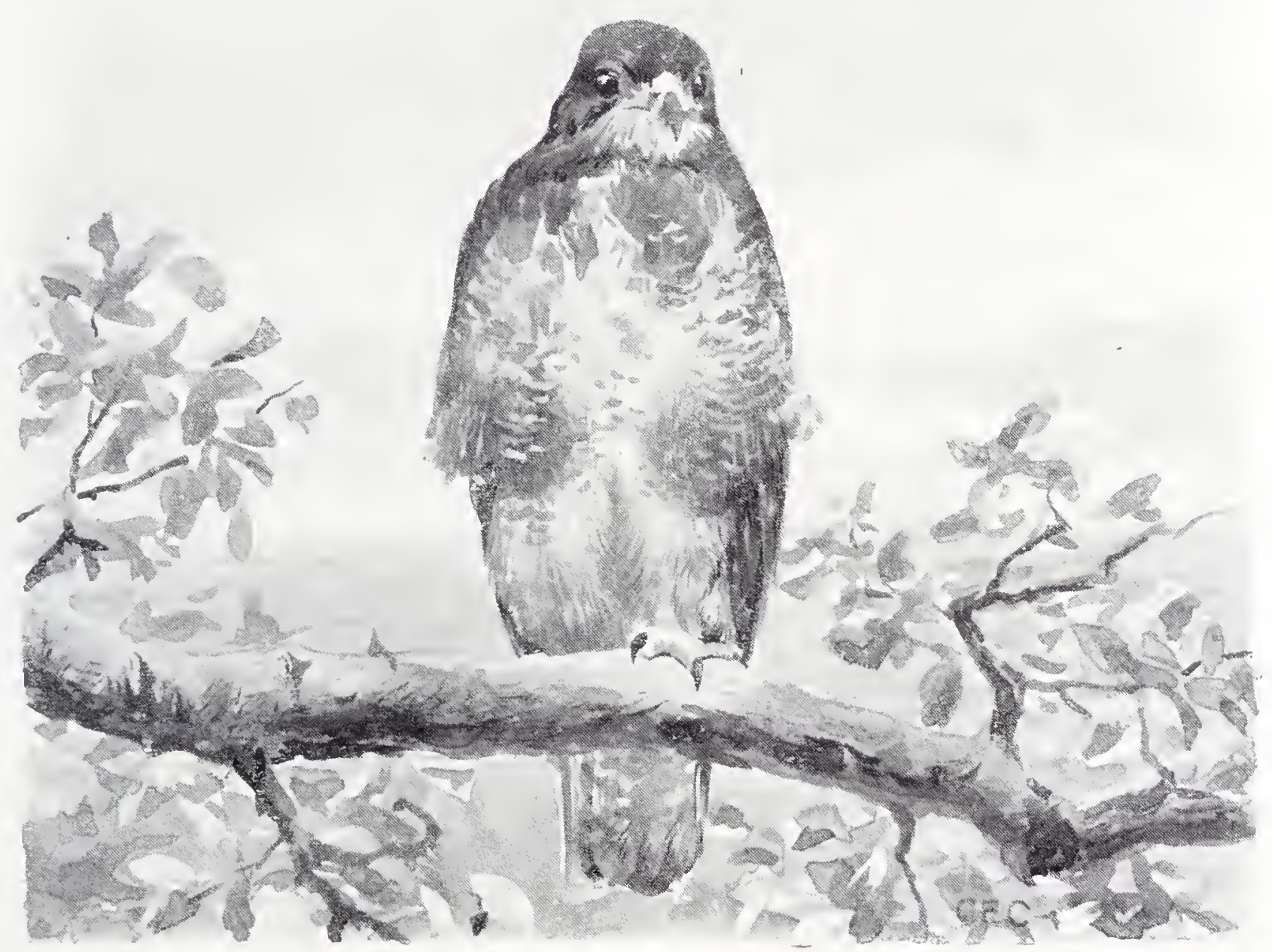

BUTZARI.

The so-called "golden eagles," which are reported from time to time as having been seen or shot in various parts of England, nearly always belong to a different species altogether, known as the White-tailed Eagle.

Not quite as big as the eagles, the Osprey is nevertheless a large bird, for it measures nearly two feet in length and letween five and six feet in spread of wing. It is found in nearly all parts of the world, and was formerly plentiful in the British Islands. But now it only comes to us as an occasional visitor, though for many years past two or three pairs have bred in Scotland. 
The osprey feeds almost entirely upon fish, and may be seen sweeping to and fro over the sea, keenly watching for its victims as they rise to the surface. When it catches sight of a fish it swoops down upon it, phunges into the water with a great splashing, and nearly ahways rises again a moment or two later with the fish struggling in its talons. But it does not always succeed in reaching the shore with it, for the white-tailed eagle is also very fond of fish, though it does not like the trouble of catching them. So it lies in wait for the osprey as it returns from a fishing expedition, and beats it about the head with its great wings until it is glad to drop its victim in order to escape.

Sometimes, how ever, a number of ospreys will combine together in order to attack an eagle which has been robbing them in this way, and will make so furious an onslaught upon it that at last it is obliged to beat a retreat with the loss of a good many feathers.

Theosprey malies a large nest of sticks, which is usually placed in the upper branches of a very tall tree. Three eggs are generally laid, which are whitish in colour, with blotches of brown.

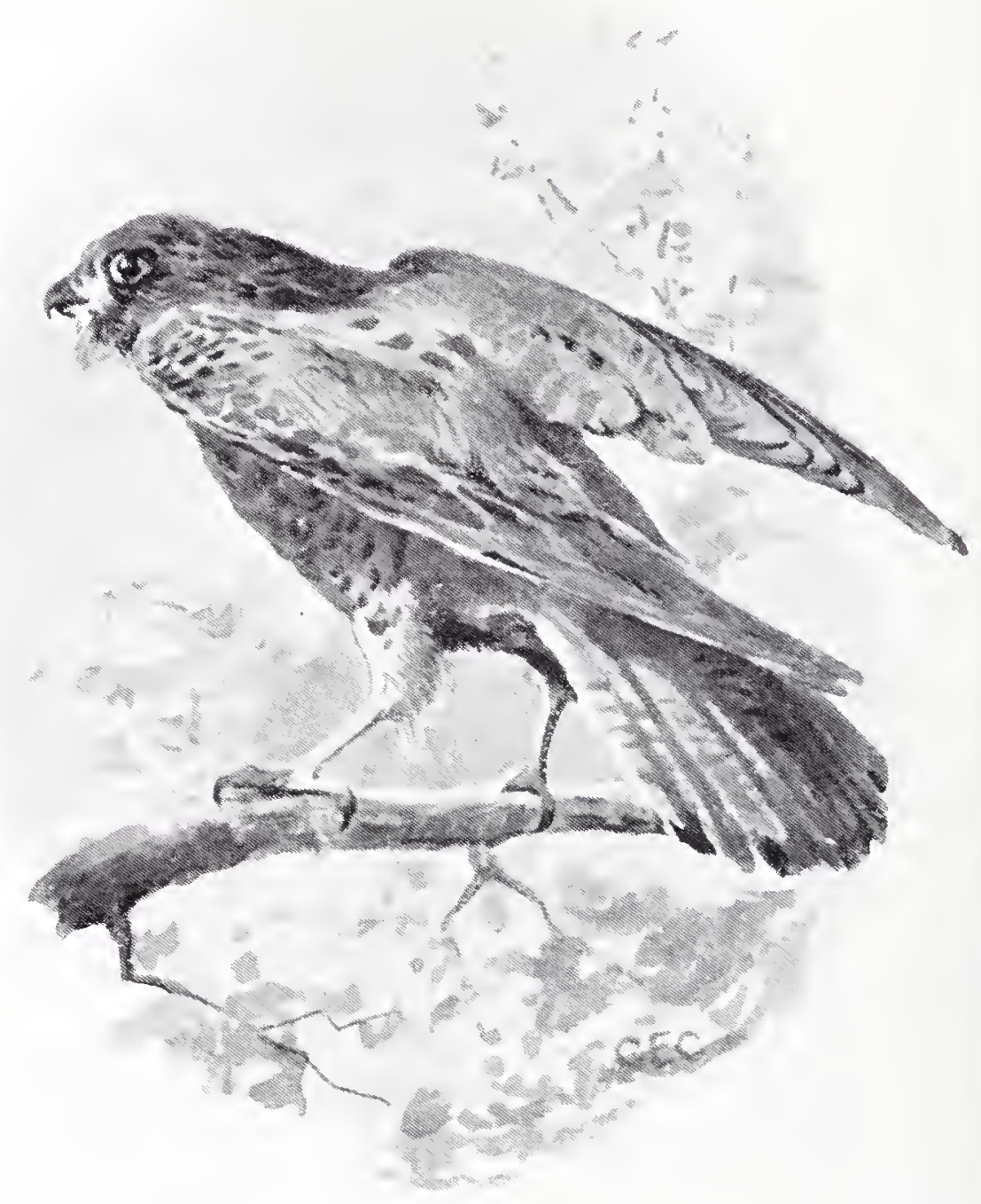

KESTREL.

This bird is also known as the Fishing Hawl.

In many parts of England Buzzards are still to be seen, and in Scotland and Ireland they are fairly plentiful. They are remarliable for having very soft, downy plumage, like that of an owl, which enables them to fly noiselessly through the air, and to pounce upon their victims before they know that they are in any danger. But they are very cowardly birds, and never seem to attack any victims which are likely to show fight, while they have often been known to fly in terror before the onslaught of a single carrion crow. In one case, at least, however, a pair of 
buzzards have been known to drive carrion crows from off their nest and to take it for themselves.

You can easily tell a buzzard when you see it by its very long, square tail, which has from ten to thirteen dark bars running across it. The general colour of the plumage is dark brown above and greyish-white below, marked with spots and streaks of brown. But these birds vary a good deal in colour, and it is seldom that two can be found which are quite alike.

\section{Buzzards sometimes} build in the branches of a tree, and sometimes among rocks, the nest being made of grass, heather and roots, and lined with leaves and wool. From two to five eggs are laid, which are white blotched with brown.

Passing by a number of very interesting birds of prey, which space will not allow us to mention, we come to two hawks which are still tolerably plentiful in the British Islands.

The first of these is the Kestrel. You may often see it hovering high in the air, three or four hundred feet from the ground, and carefully watching for the mice upon which it feeds. And it has eyes like telescopes, so that as soon as a mouse polies its head out of its burrow it catches sight of it, swoops down upon it, seizes it in its talons, and carries it off to be devoured.

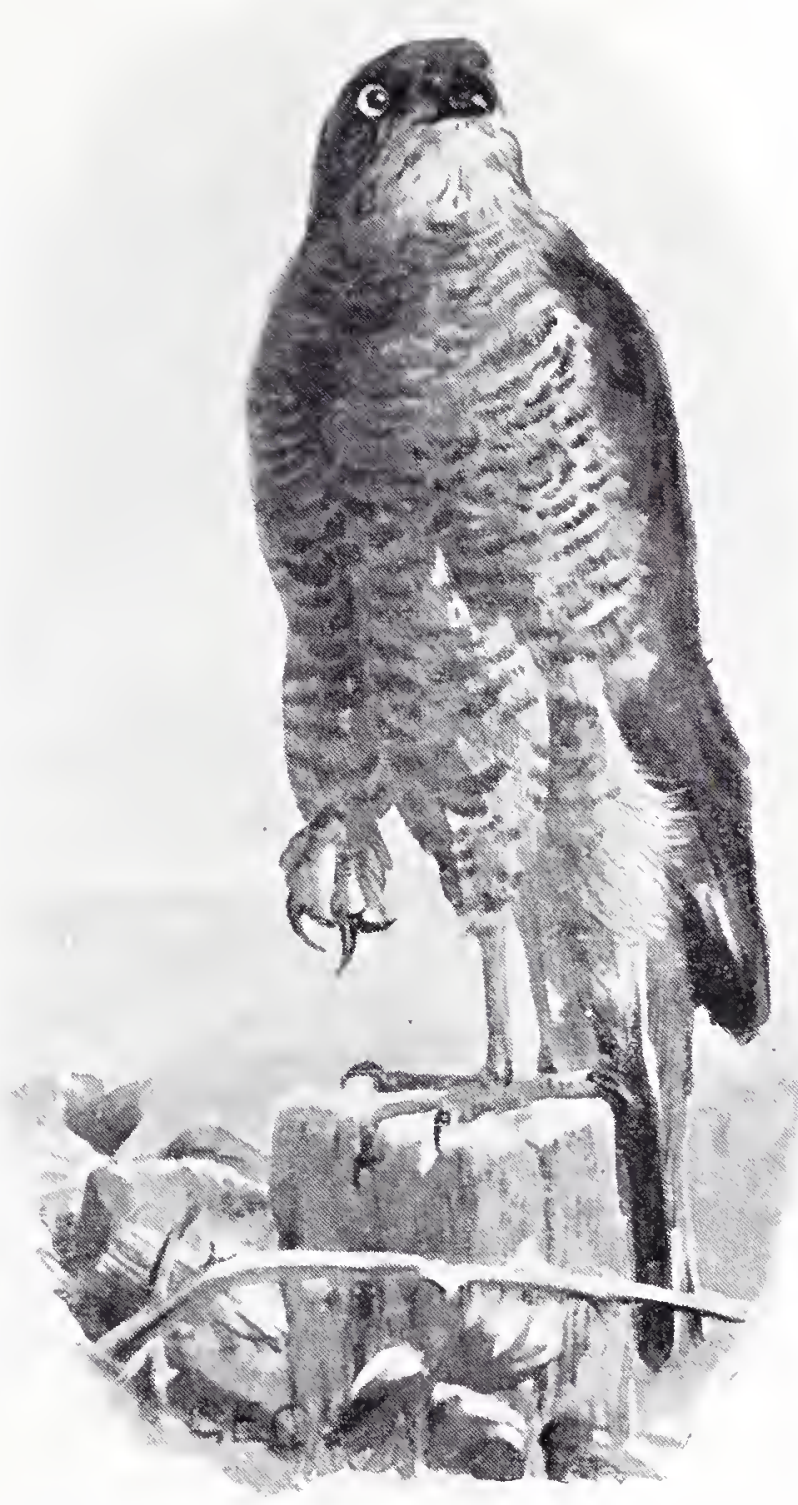

SPARROW HAWK. The number of mice which it catches in this way is very large indeed, and it has been estimated that at least ten thousand of these destructive little creatures are liflled by every kestrel in the course of every year. So we must look upon the bird as one of the very best friends of the farmer.

When it cannot find any mice the kestrel will sometimes eat small birds, although it never seems to carry off young partridges and pheasants, as gamekeepers accuse it of doing. And now and then it will feed upon cockchafers and other large 
insects, catching them in its claws as they fly, and then passing them up to its beak.

Festrels sometimes build in trees and sometimes in towers and old buildings. But very often, indeed, they malie use of the deserted nest of a magpie or a crow. From four to six eggs are laid, which are blotched with reddish-brown on a bluish-white ground.

The Sparrow Hawk is not nearly so often seen as the kestrel, for it is much more shy, and very seldom ventures out into

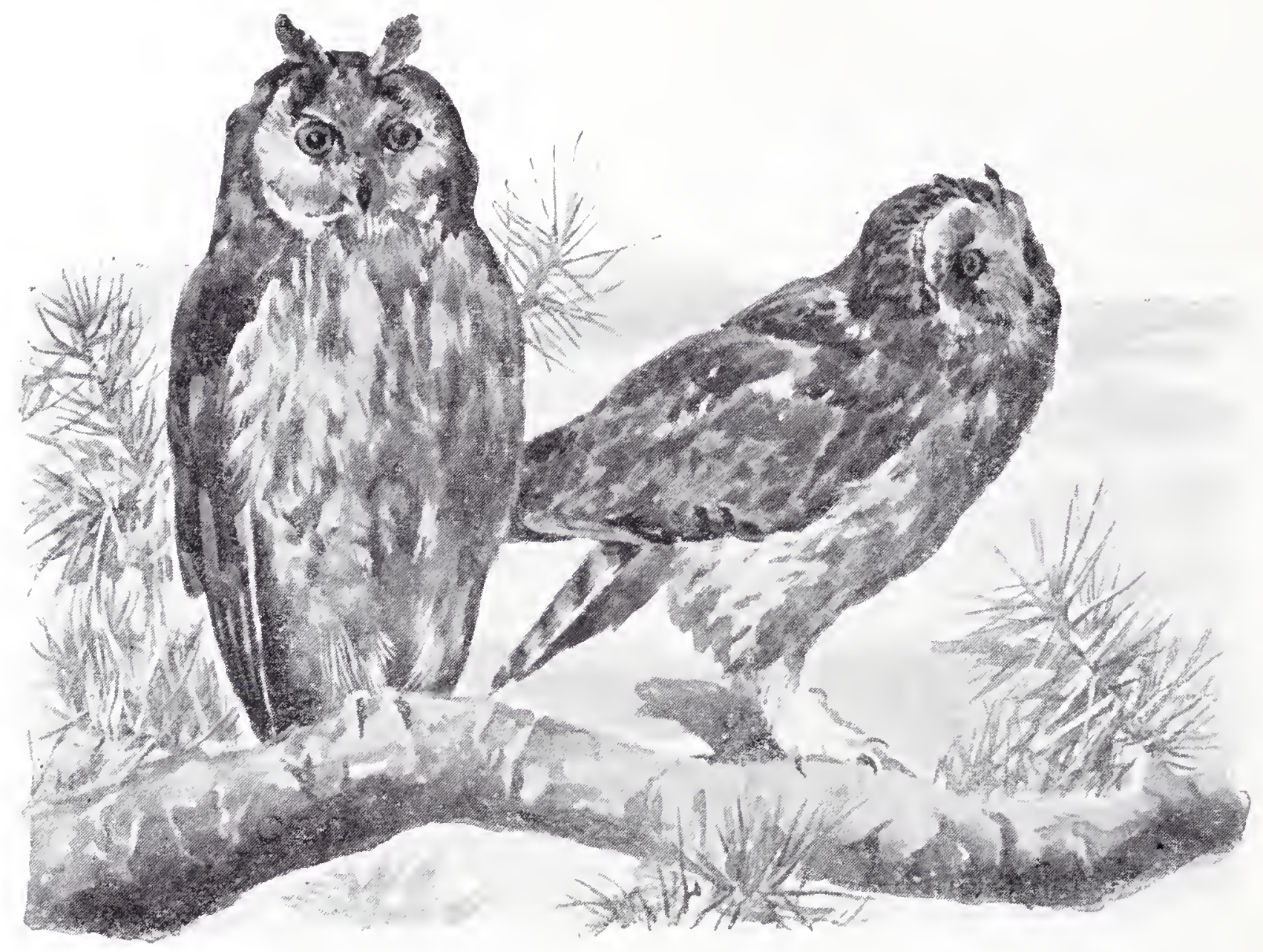

T.ONG-EARED ANI, SHORT-EAREI) OWLS.

the open country. Yet in other ways it is a far more lashing and courageous bird, for it has been known to attack herons and several of the larger hawks, and even to strike the golden eagle!

This hawl feeds chiefly on small birds, and will often dash into a flock of sparrows or chaffinches and carry one of them off in its talons. It will sometimes swoop down into a farmyard, too, and snatch up a chicken or a duckling, while numbers of young pheasants and partridges fall victims to its ravages. In days of old it was sometimes captured and trained for hawking, like the merlin and the falcon, and it is said that a single tame sparrowhawk would sometimes kill as many as seventy or eighty quail in a single day. 
Yet, strange to say, the bird is very easily startled, and then seems to become quite paralysed with fear, losing for some little time even the power of standing.

Sparrow hawks seldom take the trouble to build a nest of their own, but nearly always make use of the deserted abode of a crow or magpie, in which they lay three or four greyish-white eggs marked with a number of dark-brown spots and blotches.

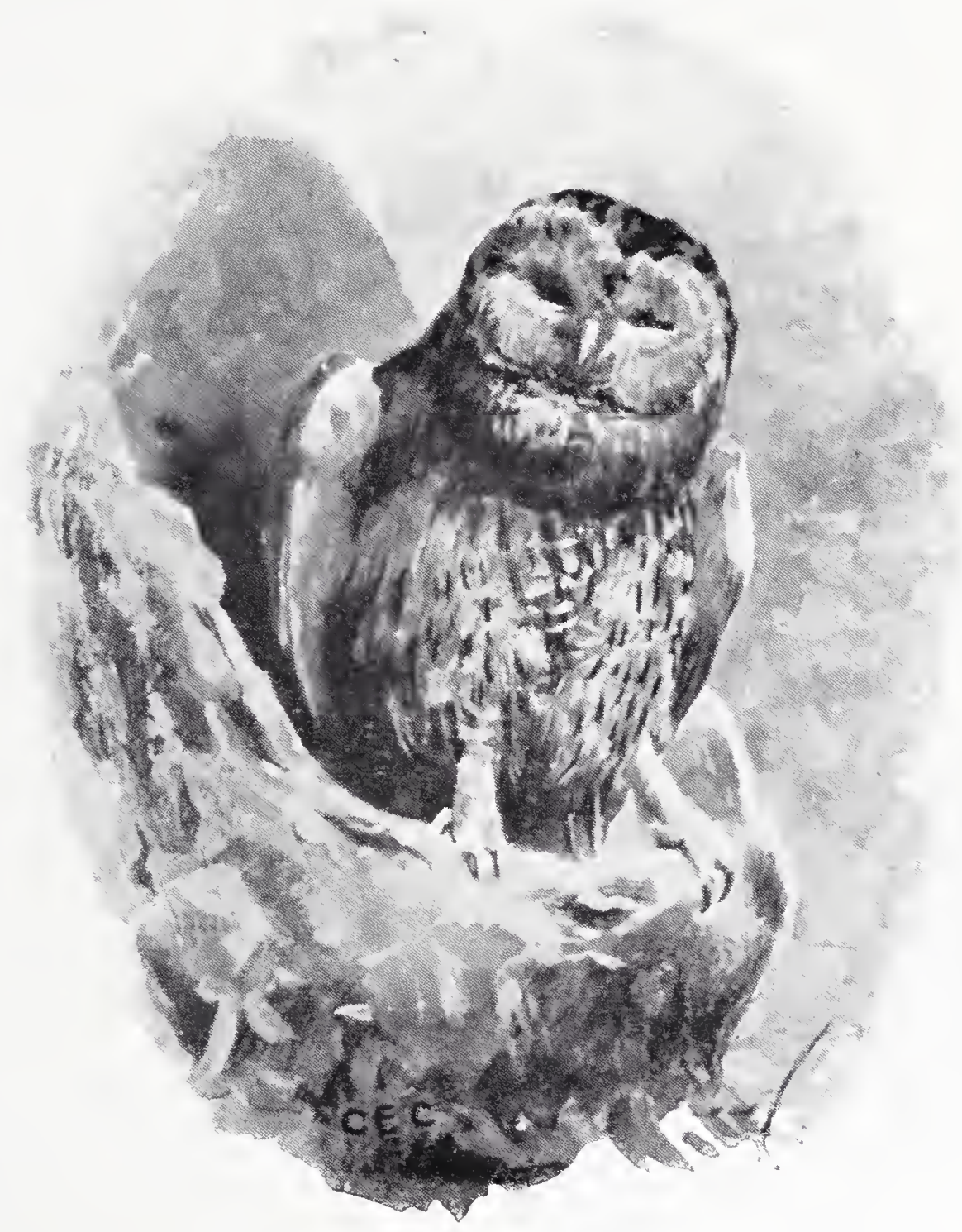

BROWN OWL.

Next in order come those very singular birds which we call Owss, and which are really hawks that fly by night.

The eyes of these birds are very much like those of cats, being formed in such a way as to take in eren the faintest rays of light. Owing to this fact owls can see on even the darkest of nights, and can fly with as much certainty and catch their prey with as much ease as other birds can in the daylight. And the great feathery discs which surround their eyes are very useful indeed, for they enable them to see in almost every direction without turning their hearls. 
This is very important, for wild animals are always alarmed by motion, while they hardly ever notice creatures which lieep perfectly still. If you sit or stand for a while without moving even a finger, for example, rabbits and squirrels will often come quite close to you, and never seem to see you at all. But at your very first movement they will take fright and scamper away. So if an owl had to be constantly turning its head from side to side in order to look for prey, its victims would certainly see it, and would make good their escape. But as its eyes are set in the middle of those great feathery circles there is no need for it to do so, for it can look out in almost every direction without moving its head in the least.

There are a good many different kinds of owls, several of which are found in the British Islands. There is the Long-eared Owl, for instance, which has two rather long feathery tufts upon its head; and there is the Short-eared Owl, which has short ones. As a rule, these tufts lie flat upon the head. But when the bird is excited

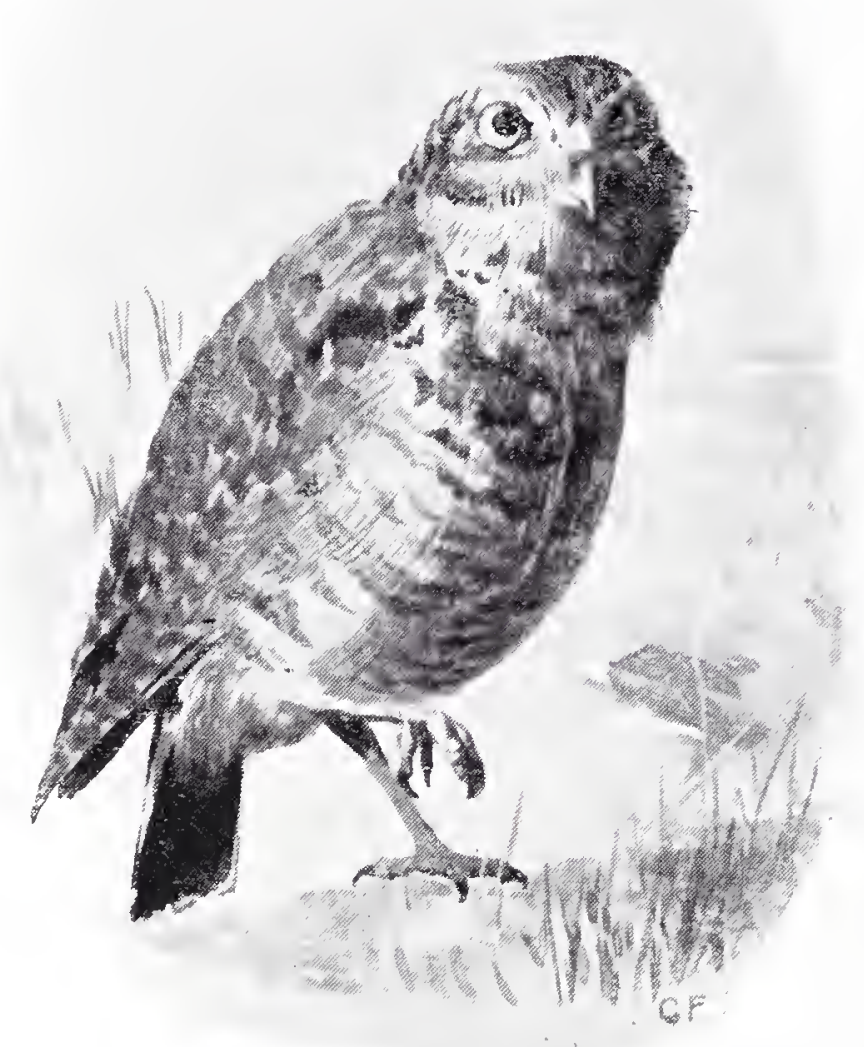

BURROWING OWL. they stand upright, and give it a very odd appearance. Then there is the Brown Owl, which utters that mournful hooting sound which one so often hears by night in wooded districts. But the commonest and best known of the British owls is undoubtedly the Barn Owl, or White Owl, which can be at once recognised by its colour.

Very often as one is walking along a country lane in the evening one of these birds sweeps suddenly by and disappears into the darkness. It is busy searching for mice, and the number which it catches must be very great. For it has been found that when a pair of these birds have little ones, they bring a mouse to them about once in every quarter of an hour all through the night! And, besides that, their own appetites have to be satisfied; and owls seem always to be hungry.

One day the late Lord Lilford tried to see how many mice a barn owl really could swallow. So he caught one of these birds and put it in a cage, and gave it seven mice one after the other. 
Six of these it gulped down without any hesitation; but though it tried hard to swallow the seventh it could not quite manage to do so, and for about twenty minutes the tail of the mouse was dangling from a corner of its beak. At last, however, the tail disappeared; and three hours later the owl was actually hungry again, and ate four more mice!

None of the owls ever contrive to digest the bones of their prey, which after a time are returned through the mouth in the form of "pellets." Very often large quantities of these pellets are found in hollow trees in which owls have been roosting, more than a bushel having been taken from a single tree. The birds do not make a nest, but lay their eggs on a heap of these pellets instead; and they have an odd way of laying them at intervals, so that sometimes half-fledged little ones, newly-hatched little ones, and freshly-laid eggs may all be found together.

When the young owls are waiting for their parents to return with a mouse, they always get very much excited and make most odd noises, something like loud hisses followed by loud snores. And when at last one of the old birds returns with a mouse in its talons, the outcry grows louder than ever.

In colour the barn owl is pale buff, with black, grey and white spots and marlings.

Perhaps the oddest of all the owls is the Cooumino, or Burrowing Owl, which is found both in North and in South America.

In some districts this owl makes burrows of its own, scratching out the earth with its claws and beak to a depth of about eighteen inches. But it is not at all fond of taking trouble, and much prefers to settle down in the deserted burrow of a prairiedog, or a viscacha, or even to share an occupied tunnel with its lawful inmates. In a "dog-town," as the warren of these little animals is generally called, numbers of burrowing owls may sometimes be seen, some hunting about for beetles and grasshoppers, on which they chiefly feed, and others sitting at the entrances of the burrows and surveying the surrounding country. They are not at all timid, and if a man approaches them they will remain where they are until he is quite close, bobbing up and down from time to time as though they were politely bowing to him. If he continues to walk towards them they will rise into the air, fly two or three times round his head, screaming loudly as they do so, and then settle down on another mound a few yards away and bow to him again. But if he walks round them instead they will turn their heads to look after him, without noving their bodies, until one would almost think that they would twist them off altogether.

When neither prairie-dogs nor viscachas live in the neighbourhood, these queer little owls will sometimes take up their quarters in the burrow of a wolf, a fox, or a badger. They make a very rough nest of grass and feathers, in which they lay from six to eleven eggs. 


\section{CHAPTER XXI.}

CICKOOS, NIGHTJARS, HUMMING BIRIS, WOODPECKERS, ANI TOUCANS.

FIERTBODY linows the note of the Cuckoo. Nevertheless there are a great many people who do not know the cuckioo itself when they see it, but mistake it for a sparrow hawk. And the two birds are really so much like one another that even the smaller birds do not always know the difference between them, and may be seen "mobbing" a cuckoo which they have taken for a hawk. But if you look closely at the bird you will notice that its beak is shaped quite differently from that of a hawk, and gives the head a pointed appearance, whereas that of the sparrow hawk always looks round.

Cuckoos are among those birds which we call "summer visitors," because they only remain in the British Islands during the summer months, and fly away to warmer countries to spend the winter. They generally reach us about the second week in April, and very soon after that time the cock bird may be heard uttering his well-known cry, which is one of the most familiar sounds of the country, until a couple of months later. Then the bird's voice breaks, and after crying "cuck-cuck-cuck-oo" for a few days, instead of the simple "cuclioo," he becomes quite dumb, and is quite unable to utter his note again until the following spring.

The cuckoo is famous for its singular habit of placing its egg in the nest of some other bird, instead of making a nest of its own. The hen bird seems, first of all, to lay her egg on the ground; then, picking it up in her beak, she flies off to look for a suitable nest in which to put it, generally-but by no means always - choosing that of a hedge-sparrow, a wagtail, or a meadow pipit. Having found one, she waits her opportunity, and then slips in the egg and flies away. The owner of the nest, strange to say, hardly ever seems to notice when she comes back that there is a strange egg among her own, although very often it is not in the least like them in colour and markings. So before very long a young cuckoo is hatched out, together with her own little ones. Then on the very day of its birth the cuckoo seems to make up its mind that before long there will be no room in the nest for anyone but itself, and actually pushes all its little foster-brothers and sisters over the side, one after the other! And, strange to say, the mother-bird does not seem to mind, but just gives all the food which her own young would have eaten to the cuckoo, and takes the greatest care of it in every way until it is able to $\mathrm{fly}$. 
The cuclioo feeds chiefly upon caterpillars, seeming to prefer those whose bodies are covered with long hairs, and you may often see the bird flying along a hawthorn hedge and picking off its victims in dozens.

"In July," says the old rhyme of the cuclioo, "he begins to fly; in August, go he must." And generally by the end of the second week in August all the cuclioos have left our shores and flown off to warmer climates for the winter.

Another of our summer visitors is the Nightjar. You do not often see it because it only flies by night. But late in the

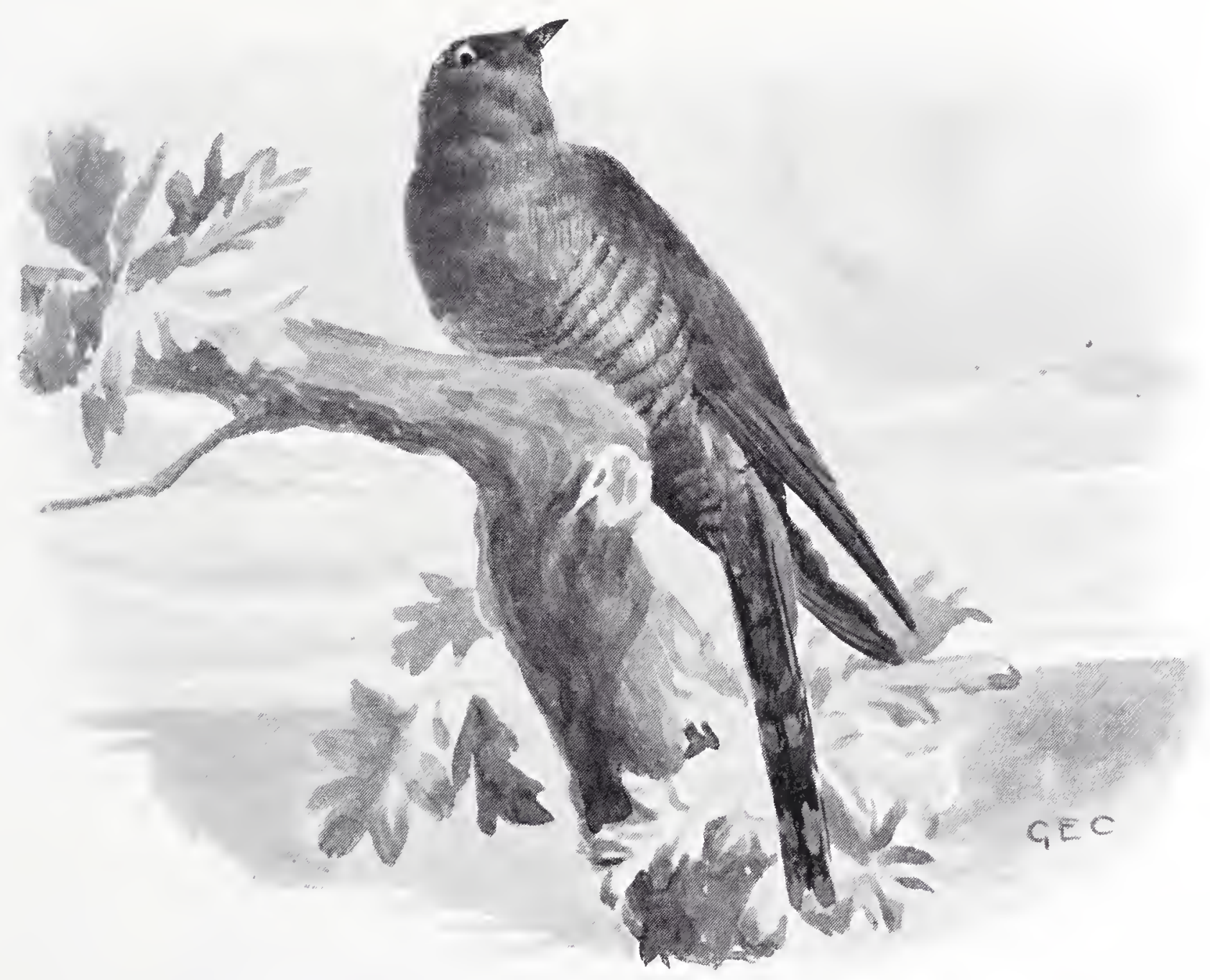

CLCKOO.

evening you may often hear it uttering its curious note"chur-r-r-r-r-r" - which sometimes goes on without any break at all for three or four minutes. How the bird manages its breath all that time is a mystery. And if you manage to creep up to the tree in which it is sitting, you will notice that it always perches along a branch, and not across it as other birds do.

The nightjar is a great insect-eater, and how many flies and beetles and moths it devours every night I should not like to say. In order that it may be able to capture these it has its beak and mouth most curiously formed. In the first place, the 
"gape" is exceedingly wide, so that when the beak is open, the bird looks almost as if its head were cut in two. Then the tongue is exceedingly sticky, like that of an ant-eater. And, besides this, the sides of the beak are fringed with long, stiff bristles. So, you see, when the bird catches an insect, its victim nearly always sticlis firmly to its tongue, while, if it should breali away from that, the bristles act just like a cage, and prevent it from escaping.

This bird is often known as the goat-sucker, owing to an old belief that it sucks the milk from goats. But of course this is quite a mistake.

The nightjar makes no nest at all, but lays its eggs in a small hollow in the ground, generally under the shelter of a fern, or a tuft of bramble or heather. These eggs are never more than two in number, and are greyish-white in colour, mottled and marbled with grey and buff.

Of course you know the Swift very well by sight. This, too, is a summer visitor, coming very late in the spring and leaving very early in the autumn. For it never makes its appearance until about the second week in May, and alvays leaves us again by the middle of August. Sometimes it is supposed to be a relation of the martin and the swallow. But in reality it is much more closely connected with the nightjars, and forms a kind of link between them and the humming birds.

The swift feeds upon flies and small beetles, which it catches in the air, and on any fine summer's day you may see it hawking for prey. It well deserves its name, for it dashes through the air with most wonderful speed, and is said to be able to fly at the rate of no less than two hundred miles in an hour! And as it flies it keeps on twisting and turning after the fashion of a bat, and is evidently snapping up insect after insect as it goes.

Yet, strange to say, the bird never seems to be tired. It is often on the wing before three o'clock in the morning, and is still darting about as actively as ever after nine o'clock at night. As it flies it constantly utters sharp, piercing screams, which seem very loud to come from the throat of so small a bird. These cries appear to be the call of the male, and are sometimes answered by a low, twittering note from the hen as she sits in her nest.

The swift nearly always builds in a hole under a roof, and makes its nest of straw, hay and feathers. The eggs are from two to five in number, and are pure white, without any markings at all.

Although they are not very much like swifts, the HUMMING BIRDs are closely related to them, and have powers of flight which are really almost as wonderful. Indeed, if you alarm one of these birds when it is hovering over a flower, it will dart away with such astonishing speed that it is almost impossible for the 
eye to follow its course. And even while it is hovering the wings vibrate so rapidly that you cannot see them, all that is visible being a faint blur on either side of the body.

These exquisite little birds are found only in Central and South America, and in the West Indian Islands. As a rule they are most beautifully coloured, their plumage shining with metallic gold, and copper, and bronze, and purple, and crimson, and blue, and green.

Sometimes, too-for there are a great many different species - there is a ruff round the neck, or long tufts upon the head; or

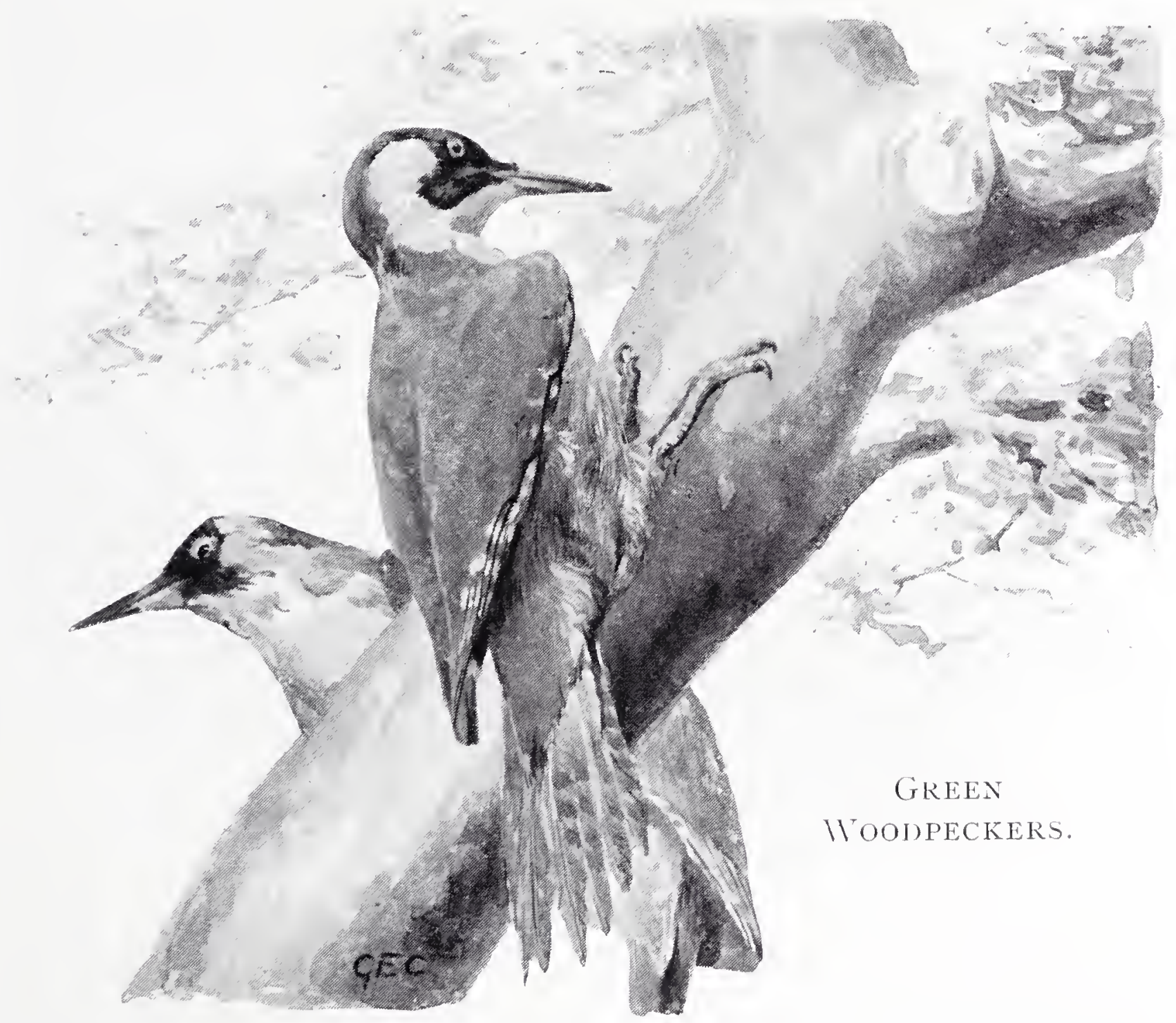

perhaps two of the tail feathers may be produced until they are longer than the head and body and the rest of the tail put together.

As a rule, the beaks of humming birds are very long, in order that they may be poked into flowers in search of any insects which may be lying hidden within them. And the bird will hover over a bush, and move on from one blossom to another, until every one has been thoroughly explored.

The nests of humming birds are nearly always very small 
and cup-shaped, and are made of little bits of lichen and moss neatly fastened together with the silken threads of certain spiders. Only two eggs are laid, which are quite white, and so tiny that it seems quite impossible that a bird could possibly be hatched out of them. At least five hundred linds of these beautiful little birds have already been discovered.

Now let us pass to the Woodpeckers.

One of these very interesting birds-the Green Woodpeclier - is not at all uncommon in the British Islands, and there are not many woods in which it is not to be found. And yet one very seldom sees it. The reason is that it is so exceedingly shy. It does not like to be looked at, and as long as it knows that there is anyone close by who can see it, it will do its very best to lieep out of sight. But if you sit down for awhile at the foot of a tree, and keep very still indeed, without moving even so much as a finger, it will never notice you, and will very likely come and sit on the trunk of another tree close by and begin to peck away with its long, sharp beak in search of insects.

How it makes the chips fly! Its beak is just like a chisel, and when the bird finds that a beetle or a grub has burrowed into the trunk, it does not take very long to dig it out. And it also has an extremely odd tongue, which is very long, and very slender, and very sticky, and has a curious brush-like tip. Byy means of this tongue the bird can often lick an insect out of its burrow without being obliged to dig right down to it.

But sometimes woodpeckers make a most amusing mistake. They hear the humming of a telegraph wire, and think that it must be caused by insects living in the posts. So they set to work with the utmost energy to dig them out, and are so diligent and so persevering that they have often been known to cut a big hole right through a telegraph post before finding out that there were no insects there after all!

There is just one more thing that I should like you to notice about the woodpecker, and that is the way in which it is enabled to sit on an upright tree-trunli for a long time without getting tired. The fact is that it really sits on its own tail, which serves as a kind of camp-stool! If you look at a woodpeclier's tail you will find that the feathers are very short and very stiff, and that they are bent downwards. When the bird perches on the trunk of a tree the tips of these feathers rest upon the bark and prop it up, so that there is very little strain upon the muscles of the feet and legs.

Woodpeckers do not make any nest, but lay their eggs upon a heap of wood-chips in a hole in the trunk of a tree.

Very much like a woodpecker in some ways is the odd little bird which is called the WrynECK, because of the snake-like way in which it can twist its head and neck about. If it is captured or injured in any way, too, it will lie on its back and hiss 
just like a snake, and for this reason it is sometimes known as the "snake-bird."

The Wryneck is a summer visitor to our British Islands, and comes to us just about the time when the ants are leaving their winter retreats. For it feeds chiefly upon these and other tiny insects, sometimes hunting for them upon the ground, and sometimes running up and down the trunks and branches of trees in search of them, and licking them up in numbers by means of its long and sticky tongue.

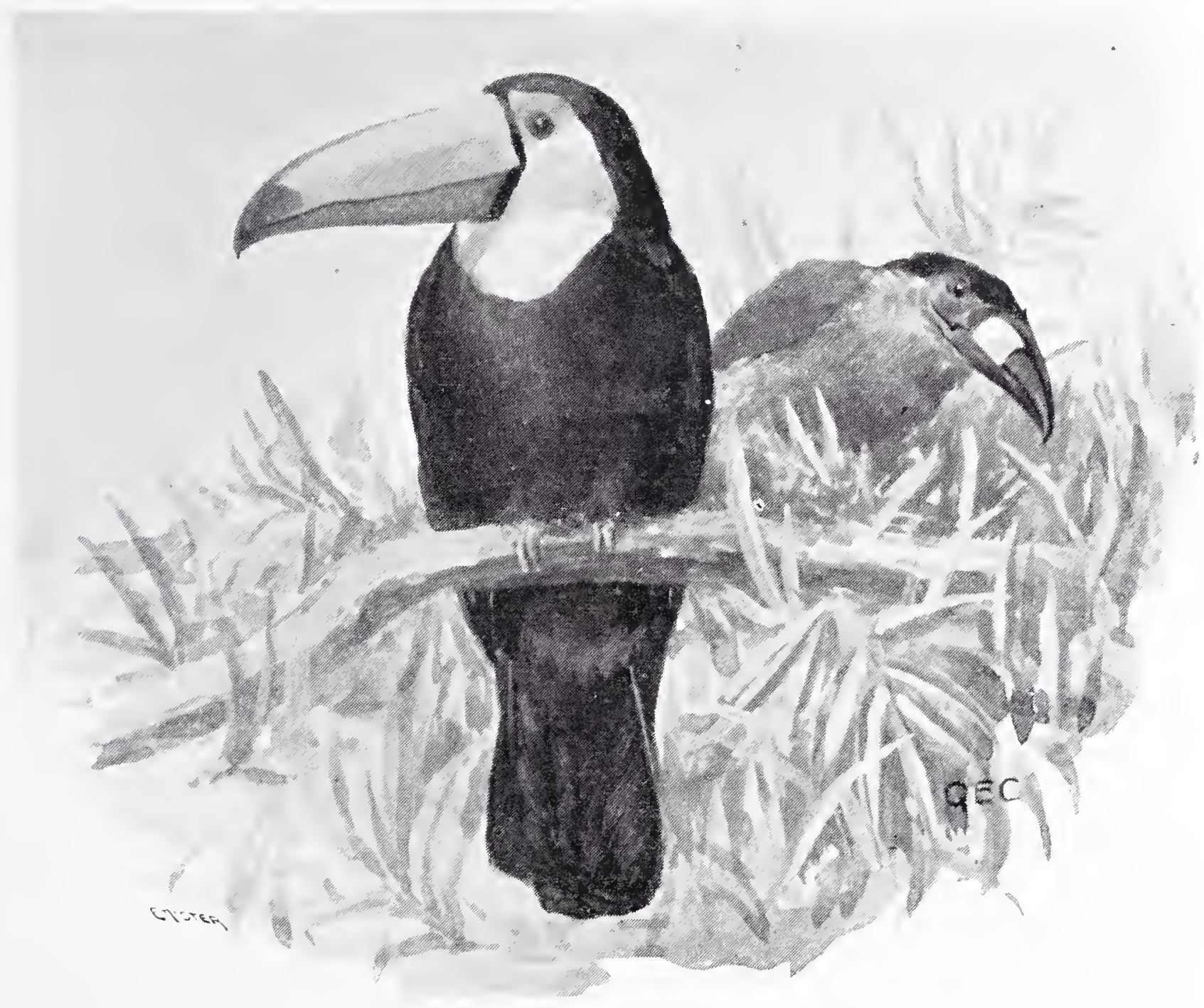

TOUCANS.

The wryneck builds no nest, but lays its eggs in a hole in a tree. If it can find a hole in which another bird has built before it, however, it is quite ready to make use of the deserted nest. It lays from five to ten eggs, which are white in colour, with a delicate tinge of pink.

We now come to a group of really extraordinary birds, which are known as Toucans. They are found in the forests of Central and South America, and are chiefly remarkable for their beaks, which in the first place are so enormous that they look as if they had been intended for birds at least six times as big, 
and in the second place are most gaudily coloured. It is not very easy to describe them, because there are a good many kinds of toucans, and each has its bill differently coloured. In one, the beak is partly orange and partly black, with a lilac base. In another, it is light green, with the tip and edges of the most brilliant scarlet. In a third, it is half scarlet and half bright yellow; while in a fourth, it is creamy white with a broad streak of crimson running along the middle; and in a fifth is a most singular mixture of orange and blue and chocolate-brown and white.

Owing to the great size of their bills these birds are most ungainly in appearance, and one cannot help wondering how they manage to hold up their heads at all. But in reality these huge beaks are not at all heavy, for instead of being made of solid horn, the whole of the interior is broken up into cells, the divisions between which are no thicker than paper. And this structure gives them not only great lightness but great strength as well.

Toucans live chiefly in the trees, and spend most of their time in the topmost branches, where they are fond of gathering together in large flocks. They are very noisy birds, for they not only utter hoarse cries and loud yells in chorus, but have a way of clattering their beaks together as well. Owing to this habit the natives of South America sometimes call them "preacher-birds."

When they go to sleep toucans double their tails over upon their backs, just as though they had hinges at the base, and bury their great beaks among the feathers of their shoulders. The consequence is that they do not look like toucans at all, or even like birds, and seem to be mere bundles of loose feathers.

More extraordinary still, even, are the HornBlLLs, some of which have beaks so enormous that they look as if they liad been meant for birds twelve times instead of only six times as big as themselves. And the strangest thing of all is that upon the upper part is a great horny helmet, which in some cases is quite as large as the beak itself. In the Rhinoceros Hornbill, indeed, the beak and helmet together are pretty well as big as the body.

Both beak and helmet, however, except in one species, are made just like the bills of the toucans, so that in spite of their enormous size they are not at all heavy. But why they should be so big is more than I can tell you.

Hornbills are found in many parts of both Africa and Asia, and most of them live in the trees. They nearly always hop from one branch to another until they reach the very topmost boughs, where they will sit for hours together, occasionally uttering a series of loud, roaring cries which can be heard for a very long distance. And when they fly they keep on opening and closing their beaks, and so making an odd clattering noise which generally puzzles travellers very much when they hear it for the first time.

But there are two kinds of hornbills which live on the ground. One of these is found in South Africa, and the Kaffirs 
have a very curious idea about it, which is due to the fact that after death its body smells very nasty. They think that if one of these birds is killed and thrown into a river it will make the stream feel ill, and that a heavy fall of rain will take place in order that the carcase may be washed into the sea! So in times of drought they always try to kill a ground hornbill and fling it into the nearest river.

Three or four of these

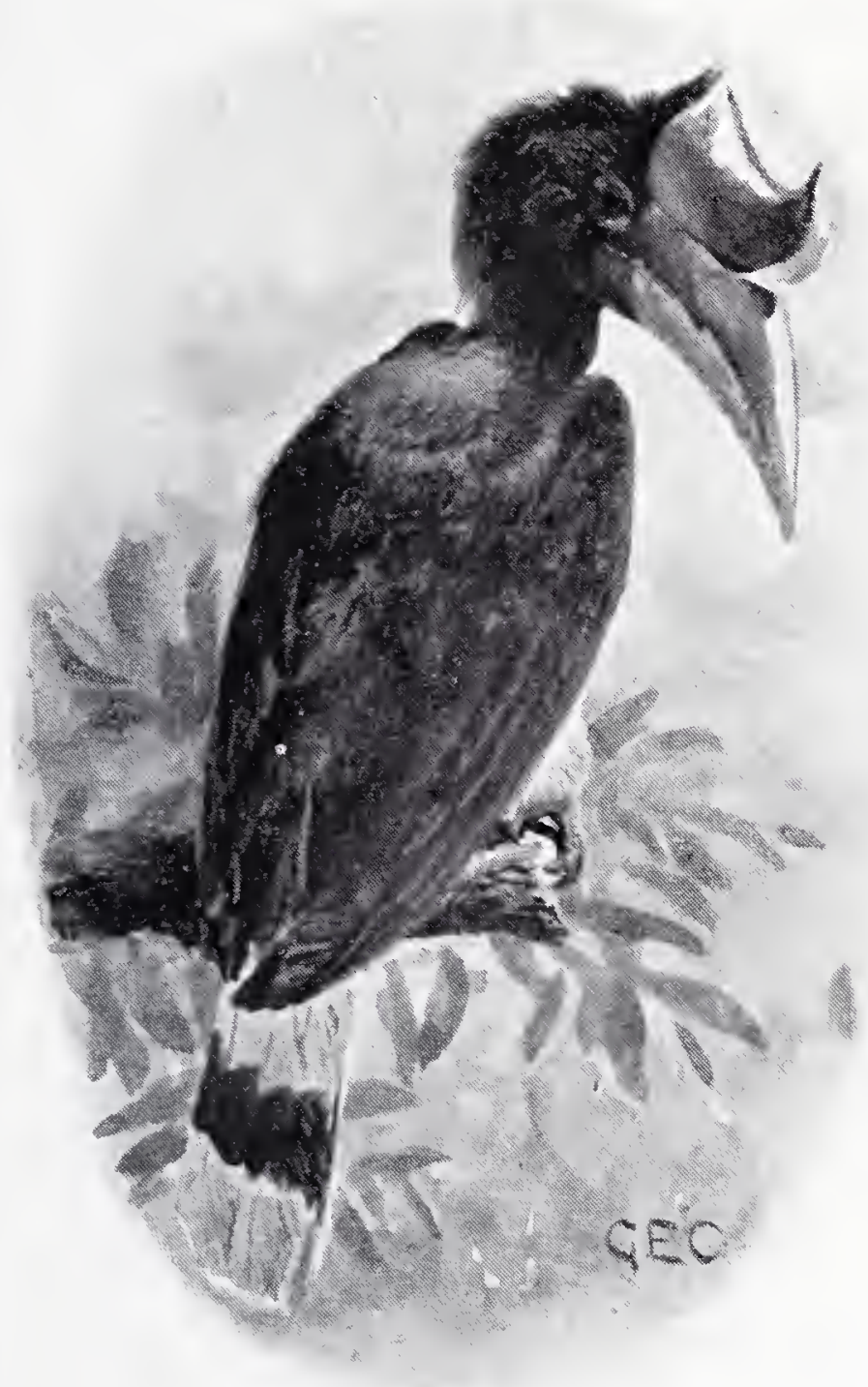

RHINOCEROS HORNBIL. birds often attack a snalie together. Their plan is to advance upon it sideways with their wings spread out, and to irritate it with the tips of the feathers until it strikes. Then they all peck it together before it can recover itself, and nearly always succeed in killing it in a very short time.

The Hoopoe, too, is a very odd-looking bird; but instead of having a horny helmet like the hornbills, it has a crest of very long feathers. These feathers, which can be raised or lowered at will, are tawny brown in colour, with blacli tips, just before which is a streak of white. The body is greyish-brown above and nearly white below, and the wings and tail are black, barred with white. Just now and then a hoopoe finds its way to our British Jslands; but the real home of the bird is in the sandy deserts of Northern Africa and Southern Asia. There its plumage harmonises so well with the colour of the soil that it is very difficult to see it, and it is said that when a hawk appears the hoopoe only has to flatten its body against the sand and remain perfectly still, when it is quite sure to be overlooked by its enemy.

The hoopoe utters its cry in a very curious manner. First it puffs out the sides of its neck, and then it hammers its beak thrce times upon the ground. Each time that it does so some of the air in its throat escapes, and the result is a noise like the syllable "hoo" three times repeated. 
The Arabs have a very odd legend about the hoopoe. One day, so the quaint old story runs, King Solomon was travelling through the desert, and was very much oppressed by the heat of the sun, till a large flock of hoopoes came and flew just above his head, so as to protect him from its rays. At the close of the day the grateful monarch wished to know how he could reward them for their kindness, and the foolish birds aslied that crowns of gold might grow upon their heads. Their request was granted, and for a few days they admired themselves immensely, and spent most of their time in gazing at their reflections in pools of water.

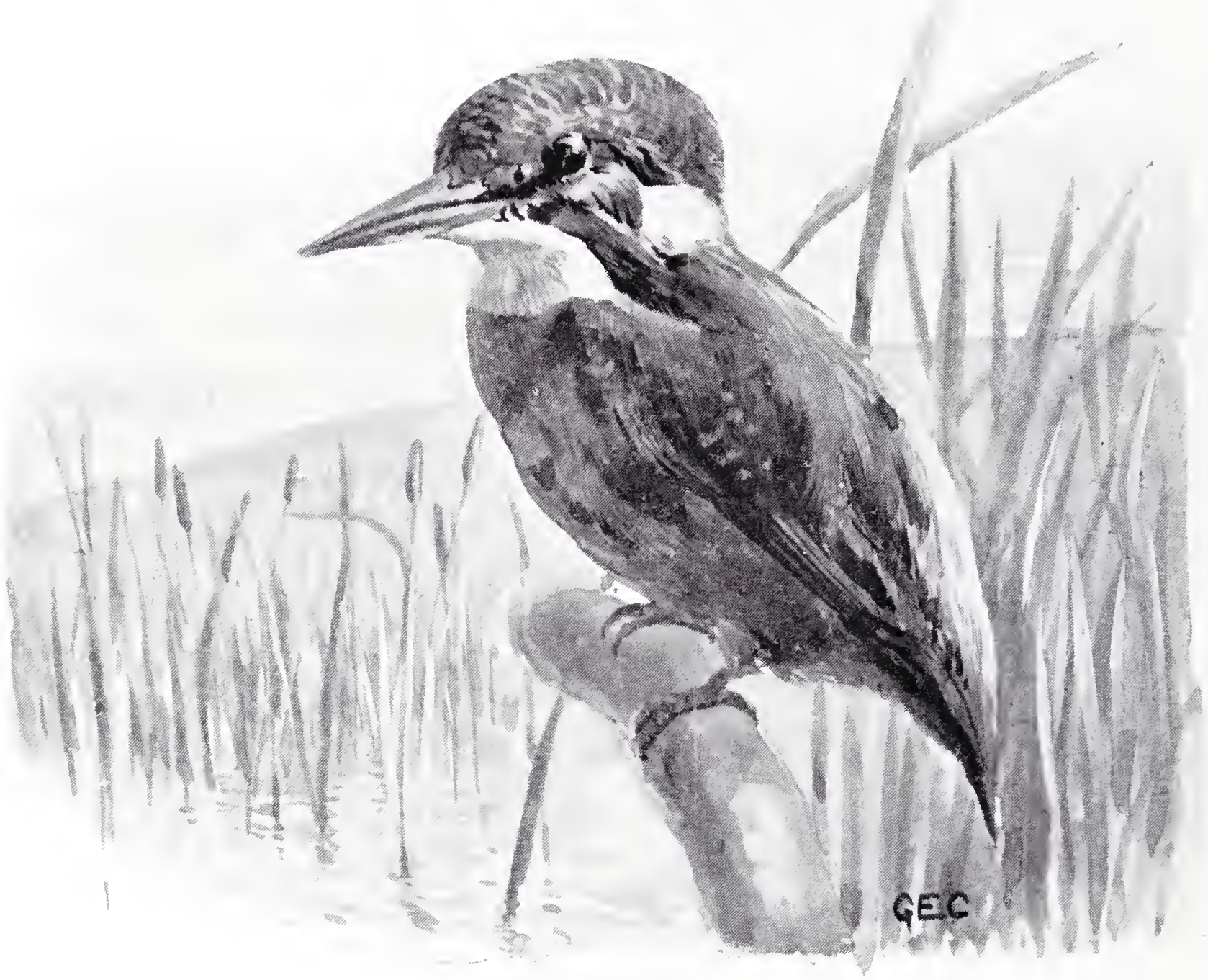

KINGFISHER.

Very soon, however, great numbers of them were snared by the fowlers for the sake of their valuable ornaments, and it seemed as though in a short time not one would be left alive. So at last the survivors went back to King Solomon, and begged that their golden crowns might be taken away. Once more the ling listened to their petition, and gave them crowns of feathers instead, and that is how hoopoes come to have crests upon their heads.

Most beautiful, perhaps, of all the birds of our own country is the Kingfisher. It is not very easy to describe it, as its colouring is so very varied. But we may briefly do so by saying 
that the upper part of the head and neck is dark green flecked with blue, that the back is dark green above and light violet or blue below, and that the wings are partly dark green and partly light green, with bluish spots, while the tail is deep indigo. Then there is a white patch rumning from the eye to the back of the neck, with a dark green streak underneath it, the eyes are crimson and the throat and chin are white, while the whole of the under surface is light chestnut brown.

Kingfishers have been terribly persecuted, so that they are not nearly so plentiful as they were. But still, as you walk along the banks of a stream, you may often see them darting through the air, and looking almost like streaks of coloured light. And if you sit down and keep perfectly still for a little while you may, perhaps, see one of them fishing. It perches on a branch over-hanging the water, and waits patiently till a fish passes underneath. Then suddenly it drops into the water like a stone, splashes about for a moment or two, and then returns to its perch with its victim struggling in its beak.

The King fisher builds in

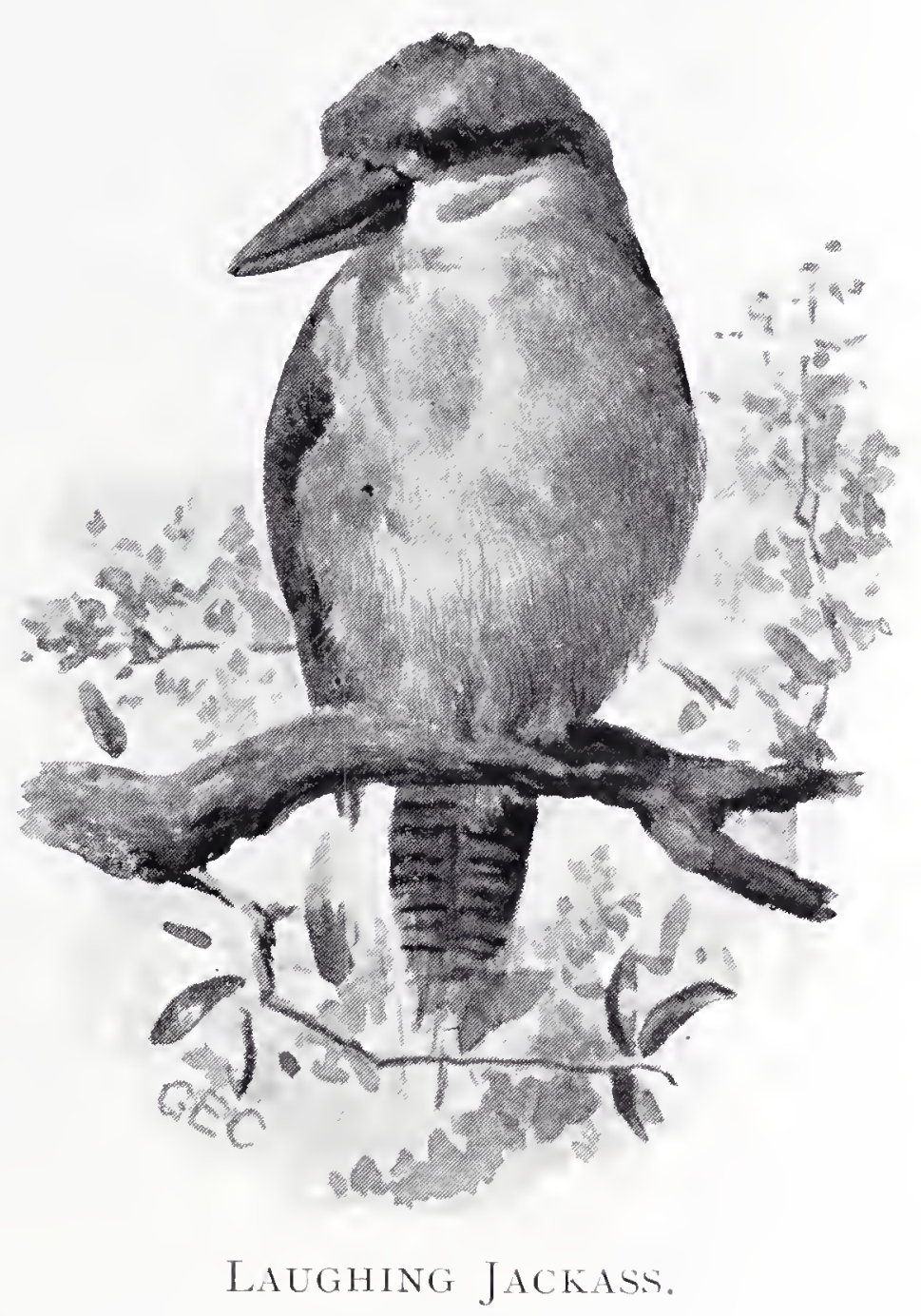
holes in the banks of streams, generally choosing the deserted burrow of a water vole. And what do you think the nest is made of? Why, of the bones of the fishes which the bird has devoured, and which it always returns, undigested, through its beak! It arranges these in the form of a mound, with a hollow in the middle, in which it lays from six to eight pinkish-white eggs.

A good many different linds of kingfishers are found in various parts of the world, one of them, which lives in Australia, being known as the Laughing Jackass, on account of its singular cry. 


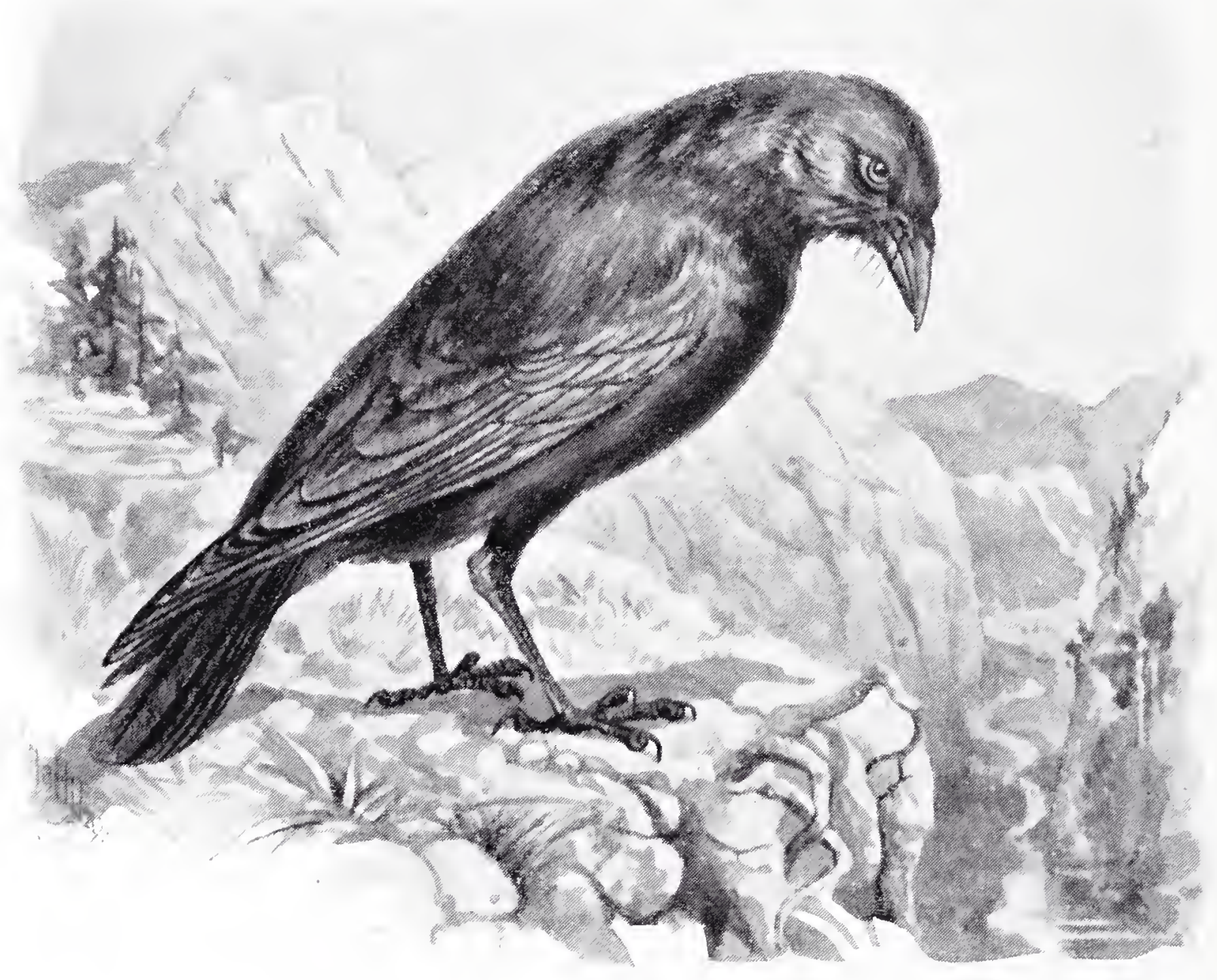

RAIEN.

\section{CHAPTER XXII.}

CROIIS, BIRDS OF PARADISE, AND FINCHES.

THE Crow Tribe contains several most interesting birds, first among which stands the Raven.

In days of old this great black bird might have been seen in almost any part of the British Islands; but nowadays it is almost entirely confined to the mountainous districts of Scotland and Ireland. And even there it is not nearly so common as it was, for it is so fond of killing weak and sickly lambs that the shepherds trap or shoot it whenever they have an opportunity. And the gamelieepers dislike it quite as much, because of the numbers of hares, rabbits, partridges, and grouse which fall victims to its terrible beak.

Ravens have often been tamed, and have even learned to talk almost as well as parrots. But they are exceedingly mischierous birds, and, in addition, are only too ready to peck anyone. 
who comes near them with the full force of their sharp and powerful bills; so that they cannot be at all recommended as pets.

The nest of the raven is a rather clumsy structure of sticks, and is nearly always placed in the upper branches of a very tall tree. When the young birds are nearly fledged, they often tumble out of the nest, and are found by the shepherds fluttering helplessly about on the ground. Most of the ravens which are kept in captivity have been caught in this way.

Except that it is a good deal smaller, the CARrIon Crow is very much like the raven. As its name implies, it feeds chiefly on the flesh of dead animals. But it also preys upon such creatures as rabbits, hares, mice, frogs, and lizards, while it will also search for the nests of game birds and poultry, and carry off the eggs and the young. Sometimes, too, it will visit the sea-shore,

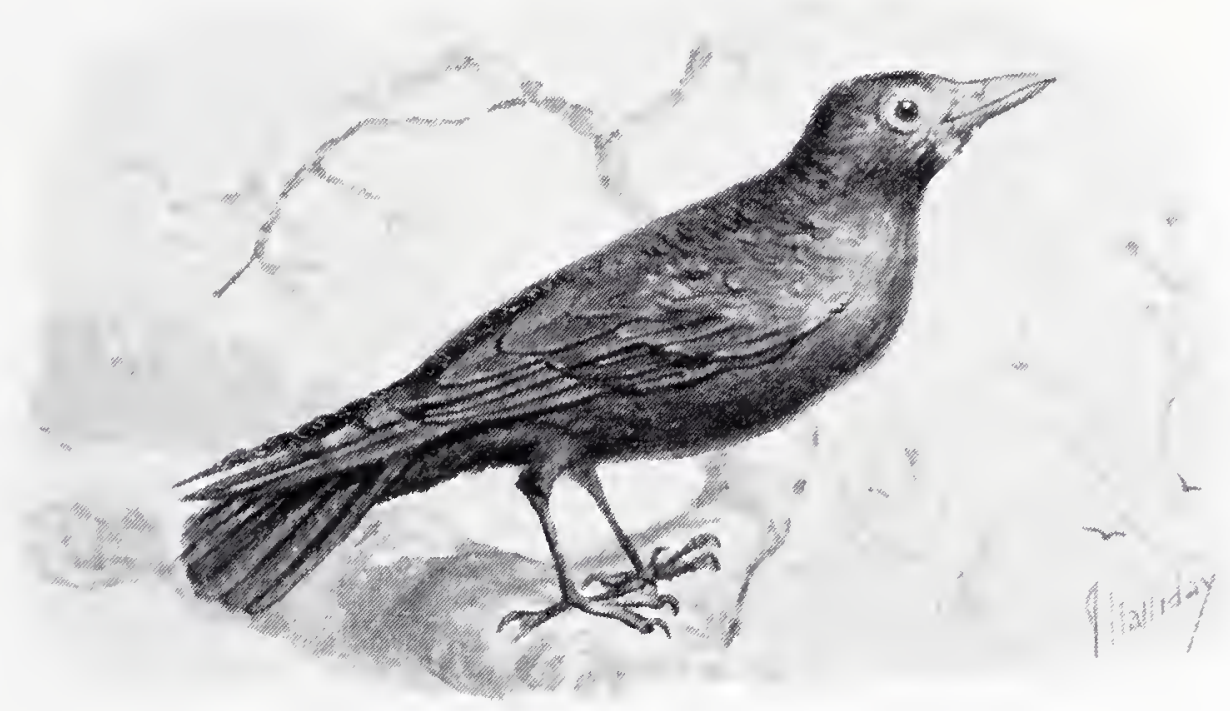

ROOK.

and feast upon the crabs, limpets, and mussels which it finds among the rocks at low water. In order to crack the shells of these creatures, it is said sometimes to carry them up into the air and drop them upon a rock.

Crows are generally seen either singly or in pairs, though sometimes in the evening eight or ten will gather together and chatter loudly, as though they were telling one another what they had been doing during the day. They make their nests of sticks, lined with grasses, roots, and horsehair, and nearly ahways build in the topmost branches of a tall tree.

The Hooded Crow, which may often be seen in numbers near the sea-shore, may be recognized at once by its grey body, the head, neck, wings, and tail being glossy bluish-black. In habits it does not differ from the carrion crow.

Everybody, of course, knows the Rook by sight, and everybody is familiar with the "rookeries" in which a number of these 
birds nest together year after year. Indeed, they use the same nests over and over again, just putting them into proper order shortly before the eggs are laid.

The scene when building operations begin is always a very lively one, and all day long the birds are very busy indeed. But oddly enough they never seem to know when the winter is really over, and when a thaw comes after two or three frosty days in December, or even earlier still, they get as excited as possible, setting to work and gathering sticlis, and evidently thinking that spring is beginning!

Roolis have very strict rules when they are building. For one rook to steal a stick from another rook's nest, for example, is a very serious crime incleed, and sometimes is punished even with death. And young birds are not allowed to build in a tree

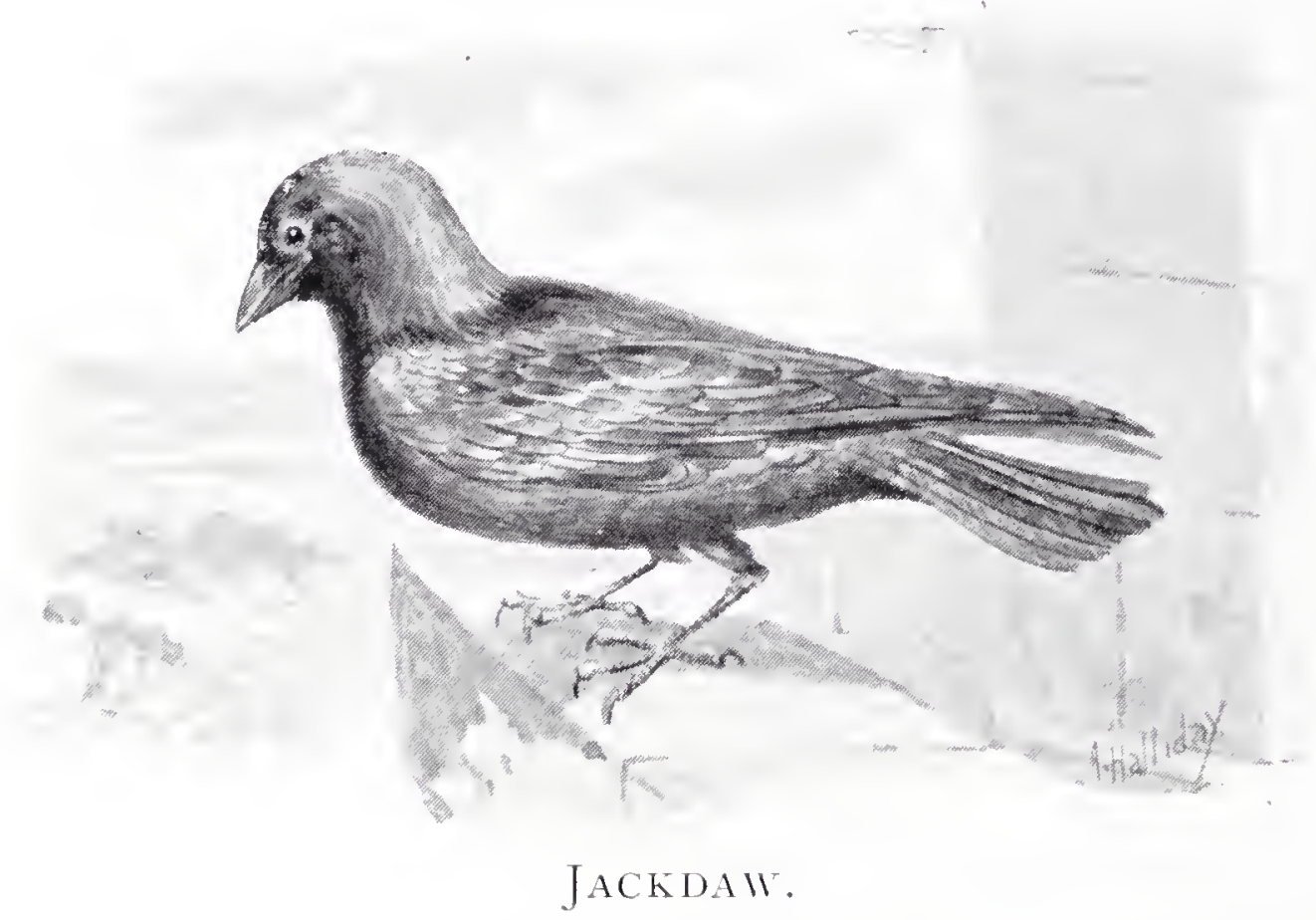

outside the rookery, their nest being at once pulled to pieces by the older ones if they attempt to do so.

Rooks are extremely useful birds, for they devour enormous quantities of mischievous grubs, more especially those which live at the roots of cultivated plants, where other birds cannot get at them. And you may often see them following the plough, and picking up their victims in scores.

In appearance the rook is very much like the crow, but you can always distinguish it by the bare patch at the hase of the beak.

The JACKDAw is a smaller bird than the rook, and can easily be recognized by the grey feathers of the back of the head and the neck. It is generally found near houses, being very fond of nesting in church towers, or in old ruins. But very often a colony of jackdaws will settle in a lofty cliff, and build on rocliy ledges far beyond the reach of even the boldest climber. 
The jackdaw is easily tamed, and is a very interesting bird when kept as a pet, soon learning to talk almost as well as a parrot. But it is dreadfully mischievous, and if it finds any small glittering object is almost sure to carry it off and hide it. Sometimes, too, it will play very amusing tricks. I knew a tame jackdaw once which lived in a very large garden. One day the butcher's cart drove up, and the butcher went round to the kitchen entrance to take the orders. No sooner had he disappeared than the jackdaw flew up on the box, and called out, "Gee

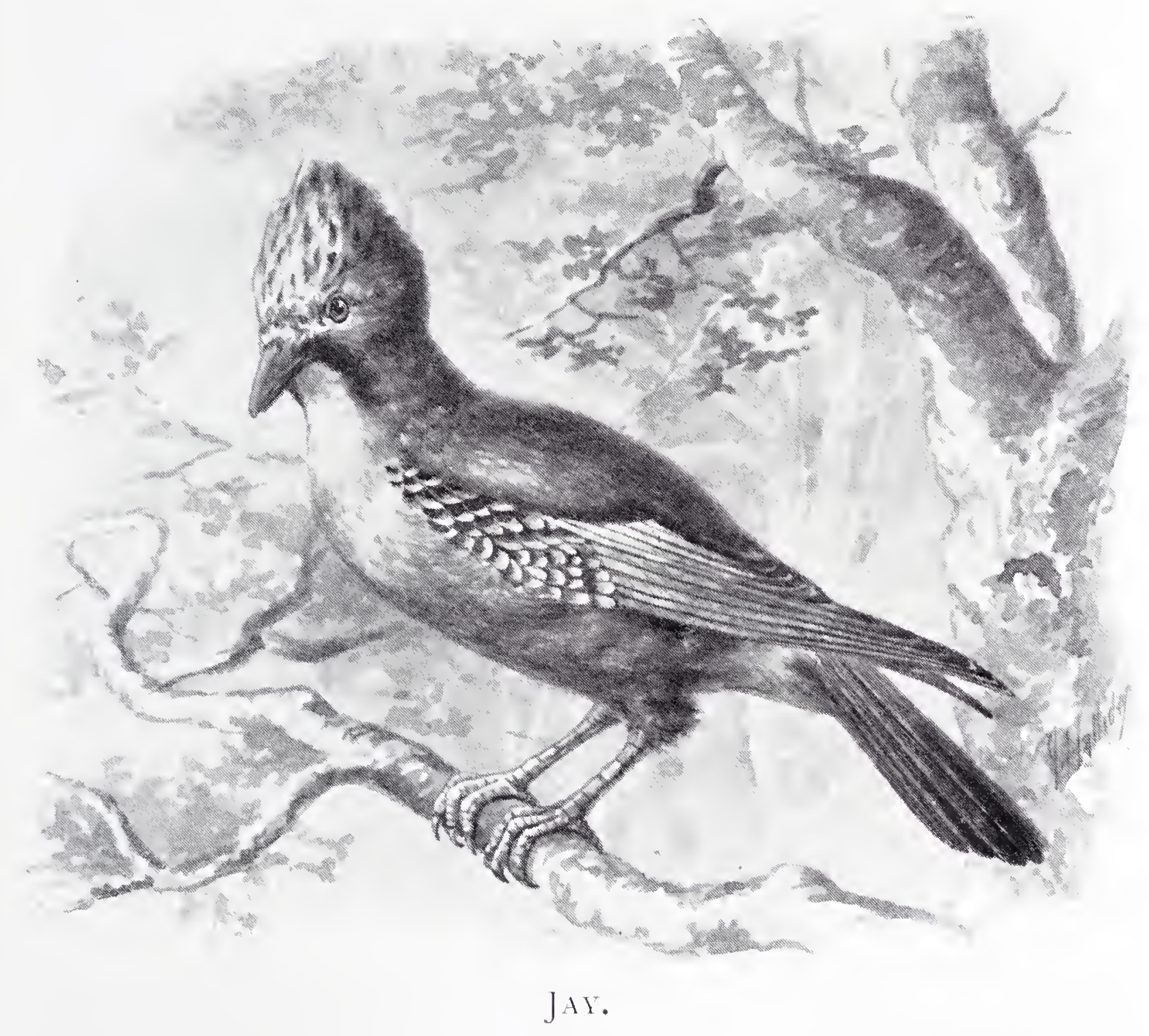

up!" Oft started the horse at once, and if the gardener had not happened to meet the cart as it was passing out of the gate, with only the jackidaw inside, the butcher would certainly have been obliged to walk all the way home!

The nest of the jackdaw, like that of the rook, is built of sticlis, and is lined with hay, wool, and feathers. It generally contains five eggs, which are bluish-green, spotted with grey and brown.

What a beautiful bird the JAY is! And how very seldom 
one gets a really good view of it! For it is one of the shyest of all birds, and never allows itself to be seen if it can possibly help it. And the very moment that it catches sight of one it flies off with a terrified squall which can often be heard from nearly half a mile away.

Other birds do not at all like the jay, for it is very fond of visiting their nests and stealing the eggs. It will carry off young birds, too, and derour them, and many a young partridge and pheasant falls victim to its appetite. But it also eats caterpillars, moths, beetles, and other insects, as well as fruit and berries: while sometimes it will visit a kitchen garden early in the morning, and feast heartily on the young peas.

In colour the jay is light reddish-brown. On either wing is a patch of azure blue banded with black, while the head is

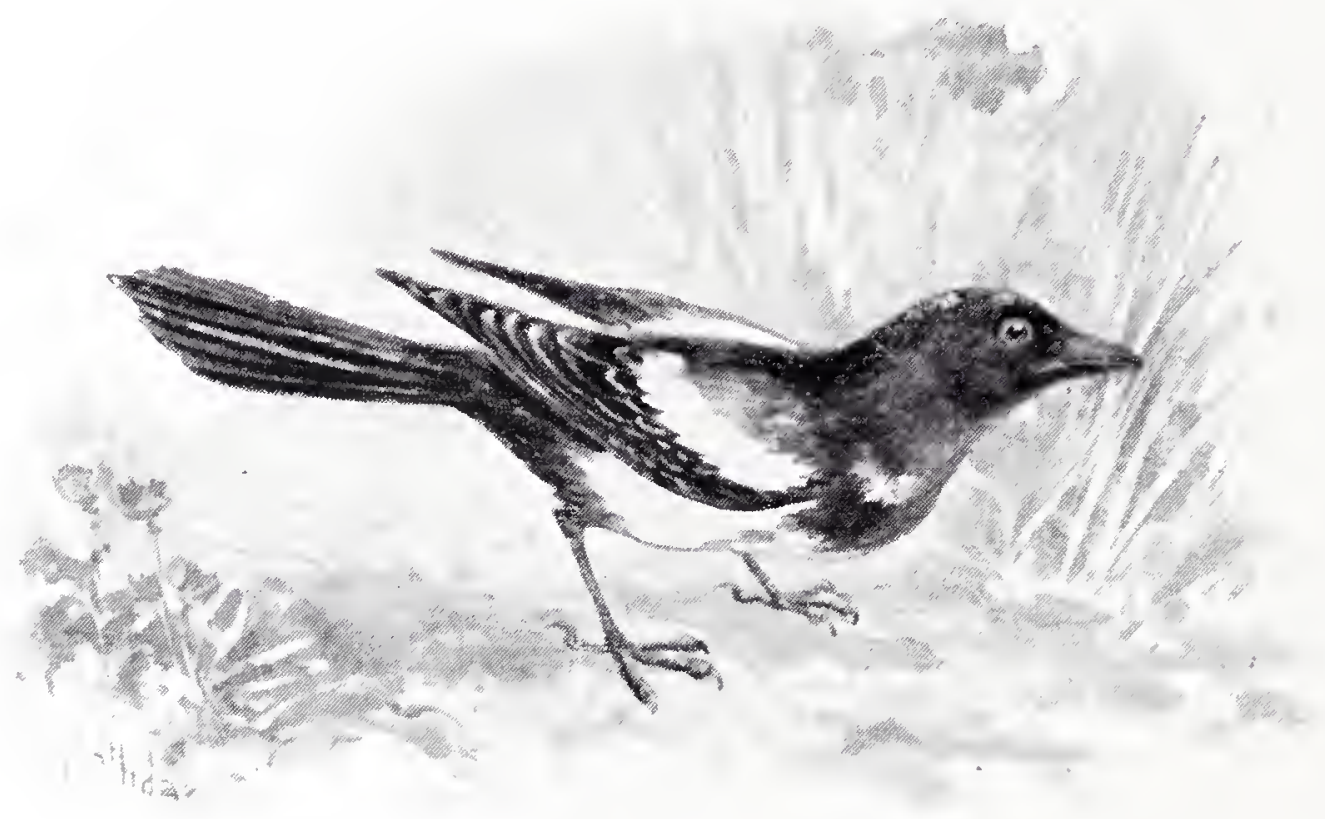

MAGPLE.

decorated with a crest of grey feathers, with black spots, which can be raised and lowered at will. The quill feathers of the wings and tail are black. The nest is not mnlike that of the jackdaw, and is built in the upper branches of a tall tree.

Of course you know the MAGPie very well by sight, with its glossy black and white plumage, its long tail, and its curious dipping flight. It is found in most parts of our British Islands, but never wanders far away from the shelter of large woods, where it knows that it is much safer from the attacks of hawks than in the open country.

The magpie is as mischievous out of doors as the jay, and as mischievous indoors as the jackdaw; so that it cannot be said to bear a very good character! But at any rate it makes a very amusing little pet, even if it does steal any small object that it can carry away, and hide it in some hoard of its 


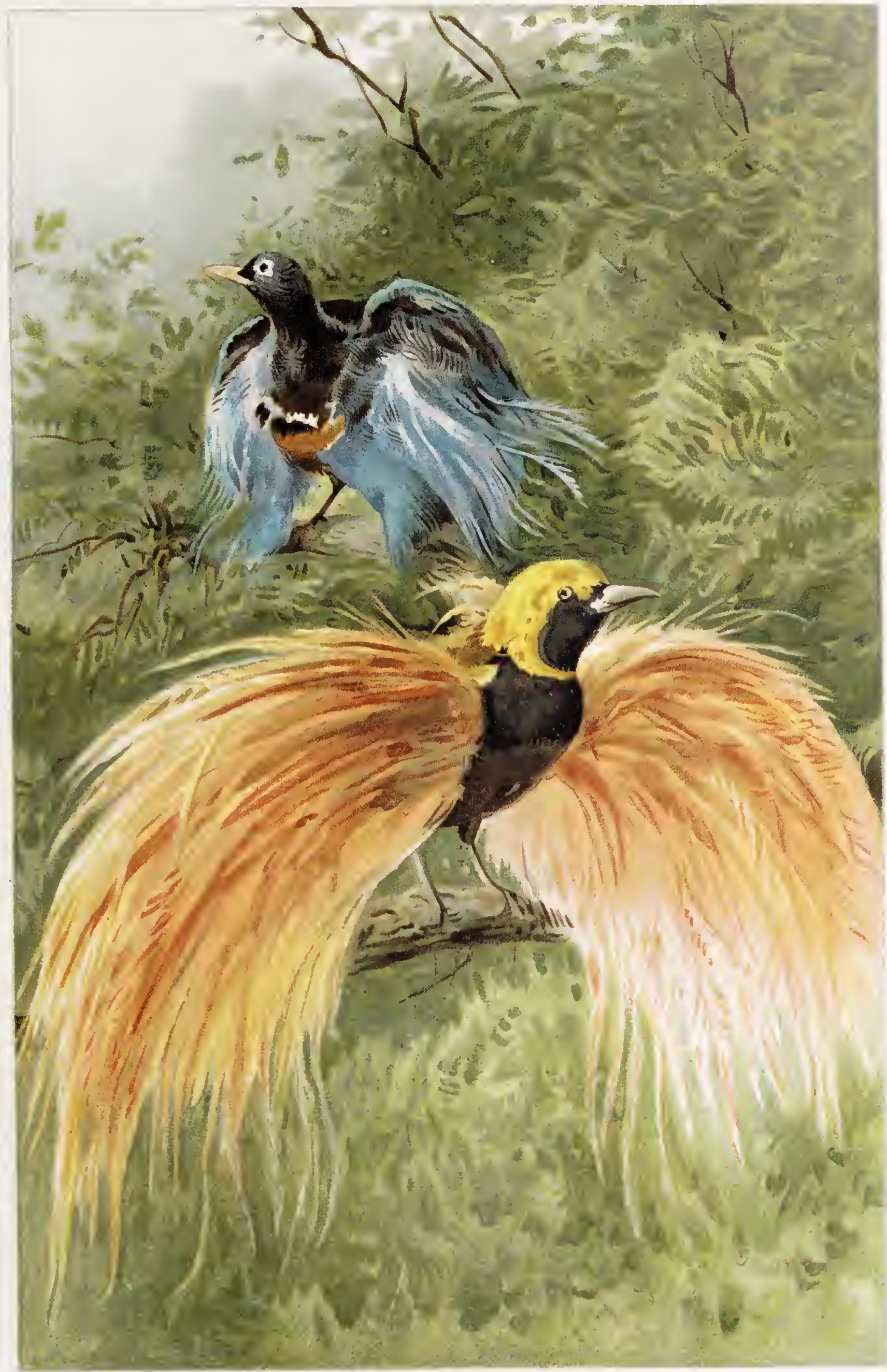



own. But with a little careful instruction it very soon learns to talk quite well.

The nest of the magpie cannot be mistaken for that of any other bird, for although it is made of sticks, like that of the jackdaw and the jay, it is always domed above, and has the entrance at the side. It is generally situated in the upper branches of a pine tree, although just now and then the birds will build in a low bush quite close to the ground. There are generally from five to seven eggs, which are bluish-white in colour, blotched and spotted with brown.

Next in order to the crows come the Birds of PARADise, which include some of the most beautiful of all the feathered race. They are nearly all found in New Guinea and the Papuan Islands, and there are altogether about fifty different kinds.

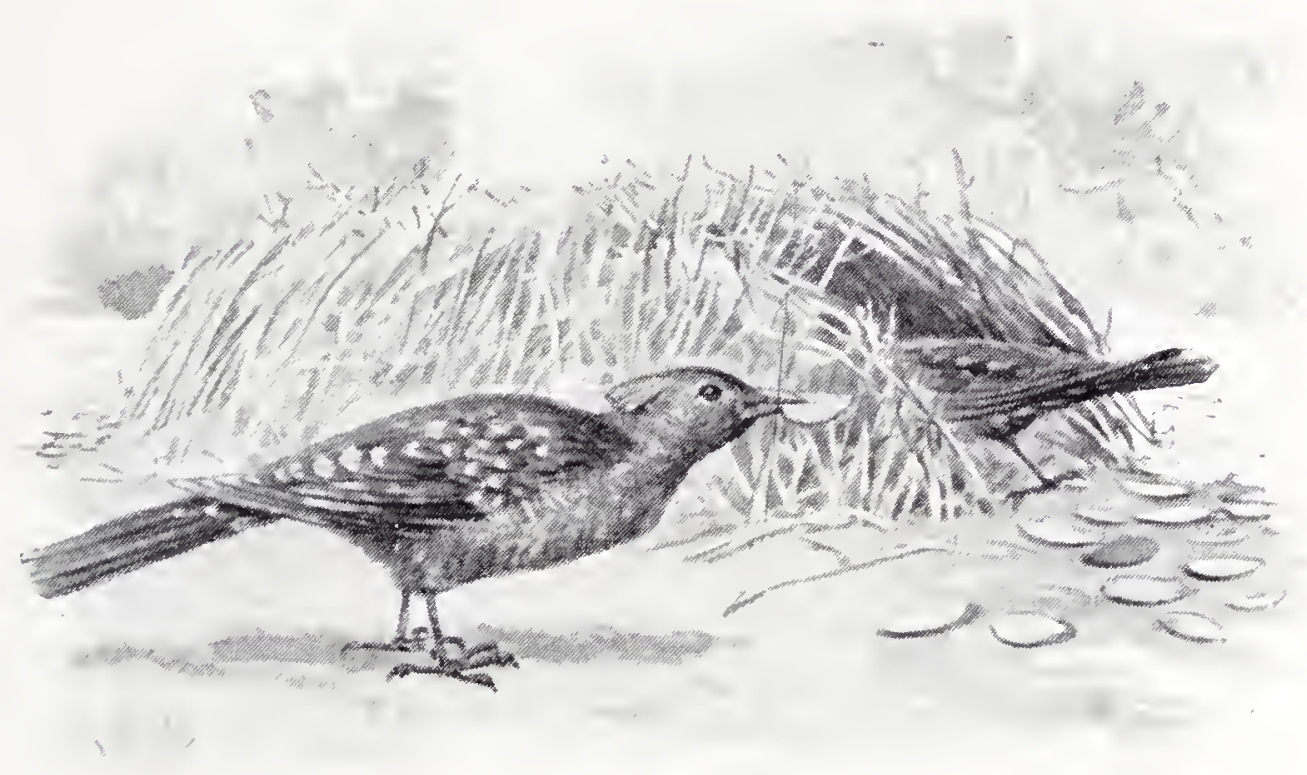

BOWER BIRDS.

Most beautiful of all, perhaps, is the KING BIRD OF PARADISE, which it is very difficult indeed to describe in words. The upper part of the body is rich chestnut, with a kind of wash of purple, and the lower part is pure white. Then across the breast runs a band of golden green, which deepens into blackish brown, while the upper part of the head and neck is pale strawcolour. Most exquisite of all, however, are the great masses of long, slender, drooping plumes, which spring from either side of the body beneath the wings. These plumes are nearly two feet long, and are of the most beautiful golden yellow, darkening towards the tips into pale brown.

This exquisite plumage is only found in the cock bird, the hen being of a dull brown colour all over, without any plumes at all.

Very little is known about the habits of birds of paradise, 
for few people ever have the opportunity of seeing them in their native forests, while they usually die almost immediately when placed in captivity.

The Bower Birds of Australia owe their name to their singular habit of making bowers in which to play! These bowers are built of sticks and long pieces of grass, arranged in such a way that they meet at the top so as to form a kind of avenue, and are often three feet long. Stranger still, they are ornamented with stones, brightly coloured shells, and the blue tail-feathers of parrakeets, which the birds carefully fasten up among the sticks, evidently in order to make the bower look pretiy. Then, when it is finished, they run through it, round and round, over and over again, chasing one another, and seeming to enjoy their game immensely.

There is one of these birds, found in Papua, which builds

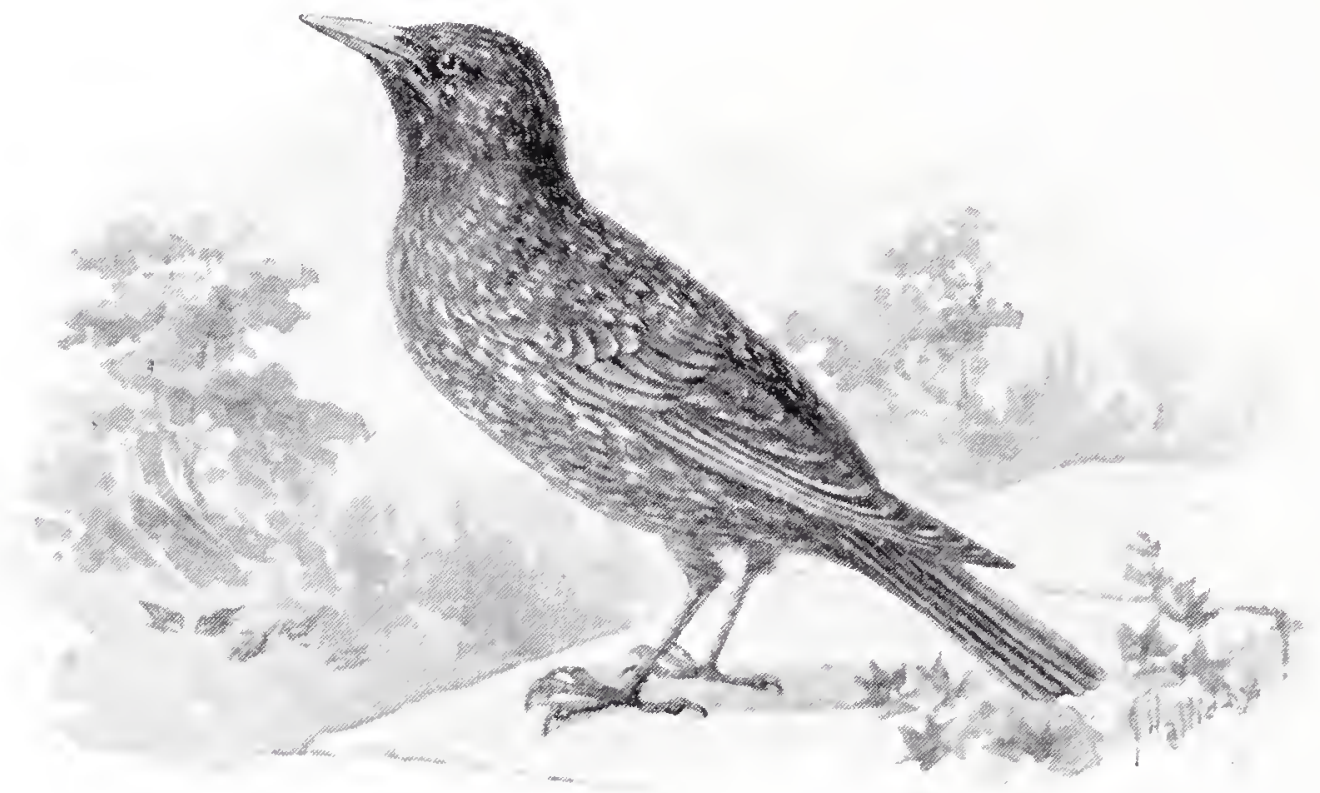

STARLING.

a hut about two feet high instead of a bower, and then makes a sort of garden in front of it. This garden is decorated with bright coloured flowers and berries, and as soon as they fade the bird throws them away and puts fresh ones in their place! It is called the Gardener Bird in consequence.

I need not describe the STARLing, for it is almost as well known as the sparrow. No doubt you have often seen it on the lawn, every now and then plunging its beak into the ground, and pulling out a grub or a worm. And most likely you know its great untidy-looking nest, which it is so very fond of building in water-pipes and other places just where it is not wanted.

Starlings often travel about the country in great flocks, which frequently consist of several thousand birds. Sometimes, too, several of these flocks join together at night, and then separate again next morning. I have seen a little copse so full of 
roosting starlings that every branch of every tree was occupied from end to end, while thousands more kept flying in, and trying to turn the first-comers off their perches! And they made so much noise that I could hear them chattering and quarrelling when I was more than a mile away!

Each flight of starlings seems to have its leader, whose orders are instantly obeyed, so that every bird in the whole flocki swerves, and wheels, and turns at the same moment. But how those orders are issued nobody knows.

Starlings are very useful birds, although they certainly steal a great deal of fruit; for if it were not for their labours our corn and vegetable crops would certainly be destroyed by the mischierous grubs which live at the roots. So I think that we ought

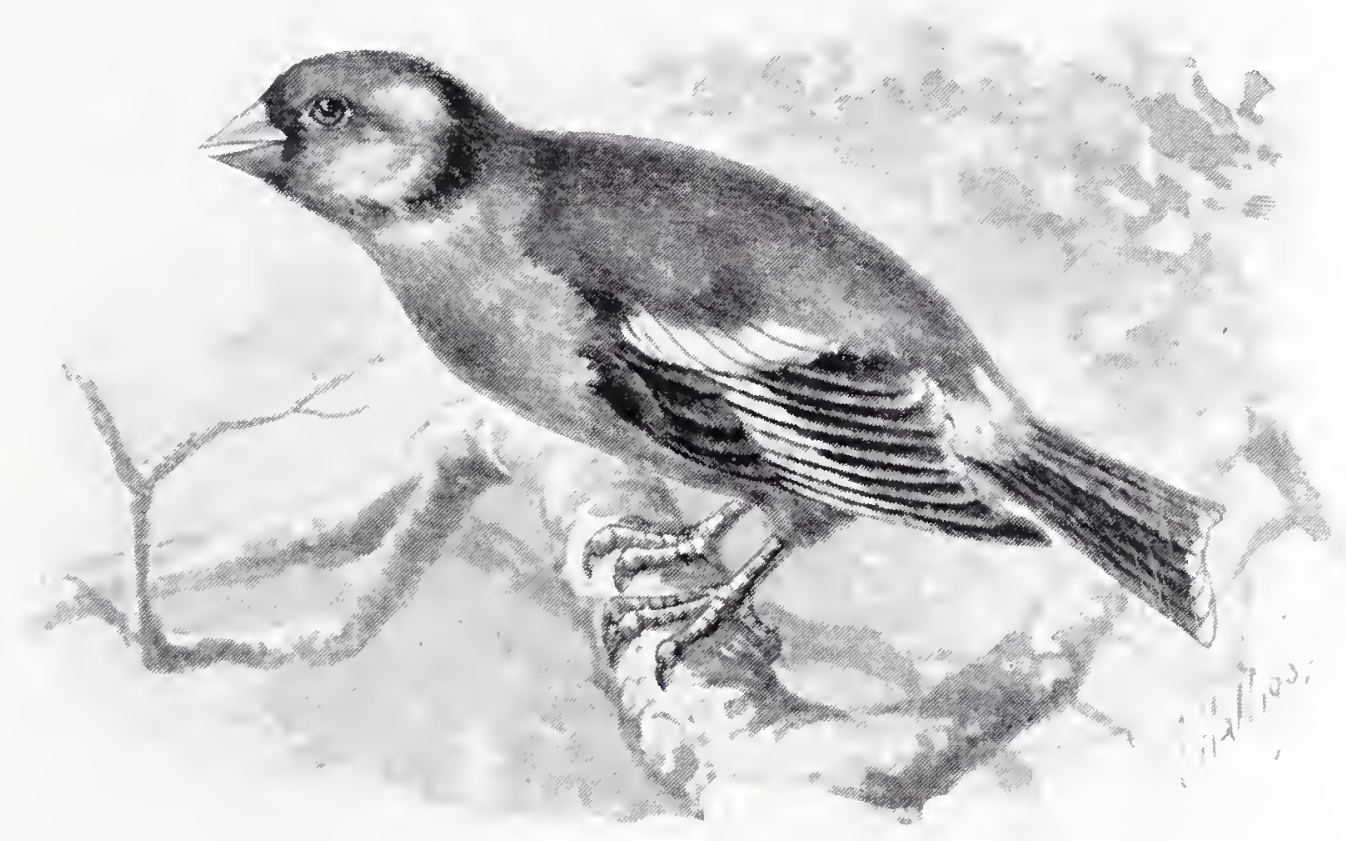

GOLDFINCH.

to look on the fruit which starlings take as the wages that we have to pay them for their work.

We now come to the great group of the Finches, which can easily be recognized by their short, stout, strong beaks.

Ve have several of these birds in our British Islands. There is the GREEN-FINCH, or Green Linnet, for example, which everybody knows by sight. And its note, when once heard, cannot easily be forgotten. It is just a kind of hoarse, high-pitched croak, as though the bird were trying to pronounce the syllable: "twee-e-e," and not quite succeeding. And this is repeated over and over again for hours together. But sometimes it utters a kind of mournful chirp as well, while just now and then it has a double call, which rather reminds one of that of the lapwing.

The nest of the green-finch is made of twigs and roots, and is lined with moss, wool, and hair. It is always placed in 
a hedge, or a thick bush, and contains five light-grey eggs speckled with purple.

Then there is the Hawfinch, which you cannot possibly fail to recognize if you see it, because its beak is quite twice as large as that of any other British finch. But one very seldom does see it, for it is an extremely shy bird, and always takes great care to keep out of sight. In the early morning, however, when nobody is about, it will visit kitchen gardens, and there feast heartily on green peas. And it will also find its way into orchards in search of cherry stones, which it splits across with its powerful beak in order to obtain the kernels,

The general colour of the hawfinch is reddish-brown above and purplish-red below, with the wings partly black and partly white. The back of the neck is grey, and there is a patch of black feathers round the base of the bill. The nest is placed in trees or tall bushes, and is made of twigs, grass, and lichens, lined with roots and hair. There are from four to six eggs, which are either olive green or buff in colour, with spots and streaks of brown.

The pretty little Goldfinch is not nearly so plentiful as it used to be, owing to the way in which it has been persecuted by bird-catchers. This is a very great pity, for besides being the prettiest of our native finches, it is extremely useful to the farmer, its favourite food consisting of the seeds of thistles. It also feeds upon those of the dandelion, burdock, and groundsel, sometimes taking them as they grow upon the plant, and sometimes chasing and seizing them as they are borne along by the breeze.

The nest of this bird is most beautifully built, and is so carefully hidden among the foliage of a tree-branch or a thicli bush that it cannot be found without very great difficulty. It is made of fine grasses, lichens, moss, wool, hairs, and very fine roots, and is lined sometimes with feathers, and sometimes with the warm, cottony down of the colt's-foot plant. There are either four or five eggs of a pale bluish-white colour, marked with dots and streaks of purplish brown.

As a cage bird the goldfinch is a great favourite, for it is not only very easily tamed, but is so clever that it soon learns to perform all kinds of amusing triclis.

Next to the goldfinch, the Bullfinch is by far the handsomest of our British finches, with his jetty black head and neck, bluish-grey back, and light red breast. The wings and tail are black, and the hinder part of the body is pure white. Unfortunately, however, the bird is a very mischievous one, being very fond of pecking fruit-buds to pieces, and sometimes entirely stripping gooseberry bushes and plum and cherry trees of their blossoms.

The natural note of the bullfinch is merely a plaintive whistle. But the cock bird has great powers of imitation, and if 
he is caught while quite young and carefully trained, he can even be taught to whistle tunes. No doult you have heard of "piping bullfinches." But sometimes, when the moulting season comes, they forget all that they have learnt; while if they are kept in the same room with other singing birds they are sure to pick up part of their song and mix the two up together!

The bullfinch generally builds in a hedge or a thick bush,

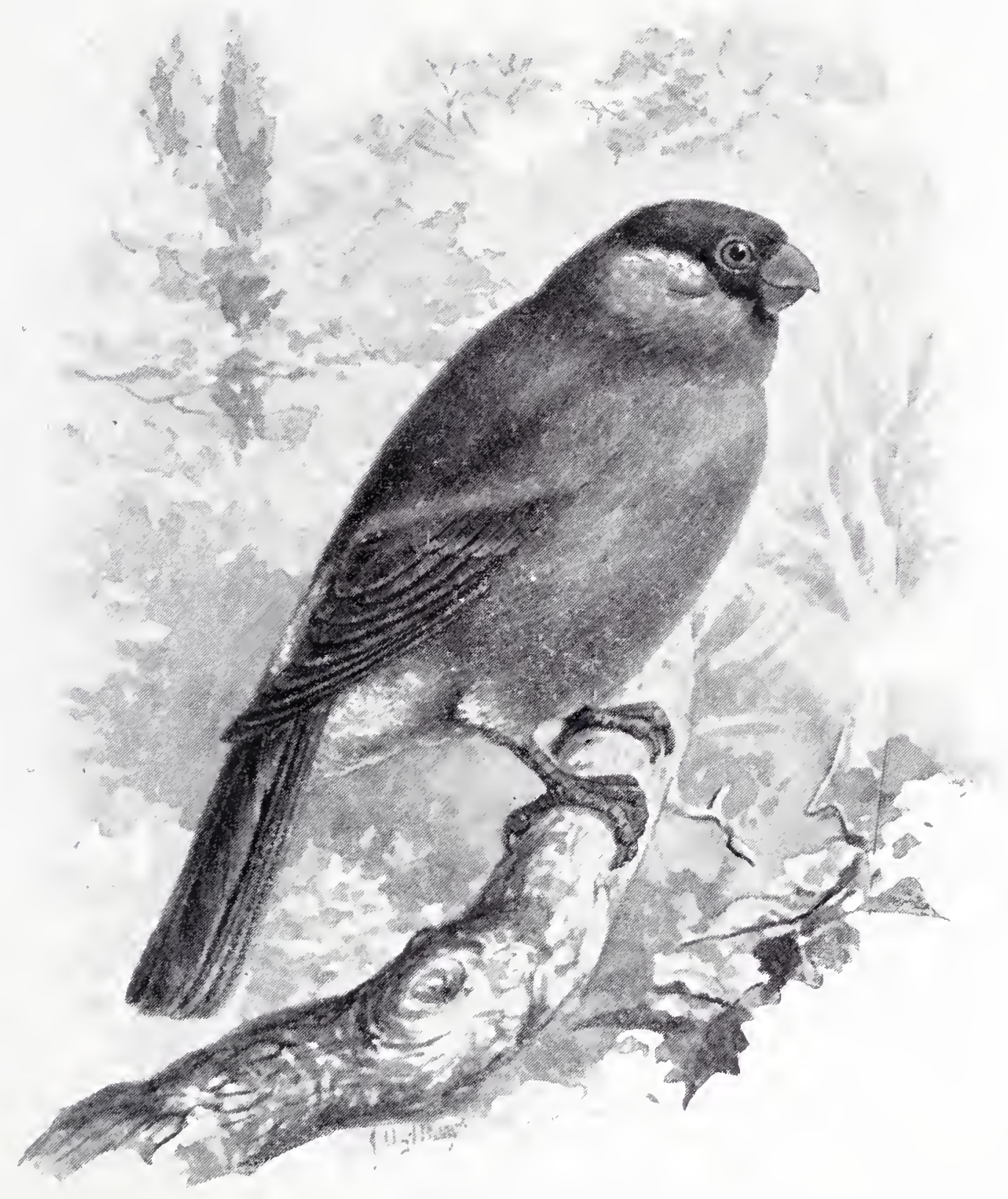

BULLFINCH。

making its nest of small twigs and dry grass, and lining it with fine roots. Five eggs are usually laid, which are light greenish blue in colour, speckled and streaked with purple and red.

Very pretty, too, is the Chaffinch, and very mischievous sometimes, when it pays a visit to our gardens and pulls the polyanthuses to pieces, or scratches up the seeds which the gardener has sown with such care. But then it devours very large quantities of the seeds of weeds, and feeds its little ones upon 
caterpillars and other destructive insects as well, so that in some ways it does a great deal of good.

In autumn and winter chaffinches fly about in large flocks, and it is a very curious fact that all the cock birds keep together in one flock, and all the hen birds in another.

The chaffinch has two notes, the first of which is like the syllable "twink," and the other like "tweet." And when you hear the latter note repeated a sood many times, while the bird seems restless and anxious, you may be quite sure that its nest is close at hand, and that it is very much afraid that you will find it.

This nest is alway's most beautifully made, and is composed of moss, dry grass, roots, lichens, and wool, lined with hair and feathers. It is generally placed among the twigs of an apple tree, and generally contains five eggs, which are greenish purple in colour, streaked and spotted with dark brown.

Another finch which is often seen in large flocks during the autumn and winter is the LINNET, so well-known as a song-bird. But it only sings during the spring and summer, its note during the rest of the year being a simple whistling call.

Linnets are very useful birds, and spend the greater part of the day in searching for the seeds of charlock, thistles, dandelions, and other troublesome weeds. Towards evening they make their way to a furze-covered common, and spend the night roosting in the bushes. There, too, they generally build their nests, which are made of roots, small twigs, moss, and wool, and are lined with feathers and hair. Four or five bluish-grey egos are laid speckled with dark red.

The SPARrow, of course, is a finch, but is so very well known that I need not stop to describe it. Let us pass at once to the Yellowhammer, or Yellow Bunting, whose odd little call you must often have heard on a summer's afternoon. "A little bit of bread and no-o-o-cheese," it twitters out, over and over again, always dropping to a lower note on the word "cheese." And you can scarcely walk along a country lane without noticing its bright yellow plumage as it flits in and out of the hedge, often 
lieeping just a few yards in front of you, and spreading its wings and tail as though it were anxious to be admired.

In winter these pretty birds may often be seen in large flocks in the stubble-fields, or even in farm-yards.

The nest of the yellowhammer is placed close to the ground-sometimes actually on the ground-among the long grass on the edge of a meadow. It is made of dry grass, with a lining of hair, and contains five greyish-white eggs, dotted and scribbled all over with purplish-brown. If the eggs are wetted, strange to say, these markings can easily be rubbed off.

Canaries, too, are finches, and are plentiful in the islands from which they take their name. But if you were to see them in their own home you would hardly recognize them; for a wild canary that is yellow all over is hardly ever seen. Our cage canaries, in fact, are an artificial breed, the natural colour of the plumage being olive green, marked with black and yellow. Neither would you recognize the song of the wild birds, which is not nearly so powerful nor so varied as that of the feathered pets which we all know so well.

Just now and then talking canaries have been known, which had learnt to utter a number of different words quite distinctly.

The SKYLARK is such a very well-known bird that it is scarcely necessary to do more than mention it. Everybody has listened to its joyous song as it mounts higher and higher in the air, till at last it looks a mere speck in the sky. For nearly eight months in the year it sings, and one can scarcely take a ramble in the country without seeing and hearing it.

The skylark builds upon the ground, in some little hollow, and its nest is so well hidden that one scarcely ever finds it. It is made of dry grass, leaves, and hair, and contains four or five yellowish-grey eggs speckled with brown. 


\section{CHAPTER XXIII. \\ IVAGTAILS, SHRIKES, THRUSHES, ETC.}

FIVE different kinds of Wagtails are included in the list of British birds, but two of these are only occasional visitors. Of the other three, perhaps the Pied Wagtail is that which we see most frequently.

One can scarcely walk along the banks of a stream in spring or summer without noticing this pretty and graceful bird, sometimes running along near the edge of the water, and stopping every now and then to pick off an insect from the herbage, and sometimes rising into the air to catch a fly or a gnat. And one can easily understand why its name has been given to it, for no matter whether it is flying or running its tail is never still. Sometimes, too, it may be seen in a damp meadow, or even on a lawn in a garden; and where one wagtail is, others are sure to be not very far off.

The nest of this bird is usually placed in a hole in a river bank, or else among the spreading roots of a tree. It is made of dry grass, withered leaves, and moss, and is lined with hair, wool, or feathers. The four or five eggs are bluish-white, speckled with dark grey, and there are two or even three broods in a season.

Most of these birds leave our shores during the autumn and do not return until the spring; but just a few appear to remain with us all the year round.

Running about on the trunks and branches of trees, and looking very much like a feathered mouse, you may often see the Creeper. It is about as big as a willow wren, and has a long, slender, and slightly curved beak, which it is constantly polking into the craclis and crevices of the bark in search of insects. It always begins its quest low down on the trunk, and works its way gradually upwards, peering into every little cranny, and seldom remaining still for a single moment. The larger boughs are examined in just the same, way, and when the bird has reached the top of the tree it flies down to another and begins again, and so on all through the day. And in order to prevent it from getting tired, it has a short, stiff tail like that of the woodpecker, which serves as a lind of camp-stool, and supports the weight of the body.

The nest of this quaint little bird is nearly always placed in a hole in a tree-trunls. It is made of roots, twigs, fragments of bark, and grass, and is lined with wool and feathers. From 
six to nine eggs are laid, which are whitc in colour, prettily spotted with yellowish red.

Another bird that one may often see running about on the trunk of a tree is the Nuthatch. It is shaped rather like a wren, but is a little bigger than a sparrow, and has a bluish-grey head and back, a white throat, and a dull red breast. And, unlike the creeper, it runs both up and down the trunk, seeming perfectly at its ease in any position.

The nuthatch is very fond indeed of nuts, which it cracks in a most curious way. First of all, it wedges a nut firmly in

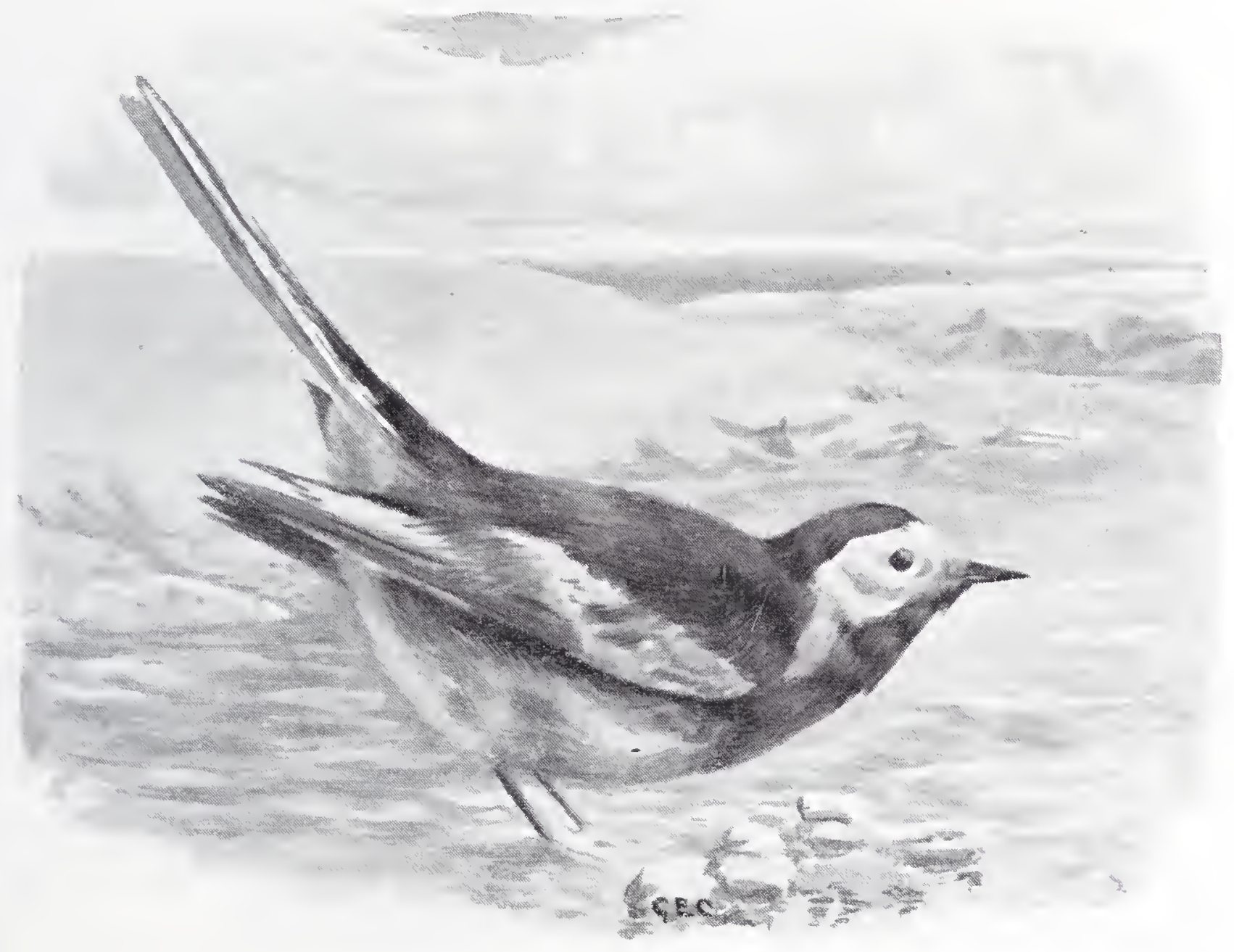

PiEd IVAGTAIL.

some crevice in the bark of a tree. Then, taking up its stand on the trunk just above, it deals blow after blow on the nut with its stout little beak, swinging itself up into the air every time that it does so and giving a flap with its wings, so as to add force to its stroke. It turns jtself into a kind of live pickaxe, indeed, and after a very few blows the nutshell is split open, and the clever little bird is able to get at the kernel.

If you look at the trees as you walk through a wood you may often find the empty shells of nuts which the nuthatch has opened in this singular manner, still firmly wedged in the cracks of the bark. 
The nuthatch makes its nest in a hole in a tree, and if the entrance is rather larger than it likes will partly plaster it up with mud and gravel. The nest is generally made of small pieces of birch bark, lined with dry leaves. When the mother bird is sitting upon her egrs, which are white in colour, spotted with pink, she will pecli most savagely at any enemy which may try to enter, hissing as she does so, just like a snake.

Titmice can be seen almost everywhere, and very pretty and attractive little birds they are as they run about on the trunlis and branches of trees, not seeming to mind in the least whether they are perching upon a bough, or hanging upside down underneath it. And all the while they are searching every little chink and cranny, in order to see whether any small insects are hiding within it.

It is a very good plan in winter-time

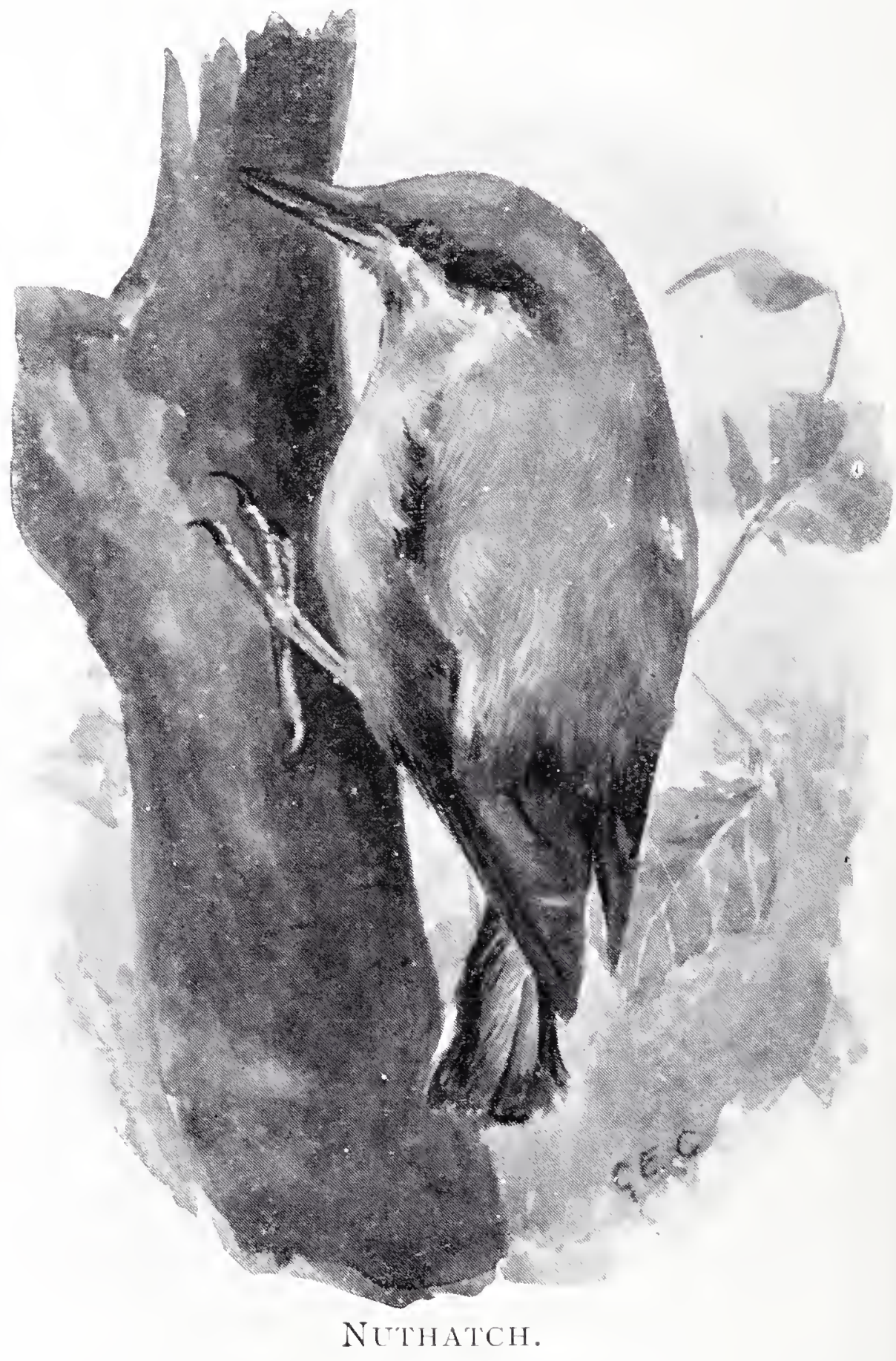
to take a marrow-bone, or a little network bag with a lump of suet in it, and hang it from:the branch of a tree for the titmice. Day after day the little birds will visit it, clinging to it in all sorts of positions, and pecking vigorously away at the suspended dainty. And they will like a cocoa-nut which has been cut in half almost as well.

Several different kinds of titmice are found in the British Islands, of which the Great Tit, the Cole Tit, and the Blue Tit are plentiful almost everywhere. They are all very much alilie in habits, and they all build in holes in trees, maling their nests of moss, hair, wool, and feathers, and laying six or eight white eggs, prettily speckled with light red. 
But there is one kind of titmouse which builds in quite a different way. This is the Long-tailed Tit, or Bottle Tit, as it is sometimes called, because its nest is shaped just like a bottle without a neck. It is sometimes placed in the fork of a branch, but more generally in the middle of a thick bush, and is made of wool, moss, and spider-silk, and is lined with quantities of soft downy feathers. And although it is by no means small it is very easily overlooked, for the clever little birds cover all the outside with bits of grey lichen, so as to make it look as much like the surrounding branches as possible.

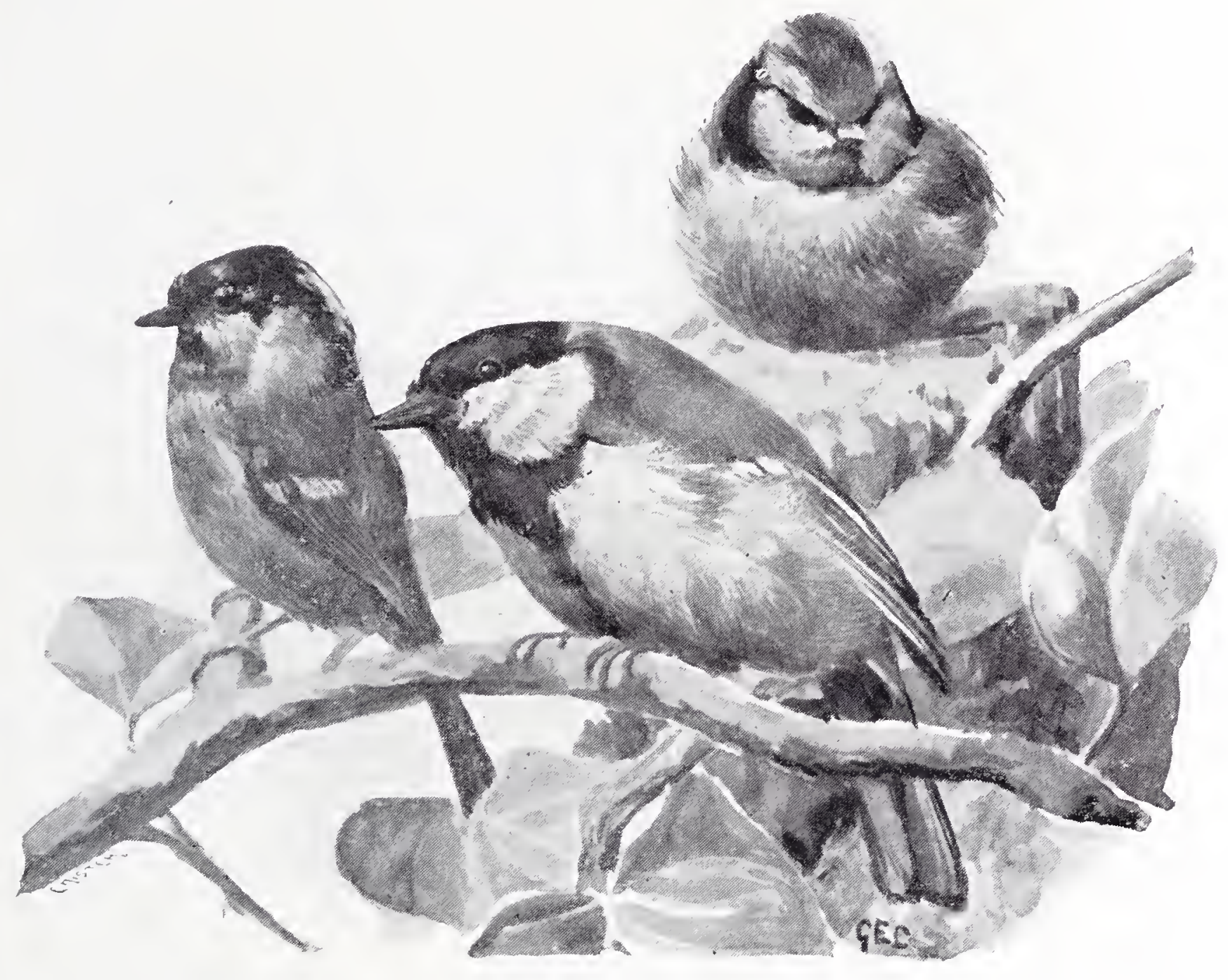

COLE 'ITT.

GREAT 'ITT.

BLUE TIT.

In this beautiful and cosy nest from ten to twelve eggs are laid, which are white in colour, with just a few very smail reddish spots. When the young birds are nearly fledged they quite fill up their nursery, and you can actually see the walls swelling out and contracting again as the little creatures breathe. And how they all manage to keep their long tails unruffled in those narrow quarters nobody knows at all.

In winter you may often see a whole family of these pretty birds-father, mother, and ten or a dozen little ones-all flying about together, for they never separate mintil the spring. 
A very odd bird, indeed, is the SHRIkE, which comes to us early in May, and goes away again before the end of summer. It is often known as the Butcher Bird, owing to a most curious habit. It is a bird of prey, feeding upon all sorts of small creatures, and it seems to linow that though it can catch plenty of these on warm, sunny days, they will all be hiding away in their retreats when the weather is cold and rainy. So on a fine, bright morning it will catch many more victims than it wants at the time, and put them away in its larder! Sometimes you may find a hawthorn bush with four or five mice, half a dozen unfledged birds, two or three fat caterpillars, a big beetle or two, and perhaps a bumble bee, all stuck upon the thorns, like the joints of meat hung up in a butcher's shop. Then you may be quite sure that you have discovered a butcher bird's larder. And by and by, when a cold and wet day comes, and the bird can catch no prey, it just comes and takes some of these creatures from the thorns, and so obtains plenty of provisions!

Three linds of shrike are found in the British Islands, but only one of them is at all common. This is the RED-BACKED SHRIKE, the male of which is a very handsome bird, with a grey head and neck, reddish-brown back, black wings edged with red, black and white tail, and rose-coloured breast. The hen is brownish-grey with a brown tail, and a dull white body barred with brown. The nest is placed in a hedge or a low bush, and is made of twigs, roots and grasses, lined with hair and moss. The eggs are grey or cream-coloured, mottled and spotted with darker grey and brown.

We now come to the family of the Thrushes, first among which stands the Song Thrush.

I need not describe this bird, because it is so very common and so very well known. Doubtless, too, you have often seen its great untidy nest, made of grass stems, roots, and moss, and plastered inside with clay, which is often built in such a position that no passer-by can help seeing it. But I wonder if you know how very useful this bird is in a garden.

The fact is, that it feeds very largely on snails, which it eats in a most curious way. First of all, it finds a large stone. Then it goes and fetches a snail, takes up its stand close to the stone, and begins to hammer its victim upon it, striking again and again, until the shell is craclied all over. It then holds the snail down upon the ground, carefully picks off all the pieces of shell, and swallows its body.

You may often find these "thrush-stones" in a garden, surrounded by the shells of snails which have been lilled in this singular way. And every thrush seems to have a stone of its own, to which it brings all the snails that it catches.

Now if you remember that for many months in the year the thrush is destroying snails in this way, you will easily be able 
to understand what a very useful bird it is to the gardener. And I think it may well be forgiven if sometimes it steals a little fruit.

There is a larger kind of thrush, called the Misser Thrush, because it is so fond of mistletoe berries. Sometimes, too, it is called the Storm Cock, because it may be heard singing gaily during the stormiest weather. It is a common bird, but is rather shy, so that it is not very often seen. But when you do see it, you can easily recognize it, not only by its size, but also by the

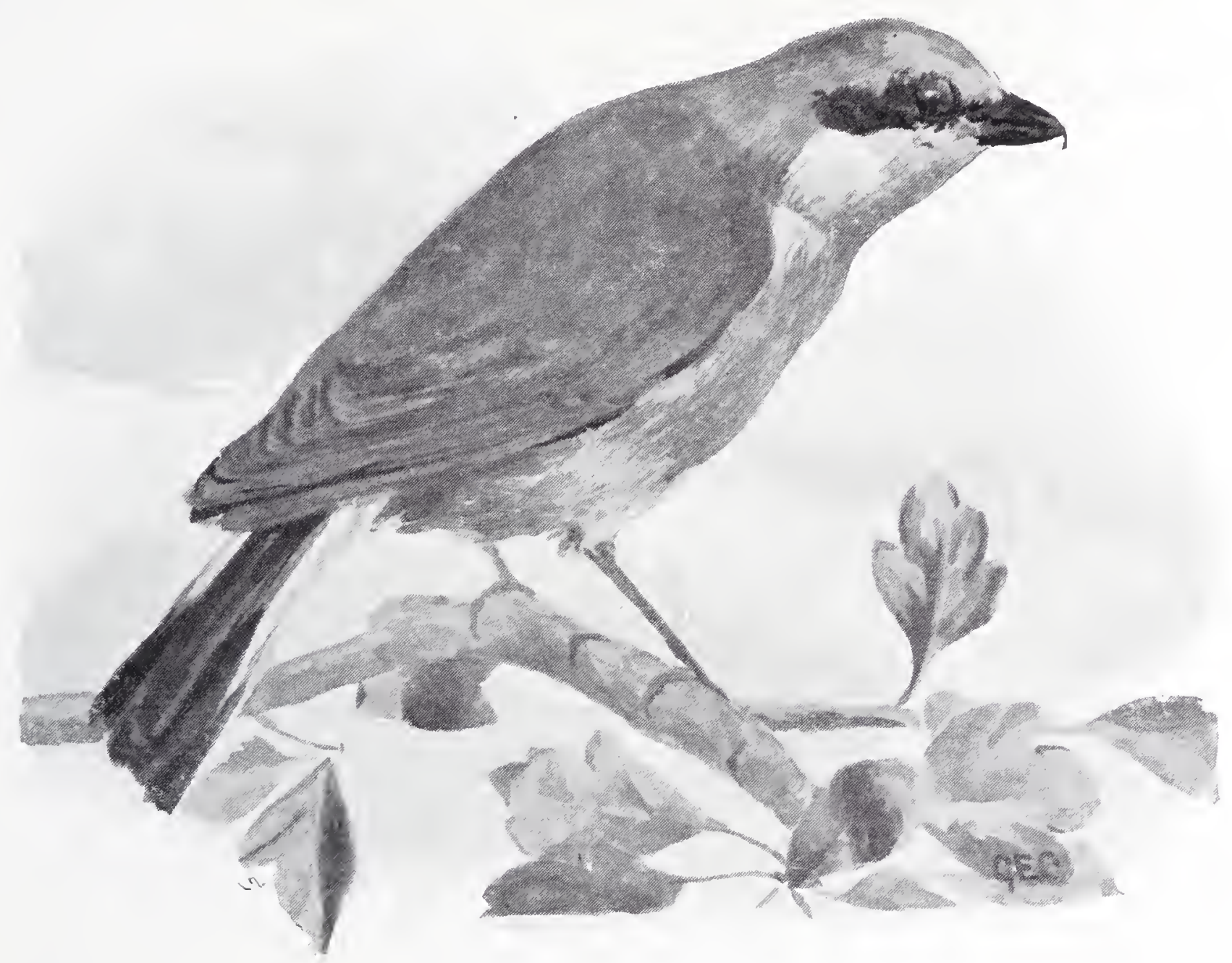

RED-BACKED SHRIKE.

fact that the whole of the under part of the body is white, spotted with black.

Then the BlackBird is a nember of the Thrush family, and, like the song thrush, is so common that it need not be described. Most likely, too, you have often found its nest, which is almost as untidily built as that of the thrush, and is very often placed in a bush in a garden. Except when it has little ones to take care of, the bird is extremely timid, and will fly off with loud cries of terror if one approaches the bush in which it is nesting. But when the eggs are hatched it becomes much more couragcous, and has often been known so fiercely to attack a cat 
which had ventured near its nest that the animal was quite bewildered, and at last ran ignominiously away!

The blackbird feeds chiefly on worms and insects. But it is very fond of fruit, and is sometimes most mischievous in the kitchen garden.

The Robin is a favourite with us all, because it is so very trustful. I have actually had one of these birds perching on my linee for quite a minute, while it looked about for worms in a plot of ground which I had just been digging. But it is by no means so gentle a bird as many people think. In fact, it is a very quarrelsome bird, for if two cock robins meet they are almost sure to fight, and very often the battle goes on until one of the two is killed!

A robin once took up his abode in Hereford Cathedral, and seemed to think that it was his own private property. For one day, when another robin came in, he was seen chasing it all over the building, and was at last found sitting triumphantly on its dead body!

You may find the nest of the robin in a hole in a bank or a wall, or perhaps in the stump of a tree. It is made of dry leaves, roots, grass, and moss, lined with hair, or wool, and contains either five or six yellowish-white eggs, spotted with light brown. For some time after they are fledged the little birds are very much like young thrushes.

I wonder if you have ever heard the Nightingate sing. This famous songster reaches our shores about the middle of April, and in some parts of the country may be heard almost all night for weeks afterwards, and sometimes nearly all day as well. But to other districts it never comes at all. You will never hear it, for instance, in Scotland or the north of England, and hardly ever in the west.

If one passes near a bush in which a nightingale is singing, it is worth while to stop and to whistle a few low notes. The bird imagines that it is being challenged by another nightingale, and begins to sing louder than before. Then it stops and listens; and if one whistles a few notes more it becomes very much excited, and comes closer and closer, singing all the time, till at last it finds out how it has been taken in. And then it begins to scold, chattering away in the greatest indignation at having been deceived!

Only the cock nightingale sings, and even he is only able to do so for a few weels. For very soon after the eggs are hatched his voice brealis, just as that of the cuclioo does, and the only note which he is able to utter until spring comes round again is a harsh whistle, followed by a hoarse croak.

The nest of the nightingale is placed on the ground under a low bush, and is made almost entirely of dead leaves. It contains either four or five eggs, which are dark olive brown all over. 
Another favourite song bird is the BLACKCAP, which is also a summer visitor to the British Islands. When it first arrives it seems to practise its song, hiding away in a thick bush, and trying certain passages over again and again. In a few days its performance is quite perfect, and then it leaves its retreat and sings much more boldly, evidently feeling certain now of its own powers.

You may often see a blackicap searching a rose bush or a fruit tree for caterpillars, green-fly, and the other mischievous

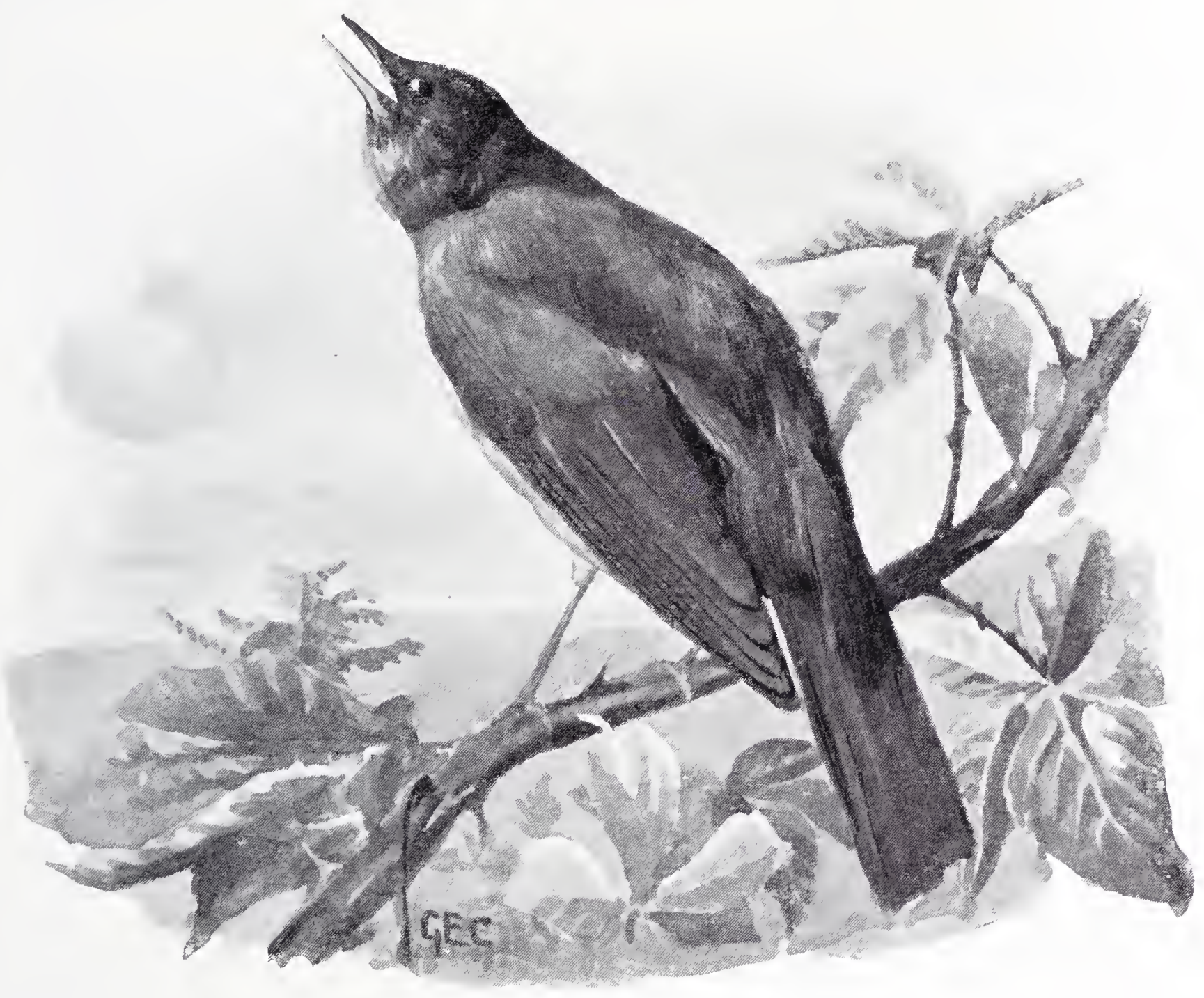

NightThGale.

insects which infest them. But when the raspberries ripen it steals a great many to give to its little ones, besides feeding upon them itself; so that it is not altogether a good friend to the gardener.

The blackcap builds in a hedge or a low bush, and makes its nest of grass stems, lining it with fine roots and hair. The eggs are greenish white, mottled with brown.

The female of this bird ought really to be called the "redcap," for the feathers on the top of her head, instead of being black, are rusty red.

The first of all the "summer visitors" to reach us in the 
spring, and the last to leave us in the autumn, is the pretty little CHIfF-CHAFF, and during the whole time that it is with us one can hardly walk along a country lane without hearing its gay little call, "chiff-chaff, chiff-chaff," repeated over and over again. And in its small way it is really a very useful little bird, for it will visit a garden day after day, and clear off the mischievous little "green-fly" insects which are doing so much harm to the rose bushes and the fruit trees.

You may often find the nest of the chiff-chaft among thick herbage quite close to the ground, or even on the ground. It is rather like that of the wren, being covered over at the top, and having the entrance at one side. In some parts of the country it is called a "wood-oven." It is made of leaves, grass, and moss, lined with feathers, and contains five or six pretty little greyish white eggs, speckled with red.

The Hedge SPARrow, of course, is not really a sparrow. You can tell that at once by its slender and delicate beak, which is as different as possible from the stout, strong bills of the finches. It is a warbler, like the blackcap and the nightingale, although it is not nearly so famous as a songster. But in plumage it certainly does look rather sparrow-like,

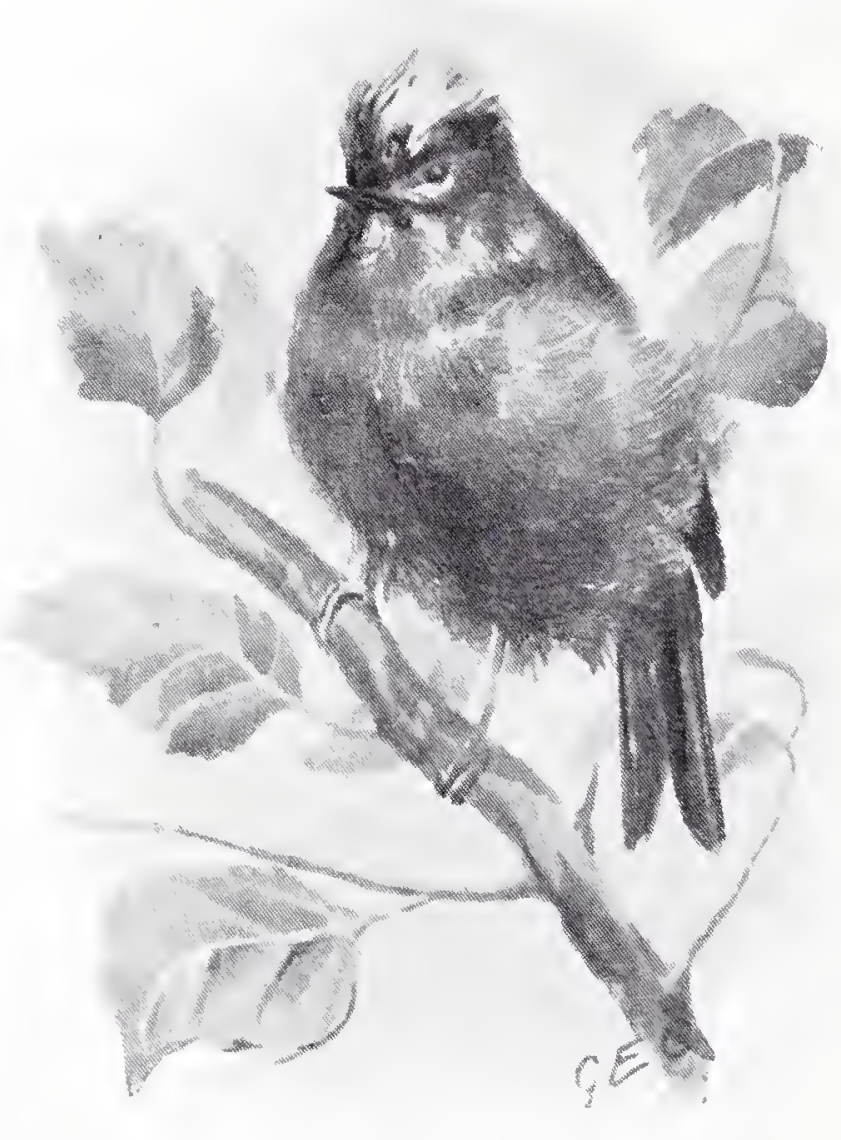

GOLD-CREST. so that one can easily understand why it has received its popular title.

This is a very quiet and unassuming bird. You may see it hopping about at the foot of a hedge, or underneath a thick bush, looking almost like a mouse as it steals in and out of the herbage, or sitting, perhaps, on the top of a low shrub, and pouring out its cheery little song. And its nest is one of the easiest of all nests to find, for it is often finished before there are any leaves on the bush in which it is placed. Who does not linow the four or five pretty blue eggs, without any spots at all, which may be found within it? Sometimes, however, there is a cuckoo's egg as well, for there is no other bird which a cuckoo likes quite so well as a foster-mother for her little one.

Just as the hedge sparrow is not really a sparrow, so the Golden-crested Wren is not really a wren. It is better to call 
it the "Gold-crest." Most likely it was called a "wren" on account of its size, for it is the smallest of all our British birds.

You may often see this beautiful little bird running about on the trunks and branches of a pine tree very much after the manner of a creeper, and peering into every little crack and cranny in search of insects. And if you look very carefully you may find its nest. But it is so carefully concealed that it is not at all easy to see. It is generally suspended from one branch and supported by another, and is nearly always shaded by foliage, while the mosses

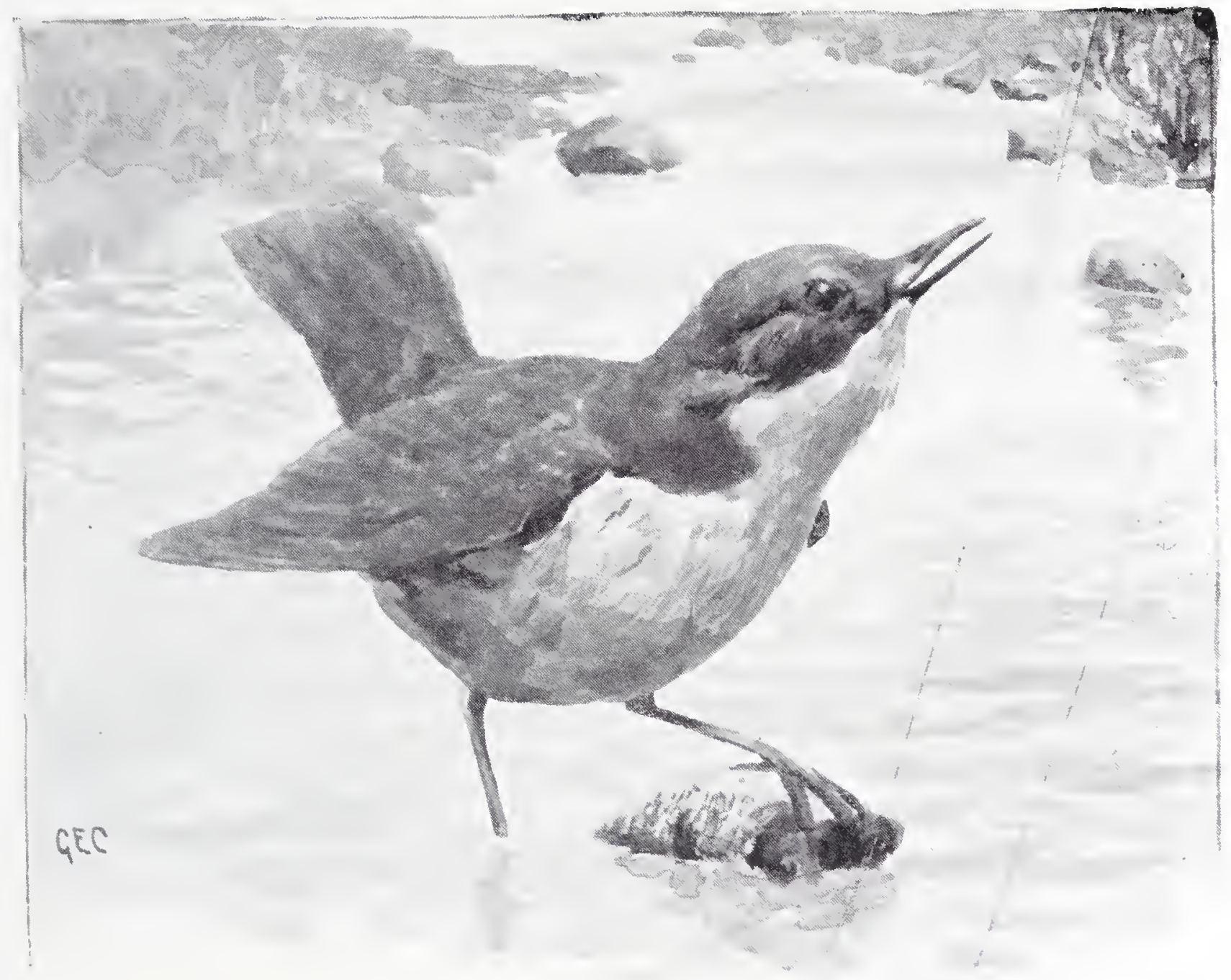

DIPPER.

and lichens of which it is made look so like the surrounding bark that one might easily look straight at it without noticing it at all. This beautiful nest is thickly lined with soft, warm feathers, and inside it are from six to ten cream-coloured eggs, no bigger than ordinary peas.

Of course, you know the nest of the true WREN, which is placed sometimes in a hole in a tree-trunk, sometimes among the branches of ivy growing on a wall, and sometimes under the eaves of a shed. It is always domed above, with the entrance in the side, and generally has the outside covered with dead leaves, and the inside lined with feathers. 
Wrens have a curious way of beginning to build nests, and leaving them half finished. These are sometimes supposed to be the work of the male bird alone, and are called "cocks' nests" in consequence; and certainly the cock does not seem to take any part in building the true nest, for he simply sits on a branch close by and sings, while the hen does all the work. Perhaps he is lazy; or perhaps she thinks that she can build much better than he can, and so will not let him help her. And therefore it may be that he makes these "cocks' nests" just to show her what

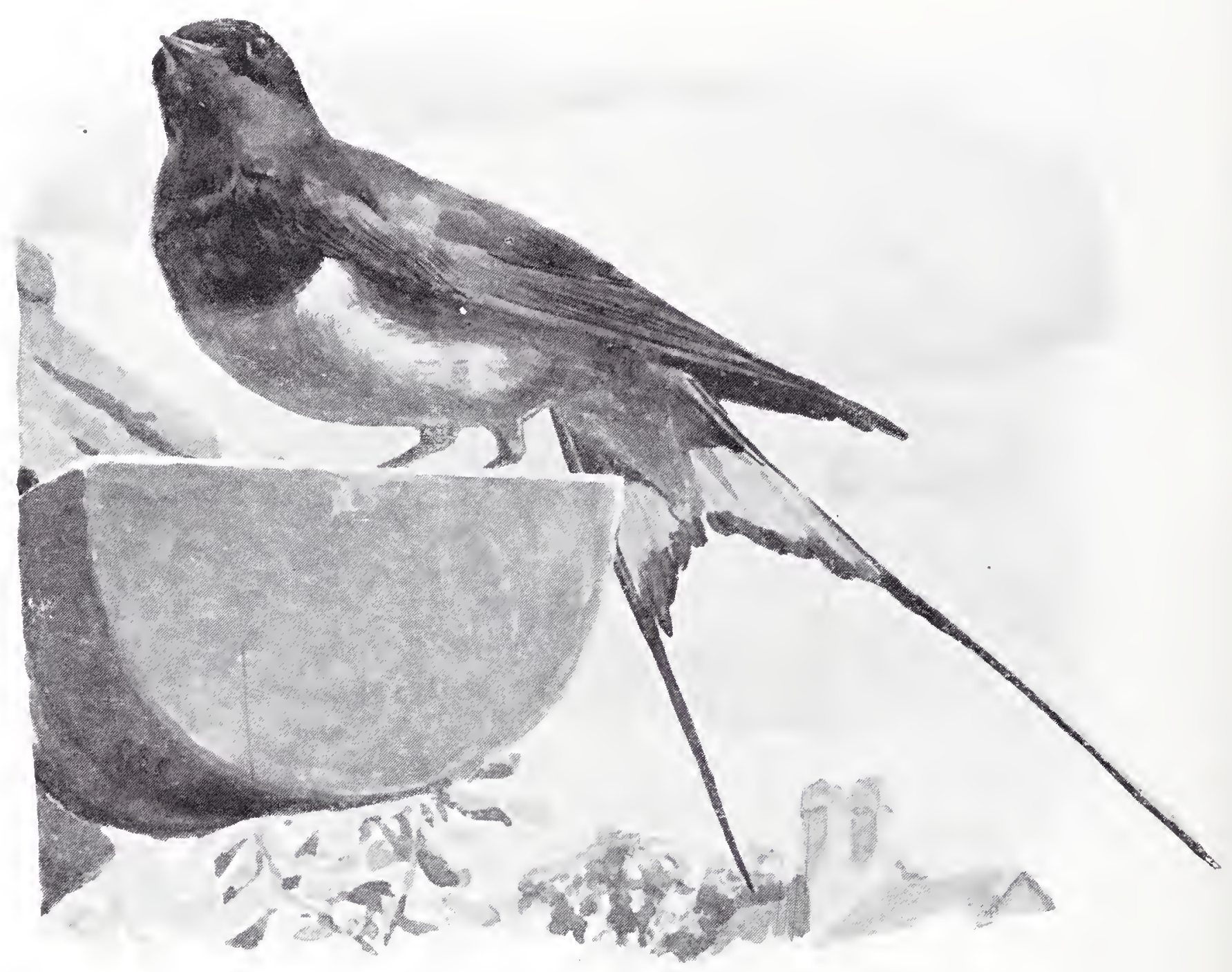

SWALLOW.

he can do. But as wrens are very timid birds, and will often lesert their nest if one even puts one's finger inside, it seems rather more likely that they are nests which the birds have left unfinished because they thought that some enemy had discovered them.

The eggs are usually from six to eight in number, and are white in colour, spotted with pink.

Not unlilie a very big wren with a white throat and breast is the curious and interesting Dipper. It is never found far from water, and you may often see it perched upon a stone in the 
shallows of a river, bobbing up and down every now and then just as though it were making a curtsey. And every time that it does so it gives a quick little jerk to its tail, just as the wren does. It also makes a nest like that of the wren, which is generally placed in a hole in the bank of a stream. Yet it is not really a wren, and seems to be more closely related to the flycatchers. It feeds on insects and water-shrimps, etc., and you may often see it busily hunting for the little beetles which are hiding among the moss on the large stones in the bed of a stream. It can swim

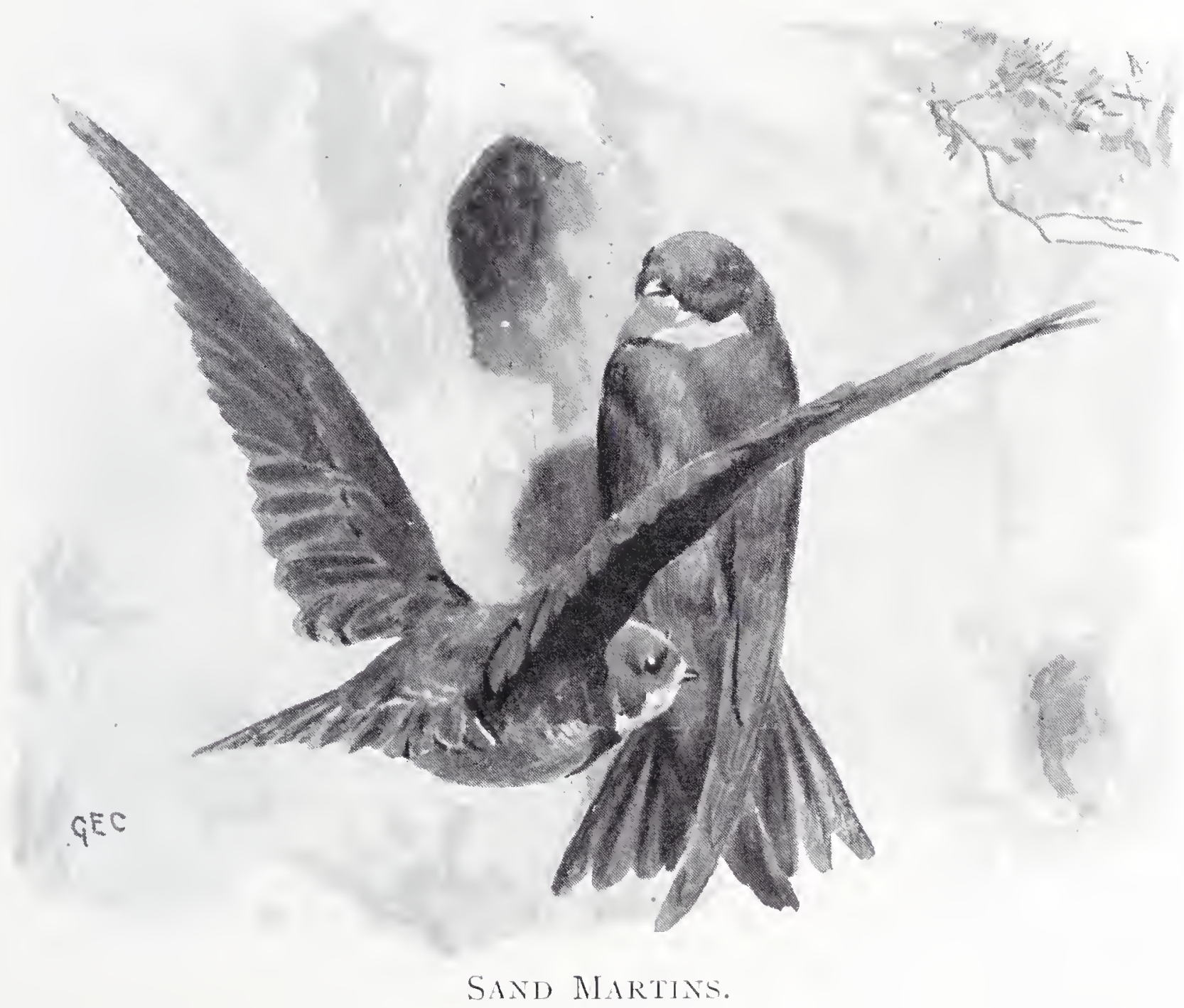

and dive perfectly well, and lieeps itself beneath the surface by flapping with its wings, while it searches for grubs in the mud at the bottom of the water.

The dipper has a very bright and gay little song, which may often be heard in the winter. And even in the very worst weather the bird always seems happy, and busy, and active.

Almost the last of the "summer visitors" to arrive is the Spotted Flycatcher, which hardly ever appears until quite the end of May. But after that, until nearly the end of September, you may see it catching flies in almost any large garden. Its usual plan is to sit upon a post, or a low bough, and to wait 
there until a small insect flies past. Then it darts after it, catches it in the air, and returns to its perch to wait for another.

Flycatchers mostly build their nest on the bough of an apple-tree, or else among the foliage of a fruit-tree which is trained against a wall. It is made of moss, straw, and hair, lined with feathers, and contains four or five eggs, which are pale bluish white, spotted with reddish brown. The young birds must be very liungry little creatures, for their parents have been known to feed them no less than five hundred and thirty-seven times in the course of a single day!

The Swallows and Martins form a very distinct little group of birds. They come to our British Islands in the spring, and fly south again in the autumn, assembling together in large flocks before they go. No doubt you have often seen them sitting in hundreds upon telegraph wires about the end of September, just before starting on their long journey to Northern Africa.

The Swallow is easily distinguished by its long forked tail, which it spreads widely while it is flying, and the Martin by the broad bar of white across the hinder part of its back. The under surface of the body is also white. The Sand Martin is a much smaller bird, mouse-coloured above and greyish-white below, and can scarcely be mistaken for either.

All these birds feed on small insects, which they catch in the air, snapping them up by hundreds as they dart swiftly to and fro. When they have little ones to feed they contrive to pack away wonderful quantities of these tiny victims in their mouths, and they must catch many thousands in the course of a single day.

The swallow builds an open nest of mud and straw, lined with feathers, placing it in a chimney, or an outhouse, or an old tower, or under the overhanging eaves of a house. It contains four or five white eggs, spotted with dark red, and there are two or even three broods in a season. The nest of the martin is nearly always built against the wall of a house, with the rim closely pressed against the eaves. It is made almost entirely of mud, and is cup-shaped, with a semi-circular hole in the side by way of an entrance. The eggs are pure white. The nest of the sand martin, however, is always placed at the end of a burrow, often two or three feet long, which the bird scoops out in the side of a sandy cliff. Large numbers of these burrows may be seen quite close together. The nest itself is little more than a handful of hay and feathers, and contains five or six pinkish white eggs. 


\section{CHAP'IER XXIV.}

PARROTS, PIGEONS, PEA-FOWL, PHEASANTS, ETC.

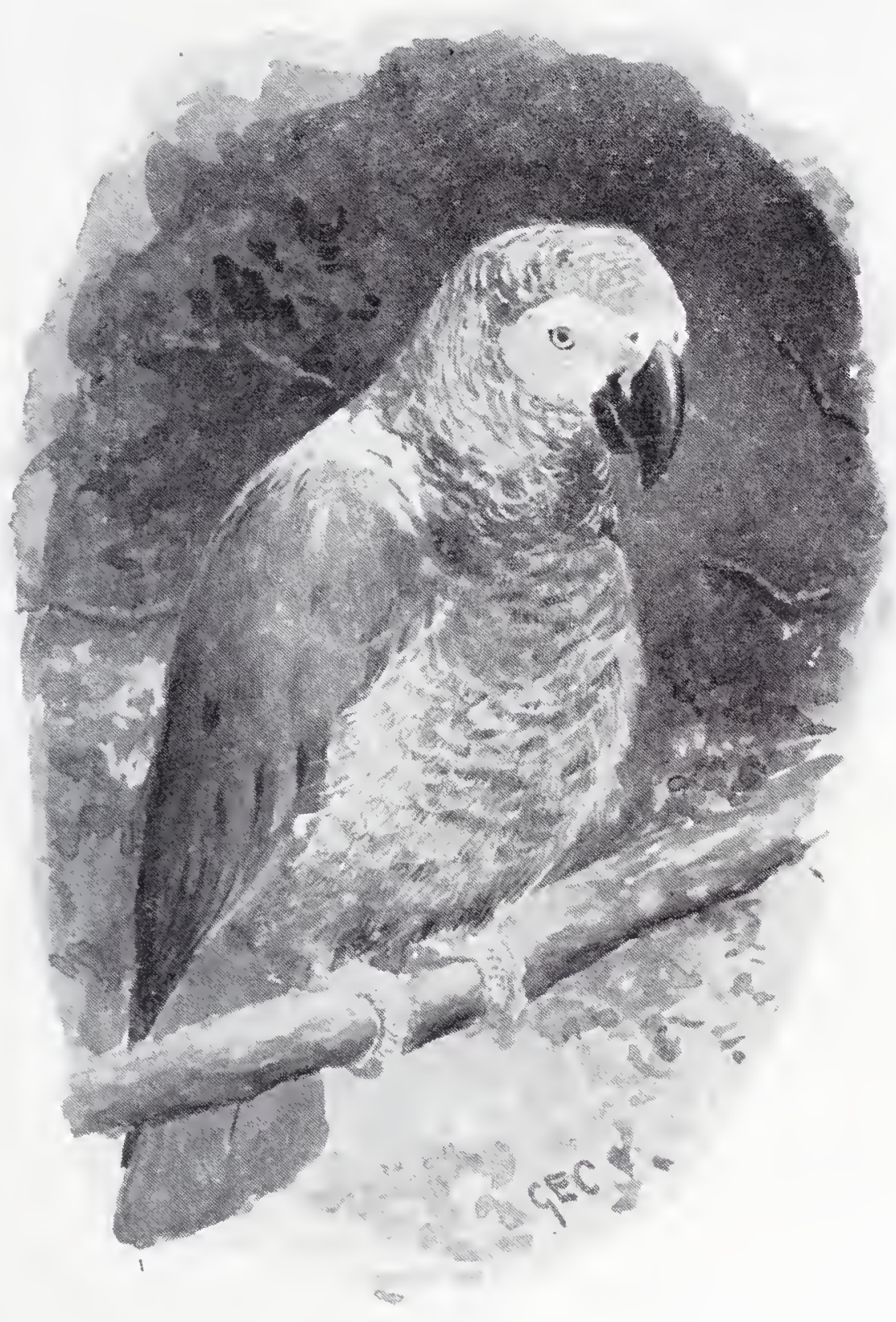

GREY PARROT.
THE members of the Parrot family are very interesting birds indeed; in the first place because they are generally so gaily coloured, in the second place because they are so easily tamed, and in the third place because many of them are such capital talkers. They nearly all spend the greater part of their lives in the trees, and if you look at their feet you will see that the first and fourth toes are turned backwards while the second and third are directed forwards. This gives the birds a great power of grasp, and helps them very much indeed in climbing.

At least five hundred different kinds of these birds have been discovered in different parts of the world, but I shall only he able to tell you about a very few of them. Let us take first a parrot, then a parrakeet, then a cockatoo, then a macaw, and then a love-bird.

The parrot shall be the Grey PARroT, because that is the one which we see most often in cages. It comes from Central Africa, and, like most parrots, is generally seen in large flocks, which fly about together. During the day time these birds often travel to long distances in search of food, which consists chiefly of fruits and nuts. But in the evening they always return to their regular roosting-places, just as rooks do in our own country. 


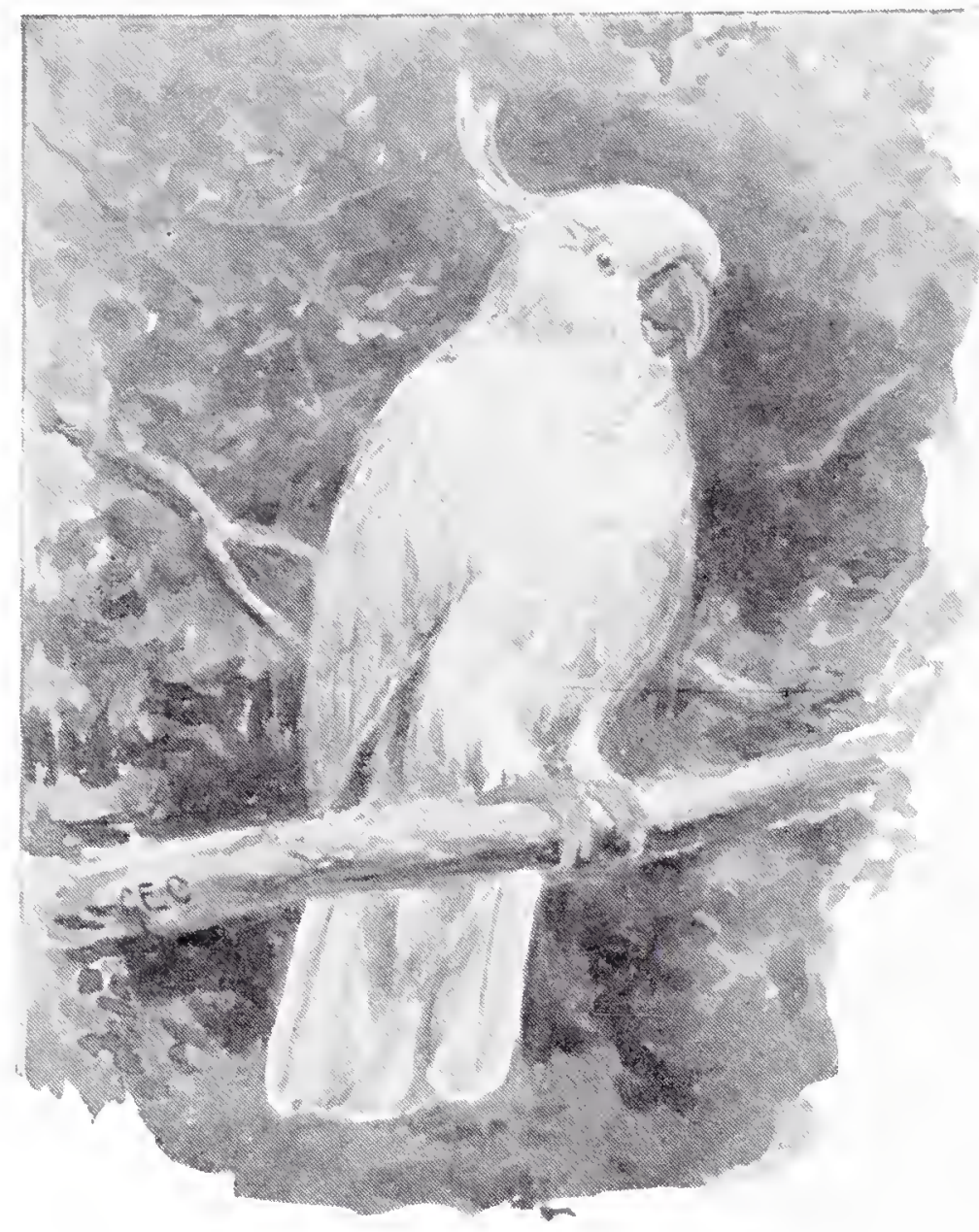

SULPHUR-CRESTED COCKATOO.

This parrot makes no nest at all, but just lays its eggs in a hole in the trunk of a tree. Both birds sit in turns, and if danger threatens they will defend their eggs or their little ones with the greatest courage. And if they seem to be getting the worst of the fight it is said that the rest of the flock will come to their rescue, and will nearly always succeed in driving the enemy away. When they are kept as pets grey parrots nearly always learn to talk well, and sometimes malie such suitable remarks that it really almost seems as if they must understand what they say. They live to a very great age, and it seems quite certain that they have sometimes been kept in captivity for seventy or eighty years.

Parrakeets are found in the hotter parts of Africa, Asia, and Australia, being very plentiful, for instance, in the forests of India. Perhaps the best-known of them is the Ring-necked Parrakent, which is green in colour, while the male has a red ring round his neck, with a black ring underneath it. The length of the bird is about seventeen inches, of which almost exactly half is taken up by the tail.

These parrakeets are dreadfully mischievous birds, for they visit both fields and gardens, and devour enormous quantities of grain and fruit. You can easily understand how much harm four or five hundred of them can do in a short time, and flocks of this size are often seen, while sometimes they are even larger still. They have regular roosting-places, just as parrots do, to which they always return at night; and they lay their three or four white eggs in holes in trees in just the same way.

Cockatoos may easily be recognised by their feathery crests, which they can raise and lower at will. We will take the SulphurCRested Cockatoo as our example.

This favourite cage bird comes from Australia, where it is found in enormous flocks. Fancy seeing a thousand cocliatoos 
flying about together! And fancy what it must be to listen to their screams! Yet a flock of this size is not at all uncommon. The birds are not as plentiful as they used to be, however, for they did so much mischief in the cornfields that the planters shot them in large numbers, just as we sometimes have to destroy sparrows in England. Very

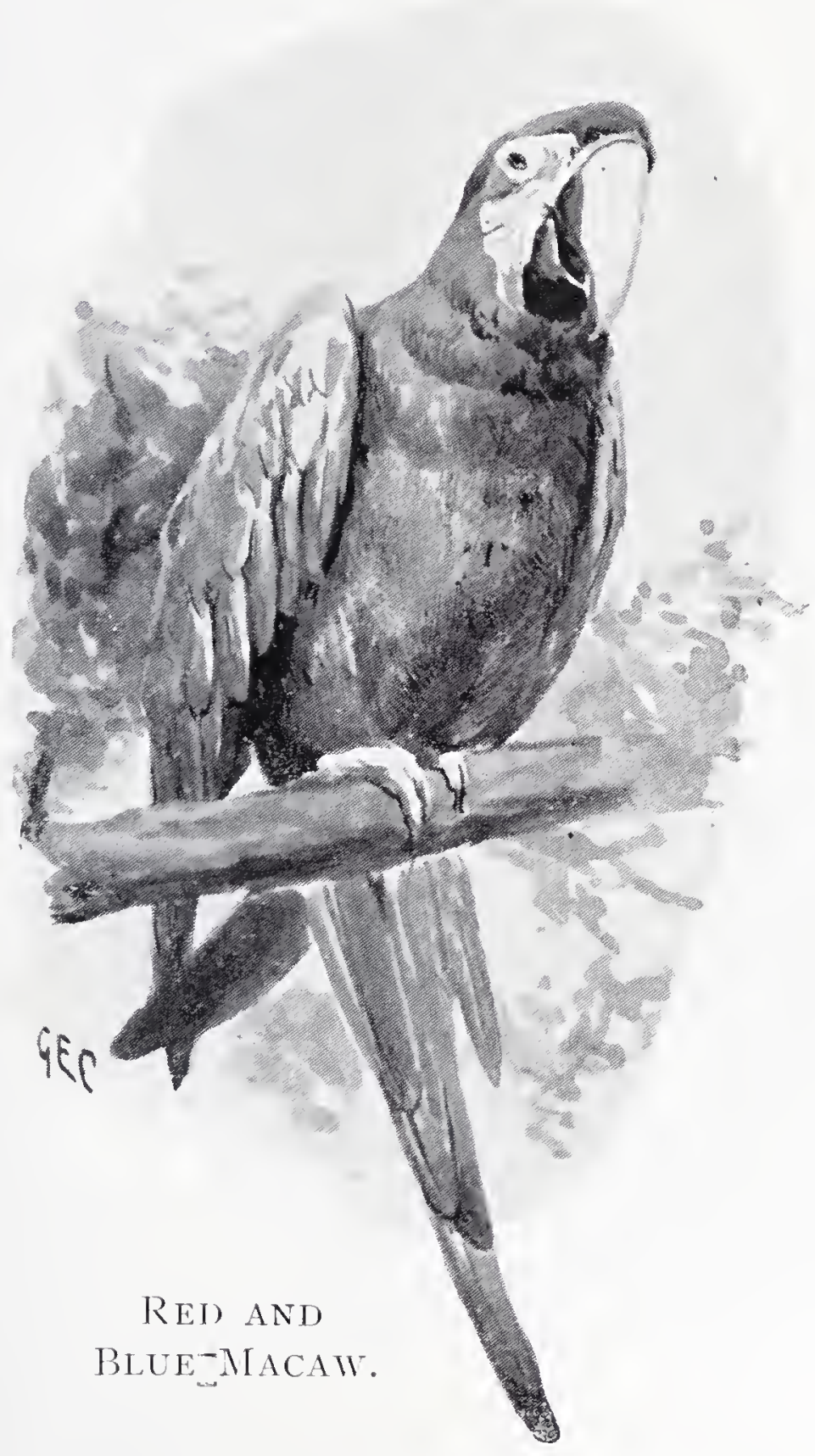
often, indeed, a field would be so full of cockatoos that from a little distance it looked just as though it were deeply covered with snow.

Cocliatoos are not nearly such clever talliers as parrots, but they soon learn to imitate all kinds of different sounds, such as the barking of dogs, the mewing of cats, the cackling of fowls, and the gobbling of turkeys. Unfortunately, however, they are very fond of screaming, and malie a most terrible outcry if they are annoyed in any way, so that they are apt to be rather a nuisance if they are liept as pets.

The Macaws are large and very handsome birds, their plumage being nearly always very brightly and even gaudily coloured. In the Red and Blue Macaw, for instance, which is one of the best linown, the general colour is bright vermilion red, with a patch of yellow feathers on the upper part of each wing. Then the lower part of the back, together with the quills of the wings and the outside feathers of the tail, is blue, while the central tail feathers are scarlet with blue tips. But even this is not all, for underneath the wings and tail are golden red, varied by patches of yellow feathers tipped with green. This magnificent bird is nearly three feet long, no less than two-thirds of that length being occupied by the tail.

Macaws are found in large flocks in the great forests of tropical America, where they may be seen sometimes flying high in air, and sometimes sitting on the topmost branches of the tallest 
trees. Their cries are perfectly deafening, and can be heard from a very long distance away.

Macaws are just as mischievous in the cornfields as parrots and cockatoos are in other parts of the world, and are much more difficult to lill; for before they settle down to feed they always post a sentinel in the very top of a tall tree, whose duty it is to give the alarm as soon as he sees the very slightest sign of danger. And he is so sharp-sighted that it is almost impossible for anyone to approach within gun-shot without hearing a loud cry of warning, and seeing all the gaily-hued robbers flying away.

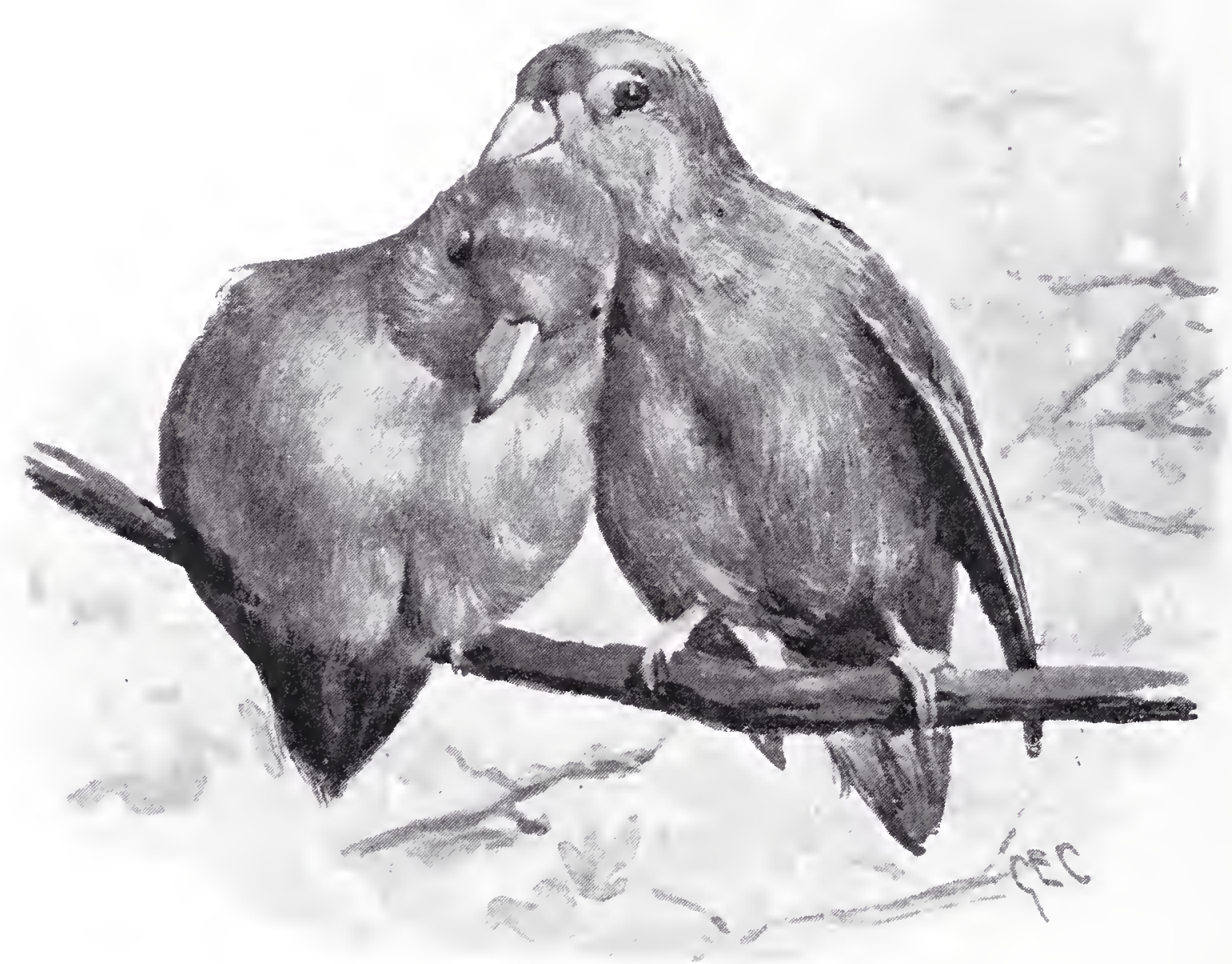

LOVE BIRDS.

Macaws lay their eggs:in holes in tree-trunks, just as parrots do, and are said to enlarge them to suit their requirements by means of their powerful beaks. They are not very clever birds, for when they are sitting they often leave their long tails projecting out of the hole, to be seen by every passer-by!

Of all the birds which belong to the Parrot family the Love Birds are the smallest, being very little bigger than finches. Seven different kinds are known, which are all found in Africa south of the Desert of Sahara.

These pretty little creatures are called "love birds" because they seem so very fond of one another. If two or three are liept 
in a cage together they always snuggle up as closely as possible, and will sit side by side for hours, perfectly happy in each other's company. And very often, if one of a couple dies, the other will pine away in a very short time and die too, apparently from sorrow.

But just now and then love-birds are very quarrelsome creatures, and cases have been linown in which they spent most of their time in fighting!

In a wild state love birds are generally seen in small flocks, which fly very rapidly, and constantly utter their sharp screaming cry. 'They do not seem to make any nests for themselves, but

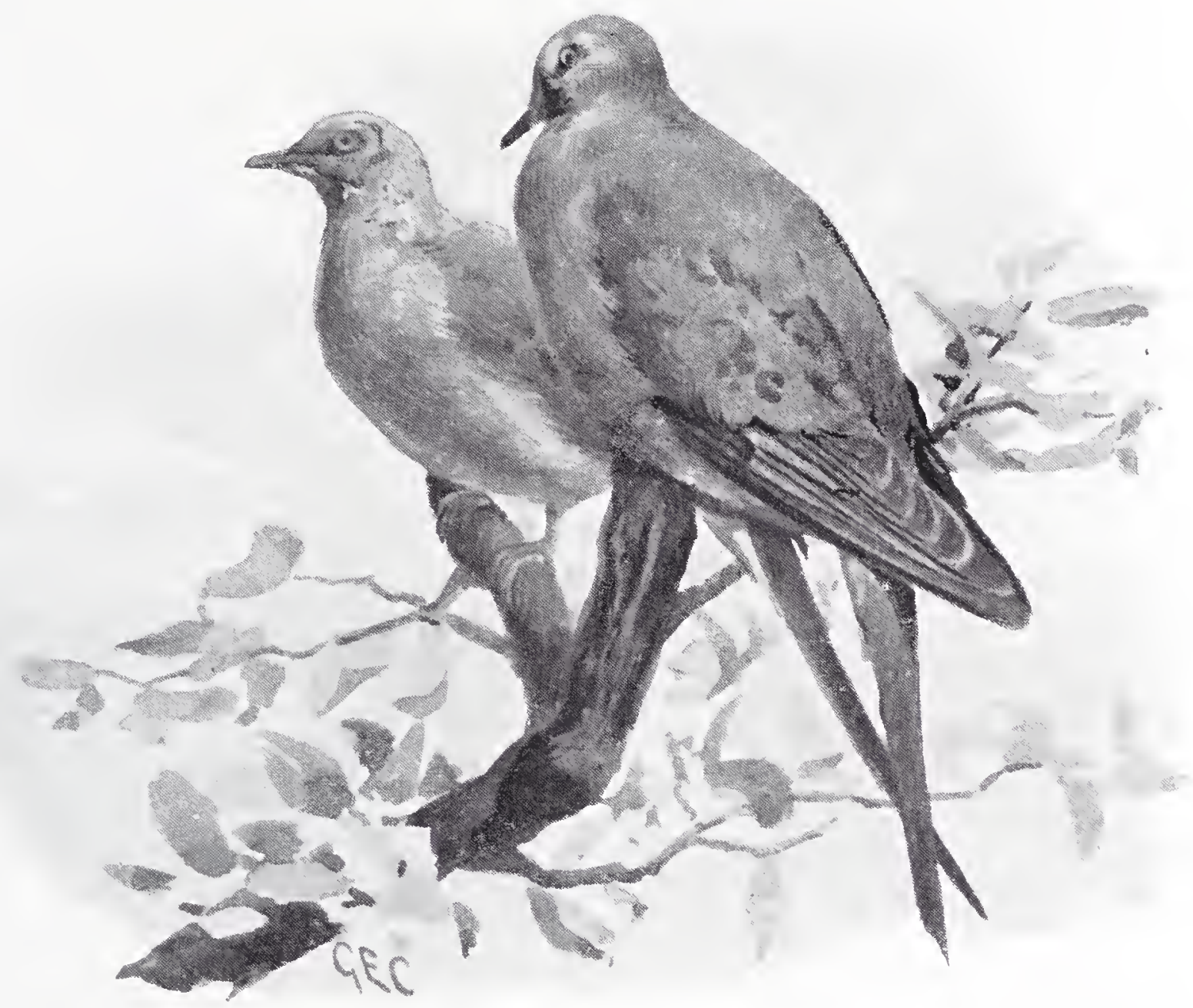

Passenger Pigeons.

make use of those of other birds instead. Whether they turn out the rightful owners, however, or merely talie possession of nests which have been deserted, nobody quite seems to know.

I shall only be able to tell you about two members of the great Pigeon family, the first of which shall be the Wood Pigeon, or Ring Dove.

This is a very common bird in almost all parts of the British Islands, and one can scarcely walk through a wood without startling it from its retreat in the thick foliage of some tall tree, or ramble through the fields without seeing at least one flock on 
its way to its feeding grounds. Unfortunately, it does a good deal of mischief, for it has a most enormous appetite, and carries off immense quantities of grain from the corn-fields. Just to give you some idea of the amount of food that it will eat, I may mention that no less than eight hundred grains of corn have been taken from the crop of a single wood-pigeon, six hundred peas from that of another, and one hundred and eighty beech nuts from that of a third; while one naturalist tells us that the bird will sometimes pack away sufficient turnip-tops to fill a pint measure when they are well shaken up!

On the other hand, however, the wood-pigeon devours great quantities of the seeds of weeds; so although it is mischievous in one way, it is useful in another.

The nest of the wood-pigeon, which is mostly placed in the upper branches of a tall tree, is very clumsily made. Indeed, it is very little more than a platform of sticlss, which are often so loosely put together, that as you look up from below you can see the eggs through the gaps between them! There are never more than two eggs, which are perfectly white.

The Passenger Pigeon, which is found in North America, is remarkable for two reasons.

In the first place, it is found in the most astonishing numbers. Flocks of these birds, many miles in length, have often been seen, while large tracts of forest are sometimes so thronged with their nests that all the smaller branches are destroyed, and many even of the larger ones are broken down. Just fancy what it means when a nesting-place is thirty miles long and several miles broad, while as many as a hundred nests may be found in a single tree!

And then, in the second place, the bird is renowned as a traveller. That is why it is called the "passenger" pigeon. All over the length and breadth of the country these vast flocks fly, coming no man knows whence, going no man knows whither, roosting just for one night in one place, and passing on again early next morning. The floclis are not so large as they were, however, for many millions of the birds have been destroyed; and as these pigeons never lay more than two eggs, they do not multiply very fast. But still they often appear in vast numbers, and the noise which they make as they fly overhead is so great, that a man cannot make himself heard without shouting at the very top of his voice.

What a magnificent bird the PEAcock is, with his great train raised and spread, so as to show off all the beautiful eye-like markings! And how very proud of it he is, as he struts about to be admired, knowing quite well that everybody is looking at him!

People sometimes speak of this train as the "tail." But it really consists of those feathers which are called the "tail coverts," the true tail lying underneath it, and serving to support it when it is spread. 
Peacocks are natives of Asia, and are found most commonly, perhaps, in India, where flocks of thirty or forty may often be seen. And one traveller tells us that he once sav quite fifteen hundred of these splendid birds all together! They are sometimes caught in a very curious way. The hunter rides up quietly to within a short distance of them as they are feeding on the ground, and then suddenly dashes at them at full speed. Of course they at once rise into the air, and just as they are passing out of reach he strikes at one of them with a very long whip, which coils round its neck like a lasso. Then all that he has to do is to pull it down to the ground.

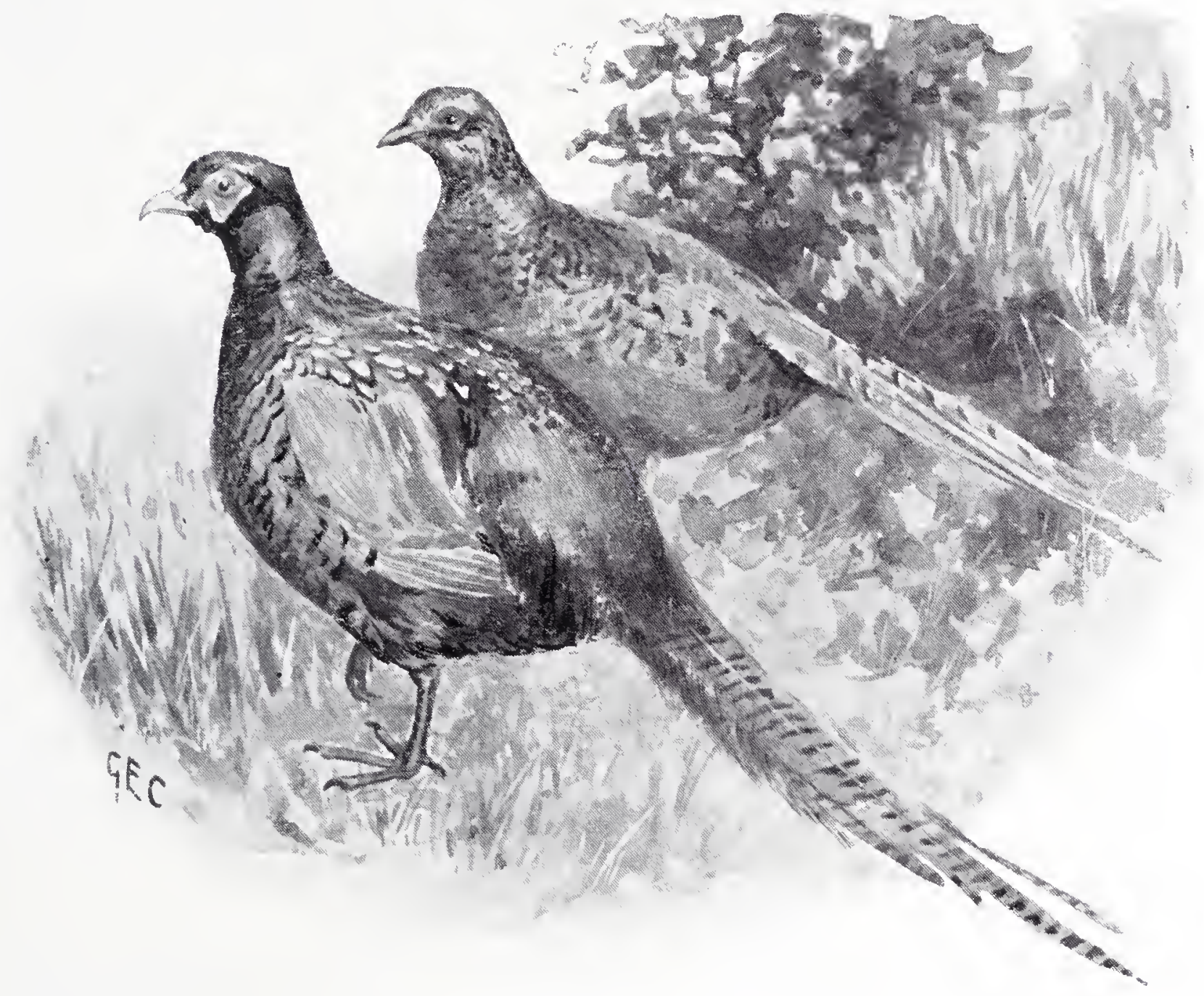

PHEASANTS.

In some parts of India, however, these birds are regarded by the natives as sacred, and no one is allowed to kill them, or even to take them alive.

Everybody takes an interest in the TURKEY-more especially at Christmas time! - and a good many people think that it comes from the country of Turkey. This, hovever, is quite a mistake, for it is a native of North America, in many parts of which it is still found in great abundance. In the autumn, indeed, it is not at all uncommon for a flock of eighty or a hundred turkeys to be seen feeding together. 
Some of these flocks seem to consist of cock-birds only, and others of hens and young, the reason being that the coclis are very fierce and quarrelsome birds, and will attack and even kill the young ones if they have an opportunity. Until long after her little ones are fledged, indeed, the mother turkey has to take the greatest care of them; for not only are they in constant danger from their unnatural father, but all kinds of other enemies, such as lynxes and horned owls, have to be guarded against as well. So she keeps them nearly always under cover, and when at last they are big enough to be taken for a little ramble, she never brings them back to the nest by the path by which they left it.

Turkeys often travel for very long distances. When they come to a river they perch in the upper branches of the tallest

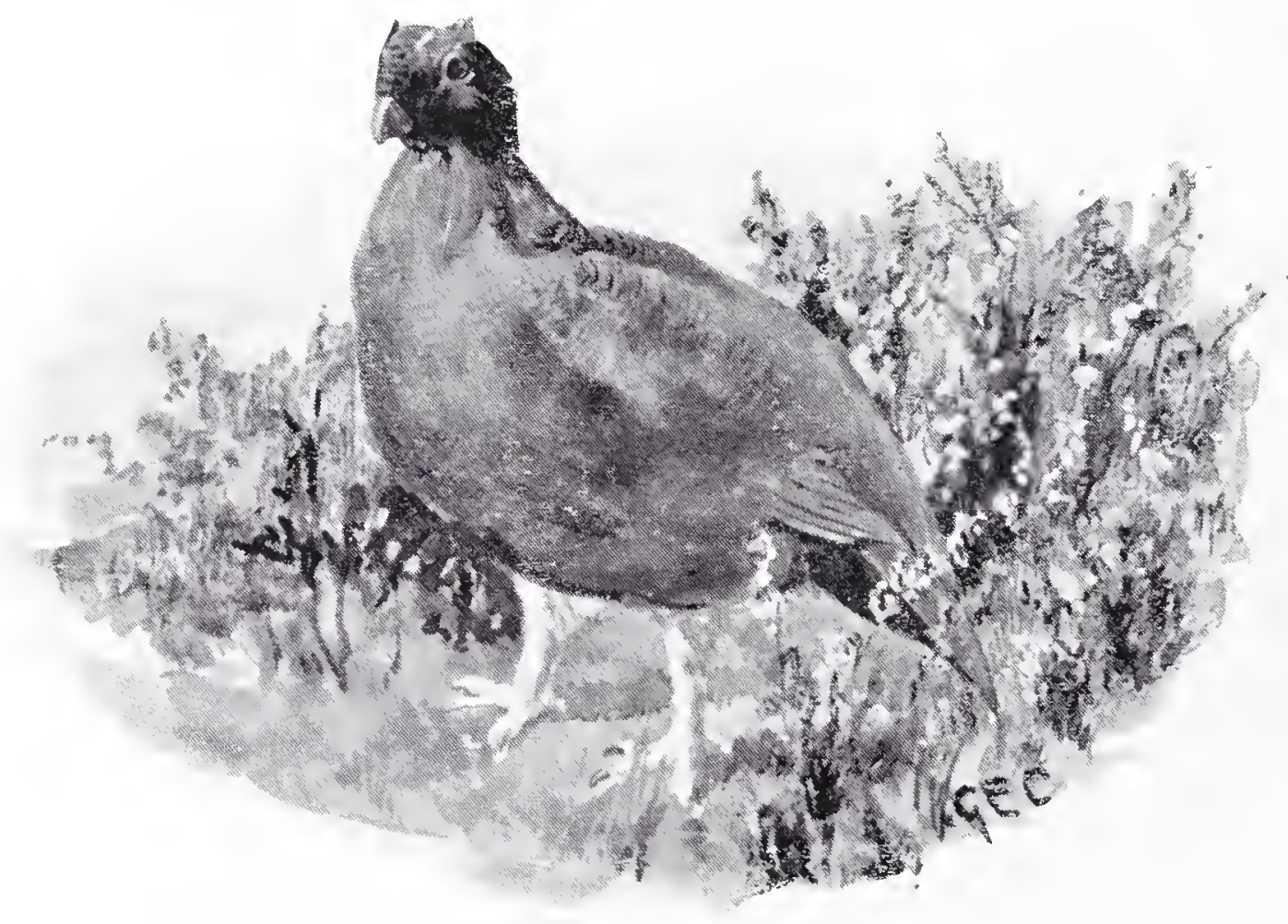

RED Grouse.

trees they can find, and then fly across together at a given signal. They are not very strong on the wing, and some of them nearly always manage to fall into the water. But by spreading out their tails and paddling hard they generally manage to make their way to shore.

The Pheasant is a native of south-eastern Europe and Asia Minor; but it has lived in our own country for so long that it is fully entitled to rank among our British birds. It has so many enemies, however, that if it were not carefully "preserved" it would very soon disappear.

Pheasants nearly always live in woods, though they often venture out into the open fields to search for food, which consists of acorns, grain, beech-mast, seeds, and small insects. During the 
winter, however, they have to be fed, or they would be very likely indeed to die from starvation.

These birds do not make a regular nest, the hen merely scratching a slight hollow in the ground, and there laying her ten to fourteen olive-brown eggs. When she is sitting it is very difficult to see her, for her light-brown mottled plumage looks just like the dead leaves among which she is resting, and even the sharpest eye might often pass her by.

The RED GRouse is remarkable for tivo reasons. The first is, that it is found only in the British Islands, and not in any other part of the world; and the second is, that it varies so very greatly in colour. Sometimes it is almost entirely black, sometimes

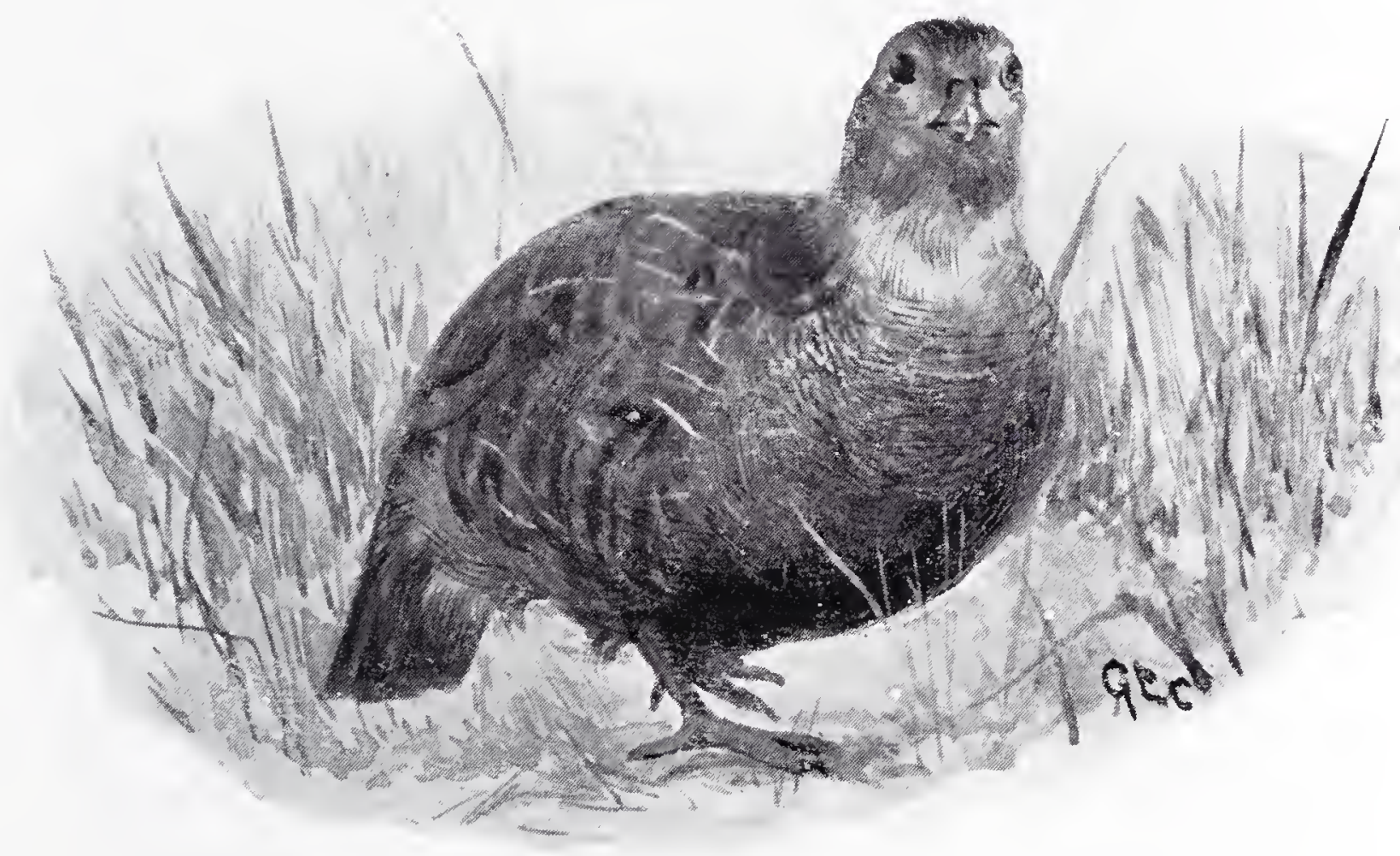

PARTRIDGE.

it is reddish chestnut, and sometimes nearly all the feathers are broadly tipped with white.

This bird is found on moors and mountain-sides wherever there is plenty of heath or heather, and where it can obtain the whortleberries, cranberries, and tender shoots of cotton-grass and sedge upon which it feeds. And though it has many natural enemies, such as hawks, and crows, and foxes, and stoats, while it is shot in thousands by sportsmen, it never seems to decrease in abundance.

As a general rule the grouse does not fly much, but runs with great swiftness among the heather. It makes a very rough nest of straws and twigs in a hollow in the ground, and often sits so closely on its eggs that it may almost be trodden on before it 
will move. When the little ones are hatched they seem to know without being taught how to conceal themselves in moments of danger, and if they cannot find cover will flatten themselves against the ground and look just like stones, so that even the sharp eye of a hawk or a hooded crow will pass them by.

PARTRIDGES, of course, are found almost everywhere, being carefully protected for purposes of sport; and they lay so many eggs that they are scarcely likely to become less plentiful. Very fer nests, indeed, contain less than ten eggs, while fifteen or even

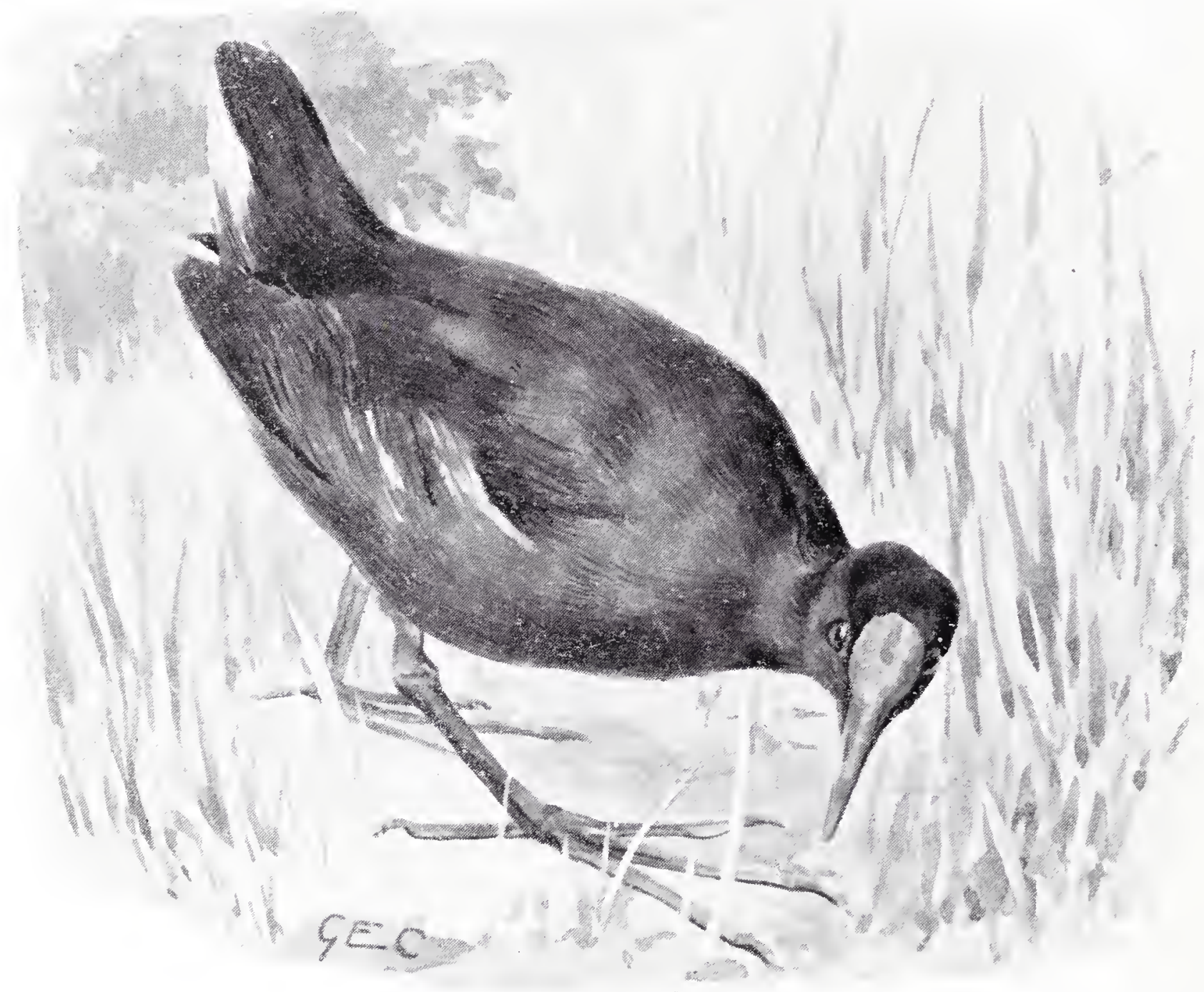

MOOR-HEN.

more are frequently laid; and instances have been recorded in which as many as thirty-three eggs have been found in a single nest. But in these cases two birds have most likely laid together. 'The mother bird sits very closely-so closely, indeed, that when she has nested in a meadow and the grass is being mown, she often fails to move out of the way of the scythe in time, and is found lying on the ground with her head cut off after the reapers have passed by.

When the little ones are hatched, both parents go about with them, and the "covey," as it is called, keeps together all through the autumn and winter. 
Partridges are very fond of feeding upon ants, and when they find a nest of these insects they will scratch it all to pieces and devour not only the ants themselves, but their grubs and pupx as well. But they also feed on seeds and grain, and are sometimes said to do a good deal of mischief in the cornfields.

Three of the Rails must be briefly mentioned.

The first of these is the LAND RaIL, or Corn Crake, which is a summer visitor to our British Islands. You must often have heard its harsh, grating cry, which you can easily imitate by

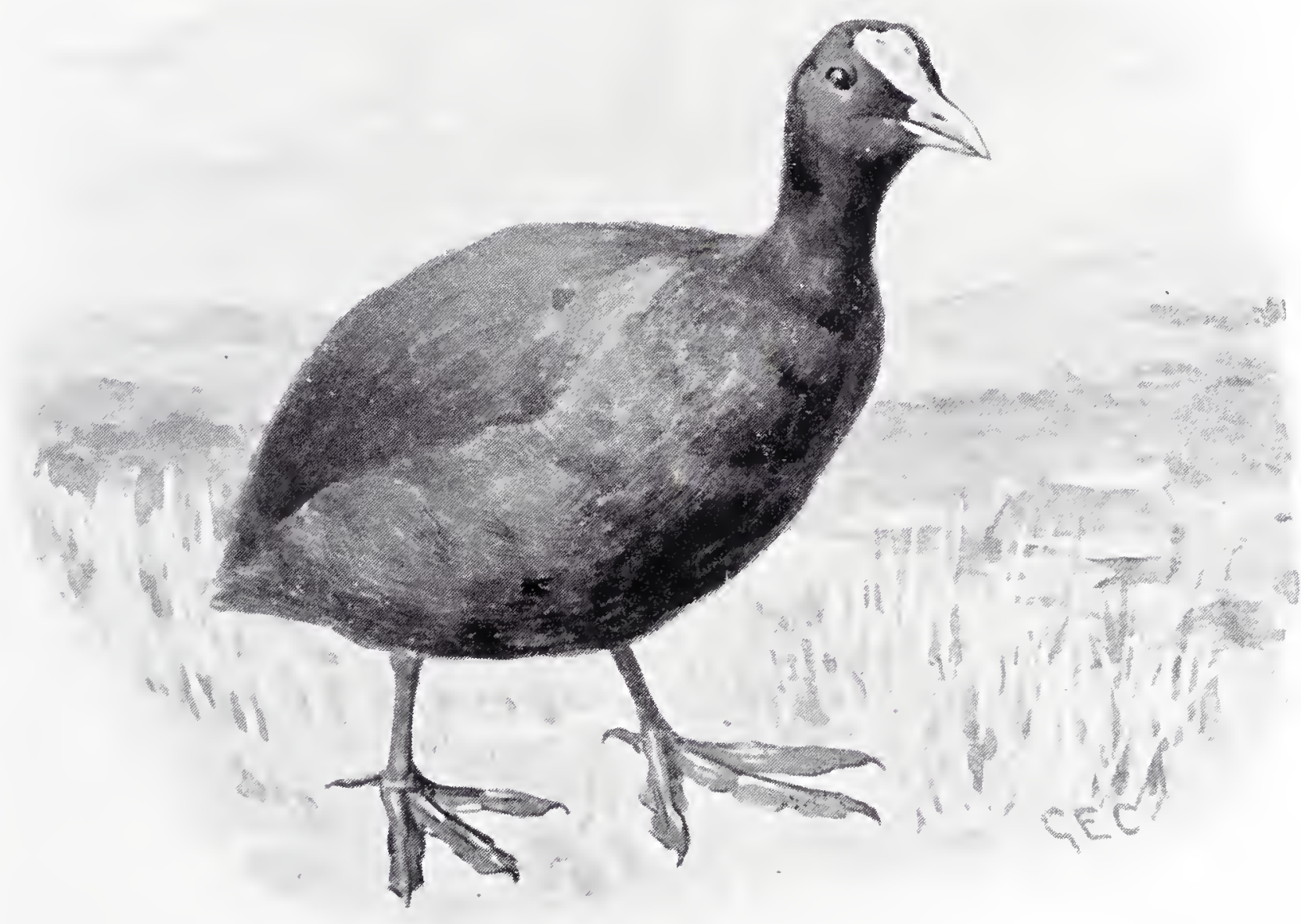

Coot.

drawing a piece of stick sharply across the larger teeth of a comb. And the odd thing is that although the cry is so loud and distinct, you can never tell whereabouts the bird is. It may seem to be exactly in front; but if you walli towards it, you will find that it is far away to one side, or even behind you. The fact is, that the corn crake runs with very great swiftness, threading its way through the herbage in the most wonderful way; and as soon as it hears you coming it rushes away, and then croaks loudly just as if it were laughing at you!

The corn crake hardly ever uses its wings, and is so fond of keeping under cover that many people who have been familiar 
with its note all their lives have never once seen it. The nest is placed in a hollow in the ground, and consists merely of a few straws or grass-stems, among which the bircl lays from eight to twelve yellowish-brown eggs spotted and speckled with greyish-red.

Next comes the Moor-Hen, or WVater-hen, which you may see swimming about in almost any river or lake, or pond, with an odd, jerky motion, and every now and then giving a little dip with its head. If it catches sight of you it will disappear at once, either seeking refuge among the reeds, or else diving under water and clinging to the herbage at the bottom until it thinks that you have gone away again. While it is diving it generally keeps just the tip of its beak above the surface, so as to be able to breathe.

The nest of the moor-hen is very large for the size of the bird, and is generally built in the branches of a bush which overhangs the water, or else on some little island among the reeds. It is made of sticks, sedge, and leaves, and the mother bird has an odd habit of covering up her eggs with rushes and other waterweeds when she leaves the nest for a little while. Most likely she does this to protect them from magpies and crows. The young birds are able to swim almost as soon as they are hatched, and you may often see them paddling about with their mother, and looking like little fluffy balls of black down.

Lastly there is the CooT, which in some ways is very much like the moor-hen. But you can easily tell it by the white patch just above the base of the beak, which can easily be seen from some little distance. During the nesting season, however, this patch becomes rosy red. Then its feet are quite different from those of the moor-hen, for although the toes are not joined together by membrane, like those of the duck and the other swimming birds, each toe has a web of its own, spreading out on either side. So, you see, its feet make capital paddles, while at the same time the bird is able easily to perch upon a bough.

The nest of the coot is made of dead rushes, often mingled with marsh-marigold stalks, and is built among reeds, or among the twigs of a bough that juts out into the water. When there is a flood the nest is sometimes swept from its support and carried floating away. But the coot does not mind in the least, and continues to sit as before, while somehow or other the water never seems to get in. There are generally about eight eggs, which are light brown or yellowish-grey in colour, marked with a number of small dots of brownish-black. 


\section{CHAPTER XXV.}

OSTRICHES, HERONS, CRANES, IBISES, ETC.

THE OsTRICH is a very remarkable bird indeed.
In the first place, it is by far the largest of for a fully-grown male ostrich is taller than a very tall man. Then its head is like that of a camel, and its neck like that of a giraffe-very long indeed, and very slender, with scarcely any feathers upon it. Next, its wings are so small that they cannot be used for flight. All that an ostrich does with its wings, indeed, is to spread them out when it is running, so that they may help it in keeping its balance. And, finally, its legs are as stout and as strong as those of a horse, while it has only two toes on each foot.

Ostriches live in the great desert plains of Africa, where they are mostly found in small flocks. Although they cannot fly, they can run with very great speed, and in fair chase will distance even a swift horse. But for some strange reason they always run in circles, so that all that a hunter has to do is to notice whether they are swerving to the right or to the left, and then to gallop across and cut them off.

When an ostrich is running at full speed it takes most wonderful strides, its toes scarcely touching the ground as it dashes along. By careful measurement, indeed, it has been found that there is sometimes a distance of no less than twenty-eight feet between its footmarks!

The ostrich is rather a formidable bird, for it can kick with terrific force. But if a man lies down he is fairly safe, for the kick cannot be properly delivered at a height of less than three feet. Or if he has a forked stick he can hold the bird back by pressing the fork against its neck.

Of course you have often seen ostriches' eggs, which are so large that one of them will make a good meal for eight men. The bird does not make a nest, but scoops out a hollow in the sand about three feet across and a foot deep, and then arranges its eggs in it, each egg standing upright, and being lightly covered with sand. Twenty eggs or more are often hatched together, and in addition to these the bird generally lays a number round the edges of the hole, which appear to serve as food for the young. During the day the hen sits, the cock taking her place by night.

The appetite of the ostrich is proverbial, and it would really be difficult to say what an ostrich will not swallow. Stones, coins, bunches of lieys, tobacco-pipes, newspapers done up for post, brickbats, old shoes, and tenpenny nails have all been taken from its crop; and it seems to be very seldom indeed that any of these 
things disagree with it! Its natural food, however, consists chiefly of wild melons, which also supply it with all the moisture that it needs.

Ostriches are very valuable to man, on account of the beautiful plumes which are obtained from the male. These birds are therefore kept in great numbers in "ostrich farms," so that the plumes may be regularly cut once in every year.

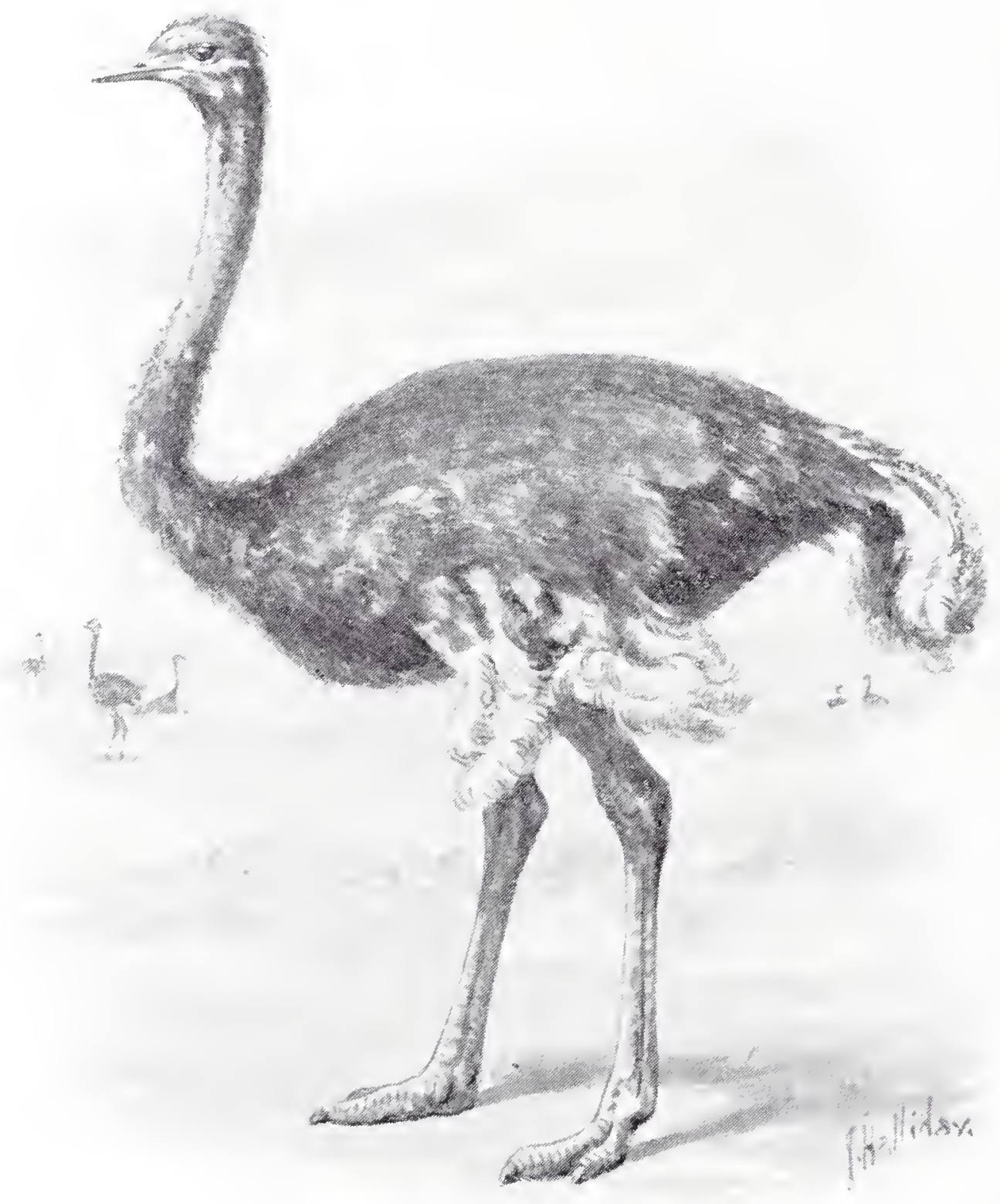

OیTRICH.

In Australia the place of the ostrich is taken by the Eneu. It is a smaller bird, however, though a fully-grown hen-which is bigger than the cock-is often six feet in height. And it has three toes upon each foot instead of two.

Emeus were formerly very common indeed in many parts of Australia, but they have been so terribly persecuted that they are fast becoming exceedingly scarce. They are generally hunted with dogs, which are trained to spring at their necks, so as to be 
out of reach of their terrible feet. For emeus do not lick forwards, as ostriches do, but strike sideways and backwards, like a cow.

The emeu only lays six or seven eggs, which are of a beautiful dark green colour, without any marlings at all. They are laid in a hollow scooped in the ground. During the nesting season the female bird utters a loud booming sound, which is due to a very curious pouch in the throat.

There are also several ostrich-like birds in South America, which are known as Rheas. They are not nearly so large as ostriches and emeus but are quite as swift of foot, so that it is

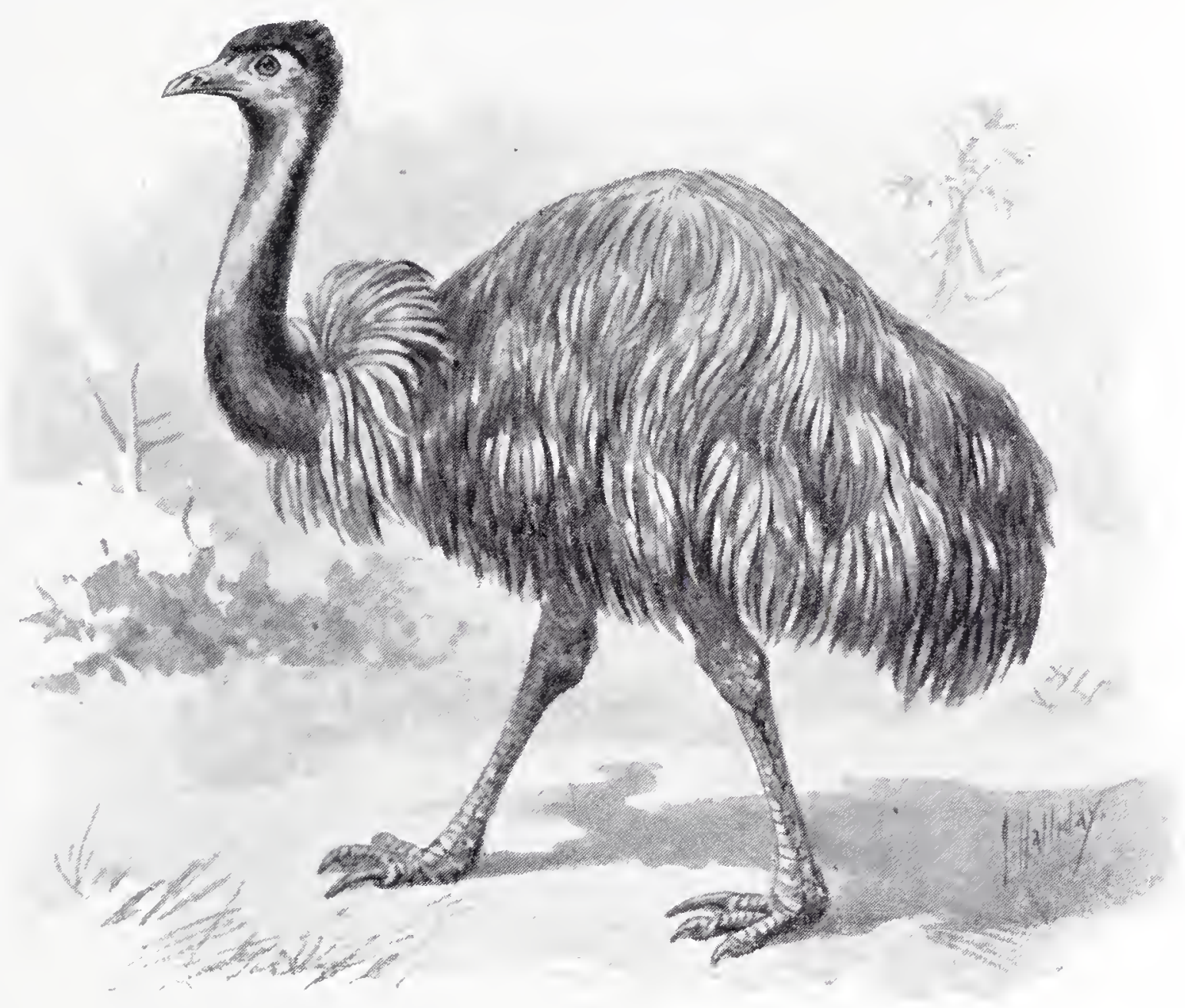

EMEU.

not at all easy for a man mounted on even a fast horse to overtake them. They are generally hunted with the "bolas," which is a long cord with a heavy ball at each end, and is flung at the bird in such a manner as to wind round its neck and hold it prisoner.

Rheas always lay their eggs in hollows in the ground, and the number of eggs in a nest seems to vary from twenty to twentyfour. The male bird, apparently, sits upon them, the hen taking no part in the task of hatching them out. Neither does she seem to take any care of the little birds when at last they make their appearance, for they always travel about with the cock.

Next we come to the Cassowaries, of which there are a 
good many kinds. They are formed like ostriches and emeus, but have shorter neckis, which are sometimes wattled and are marked with patches of brilliant red and blue and green. The legs are stout and the feet are perfectly enormous. But their most striking feature is the odd bony crest upon the top of the head, which is covered with naked skin.

Cassowaries are found only in Austratia, New Guinea, Ceram, and some of the neighbouring istands, and, unlike all the preceding birds, are dwellers in the forest. And they are so shy that they are very seldom seen, so that we do not know very much about their habits. The Australian natives, however, often keep them in captivity, and treat them ahmost as we treat poultry. But they are rather dangerous creatures, for they can kick very hard with their great, strong feet, and are very ready to attack anyone who is a stranger to them.

Cassowaries only lay from three to five eggs, and it seems that the cock bird alone sits on them, and that he also takes care of the little ones after they are hatched.

More curious still are the Krwis of New Zealand, whose wings are so very small, and so completely concealed under the feathers of the body, that practically they may be said to have none at all. Besides this, the beak is so long and slender that it reminds one of that of a woodcock or a snipe. The nostrils are placed at the very tip of this beak, and the bird appears to use it by plunging it deeply into soft ground, and then smelling for worms.

When it finds a worm it seems to coax rather than to pull it out of the ground, and then throws up its head and swallows it whole.

Kiwis have several times been brought to the Zoo, but hardly anyone ever saw them, for all day long they were fast asleep amongst their straw. If the keeper took them out and woke them they would just yawn once or twice, opening their beaks to the widest possible extent, and then fall fast asleep again.

After dark, however, these birds become very lively, and will run with such speed that even a dog can scarcely overtake them.

The egg of the kiwi is enormously large. Indeed, it is almost a quarter of the size of the bird itself, and when two eggs have been laid and the bird is sitting on them, the ends project beyond the feathers on either side of its body.

The Bustards, also, are able to run very well, although, unlike the birds belonging to the ostrich family, they are also able to fly.

The finest of these birds is the Great Bustard, which until about the year I 840 was found wild in Great Britain. The cock stands between three and four feet in height, and the head and body together are nearly four feet long, while when the wings are 
fully spread they measure quite eight feet from tip to tip. The hen is a good deal smaller.

The great bustard lives in wild, open plains, and is so extremely wary that it is almost impossible to approach within gun-shot. Except during the nesting season it is found in small flocks, and both by day and by night two of the party act as sentinels and stand always on the watch, ready to give the alarm

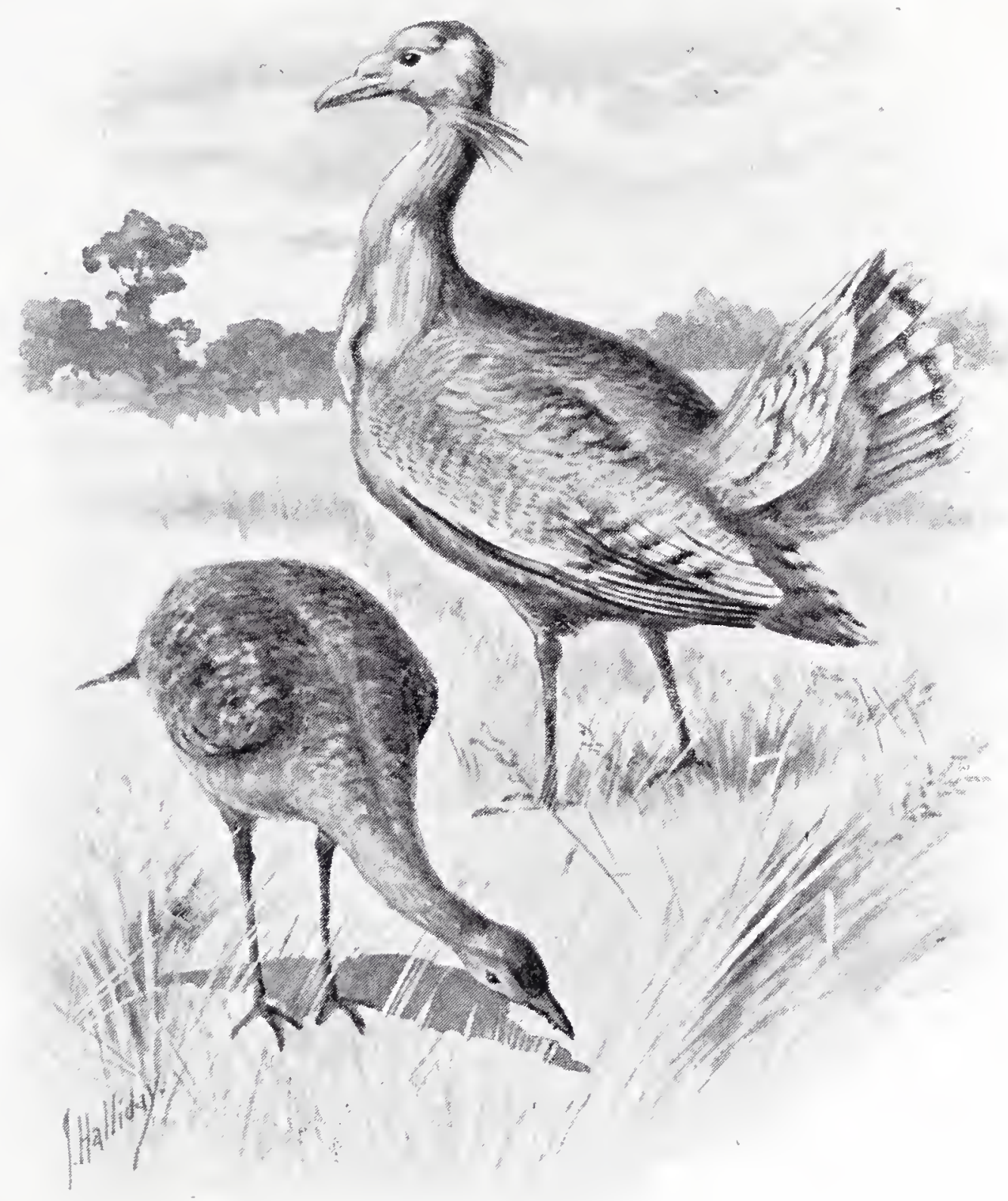

GREAT Bustarins.

at the very first sign of danger. They have most wonderfully sharp sight, and will detect a man long before they can be seen by him. Almost the only way to shoot them, indeed, is to dig a pit in the ground and hide inside it, covered over with branches, until they pass by.

These magnificent birds are now found chiefly in the steppes of Eastern Europe and Asia, where they feed upon seeds and grain, and also upon insects and even upon small animals. They 
lay two or three eggs in a hollow in the ground, in which sometimes, but not always, they place a few grass-stems by way of a nest.

The cock bustard can easily be distinguished from the hen, not only by its greater size, but also by the tuft of feathery hairs which grow on either side of the beak, and looks just like a moustache.

Another bird which was formerly an inhabitant of the British Islands, but is now only a very occasional visitor indeed,

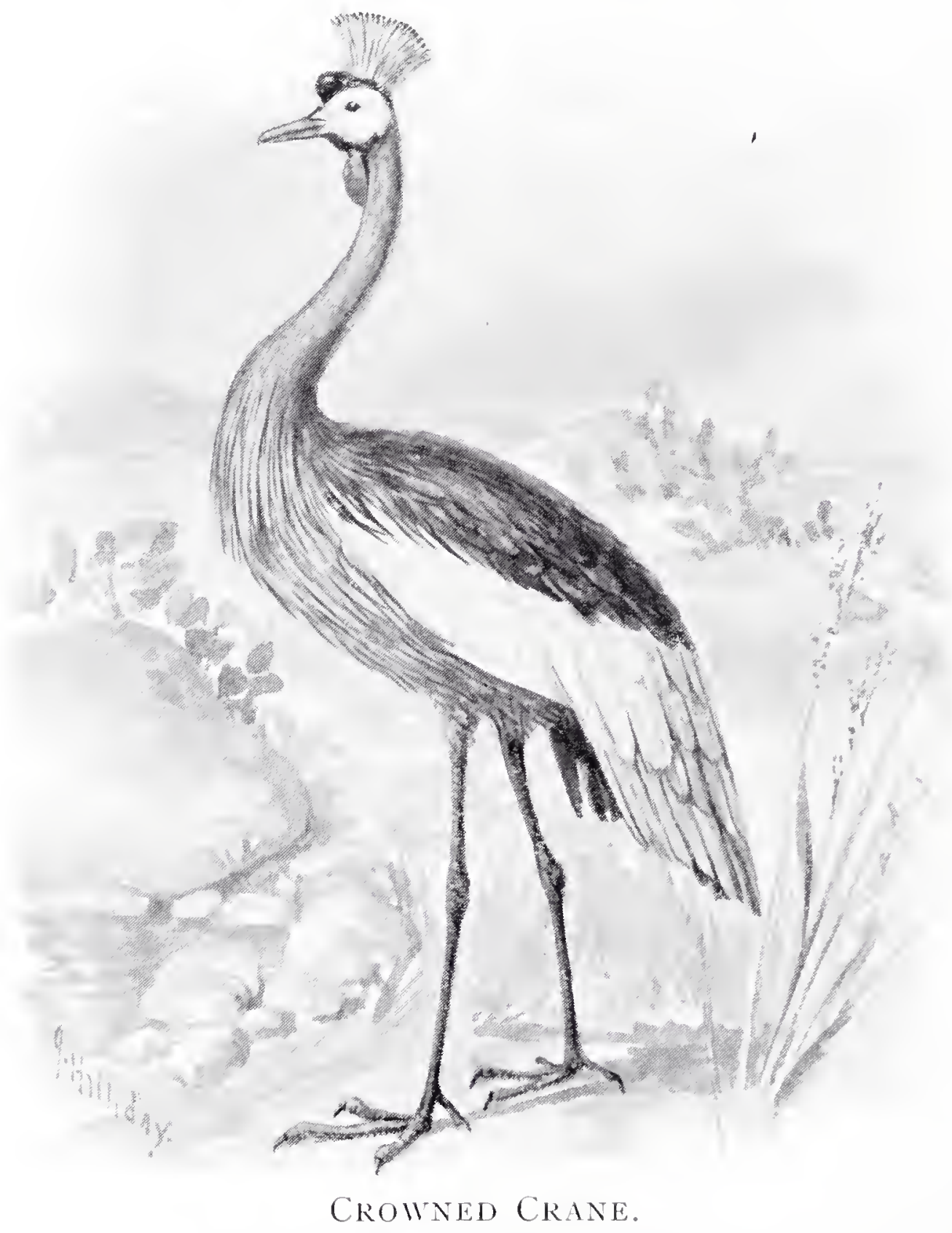

is the Crane. It is found in many parts of Europe, however, and is plentiful in Central and Northern Asia, coming north to breed, and retiring southwards again during the winter.

Cranes generally travel about in flocks, which nearly always fly in the form of a wedge, each bird having its long legs stretched stiffly out behind it. Each flock is under the guidance of a leader, whose orders are given in some mysterious way, and are instantly obeyed by all his followers. And the birds are most careful, when 
they alight, to do so in some open place where they can see for a long distance in every direction, so as to guard against the danger of being surprised by an enemy.

Cranes are generally to be seen in marshy districts, where they can find plenty of frogs, newts and worms. But sometimes they will make their way to a newly-sown cornfield and dig up all the grain. Their nests are generally placed on the ground, among osiers or in reed beds, though now and then they will build on the very top of an old ruin.

The Crowned Crane, which is found in Northern and Western Africa, is a very odd-looking bird, for it has a large bunch of upright golden feathers on the top of its head, and a scarlet wattle on the throat. From a little distance, indeed, it really looks as if it were wearing a bright yellow bonnet, tied with a bow of scarlet ribbon underneath its chin!

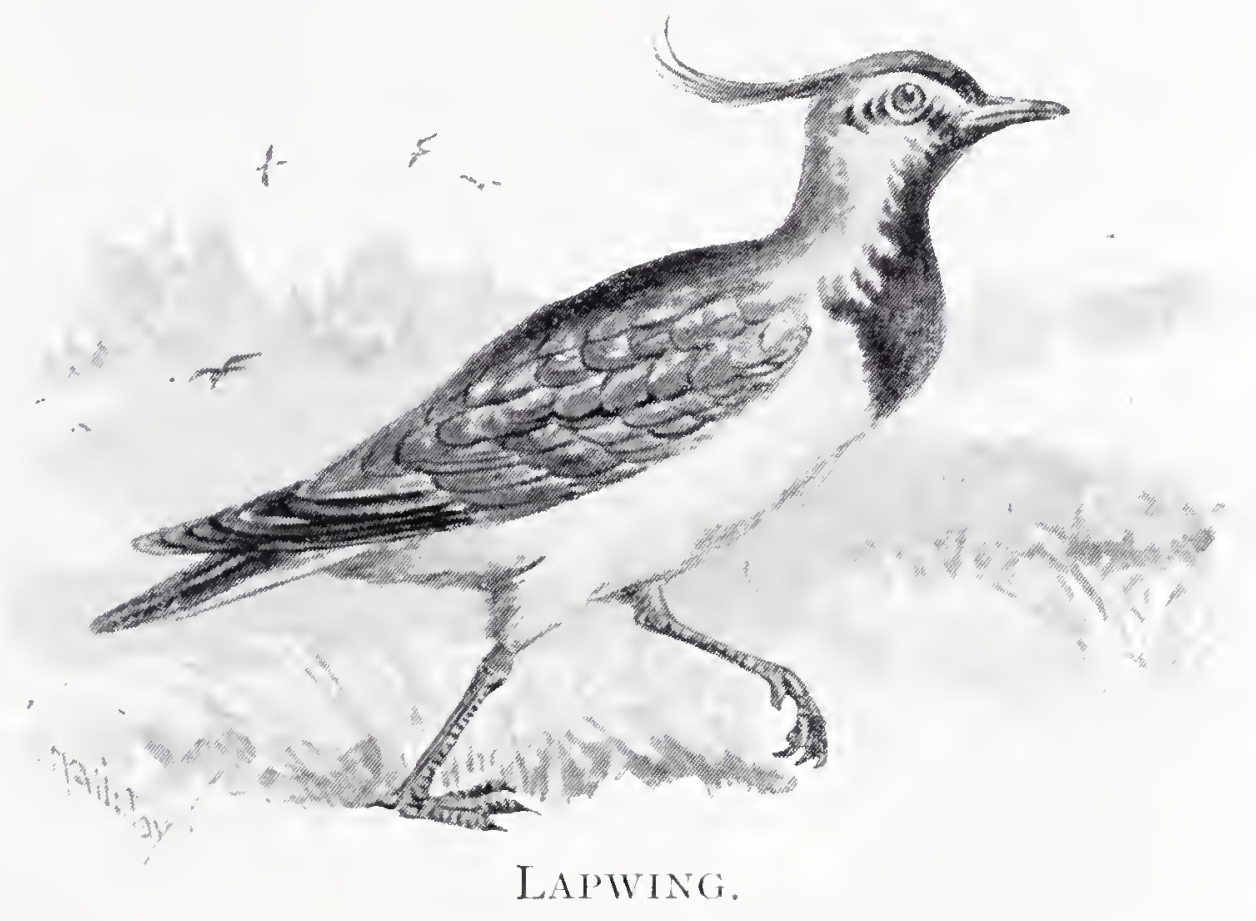

No doubt you have often seen Lapwings flying slowly to and fro over downs or marshy commons, and uttering their mournful cry of "pee-wit, pee-wit," as they do so. 'They are beautiful birds with their black and white plumage and the tuft of long feathers at the back of the head, and very often one may see hundreds, or even thousands, of them together. And early in the spring one may find their four long, pointed eggs, which are olive brown in colour, spotted and blotched with brownish black, and are always laid in a little hollow in the bare ground with their small ends inwards in the form of a cross. But somehow or other, although they are quite large eggs, it is very difficult to see them, and you might pass close by a dozen nests, and even look straight at them, and yet never notice the eggs at all.

If you happen to find a hen lapwing sitting on her eggs, she will often pretend to be wounded, and will flap and tumble 
along the ground in the hope of inducing you to chase her, and so of leading you away from her nest.

The CURLEw is a well-known bird in the British Islands,

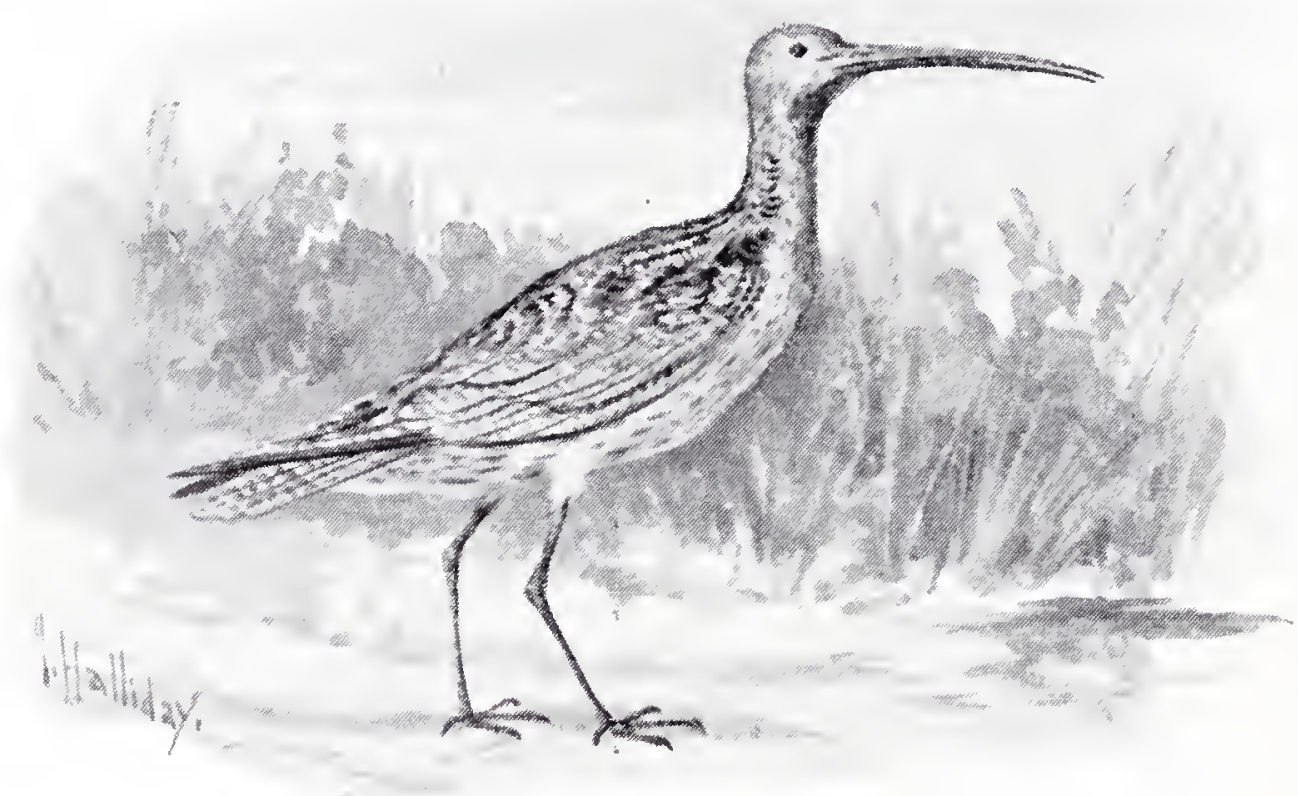

CURLEW.

and may often be noticed on moors or in marshes during the summer, or on the sea coast in the winter. But generally one only sees it in the distance, for it is extremely wary, and takes to

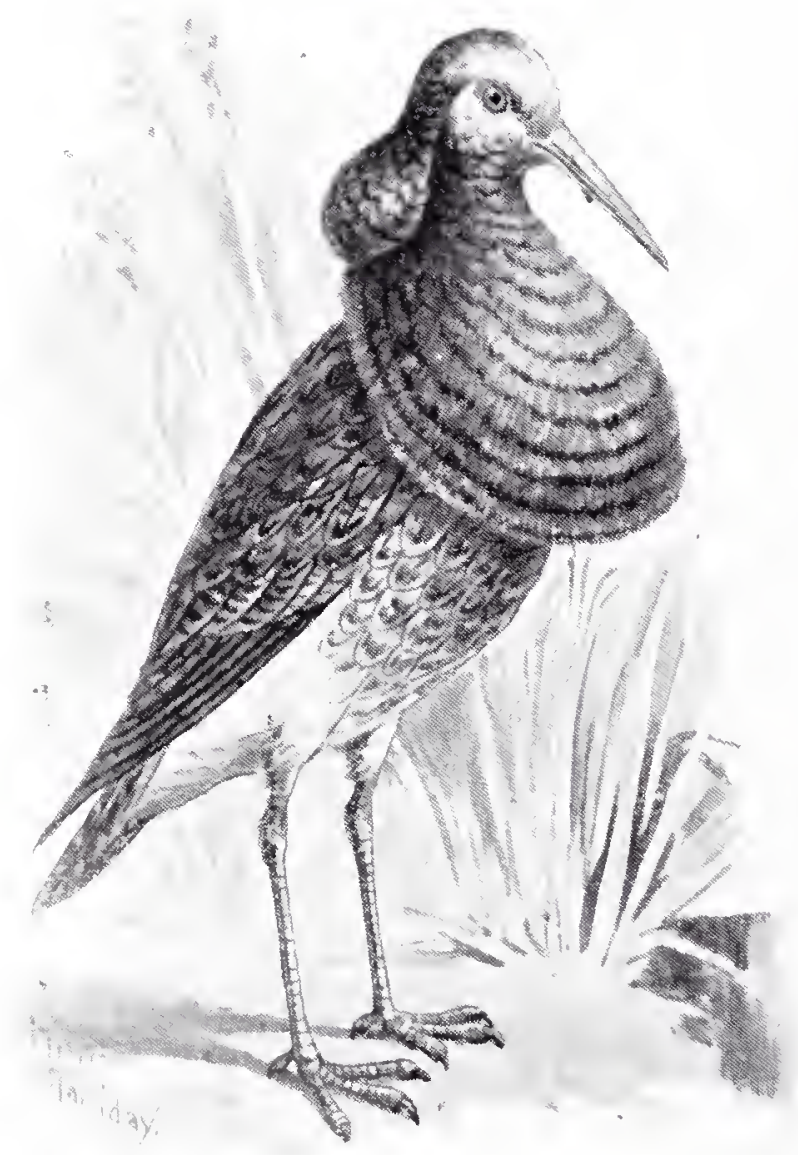

RUFF. flight at the very slightest alarm.

All through the winter months curlews live in floclis, and one may hear them uttering their mournful cries in chorus together. But early in the spring they separate, and each pair selects some little hollow in the ground which may serve as a nest. In this they lay four pearshaped eggs, which are olive green in colour, spotted with grey and brown. When the eggs are hatched the parents take the greatest care of their little ones, and if anyone should come too near the nest they will often fly round and round his head in the most excited manner, and do their very best to drive him away.

In colour the curlew is pale brown above, with darker spots and streaks, and greyish-white beneath. Its total length is about twenty- 
four inches, and the beak is long and slender, with a downward curve.

The RuFf is remarkable for three reasons.

In the first place, during the breeding season, the male bird has a great frill or "ruff" of long feathers round his neck, which he can raise and lower at will. In the next place, two male ruffs are never coloured alike, while sometimes they look so perfectly different that it is quite hard to believe that they can really belong to the same species. And, in the third place, they are so dreadfully quarrelsome when the nesting season begins, that two male ruffs can never meet without fighting! More than that, they actually have regular fighting places, to which numbers of the birds resort when they want to settle their quarrels!

Although they fight very savagely, however, they never seem to do each other very much harm.

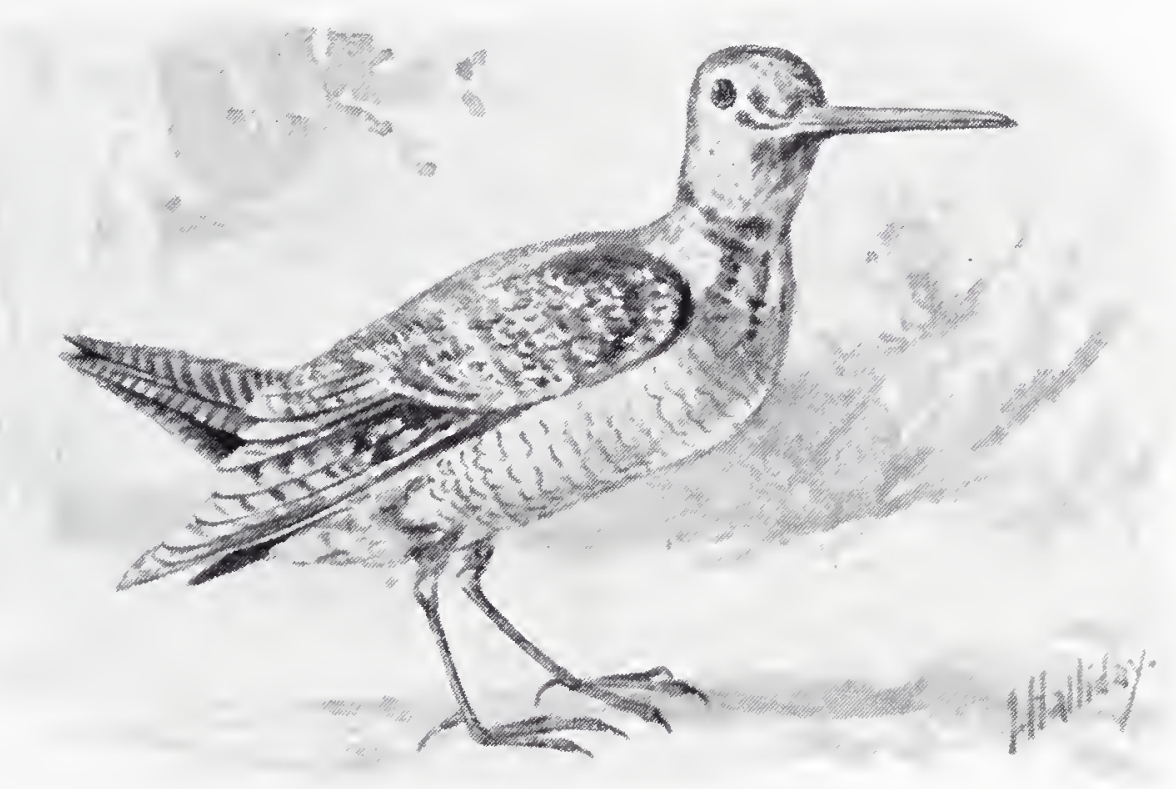

IVOOJCOCK.

At one time ruffs were very common in the marsliy parts of England, and as many as six dozen have been caught by a single bird-catcher in a single day. But now they are very rarely seen, and appear to spend only a day or two with us in spring or autumn, as they travel North or South.

The WOODCOCK is generally a winter visitor to our British Islands, arriving about the third week in October, and leaving us again in the spring. When it arrives it is often so tired by its journey across the sea that it may actually be caught by hand!

Just now and then, however, woodcocks remain with us to breed, laying their eggs in a hollow in the ground, which they line with dry grass and leaves. When the mother bird is sitting it is almost impossible to see her, for she nearly always nests among dead ferns, which are of exactly the same hues as her own plumage. Generally, indeed, it is her eyes that are noticed, and if she only 
had the sense to keep them shut she would probably never be detected at all!

Voodcoclis are hardly ever seen unless they are disturbed, for they hide during the day-time in thick bushes in woods, and only come out to feed in the evening. Their food consists chiefly of worms, which they pull out of soft, muddy ground by means of their long, slender beaks.

If two male woodcocks meet during the nesting season they almost always quarrel, and will fight nearly as savagely as Ruffs.

The SNIPE is something like the woodcock, both in appearance and in habits. But it is considerably smaller, and is found in damp, marshy ground instead of in woods. When it is flushed it flies away for a few yards quite straight, and then begins to twist and turn about in a most extraordinary way, changing the direction

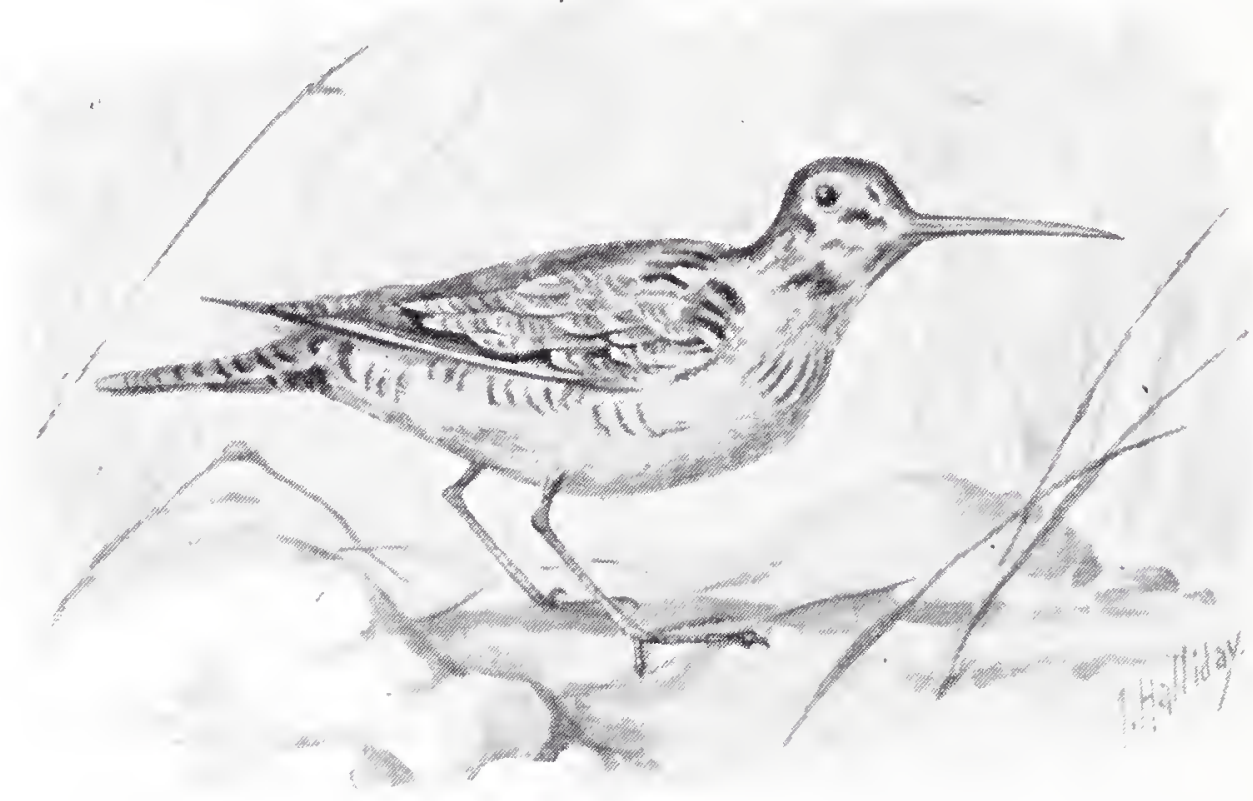

SNIPE.

of its flight at almost every yard. In consequence of this habit it is not at all an easy bird to shoot.

The male snipe is very fond of rising to a great height in the air, and there uttering his curious cry of "chick! chick! chick-a!" over and over again. At the same time he also makes a strange drumming sound, which seems to be caused in some way by the motion of the wings, as it is only produced while he is "stooping" down towards the ground.

The snipe generally nests in the middle of a tussock of coarse grass, or rushes, where it lays four buff or olive green eggs marked with dark brown blotches.

The Jack Snipe is a much smaller bird, which is seldom seen in the British Islands except during the winter months.

One of our finest British birds is the HERON, which you may often see flying high in the air with its long legs stretched stiffly out behind it. And sometimes you may see it standing 
quite motionless in the shallower parts of a stream, watching for the fishes on which it feeds. After a time it will slowly stoop, plunge its long beak into the water, and draw it out again with a roach or a trout struggling in its grip. Then it holds its beak almost upright, gives a gobble and a gulp - and the fish disappears! The heron feeds largely on frogs, water-voles, insects and

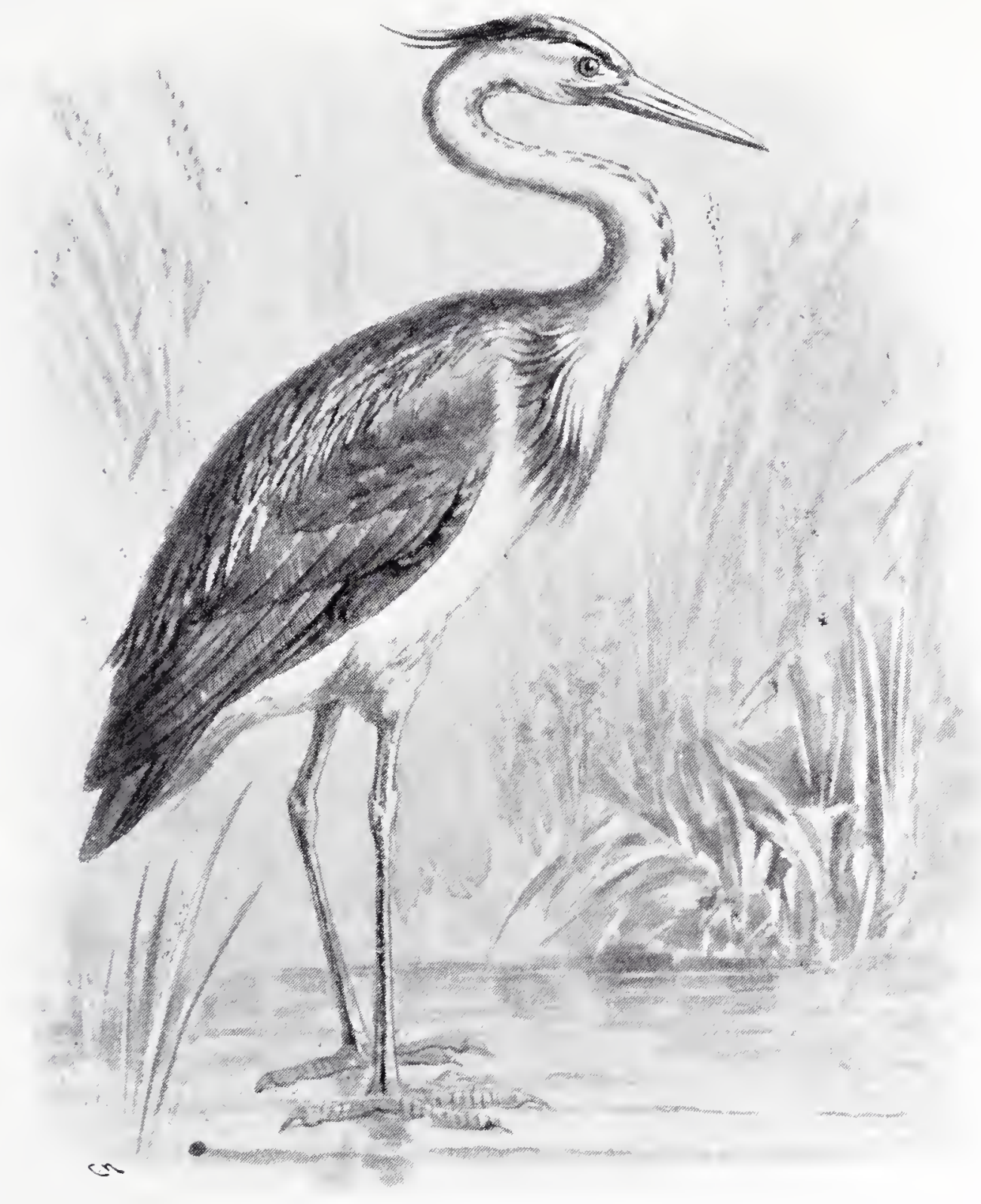

HERON.

worms, however, as well as upon fishes. And more than once it has been known to capture and swallow a small snake.

Herons build their nests in the upper branches of tall trees, making them of sticks and $t$ wigs, lined with grass and roots. A number of these birds generally nest together in the same clump of trees, just as rooks do, and in each nest are laid either three or four bluish-green eggs, without any markings at all.

If a heron is attacked, it uses its long, dagger-like beak with great address, and always tries to strike at the eyes of its enemy. 
The SToRk is found in most parts of Europe, and also in Asia and Northern Africa. In olden days it was plentiful in Great Britain, but is now nothing more than a very occasional visitor.

When storks are migrating, they fly in great flocks, which sometimes consist of many thousand birds. As soon as they arrive, they spread themselves over the country, being especially fond of marshy districts, where they can find plenty of frogs, toads, lizards,

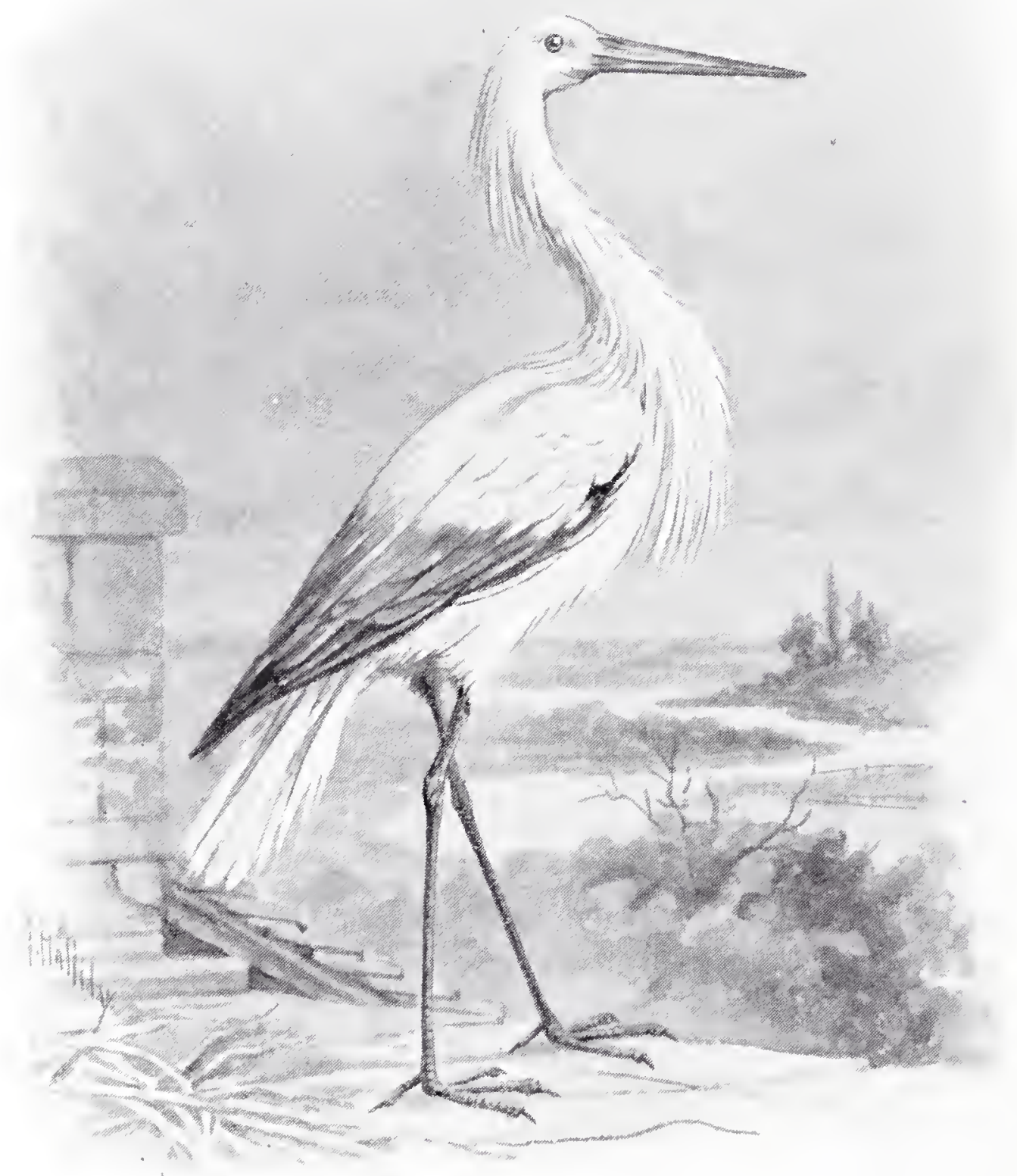

STORK.

and the other small creatures upon which they feed. But they also devour large quantities of the offal which they find in the streets of the villages and towns, so that they, too, belong to the great army of "Nature's Dustmen," about which we have read once or twice already.

In Holland and Germany storks breed in great numbers. Their nests, which are usually placed on the tops of chimneys, 
are little more than clumsy piles of sticks, and as fresh sticks are added every year, they gradually get bigger and bigger until at last they reach a very great size. From three to five pure white eggs are laid, and the young birds remain in the nest until they are well able to fly.

Very much like storks in some ways are the IBISEs, which are found in many parts of Asia, Africa, and America. They are generally found in flocks, which live in marshes or on the banks

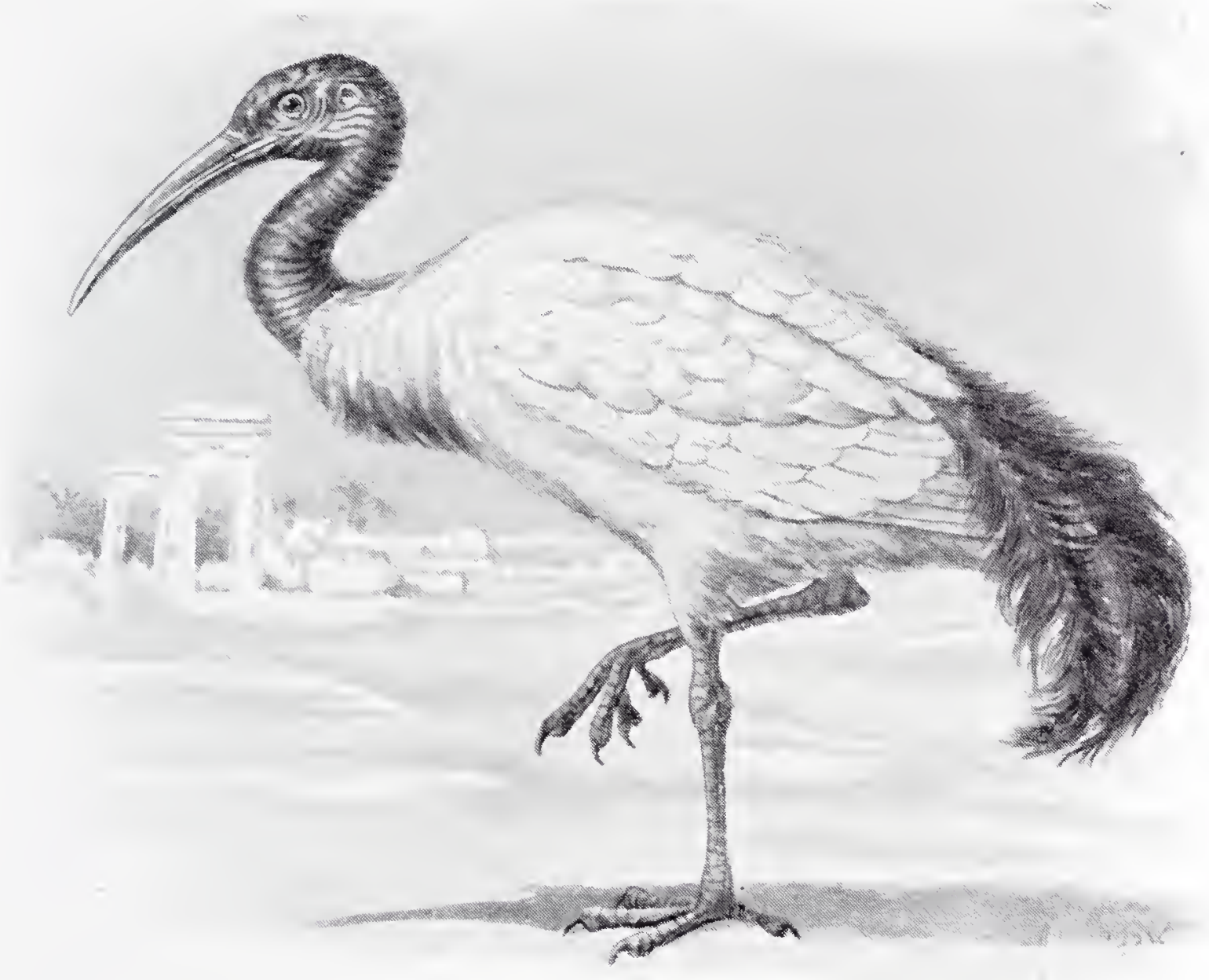

IBIS.

of rivers and lakes, where they spend most of their time dabbling in the water with their long beaks in search of food.

One of these birds was worshipped by the Egyptians of old, who treated it with the greatest reverence during life, and carefully embalmed its body when it died. For this reason it is linown as the Sacred Ibis, and in the Egyptian Gallery of the British Museum you may see quite a number of ibis mummies, which were taken from the tombs of the lings. In colour this bird is snowy white, with a black head and neck, and long black plumes on the hinder part of the back. You may generally see it in the Zoo, together with the beautiful Scarlet Ibis, whose plumage is bright red in colour, with black tips to the wings. 


\section{CHAPTER XXVI.}

SIVIMMING BIRDS.

$I N$ the birds belonging to this group the feet are webbed, so that they may be used as paddles. And some of them are very curious indeed.

First of all, there is the well-known red and white Flamingo, which is quite an extraordinary bird, for it has extremely long, stilt-like legs, and an extremely long, snake-like neck, which it can twist and coil about as easily as if it were just a piece of rope. There is no part of its body which a flamingo cannot reach with its beak, so that it can preen its feathers quite easily. And when it wants to feed it wades into the water, bends down its long neck, turns its head upside down, so that its forehead rests upon the bottom, and scoops up great mouthfuls of mud. Then, by means of the grooves at the sides of the bill, it gets rid of the mud, while all the grubs, etc., which were lying buried in it, are left behind to be swallowed.

The nest of the flamingo is a cone-shaped heap of mud, sometimes as much as a couple of feet high, with just a little hollow at the top to contain the eggs. Thousands of these birds nest together, and when they are sitting they look just like a great rosy-white cloud resting upon the ground. And if they are startled and fly away, their nests look as though hundreds of children had been making big sand-pies on the beach and neatly arranging them in rows.

Flamingoes are found in the warmer parts of all the great continents except Australia. Nine different linds are known, some of which stand well over six feet in height.

Of wild geese there are at least forty species, which are found in almost all parts of the world. Let us take the common Grey-LAG Goose as our example.

This is the only wild goose which breeds in our British Islands, and it seems to be the ancestor of the domestic geese which we see in every farmyard. It lives in flocks, which frequent marshes, lakes, and boggy moors during the greater part of the year, but often visit the sea-coast in winter. Sometimes, too, they may be seen near the mouth of a great river. They are very shy birds, and when sportsmen wish to shoot them they have to resort to all kinds of tricks in order to approach them without being seen. 


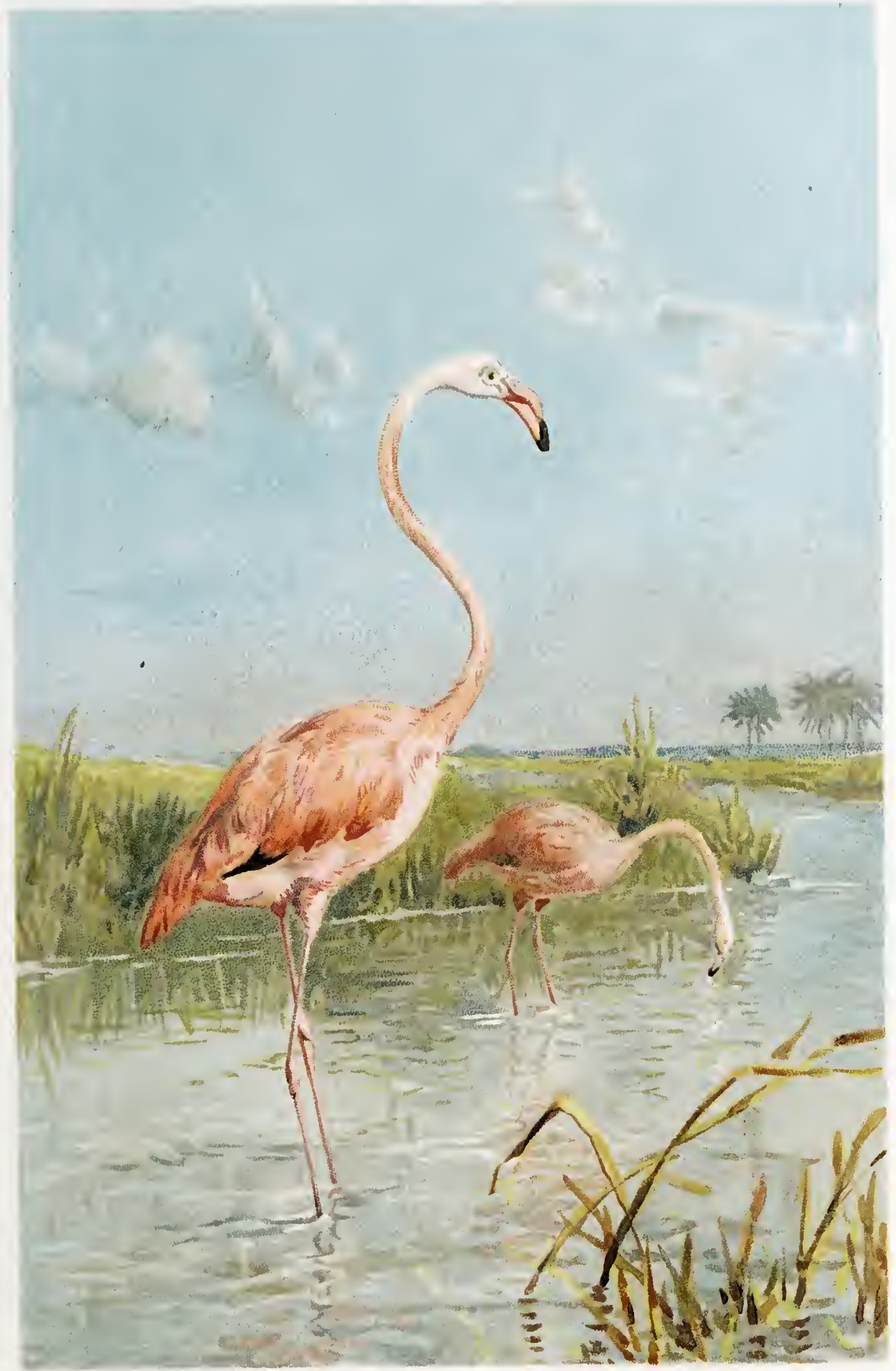




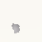


When wild geese fly, they generally do so in the form of a half-opened pair of compasses, with the angle in front. But now and then they may be seen in the air in an irregular wavy line. As they fly they make a curious "gaggling" cry, which can be heard from a very long distance.

The nest of this goose is made of grass and flags, and is generally placed at the base of a tussock of coarse grass. It usually contains six plain white eggs.

Swans, too, are found wild in many parts of the world, and are winter visitors to the northern parts of the British Islands. Four linds at least have been linown to visit our shores, but the great majority of those which come to us are Whoopers, or Whistling Swans, which are so called on account of their curious whooping cry. They generally arrive in October, and travel"north again

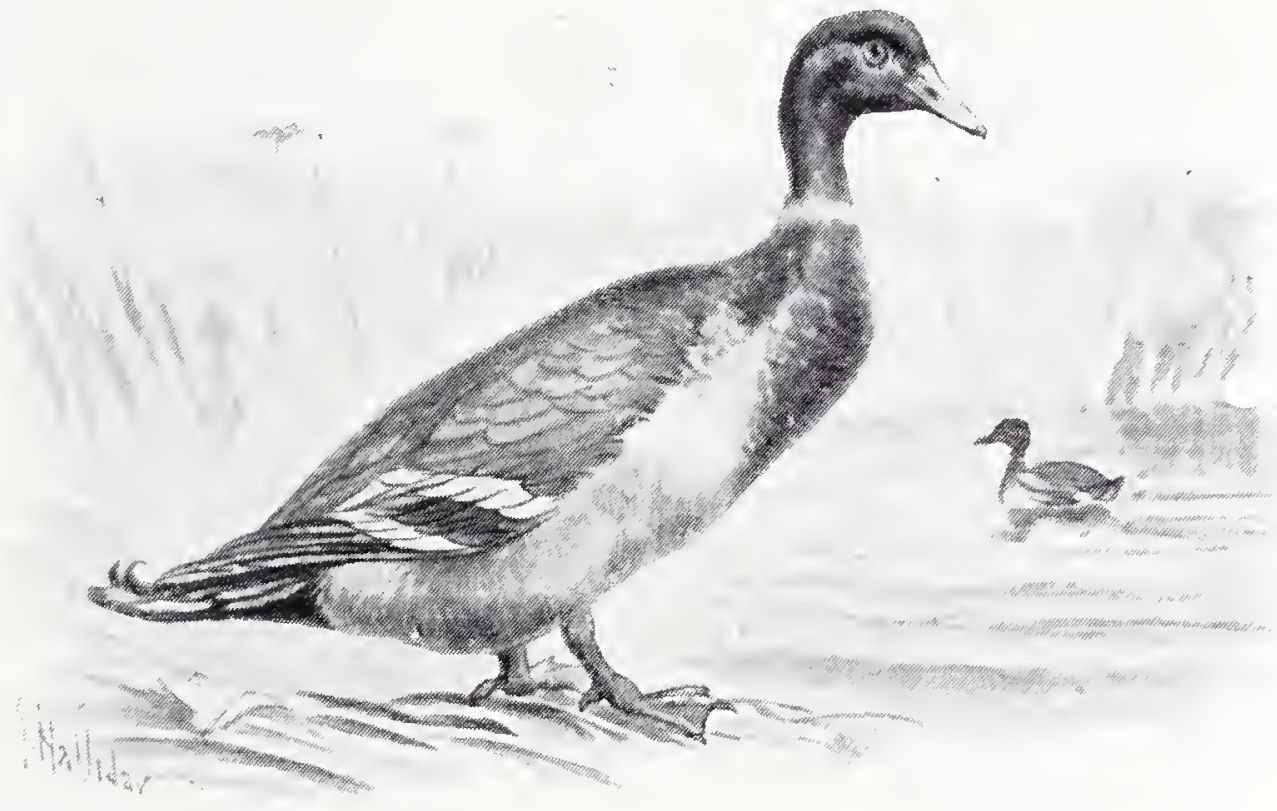

VILD DUCK.

very early in the spring, coming back year after year to the same districts.

Swans are most graceful birds in the water, and as their limbs are set very far back they can swim with great ease. But for the same reason they are very clumsy upon dry ground, and waddle along in the most awkward way, seeming to find it very difficult to keep their balance.

During the nesting season the male swan generally becomes very savage, and will attack anyone who ventures too near to his nest. And as a single stroke from his wing is sufficient to break a man's arm, he is apt to be a very formidable adversary.

The nest of the swan is a very large structure of reeds, rushes, and grass, and is generally placed quite close to the water's edge. It contains six or seven large greenish-white eggs.

A great many kinds of duck are known, but I can only mention the WILD Ducr, which still visits the British Islands 
every winter in considerable numbers, a few of which remain to breed.

The male duck is called the Mallard, and from October till May he is a very handsome bird indeed, with a dark green head and neck, a white collar round the lower part of his throat, brownish grey wings, chestmut brown breast, and white hinder parts. But when he moults he puts off this beautiful plumage,

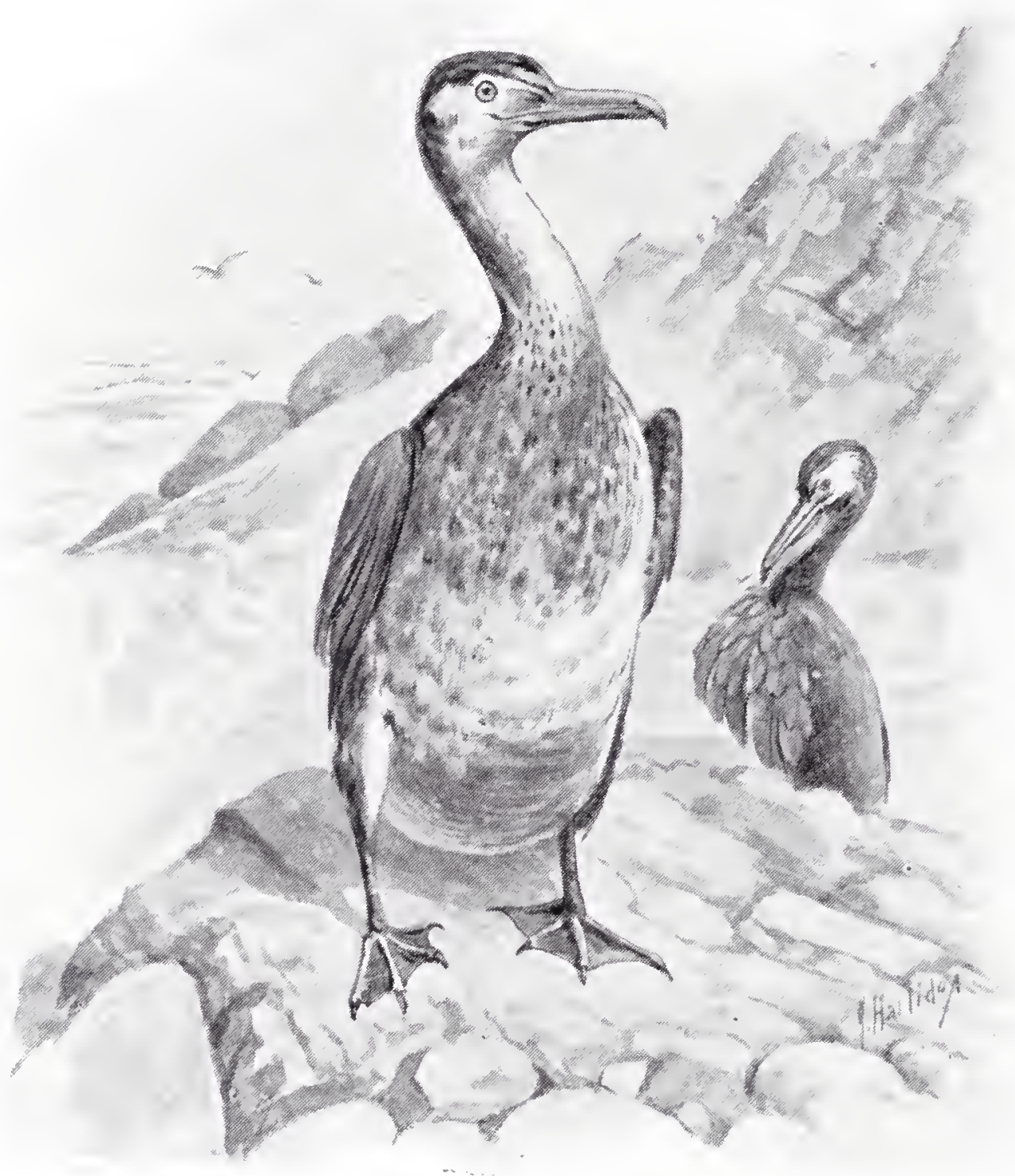

CORMORANT.

and for the next five months is mottled all over with brown and grey, just like his mate.

Wild duck are found chiefly in marshes and fens, and on the borders of rivers and lakes. But when they come over in the autumn they often spend the claytime ont at sea resting on the water. They make their nests of grass, lined with down from the mother bird's own breast; and the little ones are able to swim as soon as they leave the egg-shell. When they are about half grown they sometimes use their wings in diving, and you may see them 
flapping their way along beneath the surface, and really flying under water.

Cormorants are very odd birds. You may see them on many parts of our British coasts, sitting on rocks which overhang the water, and every now and then you may notice that one of them drops into the sea, splashes about for a moment or two, and then returns to his perch. Then you may be quite sure that he has caught and swallowed a fish. And sometimes you may see them swimming along with their heads under water, watching for victims in the depths below.

Cormorants are famous for their big appetites--perhaps it would be more correct to say for their horrible greediness, for they will go on eating till they simply cannot swallow another morsel, and yet will try hard to catch every fish that comes near

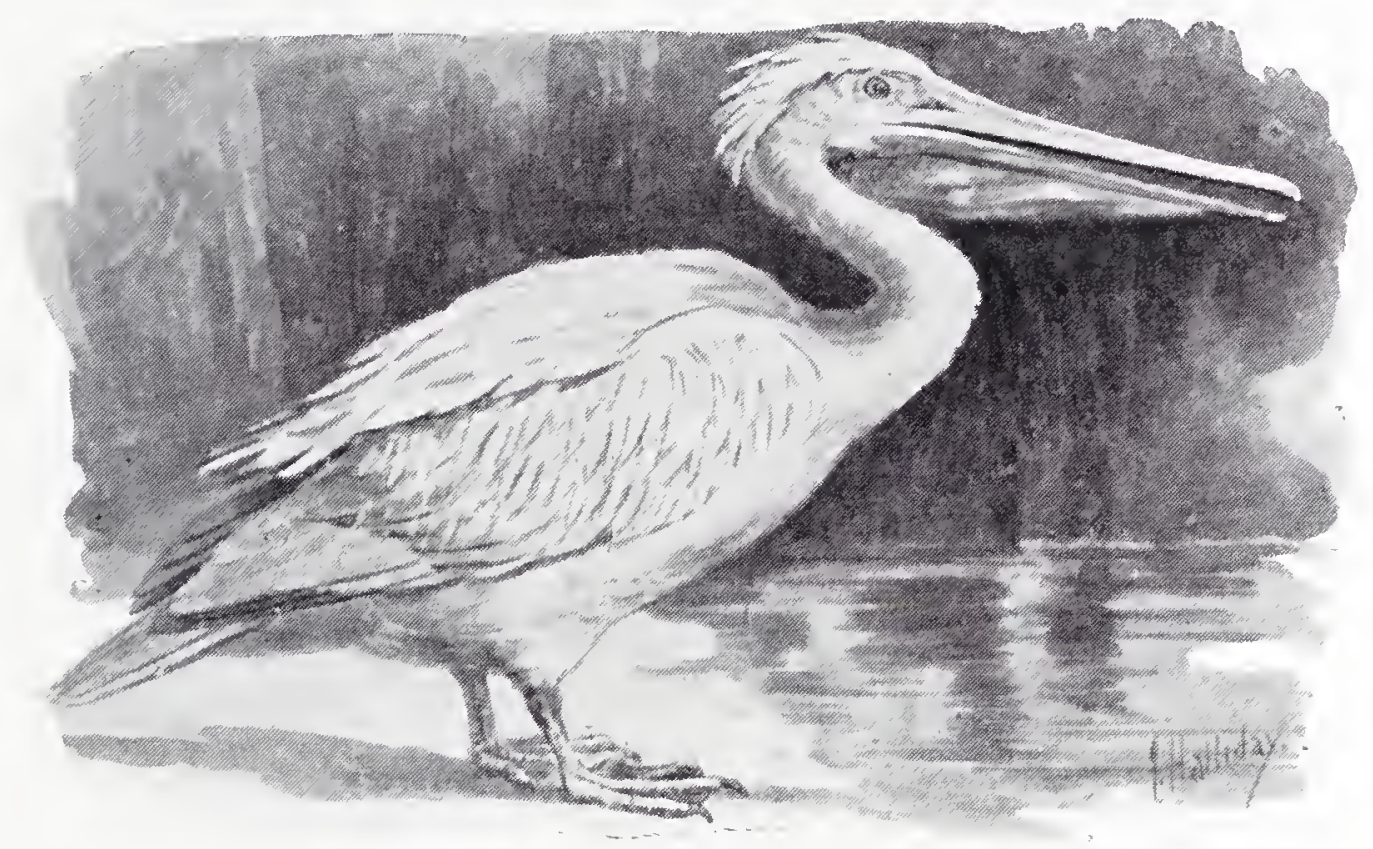

PELICAN.

them. The little ones feed in a most extraordinary way, for they actually poke their heads down their mother's throat, and take as much food as they want from her crop!

When these birds really feel that they have had enough to eat, they sit upon a rock for an hour or two while they digest their dinners. They also take the opportunity of drying their wings, and spread them out to the fullest extent on either side, so that they look very much like rows of black clothes hung out to dry!

In China cormorants are often trained to catch fish for their masters, a strap being fastened round the lower part of the neck to prevent them from swallowing their victims. They were formerly used in England in just the same way.

More curious still are the PeLicans, which have a huge pouch underneath their long bills, capable of holding quite two 
gallons of water. You cannot see this pouch as a rule, because it is folded closely up underneath the beak. But when the bird is fishing, it packs victim after victim into it until it is quite full, when it really looks almost half as big as the body.

In this way pelicans carry back food for their hungry little ones. But on their way they are sometimes robbed, for there is a kind of large hawk which is very fond of eating fishes, but is not at all fond of the trouble of catching them. So he waits till he sees a pelican returning home from a fishing expedition, and then dashes at it, and begins to beat it about the head with his wings. The poor frightened pelican, thinking that it is about to be killed, opens its beak to scream. This, of course, is just what the havk wants, and snatching a fish out of the pelican's pouch, he flies off with it in triumph.

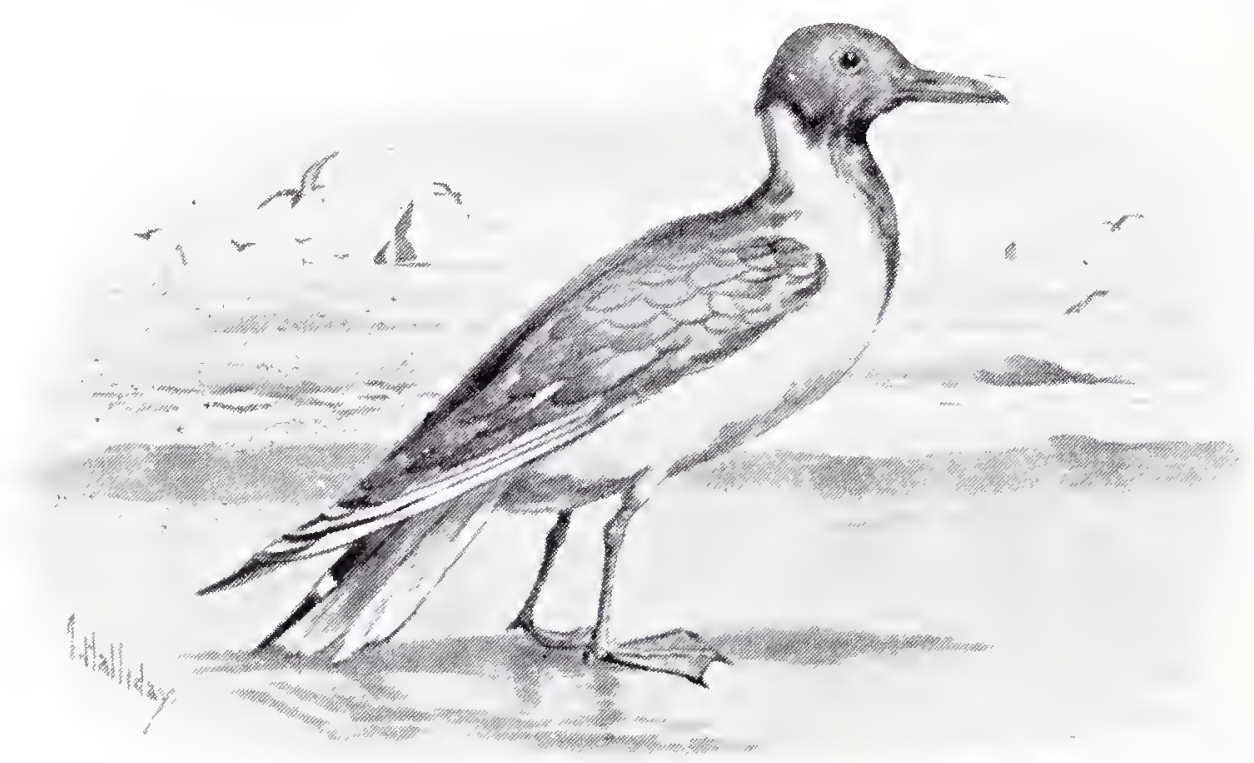

BLACK-HEADED GULL.

Pelicans are very plentiful indeed in many parts of the world, and are often seen in vast flocks. All the birds in a flock will sometimes go out fishing together. Arranging themselves in a great semi-circle, about a yard apart, they all paddle slowly forwards, and in this way will drive a great shoal of fish into shallow water, where they may be snapped up without difficulty.

Sea Gulls, of course, you know very well by sight, for they are common on all parts of our coasts, and on many of our lakes as well, while numbers of them may be seen even on the ornamental waters in the parlis of London. In stormy weather, too, they often fly inland, and sometimes great numbers of them may be seen in newly-ploughed fields, hunting for worms and insects. Most of them go north for the breeding season, visiting certain islands and rocky cliffs in immense numbers, and making their nests of sea-rveed. But the Black-headed Gull nests in marshes, merely trampling down the broken tops of sedges and reeds, and so forming a slight hollow in which to lay its eggs. 
At least fifty different kinds of gulls are linown. But many of them are very difficult to distinguish, for their summer plumage may be quite unlike that with which they are clothed during the

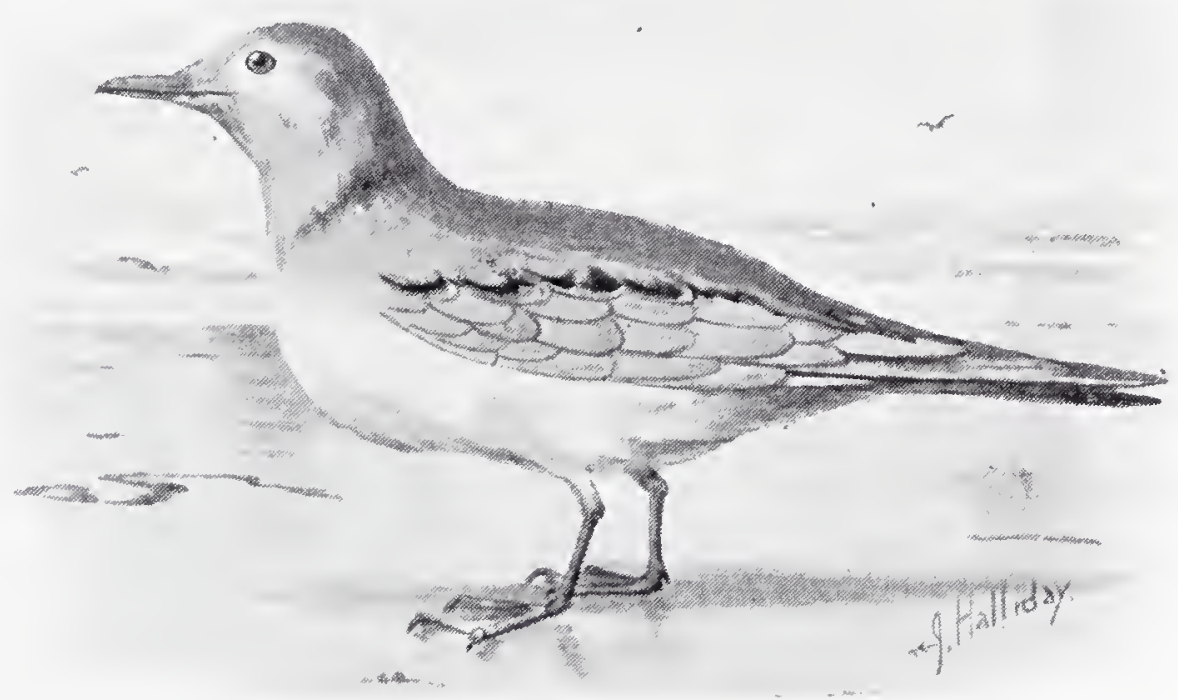

KITTIWAKE.

winter, while the young birds are not marked like their parents till they are two or even three years old. Those which are most common in Great Britain are the Kittiwake, the Common Gull,

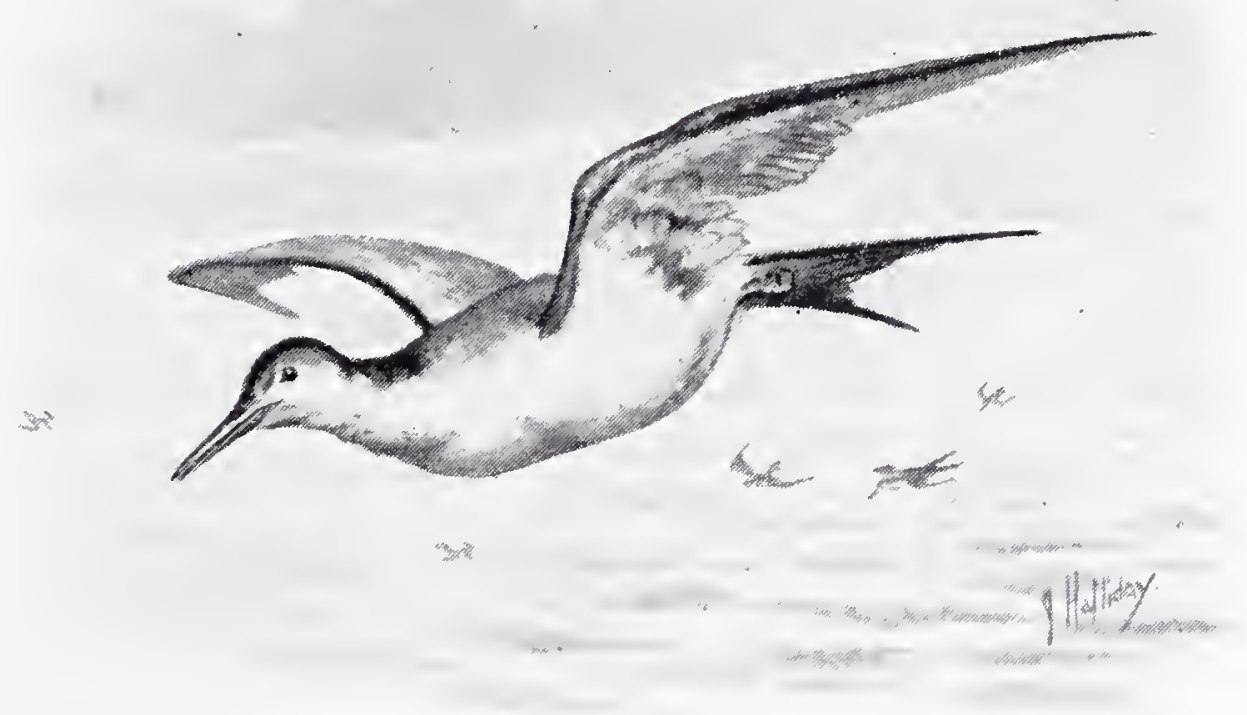

TERN, OR SEA SWALLOW.

and the Black-headed Gull, while the great Black-backed Gull and the Herring Gull are tolerably plentiful.

Flying to and fro over the sea, or over a large inland lake, you may sometimes see a number of birds which look like gulls, but are much smaller, and have long, forked tails like swallows. 
These are Terns, or "Sea Swallows," as they are often called, and are most elegant and graceful in their movements, gliding and sweeping through the air, and twisting and turning with the most wonderful swiftness and ease. They are summer visitors only, coming to us in May and flying south again in September, and they breed on flat shores, generally laying their two or three eggs in a small hollow in the shingle. They feed on small fishes and shrimps, and also on the sand hoppers and the various insects which are so plentiful upon the beach.

Guillenots are very common on some parts of our British

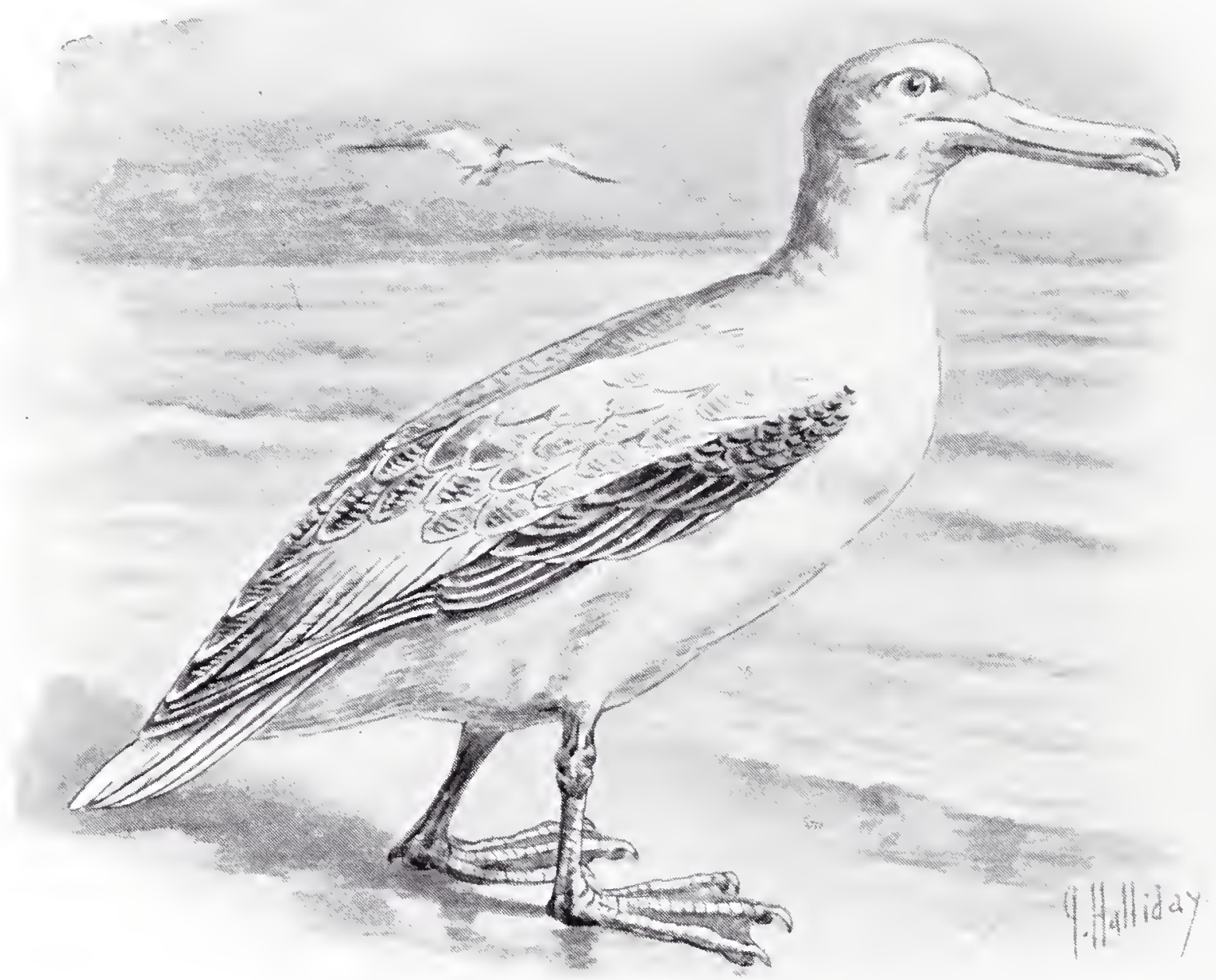

ALBATRUSS.

coasts. But few people see them, because for the most part they keep well out to sea. They can easily be recognised by their black and white colouring, their short necks, and their long, sharp beaks.

Guillemots feed entirely upon fishes, which they chase under water, using both their wings and feet, just as dabchicks do. They do not make any nest, but lay a single egg on a bare ledge of rock which is often only a very few inches wide. One would think that this egg would be in great danger of being knocked 


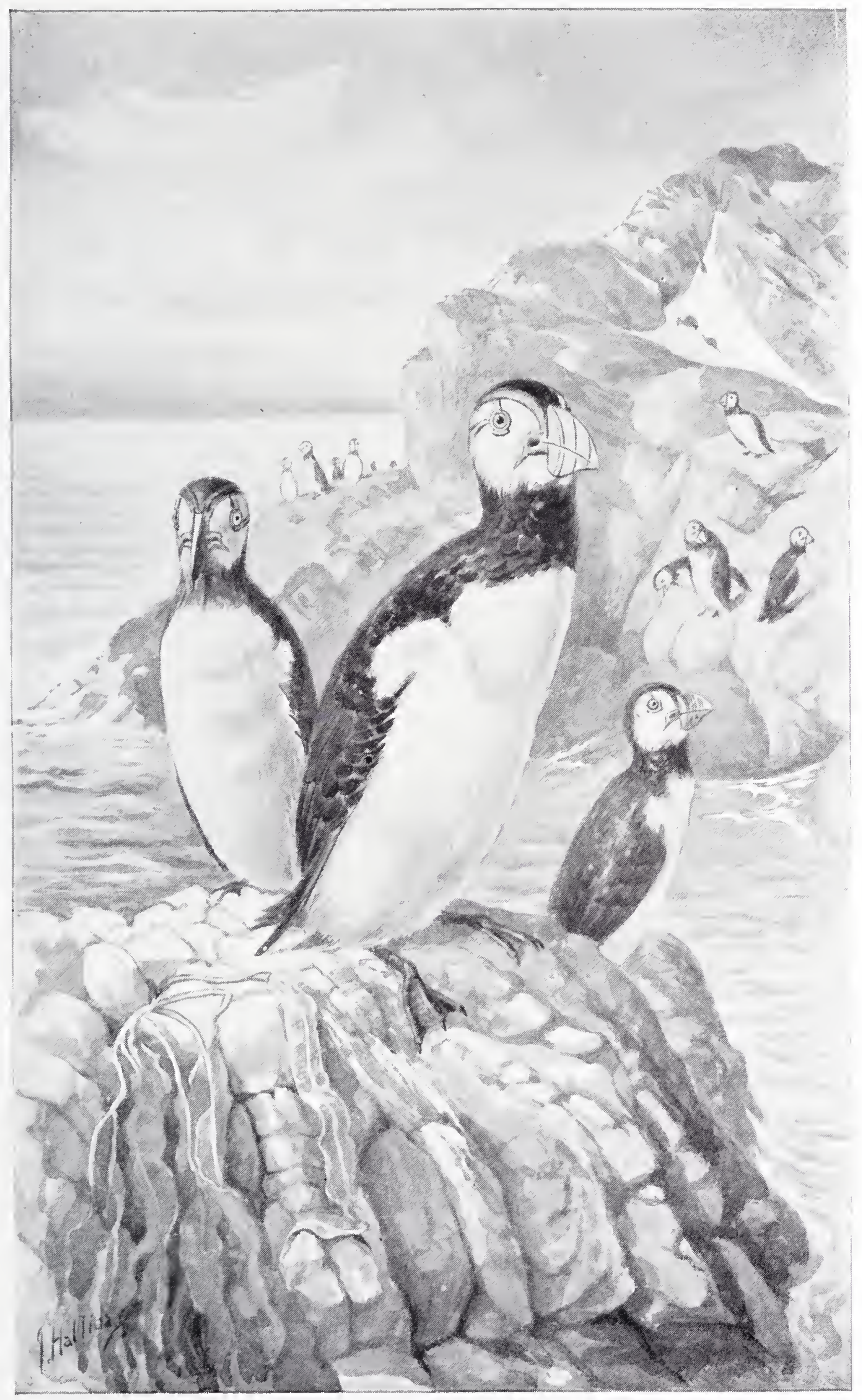



over the edge. But it is very large at one end and very much pointed at the other, so that if it is struck it only rolls round and round. In colour it is green or blue, blotched and streaked with black.

One of the largest of all the sea birds is the Albatross,

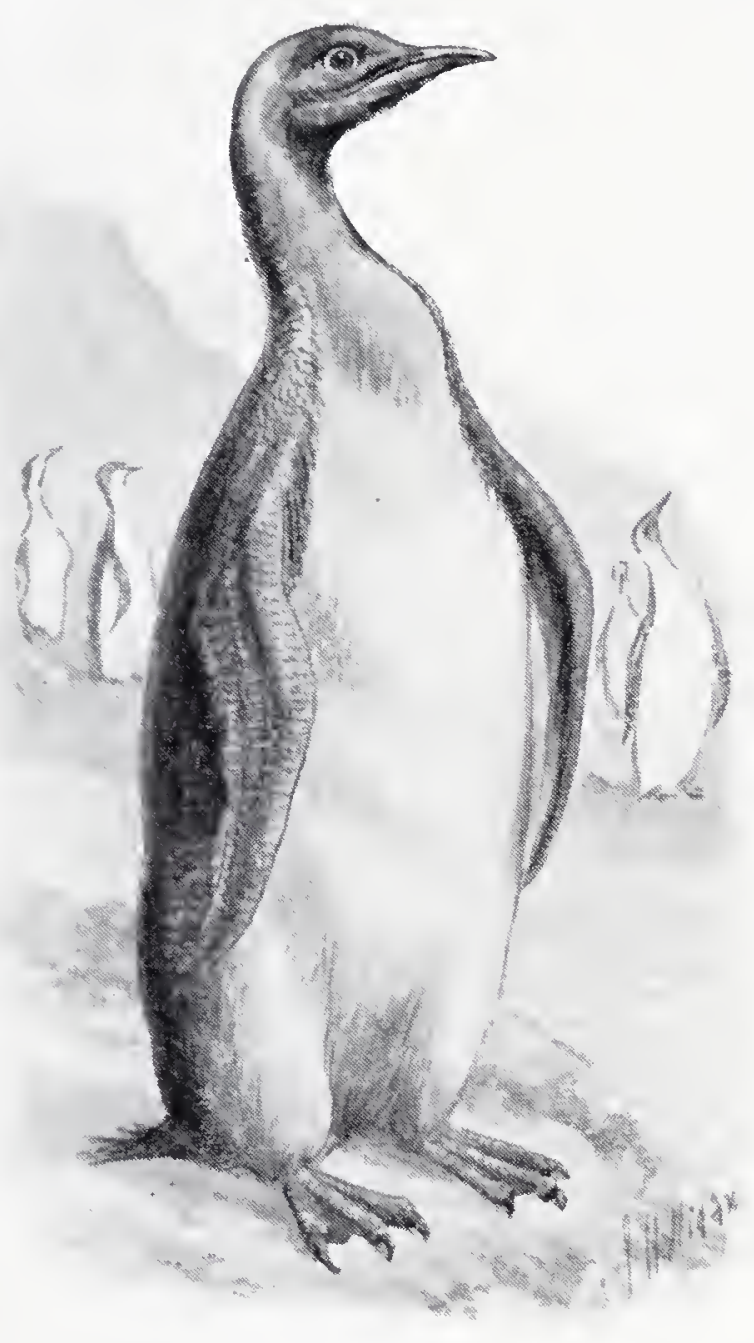

PENGUINS. which is found chiefly in the tropical seas. When the wings are fully spread, they sometimes measure nearly twelve feet from tip to tip. Yet the entire weight of the bird is not more than sixteen or seventeen pounds. It often remains at sea for weeks or months together, sometimes remaining in the air all through the night as well as all through the day, and following ships for hundreds of miles in order to feed upon the refuse which is thrown overboard. Its appetite is enormous, for it has been known to gulp down a great piece of whale's blubber, weighing between three and four pounds, and then to return almost immediately for more!

Great numbers of albatrosses nest together on uninhabited islands, each pair scooping together a quantity of clay, grass, and sedge, which they arrange in a conical heap about ten or twelve inches high, with a little hollow at the top. Only a single egg is laid, which is quite white, and is rather larger than that of a goose.

Two most curious birds must be mentioned in conclusion.

The first of these is the PUFFin, which is found plentifully on some parts of our British coasts. An odder and more quaint looking bird it would be difficult to imagine, for it has a beak quite large enough for a bird six times its size, while that beak, which is banded with bright crimson, grey and brilliant yellow, looks just as if it had been stuck on with glue! More than that, it does not appear to fit very well; so that altogether, with its short, squat body, and stout little legs, the puffin is by no means a graceful bird. It is often known as the Sea Parrot.

On dry land, the puffin is very awkward, and can only waddle along very slowly and clumsily. But it is a good swimmer and diver, and can chase and overtake small fishes with the greatest of ease. It is also able to fly very well, and takes long journeys over the sea when it comes to us in the spring, and again when 
it goes away in the autumn; for it is only a summer visitor to our shores. It makes no nest, but digs out a hole in the face of a cliff to the depth of about three feet, and lays a single greyishwhite egg at the end.

Odder still, even, is the Penguin, which has flappers instead of wings, with scales upon their upper edges instead of feathers! It cannot fly, of course; but it uses its wings for two purposes. For if it is frightened upon land it throws itself down on its breast and scuttles along on all fours, just as though its wings were legs, and if it wants to chase a fish in the sea it swims with them, just as though they were paddles.

There are a good many different kinds of penguins, all of which are found in the southern hemisphere. On some of the islands in the Pacific and Antarctic Oceans they are found in immense numbers, and have a curious way of standing side by side upon the shore in long rows, with their flappers hanging down on either side of their bodies. From a distance, indeed, they might almost be mistaken for lines of soldiers standing at "attention." When the breeding season begins they become very busy indeed, picking up stones, carrying them about with a great deal of fuss, and then carefully arranging them in position, every now and then turning their beaks up to the sky, waving their flippers, and making a curious gobbling noise. If a sitting hen leaves her nest for a little, all the other hens become very excited indeed, and peck at her as she passes by in order to drive her back again, croaking loudly in chorus, and evidently feeling extremely indignant with her for neglecting her duties.

When these odd birds are sitting on a ledge of ice, and want to get down into the sea, they often throw themselves upon their breasts, and "toboggan" down the slope into the water! 


\section{REPTILES.}

\section{CHAPTER XXVII.}

\section{TORTOISES, TURTLES AND LIZARIS.}

WE now come to the Cold-blooded Animals, which are divided into three Classes. First we have the Reptiles, whose hearts are formed of three chambers, and which breathe air by means of lungs. Next come the Amphibians, which are like the reptiles in many ways, but which have to pass through a tadpole stage before they reach the perfect form. And, thirdly, there are the Fishes, whose hearts are divided into two chambers only, and which breathe water by means of gills.

At the head of the reptiles stand the Tortoises and Turtles, which are very odd creatures indeed; for their bodies are shut up in a kind of horny box, which we generally call the "shell." In reality, however, it is not a shell at all; for the upper part, which we call the "carapace," is a development of the spine and the ribs, while the lower part, which is known as the "plastron," is a development of the breast bone. These animals, in fact, have part of their skeletons inside their bodies and part outside: so that they are really shut up in their own bones!

The so-called "shell" of a tortoise or a turtle is always very hard and strong, so that you can stand upon quite a small tortoise without hurting it in the least. And the head and legs can nearly always be tucked away inside it, so that the animal is safely protected from almost every foe.

None of the turtles and tortoises have any teeth. But the edges of their jaws are so sharp and horny, that they can often inflict a very severe bite. Some of the larger turtles, indeed, could snap off the fingers of a man's hand as easily as you could bite through a carrot!

The best known of all the tortoises is the common LANn Tortoise, or Greek Tortoise, which is found in many parts of the South of Europe, and also in Asia Minor. This is the animal which is so often kept as a pet. It does not grow to any great size, but will live in a garden for many years, crawling about by night as well as by day. Early in the autumn it buries itself underground, and falls into a deep sleep, from which it does not awake until the spring.

This tortoise is a vegetable feeder, and is very fond of lettuce leaves, more especially when they are quite crisp and fresh, so that it can easily nip them to pieces with its sharp jaws. If they are rather old and stringy, it will hold them down with its 
front feet while it tears them asunder. And if you keep one of these animals as a pet, and want to give it a great treat, there is nothing that it likes better than a little millk. You will be amused to see how it drinks, I think, for it first scoops up a little milk in its lower jaw, just as if it were using a spoon, and then holds up its head in order that the liquid may trickle down its throat.

There are a good many other kinds of land tortoises, some of which grow to a very great size. The largest of all comes from the Galapagos Islands, and is quite a giant; for an example which lived for some little time in the Zoo was more than four feet long, and weighed between eight and nine hundred pounds! These huge creatures, however, are now very nearly extinct.

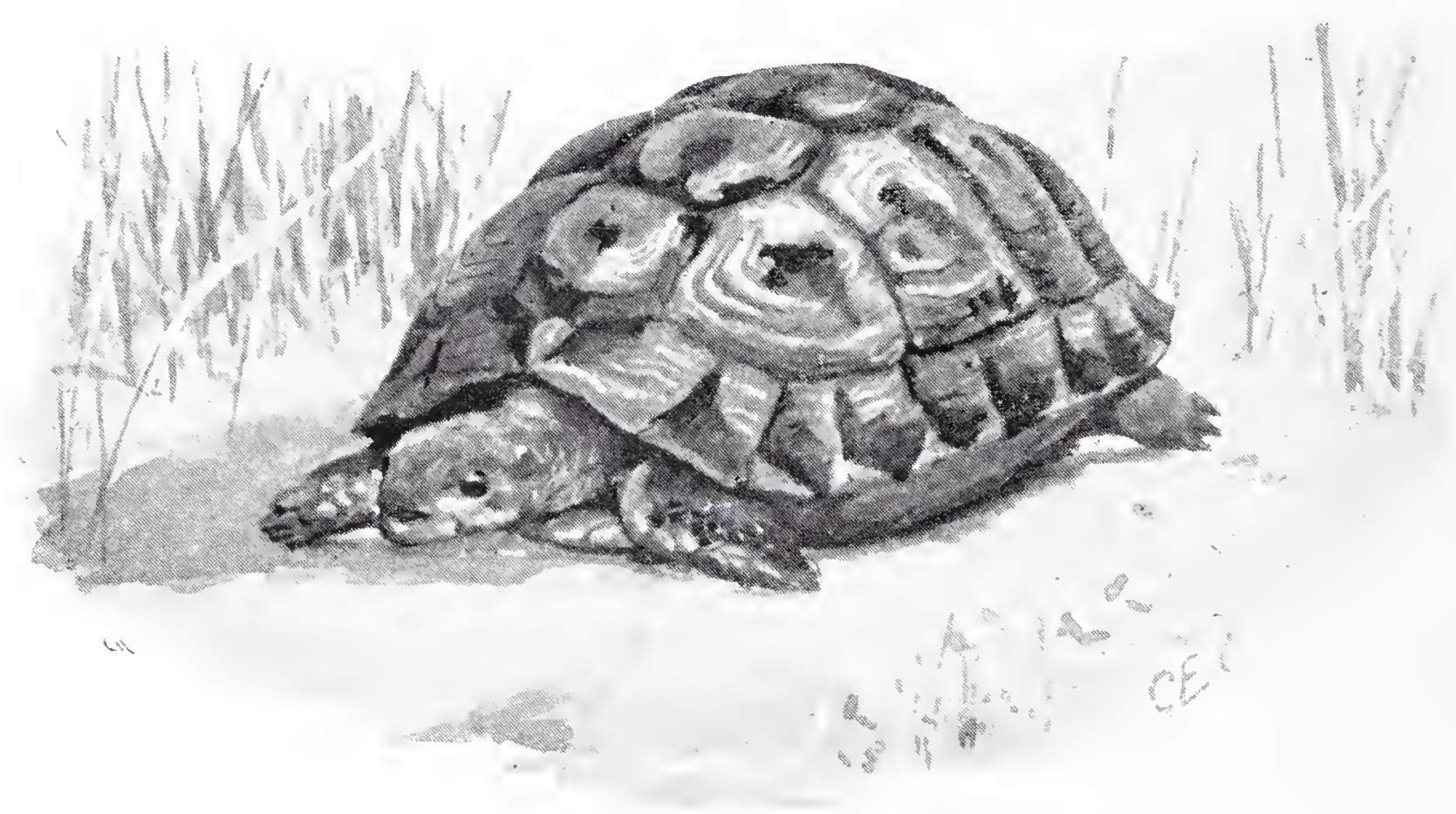

TORTOISE.

Then there are some tortoises which live in the water.

One of these is the Chicken Tortoise, of North America. It is very common in ponds and lakes, and if you were to walk up quietly to the water's edge on a warm and sunny day, you would very likely see hundreds of the little creatures basking on stones, or on the trunks of fallen trees. But they are very hard to catch, for they always seem to sleep, as we say, with one eye open, and the instant that they are alarmed they tumble into the water and swim quickly away.

When this tortoise is swimming, it always keeps its head and neck just above the surface, so that from a little distance it looks almost exactly like a small snake. It is called the "Chicken" tortoise because its flesh is as tender and delicate as that of a young chicken.

This tortoise, when fully grown, is only about ten inches 
long. But there is another water tortoise, called the Alligator Terrapin, which is sometimes more than three feet long, and which really looks very much like a short and stoutly-built alligator with a shell upon its back.

This huge and ungainly creature lives in the rivers and pools of North America, and is not at all uncommon. But it is very seldom seen, for it nearly always keeps in deep water, and even when it is floating upon the surface will always dive at the slightest alarm. If it is taken prisoner it snaps with the utmost fury, over and over again, and its jaws are so sharp and so strong that it has been known to bite asunder a stick half an inch in diameter.

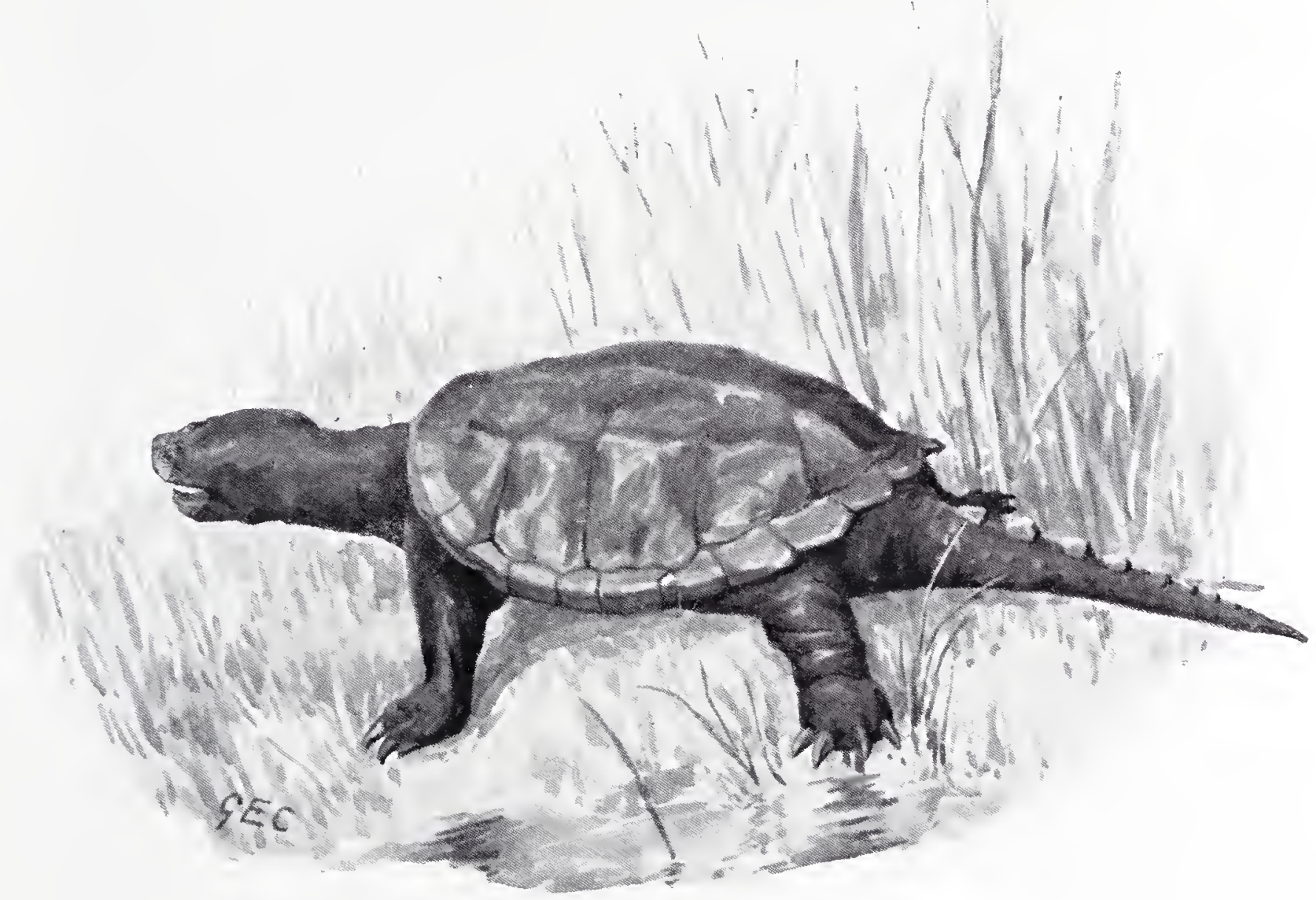

ALIIGATOR TERRAPIN.

The Turtles are distinguished from the tortoises by the structure of their feet, which are flattened out in such a way as to serve as paddles in the water. For this reason these reptiles hardly ever come upon land except when they want to lay their eggs; and they can swim so well that they are often met with many hundreds of miles out at sea.

One of the best known of these creatures is the HawksBill Turtue, which is so-called because its mouth is shaped just like the beak of a liawk. The carapace is not all in one piece, as is the case in the tortoises, but is made up of thirteen large scales, which overlap one another for about a third of their length, just like the slates on the roof of a house. 
These scales are very valuable, for the best "tortoiseshell" is obtained from them. When they are first taken from the animal they do not look like "tortoise-shell" at all, for they are dull and crumpled and brittle. But after they have been boiled, and steamed, and pressed for some hours they quite change their character, and become so soft that they can easily be moulded into any required shape.

The eggs of this turtle are laid in a hole which the mother scrapes in the sand, and are hatched by the heat of the sun. As soon as the little turtles make their appearance they hurry ofl as fast as they can towards the water. But they are very good

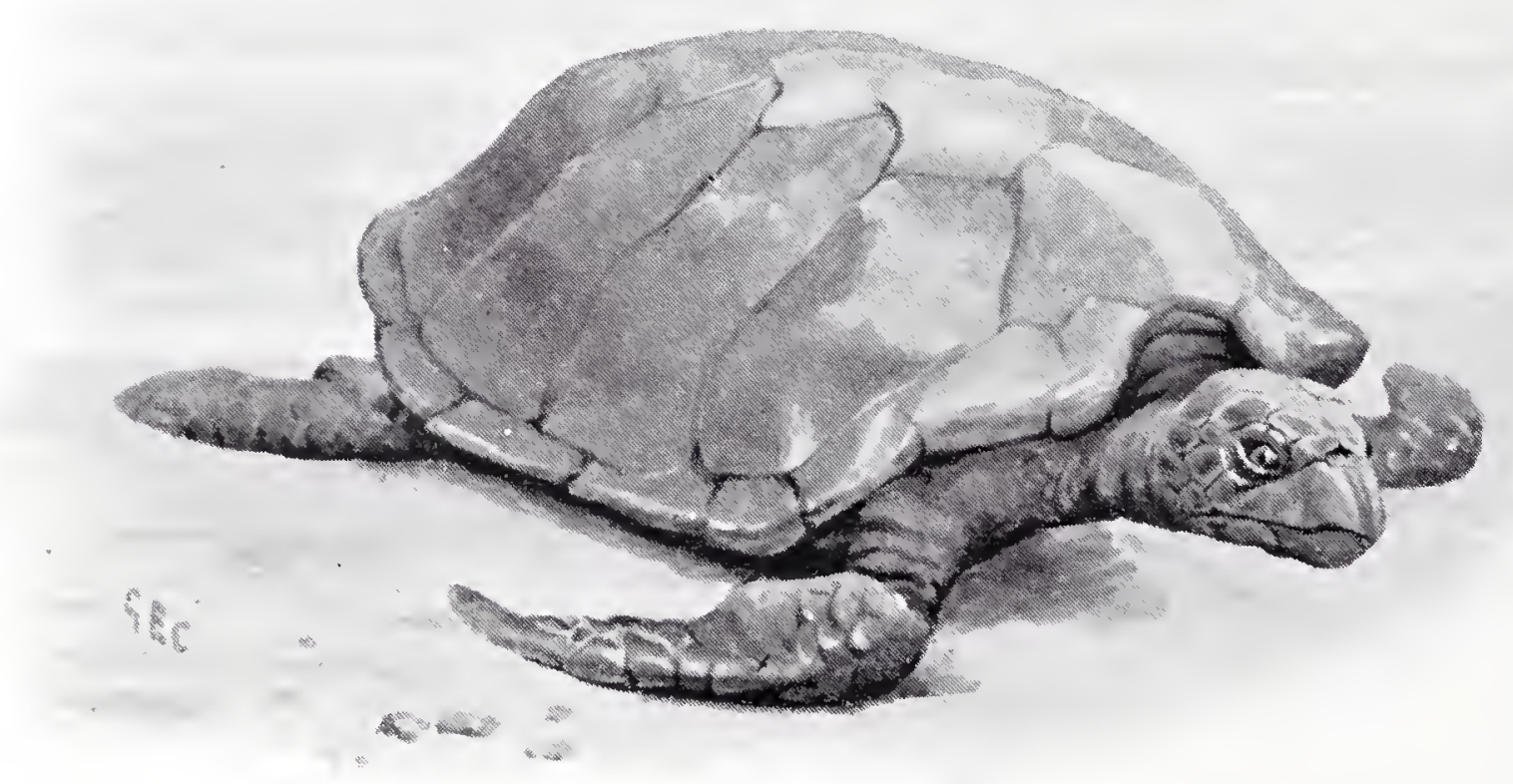

HAWKSBILL 'TURTLE.

to eat, and a number of hungry animals and birds are always on the look-out for them, so that a very great many are snapped up and devoured before they can plunge into the waves.

The famous "turtle soup," which is considered so great a dainty, is made from the flesh of the Green Turtue, which is found most plentifully off the Island of Ascension. It grows to a great size, for it is often four feet six inches in length and three feet in breadth, while it may weigh nearly three quarters of a ton. Of course it is not at all easy to capture such big creatures. But they are generally pursued when they come on shore to lay their eggs, and are turned over on their backs by means of a lever. They are then perfectly helpless, and can be left lying where they 


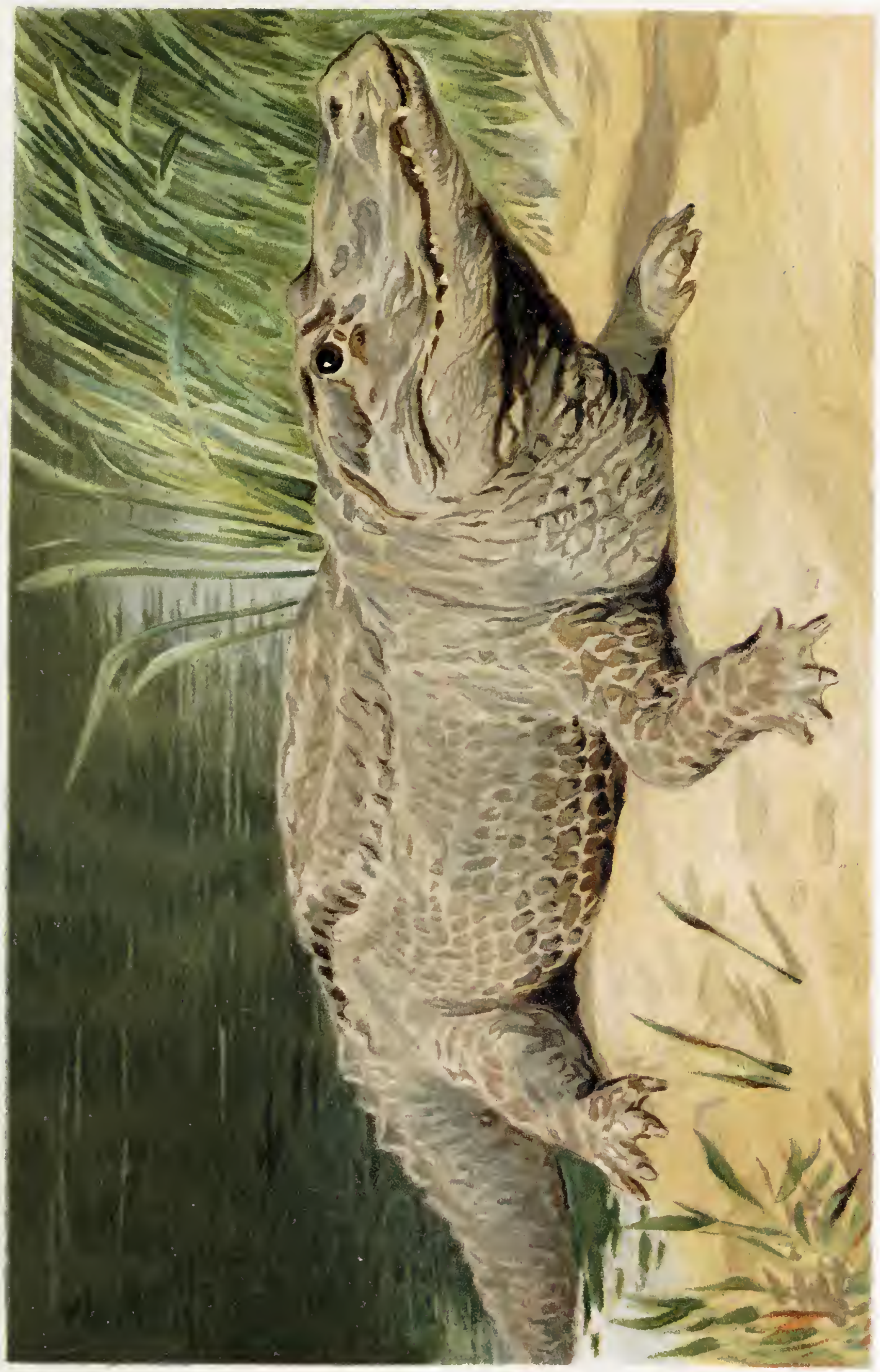



are until a number of others have been overturned in the same way, when they are lifted into a boat one by one, and are taken on board ship. There they thrive quite well if a pail of water is thrown over them two or three times a day, and are generally in very good condition when they reach this country.

It is said that if one of these turtles has once begun to lay her eggs in the sand, nothing will induce her to pause in her task until she has finished it, and that even if the eggs are taken away from her as fast as she lays them, she will still go steadily on just as if she were undisturbed.

Next in order to the Tortoises and Turtles come the huge creatures which we call Crocodiles and Alligators. Of course

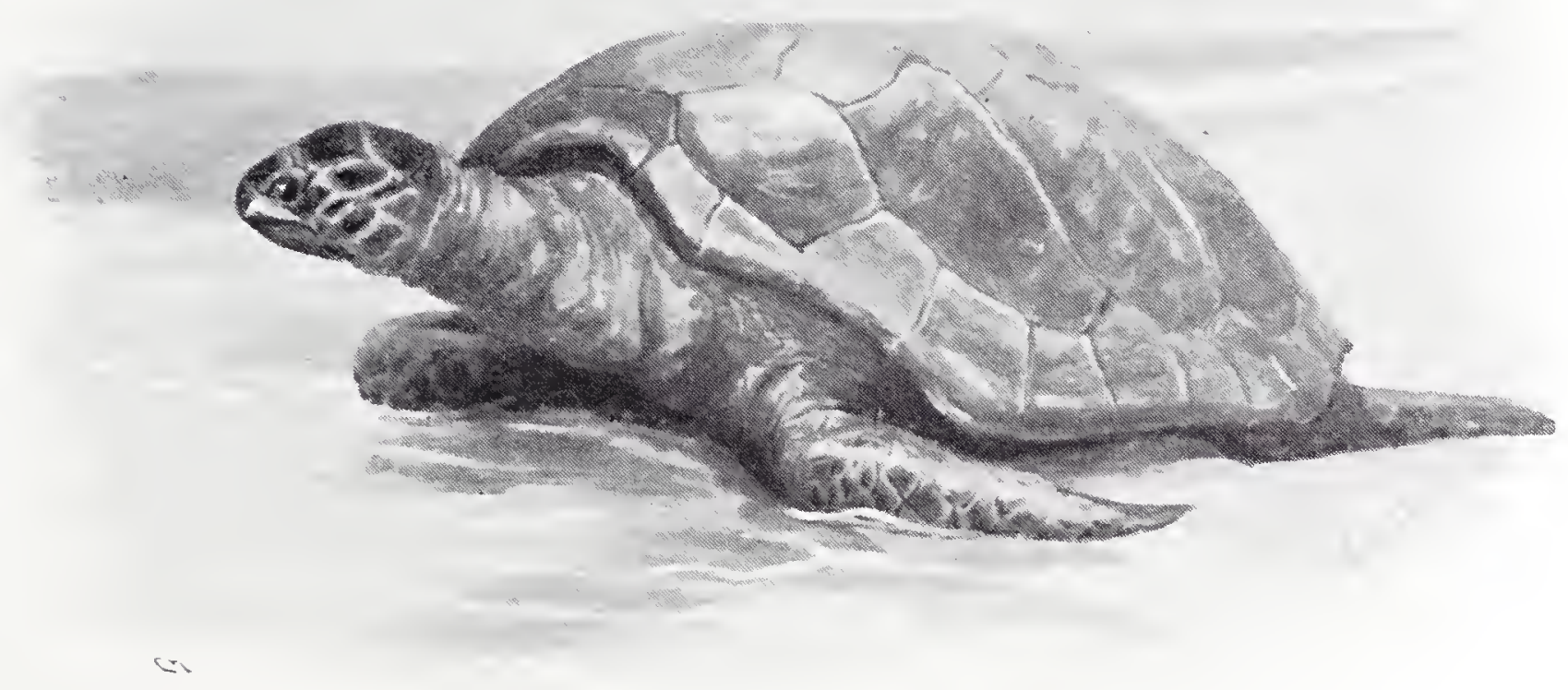

Green Turtie.

you know what they are like. They are just enormous lizards, fifteen, or twenty, or even thirty feet long, with very short legs, and very clumsy bodies, and very long tails. And their great jaws are armed with rows of most terrible teeth.

But what is the difference between crocodiles and alligators?

Well, in some ways they are certainly very much alike; but you can always tell them by the shape of their heads, for the inuzzle of a crocodile is always narrowed just behind the nostrils, while that of an alligator is not. And in the crocodiles the fourth lower tooth fits into a notch in the edge of the upper jaw, so that you can distinctly see it even when the mouth is closed.

All these creatures live in the water, and spend a great deal 
of their time lying motionless on the surface, when they look just like floating logs. One would think that they were fast asleep. But woe betide any animal which comes to drink from the bank close by, for one of the great reptiles instantly dives, swims swiftly along under water, and linoclis it into the stream by a blow from its mighty tail.

There is scarcely any animal which does not fall a victim at times to these giant lizards. And as soon as the unfortunate creature is knoclied into the water it is dragged beneath the surface, and held there until it is drowned. You would think that the reptiles themselves would be drowned, wouldn't you, as they have to remain submerged for many minutes with their javs widely opened? But they have a very curious valve at the back

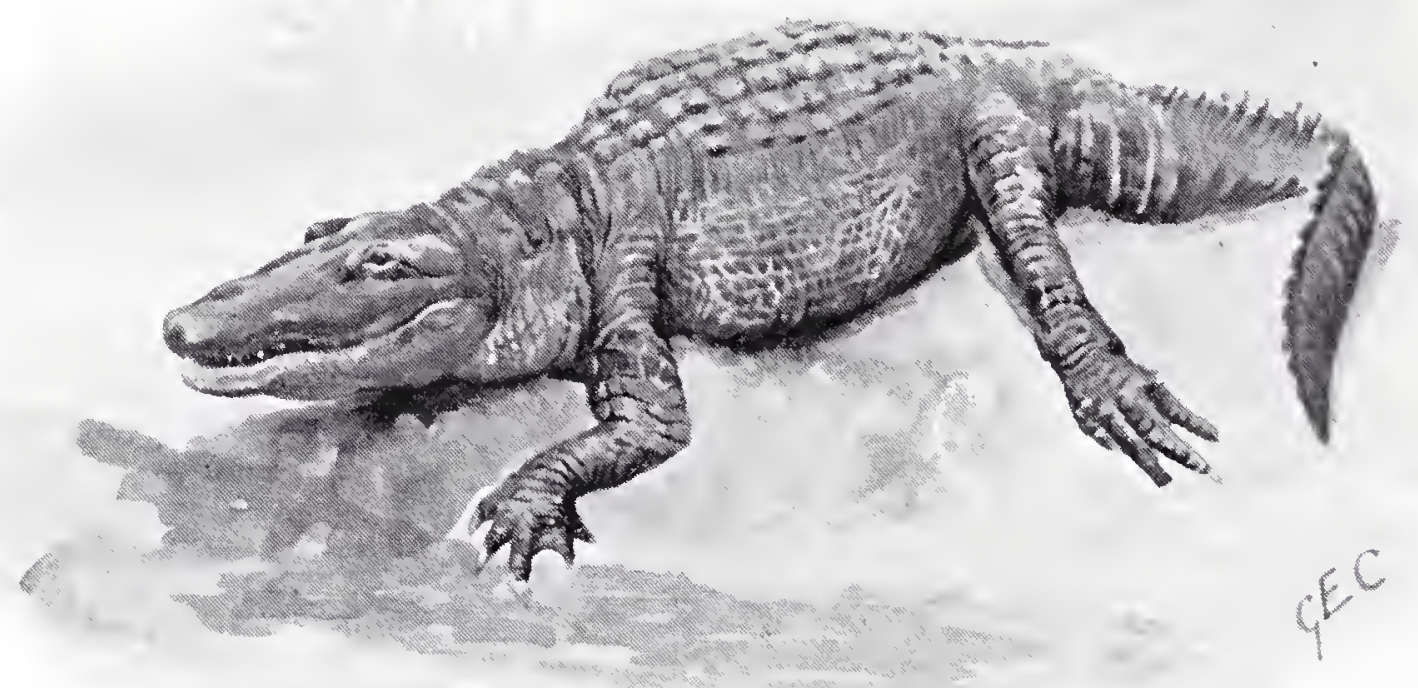

ALLIGATOR.

of the throat, and as soon as the mouth is opened this closes so tightly, that not even the tiniest drop of water can find its way down the throat.

Both crocodiles and alligators swim with very great speed by waving their powerful tails from side to side in the water. They can run, too, with some little pace upon land. But it is very easy to avoid them, for the bones of their necks are made in such a way that they cannot turn their heads, and all that one has to do if pursued is to spring suddenly to one side. But of course it is necessary to avoid the stroke of the tail.

These great lizards always lay their eggs in the sand on the bank of a river. The eggs are about as big as those of a goose, and are generally buried at a depth of a couple of feet. 
The mother reptile always sleeps on the top of the nest, and it is said that when the little ones are ready to hatch out they utter a curious little cry. The mother hears this, and scoops avay the sand under which they are buried, in order that they may have no difficulty in making their escape.

Crocodiles are found in the warmer parts of Africa, Asia, America, and Australia, and in some of the larger rivers are very plentiful indeed. Just now and then they venture down into the sea. Alligators, which are also known as "caimans" and "jacaras," are only found in America.

Three kinds of Lizards are found in the British Islands.

The first of these is the pretty and graceful little Scaly LizARD, which you may see on any warm, sunny day darting actively about on heaths and commons. When the sun is hot it

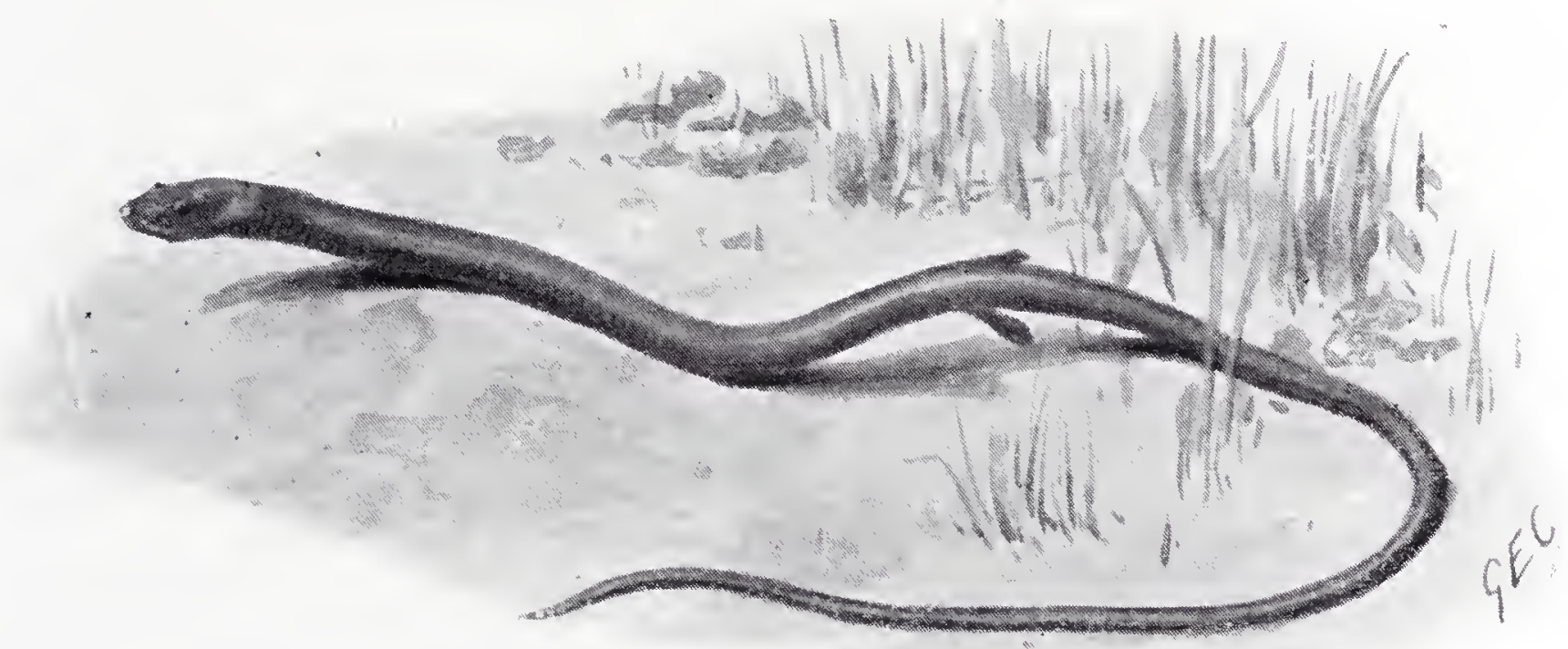

SCALY LIZARD.

is so quick in its movements that it cannot be caught without great difficulty, for it seems to know exactly when one is going to try to seize it, and suddenly dashes into the middle of a clump of heather or furze. But when the weather is cold it becomes quite torpid, and never leaves its retreat at all.

This lizard feeds upon flies and small insects, which it snaps up by means of its long and sticky tongue before they have the least idea that they are in any danger.

It is not very easy to describe the Scaly Lizard, because it varies a good deal in colour, so that you may sometimes find half a dozen examples one after the other, no two of which will be quite alike. But the upper part of the body is generally dark greenish-brown, and the lower part yellow, with black spots in the male and greyish ones in the female. The reptile grows to a total length of about six inches.

The second of the three British Lizards, which is generally 
known as the SAND LIZARD, is even more variable still. Its colour seems to depend a good deal upon the place in which it lives, for those lizards which are found among grass are generally green, while others which come from sandy heaths are brown. It is not quite so quick in its movements, perhaps, as the Scaly Lizard, but on hot day's, nevertheless, it cannot be caught without some little difficulty.

This lizard lays its eggs in the ground, generally scraping a hole for them in the side of a sandy bank, covering them lightly over, and then leaving them to be hatched by the heat of the sun. When once the eggs have been laid the mother reptile never troubles herself about them at all; so that even if she were to meet them later on, she would never know her own little ones!

You can tell the Sand Lizard from the Scaly Lizard in several ways. In the first place, its head has a much blunter and more stumpy look about it. In the next place, there is nearly always a tinge of green, at least on its sides. In the third place, its tail is not nearly so long in proportion to the size of the body. And in the fourth place, it is considerably larger, being sometimes nine or ten inches in total length.

The third of our British Lizards does not look in the least like a lizard. It loolis much more like a snake, for it is covered with scales, has no legs at all, and glides over the ground just as a snake does. No doubt you have often seen it as you walked through the fields-a slender brown creature about ten or twelve inches long, with a very shiny skin, and sometimes a dark streak running down the middle of its back. And no doubt, too, you were quite afraid to pick it up!

Yet the Blindworm, or Slowworm, as this creature is called, is perfectly harmless. It cannot bite you, for its teeth are far too tiny to pierce the slin; and it cannot sting you, because it has no sting! There is its odd little forked tongue, of course, which is always darting in and out of its mouth, just like that of a snake. But then this tongue is only a feeler. A great many people are very much afraid of it, no doubt; but if you watch a blindworm for a little while, you will notice that whenever it comes to an object it does not quite understand, it touches it gently all over with the tip of its tongue, just as we might touch it with the tips of our fingers. Now that is the only use to which the blindworm ever puts its tongue, and you need not be in the very least afraid that it can hurt you.

Notwithstanding its name, the blindworm is not blind, for it has a pair of very good, though rather small, beady black eyes. And, of course, it is not a worm.

During the day-time the blindworm mostly lies hidden underneath a large stone; and on turning such a stone over, one may sometimes find two or three of these lizards all coiled up together. But in the evening they leave their hiding places, and go out to search for the tiny white slugs on which they feed. 
When it is suddenly startled the blindworm sometimes behaves in a very odd way indeed. It stiffens its body, gives a kind of shudder and a twist, and actually snaps off its own tail! Then the tail begins to writhe about on the ground, wriggling and curling and even leaping up into the air in the most curious manner; and while you are watching its antics, the blindworm creeps away into some place of safety! You would think that it must suffer a great deal of pain from this extraordinary injury, wouldn't you, and that the blindworm would feel it quite as much as a man would feel if his leg were cut off? But, strange to say, it does not seem to suffer at all; and stranger still, a new tail very soon begins to grow in the place of the old one, so that in the course of a very few weeks the lizard is just as perfect as it was before! SKINkS are queer little lizards with four short legs and very

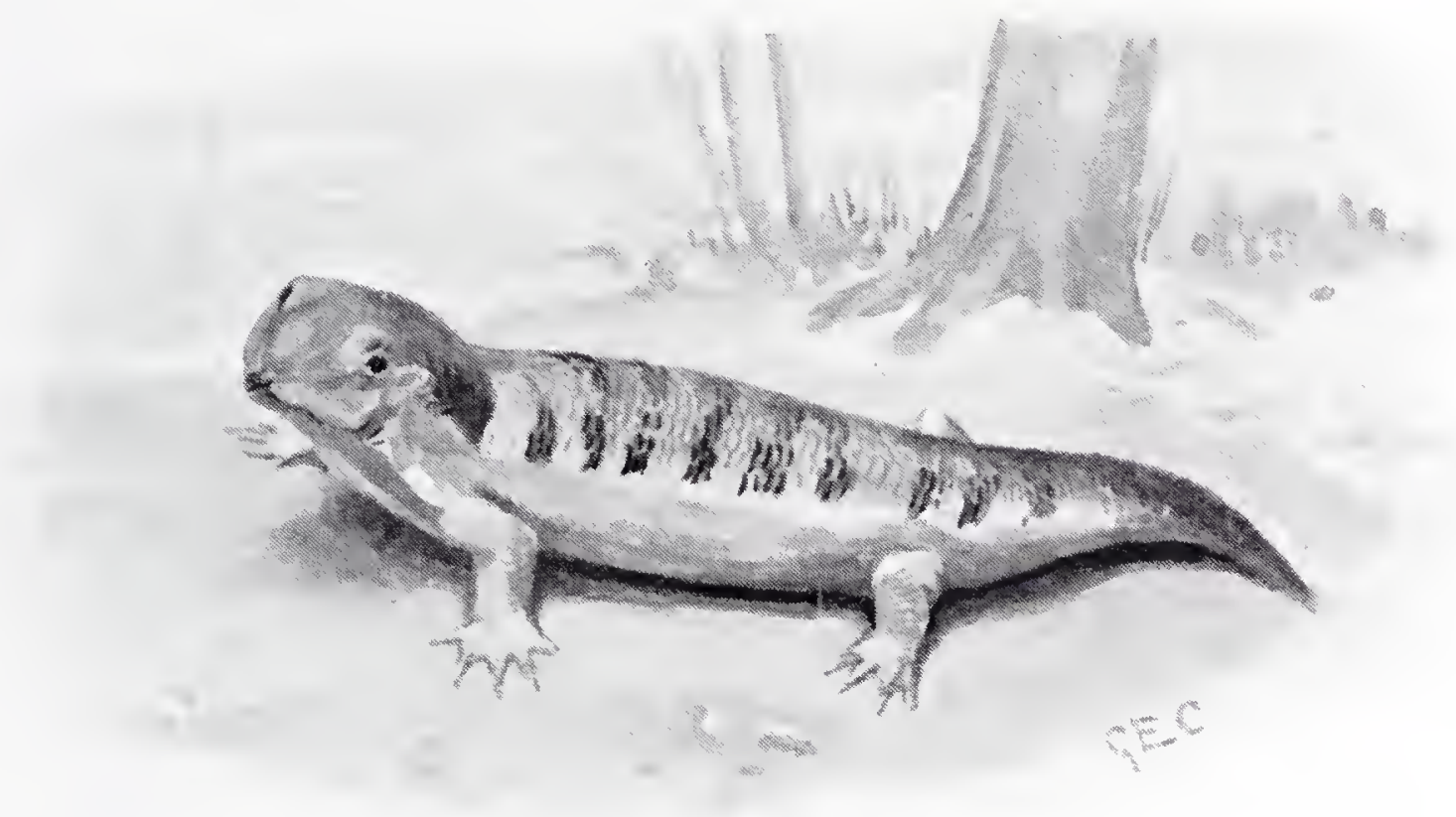

COMMION SKINK.

stumpy tails, which are found in many parts of Africa and Asia. They live in sandy deserts, and are rather slow in their movements as a rule. But if a fly should settle anywhere near them they will dart upon it with the most surprising quickness, and will hardly ever fail to capture it. And if they are alarmed they will burrow into the sand so rapidly that they really seem to sink into it just as if it were water. In a very few seconds, indeed, they will bury themselves to a depth of at least two or three feet.

In olden days skinks were very much used in medicine, and the powder obtained from their dried bodies was thought to be a certain cure for many diseases! It does not seem a very nice idea, does it? Yet even to this day skinks are used for the same purpose in Eastern countries.

There are several different linds of these curious lizards, of 
which the Common SkInk, found in Northern Africa, is the best known. It is about three inches and a half in length, and is yellowish brown in colour, with a number of darker bands on the sides of the body.

Odder still are the Geckos, which have their toes swollen out at the tips into round sucker-like pads, by means of which they can climb a wall or a pane of glass with the greatest ease, or even walk about like flies on the ceiling. They are very fond of getting into houses, generally remaining hidden in some dark corner during

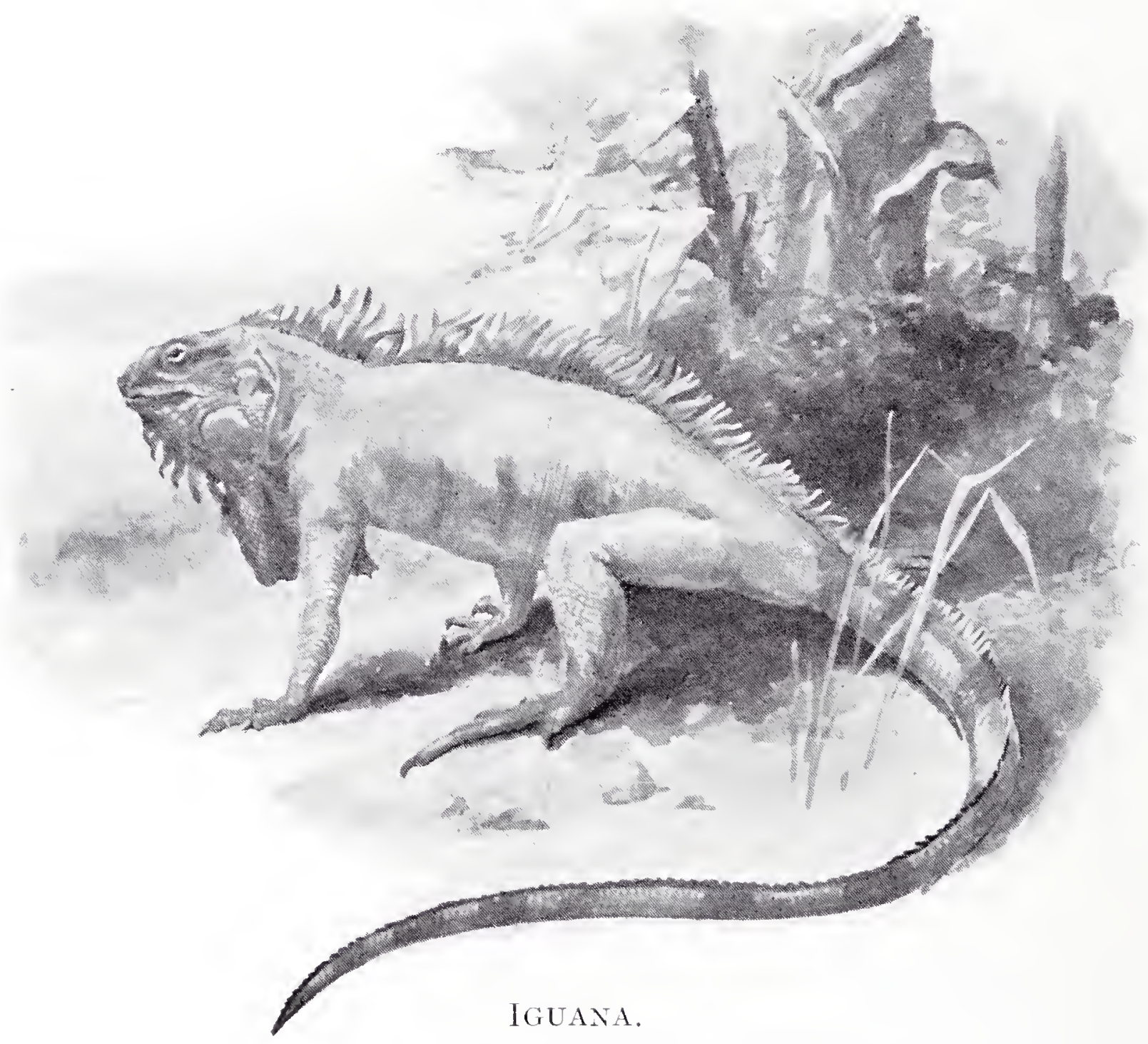

the day, but coming out towards evening to search for insects, and continually uttering their curious little cry of "geck-geck-geck-o."

People used to be very much afraid of geckos, some thinking that they could squirt out poison from the pads of their toes which would act like the sting of a nettle, and others declaring that their teeth were so sharp and strong that they could pierce even a sheet of steel! But the real fact is that these lizards are perfectly harmless, and cannot injure any living creature except the insects upon which they feed. When they take up their quarters in a house they soon become extremely tame, and will eren climb up on the dinner-table to be fed. 
Geckos are found in almost all hot countries, and nearly three hundred different kinds have been found altogether.

Next we come to the very curious lizard known as the IGUANA. This is quite a large animal compared with those about which we have just been reading, for when it is fully grown it is at least four feet long from the muzzle to the tip of the tail. And it looks rather a forbidding creature, for a row of sharp spilies runs right along its back, while underneath its chin is a great dewlap. Yet it is not quite so terrible as it seems, for though it will bite fiercely if it is driven to bay, and use its long tail like the lash of a whip, it will always run away if it can, and will either climb into the topmost boughs of a tree, or plunge into a stream and swim away.

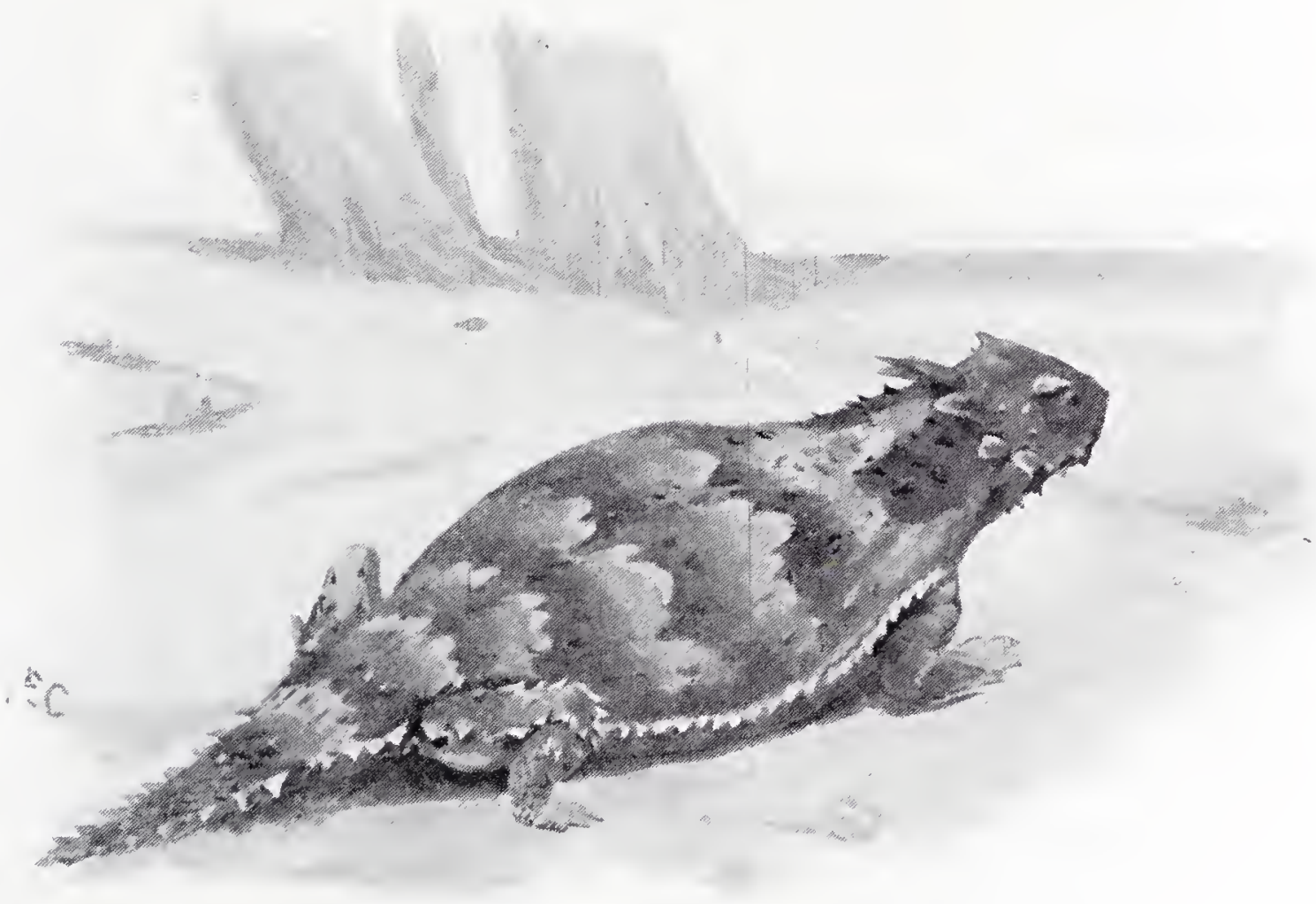

HORNED TOAD OF CALIFORNiA.

This reptile is a very good swimmer, driving itself rapidly through the water by waving its long tail from side to side, just like a crocodile or an alligator. And it can dive beneath the surface and remain at the bottom for a very long time without coming up to breathe.

Iguanas are found in the warmer parts of America, living chiefly among the branches of trees which overhang the water. Their flesh is said to be very good to eat, and to be quite as tender as the breast of a young chicken. Their eggs, too, which they bury in the sand on the river bank, are often used as food, and it is said that, no matter how long they may be boiled, they never become hard.

Now I must tell you about just three more lizards, all of 
which are very curious and interesting. Indeed, I scarcely know which of the three is the oddest.

The first of these creatures is the HORNED TOAD of California.

Of course it is not really a toad at all; but it is so called because it sits in a very toad-like attitude. And it has two great peculiarities.

One of these is that it is covered almost all over with long and sharp spikes. Those on its head, which are directed bacliwards, are the longest; and from these it gets its name of "horned" toad. But those on the back are very nearly as long, while there are several rows upon the tail as well. Indeed, the reptile rather reminds one of a tipsy cake! Yet it is perfectly harmless, for even when it is caught for the first time it never seems to use either its spikes or its teeth.

But it has another peculiarity which it sometimes uses as a means of defence, and that is a very strange one indeed. It actually squirts out little jets of blood from its eyes! That seems impossible, doesn't it? Yet there is no doubt at all about it, for when these lizards have been kept in captivity, and have been rather roughly handled, they have been known to squirt several drops of blood at a time to a distance of twelve or fifteen inches! Yet nobody seems to know how they do it.

Horned toads are quite common in some parts of California, and are mostly found in sandy districts, where they feed chiefly upon ants and tiny beetles.

Next comes the FriLLed LizARD, which is a native of Australia.

This creature is not in the least like the horned toad, but in appearance is even odder still, for all round its neck it has a kind of frill, or ruff, from six to eight inches in diameter! As a rule this frill is folded round the throat, so that from a little distance one would scarcely notice it. But as soon as the reptile is excited or alarmed it spreads it out, sits on its hinder legs and its tail, raises its head and body, and shows its teeth, just as if it were going to fly at its enemy. This is only pretence, however, for though the lizard grows to a length of nearly three feet, it is quite harmless.

Another very curious habit which this lizard has is that of walking upright on its hind legs, in the attitude of a dog when "begging." It will even run in this position, and most odd it looks. In fact, it has been compared to a batsman at cricket when running between the wickets! It is a capital climber, and spends most of its life in the trees, to which it always tries to escape when it thinks itself in danger. with black.

In colour the frilled lizard is yellowish-brown mottled

Strangest of all strange lizards, however, is the Chameleon.

In the first place, this lizard has a very long tongue, which it can dart out to a really wonderful distance from its mouth. 
This tongue looks very much like a worm, and is exceedingly sticky, so that all that a. chameleon has to do when it sees a fly settling near it is to dart out its tongue and touch it with the tip. Then the fly adheres to it, and is carried back into the mouth so quickly that it is almost impossible to see what becomes of it. In this way it can catch a fly at a distance of fully six inches.

Then the chameleon has most extraordinary eyes. They are about as big as peas; but instead of having lids which move up and down, as ours do, they are entirely covered by the lids with the exception of just a tiny round space in the middle. The lizard sees, in fact, through a hole in the middle of its eyelid! That is strange enough, isn't it? But what is even stranger still is that the animal can move its eyes in different directions

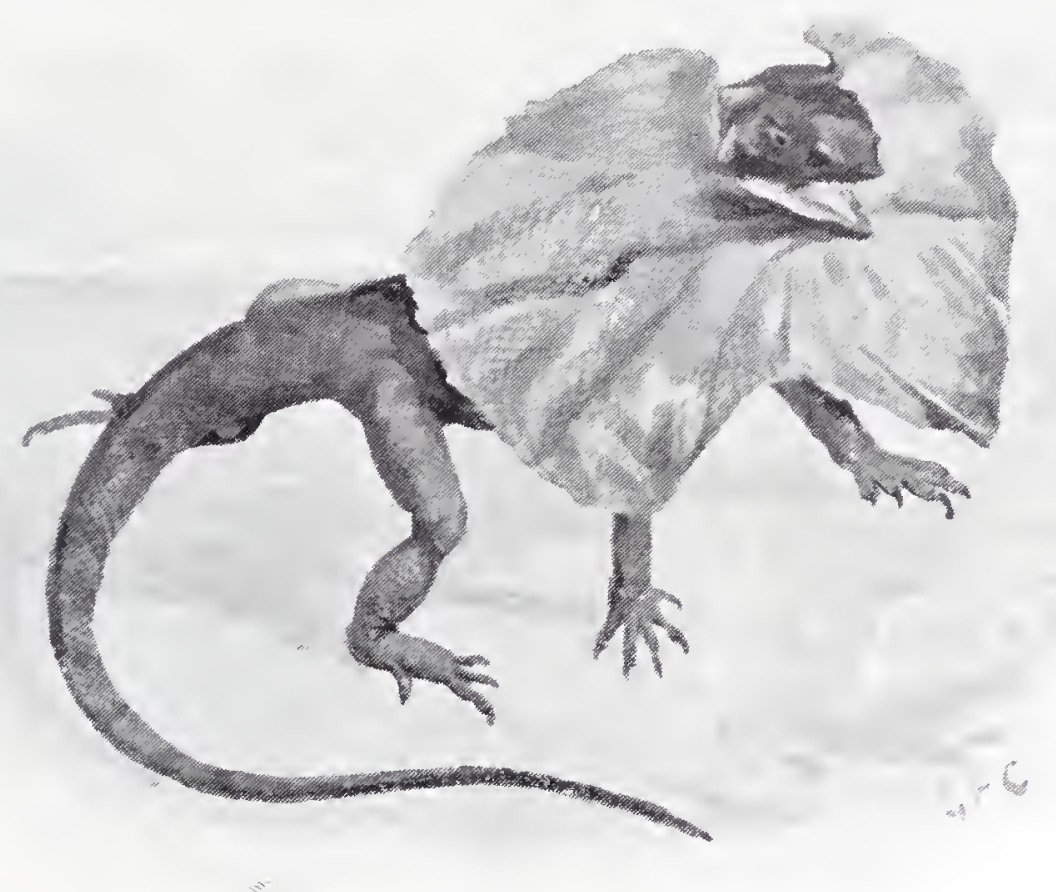

FRILLED LIZARD.

at the same time! They are hardly ever still for a single moment. But instead of moving together, like those of all other animals, one may be looking upwards towards the sky and the other downwards towards the ground; or the right eye may be peering forwards in front of the nose while the left one is glancing backwards towards the tail! Indeed, it would be very difficult to find an odder sight than that of a chameleon when it is moving its eyes about. They really look just as if they belonged to two different animals.

But the most wonderful fact of all about the chameleon is that it can change its colour whenever it chooses!

How it does so no one quite knows. But the very same animal which is brown all over as it sits upon a branch will 
become green all over if you put it among leaves. The last thing at night, probably, you will find that it is grey. Next day, perhaps, brown spots will appear upon its body, and pinkish stripes upon its sides. And occasionally it may be violet, and sometimes yellow, and sometimes nearly black! So that if you were to go and look at a chameleon, and then go and look at it again half an hour afterwards, you might very likely take it for a perfectly different animal!

Then the chameleon has very odd habits.

If it is annoyed, for example, it puffs out its body in the

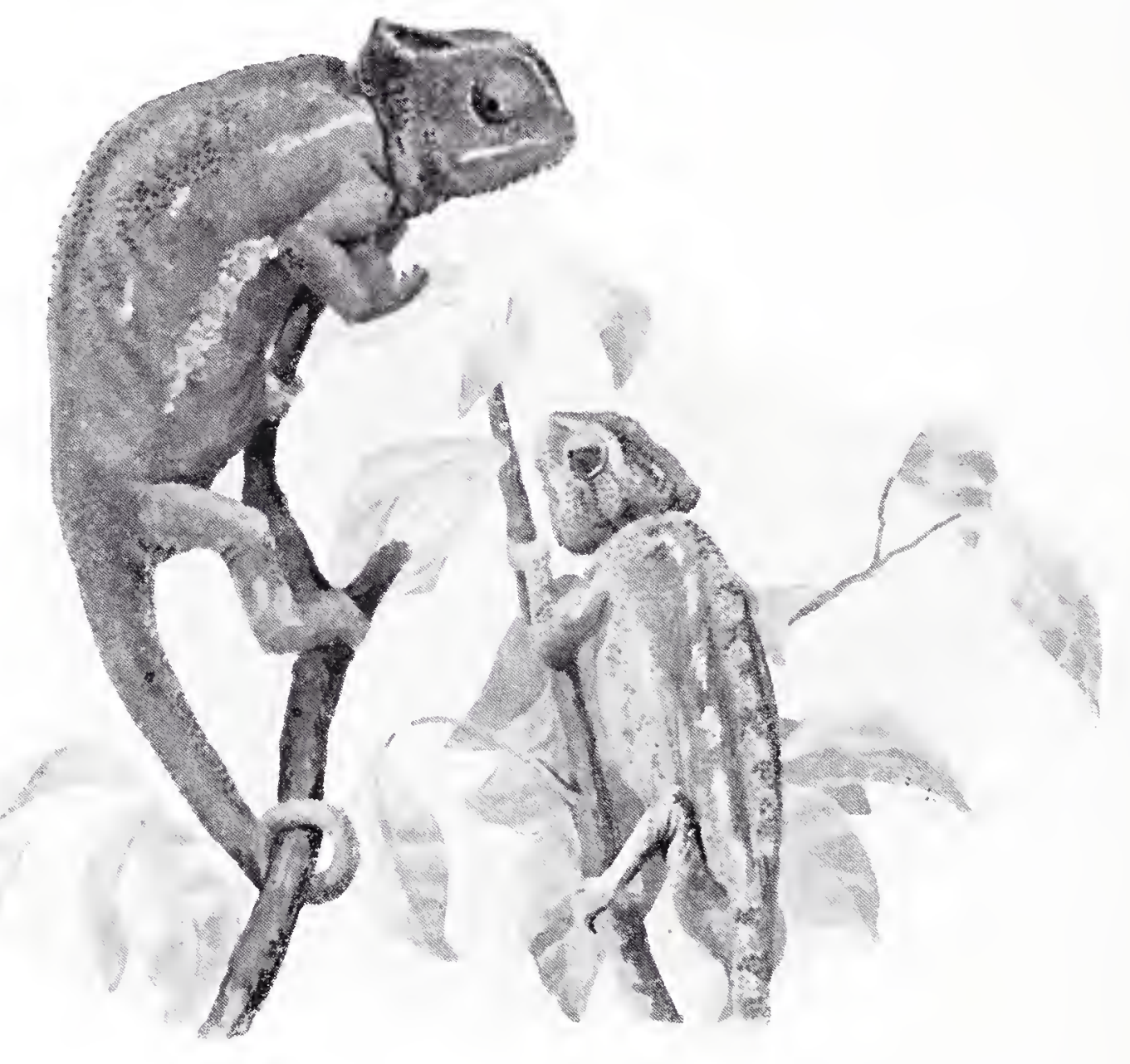

CHAMELEONS.

most extraordinary way till it is nearly double its ordinary size and its slin is stretched almost as tightly as the parchment of a drum. When it is caught it hisses like a snake. And really it must be the very laziest creature on earth. If it lifts a foot into the air it will often wait for quite a minute before it puts it down again, and for two or even three minutes more before it talies a second step. Then it always has to rest for some little time after uncoiling its tail from a branch, while when it coils it round another it stops and rests again. It will hardly travel a couple of yards, in fact, in a day.

Chameleons are found in many parts of Africa and Asia and also in south-eastern Europe. 


\section{CHAPTER XXVIII.}

\section{SNAKES.}

THERE are a great many different kinds of snakes; but before we read about some of them, I must tell you something about the wonderful way in which their bodies are made.

In the first place, then, remember that snakes have a very large number of those little joints in the spine which we call "vertebræ." We ourselves only have thirty-three of these little joints when we begin life, and twenty-six afterwards; this difference in number being caused by the fact that five of the joints very soon unite into a bony mass, which we call "sacrum," while four more unite into another, which we call the "coccyx." But some snakes have hundreds of these vertebra. The boa constrictors, for example, have no less than three hundred and four!

In the next place, remember that all these vertebra are fastened together by what we call "ball-and-socket" joints. 'That is, there is a round knob at the back of each vertebra which fits into a socket in front of the vertebra behind it. This gives to the spine of a snake great strength, for a vertebra cannot be forced out of its place without breaking the vertebra behind it. And it also allows the spine to be curled and twisted about in almost any direction; so that a snake can easily coil up its body like a spring, or even tie it into a knot.

Then, remember that a snake has a great many ribs. Ve have twelve pairs of these important bones, most of which are jointed to the breast-bone in front. But a snake may have as many as two hundred and fifty-two pairs of ribs, while it has no breast-bone at all; so that the tips of all the ribs are free. And every rib is fastened to a vertebra of the spine by a balland-socket joint, just like those which fasten the vertebra themselves together. Besides this, there are no less than five separate sets of muscles connected with the ribs, so that the snalie can move those bones about quite easily.

It is really by means of its ribs that a snake is able to glide over the ground. If you were to look at the lower part of a snake's body, you would see that the scales are quite different from those on the upper part. On the back and sides the scales are quite small, and are almost oval, or oblong. But underneath the body they are very long and very narrow, like the laths of a Venetian blind.

Now the tips of every pair of ribs in a snake's body are 
fastened to one of these long scales in such a manner that when the snake moves the ribs forward the edge of the scale is raisedvery much as you can raise the laths of the Venetian blind by pulling the cord at the side. And the snalie travels by moving forward its ribs in turn, and catching hold of the ground with the edges of the scales, using first the ribs of one side and then of the other.

When a snake is crawling, however, it does not curve its body into upright loops, but keeps it pressed flat upon the ground, so that the scales may be able easily to take hold of any little roughness upon the surface. And when it climbs a tree it does not twine its body round and round the trunk, but crawls straight up it, just as it crawls along the ground.

Then the mouth of a snake is very curiously made. I am not speaking now of the fangs of the poisonous serpents; I will tell you about these by-and-by. But remember that the mouth must be made in a very strange way, in order to allow these creatures to swallow their victims, which are often a good deal larger round than their own throats.

It sounds impossible, doesn't it? Yet the snake can swallow an animal larger in diameter than its own throat quite easily, because the bones of its jaws, instead of being firmly fastened together as ours are, can be forced a long way apart, so as to make room for the carcase to pass.

besides this, it has no less than six separate jaw-bones, four in the upper part of the mouth and two in the lower, every one of which is set with sharp, hooked teeth; and the points of these teeth are directed towards the throat. Now every one of these jaw-bones can be moved backwards and forwards at will. So when a snake wishes to swallow the body of a victim, it first of all seizes it in its mouth, and then pushes one of the jaw-bones forward and takes a firm hold with the teeth. Then it pushes another forward, and then a third, and then a fourth; and so it goes on, each time taking a fresh hold with the hooked teeth, till at last the carcase is forced into the mouth. Then the bones separate, so as to make plenty of room for it to pass, and the alternate action of the jaws goes on as before till the carcase is forced into the throat. And then the flesh of the throat, which is very elastic, stretches out too, till before very long the carcase disappears altogether.

Then I must just tell you about the eyes of snakes, which are made in a very curious way incleed. For the eyelids, which are quite transparent, do not open and shut as ours do, but cover the eyes altogether. So a snake cannot blink; and it looks at you through its own eyelids, which are very much like little spectacle-glasses fastened into the skin!

When a snake throws off its skin, which it always does once in a year, and sometimes oftener, the eyelids are thrown 
off with it, and a pair of new ones are found lying below, all ready to take their place.

Now I must tell you something about the different linds of snakes.

First, there is the Grass Snake, or Ringed Snalie, which is very common in most parts of our own country. You can always tell it when you see it by the two bright yellow patches behind the head. And when you see a snake with these patches you need not be afraid of it, for it has no poison-fangs, and its

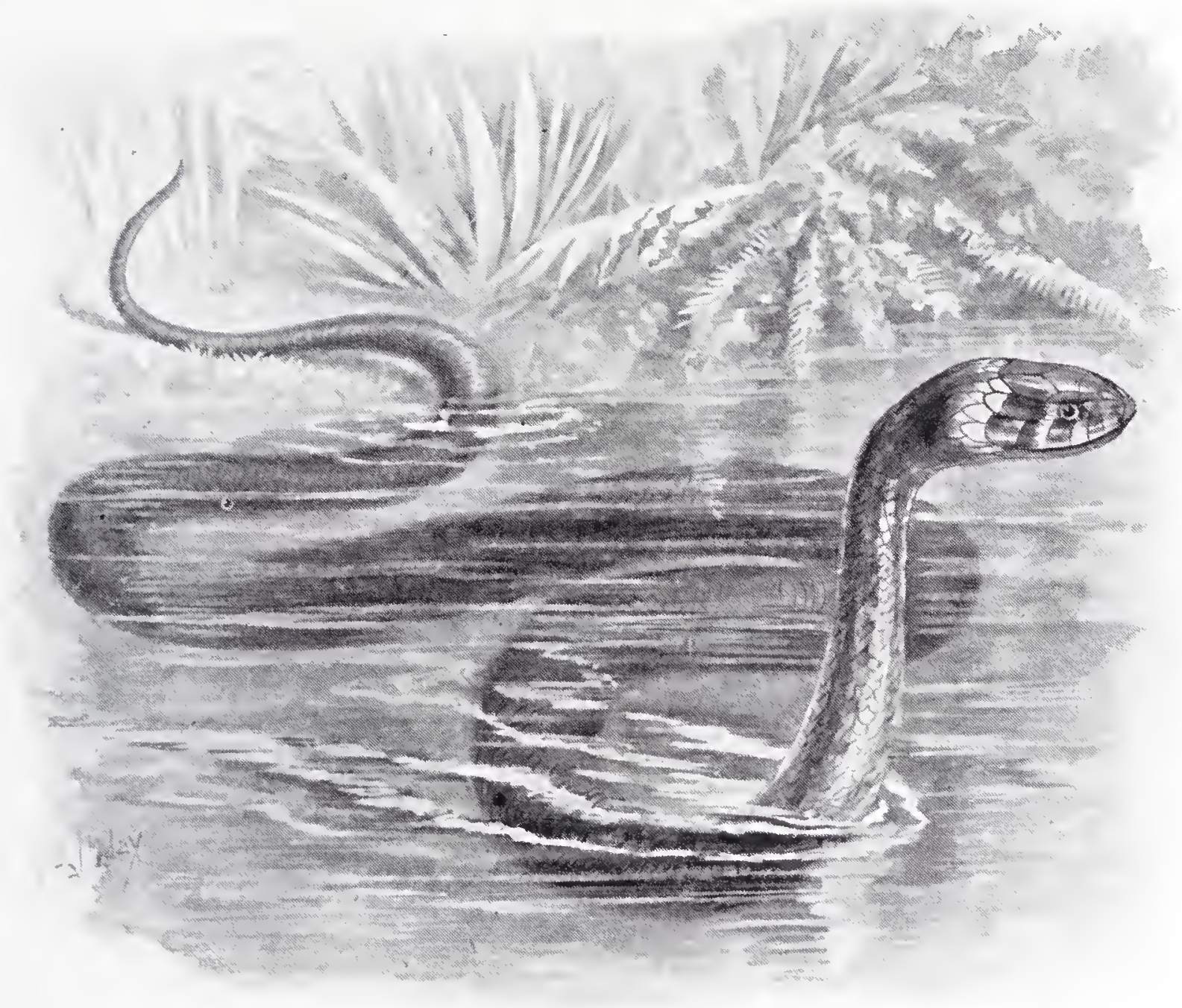

RINGED SNAKE.

teeth are not long enough to bite you. I do not altogether advise you to pick it up, however, for if you do so it will pour out a most disgusting odour all over your hand, which you will not be able to wash off for some little time. But at any rate it cannot really hurt you, and if you were to make a pet of it and treat it kindly, it would soon allow you to handle it without pouring out this unpleasant odour at all.

The grass snake feeds chiefly upon frogs. But its appetite is not a very large one, for it has been found that the snake will remain in perfect health if it only has three frogs to eat during 
the year! It would seen rather odd, wouldn't it, if we ourselves had breakfast about the end of April, dimner in the middle of July, and supper early in September, and then went without any meals at all till the following spring? But really that is just what a snake does without seeming to suffer from hunger at all.

But sometimes the grass snake will eat mice and young birds, and now and then it will enter the water and catch a fish. It is a capital swimmer, driving itself along by means of its tail; and it can also remain at the bottom for a long time without coming up to the surface in order to breathe.

The eggs of the grass snake are about twenty in number, and are nearly always buried in a heap of decaying leaves, so that they may be hatched by the warmth. Sometimes you may find them by digging in a hot-bed, and, if you do, you will notice that they are all fastened together by a kind of white cord.

Early in the autumn this snake hides away in some snug retreat and falls fast asleep until the spring, just like the squirrel and the hedgehog and the dormouse.

Very curious indeed is the EGG-EATing SNAkE, which is nearly always to be seen in the reptile house at the $Z$ oo. It is quite a small snake, not more than two feet long, and scarcely thicker in body than a man's little finger; yet it will swallow pigeons' eggs quite easily, and, if it is very hungry indeed, will dispose of a hen's egg! This, of course, is owing to the way in which the bones of the mouth are made. But if you were to watch one of these snakes as it was eating an egg, you would see a very strange thing happen. The egg would pass down the throat, and for a few moments you would be able to watch its outline as it moved along towards the stomach. Then, quite suddenly, the swelling would disappear! The fact is this. About thirty of the vertebra have each a long, slender spine springing from the lower surface, and the tips of these spines pass through the upper part of the throat and project inside it, just like a row of little teeth in the wrong place. Just as the egg, while it is being swallowed, comes against these teeth, the snalie contracts the muscles of its throat. The result is that the teeth pierce the egg from end to end and cut it in two. 'Then the contents flow onwards down the throat, while the two halves of the shell, nearly always packed one inside the other, are shortly afterwards returned through the mouth.

Isn't that an odd way of eating eggs?

The egr-eating snalie is found in South Africa, and spends nearly all its life in the trees.

The Pythois are very formidable snalies indeed; not because they are venomous-for they have no poison-fangs-but owing to their immense size and strength. When fully grown they may measure as much as thirty feet in length, while their bodies are as big round as a man's thigh: and even when they 
are only half as long they are still most dangerous creatures, for they could crush a man to death in two or three minutes.

When a python attacks, it seizes its victim with its jaws, flings its coils one over another around it, and then squeezes so hard that in a very few minutes the bones fly into splinters, and the body is reduced to pulp. And a large python can swallow a half-grown sheep or a good-sized dog without any difficulty at all.

After the snake has swallowed its victim it beconnes very drowsy, and often sleeps heavily for several days.

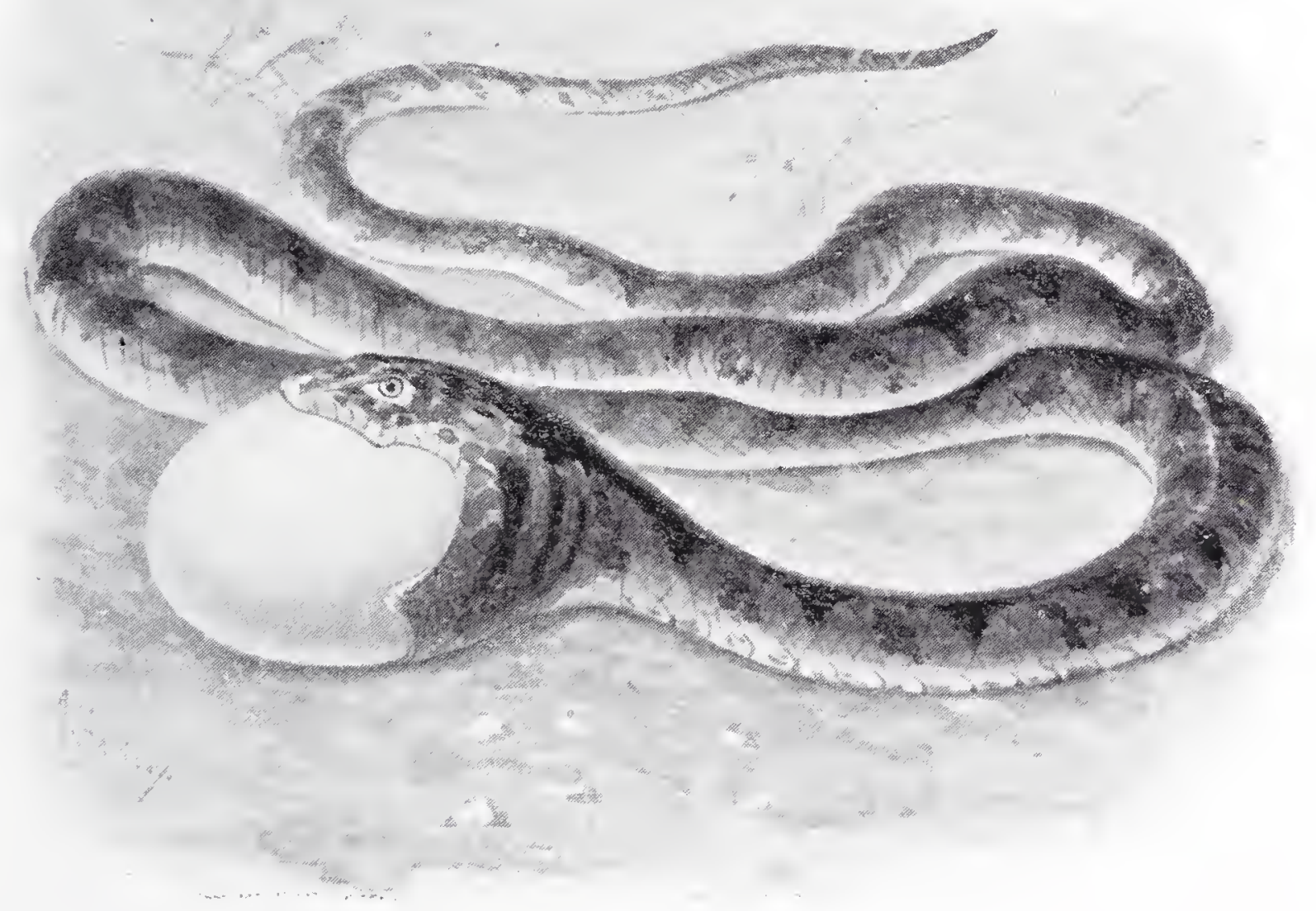

EGG-EATING SNAKE.

Another very curious fact with regard to the python is that it actually hatches its eggs by the warmth of its own body. It first collects the eggs into a little pile, and then coils itself round them, after which it remains perfectly still for nearly two months. During the whole of that time its bodily heat is much greater than usual, and at last the egg-shells split, and out from each comes a baby python. A fortnight or so later they change their skins, and then are quite large and strong enough to kill and swallow small birds.

Pythons inhabit nearly all the hotter parts of Africa, Asia and Australia, and are sometimes known as "Rock Snakes." 
BOA Constrictors are found only in tropical America and in Madagascar, and spend the greater part of their lives in the trees. They are quite as large as the pythons, and quite as formidable. It is said, indeed, that the ANACONDA, which is the largest of all, sometimes reaches a length of forty feet; and there is a stuffed skin, twenty-nine feet long, in the Natural History Museum at South Kensington. One can easily imagine what a terrible enemy such a snake as this would be, and how helpless even a strong man would find himself when wrapped in its mighty coils!

The anaconda is very fond of lying in the water with only just its head raised above the surface, and there waiting for some animal to swim within reach. But most of the boas lie in wait

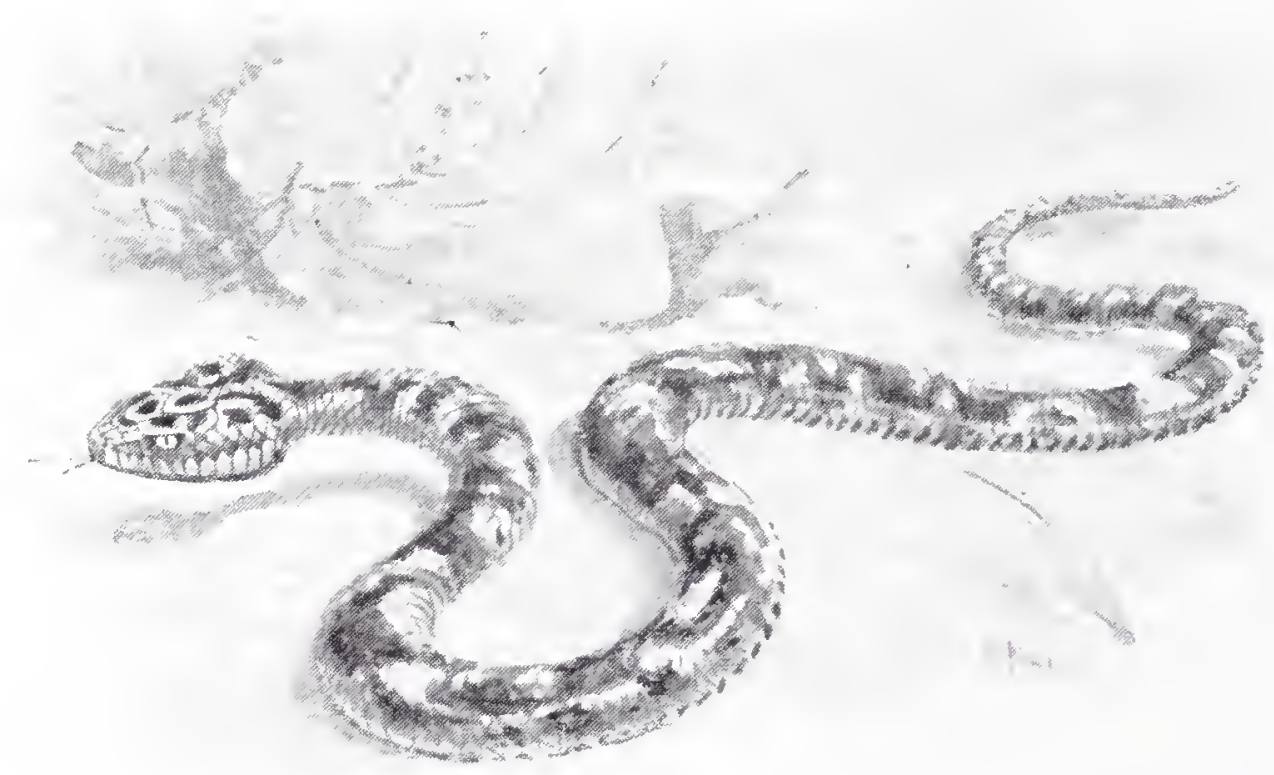

YIPLR.

for their prey on one of the lower branches of a tree, in readiness to strike at any small creature that may pass beneath.

Some years ago a most singular accident happened in the reptile house at the $Z$ oo. Two boas, one eleven feet long and the other nine feet, were living in the same cage, and always seemed on the very best of terms. One night a couple of pigeons -one for each snake-were put into the cage, and the house was shut up as usual. Next morning, however, when the keeper opened it, the smaller snake had disappeared, and there was no hole in the cage through which it could possibly have escaped. At first the keeper was puzzled; but soon he noticed that the larger serpent was not coiled up as usual, but was lying stretched out straight upon the ground. Then he understood what had happened. The big snake had swallowed the smaller one during the night, although it was only two feet shorter than itself!

Most likely hoth snakes had seized the same pigeon at the 


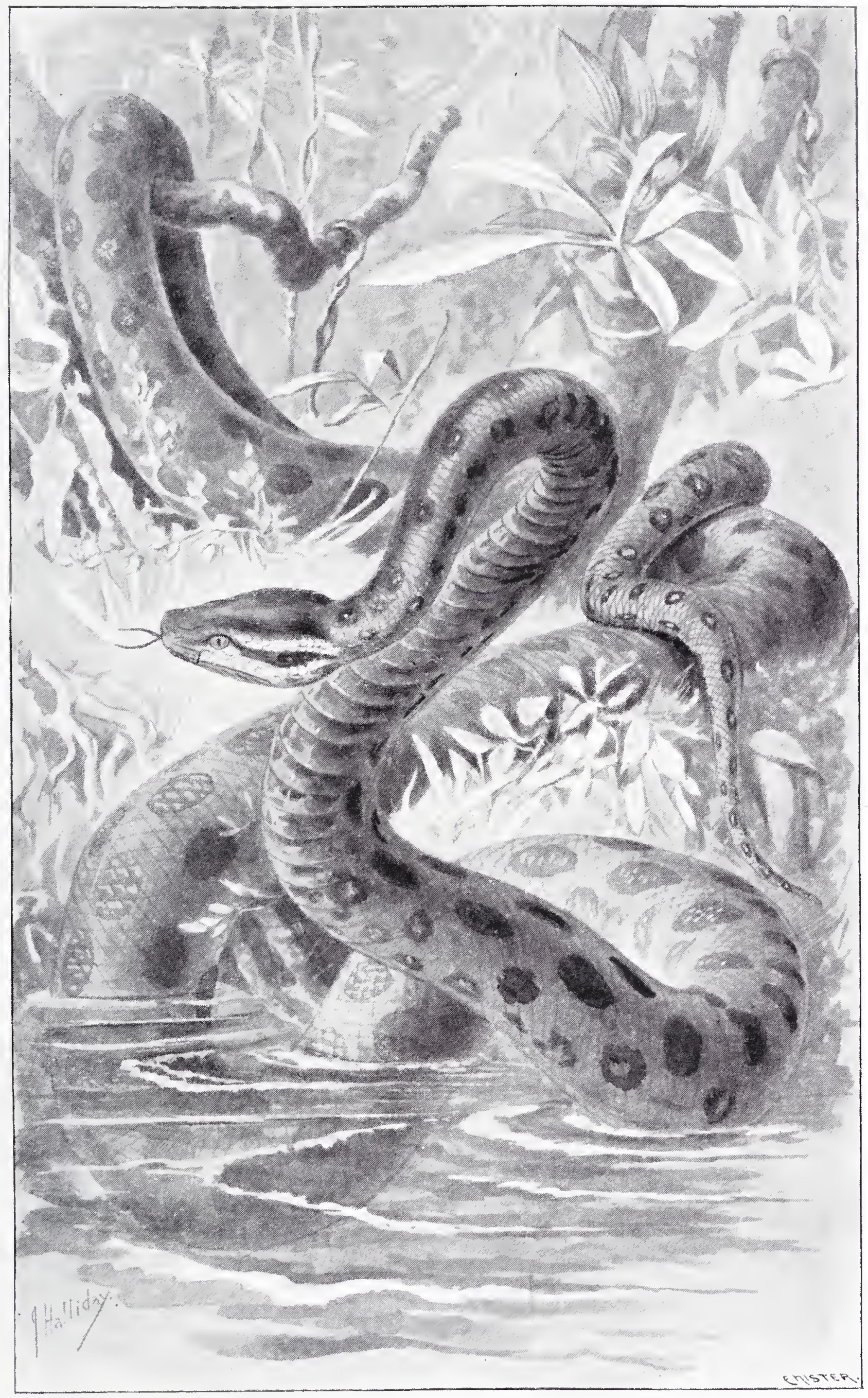

ANACONDA. 


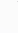


same moment. Before very long, of course, their jaws would have met in the middle. Now when one of these big snakes has once seized its rictim it cannot let go, because of the way in which its jaws and teeth are made, but must go on trying to swallow it. So, you see, when the jaws of the two snakes met in the middle of the pigeon neither could give the bird up to the other, because neither could withdraw its teeth, and the larger one, in fact, could not help swallowing the smaller! And since that time two or three other accidents of the same character have been prevented only by the constant watchfulness of the keeper.

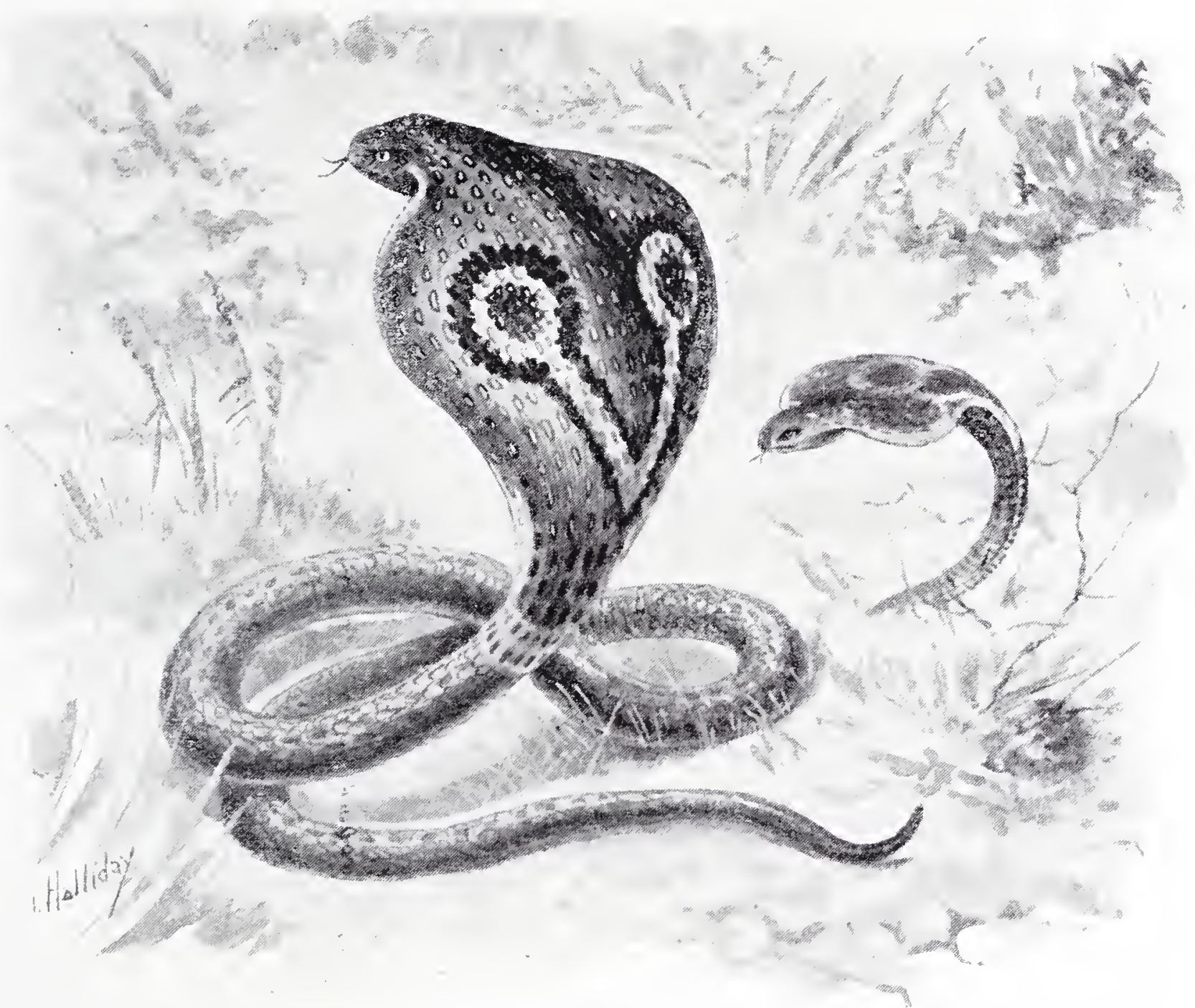

COBRA.

We now pass to the poisonous snakes.

In all these reptiles the poison-fangs are two in number, and are situated in the upper jaw. They are very sharp indeed, and are almost as brittle as glass. So while they are not in use they are folded back out of harm's way upon the roof of the mouth. But if by any chance they should be broken, there are three or four other pairs lying ready for use behind them which can always be moved forward to take their place.

Generally there is a tiny hole just underneath the tip of the fang, which opens into a narrow passage running right through 
the centre. But in some snalies there is only a groove outside the fang. In either case, however, the muscles which surround the poison-bag are arranged in such a way that as soon as the snake strikes its victim a drop of poison is squirted down each of the fangs, and so into the wound.

The only poisonous snake found in Great Britain is the Viper, or ADDER. It is not by any means a large snake, for it is seldom more than twelve or fourteen inches long, and you can always recognize it by the zigzag chain of black, lozenge-shaped marlings which rum all the way along its back. Besides that, it is without the yellow patches behind the head which are so noticeable in the grass snalie.

Vipers are generally found on heathy commons and moors, and are very fond of lying on a patch of bare, sandy ground and enjoying the warmth of the sun. They never attempt to bite unless

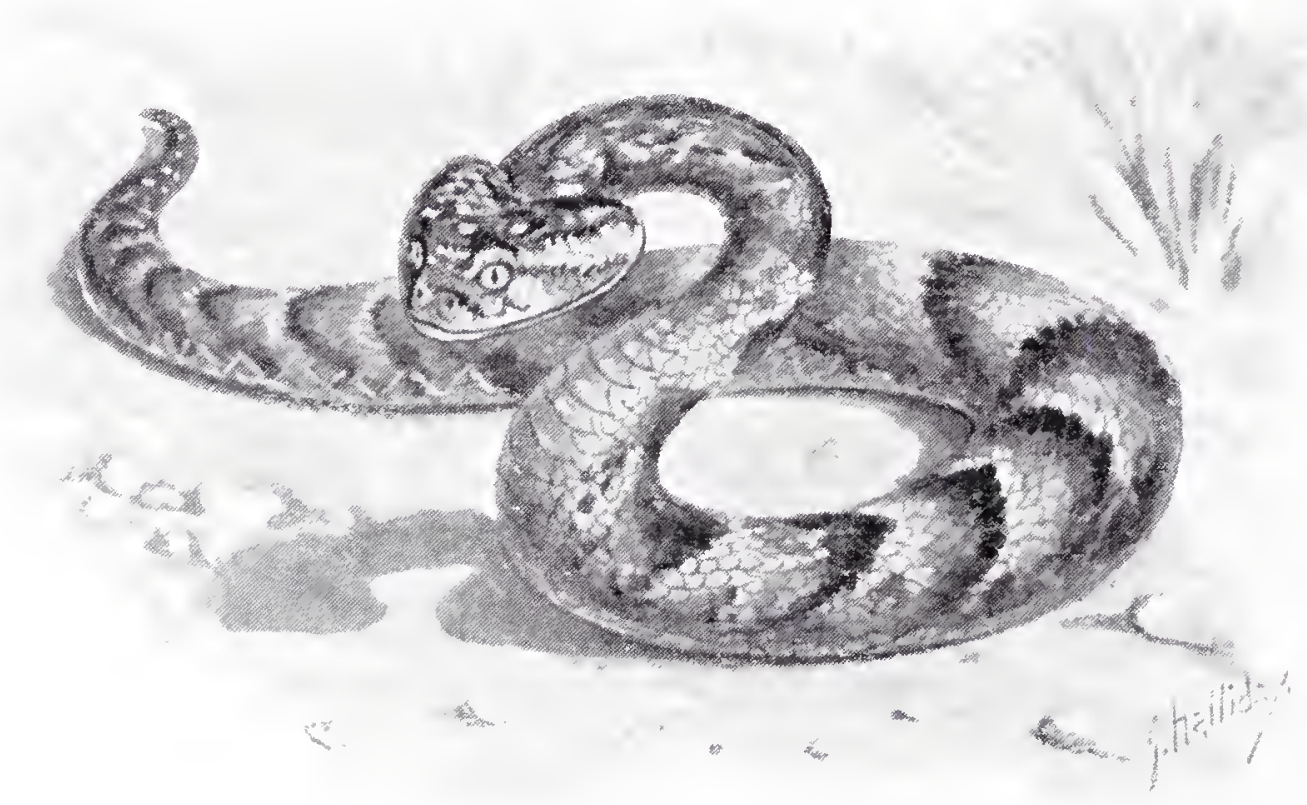

PUTIF ADHER.

they are interfered with, but always try to crawl away, if they are alarmed, into a place of safety. Their poison is not strong enough to liill a man, unless he happens to be in a very bad state of health at the time when he is bitten. But it would be quite sufficient to cause the bitten limb to swell up to double its size, and to lead to a great deal of suffering and sickness. So if y'ou should ever happen to meet with a viper, the best thing that you can possibly do is to pass by without meddling with it.

Far more deadly is the bite of the Copra, which is found plentifully in India. Indeed, anyone who is bitten by this formidable snake is almost sure to die within two or three hours.

The upper part of a cobra's neck is widened out into what is called the "hood," which can be spread out or folded up at will by the action of the ribs. On the upper part of this hood 
is a dark mark, which looks almost exactly like a pair of spectacles. When a cobra is about to strike it always raises its head and neck and spreads this hood before darting at its foe.

In many parts of India cobras are caught and tamed by men who are called "snake charmers," and who capture them by playing an odd tune upon a sort of wooden pipe. This music seems to fascinate the snake, which comes out of its hole, rears up its head and neck, and begins to sway slowly from side to side. Then, still playing, the charmer moves his right hand very slowly

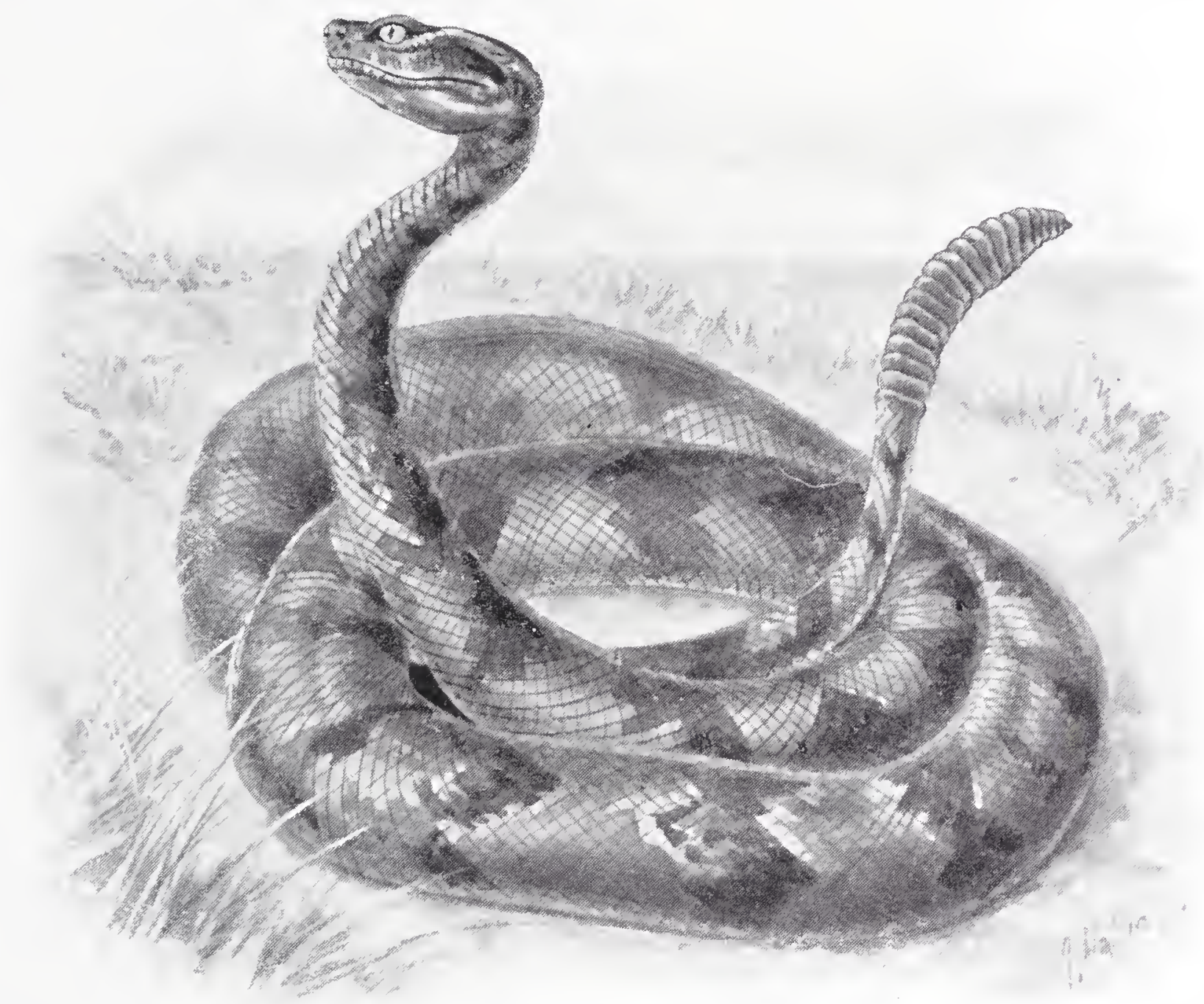

RATTLESNAKE.

indeed until it is just behind the snake's head, when he suddenly grasps the reptile round the neck. It is now, of course, quite helpless, and is quickly transferred to his bag.

Many charmers carry cobras about with them, which they handle quite freely. But in these cases the poison fangs have been carefully extracted, so as to render the reptiles harmless.

Cobras are very fond of eggs, and if they can find a rathole which opens into a hen-house they will often take advantage of it in order to rob the nests. But sometimes, when they have swallowed several eggs, and the hole happens to be a small one, they cannot crawl out again, and are found and killed when the house is openerl in the morning. 
Quite as deadly is the Purf Aduer, of Africa, which is a very dangerous snake indeed. For it has a way of lying almost buried in the sand, so that it is not easily seen. And if it is disturbed it does not crawl away, as most poisonous snakes do, but remains quite still, merely drawing back its head in order to strike. When fully grown it is about six feet long, and its poison is so deadly that even a horse has been known to die within two or three hours of being bitten.

This snake is called the "puff" adder because it draws in a very deep breath when it is annoyed or irritated, and puffs out its whole body to nearly double its proper size. It then allows the air to escape gradually, with a kind of sighing noise, and draws in another deep breath, and so on over and over again.

I can only mention one more poisonous serpent, namely, the famous Rattlesnake of North America.

This snalie owes its name to the curious "rattle" at the end of its tail. This rattle is made of a number of horny rings, which are fastened to one another, but yet can be moved quite freely. When the snake is disturbed, or irritated, it shakes its tail with a peculiar quivering motion, and so causes the horny rings to rattle together. The sound which it makes in this way can be heard from some little distance, and seems to terrify all living animals, even if they have never seen a rattlesnake or heard the sound before. But what the use of this curious organ may be no one has ever been able to discover.

The number of joints in this rattle varies a good deal, and increases as the snake grows older. In a small rattlesnake there are only two or three; in a large one there may be more than twenty.

Rattlesnakes are generally found in dry and sandy listricts, more especially where there are plenty of bushes. In some parts of North America they are very common, and often take up their quarters in the burrow of a prairie dog. During the winter months they hibernate, and it is a curious fact that many hundreds, or even thousands, of these snakes will often gather together in the same retreat and huddle together in great masses for the sake of warmth. 


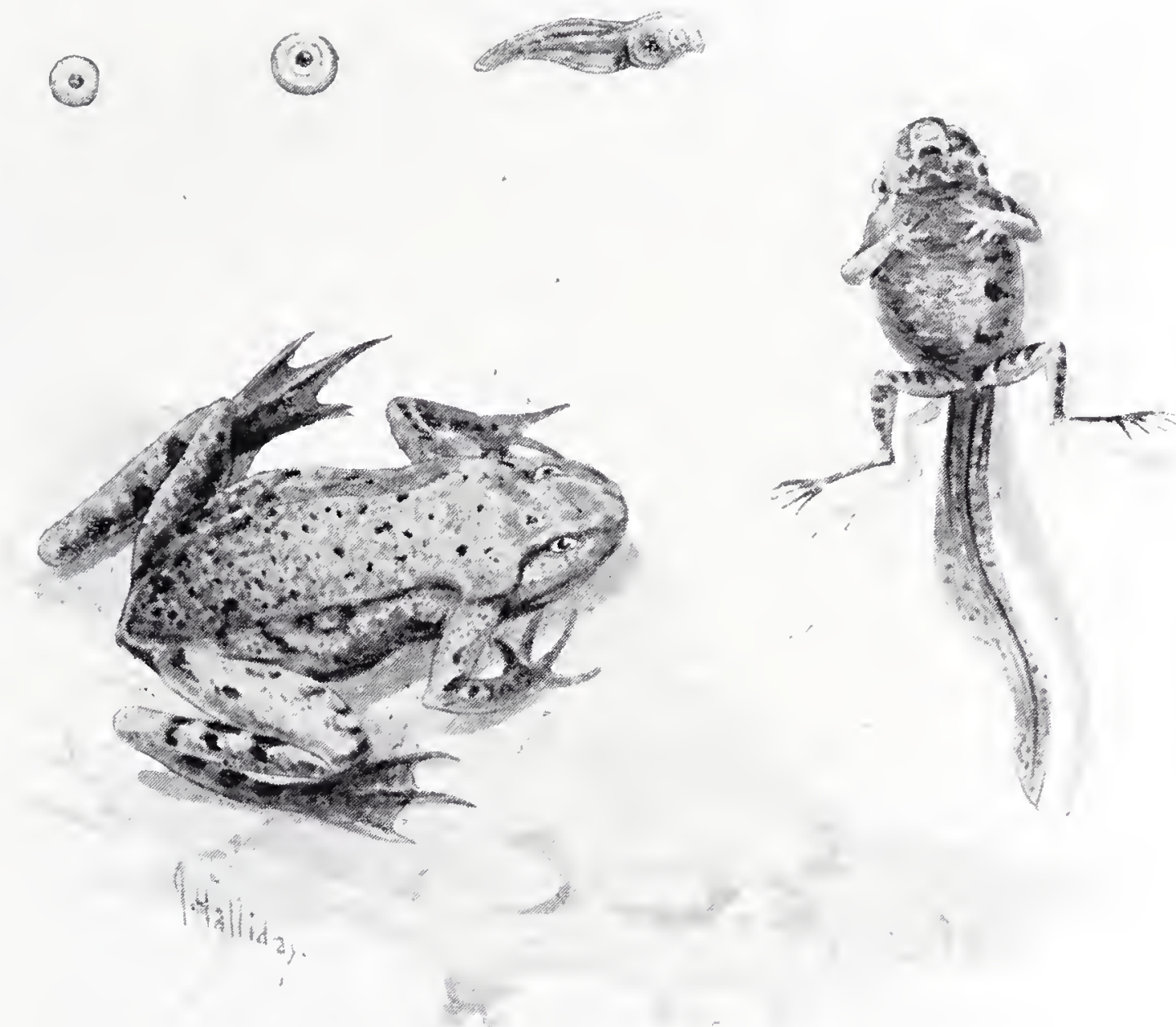

THE FROG IN ITS VARIOUS StTages.

\section{CHAPTER XXIX.}

AMPHIBIANS.

YOU will remember that the Amphibians are distinguished from the true Reptiles by having to pass through a tadpole stage before they obtain their perfect form. Several of them are found in our British Islands.

First of all, there is the FroG, which is so very common everywhere that there is no need for me to describe it. No doubt, too, you have often seen great masses of its jelly-like spawn floating on the surface of ponds early in the spring. And I think that you must have wondered how such small creatures as frogs could possibly lay such enormous batches of eggs.

But the fact is that when these eggs are first laid they are very tiny. Each egg is only about as big as a small pin's head. Instead of having shells, however, they are covered with a very elastic skin, while at the same time they soak up water. So, as soon as they pass into the pond they begin to swell, and very soon each egg is as big as a good-sized pea.

In the middle of each egg is a round black spot, which increases in size every day. This is the future TADpole, and after 
a time the egg-slin splits, and out it tumbles into the water. It is an odd-looling creature-just a big round head with a tiny pair of gills and a little wavy tail, and nothing else at all. But it manages to swim by waggling its tail, and it feeds on the tiny scraps of decaying matter which are always floating about in the water of the pond. Before long a little pair of legs begin to show themselves just at the base of the tail. A few days later another pair begin to grow in front of them. Then, by slow degrees, the tail passes back into the substance of the body, and so do the gills, while lungs are developed and nostrils are opened. And by the time that all these changes have taken place the tadpole has ceased to be a tadpole and has turned into a frog.

It leaves the water now and lives upon land, feeding upon small insects, which it catches in a most curious way. Its tongue

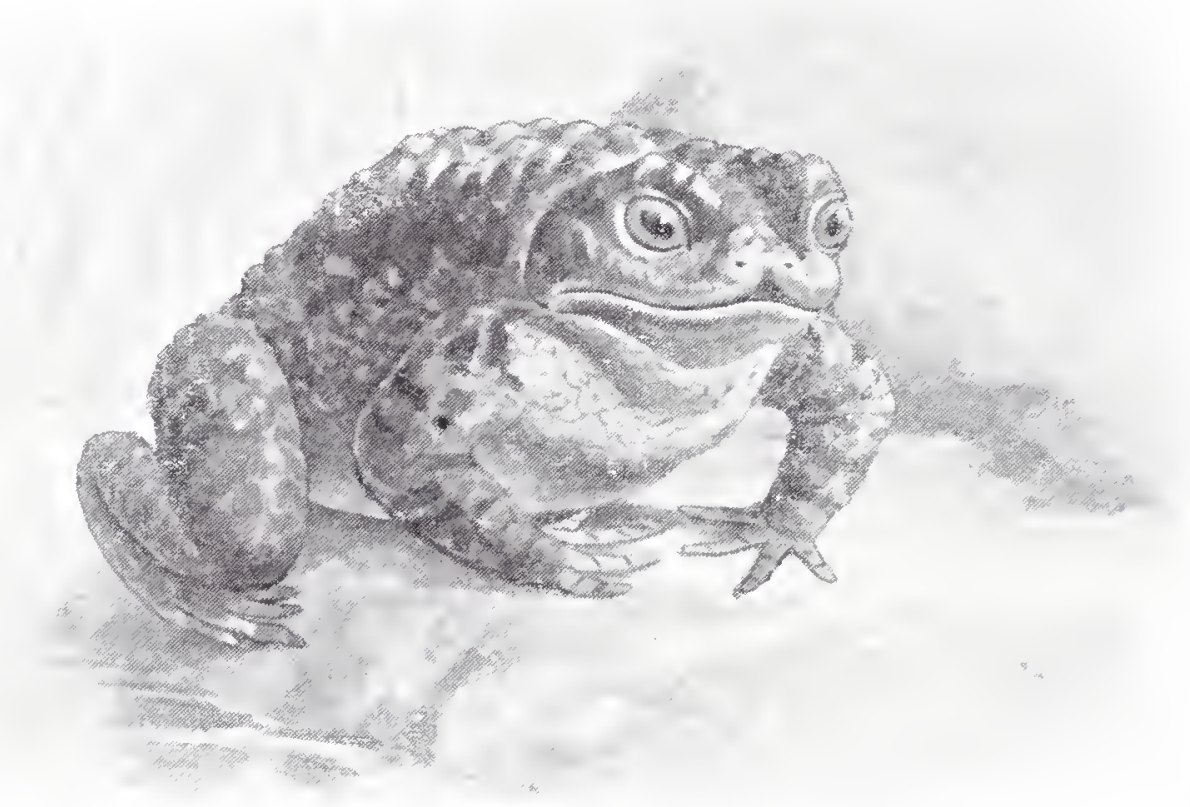

To\1).

is turned, as it were, the wrong way round; for the root is just insicle the lips, while the tip is down the throat. Besides this, the tongue is very elastic and rory sticky. So the animal catches its victims just as the chameleon does, flicking out its tongue at them and just touching them with the tip, to which they adhere. And as the tongue is drawn back into the mouth it polies them down the throat; so that frogs do not even have to take the trouble of swallowing their dinner.

If you look at a frog's hind feet, you will notice that the toes are joined together by wehbing. This allows them to be used in the water as well as upon dry land. It is generally said that frogs swim. But if you watch them in the water you will see at once that they do not really swim at all, but leap along, just as they leap along the ground. And each leap carries them through the water for some little distance. 
Tosds, in some ways, are lilie frogs; but you can tell them at once by their rough, dry skins, which are covered with wartlilie glands. And they crawl over the ground, instead of leaping as frogs do. They are very common almost everywhere, and you may often find them hiding beneath logs, or under large stones, during the day-time.

Toads do not lay their eggs in great masses, as frogs do, but arrange them in strings about four feet long and an eighth of an inch wide. Each of these strings consists of two rows of eggs fastened side by side together. The tadpoles are very much like those of the frog, the chief difference being that they are rather smaller and blacker.

There is another lind of toad, called the NATTERJACk, which is not uncommon in some parts of England. If you should

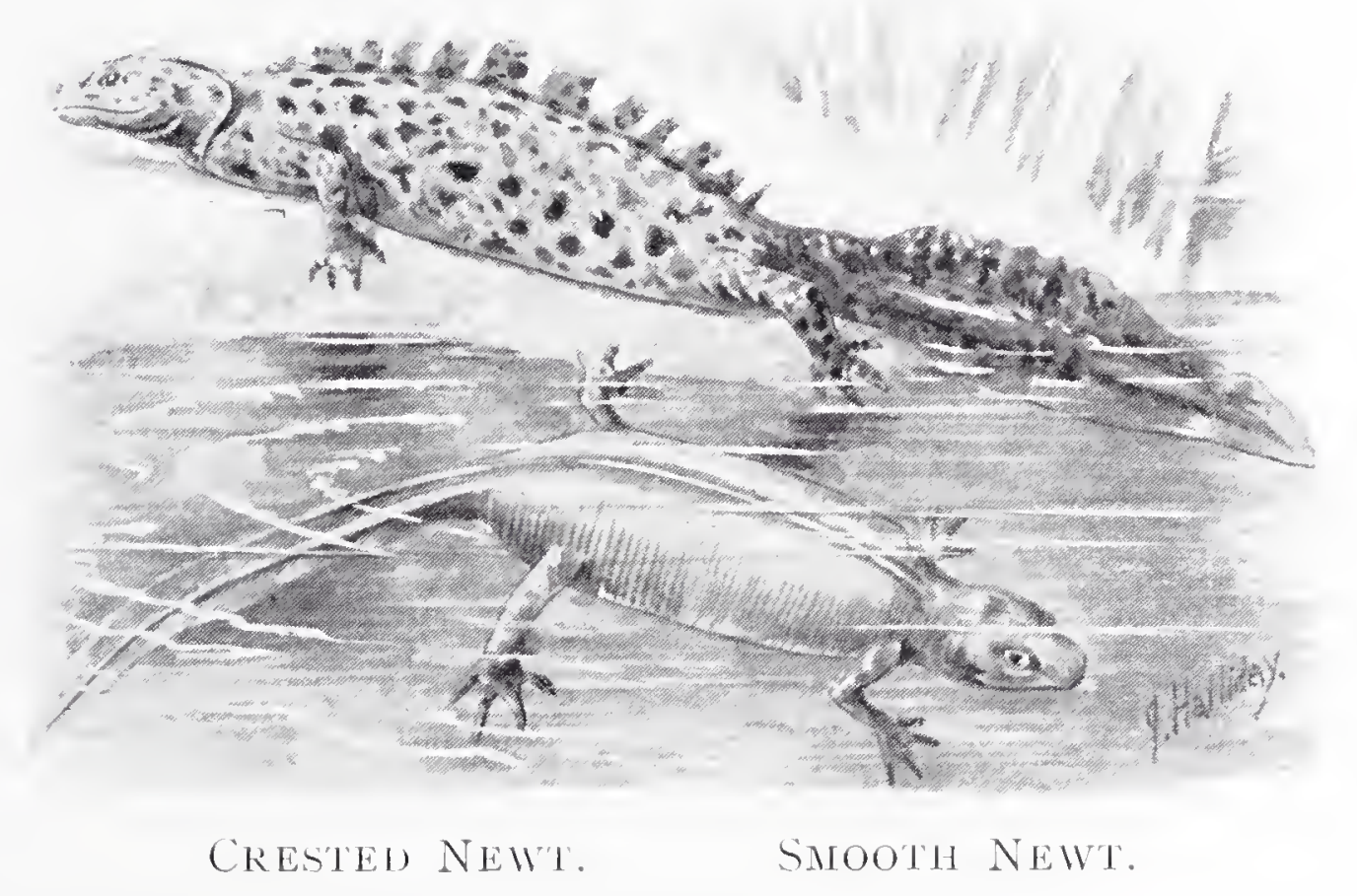

meet witl it you will lave no difficulty in recognising it, for a bright yellow stripe runs along the middle of its back. Ind besides that, instead of crawling, like the common toad, it runs almost like a lizard.

Next come the Newts, or Efts, which lieep their tails all through their lives instead of losing them when they cease to be tadpoles.

You can find newts in plenty all through spring and summer by fishing with a small net in any weedy pond; but you will find that they are not all alike. Some have wavy crests running all along their backs; others have none. And some are coloured with rich orange underneath their bodies, while others are plain olive green all over.

The fact is, first, that there are several different linds of newts. In almost every pond, for instance, Smooth Newts and 
Crested Newts may be found living together. And, besides this, the male newt is much more handsome in the early part of the summer than he is during the rest of the year. It is only the male which is coloured with orange; and this bright colour begins to appear about the end of April, and fades away again early in July.

Newts lay their eggs in a very curious manner. They do not fasten them together in great batches, like the frog, or in long, narrow strings, like the toad. They lay them one by one. And the mother newt talies each egg as she lays it, places it in the middle of the narrow leaf of some water plant, and then twists the leaf neatly round it with her little fore feet, so as to wrap it up in a kind of parcel! The tadpole which hatches out of this egg is very much like that of a toad or a frog; but the front legs

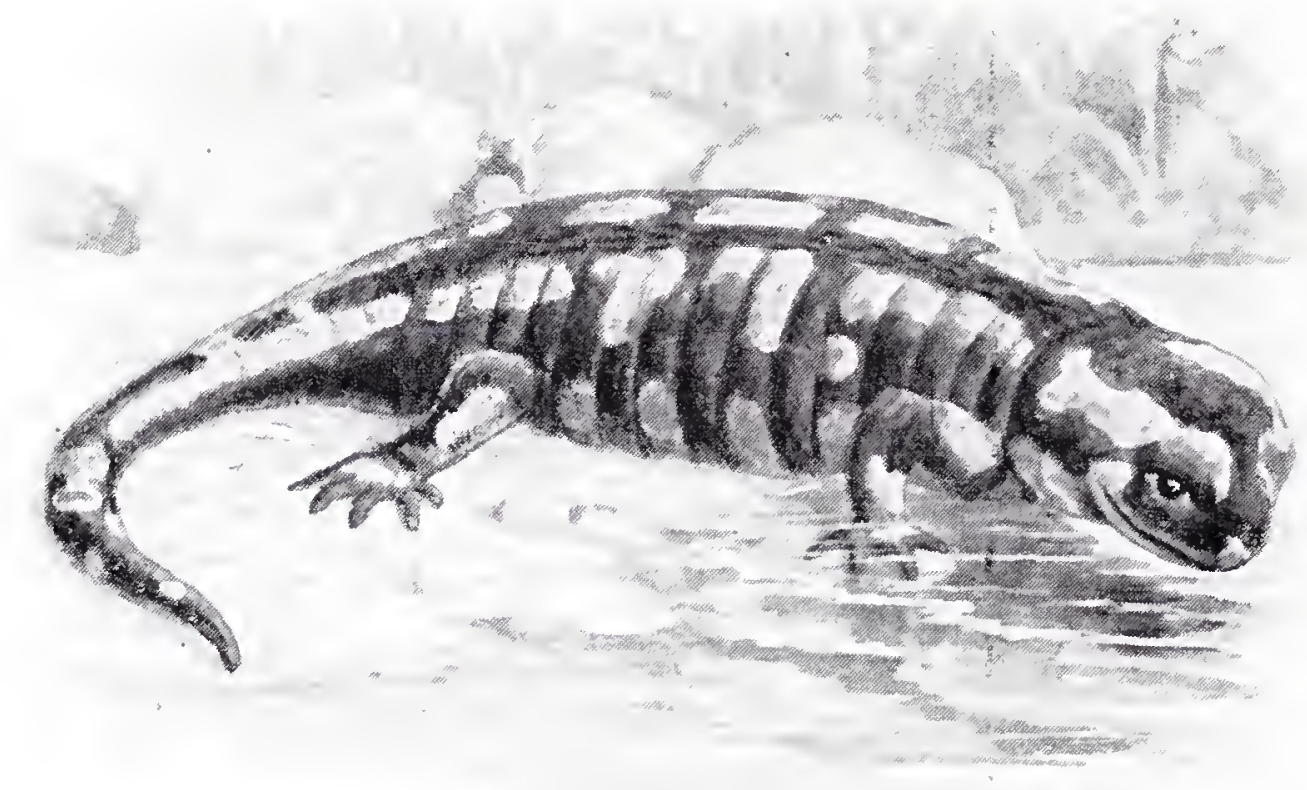

SPOTTED SALAMANDER.

are the first to appear, instead of the hind legs, while the tail, of course, does not pass back into the substance of the body.

Newts swim with their tails, and very pretty and graceful they look as they move through the water. When they cease to be tadpoles, of course, they breathe air, just as toads and frogs do, and have to come up to the surface every two or three minutes to obtain it. And as long as they live in the pond they feed upon grubs and worms and tiny water insects.

Most newts, however, leave the water towards the middle of the summer, and spend the rest of the year on dry land. And when autumn comes they bury themselves underground and fall fast asleep until the spring.

The curious creatures known as Salamanders are related to the newts, and begin their lives in just the same way. But after they have ceased to be tadpoles they only visit the water for two or three weeks in the spring. 
The best known member of this group is the SpotTeD Salamander, which is found in Central and Southern Europe, and also in Algeria and Syria. When fully grown it is about eight inches long, and may be known at once by the two rows of large yellow blotches which run down from the back of its head, right along its body, to the very tip of its tail.

In days of old it was thought that the salamander had the power of walking through fire without being burnt! And it was also supposed, if it were attacked, to spring upon its enemy, bite out a piece of his flesh, and then spit fire into the wound! As a matter of fact it is almost harmless, and may be picked up and

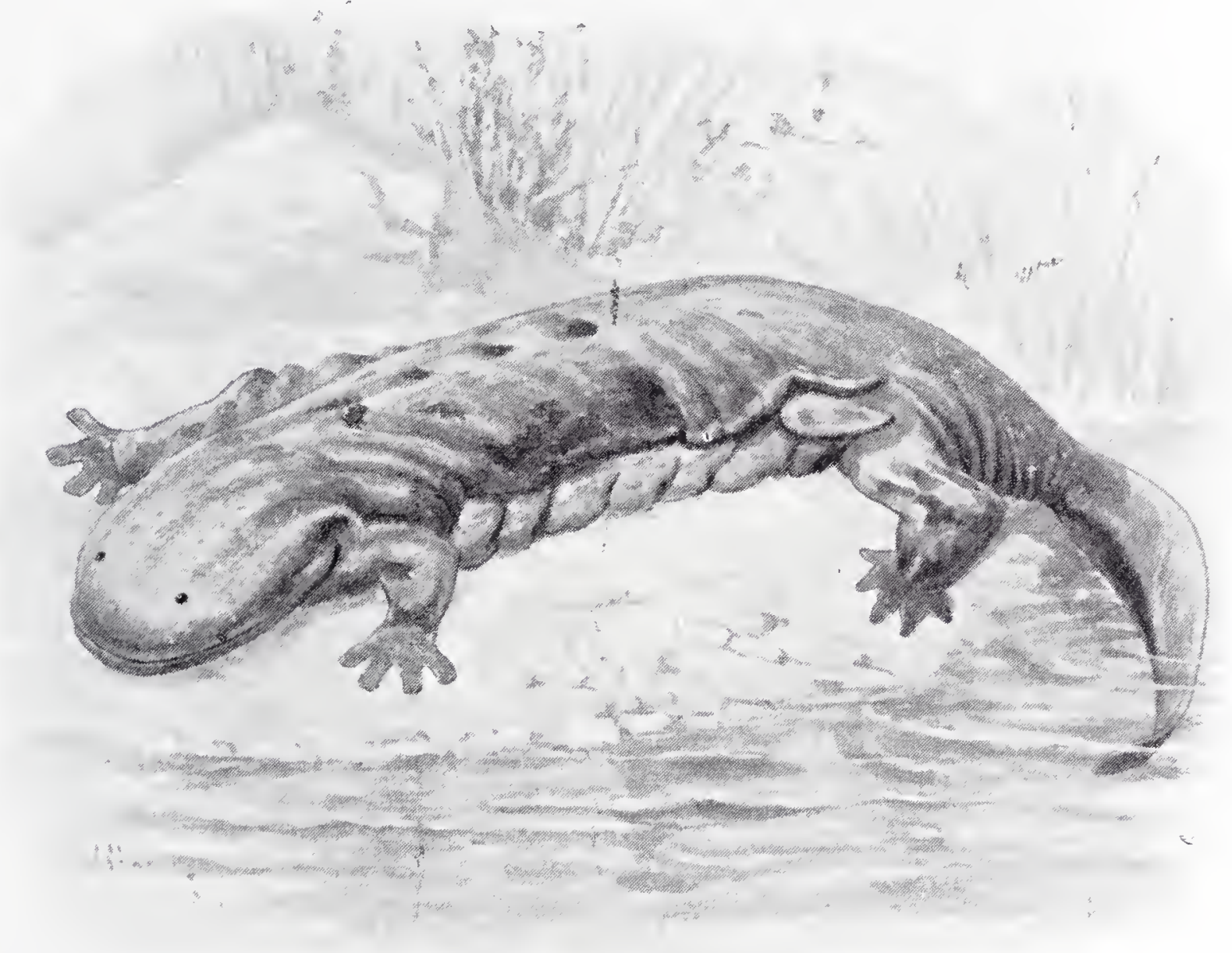

GIAN SALAMANIER.

handled withont the slightest danger. But the glands on its skin, like those on the toad's head and back, contain a rather poisonous fluid, which is squirted out if they are squeezed. So that if a dog were to pick up a salamander he would be quite sure to drop it again very quickly, and would most likely foam at the mouth for some little time.

Salamanders are very slow and timid creatures, and generally spend the whole of the day concealed in some crevice, or in the hollow trunk of a tree, or perhaps under a large stone. They feed upon slugs and small insects.

The Giant Salamander, which is sometimes nearly a yard 
long, is found in the rivers of China and Japan, and spends the whole of its life in the water. It feeds chiefly upon fishes.

One of the most singular of all the Amphibians is the Axolote, which is found in North America. For sometimes it

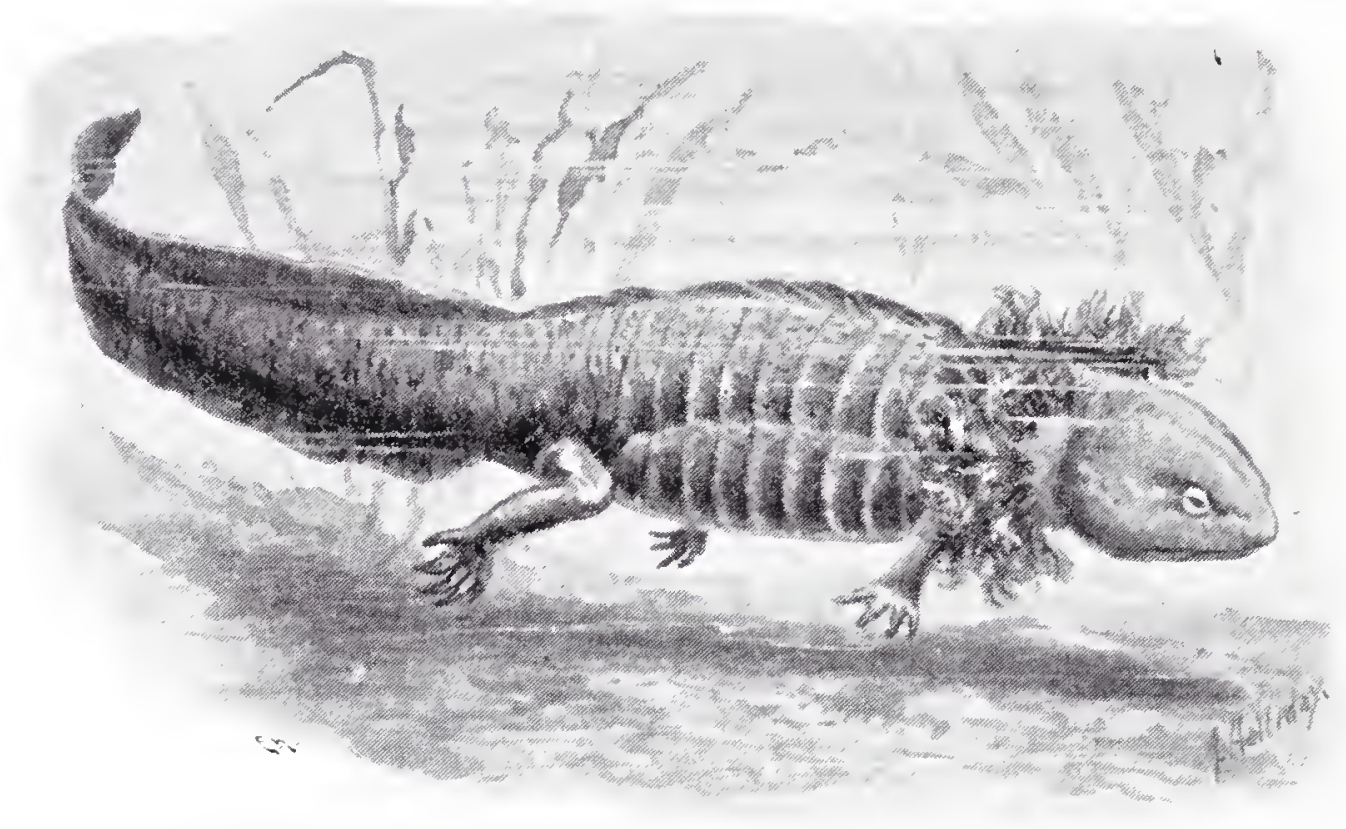

AXOLOTL.

develops into its perfect form, and sometimes it remains a tadpole all its life, and yet lays eggs just as though it were adult!

In the lalies of the United States the life of this creature is just like that of any other batrachian. That is, it is hatched out of the egg as a tadpole, grows first one pair of legs and then another, loses its gills by degrees, and at last appears in a lizardlike form, leaving the water and living upon dry land. But in the lake which surrounds the city of Mexico it never becomes anything more than a big tadpole, keeps its gills throughout its life, and does not leave the water at all.

The OLm, or Proteus, is found only in the underground lalies of Carniola and one or two other parts of Central Europe. It is about a foot long when fully grown, and has a slender, snake-like body, with a pair of tiny legs just behind the head, and another pair at the base of the tail. It is perfectly blind, the eyes being hidden under the skin, and yet cannot bear light. For if it is liept in captivity it will always hide in the darliest corner that it can find. And it has been linown to live in confinement for five whole years without once taking any food at all!

What the habits of this extraordinary animal are in nature no one knows, as it has never been found except in these underground lakes.

In colour the olm is pinkish grey, with bright red gills, and there are trom twenty-four to twenty-seven grooves upon either side of its body. 


\section{F I S H E S.}

\section{CHAPTER XXX.}

FRESH-IVATER FISHES. THE lowest class of the vertebrate animals consists of the
Fishes.

These are easily distinguished. Some of the reptiles, it is true, are very fish-like. But then they have three chambers in their hearts, while the true fishes only have two. Then fishes never have limbs, the place of which is taken by fins; and further, they breathe water by means of gills. There are other differences as well; but these are quite sufficient to show us that reptiles and fishes cannot possibly be mistaken for one another.

Between the two, however, come several very curious creatures, which seem to be partly reptiles and partly fishes; for they have four slender members which hardly seem to be legs, though they cannot possibly be described as fins, while they possess not only gills but lungs as well.

I can only tell you about one of these, namely, the very odd MUD Fish of the African rivers.

In general appearance this animal looks something like an eel, and it grows to a length of about three feet. Its four long ray-like limbs seem to be quite useless to it, and it swims by means of its tail, along the upper part of which runs a narrow fin. It is a creature of prey, feeding upon other fishes. And when food is plentiful, it just takes one bite out of the lower part of their bodies and no more.

This creature has a very strange habit in summer. At that time of the year the rivers in which it lives often dry up altogether, and the mud at the bottom is baked as hard as a brick by the rays of the sun. So as soon as the water begins to get shallow the animal burrows deeply down into the mud, curls itself up like a fried whiting, and falls fast asleep for several months, just as hedgehogs and dormice do during the winter in cold countries. Then, when the rainy season comes and the rivers fill up again, it comes out from its retreat and swims about as before. It is from this habit that it gets its name of "mud-fish."

Now we come to the true fishes; and I think that our best plan will be to read about some of the fresh-water fishes first, and afterwards about some of those which live in the sea. 
Let us begin with a little fish which is very common in almost every pond, but is nevertheless very curious and very interesting. I mean the Three-spined Stickleback.

Sometimes it is called the Tittlebat, and sometimes the Tittler. No doubt you have often seen it. When fully grown it is about three inches long, and you can tell it at once by the three sharp spines on its back, which it can raise and lower at will.

It uses these spines in fighting. For the male sticklebacks, at any rate, are most quarrelsome little creatures, and for several weelss during the early part of the summer they are constantly engaged in battle.

At this season of the year they are really beautiful little fishes, for the upper parts of their bodies are bright blue and the lower part rich crimson, while their heads become pale drab, and their eyes bright green! And apparently they are very jealous of one another, for two male sticklebacks in their summer dress never seem able to meet without fighting. Raising their spines, they dash at one another over and over again with the utmost fury, each doing his best to swim underneath the other and cut his body open. When one of them is beaten he evidently feels quite ashamed of himself, for he goes and hides in some dark corner where nobody can see him. And, strange to say, as soon as he loses the battle his beautiful colours begin to fade, and in a very few hours they disappear altogether.

About the beginning of June, all the male sticklebacks which have not been beaten set to work to build nests. These nests are shaped like little tubs with no tops or bottoms, and they are made of tiny scraps of grass and cut reed and dead leaf, neatly woven together. As soon as they are finished the female sticklebacks lay their eggs in them. Then the males get inside, and watch over the eggs until they hatch.

Another very handsome fresh-water fish is the PERch, which is plentiful in almost every river and lake in England and Vales. In colour it is rich greenish-brown above and yellowishwhite below, with from five to seven upright dark bands on either side of its body, while the upper fins are brown and the lower ones and the tail bright red.

The front fin on the back of the perch, which can be raised or lowered at will, is really a very formidable weapon, for it consists of a row of very sharp spines projecting for some little distance beyond the membrane which joins them together. Even the pike is afraid of these spines, and it is said that although he will seize any other fresh-water fish without a moment's hesitation, he will never venture to attack a perch.

Early in the month of May the mother perch lays her eggs, which she fastens in long bands to the leaves of water plants. Their number is very great, over 280,000 having been taken from quite a small perch of only about half a pound in weight! 


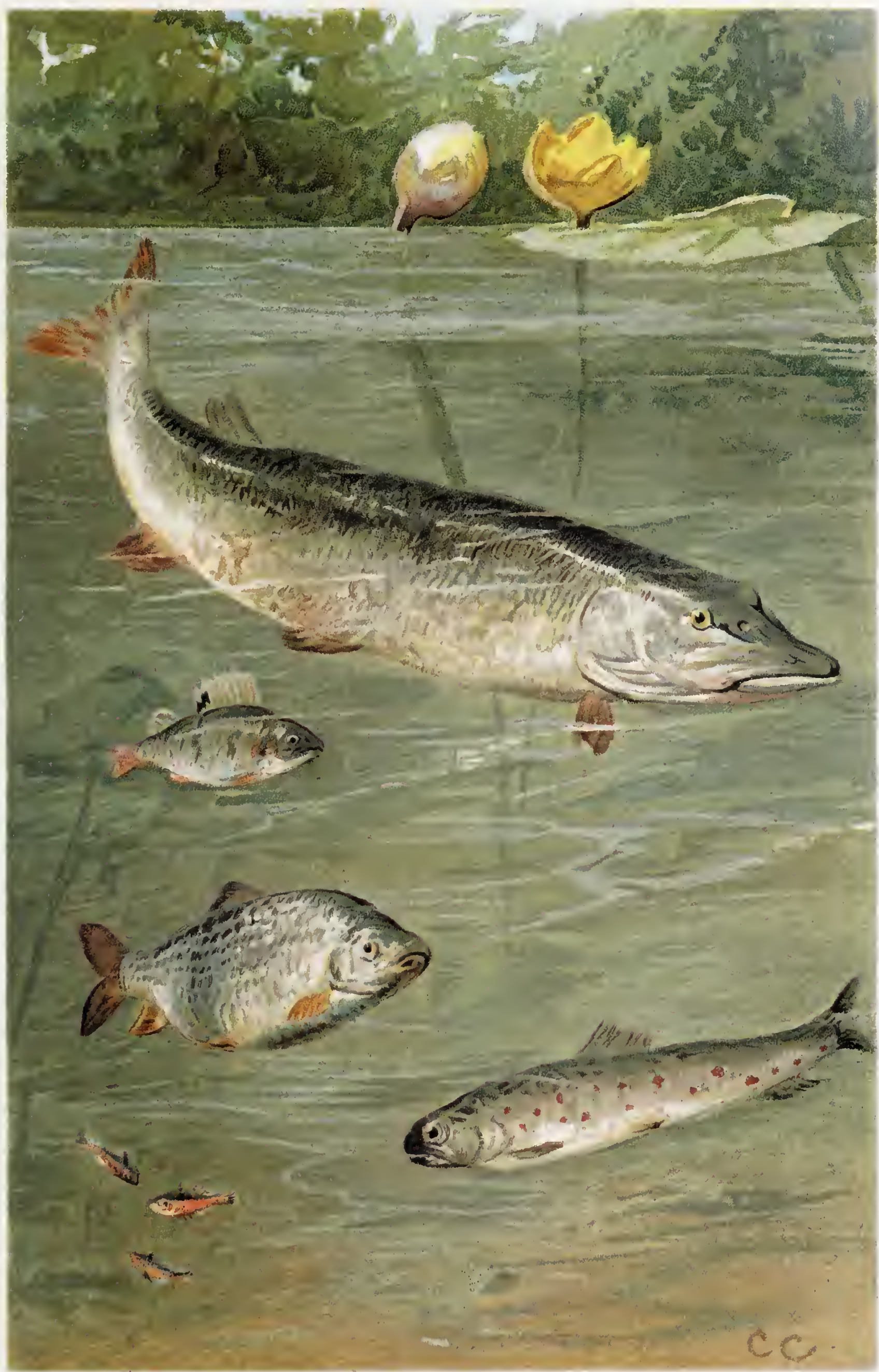

PIKE, PERCH, ROACH, TROUT AND STICKLEBACKS 
The Climbing Perch of India, notwithstanding its name, is not a true perch, but belongs to quite a different family. It is famous for its power of leaving the water and travelling for a considerable distance over dry land. It does this in the hot season if the stream in which it is living dries up; and if you were to live in certain parts of India you might perhaps meet quite a number of these fishes shuffling across the road by means of their

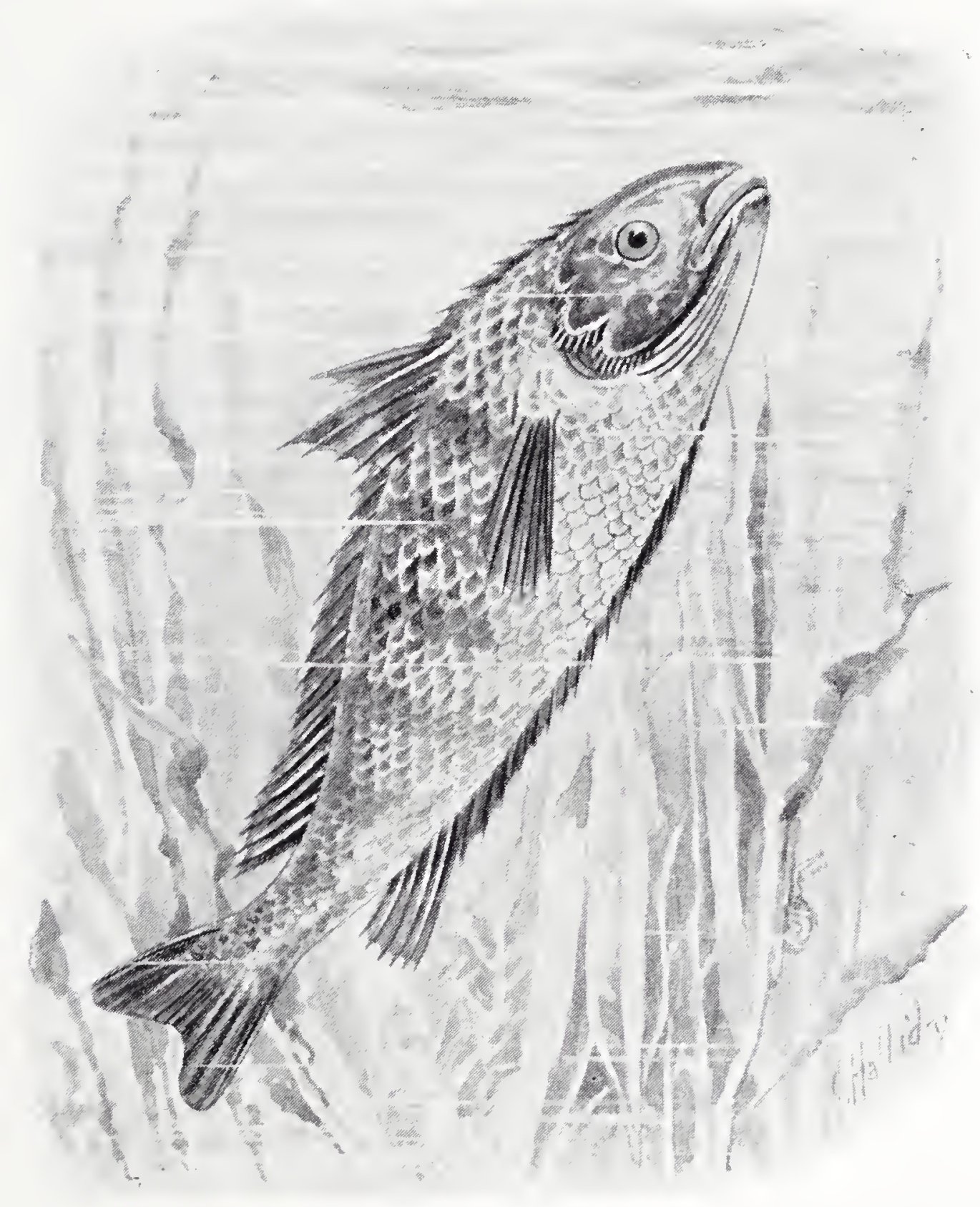

Climbing PERCh.

lower fins, and making their way as fast as possible towards the nearest river!

But how do they manage to remain out of the water for so long?

VVell, the fact is that fishes can live for a long time out of the water if their gills are kept moist. In some fishes, such as the herring, this is not possible, because their gills are made 
in such a way that they become dry ahmost immediately. But the climbing perch has a kind of cistern in its head, just above the gill-chambers, which contains quite a quantity of water. And while the fish is travelling over land this water passes down, drop by drop, to the gills, and keeps them constantly damp.

When this fish has been kept in an earthenware vessel, withont any water at all, it has been linown to live for nearly a week! Another fish which will live for quite a long time out of

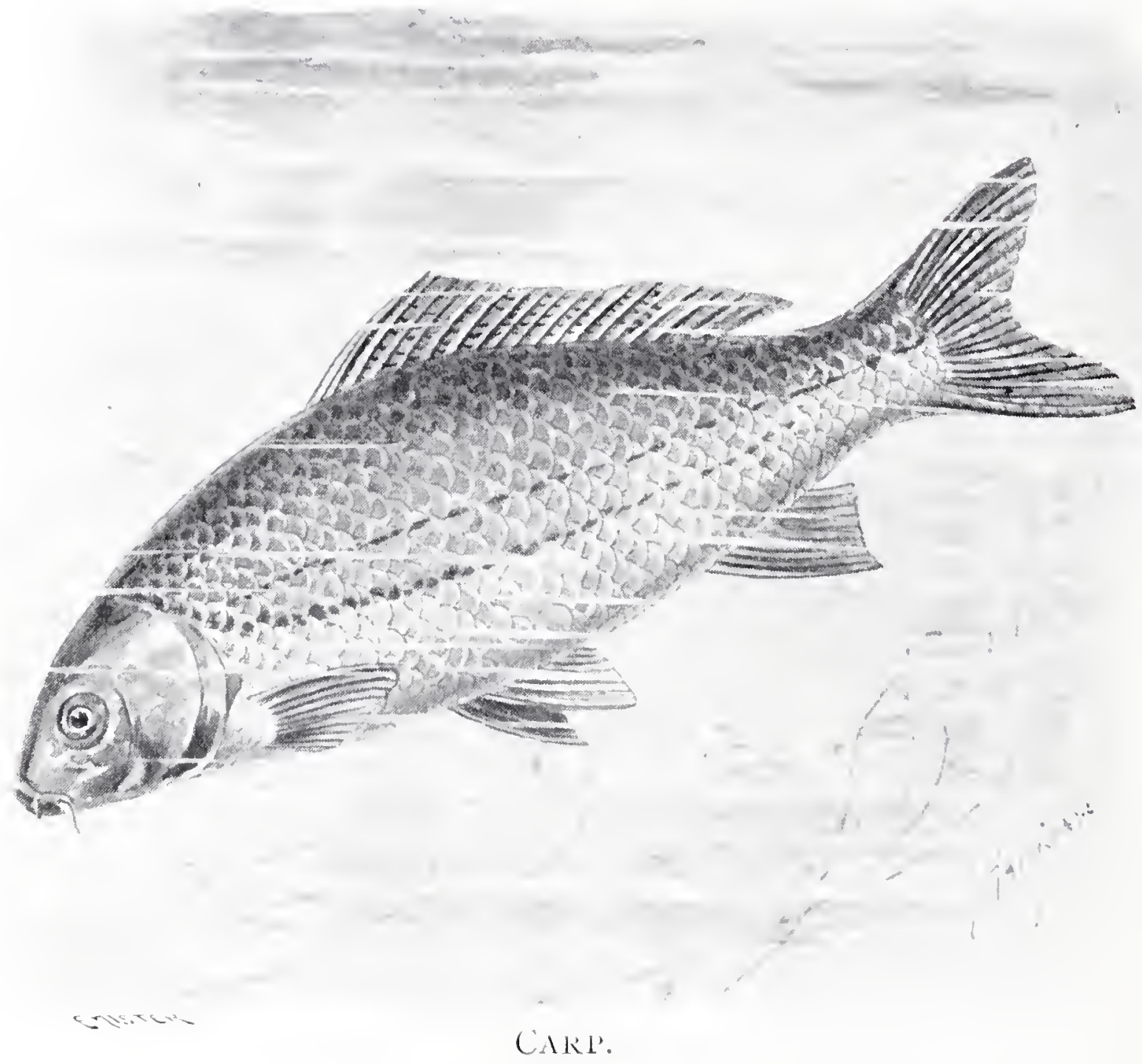

the water is the common English CARl, which has often been conveyed for long distances packed in wet moss.

This fine fish is found both in rivers and lakes, but prefers still waters with a soft muddy bottom, in which it can grovel with its snout in search of foor. During the winter, too, it often buries itself completely in the mud, and there hibernates, remaining perfectly torpid until the return of warmer weather. It is not at all an easy fish to catch, for it is so wary that it will refuse to touch any bait in which it thinks that a hook may be concealed. And if the stream in which it is living is dragged with a net, it just burrows down into the mud at the bottom and allows the net to pass over it. 
Owing to this crafty and cunning nature, the carp has often been called the Fresh-water Fox.

The carp is a very handsome fish, being olive brown above, with a tinge of gold, while the lower parts are yellowish-white. It sometimes weighs as much as twenty-five pounds, and has been known to lay more than 700,000 eggrs!

The BARBEL is found in many English rivers, and may be known at once by the four long fleshy organs which hang down from the nose and the corners of the mouth. These organs are called "barbules," and may possibly be of some help to the fish when it is grubbing in the soft mud in search of the small creatures upon which it feeds. It spends hours in doing this, and a hungry barbel is sometimes so much occupied in its task that a swimmer

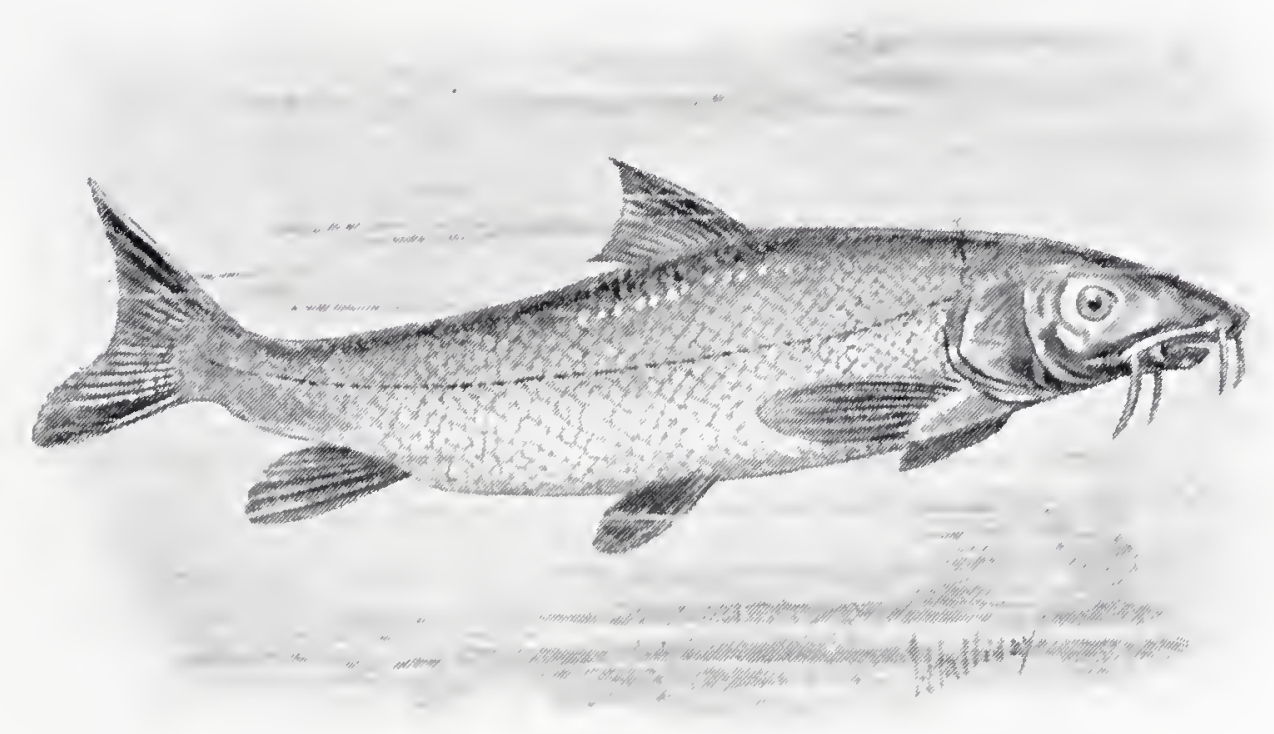

BARBEL.

has dived down to the bottom of the river and caught it with his hands!

From this curious way of feeding, and its great greediness, the barbel has sometimes been called the Fresh-water Pig.

In colour this fish is greenish-brown above, yellowish-green on the sides of the body, and white underneath. When fully grown it weighs from ten to twelve pounds.

One of the prettiest of the British fresh-water fishes is the ROACH, which is found in most of our lakes and streams. The upper part of the head and back are greyish green, with a kind of blue gloss, which gradually becomes paler on the sides till it passes into the silvery white of the lower surface. 'The fins and the tail are bright red.

The roach does not grow to a very great size, for it very seldom weighs more than a couple of pounds. It lives in large shoals, and in clear water several hundred may often be seen swimming about together. 
One of the largest and quite the fiercest of the British fresh-water fishes is the Plike, which is found both in lakes and rivers. Wonderful tales are told of the ferocity of this fish. He does not seem to know what fear is, and his muscular power is so great, and the rows of teeth with which his jaws are furnished are so sharp and strong, that he is really a most formidable foe. All other fresh-water fishes are afraid of him, while he gobbles up water birds of all kinds, and water voles, and frogs, and even worms and insects. And no matter how much food he eats, he never seems to be satisfied.

When the pike is hungry, he generally hides under an overhanging bank, or among weeds, and there waits for his victims to pass by.

The young pike is generally known as the Jack, and when only five inches long has been known to catch and devour a gudgeon almost as big as itself. With such a voracious appetite, it is not surprising that the fish grows very fast, and for a long time it increases in weight at the rate of about four pounds in every year. How long it continues to grow nobody quite knows; but pike of thirty-five or forty pounds have often been taken, and there have been records of examples even larger still.

In colour the pike is olive brown, marked with green and yellow.

One of the greatest farourites of the angler is the Trout, which is found in almost every clear and swiftly-running stream, as well as in most of our lakes. It is a very pretty fish-yellowishhrown on the back, becoming almost golden lower down, and white below, with a number of crimson spots scattered over the sides of the body from the head to the root of the tail. Some trout, however, are very much darker than others, and now and then one is caught which is almost black.

This difference in colour seems to be chiefly due to the conditions under which the fishes live, for the lightest trout are those which come from shallow and gravelly streams, while the dark ones are nearly always taken in deep pools with a muddy or peaty bottom.

The trout is an extremely active fish, and when it is hooked it tries its very hardest to break away, dashing to and fro, leaping, twisting, and fighting, and often giving the angler a great deal of trouble before he can bring it in. In small streams it seldom grows to any great size, but in some of the Scottish lochs trout weighing fifteen or even twenty pounds are often taken. It is sometimes considered, however, that these belong to a different species.

More famous still is the Salmon, the largest and finest of all our fresh-water fishes, which often reaches a weight of fortyfive or fifty pounds, and sometimes grows to an even greater size.

It is hardly correct, however, to speak of it as a fresh-water 
fish, for although salmon are nearly always caught in rivers, they spend a considerable part of their lives in the sea.

The life history of the salmon is a very curious one.

During the winter the parent fishes make their way as far up a clear and gravelly river as they possibly can, till they find a suitable place in which to lay their eggs. The mother then

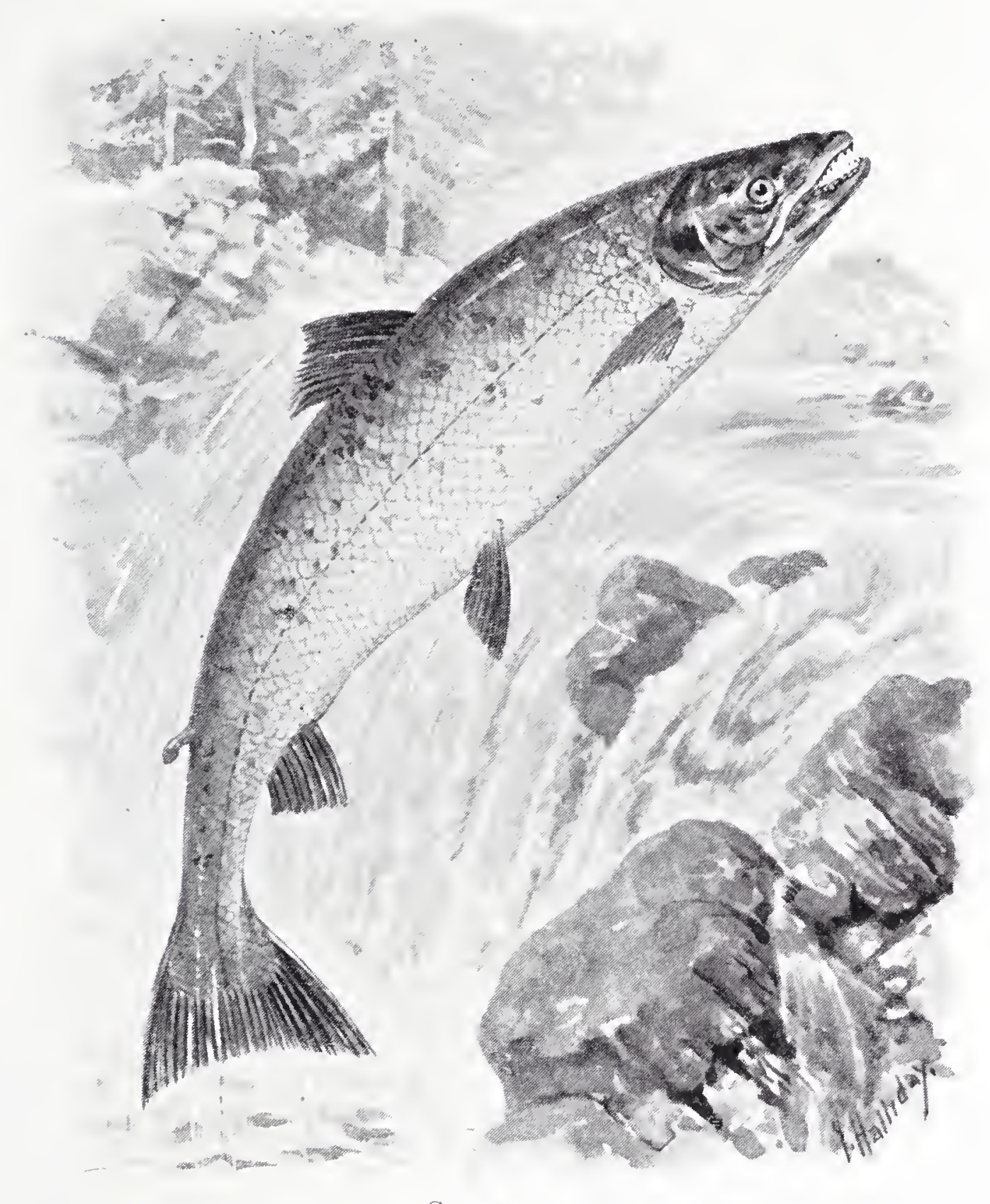

SALMON.

scoops a hole at the bottom of the stream, in which she deposits her eggs in batches, carefully covering up each batch as she does so. At this time both parents are in very poor condition. For a time they remain in the river, feeding ravenously. Then in March or April they travel down the river and pass into the sea, where they stay for three or four months, after which they ascend the river again, as before.

Meanwhile the eggs remain huried in the gravel for about 
four months. At the end of that time the little fishes hatch out, and immediately hide themselves for about a fortnight under a rock or a large stone. You would never know what they were if you were to see them, for they look much more like tadpoles than fishes; and each has a little bag of nourishment underneath its body on which it lives. When this is exhausted they leave their retreat and feed upon small insects, growing very rapidly, until in about a month's time they are four inches long. They are now called "parr" and have a row of dark stripes upon their sides, and in this condition they remain for at least a year. Their colour then changes, the stripes disappearing, and the whole body becoming covered with bright silvery scales.

The little fishes are now known as "smolts," and, like their parents, they make their way down the river and pass into the

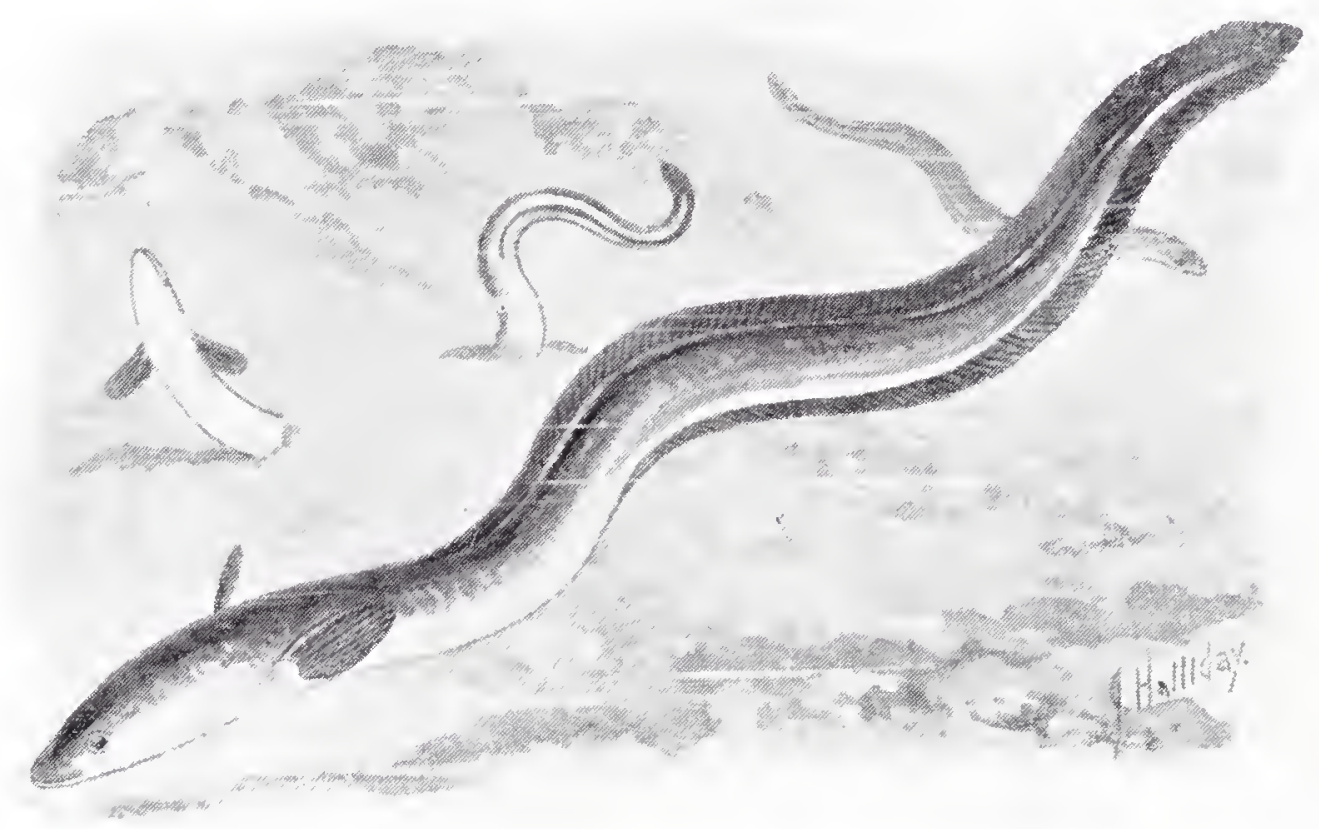

EELS.

sea. There they remain until the autumn, when they ascend the river again. By this time they have grown considerably, weighing perhaps five or six pounds, and are called "grilse." And it is not until they have visited the sea again in the following year that they are termed "salmon."

There are other names still by which these fishes are known, for during the spawning season the males are known as "kelts" and the females as "baggits."

When salmon are ascending a river and come to a waterfall, they climb it by leaping into the air and so springing into the stream above the fall, trying over and over again until they succeed. When the fall is too high to be climbed in this way, the owners of the river often make a kind of water staircase by the side of it, so that the fishes can leap up one stair at a time. This is called a "salmon ladder." 

the EeLs.

The only other fresh-water fishes which we can notice are

These are very odd creatures indeed, for they look much more like snakes than fishes. They have very long slender bodies, with a pair of tiny fins just behind the head, a long one running along the back and tail, like a crest, and another, equally long, underneath the body. And they are clothed with a smooth, slimy slin instead of with scales.

These curious creatures live in ponds and even in ditches, as well as in rivers, and are very plentiful in all parts of Great Britain. During the daytime, although they will sometimes bask at the surface in the warm sunshine, they generally lie buried in the mud at the bottom of the water, coming out soon after sunset to feed. And when the weather is damp, so that their gills are

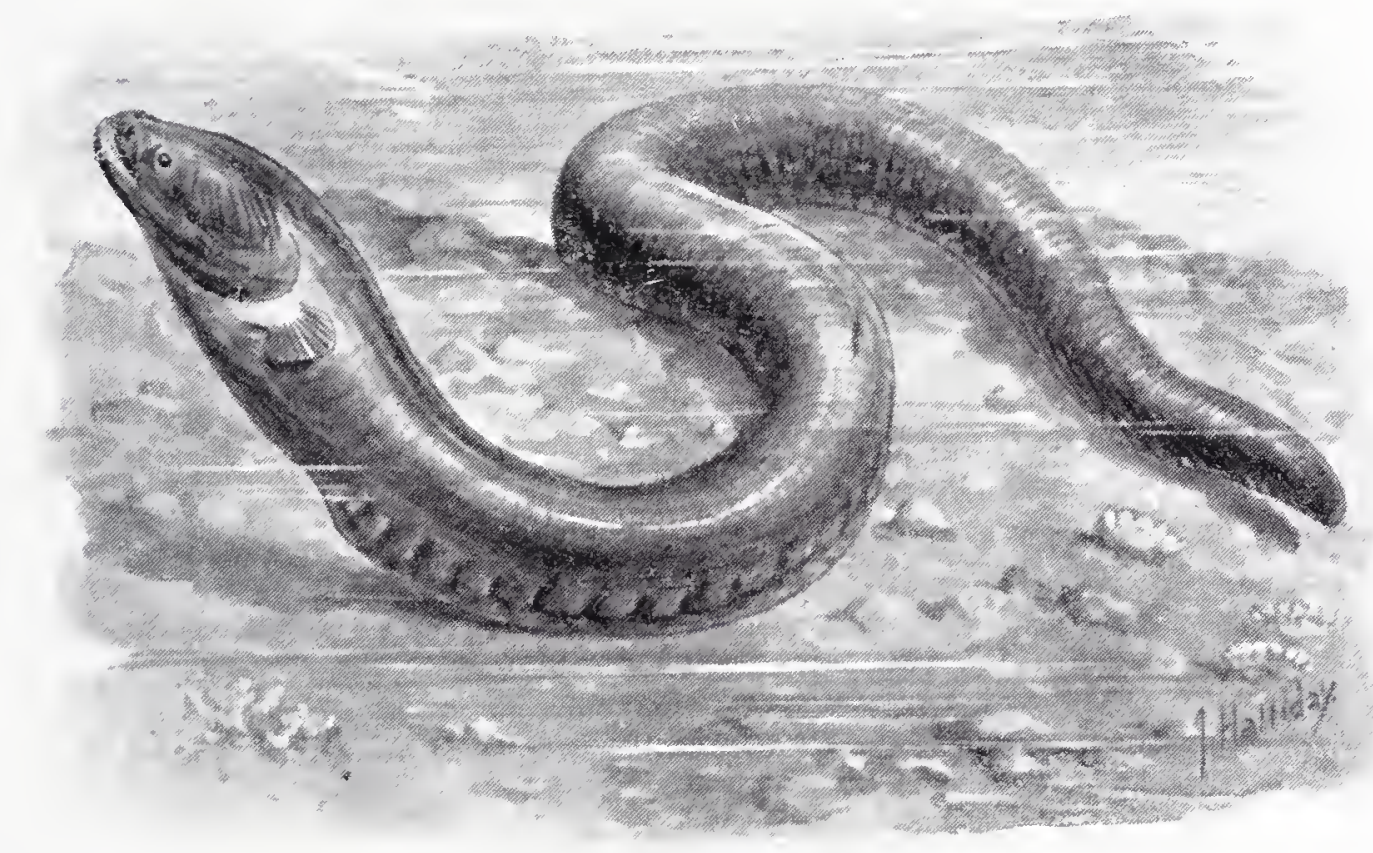

ELECTRIC EEL。

liept moist as they wriggle through the herbage, they will often leave the water and travel for some little distance overland.

They frequently do this when they are travelling towards the sea. For it is a strange fact that, although they are freshwater fishes, eels both begin and end their lives in the sea.

In the first place, the eggs are laid in the sea-generally quite close to the mouth of a river. When the little "elvers," as the young eels are called, hatch out, they make their way up the river in immense shoals. In the Severn, for instance, near Gloucester, several tons of elvers are often caught in a single day; and about thirty million elvers go to the ton! After being pressed into cakes and fried, these little creatures are used for food. But they' are so rich that one cannot eat very many at once.

When they have travelled far enough up the river, most of the elvers which have escaped capture make their way to 
different streams and pools and ditches, and there remain until their growth is completed. They then begin to journey back to the sea, and when they reach it they lay eggs in their turn. After this, apparently, they die.

In the rivers of South America a most wonderful eel is found which has the power of lithling its victims by means of an electric shock. It is called the Electric EeL in consequence, and the electricity is produced and stored up in two large organs inside the body. But how it is discharged nobody knows. If the fish is touched it merely gives a slight shudder. But the shock is so severe that quite a large fish can be lilled by it, while a man's arm would be numbed for a moment right up to the shoulder.

The LAMPREY, which is found plentifully in many of our

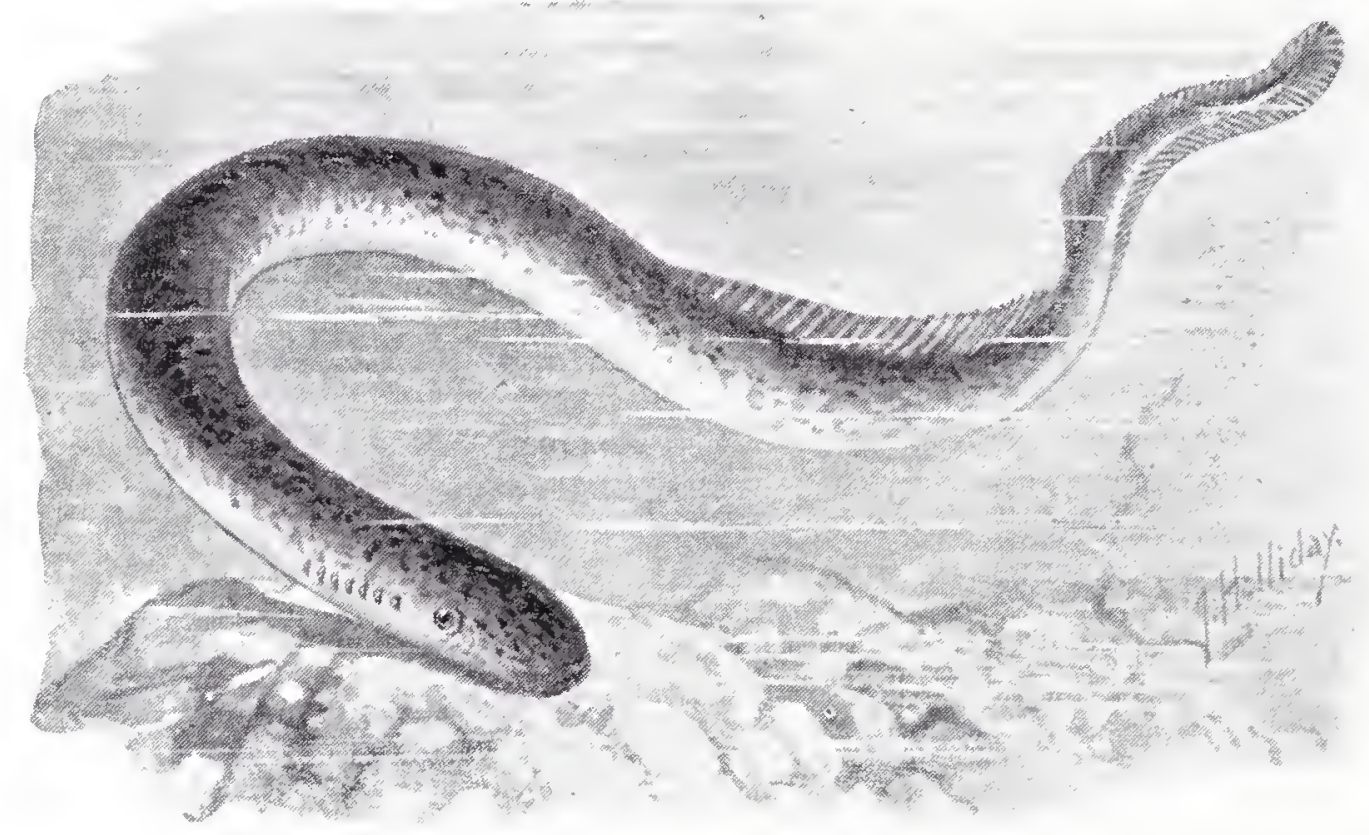

I.AMPREY .

British rivers, is very much like an eel in appearance. But it has no side fins, and instead of possessing jaws, it has a round mouth used for sucking, and resembling that of a leech. And on either side of its neck it has a row of seren round holes, through which water passes to the breathing organs.

Lampreys seem to spend the greater part of their lives in the sea, but always come up the rivers to spawn. They lay their eggs in a hollow in the bed of the stream, which they make by dragging away stone after stone till the hole is sufficiently deep. Very often a large number of lampreys combine for this purpose, and make quite a hig hole, in which they all lay their eggs together.

The length of the lamprey is generally from fifteen to eighteen inches, and its colour is olive brown. 


\section{CHAPTER XXXI.}

\section{SALT-IVATER FISHES.}

WE now come to the fishes of the sea; and at the head of these we may place the Sharlis.

Some of these savage and voracious creatures are found in our British waters, and one-the Lesser Spotted Dog Fishis quite common. You would scarcely take it for a shark, however, on seeing it for the first time, for one always thinks of sharks as very large and powerful creatures, while this dog fish is hardly ever more than eighteen inches long. Yet it really is a shark, and for its size is very formidable, being able easily to fight and lill fishes quite as large as itself.

It is called the "dog" fish because it follows shoals of fish in the water, just as a wild dog will follow the animals on which it preys upon dry land.

When you are staying at the seaside you may sometimes find the dead body of a dog fish lying on the beach, where it has been flung by a very high wave. And you will notice how very coarse and rough its skin is. This skin is often used for covering the handles of swords, as it gives such an excellent grip. And it has also been used for putting on the sides of match boxes instead of sand paper.

But even if you do not find the log fish itself lying on the beach, you may often find its eggs, which are very curious little objects indeed. They are something like oblong horny purses, of a yellowish-brown colour, with a long twisted appendage at each corner, very much like the tendrils of a vine. By means of these the egg is anchored down to the weeds at the bottom of the sea, and they hold so firmly that they are hardly ever torn away, except during a violent storm.

At each end of this singular egg is a narrow slit, through which water can pass to the gills of the little fish which is lying inside it. And one end of the egg is made in such a manner that when the fish is ready to hatch it can easily push its way out, although no enemy on the outside can possibly force its way in.

A very much larger and more dangerous fish, which often visits our British seas, is the BluE SHARK, which sometimes grows to a length of fifteen or sixteen feet. It does not often attack human beings, however, but is very destructive in our fisheries, snatching away fishes which have been hooked, and even swimming along the outside of the nets as they are being drawn in, and 
biting great holes through them, in order to get at the pilchards or herrings within. So the fishermen always kill a blue shark if they have the chance of doing so, and sometimes destroy eight or ten in a single day.

But it is not very easily caught, for if it is hooked it will often bite the line asunder, and if it cannot do this will roll round and round in the water in order to coil it round its body, and will then snap it with a sudden jerk. And even when it is caught it is not killed without much difficulty, for it

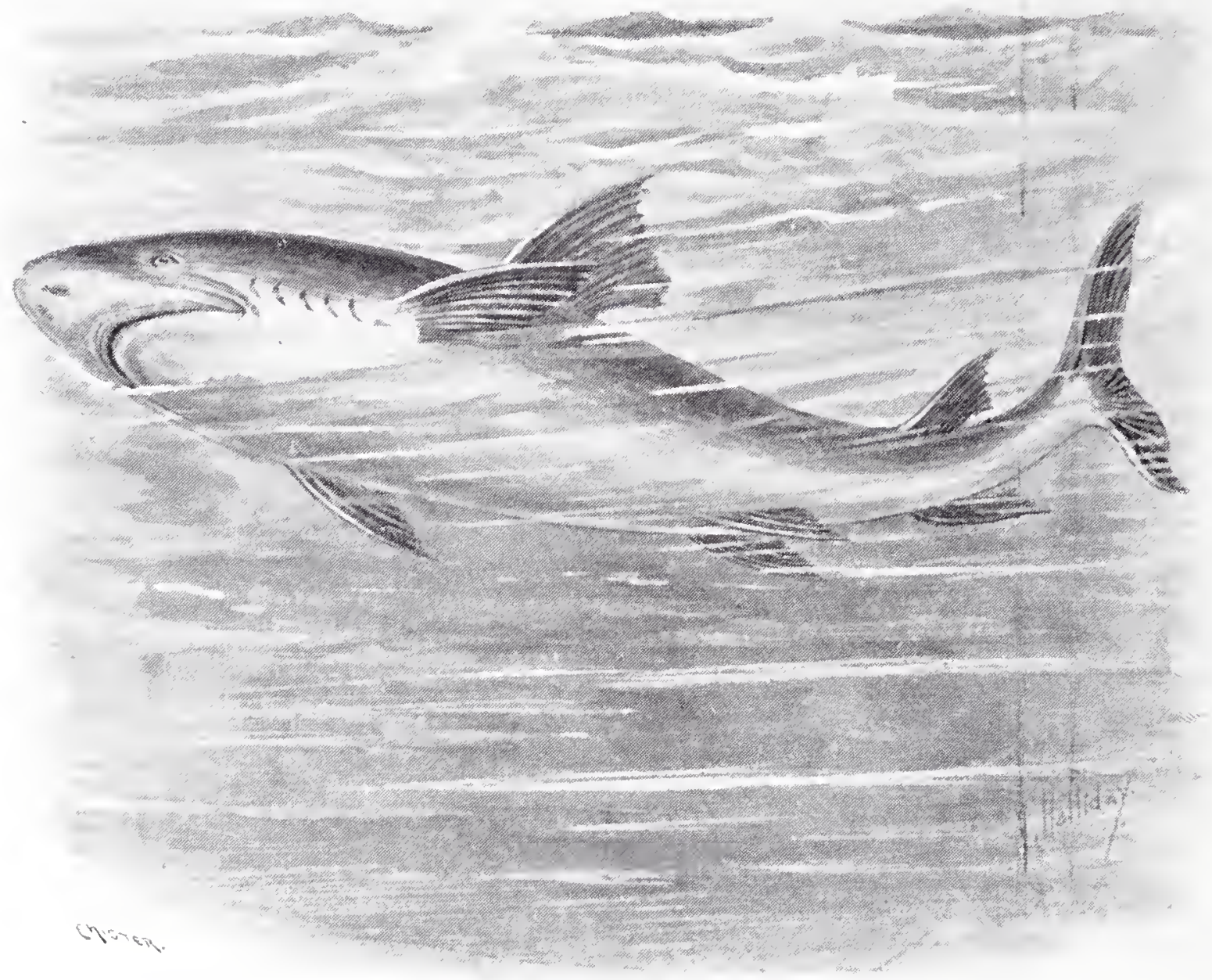

ITHITE SHARK.

thrashes its great powerful tail about in such a manner that it cannot be approached without danger. So the first thing that the fishermen always try to do when it is captured is to chop off its tail with an axe. beneath.

The colour of this shark is slaty-blue above and white

Even larger and more dangerous still, the Great White Shark, or Rondeleti's Shark, is one of the most formidable creatures that roam the seas. It often grows to a length of thirtyfive or even forty feet, and weighs ten or twelve tons, while one 
snap of its huge jaws will shear off a man's legs or cut his body in two.

This enormous fish is found in all the warmer parts of the sea, but has only once or twice been seen in British waters.

Then there is a shark which is very curious indeed in appearance. This is the HAMMER-HEAD, which has its head formed just like that of a hammer, the eyes being placed at each end of the projecting lobes. It grows to a length of fifteen or sixteen feet, and is very fierce and savage, attacking human beings without the least hesitation. It is nearly always found in the tropical seas, but has been several times captured off the coasts of Great Britain.

Lastly, there is a shark which is very curious indeed in habits. This is the THREsher, which grows to a length of ten or twelve feet, and is common in the Mediterranean Sea and the

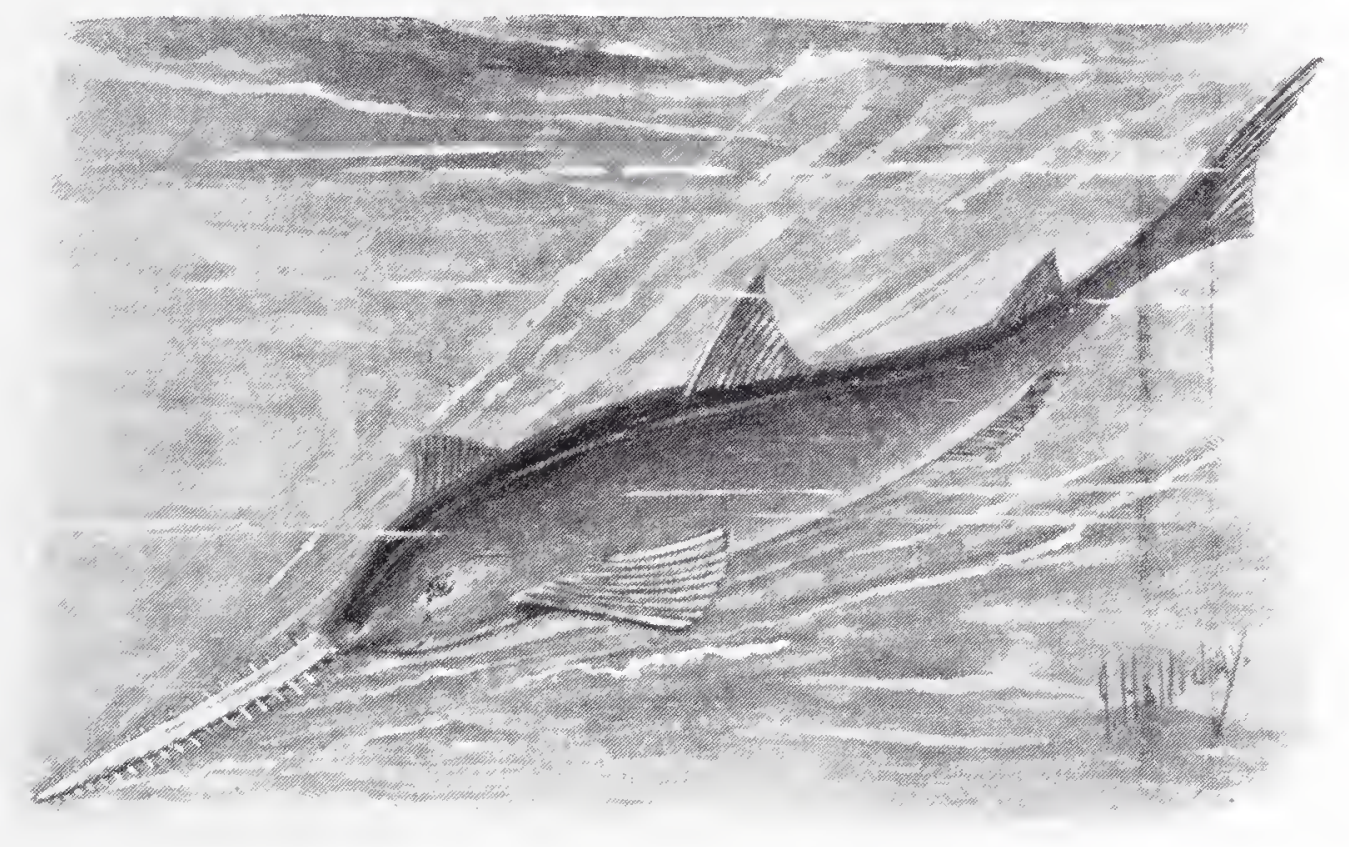

SAW FISH.

Atlantic Ocean. It feeds chiefly upon herrings, darting into the midst of a shoal and snapping them up in hundreds.

What it is specially famous for, however, is its habit of attacking whales. For this purpose several threshers will unite together, and their plan is to leap up into the air and strike tremendous blows with their long tails upon the whale's body as they fall back into the sea. This seems to terrify the whale, and he dives under water in order to escape from his tormentors. knowing that he must very soon rise again, however, they wait for his re-appearance, and then attack him again in the same way. This happens again and again, until he is quite worn out by his exertions, and by the impossibility of remaining long enough at the surface to breathe properly. Then if any sword fishes happen to be in the neighbourhood, they come and attack 
him too, driving their long swords deeply into his body. And before very long the whale is dead, and both threshers and sword fishes are tearing great strips of flesh from the carcase and greedily devouring them.

Next to the Sharlis come the SAw-Fishes, which have the upper jaw drawn out into the form of a long, narrow beak, set on either side with a row of large, pointed teeth. So it really looks very much indeed like a saw. The fish uses this curious weapon by dashing into the midst of a shoal of smaller fishes and

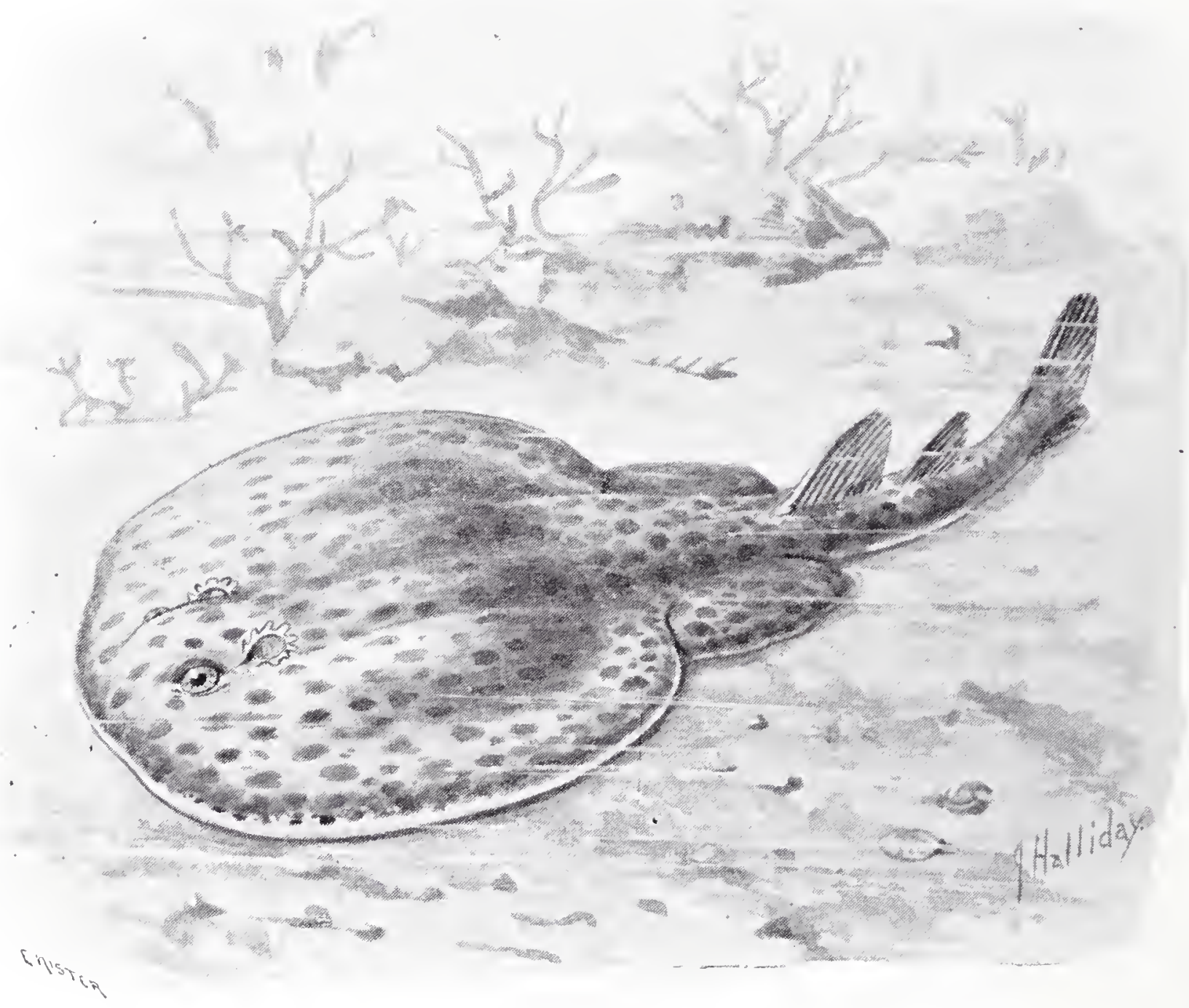

TORPEIO.

striking them right and left with its saw. In this way it is sure to disable a good many, which it then swatlows leisurely one after the other.

Saw fishes are found in all the warmer seas, and sometimes grow to a length of fifteen or twenty feet.

Next in order come the Rays, which have very broad flattened bodies, and very long and slender tails. In consequence of this structure they cannot swim by means of their tails, as nearly all other fishes do, but travel slowly through the water by waving their side fins, like soles and flounders. 
One of the best known of these fishes is the SkATE, which is not at all uncommon off most parts of the British coasts. When fully grown it sometimes measures as much as six feet in length from the snout to the tip of the tail, and five feet in width of body. As it cannot swim fast enough to overtake other fishes, it preys chiefly upon crabs, lobsters, and shell-bearing molluscs, which it is able easily to crunch up, shells and all.

The eggs of this fish may be found in great numbers on the seashore. They are very much like those of the dog-fish, but are nearly black in colour, and instead of a long twisted tendril at each corner, they only have a blunt projection about an inch long. They remind one, in fact, of a hand-barrow, and the fishermen often call them "skate barrows" in consequence.

In colour, the skate is greyish-brown above and greyishwhite beneath.

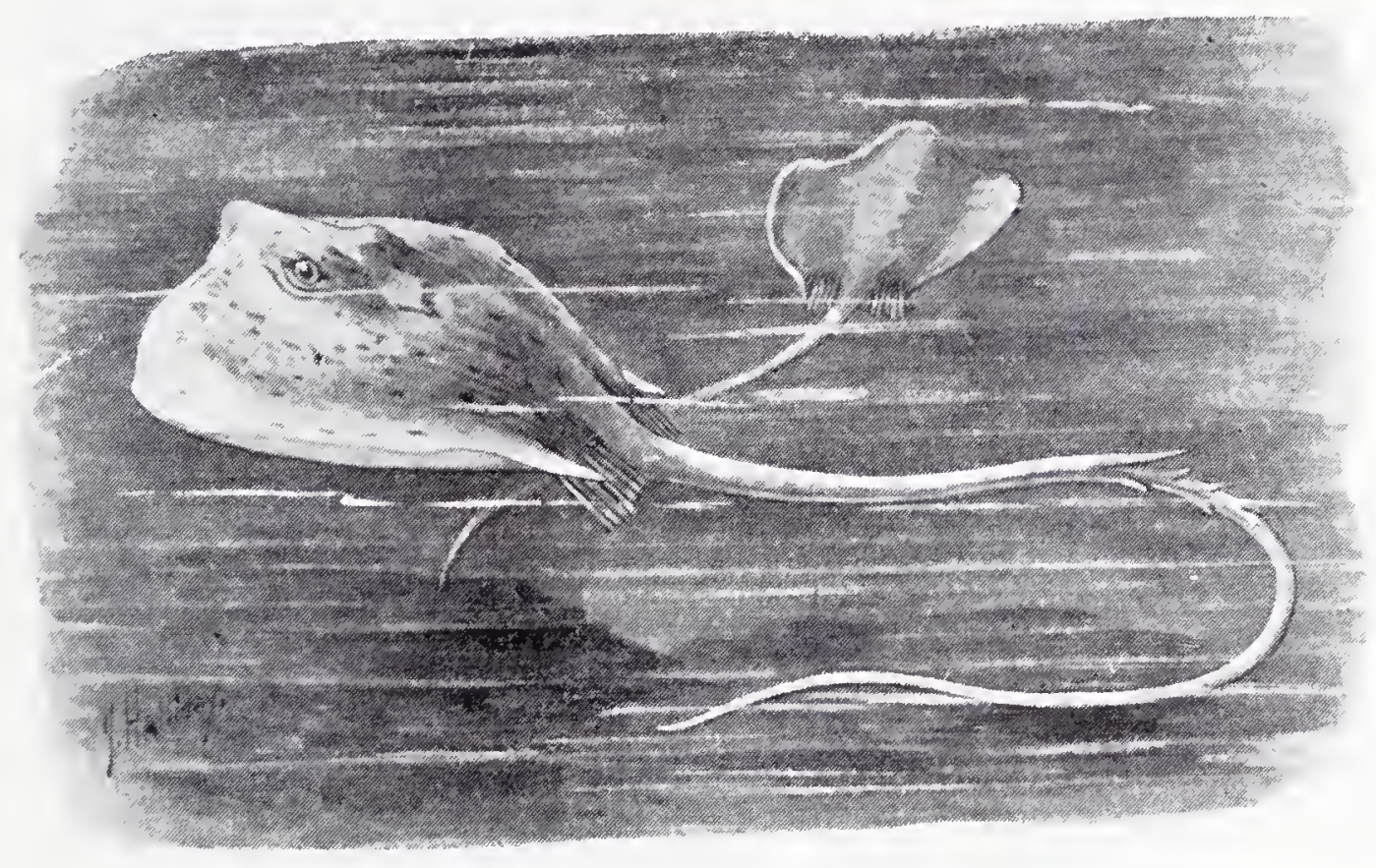

SIING RAY.

Another very curious ray is the Torpedo, which is also found occasionally off the shores of Britain.

This is an electric fish, having a kind of electric battery inside its body, from which a very powerful shock can be discharged at will. This battery, in appearance, is something like a honeycomb, consisting of a number of six-sided columns, which run from the skin of the back to that of the lower surface of the body. Each of these columns is divided into a number of cells, or chambers, by thin walls of membrane; and each cell contains a liquid which seems to consist chiefly of salt and water.

How the electricity is produced and stored up in these organs, of course, nobody knows, but it seems to be discharged along four great nerves, which run from the battery up to the brain. The shock is sufficiently strong to liill a duck; and not 
only has an electric bell been rung by it, but an electric spark has been actually obtained. And when five persons held one another's hands, and the person at each end laid his finger upon the torpedo, every one of the five persons felt the shock.

Even more formidable, though in quite a different way, is the Sting Ray.

At the base of its long whip-like tail this fish has a bony spine set with sharp teeth, like a saw; and its favourite mode of attack is to coil this tail round the body of its victim and then to drive the spine into his flesh, working it backwards and forwards

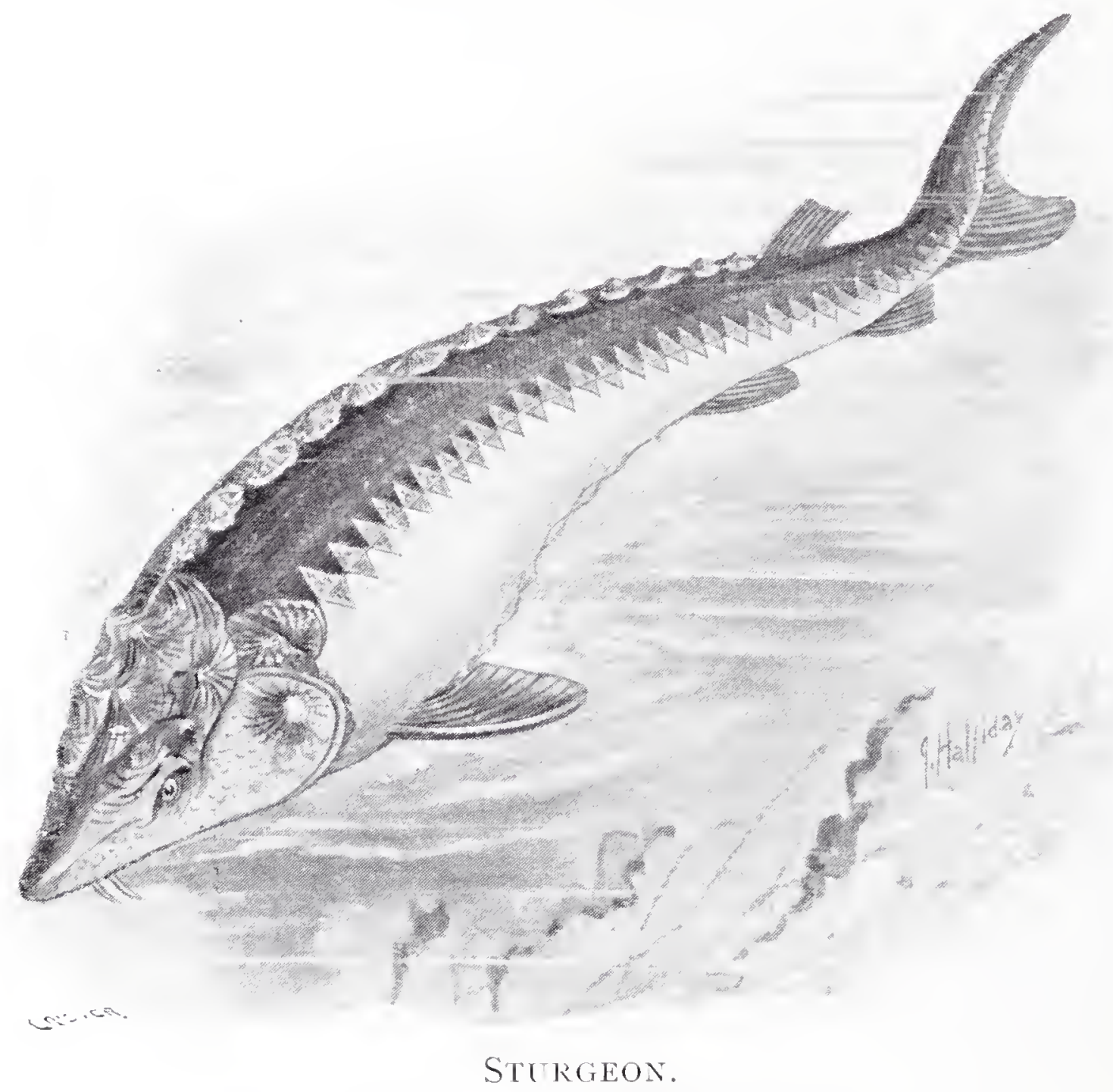

in such a manner as to cause a very serious wound. And the spine appears to be poisoned, for its wound is always followed by very severe inflammation, which has been known to result even in death.

Some of the rays which are found in the warmer seas grow to a very great size. Indeed, a ray measuring over eighteen feet in length has more than once been captured. They are dangerous creatures to meddle with, for a fish of this size is quite strong enough to overturn a boat, while if a man were once seized by one of them, he would have very little chance of escape.

These huge creatures are generally lnown as "devil fish." 
The STURGEON belongs to quite a different group of fishes, which may be distinguished by two points. In the first place their slieletons are made, not of bone, but of gristle; and, in the second place, five rows of shield-like bony plates run along the back and sides of their bodies, forming a kind of natural armour.

The sturgeon is quite a large fish, for it is often eight or nine feet long, and weighs three or four hundred pounds. It spends most of its life in the sea, but ascends the rivers in order to spawn, like the salmon. It is not very common in British waters, although sturgeon are taken in nearly all our larger rivers from time to time. But in some parts of Europe, and especially in Russia, it is very plentiful indeed.

Three valuable articles are obtained from the sturgeon.

Perhaps you may have heard of "caviare." Well, caviare

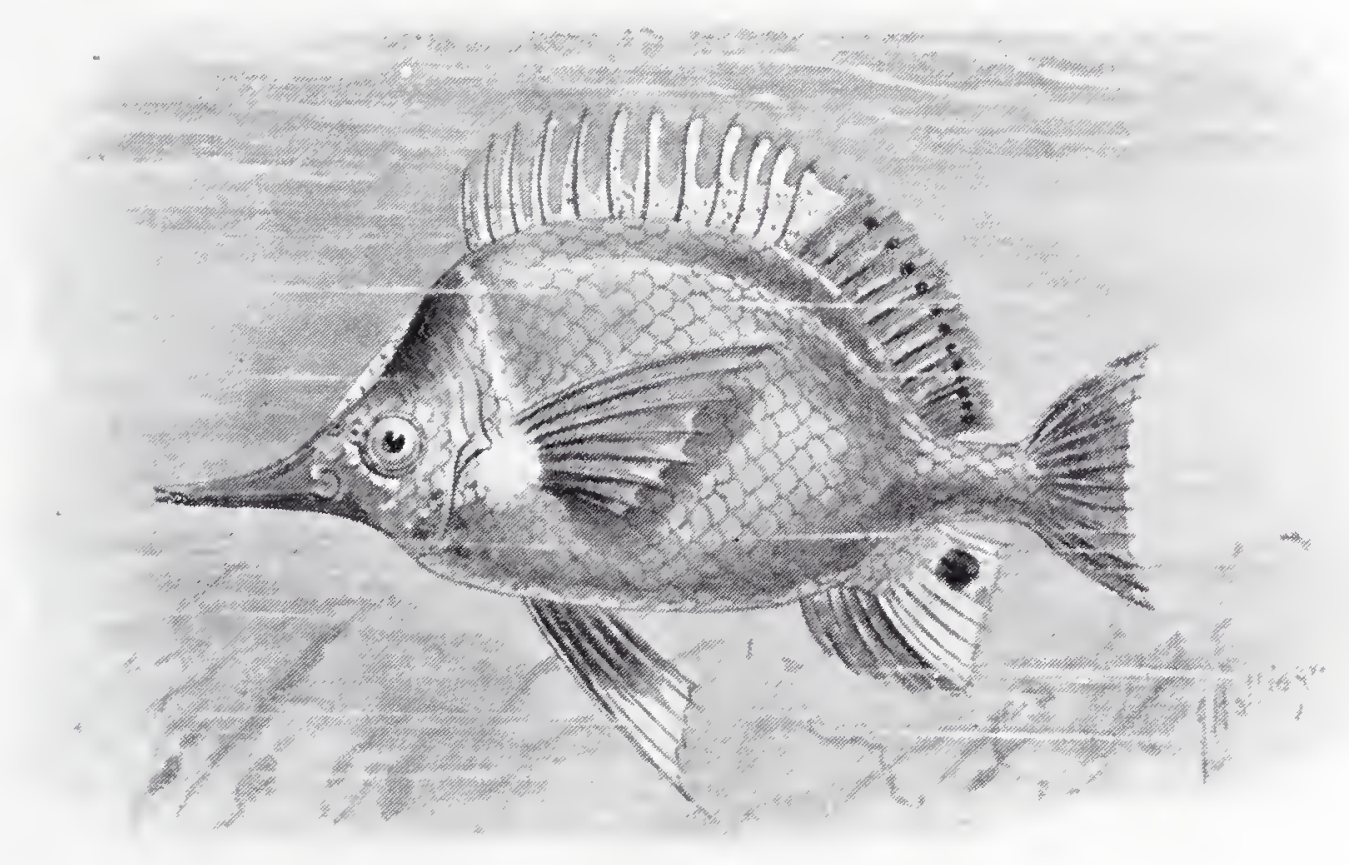

BEAKED CH.ETODON.

is made from the sturgeon's roe. The membranes which separate the eggs from one another are all removed, and the eggs are then salted and pressed into small barrels, being afterwards eaten as a kind of preserve.

Then of course you have heard of "isinglass"; and the best isinglass is made from the sturgeon's swimming bladder, which has so much gelatine in it, that if a small quantity is dissolved in a hundred times as much boiling water, it will form a stiff jelly when it is cold.

And then, thirdly, the sturgeon's flesh is very good to eat, for it is not only very well-flavoured, but is so firm and solid that it is almost like meat.

In England the sturgeon is known as a "royal" fish, hecause in days of old, when one of these fish was caught in an English river, it was always kept for the table of the king. And 
even now, if a sturgeon is captured in that part of the Thames which is under the control of the Lord Mayor of London, it belongs by right to the Crown.

Several kinds of sturgeon are known, one of which, found in the Blacli Sea and the Sea of Azov, sometimes grows to a length of five-and-twenty feet.

A great many fishes are very odd to look at, and the BEAKED CHatodon is one of the oddest. It is not very easy to describe. Imagine a fish with an almost circular flattened body, with five brown bands edged with white running round it, luge round eyes, enormous triangular fins both above and below the body, a broad tail, which looks as if it were tied tightly in by a piece of ribbon at the base, and a mouth drawn out into a long slender beak! 'That sounds odd, doesn't it? And this fish has a habit which is even odder still, for when it sees an insect sitting

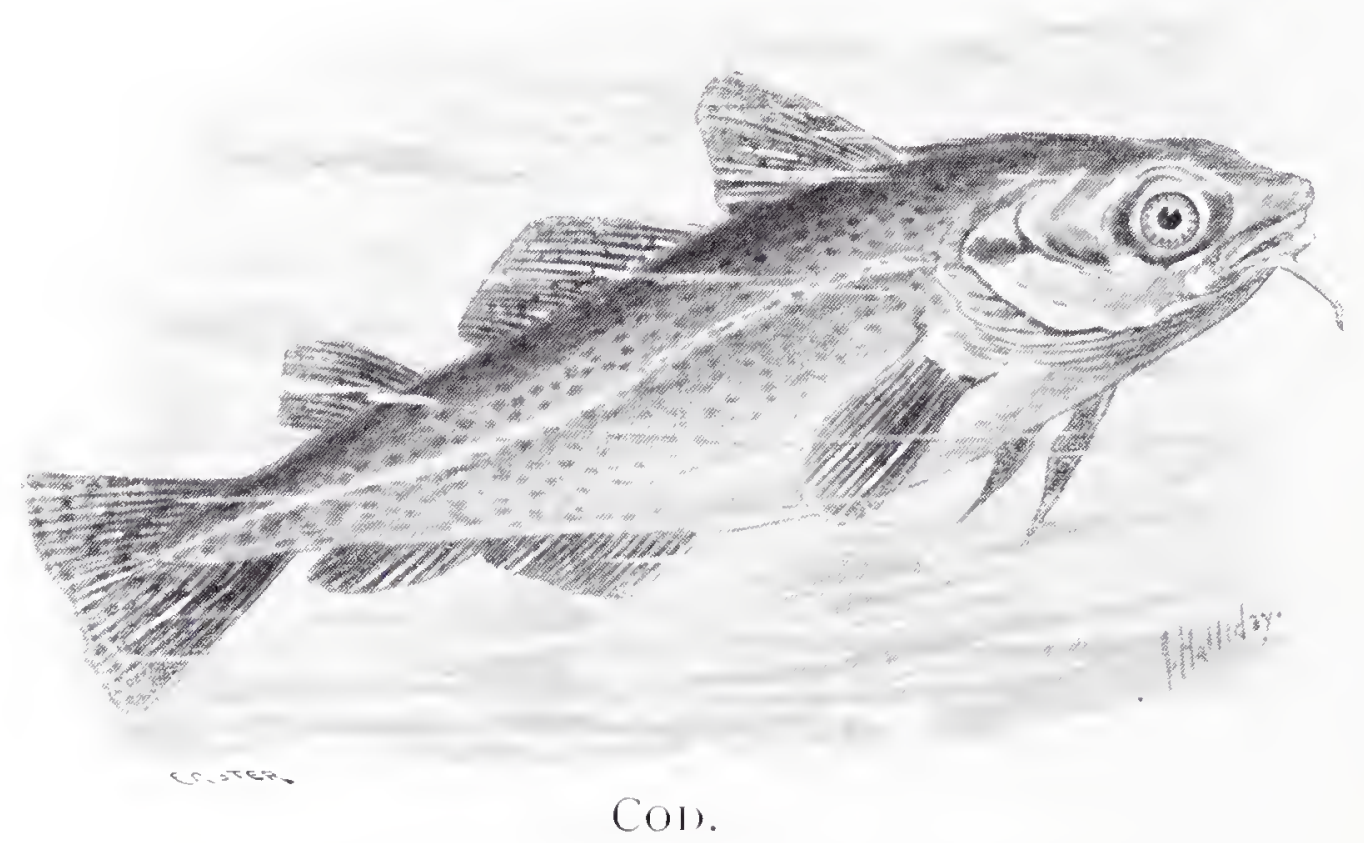

on a leaf which overhangs the margin of the sea, it takes careful aim, squirts a drop of water at it from out of its long beak, and nearly always succeeds in linocking it into the water below!

This fish lives in the Indian and Polynesian Seas, and is sometimes liept as a pet by the Japanese, who often amuse themselves by fastening a fly to the end of a piece of stick and holding it over the bowl in which the fish is living, just in order to see it linocked off its perch by a pellet of water.

The COD is found throughout the northern seas, in some parts of which it is taken in immense numbers. The largest and finest of all, which sometimes weigh more than Ioo pounds, come from the shores of Newfoundland, but very fine ones have been taken off the coast of Cornwall.

Cod are mostly captured by means of long lines, each about forty fathoms in length, to which a number of smaller lines are 
fistened at intervals. The hooks are placed on the side lines, and are generally baited with whellis. Each boat carries about eight miles of these lines, with nearly five thousand hooks, so that the work of baiting, lowering, and raising them is very heavy indeed. The fishing takes place in the winter, and the boats are generally out in all weathers for several months at a time.

One would think that with so many boats engaged in codfishing, each with so many miles of line, pretty well all the cod in the sea would very soon be caught. But then a single cod,

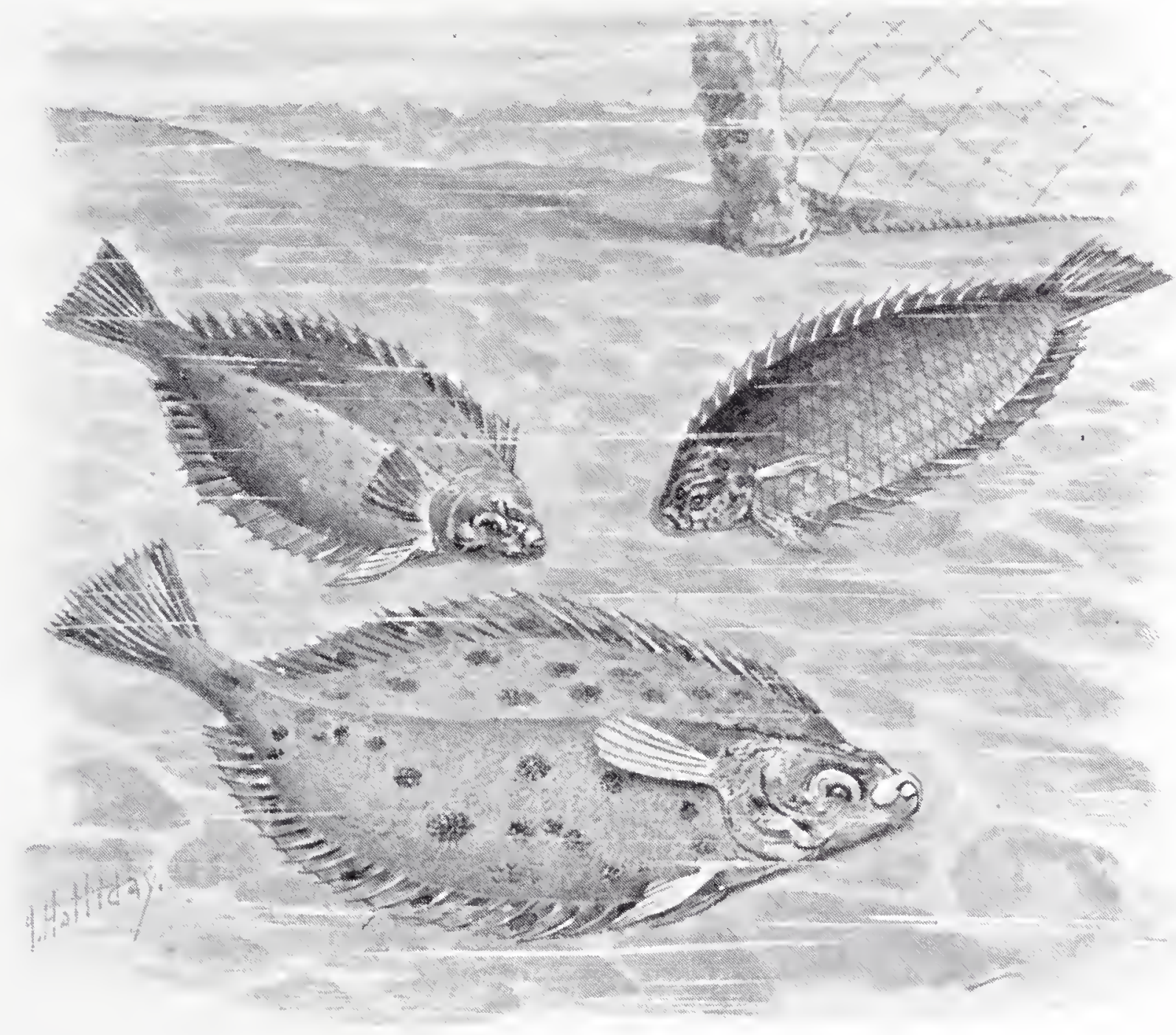

FlotNiner, PlateE, SOLE.

in a single year, will often lay eight or nine million eggs, so that notwithstanding the immense number of these fishes which are taken, they still seem as plentiful as ever.

The so-called "Flat Fishes," such as the Sole, the Plaice, the Flounder, and the DAB, are very curious creatures indeed. Although we call them "flat," we ought really to call them "thin." Because what we always consider as the back of a sole is really one of its sides, and what we always consider as the lower surface is the other side!

Doesn't that sound strange? Wut the fact is this. When 
these fishes are quite small, they swim upright in the water, just as other fishes do, and drive themselves along by means of their tails. But when they are about a month old, a strong desire comes orer them to go and lie down on the mud at the bottom of the sea. And then three most remarliable things happen.

First, their colour changes. Up till now, both sides of their bodies have been nearly white. But if a white fish were to lie down on dark brown mud, of course it would very easily be seen, and most likely woukd very soon be devoured by one of its many enemies. So as soon as the little fish lies down at the bottom of the water its upper surface begins to grow darlier, and before very long it exactly resembles the hue of the surrounding mud. Or if the fish should lie upon sand, as the plaice does, then its upper

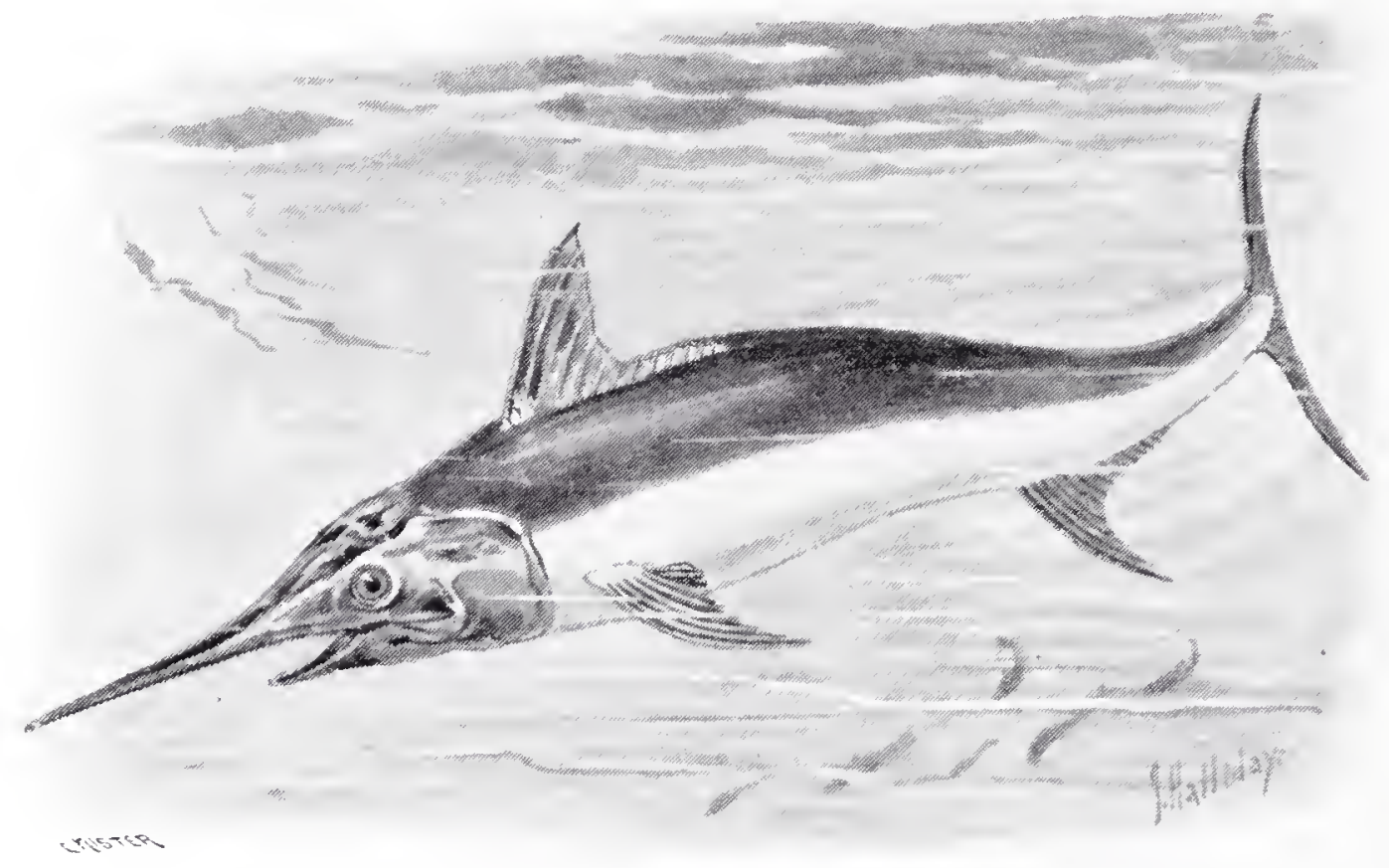

SIIORD-FISH.

surface becomes coloured like the sand. So as long as it lieeps still its enemies may pass quite close to it without noticing it.

The next thing that happens is that the little fish changes its way of swimming. Hitherto it has driven itself through the water by means of its tail; now it uses what were formerly its upper and lower fins, but have now been turned into side fins. And by a very graceful waving movement of these fins it winds its way, as it were, through the water.

But the third change is the strangest of the three. One of the eyes would now seem to be useless, since it is on the lower surface of the head as the fish lies on the sea bottom, and would he completely buried in the mud. But as soon as the fish goes and lies down at the bottom of the sea, this eye actually begins to travel along the lower surface of the head, till at last it works its way round and settles down by the side of the other! 'This sounds too strange to he true, doesn't it? Yet it happens in every 
case with all these so-called "flat fishes." And if you look at the soles or the flounders next time you pass by a fishmonger's shop, you will see that both eyes are placed quite close together above the same corner of the mouth. That is because the lower eye travelled round the head till it found a resting-place by the side of the other.

In habits, all these fishes are very much alike. They are found in almost all seas, except those of the Polar regions, and in most parts of the world are exceedingly plentiful. More than a hundred thousand turbot, for instance, are brought every year to the great fish market at Billingsgate alone, while soles, brill, plaice, flounders, and dabs are caught literally in millions.

A very odd-looking creature is the Sword-FISH, which

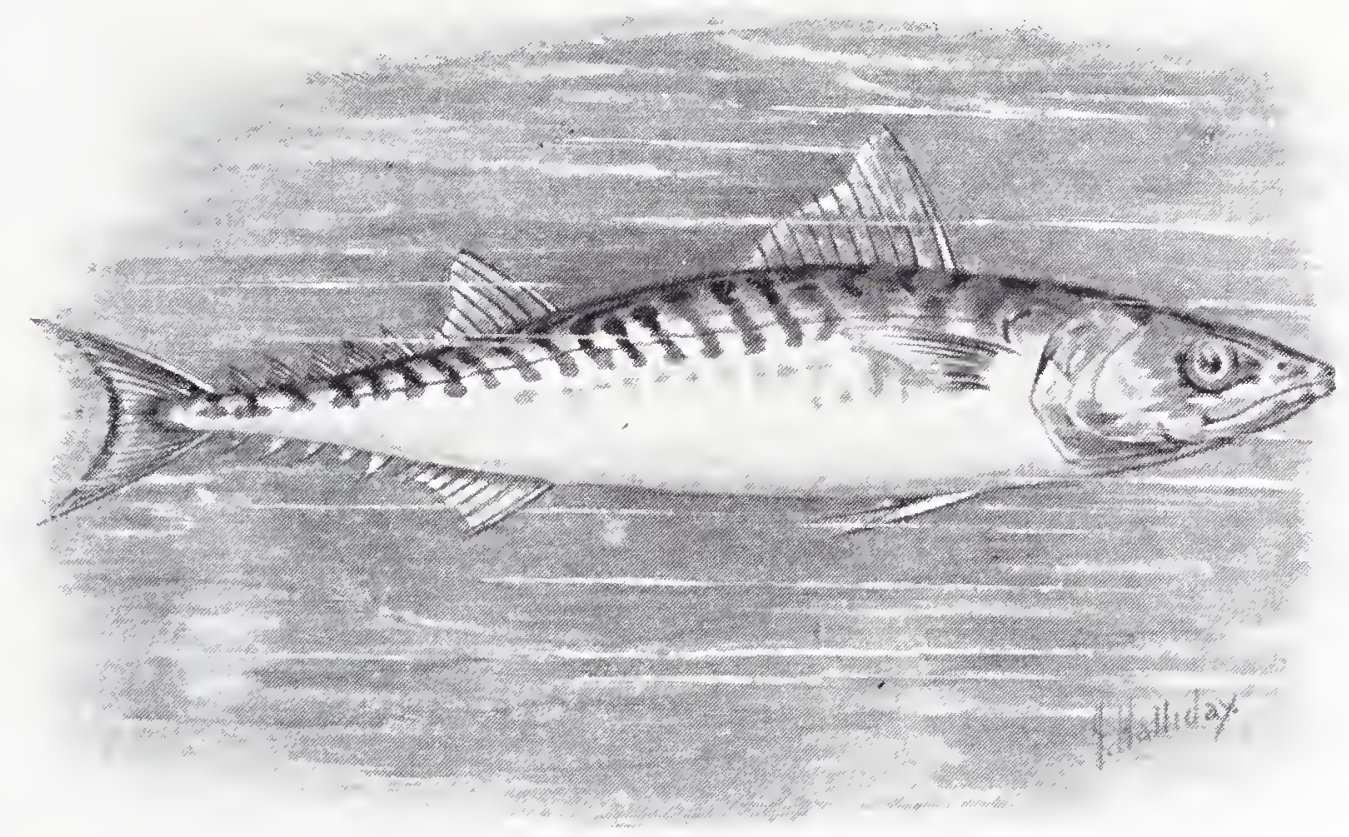

MACKEREL.

abounds in the Atlantic, and also in the Mediterranean. It has often been captured off the coasts of Scotland, and ras once taken in the River Nen, just below Peterborough.

In this fish the upper jaw, which has hardly any teeth in it at all, is drawn out into a long, slender, pointed beak, which is really a very formidable weapon. With this "sword" the fish impales its victims, which are often of considerable size. But how it gets them off its beak again in order to eat them nobody seems to know.

This fish sometimes drives its way through the water with such tremendous force that it has been known to pierce the planking of a boat with its sword, which it had to snap short off in order to release itself.

In the Natural History Museum at South Kensington, for example, there is part of a beam taken from the hull of a ship, into which one of these fishes had driven its sword to a depth of no less than twenty-two inches. 
One of the best known of all the British salt-water fishes is the MACKEREL.

This fish lives in enormous shoals, which are always travelling from place to place, and visit the same parts of our coasts at about the same season in every year. Sometimes they are caught in most extraordinary numbers, so that while they may fetch two or three shillings apiece before the shoal arrives, they can afterwards be purchased at the rate of six or seven for a shilling. In some cases, indeed, the catch has been so heavy that it has been found quite impossible to draw in the nets, which had to be allowed to sink to the bottom with the fishes still in them.

These nets are generally made with rather large meshes, not quite wide enough to allow the fishes to swim through. When the mackerel are caught they try to force their way through the meshes, but find that they cannot do so. They then attempt to back out. In doing this, however, the thin twine of which the net is made is almost sure to become entangled with their gill covers, so that they are held helpless prisoners until the net is lifted from the water.

When fully grown the mackerel is about sixteen inches long, and weighs perhaps a couple of pounds.

The Sucking Fishes, of which there are about a dozen different linds, are distinguished by the odd sucker-like disc on the upper part of the head, by means of which they can attach themselves firmly to any object to which they wish to cling. They often fasten themselves in this manner to the hulls of ships, and also to the bodies of sharks and the shells of turtles, and so are carried for long distances without any exertion of their own at all.

It rather reminds one of small boys hanging on to carts, and so getting a ride for nothing, doesn't it?

So firmly do these odd little fishes cling, that it is most difficult to remove them without injuring them. And the sharks and turtles, of course, have no means whatever of forcing them to loose their hold!

It is a very odd fact that the colouring of the sucking fishes is just the opposite of that which we find in almost all other fishes. Instead of the upper surface being darli it is light, and instead of the lower surface being light it is dark. But then, you see, when one of these fishes is clinging to a shark it is the lower surface which is seen, not the upper one; for that is pressed against the body of the shark. And in order to prevent its enemies from seeing and eating it, the lower parts of its body are coloured just like the slin of the shark.

Next we must notice the Weavers, two of which are found in the British seas. One of these is known as the Greater, and the other as the Lesser Weaver.

Both these fishes are highly poisonous, a prick from the spines of the upper fin or the gill corer heing almost as serious as the sting of a scorpion. The poison lies in a deep double 
groove on each spine. And as the fishes have a habit of burying themselves in the sand at the bottom of shallow water, with only just the sharp spines projecting, they are rather apt to be trodden upon by bathers.

When a fisherman catches a weaver-fish he always cuts of its back fin and the spines of its gill covers at once; while in France and Spain he is compelled to do so by law.

One of the most curious of all fishes is the ANGLER.

It is a hideous creature-about five feet long when fully grown, with a huge mouth, a great broad body shaped very much like that of a seal, two big round eyes which look almost straight up into the water above, and a row of long, slender spines on the back instead of the usual fins. And we notice at once, on looking at the fish, that the first of these spines has a broad, tufted, glittering tip.

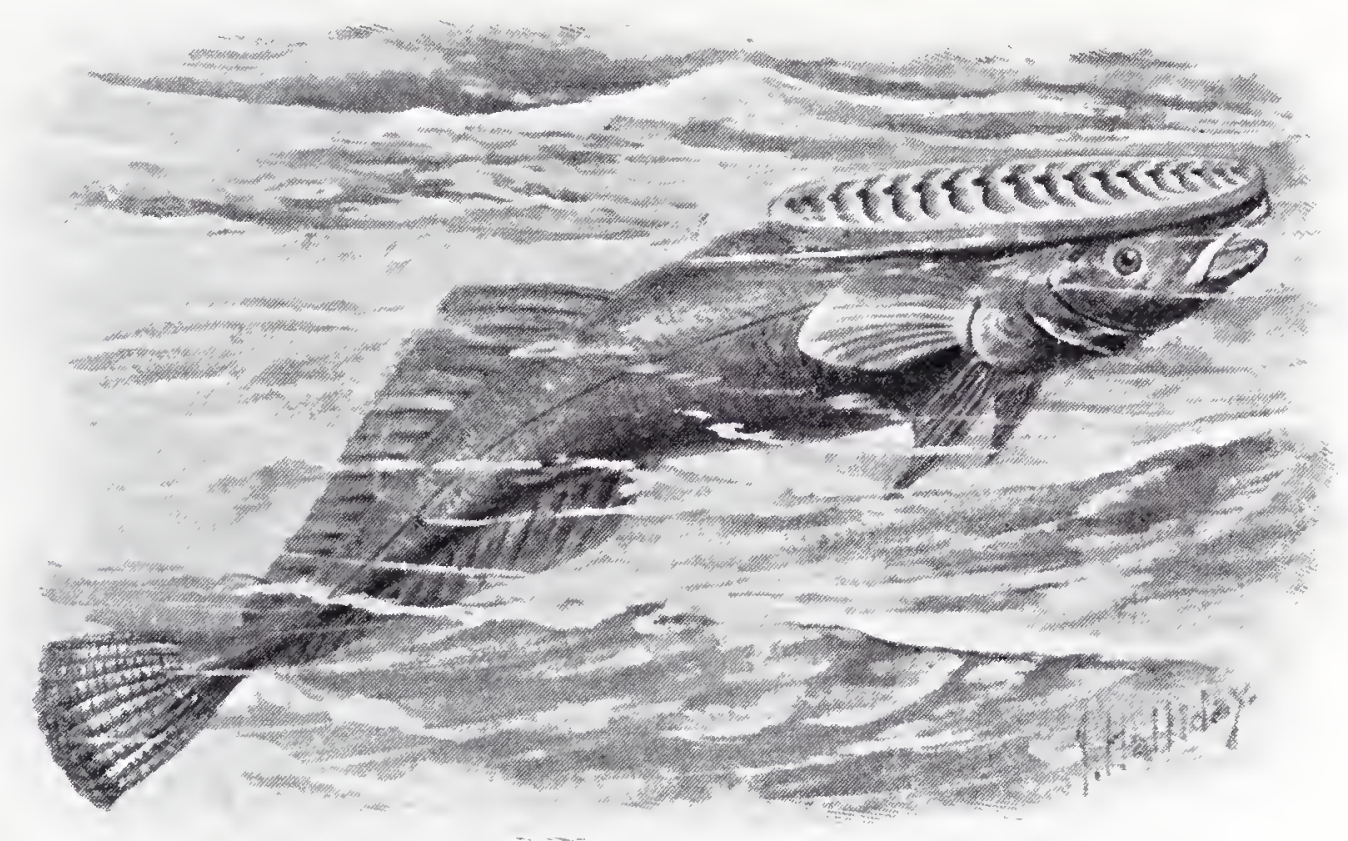

SUCKING FISH.

The fish uses this tuft for a most singular purpose.

It is a creature of prey, feeding entirely upon other fishes; and it has a most enormous appetite, which is hardly ever satisfied. But, at the same time, it is so slow in its movements that if it were to try to chase its victims it would never get anything to eat at all. It seems to know perfectly well, however, that fishes are very inquisitive creatures, and that they are always greatly attracted by any object that glitters. So when it feels hungry it lies down at the bottom of the sea, stirs the mud gently up with its side fins, so as to conceal itself from view, and dangles the glittering spine up and down in front of its open mouth. Before very long some passing fish is sure to come swimming up to see what this strange object can possibly be; and then the angler just gives one snap with its great jaws, and that fish is seen no more. Then immediately it begins to angle for another. 
Just to show you how successful it is in its fishing, I may tell you that from the body of a single angler no less than seventyfive herrings have been taken, while another had swallowed twentyfive flounders and a John Dory!

There is another kind of angler which lives down at the bottom of the deep sea, where it is always perfectly dark. There, of course, a glittering spine would he useless, for the other fishes

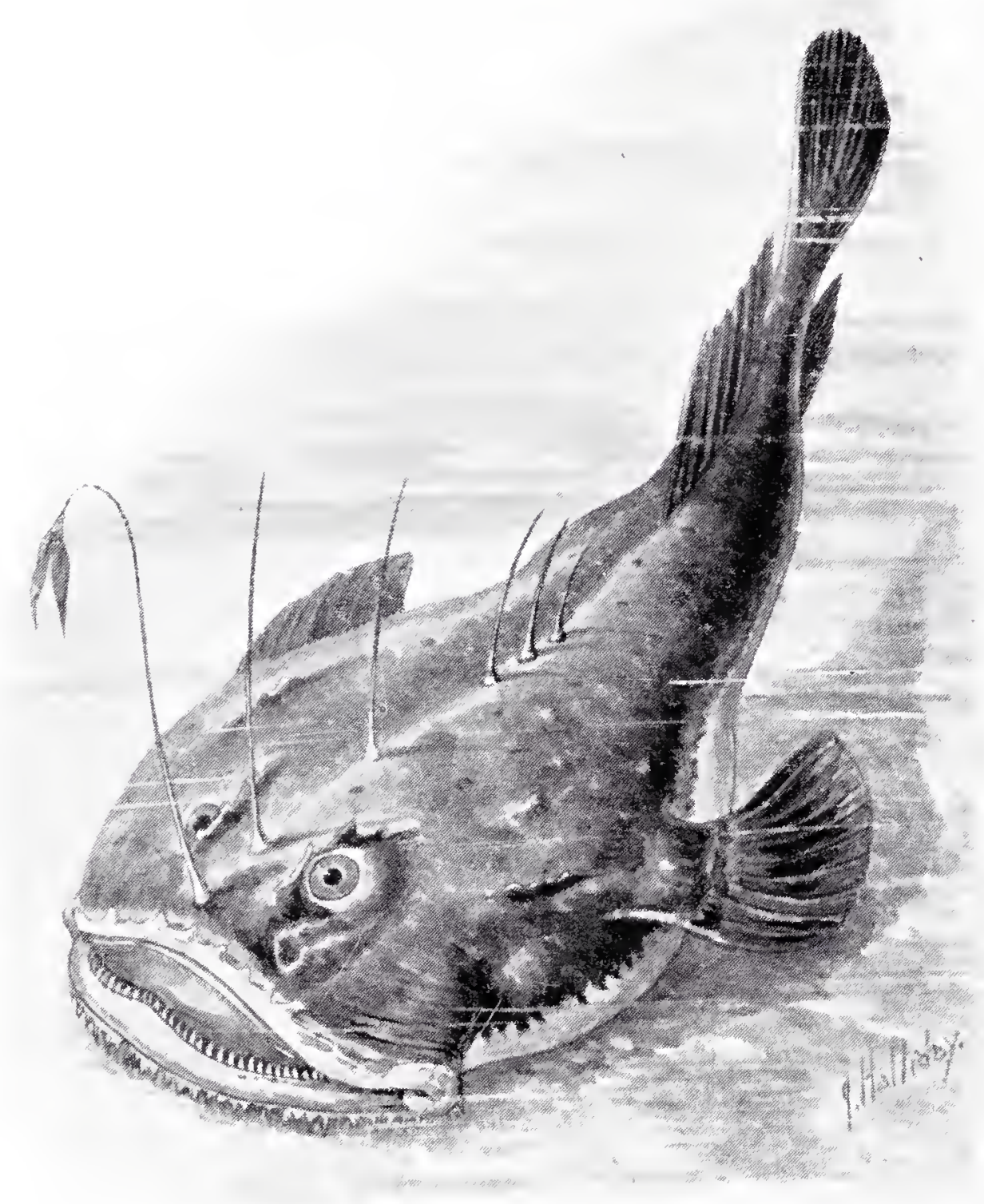

ANGLER FISH.

woukd not be able to see it. So this angler has a spine which shines at the tip like a fire-fly, so that it can be seen from a considerable distance as the fish dangles it up and down!

The angler fish is sometimes known as the "fishing frog," because it is supposed to look like an enormous frog as it lies at the bottom of the water.

Crumards, too, are very remarkable fishes.

Yon can tell them at once by their huge square heads, which 
look ever so much too big for their bodies, and also by the fact that the first three rays of their pectoral, or breast fins, are made just like fingers. And they are used like fingers, too, for they serve as organs of touch, while the fish also walks with them along the sand at the bottom of the sea.

At least forty different kinds of gurnards have been discovered, seven of which are natives of the British seas. 'The handsomest of these, perhaps, is the RED GURNARD, which grows to a length of twelve or fourteen inches, and is bright red above and silvery white below.

F IYING Fishes are very curious creatures, and everyone who journeys through the warmer seas must watch them with the greatest interest.

They do not really fly however. They merely skim for long distances through the air, just as the flying squirrel and the

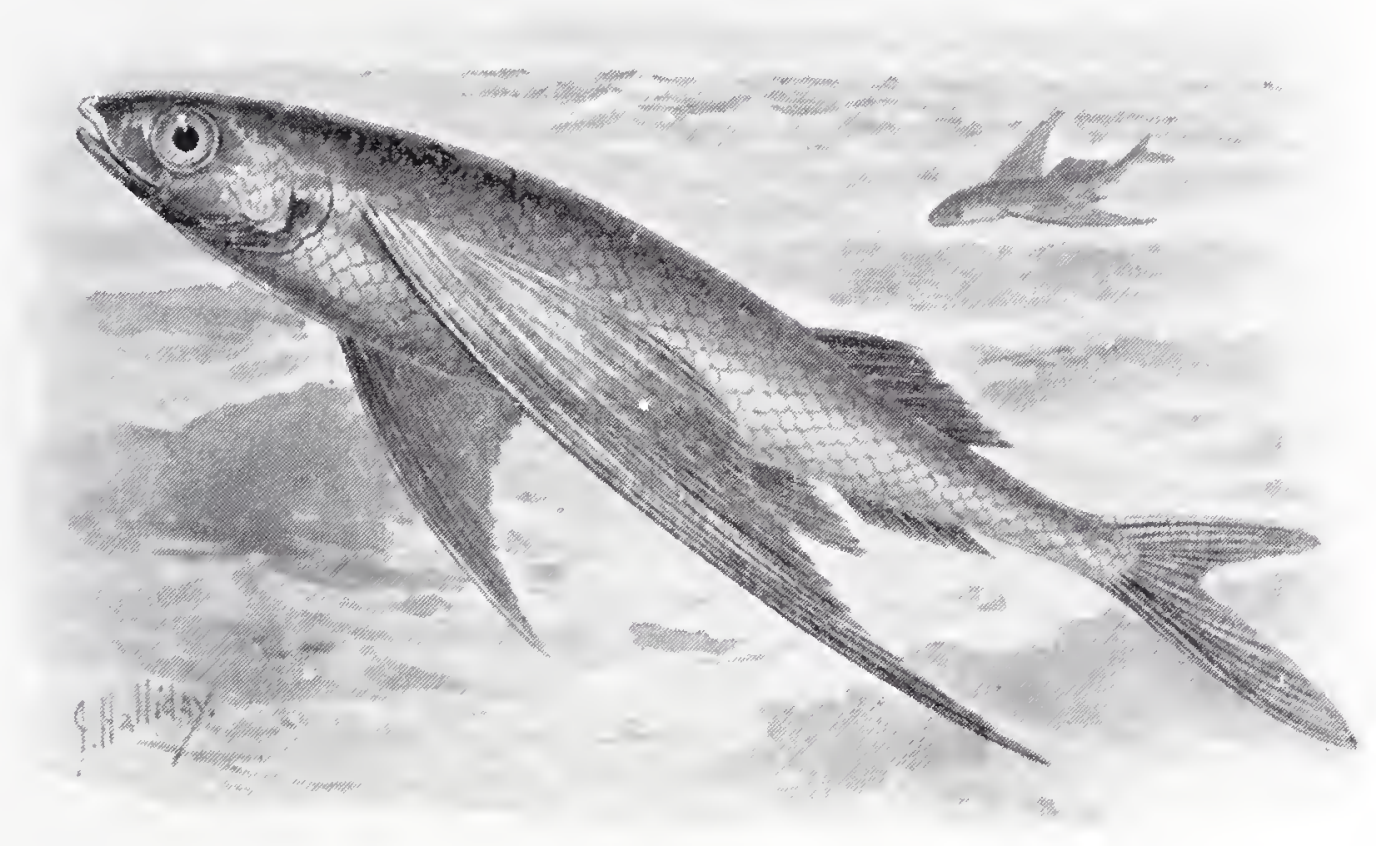

FLYING FISHES.

flying dragon do. Only instead of having a broad parachute-lilie membrane to buoy them up, they are supported in the air by the pectoral, or breast fins, which are very large indeed. These fins do not beat the air, like the wings of a bird. They merely support the body. And the power of the so-called "flight" is dne to a strolie of the tail just as the fish leaves the water.

The reason why these fishes take their long voyages through the air appears to be that they are very much persecuted by other fishes, which are ever so much bigger and stronger than themselves, and that they know quite well that they will be overtaken if they remain in the water. They do not generally rise to a height of more than a few feet above the surface, and the greatest distance to which they can travel without falling hack into the water seems to be about a comple of hundred yards. Whether 
they can alter the direction of their course while they are in the air is uncertain. Some observers say that they can, while others declare that they cannot. But it is possible that they may sometimes do so by just touching the crest of a wave with their tails.

Flying Fishes are found in all the warmer parts of the sea, and are very common in the Mediterranean.

The HERring, like the mackerel, is one of those fishes which live in vast shoals. These shoals consist of millions upon millions of fishes, and when they are swimming near the surface of the sea their presence can generally be detected by the numbers of sea-birds which follow them and devour them in countless thousands. Whales, too, often follow the shoal for days together, and sharlis and many other big fishes do the same. Yet nothing seems to lessen their numbers.

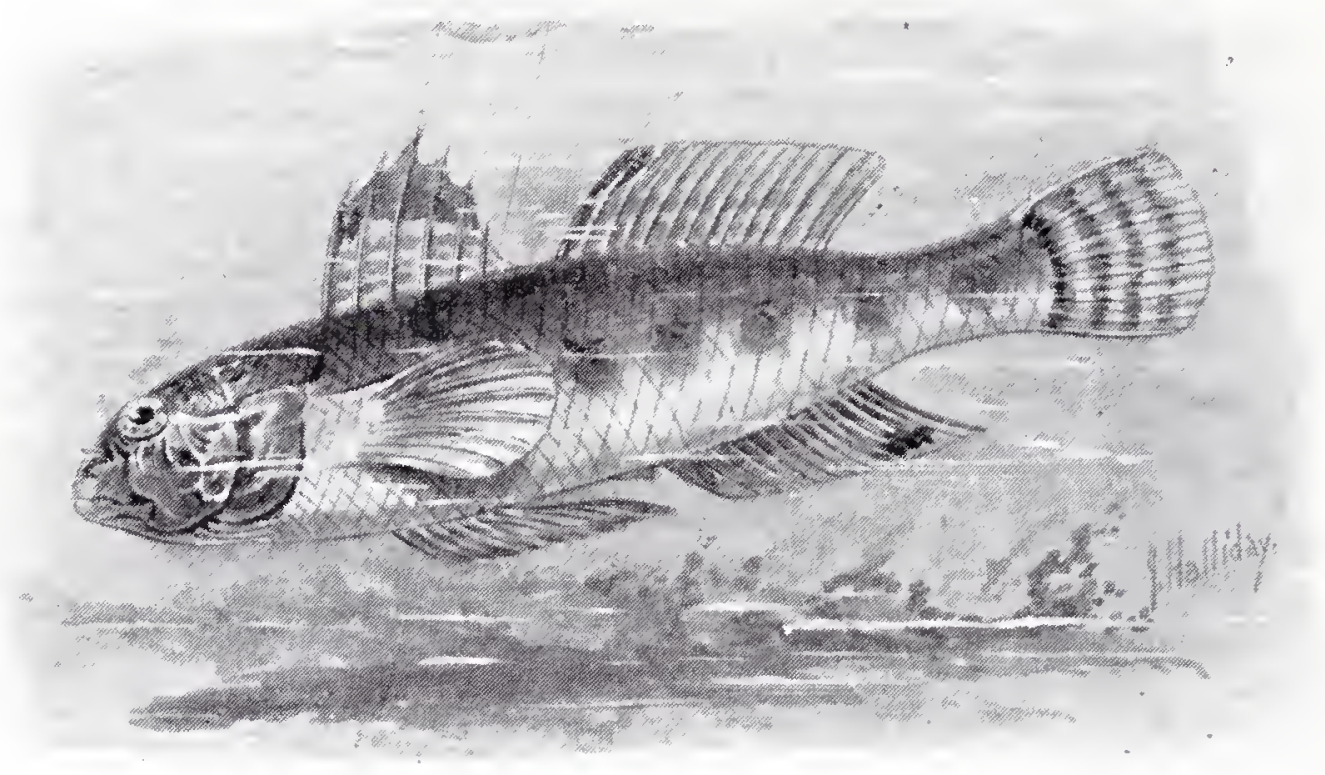

BLACK GOBY.

These shoals generally appear in the same parts of the sea, year after year, at the same season. But sometimes they will desert their favourite haunts without any apparent cause. During spring and early summer they remain in deep water; but in June and July they come in nearer the coast in order to spawn. As a rule they are seen about the Hebrides in June, near the Shetland Islands in July, off the east of Scotland from August till October, and off the western coast of England from October till December. And sometimes they are talien in such enormous numbers that it is almost impossible to raise the nets. From Scotland alone, indeed, at least half a million barrels of herrings are sent away every year; and in every one of these barrels there are 550 fishes!

There are still several very curious and interesting fishes about which I should like to tell you; and among these are the Gobies.

A great many different linds of these odd little creatures 
are found in different parts of the world; but perhaps the best known of all is the BLACr Gobr, which is very common indeed off our British coasts. You can very often catch it by fishing with a small net in the pools which are left among the rocks as the tide goes out. And if you look into these pools from above, you may often see it clinging to the rocks round the margin. It does this by means of the fins on the lower part of its body, which are made in such a manner that when they are placed side by side together they form a kind of sucker. And if you keep the fish in an aquarium, it has an odd way of suddenly darting at the side of the tank, clinging to it with its fins, and staring at you through the glass.

Some of the gobies makie nests in which to bring up their little ones, just as the sticklebacks do. One of them, the Spotten

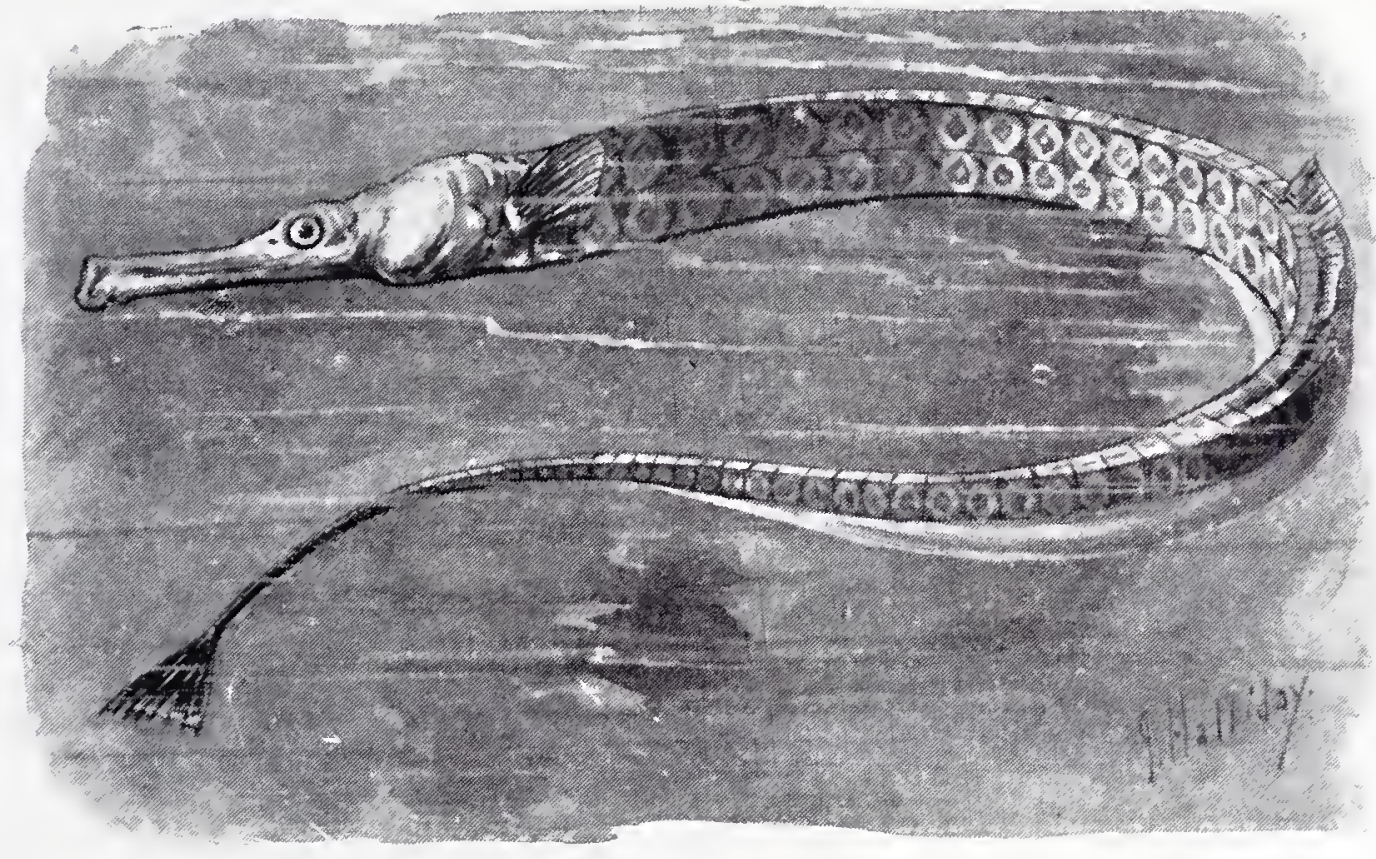

PIPE FISH.

GoBY, which is found rather commonly in the lower reaches of the Thames, nearly always takes one of the shells of a cockte for this purpose. First it turns the shell upside down; then it scoops out the sand from beneath it, and smears the surface of the hollow with slime from its own body; and then it piles loose sand over the shell, so as to keep it in position. Lastly, it makes a little tunnel by which to enter the nest from outside. This work is always performed by the male. When the nest is quite finished the female comes and lays her eggs in it, after which the male keeps guard over them until they hatch, about eight or nine days later.

More curious still are the MUD SkIPPERS, which are found on the coasts of the tropical seas, and often make their way for some little distance up the estuaries of rivers. They have most singular eyes, which are set on the upper surface of the head, and can be poked out to some little distance and drawn back again 
in the oddest way. And besides that, these eyes have eyelids. Then the lower fins are made just like those of the gobies, but with an even greater power of clinging, so that the fish can climb by means of them. And very often these queer little creatures leave the sea altogether and skip about on the muddy shore, or even climb up the trunks of the trees which overhang the water. Sometimes they will rest for quite a long time on the spreading roots, snapping at the flies and other small insects which come within reach. They do not look like fishes at all as they do so. They look much more like rather big tadpoles. And if they are suddenly startled they go hopping and skipping back into the water, not diving at once, lout leaping along over the surface, very much as a flat stone does when thrown sideways from the hand.

Some of these fishes were kept for some time at the $Z$ oo, and when they were out of the water they had an okd way of lying at full length and raising their heads and the front part of their bodies by means of their lower fins, so that they reminded one very much of a man with his ellows resting upon the table.

A more odd-looking creature than the PIPE Fish it would not be easy to find. Its mouth is drawn out into a very long snout, so that it forms a lind of tube; the body is sixteen or eighteen inches long, yet scarcely stouter than an ordinary drawing-pencil; and the only fin, besides a small one on the back, is a tiny one at the very tip of the tail. Besides this, the whole head and body are covered with bony plates, which form a lind of coat of mail.

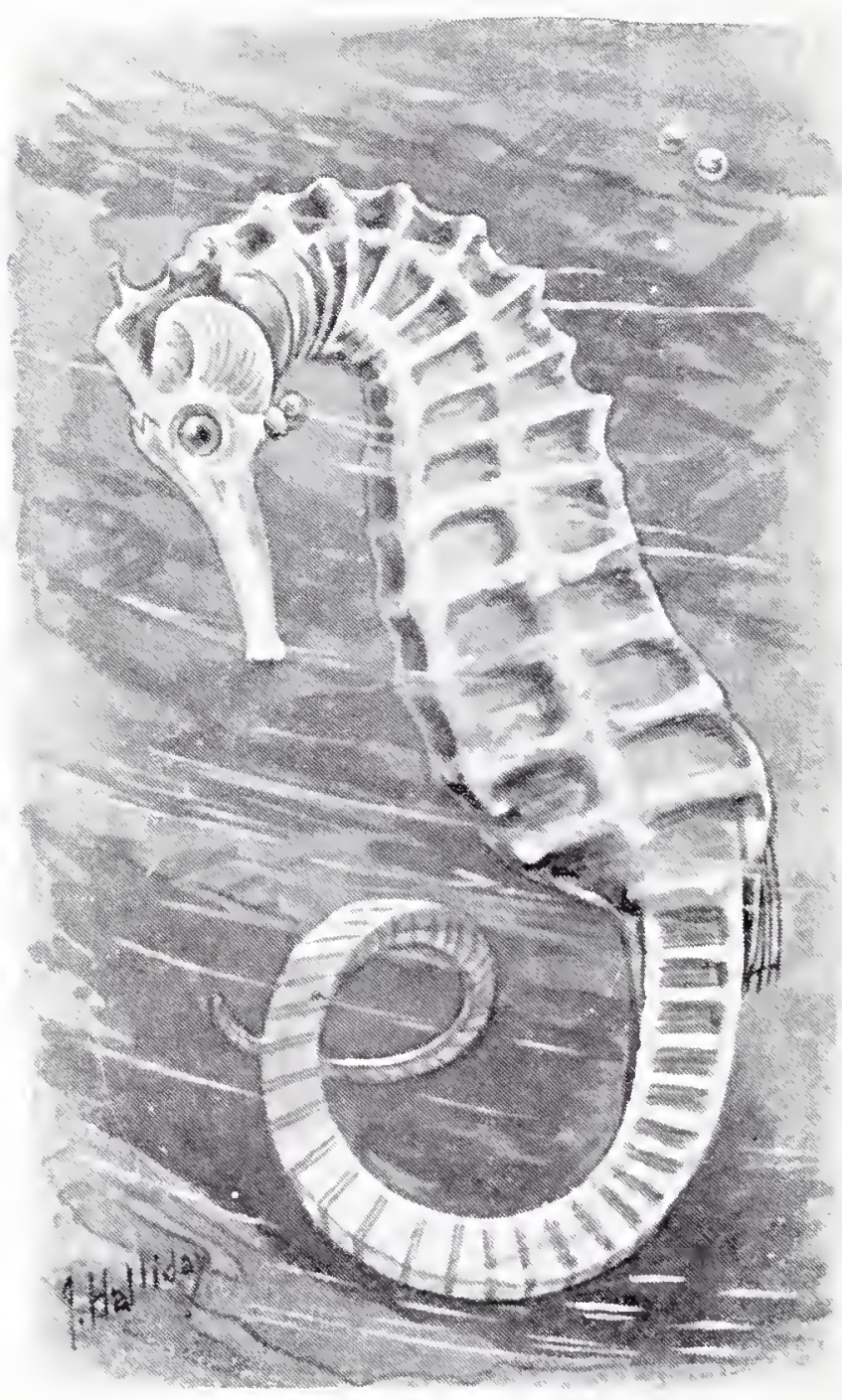

SEA HORSE.

And the fish is even odder in habits than in appearance, for when the eggs are laid they are put into a pouch in the lower part of the body of the male, and are kept there until they hatch!

It is even said that after the little ones are hatched and are able to swim about in the water, they will return into the pouch of the parent in moments of danger, just as young kangaroos will into that of their mother. But this does not seem to have been proved. 
Pipe Fishes are not uncommon on our British coasts, and you may often find them in the pools among the rocks when the tide is out. They swim half erect in the water, and if you watch them carefully you may see them poking their long snout-like mouths in among the seaweeds in search of food, or blowing furrows in the sand at the bottom of the pool in order to turn out any small creatures which may be lying hidden in it.

The SEA Horse, which is closely related to the pipe fish, always reminds one very much of the knight in a set of chessmen. But it has a long and slender tail, which is prehensile, just like that of a spider monkey; and by means of this organ the fish anchors itself firmly down to the stems of seaweeds, or to any small object which may be floating on the surface of the water.

The eyes of this fish are very odd indeed, for they can be

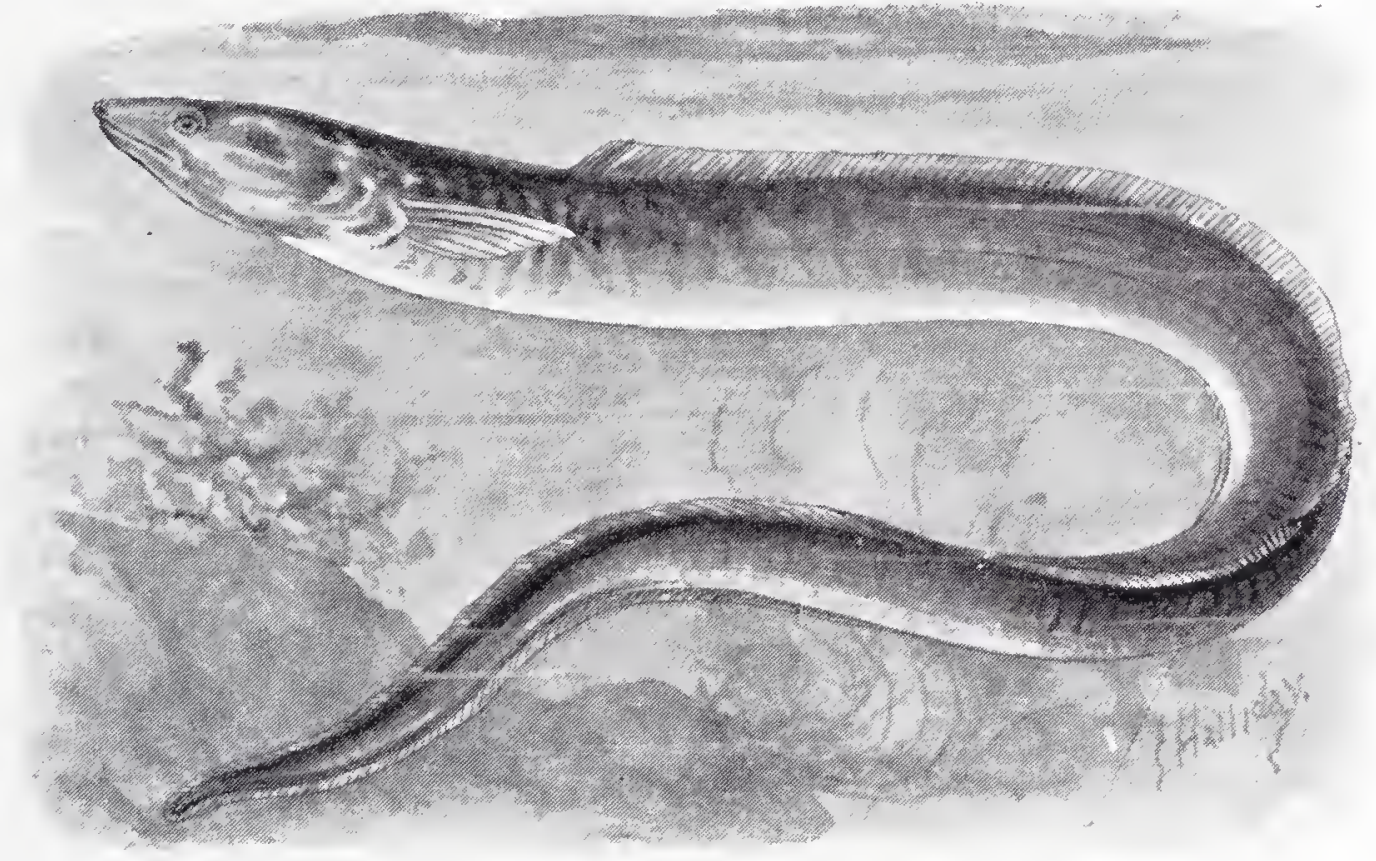

CONGER EEL.

moved quite independently of one another, like those of a chameleon. And if you keep one of these creatures in a bowl of sea water and watch it for a few minutes, you will find it yuite hard to believe that it is not purposely "making faces" at you!

The male sea horse, like the male pipe fish, has a pouch underneath his body, in which the eggs are placed as soon as they are laid, and are kept until they hatch.

The sea horse swims by means of a single fin on its back, which acts on the water very much like the screw of a steamboat. Just at the back of its head are two more fins, and when these are thrown forward they look just like the ears of a horse.

Sea horses are found in most of the warmer seas, and have several times been taken off the southern coasts of Great Britain. Just as there are eels which live in the fresh water, so there are cels which live in the sea. These are known as con- 
gers, and very often they grow to a great size. A conger eight feet long, indeed, is by no means uncommon; and a fish of this length will weigh at least one hundred pounds.

CONGERS generally live in rather shallow water off a rocky coast, where there are plenty of noolis and crevices in which they can hide during the day-time. It is rather curious to find that those which live in muddy places are nearly always dark brown or black in colour, while those which lie upon sand are light coloured, and sometimes almost white.

These eels are generally caught by means of long lines, which are set at intervals with short "snoods" just like those which are used in catching cod. The hooks are generally baited with pilchards, or else with pieces of the long "arms" of cuttles. When the congers are lifted on board the scene is generally a very exciting one, for they are very powerful and very active, and go twisting and writhing about in the most extraordinary manner, slapping vigorously on all sides with their long tails. These tails, too, to some extent, are prehensile, and sometimes the fishes will seize the gunwale of the boat, and then, with a sudden effort, pull themselves over the side and drop back into the water. So as soon as they are lifted on board, the fishermen always try to stun them by a heavy blow on the lower side of the body, after which, of course, they can be easily killed.

Congers feed, as a rule, upon those creatures which we wrongly call "shell-fish," devouring them shells and all. They will also eat small fishes, however, and sometimes they are cannibals; for inside the body of one of these fishes a young conger was found no less than three feet in length!

Last among the fishes comes the LANCELET, a creature so curiously formed that a good many naturalists have doubted whether it ought to be ranked among the fishes at all. For in appearance it is much more like a slug; and it has no skull, and no brain, and no bones, and no eyes, and no gills, and no heart! It has a fin running along its back, however; and although it has no spine, it possesses a spinal cord. So it is considered as the very lowest of all the fishes, and as a kind of link between the animals with bones and those without them.

This strange little creature is about two inches and a half long when fully grown, and is so transparent that one can almost see through its body. It is very active, and can wriggle and twist about in the water, or on the mud, with considerable speed. It spends most of its life concealed under large stones, or lying almost buried in the muddy sand at the bottom of the sea. And it seems to feed upon those minute atoms of decaying animal and vegetable matter which are always floating about in countless millions in the waters of the sea. 


\title{
INVERTEBRATES.
}

\author{
CHAPTER XXXII.
}

INSECTS.

WE now come to the second of the two great divisions of the animal kingdom, namely, the Invertebrates, which includes all those creatures which have no bones. This division in its turn consists of a good many Classes, just as that of the Vertebrates does; and just among these is that of the Insects which have to pass through three stages of development before they reach their perfect form. First there is the egg; then the grub, or caterpillar; and then the chrysalis, or pupa.

You can easily tell an insect when you see it by remembering one or two simple rules.

In the first place, its body is always divided into three principal parts, which are known as the head; the thorax, or chest ; and the hind-body. That is why it is called an "insect." The word "insect" means "cut into"; and its body is cut, as it were, into these three parts.

In the second place it always has six legs. Spiders have eight legs. Centipedes and millipedes have many legs. But an insect never has more or less than six. And each of these limbs is made up of a thigh, a lower leg, and a foot; while the foot itself is made up from two to five little joints, the last of which usually has a pair of tiny claws at the tip.

Besides these, there are several other ways in which insects differ from the rest of the vertebrates. I need only tell you about one of them, however, and that is that in some form or other they always have four wings. Sometimes, it is true, you cannot see these wings. That is because they are not developed and cannot be used for flying. But still they are there, and by means of the microscope it is almost always easy to detect them.

These wings, however, take all sorts of different forms. The wings of a butterfly, for example, are very different from those of an earwig or a bee. And because of these differences in the wings, insects are divided into several smaller groups, which we call Orders.

First comes the Order of the Beetles. These are called Coleoptera, or "shcath-winged" insects, because their front wings, instead of being formed for flight, are turned into horny or leathery sheaths, which cover up and protect the lower pair while not in use. 


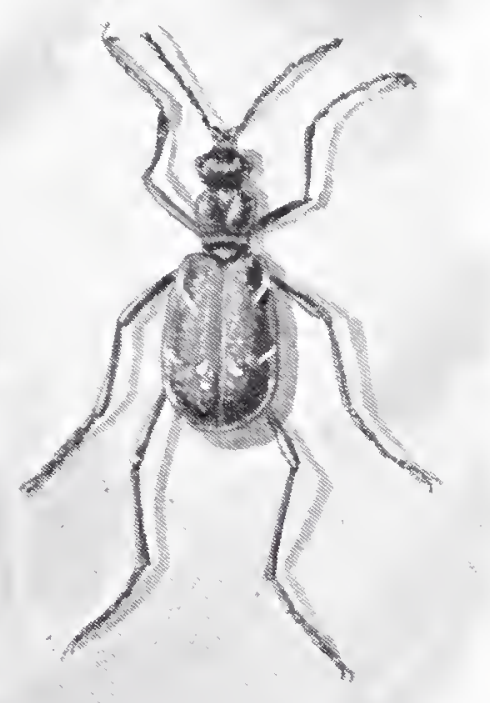

TIGER BEETIE.

At least I 50,00o different kinds of beetles have already been discovered in various parts of the world, and even in our British lslands we have nearly 3,500! Of these I can only mention just a few of the most interesting.

First of all, then, there are the Tiger Beeties, which are so called because they are such fierce and voracious insects, spending most of their time in chasing and devouring other insects. The commonest of them is about half an inch long, and is bright green above and coppery below. You may often see it darting about on heathy commons in the hot sunshine, and if you try to catch it you will generally find that it flies away as quickly as a blue-bottle.

The Purple Ground Beetle is common in gardens. It is about an inch long, and is deep black in colour, with a narrow band of violet running round the outer edge of its wing cases. This, too, is a creature of prey. It cannot hurt you; but if you pick it up it will make your fingers smell very nasty. For it can pour out from its mouth a drop or two of a dark brown liquid which has a very horrible odour indeed.

Then there are a good many beetles which live in streams and ponds, and are called IVAter BeETLES in consequence. They can swim and dive very well, and are also able to fly. Almost every night they go for long journeys through the air. And when they want to go back into the pond they hover above it for a moment, fold their wings, and drop into the water with a splash. Only sometimes they fly over the roof of a greenhouse, and mistake that for a pond; and then you can imagine the result!

The Cocktalls have very short wing-cases and very long,

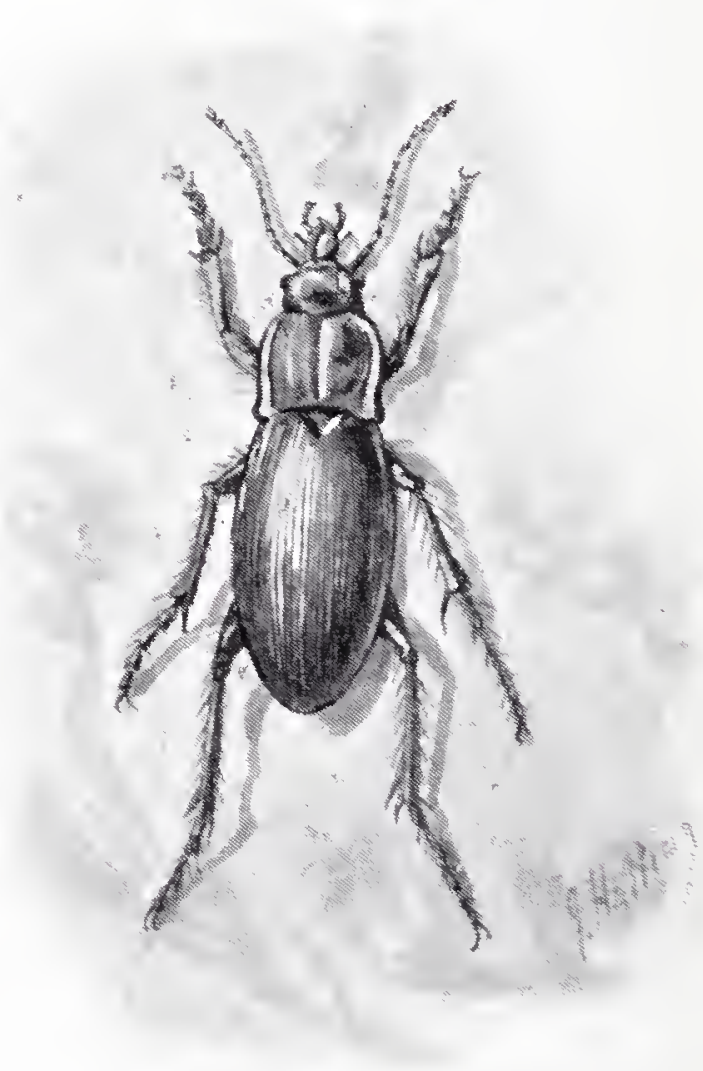

PURPLe Ground BeEtre. 
slender bodies. Some of them are quite large, like the ugly black "Coach Horse," which you may sometimes see running about in the garden, and which can give quite a sharp nip with its cruellooking jaws if one gives it the chance. But many of them are very small. Indeed, most of the "flies" which get into one's eyes on warm sunny days are really tiny cocktail beetles, and the reason why they make one's eyes smart so dreadfully is that they pour out a little drop of an evilsmelling liquid from their mouths, just like the purple ground beetle.

The Burying Beetles are so called because they bury dead animals. Have you ever wondered why we so seldom find a dead mouse or a dead bird, although these creatures must die in thousands every day? Well, the chief reason is that as soon as they are dead a couple of burying beetles are almost sure to come

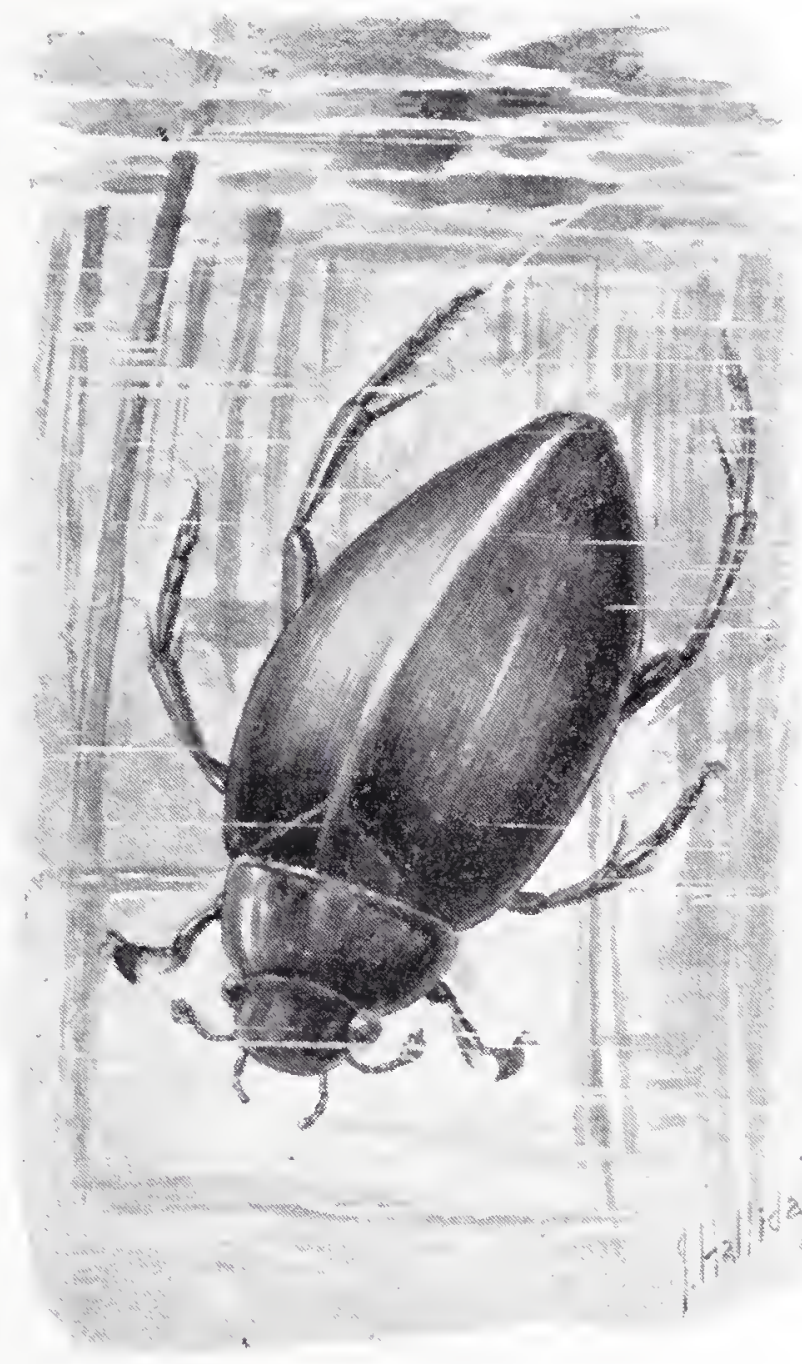

IVATER BEETLE. and bury them. They are big black beetles, sometimes with two broad yellow stripes across their wing-cases, and they dig by means of their heads, "scooping out the earth from underneath the
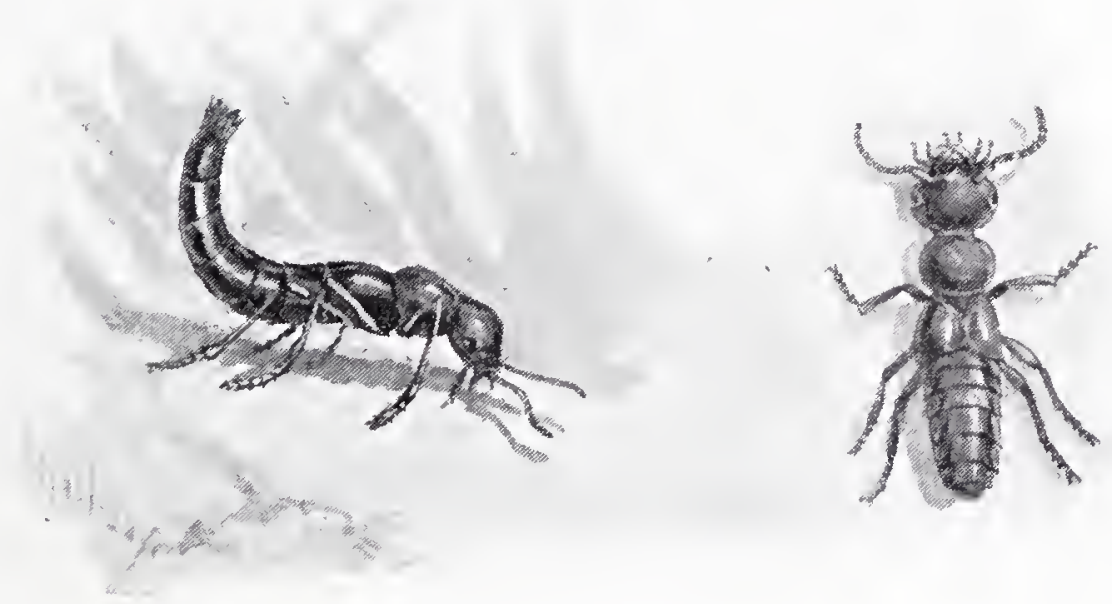

ColCH HORSE BeEtLes.

carcase till it has sunk well below the surface of the ground. Then they lay their eggs in it, come up to the surface, shovel back the earth till the dead body is quite covered over, and then 
fly away. And when the eggs hatch, the little grubs which come out from them feed upon the carcase.

The largest of all the British beetles is called the STAG

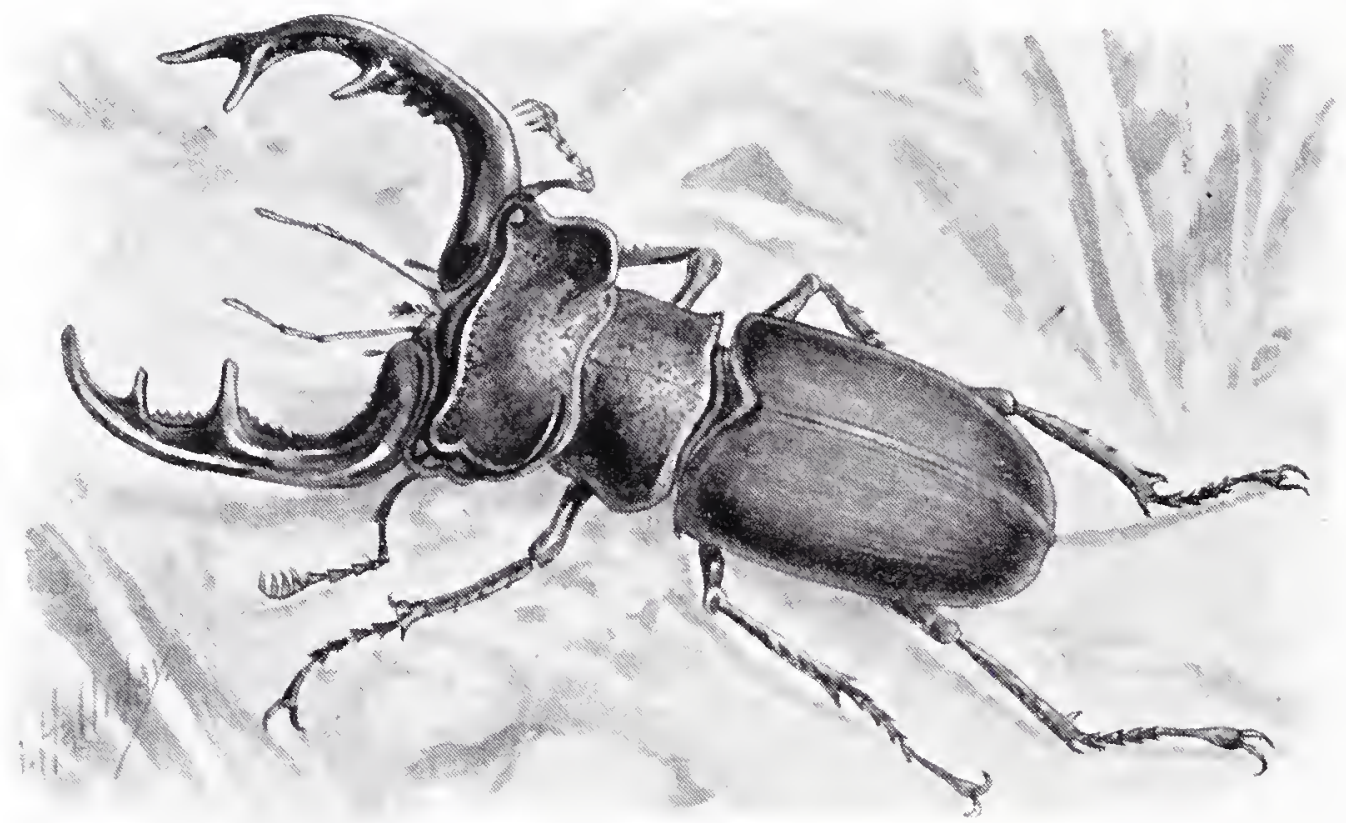

StAG BeEtLe.

Beetle, because the jaws of the male look very much like the horns of a stag. Those of the female are much smaller, but are so sharp and strong that they can really give a rather severe bite.

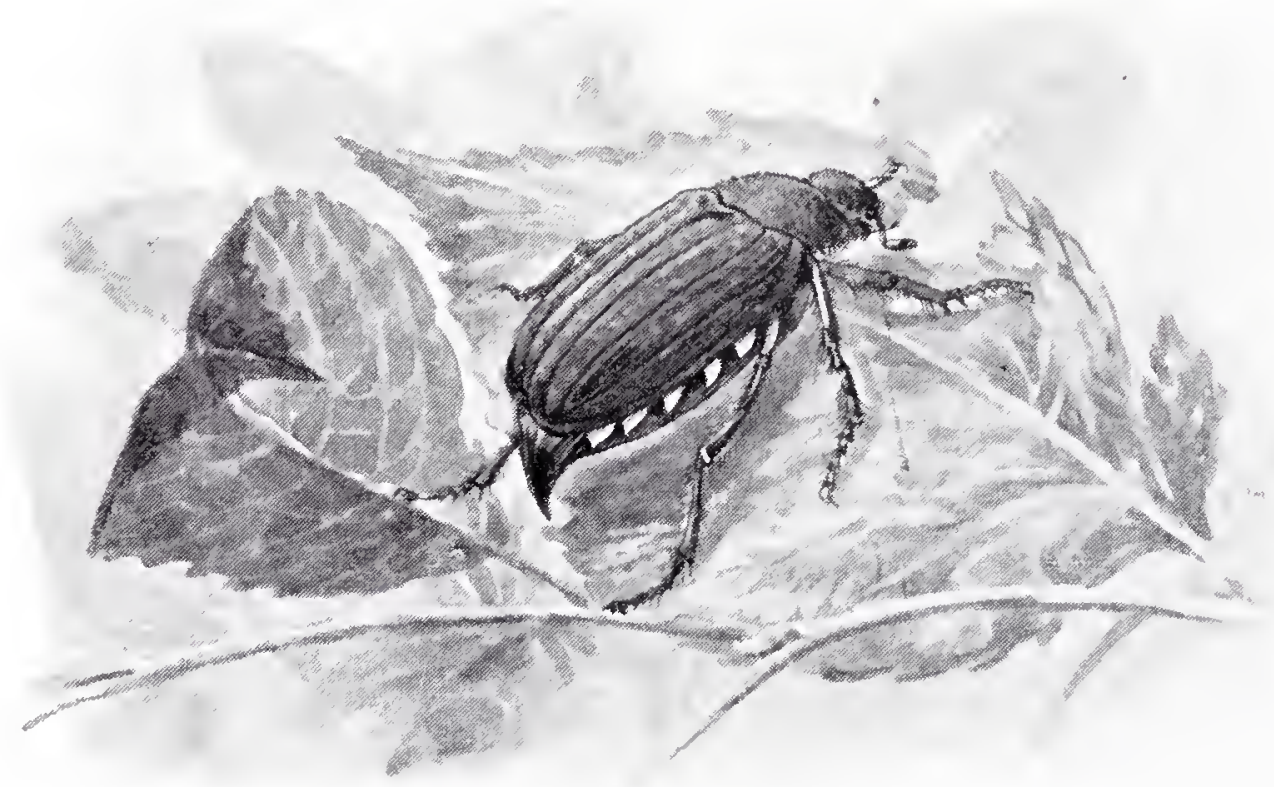

COCKCHAFER.

This beetle is very common in some parts of England, while in others it is never seen at all. If you happen to live in a neighbourhood where it is found, you may often see it flying slowly 
along on a warm summer's evening, generally about twenty or thirty feet from the ground.

The Cockchafer is common everywhere in spring, and if you shake a young birch tree, or a hazel bush, three or four of the great clumsy insects will very likely come tumbling down. They are rather more than an inch long, very stoutly and heavily built, and are chestnut brown in colour, while their bodies are drawn out into a kind of point behind. The grubs of these beetles live underground, and do a great deal of mischief in fields and gardens, for they feed upon the roots of the plants, and very soon lill them.

Dor Beetles, too, are very common everywhere. You may often see them flying round and round in great circles on warm summer evenings, making a loud humming noise as they

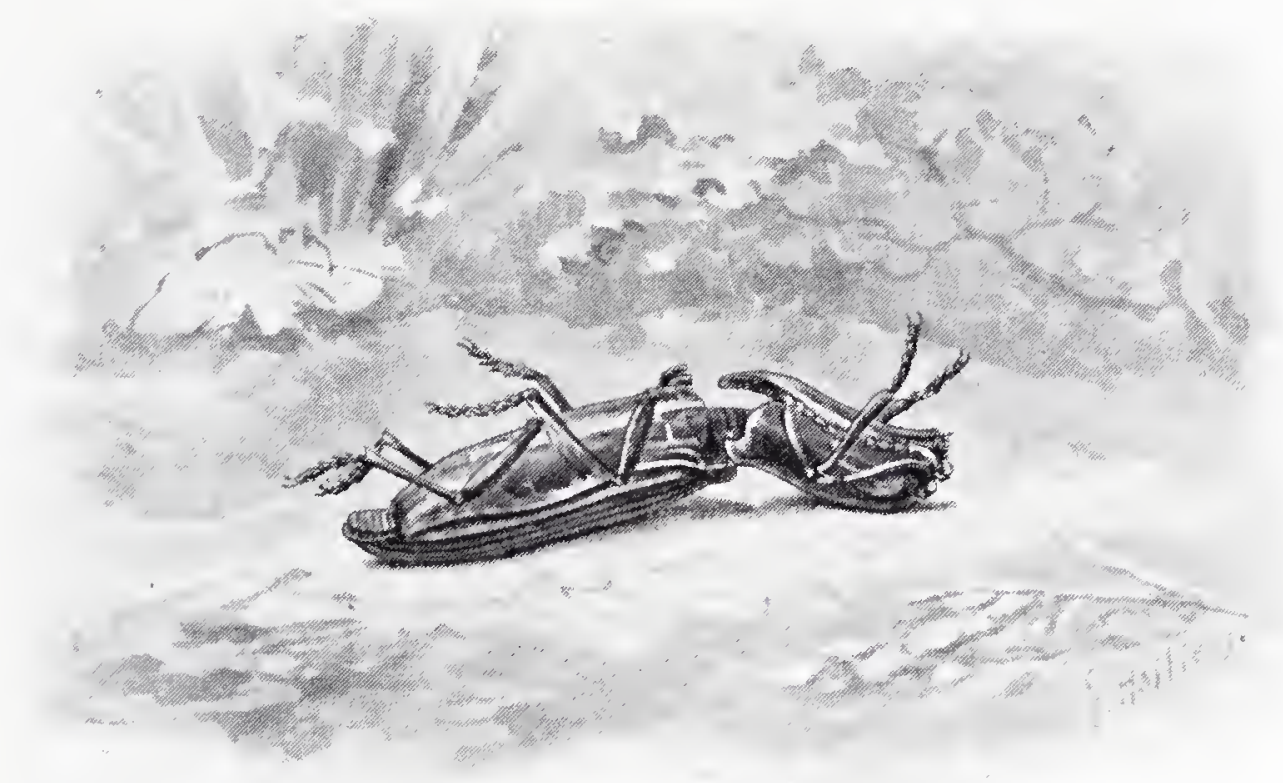

SKIPJACK,

do so; and if you catch one you will find that it is nearly black above, and rich metallic blue below. You will also see that its front legs are very broad and very strong, and that they are set with a row of stout horny teeth. With these legs the beetle digs, using them with such address that in the course of an hour or two it will sink a hole in the ground ten or twelve inches deep, in order to lay its eggs at the bottom.

The famous Scarabæus of Egypt, which in days of old the people of that country used to worship, is really a kind of dor beetle.

SkIPJACks, too, are beetles. You may linow them by their long, narrow, glossy bodies, and by the fact that the head is hidden underneath the thorax, so that you can hardly see it from above. One very odd thing about them is that they are constantly losing their footing and rolling over on their backs; and their bodies are so shiny, and their legs are so short, that when they do so they cannot get up again in the ordinary manner. 
But after lying still for a moment they arch themselves into the form of a bow, resting only upon their heads and the very tips of their tails, and suddenly spring into the air, making an odd clicking noise as they do so. And as they fall they turn half round, and so alight upon their feet. For this reason they are often known as "Click Beetles."

These insects are the parents of the well-known "wireworms," which often do such terrible mischief in our fields and gardens, living underground for three or even four years, and feeding upon the roots of the crops.

Then the Glowworm is a beetle. Perhaps you may have seen its little pale green lamp shining in the grass on a summer's evening. The light comes from a liquid inside the hinder part of the body, the skin of which is transparent, and forms a kind of window, so that it can shine through; and the insect has the power of turning on its light and shutting it off at will. The lamp of the female beetle is very much brighter than that of the male, and it is very odd to find that while the male has both

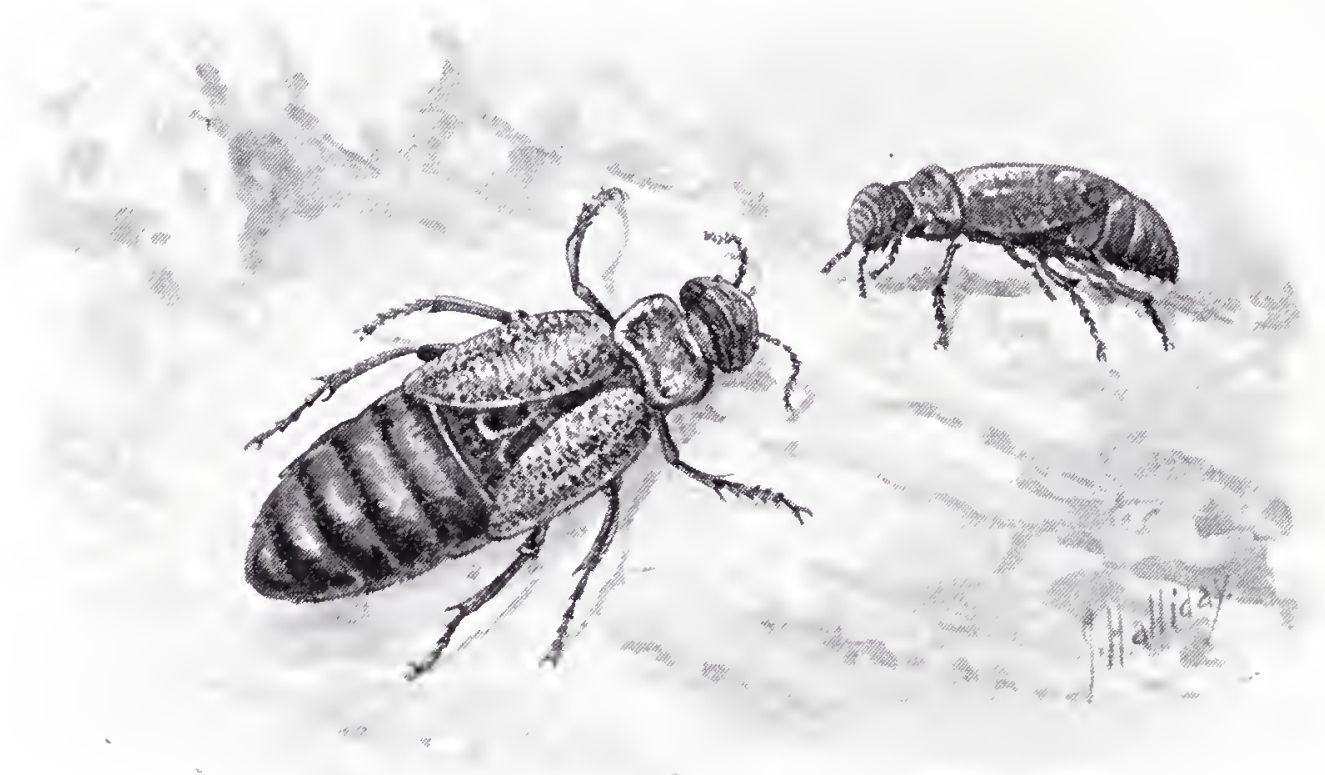

Oil Beetles.

wing-cases and wings, and can fly very well indeed, those of the female are so small that one can hardly see them. Indeed, she looks much more like a grub than a beetle.

DEATH-WATChEs are small brown beetles which burrow into dead wood and call to one another by tapping with their horny heads. You may often hear them if you happen to be lying awake at night in a room in which there is old woodwork; and in days of old people were silly enough to think that when this sound was heard it was a sign that somebody in the house was going to die! That is why these beetles are called "deathwatches." They are quite small, and are brown in colour, with rather long feelcrs and legs. 
Crawling on grassy banks in the warm sunshine on bright spring days, you may often see a number of Oil Bentles. These are large bluish-black insects which have an odd habit, if you pick them up, of squeezing out little drops of a yellow oily liquid from the joints of their legs! This oil smells very nasty, and no doubt prevents birds, etc., from eating them. You will notice that the female beetles have enormous hind-bodies, which they can hardly drag along over the ground. This is because they contain such a very large number of eggs, thirty thousand often being laid by a single beetle. She places them in batches in holes in the ground, and very soon afterwards they hatch, and odd-looking

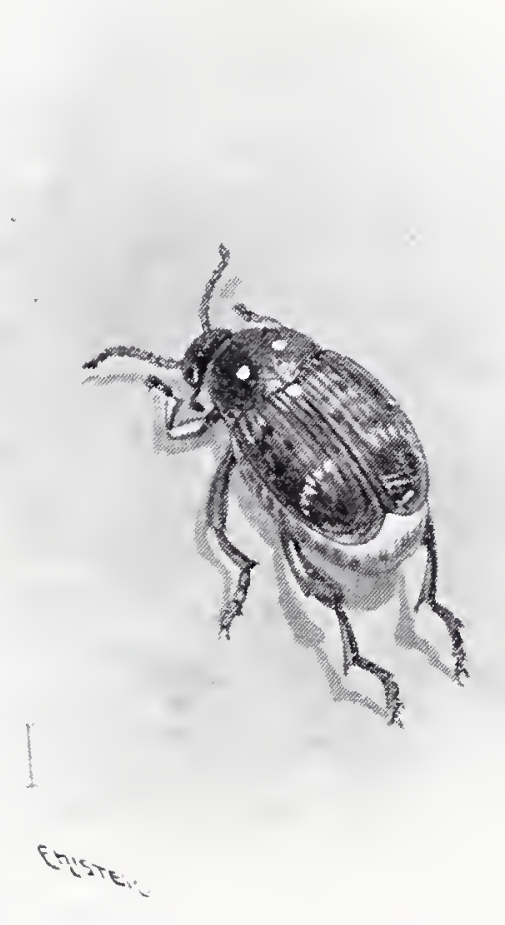

CORN IVEeviL.

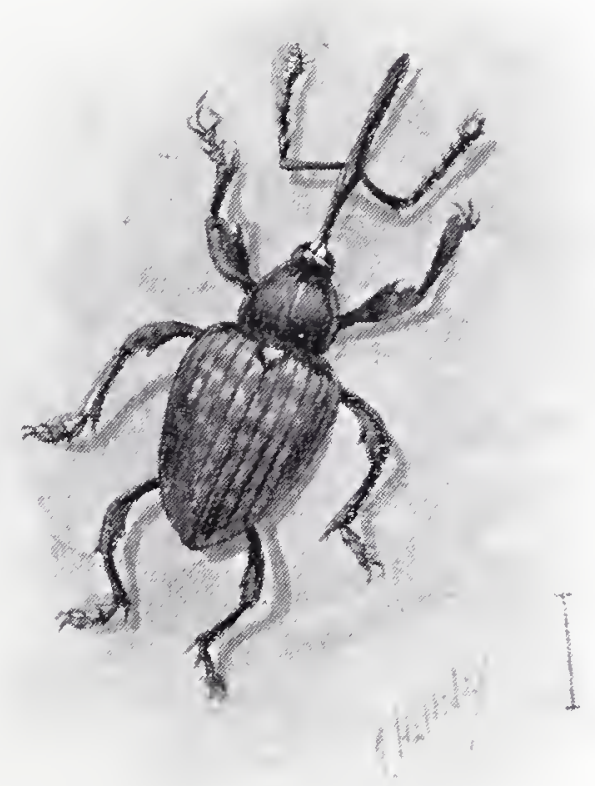

NuT IVEETL.

little grubs with six very long legs come out of them. No sooner have they left the eggshells than these tiny creatures hunt about for a flower with sweet juices, which is likely to be visited by a wild bee. When they find one, they climb up the stem and hide among the petals. Then, when the bee comes, they spring upon it and cling to its hairy body, and so are carried back to its nest, where they feed upon the food which the bee had stored up for its little ones.

Then there are a great many beetles which have a long beak in front of the head, with the jaws at the very tip. These are called "Weevils," and many of them are very mischievous. Grain of various liinds, for example, is destroyed in enormous quantities by the Corn Weevil and the Rice Weevil, while the Nut Weevit is the cause of those "bad" nuts which I suppose 
most of us know only too well. The mother beetle bores a hole through the shell of the nut while it is small, and the little grub which hatches out from it feeds upon the kernel, leaving nothing behind but a quantity of evil-tasting black dust.

One of the handsomest of all British insects is the Musk BeETLE, which you may often find sunning itself on the trunks and leaves of willow trees in July. And very often you can smell it long before you find it, for it gives out a strong odour very much like that of musk. This beetle is sometimes nearly an inch and a half long, with long legs and still longer waving black feelers. In colour it is rich golden green with a tinge of copper. But if you put one of its wingcases under the microscope, it looks like a piece of green velvet studded all over with

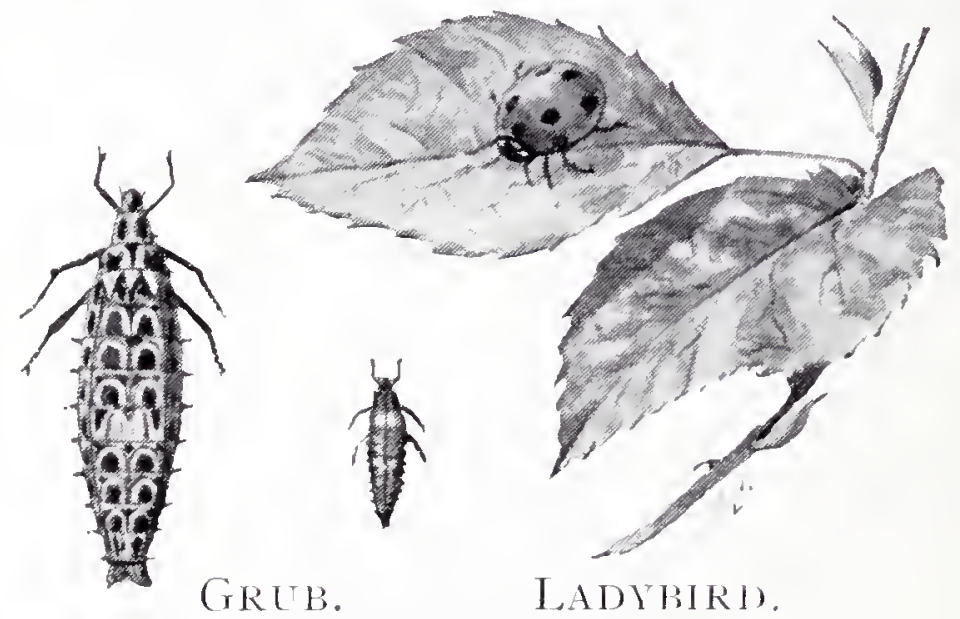

Enlarged. Natural Size. diamonds, and rubies, and sapphires, and emeralds, and topazes, which seem to turn into one another with every change of light. The grub of this beetle lives inside the trunks of dying willow trees, and feeds upon the solid wood.

Then there are the TURNIP FLEAS-little black beetles with a yellow stripe on each wing-case which skip about just as fleas do, by means of their hinder legs. They are only too common in turnip fields and often do most serious mischief, nibbling off the seed leaves of the young plants as soon as they push their way above the surface of the ground, and so destroying the greater part or even the whole of the crop.

And, lastly, there are the LADyBIRDs, of which we have about five and twenty different kinds in Great Britain.

Of course you know these pretty little beetles very well by sight, for they are common everywhere. But perhaps you did not know that they are among the most useful insects which we have in this country. The fact is that both as grubs and as perfect insects they live upon the "green blight," or "green fly," which is so terribly mischievous in our fields and gardens, and destroy it in thousands of thousands. And wherever the blight appears, the ladybirds are sure to follow it before very long. Indeed, if it were not for ladybirds, and for one or two other insects which help them in their task, we should find it quite impossible to grow our crops at all.

Next after the beetles comes the Order of the Euplexoptera, which means "beautifully-folded wings." This Order contains the Earwigs.

Perhaps you did not know that earwigs have wings; and 
certainly one does not often see them flying. But nevertheless they have very large and powerful wings; only during the daytime, while they are not being used, these organs are folded away in the most beautiful manner underneath the tiny wing-cases. By night, however, earwigs often fly; and when they settle, they fold up their wings most cleverly by means of the horny pincers at the end of their bodies, and then pull the wing-cases down over them!

That is the real use of the pincers, although, as we all know, the earwig is able to give quite a smart pinch with them if it is interfered with.

Another very curious fact about the earwig is that the mother insect heaps her eggs together into a little pile, and sits over them until they are hatched. If you turn over large stones early in the spring you may often find a mother earwig watching

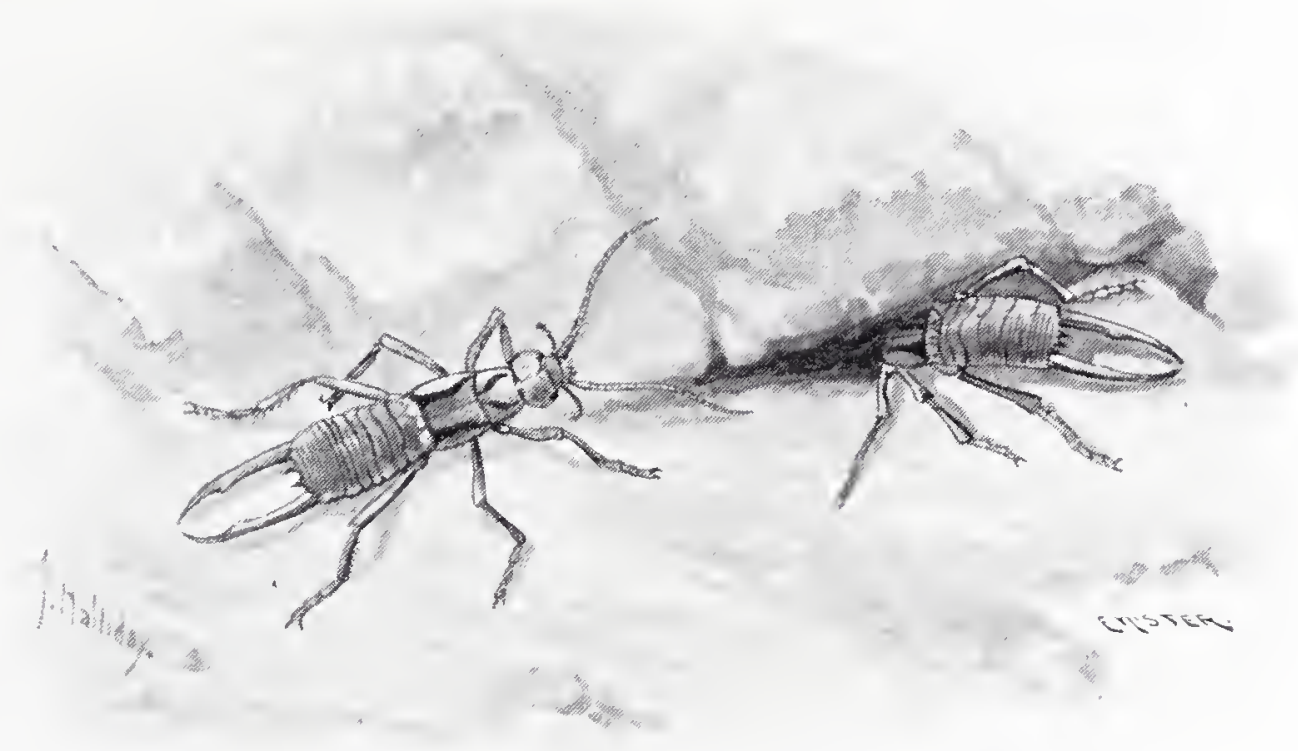

EARWIGS.

over her eggs in this odd manner, and she will allow herself to be torn in pieces rather than desert her charge.

Besides the Common EARwig, there is another lind called the LitTle EARwig, which is very common indeed in many parts of the country. It flies by day, and you may sometimes see hundreds in the air together, looking just like a swarm of flies. And there is also a very big earwig, with very long forceps, which is sometimes found upon the sea-shore. This is known as the Giant Earivig.

Next comes the Order of the Orthoptera, or "Straightwinged" insects, so-called from the way in which the wings are folded. This order contains many very well-known insects.

There is the Cocrioach, for example, which is so common and so mischievous in our houses. It is generally called the "black beetle," although it is not a beetle at all, and is not black, but "lark reddish brown. It is remarkable for several reasons. One 
is that while the male has large wing-cases and broad, powerful wings, those of the female are very small indeed, so that she cannot possibly fly. And another is that the eggs are laid in a kind of horny purse, about a quarter of an inch long, with a sort of clasp on one side. These little purses are hidden away in all sorts of dark corners, and if you open one you will find two rows of little eggs inside it, arranged rather like the peas in a pod.

The Crickets, too, belong to this order.

Of course you have often heard the House CRICKET chirping merrily away in the kitchen. It is not correct, however, to speak of the "note" or "song" of this insect, for it is not produced in the throat at all, but is caused by rubbing one of the wing-cases upon the other. You will notice, on

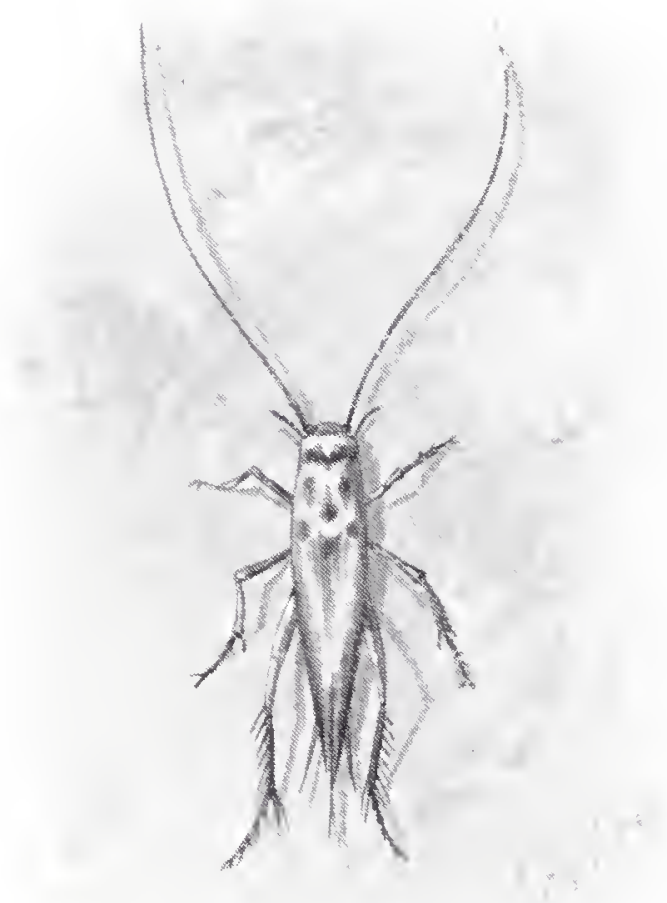

HOUSE CRICKET. looking at a cricket, that in each wing-case there is a kind of stout horny rib, which starts from a thickened spot nearly in the middle. Now in the right wing-case this rib is notched, like a file, and when it is rubbed sharply upon the other the loud chirping noise is produced.

The feelers of the cricket are very long and slender, and at the end of the body of the male are two long hairy bristles, which seem almost lilie a second pair of feelers, warning the insect of danger approaching from behind. At the end of the body of the female is a long spear-like organ, with a spoon-like tip. This is called the "ovipositor," and by means of it the eggs are laid.

Crickets have large wings, and fly rather like woodpeckers, rising and falling in the air at every stroke.

Another lind of cricliet lives in holes in the ground, which it digs by means of its front legs. These limbs are formed almost exactly like the fore feet of the mole, and for this reason the insect is linown as the Mole Cricket. It is generally found in sandy fields, and scoops out a chamber almost as big as a hen's egg at the end of its burrow, in which to lay its eggs.

Grasshoppers are common everywhere, and several different kinds are found in Great Britain. The largest and finest is the Great Green Grasshopper, which is often mistaken for a locust. But you can always tell it by its very long thread-like feelers, those of a real locust being quite short.

This grasshopper generally lives in hedges or low trees, 
and its chirp is so loud that it can be heard from a long distance away.

True Locusts are hardly ever found in Great Britain. But in warmer countries they are generally very plentiful, and in many parts of the world they often appear in such immense numbers that they devour every green leaf and every blade of grass, and leave the ground as bare as if it had been burnt with fire. The insects travel in dense clouds, often many miles in length, which darken the very sky. Nothing that man can do is of any avail against them. Even if millions of them are killed, millions of others take their place at once. And when they have passed over a tract of country and laid it waste, their eggs are sometimes collected and destroyed in hundreds of tons!

The wonderful Stick and Leaf Insects also belong to this

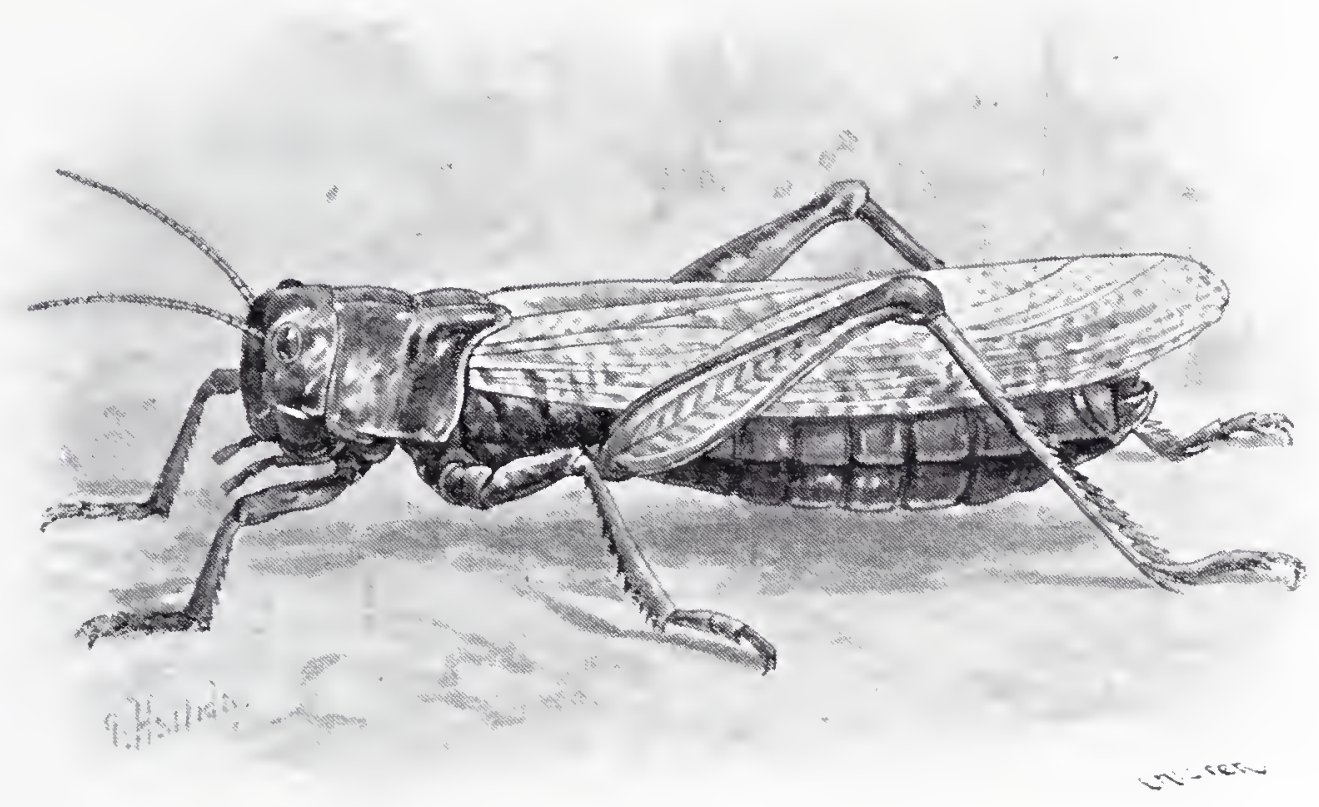

I.OCUS'

order. They are so marvellously like the objects after which they are named that as long as they keep still it is almost impossible to see them. They seem to know this perfectly well, and will remain for hours together without moving, waiting for some unwary insect to come within reach. They are found in all the warmer parts of the world.

Equally curious, too, is the Praying Mantis, which also is very much like a leaf. It has very long front legs, with a row of sharp teeth running along their inner margin, and when it is hungry it holds these limbs over its head, in very much the attitude of prayer. That is why it is called the Praying Mantis. Then when an insect comes within reach it strikes at it, and seizes it between the upper and lower parts of these limbs, so that the long spike-like teeth enter its body and hold it in a grip from which there is no escape. 
The DRAgon Flies belong to another division of the Orthoptera. Of course you know these insects very well by sight, with their long slender bodies and their broad gauzy wings; for they are very common indeed in almost all parts of the country, and you can hardly go for a ramble on a sunny day in summer or autumn without seeing them in numbers. There are a good many different kinds. Some have yellow bodies, some blue ones, and some red ones, and the loveliest of all perhaps are the graceful Demorseldes, whose wings are rich metallic purple. You may sometimes see these beautiful insects flitting to and fro over streams and ditches.

All the dragon flies spend the earlier part of their lives in the water. The grubs are very curious creatures and catch their prey in a very curious way. Underneath the head is an organ called the "mask." This consists of two horny joints, which fold

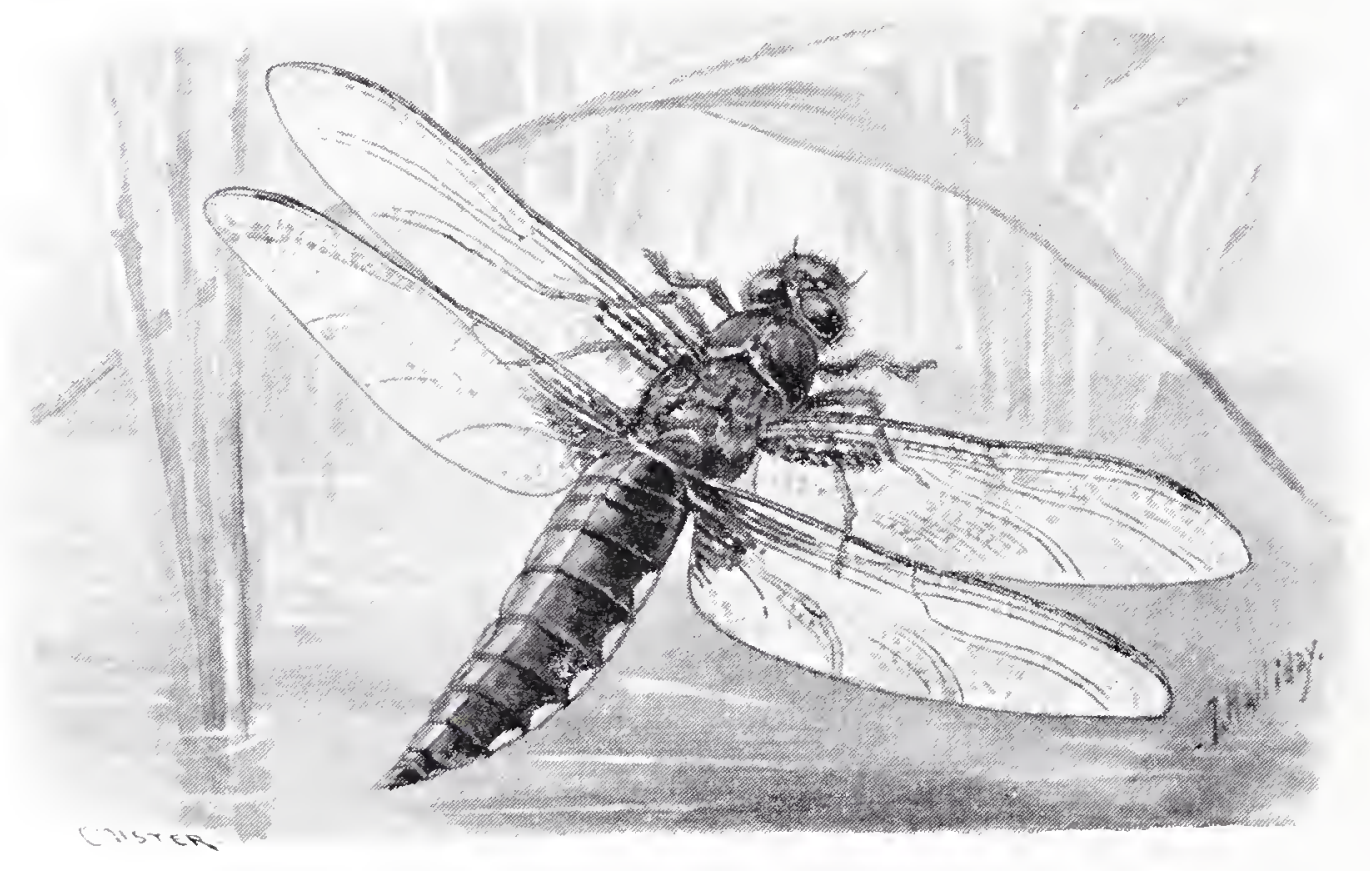

DRAGON FLY.

upon one another while not in use. At the end of the second joint is a pair of great siclile-shaped jaws, and when the grub sees a victim it swims quietly underneath it, unfolds the mask, reaches up, and seizes it with the jaws. Then it folds the mask again, and by so doing drags the prisoner down against the true jaws, by means of which it is leisurely devoured.

This grub swims, too, in a very singular manner. At the end of its body you will notice a short, sharp spilie. Now this spike really consists of five points, which can be opened out into the form of a star; and in the centre of this star is a small round hole, which is really the entrance to a tube running right through the middle of the body. And the grub swims by filling this tube with water, and then squirting it out again with all its force, so that the escaping jet pushes, as it were, against the surrounding water, and drives the insect swiftly forwards by the recoil. 
Dragon flies are very voracious insects indeed, and always seem to be hungry. They feed entirely upon other insects, and spend almost all their time in chasing and devouring them.

The MAY FLY also belongs to this order. It is a very wellknown insect, and one sometimes sees it in thousands, dancing, as it were, up and down in the air towards evening on warm spring days, in the neighbourhood of water. And you can always tell the insect by the three long thread-like bristles at the end of its body.

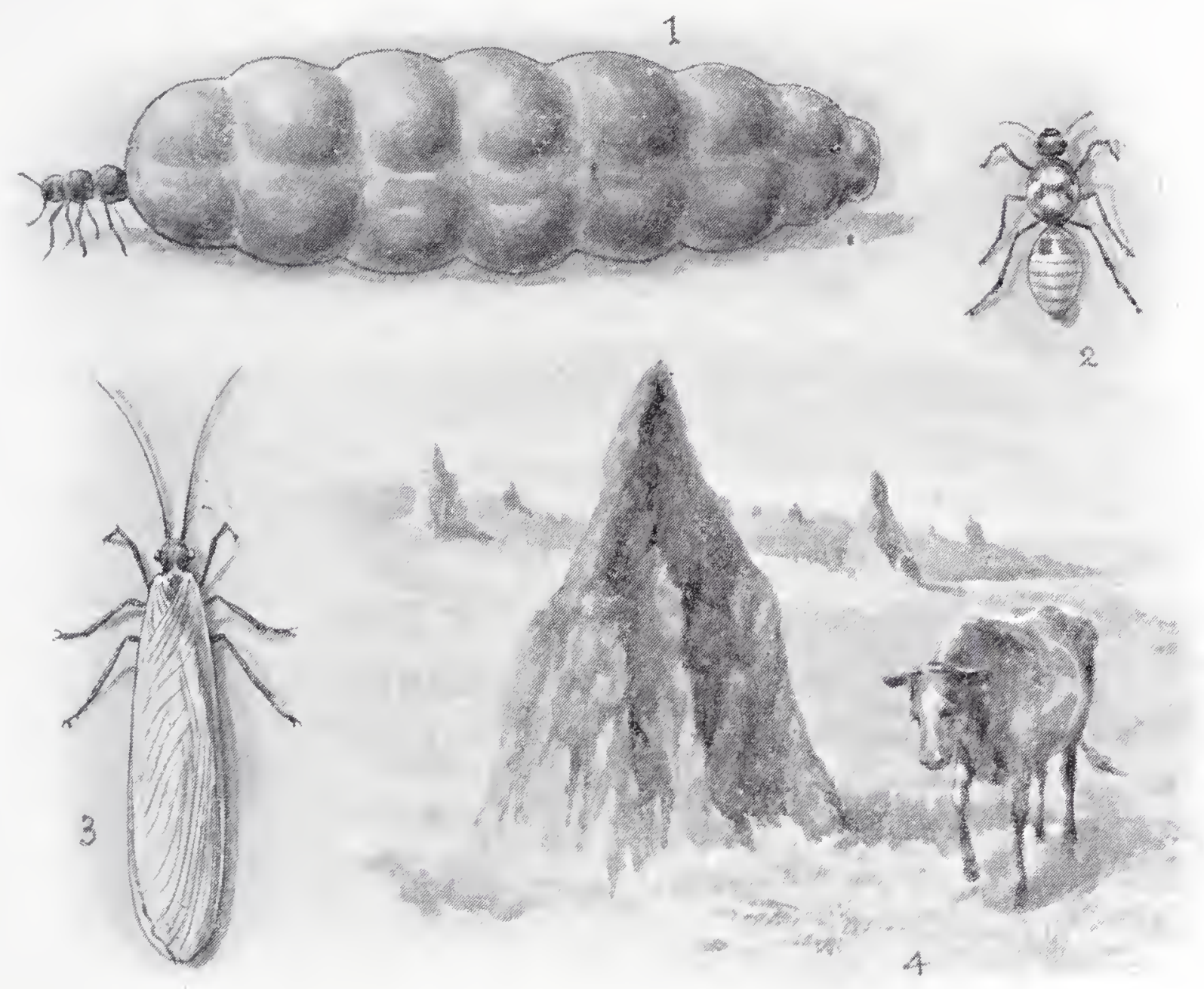

I. Queen Termite. 2. Wixgiess (Soldier) Teraite. 3. Male Termite. 4. Terimte Nest.

Most people think that this insect only lives for a single day. 'This, however, is not strictly true, for in damp weather many May-flies live for three or four days. And before they become perfect flies they live for very nearly two years in the muddy banks of rivers and ponds, in the form of long slenderbodied grubs. These grubs always make their burrows with two entrances, in the form of the letter " $U$ " turned sideways, so that they can easily leave them without having to turn round.

The most wonderful of all the insects which belong to this order, however, are the Termites.

Very often these creatures are known as "white ants," and although they are not really ants, they are certainly very much 
like them. They malie most marvellous nests, for example, of clay, which are often twelve or fourteen feet high, and are so very large that a church, a parsonage house, and a schoolroom have been built of clay slabs cut from the walls of a single termite's nest! These nests are made up of a wonderful series of chambers and galleries, and in the middle is the royal cell, in which the "King" and "Queen" live. For in every termite's nest there is one perfect male and one perfect female, which are treated with very great respect, and have a kind of palace, as it were, all to themselves. And the rest of the insects in the nest are either imperfect males, which are called "soldiers," or imperfect females, which are called "workers."

The "King" is quite a handsome and graceful insect, with broad and powerful wings; and the "Queen," at first, is very much like him. But they never take more than one flight in the air, and as soon as that is over they actually break off their own wings close to their bodies! Then they burrow into the ground and begin to form a nest. Before long, the workers build the palace for the royal couple; and as soon as they have been shut up inside it the body of the queen swells to a most enormous size, so that she can no longer walk at all. This is because of the vast number of her eggs, which she at once begins to lay at the rate of many thousands in a single day. And as fast as she lays them they are carried off by the workers, which also take care of the little grubs that hatch out from them, just as bees do.

The duty of the soldiers, as their name implies, is simply to fight, and if a hole is broken in the side of the nest they hurry to the spot at once, and begin to snap with their jaws at the foe. And these jaws are so sharp and so powerful that they can really give a very smart bite. The workers are a good deal smaller, and they have to build the nest and keep it in repair, to find food for the grubs, and take care of them and wash them and feed them, and do everything else that is necessary for the welfare of the colony.

The grubs of these insects are fed upon dead wood, which is generally obtained from the trunks and branches of trees. But termites are sometimes very troublesome indeed in houses, for they will devour the woodwork and the furniture and the books, leaving nothing but just a thin shell of wood or paper behind them.

There are a good many different kinds of these wonderful insects, and they are found in warm countries in all parts of the world.

Next we come to the Neuroptera, or "nerve winged" insects, whose wings are divided up by horny nerves, or "nervures," into such numbers of tiny cells, that they look as if they were made of the most delicate lace.

The CADDIS Flies belong to this order. You have often seen them, of course-brownish insects with long thread-like feelers and broad wings, which are folded tent-wise over the body when 
they are not being used. They are very common indeed near ponds and streams, in which they pass the earlier part of their lives, living down at the bottom in most curious "cases," which cover them entirely up with the exception of their heads.

These cases are made of all sorts of materials. Some caddis grubs merely fasten two dead leaves together, face to face, and live between them. Others make a kind of tube out of grains of sand, or tiny stones, or little bits of cut reed, all neatly stuck together with a kind of glue which resists the action of water. But the oddest case of all is made of tiny water snails, and you may sometimes see fifteen or twenty little snails all trying to crawl in different directions, while the grub is unconcernedly pulling them along in another!

The grubs never leave these cases, but drag them about with them wherever they go. And when they find that their odd little homes are becoming too small, they just cut off a little piece at the end and add a little piece on in front, rather larger in diameter. And so they always manage to keep their homes of exactly the proper size.

Most likely, too, you have heard of the ANT Lion, which is a rather large fly with a slender body and four long narrow wings, and is found in many parts of the South of Europe. But the interest lies in the grub, which has a most singular way of catching its insect victims. It digs a pit in the sand, about three inches in diameter and two inches deep, by means of its front legs and its head. Then it almost buries itself at the bottom, and lies in wait to snap up any ants or other small insects which may be unfortunate enough to fall in. And if by any chance they should escape its terrible jaws and try to clamber up the sides, it jerks up a quantity of sand at them, and so brings them rolling down again to the bottom.

A relation of the ant lion lives in England. It is called the LACEwing FLY, and is a pretty pale green insect with most delicate gauzy wings, over which, if you look at them in a good light, all the colours of the rainbow seem to be playing. And its eyes glow so brightly with ruby light that one can scarcely help wondering if a little red lamp is burning inside its head. You may often see it sitting on a fence on a warm summer's day, or flitting slowly to and fro in the evening.

This fly lays its eggs in clusters on a twig, or the surface of a leaf, each egg being fastened to the tip of a slender threadlike stalk. The result is that they do not look like eggs at all; they look much more like a little tuft of moss. When they hatch a number of queer little grubs come out, which at once begin to wander about in search of the little green-fly insects upon which they feed. And when they have sucked their victims dry, they ahways fasten the empty skins upon their own backs, till at last they' are covered over so completely that you cannot see them at all! 


\section{CHAPTER XXXIII.}

\section{INSECTS (Contimer).}

WE now come to a very large and important order of insects indeed-that of the Hymenoptera. This name means " membranewinged," and has been given to them because their wings are made of a transparent membrane stretched upon a light horny framework. It is not a very good name, however, for many insects which do not belong to this order at all have their wings made in just the same way. All the Hymenoptera, however, have the upper and lower wings fastened together during flight by a row of tiny hooks, which are set on the front margin of the lower pair. And these hooks fit into a fold on the lower margin of the upper ones.

The Bees belong to this order, and most wonderful insects they are-so wonderful, indeed, that a big book might easily be written about them. They are divided into two groups, namely, Social Bees and Solitary Bees.

The Social Bees are those which live together in nests; and our first example, of course, must be the Hive BEE.

In every beehive, as no doubt you know, there are three kinds of bees.

First, there are the drones, which you can easily tell by their stoutly-built bodies and their very large eyes. They are the idlers of the hive, doing no work at all, and sleeping for about twenty hours out of every twenty-four. For six or eight weeks they live only to enjoy themselves. But at last the other bees become tired of providing food for them. So they drive them all down to the bottom of the hive and sting them to death one after another. And that is the end of the drones.

Next comes the queen, the mistress of the hive. You can easily recognise her, too, for her body is much longer and more slender than that of the other bees, and her folded wings are always crossed at the tips. The other bees treat her with the greatest respect, never, for example, turning their backs towards her. And wherever she goes a number of them bear her company, forming a circle round her, in readiness to feed her, or lick her with their tongues, or do anything else for her that she may happen to want. Her chief business is to lay eggs; and she often lays two or three hundred in the course of a single day.

Lastly, there are the workers. There are many thousands of these, and they have to do all the work of the live, making wax and honey, building the combs, and feeding and tending the young. 
The comb, as of course you know, is made of six-sided cells, and is double, two sets of cells being placed back to back. Some of these cells are used for storing up honey. But a great many of them are nurseries, so to speak, in which the grubs are brought up. These grubs are quite helpless, and the nurse-bees have to come and put food into their mouths several times a day.

Fastened to the outside of the combs, there are always several cells of quite a different shape. They are almost likic pears in form, with the smaller ends downwards. These are the royal nurseries in which the queen grubs are brought up.

Bees feed their little ones with a curious kind of jelly,
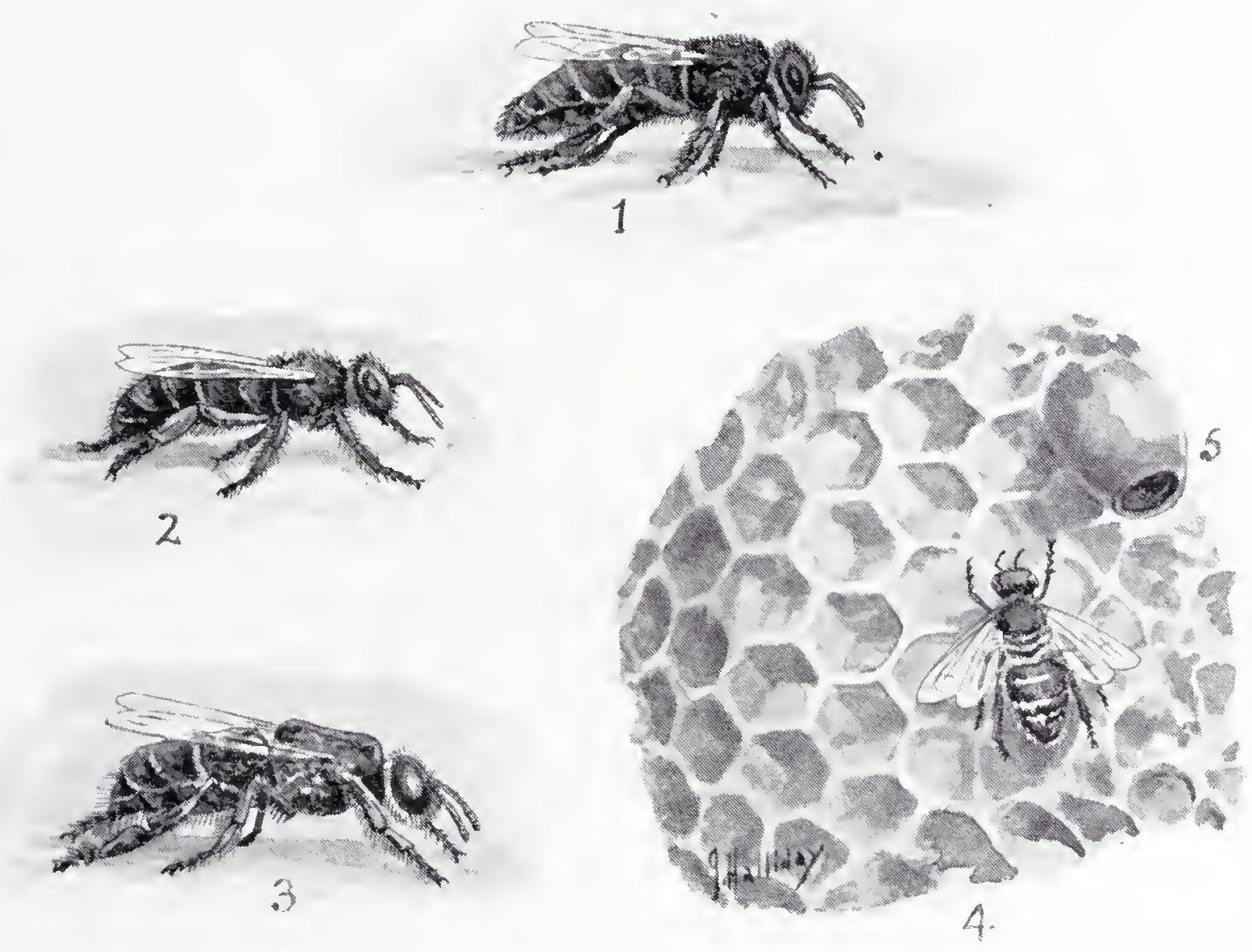

BEES.

I. Uneen. 2. Worker. 3. Mrone. 4. Comb. 5. Uneen Cell.

made partly of honey and partly of the pollen of flowers. This is called "bee-bread"; and it is rather strange to find that one kind of bee-bread is given to the grubs of the drones and the workers, while quite a different kind is given to those of the queens.

You will want, of course, to know something about the sting of the bee. This is a soft organ, enclosed in a horny sheath, with a number of little barbs at the tip. When a bee stings us, it is often unable to draw the sting out again, because of these barbs. So it is left hehind in the wound, and the bee very soon dies. The poison is stored up in a little bag at the base of the sting, which is arranged in such a way that when the sting is used a tiny drop of poison is forced through it, and so enters the wound. 
Then, no doubt, you would like to know how bees make honey; but that neither I nor anyone else can tell you. All we lnow is, that the bee sweeps out the sweet juices of flowers with its odd brush-like tongue and swallows them; that they pass into a little bag just inside the hinder part of its body, which we call the "honey-bag"; and that by the time the bee reaches the hive they have been turned into honey. But how or why the change takes place no one knows at all.

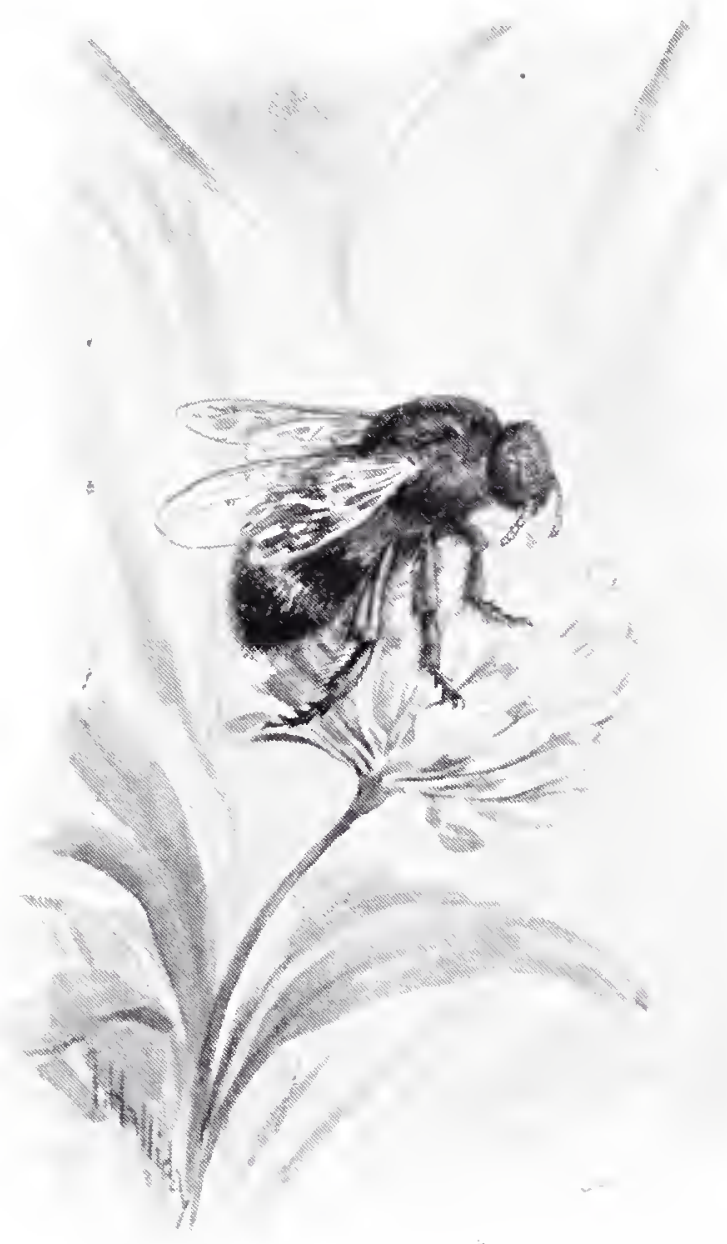

HUMBLE BEE.

Humble Bees are also Social Bees; but their nests are not quite as wonderful as those of the hive bee, and their combs are not so cleverly made.

One of these bees is called the CARDER, and you may sometimes find its nest in a hollow in a bank. But it is not at all easy to see, for the bee covers over the hollow with a kind of roof, which is made of moss and lined with wax. And this looks so like the surrounding earth that even the sharpest eye may often pass it by. When this roof is finished, the bee makes a kind of tunnel, eight or ten inches long and about half an inch in diameter, to serve as an entrance; and this is built of moss and lined with wax in just the same way.

On a warm sumny day in spring you may often see one of these bees flying up and down a grassy bank searching for a suitable burrow in which to build. Then you may be quite sure that she is a queen. For among humble bees the drones and workers die early in the autumn, and only the queens live through the winter.

Solitary Bees are very common ahmost everywhere, and you may find their nests in all sorts of odd places. One kind of solitary bee, for example, builds in empty snail-shells, and another in key-holes. A third gnaws out a burrow in the decaying trunk of an old willow tree, and makes a number of thimble-shaped cells out of little semi-circular bits of rose-leaf, which it cuts out with its scissor-like jaws. Haven't you noticed how often the leaves of rose-bushes are chipped round the edges, quite large pieces being frequently cut away? Well, that is the work of the Leaf-cutter Bee, as this insect is called, and very often not a single leaf on a bush is left untouched. 
But the commonest of all the solitary bees burrows into the ground. As you walk along the pathway through a meadow in spring, you may often see a round hole in the ground, just about large enough to admit an ordinary drawing pencil. Well, that is the entrance to the burrow of a solitary bee; and if you could follow the tunnel down into the ground you would find that it was about eight or ten inches deep, and that at the bottom were four round cells. In each of these cells the bee lays an egg. Then it fills the cells perfectly full with flies, or spiders, and caterpillars, or beetles, for the little grubs to feed upon when they hatch out. For solitary bees do not nurse their little ones, as social bees do, and feed them several times a day. But at the same time the grubs are quite helpless, and cannot possibly go to look for food for themselves. So the mother bee has to store up sufficient to last them until the time comes for them to spin their cocoons and pass into the chrysalis state.

Wasps make nests which are really almost as wonderful as those of the hive bee.

That of the

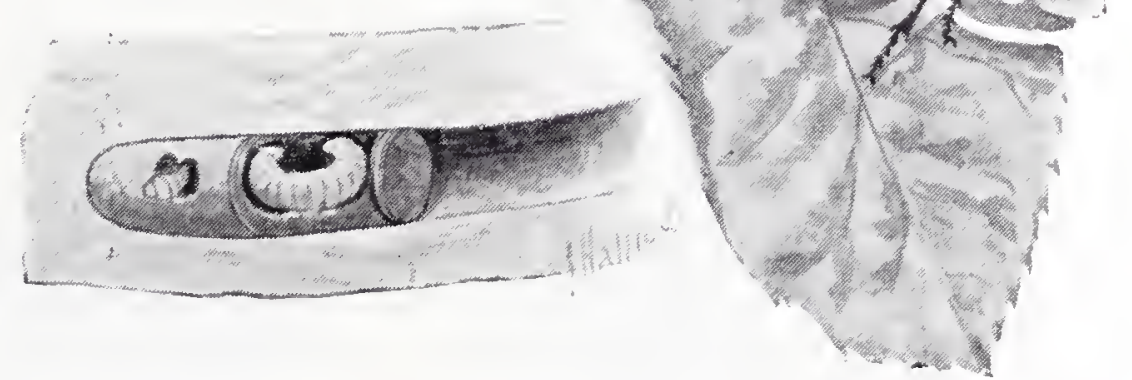

T.ARTA IN CEI, IN IVOOD. T.EAF CUTTER BEE.

Common WASP is generally placed in a hole in the ground, and is made of a substance very much like coarse paper, which the wasps manufacture by chewing wood into a kind of pulp. You may often see them sitting on a fence, or on the trunk of a dead tree, busily engaged in scraping off shreds of wood for this purpose. When the nest is finished it is often as big as a football, and of very much the same shape; and inside it are several storeys, as it were, of cells placed one above another, and supported by little pillars of the same paper-like material. These cells are six-sided, like those of the hive bee, but they are squared off at the ends, instead of being produced into pointed caps, and they always have their mouths downwards. In a large nest there may be several thousands of these cells, and very often three generations of grubs are brought up in them, one after the other.

The HORNET, which is really a kind of big wasp, makes its nest in just the same way, but places it on a beam in an outhouse, or in a hole which the sparrows have made in the thatched roof of a house, or in a hollow tree. 
Even more wonderful than bees and wasps are the AnTs, which sometimes do such extraordinary things that I am almost afraid to tell you about them, for fear that you might not belicve me. There are ants, for example, which actually take other ants prisoners and make them act as slaves, forcing them to do all the work of the nest, which they are too lazy to do themselves; and there are ants which lieep large armies, sometimes more than one hundred thousand strong, and actually have officers to give the necessary orders; and there are ants which make a kind of field round their nest, and sow the seech of a sort of grass in it, and tend the crop until the grain is ripe, and then harvest it, and
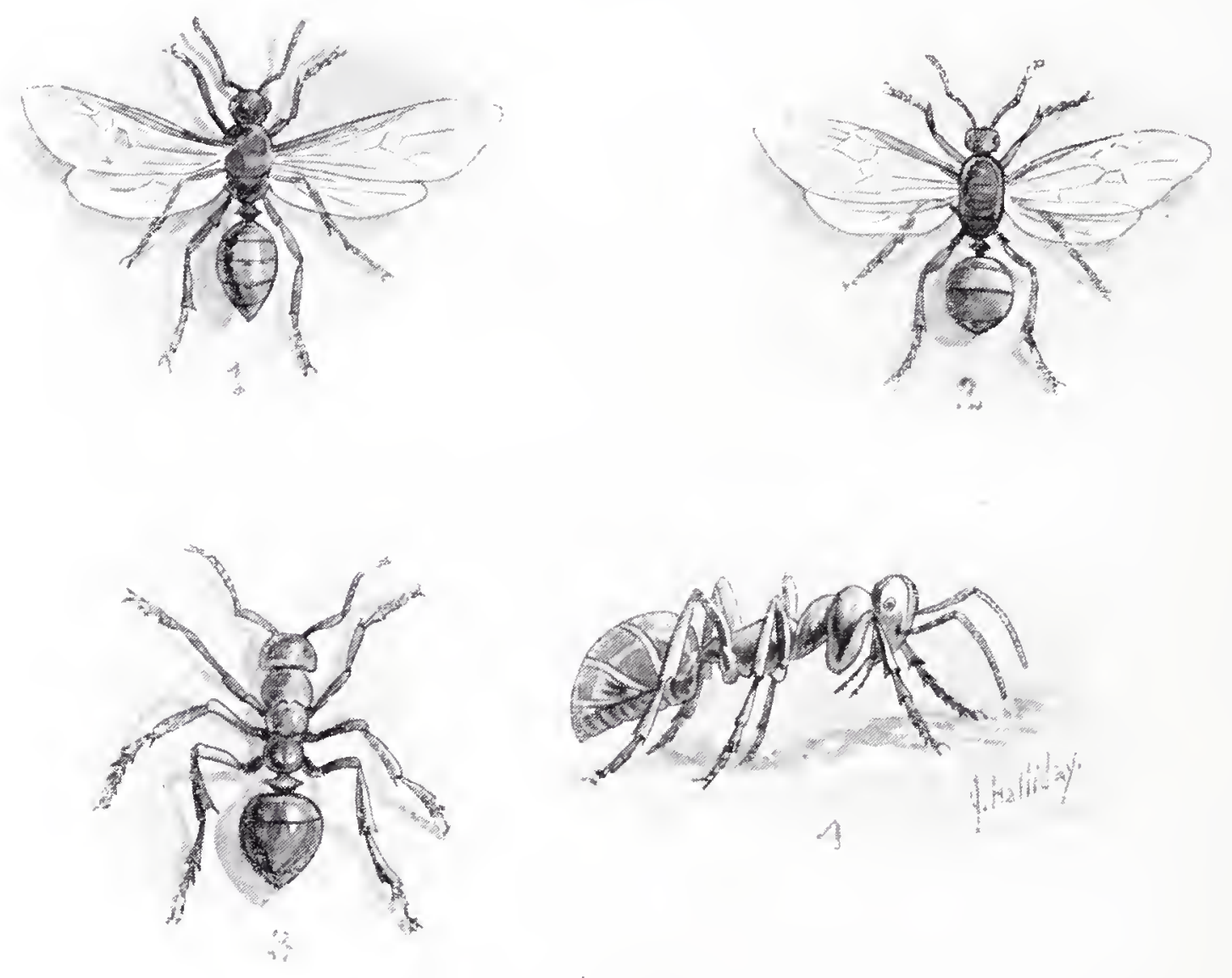

ANTS.

r. Wale Drone. 2. (Jueen. 3. Worker. t. Worker, Side View.

store it away in underground barns! Nany ants, too, keep little beetles in their nests as pets, and fondle and caress them just as one might pat a dog, or stroke a favourite cat. They even allow them to ride on their backs; while, if the nest is opened, the first thing they think of is the safety of their pets, which they pick up at once and hide away in some place of safety, even before they carry off their own eggs and young. They also pet tiny crickets and small white woodlice in just the same way.

Then of course you know that ants have little cows of their own, which they "milk" regularly every day. These are the "green fly" insects which do so much harm in our gardens and fields, plunging their beaks into the tender shoots and fresh 
green leaves of the plants, and sucling up their sap unceasingly. And as fast as they do so they pour the sap out again through two little tubes in their backs, in the form of a thin, sticky, very sweet liquid which we call "honey-dew." Now the ants are very fond of this liquid, and if you watch the green-fly insects which are almost always so plentiful on rose-bushes, you may see the ants come and tap them with their feelers. Then the little creatures will pour out a small quantity of honey-dew from the tubes on their backs, which the ants will lick up. That is the way in which ants milk their little cows, and they are so fond of the honey-dew that they will even lieep a large herd of cattle in their underground nests all through the winter, so that they may never be without a supply of their favourite beverage!

Ants, like bees and wasps, almost always consist of drones, queens, and workers. Only the drones and queens have wings, and these are seldom seen until the end of August. But then they make their appearance in vast swarms, which are sometimes so dense that from a little distance the insects really look just like a column of smoke. They only take one short flight, however, and when this is over they come down to the ground and snap off their wings close to their bodies, just as termites do.

One of the most curious of all these insects is the PARASOL Ant, of South America, which makes enormous dome-shaped nests of clay. But as the clay will not bind properly by itself, the insects work little pieces of green leaf up with it. These pieces of leaf are generally ob-

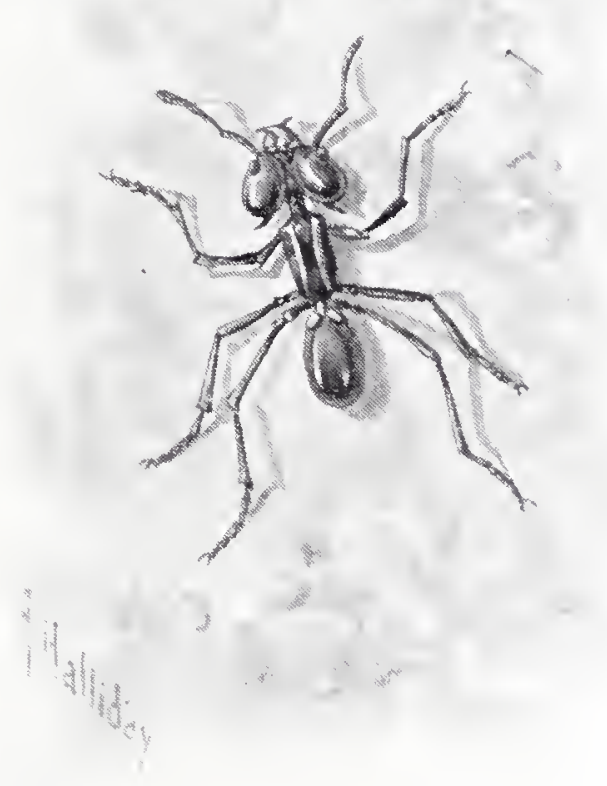

PARASOL ANT. tained from an orange plantation, perhaps half a mile distant. And when the ants are returning from their expedition, each holds its little piece of leaf over its head as it marches along, just as if it were carrying a tiny green parasol!

Another very famous ant is the Driver, also of South America, which owes its name to the way in which its vast armies drive every living creature before them. Insects, reptiles, deer, monlieys, even man himself must give way before the advancing hosts of the drivers; for it is certain death to stand in their path.

The SAw Flies also belong to the order of the IIymonoptera. These flies are so called because the female insects have two little saws at the end of the body, which work in turns, one being 
pushed forward as the other is drawn back. With these they cut little grooves in the bark of twigs, or in the midribs of leaves, in which they place their eggs.

Some of these insects are extremely mischievous. 'The grub of the Turnip Saw FLy, for instance, often destroys whole fields of turnips, while the CURRANT SAw FLY is equally destructive to currants and gooseberries. One often sees bushes, indeed, which have been entirely stripped of their leaves.

You may always know a saw-fly grub by the fact that it has no less than twenty-two legs-three pairs of true legs on the front part of the body, and eight pairs of false legs, or "prolegs," as they are often called, on the hinder part.

There is one little family of

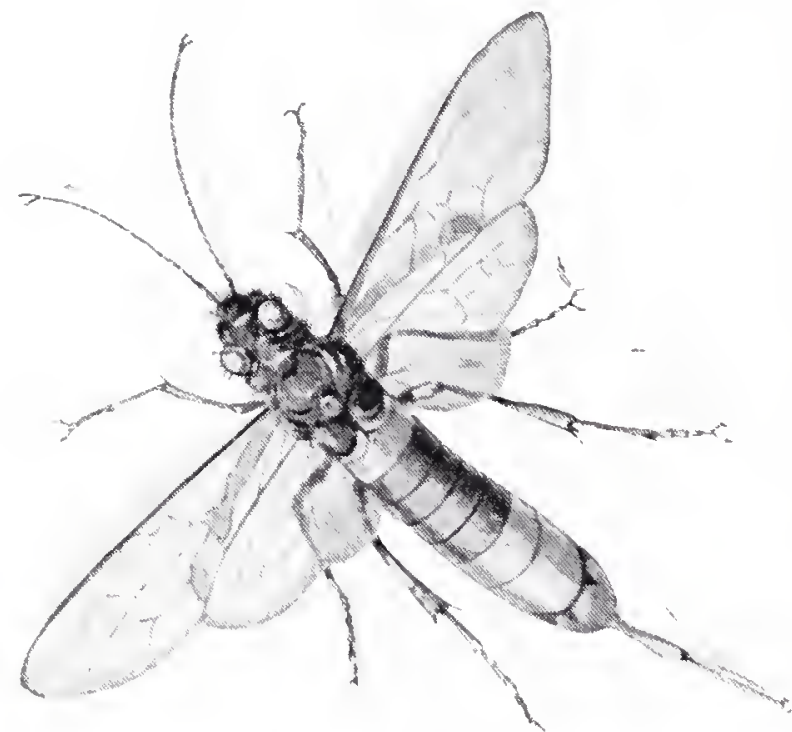

SAII FLY. saw flies, however, which are quite unlike all the rest, for instead of having saws at the ends of their bodies, they have long boring instruments, very much like bradawls. With these they bore deep holes in the trunks of fir trees, in order to place their eggs at the bottom; and the grubs feed, when they hatch out, on the solid wood.

These insects are linown as Horn-tailed Saw Flies, and one, which is very common in pine woods in many parts of Great Britain, is very large, sometimes measuring an inch and a half from the head to the tip of the tail, and very nearly three inches across the wings, while the boring tool is fully an inch long. It is a very handsome insect, and looks rather like a hornet, the head and thorax being deep glossy black and the hind-body bright yellow, with a broad black belt round the middle. The feelers are also yellow, and the legs are partly yellow and partly black.

Another group of the Hymenoptera consists of the GaLL Fures. These are all small insects, which lay their eggs in little holes which they bore in roots, twigs, and the ribs and nervures of leaves. In each hole, together with the egg, they place a tiny drop of an irritating liquid, which causes a swelling to talie place, on the substance of which the little grub feeds. Sometimes these "galls," as they are called, talie most curious forms. The pretty red and white "oak-apples" of course you know; and no doubt, too, you have often found the hard, woody, marble-shaped galls which are so common on the twigs of the same tree. Then some galls look like bunches of currants, and some look like scales, and some look like pieces of sponge. And if you cut one of them open you will find perhaps one little grub, or perhaps several, curled up inside them. 
The last group of Hymenoptera which I can mention is that of the ICHNEUNON FLIES.

These insects lay their eggs in the bodies of caterpillars or chrysalids, and sometimes in those of spiders, boring holes to receive them by means of their little sting-like ovipositors. Before long the eggs hatch, and the little grubs at once begin to feed upon the flesh of their victims. For some little time, strange to say, the unfortunate creature seems to suffer no pain, or even discomfort, but goes on feeding and growing just as before, although hundreds of hungry little grubs may be nibbling away inside it. Sooner or later, however, it dies; and then the little grubs spin cocoons and turn to chrysalids, out of which other little flies appear in due course, just like the parents.

Millions of caterpillars are destroyed by these little flies every year. Out of every hundred of those which do so much damage to our cabbages and cauliflowers, for example, at least ninety are sure to be "stung.' Indeed, if it were not for ichneumon flies we should find it quite impossible to grow any crops at all, for they would all be eaten up by caterpillars.

Next we come to the Butterflies and Moths, which are called Lepidoptera, or "scale-winged" insects, because their wings

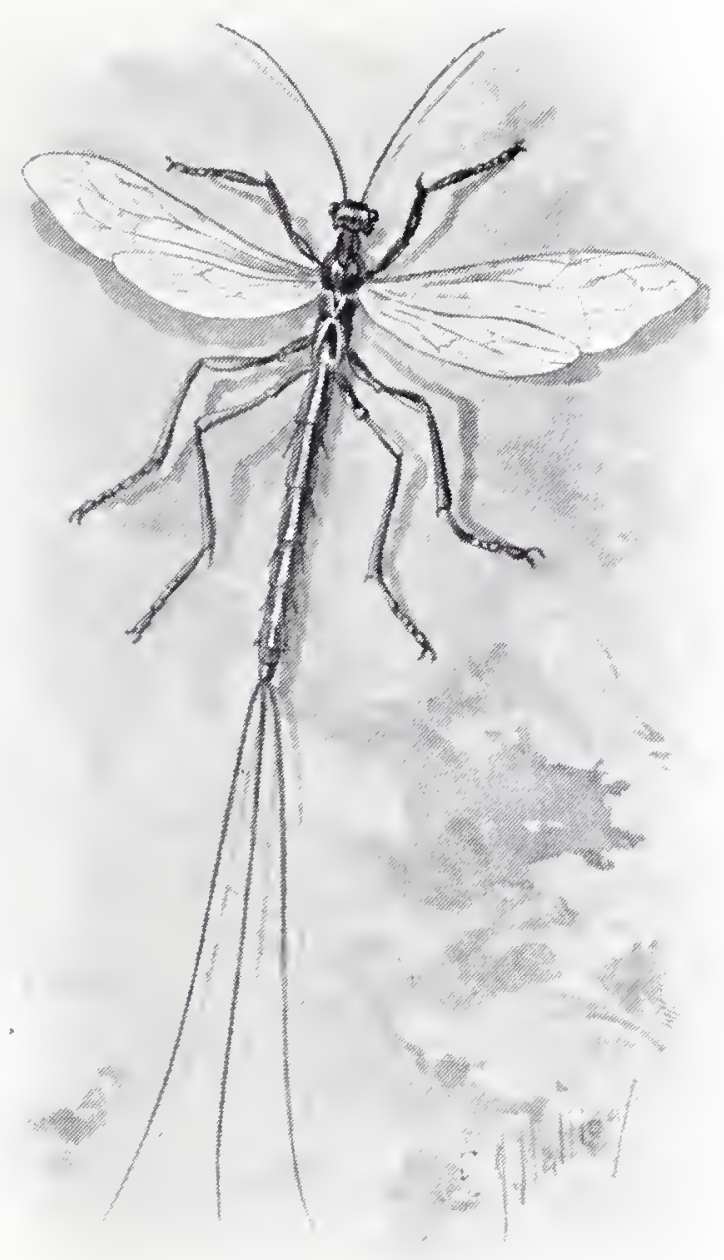

are covered with thousands upon thousands of tiny scales. You know, of course, that if you catch a butterfly and let it go again, a kind of mealy dust is left upon your fingers. Well, if you look at a little of this dust through a microscope, you will find that it consists simply of little scales, of all sorts of shapes. Some are like battledores, and some like masons' trowels, and they are nearly always most beautifully sculptured and chiselled. These scales lie upon the wing in rows, which overlap one another like the slates on the roof of a house. And sometimes there are several millions on the wings of a single insect.

Rather more than sixty kinds of butterflies are found in Great Britain. The largest and finest of all is the SwaLlow TalL, which is only taken in the marshes of Cambridgeshire, 
Norfolk, and Lincolnshire. Very handsome, too, is the PURPLE Emperor, which you may sometimes see flying round the tops of the tallest trees in large woods in the South of England. Far commoner, however, are the Large, Small, and Green-veined Whites, whose caterpillars are so destructive to cabbages; the Scarlet Admiral, with broad strealis of vermilion across its glossy black wings; the PEACOCk, with its four eye-like blue spots on a russet ground; the TorToIseshelLs, mottled with yellow and hrown and hlack; and the pretty little "Buues," which one may

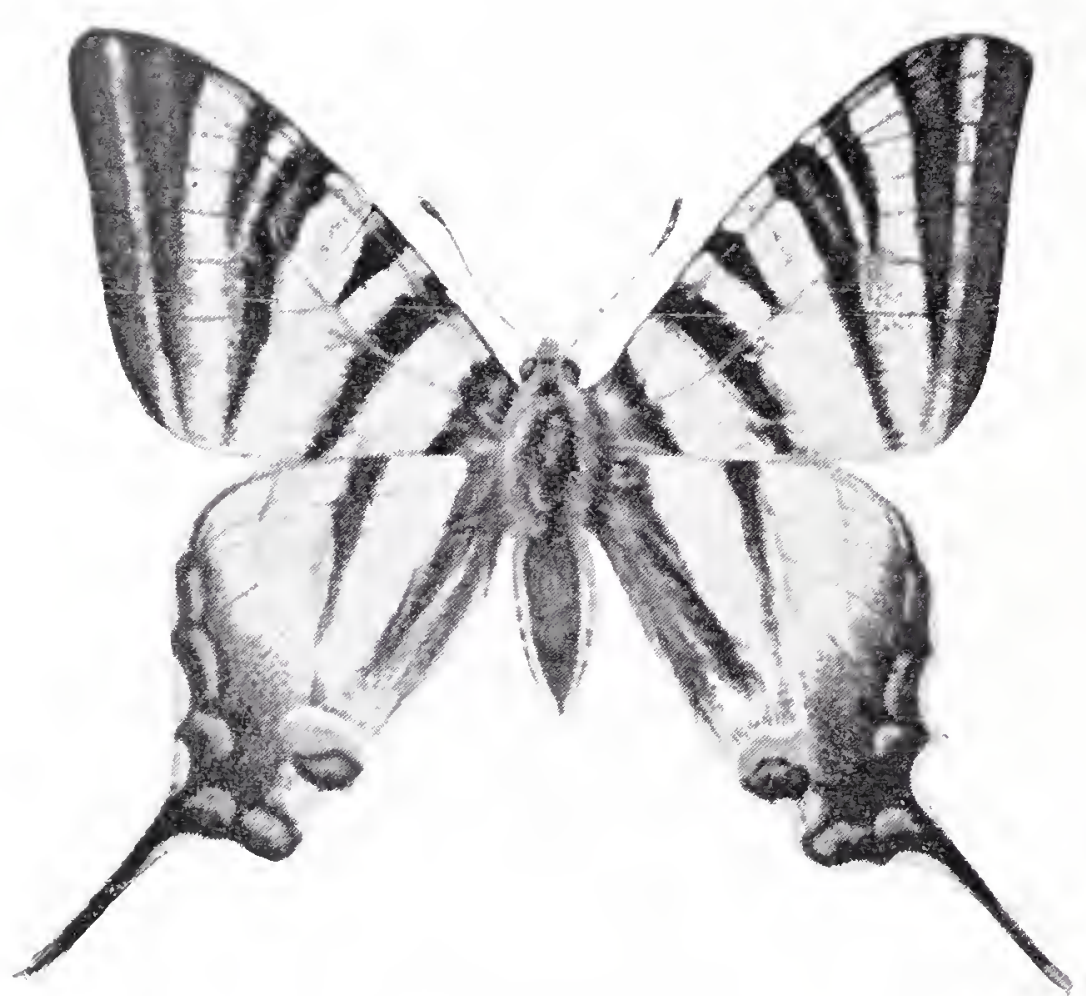

SWALIOW TAII. see in almost every meadow from the middle of May till the end of September. Then there are the Brimstone, with its pale yellow wings, with which one often meets quite in the early spring; the Meadow Brown and the Large. Heath, to be seen in thousands in every hayfield; the Small Heath and the Small Copper, even more plentiful still; the Fritillaries, some of which live in woods, and some on downs, and some in marshy meadows; the pretty ORANGE 'TI', with pure white wings tipped with yellow; and the odd little Skippers, which flit merrily about grassy banks in the warm sunshine in May and again in August-besides several others, which are so scarce or so local that hardly anybody ever sees them.

You can easily tell moths from butterflies by looking at their antenna, or feelers, which have no linols at the tips, as those of butterflies have. Their number, even in Great Britain alone, is very great, and I can only mention just a few of the most remarkable.

lirst, then, there is the splendid Death's Head Hawk, the largest of all the British insects, which sometimes measures five inches from tip to tip of its wings when they are fully spread. It orves its name to the curious patch of light brown hairs on its thorax, which looks just like a sliull. The caterpillar is a huge yellowish creature, often nearly six inches long, with a blue horn at the end of its hody, and seven blue stripes, edged with white, on either side. It lives in potato fields, hiding underground by day and coming ont at night to feed upon the leaves. And 
it is an odd fact that both the caterpillar and the perfect insect have the power of squeaking rather loudly. The moth appears in October.

The Humming Bird Hawr flies by day, and you may often see it hovering over flowers in the garden, with its long trunk polied down into a blossom in order to suck up the sweet juices. As it does so it makes quite a loud humming noise with its wings, like the little bird from which it takes its name. And sometimes you may see a BEE HAwk, which has transparent wings, hovering in front of rhododendron blossoms in just the same way.

The Swifts fly between sunset and dark, and the largest of them is very curious indeed. For although it has glossy white wings, so that one can see it quite clearly in the dusk, it will suddenly disappear. The fact is that although its wings are white

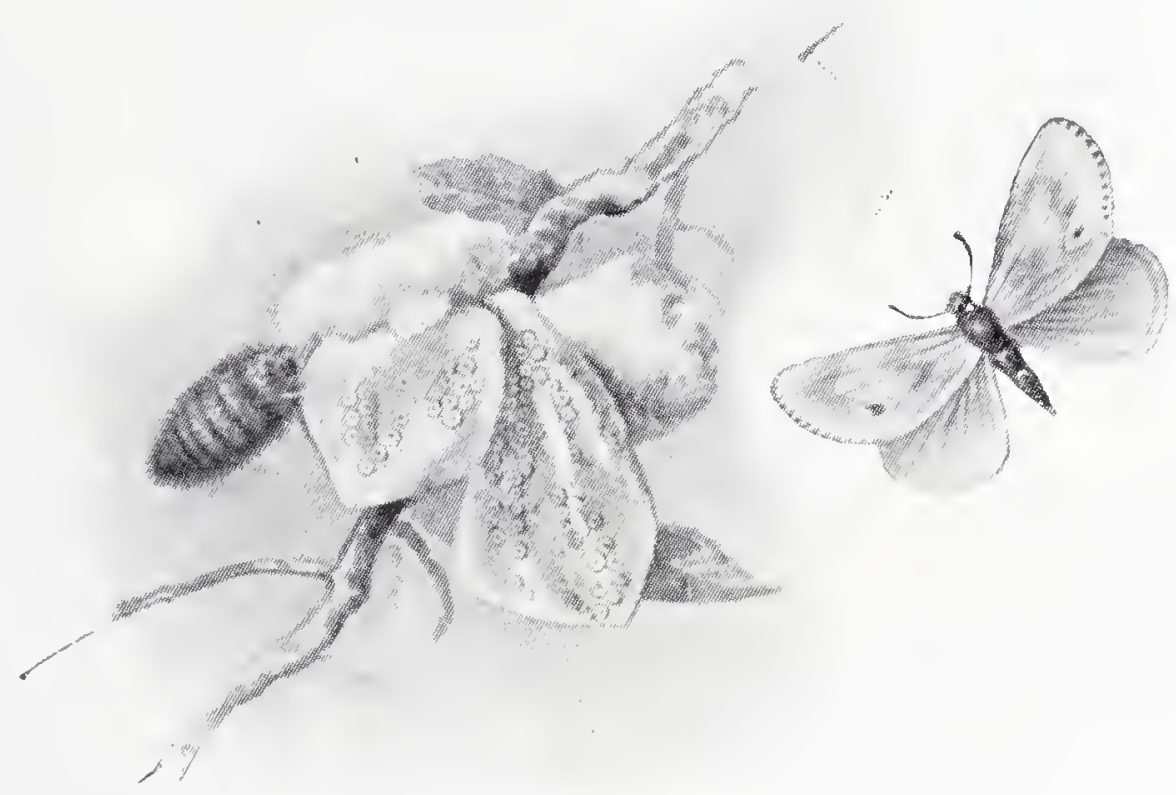

VAPOURER MOTH.

above they are yellowish-brown below; so that when it suddenly settles, and folds them over its back, it at once becomes invisible. The Goat Mотн is a large, heavily-built insect, with brownish grey wings marked with a number of very short upright dark streaks. The caterpillar is a great reddish-brown creature with a broad chocolate band running down its back, which lives for three years in the trunks of various trees, and then spins a silken cocoon in which to turn to a chrysalis.

Perhaps you know the Tiger Moth by sight, with its brown fore-wings streaked with white, its scarlet hind wings with bluish-black spots, and its bright scarlet body. But if you do not know the moth you must at any rate know its caterpillar, which is very common in gardens, and is generally called the "woolly hear," because of the long brown hairs which cover its body.

Very beautiful indeed are the Burnets, which have dark 
green front wings, with either five or six large red spots, and crimson hind wings, edged with black. You may often see them resting on flowers and grass stems by the road-side in the hot sunshine. And in some parts of the country the Cinnabar Moth is almost equally plentiful. You can recognize it at once by the crimson hind wings, and by the streak and the two spots of the same colour on the front ones. The caterpillar, which is bright orange in colour, with black rings round its body, feeds upon ragwort.

The VAPOURER Moth is very common towards the end of summer, and even in London one may often see it dashing about in the hot sunshine with a strange jerky flight. But one only sees the male, which is a bright brownish-yellow insect measuring about an inch across the wings; for the female is much more like a grub than a perfect insect, and has wings so small that they are hardly visible. Of course she cannot fly; and her body is so big and clumsy that she cannot even walk. So she spends her life clinging to the outside of the cocoon in which she passed the chrysalis state, and covers it all over with her little round white eggs. And when she has laid the last of these she falls to the ground and dies.

Very handsome indeed is the Emperor Moth, which has a big eye-like spot in the middle of each wing, something like those of the Peacock Butterfly. But its caterpillar is even more beautiful still, for its body is of the loveliest grass-green colour, sprinkled all over with little pink tubercles, each of which is enclosed in a ring of black, and has a tuft of glossy black hairs sprouting from it. This caterpillar feeds on bramble and heather, and when it reaches its full size it spins a light brown cocoon among the leaves of its food plant, and then turns to a chrysalis, from which the perfect moth hatches out in the following April.

Very often one finds caterpillars which look just like little bits of stick, and which walk in a most curious fashion by hunching up their backs into loops, and then stretching them out again, just as if they were measuring the ground. These caterpillars are called "Loopers," and they turn into moths with large broad wings and very slender bodies.

There are a great many kinds of these moths. One, called the Sivallow-Tail, may often be found hiding among ivy in July. It has large wings of a pale yellow colour, with little tails upon the hinder pair. Then there are the Sulphur, a smaller insect with wings of a brighter yellow; the Emeralds, of the most delicate green; the MAGPIE, which has wings of the purest white, marked with streaks of orange and numbers of almost square black spots and blotches; and many others far too numerous to mention. If you ever shake a bush in summer-time you may often see quite a dozen of them flying away to seek for some fresh hiding-place. 


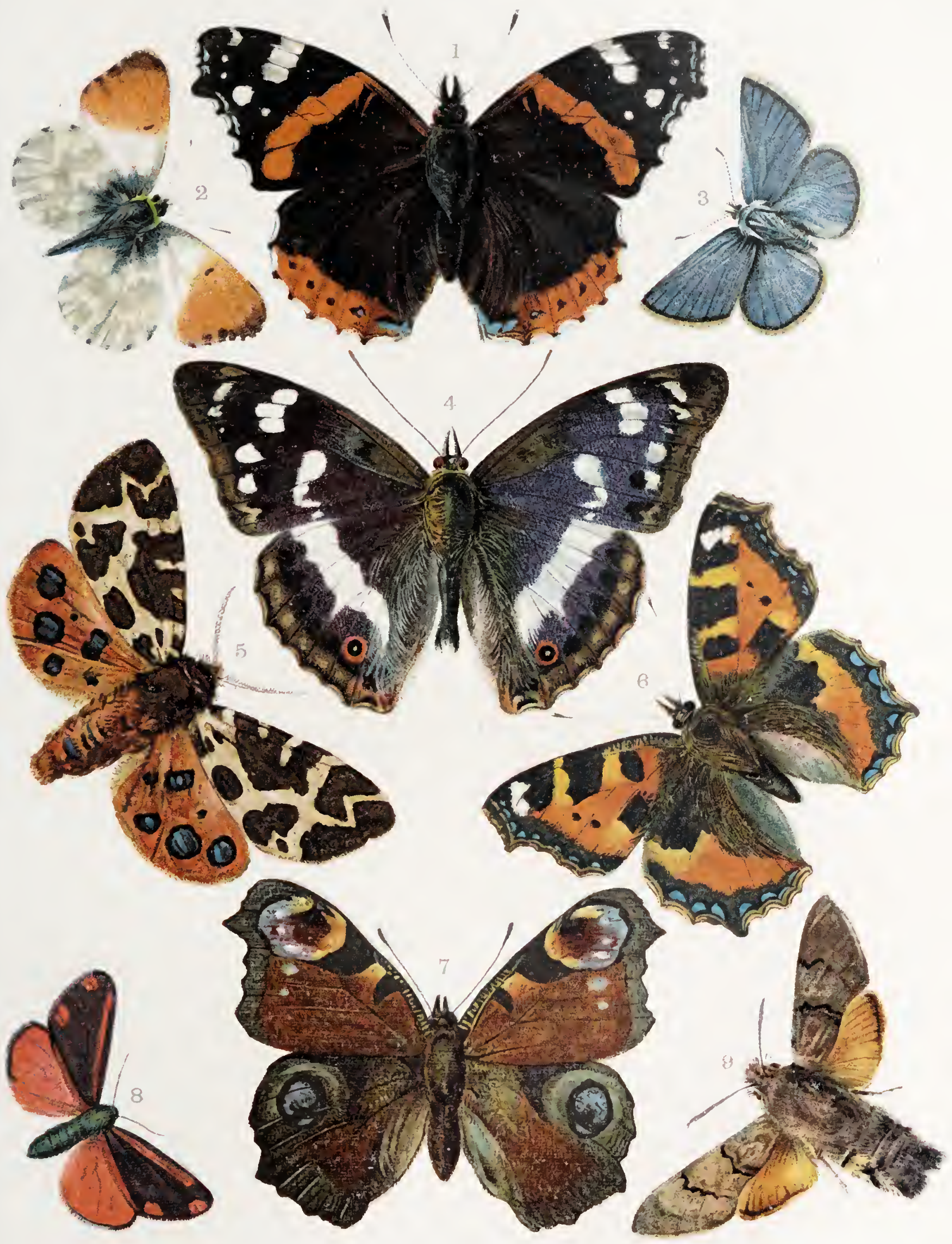



Then there is a large moth known as the Puss, because it is coloured rather like a brindled grey cat. The caterpillar is bright green, with a big hump in the middle of its body, and two long thread-like organs at the end of its tail, with which it will sometimes pretend to be able to sting you. But in reality it is perfectly harmless. You may often find it feeding on the leaves of willow trees in August, and when it is fully fed it spins a hard, oval cocoon in a crack in the bark. And there are three smaller moths belonging to the same family, which are linown as Kittens!

Another very large group of moths is that of the Noctuce, or "night-fliers." But we so seldom see these unless we go out specially to look for them that I shall pass them by without further mention.

The next Order is that of the Homoptera, or "same-winged" insects, which are so called because their upper and lower wings are just alike.

The "Frog-hoppers" all belong to this order. I wonder if you know them-little brown or grey insects, sometimes marked

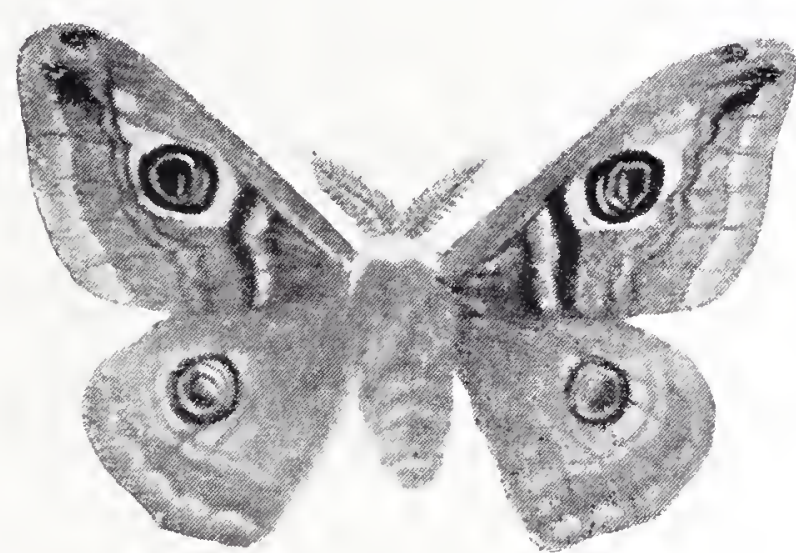

EMPEROR MOTH. or marbled with white, which carry their wings folded tent-wise over their backs, and hop about with really wonderful activity. It has been calculated, indeed, that if a man of ordinary height could leap as well as a frog-hopper, in proportion to his greater size, he would be able to cover nearly a quarter of a mile at a single jump!

But if you do not lnow the frog-hoppers by sight you must at any rate know something of their grubs; for these are the creatures which cause the "cuckoo spit" of which one sees so much during the early summer. Very often the weeds and long grass in a meadow, or by the road-side, are almost covered with the odd little masses of froth, so that one's feet get quite wet as one wallis through the herbage. And in the middle of each mass is a fat little grub, which is sucling up the sap of the plant upon which it is resting, and pouring it out again in frothy bubbles.

The mischievous little Aphides, or Green-fly Insects, also belong to this order. There are a great many different kinds, some of which do most terrible damage to hops and corn and all sorts of cultivated plants. I have already mentioned these when describing the habits of ants, and you will recollect that they have sharp little beaks, which they thrust into young shoots and tender leaves in order to suck up the sap; and that as fast as they do so they pour it out again through two little tubes upon their backs in the form of the thin, sweet, and very sticky 
liquid which we call "honey-dew." You will remember, too, how fond ants are of this liquid, and how they "milk" the tiny insects just as if they were little cows.

So, you see, the aphides injure plants in two ways. First, they draw off all their sap, which is really their life-blood; and then they drop this sticky honey-dew on to the leaves below, and choke up the little holes by means of which they breathe. And the worst of it is that these insects multiply so rapidly. Where there is one to-day there will be five and twenty to-morrow; and two days later there will be five and twenty times five and twenty; and two days later still there will be five and twenty times five and twenty times five and twenty! Indeed, if it were not for ladybirds and lace-wing flies and one or two other insects which feed upon aphides, every green leaf would be destroyed by them in a very few months' time.

A very curious fact about these insects is that as long as they can find plenty of food they do not grow any wings. But as soon as the sap becomes scanty or thin, wings make their appearance, so that they can fly away and seek for better food elsewhere.

The order of the Homoptera, or "same-winged" insects, is followed by that of the Heteroptera, or "different-winged" insects, in which that part of the wings nearest to the body is hard and leathery, while the rest is softer and thinner, and is generally almost transparent. Some of these live upon land, while others spend most of their lives in the water.

The curious "Bishop's Mitres" belong to the former group. There are a good many kinds, and some of them are very common. You may see them sitting upon flowers, or resting upon raspberries and blackberries in the sunshine. But although they are sometimes very pretty I do not advise you to handle them, for they have the power of pouring out a liquid which will make your fingers smell very nasty indeed. And you should be most careful not to eat any fruit on which they have been resting, for they leave a most horrible flavour behind them, which is even worse than the smell.

Among those which live in the water there are several most interesting insects. There are the Water Gnats, for example, which you can see running about on the surface of any pond, and which look like narrow-bodied long-legged spiders. But you will notice that they only have six legs, whereas true spiders always have eight. They skim about on the water by means of the middle and hinder limbs, the front pair being used in catching prey. And when they have caught a victim they suck its juices through their sharp little beaks.

Then there is the IVATER BOATMan, which always swims 
on its back. The reason why it does so is that when its body is in that position it is shaped just like a boat, while its long hind legs serve as a pair of oars. So the little insect really rows itself through the water. On a bright sunny day you may often see it resting on the surface of a pond, with its hind legs thrown forwards in readiness for a stroke. And if even your shadow falls upon it, or it feels the vibration of a heavy footstep, it will dive down in a moment to some hiding-place among the weeds.

If you ever catch a water boatman, be careful how you handle it, or it will give your finger a very painful prick with its sharp beak.

The Water Scorpion, too, is very curious. It is a flat, oval insect, of a dirty brown colour, which loolis very much like a piece of dead leaf. It seems to know this quite well, for when it is hungry it always hides among dead leaves down at the bottom of the water, and lieeps perfectly still. Then the other insects do not notice it, and as soon as one of them comes within reach it seizes it with its great jaw-like front legs, and plunges its beak into its body.

This insect is called the water "scorpron" because it has a long spike at the end of its body, which loolis something like a scorpion's sting. It is really a breathing tube, however, the top of which is poked just above the surface of the water while

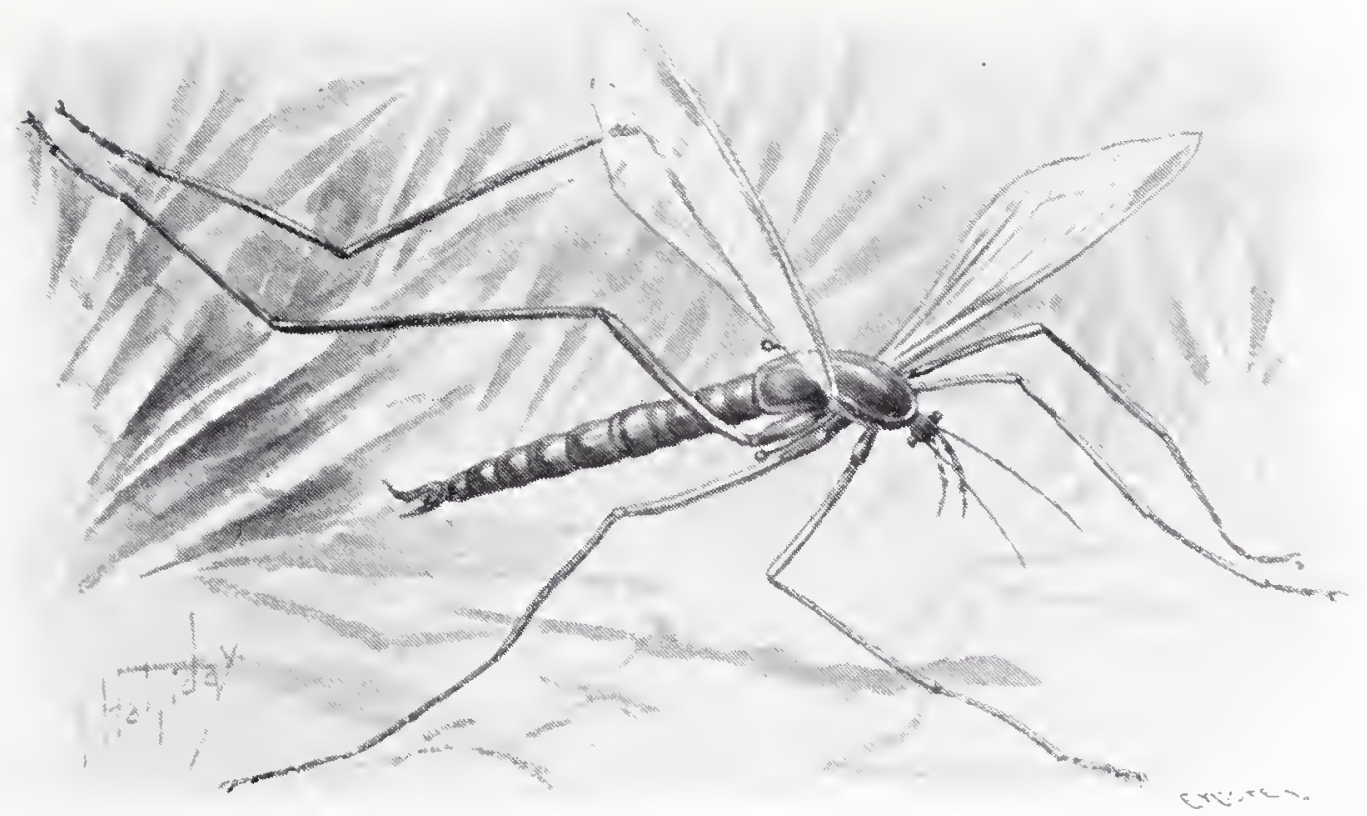

DNIMIM-LONG-LEGS.

the insect is lying at the bottom, so as to enable it to breathe quite easily.

The Order of the Aphaniptcra, or "unseen-winged" insects, is a very small one, consisting only of the Fleas. The name has been given to them because their wings are so tiny that, even with the microscope, they can hardly be seen at all. 
There are a good many different kinds of fleas, all of which suck the blood of animals through their sharp little beaks. Some of them are able to leap to a really wonderful distance, by means of their powerful hind legs. And they are so wonderfully strong that if a man were equally powerful, in proportion to his greater size, he would easily be able to drag a waggon which a pair of cart-horses could scarcely move!

The last Order of insects is that of the Diptera, or "twowinged" flies, which seem to have two wings only instead of four. But if you look at them closely, you will see a pair of little knob-like organs just where the hind wings ought to be. And these little organs, which we call "balancers," are really the hind wings in a very much altered form.

Although they are so tiny, and look so useless, these balancers are used in some way during flight; for if they are damaged or lost the insect can no longer balance itself or direct its course in the air.

Several very common insects belong to this order.

There is the GNAT, for instance, which most of us know only too well; for there are very few of us who have not suffered from the wounds caused by its beak. Its life-history is very interesting. The eggs, which are shaped just like tiny skittles, are laid in the water, and the mother gnat fastens them cleverly together in such a way that they form a little boat, which floats on the surface. After a time a little door opens at the bottom of each egg, and a tiny grub tumbles out into the water. It is a very odd-looking little creature, with a very small head, a very big thorax, and a very long tail; and it mostly floats in the water with its head downwards, and the tip of its tail resting just above the surface.

These grubs feed on the little scraps of decaying matter which are always floating in the water of the pond, and they wriggle their way about in the strangest manner, by first doubling up their bodies and then stretching them out, over and over again. After a time they throw off their slins and change to chrysalids, and out of this, a few days later, the perfect gnats make their appearance.

You will notice that some gnats have very big bushy feelers, just like big plumes. These are the males, and you need not be afraid of them, for they have no beaks and cannot bite.

Then there is the DADDY-LONG-LEGS, whose "balancers" you can see quite easily. This insect lays its eggs in the ground, and the grubs which hatch out from them are called "leatherjackets," because their slins are so very tough. They feed upon the roots of grass, and sometimes do a great deal of mischief in pasture-fields. Indeed, if it were not for such birds as the rook and the starling, which destroy them in enormous numbers, we should find it almost impossible to grow any grass at all. 


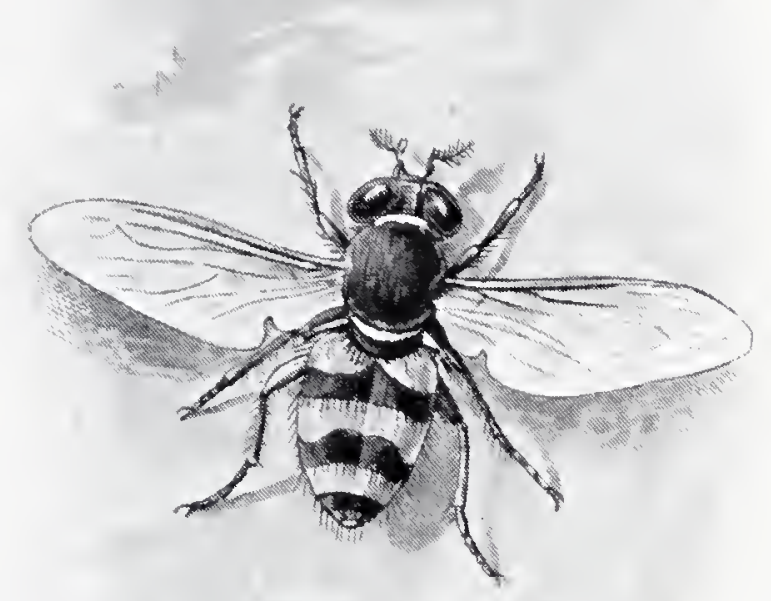

DRONE LILY.

Then there is the Drovis FLY, which really does look rather like a bee. But it only has two wings instead of four, while its body is much more stoutly built. And it has no sting, so that you need not be in the least afraid of it. You may often see it sitting on flowers on sunny days in autumn, and it is specially fond of those of the ragwort.

The grub of this fly spends its whole life buried head downwards in the mud at the bottom of some shallow pool-thick, black mud, which is largely made up of decaying leaves-and never comes out of it even to breathe. But at the end of its body it has a long tube, the tip of which rests just above the surface of the water, so that it can draw down as much air as it requires. And this tube

is made something like a telescope, so that if a heavy fall of rain should raise the level of the water, all that the grub has to do is to push out another joint, when it can breathe just as easily as before.

This grub is often known as the Rat-tailed Maggot.

As you walk through a wood in summer, you may often see a black and yellow fly hovering in mid-air. If you move, it darts away so swiftly that the eye cannot follow its flight. But if you stop, and remain perfectly still, it will come back again in a moment or two, and hover just as before.

This is a Hawk FLy, and it is very useful indeed, for the mother insect always lays her eggs on twigs and leaves which are swarming with aphides. On these insects the grubs feed, so

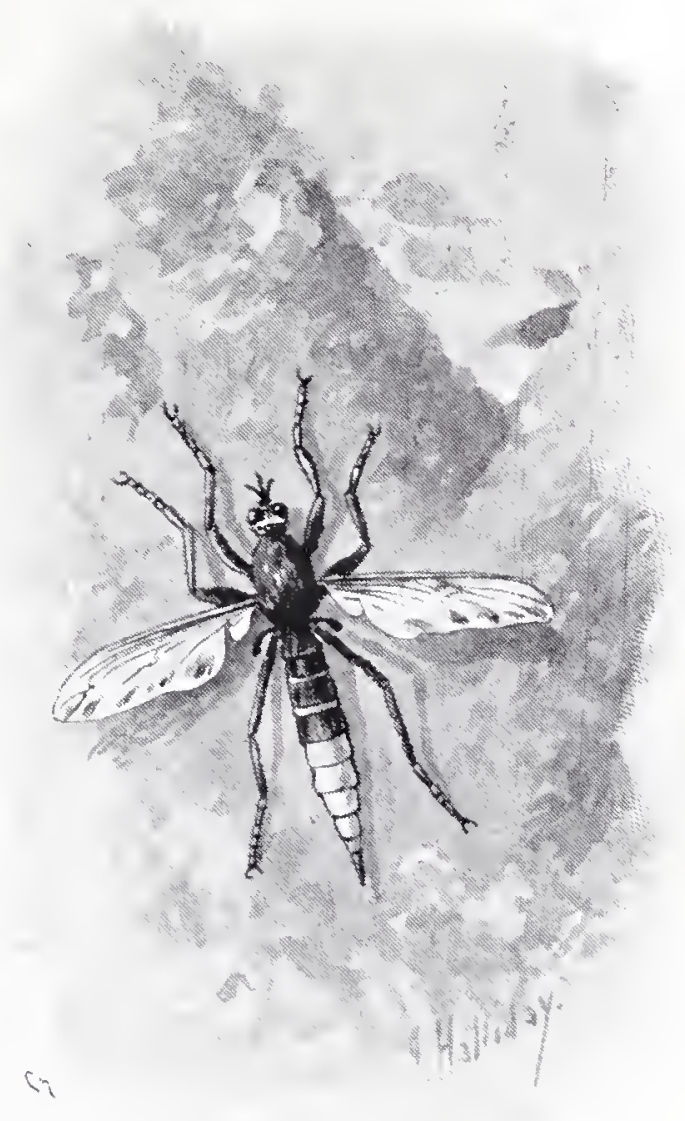

HAWK FLY. 
that as soon as they hatch out they find themselves surrounded with prey, and destroy the little insects in great numbers.

The House Fuy and the Bluebottle Fly also belong to the order of the Diptera. They are not very pleasant insects, but while they are grubs they are really most useful, for they feed upon all sorts of decaying substances. And another insect, called the FLESH FLY, is even more useful still, for it is the parent of from sixteen to twenty thousand grubs: so that if even a single fly finds the carcase of a small animal, her little ones will devour it in a very short time. And in a few days all these grubs turn into perfect flies, and in their turn become the parents of thousands of grubs: so that it has been said that three of these flies could

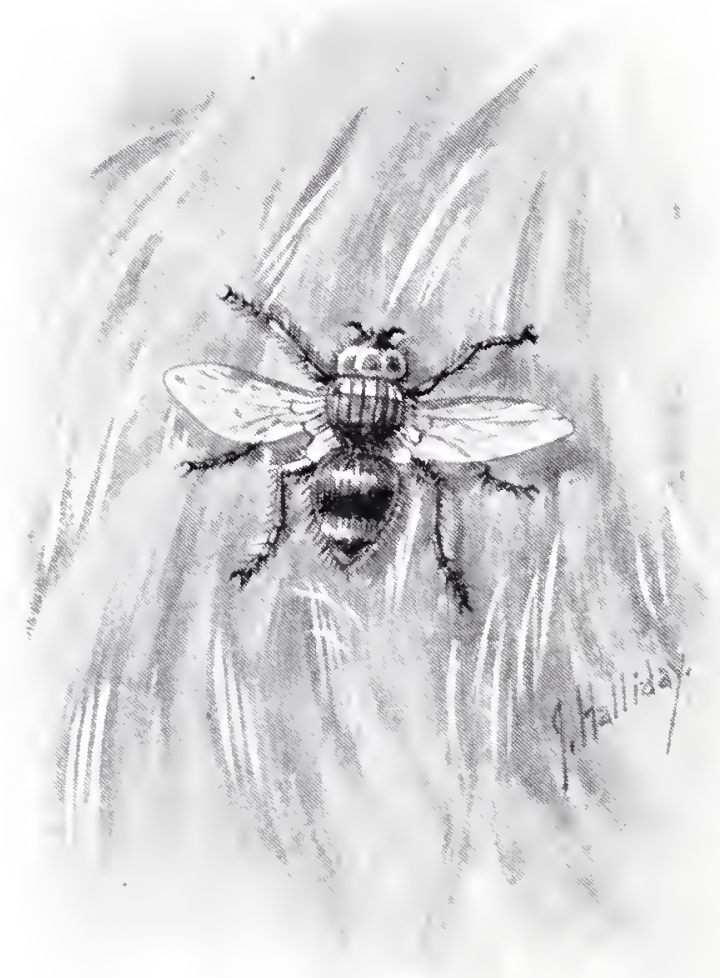

WURBLE FLY.

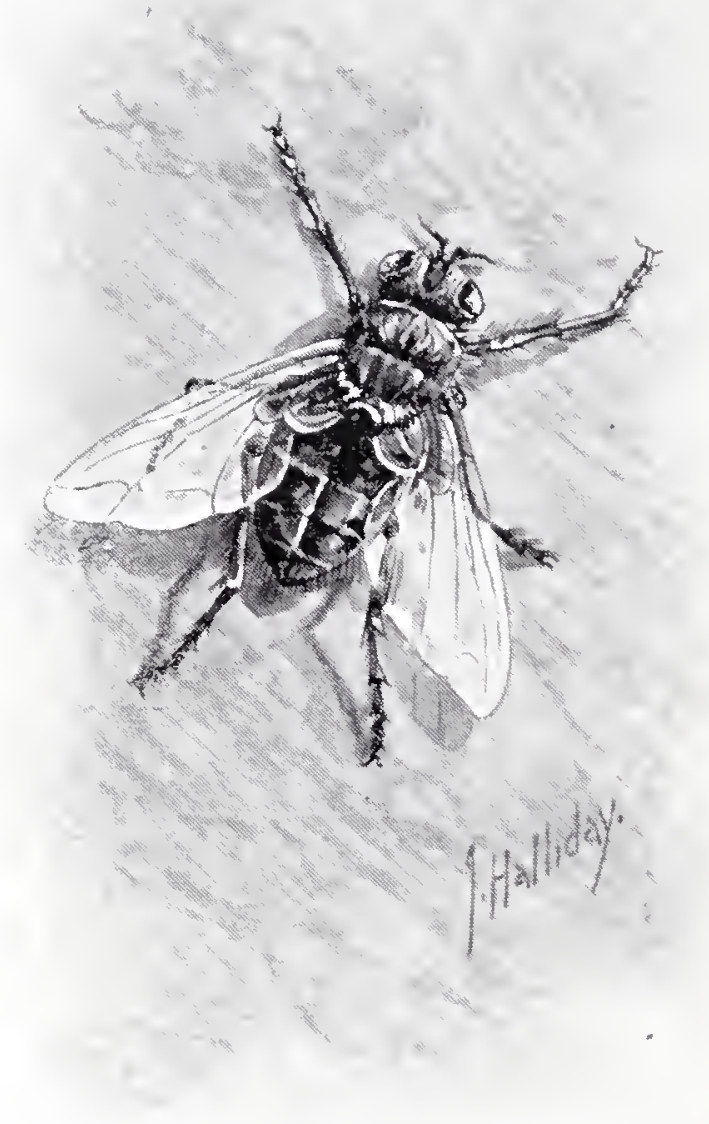

FIESH FIT.

(Slightly enlarged.)

devour an ox as fast as a lion could!

The last insect that I can mention is a brown and grey fly known as the WURble, or Warble. It is very troublesome indeed to cattle, for the mother fly lays her eggs upon their backs. Then as soon as the grubs hatch, they burrow underneath the skin of the poor animals, and form large swellings there, in which they spend the whole of their lives. When they are fully fed they wriggle out, drop to the ground, burrow into it, and turn to chrysalids, from which the perfect flies appear a few months later. 


\section{CHAPTER XXXIV.}

\section{SPIDERS AND SCORPIONS.}

MOST people think that Spiders are insects. But this is a very great mistake, for they are just about as unlike insects as they can possibly be.

Insects, for example, always have heads. But spiders never do, for their heads are so sunk and lost in their chests that you cannot possibly tell where the one leaves off and the other begins. So that spiders have their bodies divided into two parts only instead of into three, as is always the case in the insects.

Then insects always have six legs; spiders always have eight. Insects have wings; spiders have none. Insects have feelers; spiders have none. Insects nearly always have a great many eyes, which are six-sided; spiders never have more than eight eyes, which are round. And while insects may have biting jaws, or sucking jaws, or a trunk, or a beak, spiders always have poison-fangs, which no insect ever possesses.

So you see that as far as the outside of their bodies is concerned, spiders are very different indeed from insects. And the differences inside the body are just as great. Insects have no hearts, the only blood-vessel in their bodies being one long tube which runs along the back; but spiders have quite a big heart, and a good many arteries as well. Insects have no lungs, but breathe by means of slender tubes which run to every part of the body; but spiders have quite big lungs, in which the blood is purified just as it is in our own. Insects have no brains, but only bunches of nerves in different parts of their bodies; but spiders have quite big brains. And besides this, while all insects which spin silk produce it through their mouths, spiders always do so by means of organs at the very end of the body. So that inside, as well as outside, there is hardly any respect in which spiders and insects really resemble one another.

The silk organs of a spider are very wonderful indeed. Remember, in the first place, that the silk, as long as it remains in the body of the spider, is a liquid-a kind of thick gum, which is produced and stored up in six long narrow bags, or glands. Then if you look at the end of a spider's body through a good strong magnifying-glass-or, better still, through a microscopeyou will see several little projections, which we call "spinnerets." Now each of these spinnerets is covered with hundreds of tinier projections still, every one of which has an extremely small hole 
in the middle. And all these holes communicate, by means of very slender tubes, with one of the silk-glands.

So what a spider does when it wants to spin its line is to squeeze a little drop of silk into one of the spinnerets. It then just touches the object to which the line is to be fastened, and draws its body away. And as it does so a delicate thread comes out from every one of the projections on the spinneret; and all these threads unite together into one stout cord. That is why a spider's thread is so strong. It really consists of several hundred separate threads all firmly fastened together. And if the spider wants to spin a stronger line still, it can unite all the threads coming from several spinnerets into one, so as to make a very stout cord indeed.

Spiders use this silk for all sorts of different purposes.

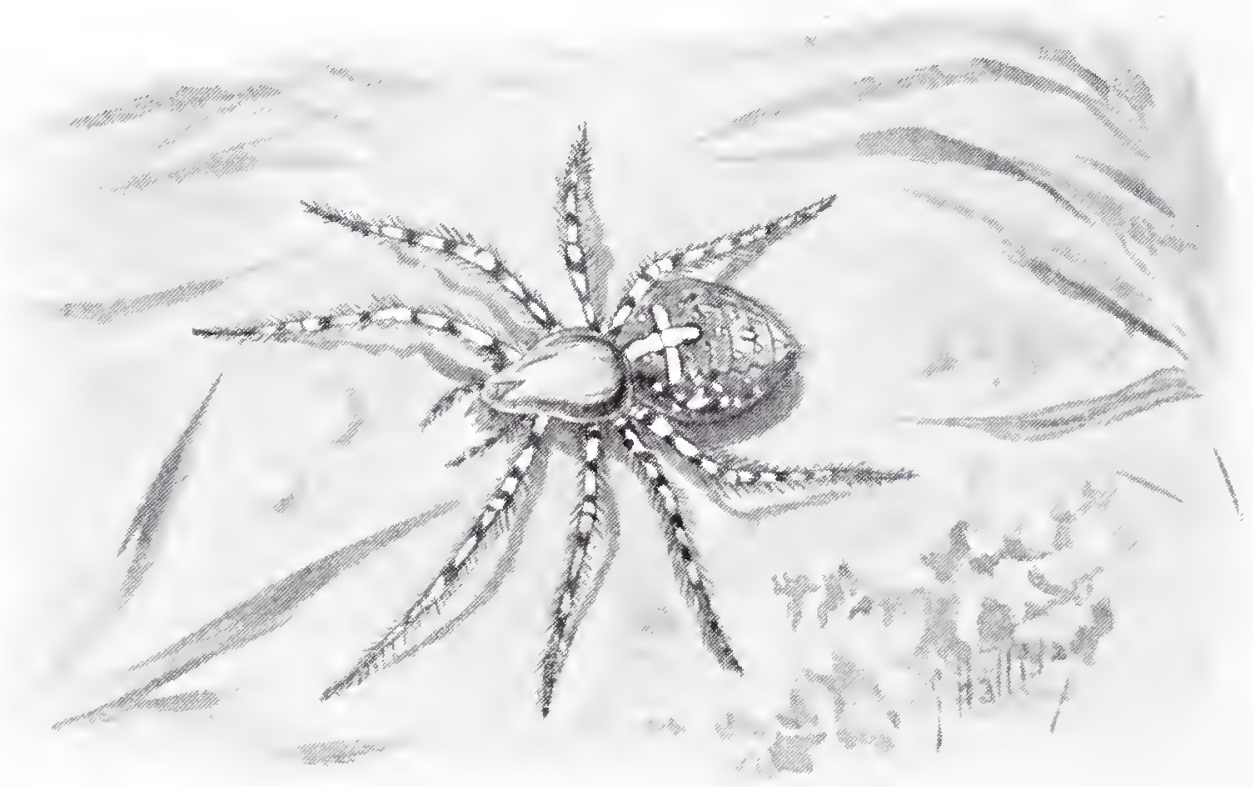

GARDEN SPIDER.

First of all, they use it for snaring insects. Let us take, for an example, the web of the common Garden Spider.

Of course you know this spider very well by sight, for it is to be seen in every garden, resting in the middle of its web; and you may always recognize it by the white cross upon its back. But I don't suppose that you have ever seen it spinning its net. For it always does so very early in the morning, generally begimning before sunrise, so that it may be quite ready for use as soon as the insects begin to fly.

First of all, the spider makes a kind of outer framework of very strong silken cords, and fastens it firmly in position by stout guy-ropes of the same material. Next, she carries a thread right across the middle and fixes it down on either side. Then, starting from the centre, she carries thread after thread to the margin, carefully testing the strength of each by giving it two or three smart pulls, and fastening it firmly down. When she has 
finished this part of her task, the web looks like a badlyshaped wheel.

The next thing that the spider does is to spin a little silken platform in the middle of her web to sit upon. And as soon as she has done this she begins to spin the spiral thread. Beginning from the centre, she goes round and round and round, fastening the thread down every time that it crosses one of the straight cords-the spokes, as it were, of the wheel-until at last the web is finished. Then she goes to the little platform in the middle, and there remains, upside down, waiting for an insect to blunder into her net.

By and by, perhaps; a bluebottle fly does so. Then she shakes the web violently for a few moments, so as to entangle it more thoroughly, rushes down upon it, seizes it, and plunges

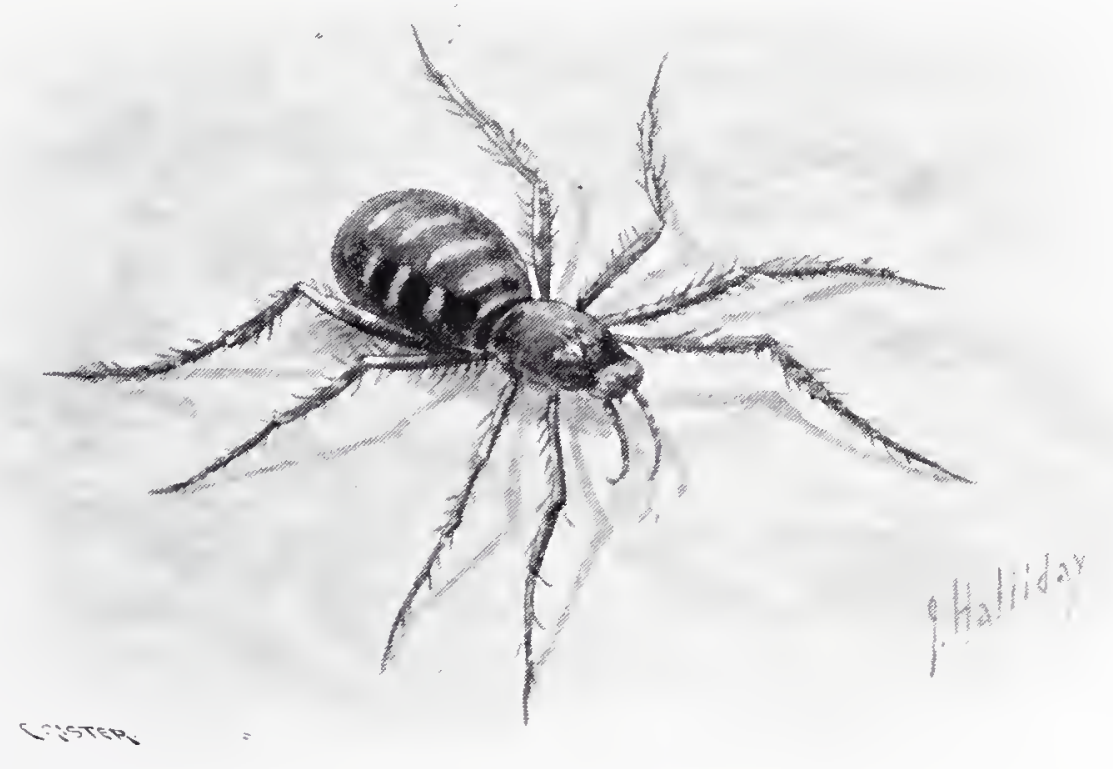

MARMIGNATIO.

her fangs into its body. But if she catches a wasp or a bee she nearly always cuts it carefully out, drops it to the ground, and then patches up the hole in her web. For she knows perfectly well that wasps and bees can sting!

Would you like to know why it is that flies stick to the web as soon as they touch it? The microscope shows us. All the way along, the spiral thread is set with very tiny drops of liquid gum. So tiny are these drops indeed, that there are between eighty and ninety thousand of them in a large web! And would you like to know why it is that the spider does not stick to the web as the flies do? Well, the fact is that only the spiral thread is set with these little gummy drops, and that as the spider runs about over her web she is most careful to place her feet only on the straight threads, and never on the spiral line. Other spiders, however, snare their prey in quite a different way. There is a very odd spider, for example, called the MARMig- 
NATTo, which is found on the great plains of North America. It is quite a small spider; yet it feeds on such large insects as grasshoppers and field crickets, which it catches in a most curious manner. First of all, it searches for a narrow passage through the herbage along which these insects are likely to pass. Then it stretches a few silken threads across this pathway, quite close to the ground, and lies in wait just opposite until a grasshopper or a cricket approaches. When it comes to the threads the insect is sure to get at least one of its feet entangled. Then it stops, and tries to shake itself free. The only result of its struggles, of course, is that its other feet become entangled too; and while it is struggling the marmignatto springs upon its back, fastens a silken thread to it, springs down again, and fastens the other end to a grass-stem close by. Over and over again it does this, and before very long the unfortunate insect is firmly fastened down by hundreds of threads, and is quite unable to break free, or even to move one of its legs. Then the spider leaps upon its back once more, plunges its fangs into its body, and proceeds to suck its blood.

Some spiders, again, do not snare their prey at all.

Perhaps you may have seen little hairy black spiders, with six white markings upon the upper part of their bodies, running about in an odd jerliy way on sunny fences and walls. These are called Hunting SPIDERS, because they hunt their prey instead of snaring it. You may see them gradually creeping up to a fly, so showly that they hardly seem to move, and then suddenly leaping upon it when they are only about two inches away. Then spider and fly, locked in one another's embrace, go falling towards the ground together. But they never reach it, for wherever a hunting spider goes it always trails a rope of silk behind it, and fastens it down at intervals. So when it springs from the fence it is

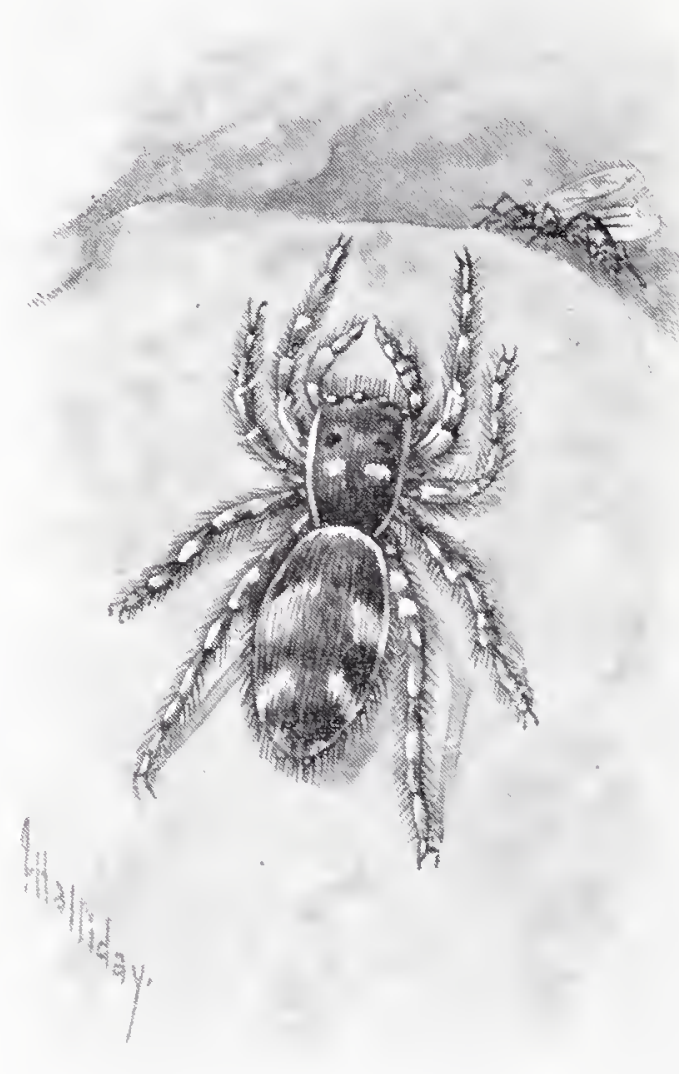

HENTING SPIJER. brought up at once by its own thread, and swings in the air till its victim is dead. Then it just climbs up its thread, and so gets back to the fence.

The great Bird SPiders of the tropics, too, hunt for prey 
in much the same way. Only instead of catching flies on walls they prowl about the branches of trees in search of small birds, springing upon them when they are roosting at night, and killing them almost immediately by a smart bite from their venomous fangs. These spiders, of course, are very large. Indeed, the body of a fully-grown bird spider is as big as a man's fist, while its

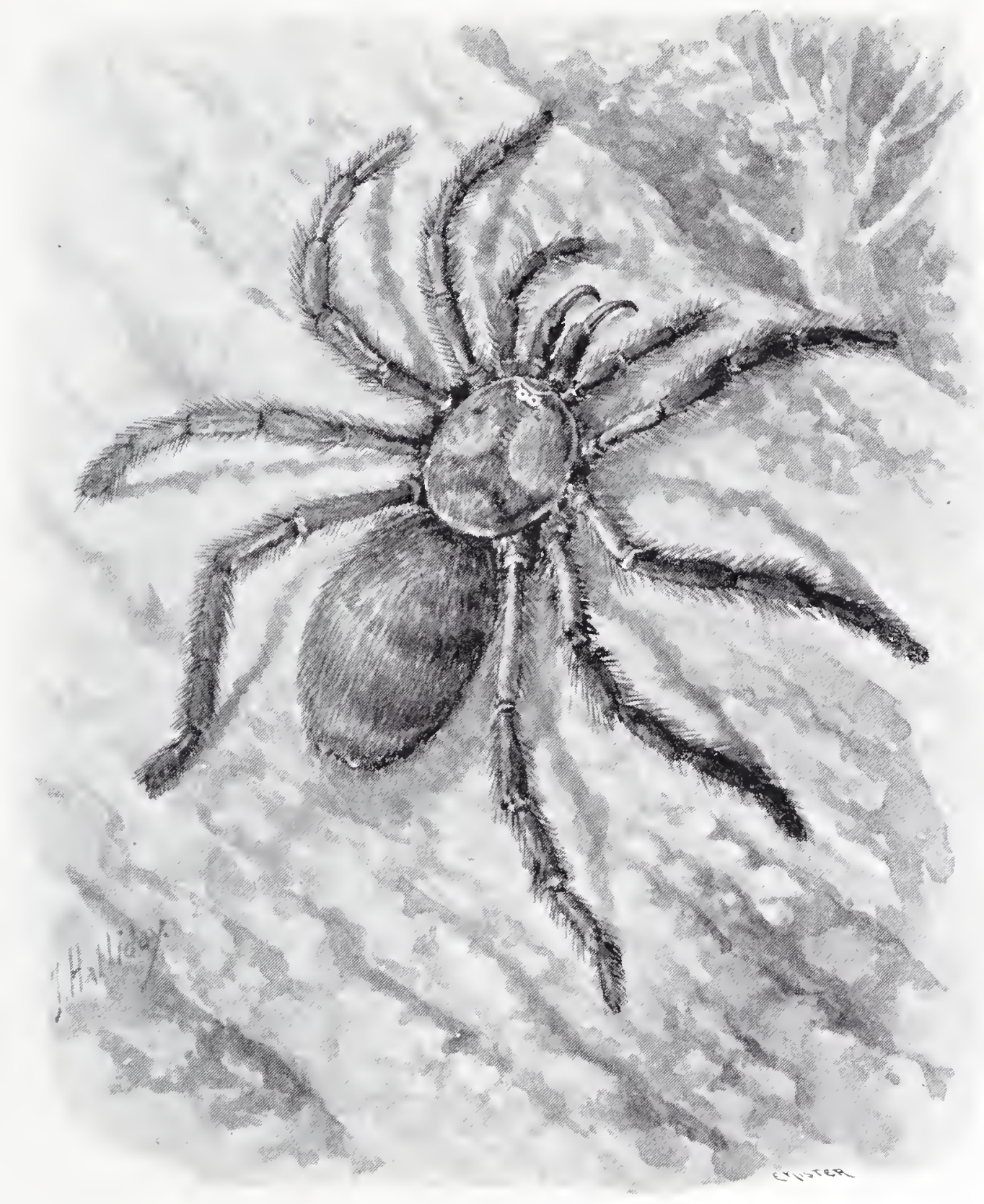

BIRD SPIDER.

great hairy legs cover nearly a square foot of ground when they are fully spread out.

Then there are the famous Trap-DOOR SPIDERS, which are found more or less commonly in all warm countries.

These spiders all live in tunnels in the ground, which they dig by means of their fangs; and as they do not want the situation of their nest to be discovered, they carry the earth away to a little distance as fast as they dig it up, and carefully hide it. 
Very often the hole which they dig in this way is eighteen inches or two feet deep. And at the bottom it always turns sideways for an inch or two, so that the general shape of the burrow is very much like that of a stocking.

This hole is always dug in the side of a bank, so that when there is a heavy fall of rain the water may run away without flooding it.

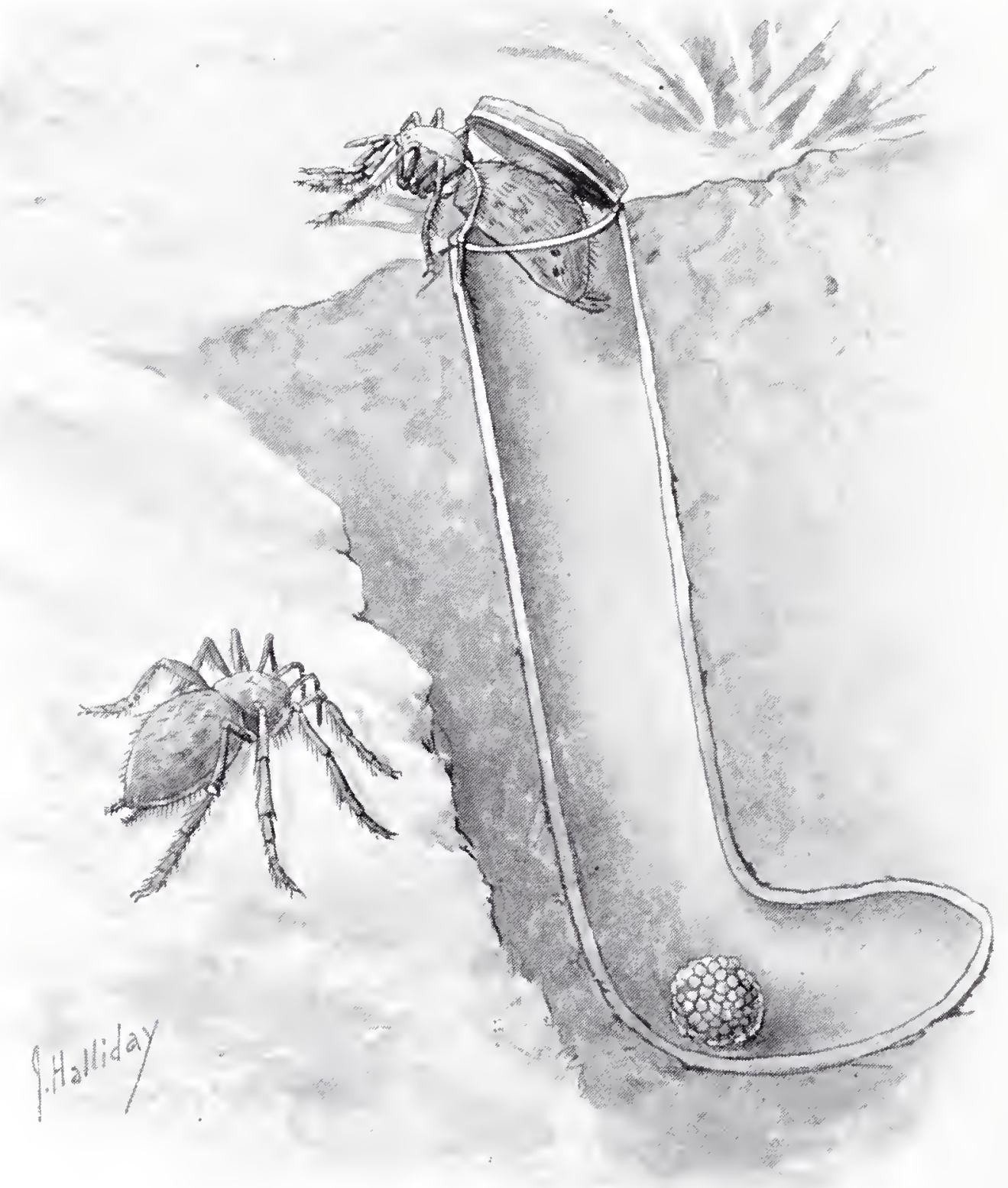

TRAP-DOOR SPIDERS.

When the burrow is finished, the spider lines it throughout with two sheets of silk. The outer sheet, which comes next to the earth, is rather coarse in texture, and is quite waterproof, in order to keep the tunnel dry. The inner one is very much finer and softer, so that the little home may be as comfortable as possible.

As soon as the lining process is completed, the spider sets to work on the trap-door. This she makes in the most clever 
manner possible. First she measures the doorway most carefully by the aid of her feelers. Then she spins a thin silken pad of exactly the same size and shape. This is sticky on the top, like the spiral thread of the web of the garden spider: and she sprinkles it all over with very small scraps of earth. Upon this she fastens another silken pad, which she sprinkles with earth in the same way. And then comes another and then another, and so on till the door is sufficiently thick. Finally, she fastens it in position by means of a hinge, which is also made of silk; and she always places this hinge on the upper side of the doorway, so that the door may fall down behind her by its own weight whenever she leaves the burrow. She is rather a lazy creature, you see, and does not want to have the trouble of shutting the door for herself! And if she left it open, every passer-by would find out where she had made her home.

The door always fits most wonderfully into its place, and the spider carefully covers the top with little bits of moss and small scraps of earth and stone, so as to make it exactly like the surface of the ground all round it. Indeed, unless one happens to see the spider push it open, it is almost impossible to find it.

When one of these spiders is in her burrow, she always fastens about half a dozen silken threads to the inner side of the door, carries them down to the bottom, and sits with one of her feet resting upon each. No one can then try to force her door open without her knowledge, and as soon as she feels the least pull upon the threads she rushes up the burrow, clings to the walls with her hind feet, seizes the door with her front ones, and pulls it downwards with all her might. And if the door is forced open in

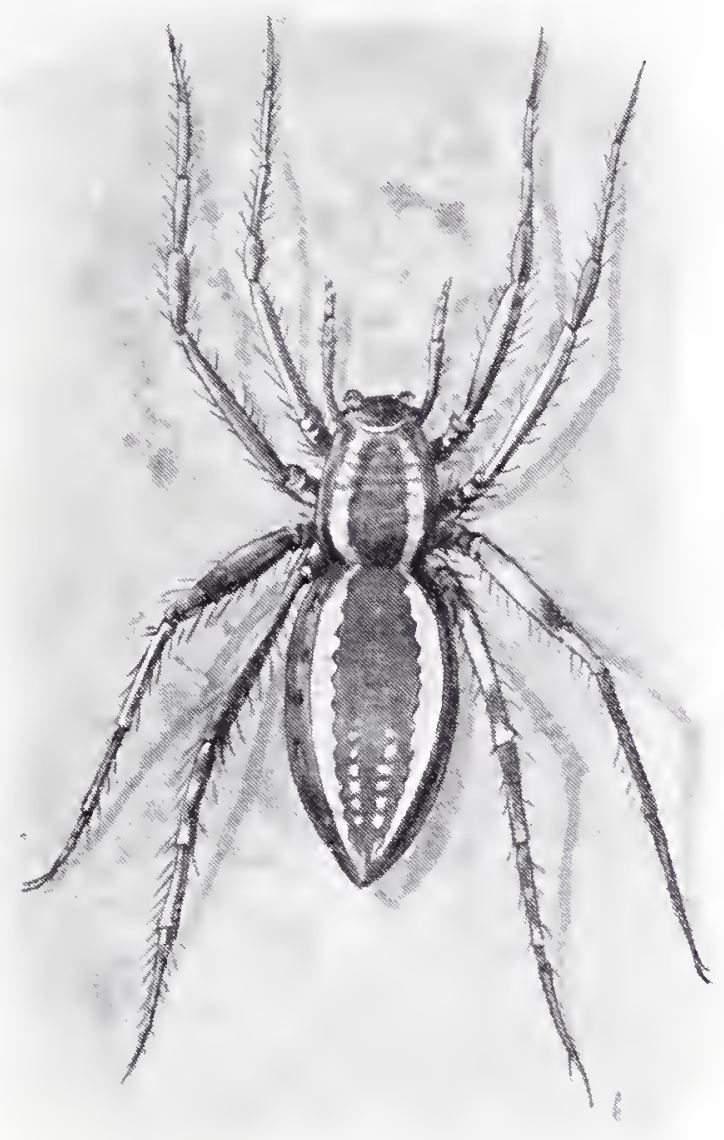
spite of her efforts, she slips into a sort of side tunnel which she always makes near the top of her burrow, and stays there until the danger is past.

Then there are several spiders which live on or in the water.

One of these is the RAFT Spider, which is found in the fen districts of England. If you should happen to meet with it you can recognize it at once, for all round the upper part of its body is a narrow hand of yellow, and inside this is a row of 
small white spots. This spider is about an inch long, and owes its name to the fact that it actually makes a little raft on which to go out searching for water insects. Collecting together a quantity of little bits of leaf and cut grass and reeds, it fastens them firmly together with silken threads, just as shipwrecked sailors might lash planks together with ropes in order to escape from a sinking vessel. In this way it makes a small floating platform, perhaps a couple of inches in diameter. When the raft is finished, the spider gets upon it, pushes off from the shore, and allows the current to carry it along. By and

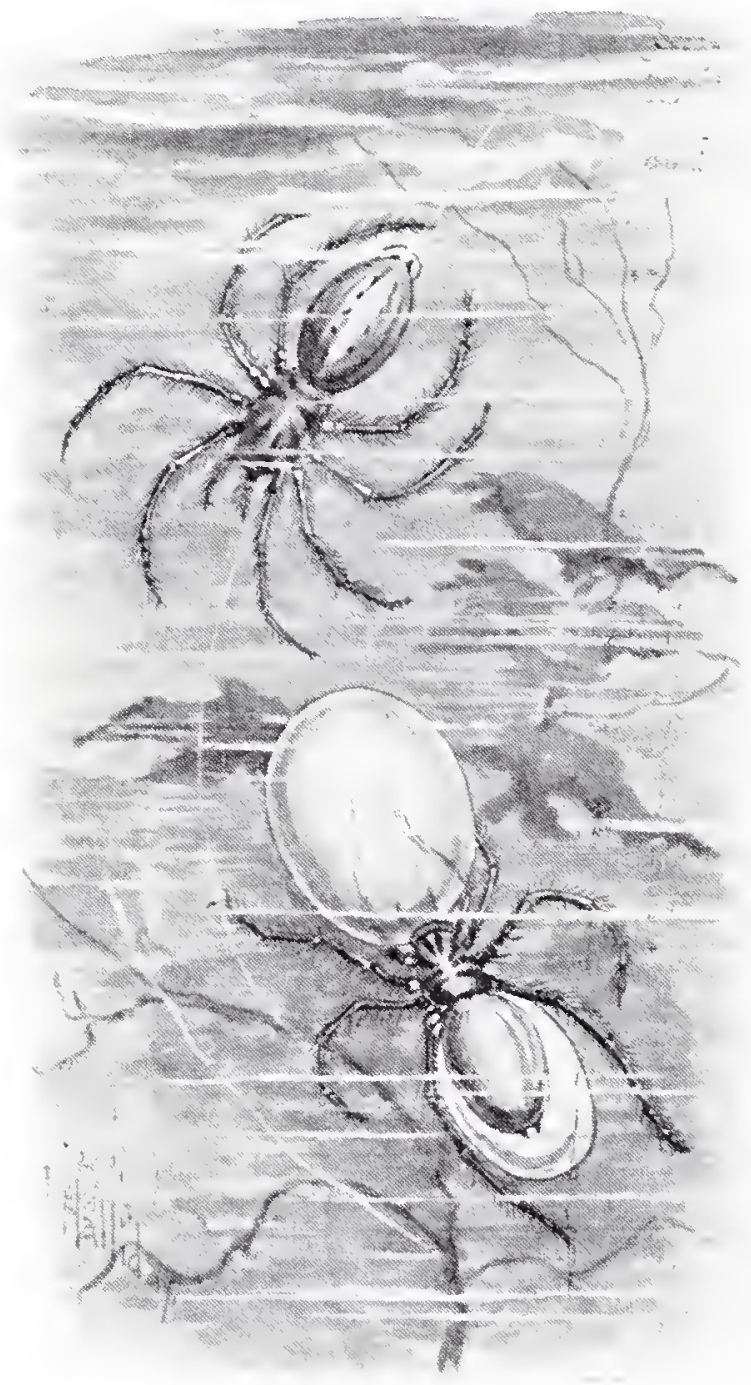

IVATER SPIDERS. by, perhaps, it catches sight of some water insect floating at the surface, or of a drowning fly which has fallen into the stream. Then it leaves its raft, runs along over the surface of the water, seizes its victim, and carries it back to the raft to be devoured. And if it should be alarmed, or think itself in danger, it gets underneath the raft and clings to the lower surface, so that it cannot be seen from above.

More curious still, however, is the Water SPIDER, which actually makes its nest under water.

This spider, which is almost black in colour, and has a very hairy body and legs, is common in ponds and canals in many parts of Great Britain, and spends almost the whole of its life beneath the water. Its little silken nest is shaped like a thimble, with the mouth downwards, and is placed among weeds, to which it is firmly fastened down by guy ropes, also of silk. And when it is finished the spider fills it with air. She does this in a most curious manner. Rising to the surface, she turns upside down, pokes her long hind legs out of the water, and crosses the tips. Then she dives again, carrying down a big bubble of air between these hairy legs and her equally hairy body as she does so. She next gets exactly underneath the entrance to her nest and separates her legs. The result is, of course, that the air-bubble floats up and occupies the upper part. Another bubble is now brought down in the same way, and so the spider goes on, fetching bubble after bubble, until at last her little nest 
is completely filled with air. Then she gets inside it, and watches for the grubs of water insects to swim by.

In this wonderful nest the spider lays her eggs and brings up her family. When the little ones have been hatched, of course, the air in the nest very soon becomes too impure to breathe. Then the little spiders cling tightly to the walls, while the mother gets outside and tilts the whole nest sideways, so that all the exhausted air floats up in one big bubble to the surface. Then she pulls the nest back into position, hurries up to the top of the

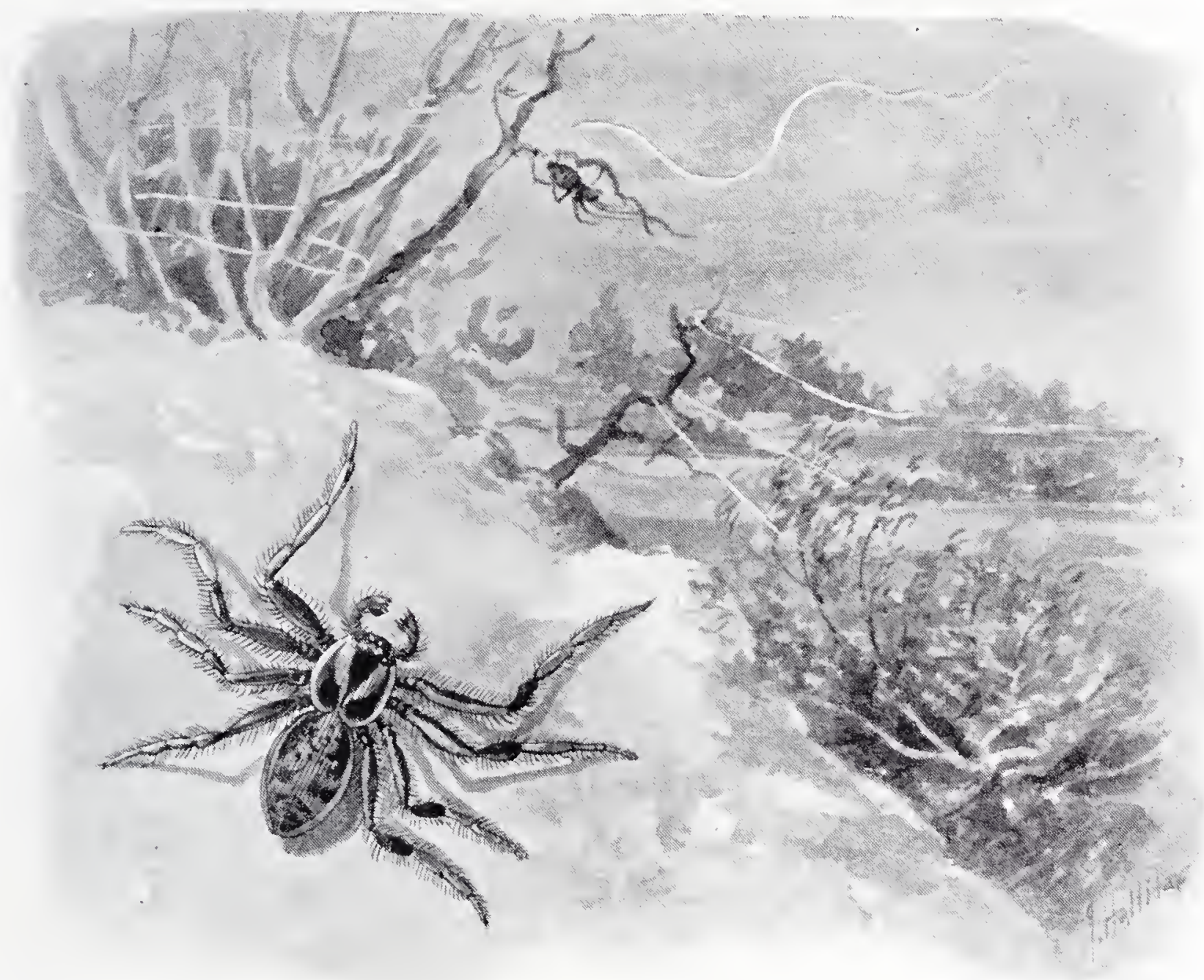

GOSSAMERS.

water and brings down a bubble of air, and then another, and so on until the nest is filled with air all over again.

If you ever catch one of these spiders, and keep it for awhile in a jar of water with a little piece of water-weed, you may see it spinning its wonderful nest, and filling it with air, perhaps half a dozen times a day.

Before we leave the spiders altogether, I must tell you something about the wonderful little creatures which are called "Gossamers."

These are really the young of a good many different kinds of spiders. It often happens, of course, that several families, with 
perhaps five or six hundred little ones in each, are all living quite close to one another. The result is that there is not sufficient food for them all. So they make up their minds to go out into the world and seek their fortunes; and this is how they do it.

Choosing a warm, sunny morning in the early part of the autumn, ail the little spiders climb the nearest bush, and each one makes its way to the very tip of a leaf. 'Then, clinging firmly to its hold, it begins to pour out a very slender thread of silk from one of its spinnerets.

Now of course you linow that on warm, sunny days the air near the ground soon becomes heated and rises, as hot air always does; and in rising it carries up these delicate "gossamer" threads, as they are called, with it. Still the little spiders hold on, and pour out their lines, till at last each has several feet of thread rising straight up into the air above it. Then suddenly they all let go, and are carried up into the air at the ends of their own threads. So they go on, up and up and up, till at last they meet a gentle breeze, which carries them along with it. So, perhaps, they travel for thirty, forty, or fifty miles, or even farther still. And when at last they make up their minds to descend, all that they have to do is to roll up the threads which have been supporting them, and down they come floating gently back to earth.

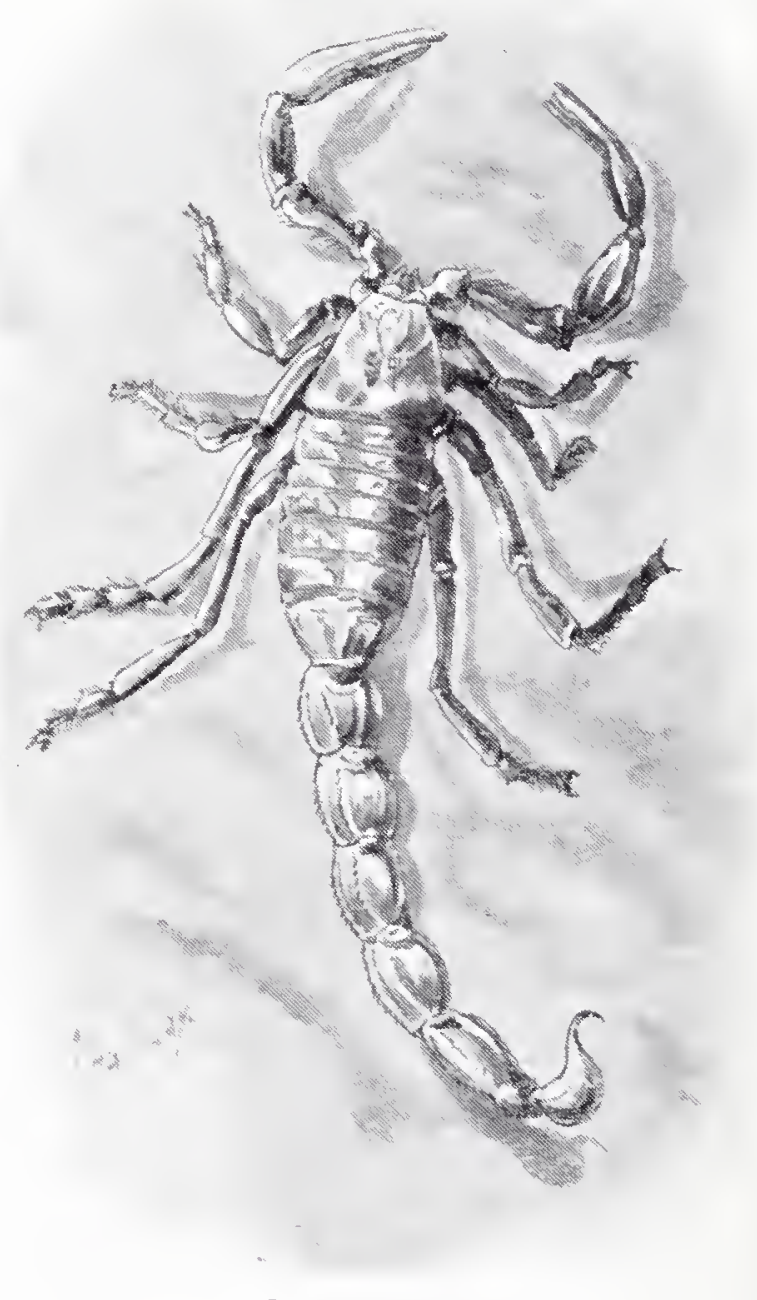

SCORPION.

Haven't you sometimes found on a warm autumn morning, that all the trees and bushes, and even the grass and low plants, on a common or a heath are quite covered with threads of silk? Well, next time that you see such a sight just look carefully, and you will find that on every thread a little baby spider is sitting. Then you may be quite sure that all these little spiders set out early in the morning to seek their fortunes, and that, borne up by their slender threads, they have travelled for many long miles through the air.

Closely related to the spiders are the formidable creatures which we call Scorpions.

These are found in all warm countries, with the exception of New Zealand, and may easily be known by two facts. In the 
first place, in front of the legs they have a pair of great, strong claws, which look very much like those of a crab. And in the second place, the last five joints of the body are narrowed into a long, slender tail, at the end of which is a claw-like sting. When they attack an enemy, or seize a victim, they grasp it with the claws, turn the tail over the back, and force the sting into its body. And the poison which is introduced into the wound is so powerful, that the sting of a large scorpion is almost as severe as the bite of an adder.

During the day-time scorpions hide away under stones and logs, or in crevices in the ground, or perhaps under the loose bark of dead trees. But very soon after sunset they come out from their retreats and prowl about all night long in search of insects.

Next we come to the Centipeues, which one can easily

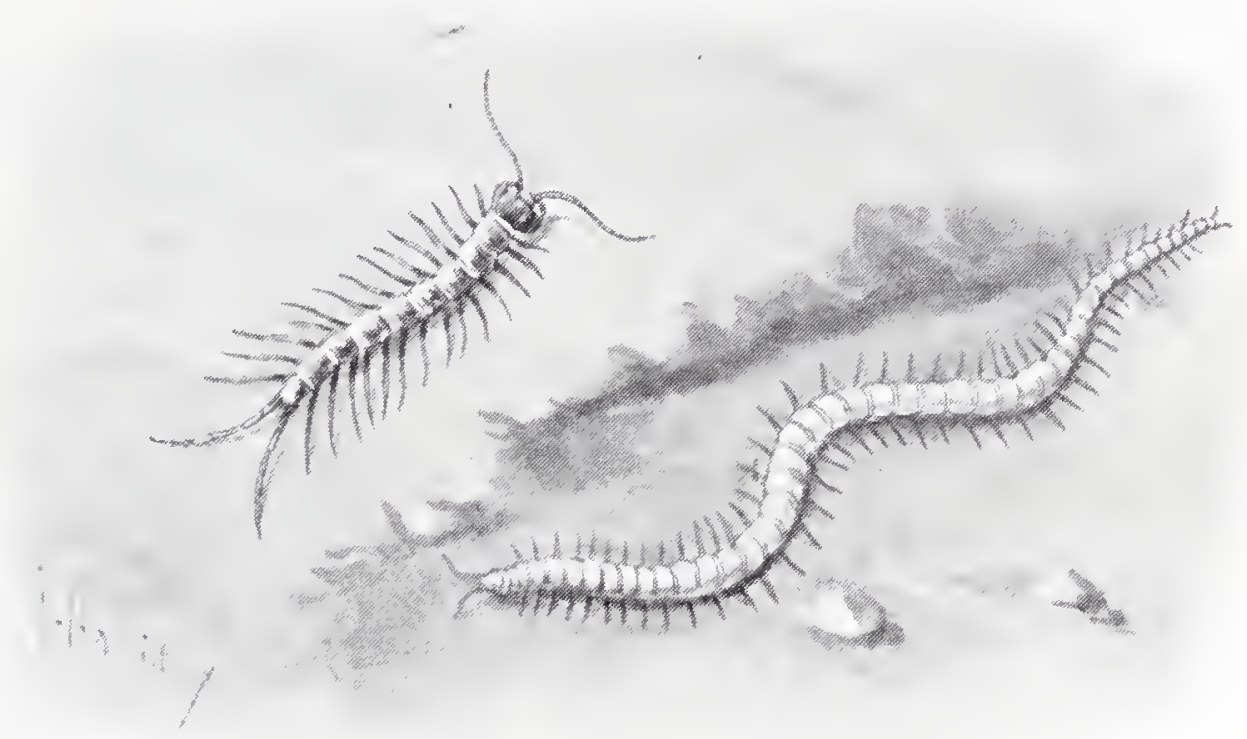

Centipedes.

recognize by the great number of their feet. The name "centipede," indeed, means "hundred-footed." None of these creatures, however, have exactly a hundred limbs. Some only have fifteen pairs of legs; some have as many as one hundred and tiventyone pairs. But whether they be many or few, the number of pairs is always odd.

Another very curious fact about centipedes is that they have no less than four pairs of jaws. But the fourth pair take the form of fangs, which are very stout and strong, and very much curved, while at their base, just inside the head, is a little bag of poison. In the British centipedes, which are quite small, the fangs are not large enough, or the poison sufficiently strong, to cause a serious wound. But some of the tropical species, which grow to the length of nearly a foot, are quite as venomous as the largest scorpions. 
The food of these creatures consists chiefly of worms and insects. But the larger ones will kill lizards, and even mice, and have been known to prey upon victims actually larger than themselves.

The eggs of centipedes are laid in little clusters on the ground in some dark, damp nook, and when they have all been deposited the mother centipede coils herself round them, and there remains guarding them until they hatch.

Millepedes, in some ways, are very much like centipedes.

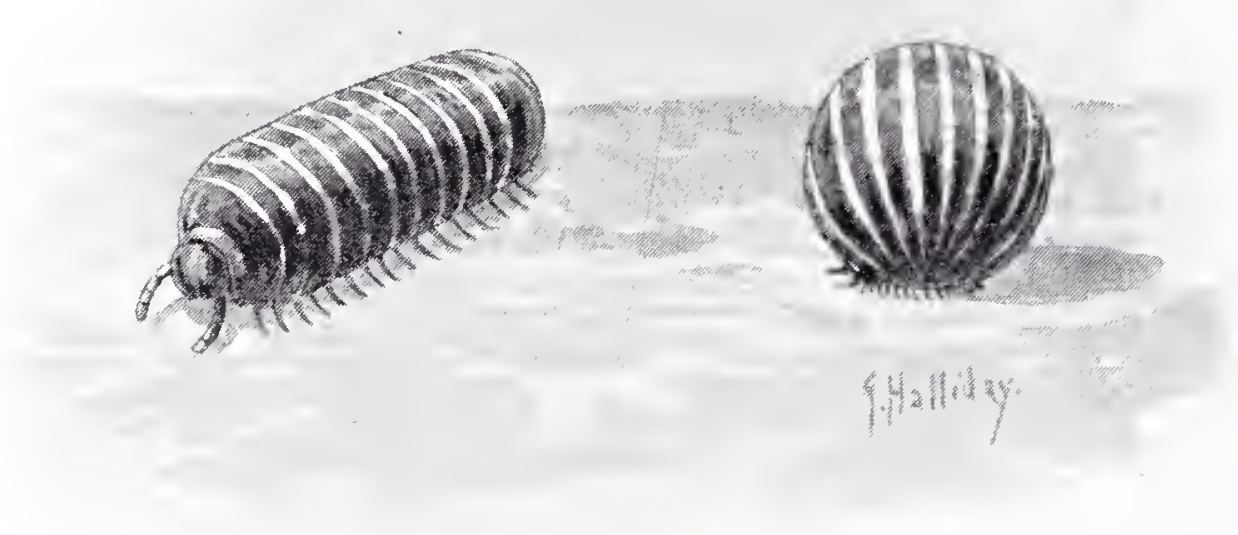

Pill Miliepedes.

But they only have two pairs of jaws instead of four, and they are nearly all vegetable feeders. Some of them are common in Great Britain, such as the Pill Millepede, which can roll itself up into a ball, and the long and slender Julus Millepedes, which are plentiful in every garden. And in tropical countries they sometimes grow to a length of six inches. Even the largest, however, are perfectly harmless, for they have no poison fangs as the centipedes have, and the only way in which they ever attempt to defend themselves is by pouring out a small drop or two of a fluid which smells rather nasty, and no doubt protects them from the attacks of birds. 


\section{CHAPTER XXXV.}

\section{CRUSTACEANS.}

WE now come to a very important class of animals, which includes the crabs, the lobsters, the shrimps, and the prawns. These creatures are often called "shell-fish." But that is a very bad name indeed to give them, for, of course, they are not fishes. And, not only that, they have no shells.

But surely crabs and lobsters have shells?

No. What we call the "shell" of a crab is not really a shell at all. It is not in the least like the shell of an oyster, for example, or like that of a whelk, or a snail. It is only a sort of "crust" upon the skin, made chiefly of carbonate of lime. That is why these animals are called crustaceans. And, instead of growing, like true shells, it never increases in size at all.

But crabs and lobsters grow?

Yes: but they do not grow as other animals do, just a very little every day. They only grow, as a rule, once a year; and they get a whole twelve-month's growth into about a couple of days!

The way in which they do this is very odd indeed.

First of all, they hide away in some crevice among the rocks, where none of their enemies are likely to find them. This is because they are going to throw off their so-called "shells"; and they know that when these are gone they will be deprived of their natural armour, and of their weapons too, and so will be quite at the mercy even of foes much smaller than themselves.

Then a very strange thing happens. Part of their flesh actually turns to water!

Sometimes, if you take up a crab at a fishmonger's shop, and shake it, you will hear water swishing about inside it. This is a "watery" crab, and is not good to eat; for it was just about to change its "shell" when it was caught. A good deal of its flesh has actually turned to water.

Now this always happens a few days before the "shell" is thrown off; and the animal wriggles and twists about inside it, in order to loosen the attachments which bind it to its body. It also rubs its feelers against its legs, and its legs against one another, in order to loosen their hard coverings in the same way. This goes on, perhaps, for three or four days. Then, suddenly, the "shell" splits across, and the animal, with a tremendous effort, springs right out of it, while the "shell" closes up again, and looks just as it did before. One might really think that there were two crabs instead of only one. 
For some little time the animal now lies perfectly still. It is exhausted by its efforts, and its muscles are so cramped that they feel quite hard to the touch. This cramp soon passes off, however; and then at once the animal begins to grow. It grows very fast. Indeed, you can almost see it grow, for a whole year's increase in size has to talie place in about thirty-six hours. Then a fresh "crust" is gradually formed upon the skin, and two or three days later the animal is once more clad in a coat of mail, and is ready to leave its retreat and face its enemies. For a whole twelvemonth after this it grows no bigger. But at the end of that time the process is repeated, and so on, year after year, until at last the animal reaches its full size.

The bodies of the crustacean animals are made up of a number of rings or "segments," like those of the insects. But there are always twenty of these rings, instead of thirteen; six forming the head, while there are eight in the thorax and six in the hind-body.

Then-again lilie the insects-crustaceans have feelers, or "antennæ," upon their heads. You can see these very well indeed in a lobster or a shrimp. But instead of having one pair of these organs, as insects have, they always possess two pairs. And it is rather curious to find that at the base of the front pair there are two little organs which seem to be ears, specially formed for hearing in the water, while at the base of the second pair are two other little organs which seem to serve as a nose, specially made for smelling in the water.

And-once more like the insects-crustaceans have to pass through several different forms before they reach the perfect state. They are hatched in the first place from eggs, which the mother animal carries about with her for some little time firmly fastened to the hairs of the "swimmerets," which we find underneath the hinder part of her body. You will often find a shrimp with quite a large bunch of these eggs; and if you look at them carefully with a good strong magnifying glass, you will see that they are all glued down to hairs.

Inside each of these eggs an odd little creature is formed, which is called the Nauplius. Sometimes it is hatched while still in that state, and swims about through the water. But in almost all the higher crustaceans a change takes place before it leaves the egg, and it appears at last in the form of a Zoaa.

This is a lind of crustacean caterpillar, and a very odd little creature it is. A great naturalist once described it as an animal "with goggle eyes, a hawk's beak, a scorpion's tail, a rhinoceros' horn, and a body fringed with legs, yet hardly bigger than a grain of sand!" Certainly it does not look in the least like the crab, or lobster, or shrimp into which it is going, by and by, to turn. And it swims in the oddest way possible, by turning endless somersaults in the water! 
These zoxas are sometimes found in immense shoals, the surface water of the sea being quite thick with them for miles. And they are useful little creatures, for they feed on the tiny scraps of decaying matter which are always floating about in the sea, just as tadpoles and gnat-grubs do in ponds, thus helping to lieep the water pure. But a very great number of them are devoured by whales. For when whale-bone whales are hungry, they swim with open mouths through a shoal of these little creatures, and then strain them out of the water by means of the whalebone fringe which hangs down from the upper jaw.

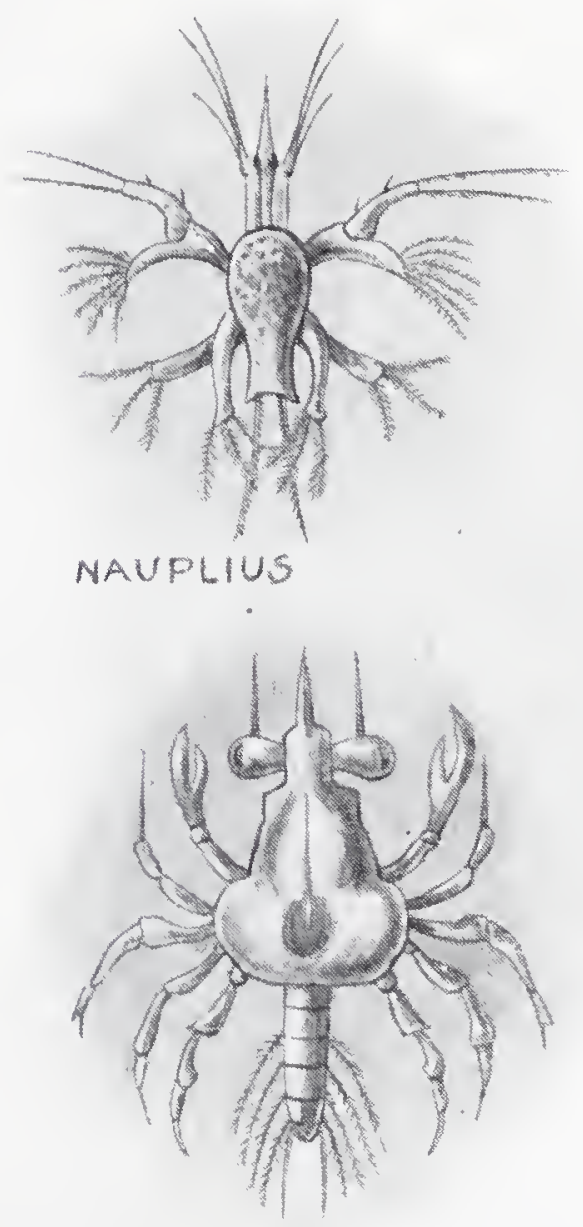

MEGALOPA

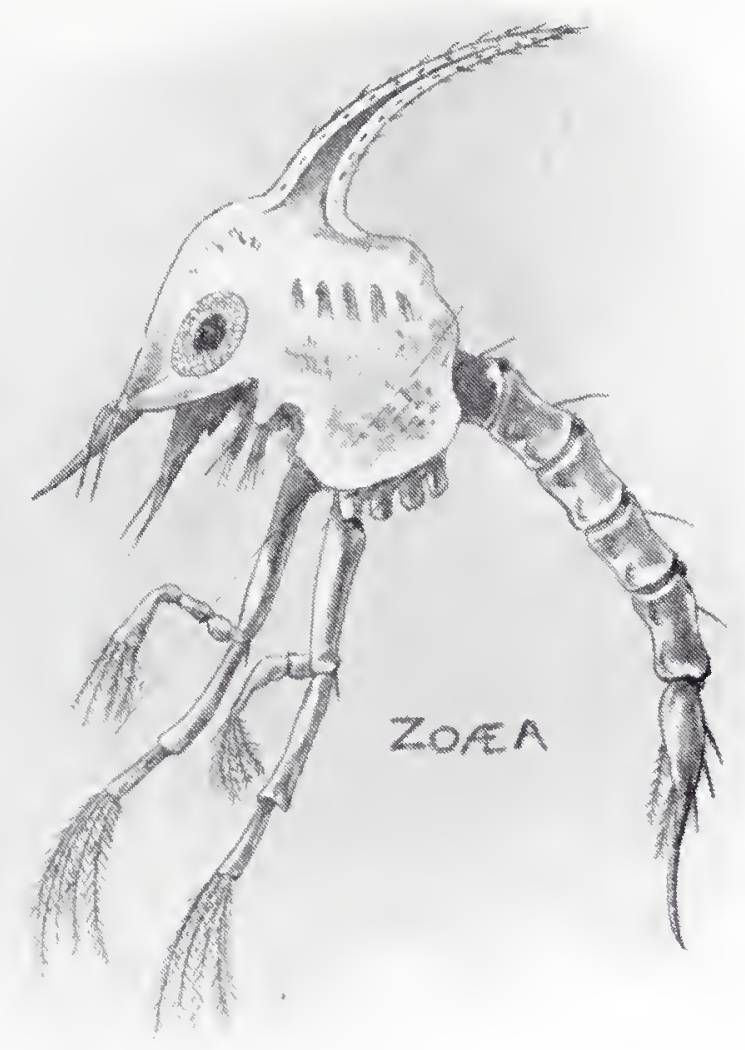

MEGALOPA. \%OLA

After a time the zowa throws oft its skin and appears in quite a different form. It is now called a Megalopa, or "big-eyed creature," because it has very large eyes indeed, which are generally set on foot-stalks, and project to quite a long distance from the sides of the head. And as the zoxa is a kind of crustacean caterpillar, so the Megalopa is a lind of crustacean chrysalis. It generally has a long, slender body, made up of several joints. And it swims by flapping this to and fro in the water.

First among the crustaceans come the CraBs, of which there are a great many different kinds. They are distinguished 
by having the tail tucked under the body, and firmly soldered, so to speak, to the "shell" on either side.

You can find several kinds of these creatures by hunting among the rocks on the sea-shore when the tide is out. There is the Common Shore Crab, for example, which is green in colour. It is generally to be found hiding under masses of growing seaweed. But sometimes you may see it prowling about in search of prey. It is wonderfully active, and will even pounce upon the sandhoppers as they go skipping about, just as a hunting spider will pounce upon flies, seldom or never missing its aim. It will catch flies, too, leaping upon them when they settle, and shutting them up, as it were, in a kind of cage formed by its legs. Then it pokes one claw carefully into this cage, seizes the prisoners, pulls them to pieces, and pokes the fragments into its mouth.

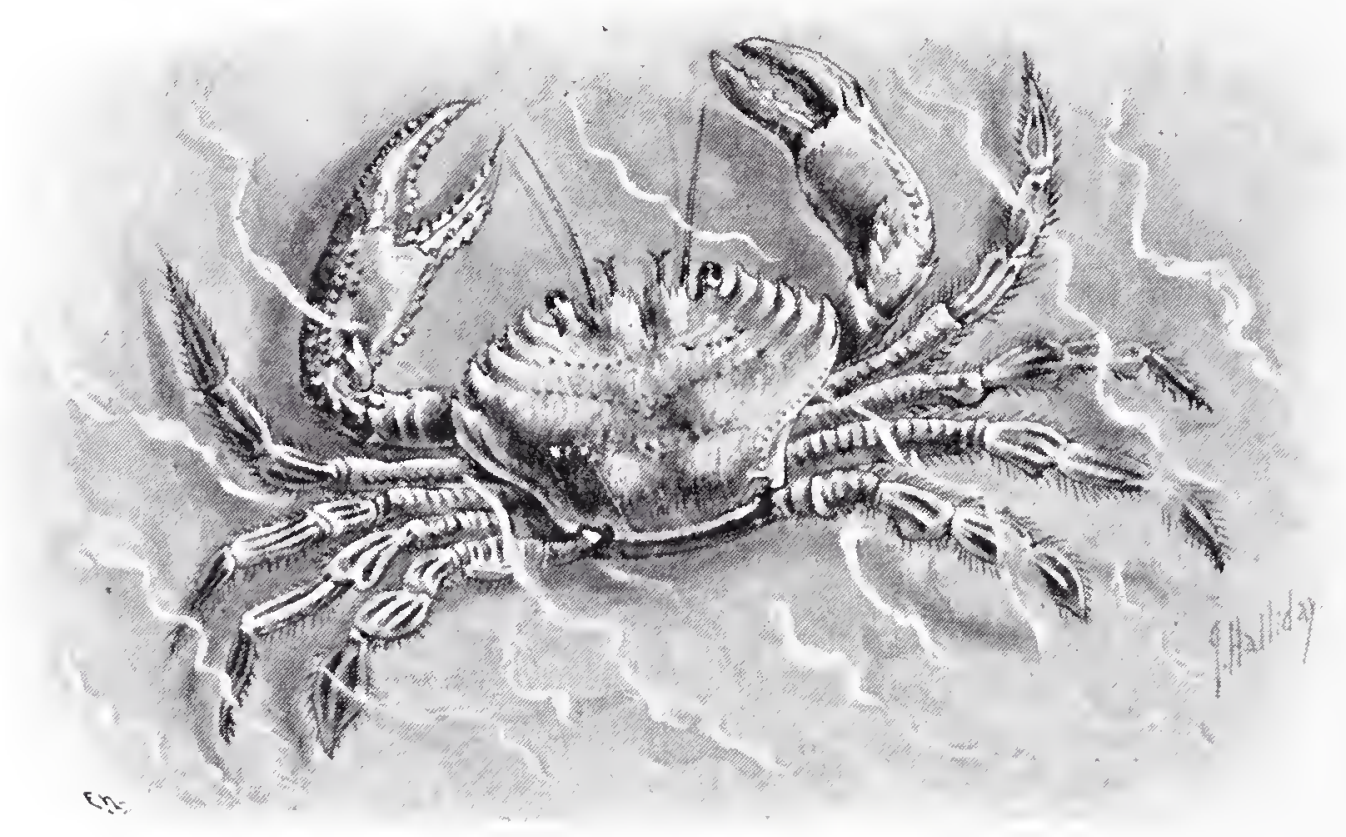

FIDDLER CRAl.

Swimming about in the pools, too, you may often find a Fiddeer $C_{\text {Rab }}$, which is so called because its movements in the water rather remind one of a man who is playing the violin. You will find that its hinder legs are very much flattened, and are fringed with stiff hairs, so that they may be used as oars. In fact, the animal rows itself through the water. Both these crabs, sad to say, are cannibals, and are always ready to attack and devour their own kind.

Then there is the EDIBLE $\mathrm{C}_{R A B}$, which is common on many parts of our coasts. You are not likely to meet with the larger examples, which live in deeper water. But even the smaller ones can give a very sharp nip with their great claws, and you will find it as well to be very careful in handling them. The best plan is to seize them with the thumb and finger just behind these claws, when they are perfectly harmless. The larger crabs, which 
sometimes weigh as much as twelve pounds, are extremely powerful, and in more than one case a man has been killed by them, having been seized by the wrist as he was groping among the rocks, and held in a grip from which he could not break away until he was drowned by the rising tide.

These crabs are captured by means of "crab-pots," made of basket-work, which have the entrance so formed that while the crabs can easily enter, they cannot possibly get out again. These pots are baited with pieces of fresh fish, and are then weighted with stones, and lowered to the bottom of the sea among the rocks, at a depth of from three to about twenty fathoms.

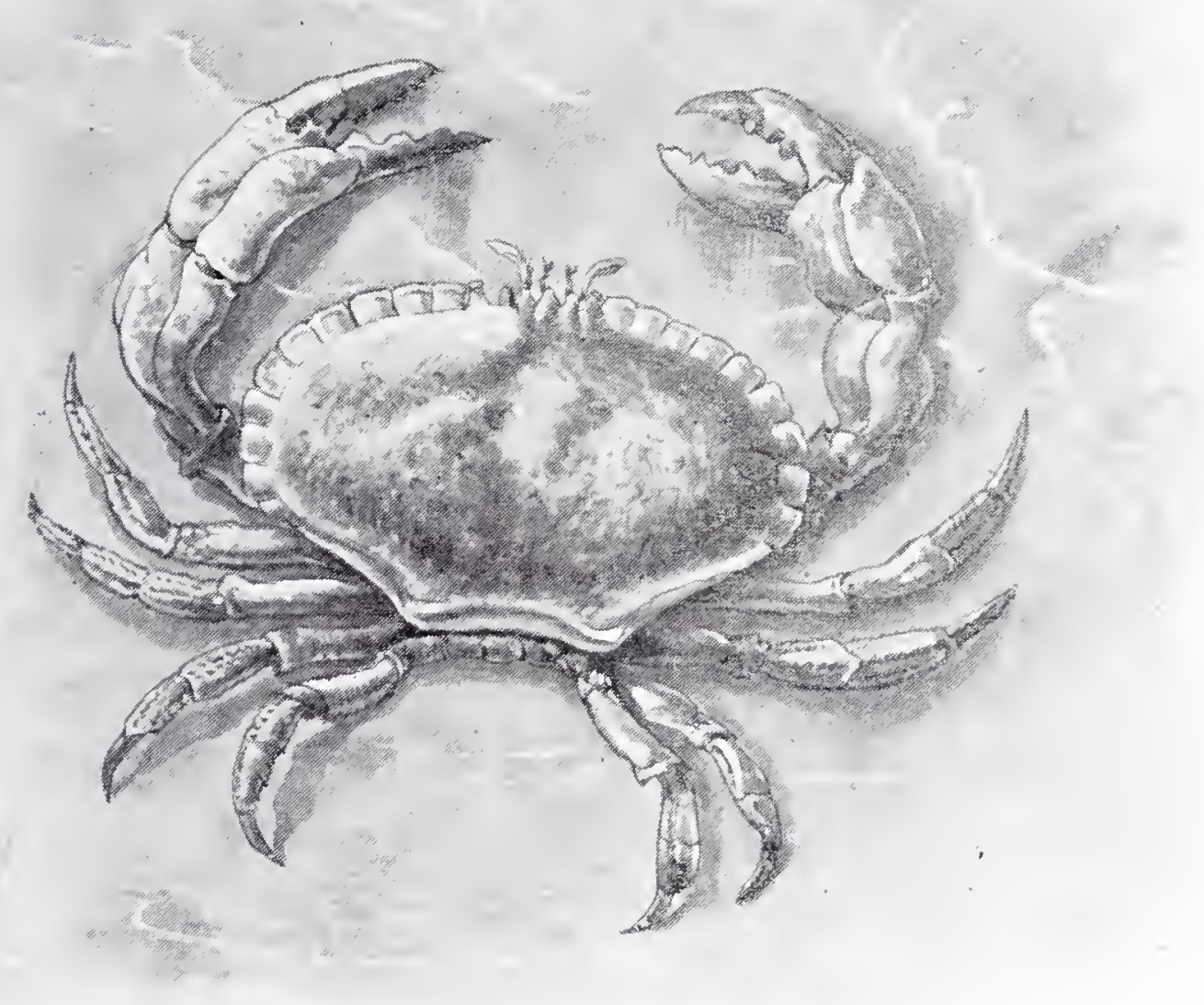

EITRLE CRAJ?

Some crabs live on dry land, sometimes at a distance of two or three miles from the sea, which they only visit at intervals. Among these are the famous Calling CRABS, which are found in many of the warmer parts of the world.

These crabs obtain their name from the fact that "one, of the great claws of the male is always very much larger than the other. So big is it, indeed, that it has to be held aloft over the body when the animal is running, in order to prevent it from losing its balance and toppling over. And as soon as the crab begins to move this huge claw is jerked up and down, just as if 
the creature were "calling," or beckoning, to its companions. The calling crabs live in burrows in the sand, which are often placed as close to one another as those in a rabbit-warren.

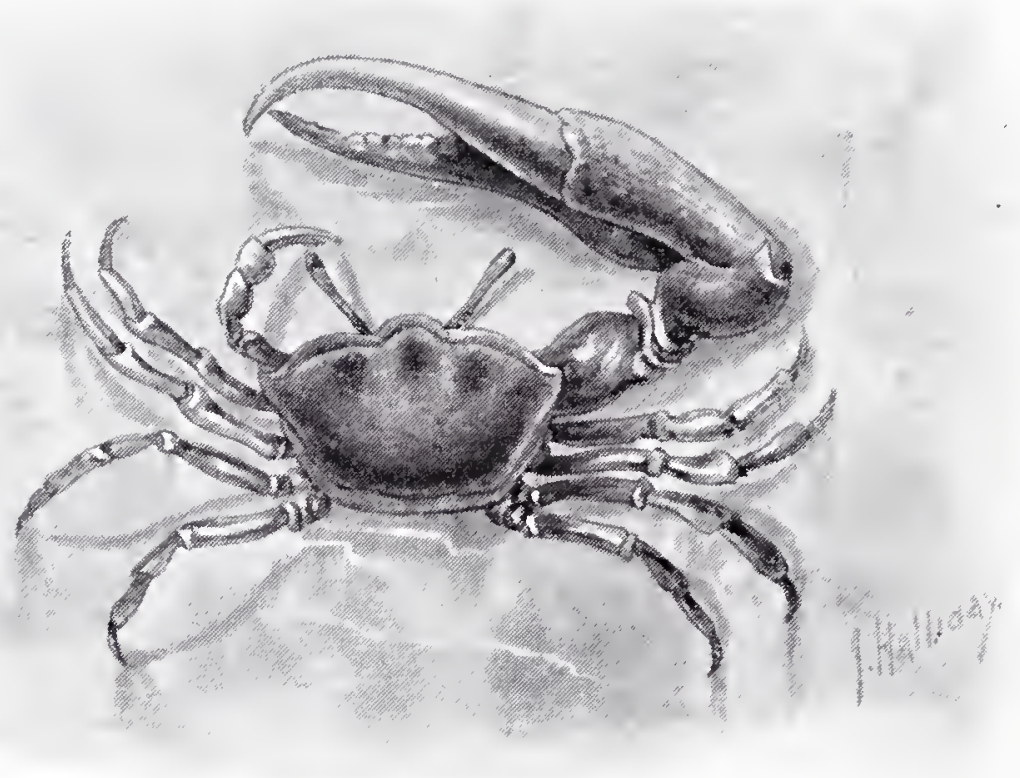

CALLING C'RAI.

Next we come to those very curious creatures which are known as Hermit Crabs.

They are not true crabs, however, but form a kind of connecting link between the crabs and the lobsters. For their

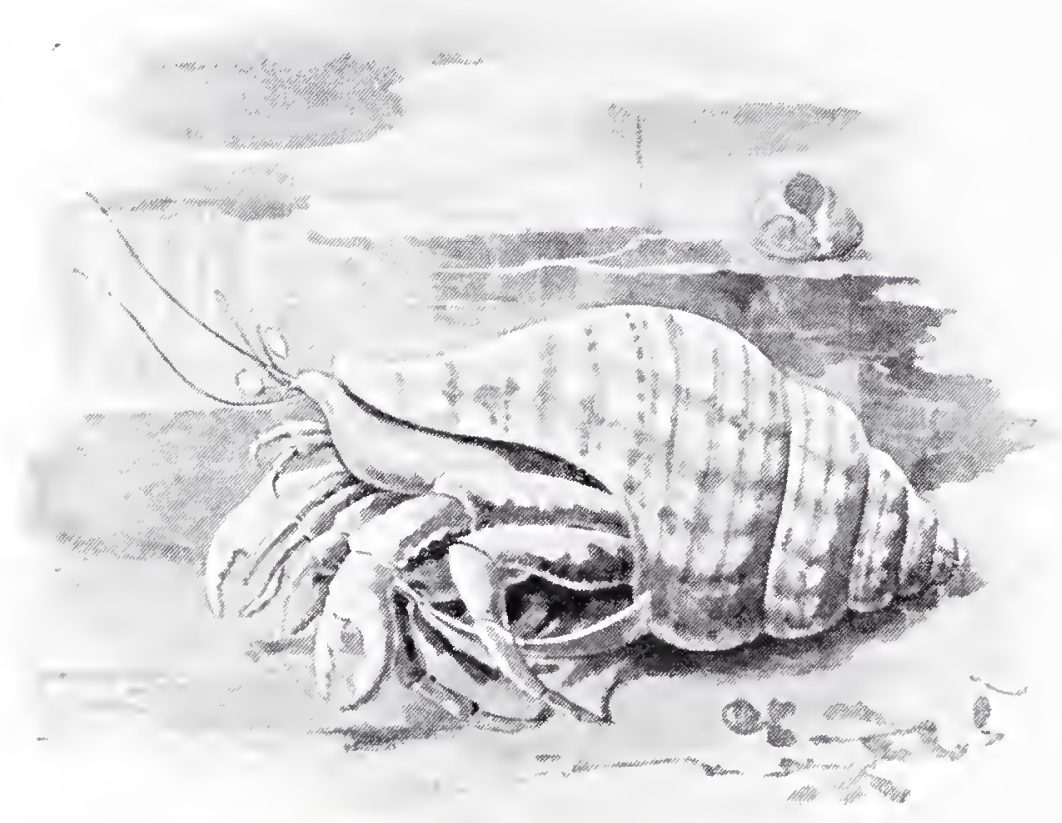

HERIIT C'RAB.

tails, instead of being firmly soldered down underneath their bodies, are quite free.

But the odd thing about these animals is that their tails 
have no shelly covering. The front part of the body is protected by a coat of mail, just as it is in all the other crabs; but the hinder part is quite bare and soft. The consequence is that a hermit crab is always very nervous indeed about his tail. He is dreadfully afraid that one of his many enemies may creep up behind, and bite it when he is not looking. So he always tuclis it away in an empty whelk-shell, which he drags about with him wherever he goes!

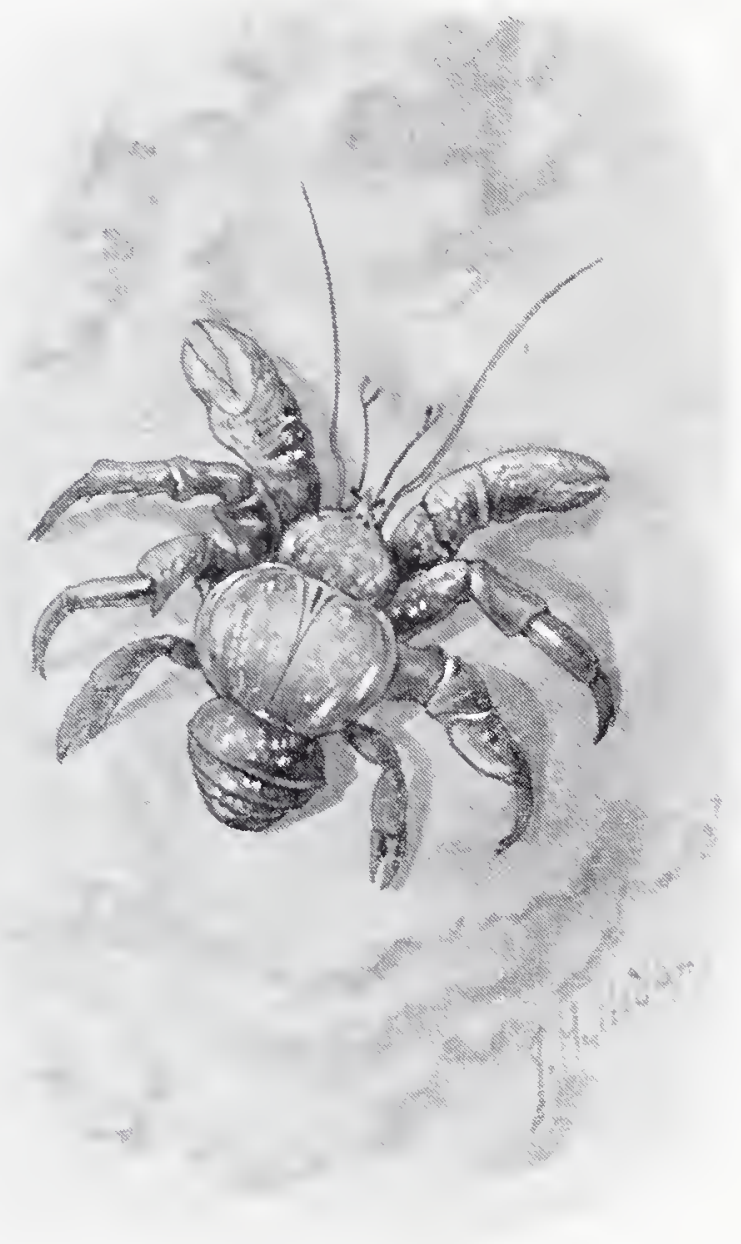

ROPBER CRII:

You may often find these curious crabs by hunting for them in the pools among the rocks at low water. The crab always sits just inside the entrance of the shell, which he guards with one of his great claws. And if you try to pull him out, you will find that you are quite unable to do so. For he has a pair of strong pincers at the end of his body, by which he holds the shell so firmly that you can tear him in two with. out forcing him to loose his grip.

Sometimes you will find that a sea anemone has fastened itself to the edge of a shell in which a hermit crab is living. This is a great advantage to the crab; for while there are many fishes which would be quite ready to crunch him up, shell and all, no fish will ever meddle with a sea anemone. So as long as the anemone remains on his shell he is perfectly safe.

And this plan is also a great advantage to the anemone, which is sure to get plenty of food without any trouble. For when the crab finds the dead body of some small creature, and begins to pull it to pieces, a quantity of small fragments are sure to float upwards in the water. And the anemone catches them with its spreading tentacles and feeds upon them.

One of the most curious of all these creatures is the RoBBER CRAB, which is found in many of the islands in the Indian Ocean. It is like the hermit crabs in some ways, but the tail is covered with shelly plates, just like the rest of the body. And instead of living in shells in the sea, it lives in deep burrows on dry land.

But the oddest thing of all with regard to this crab is its food. What do you think it feeds upon? You would never guess, so I must tell you. Cocoa-nuts! That seems impossible, doesn't 
it? One would imagine that the crab could never get the nuts open. But it manages in this way. First of all, it pulls away the fibres from that end of the nut at which the three eye-holes are situated. With one of its stout claws it then hammers away at one of these till it breaks its way through. And finally, after allowing the milk to run away, it poles its: hinder claws, which are very slender indeed, through the opening, and picks out the white fleshy part of the nut a little piece at a time.

It is said, too, that this crab sometimes opens a nut by poking the smaller joint of one of its claws into the hole, and then striking it over and over again upon a big stone.

The burrow of the robber crab is rather a deep one, and is nearly always situated beneath the roots of a tree. And at the

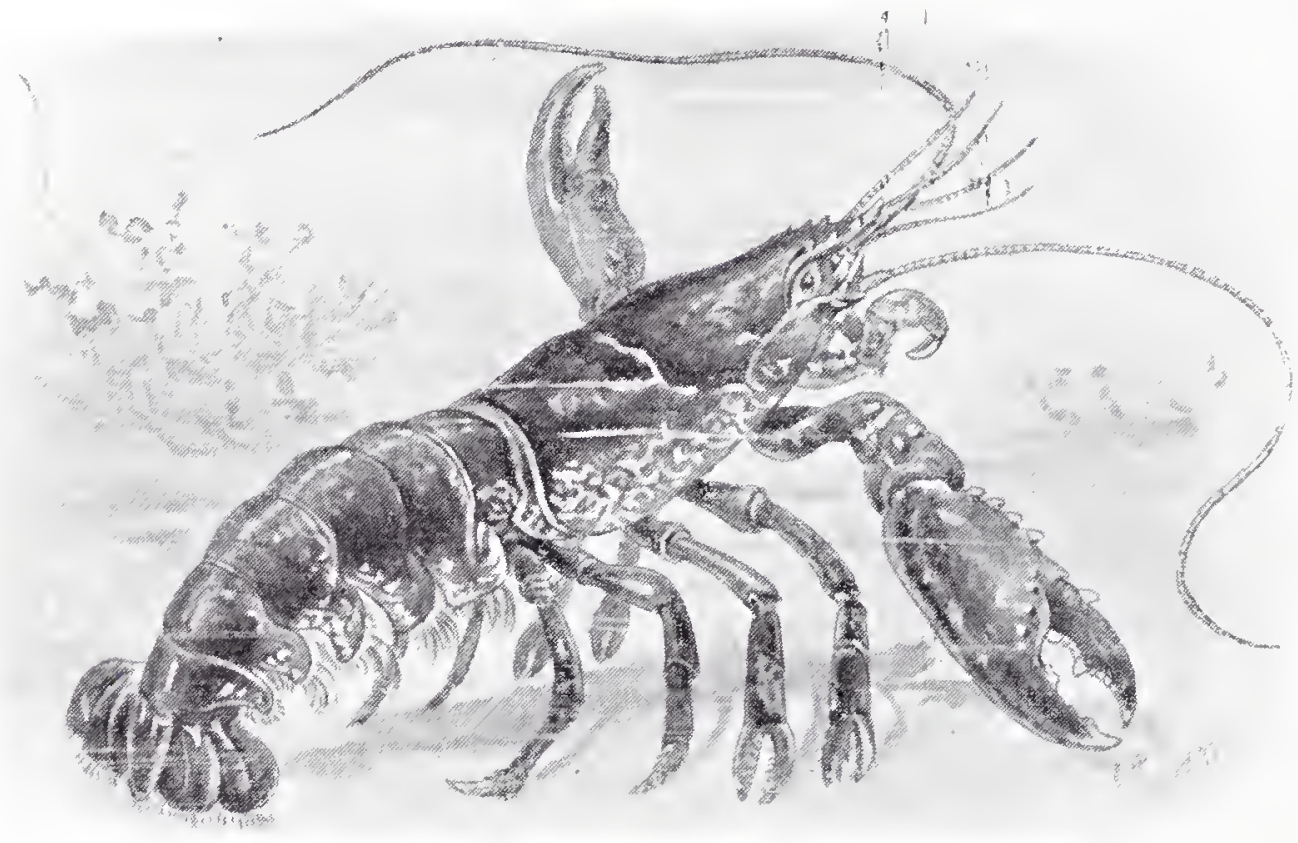

J.OHSTER.

end of the burrow is a large chamber, in which the crab piles up a quantity of cocoa-nut fibre to serve as a bed.

Of course, you know the LoBster very well by sight; and of course you know that until it is boiled it is black, not red. But I wonder if you know how it swims.

Well, the fact is that it has two different ways of swimming. When it is not in a hurry it sivims slowly forwards, by means of its swimmerets, of which it has five pairs underneath the hinder part of its body. But if it is startled or alarmed it swims swiftly backwards by means of its tail.

If you look at a lobster's tail, you will see that it is very broad and flat, and that on either side of it are two plates, which are quite as flat, and, if anything, are rather broader. So, when these are spread, the tail looks like a fan. And the animal swims by first stretching out its body almost straight, and then doubling it suddenly with all its force. As it does so, the tail and the tail- 
plates spread out, and act very much like a broad oar. And the result is that the lobster darts swiftly backwards through the water. Shrimps and prawns swim in exactly the same way.

Lobsters are very quarrelsome creatures, and are constantly fighting; and it very often happens that in these battles they pull off one another's limbs. They seem to feel very little pain, however, from such an injury, and before very long néw legs begin to grow in place of the old ones, so that in course of time the wounded creatures are just as perfect as ever.

Sometimes lobsters will throw off their limbs when they are not attacked at all. They do so, for example, if they are suddenly frightened; and it is said that if a heavy gun is fired near the surface of the water, every lobster for a long way round will shed its great claws in alarm. It seems rather a silly thing to do, doesn't it, as these claws are the only weapons which these creatures possess?

You will notice, on looking at a lobster, that one of the great claws is a good deal smaller than the other; and sometimes people think that this is a new claw which is growing in place of one that has been lost, and that it has not yet reached its full size. This, however, is a mistake, for one of the claws is always much bigger than the other; and the reason is that they are used for different purposes. The larger claw is intended as a weapon, and with this the lobster fights. But the

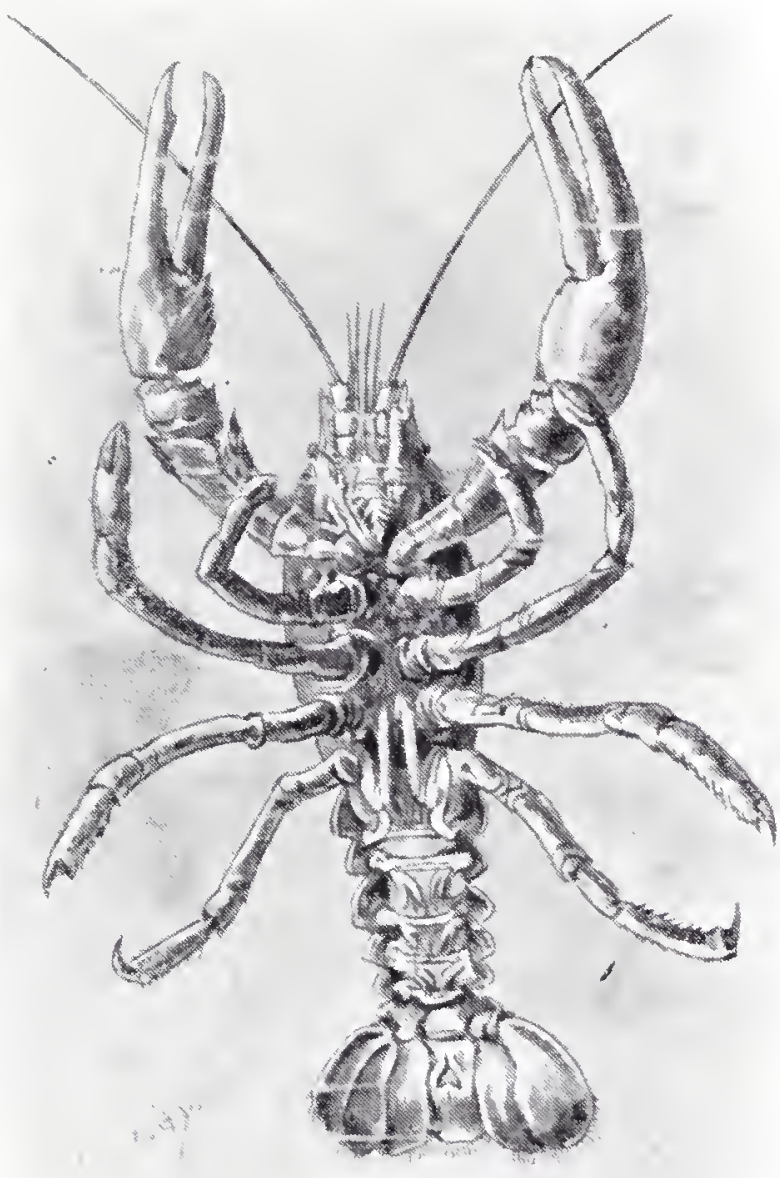
smaller one is chiefly employed as a kind of anchor, by means of which the animal can cling to the weeds or rocks at the bottom of the sea. Lobsters are caught in "pots" made of basket-work, just as crabs are. But they are not nearly so dainty as crabs, and do not mind if the bait is fresh or putrid. They are always very much attracted, too, by any object that glitters, and many a lobster has been lured to its death merely by one or two oyster shells hung up inside the pot in such a manner as to show the shining pearly interior.

The CRAYFish is a kind of fresh-water lobster, and is found commonly in many English streams. But you would never see it 
unless you went specially to look for it, because all day long it hicles under the projecting edges of big stones, or in holes in the bank, only coming out after nightfall to search for food. It is particularly fond of the deserted burrow of a water-vole, and as it sits inside it always guards the entrance with its great claws, striking fiercely at any enemy which may be bold enough to come within reach.

Crayfish are very good to eat, for their flesh is quite as (lelicate as that of the lobster, and is a good deal more tender. They are generally caught by means of a shallow bag-like net fastened inside an iron ring. The bait is fixed to the middle of the net, which is then lowered to the bottom of the stream, and when it is pulled up again, about half an hour later, two or three crayfishes are nearly always to be found inside it.

Shrimps and Prawns are really only tiny lobsters, and if you examine them cartully you will find that their bodies are made in exactly the same way. They swim, too, by means of their tails, and dart about so swiftly that it is almost impossible to follow their movements. You may often find them in numbers in the pools which are left among the rocks by the retreating tide. But as they are almost colourless until they are boiled, it is very difficult indeed to see them, and they look just like shadows larting to and fro in the water.

You can easily tell a prawn from a shrimp, for the "beak" which projects in front of its head is covered with sharp points, which are almost exactly like the teeth of a saw. It is one of "Nature's Dustmen," of which we have heard several times already, for it feeds upon the bodies of the various small creatures which die by millions every day. In this way it helps to keep the water of the sea pure. It feeds in a curious way, tearing off tiny scraps of flesh with the little pincers at the tips of the second pair of legs, and poling them into its mouth one after another. 'The sides of these limbs are covered with hairs, so that they form little brushes; and with these the prawn carefully cleans its body and limbs, rubbing off every little speck of dirt which may happen to cling to them.

SAND-HOPpers, of course, you know quite well by sight; for you can hardly walk along a sandy shore when the tide is rising without seeing them leaping and twisting about in thousands. If you turn over a bunch of sea-weed, too, which has been flung up by the waves just above high-water mark, you are almost sure to find forty or fifty of these odd little creatures hiding underneath it. In some ways they are rather like shrimps. But they differ from them in having their eyes set on the head itself, instead of on little foot-stalks projecting from it. And they have no "carapace," or shelly shield, covering the middle part of the body.

How do these creatures hop?

Why, by first doubling up their bodies, and then straightening them out again with a kind of jerk. It is exactly opposite, in fact, to the way in which shrimps and lobsters swim. 
Sand-hoppers do not follow the retreating tide, but bury themselves in the sand very soon after the waves have ceased to break over them. Even when the surface of the sand is quite dry you can find their burrows by stamping with your foot, when a number of little round holes will suddenly open all round you.

These creatures have wonderfully sharp little teeth, and if you allowed a swarm of them to rest for a little while on your handkerchief, you would most likely find that it was full of tiny holes when you took it up. They will eat almost anything, either animal or vegetable, and are quite as useful as the shrimps and prawns in helping to keep the sea-water pure. But they have a great many enemies, for sea birds, land birds, crabs, and all sorts of other creatures, destroy them literally in millions.

Very much like the sand-hopper, in some ways, is the Fresh-

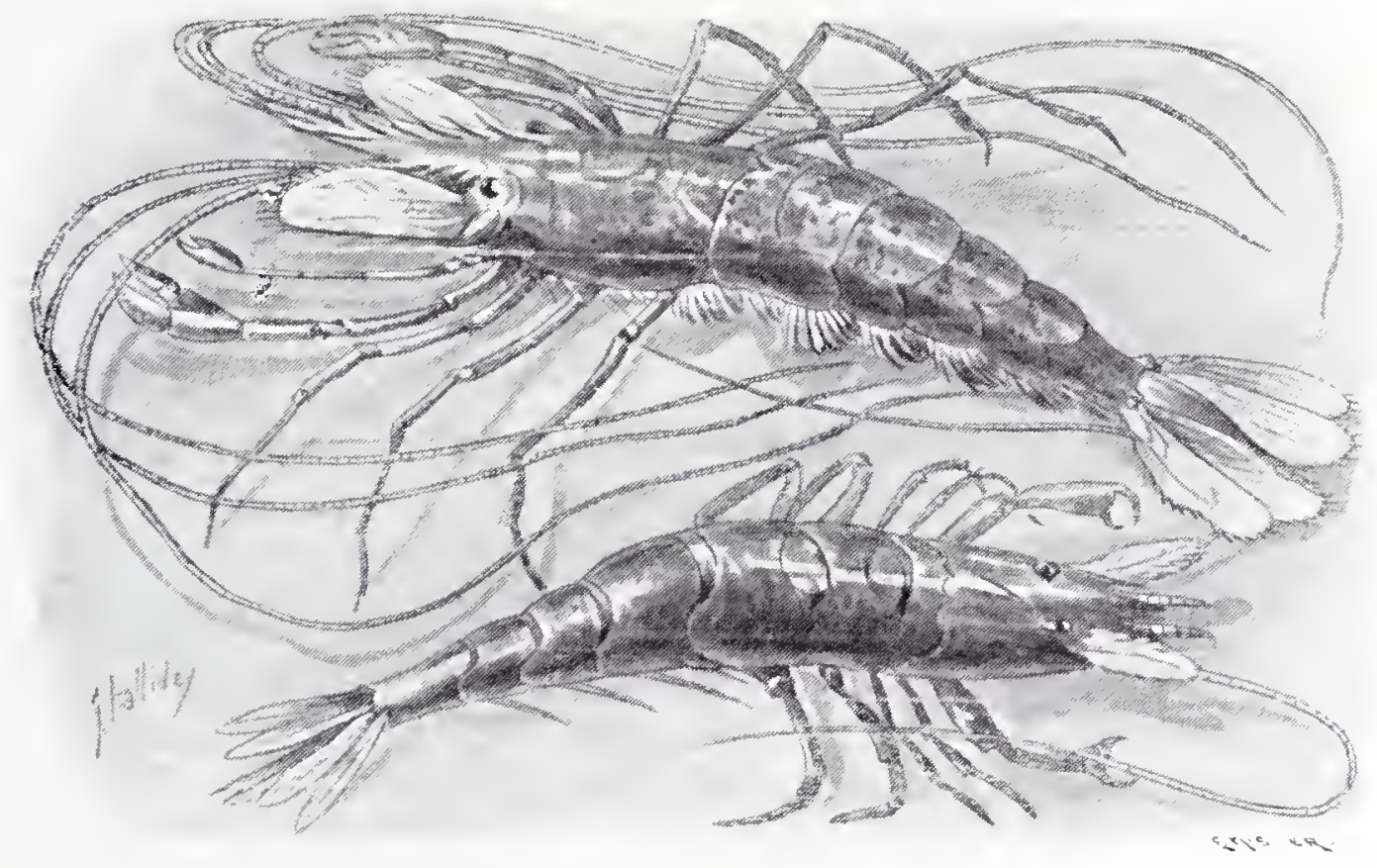

PRAWN.

SHRIMP.

WATER Shrinp, which you may find in numbers in almost any small stream and rivulet. It hides under stones, or in little crevices in the bank, darting out now and then to seize one of the tiny creatures upon which it feeds, and then hurrying back with it to its retreat. When it is in the water it travels along by a series of jerks; sometimes swimming with its back uppermost, and sometimes on one side. But if it is placed on dry ground it is perfectly helpless, for its legs are not nearly strong enough to carry it, and the only result of its struggles is to turn it round and round in a screw-like manner without forcing it forward at all.

The odd little creatures which we call Woodice are really crustaceans, although they belong to quite a different group from that about which we have just been reading.

Of course, you know these creatures very well indeed by 
sight, for they simply swarm in all damp places. Under logs, in heaps of decaying leaves, and under the bark of dead trees, they are always extremely plentiful, and you may also find them in hundreds in cellars and outhouses. There are several different kinds, one of which rolls itself up into a ball when it is touched or alarmed. This is called the Pili. Woodlouse, or Pili. Armadilio. And another, which is very much larger, is found under large stones on the coast, or on the banks of tidal rivers, and is generally called the SEA SLATER. It is remarkable for the fact that the mother carries her little ones about with her in a pouch underneath her body for some little time after they are born.

You would hardly think that BARNACLES were crustaceans, would you? Yet they are; though certainly they are very unlike any of those about which we have been

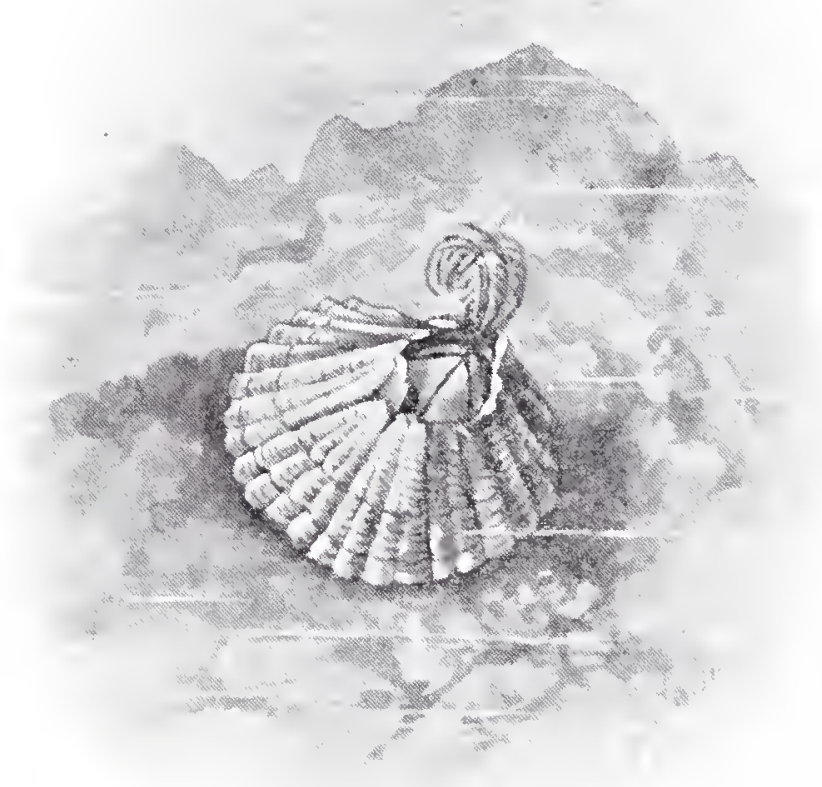

ACORN BARNACLE. reading. You can find them in countless thousands upon the rocks which are left bare by the tide at low water, and very often the hulls of ships are so covered with them that the vessels have to be taken into dry dock and thoroughly cleaned before they are fit to start upon a voyage.

These animals fasten themselves down to their hold by a liind of foot-stalk, which is firmly attached by a very strong cement. The upper part of the body is covered with a shell, consisting of several pieces, or valves; and between these, six odd little limbs can be polied out at will. These limbs are very hairy, and are always waving about, so as to sweep into the mouth any tiny scraps of food which may be floating in the water.

There are a great many linds of barnacles, some of which look very much like acorns, and grow to a considerable size. These are known as ACORN BARnacles. And there is another, shaped rather like a piece of round tube, which actually burrows into the skin of whales, in which it spends all the remainder of its life! Sometimes it bores its way down so far that it actually reaches the blubber.

The young of these strange creatures pass through several transformations, just like those of the lobster and the crab. First, there is a Nauplius, then a Zoaa, and then a Megalopa, all of which swim freely about in the water, never fastening themselves down until they are ready to pass into the perfect form. 


\section{CHAPTER XXXVI.}

SEA URCHINS, STAR-FISHES, ANI) SEA CI'CTMBERS.

NEXT in order to the crustaceans comes a group of animals which live in the sea, and which are known as Echinoderms. That is a rather dreadful name, isn't it? But if we turn it into English we can easily remember it, for it simply means "spinyslins." This group inchudes the Sea Urchins, the Star-fishes, and the Sea Cucumbers.

You can find a good many of these creatures when you go to the seaside, by hunting about on the beach at low water. In some places, for example, SEA URCHIns are very common indeed. Sometimes they are known as Sea Eggs, and in many countries

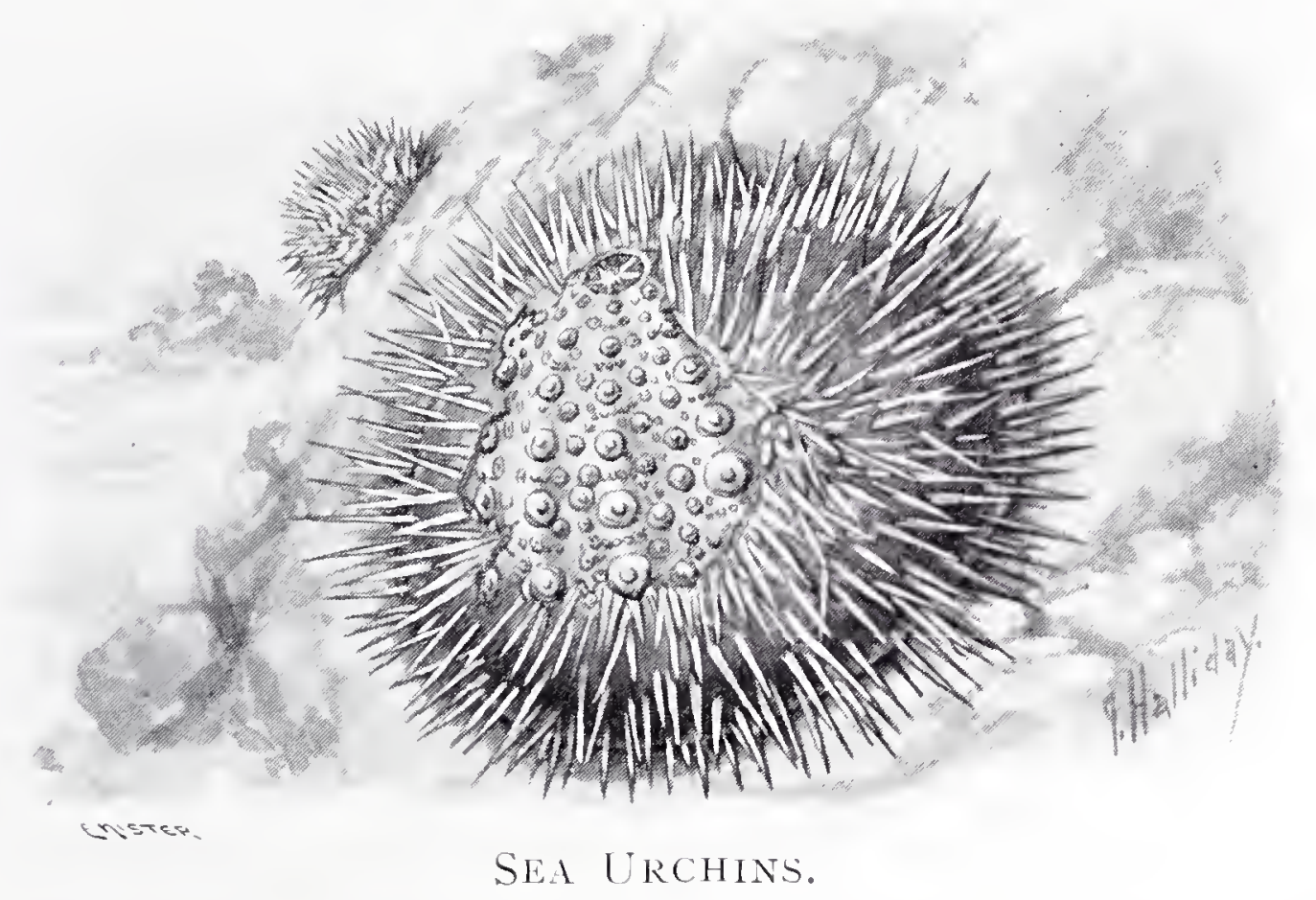

they are actually boiled and eaten as food, just as we eat the eggs of fowls and ducks. And their shells are so thickly covered with spines that they look just like little hedgehogs, which have rolled themselves up into balls.

When the animal is alive it can move these spines at will, each of them being fastened to the shell by a ball-and-socket joint, just like those which I described to you when we were reading about the vertebræ of the snakes. But after it has been dead for a few days they are nearly always knocked off by the action of the waves, so that the shell is left quite smooth and bare.

By means of these spines a sea urchin can bury itself in 
the sand at the bottom of the sea in a very short time, only just a little funnel-shaped pit being left to show where it is hiding. And in some of the larger kinds they are really formidable weapons, for they grow to a length of eight or ten inches, and are so sharp and strong that they can actually pierce the sole of a stout boot. Besides this, they have poison glands connected with them, so that they can easily inflict a really serious wound.

In the shell of a sea urchin are a number of little holes, through which the animal polies out most curious sucker-like feet when it wants to climb about over the rocks. By means of the sucliers on the upper part of the shell it often clings to small stones, which it sometimes gathers up in such numbers as to conceal itself entirely from sight.

Just inside the mouth of the urchin are five very large chisel-like teeth. These are formed just like the front teeth of the rodent animals, and grow as fast as they are worn away.

Fossil sea ur-

chins are not at all uncommon, and you may often dig them out of a chalk or limestone cliff.

More plentiful still than the sea urchins are the very singular creatures which we call STarFISHES-although, of course, they have nothing at all to do with the true fishes.

The commonest of these is the Five Finger Star-fish, which you are almost sure to meet with in the course of a ramble

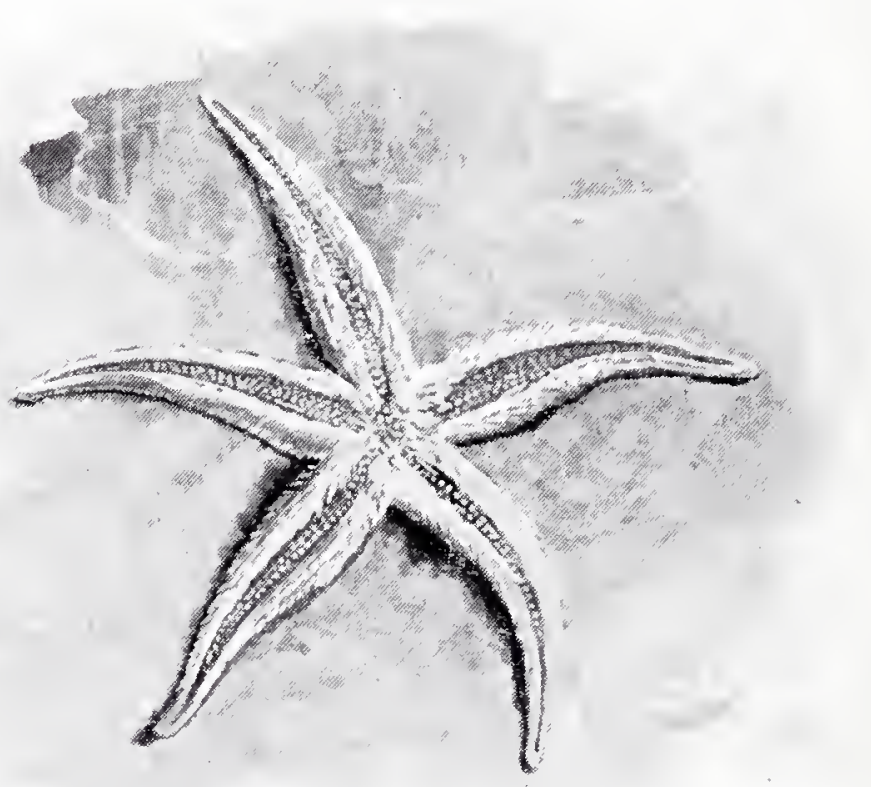
along the sea-shore. But although it is so abundant, very few people seem to know what a curious creature it is.

It has hundreds of little sucker-like feet, for example, just like those of the sea urchin. You cannot see these, as a rule, because the starfish lieeps them tucked away inside its skin. But when it wants to use them it can poke them out in a moment.

If you want to look at these odd little feet, the best way to do so is to take a live star-fish, put it at the bottom of a pool of sea water, and then wait patiently for ten minutes or a quarter of an hour. By the end of that time you are almost sure to see that the animal is slowly moving. Then snatch it out of the 
water, turn it upside down, and you will see hundreds of little white objects waving about on the lower surface of its body. These are its feet, and if you look at them through a good strong magnifying glass, you will see that they are shaped just like wine-glasses, each having a lind of fleshy cup at the end of a slender stem. And at the end of the cup is the suclier.

In the very middle of the lower part of the body of a starfish is its mouth. This is generally rather large, for the animal feeds chiefly on shell-bearing animals which it swallows whole, shells and all. Then, when it has digested the bodies of its victims, it turns their empty shells out again through its mouth. That is an odd way of feeding, isn't it? But sometimes it feeds in an odder way still, for when it finds a creature

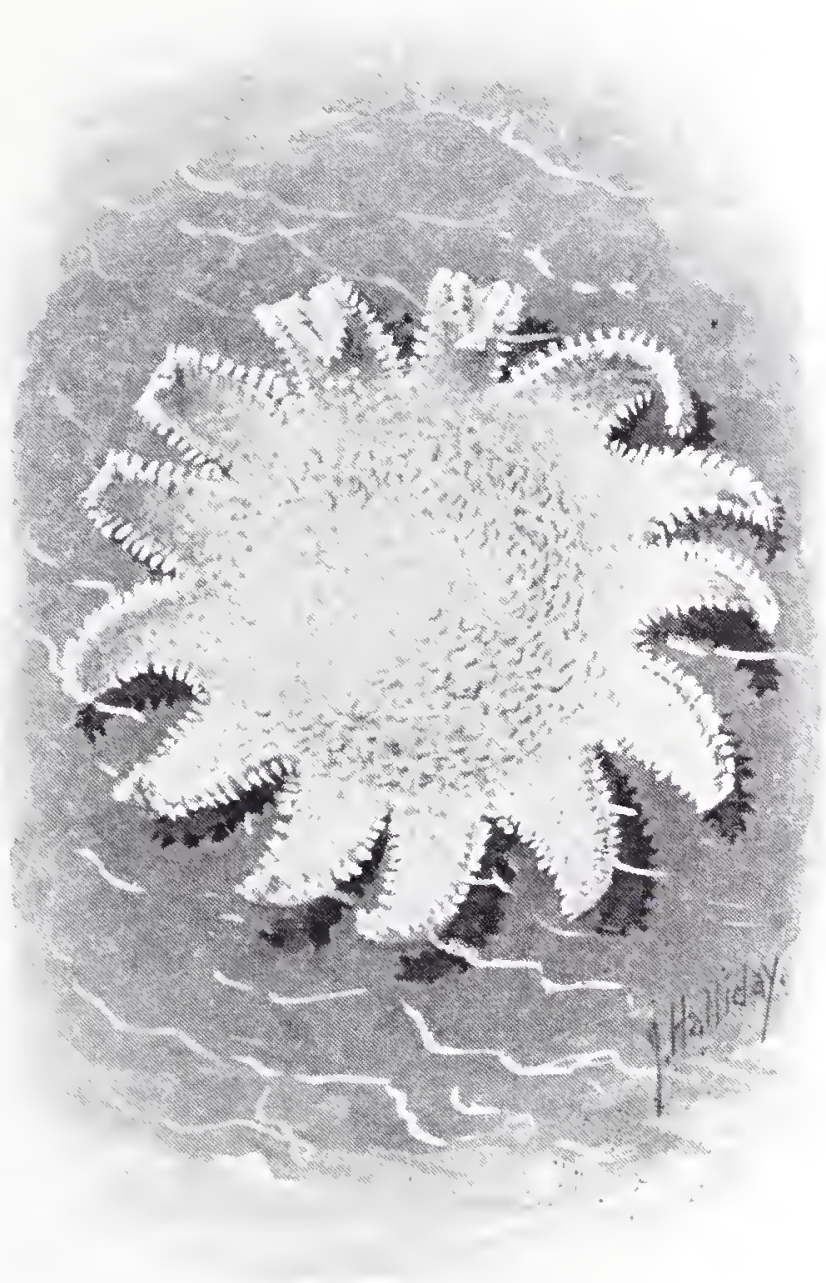

SUN STAR-HISH. which is too big to be swallowed, it will actually turn its own digestive organs out of its mouth, wrap them round its victim, hold them there until it is digested, and then swallow them again and go off to look for another victim!

Star-fishes eat a great many oysters in this way. So many do they destroy, indeed, that they are the very worst foes with which oyster fishers have to deal, and the damage done by them in one single oyster bed on the coast of North America is estimated at no less than fifty thousand dollars every year.

There are a great many different kinds of star-fishes, several of which are found on the British coasts. There is one, for example, which has twelve rays instead of five, and looks very much like a live sunflower. This is called the Sun STar, and you may often find it lying upon the sandy shore in places where the coast is rocky. Then there is another which has its five rays all joined together by webbing, very much like the toes on a duck's foot. This is known as the BIRD's FoOT STAR. It is a very handsome creature indeed, for while the greater part of its body is bright yellow, it has a broad band of crimson running all the way round the outer margin, and another stripe of the same colour down the outer edges of each ray, while the membrane between them is fringed with yellow hairs. But you are not very likely 


\section{HH A NATURAL IIISTORY OF BIRDS, FISTIES, ETC.}

to find it, for it lives in rather deep water, and is hardly ever caught except by means of that useful net which is called a "dredge."

Odder by far than any of these, however, are the BRITTLE

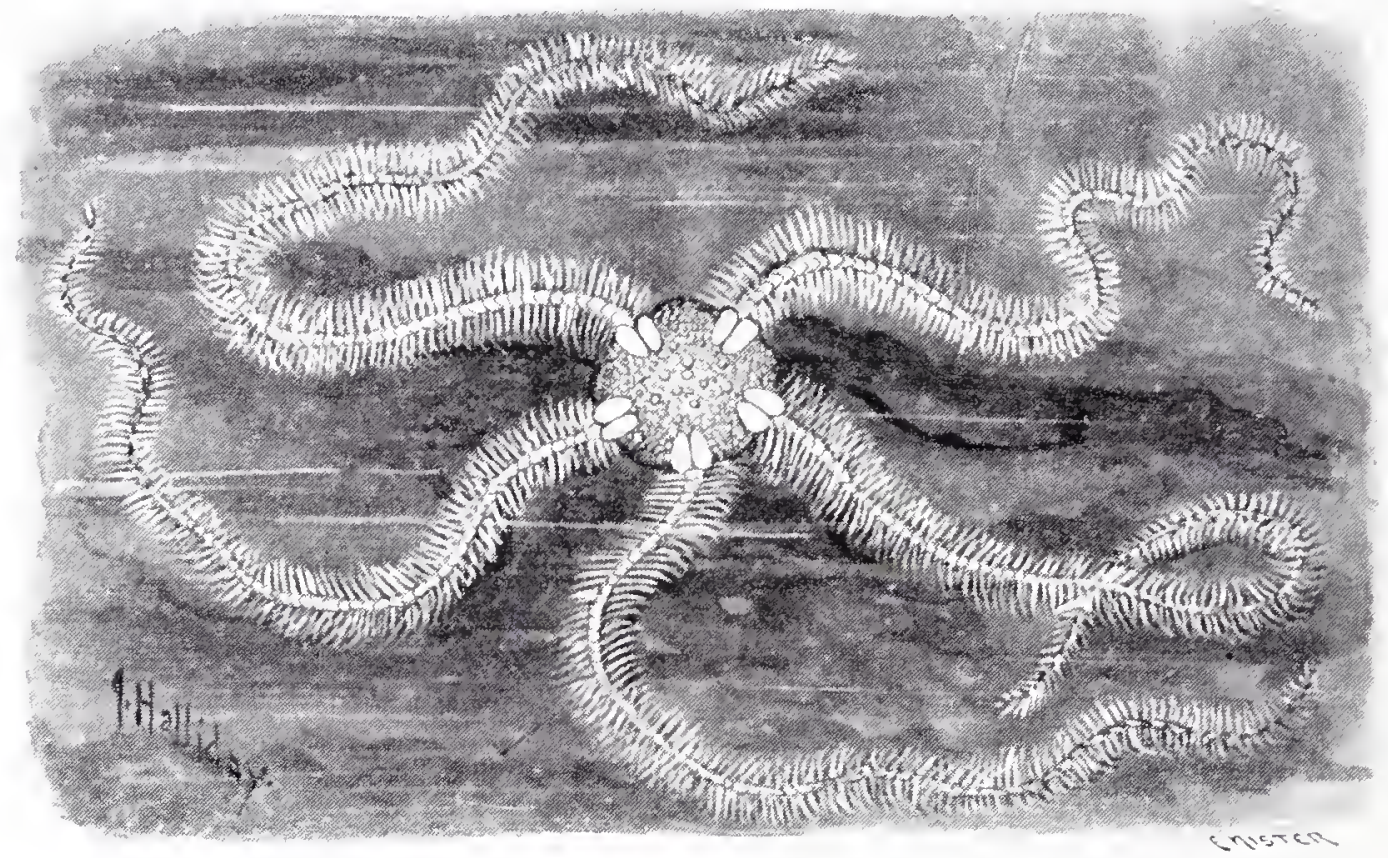

BRITTIE STAR.

STARS, which owe their name to their extraordinary habit of breaking themselves to pieces! They nearly always do this if they are touched or alarmed. In fact, they are so ready to do

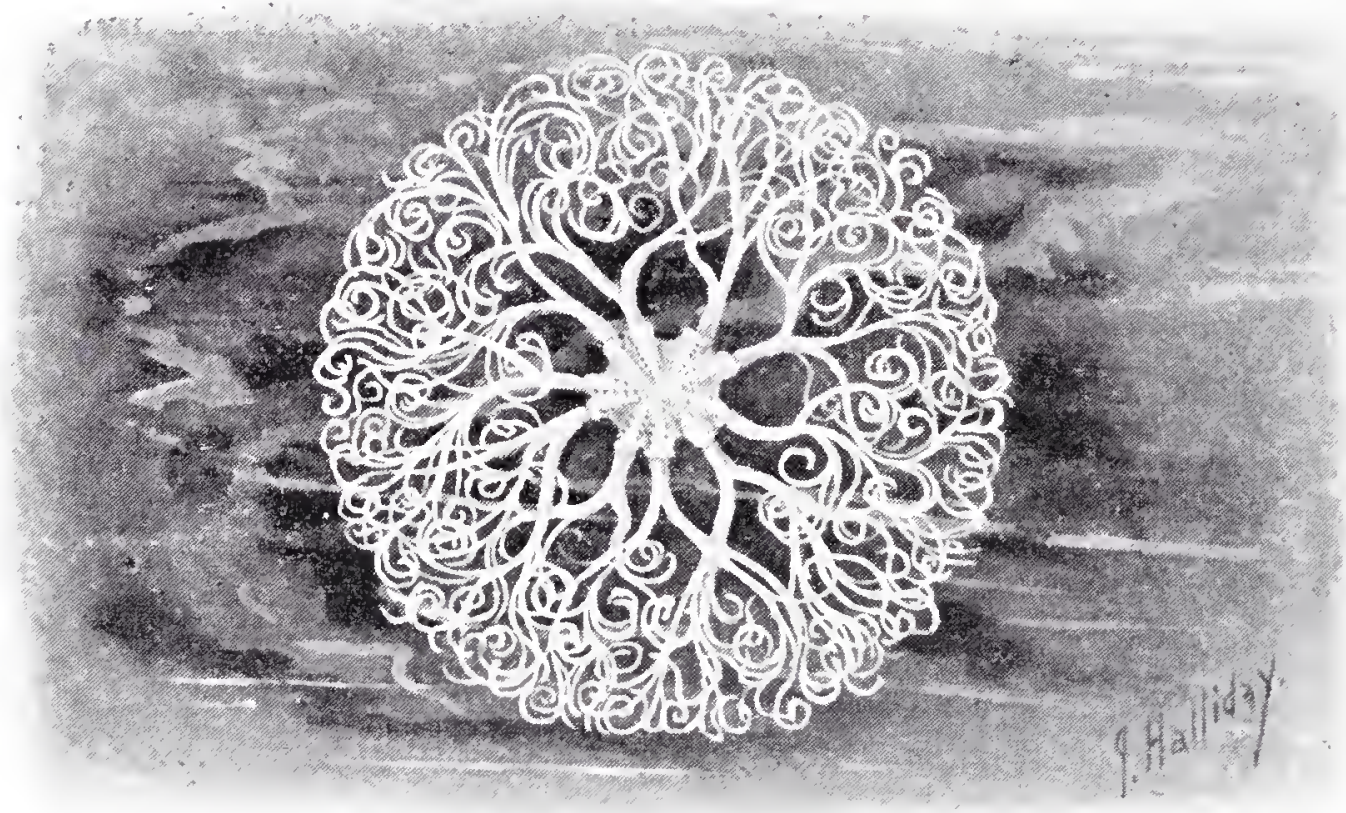

ARGUS S'TAR.

so, that it is very difficult indeed to obtain a perfect brittle star for a museum. The creature just gives a kind of shudder, and its five rays all drop off and break up into little pieces, all that is 
left of the animal being just the central disc. But it does not appear to suffer any pain, and loses hardiy any blood. And before very long new rays grow in the place of the old ones, so that in a few weels' time the star-fish is just as perfect as ever!

The brittle stars have five very long and very slender rays, which are generally fringed on either side with yellow hairs. And these rays are hardly ever still, but twist and writhe and curl about so actively that they really look almost like so many centipedes!

Very curious indeed, too, is the Argus STAR, which at first

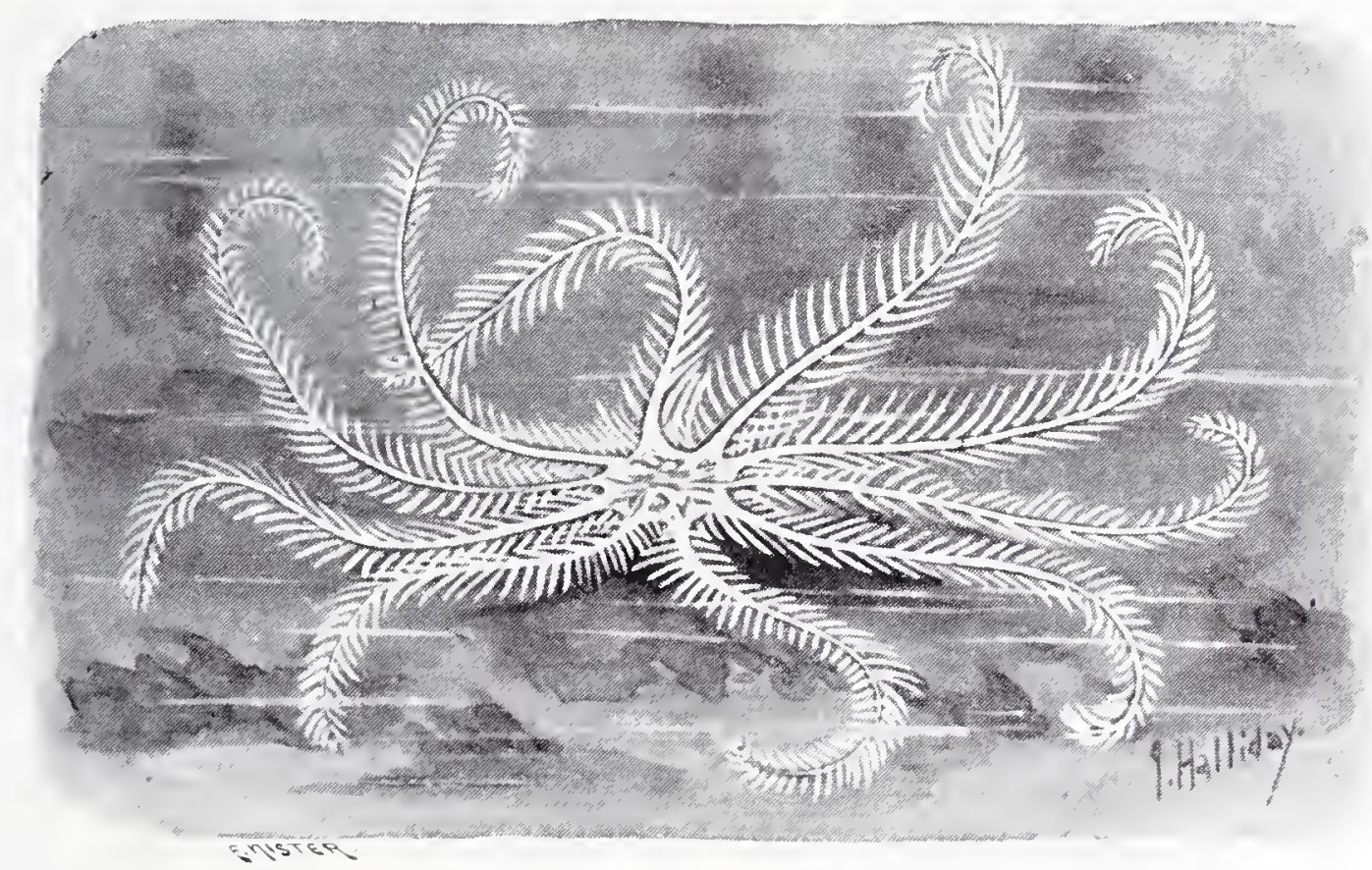

ROSY FEATHER STAR.

sight does not look like a star-fish at all. The reason is that, close to its body, each of the five rays divides into two. Then each of the branches divides into two again, and each of those into two more, and so on over and over again, till sometimes there are more than eighty thousand little arms altogether!

The argus star catches its prey by means of these wonderful rays, which it wraps all round it in the form of a circular basket. It is not at all a common creature, and is only found in deep water.

But perhaps the oddest of all these creatures is the Rosy Feather Star, which actually grows on a stalk whilst it is young, and looks just like a flower with its petals spread. The stalk, which is fastened down to a rock at the bottom of the sea, is made up of a great number of tiny joints, and grows longer and longer. And when it reaches its full length the animal breaks itself free and swims away, leaving the stem behind.

The curious objects known as "encrinites," and sometimes as "St. Cuthbert's Beads," are really the joints of feather stars which lived and died thousands upon thousands of years ago. 
The rosy feather star lives in rather deep water, from which it is sometimes brought up by means of the dredge. It can crawl about on the ground by means of its odd little sucker-like feet, and can swim through the water with some little speed. And very often, to save itself trouble, it will cling by means of its rays to a piece of floating wood, and allow itself to be carried for long distances by the waves. The very strange creatures

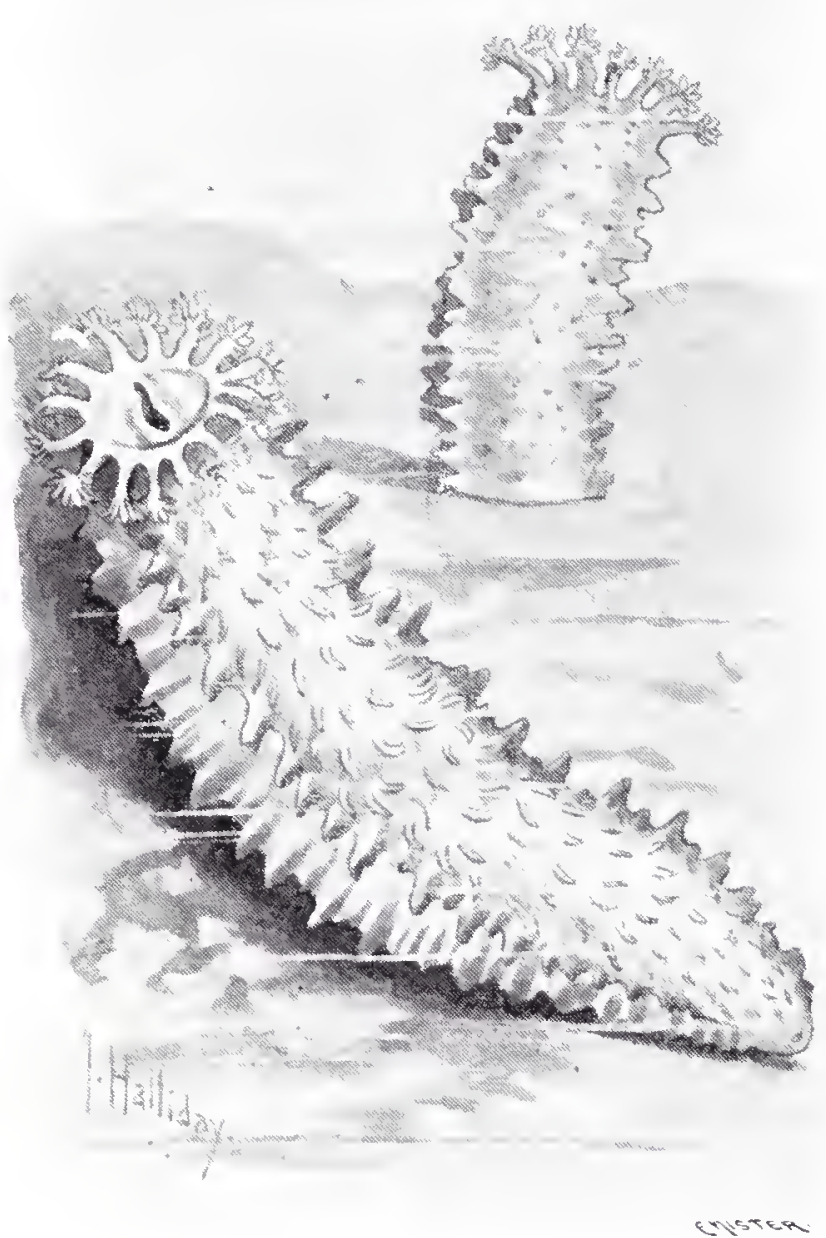

SEA CUCUMBERS. which are generally known as Sea Cucumbers are really relations of the star-fishes, although they do not look in the least like them; for they closely resemble the vegetables after which they are named. In front of the slit at one end of the body, however, which serves as a mouth, there is a feathery tuft. This consists of delicate little tentacles, or feelers, by means of which the animal fishes for its food, and which can be drawn back inside the body when it is not hungry. And if it were not for this tuft one really might almost mistalie the animal for a greyish-white cucumber.

TVe saw just now what a very odd animal the brittle star is, since it brealis off its own rays at the slightest alarm. But the sea cucumber, in this way, is even odder still, for if it eats anything which disagrees with it, as it sometimes does, it turns all its digestive organs out of its mouth, cuts them off, and allows them to float away! Then for three or four months it is very little else than a bag of empty skin, with just a slit at one end and a tuft in front of it. But at the end of that time new digestive organs begin to grow in the place of the old ones, and very soon the sea cucumber is as perfect as ever!

Isn't that an odd way of curing indigestion?

Some of the sea cucumbers grow to a very great size. One indeed, when fully grown, is nearly six feet long. And in China they are largely used as food, under the title of "trepang," and are looked upon as a very great dainty. 


\title{
CHAPTER XXXVII.
}

\author{
MOLLUSCS.
}

THE class of the Molluscs is a very large one indeed, for at least fifty thousand different kinds of these creatures are already known, while new ones are constantly being discovered. They may be described as soft-bodied, boneless animals, which are enclosed in a tough muscular slin called the "mantle." And they are divided into five orders, the first of which includes the singular creatures known as SQUids, or Cutrles.

You may sometimes find these animals hiding in the pools which are left among the rocks when the tide goes out; and you can recognize them at once by the long, fleshy tentacles, or arms, which spring from the upper part of the head. Some of them have ten of these arms, and are called "Decapods"; the rest have only eight and are known as "Octopods." And the lower surface of each arm is furnished with a row of circular suckers, the grip of which is so powerful that the tentacle may even be torn in two without causing them to release their hold. Indeed, if quite a small cuttle were to seize you with one of its arms, you would not find it at all easy to make it let go again without killing it.

The cuttles employ these suckers for two purposes.

In the first place, they use them in walking. When a cuttle is crawling along at the bottom of the sea it pushes one or two tentacles forward, takes firm hold of a rock or a large stone with the suckers underneath them, pulls up the body, and then thrusts them forward again. And in the second place, they use them in catching their prey. Quite large victims are often seized by cuttles, and when once the deadly suckers have fastened upon them there is no hope of escape. In spite of their struggles one tentacle after another comes closing in, till they are completely surrounded by the long, slimy arms, soft almost as jelly, yet strong as steel. Then they are pushed down against the sharp, strong beak, by which they are quickly torn in pieces.

On the upper part of the head of the cuttle there is another curious organ known as the "siphon," which consists of two tubes lying side by side together, like the barrels of a double-barrelled gun. This organ is used in three different ways.

First, it is used in breathing. The cuttles, like the fishes, breathe water, by means of gills. These gills lie inside the head, and the water passes down to them through one of the siphon tubes, and then out again through the other. 
Next, it is used in swimming. When cuttles are not in a hurry they crawl along by means of their long tentacles, as I told you just now. But if they are startled, or alarmed in any way, they fold all their tentacles together in a straight line, fill both the siphon tubes with water, and then squirt it out again as hard as they possibly can. The result is, of course, that they are driven rapidly backwards by the recoil, just like the dragonfly grub, of which we read in Chapter XIII.

But the third use of the siphon tubes is the most curious. If you discover a small cuttle hiding in a rock pool, you will very likely find that the water all round it suddenly grows dark as night, just as if a quantity of ink had been poured into it. The fact is this. Inside its body the cuttle has a bag filled with a quantity of a deep black liquid called "sepia." This bag is surrounded by strong bands of muscle, and opens into the siphon tubes. So, you see, when the animal suddenly contracts the muscular bands, the sepia is squirted out through the siphon into the water, which is immediately darkened for some little distance all round. And under cover of the darkness the animal escapes.

The eggs of the cuttle are laid in a very curious way, for they are fastened by little stallis to a stem of seaweed, so that they look very much like a bunch of grapes. Fishermen, indeed, nearly always speak of them as "sea grapes."

The cuttles which are found in the British seas are always quite small. But in some parts of the ocean these creatures grow to a giant size. Fragments of the tentacles of an enormous cuttle, for instance, have been found lying on the coast of Newfoundland; and by careful calculation it was shown that if the animal to which they belonged had stretched them out at right angles to its body, they would actually have measured more than eighty feet from tip to tip!

These huge creatures seem to form the principal food of the spermaceti whale.

The Chambered Nautilus is a near relation of the cuttles. This animal lives in a shell, which cannot increase in size. The mollusc itself grows, however, and soon becomes too big to live in its home; so it forms a second and larger compartment outside the first one. Time after time this happens, till at last the shell consists of about thirty-six chambers, only the outside one being inhabited by the nautilus.

This shell is often more than a foot in diameter. But if you were to see it when it is first taken out of the sea you would never think that it was a shell at all. Indeed it looks much more like a big shapeless lump of blubber, for the animal covers it entirely with its muscular "mantle," so that the shell itself is completely concealed.

Very little indeed is known of the habits of the chambered nautilus, for it lives at the bottom of the sea, at a depth of two 
or three hundred fathoms. It is found in various parts of the Indian and Pacific Oceans.

The next Order of Molluscs is that of the Gastropods, which is a very large one indeed.

A great many very well-known creatures belong to this group, first upon the list being the SLUGS.

I need not describe these animals, because everyone knows

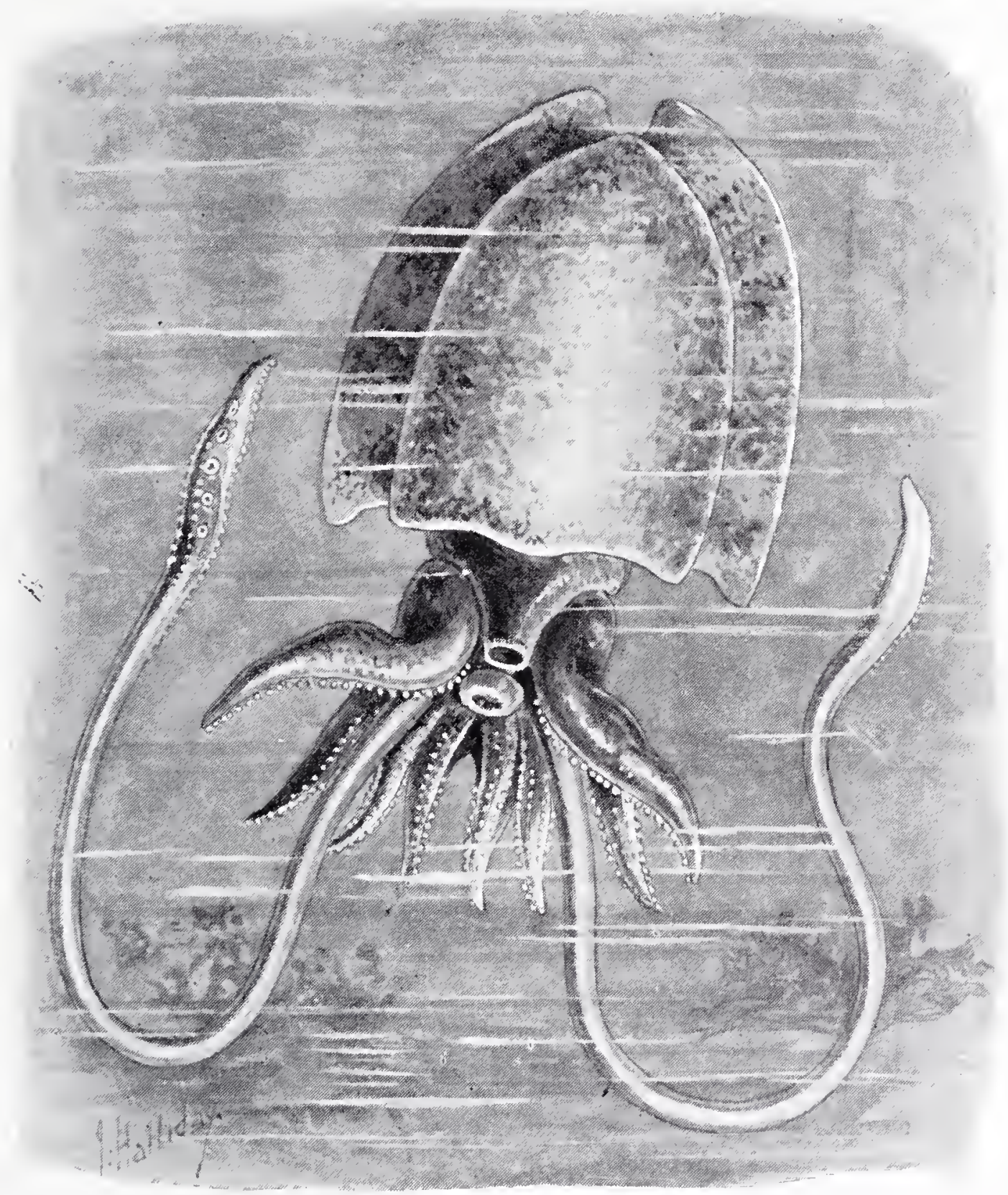

CutTle.

them very well indeed by sight. But perhaps you will be rather surprised to hear that they have shells! These shells are very small, however, and are entirely covered over by the mantle, so that they cannot be seen unless the body is dissected.

Slugs have the most wonderful power of stretching out and drawing up their bodies. You may see one of these creatures crawling about on a damp evening, and measuring fully five inches 
in length. But at the slightest touch it begins to contract, and in a few seconds it is just a shapeless lump, scarcely half as long as it was before. And the odd little tentacles are drawn back into the head, and the head is drawn back into the body, so that if you did not happen to know what it was you might easily mistake it for a pebble.

On the right-hand side of a slug's body, as it crawls along, you will notice a rather large and almost round hole. This is the entrance to the breathing organs, which lie just behind the head and underneath the mantle.

During the day-time slugs remain in hiding; they are very fond of lying up behind the loose bark of dead trees, or under logs and large stones, or in heaps of decaying leaves. And if the weather is very hot and dry they do not come out even at night,

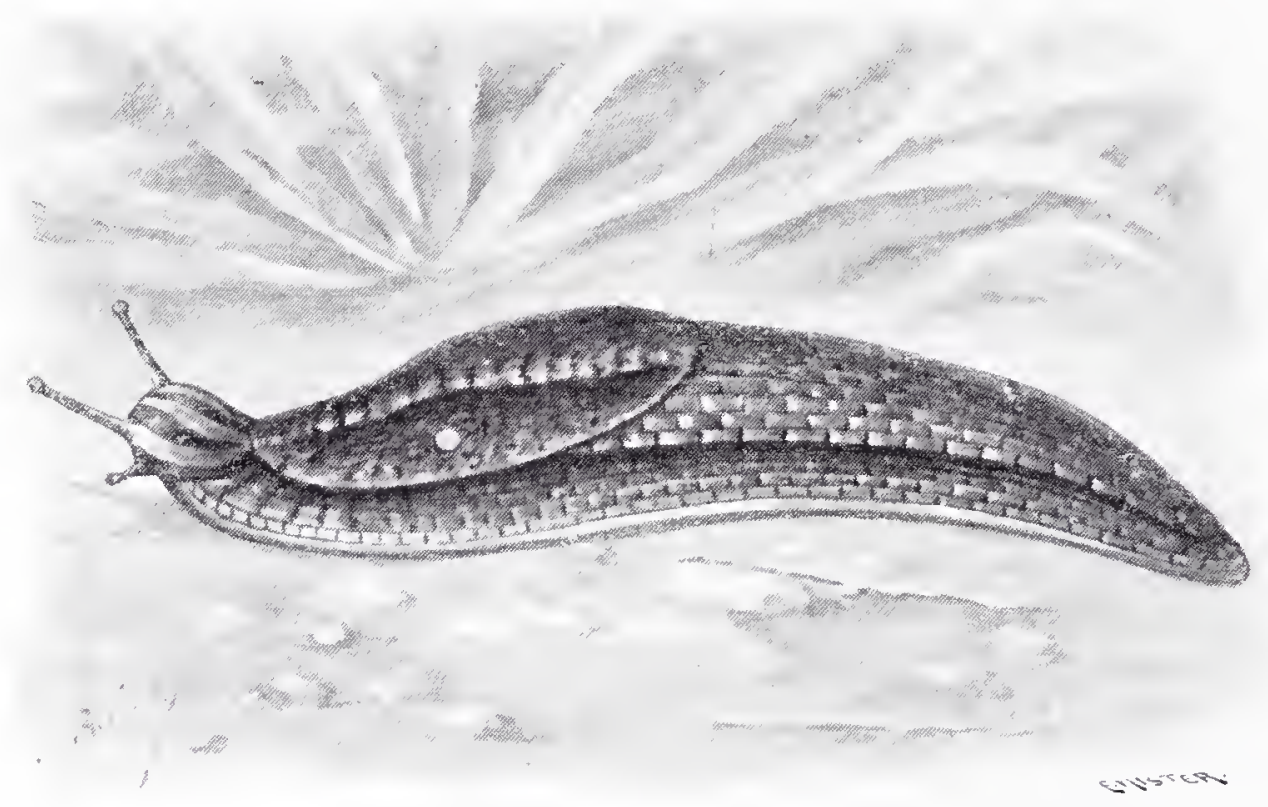

BIACK SIUG.

or they very soon die if they are deprived of moisture. But on warm damp evenings they travel for long distances in search of food, which is almost entirely of a vegetable character. And every gardener knows only too well what mischief they do in gardens.

A good many different kinds of slugs are found in Great Britain. The largest of all is the Great Grey SLUG, which often grows to a length of more than six inches. Then the BLACK SLUG is very common indeed in many parts of the country. It is not always black, however, for you may often find examples which are brown, or yellow, or grey, or even white. 'The Milky SLug, too, which has a thick creamy slime, is very plentiful everywhere. And sometimes you may dig up the very curious slug known as the Testacelia, which feeds on earth-worms, and follows them down to the very bottom of their burrows. You can easily recognise it if you find it, for the shell is outside the skin instead of inside. 
But it is very small indeed, and only covers a tiny part of the tail end of the body.

When the weather is cold, this slug makes a kind of cocoon

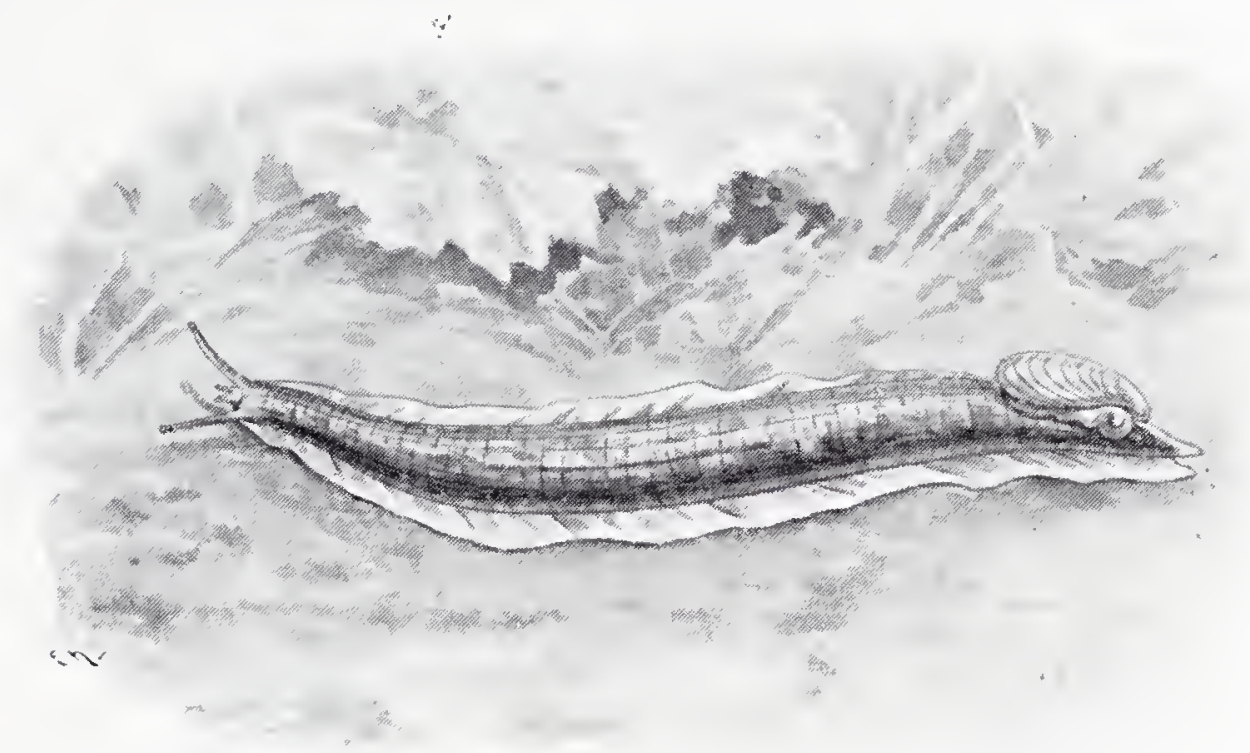

J'ESTACLLLA.

of earth and slime, and lies fast asleep inside it, often for many months at a time.

In many ways Snails are very much like slugs. But the shell is large enough to contain the entire body when the animal withdraws inside it. About five and twenty different linds are found in Great Britain.

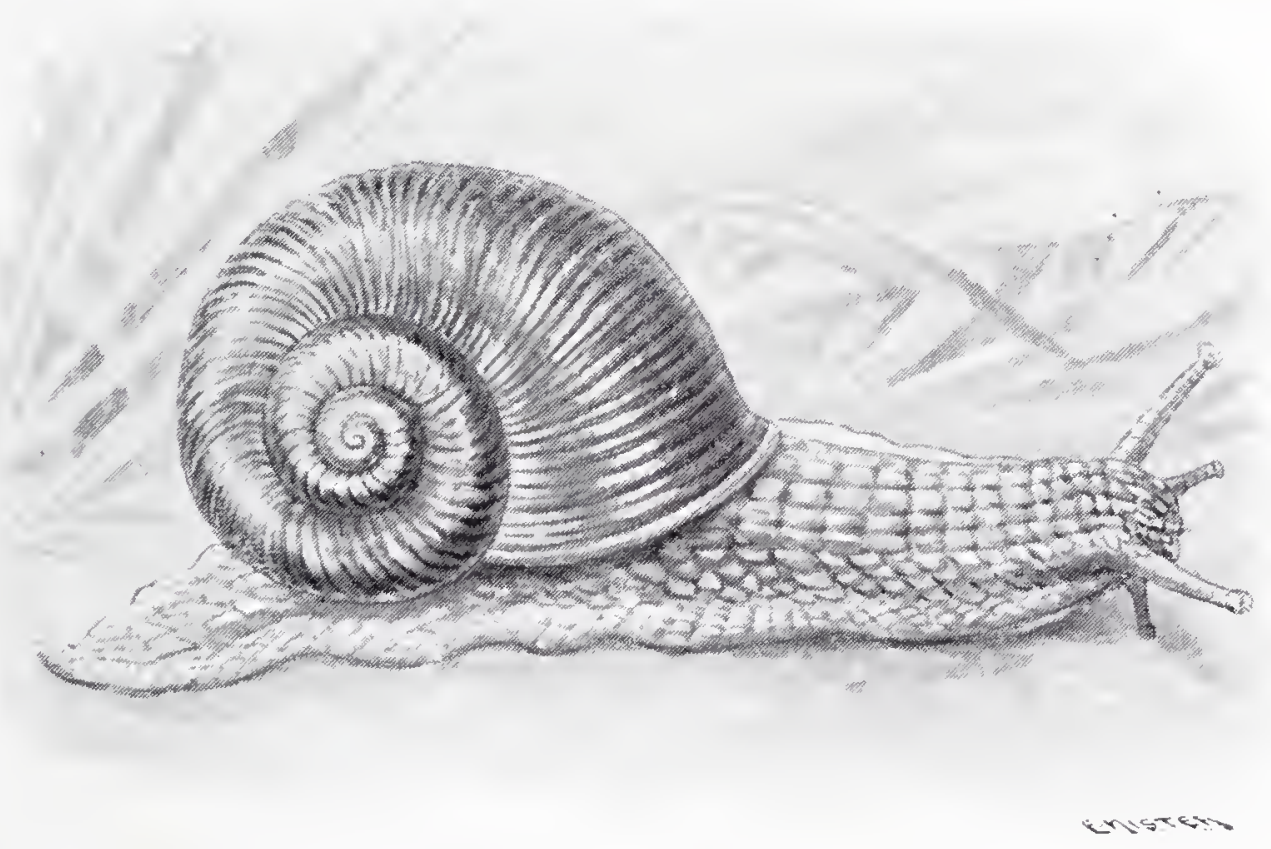

EDIBLE SNAIL.

The commonest of these, of course, is the Garden Snall, which is far too well known to need description. One finds it in hundreds and thousands almost everywhere. And very often, 
when digging in the garden, one turns up its eggs, which are soft and round and white, with very delicate skins, and look almost exactly like rather small mistletoe berries. About sixty or eighty of these are laid by a single snail, and the little ones make their appearance from three to six weels later.

When winter draws near all the snails go into hiding, and they have a most curious way of closing the entrances to their shells by making little doors across them, composed partly of slime and partly of very small fragments of earth. This is in order to prevent the frosty air from getting in and killing them. But it would never do, of course, to keep all the air out, for in that case they would be unable to breathe. So they always leave a very tiny hole in the middle of each door, through which just enough air can pass to prevent them from being suffocated.

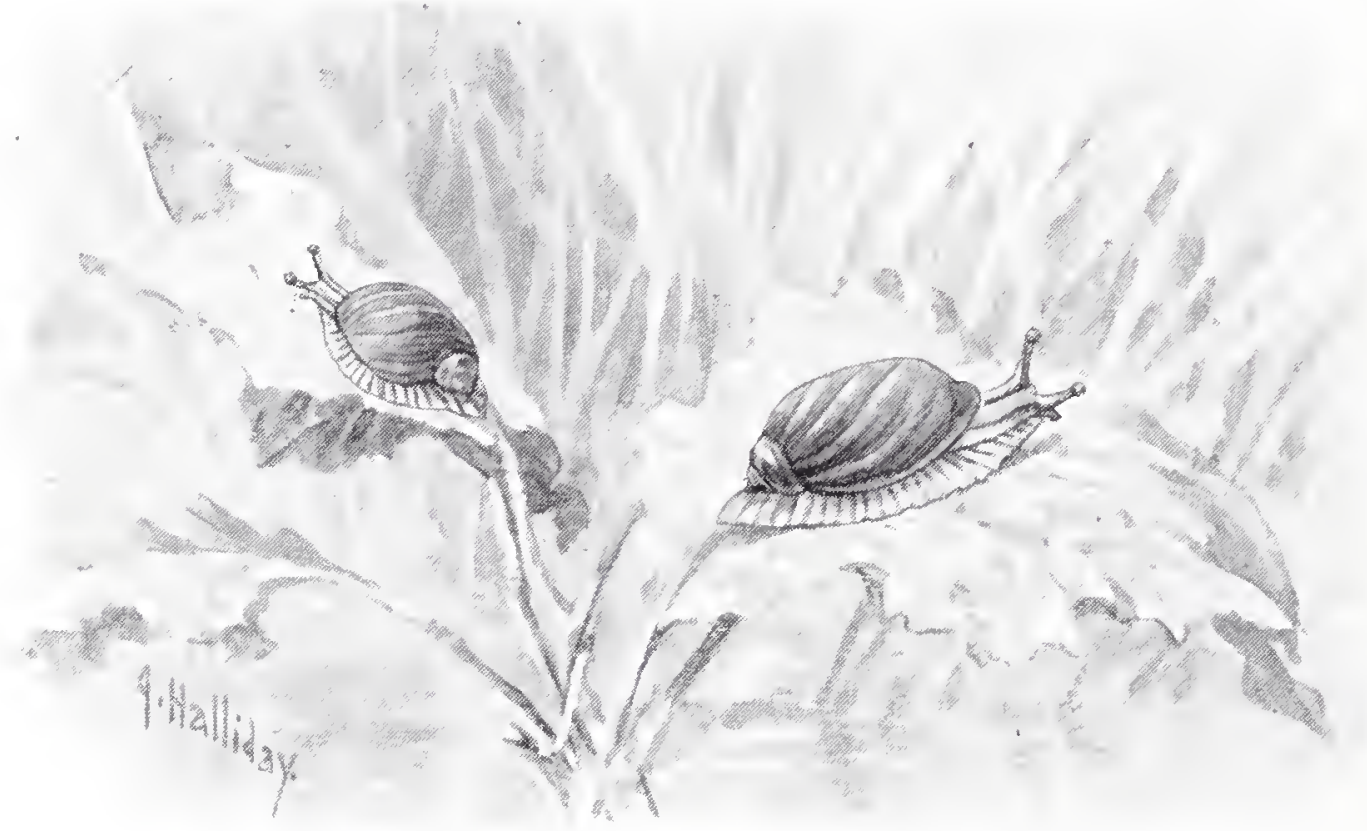

IVATER SNAILS.

Quite twice as large as the common snail is the Edible SNAIL, which is largely used for food in many parts of Europe. It does not seem to be really a native of Great Britain, and was most likely brought over by the Romans nearly two thousand years ago. And even now it is to be found plentifully in the neighbourhood of almost all the old Roman encampments.

Most of the Gastropod Molluscs, however, live in the water, some inhabiting ponds and streams, while others dwell in the sea.

In almost every brook and every ditch, for example, you may find IVATER SNaILs of different linds. Some are quite flat, and some are conical and pointed. Some are as large as land snails, and some are so tiny that they are almost always overlooked. Most of them feed upon decaying leaves, and they have an odd way of travelling by floating upside down on the surface 
of the water, each with its broad fleshy "foot" expanded, so as to convert themselves into tiny boats. You may sometimes see quite a fleet of these little creatures being carried along by the stream. But if you throw a stone into the water they all sink down to the bottom at once, and do not resume their journey until many hours or even days afterwards.

The eggs of this snail are laid in long jelly-like ribbons, which are generally fastened either to the stems and leaves of water plants, or underneath the edges of large stones lying at the bottom of the stream.

A very large number of Gastropods live in the sea. One of the best known of these is the Common WHeLk.

There is no need for me to describe the shell of this creature,

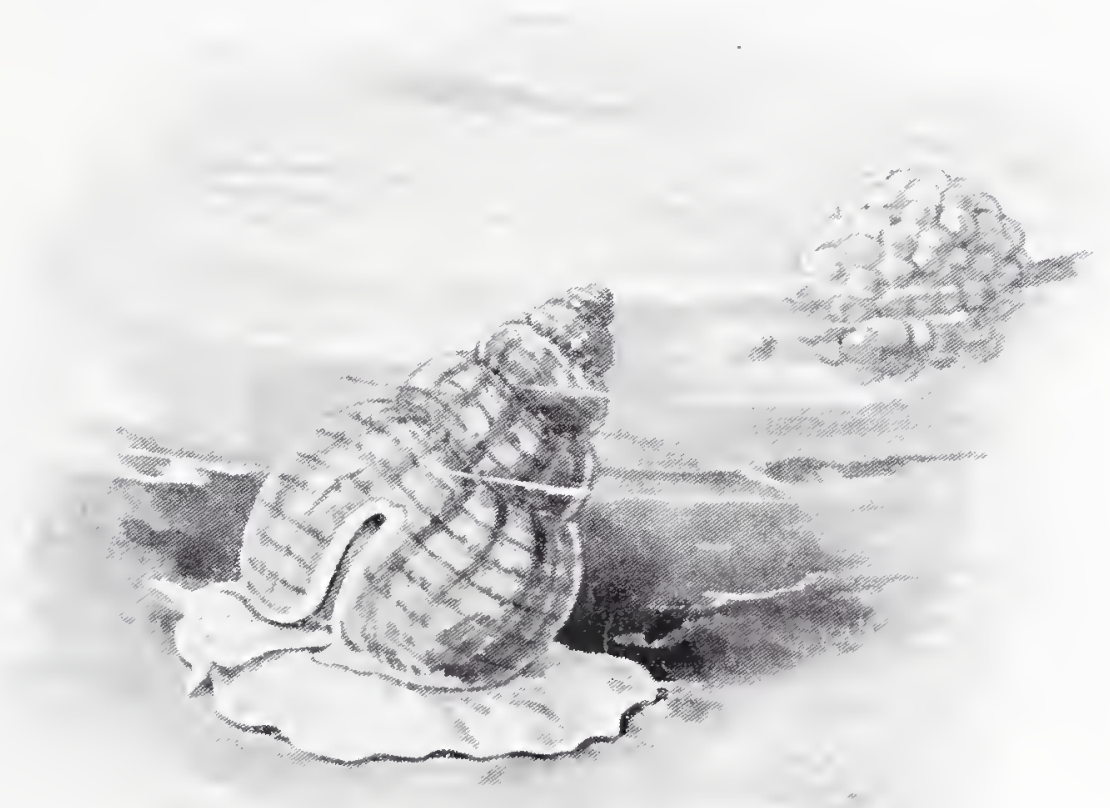

WHELK AND EGGS.

because everybody knows it very well indeed by sight. On almost every sandy and shingly beach, indeed, one may find it lying about in hundreds; and even in large inland towns one often sees whellis for sale, both in fishmongers' shops and on barrows at the corners of the streets. But I wonder if you know what its eggs are like. Perhaps you may have seen them-small, yellowishwhite objects of about the size of peas, made of tough, parchment-like skin, and fastened together in bundles about as big as cricket-balls. When you go to the seaside you may often find these bundles on the shore in dozens; and most likely you will wonder how the whelk ever managed to lay a batch of eggs a good deal bigger than itself.

But the fact is that the eggs of the whelk are just like those of the frog. When they are first laid they are very tiny indeed. But the tough skin of which they are made is very 
elastic, so that it will stretch almost like a picce of india-rubber. Besides this, it has the curious property of allowing water to soak in from the outside, but not to pass out again. So as soon as the eggs are dropped into the sea they begin to swell, and

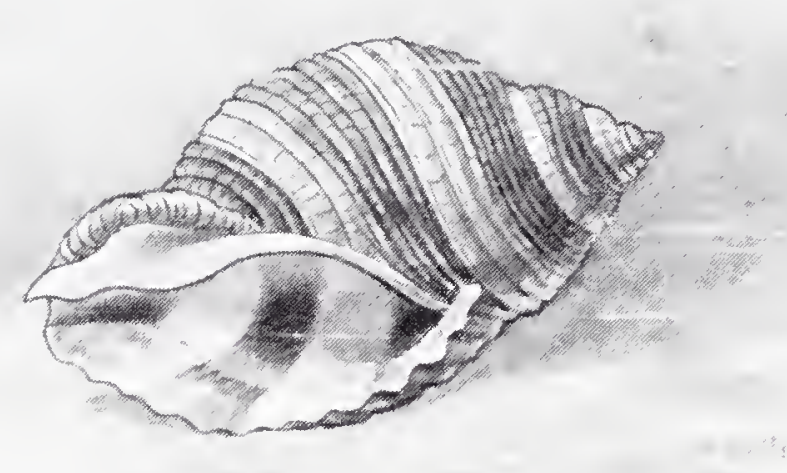

PURPURA.

before very long they are quite twenty or thirty times as large as they were when first they were laid.

Another shell that one often finds lying on the shore is that of the Purpura. It is something like a rather small whelk.

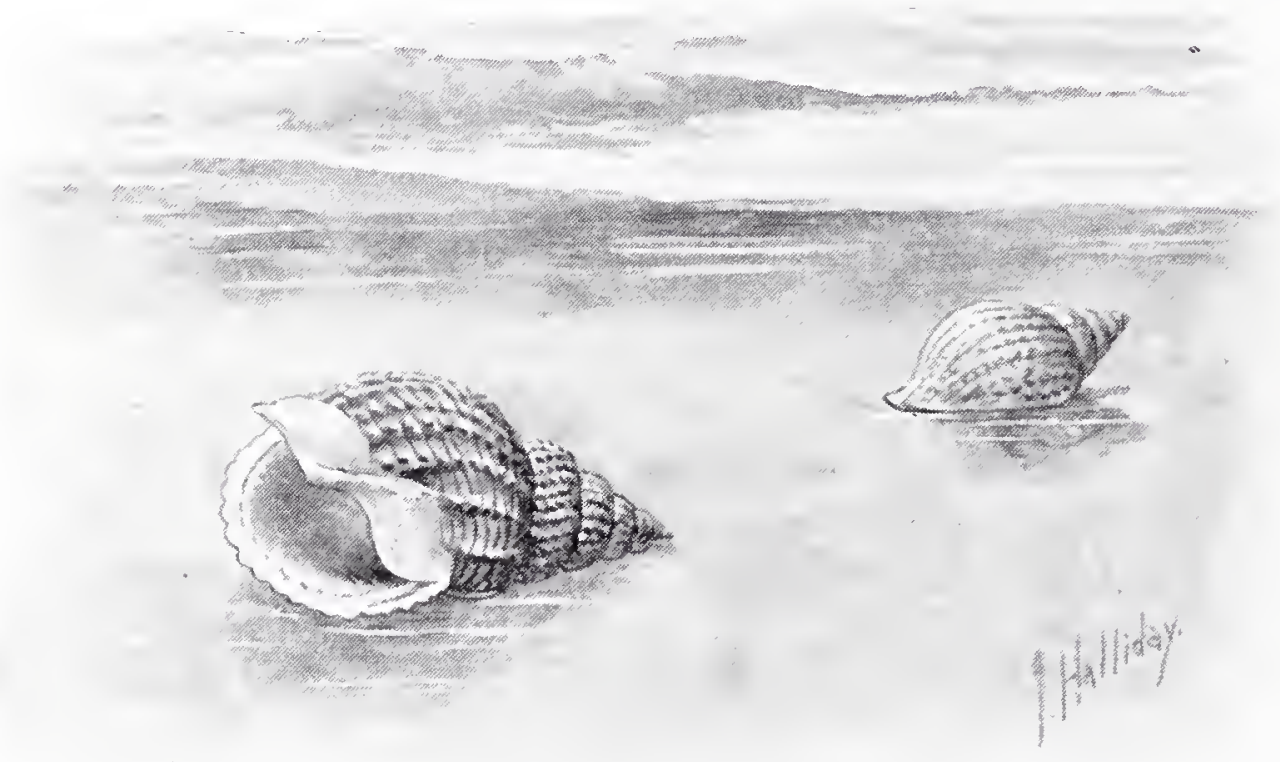

DOG WHELKS.

But the shell is very much stouter, and instead of being white or yellow all over, it is banded with yeliowish brown.

The purpura is rather a famous creature, because of the purple dy'e which is obtained from its body. This dye is contained 
in a little bag behind the throat, which holds just one small drop of liquid, and no more. And if you were to see it you would never think that it was dye at all, for it looks only like rather yellowish water. But if it is squeezed out on a sheet of white paper, and laid in the sunshine, it very soon begins to change colour. First it becomes green, then blue, and then purple. And it is really the dye which the ancient Romans valued so highly that no one who did not belong to the royal family was allowed to dress in purple raiment.

Very common, too, in many parts of the coast, is the Dog Whelk. It is not so large as the common whelk, and you can recognize it at once by the stout ridges which run spirally down the shell.

This creature certainly looks harmless enough. Yet in

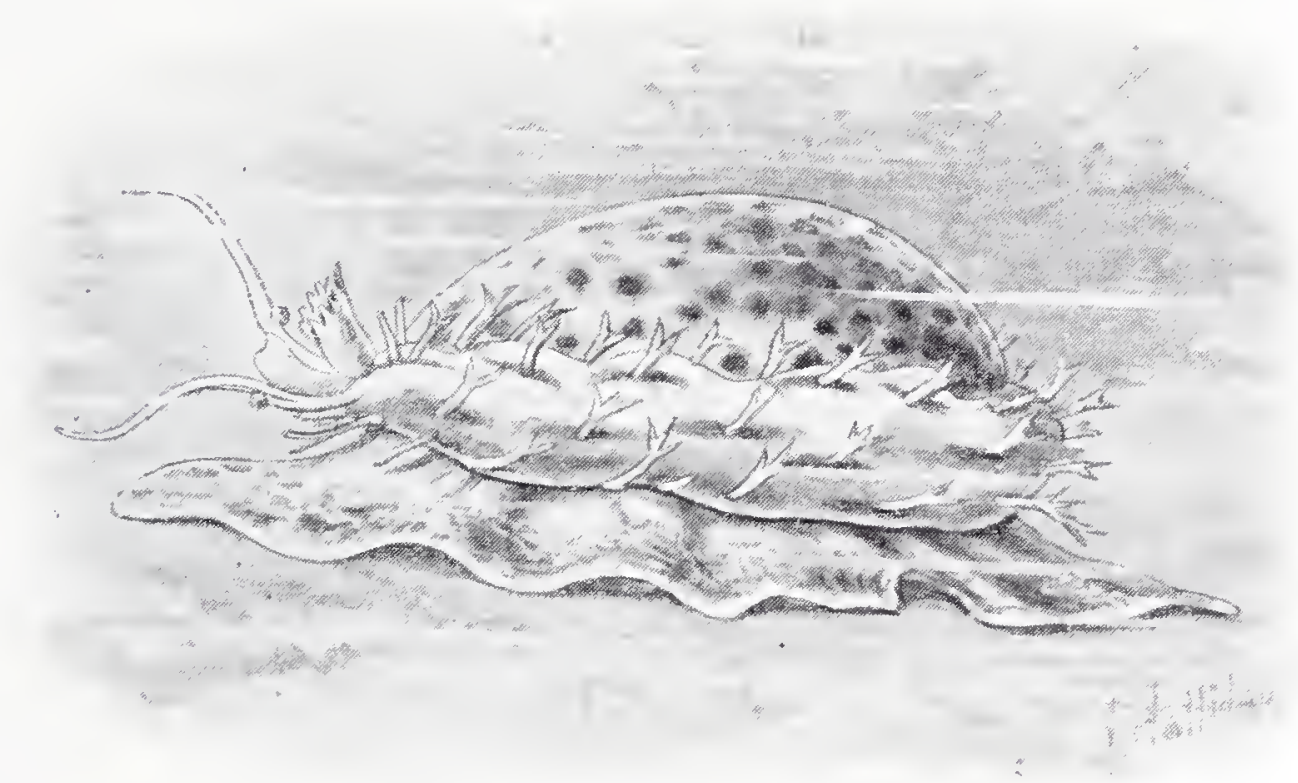

COWRY.

reality it is one of the most bloodthirsty of all the inhabitants of the sea, for it spends its whole life in seeking and devouring other shell-bearing molluscs. It kills and eats these in a very curious way. Like all the gastropods, it possesses what we call a "toothribbon"- that is, a narrow strip of very tough gristle, set with row upon row of sharp, notched, flinty teeth. There are sometimes more than six thousand of these teeth, and although they are so small that they cannot be seen without the aid of a powerful microscope, they are nevertheless very formidable. For every tooth is hooked, with the points of the hook directed towards the throat.

The tooth-ribbon is used in this way. When a dog whelk meets with a victim, it fastens itself to it by means of its fleshy, muscular "foot." Then it bores a round hole through its shell, as neatly as if it had been pierced by a drill. And then it pokes 
the tooth-ribbon down into the body of the creature inside, and draws it back again. As it does so, of course, the hooked teeth tear away little bits of the victim's flesh. The dog whelk swallows these, and then pokes down its tooth-ribbon once more. And so it goes on, over and over again, until the shell of its victim has been completely emptied, when it goes off to look for another.

Periwinkles, of course, you linow very well by sight; and perhaps you have tasted them too. They are very common indeed on many parts of the coast, and you may find them crawling about on the weed-covered rocks in thousands when the tide is out. They have tooth-ribbons just like that of the dog whelk. But they do not use them in the same way, for they feed only upon seaweeds. And they are remarkable for having the "foot" divided by a kind of groove, which runs right down the middle. When a periwinkle crawls, it moves first one side of this "foot"

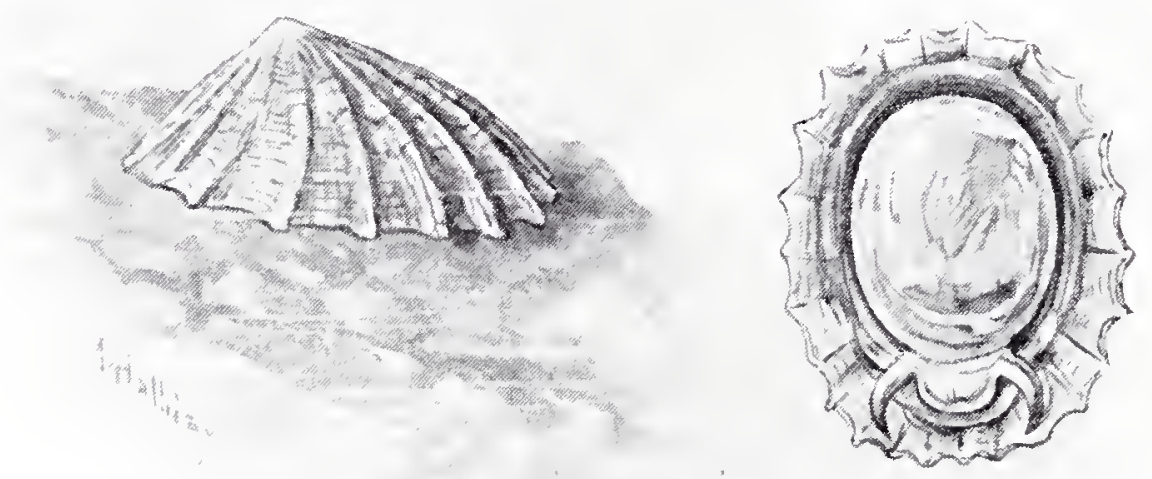

LIMPETS.

forward, and then the other side, so that although it has no legs it may really almost be said to walk.

One of the prettiest of the gastropod shells is that of the Cowry. You may find it commonly on sandy coasts, especially if you hunt for it among the small coal which has been thrown out from passing steamers and washed up by the tide. It is white in colour, sometimes tinged with pink, and a number of ridges run across it from one end to the other. When the animal is alive the two lobes of the mantle are expanded in such a way that the shell is almost completely covered.

In the warmer seas cowries are found of a much larger size, and in some parts of Africa they are used as money. It would seem rather strange to earn one's living just by picling up money on the sea-shore, wouldn't it? And perhaps you might think that everyone who lived near those parts of the coast where cowries are found must be very well off. But then sixteen hundred 
of these shells are only worth about a shilling, so that you would have to hunt for a very long while and stoop a great many times in order to obtain sufficient even to buy food. And it must be very awkward to have to carry several sacks of money when one goes out marketing!

Commoner still are the Limpets, which you may find in thousands clinging to the rocks which are left bare when the tide goes out. They fasten themselves down by means of the broad, fleshy foot, which acts as a big sucker. And so firmly do they' hold that it is almost impossible to pull them away.

After a time, the edges of a limpet's shell cut a circular groove in the rock to which it clings, so that even the sea-birds cannot drive their beaks underneath and force it from its hold. And though, when the tide is up, the mollusc will wander to a

\section{Prickly Chiton.}

distance of two or even three feet in search of food, it always seems to return to its resting-place before the retreating waves again leave the rock uncovered.

Limpets are sometimes used as food, although their flesh is rather coarse and stringy, and in some parts of Cornwall they may be bought, ready boiled, for about one shilling a quart. They are largely used, too, as bait, more than eleven million being employed for this purpose every year in Berwick alone.

The next Order of Molluscs is called the "Amphineurans," and contains the curious creatures which are known as Chitons. These may be described as sea armadillos, for they are covered with a kind of shelly armour, consisting of a series of plates, and can roll themselves up into balls, in order to protect themselves from the attacks of their enemies.

One of these molluscs is called the PrickLy Chiton, because 
it is covered all over with sharp spines, like a hedgehog. It grows to a length of nearly six inches. But long before it reaches its full size the spines are rubbed off, so that a large example of this creature is nearly always perfectly bare.

If you want to find a chiton you must look for it among the muddy rocks at low water, at seasons of spring tide. But generally these odd-looking creatures are brought up by means of

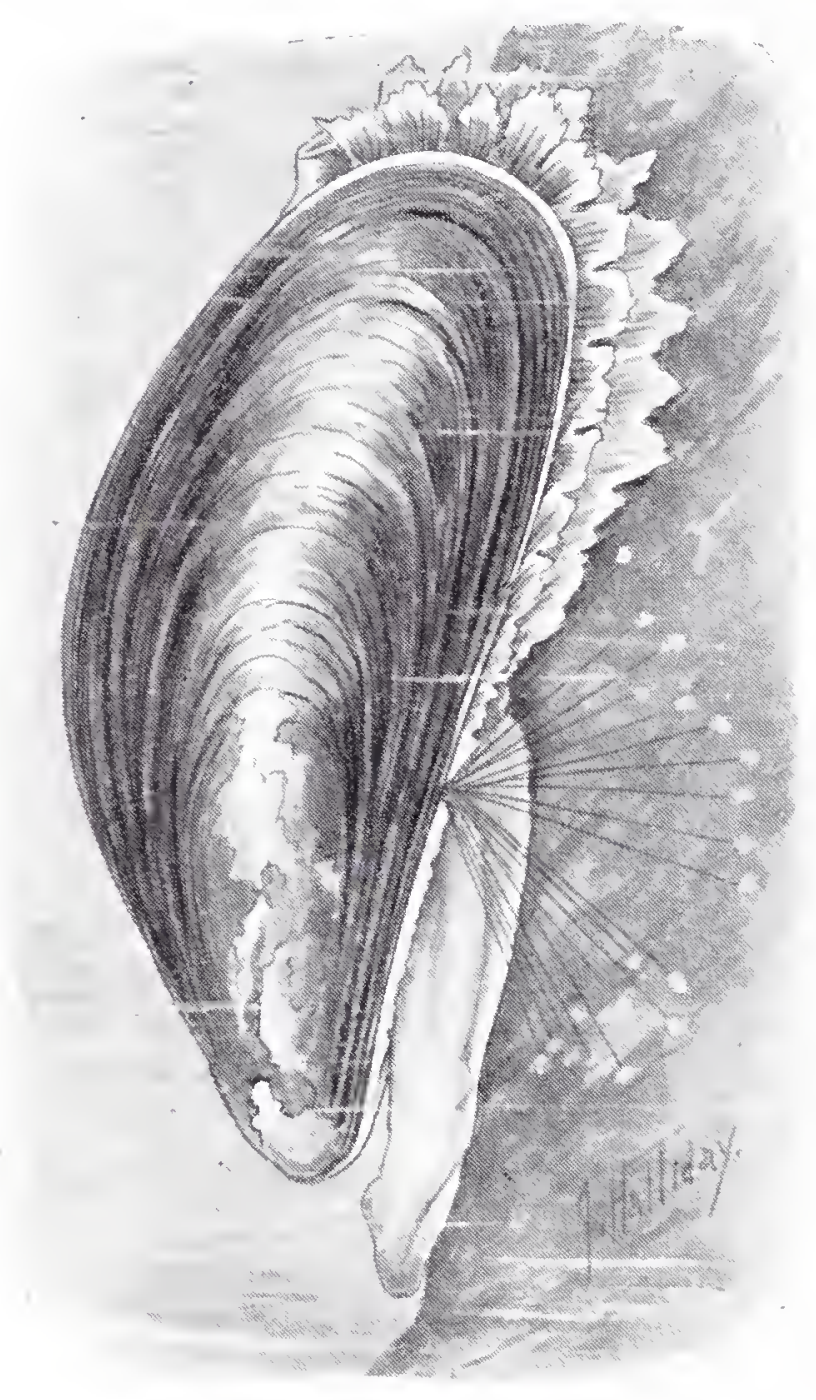

ÈDible Mussel. the dredge.

The Order of the Amphineurans is quite a small one, and so is that of the Scaphopods, which consists only of the Tooth Shells. Very likely you may know these by sight, for they are very common on our sandy coasts, and look rather like very tiny elephants' tusks. But the Order of the Bivalves is a very large and important one indeed.

All these creatures have their shells made of two parts, or "valves," which are fastened together by means of a hinge. They have no heads, and the mantle forms a kind of flap on either side of the body. They are found both in fresh and salt water.

By way of an example of the fresh-water bivalves, let us talie the common River Musser.

This creature is very plentiful in streams with muddy bottoms, and is very dangerous to bathers, owing to its habit of burying itself in the mud, with only just the edges of its shells projecting above the surface. And as these edges are as sharp as linives, the feet of anyone who wades in the stream are very likely to be badly cut. It multiplies very rapidly, for a single mussel will sometimes produce as many as three hundred thousand little ones in the course of a single year; and it is rather odd to find that the young live for some time in the gills of the mother before they pass out into the water and enter upon life for themselves.

Pearls are sometimes found inside the shells of the river mussel. As a rule they are quite small ones, and their quality is not sufficiently good to render them of much value. But a pearl was once taken from one of these creatures which was so 
very large and fine that it actually found a place in the crown of England!

The EDible Mussel is another of those molluscs which are far too well-known to need description. It is perhaps the very commonest of all, being found in vast numbers on almost all parts of the British coasts, clinging to rocks and submerged timber. 'The way in which it fastens itself to its hold is very curious, for instead of turning the whole of the "foot" into a big sucker, as the limpet does, it spins a number of very strong threads from that part which lies nearest to the hinge; and every one of these threads is separately fastened to the support, so that the creature is moored down, as it were, by a kind of cable. These threads are known as the "byssus," and hold so firmly that it is not at all easy to pull them away.

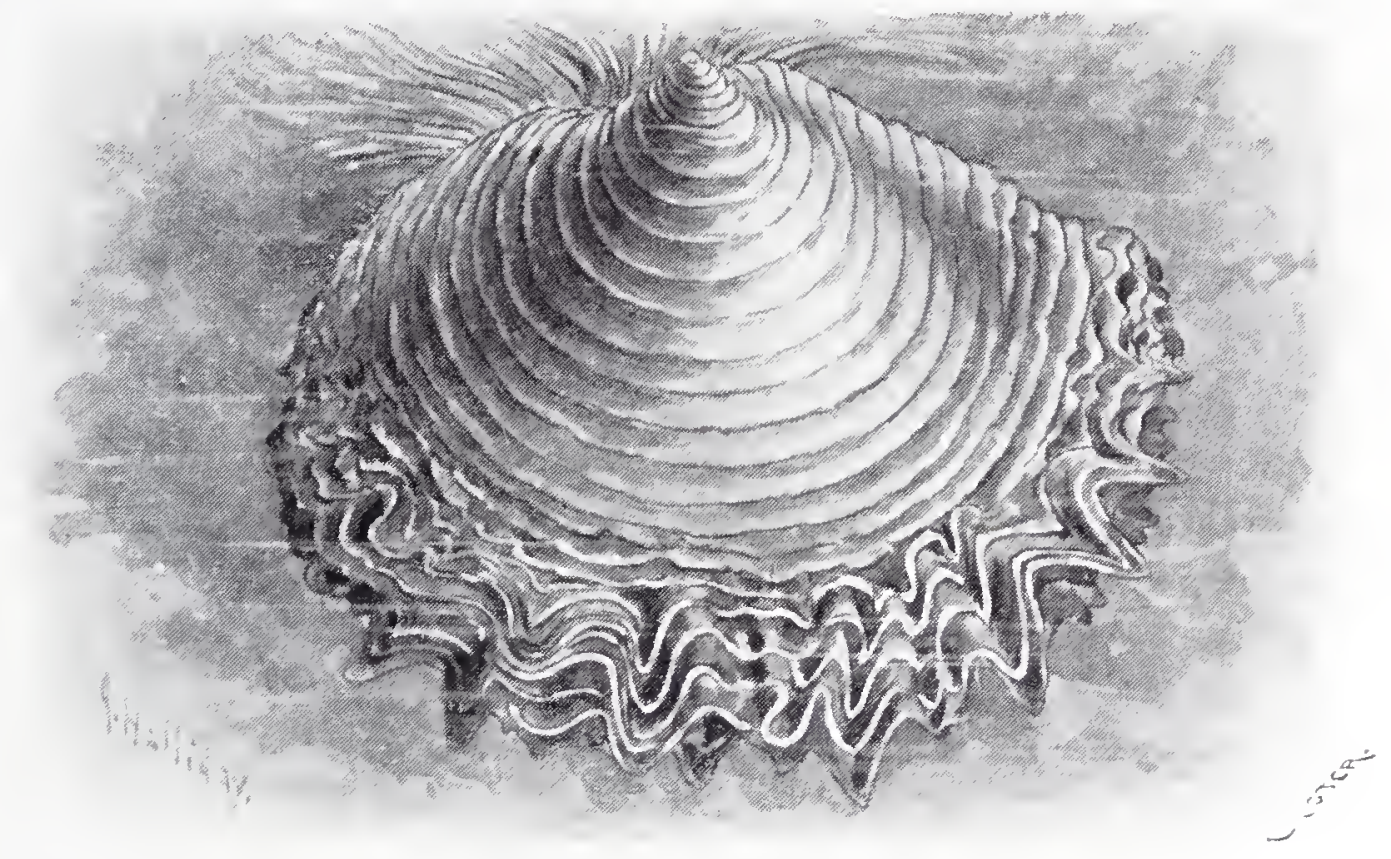

PEARL OYSTER.

The Orster belongs to another family of bivalves, in which one part of the shell is a good deal larger than the other.

The early life of this mollusc is very curious. The spawn is known as "spat," and is produced in such enormous quantities that an oyster may be the parent of seven or eight hundred thousand little ones at a single birth! This "spat" looks at first like very fine grey dust, and remains for some little time within the shells of the parent. But one day in early summer the oyster opens its valves a little way, and squirts it out like a cloud into the water. For a few weeks the little oysters are able to swim, and they generally travel backwards and forwards with the tide. But after a while they attach themselves to some object at the bottom of the water, and there they remain without moving any more for the rest of their lives.

One would think that, since a family of oysters is so 
enormously large, these creatures must be the most plentiful molluscs in the sea. But by far the larger number are destroyed by other creatures before they are able to settle down; while even after that they have a great many enemies. I have already told you how mischievous star-fishes are in the oyster beds. Then dog whellis are almost equally troublesome, and besides these there is a curious lind of sponge, called the Cliona, which burrows into the shells of the mollusc and gradually destroys them, sometimes actually causing them to fall to pieces.

Pearls are obtained chiefly from the Pearl Oyster, which is found in warm seas in many parts of the world, the principal fisheries being in Ceylon, the Persian Gulf, the South Sea Islands, and off the north-east coast of Australia. They are deposited by the mantle, and it is most likely that they are really due to a grain of sand, which has lodged inside the shell and set up irritation.

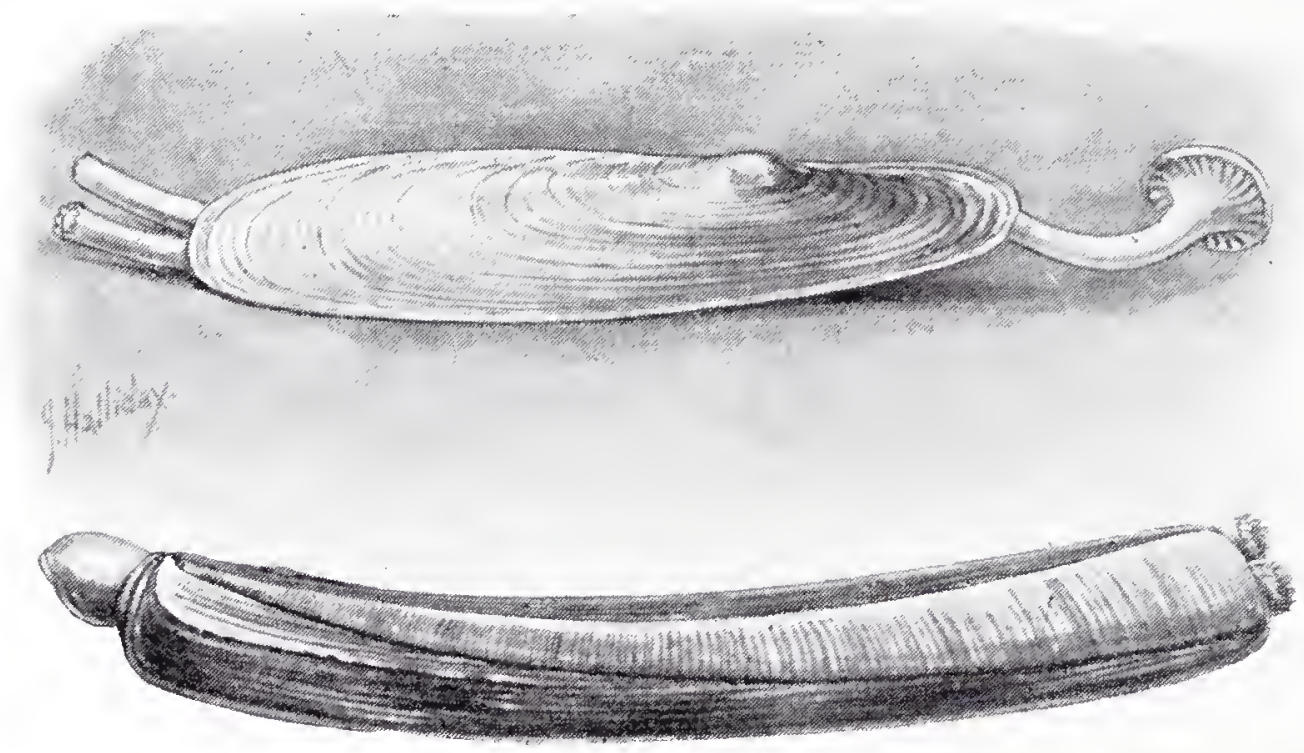

RAZOR-SHELLS.

Indeed, it has been found that if small objects, such as tiny stones, are forced between the valves of one of these oysters, they become covered with layers of pearl in a very short time.

The best "mother-of-pearl" is also obtained from the shells of the pearl oyster.

Another very well-known bivalve is the Cockle, whose heart-shaped shells, covered with low ridges, you must know by sight very well indeed. This is one of the burrowing molluscs, spending its life buried in sandy mud. It is especially common at the mouths of large rivers, where enormous quantities are collected to serve as human food. And its large muscular foot is not only used in digging, but also enables it to leap to a considerable height.

RAZOR-SHELLS, too, are inhabitants of the mud, and if you want to find their burrows it is very easy to do so. All that you have to do is to visit a patch of sandy mud when the tide 


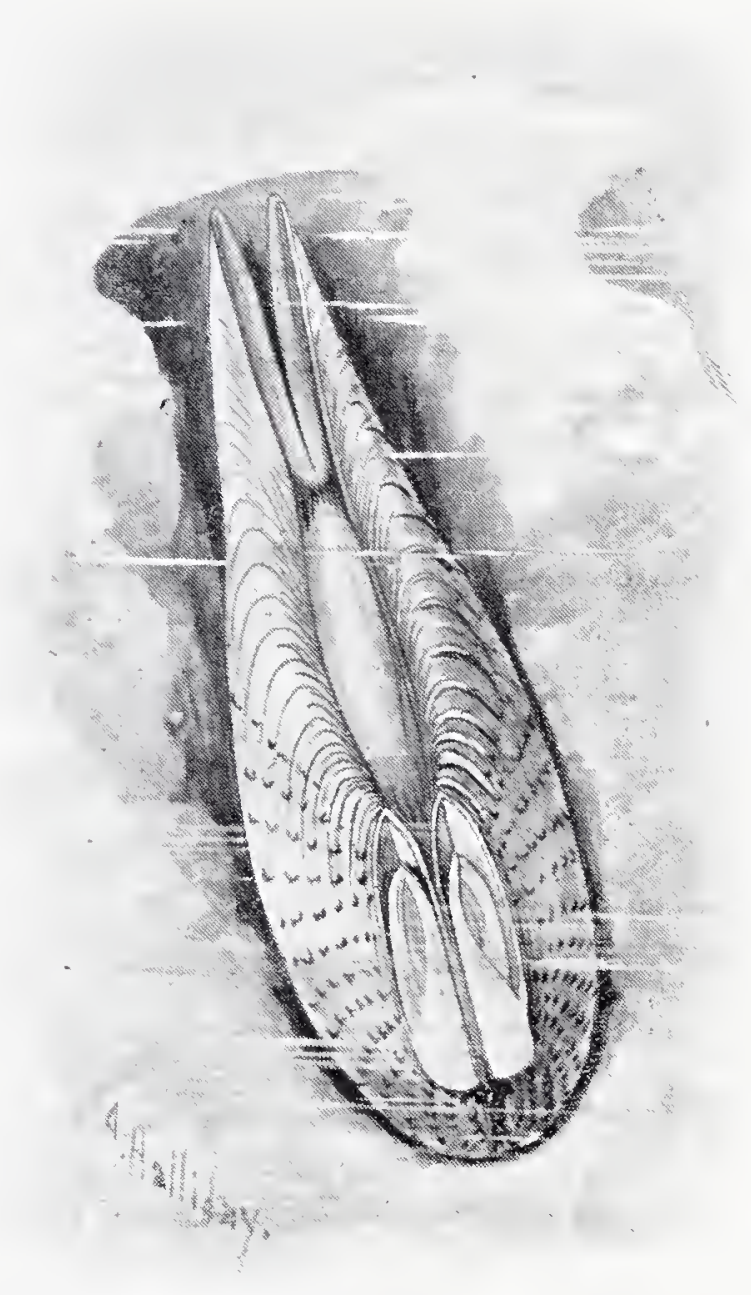

PIDIOOCK.

is out, and stand quietly watching it. Before long you are sure to see a little jet of water spurt out of the mud to a height of three or four inches. Now this water has been squirted out of the siphon tubes of a razor-shell, and if you walk to the spot, treading very carefully, you will find a tiny hole in the mud. This is the entrance to the burrow, and if you want to get the animal out, the best way to do so is to drop a little salt down the hole. For it is a very strange fact that although the razor cannot live in mud at the bottom of fresh water, it does not like pure salt at all, and is sure to come up to the surface and try to get rid of it. But if you fail to seize it at once it will retreat to the very botton of its burrow, and no amount of salt will persuade it to come up again.

One of the most wonderful of all the bivalves is the PIDDOCK, whose empty shells you may often find lying about on the beach. It is a boring mollusc, living buried in the solid chalk or limestone. If you examine the rocks which are left bare at low water you will often find that they are pierced by numbers of rather large round holes. These are the entrances to the burrows of piddocks, and if you could split the rock open you would find several of these creatures lying in their tunnels.

Sometimes, when they are boring, their burrows become choked up behind them with the material which they have scraped away. Then they just squirt out a jet of water from their siphon tubes, and so wash the passage clear.

It is really owing to the work of the piddocks that chalk and limestone cliffs are so much cut away by the sea. The waves by themselves can do very little in this way. For when they wash up against the face of the cliff they leave the spores of seaweeds behind them; and these very soon grow, and cover the whole surface with a mantle of living green, which almost entirely prevents the cliff from being worn away. But the piddocks drive their burrows into the rock just below the surface of the water, boring backwards and forwards till it is completely honeycombed by their tunnels, which only have just the thinnest of walls left 
between them. Then the sea washes into the burrows, and brealis these walls down, so that the whole foundation of the cliff is cut away. Very soon, of course, there is a landslip, and hundreds of tons of chalk or limestone, as the case may be, come falling down. Then the piddocks begin worling again a little farther back, and the process is repeated; and so on over and over again. You know, of course, that on many parts of our coasts long stretches of roclis run ever so far out into the sea, and are only partly left bare at low water. Well, those rocks were once the bases of cliffs, which the piddocks and the waves together have cut away. And it even seems almost certain that the Straits of Dover were cut in this manner, and that if it had not been for the labours of the piddocks, carried on day after day for thousands upon thousands of years, Great Britain even now would not be an island, but would still form part of the Continent of Europe, as we know that it did in ages long gone by!

Then there is a bivalve mollusc which burrows into submerged timber, such as the hulls of wooden ships, or the beams of piers and jetties. This is called the SHIP-wori, and certainly it does look much more like a worm than a mollusc, for it has a long cylinder-shaped body something like a foot in length, with a forked tail, while the shell only covers just a little part at one end. How it burrows into the wood nobody quite knows. It is generally supposed to do so by means of the foot. But in a very short time it will honeycomb a great beam of timber with its burrows, which it always lines with a kind of shelly deposit, weakening it to such a degree that at last it gives way beneath the slightest pressure.

Like a great many other molluscs, the ship-ivorm passes through a kind of caterpillar stage before it reaches its perfect form. While it is in this condition it is able to swim freely about in the water, and looks rather like a very tiny hedgehog, being almost globular in shape, and covered all over with short projecting hairs. It is by means of the action of these hairs upon the water that it is able to sivim. 


\section{CHAPTER XXXVII.}

\section{ANNELIDS AND CELENTERATES.}

THE important class of the Annelids contains those creatures which we generally call Worms. There are a great many of these, but I shall only be able to mention one or two.

First, of course, there is the common EARTHwORM, which is really a most interesting as well as a most useful animal.

The way in which it crawls, for instance, is very curious. On the lower part of every one of the rings of which its body is made up, with the sole exception of the head, are four pairs of short, stiff, little bristles, projecting outwards from the skin. The worm really hitches itself along by means of these bristles. First it takes hold of the ground with those underneath the front rings, then it draws up its body and takes hold with those underneath the hind ones, and then it pushes its head forwards and repeats the process; and so on, over and over again.

If you take a worm and pass it between your finger and thumb from the tail end towards the head, you can feel these little bristles quite easily.

A worm does not often leave its burrow, however, but generally keeps the tip of its body just inside the entrance, so that it can retreat in a moment in case of danger.

Worms make their burrows in a very odd manner, for they actually eat their way down into the ground, swallowing mouthful after mouthful of earth until their bodies can contain no more. They then come up to the surface and pour out the mould which they have swallowed in the form of what we call a "worm-cast," after which they go down again and swallow more, and so on until the burrow is sufficiently deep.

You will be surprised, I think, to hear how much earth is swallowed by the worms in this way. Just think of it. Every year, in every acre of agricultural land all over the country, worms bring up from below, on an average, and spread over the surface in the form of worm-casts, no less than fourteen tons of earth, or about seven large cartloads!

This is why worms are such useful creatures. They are always, as it were, digging and ploughing the soil. After a time the earth at the surface becomes exhausted. Nearly all the nourishment is sucked out of it by the roots of the plants. But the worms are always bringing up fresh, rich, unused soil from below, and spreading it over the surface in the form of what farmers call a "top-dressing." They are doing, in fact, exactly 
what we do when we dig our gardens or plough our fields, burying the used-up soil that it may rest, and bringing up fresh mould to take its place.

But, besides turning the soil over, they manure it; for ahmost every night from early spring to late autumn worms are busy dragging down leaves into their burrows. With some of these leaves they line their tunnels, with some they close the entrances, and on some they feed. And most of them decay

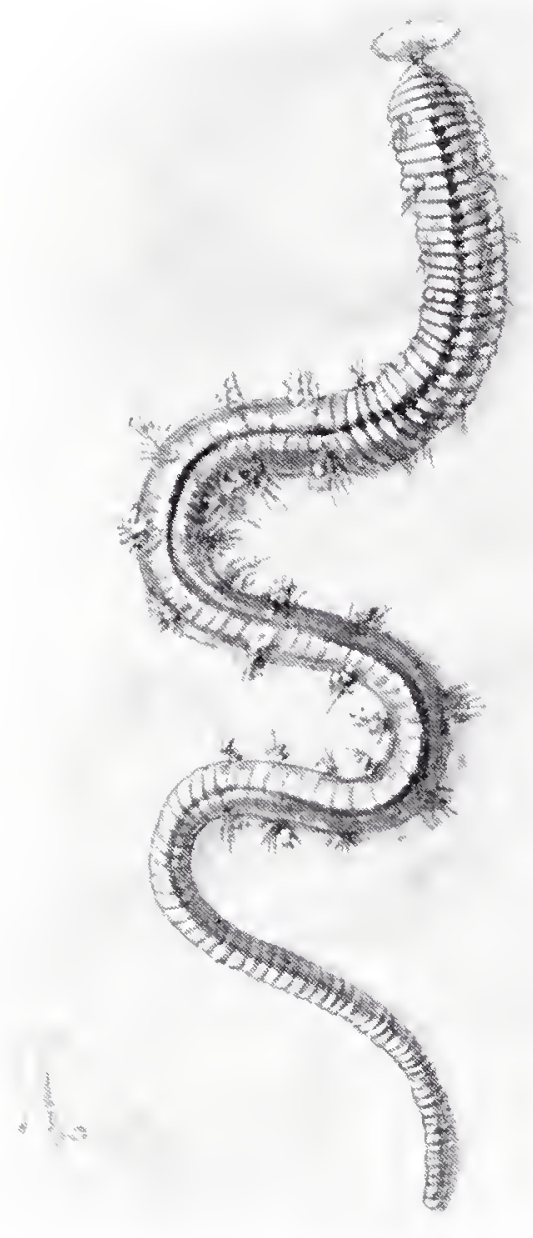

LUG IVORM. before very long and turn into leaf-mould, which is just about the very best manure that there is. So you see, the worms do not merely turn the soil over, they enrich it as well, and help very largely indeed to keep it in such a condition that plants can continue to grow in it.

The Lug Worm lives in sandy mud on the sea-shore; and when the tide is out you may often see its "casts" in thousands. It is very largely used by fishermen as bait. When it is carefully washed it is really quite a handsome creature, for sometimes it is deep crimson in colour, and sometimes dark green, while on its back are twenty-six little scarlet tufts, arranged in pairs, which are really the gills by which the worm breathes.

The burrows of the lug worm are not quite like those of the earth worm, for as it tunnels through the sand it pours out a kind of glue-like liquid, which very soon hardens and lines the walls, so as to form a kind of tube and prevent the sides from falling in.

There is another kind of worm, however, which forms very much stronger tubes. This is the Terebelta, which is common on many parts of our coasts. But it is not very easily found, for at the slightest alarm it retreats to the very bottom of its burrow, which nearly always runs under large stones and rocks.

The terebella makes its tube by means of the little feelers, or tentacles, which spring from the front part of its body. These have a most wonderful power of grasp, and one after another little grains of sand are seized by them, and carefully arranged in position. And when the tube is quite finished, the animal 
constructs a little tuft of sandy threads, so to speak, round the entrance, which you may often see in the pools left among the rocks by the retreating tide.

Looking far more like a hairy slug than a worm, the SEA Mouse also belongs to the class of the annelids. You can easily find this creature by hunting in muddy pools among the rocks just above low-water mark; and most likely you will consider it as one of the dingiest and most unattractive-looking animals that you have ever seen. But if you rinse it two or three times over in clean water till every atom of mud has been washed out of its bristly coat, I think you will change your opinion. For now you will see all the colours of the rainbow playing over itcrimson, purple, orange, blue, and vivid green-just as if every hair were a prism. It would be difficult, indeed, to find any

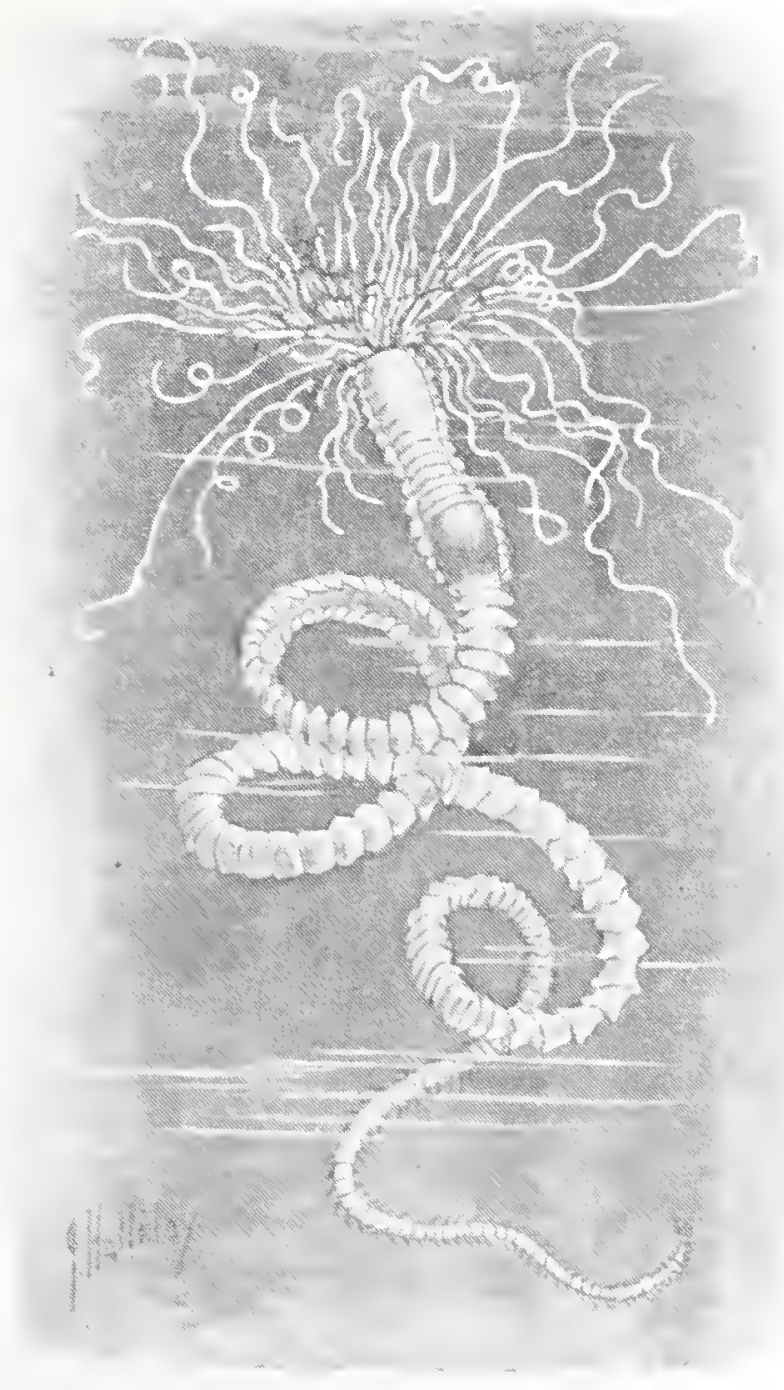

TERERELLA. creature more beautiful in the waters of the sea.

This bristly coat is really a kind of filter, which strains out the mud from the water that passes to the gills.

LEECHES, too, are annelids, living in fresh water instead of in salt.

These creatures

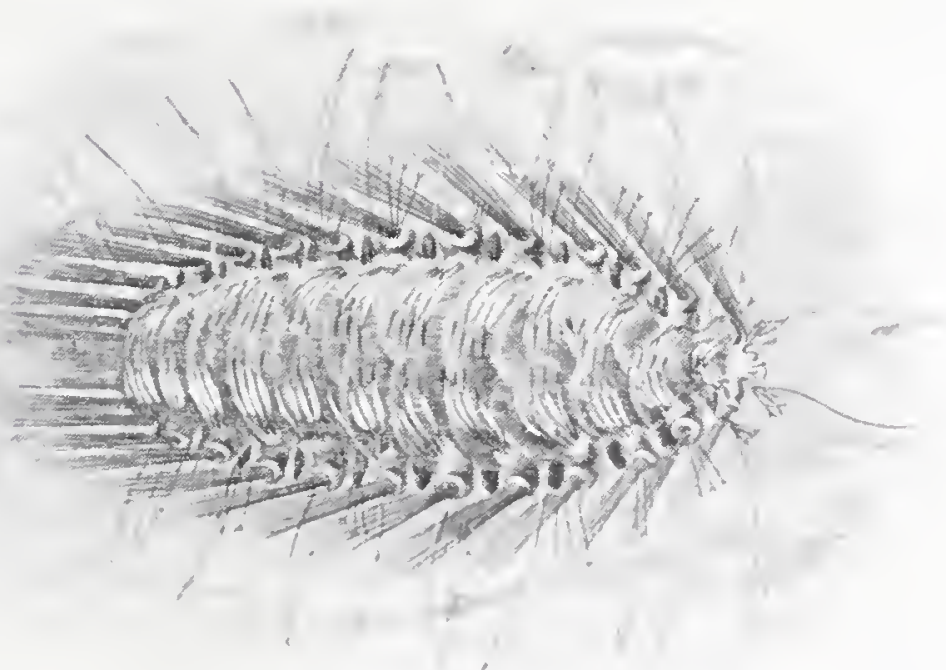

SEI MOLSTE are famous for their blood-sucking habits, and when we examine their mouths through a microscope we find that they are provided with three sets of very small sawlike teeth, which are set in the form of a triangle. When a leech wants to suck the blood of an animal, it fastens itself to the slin of its 


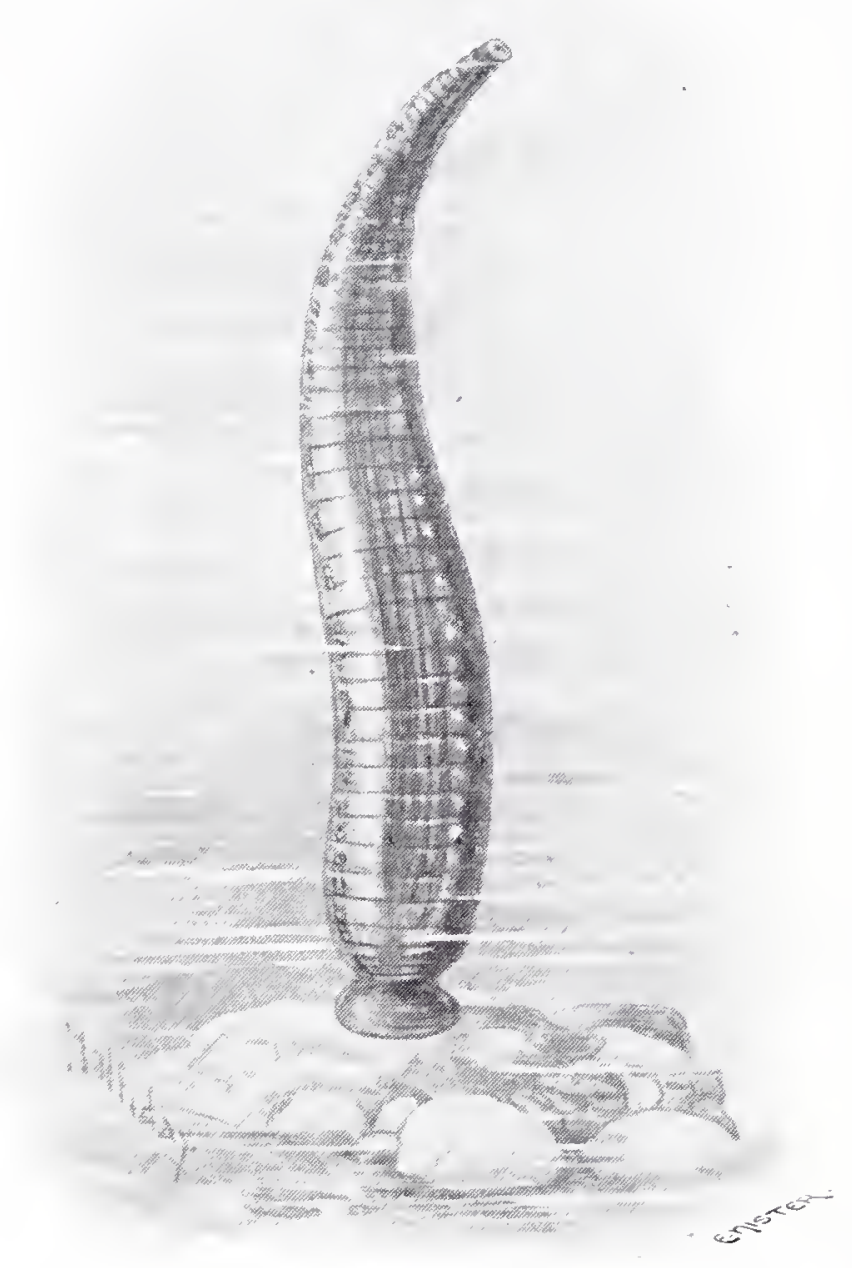

LEECH.

victim by means of its suckerlike lips, and then saws out a tiny triangular piece of skin. That is why it is so difficult to stop the bleeding after a leech has bitten one. An actual hole is left in the skin, which does not heal over for some little time. And a great deal of blood is generally taken by the leech itself, which will go on sucking away until its body is stretched out to at least double its former size.

That is rather a big meal to take, isn't it? But then such meals come very seldom. Indeed, when a leech has once gorged itself thoroughly with blood, it will often take no more food at all for a whole year afterwards!

Leeches lay their eggs in little masses, called "cocoons," which they place in the clay" banks of the pools in which they live. In each of these cocoons there are from six to sixteen eggs.

We now come to the last great class of animals about which I shall be able to tell you-that of the Coelenterates. It contains three most interesting groups of creatures.

First there are the Jelly-Fishes. You have seen plenty of them, of course, when you have been staying at the seaside, for they are often flung up on the beach by the retreating tide. But if you were to go and look for them two or three hours afterwards, on a bright sunny day, you would find that they had disappeared. All that would be left of them would be a number of ring-like marks in the sand, with just a few threads of animal matter in the middle of each. The reason would be that they had evaporated! That sounds rather strange, doesn't it? But the fact is that the greater part of the body of a jelly-fish is nothing but water! It is quite true that if you cut it in half the water does not run away. But then that is equally true of a cucumber; and cucumbers, too, are made almost entirely of water. The reason is the same in both cases. The water is contained in a very large number of very tiny cells; and when you cut either the animal or the vegetable across, only a few of these cells are divided, and only a small quantity of the water escapes. 
Round the edge of the disc of a jelly-fish which has just been flung up by the waves you will find a number of long, slender threads. These are its fishing-lines, with which it captures its prey, and they are made in a very curious manner. All the way along they are set with a double row of very tiny cells, in each of which is coiled up an extremely sharp and extremely slender dart. These cells are so formed that at the very slightest touch they fly open, and the little darts spring out; and, besides this, the darts are poisoned. So as soon as any small creature swims up against these threads a number of the venomed darts bury themselves in its body, and the poison acts so quickly that in a very few seconds it is dead. Then other threads come closing in all round it, and in a very short time it is forced into the mouth and swallowed.

Some jelly-fishes are so poisonous that they are most dangerous even to man. Only one of these, however, is found off the British coasts, almost all the jelly-fishes that one finds lying about on the beach being perfectly harmless. But if, when you are bathing, you see a yellowish - brown jelly-fish about as big as a soupplate swimming near

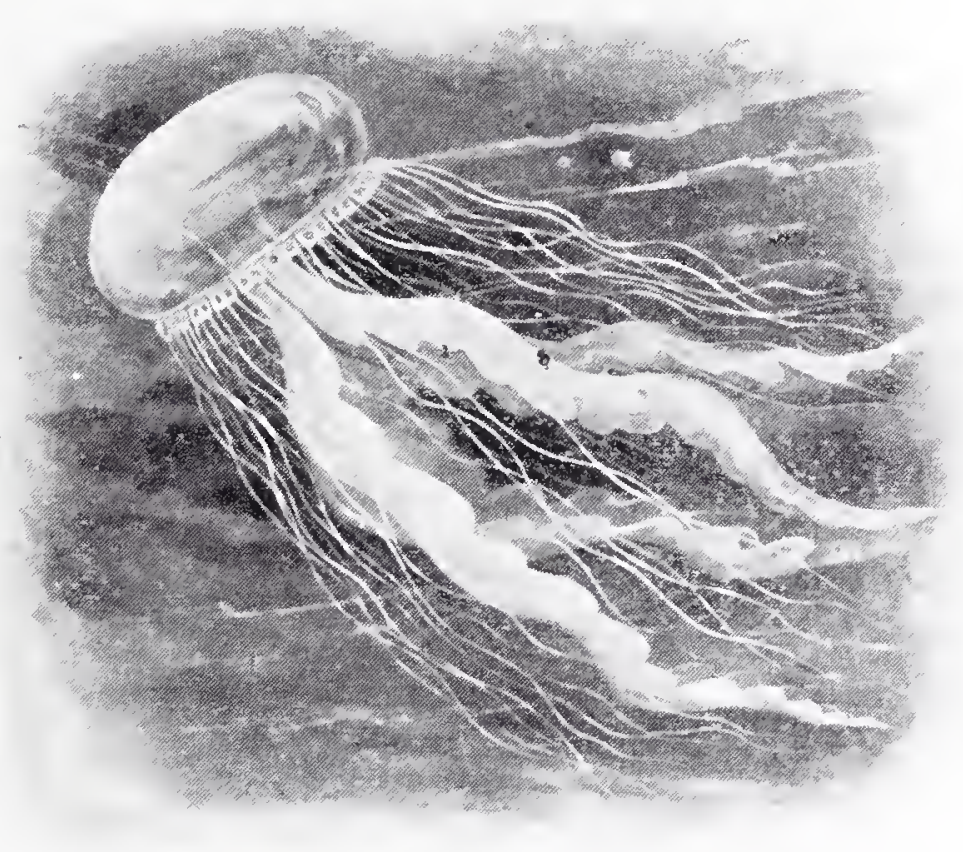

JELLY-EISH.

you in the water, be sure to get out of its way as fast as you possibly can; for if its threads should touch any part of your body, you are almost sure to be very badly stung. There is very little doubt, indeed, that many swimmers have been killed by these creatures; while thousands of unwary bathers have been laid up for days, or even weelis, from the effects of their poison.

What beautiful creatures the SeA Anemones are-just like flowers growing under the sea! Some are like dahlias, some like chrysanthemums, and some like daisies, of all shades of crimson, and purple, and orange, and green, and it is very hard to believe that they are really living animals.

The tentacles of these creatures, which look so like the petals of flowers, are set with little cells containing poisoned darts, just like the fishing-threads of the jelly-fishes. They can be spread out or drawn back into the body at will, and when they have all 
been withdrawn the anemone seems to be nothing more than a shapeless lump of coloured jelly.

Anemones spend the greater part of their lives clinging to the surface of a rock at the bottom of the water, the broad base of the body acting just like a big sucker. They can crawl about, however, at will, and sometimes they will rise to the surface of the sea, turn upside down, hollow their bodies into the form of little boats, and then float away, perhaps for quite a long distance.

You may often find numbers of sea anemones in the rockpools at low water. The commonest of all, perhaps, is the BEADLET, which has a row of little pearl-like beads, as it were, just at the base of its tentacles. Many hundreds of these creatures may often be seen in a single small pool.

Last upon our list

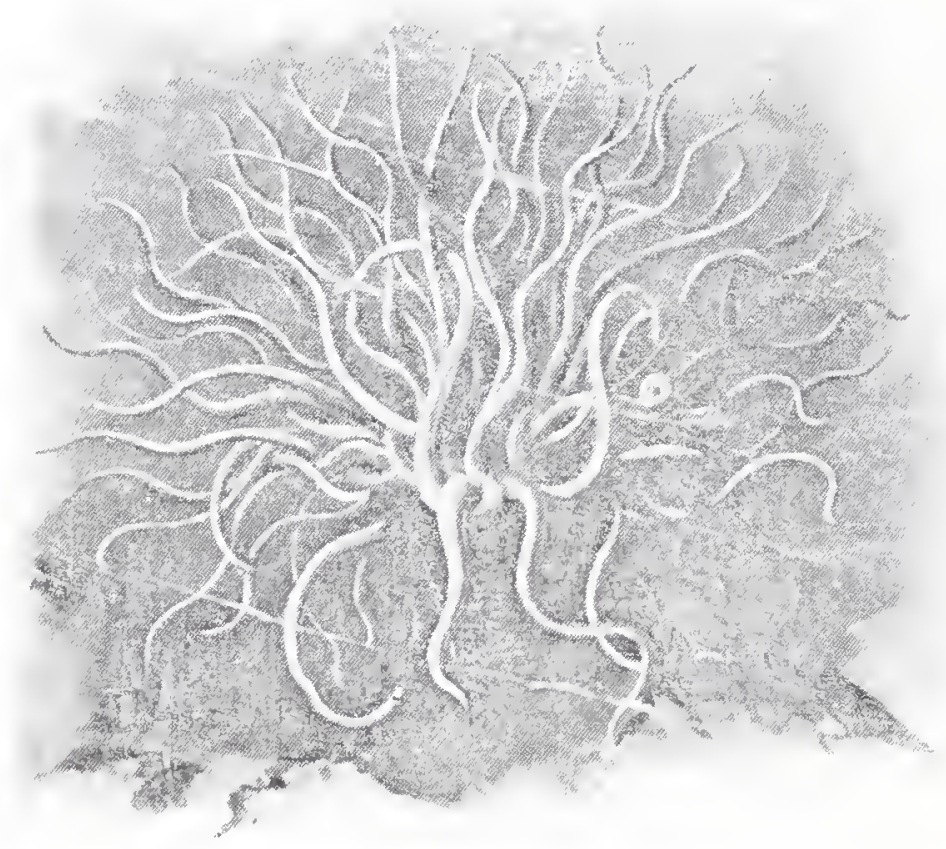

SHA ANEMUNL. come those most wonderful little creatures which are known as CoRALs.

These are often called "coral insects," but that is a very great mistake. For they have nothing to do with insects at all, and are as different from them in every way as they can possibly be. 'They are properlycalled "polyps," and we can best describe them, perhaps, as very small sea anemones. But they have one property which the anemones do not possess,

namely, the power of extracting lime out of the sea water, and building it up round themselves in the form of coral.

'These creatures may be roughly divided into two groups, the one consisting of the "simple corals," which only live together in very small numbers, and the other of the "reef-builders," which live in vast colonies, and build up masses of coral of enormous size. The latter are by far the more interesting, and the way in which they build up immense banks of coral is very wonderful indeed.

Remember, first of all, that these animals multiply in two different ways-sometimes by exrs, and sometimes by little buds, so to speak, which grow out of the body of the parent. The polyps which hatch out from egrs swim about for some little time quite freely. But after a few days they fasten themselves down to the surface of a submerged rock, and after that they never 
move again. Other polyps very soon come and settle down by them, and before very long there will be thousands upon thousands of the Jittle animals all growing, as it were, close together, and all gradually building up coral underneath and round the margins of their bodies.

When they reach their full size they begin to multiply by "budding." Baby polyps sprout out all over their bodies, and these, instead of swimming about for a few days like those which

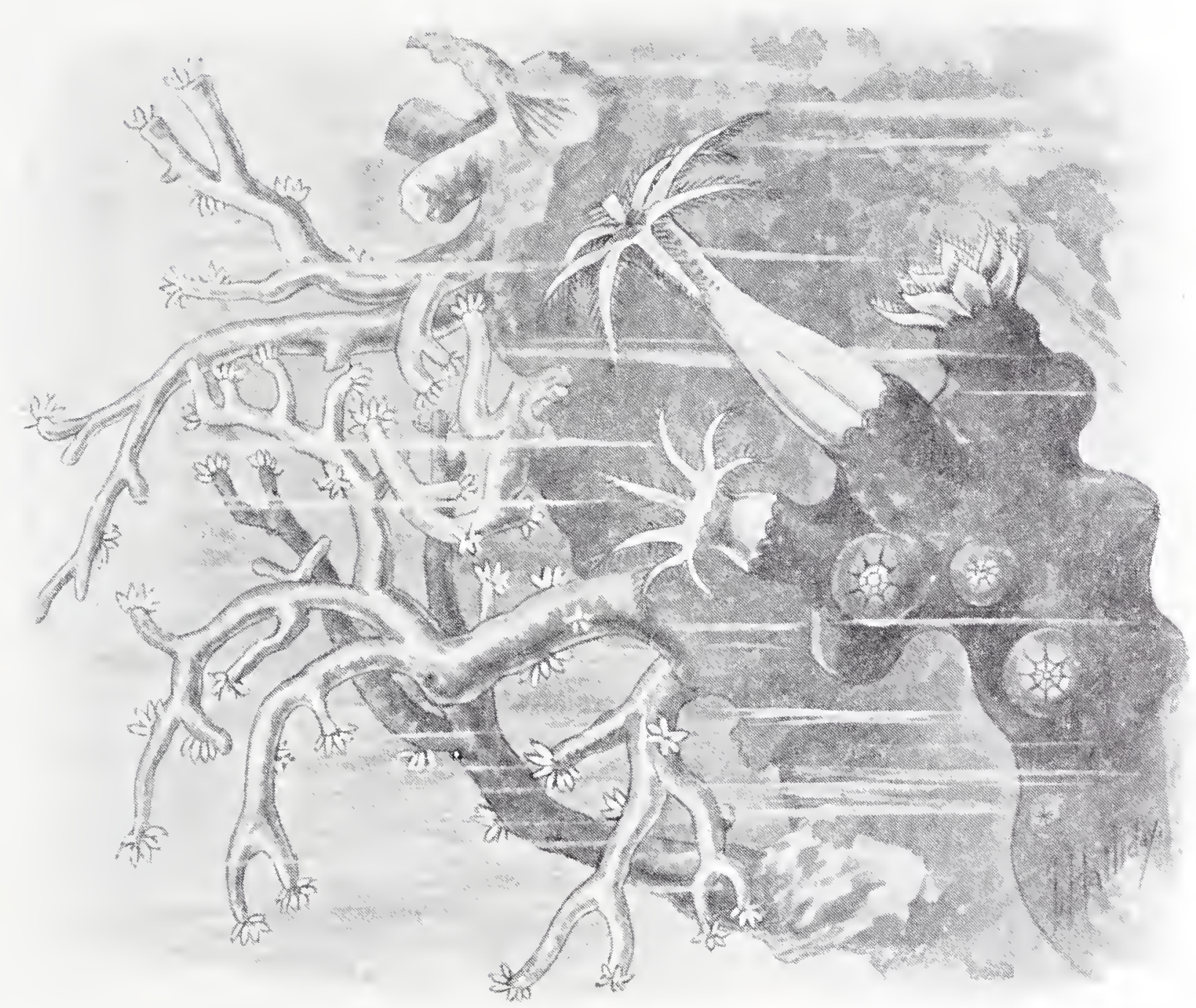

Polyes of ReD CORAL.

are hatched from eggs, remain fixed where they are for the whole of their lives. Then they, in their turn, begin to deposit coral, and as they have nowhere else to put it they place it on the bodies of their parents, which before very long are completely covered in. Now, you see, there is a second layer of coral on the top of the first. Then in due course of time a third layer is formed upon the second, and a fourth layer upon the third, each generation being built in by the one that comes after it, till at last the coral bank rises above the surface of the water. Then the work has to stop; for these little creatures cannot live unless 
the waves can constantly break over them. But although the bank cannot be raised higher it can still be extended on all sides; and so the little polyps go working on, year after year, till at last the results of their labour are almost too wonderful to realize.

These coral banks take three different forms.

First of all, there are "Fringe Reefs."

These are great banks of coral surrounding the shores of a tropical island, or running for long distances on the coasts of the mainland. The island of Mauritius, for example, is entirely surrounded by a fringe reef. These reefs often spread

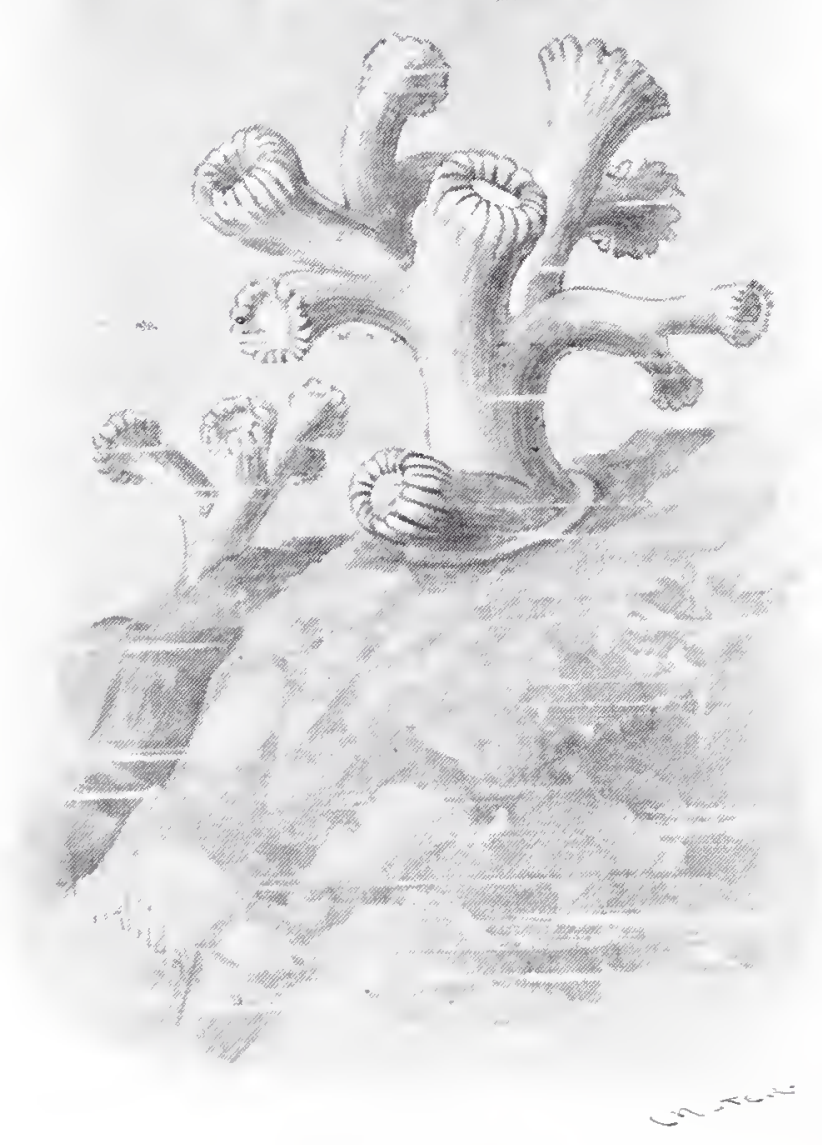

TEFT CORML. out for miles into the sea, and they are only broken here and there by narrow passages, where some river or stream is flowing out. For the polyps cannot live in fresh water. Reefs. Next, there are Barrier

These are great walls of coral at a distance from the shore, with deep water between the two. For the polyps are unable to work at a greater depth than about thirty fathoms, or one hundred and eighty feet, below the surface; and it often happens that while there is deep water close to the shores of a tropical island, there is shallow water farther out. In such a case the polyps have to build out at sea, instead of close into the land, and there is a kind of moat between the coral bank and the shore. In this case the bank is called a "barrier reef," and sometimes it is of enormous size. The Great Barrier Reef, for instance, runs for no less than I,250 miles along the north-east coast of Australia, and is of such vast bulk that England and Wales and Scotland and Ireland might all be made out of it, and even then there would be huge quantities of coral left over!

Then, thirdly, there are "Coral Islands," or "Atolls."

There are thousands of these wonderful islands in the Pacific and the Indian Oceans, and others are still being slowly pushed up out of the sea. They always take the form of more or less circular rings, in the centre of which is a lake of sea water 
called a "lagoon." The coral bank of which they consist is seldom more than a few hundred feet wide, but sometimes the islands are very large indeed. The biggest of all is no less than ninety miles long and sixty miles broad, while several others are not very much smaller. And soon after they rise to the surface of the sea a kind of soil is deposited upon them, made up partly of powdered coral, ground up by the action of the waves, and partly of decaying vegetable matter which has been flung up on them. Then sea birds bring mud upon their feet from the mainland, or from another island at a distance, and leave some of it behind them when they settle down to rest; and in that mud are the seeds of plants, which soon begin to sprout and grow. So in a very few years' time the island is covered with low vegetation. Then one day, perhaps, a floating cocoa-nut is flung up, and that, too, takes root and grows, so that in course of time there is a palm-tree. Other palm-trees, of course, follow; and the result is that the first glimpse which a traveller gets of a coral island is nearly always that of a row of palm-trees upon the horizon.

The simple corals live in almost all parts of the ocean. Some of them, such as the Tuft Coral and the Devonshire Cup Coral, are occasionally dredged up off our British coasts, and can live in very cold water. But the reef builders are only found in warm seas, and are never found working far outside the boundaries of the tropics.

How wonderful it seems that tiny creatures such as these polyps, which really do not appear to be much more than little lumps of living jelly, should be able to build up these vast masses of coral from out of the depths of the sea! One cannot help wondering what the results of their work will be if the world should last for a few thousand years longer. It would really seem that by that time the tropical seas will be cholied up with coral islands, and the lagoons inside them will be filled up with coral too; so that not merely islands but continents will have been raised from the ocean by some of the smallest and weakest and most insignificant of all living animals! 


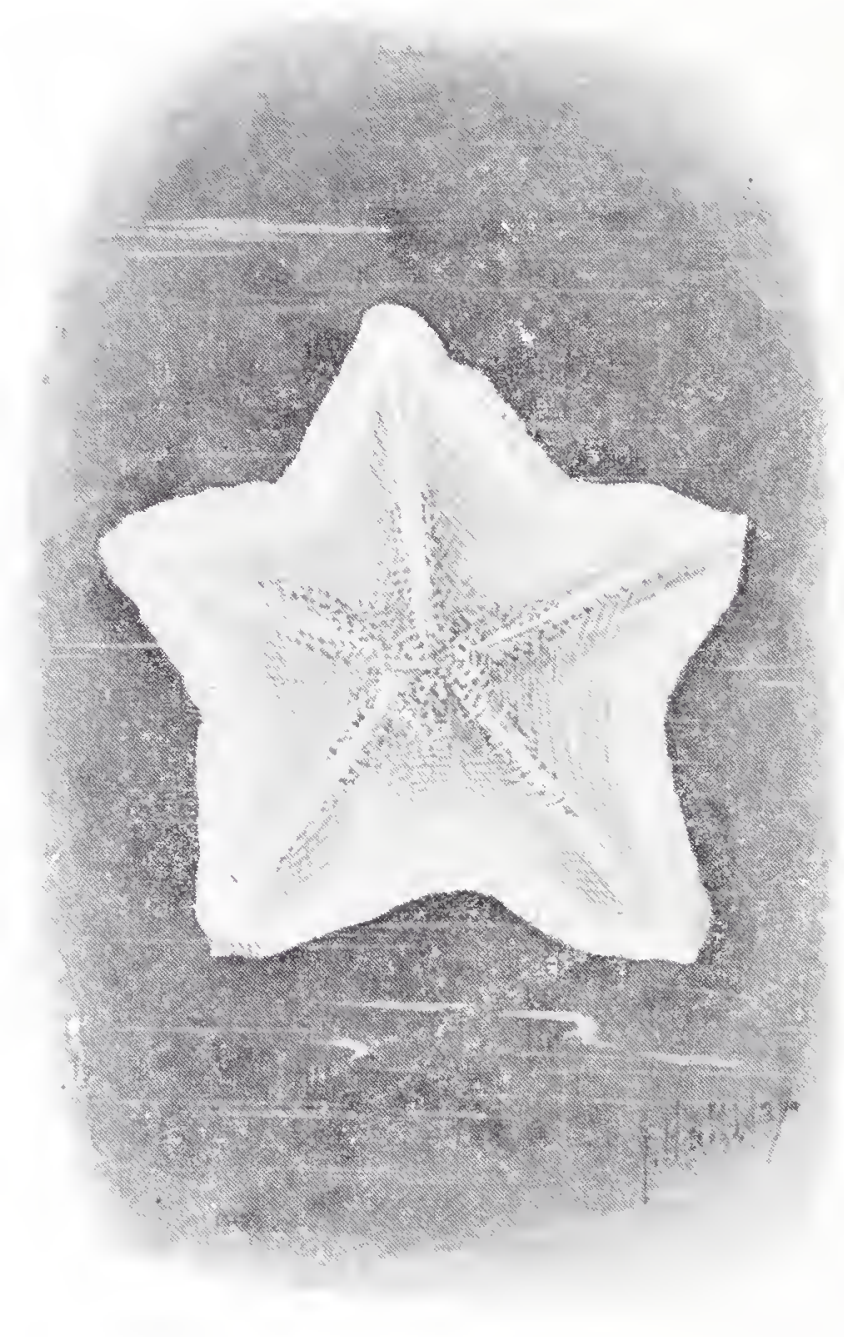

BIRD'S-FOOT STAR-FISH. 


\section{LIST OF ILLUSTRATIONS.}

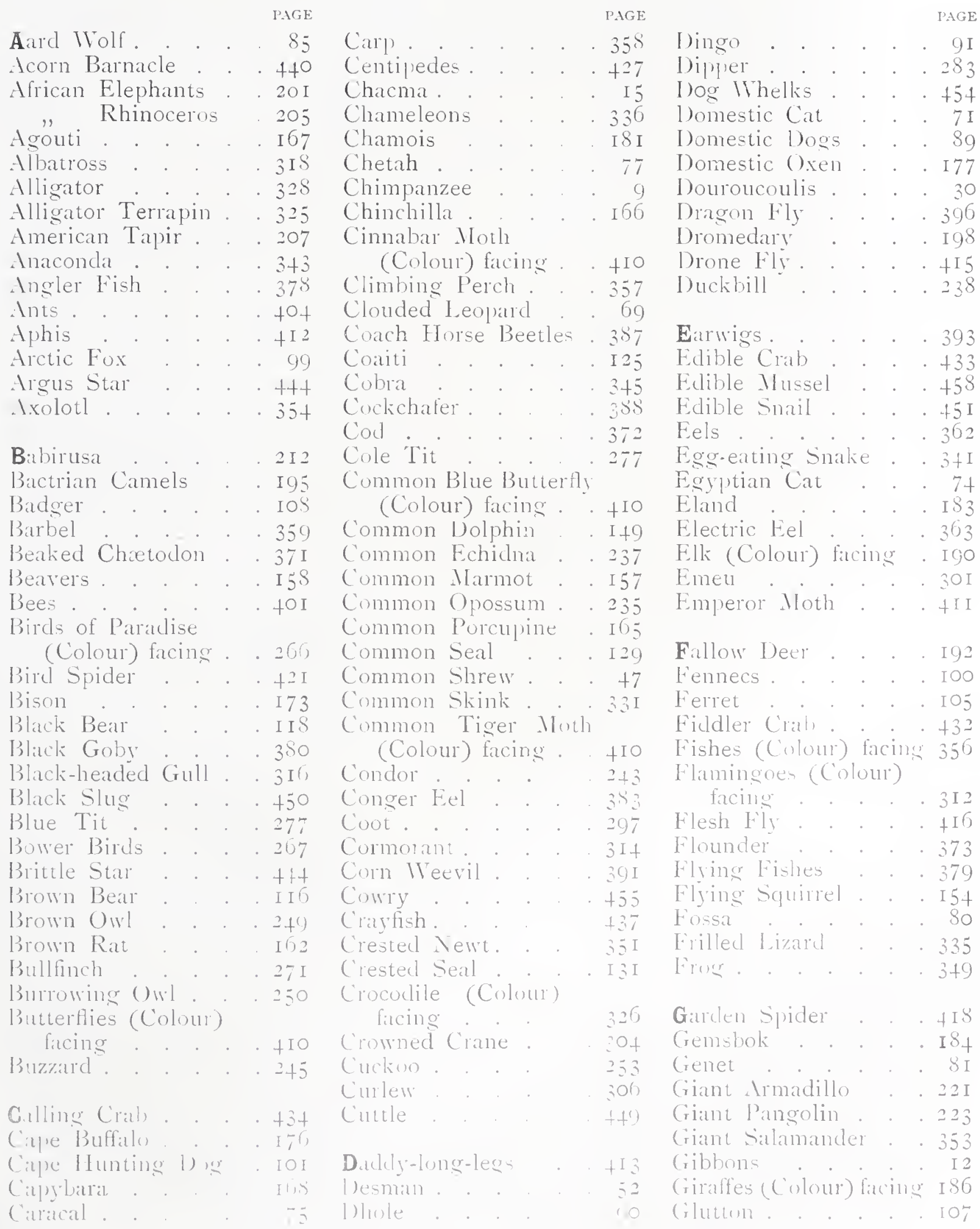


Ginus

Gold-Crest. . . 282

Golden Fagle (Colour) facing

Golifinch . . . . 260

Gorilla (Colomi) fincing IO

Gossamers. . . . 425

Cirampus . . . It7

Great Ant-Fater . . 219

Great Bustard . . 303

Cireat Horse-Shoe bat 39

Greal Til . . . 277

Greenland IThale. . Ifo

Green Monkey . . 2 I

Gieen Turtle". . . 327

Gieen Moodpeckers . 255

Grey Pamot . . . 287

Grizzly Bear. . . I I

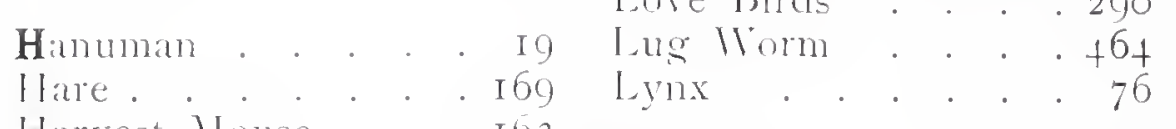

Harvest Mouse . . I63

Ilawk Fly . . . 4I5

Iawksbill Turtle . . 326

Hedgehos . . . . 45

ITermit Crab. . . $43+$

Ileron . . . . 309

llippopotami . . . 209

llooloc's . . . . I 3

Horned Toal of Californial . . . 333

Itouse Cirickel . . 394

Humble Bee. . . 402

I Iumming Bird llawk Moth (Colour) Fiacing t 10 IInting spicler . . . +20

Ilyrax . . . . 206

Ite.

Ihis

lchneumon .

Isuana

Indian Elephants

Indian Mongoose

Indian Palm Civet

Indian Rhinoceros

Jackuaw.

laguar

lal

Jelly fish

Jerboia

Jumping Shrews.

Kalong

liangaroo Rill

Kangareos

kiestrel

Kingfishel

Kinkajou
I'IGE

IS5

$2+4$

I SO

3 I I

Kittimake

P.AB

Ladrbird and (irul . 392

Lammergeier . . . 24 I

Lamprey . . . . $36 t$

I apwing . . . . 305

Laughing lackass . . 261

Leaf-cutter Bee. . . 403

I.eech . . . . $\$ 6 \dot{6}$

Leopard

fimpets .

Lions (Colour) frontispiece

I lama (Guanico) . . I 99

bohster. . . . 436

locust . . . . 395

Long-eared Bat . . 36

Lomo-eared Owl . . 2ts

Long-tongued l'ampile +

Lore Birds . . . 290

Lyix . . . . . . 76

Mackerel . . . . 375

Magpie. . . . . 266

Malayan Tapir . . 20S

Manatee . . . . I 50

Mandrill . . . . I6

Marmignatto. . . + + 9

Marmosets . . . 3I

Hegalopa . . . . 431

Mole. . . . 53

Moor-hen . . . . 296

Musk Deer . . . I94

Musk Ox. . . I79

Narwhal . . . . I +3

Nauplius . . . + $43 \mathrm{I}$

Nightingale . . . 2SI

Noctule. . . 37

Nuthatch . . . . 276

Nut Weeril . . . 39I

332

203

$\mathrm{S}_{3}$

$\mathrm{S}_{2}$

202

264

67

265

ti7

I 59

50

126
Ocelot . . . . 73

Oil Beetles . . . 390

Okapi . . . . Iss

Grange Tip (Colour) ficing . . + t

Orang Utan . . . I I

(ospres . . . . $24 t$

() strich . . . 300

Otters . . . . I I I

()unce . . . . 65

Pinda . . . . . I 22

Parasol Ant . . . 405

Partridge . . . 295

Passenger Pigeons . . 29I

Patagonian Sea Lion . I 30

Peacock Butterfly

(colour) lacing. l'earl (Iyster.

I'.AGE

P'eccaries . . . 2 25

I'elican . . . . . 3I5

P'enguins . . . . $32 \mathrm{I}$

Pen-tailed 'Tree Shrew 5I

Perch (Colour) facing 356

Pheasants . . . . 293

Pichiciago. . . . 222

Piddock . . . . 46 I

Pied Mialail. . . 275

Pigmy I Iippopolamus . 2 Io

P'ike (Colour) facing . 356

Pill Millepecles . . + +28

Pipe Fish . . . . 3SI

Plaice . . . . 373

Polar Bears (Colour) facing. . . . I It

Pole Cal . . . 104

Polyps of Red Coral . 460

Porpoise . . . I 45

l'ouched Mouse. . . 233

Prairie Dog . . . I55

Prawn . . . . . 439

Prickly Chilon . . +57

Prohoscis Monkey . . I 7

Puff Adder . . . $3+6$

Putfins . . . . 3I9

Pumal . . . 689

Purple Fimperor

(Colour) facing. . + IO

Pirple Ground Bectle 336

Purpura. . . . . 454

Racoon. . . . 124

Rafi Spider . . . +23

Rattlesnake . . . 3f7

Raven . . . . 262

Razor-Shells . . + 460

Red and Blue Macam 289

Red-backed Shrike . . 279

Red Deer . . . 191

Rel-ficed Omakari . 29

Red Grouse . . . 29+

Red IIowler . . . 2 2J

Reindeer . . . . 189

Rhinoceros Hornbill . 259

Ringed Snake . . . 339

Roach (Colour) facing 356

Robber Crab. . . + 435

Roebuck . . . . I93

Rook. . . . . . 263

Rorquil . . . . I +1

Rosy lieatler Star. . $t+5$

Ruff . . . . 306

Sable . . . . In厂

Salmon. . . . . 36I

Sand Martins. . . 285

Saw Fish . . . . 367

Sian Fly . . . 406 
Scaly Lizard . . . 329

scarlet Admiral

(Colour) facing. . + Io

Scorpion . . . . 426

Sea Anemone. . . 468

Sea Cucumbers . . $4+6$

Sear Elephant . . 133

Sea Horse . . . . 382

Sea Mouse. . . . . 465

Sea Irchins . . . . 44I

Serval . . . . 72

Short-eared Uwl. . 248

Shrimp . . . . + +39

Side-striped Jackal. . 97

Skipjack . . . . 389

Skunk . . . . . I I

Slender Loris . . . 32

Sloth Bears . . . II9

Sloths . . . . 2Is

Small Tortoise Shell Butterfly (Colour) facing . . . . + $1 \mathrm{O}$

Smooth Newt. . . 35 I

Snipe . . . . 308

Sole . . . . . 373

Sparrow Hawk . . 247

Sperm Thale . . . I37

Spider Monkeys . . 25

Spotted Hyena . . 87

Spotted Salamander . 352

Squirrel . . . . I53
Stag Beetle . . 3 388

Star-fish . . . 442

Starling. . . . 268

Star-nosed Mole . . 55

Sticklebacks (Colour) facing . . . . 356

Sting Ray. . . . 369

Stork. . . . 3IO

Striped Hyena . . 86

Sturgeon . . . . 370

Sucking Fish. . . 377

Sulphur-crested Cockatoo . . . 288

Sun Bear . . . . I 2 I

Sun Star-fish . . . $4+3$

Swallow. . . . 284

Swallow Tail Butterfly 408

Sword Fish . . . 374

Tamandua . . . 220

Tarsier . . . . 33

Tasmanian Wolf . . $23 \mathrm{I}$

Terebella . . . 465

Termites . . . . 397

Tern, or Sea Swallow. 3 I 7

Testacella . . . 45 I

Tiger Beetle. . . 386

Tigers . . . . $6 \mathrm{I}$

Toad . . . . 350

Torpedo. . . . 368
Tortoise.

LAGE

Toucans 327

Trap-door Spiders 257

Trout (Colour) facing 356

Tuft Coral . . 470

Yapourer Moth . . 409

Viper . . . . 3+2

Walrus . . . I 34

Wart Hog. . . . 2I3

Water Beetle. . . 387

Water Shrew . . +8

Water Snails . . 452

Water Spiders . + +24

Water Tole. . . I6I

IVeasel . . . . 103

Whelk and Eggs . 453

White Shark. . . 366

Wild Boar . . 2II

Wild Duck . . . 313

Woodcock . . . 307

Wolves . . . . 93

Wombats . . . . 229

Wruble Fily . . . tro

Yak . . . . . 172

Yellowhammer . . 272

Zebra (Colour) facing . 200

Zocea . . . 43I 


\section{INDEX.}

P.AGE

Aard Tark . . . 222

. Molf . . . 85

Acorn Barnacles. . 440

Adcler . . . . 346

Adder, Puff . . . 3+s

African Elephant . 202

" Rhinoceros . 208

Igouti . . . . I67

Iibatross . . . . 32 I

Mlligators . . . . 327

Alligator Terrapin . . 325

American Monkeys . 23 Tapir . . 2 I I

Anacunda . . . 342

Inemones, Seal . . 467

Angler . . . . . 377

Int Bears. . . . 217

Int Eatels . . . 217

Banded . 234

Great. . 2 I7

Scaly . 22I

" Spiny . . 23S

Intelopes . . . . IS2

Ants... . tot

" Driver . . . to5

, Lion. . . . 399

"Parasol. . . 405

"Nhite . . . 397

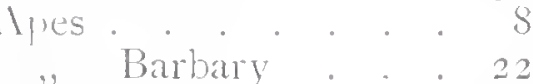

Aphides. . . . . 4II

Arabian Baboon. . . IS

Camel . . 198

Iretic Fox . . . 99

Argali . . . 176

Arertis Star-fish . . $4+5$

Irmadillos . . . 220

Giant . 220

Irmalillo, Pill . . $4+0$

" Six-banded 220

Iswail . . . . I 23

Auroch . . . . I75

Iustralian Bear. . . 230

Mrolutl Monkey . 231

Ire-alie

as

Bj.lirusál

$2 \mathrm{I}+$
Baboons

Arabian $\cdot$ It

Chacma . It

Drill . . I 7

Gelada . . I7

Mandrill . . I6

Bactrian Camel . . I99

Badger . . . . . IO9

Bald Chimpanzee . . 9

Banded Ant-Eater . . 234

Bandicoots . . . 232

Barbary Ape . . . 22

Barbel . . . . 359

Barking Squirel . I56

Barn Owl . . . 250

Barnacles . . . 440

"Acorn . . t+o

Bats. . . . 35

. Flying loxes . 4I

, Great . . . 39

, Great Horse-shoe to

, Kalong. . . 43

" Long-eared . . 37

, Long-tongued

Tampire” . . 40

, Noctule . . 39

"Pipistrelle. . 39

Beadlet . . . . +468

Beaked Chrctodon . 372

Bear-cat . . . \$2

Bearts . . . . . I I5

$"$ Ant. . . 2 . 27

" Aswail . . . 123

, Australian . 230

," Black. . . I 2 I

," Brown . . I I6

" Grizzly . . . I Is

"Northern Sea . I33

". Polar. . I I5

". Sea . . I 132

"Sloth. . . I 23

, Sun . . . I 22

" White. . . II5

Beaver. . . . I57

Bee Hawk Moth . . fog

Bees. . . . 400

"Carder. . . 402

Hive. . . 400

Humble. . . 402

Leaf-cutter . + to2
Bees, Solitary . . . 402

Beetle, Burying . . 397

, Click . . . 390

, Coach Horse . 387

. Dor . . . 399

, Musk. . . 392

, Oil . . 391

,, Purple Ground $3 \$ 6$

, Stag . . . 3SS

, Tiger. . . 3\$6

$"$ Water. . 356

Beluga . . . . 146

Bettong, Brush-tailed . 229

Binturong . . . . 82

Bird, Butcher . . . 278

"Gardener . . 2 $2 \mathrm{~S}$

"Humming . . 254

"Love . . . 290

, Spider . . . 420

Birds, Buwer. . . $26 \mathrm{~S}$

Bird's-root Star-fish , $4+3$

Birds of Paradise . .267

Bishop's Mitres . . + I 2

Bison . . . . 172

Black-backed Gull . . 3I7

Black-backed Jackial . 9S

Black Beal . . . I 2 I

Blackbird . . . . 279

Blackcap) . . . . $2 S I$

Blackfish . . . I 8

Black Goby . . . 3S'I

Black-headed Gull . 3i6

Black kat. . . I63

, Saki... $2 \$$

"Slug . . . . + +50

Blind NTorm . . . 330

Bluebottle Fly . . tif

Blue Butterfly . . tos

., Shark. . . 365

"Tit . . . 276

Bual Constrictor. . $3 t^{2}$

Boar, Wild . . . 213

Boatman, Mater. . + +12

Bobac . . . . I57

Bosch-Katte . . . $7 \mathrm{I}$

Bottle-nosed 1)olphin. I50

Bottle-nose IThales . I 12

Bottle Iit . . . 277

Bower Birds . . . . 268

Brimstone Butterfly . 40.S 
Brindled Gnu . . . I86

Brittle Star-fish . . 444

Brown Bear . . . I16

Hyena . . 88

Owl . . . 250

Rat . . . $\mathrm{I}_{3}$

Brush-tailed Bettong . 229

Buansuah . . . . 90

Buffalo, Cape . . I 75

Bullfinch . . . 270

Bungari . . . . 228

Bunting, Yellow . .272

Burchell's Zebra . . 200

Burnet Moth. . . 409

Burrowing Owl . . $25 \mathrm{I}$

Burying Beetle. . 387

Bush Cat . . . . 7 I

Kangaroo . . 228

Bustard, Great . . 302

Butcher Bird . . . . 278

Butterflies, Blue . . 408

Brimstone . tos

Fritillaries - 408

Green-reined

white. . 408

Large Heath . fos

Neadow Brown fos

Orange Tip . to8

Peacock . tos

PurpleEmperor tos

ScarletAdmiral yos

Skippers . . 408

Small Copper tos

Small Heath . tos

Swallow Tail . to7

Tortoiseshell . to8

Buzzards . . . 246

Caaing Whale

$14 S$

Cachalot . . . . I 40

Caddis Fly . . . 398

Caffre Cat . . . 73

Caimans . . . 329

Calling Crab . . . +33

Camel . . . . . 197

"Arabian . . I98

" Bactrian . . 199

" Dromedary . . I98

Canaries . . . . 273

Cape Buffalo . . . I75

Cape Hunting Dog . IO2

Capybara . . . . I6S

Carracal . . . . 75

Carder Bee . . . 402

Caribou . . . . I90

Carp, English . . 358

Callion Crow . . .263

Ciassowaries
Cat, Caffre . . . 73

" Egyptian . . 72

" Jungle . . . 75

"Narbled . . . 70

"Tiger . . 72

, Wild. . . . 74

Centipedes . . . 427

Chacma . . . . It

Chretodon, Beaked . 372

Chaffinch . . . . $27 \mathrm{I}$

Chambered Nautilus . $4+8$

Chameleon . . . 334

Chamois . . . I $8 \mathrm{I}$

Chaus . . . . 75

Chetah . . . . . 77

Chicken Tortoise . 324

Chiff-chaff . . . . 282

Chimpanzees . . . 8

, Bald . . 9

Chinchilla. Common 99

Chipmuck . . . I55

Chipping Syuirrel. I 155

Chiton . . . . 457

" Prickly . . +57

Cinnabar Moth. . tIO

Civets . . . . 79

$\begin{array}{lll}. & \text { Indian . } . ~ & \$ \\ . & \text { Indian Palm } & \$_{2} \\ . & \text { Palm. . . } & \$_{I}\end{array}$

Click Beetle. . 390

Climbing Perch . . 357

Clouded Leopard . 70

Tiger . . 70

Coach Horse Beetle. . 387

Coaiti . . . I 26

, Mondi. . . I 26

Cobego . . . . 44

Cobra . . . . 346

Cockatoo, Sulphur Crested

$28 S$

Cockchafer . . . 389

Cockle . . . . 460

Cockroach . . . 393

Cocktails . . . 286

Cod . . . . . 372

Cole Tit . . . . 276

Colugo . . . . $4+$

" Flying . . 44

Condor . . . 242

Coney . . . . 209

Conger Eel . . . $38+$

Coot. . . . . 298

Copper Butterfly, Small tos

Coquimbo . . . 25 I

Corals . . . . $4^{68}$

" Deronshire Cup 47 I

". Tuft. . . 472

Cormorant . . . 315

Com Cralie . . . 297
Com Weevil. . . 391

Cowry . . . . . 456

Coyote. . . . 96

Crab . . . . + +3I

"Calling . . . +33

"Common Shore . 432

$"$ Edible . . . + +32

" Fiddler . . . +32

" Hermit . . . +34

"Robber. . . +35

Crab-eating Dos . . 92

" Mlacaque. 22

Crake, Corn Opossum . 237

Crane . . . . 304

Crayfish . 305

Creeper . . . . 274

Crested Newt . . 352

" Seal. . I 33

Cricket . . . $39+$

"House . . 39t

Crocodiles $\quad \cdot 397$

Crow, Canion . . 263

, llooded. . 263

Crowned Crane. . 305

Cuckoo... . . 252

Cucumbers, Sea . . +46

Curlew . . . . 306

Currant Saw Fly . + +06

Cuttles. . . . $4+7$

Cuxio . . . 28

Dah . . . . . 373

Daddy-long-legs . . + it

Dasyures . . . 234

Death's Head Hawk Moth . . . to8

Death-watches . . 390

Deer . . . . . I88

" Caribou . . I90

, Elk. . . . I90

"Fallow. . . I92

" Moose . . . I90

" Musk . . . I93

"l lied. . . I92

, Rein- . . . I90

"Roebuck . . 193

Demoiselles . . . 396

Desman . . . . 50

, Pyrenean. $5 \mathrm{I}$

Devil Fish Russian • 5 I

Devil, Tasmanian · 370

Devonshire Cup Coral t7

Dhole . . . . . 90

Diana Monkey . . . 2 I

J)ingo . . . . . 9I 


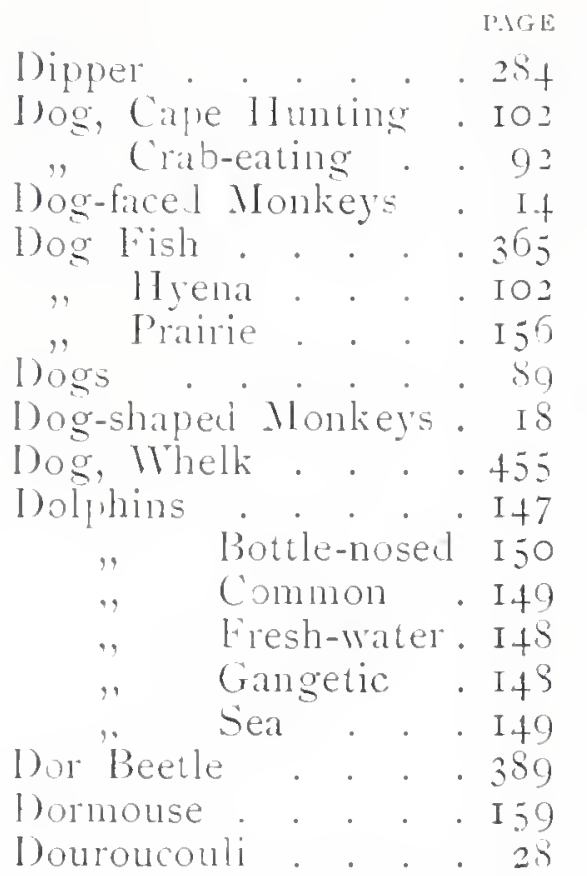

" Three-banded 29

Dore, Ring . . . 29I

Dragon Fly . . . 396

1)rill. . . . 17

Driver Ant . . . . 405

bromedary . . . I98

Jrone Fly. . . + + I5

l) uckibill . . . 2 239

l)uckbilled Platypus . 239

l) uck, Wild . . . 3I 3

l)ugong . . . . I50

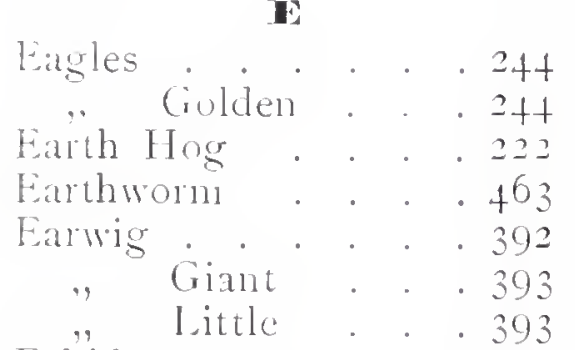

Echidna . . . 238

" Common, . . 239

Edible Crab . . . 432

, Mnssel . . 459

Fel Snail. . . +52

Conver $\cdot 363$

Electric . . $36+$

Efts . . . . 35 I

Fgg-eating Snake . 340

Eggs, Sea. . . 4t

Egyptian Cut . . 72

Egyptian Mongoose . 84

Eland . . . I I82

Electric Hel . . . $36 t$

Elephants . . 20I

$\begin{array}{ll}\text { " Ifrican . } & 202 \\ \text { Indian. } & 206\end{array}$

Elephant, Sea . . I34

$"$ shrew . 49
Elk

Emerald Moth

Emperor Noth

Enien aror

English Carp . . . 358

Fallow Deer . . . I92

fiennec. . . . IOI

ferret . . . 106

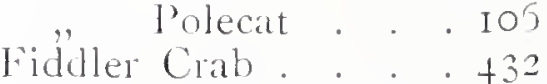

Field Mouse, Longtailed. . I6t Tole. . I62

Fin Whates. . I t4

Finner, Sharp-nosed. Itt

Fish, Black . . I I

" Devil . . 370

" Dog . . . 365

, Flying . . . 379

" Jelly. . . 466

" Yud. . . . 355

" Pipe. . . . 392

"Saw . . . 368

"Sucking . . $37^{6}$

$"$ Sword . . . 375

Fishing Hawli . $24^{6}$

Five-finger Star-fish $\cdot t^{2}$

Flamingo . . . . 3I 2

Fleas . . . + + 33

Flea, Turnipr. . . 392

Flesh Fly. . . + 4 ${ }^{6}$

Flounder . . . 373

Fly, Bluebottle. . 4 I $^{6}$

"Caduis . . . 398

"Currant Saw . . 406

". Dragon . . . 395

" Drone. . . 4 45

" Flesh. . . + 46

"Green. . . + tII

" Gall. . . 405

"Hom-tailed saw . 406

" House . . . +16

"Hawk. . . . +15

" lchneumun. . . to7

" lacewing . . 399

"May . . . 397

"Saw . . . . 405

"Tumip Sin . . 406

Fiycatcher, Spouted . 285

Flying Colugn . . tt

, Fish. . . 379

" Fokes . . + t

"Squirrel. . I5t

Fossa . . . . 79

Foumart . . . . 106

Foxes . . . 98

$" \begin{array}{lll}\text { Arctic } & \text { Common } & 99 \\ & . & 9\end{array}$
Foxes, Flying

Fox, Fresh-water . 359

Fresh-water Dolphins. I 48

" " Fox . 359

" $\quad$ " Pig . 359

Frilled Hizard . . . $33+$

Fritillaries. . . . to8

Frog . . . . . 349

Frog-hoppers . . 4 4 I

Fur Seal . . . I32

Gall Fly . . . 406

Gangetic Dolphin. . I4s

Garden Snail. . . $45 \mathrm{I}$

Spider. . + I 8

Gardener Bird . . 268

Gastropods . . . 449

Gaur . . . . . I7I

Gazelles . . . I 85

Geckos . . . . 332

Gelada . . . I7

Gemsbok . . . I 83

Genets . . . \$I

"Common . S I

Giant Armadillo . 220

," Earwig . . 393

" Pangolin. . . 222

, Salamander . . 353

Gitbons . . . I2

" Hoolock. . I3

$"$ Lar. . . I 3

Giraffes. Siamang • I 3

Gloworm . . . 390

Glutton . . . . 107

Gnat . . . . 4I4

" Viater. . + ti2

Gnu, Brindled . . Is6

. White-tailed. . I86

Goat Moth . . . 409

Goats . . . I 80

Goby, Black . . . 38I

"Spotted . . 3 38

Gold-Crest . . . 283

Golden-Crested Wren . 282

Golden Eagle . . 244

Goldfinch . . . 270

Goose, Grey-lag. . . 3I 2

Gorilla . . . 9

Gossamers . . . . 425

Grampus . . I 47

Grasshopper . . . 394 , Great Green 394

Grass Snake . . 339

Great Ant Eater . . 217

, Birt . . . . 39

Bustind . . 302

Horse-shoe Bilt to 
I.AG E

GreatGreenGrasshoper 394 Grey Slug . 450 'Tit.. . 276

White Shark . 366

Greater IVeaver . . 376

Greek Tortoise . . 323

Gleen-finch . . . 269

Green Fly. . . . 4II

Greenland Whale . I It

Green Linnet . . 260

" Monkey . . . 20

"Turtle . . 326

- Veined White

Butterfly. . tos

Noodpecker . 256

Grery's Zebra . . 200

Grey-Lig Goose . 3 I2

Parlot . . 257

Grizzly Bear . . . I I

Grouse, Red . . . 295

Guanaco . . . . I99

Guenons . . . . 20

Guillemol . . . . 3 I 8

Gull. . . . . \$17

, Black-headed . 316

," GreatBlack-backed 3 I 7

, Herring. . . 3I 7

, Sea . . . 3I6

Gurnards . . . 378 , Red . . 379

Hackee . . . . I55

Hair Seals . . . I 3 I

Hammer-head Shark . 367

Hamster . . . . I60

Hanuman . . . . I9

Hale . . . . . I60

Marvest Mouse . . I64

Hawfinch . . . . . 270

Hawksbill Turtle . 325

Ilawk, Fishing . . . 246

, Fly . . . I I5

, Sparrow. . 248

Ilazel Nouse. . . I59

Heath Butterfly, Large tos

", Small tos

I ledgehog . . . . 45

lledge Sparrow . . 282

Iermit Crab . . . + $+3 t$

IJeron . . . . 30s

Hering . . . . 380

" Gull . . 3 I7

Hippopotamus . . 2 I 2

Ilive B̈ee. . . . . 400

$1 \log$, Earth . . . 222

, Sea . . . I 46

"Wat. . . 2It

Honey Ratel
IIoney II easel

Hooded Crow

I oolock

, Rininoceros $\cdot 258$

Ilorned 'Toad of California . . . $33 t$

Hornet . . . . 403

Hon-tailed Saw Fly . 406

Horse, River. . . 2 I 2

, Sea . . I 35

, . . . . $3 \$ 3$

Ilorse-shoe Bat, Gieat to

House Cricket . . 394 " Fly . . + + I6

Howlers . . . 24

Humble Bee . . . +02

Humming Bird . . $25+$ , llawk Moth tog

Hunting Leopard . . 77 , Spidel. . +20

Hyena Dog . . . IO2

Hyenas . . . $\$$. 86

, Brown. . SS

, Laughing . $\$ 8$

, Spotted . $\$ S$

"Striped . . $\$ 7$

Hylax . . . . 209

Ibex . . . . . ISO

Ibis . . . . 3 II

, Sacred . . 3 3 I

"Scarlet . . 3 II

Ichneumon Fly . . 407

Iguana . . . . 333

Indian Buffalo . . 175

" Civet . . . So

" Elephant . 206

,$\quad$ Mongoose . . $\$_{3}$

, Palm Civet . 82

, Pangolin. . 222

," Rhinoceros. . 207

Insect Eaters. . . tt

Insects, Leaf . . . . 395

, Stick

Jacalas . . . . 329

Jack . . . 360

Jackils, Black-backed. 98

Common . . 97

,. Side-striped 98

Jackiss, Laughing . . 26 I

Jackdaw . . . 264

lack Snipe . . . 308

laguar . . . . 66

Jay . . . . . 265

Jelly Fish. . . 466
Jerboas . . . . . I60

, Common . . I60

"Kangaroo . . 230

Julus Millepede . . +28

Jumping Shrew . . 49

Jungle Cat . . . 75

Kalan . . . . . I If

Killong . . . . . 43

Kangaroos . . . 224

" Bush . . 226

" Tree . 228

Kangaroo Rat . . 229

Kestrel . . . . 247

Kholsun . . . . 90

Killer Whale. . . . I47

Kinkajou . . . . I 27

King Bird of Paralise 265

Kingfisher . . . . 260

Kitten, Noth. . . . tII

Sittiwake . . . 3I7

Kiwis . . . . 302

Kioala . . . . 230

Koodoo... . . I I 3

Lacewing Fly . . 399

Ladybird . . . . 392

Lammergeier . . . 242

Lamprey . . . . 364

Lancelet . . . 384

Land Rail. . . . 297

land Tortoise . . . 323

Langurs . . . 20

Lapwings . . . 305

Lar Gibbon . . . . I 3

Laughing IIyena . . 88

Laughing Jackass . . 25I

Leaf-cuttel Bee . . 402

Leaf-Insects . . . 345

leather-Jackets . . tIt

leech . . . . 465

Lemmings . . . . I62

Lemurs . . . . 30

Leopard . . . . 64

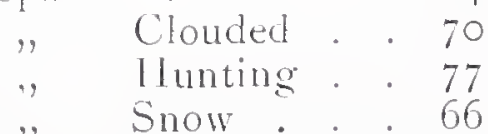

Lesser Rorqual . . I +4

Lesser Spotted Dog

lish. . . . 365

Lesser IVearer . . 376

Limpets . . . . 457

linnet . . . . 272

Lion Green . . 269

Lion . . • . . 59

Ant . . . 399

, Patagonian Sea. I 3 
Podel

I.ion, Sea . . . I3I

Little Earwig . . . 393

lizard, Frilled . . 334 Sand. . 330

, Scaly. . . 329

Llimas . . . . . 199

Lobster . . . . 436

Locusts . . . . 395

Long-eared Bat . . . 37

" , (1) . 250

Long-tailed Field

Mouse . . . I6t

I.ong-tailed Tit . . . 277

Long-tongued l'ampire 40

Loris, Slender . . 32

Love Birds . . . 200

Lug ITorm . . . $46 t$

Lyinx . . . . 76

,, Pardine . . 77

Nicaques . . . 22 Crab-eating 22

Nacaw, Red and Blue 289

Mickerel . . . 376

Maggot, Rat-tailed. 4 45

Magot . . . . 22

Magpie. . . . 266

Magpie Moth. . . tro

Malayan Tilpir. . . 210

Manatee . . . I 50

Mandrill . . . . I6

Mangabey's . . . 21

Mantis, Proying. . 395

Marbled Cat . . . 70

Margay . . . . 72

Marmignatto Spicler . 4I9

Marmoset . . . 29

Marnot, Common . 156

Varsupials 128

Marten, Pine. . . 107

Martens . . . . IOZ

Martins . . . . 286

Martin, Sand. . . 286

May Fly . . . . 397

Meadow Brown Butter-

Al. . . . . 408

Meerkat . . . 84

Megalopa . . . + 43I

Merian's Opossum . 237

Milky Slug . . . +50

Millipede, Julus. . . 428

Pill . $+2 S$

Missel Thrush . . 279

Mitres, Bishop's. . + + 2

Mole, Common . . 5I

$\begin{array}{llr}, \quad \text { Cricket. } & 394 \\ " & \text { Pouched } & 235 \\ . & \text { Star-mosed } & 35\end{array}$

\begin{tabular}{|c|c|c|c|c|}
\hline & & IAGE & & $\Gamma A, E$ \\
\hline Mongoose & Egyplian & $s_{4}$ & Mouse, Harvest & $.16+$ \\
\hline & Indian, . & 83 & Hazel & . 159 \\
\hline Monkeys, & American & 23 & Long-tailed & \\
\hline, & Australian & $23 \mathrm{I}$ & Field. & I $6_{4}$ \\
\hline , & Aye-aye & 33 & Pouched & 34 \\
\hline , & Bartary Ape & 22 & Sea & 46 \\
\hline ,. & Black Salki. & 28 & Mud Fish & \\
\hline ," & Cuxio. & 28 & " skippers & \\
\hline, & Diana & $2 \mathrm{I}$ & Musk Beetle & \\
\hline , & Dog-faced & It &,$\quad 1$ )eer & \\
\hline ", & Dog-shaped. & I $S$ & $\because \quad()^{\prime}$. & 17 \\
\hline , & Douroucouli & & Musquaw & \\
\hline & Three-banded & 28 & Mussel, Edible & \\
\hline " & 1)ouroucouli & 28 & River . & \\
\hline ,. & Green & 20 & Myrmecobius. & \\
\hline ," & Guenons & 20 & & \\
\hline ., & Hanuman & I9 & $\mathrm{v}$ & \\
\hline ," & Howlers & 24 & Narwhal & \\
\hline ,, & Howlers Red & 24 & Natterjack & \\
\hline ", & Langurs. & 20 & Nauplius . & \\
\hline$"$ & L.emur, Ring- & & Nautilus; Chambered & \\
\hline , & Lemur, & jo & "Crested & \\
\hline & Ruffecl & $3 \mathrm{I}$ & ,Smooth & \\
\hline ", & Macaques & 22 & Nightingale & $\cdot$ \\
\hline ", & Macaques, & & Nightjar. & \\
\hline & Crab-eating. & 22 & Night Monkeys & \\
\hline & Magot & 22 & Noctule. & \\
\hline ", & Mangabeys. & $2 \mathrm{I}$ & Northern Sea Bear & \\
\hline ," & Marmoset & 29 & Nuthatch & \\
\hline & Night & 28 & Nut Weevil & \\
\hline
\end{tabular}

Oared Shrew . . . 49

Ocelnt . . . 72

(oil Beetle. . . 39I

()kapi . . . . I 89

Olm . . . . . 354

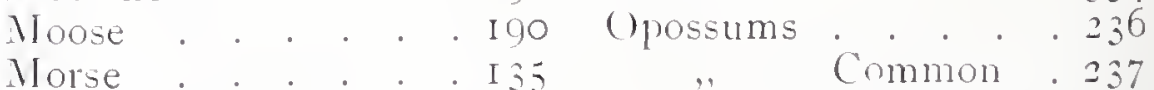

Woth Bee llawk .

"Burnet. . tog

Crab-eating 237
.$\quad$ Merian's 2.37

". Yapock. . 237

()ange Tip Butterfly . tos

Orang-Utan . . 10

()sprey . . . . 245

()strich . . . 299

()tter . . . II 3

" Sea . . . . I I4

(Makari, Red-faced $\cdot 27$

()uistiti. . . . 30

()unce ... 66

Owl, Barn. . . 250

"Brown . . 250

"Burrowing . . 25I

"Coquimbo . . 25I

"Long-eared. . .250

"Short-eared. . 250

"White. . 250

Oxen . . . . 177 
PAGE

Ox, Musk. . . . I7I

()yster. 450

, Pearl

$+60$

Painter

耳

Palm Civers

Panda . . . . . I 24

Pangolins . . . . 22I

Giant . 222

Indian . . 222

Panther. . . . 64

, . . . . 70

Parradise, Birds of . . 267

King Bird of 267

Parrakeets. . . . 2.88 Ring-neciked $285^{\circ}$

Parasol Ant. . . 405

Pardine Lynx . . . 77

Parrot, Grey . . . 287

"Sea . . .32 I

Partridge . . . . . 296

Parsenger Pigeon . . 292

Patagonian Sea Lion. I 32

Peacock. . . . . 292

Peacock Butterfly . . tos

Pearl Uyster . . . 460

Peccaries . . . 215

Pelican . . . . 315

Penguin. . . . . 322

Pen-tailed Tree shrew 50

Perch . . . . 356

"Climbing. . 257

Periwinkles : . . +56

Petaurist, Squirrel . .230

Pheasant . . . 294

Pichiciago . . . . $22 \mathrm{I}$

Piddock . . . . . $+6 \mathrm{I}$

Pied Wagtail. . . 274

Pigeon, Passenger . . 292 Wl . $29 \mathrm{I}$

Pig, Fresh-water . . 359

Pigmy Hippopotamus. 2 I 3

Pike . . . . 360

Pill Armadillo . . +40

. Milleprede. . 428

"Woodlouse . . + 40

Pine Marten . . . 107

Pipe lish . . . . 392

Pipistrelle . . . 39

Plaice . . 373

Playtypus, 1)uck-billed 23 ?

Polar Beal . . . I 5

Polecal . . . . . 106

" lenel. . . Ió

Porcupine . . . . 165

Porpoise . . . $1+6$

Potto . . . . . 127

Potoroos . . . . 220)

Pnuched Mice . . 234
Pouched Vole PAGE

Prairie I)og. . . 156

, Marmot. . I56

Prawns . . . . 438

Praying Mantis . . 395

Prickly Chiton . . 457

Proboscis Monker. Is

Proteus . . . . 354

Puff Adder. . . . 348

Puffin . . . . $32 \mathrm{I}$

Puma . . . . . . 69

Purple Emperor ButterH. . . . . 408

Purple Ground Beetle. 386

Purpura. . . . . 454

Puss Moth . . . . +II

Pyrenean Desman! . 5I

Pythons. . . . 340

Rabbit . . . . I69

Racoons . . . . I 25

$\begin{aligned} \text { Common * } & 125 \\ \text { Raft Spider * . } & +23\end{aligned}$

Rails. . . . 297

" Land . . . 297

Rat, Brown . . . 163

"Black . . . I63

"Kangaroo . . . 229

R" Nater . . . I6I

Ratel · • · . $\begin{aligned} & \text { IO9 } \\ & \text { IJoner }\end{aligned}$

Rät-tailed Nínggot. + +15

Rattlesnake . . . $3+8$

Rays . . . . . 368

Ray, Sting. . . . 370

Raven . . . . 202

Razor-Shells . . . +60

Red and Blue Milcilw. 2sio

Red-backed Shrike . . 278

Red Deer . . . . . 192

Red-faced Uuakini . 27

Red Grouse . . . 295

, Gumards . . 379

. Howler. . . 24

Reindeer . . . . I90

kheas . . . . 30I

Rhinoceroses . . . 207

Alrican . 20 ?

Common 20s

Indian . 207

Rhinoceros Hornhill . 253

Rice lleevil. . . 39 I

Rimau-dehan . . . 70

Ring Dore. . . . $29 \mathrm{I}$

Ringed Snake . . 339

Ring-necked Parrakeet 288

Ring-tailed Lemur . 30

River Horse . . . 2 I 2

$+58$
Roach

Robber Cab- 359

Robin 435

Rock Snakes. . . 34I

Rodents . . . . 152

Roebuck . . . 193

Rondeleti's Shark. . 366

Rook. . . . . . 263

Rorqual, Common. I It4

" Lesser. . I 44

Rosy Feather Star-fish +45

Ruff . . . . . 307

Ruffed Lemur . . 3 3 I

Russian Desman . . 5 I

Sable . . . . 107

Sacred [bis . . . 3II

Salamander . . . 352

Giant. . 353

Salmon

Salmon . . . . 360

Sand-hoppers. . . +38

Sand Lizard . . . 330

, Nartin . . . 286

Saw Fish . . . 368

, Fly . . . 405

Scaly Ant-eater . . $22 \mathrm{I}$

," Lizard . . . 329

Scarabcus . . . . 389

Scarlet Admiral. . tos

, lbis . . . 3II

Scorpions . . . 426

Scorpion, llater. . 4I3

Sea Anemones . . . +67

"Bear . . . I 32

"Bear, Northern. I33

"Cucumbers . . +46

"Dolphins . . . It?

"Eges . . . . +4I

"Elephant . I I3t

, Gulls. . . . 316

" Hor . . . . 146

"Horse. . . . 383

"Horse. . . I 35

". Lions. . . I 31

"Lion, l'atagonian I32

"Nouse . . . +65

. ()tter. . . IIt

"Parrot. . . . \$2I

"Sliater. . . . +40

"Swallows. . . 3IS

"Lnicorn. . . I 45

"Urchins. . . t+I

Seals . . . . I 28

"Common. . . I 130

" Crested . . I33

" Fur . . . 132

"llair . . . I31

Secretary Bird. . $2+3$ 
Serval

Shark, Blue Great White. 366 Hammer-head . 367 Rondeleti's . 366 Thresher

Sharp-nosed Fimner

Shells, Razol . +60 ." Tooth... . 458

Ship Wrom . . 462

Shore Crab . . . 432

Short-eared Owl. . . 250

Shrews. . . . 47

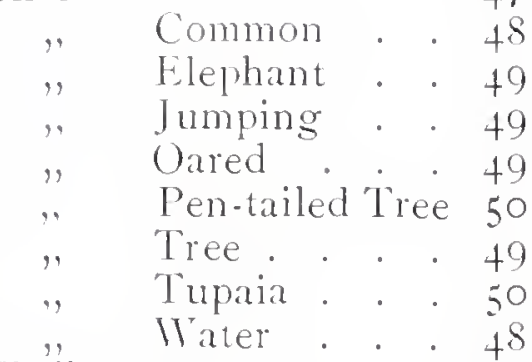

Shrike... . 278

," Red-backed . 278

Shrimps. . . 438

Shrimp, Fresh-water · 439

Siamang . . . . I3

Side-striped Jackal . . 98

Sirenia . . . I50

Six-banded Armadillo . 220

Skate. . . . 369

Skink . . . . \$3I

. Common . . 332

Skipiack . . . . 359

Skipper Butterfly . . 408

Skippers, Mud". . 38I

Skunk . . . . II 3

Skylark... . 273

Slater, Sea. . . 440

Slender Loris . . 32

Sloth Bear . . . I23

Sloths . . . . 2I7

Slow Wrorm . . . 330

Slugs. . . . 449

Slug, Black . . 450

. Great Grey . . 450

" Milky. . . 450

Smooth Newts. . 35I

Snail, Garden . . $45 \mathrm{I}$

Edible.. . 452

Water. . 452

Snatie, Egg-eating . 340

Grass . . . 339

Rattle- . . 348

Ringed . . 339

Rock . . 34

snipe.

Jack

Snow Leopard

sole

Solitary Bee

308

308

66

. 373
Song Thrush

Sparrow .

Sparrow-Hawk

$$
\text { Hedge }
$$

Spermaceti Whale

Sperm Whale

Spicler, Bird

$$
\begin{aligned}
& \text { " Garden. } \\
& \text { "Gossamer } \\
& \text {, Hunting. } \\
& \text {, Narmignatto } \\
& \text {, Monkeys } \\
& \text { Raft } \\
& \text { Trap-door } \\
& \text { Water. }
\end{aligned}
$$

Spiny Ant-eater

Spotted Flycatcher. Goby.

Hyena

Salamander

Springbok

Squids

Squirrels

",

Stag Beetle

185
Barking.
153
156

Barking - I56 Flying Petaurist . 230 Sugar

Star-fish.

" Argus
$" \quad$ Bird's-foot
" $\quad$ Brittle.
" Rive-finger
" Rosy Feather
Sun .

Starling.

Star-nosed Mole

Stick Insects

Stickleback, Threespined

Sting Ray.

Stoat

Stork.

Storm Cock

Striped Hyena

Sturgeon

Sucking Fish .

Sugar Squirrel

Sulphur Crested Cockatoo

Sulphur Moth

Sun Bear

". Star-fish

Suricate

402
Susu .

Swallow.

$$
\begin{gathered}
" \quad \text { Tail Butterfly +o7 } \\
" \quad \text { Moth. 4IO }
\end{gathered}
$$

PAGE

Swans. . . 3I3

." Whistling . . $3 I_{3}$

Swift . . . . 254

,Noth... . . . . .

Swine . . . . 213

Sword Fish . . . 375

Taguan . . . . I54

Tamandua . . . 2 29

Tapirs . . . . 2 Io

, American . . 2II

Tarsier Malayall • 211

Tasmanian Devil . 233

" Wolf . . 232

Terebella . . . . 464

Termites . . . . 397

Terns . . . . 3IS

Terrapin, Alligator. . 325

Testacella . . . +50

Three-banded Douroucouli . . . 28

Three-spined Stickleback. . . . 356

Three-toed Echidna . 239

Thresher Shark . . 367

Thrush, Missel . . 279

"Song. . . 278

Thylacine . . . . 232

Tiger . . . . 60

"Beetle. . . 386

, Cat . . . 72

" Clouded . . . 70

"Noth. . . 409

.$\quad$ Tolf . . . 88

Tit, Blue... . . 276

"Bottle. . . 277

"Cole. . . . 276

, Great. . . . 276

, Long-tailed . . 277

Titmice. . . . 276

Tittlebat . . . 356

Tittler . . . . 356

Toad . . . . . $35 \mathrm{I}$

"Horned . . 334

Tooth Shells... . 458

Torpedo. . . . . 369

Tortoise, Chicken . 324

Greek . . 323

Land . . 323

4 Io Tortoiseshell Butterfly tos

I22 Toucans. . . . 257

443 Trapdoor Spider . 42

Tree Kangaroo . . 228

," Shrew . . . 49

Trout . . . 360

Tuft Coral. . . 47 I

Tupaia. . . . 50

Turkey. . . . . 293 
I'.SGE

Tumip Flea . . . 392

"Saw lily . . 406

Turtle, Green • . . 326 " Hawkshill . .325

Unicorn, Sea . . I +5

Urchins, Sea . . +t I

Tampire, Long-tongued 40

Vapourer Moth . . + to

Viper. . . . . 346

Viscacha . . . 166

Vlacke Vark. . . 2It

Vole, Field . . . I62

" Vater . . I6 I

Vultures. . . . 24I

Wagtail, Pied

\section{W}

Wah . . I 24

Wallabies. . . 228

Walrus . . . . I 35

TVarble . . . + +16

Wart Hog . . . . 2 It

Wasp . . . . to3

Water Beetle. . . 356

: Boatman . . + 12

Gnat . . . + I 2

-Hen . . . 298

Rat . . . I6I

Scorpion. . + 13

Shrew. . +4
Thater Snail o . O

452

$42+$

"Spider

"l Vole . . I6I

Weasels . . Iot

" Honey. . Iog

Weaver, Greater . 376

Lesser . 376

Weeril, Corn . . . 39I

"Nut . . . 39I

"Rice . . . 39I

Whales.... . I 36

"Bottle-nose. If2

" Caaing. . I +8

" Fin. . . I4t

" Greenland. It+

" Killer. . I 47

"Sperm . . Ifo

"Spermaceti . Ifo

" Whalebone. I 42

"White. If6

Whalebone Whales. I 2

Whelk, Common . 453

, Dog . . . +55

Whistling Swans . 3I3

White Ants . . . 397

$"$ Bear . . . I I5

" Shark, Great . 366

IThite-tailed Gnu . I 86

White Whale. It6

Whoopers. . . . 3I 3

Wild Boar . . 2r 3

, Cat . . . 74

". Duck . . 3I 3
Mildebeests . . . IS6

Wish-ton-Wish . . I56

Wolf, Aard . . 85

"Common . . 95

". Coyote . . 96

"Tasmanian . . 232

" Tiger. . . 88

Wolverena. . . I07

Wolves... . . 95

Wombat . . . $23 \mathrm{I}$

Woodcock. . . 307

Woodpecker, Green . 256

Wood-lice . . . 439

Voodlouse, Pill . . +40

Wrood Pigeon . . 29I

Worm, Earth. . . +63

,$\quad \mathrm{I}$. . . . $46 t$

"Ship . . . 462

Wren . . . . 283

"Golden Crested . 282

Wryneck . . . 256

Wurble. . . . + + 6

Yak . . . . I 7

Tapock Opossum . 237

Yellow Bunting . . . 272

rellowhammer . . .272

Zebras . . . . . 200

"Burchell's. . 200

" Grery"s . . 200

"Nountain . 200

Zova . . . + +30 


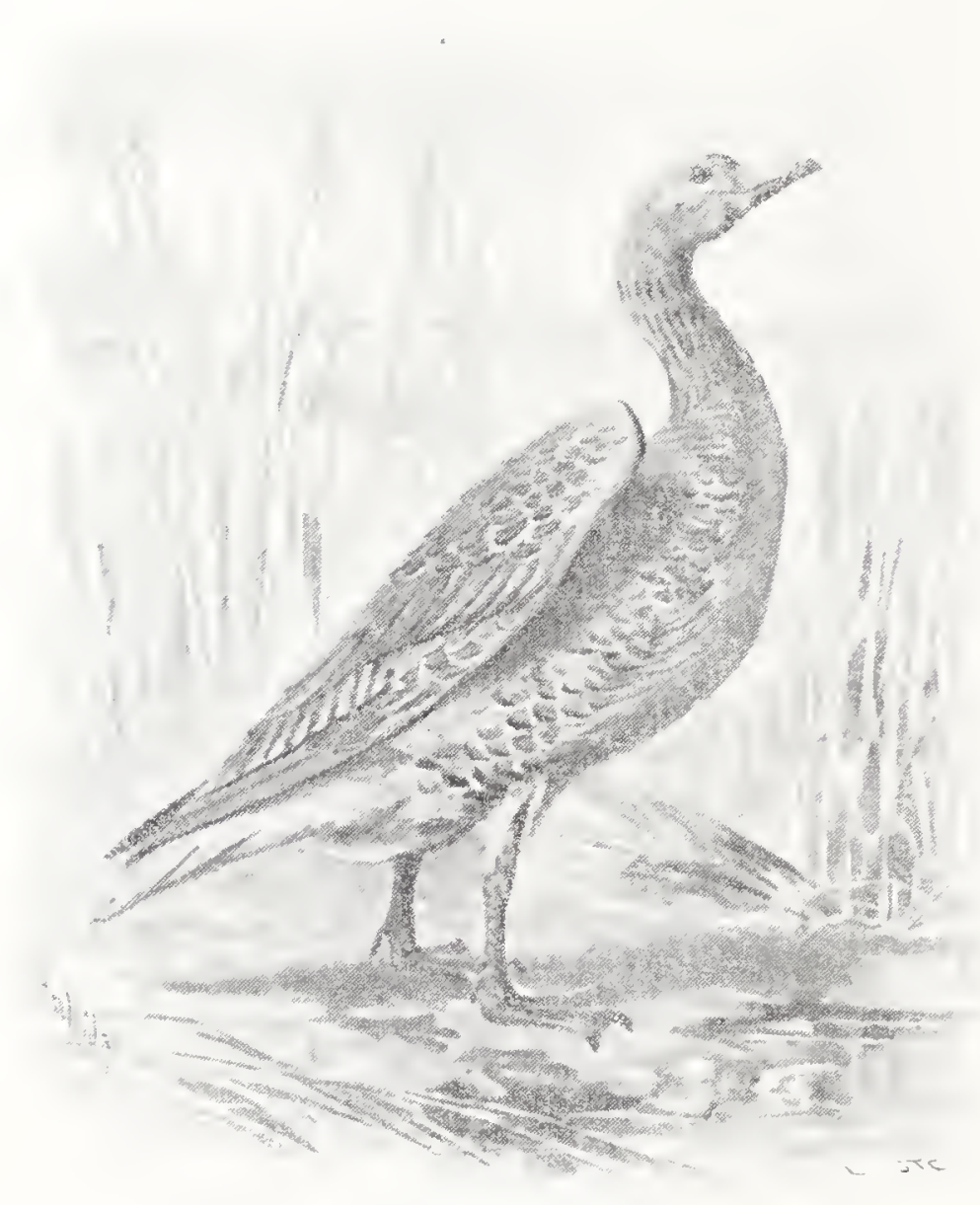

GREY-I.IG GOOSE. 



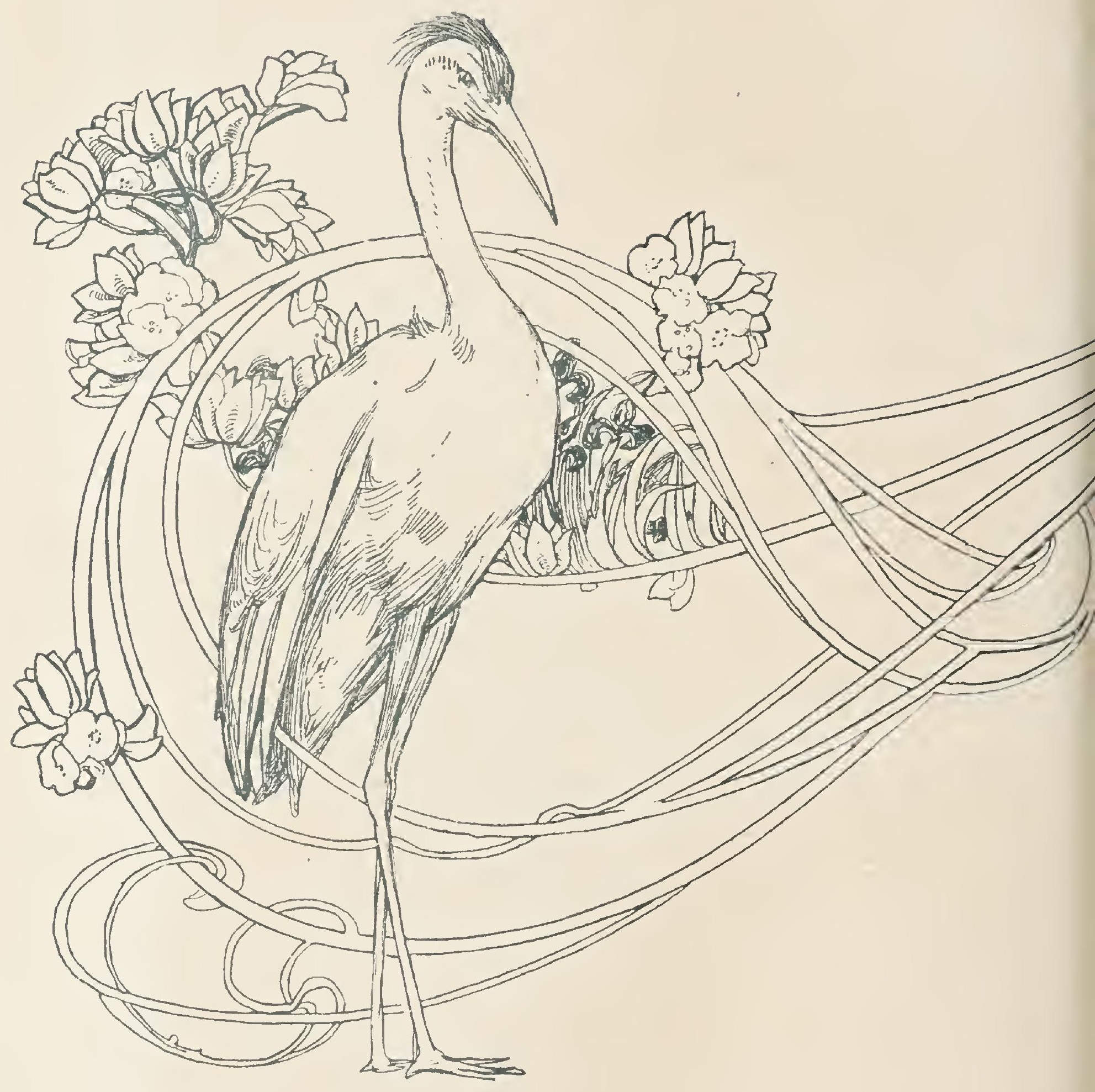


